\title{
Le droit international humanitaire et la protection des enfants en situation de conflits armés
}

Etude de cas de la République Démocratique du Congo

\section{MUMBALA ABELUNGU Junior}

- Master de spécialisation en Droit international (ULB, Belgique)

- Master de spécialisation en Analyse interdisciplinaire de la construction européenne (UCL USL-B, Belgique)

- Master complémentaire en Droits de l'homme (UCL- UNamur - USL-B, Belgique)

Promoteurs: Prof. Dr. An CLIQUET Prof. Dr. em. Eduard SOMERS

Année académique : 2016 - 2017

Thèse de doctorat présentée et défendue à la Faculté de Droit de l'Université de Gand en vue de l'obtention du grade de Docteur en Droit

IIIIIII 
Le droit international humanitaire et la protection des enfants en situation de conflits armés

(Etude de cas de la République Démocratique du Congo)

Thèse de doctorat en Droit

Junior MUMBALA ABELUNGU

Master de spécialisation en Droit international (ULB, Belgique)

Master de spécialisation en Analyse interdisciplinaire de la construction européenne (UCL - USL-B, Belgique) Master complémentaire en Droits de l'homme (UCL- UNamur - USL-B, Belgique)

Promoteurs: Prof. Dr. An CLIQUET et Prof. Dr. em. Eduard SOMERS

Année académique 2016 - 2017

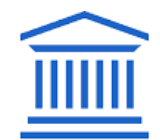

UNIVERSITEIT GENT 


\title{
RESUME
}

Le régime de protection de l'enfant en situation de conflits armés tel qu'institué par le droit international humanitaire complété par le droit international des droits de l'homme, voire le droit international pénal, reste sujet à de nombreux écueils. Ceux-ci sont à situer plus au niveau de la définition des obligations des parties au conflit et des mécanismes devant assurer la mise en œuvre de ces obligations. Ainsi, prenant pour cadre d'investigation la République Démocratique du Congo, pays qui comptait plus de 30.000 enfants soldats (plus ou moins $15 \%$ des filles) et dont les enfants demeurent victimes des atrocités indicibles de forces et groupes armés, la présente dissertation doctorale s'interroge sur le contenu et l'efficacité de la protection spéciale réservée à l'enfant - civil ou soldat - en situation de conflits armés.

\begin{abstract}
The system of protection for children in situations of armed conflict, as established by international humanitarian law and supplemented by international human rights law and international criminal law, remains subject to numerous pitfalls. These pitfalls are closely intertwined with the definition of the obligations of the parties to the conflict and the mechanisms that ensure the implementation of the aforementioned obligations. Using the Democratic Republic of the Congo as a case study, a country that is estimated to have more than 30,000 child soldiers (with approximately 15\% of the child soldiers being girls) and whose children remain victims of the unspeakable atrocities of armed forces and groups, this doctoral dissertation aims to question the content and effectiveness of the special protection of children, civilian or soldier, in situations of armed conflict.
\end{abstract}

\begin{abstract}
Het systeem ter bescherming van kinderen tijdens gewapende conflicten, zoals vastgesteld in het internationaal humanitair recht en aangevuld door de internationale mensenrechten en het internationaal strafrecht, blijft onderhevig aan valkuilen. Deze valkuilen zijn nauw verwant met de definitie van de verplichtingen van de partijen bij het conflict en de mechanismen die instaan voor het verzekeren van de uitvoering van de bovenvermelde verplichtingen. Gebruik makend van een case study van de Democratische Republiek Congo, een land dat naar schatting meer dan 30,000 kindsoldaten heeft (waarvan bij benadering 15\% meisjes) en waar kinderen het slachtoffer blijven van onuitsprekelijke wreedheden gepleegd door strijdkrachten en -groepen, beoogt dit doctoraal proefschrift de bevraging van de inhoud en effectiviteit van de speciale bescherming van kinderen - burger of soldaat - in situaties van gewapend conflict.
\end{abstract}




\section{DEDICACE}

A mes parents, Protais MUMBALA et Anne MUNSAYONGO, que le destin n'a pas permis de lire ces lignes dédiées à l'enfant, couronnement de leurs abnégations consenties plus de trois décennies durant...Puisse la terre de nos ancêtres leur demeurer douce et légère.

A Guerline NIZET, compagne de première heure de combat, le nec plus ultra de ma vie, pour son amour, sa patience, son optimisme, ses sacrifices incalculables qui n'ont laissés aucunement raison à l'abandon et au désespoir. Elle sait mieux que quiconque le coût vital de ces lignes...A travers elle, à toute la famille NIZET.

A Zelya Julie Cedrick MUMBALA-NIZET, dont la présence ne cesse d'illuminer le quotidien de ma vie d'immense bonheur parfait et à qui j'adresse affectueusement ce poème de Mahatma Gandhi, mon Maître à penser :

Prends ton sourire, et donne-le à celui qui n'en a jamais eu.

Prends un rayon de soleil, et fais-lui percer les ténèbres.

Découvre une source, et purifie celui qui est dans la boue.

Prends une larme, et dépose-la sur le visage de celui qui ne sait pas pleurer.

Découvre un sens à la vie, et partage-le avec celui qui ne sait plus où il va.

Prends dans tes mains l'espérance, et vis dans la lumière de ses rayons.

Prends la bonté, et donne-la à celui qui ne sait pas donner.

Découvre l'amour, et fais-le connaître à tous.

A Agnès MUNSAYONGO, “m'aleki”, à l'égard de qui je demeure très redevable. Ses bienfaits inestimables frisant souvent l'expression de sacrifices suprêmes restent sans mots. Par son canal, mes pensées à la famille MUMBALA, à mes oncles, tantes, cousins et cousines.

Aux enfants, d'hier et d'aujourd'hui, victimes des atrocités indicibles sur les champs de bataille en République Démocratique du Congo. 


\section{REMERCIEMENTS}

S'il est vrai que la qualité d'auteur m'attribue la responsabilité de ces lignes, il est aussi vrai que sans le concours de certaines institutions et des personnes bienveillantes, la présente dissertation doctorale n'aurait pas vu le jour. Il m'est donc agréable de leur exprimer mes sentiments de reconnaissance.

Mes remerciements s'adressent en premier lieu à la Coopération Technique Belge (CTB) pour la bourse qu'elle m'a octroyée pour effectuer ces recherches, plus particulièrement aux différents gestionnaires de cette bourse pour leurs encouragements et flexibilités concernant mes diverses demandes tout au long de cette thèse.

«Jeune Chercheur, on n'est pas son propre guide!» écrivait Olivier de Frouville dans sa dissertation doctorale ${ }^{1}$, c'est avec joie incommensurable que je témoigne ma profonde gratitude à mon promoteur de thèse, Monsieur Eduard Somers, Professeur émérite et doyen honoraire de la faculté de droit de l'Université de Gand. Sa confiance à ma modeste personne, son soutien permanent même à son admission à l'éméritat, sa disponibilité à mes préoccupations, ses conseils scientifiques avisés et son humanisme ont été précieux à l'aboutissement de cette œuvre. Qu'il en soit ainsi remercié infiniment !

Dans la même optique, mes sentiments de reconnaissance s'adressent à Madame An Cliquet, Professeure à la faculté de droit de l'Université de Gand, pour l'attention soutenue qu'elle a toujours réservée à mes recherches. Sa disponibilité, sa considération, ses conseils pour l'issue positive de ce travail continuent de me marquer. En outre, je lui suis entièrement reconnaissant pour avoir accepté la responsabilité institutionnelle de cette thèse après l'admission à l'éméritat du Professeur Eduard Somers.

Monsieur le Professeur émérite Rik Coolsaet, membre du Comité d'encadrement de cette thèse, doit être sincèrement et infiniment remercié également. Ses remarques, conseils et différentes questions, lors des évaluations de ces recherches, m'ont permis de baliser conséquemment les voies pour arriver à bon port.

A travers eux, que toutes les autorités académiques de l'Université de Gand et celles de sa faculté de droit soient sincèrement remerciées.

Ma profonde reconnaissance à Madame Kristien Ballegeer et à Monsieur Luc De Bie pour leur promptitude à réserver des réponses positives à mes préoccupations durant ce doctorat.

Que le Professeur Jean Berchkmans Labana Lassay'Abar, Recteur honoraire de l'Université de Kinshasa, soit infiniment remercié pour son accompagnement de plus de dix ans sur ce long processus d'apprentissage et du savoir. Puisse le Professeur Thierry Moreau de l'Université Catholique de Louvain, source d'inspiration de cette réflexion, être à jamais remercié également.

Cette thèse n'aurait pas la forme actuelle, en dépit de ses imperfections persistantes, sans les différents séjours de recherche effectués ici et ailleurs. C'est ainsi que je témoigne ma profonde gratitude à l'Institut de Recherche en droit international et européen (IREDIES) de l'Université Paris 1 Panthéon-Sorbonne, au Centre de Recherche sur les droits de l'homme et

\footnotetext{
${ }^{1}$ FROUVILLE, Olivier de, L'intangibilité des droits de l'homme en droit international. Régime conventionnel des droits de l'homme et droits des traités, Paris, éd. A. Pedone, 2004, p. XI.
} 
le droit humanitaire $(\mathrm{CRDH})$ de l'Université Paris 1 Panthéon-Assas et au Centre de droit international (CDI) de l'Université Libre de Bruxelles (ULB) de m'avoir accueilli favorablement en qualité de chercheur invité. Je remercie, dans le même ordre, l'Institut International de droit humanitaire (Sanremo/ Italie) pour les facilités et la bourse m'accordées afin de parfaire ma connaissance en droit international humanitaire en son sein. Je ne saurais, dans ce sens, exprimer avec des mots appropriés ma profonde reconnaissance au Professeur Michel Veuthey, Vice-Président de l'Institut International de droit humanitaire, pour les échanges fructueux effectués, d'abord physiquement à Sanremo et ensuite par mails, au sujet de cette thèse. Lesquels échanges ont permis d'améliorer considérablement le plan et le contenu de cette thèse.

Toute ma reconnaissance aux Professeurs Eva Brems et Tom Ruys de l'Université de Gand pour avoir accordé une oreille attentive à mes balbutiements en dépit de leur emploi du temps surchargé. Ces mêmes sentiments s'étendent au Professeur Djamchid Momtaz de l'Université de Téhéran, qui en marge de son Cours général à l'Académie de Droit international de La Haye (2014) a daigné m'accorder du temps pour présenter les lignes maîtresses de cette réflexion et y a formulé des observations avisées.

Je suis très rédévable à l'égard du Professeur Fidèle Zegbe Zegs. Il a accepté sans atermoiements et avec gentillesse de relire le manuscrit de cette thèse et formuler non seulement des avis critiques mais également des encouragements patriotiques. Ces sentiments s'adressent aussi à Pauline Warnotte, qui en dépit de ses lourdes charges professionnelles, n'a point hésité à relire méticuleusement cette dissertation. Ses observations et avis critiques sur le plan formel et substantiel ont été d'un grand apport. Dans le même sens, que Jesus Perès Sanchez et Jelena Aparac soient remerciés pour leurs lectures bienveillantes et critiques à l'égard de ce travail.

Ma profonde reconnaissance s'adresse à mes Professeurs du Centre de droit international de l'ULB qui m'ont marqués très positivement dans la manière d'appréhender le droit international. Leur esprit critique aiguisé, leur rigueur dans la formation sans compter leur entière disponibilité aux préoccupations des étudiants ont rendu agréable mon séjour d'études en Master de spécialisation en droit international. Ainsi, que les Professeurs Eric David (mon directeur de mémoire), Olivier Corten, Pierre Klein, Nicolas Angelet, François Dubuisson, Vaois Koutroulis, Vincent Chapaux et Anne Lagerwall soient infiniment remerciés. Une mention particulière au Professeur Olivier Corten, dont le savoir, la gentillesse et la simplicité m'ont toujours émerveillé, pour ses réponses positives réservées à mes diverses demandes durant mes séjours de recherche et de formation au Centre de droit international de l'ULB. Ceci vaut aussi à Madame la Professeure Anne Lagerwall qui, au-delà de m'avoir façonné dans les enseignements de Responsabilité internationale, m'a permis de réaliser le rêve de gamin, celui d'assister à la prestation de serment en qualité de juge ad hoc du célèbre internationaliste Mohammed Bedjaoui, au siège de la Cour internationale de justice à La Haye (Pays-Bas).

Dans le même ordre d'idées, je demeure rédévable à mes Professeurs des Universités Catholique de Louvain, Saint-Louis, et de Namur pour des précieux enseignements reçus durant mes formations de Masters de spécialisation en droits de l'homme et en Analyse interdisciplinaire de la construction européenne. Que Madame la Professeure Nathalie Colette-Basecqz, qui a guidé mes premiers pas sous ce thème, trouve ici l'expression de ma sincère reconnaissance.

Je ne saurais oublier mes Professeurs des Universités congolaises, particulièrement ceux de l'Université de Lubumbashi, qui ont forgé mes premiers pas dans les arcanes du droit. Une 
mention particulière aux Professeurs Lunda Bululu (mon modèle), Kishiba Fitula (Recteur de l'Université de Lubumbashi), Yav Katshung, Tshitambwe Kazadi, Tshizanga Mutshipangu, Jan Gorus et Georges Mulumbeni. Dans la même optique, que le juge Zephirin Losange, enseignant à la faculté de droit de l'Université de Lubumbashi, soit remercié pour tout.

Que les Professeurs Mande Mutombo, Armand Kabange (Directeur général de l'ISC/Lubumbashi), Kizobo O’bweng (Secrétaire général Académique de l'Université de Lubumbashi), Jean-Pierre Mayele Ilo, Kitaba Kya Ghoanis, Kayiba Bukasa, Monsieur Mubinda Ngampey et collègues de l'ISC/Lubumbashi soient vivement remerciés pour leur soutien à l'achèvement de ces recherches.

Cette thèse de doctorat ne serait réalisée sans le soutien de mes familles, amis et proches qu'il serait impossible de citer exhaustivement. Les expressions demeurent insignifiantes pour leur traduire exactement ma marque de reconnaissance et d'attachement.

Tout de même, de tout cœur que la Famille Nizet - Jean-Louis Nizet, Dominique Ledent (Mamy Do), J.B Nizet et Solange, Amandine Nizet et Hatem Soua, Mamy Ines - soit vivement et infiniment remerciée pour son soutien inlassable à l'aboutissement de cette œuvre.

Toute ma reconnaissance à la congrégation de Témoins de Jéhovah, particulièrement à la famille Shamuska.

Que les familles Aimé Katalisi et André Okitapoy soient vivement remerciées pour tout.

Mille mercis à Manissa Mbungu Fiston et Madame Yana Pongo (Bobila), Marcellin Kazadi, Me Carlos Kalonji, Françis Salumu (Mirage supersonic), «Les Amis de Masina PetroCongo », la Famille Ejalcom dont la présence dans ma vie ne cesse de me rappeler mes origines et une lutte pour l'avenir.

Un immense merci à Clément Lokandja Tokenge, affectueusement nommé Pierre Avril (du nom d'un juriste constitutionnaliste français), mon alter ego, plus qu'un frère. Ensemble avec lui, la raison et l'amour ont construit indéfectiblement notre amitié, une arme efficace sans laquelle je n'arriverais jamais au bout de cette aventure. Mes chaleureux remerciements, dans le même sens, vont droit à Me Adolphe Bambi Kabambi (Coordonnateur général de la Brigade), Dr. Blaise Ntirumenyerwa, Yannick Mamengi wa Mamengi, Cédrick Mayele Mabilu (idéologue), Cédrick Bandasi, Marcel Makwekele, Lessix Mopembe Tamango, Me Pitchou Kalala, Me Patrick Tshokote, Kadi Lapika, Adalbert Atakana, Me Patrick Kiba, Me Gambool Mabenga et Denis Ponge pour leur soutien infaillible.

Toute ma gratitude à Ezéchiel Amani Cirimwami pour nos vives et passionnantes discussions sur le droit international, le droit international humanitaire et le droit international des droits de l'homme.

A travers cet échantillon d'amis, représentant par là ceux non mentionnés mais pas oubliés, j'adresse cette belle parole d'Epicure : «Ce n'est pas tant l'intervention de nos amis qui nous aide mais le fait de savoir que nous pourrons toujours compter sur eux ». 
«Les conflits armés causent d'énormes souffrances aux enfants. Or, nombre de ces souffrances pourraient être évitées si les règles du droit international humanitaire étaient mieux connues et respectées ».

Assemblée générale des Nations Unies, 70e session, 3ème Commission, Point 68 de l'ordre du jour. Déclaration du CICR, New York, le 15 octobre 2015, § 8. 


\section{LISTE DE PRINCIPALES ABREVIATIONS}

AFDI

AFDL

AG/NU

art

« art. cit. »

ASADHO

BCNUDH

BUNADER

CAEDBE

CDE

CDI

CEDH

cf.

CG

CG I

CG II

CG III

CG IV

CICR

\section{CIJ}

CIRGL,

CJCE

CJUE

CM

CMM

CMO

CNDP

CONADER

CPI

CS/NU

DDR

DI

DIDH

DIH

DIPé

DUDH

EAFGA

FAC

FARDC

FAZ

FDLR

GLN

GRIP

HCDH

Ibid.

Annuaire français de droit international

Alliance des Forces Démocratiques pour la Libération du Congo - Zaïre

Assemblée générale des Nations Unies

Article

Article cité

Association Africaine de Défense des Droits de l'Homme

Bureau Conjoint des Nations Unies aux Droits de l'Homme

Bureau National pour la Démobilisation et la Réinsertion

Comité africain d'experts sur les droits et le bien-être de l'enfant

Convention relative aux droits de l'enfant (20 novembre 1989)

Commission du droit international

Cour européenne des droits de l'homme

Confer

Conventions de Genève du 12 août 1949

Convention (I) de Genève pour l'amélioration du sort des blessés et des malades dans les forces armées en campagne, 12 août 1949.

Convention (II) de Genève pour l'amélioration du sort des blessés, des malades et des naufragés des forces armées sur mer, 12 août 1949.

Convention (III) de Genève relative au traitement des prisonniers de guerre, 12 août 1949.

Convention (IV) de Genève relative à la protection des personnes

civiles en temps de guerre, 12 août 1949.

Comité international de la Croix-Rouge

Cour internationale de Justice

Conférence Internationale de la Région des Grands Lacs

Cour de justice des Communautés européennes

Cour de justice de l'Union européenne

Cour Militaire

Commission Militaire Mixte

Cour Militaire Opérationnelle

Congrès National pour la Défense du Peuple

Commission Nationale de Désarmément, Démobilisation et Réinsertion

Cour pénale internationale

Conseil de Sécurité des Nations Unies

Désarmement, Démobilisation et Réinsertion (Réintégration)

Droit international

Droit international des droits de l'homme

Droit international humanitaire

Droit international pénal

Déclaration Universelle des droits de l'Homme

Enfants associés aux forces ou groupes armés

Forces Armées Congolaise

Forces Armées de la République Démocratique du Congo

Forces Armées Zaïroises

Forces Démocratiques pour la Libération du Rwanda

Guerre de Libération Nationale

Groupe de recherche et d'information sur la paix et la sécurité

Haut Commissariat des Nations Unies aux Droits de l'Homme

Ibidem 
IDI

J.D.J

LRA

M23

MLC

MLN

MONUC

MONUSCO

OCHA

OI

OIT

ONG

ONU

op. cit.,

OUA

PA

PA I

PA II

PA III

PIDCP

PIDESC

PNDDR

RADIC

RBDI

RCD

RCD/KML

RCD/N

RDC

RDIDC

$R D P C$

RGDIP

RICR

RQDI

RTDH

RTNU

SADC

SG/NU

SPE

TMG

TSSL

UA

Institut de droit international

Journal du droit des jeunes

Lord's Resistance Army

Mouvement du 23 mars

Mouvement de Libération du Congo

Mouvement de Libération Nationale

Mission de l'Organisation des Nations en République Démocratique du Congo

Mission de 1'Organisation des Nations unies pour la Stabilité en

République Démocratique du Congo

Bureau de Coordination des Affaires humanitaires

Organisation internationale

Organisation Internationale du Travail

Organisation non gouvernementale

Organisation des Nations Unies

Opus citatum

Organisation de l'Unité Africaine

Protocole additionnel aux Conventions de Genève du 12 août 1949

relatif à la protection des victimes des conflits armés internationaux

(Protocole I), 8 juin 1977.

Protocole additionnel aux Conventions de Genève du 12 août 1949

relatif à la protection des victimes des conflits armés internationaux

(Protocole I), 8 juin 1977.

Protocole additionnel aux Conventions de Genève du 12 août 1949

relatif à la protection des victimes des conflits armés non internationaux (Protocole II), 8 juin 1977.

Protocole additionnel aux Conventions de Genève du 12 août 1949

relatif à l'adoption d'un signe distinctif additionnel (Protocole III), 8

décembre 2005

Pacte international relatif aux droits civils et politiques

Pacte international relatif aux droits économiques, sociaux et culturels

Programme National de Désarmement, Démobilisation et Réinsertion

Revue africaine de droit international et comparé

Revue belge de droit international

Rassemblement Congolais pour la Démocratie

Rassemblement Congolais pour la Démocratie/Kisangani - Mouvement de libération

Rassemblement Congolais pour la Démocratie/ Nationaliste

République Démocratique du Congo

Revue de droit international et de droit comparé

Revue de droit pénal et de criminologie

Revue générale de Droit International Public

Revue internationale de la Croix-Rouge

Revue québécoise de droit international

Revue trimestrielle des droits de l'homme

Recueil des Traités des Nations Unies

Southern African Development Community

Secrétaire général des Nations Unies

Section de Protection de l'Enfant de la MONUSCO

Tribunal Militaire de Garnison

Tribunal spécial pour la Sierra Leone/ Special Court for Sierra Leone

Union Africaine 
UE

UEPNDDR

UNICEF

UPDF

Voy.

$\S / \S \S$
Union européenne

Unité d'exécution du Programme national de désarmement, démobilisation et réinsertion

Fonds des Nations Unies pour l'enfance

Uganda People's Defense Forces

Voir

Paragraphe/ Paragraphes 


\section{SOMMAIRE}

PREMIERE PARTIE

LE DROIT INTERNATIONAL HUMANITAIRE ET LA PROTECTION DES ENFANTS EN SITUATION DE CONFLITS ARMES

CHAPITRE PREMIER

DEFINITION DU CADRE CONCEPTUEL

CHAPITRE II

DROIT INTERNATIONAL HUMANITAIRE : REGLES ET MECANISMES DE PROTECTION : QUELLE MISE EN GEVRE ?

CHAPITRE III

LES REGLES DE PROTECTION DES ENFANTS DANS LES CONFLITS ARMES EN DROIT INTERNATIONAL HUMANITAIRE

CHAPITRE IV

LES MECANISMES DE PROTECTION DES ENFANTS EN SITUATION DE CONFLITS ARMES

DEUXIEME PARTIE

LE DROIT INTERNATIONAL HUMANITAIRE ET LA PROTECTION DES ENFANTS EN SITUATION DE CONFLITS ARMES EN REPUBLIQUE DEMOCRATIQUE DU CONGO

CHAPITRE PREMIER

CONFLITS ARMES ET ENFANTS EN REPUBLIQUE DEMOCRATIQUE DU CONGO

CHAPITRE II

LES REGLES DU DROIT INTERNATIONAL HUMANITAIRE RELATIVES A LA PROTECTION DES ENFANTS EN RDC

CHAPITRE III

LES MECANISMES DE PROTECTION DES ENFANTS EN SITUATION DE CONFLITS ARMES EN RDC 


\section{INTRODUCTION}

«Durant les conflits des dernières décennies, des millions d'enfants ont été victimes, handicapés, abandonnés, traumatisés ou sont restés orphelins $»^{2}$. Ils «constituent $40 \%$ des victimes civiles des conflits et plus de $50 \%$ des réfugiés et des personnes déplacées $»^{3}$. Ces graves violations dont sont victimes les enfants ont donc gagné en intensité dans différentes situations conflictuelles à l'heure actuelle ${ }^{4}$. «Ces dernières années, les représentants des structures de protection de l'enfant des Nations Unies ont noté avec préoccupation que la nature changeante des conflits armés et des tactiques employées dans ce cadre créaient des menaces sans précédent pour les enfants $»^{5}$. S'il est vrai que depuis la nuit de temps les enfants ont toujours pris part à la guerre notamment dans un rôle de soutien aux troupes comme espions, guetteurs, messagers, cuisiniers, esclaves sexuels, etc., plus rarement comme combattants, ils sont actuellement de plus en plus impliqués dans les combats ${ }^{6}$. C'est au cours des dernières décennies du $\mathrm{XX}^{\mathrm{e}}$ siècle, plus précisément au début des années 1990, que ce phénomène a atteint une ampleur jusqu'alors inconnue ${ }^{7}$. «Jamais autant d'enfants n'ont fréquenté les champs de bataille $[\ldots]^{8}{ }^{8}$. Cette implication massive des enfants est en partie justifiée par la prolifération et la nature changeante des conflits armés caractérisée par plus de guerres civiles que de guerres classiques ${ }^{9}$. Guerres civiles dans lesquelles les enfants constituent des cibles directes d'attaques et des «moyens indiqués » de réaliser les objectifs des belligérants.

\footnotetext{
${ }^{2}$ BETTATI, Mario, Droit humanitaire, $1^{\text {re }}$ édition, Dalloz, Paris, 2012, p. 189. Voy. aussi AMANN, Diane Marie, «Children », in SCHABAS, William A. (ed.), International criminal law, Cambridge University Press, Cambridge, 2016, p. 253.

${ }^{3}$ BOUCHET-SAULNIER, Françoise, Dictionnaire pratique du droit humanitaire, éd. La Découverte, Paris, 2013, p. 342.

${ }^{4}$ Voy. les paragraphes 4-5 de la Résolution AG/NU et CS/NU A/70/836-S/2016/360, Le sort des enfants en temps de conflit armé, Rapport du Secrétaire général, in http://www.un.org/fr/sc/documents/sgreports/2016.shtml (Source consultée le 5 juillet 2016).

5 §9 de la Résolution AG/NU et CS/NU A/67/845- S/2013/245 Le sort des enfants en temps de conflit armé, Rapport du Secrétaire général, in http://www.un.org/fr/sc/documents/sgreports/2013.shtml (Recherche menée le 06 décembre 2013).

${ }^{6}$ SCHMITZ, Marc, « Les enfants-soldats, un phénomène universel de plus en plus préoccupant », in SCHMITZ, Marc, (coord.), La guerre. Enfants admis. 300.000 enfants-soldats dans le monde: comment combattre ce fléau? éd. GRIP - éditions Complexe, Bruxelles, 2001, pp. 24-25; Voy. HAPPOLD, Matthew, « Protecting children in Armed conflict: harnessing the Security Council's "Soft power" », in Israël law Review, vol. 43, 2010, p. 360; LOUYOT, Alain, Les enfants soldats, éd. Perrin, Paris, 2007, pp. 10-11; KALONJI, Anne, « La protection des enfants au cœur des premières poursuites intentées devant la Cour pénale internationale et le tribunal spécial pour la Sierra Leone ", Sociétés et jeunesses en difficulté, $\mathrm{n}{ }^{\circ} 6 / 2008$, p. 2 disponible sur http://sejed.revues.org/index4933.htmlp (Source consultée le 26 mai 2016); HABIBU, Jean Bosco, L'effectivité du Statut de la Cour Pénale Internationale: Référence spéciale à la situation concernant la République Démocratique du Congo, édition de l'ACAT, Bukavu, 2007, p. 53.

${ }^{7}$ CHAPLEAU, Philippe, Enfants-soldats. Victimes ou criminels de guerre?, éditions du Rocher, Monaco, 2007, p. 20 ; MARTIN CHENUT, Kathia, «La protection des enfants en temps de conflit et le phénomène des enfantssoldats », in SOREL, Jean-Marc et POPESCU, Corneliu-Liviu (dir.), La protection des personnes vulnérables en temps de conflit armé, éd. Bruylant, Bruxelles, 2010, p.161.

${ }^{8}$ CHAPLEAU, Philippe, Enfants-soldats. Victimes ou criminels de guerre ?, op. cit., p. 19.

${ }^{9}$ SCHMITZ, Marc, «Les enfants-soldats, un phénomène universel de plus en plus préoccupant », «art. cit. », p. 25. Voy. aussi JEANGENE VILMER, Jean-Baptiste, «L'éthique de la guerre », in JEANGENE VILMER, JeanBaptiste et CHUNG, Ryoa, (dir.), Ethique des relations internationales, PUF, Paris, 2013, p. 157 ; MARTIN CHENUT, Kathia, «La protection des enfants en temps de conflit et le phénomène des enfants-soldats », «art. cit. », p. 161.
} 
Face à ce drame, le droit international humanitaire (DIH) s'emploie à redonner l'espoir perdu par la protection qu'il tente d'assurer en pleine situation de conflits armés. A cet effet, il institue au plan conventionnel des droits ${ }^{10}$, des règles et des mécanismes pour assurer une protection spéciale aux enfants en raison de leur vulnérabilité physique et psychique particulière. Si cette protection est observée dès les Conventions de Genève du 12 août 1949 (CG) pour les enfants - civils -, ce n'est que tardivement que la situation des enfants -soldatssera prise en compte par le DIH à travers les Protocoles additionnels I et II du 8 juin 1977 (PA I et II).

Cependant, le régime de protection de l'enfant en situation de conflits armés tel qu'institué par le DIH et complété par le droit international des droits de l'homme (DIDH), voire le droit international pénal (DIPé), reste sujet à de nombreux écueils. Ceux-ci sont à situer plus au niveau de la définition des obligations à l'endroit des parties au conflit et des mécanismes devant assurer l'effectivité de ces obligations sur le champ de bataille au profit des enfants. Dans cette optique, prenant pour cadre d'investigation la République Démocratique du Congo (RDC), pays qui comptait 30.000 enfants soldats (dont plus ou moins $15 \%$ étaient des filles) soit les $10 \%$ des enfants soldats du monde ${ }^{11}$, et dont les enfants demeurent victimes des atrocités indicibles de forces armées, de groupes armés et d'affrontements intercommunautaires $^{12}$, la présente dissertation doctorale s'emploie à s'interroger sur le contenu et l'efficacité de la protection spéciale réservée à l'enfant - civil ou soldat, y compris le fonctionnement des mécanismes de mise en œuvre de cette protection.

\section{Contexte}

\section{1. Protection générale accordée aux enfants en situation de conflits armés}

«La guerre n'est plus ce qu'elle était ${ }^{13}$. Le droit n'est toujours pas ce qu'il devrait. L'une

10 Voy. GAGGIOLI, Gloria, L'influence mutuelle entre les droits de l'homme et le droit international humanitaire à la lumière du droit à la vie, éd. A. Pedone, Paris, 2013, pp. 251-252.

${ }^{11}$ Voy. Comité des droits de l'enfant, Examen des Rapports présentés par les Etats parties en application de l'article 44 de la Convention, Rapports périodiques des Etats parties devant être soumis en 1997, République Démocratique $d u \quad$ Congo, CRC/C/COD/2, 24 juillet 2008, p. 47, \$201, in http://tbinternet.ohchr.org/_layouts/treatybodyexternal/TBSearch.aspx?Lang=en\&TreatyID=5\&TreatyID=10\&T reatyID=11\&DocTypeID=29\&DocTypeCategoryID=4 (Source consultée le 10 janvier 2016). Voy. aussi Nations Unies, Haut Commissariat aux droits de l'homme, Rapport du Projet Mapping concernant les violations les plus graves des droits de l'homme et du droit international humanitaire commises entre mars 1993 et juin 2003 sur le territoire de la République démocratique du Congo, Août 2010, p. 343, §673.

${ }^{12}$ Voy. les paragraphes 44-57 de la Résolution AG/NU et CS/NU A/70/836-S/2016/360, Le sort des enfants en temps de conflit armé, Rapport du Secrétaire général, in http://www.un.org/fr/sc/documents/sgreports/2016.shtml (Source consultée le 5 juillet 2016).

13 «Depuis un siècle, et plus nettement encore depuis la fin de la seconde guerre mondiale, les moyens de combat se sont à la fois accrus et diversifiés. Sans même évoquer la question des armes nucléaires, les techniques de la menace ou de l'usage de la violence se sont multipliées. Terrorisme, prise d'otages, recours aux moyens d'intimidation ou de répression massive des populations, utilisation de mercenaires ou de personnel privé ont atténué la distinction entre combattants et non-combattants. On estime ainsi que, durant la première guerre mondiale, la proportion de pertes fut de vingt combattants pour un civil. Elle serait désormais de dix civils pour un combattant. Le renforcement du droit humanitaire et de sa mise en œuvre n'en sont que plus nécessaires et plus difficiles». Voy. COMBACAU, Jean et SUR, Serge, Droit international public, éd. Montchrestien, 7è édition, Paris, 2006, 669-670; Lire SASSÒLI, Marco et BOUVIER, Antoine A., Un droit dans la guerre ?, Vol.1, CICR, Genève, 2003, p. 178. ; République Française, Ministère de la défense, Direction des 
progresse dans la force de destruction quand l'autre persiste dans la faiblesse des protections. De cet affrontement des réalités et des attentes naît l'artifice juridique. Face à une guerre qui s'impose dans le hasard ou la nécessité, l'homme veut en limiter les conséquences par une réglementation de son exercice $»^{14}$.

«On ne peut définir le cadre juridique international qui réglemente la protection ou la participation des enfants aux hostilités sans aborder celui plus large de la protection accordée par le droit aux enfants dans la guerre. L’interrogation consommée « Enfants-soldats : victimes ou bourreaux ? » trouve en fait tout son sens dans la réponse partielle - parce que juridique - que le droit international [DI] et plus particulièrement le [DIH] lui a donnée. En effet, le [DIH], soit le droit applicable en cas de conflit armé, accorde une protection juridique à l'enfant en cas de conflit, qu'il soit victime ou acteur ${ }^{15}$. « Cette protection sera déclinée en fonction de ce que l'enfant sera considéré comme un simple civil ne participant pas aux hostilités, comme un civil particulièrement vulnérable en raison de son jeune âge, ou encore comme un combattant $»^{16}$.

En effet, « [1] ors d'un conflit armé - qu'il soit international ou non - l'enfant bénéficie de la protection générale accordée par le $[\mathrm{DIH}]$ aux personnes civiles qui ne participent pas aux hostilités $»^{17}$. Ainsi, considéré comme une personne qui ne prend pas part aux hostilités et se trouvant au pouvoir d'une partie au conflit, l'enfant bénéficie d'un ensemble de dispositions des CG et des PA qui imposent généralement aux parties de lui accorder, à l'instar d'autres personnes civiles, un traitement humain ${ }^{18}$ - entendu comme «le minimum de ce qui doit être réservé à l'individu pour qu'il puisse mener une existence acceptable ${ }^{19}$ - en toutes circonstances $^{20}$ et de le protéger contre tout acte pouvant porter atteinte à sa vie et à son intégrité physique et morale.

Pris comme acteur d'une partie dans un conflit armé international (CAI), l'enfant n'est non moins un sujet protégé. Il se verra donc reconnaître la qualité de combattant, par opposition à une personne civile. « [c]e qui [lui] permet en cas de capture de bénéficier du statut de prisonnier de guerre au sens de la III $^{\mathrm{e}}$ Convention de Genève relative au traitement des prisonniers de guerre du 12 août 1949. [...] $»^{21}$. Dans le cas des conflits armés non internationaux (CANI), l'enfant, notamment celui de moins de quinze ans, qui prend (ou a

affaires juridiques, Manuel de droit des conflits armés, SGA/Com, Paris, 2003, p. 11.

${ }^{14}$ FURET, Marie-Françoise, MARTINEZ, Jean-Claude et DORANDEU, Henri, La guerre et le droit, éd. A. Pedone, Paris, 1979, p. 5.

${ }^{15}$ KÜNTZIGER, Isabelle et GALAND, Renaud, «Quels règles et mécanismes internationaux pour protéger les enfants dans la guerre? », in SCHMITZ Marc (Coord.), La Guerre Enfants admis. 300.000 enfants-soldats dans le monde : comment combattre ce fléau, op. cit., p. 127.

${ }^{16}$ Ibid.

${ }^{17}$ MARTIN CHENUT, Kathia, «La protection des enfants en temps de conflit et le phénomène des enfantssoldats », « art. cit. », p. 173

${ }^{18}$ Signifions, à titre indicatif, que «Toutes les 3 chambres du TPIR ont eu à décider, souvent à l'unanimité, que l'une des conséquences de la règle de traitement humain réside dans la nécessité de fournir une protection renforcée aux catégories de personnes civiles qui subissent, d'une façon particulièrement grave, les effets des conflits armés et qui se retrouvent, de ce fait, dans une situation de grande détresse (BIRUKA Innocent, La protection de la femme et de l'enfant dans les conflits armés en Afrique, éd. L'Harmattan, Paris, 2006, p. 217).

${ }^{19}$ PICTET, Jean, Les principes du droit international humanitaire, CICR, Genève, 1966, p. 31.

${ }^{20}$ GASSER, Hans-Peter, «Protection of the civilian population », in FLECK, Dieter (ed.), The Handbook of humanitarian law in armed conflicts, Oxford University Press, New-York, 1995, pp. 216-217.

${ }^{21}$ KÜNTZIGER, Isabelle et GALAND, Renaud, op.cit., pp. 131-132. 
pris) directement part aux hostilités, se retrouvera également sous le régime applicable aux personnes qui prennent part (ou ont pris part) aux hostilités sous ce type de conflits.

Bien plus, comme pour les personnes civiles ou combattantes en général, le corpus juridique relatif à la protection des enfants en période de conflits armés ne se limite pas au seul $\mathrm{DIH}^{22}$. Au-delà des CG et de leurs PA, ou du DIH coutumier, l'enfant se trouve également sous la protection des instruments du DIDH en conflits armés. Ces deux branches -DIH et DIDH-, indique Jean PICTET, «sont complémentaires et se complètent admirablement ${ }^{23}$. Ainsi, l'application des règles du DIH n'est pas exclusive de l'application des instruments de protection du $\mathrm{DIDH}^{24}$. Cette complémentarité est d'ailleurs rappelée par le PA I en son article $72^{25}$ et par le PA II en son préambule ${ }^{26}$. Le DIPé et le droit international général ne se trouvent pas non plus exclus d'application.

\section{2. Protection spéciale accordée aux enfants en situation de conflits armés}

«Etant donné la vulnérabilité particulière de l'enfant, les Conventions de Genève et leurs protocoles additionnels prévoient également un régime de protection spéciale en sa faveur, qui bénéficie même à l'enfant qui prend directement part aux hostilités ${ }^{27}$. Ces dispositions ${ }^{28}$ accordent aux enfants une protection spéciale «afin que les droits des plus faibles ne soient pas ceux d'un faible droit $»^{29}$. En termes de protection spéciale, la CG IV vise par exemple : le droit des parties au conflit de créer sur leurs propres territoires ou sur les territoires occupés

\footnotetext{
${ }^{22}$ MARTIN CHENUT, Kathia, «La protection des enfants en temps de conflit et le phénomène des enfantssoldats », « art. cit. », p. 166.

${ }^{23}$ PICTET, Jean, «Le droit international humanitaire : définition », in Les dimensions internationales du droit humanitaire, Institut Henry Dunant -UNESCO -Pedone, Genève-Paris, 1986, p. 15. Voy. aussi DAVID, Eric, Principes de droit des conflits armés, $5^{\mathrm{e}}$ édition, Bruylant, Bruxelles 2012, pp. 93-102. Lire aussi avec intérêt FALILOU DIOP, Mamadou, Droit international des droits de l'homme et droit international humanitaire. Réflexions sur la complémentarité de deux faces d'une même médaille, L'Harmattan, Paris, 2016, 235 p. Pour ce sujet, Eric DAVID renseigne que « [1] problème de l'application des droits de la personne aux conflits armés et de leurs relations avec le droit des conflits armés a suscité une littérature abondante ». Voy. DAVID, Eric, Principes de droit des conflits armés, $5^{\mathrm{e}}$ édition, op.cit., p. 93

${ }^{24}$ Voy. MEYER, Antoine, «La protection de l'enfance dans les conflits armés : perspectives de mise en œuvre des normes du droit international humanitaire et du droit international des droits de l'homme ", in BIAD, Abdelwahab et TAVERNIER, Paul (dir.), Le droit international humanitaire face aux défis du XXIe Siècle, Bruylant, Bruxelles, 2012, p. 223. ; TIGROUDJA, Hélène, « La Cour suprême israélienne et la protection des personnes en temps de conflit», in RGDIP, 2009-3, p. 573 ; GUELLALI, Amna, «Lex speciali, droit international humanitaire et droits de l'homme : leur interaction dans les conflits armés », in RGDIP, 2007-3, p. 543. ; Voy. aussi CIJ, Conséquences juridiques de l'édification d'un mur dans le territoire palestinien occupé, avis consultatif du 9 juillet 2004, Recueil 2004, p. 178, §106; CIJ, Affaire des Activités armées sur le territoire du Congo (République démocratique du Congo c. Ouganda), arrêt, Recueil 2005, p. 243, § 216.

${ }^{25}$ Article 72 du PA I : «Les dispositions de la présente section complètent les normes relatives à la protection humanitaire des personnes civiles et des biens de caractère civil au pouvoir d'une partie au conflit énoncées dans la $\mathrm{IV}^{\mathrm{e}}$ Convention, en particulier aux titres I et III, ainsi que les autres normes applicables du droit international qui régissent la protection des droits fondamentaux de l'homme pendant un conflit armé de caractère international » (nous soulignons). Et sous ladite section s'y trouvent les articles 77 et 78 relatifs respectivement à la Protection des enfants et à l'Evacuation des enfants.

${ }^{26} 3^{\mathrm{e}}$ considérant du Préambule du PA II : «Rappelant également que les instruments internationaux relatifs aux droits de l'homme offrent à la personne humaine une protection fondamentale, »

${ }^{27}$ MARTIN CHENUT, Kathia, «La protection des enfants en temps de conflit et le phénomène des enfantssoldats », « art. cit. », p. 173.

${ }^{28}$ Voy. à ce sujet «Dispositions du droit international humanitaire accordant une protection spéciale aux enfants », in RICR, n759, mai-juin 1986, p. 173.

${ }^{29}$ DEYRA, Michel, Le Droit dans la guerre, Gualino Lextenso éditions, Paris, 2009, p. 155.
} 
des zones et localités sanitaires et de sécurité afin de mettre les enfants de moins de quinze ans à l'abri des effets de la guerre (art.14) ; l'évacuation des enfants d'une zone assiégée ou encerclée (art.17); le libre passage de tout envoi des vivres indispensables, des vêtements et des fortifiants réservés aux enfants de moins de quinze ans (art. 23); les mesures nécessaires à prendre par les parties au conflit au profit des enfants de moins de quinze ans, orphelins ou séparés des familles du fait de la guerre, pour que soient facilités leur entretien, la pratique de leur religion et leur éducation (art. $24 \S 1$ ); l'accueil des enfants en pays neutres (art. $24 \S 2$ ); l'identification des enfants de moins de douze ans (art. 24 §3); le droit au traitement préférentiel pour les enfants de moins de quinze ans, des femmes enceintes et des mères d'enfants de moins de sept ans (art. 38, §5) ; l'intangibilité du statut personnel de l'enfant interdisant à la Puissance occupante de modifier sa situation de famille, son état civil et sa nationalité (art. 50 alinéa 2) ; l'obligation pour la puissance occupante de ne pas entraver l'application des mesures préférentielles prises en faveur des enfants de moins de quinze ans (art. 50, alinéa 5) ; l'obligation de ne pas astreindre au travail des personnes de moins de dixhuit ans (art. 51 alinéa 2) ; l'interdiction des peines de mort (art. 68 alinéa 4) ; l'entretien des personnes dépendant des internés par la Puissance détentrice (art. 81 alinéa 3) ; le regroupement des internés notamment ceux issus d'une même famille en particulier les parents et leurs enfants (art. 82) ; le droit à l'alimentation suffisante et saine dont des suppléments - proportionnés aux besoins physiologiques- pour les femmes enceintes et en couches, et les enfants de moins de quinze ans (art. 89) ; l'assurance de la pratique des activités intellectuelles, éducatives, récréatives et sportives des enfants (art. 94) ; la possibilité de libération, du rapatriement, du retour au lieu de domicile ou l'hospitalisation en pays neutre des enfants, des femmes enceintes et des mères avec nourrissons et enfants en bas âge pendant la durée des hostilités (art. 132).

A cet égard, le PA I traite de: l'appartenance à la catégorie des blessés et malade des femmes en couches, des nouveau-nés, des femmes enceintes (art. $8 a$ ) ); la priorité d'accès au secours et le traitement de faveur pour les enfants, femmes enceintes ou en couches et les mères qui allaitent (art. $70 § 1$ ); les garanties spécifiques pour les enfants détenus, arrêtés ou internés notamment l'interdiction de l'exécution d'une condamnation à mort (art. 77 §5) et la réglementation pour l'évacuation des enfants (art. 78). Enfin, le PA II accorde des garanties fondamentales en son article 4 (équivalent de l'article 75 du PA I ou de l'article 3 commun aux $\mathrm{CG}$ ) et précise au paragraphe 3 alinéa 3 que la protection spéciale que prévoit ledit article restera applicable aux enfants s'ils prennent part aux hostilités et sont capturés.

En ce qui concerne l'interdiction de recrutement et de participation des enfants aux hostilités, la question se trouve réglée par les articles 77 \$2 du PA I et $4 \$ 3$ c du PA II. Une protection spéciale doit être réservée aux enfants de moins de quinze ans capturés (cf. art. 77 §3 du PA I et art. $4 \S 3 d$ du PA II). Toutefois, les enfants qui prennent directement part aux hostilités, sans être capturés, devraient être traités comme tout «combattant». La protection spéciale à cet effet ne peut être invoquée ${ }^{30}$ (cf. infra). En outre, différents instruments du DIDH et du DIPé abordent également cette question et renforcent davantage les dispositions précitées (cf. infra).

\footnotetext{
${ }^{30}$ DINSTEIN, Yoram, The Conduct of Hostilities under the Law of international Armed Conflict, Cambridge University Press, Cambridge, 2004, p. 150.
} 
Il existe également des dispositions de la CG IV ou du PA I qui n'évoquent pas expressément les enfants mais ne sont non moins appréhendées comme renforçant la protection spéciale des enfants $^{31}$. Il s'agit de: droit de correspondance familiale (art. 25 de la CG IV); facilitations par les parties au conflit des recherches entreprises par les membres des familles dispersées pour remettre en contact les uns avec les autres (art. 26 de la CG IV) ; règles encadrant les mesures exceptionnelles de transferts, de déportations ou évacuations (art. 49 de la CG IV) ; obligation pour la Puissance occupante de ne pas astreindre des personnes protégées à servir dans ses forces armées ou auxiliaires (art. 51 alinéa 1 de la CG IV) ; traitement des détenus (art. 76 de la CG IV ); regroupement des familles dispersées (art. 74 du PA I) ; préservation de l'unité familiale en cas d'arrestation, détention ou internement des familles (art. 75 §5 de la CG IV) voire des garanties fondamentales prévues dans la même disposition dans son ensemble.

En somme, cette présentation atteste une réglementation plus avantageuse pour l'enfant « civil » que pour l'enfant qui prend part aux hostilités, « l'enfant soldat ».

\section{Définition du problème}

Le régime de protection spéciale réservé à l'enfant pour palier sa vulnérabilité d'ordre physique et mental, tel que présenté ci-dessus, ne va pas sans poser problèmes.

En effet, au-delà du fait que les CG et leurs PA ne définissent pas le terme «enfant » et utilisent différents termes semblables tels que «mineurs» (cf. art. 76 \$5 de la CG IV), «adolescent» (cf. art. $94 \$ 2$ de la CG IV) sans toutefois les définir non plus, de sérieuses difficultés sont à identifier au niveau de la formulation de leurs dispositions (II.1), de distinction d'âges d'enfants qu'ils entretiennent occasionnant ainsi une protection sélective (II.2) et des mécanismes de protection spéciale de l'enfant en situation de conflits armés (II.3).

\section{II.1. Formulation des dispositions relatives à la protection des enfants en situation de conflits armés laissant une large marge d'appréciation aux Etats.}

La CG IV contient différentes dispositions relatives à la protection spéciale des enfants en conflits armés mais n'énonce pas le principe général fondant cette protection ${ }^{32}$. Cependant, les deux PA comblent cette lacune ${ }^{33}$. A ce titre, l'article $77 \S 1$ du PA I dispose que «[1]es enfants doivent faire l'objet d'un respect particulier et doivent être protégés contre toute forme d'attentat à la pudeur. Les parties au conflit leur apporteront les soins et l'aide dont ils

\footnotetext{
${ }^{31}$ Voy. à ce sujet les «Dispositions du droit international humanitaire accordant une protection spéciale aux enfants », in RICR, n ${ }^{\circ} 759$, mai-juin 1986, p. 173.

${ }^{32}$ PLATTNER, Denise, «La protection de l'enfant dans le droit international humanitaire », in RICR, $n^{\circ} 747$, mai-juin 1984, p. 150.; SINGER, Sandra, « La protection des enfants dans les conflits armés », in RICR, ${ }^{\circ} 759$, mai-juin 1986, p. 145 ; MARTIN CHENUT, Kathia, « art. cit », in SOREL, Jean-Marc et POPESCU, CorneliuLiviu (dir.), op.cit., p.172.

${ }^{33}$ MARTIN CHENUT, Kathia, «art. cit», in SOREL, Jean-Marc et POPESCU, Corneliu-Liviu (dir.), op.cit., p.172.
} 
ont besoin du fait de leur âge ou pour toute autre raison » (nous soulignons). Pour sa part, le PA II l'énonce en son article $4 \S 3$ de manière suivante : «Les enfants recevront les soins et l'aide dont ils ont besoin [...]». Et différentes mesures spéciales se trouvent prévues pour matérialiser ce principe général.

En effet, s'il est vrai que le principe fondant la protection spéciale des enfants dans les conflits armés s'exprime de manière impérative, les différentes dispositions qui consacrent réellement cette protection ne sont pas uniformes. Ainsi, la lecture attentive des instruments juridiques précités atteste qu'ils accordent une large marge d'appréciation aux parties au conflit dont les Etats particulièrement. Les Etats assurent donc leur mise en œuvre en fonction de leurs moyens disponibles. A titre indicatif, cette affirmation peut être observée à l'article 14 de la CG IV qui dispose que « [...] les parties au conflit pourront créer sur leur propre territoire et, s'il en est besoin, sur le territoire occupé, des zones et localités sanitaires et de sécurité organisées de manière à mettre à l'abri des effets de la guerre [...] les enfants de moins de quinze ans [...]». C'est ce qui fait écrire à Yves SANDOZ que « la création de ces zones n'est cependant imposée ni aux autorités qui devraient les établir pour leur propre population, ni aux autorités adverses, sans l'accord desquelles cette création n'aurait évidemment aucun sens. Il ne s'agit donc que d'une possibilité ouverte par les conventions, étant entendu cependant que le respect de ces zones est exigé au cas où elles sont créées d'un commun accord entre les parties adverses » (nous soulignons) ${ }^{34}$. Dans la même optique, l'article 17 de la même Convention, par exemple, dispose que "[1]es parties au conflit s'efforceront de conclure des arrangements locaux pour l'évacuation d'une zone assiégée ou encerclée [...] des enfants » (nous soulignons). Terme repris également au niveau de l'article 24 §3 de la CG IV pour des mesures nécessaires d'identification des enfants de moins de douze ans.

Bien plus, la situation ci-haut décrite est encore attestée au niveau des PA. En effet, le paragraphe 2 de l'article $77 \S 2$ du PA I dispose que « [1] es parties au conflit prendront toutes les mesures possibles dans la pratique pour que les enfants de moins de quinze ans ne participent pas directement aux hostilités [...]» (nous soulignons). L'expression «toutes les mesures possibles dans la pratique» apparaît réductrice de protection. Elle fait incontestablement appel à une interprétation très large et diverse. Car toute mesure possible ou faisable pour une partie ne l'est pas nécessairement pour toutes les autres. La mise au point de ces mesures reste donc fonction des possibilités ou des moyens en présence. Les Etats n'ont donc pas souhaité « contracter des obligations inconditionnelles » alors qu'initialement, l'expression plus contraignante de «mesures nécessaires» était proposée par le $\mathrm{CICR}^{35}$. Ceci vaut par exemple pour l'interdiction, observée dans ce même article, de «participation

\footnotetext{
${ }^{34}$ SANDOZ Yves, « La notion de protection dans le droit international humanitaire et au sein du Mouvement de la Croix-Rouge », in SWINARSKI Christophe (éd.), Etudes et essais sur le droit international humanitaire et sur les principes de la Croix-Rouge en l'honneur de Jean PICTET - Studies and essays on international Humanitarian law and Red Cross principles in honour of Jean PICTET, Comité International de la Croix-Rouge, Martinus Nijhoff Publishers, Genève - La Haye, 1984, p. 978. Voy. aussi le commentaire de la CG IV qui souligne le caractère facultatif de la création de zones et localités sanitaires et de sécurité, PICTET, Jean S. (dir.), Commentaire, IV La Convention de Genève relative à la protection des personnes civiles en temps de guerre, CICR, Genève, 1956, p. 134.

${ }^{35}$ SANDOZ Yves, SWINARSKI, Christophe et ZIMMERMANN, Bruno, (éd.), Commentaire des protocoles additionnels de 1977 aux conventions de Genève de 1949, CICR/Martinus Nijhoff Publishers, Genève/Dordrecht, 1986, p. 924.
} 
directe » des enfants aux hostilités au lieu de «participation » simplement (cf. infra). En clair, moins d'obligations absolues s'y trouvent exprimées que d'obligations relatives pour assurer la protection spéciale des enfants dans les conflits armés.

Il ressort de ce qui précède que ces formules sont de nature à ménager la souveraineté des Etats et affecter la mise en œuvre du $\mathrm{DIH}^{36}$ dont la protection spéciale de l'enfant en conflits armés en particulier. Il n'est donc pas impossible pour un Etat de «s'abriter derrière cette formulation imprécise pour ne pas appliquer les Conventions et les Protocoles comme il devrait le faire ${ }^{37}$.

\section{II.2. Différence de protection entre les catégories d'âges d'enfants : protection sélective des enfants}

«[L]es textes relatifs à la protection des enfants dans les conflits armés distinguent généralement les enfants de moins de quinze ans et ceux de moins de dix-huit ans. Les règles varient selon que l'âge de l'enfant est inférieur à quinze ans ou varie[nt] entre quinze et dixhuit ans non révolus $»^{38}$.

De manière plus précise encore, de la lecture des dispositions accordant la protection spéciale à l'enfant (cf. le point I.2), il apparaît que le DIH ne prend pas en charge la protection spéciale de tous les enfants victimes des conflits armés de la même manière. L'âge de l'enfant varie suivant l'objet de la protection ${ }^{39}$. Suivant les cas, la protection spéciale porte sur l'enfant à naître notamment par la protection des femmes enceintes ; des nouveau-nés et enfants en bas âge notamment ceux de sept ans ; les enfants de douze ans ; ceux de moins de quinze ans et ceux de moins de dix-huit ans exceptionnellement pour le travail obligatoire et l'interdiction de la peine de mort. Comme mentionné précédemment, le DIH se réfère « à plusieurs reprises à l'âge de quinze ans comme âge limite au dessous duquel l'enfant doit jouir d'une protection spéciale. Il est généralement admis qu'au-dessus de quinze ans le développement des facultés de l'enfant sont telles que des mesures spéciales ne s'imposent pas systématiquement avec la même nécessité ${ }^{40}$. Par exemple, les zones et localités sanitaires et de sécurité précitées sont profitables aux enfants de moins de quinze ans expressément cités dans l'article 14 de la CG IV. Le traitement préférentiel dans l'assistance nutritionnelle et médicale (cf. art. 23, alinéa $1^{\mathrm{er}}$, de la CG IV), les mesures nécessaires pour faciliter en toutes circonstances l'entretien des enfants, la pratique de leur religion et leur éducation ne concernent que les enfants de moins de quinze ans (cf. art. 24, alinéa $1^{\text {er }}$, de la CG IV). L'interdiction de recrutement et de participation des enfants aux conflits armés vont également dans le même sens (cf. art. 77 §2 du PA I et art. $4 \S 3$ c du PA II). Suivant la même logique, le Statut de Rome de la CPI (relevant du droit international pénal) érige en crime de guerre, en CAI (art. $8 \S 2$ b xxvi) et en CANI (art. $8 \$ 2 \mathrm{~d}$ vii), la conscription ou l'enrôlement d'enfants de moins de quinze ans dans les forces armées ou les groupes armés, et leur participation active aux hostilités. Une telle

\footnotetext{
${ }^{36}$ NIYUNGEKO, Gérard, «La mise en œuvre du droit international humanitaire et le principe de la souveraineté des Etats », in RICR, n788, mars-avril 1991, p. 129.

37 Ibid.

${ }^{38}$ DAVID Eric, Principes de droit des conflits armés, 5è édition, op. cit., p. 567.

${ }^{39}$ DEYRA, Michel, Le droit dans la guerre, op.cit., 155.

${ }^{40}$ DUTLI, Maria Teresa, «Enfant-combattants prisonniers », in RICR, n 785, Septembre - octobre 1990, p. 458.
} 
sélectivité est critiquable ${ }^{41}$ et pose problème dans la pratique de la protection des enfants. Si la temporalité de l'enfant avec ses spécificités oblige à ne pas considérer tous les enfants de la même façon ${ }^{42}$ notamment pour les cas des nouveau-nés et des enfants de sept ou douze ans, il y a tout de même lieu de s'interroger sur le sort des enfants de plus de quinze ans non pris en compte. Il va sans dire que cette législation reste de nature à entretenir une situation discriminatoire entre enfants se trouvant matériellement dans un même état.

Par ailleurs, une certaine évolution est remarquée en DIDH. Si la Convention relative aux droits de l'enfant du 20 novembre 1989 (CDE) ne conduit nullement au renforcement du DIH mais plutôt à son affaiblissement ${ }^{43}$, en opérant une reconduction en son article $38 \S 2$ et $3^{44}$ des dispositions du PA I (art. 77 §), d'autres instruments tentent l'amélioration. C'est notamment le cas du Protocole facultatif à la CDE concernant l'implication d'enfants dans les conflits armés du 25 mai 2000. L'âge d'enrôlement obligatoire et de participation directe aux hostilités est ici relevé à moins dix-huit ans pour les forces armées (cf. art. $1^{\mathrm{er}}$ et 2). Moins dixhuit ans est également l'âge retenu pour l'interdiction aux groupes armés d'enrôlement facultatif et obligatoire - et d'utilisation des personnes aux hostilités (art. 4 §1). Cet instrument reconnaît expressément en son article 3, §1, que « les personnes âgées de moins de dix-huit ans ont droit à une protection spéciale» (nous soulignons). La Charte africaine des droits et du bien-être de l'enfant s'inscrit dans la même logique (art. 22).

Pour leur part, les Etats les plus concernés par les conflits armés en RDC (RDC, Ouganda et Rwanda) ont émis, dans leurs droits internes respectifs, un standard de protection contre le recrutement et la participation directe ou indirecte d'enfants (de moins de dix-huit ans) dans les conflits armés, du moins après 2005 (année d'adoption de la dernière législation au plan interne: la loi ougandaise interdisant l'enrôlement de mineurs de dix-huit ans dans les forces armées) ${ }^{45}$. Toutefois, en dépit de ces interdictions, les enfants sont régulièrement recrutés et utilisés dans leurs forces armées respectives et dans des groupes armés ${ }^{46}$.

\footnotetext{
${ }^{41}$ MARTIN CHENUT, Kathia, « art. cit», in SOREL, Jean-Marc et POPESCU, Corneliu-Liviu (dir.), op. cit., p. 172.

${ }^{42}$ YOUF, Dominique, Penser les droits de l'enfant, PUF, Paris, 2002, p. 95.

43 ZANI, Mamoud, La Convention internationale des droits de l'enfant: portées et limites, Paris, Publisud, 1996, p. 39.

${ }^{44}$ L'art. $38 \S 2$ et 3 de la CDE dispose : «2. Les Etats parties prennent toutes les mesures possibles dans la pratique pour veiller à ce que les personnes n'ayant pas atteint l'âge de quinze ans ne participent pas directement aux hostilités. 3. Les Etats parties s'abstiennent d'enrôler dans leurs forces armées toute personne n'ayant pas atteint l'âge de quinze ans. Lorsqu'ils incorporent des personnes de plus de quinze ans mais de moins de dix-huit ans, les Etats parties s'efforcent d'enrôler en priorité les plus âgées ».

${ }^{45}$ Voy. pour plus d'approfondissement la II ${ }^{\mathrm{e}}$ Partie de la présente thèse de doctorat, Titre II, Chapitre III, Section III, §2 «La protection spéciale des enfants en conflits armés en vertu du droit congolais ».

${ }^{46}$ Voy. République de l'Ouganda Comité des droits de l'enfant, Examen des Rapports présentés par les Etats parties en application de l'article 44 de la Convention, Observations finales: Ouganda, Quarantième session, Genève, 12-30 septembre 2005, CRC/C/UGA/CO/2, 23 novembre 2005, pp. 13 et 14 , $\S 65$ et 67 in http://tbinternet.ohchr.org/_layouts/treatybodyexternal/Download.aspx?symbolno=CRC $\% 2 \mathrm{fC} \% 2 \mathrm{fUGA} \% 2 \mathrm{fCO} \%$ 2f2\&Lang=en (Source consultée le 22 janvier 2016); Pour la République du Rwanda, Voy. Comité des droits de l'enfant, Examen des Rapports présentés par les Etats parties en application de l'article 44 de la Convention, Observations finales : Rwanda, CRC/C/15/Add.234, Trente-sixième session, $1^{\text {er }}$ juillet 2004, $\S 5,2$ et p. 15, §62 in

http://tbinternet.ohchr.org/ layouts/treatybodyexternal/Download.aspx?symbolno=CRC $\% 2 \mathrm{fC} \% 2 \mathrm{f} 15 \% 2 \mathrm{fAdd} .23$ 4\&Lang=en (Source consultée le 22 janvier 2016).
} 
Bien plus, la pratique d'un nombre considérable d'Etats et celles des OI (ex : ONU, UA, UE, etc.) ou du CICR retiennent également l'âge de moins dix-huit ans comme celui auquel l'enfant ne peut être recruté ni prendre part aux hostilités ${ }^{47}$. Toutefois, cette pratique n'étant pas uniforme, le consensus réside au tour de l'âge de moins de quinze ans ${ }^{48}$. "Ainsi, l'interdiction de recruter [et de faire participer] des enfants de moins de quinze ans est solidement ancrée dans le droit positif ${ }^{49}$. L'adoption du Statut de Rome portant création de la CPI l'atteste d'ailleurs.

\section{II.3. Mécanismes de mise en ouvre des mesures de protection des enfants en situation de conflits armés}

« Il est d'un constat unanime que les mécanismes existants, visant à assurer le respect du droit humanitaire, fonctionnent très mal ou ne fonctionnent pas du tout $[\ldots] »^{50}$. En d'autres termes, « le droit international humanitaire existant refuse d'organiser efficacement sa propre mise en œuvre ${ }^{51}$. Et à Mario BETTATI d'ajouter que «non seulement que ces traités sont dépourvus des moyens suffisants de mise en œuvre, mais ils comportent diverses lacunes qui ont justifié l'adoption de toute une série de textes, conventionnels ou unilatéraux [...] en vue de renforcer la protection de ces victimes $»^{52}$. Protection des victimes qui ne serait donc rien sans l'institution des mécanismes de mise en œuvre appropriés.

Ainsi qu'on peut bien le remarquer, si de difficultés sérieuses se posent par rapport à la mise en œuvre du DIH en faveur d'une protection générale réservée aux personnes civiles dans leur ensemble, sans aucun doute elles seront encore plus sérieuses pour une protection que l'on voudrait bien spéciale vis-à-vis de l'enfant. Laquelle doit prendre en compte des circonstances et situations spécifiques dont la vulnérabilité physique et psychique que présente l'enfant. En effet, pour la protection de l'enfant sur le champ de bataille, l'on remarquera qu'il n'existe presque pas, sous l'angle strictement du $\mathrm{DIH}$, des mécanismes de mise en œuvre aussi spécifiques. Et la matérialisation des mesures telles que « Evacuation, création des zones et localités sanitaires et de sécurité pour les enfants... » est sujette à de sérieux écueils. Ces mesures nécessitant des moyens considérables de la part des parties aux conflits ne seront pas toujours bien vues par elles notamment les Etats qui se trouvent déjà fragilisés économiquement et financièrement par l'effort de guerre (ex : RDC, Rwanda, Ouganda, etc.).

Cependant, «[1]es Nations Unies ont aujourd'hui mis à contribution de nombreuses

\footnotetext{
${ }^{47}$ Lire HENCKAERTS, Jean-Marie et DOSWALD-BECK, Louise, Droit international humanitaire coutumier, Volume I : Règles, Bruxelles, Bruylant - CICR, 2006, pp. 636-644.

${ }^{48}$ Voy. Ibid., pp. 640 et 644.

${ }^{49}$ BUGNION, François, «Les enfants soldats, le droit international humanitaire et la Charte africaine des droits et du bien-être de l'enfant», in RADIC, Vol. 12, n², 2000, p. 269

${ }^{50}$ CONDORELLI, Luigi, "La Commission internationale humanitaire d'établissement des faits : un outil obsolète ou un moyen utile de mise en œuvre du droit international humanitaire ? », in TAVERNIER, Paul et BURGORGUE-LARSEN, Laurence (dir.), Un siècle de droit international humanitaire. Centenaire des Conventions de la Haye, Cinquantenaire des Conventions de Genève, Bruylant, Bruxelles, 2001, p. 87.

${ }^{51}$ TAVERNIER Paul, «Réflexion sur les mécanismes assurant le respect du droit international humanitaire conformément aux Conventions de Genève et aux Protocoles additionnels ", in Actualités et Droit International, Revue d'analyse juridique et d'actualités internationales http://www.ridi.org/adi/200004a1.htm (Source consultée le 13 juillet 2016).

52 BETTATI, Mario, Droit humanitaire, Textes introduits et commentés, Editions du Seuil, Paris 2000 , p. 65.
} 
institutions et cette multiplicité d'acteurs, par le renforcement de la répression pénale internationale, dépasse même le cadre strictement onusien. [Le Représentant spécial du Secrétaire général pour les enfants et les conflits armés], l'UNICEF, le Comité international de la Croix-Rouge (CICR) et un grand nombre d'organisations non gouvernementales se consacrent aujourd'hui à la protection des enfants dans les conflits $»^{53}$. Sur le terrain, aucune amélioration certaine sur la situation des enfants dans les conflits armés n'est réellement observable (cf. supra). D'où le sens de cette interrogation sur le rôle de ces différents mécanismes.

\section{Etude de cas de protection des enfants en RDC}

\section{III.1. Objectif de l'étude de cas}

La présente dissertation doctorale se propose la mission de déterminer le contenu des règles du DIH, complétées par celles du DIDH, qui assurent la protection spéciale de l'enfant - civil et soldat - en période de conflits armés en RDC plus précisément. Déterminer le «contenu » de cette protection impliquera par la suite de critiquer, d'évaluer, mieux d'examiner si ces règles font preuve d'efficacité.

En effet, «l'efficacité du droit [...] réside dans le fait que les hommes sont amenés à observer la conduite requise par la norme, par l'idée même de cette norme $»^{54}$. Une norme efficace est celle «qui produit l'effet recherché. L'efficacité est évaluée en confrontant les objectifs assignés à la norme et les résultats obtenus » ${ }^{55}$. Pour tout dire, l'efficacité «conduit à s'interroger sur la pertinence du moyen choisi par le législateur en vue d'atteindre l'objectif visé ${ }^{56}$. Dans le cadre du DIH, l'efficacité voudrait donc que l'on s'interroge sur l'amélioration réelle du sort des victimes ${ }^{57}$, les enfants dans le cas d'espèce.

Ainsi, il va sans dire que cette réflexion va au-delà du constat « que le droit $[\mathrm{DIH}]$ produit un effet $»^{58}$, que le droit est «effectif ». Ce qui renvoie à l'idée de l'effectivité du droit entendue comme « la réalisation de quelque chose qui existait auparavant sur le plan [...] du droit [...] ${ }^{59}$. L'effectivité désigne ainsi «l'utilisation du droit de manière conforme à la volonté du législateur; utilisation entendue comme la mise en relation d'une situation concrète avec le

\footnotetext{
${ }^{53}$ LARRALDE, Jean-Manuel, «Les réponses du droit international à la question des enfants soldats », in $C R D F$, $\mathrm{n}^{\circ} 5,2006$, p. 71.

${ }^{54}$ KELSEN, Hans, Théorie générale du droit et de l'Etat suivi de la doctrine du droit naturel et le positivisme juridique, (Traduit par Béatrice Laroche et Valérie Faure, introduction de Stanley L. Paulson), Bruylant, L.G.D.J, Bruxelles - Paris, 1997, p. 90.

${ }^{55}$ CHAMPEIL-DESPLATS, Véronique et LOCHAK, Danièle (dir.), A la recherche de l'effectivité des droits de l'homme, Presses Universitaires de Paris 10, Paris, 2008, p. 29.; MINCKE, Christophe, L'efficacité, efficience et légitimité démocratique du ministère public. Quand l'arbre cache la forêt, Presses Universitaires de Louvain, 2002, p. 27.

${ }^{56}$ OST, François et VAN DE KERCHOVE, Michel, De la pyramide au réseau ? Pour une théorie dialectique du droit, Facultés universitaires Saint-Louis, Bruxelles, février 2010, p. 331.

${ }^{57} \mathrm{CICR}$, «Protection des victimes de la guerre », Préparation de la Réunion du Groupe d'experts intergouvernemental pour la protection des victimes de la guerre, Genève 23-27 janvier 1995, Suggestions du CICR, Genève, avril 1994, RICR, n 809 , CICR, Genève, septembre - octobre 1994, p. 478.

${ }^{58}$ MINCKE, Christophe, L'efficacité, efficience et légitimité démocratique du ministère public. Quand l'arbre cache la forêt, op. cit., p. 27.

${ }^{59}$ COUVEINHES-MATSUMOTO, Florian, L'effectivité en droit international, Bruylant, Bruxelles, 2014, p. 2.
} 
modèle offert par la règle de droit $»^{60}$. Elle est d'ailleurs une condition nécessaire mais pas suffisante de l'efficacité du droit ${ }^{61}$. Cette thèse se veut une contribution à l'efficacité du DIH à travers l'analyse des règles et mécanismes assurant la protection spéciale des enfants en situation de conflits armés. Ceci dans le seul but de faire progresser - tant soit peu - cette branche du DI. Car comme le dit avec circonspection Marie-Anne COHENDET: «Votre mémoire, votre thèse, ou la manière dont vous le traitez, doit permettre de faire progresser la recherche juridique ${ }^{62}$. Plus que tout autre, elle doit être un travail personnel, critique, original et exhaustif ${ }^{63}$.

En conclusion, cette dissertation doctorale entend répondre à ce que doit être une recherche dans le domaine du DIH tout comme du DIDH comme l'exprime si bien NTIRUMENYERWA M. Kimonyo : «La recherche des obstacles à l'application effective des normes des droits de l'Homme [ou du DIH] et la mesure de l'efficacité de l'action des institutions nationales et internationales pour [leur] mise en œuvre [...] sont les deux axes centraux de toute recherche dans ce sens ${ }^{64}$. C'est dans cette optique qu'elle se propose d'analyser le contenu du cadre de protection de l'enfant en DIH, relever ses carences, avec pour champ d'investigations les conflits armés en RDC, afin de proposer des pistes d'amélioration.

\section{III.2. Intérêt de l'étude de cas}

«Les conflits actuels, le développement de nouvelles formes de combat et de stratégies adoptées par les parties à un conflit, affectent de plus en plus d'enfants. Ainsi, loin d'être épargnés, les enfants sont désormais placés au cœur des conflits et en deviennent l'une des principales victimes non seulement du fait qu'ils constituent une large part de la population civile mais aussi en raison de leur vulnérabilité même ${ }^{65}$.

En RDC, pays qui vit depuis plus d'une décennie en conflit armé intermittent dont le coût humain serait le plus élevé à l'échelle d'un Etat après la Seconde Guerre mondiale ${ }^{66}$, les enfants font parties des personnes civiles dont les droits sont les plus violés.

En effet, suivant Colette BRAECKMAN, c'est « dans les régions occupées que la situation

\footnotetext{
${ }^{60}$ MINCKE, Christophe, L'efficacité, efficience et légitimité démocratique du ministère public. Quand l'arbre cache la forêt, op.cit., p. 26. Voy. aussi OST, François et VAN DE KERCHOVE, Michel, De la pyramide au réseau? Pour une théorie dialectique du droit, op.cit., p. 329 ; LEROY, Yann, «La notion d'effectivité en droit », in Droit et société, 2013/3 (n79), p. 717.

${ }^{61}$ ARNAUD, André-Jean et al. (dir.), Dictionnaire encyclopédique de théorie et de sociologie du droit, $2^{\mathrm{e}}$ édition, L.G.D.J, Paris, 1993, p. 220.

${ }^{62}$ COHENDET, Marie- Anne, Méthodes de travail : droit public, éd. Montchestien (3è éditions), Paris, 1998, p. 209.

${ }^{63} \mathrm{Ibid}$

${ }^{64}$ NTIRUMENYERWA M. Kimonyo, «Le système de protection des droits de l'homme : Mécanismes de protection fondés par la Charte des Nations - Unies : Ecosoc, CDH, HCNUDH », in Droits de l'homme et droit international humanitaire, séminaire de formation cinquantenaire de la Déclaration universelle de droits de l'homme 18 nov.-10 déc.1998, P.U.K., Kinshasa 1999, p. 67.

${ }^{65} \mathrm{CICR}, 1999$ : http://www.ictc.org (Source consultée le 16 février 2011).

${ }^{66}$ Le bilan de ce conflit armé est estimé à 5,4 millions de morts entre 1998 et 2006 par « International Rescue Commitee », dans son rapport de 2007. Et logiquement, le bilan doit être revu à la hausse au regard de nombreux troubles survenus après la période sus indiquée.
} 
des enfants a été particulièrement catastrophique. L'Est du Congo, la Province Orientale, l'Equateur sont devenus des régions sans foi ni loi, où tous les mouvements rebelles vivaient sur l'habitant, réquisitionnant les récoltes des paysans, enlevant les enfants pour en faire des soldats, et pratiquant une politique des viols systématique ${ }^{67}$. Se limiter à ne citer que les mouvements rebelles dans ces violations porterait à croire que la partie gouvernementale n'y était pas impliquée. Loin est le cas !

Dans l'une de ses publications en rapport avec le conflit armé en RDC, l'ex- Mission de l'Organisation des Nations Unies en République Démocratique du Congo (MONUC) ${ }^{68}$ affirmait que « les FARDC [Forces Armées de la République Démocratique du Congo] et la PNC [Police Nationale Congolaise] restent parmi les principaux auteurs des abus des droits de l'homme dans le pays ${ }^{69}$. Ainsi, toutes les parties au conflit en RDC, le Burundi, le Rwanda, l'Ouganda, hormis les forces alliées de Kinshasa (Angola, Namibie, Zimbabwe) ont recouru régulièrement à l'utilisation des enfants soldats ${ }^{70}$. Différentes résolutions des Nations Unies n'ont cessé de stigmatiser ces violations des droits de l'enfant dont l'enrôlement d'enfants à l'endroit de toutes les parties belligérantes, sans distinction. Ainsi, la résolution 1332 (2000) adoptée par le le Conseil de sécurité des Nations Unies (CS/NU) à sa 4247è séance le 14 décembre 2000 disposait dans l'un de ses paragraphes que "le Conseil de Sécurité, profondément préoccupé par la poursuite du recrutement et de l'utilisation d'enfants soldats par des forces et groupes armés, y compris les recrutements à travers les frontières et les enlèvements $[\ldots] \gg^{71}$. Ce paragraphe a été repris également par la résolution S/RES/1341 $(2001)^{72}$ adoptée par le CS/NU à sa 4282è séance le 22 février 2001 voire plusieurs autres (cf. infra). Le Rapport du Secrétaire général des Nations Unies (SG/NU) sur Le sort des enfants en temps de conflit armé du 20 avril 2016 va également dans le même sens ${ }^{73}$. D'importants rapports (cf. Chapitre IV de la deuxième partie de cette thèse) d'autres organismes onusiens (ex: UNICEF, MONUSCO, etc.), des ONG nationales (ex : ASADHO, Bureau des Volontaires pour l'enfance et la Santé (BVES), etc.) et internationales (CICR, Amnesty International, Human Right Watch, International Rescue Commitee, War child International, Save The Children, S.O.S Villages Enfants, Child Soldiers International (CSI) (Enfants Soldats International), Watch List on Children and Armed conflict, Bureau International

\footnotetext{
${ }^{67}$ BRAECKMAN, Colette, «Afrique centrale : des enfances immolées », in Nouvelle Tribune Internationale des droits de l'enfant, Bulletin trimestriel de défense des enfants- international $n^{\circ}$ 6, Bruxelles, juillet 2004, p. 4.

${ }^{68}$ Avec la résolution 1925 (2010) adoptée par le Conseil de Sécurité à sa 6324è séance, le 28 mai 2010, la Mission de l'Organisation des Nations en République Démocratique du Congo (MONUC) s'appelle à partir du $1^{\text {er }}$ juillet 2010 « Mission de l'Organisation des Nations unies pour la Stabilité en République Démocratique du Congo » ou «MONUSCO » puisque la République Démocratique du Congo est entrée dans une nouvelle phase de sa transition vers la consolidation de la paix.

${ }^{69}$ NGANGOUE, Nana Rosine, «La protection des civils : priorités des priorités », in MONUC face à la protection des populations civiles, MONUC Magazine, Vol. VIII, $\mathrm{n}^{\circ}$ 45, 2009, p. 5.

${ }^{70}$ BANZA, Kasanda, «La question des enfants soldats (Cas de la RDC)», in Le travail en Afrique noire : servitude ou libération? Actes des premières journées philosophiques Théophile Reyn tenues à Lubumbashi du 07 au 09 novembre 2002, Publication de l'Institut Facultaire Théophile Reyn Lubumbashi, RDC 2004, p. 67.

${ }_{71} 16^{\mathrm{e}}$ considérant de la Résolution S/RES/1332 (2000) disponible sur http://www.un.org/fr/documents/view_doc.asp?symbol=S/RES/1332(2000) (Source consultée le 20 juillet 2016). 72 Lire le $8^{\mathrm{e}}$ considérant de la Résolution S/RES/1341 (2001) disponible sur http://www.un.org/fr/documents/view_doc.asp?symbol=S/RES/1341(2001) (Source consultée le 20 juillet 2016).

$73 \S \S 44-57$ de la Résolution AG/NU et CS/NU A/70/836-S/2016/360, Le sort des enfants en temps de conflit armé, Rapport du Secrétaire général, in http://www.un.org/fr/sc/documents/sgreports/2016.shtml (Source consultée le 5 juillet 2016).
} 
Catholique de l'Enfance (BICE), etc. décrient également cette situation d'enrôlement d'enfants aux rangs des forces ou groupes armés en désignant toutes les parties belligérantes. L'arrêt de la CPI dans l'affaire le Procureur contre Thomas LUBANGA Dyilo n'en fait qu'une part.

Par ailleurs, au delà de l'enrôlement forcé des enfants par des forces ou groupes armés, les enfants sont également victimes de déportation, massacres, génocides, tueries, viols bref de traitements inhumains, cruels et dégradants de la part des belligérants. Autrement dit, en termes de stratégies de conduite des hostilités par les parties, les enfants en RDC ont été (ou sont) pris pour cibles d'attaques et sont demeurés sans protection ${ }^{74}$.

Dès lors, il importe d'analyser le régime de protection des enfants en situation de conflits armés, ses mécanismes de mise en œuvre et de déceler ainsi les obstacles d'ordre théorique et pratique afin d'améliorer ladite protection. Il ne s'agit pas d'une première étude de protection des enfants en situation de conflits armés en général et en RDC en particulier.

En effet, la question de la protection des enfants en situation de conflits armés a intéressé plusieurs disciplines scientifiques. Préalablement, il importe de signifier qu'il existe de nombreuses études menées par des organisations non gouvernementales, gouvernementales et intergouvernementales, présentées sous forme de rapports, qui traitent de la situation des enfants dans les conflits armés dont la $\mathrm{RDC}^{75}$. De la même manière, il existe différents ouvrages de vulgarisation sur la question. La littérature (notamment à travers les romans) et le journalisme, par exemple, ont marqué un intérêt croissant pour l'enfant en période de conflits armés dont principalement l'enfant soldat ${ }^{76}$. D'autres disciplines telles que l'anthropologie, la psychologie, la criminologie, les sciences politique, etc. ont également manifesté un vif intérêt pour le sujet, et plus précisément pour la question de l'enfant soldat congolais ${ }^{77}$.

\footnotetext{
${ }^{74}$ Cette situation se généralise dans différents conflits et c'est dans ce sens que le Conseil de Sécurité dans son importante résolution 1882(2009) affirme à l'endroit des Etats membres ce qui suit : " (Le Conseil de Sécurité est) Profondément préoccupé par le fait que les enfants continuent à représenter un nombre considérable des victimes de meurtres et de mutilations en période de conflit armé, notamment à la suite de leur ciblage délibéré, d'un emploi inconsidéré et excessif de la force, de l'utilisation inconsidérée des mines terrestres, des armes à sous-munitions et d'autres armes et de l'utilisation d'enfants comme boucliers humains, et également profondément préoccupé par le grand nombre de viols et autres formes de violence sexuelle commis avec une extrême brutalité contre des enfants, dans le cadre de conflits armés et liés à ceux-ci, y compris le recours au viol et autres formes de violence sexuelle ou la commission de ces actes dans certaines situations en tant que tactique de guerre, »

${ }^{75}$ Voy. à ce sujet le dernier chapitre et la Bibliographie de cette thèse de doctorat.

${ }^{76}$ Voy. par exemple, pour des romans, BONNIER, Henry, L'Enfant soldat, édition du Club France Loisirs, Paris, 1987, 341 p ; KOUROUMA, Ahmadou, Allah n'est pas obligé, édition du Seuil, Paris, 2000, 221 p., etc. ; ou encore pour des récits journalistiques ou autobiographiques: LOUYOT, Alain, Gosses de guerre, Robert Laffont, Paris, 1989, 252 p.; LOUYOT, Alain, Les enfants soldats, éd. Perrin, Paris, 2007, 216 p. ; CHAPLEAU Philippe, Enfants-soldats. Victimes ou criminels de guerre?, éditions du Rocher, Monaco, 2007,306 p.; BRIGGSS, Jimmie, Meninos soldados. Quando as grianças vào à guerra, éd. Caleidoscopio_Ediçào e Artes GrAficas, SA, Casla de Cambra, 2008, 222 p. ; KEITETSI, China, La petite fille à la kalachnikov. Ma vie d'enfant soldat, Grip- édition Complexe, Bruxelles, 2004, 265 p., etc. ;

77 Voy. par exemple BODINEAU, Sylvie, Figures d'enfants soldats. Puissance et vulnérabilité. Regard anthropologique sur l'intervention humanitaire de protection des "enfants soldats» en République démocratique du Congo entre 1996 et 2011, Presses de l'Université Laval, Québec, 2012, 124 p. ; DAXHELET, Marie-Laure, L'étude des processus défensifs, adaptatifs et anti-traumatiques chez les enfants soldats congolais, Thèse de doctorat en psychologie, Université du Québec à Montréal, janvier 2013, 89 p. ; KANTENGA MWAMBA, Dieudonné, De la construction de la figure de l'enfant-soldat aux expériences de socialisation. Le
} 
En droit international, l'analyse de la protection de l'enfant en situation de conflits armés est amplement abordée par des manuels ou précis de DIH, de DIDH, de DIPé voire de DI en général $^{78}$. Cependant, les ouvrages spécifiquement dédiés à la question sont peu nombreux. Dans ce type d'ouvrages, il y a ceux qui traitent uniquement d'enfants soldats ${ }^{79}$. Le DIH, le DIDH et le DIPé s'y trouvent au centre de débats. Une autre catégorie, encore plus rare, est celle qui ne concerne que les enfants civils $^{80}$. Un troisième groupe est constitué d'ouvrages étudiant les deux objets précédents à la fois ${ }^{81}$. Dans le même sens, la recension des écrits effectuée dans le cadre de thèses de doctorat révèle l'existence de quelques rares thèses de doctorat en droit international qui traitent de la question de l'enfant soldat ${ }^{82}$, ou de la protection de l'enfant ou de ses droits ${ }^{83}$ en période de conflits armés.

Par ailleurs, il existe de nombreux articles se rapportant à la protection de l'enfant en période de conflits armés en droit international dont particulièrement sur les enfants soldats (DIH, DIDH, DIPé) $)^{84}$.

cas de la RD Congo, Thèse de doctorat en Criminologie, Ecole de Criminologie de l'Université de Lubumbashi, 2014, 516 p. ; NGONDZI, Jonas Remy, Enfants-soldats, conflits armés, liens familiaux : Quels enjeux de prise en charge dans le cadre du processus de DDR? Approches comparatives entre les deux Congo, Thèse de doctorat en science politique, Université Montesquieu Bordeaux IV, décembre 2013, 493 p. ; ZINA, Seydina Ousmane, Analyse critique de l'économie politique de l'utilisation des " enfants soldats» (Etude de cas du pays du fleuve Mano (Libéria, Sierra Léone, Côte d'Ivoire), Thèse de doctorat en Sciences politiques et sociales, Université de Liège, 2013-2014; etc.

${ }^{78}$ Voy. les différents manuels ou précis de ces branches repris à la bibliographie.

${ }^{79}$ Voy. par exemple COHN, Ilene et GOODWIN-GILL, Guy S., Child Soldiers. The role of children in Armed conflict. A study for the Henry Dunant Institute, Geneva, Clarendon Press, Oxford, 1994, 228 p.; IDZUMBUIR Assop J. et KIENGE KIENGE INTUDI, L'enrôlement des enfants et leur participation aux conflits armés: état actuel des dispositions juridiques, éditions universitaires africaines, Kinshasa 2000; HAPPOLD, Matthew, Child Soldiers in international law, Manchester University Press, Manchester, 2005, 183 p.; MAYSTRE Magali Les enfants soldats en droit international. Problématiques contemporaines au regard du droit international humanitaire et du droit international pénal, éd. A. Pedone, Paris, 2010, 202 p.; DRUMBL, Mark A., Reimagining Child Soldiers in International law and policy, Oxford University Press, Oxford New-York, 2012, 254 p.; etc.

${ }^{80}$ Voy. par exemple KUPER, Jenny, International law concerning child civilians in Armed conflict, Clarendon Press, Oxford, 1997, 283 p.

${ }^{81}$ Voy. BABIKER Mohamed Abdelsalam et al (dir.), Enfants-soldats et droits des enfants en situation de conflit et post-conflit. Réalités et enjeux, Paris, L'Harmattan, 2013, 299 p.; Institut des Nations Unies pour la Recherche sur le Désarmement (UNIDIR), Les enfants dans les conflits armés in Forum du désarmement, 2011/3, Genève, Octobre 2013, 72 p. ; BIRUKA, Innocent, La protection de la femme et de l'enfant dans les conflits armés en Afrique, éd. L'Harmattan, Paris, 2006, 500 p. ; etc.

${ }^{82}$ Voy. FURAHA MWAGALWA, Thomas, L'interdiction de la participation aux hostilités, la démobilisation et la réinsertion des enfants soldats en République démocratique du Congo, Thèse de doctorat en droit, Université Saint-Louis - Bruxelles, Juillet 2014, 533 p.; DIKPO, Thélesphore Toliton, La question des enfants soldats: quels problèmes pour la défense du droit, le maintien, la garantie et la promotion de la sécurité internationale?, Thèse de doctorat, Droit-Science politique, Université Jean Moulin Lyon III, 2008, 667 p. ; JACQUIER, Caroline, La protection des enfants soldats par le droit international, Thèse de doctorat en Droit, Université Paul Cézanne (Aix-Marseille 3), 2006, 758 p.; KOKOUVI DODZI, Luc Akakpo, Les enfants accusés de crimes internationaux: d'une justice hétérogène à une homogénéité des théories et des pratiques, Thèse de doctorat en droit, Université d'Ottawa, 2013, 417 p. ; etc.

${ }^{83}$ Voy. KANE, Ameth Fadel, La protection des droits de l'enfant pendant les conflits armés en droit international, Thèse de doctorat en droit, Université de Lorraine, juin 2014, 490 p. ; SANTIVASA, Saratoon, La protection internationale des enfants dans les conflits armés, Thèse de doctorat, Droit international, Université Paris II, 1995 ; COUTURIER-BOURDINIERE, Lucile, La protection internationale des droits de l'enfant, Thèse de doctorat en droit, discipline : Droit international, droit européen, relations internationales, Université Panthéon-Assas (Paris II), juillet 1999, 726 p. ; AFFA'A MINDZIE, Mireille, La Protection internationale des droits de l'enfant, Thèse de doctorat, Droit international, Université de Strasbourg, 2001 ; etc.

${ }^{84}$ Voy. à titre indicatif : HAPPOLD Matthew, «Protecting Children in Armed Conflict : Harnessing the Security Counci's «Soft Power»", in Israël Law Review, Vol. 43, 2010, pp. 360-380; HAPPOLD Matthew, «Child 
Analysant le contenu et l'efficacité de la protection spéciale de l'enfant en conflits armés en $\mathrm{DIH}$ plus précisément en $\mathrm{RDC}$, la présente dissertation s'oblige, pour être complète, à appréhender ce sujet en prenant en considération la situation de l'enfant civil et de l'enfant soldat. Son vif intérêt est marqué pour les règles et mécanismes assurant cette protection. A ce titre, elle diffère des thèses énumérées ci-dessus, y compris celle proche d'elle. Laquelle étudie l'effectivité du principe de l'interdiction de recruter et d'utiliser les enfants dans les conflits armés, et le caractère juridiquement obligatoire en droit international de la démobilisation et de la réinsertion des enfants. Une analyse juridique complétée par un volet sociologique ${ }^{85}$.

Soldiers in International Law : the legal Regulation of Children's Participation in Hostilities », in Netherlands International Law Review, vol. 48, 2000, pp. 27-52 ; JESSEMAN, Christine, « The protection and participation rights of the child soldiers : an African global perspective », in African Human Rights Law Journal, vol. 1, $\mathrm{n}^{\circ}$, 2001, pp. 140-154 ; BRETT, Rachel, "Adolescents volunteering for armed forces or armed groups », in RICR, Vol. 85, n⿳852, 2003, pp. 857-866; FONSEKA, Bhavani, "The Protection of Child Soldiers in International Law », in Asia-Pacific Journal on Human Rights and the Law, 2001, vol. 2, n², pp. 69-89.; PLATTNER, Denise, «La protection de l'enfant dans le droit international humanitaire », in RICR, n ${ }^{\circ} 747$, maijuin 1984, «art. cit. », pp.148-161; SINGER, Sandra, «La protection des enfants dans les conflits armés », in RICR, n`759, mai-juin 1986, «art. cit.», pp.135-172; DUTLI, Maria Teresa, «Enfant-combattants prisonniers », in RICR, n ${ }^{\circ} 785$, Septembre - octobre 1990, «art. cit.», pp. 456-470 ; DAVID, Eric, « La protection juridique de l'enfant contre les effets directs des hostilités », in La guerre et l'enfant, Commission Communautaire Française, Collection Document, Bruxelles, 1990, pp. 5-16; BUGNION, François, «Les enfants soldats, le droit international humanitaire et la Charte africaine des droits et du bien-être de l'enfant », «art. cit. », pp. 262-275; KÜNTZIGER, Isabelle et GALAND, Renaud, "Quels règles et mécanismes internationaux pour protéger les enfants dans la guerre? » in SCHMITZ Marc (Coord.), La Guerre Enfants admis. 300.000 enfants-soldats dans le monde : comment combattre ce fléau ?, op. cit, pp. 127-147 ; MEYER, Antoine, «La protection de l'enfance dans les conflits internes : perspectives de mise en œuvre des normes du droit international humanitaire et du droit international des droits de l'Homme », in BIAD, Abdelwahab et TAVERNIER, Paul (dir.), Le Droit international humanitaire face aux défis du XXIè siècle, Bruxelles, Bruylant, 2002, pp. 219-243 ; IDZUMBUIR Assop J., «Le système onusien de protection des droits de l'homme : le groupe nécessitant une protection spéciale : cas des femmes et des enfants », in Droits de l'homme et droit international humanitaire, Séminaire de formation cinquantenaire de la Déclaration universelle de Droits de l'homme 18 nov.-10 déc.1998, P.U.K., Kinshasa 1999 ; MERMET, Joel, « Protocole facultatif à la Convention relative aux droits de l'enfant concernant l'implication d'enfants dans les conflits armés : quel progrès pour la protection des droits de l'enfant? », in Actualité et droit international. Revue d'analyse juridique de l'actualité internationale, juin 2002, 7 p.; http://www.ridi.org/adi/articles/2002/200206mer.htm (Source consultée le 12 avril 2015); ARZOUMANIAN, Naïri et PIZZUTELLI, Francesca, "Victimes et bourreaux : questions de responsabilité liées à la problématique des enfants-soldats en Afrique », in RICR, nº52, décembre 2003, pp. 827- 856 ; AYISSI, Anatole et MAIA, Catherine, « La lutte contre le drame des enfants soldats ou le Conseil de sécurité contre le terrorisme à venir...», in RTDH. (58/2004), pp. 341-352; AYISSI, Anatole et MAIA, Catherine, «Les filles-soldats, grandes oubliées des conflits armés en Afrique », in Etudes 2004/7 (Tome 401), pp. 19-29 disponible sur http://www.cairn.info/revue-etudes-2004-7-page-19.htm (Source consultée le 15 avril 2016) ; MARTIN CHENUT, Kathia, «La protection des enfants en temps de conflit et le phénomène des enfants-soldats », «art.cit. », in SOREL, Jean-Marc et POPESCU, Corneliu-Liviu (dir.), La protection des personnes vulnérables en temps de conflit armé, op.cit.,, pp. 159-255 ; KALONJI, Anne, "La protection des enfants au cœur des premières poursuites intentées devant la Cour pénale internationale et le tribunal spécial pour la Sierra Leone », in Sociétés et jeunesses en difficulté, "art. cit. », disponible sur http://sejed.revues.org/index4933.htmlp (Source consultée le 26 mai 2016) ; FURAHA MWAGALWA, Thomas, "Réflexions sur les obstacles à réprimer le crime de recrutement et d'utilisation d'enfants soldats commis en République Démocratique du Congo », in RDPC, 2013/1, pp. 218-223. ; etc.

${ }^{85}$ FURAHA MWAGALWA, Thomas, L'interdiction de la participation aux hostilités, la démobilisation et la réinsertion des enfants soldats en République démocratique du Congo, Thèse de doctorat en droit, Université Saint-Louis - Bruxelles, Juillet 2014, 533 p. Lire les pages 9-11 de cette thèse. 


\section{Des questions et hypothèses de recherche}

Les questions et hypothèses de recherche présentées ci-dessous se rapportent essentiellement à l'analyse du régime de protection spéciale de l'enfant en situations de conflits armés et à l'étude des mécanismes de protection spéciale de l'enfant dans de telles situations.

\section{IV.1. Etude du régime de protection spéciale de l'enfant en situation de conflits armés en RDC}

\section{A. Questions et hypothèses de recherche}

\section{A. 1 Questions de recherche}

Le régime de protection spéciale de l'enfant tel qu'institué en DIH, et complété notamment par le DIDH voire le DIPé, assure t-il efficacement une protection spéciale à l'enfant en situation de conflits armés ? La RDC s'inscrit-elle dans le sens de garantir une protection spéciale efficace de l'enfant en situation de conflits armés?

\section{A. 2 Hypothèses de recherche}

L'analyse des conventions relatives au DIH et au DIDH en matière de protection spéciale de l'enfant atteste l'absence d'uniformisation des termes ou mieux la présence à la fois des termes permissifs et impératifs ou contraignants suivie de l'existence de plus d'obligations de moyens que de résultats ; la distinction d'âges établie au niveau de la protection spéciale des enfants avec une protection plus accentuée des enfants de moins de quinze ans que ceux de plus de quinze ans ; etc. Ceci aurait pour conséquence d'occasionner diverses interprétations et justifications de la part des parties au conflit et fragiliser ainsi la protection dite spéciale réservée à l'enfant en plein conflit armé.

Par ailleurs, si hier il existait peu de dispositions particulières dans l'arsenal juridique national congolais qui favorisaient 1 'application du DIH qui du reste était violé à tout moment ${ }^{86}$, à l'heure actuelle, la situation semble évoluer. Il existe actuellement une loi sur la protection de l'enfant applicable même en temps des conflits armés, la loi $n^{\circ} 09 / 001$ du 10 janvier 2009 portant protection de l'enfant.

\section{IV.2. Etude des mécanismes de protection spéciale de l'enfant en situation de conflits armés en RDC}

\section{A .Questions et hypothèses de recherche}

\section{A. 1 Questions de recherche}

Les mécanismes de protection de l'enfant en situation de conflits armés sont-ils réellement spéciaux afin de fournir une protection spéciale efficace? Les mécanismes congolais de protection de l'enfant en situation des conflits armés fonctionnent-ils efficacement dans le

\footnotetext{
${ }^{86}$ Voy. ANDENDE Apindia «Le droit International Humanitaire et l'avenir du droit Congolais », in Le Droit Congolais face à son avenir (Actes des journées scientifiques de la Faculté de Droit de l'Université Protestante du Congo du 25 au 27 mai 2000), Kinshasa, 2000, pp. 13-29.
} 
sens de protection spéciale de l'enfant en telle situation?

\section{A. 2 Hypothèses de recherche}

L'étude de Paul TAVERNIER notait que «le droit international humanitaire existant refuse d'organiser efficacement sa propre mise en œuvre » ${ }^{87}$. Et à Mario BETTATI d'ajouter que « non seulement que ces traités sont dépourvus des moyens suffisants de mise en œuvre, mais ils comportent diverses lacunes qui ont justifié l'adoption de toute une série de textes, conventionnels ou unilatéraux [...] en vue de renforcer la protection de ces victimes $»^{88}$. Ainsi, pour la protection de l'enfant sur le champ de bataille, l'on remarquerait qu'il n'existerait presque pas de mécanismes de mise en œuvre aussi spécifiques pour une protection aussi spéciale, et la matérialité des mesures telles que «Evacuation, création des zones et localités sanitaires et de sécurité pour les enfants... » serait sujette à de sérieux écueils.

De nombreuses études ${ }^{89}$ sur la situation de l'enfant en temps de conflits armés en RDC attestent que ceux-ci sont victimes de multiples crimes indicibles en telle période. Ces graves violations tiendraient notamment aux faiblesses des mécanismes de prise en charge des enfants en telles situations, voire l'absence des mécanismes appropriés.

\footnotetext{
${ }^{87}$ TAVERNIER, Paul, «Réflexion sur les mécanismes assurant le respect du droit international humanitaire conformément aux Conventions de Genève et aux Protocoles additionnels », «art.cit. », in Actualités et Droit International, Revue d'analyse juridique et d'actualités internationales http://www.ridi.org/adi/200004a1.htm (Source consultée le 13 juillet 2016).

${ }^{88}$ BETTATI, Mario, Droit humanitaire. Textes introduits et commentés, op. cit., p. 65.

${ }^{89}$ Lire par exemple : Watchlist on Children and Armed Conflict, Impact des conflits armés sur les enfants en République démocratique du Congo (RDC), New-York, juin 2003, disponible en ligne : http://www.watchlist.org (Recherche menée le 05 août 2014) ; Amnesty international, République Démocratique du Congo - Enfants en guerre, AI index :Afr 62/034/2003. Secrétariat international, document public, 43 p. in http://www.kongokinshasa.de/dokumente/ngo/ai_enfants_0903.pdf (Source consultée le 05 août 2014); KALINDYE Byanjira D. et al., "Les enfants soldats face au droit international humanitaire en République Démocratique du Congo », in Nouvelle Tribune Internationale des Droits de l'enfant, $\mathrm{N}^{\circ}$ 6, juillet 2004, pp. 9-15 ; KATWEMBE Roger et VAHIGHENE, Robert, «Enfants congolais : enfants sans soldats», in Nouvelle Tribune Internationale des Droits de l'enfant, $\mathrm{N}^{\circ}$ 6, juillet 2004, pp. 7-8 ; Action des Chrétiens pour l'abolition de la torture, Effectivité des droits des enfants en République Démocratique à l'aune des objectifs du millénaires pour le développement. Regard sur la situation particulière des enfants dans les territoires de Kabare au Sud-Kivu, éd. ACAT/SudKivu, Bukavu, janvier 2010, 78 p ; CHEUZEVILLE, Hervé, KADOGO, Enfants des guerres d'Afrique Centrale, Soudan, Ouganda, Rwanda, R.D Congo L'Harmattan, Paris, 2003, 312 p. ; BRAECKMAN, Colette « L'Afrique Centrale : des enfants immolés ", in Nouvelle Tribune Internationale des droits de l'enfant, Bulletin trimestriel de défenses des enfants- international n 6 , juillet 2004, pp. 2-5 ; BRAECKMAN, Colette, « Le rêve brisé des enfants-soldats en République Démocratique du Congo », in SCHMITZ, Marc (Coord.), op.cit., pp. 42-53 ; BAILLON, Thierry, "A l'écoute des enfants-soldats », in SCHMITZ, Marc (Coord.), op.cit., pp. 97-109; BANZA Kasanda «La question des enfants soldats (Cas de la RDC) », in Le travail en Afrique noire : Servitude ou libération? Actes des premières journées philosophiques Théophile Reyn tenues à Lubumbashi du 07 au 09 novembre 2002, «art.cit.»; Nations Unies, Haut Commissariat aux droits de l'homme, Rapport du Projet Mapping concernant les violations les plus graves des droits de l'homme et du droit international humanitaire commises entre mars 1993 et juin 2003 sur le territoire de la République démocratique du Congo, Août 2010, pp. 336-359; MUMBALA ABELUNGU, Junior, «Le droit international humanitaire et la protection des enfants en situation de conflits armés en République démocratique du Congo », in Droit et cultures. Revue internationale interdisciplinaire $\mathrm{n}^{\circ} 64$ (2012), pp. 207-235, disponible sur http://droitcultures.revues.org/2913 (Source consultée le 15 février 2016), etc.
} 


\section{Méthodologie de recherche}

«Une méthode est fonction du type de problèmes à résoudre ${ }^{90}$. Ainsi par rapport à la question sous examen, le présent travail recourt à la méthode juridique.

En effet, la méthode ou « technique juridique - parfois aussi appelée « dogmatique juridique » - vise à déterminer le contenu d'une règle à partir de la prise en compte des sources formelles du droit international positif. La technique juridique vise à exposer l'état du droit tel qu'il existe et à en déterminer le contenu ${ }^{91}$.

Suivant Marie-Anne COHENDET parlant de la «dogmatique juridique », «il s'agit du domaine de la science du droit consacré à l'interprétation et à la systématisation des normes juridiques. Elle consiste pour l'essentiel dans la discipline, l'interprétation et la tentative de compléter les règles de droit en comblant des carences de la législation ${ }^{92}$.

Ainsi, au sujet de l'interprétation, il sera fait référence à ce que Marcelle JOKL nomme dans sa thèse de doctorat en $1935^{93}$ la méthode d'interprétation sur la base du texte (ex : le sens des mots, recours au contexte (y compris la pratique ultérieure suivie dans l'application du traité)) et à la méthode d'interprétation à l'aide des éléments étrangers au texte (ex : recours aux travaux préparatoires). Lesquelles méthodes ont été ultérieurement consacrées dans la Convention de Vienne sur le droit des traités du 23 mai 1969. Et conformément aux articles 31 et 32 de cette Convention de Vienne, la première est appréhendée comme les moyens principaux d'interprétation alors que la seconde est à classer au rang des moyens complémentaires. Bien que complémentaire, le recours aux travaux préparatoires, par exemple, paraît utile car comme le dit Jean SALMON « on ne peut pas comprendre un traité si on n'essaie pas de savoir en même temps les enjeux politiques qui étaient derrière ${ }^{94}$.

Toutefois, puisqu'il s'agit dans le cadre de cette dissertation de question d'interprétation visant la protection de la personne - l'enfant-, signifions que celle-ci « est à l'origine d'une règle de conflit relativement autonome dont on ne trouve guère trace et pour cause, en droit international public. Cette règle de conflit, c'est celle qui tranche en faveur de la règle la plus favorable à l'individu ${ }^{95}$. Ainsi, l'interprétation fonctionnelle ou évolutive (dite aussi dynamique) sera plus promue dans ce travail au détriment de l'interprétation historique ou génétique (dite aussi consensuelle) - privilégiant le sens originel des concepts au moment de la conclusion du traité en examen. La jurisprudence et la doctrine seront d'un précieux apport

\footnotetext{
90 DELNOY, Paul, Eléments de Méthodologie juridique. 1. Méthodologie de l'interprétation juridique 2. Méthodologie de l'application du droit, 2è édition De Boeck \& Larcier s.a, Bruxelles, 2006, p.23.

${ }^{91}$ CORTEN, Olivier, Méthodologie du droit international public, op. cit., p. 23.

${ }^{92}$ COHENDET, Marie-Anne, op. cit., 51.

93 JOKL, Marcelle, De l'interprétation des traités normatifs d'après la doctrine et la jurisprudence internationales, Thèse de doctorat, faculté de droit, Université de Caen, éd. A. Pedone, Paris, 1935, 194 p.

${ }^{94}$ Intervention de Jean SALMON au débat au tour de la Conférence d'Alain PELLET sur le « Discours et réalité du droit international. Reims : apport et limite d'une méthode » in Réalités du droit international contemporain. Les rapports entre l'objet et la méthode en droit international (Actes de la huitième rencontre de Reims, pp. 2728 mai 1989), Presses universitaires de Reims, Reims, (sans année), p. 36.

${ }^{95}$ SCHNEIDER, Catherine, «Autonomie de la protection internationale des droits de l'homme au sein du droit international », in ARSAC Pierre, CHARLOT Jean-Luc. et PALLARD Henri, Etat de droit, droits fondamentaux et diversité culturelle, édition L'Harmattan, Paris 1999, p. 24.
} 
à ce propos. La méthode d'interprétation évolutive "privilégie le sens des concepts tel que l'entendent les sociétés contemporaines au moment où surgit le différend ${ }^{96}$. Celle-ci va relayer donc l'interprétation téléologique ou finaliste. Cette dernière cherche l'objectif visé par la création de la règle ou encore mieux la raison légale (ratio legis) d'une loi ou convention $^{97}$.

Pour tout dire, tout au long de cette dissertation, la démarche sera celle de s'efforcer d'interpréter de manière téléologique et évolutive les dispositions des textes et des principes régissant la protection des enfants en DIH. Ceci nous paraît d'ailleurs logique pour l'adaptation du DIH à la naissance des nouveaux types de conflits armés avec des nouvelles méthodes de combat. De cette façon, le contenu de la "protection spéciale de l'enfant » en période de conflits armés recherché principalement dans cette dissertation sera davantage éclairé. Ce qui permettra de déceler les écarts dans la mise en œuvre de cette protection et d'en envisager des suggestions efficaces voire efficientes.

\section{Délimitation de la recherche}

La délimitation de la présente étude s'effectuera aux plans spatial (VI.1), temporel (VI.2) et matériel (VI.3).

\section{VI.1. Délimitation Spatiale}

La RDC est l'un des Etats africains qui vit des conflits armés intermittents depuis près de deux décennies. Ces conflits, en dehors de la RDC elle-même, ont fait intervenir différents acteurs étatiques visibles à savoir les Républiques d'Angola, du Burundi, d'Ouganda, de Namibie, du Rwanda, du Tchad, du Soudan et du Zimbabwe. L'on dénombre également différents acteurs invisibles dont les puissances occidentales et de multiples organisations multinationales ${ }^{104}$ sans compter d'innombrables groupes armés. Tous, si pas la majorité, à la recherche de l'exploitation des ressources naturelles de ce pays potentiellement riche dont la population croupit dans une misère indescriptible. Ce qu'atteste la qualification de guerre essentiellement économique attribuée par l'opinion publique. Celle-ci identifie également ces conflits comme une troisième Guerre Mondiale ou guerre africaine au regard du nombre croissant d'acteurs visibles et invisibles en présence mais aussi du bilan en pertes de vies humaines établi. Ces conflits ont vu des $\operatorname{Kadogo}^{105}$ portant au pouvoir un chef rebelle, Laurent Désiré Kabila.

Ainsi au regard de ce champ d'investigations, l'intérêt sera plus focalisé sur l'est de ce pays qui a payé le plus lourd tribut de guerre. Ceci ne nous permet pas de perdre de vue la situation d'autres parties de ce territoire national car c'est l'Etat congolais qui se retrouve dans un état

\footnotetext{
${ }^{96}$ Ibid.; Voy. aussi SICART-BOZEC, Michele, Les juges du tiers monde à la Cour internationale de justice, éd. Economica, Paris, p. 195.

${ }^{97}$ SICART-BOZEC, Michele, Les juges du tiers monde à la Cour internationale de justice, op. cit., p. 200.

${ }^{104}$ Voy. NTUMBA Luaba, "Grandes Puissances et avenir de la République Démocratique du Congo », in SABAKINU Kivulu (dir.), Démocratie et Paix en République Démocratique du Congo, P.U.K., Kinshasa 1999, p. 220.

${ }^{105}$ Terme swahili signifiant « petit ou enfant» généralement utilisé pour désigner « Enfant soldat ».
} 
de guerre. Et donc tout son territoire sera donc concerné.

Par ailleurs, dans la mesure où les conflits armés survenus en RDC sont enchevêtrés, en ce sens que l'on retrouve à la fois un CAI et un CANI, un regard sur la pratique de la protection spéciale des enfants par les pays précités ne sera pas exclu. Ainsi, l'on tenterait également de voir l'étendue des obligations conventionnelles de ces Etats sous l'angle du DIH et du DIDH. Ceci s'avère important si l'on sait que « la Région des Grands-Lacs est une partie de l'Afrique à hauts risques: guerres civiles et violences se succèdent depuis plusieurs décennies. L'imbrication des pays de la région, de par leurs intérêts communs, leurs alliances ou leurs antagonismes, fait en sorte qu'un conflit éclatant dans un Etat peut, par effet de domino, déclencher un véritable cataclysme dans toute la région ${ }^{106}$. Ainsi, une protection spéciale efficace (voire efficiente) de l'enfant en situations de conflits armés que l'on envisagerait à l'issue de cette étude voudrait bien telle démarche en amont.

Bien plus, il importe que cette étude trouve un intérêt capital vis-à-vis de la société. Car comme l'affirme Julius NYERERE: «Je ne crois pas que nos universités puissent, à ce moment, poursuivre la recherche pure, la science pour la science, sans négliger d'autres fonctions, lesquelles sont, pour le moment, plus importantes. Je n'ai pas dit que la Science pure est inutile, j'ai dit que dans certaines conditions, c'est un luxe ${ }^{107}$. «Dans la recherche initiée et encouragée par l'université ainsi que dans le contenu des programmes, le facteur déterminant doit être les besoins de la collectivité ${ }^{108}$. Bien que le contexte de ce propos soit par rapport aux universités africaines, il est tout au tant valable ailleurs notamment dans des universités occidentales où les recherches doivent, au-delà du progrès scientifique ou technologique attendu, trouver un intérêt immédiat ou non vis-à-vis de la société. Et cette thèse de doctorat se veut non seulement un apport à l'avancement de la science du droit, le DIH en particulier et le DI en général, mais aussi une matérialisation d'une protection spéciale efficace (voire efficiente) des enfants sur le champ de bataille en général et en RDC en particulier.

\section{VI.2. Délimitation temporelle}

Pour tenter d'être complet dans cette analyse, le point de départ de cette dissertation date d'octobre 1996, année marquant le début de la guerre menée par l'Alliance des Forces Démocratiques pour la Libération du Congo-Zaïre (AFDL). Laquelle guerre se soldera par la victoire de l'AFDL constituée en gros d'enfants soldats (Kadogo). Ceux-ci remportent cette guerre le 17 mai 1997 et placent Laurent Désiré Kabila comme Président de la RDC.

Cette guerre dite également Première guerre de libération sera à la base d'un autre conflit nommé Seconde guerre de libération. En effet, « tout commence tacitement le 27 juillet 1998 quand Kabila annonce publiquement qu'il met fin à la mission de coopération des militaires

\footnotetext{
${ }^{106}$ Commission Justice et Paix Rwanda, Burundi et République Démocratique du Congo: Analyse de la situation et perspectives, édition Commission Justice et Paix, Bruxelles, 1998, p. 5.

${ }^{107}$ NYERERE Julius cité par DITEND Yav, Grevisse, Les Pesanteurs de la Formation Universitaire au Congo, édition P.U.L., Lubumbashi, 2000, p. 42.

${ }^{108}$ Ibid.
} 
Rwandais et qu'il les remercie et les prie de regagner leur pays au plus vite $[\ldots]{ }^{109}$. «Instamment le Mouvement anti Kabila s'est dévoilé en déclenchant un mouvement des «Rebelles » cinq jours après, plus précisément le 2 août $1998{ }^{110}$. Ceci sera à la base d'un conflit enchevêtré. Il prend officiellement fin avec la signature de l'accord de Pretoria (République Sud Africaine) du 17 décembre 2002, relayée par l'adoption de la constitution de transition du 4 avril 2003 et de la mise en place d'un Gouvernement de Transition composé des membres de l'ancien gouvernement et des représentants de l'ensemble des principaux groupes rebelles en juin 2003. Depuis lors, subsistent différentes zones ou poches de conflits armés intermittents menés souvent par des officiers supérieurs dissidents. Il y a lieu de citer le colonel Tshibangu; le colonel Jules MUTEBUSI; le général déchu Laurent NKUNDA Batuare, l'officier supérieur Sultani MAKENGA avec le «M23» «fondé en avril 2012 par des déserteurs des FARDC, dont la majorité avait été intégrée en 2009 dans l'armée après la dissolution d'un autre groupe armé, le Congrès National pour la Défense du Peuple $(\mathrm{CNDP}) \gg{ }^{111}$ que dirigeait Laurent NKUNDA Batuare.

Eu égard à ces conflits intermittents, le point final de cette étude est donc actuellement.

\section{VI.3. Délimitation matérielle}

« La thèse, constant compagnon de mois voire d'années de travail, ne saurait être choisie à la légère, d'autant que, par son éventuelle influence sur l'orientation professionnelle, elle peut devenir un facteur déterminant de tout l'avenir. «Le choix » mérite donc une réflexion très sérieuse, qu'il s'agisse du choix large, celui de la discipline ou de la matière, ou du choix plus étroit, celui du sujet ${ }^{112}$. C'est pourquoi, nous conseille Bernadette PLOT, « le choix du sujet d'études, très libre il est vrai, doit être fait en fonction des affinités avec la discipline qui semble la plus attrayante et pour laquelle on se sent le mieux préparé. La discipline étant acquise, c'est vers l'aspect de la discipline qui plaît le plus qu'il faille aller ${ }^{113}$.

$\mathrm{Au}$ regard de ces recommandations fondamentales, le choix a porté sur une discipline de prédilection, le DI, précisément à travers sa branche nommée DIH. Ce dernier est la première branche du DI à tenter d'assurer la protection des enfants en situation de conflits armés. En dépit de la prise en compte de certains aspects spécifiques de l'état d'enfance notamment la vulnérabilité physique et psychique dont fait preuve l'enfant, la protection spéciale qu'assure le DIH à ce sujet s'est avérée problématique. D'où l'intérêt de cette analyse. Un complément lui est assuré par sa branche sœur qui est le DIDH, lequel s'applique en tout temps sauf dérogations ou limitations. Un autre renfort lui vient du DIPé. Et certaines questions non réglées conventionnellement trouvent solution - tant soit peu - en droit international

\footnotetext{
${ }^{109}$ HADDAD, Adnan, Pistes de réflexion sur les causes externes et internes de conflits dans la région des Grands-Lacs (Cas de la Guerre de la République Démocratique du Congo), éd. P.U.L., Lubumbashi, 1999, p. 116.

${ }^{110}$ Ibid.

111 BERGHEZAN, Georges, «Le Cancer des groupes armés au cœur de l'instabilité au Congo », in Les Nouvelles du Grip, Trimestriel n ${ }^{\circ} 69,3 / 13$, Lettre d'information du Groupe de recherche et d'information sur la paix et la sécurité (GRIP), p. 2.

${ }_{112}$ DREYFUS S., La thèse et le mémoire de doctorat en droit, édition Armand Collins, Paris 1971 , p. 69.

113 PLOT, Bernadette, Ecrire une thèse ou un mémoire en sciences humaines, Editions Champion, Paris 1986, pp. 51-52.
} 
coutumier.

En clair, l'objet de cette étude est l'examen de l'état de la législation liée à la protection de l'enfant en sa qualité de personne ne participant pas ou plus aux hostilités mais également comme personne participant aux hostilités. Au-delà de l'analyse des dispositions conventionnelles ou règles coutumières applicables en la matière où l'on se propose aussi de relever des écueils à une protection spéciale efficace (voire efficiente), il sera également question de jeter un regard scrutateur sur les mécanismes devant assurer cette protection sur le champ de bataille. Car on ne peut pas parler de la mise en cuvre du DIH ou de la protection des droits de l'homme sans la mise en place des mécanismes appropriés. Dans le cas de l'enfant, étant donné qu'on parle de la protection spéciale, il s'avère tout aussi normal que ces mécanismes soient aussi spéciaux. Cependant, dans la mesure où l'enfant est au départ une personne civile comme toute autre personne civile, bénéficiant ainsi d'une protection générale, il s'avérerait opportun et judicieux de traiter préalablement des mécanismes assurant la protection générale des personnes civiles qui concernent donc également les enfants.

\section{Plan sommaire du travail}

Pour mieux cerner le problème à analyser afin d'aboutir à des résultats fiables, il a été jugé opportun de subdiviser la présente étude en deux parties.

La première partie s'occupe du Droit international humanitaire et la protection des enfants en situation de conflits armés. Elle se consacrera à l'étude de l'application du DIH où seront analysés respectivement le cadre conceptuel (Chapitre I) et les règles et mécanismes de protection du DIH, y compris ceux du DIDH et du DIPé dans ce sens (Chapitre II). Ensuite, elle étudiera les règles (Chapitre III) et les mécanismes (Chapitre IV) du DIH de protection des enfants en situation de conflits armés en général avec le complément qu'offrent notamment le DIDH et le DIPé.

La seconde partie de cette thèse traite du Droit international humanitaire et la protection des enfants en situation de conflits armés en République Démocratique du Congo. Cette partie se préoccupera de l'examen de la mise en œuvre des règles et mécanismes, étudiés en première partie, en conflits armés en RDC au profit des enfants. En clair, elle analysera d'abord les Conflits armés et enfants en République Démocratique du Congo (Chapitre I). C'est alors que viendra l'étude de la manière dont les règles du DIH relatives à la protection des enfants sont effectivement mobilisées en RDC (Chapitre II). En dernier lieu, l'intérêt de cette dissertation portera sur le fonctionnement de différents mécanismes appelés à assurer la protection spéciale des enfants en conflits armés en RDC (Chapitre III). Et c'est donc à l'issue de ce chapitre, qu'interviendront les propositions doctorales en conclusion. 
PREMIERE PARTIE

LE DROIT INTERNATIONAL HUMANITAIRE ET LA PROTECTION DES ENFANTS EN SITUATION DE CONFLITS ARMES 
«Le DIH est constitué des règles destinées à restreindre la faculté des parties à un conflit d'utiliser les méthodes et moyens de guerre de leur choix. Il tend à protéger les personnes et les biens affectés par la guerre. On y distingue deux régimes juridiques : l'un, très élaboré, concerne les conflits armés internationaux; l'autre, encore rudimentaire mais en cours de perfectionnement, vaudra pour les conflits armés non-internationaux ${ }^{114}$. Loin de paraitre simple, le DIH est perçu par les auteurs avisés comme une des branches complexes du DI voire du droit en général. Sa complexité relève au départ du phénomène complexe pour lequel il se préoccupe de réglementer, à savoir la «violence» ou la «guerre ». En d'autres termes, le DIH « veut ordonner ce qui demeure toujours désordre. Il participe initialement de la tentative d'instaurer des règles de droit là où elles sont par hypothèse, le plus radicalement niées ${ }^{115}$. Ce phénomène mériterait légitimement d'être brièvement appréhendé ou compris avant d'être réglementé.

L'étude de la guerre comme l'a si bien démontré un des brillants spécialistes de la question, Gaston BOUTHOUL, est complexe et difficile à entreprendre suite à de nombreux obstacles. C'est dans ce sens qu'en cherchant à définir le phénomène-guerre, cet auteur affirme : « [b]ien entendu, il ne s'agit ici que de donner une définition provisoire du «phénomène-guerre ». [...] Une définition exhaustive : «La guerre c'est...» supposerait une connaissance parfaite de ce phénomène. Nous en sommes loin ${ }^{116}$. Et analysant les propos des juristes à ce sujet, Gaston BOUTHOUL signifie que «malgré mille démentis de l'histoire, les juristes continuent à assimiler dans leurs conceptions la guerre à une querelle entre individus, à une bagarre, une rixe ou un duel [...]. Les uns veulent interdire la guerre par une sorte de règlement de police. D'autres veulent, tout en la tolérant, la réglementer exactement sur le modèle du code d'honneur à l'usage des duellistes courtois ou des règles qui régissent les combats de boxe ou de football ${ }^{117}$. Et il qualifie bien cette attitude de l'Illusionnisme juridique ${ }^{118}$. Cette inquiétude de 1'auteur de la Polémologie ${ }^{119}$ atteste en même temps de la complexité de ce phénomène. Un phénomène insaisissable par nature, problématique et multidimensionnel mais que l'on tente perpétuellement de maîtriser à travers la réglementation.

Cependant, les juristes sont non moins conscients de la problématique du «phénomène-guerre ». Le juriste Paul TAVERNIER faisait observer qu' " on ne peut guère aller beaucoup plus loin que les CG et les PA sans remettre en cause la guerre elle-même et « on ne peut pas espérer étouffer l'incendie des conflits sous les normes humanitaires ». Dans cette perspective, [...] le « socle sur lequel le droit international humanitaire s'est construit» peut se définir «par trois mots: compassion, respect et solidarité $»^{120}$. D'où, dans sa réglementation, le DIH devrait être réaliste. A ce sujet, Jean PICTET martelait que «[r]ien n'est plus dangereux que l'«humanitarisme échevelé », animé des meilleures intentions, mais détaché des réalités

\footnotetext{
${ }^{114}$ BETTATI, Mario, Droit humanitaire. Textes introduits et commentés, op.cit., p.13.

${ }^{115}$ FIERENS, Jacques, Droit humanitaire pénal, éd. Larcier, Bruxelles, 2014, p. 17.

${ }^{116}$ BOUTHOUL, Gaston, La Guerre, PUF, Paris 1953, p. 28.

${ }^{117}$ Ibid., pp.7-8.

118 Ibid., p.7.

119 BOUTHOUL, Gaston a proposé le terme "Polémologie" à l'étude scientifique du phénomène-guerre considéré comme un phénomène social, pour la distinguer de la science de la guerre, telle qu'on l'enseigne dans les écoles militaires et les états majors, Voy. BOUTHOUL Gaston, La Guerre, op.cit., p. 6.

120 TAVERNIER, Paul, «De 1899 à 1999: Eclatement ou approfondissement du droit international humanitaire », « art. cit. », p. 5.
} 
$[\ldots] »^{121}$.

C'est aussi par ce réalisme que le DIH se permet de prendre en compte un phénomène sociologiquement présent dans la vie des Etats alors que juridiquement prohibé en droit international. Ce qui pourrait faire penser à une certaine légitimité de cette entreprise humaine de désolation. Mais, ce n'est nullement le cas !

La complexité du DIH se prouve également à travers son histoire. Un droit qui trouve naissance dans le contexte conflictuel et demeure fruit des civilisations aussi multiples et variées qui ont été tout de même préoccupées par la protection de l'être humain en situation des hostilités. Son évolution est empreinte des attitudes et pensées convergentes et divergentes de toutes ces civilisations. Et à l'heure actuelle, on saurait mieux déterminer ou comprendre la teneur ou la portée d'une règle de DIH notamment par rapport aux idéologies et philosophies défendues par les «hautes parties contractantes » ou puissances à la table de la négociation. Le DIH reste également complexe à travers les différents principes et règles qui constituent son contenu. Contenu à retrouver dans différentes sources conventionnelles et coutumières multiples et variées sans oublier les sources dérivées du DI, universel ou communautaire. D'ailleurs, c'est à propos de sources conventionnelles que Mario BETTATI épingle la première cause de complexité du DIH. Ainsi, il affirme que « la première cause de complexité du DIH réside dans la masse du corpus conventionnel et de son mode d'emploi. Il est dispersé dans un grand nombre de textes. Une quinzaine de conventions et déclarations forment déjà ce qu'on appelle le droit de la Haye [...]. Il faut y ajouter la dizaine de textes qui établissent le droit dit de Genève. Egalement les conventions qui forment ce qu'on appelle le droit de New York, relatives aux crimes contre l'humanité, au génocide, à la torture et aux traitements inhumains et dégradants. Ce qui fait plus de 1000 pages de textes conventionnels » ${ }^{122}$. «Cette multiplicité d'instruments conventionnels pourrait être une source de contrariété normative ${ }^{123}$. Ainsi, en rapport avec les textes, la complexité du DIH se manifeste notamment au niveau « de formulations qui ne sont pas toujours claires et de la difficulté dans certains cas à qualifier un fait au regard de telle ou telle règle $»^{124}$. En plus, le DIH est une discipline juridique qui doit, en dehors des interdictions absolues, se trouver en équilibre entre les nécessités militaires et les considérations humanitaires face aux puissances belligérantes généralement obsédées par l'esprit de vaincre.

Eu égard à ce qui précède, le DIH est un droit multiforme et en proie à des controverses parfois vives. Il est mal connu en raison de sa complexité et des confusions ${ }^{125}$ avec d'autres branches du DI qui lui sont connexes. Cette complexité n'est pas de nature à faciliter son application souhaitée par le «combattant» sur le terrain, en dépit du bon sens devant caractériser celui-ci. Il est impérieux face à une branche du droit dont les auteurs avertis reconnaissent la complexité, de réserver dans une dissertation doctorale une partie à l'analyse de ce qui constitue son contenu essentiel.

\footnotetext{
${ }^{121}$ PICTET, Jean, « La formation du droit international humanitaire », in RICR, Vol. 84, N846, juin 2002, p. 340 .

${ }^{122}$ BETTATI, Mario, Droit humanitaire. Textes introduits et commentés, op. cit., pp. 15-16.

${ }^{123}$ ROUSSEAU, Charles, Le droit des conflits armés, A. Pedone, Paris, 1983, p. 20.

${ }^{124}$ BETTATI, Mario, Droit humanitaire. Textes introduits et commentés, op.cit., p. 13.

${ }^{125}$ DAVID, Eric, Principes de droit des conflits armés, $5^{\mathrm{e}}$ édition, op. cit., p. 40.
} 
A travers cette partie portant sur le droit international humanitaire et la protection des enfants en situation de conflits armés, quatre chapitres seront étudiés. Il sera d'abord question d'examen du cadre conceptuel (Chapitre I), suivi de l'étude de la mise en œuvre du DIH en général (Chapitre II). Ceci permettrait dès lors de s'appesantir spécifiquement sur les règles (Chapitre III) et les mécanismes (Chapitre IV) du DIH relatifs à la protection des enfants en situation de conflits armés avec le complément qu'offrent notamment le DIDH et le DIPé. 


\section{CHAPITRE PREMIER DEFINITION DU CADRE CONCEPTUEL}

Avant de cerner son point névralgique, la présente dissertation s'oblige, à travers ce premier chapitre, à élucider son cadre conceptuel afin de permettre une lecture compréhensible. Ainsi, après avoir abordé en liminaire les questions de protection spéciale et générale de l'enfant en situation de conflits armés (cf. supra), le présent chapitre se concentre sur le contenu du DIH (Section I), les notions de l'enfant et de l'enfant soldat, y compris l'aperçu historique de la protection et des droits de l'enfant (Section II). Enfin, puisque traiter de l'enfant soldat appelle des questions de «recrutement» et de «participation aux hostilités », une dernière section traitera de ces termes (Section III). Par ailleurs, en principe, le présent Chapitre devait également aborder la notion de «conflits armés». Toutefois, pour donner une marque particulière à l'étude de cette notion, le deuxième chapitre de cette partie - qui se préoccupe de continuer l'examen du DIH sous d'autres aspects - se propose d'appréhender cette question avec plus de détails.

\section{Section I : Notion de droit international humanitaire}

Expression développée après la Seconde Guerre mondiale ${ }^{126}$, promue notamment par le CICR dans les années $1950^{127}$ et «officialisée [...] dans les années 1970, précisément lors de la conférence diplomatique de Genève [ sur la réaffirmation et le développement du droit international humanitaire ] réunie de 1974 à $1977{ }^{128}$, le droit international humanitaire est assez mal connu. L'exclusivité de son objet d'étude est constamment mise à rude épreuve par d'autres branches du DIP (DIDH, DIPé, droit international des réfugiés, droit du maintien de la paix, etc.) (cf. supra). La présente section se fixe pour mission de tenter de saisir ce qu'il faudrait entendre par «droit international humanitaire» $(\S 1)$ avant de se pencher sur son aperçu historique (\$2). Ensuite, elle analyse les sources de ce droit (\$3) pour clore par l'étude de ses principes $(\S 4)$.

\section{\$1. Définition du droit international humanitaire}

Nombreuses sont les définitions proposées au sujet du DIH. Une analyse de quelques unes d'entre elles mérite d'être entreprise afin d'aboutir à une définition finale.

En effet, pour François DELOOZ et Stéphane KOLANOWSKI, le DIH, « droit de la guerre ou encore, droit des conflits armés, est l'ensemble des règles qui visent, d'une part, à protéger les personnes qui ne participent pas ou ne participent plus aux hostilités et d'autre part, à limiter les méthodes et les moyens de combats ${ }^{129}$.

\footnotetext{
${ }^{126}$ EMMANUELLI, Claude, International humanitarian Law, Bruylant - éd. Yvon Blais, Bruxelles - Québec, 2009 , p. 5.

${ }^{127}$ KOLB, Robert, Ius in bello. Le droit international des conflits armés, $2^{\mathrm{e}}$ édition, Helbing \& Lichtenhahn, Bruylant, Bâle-Genève-Munich, Bruxelles, 2009, p. 14.

${ }^{28}$ BELANGER, Michel, Droit international humanitaire général, Gualino éditeur, EJA, Paris, 2007, p. 15. Voy. aussi dans ce sens PICTET, Jean, «Le droit international humanitaire : définition », in Les dimensions internationales du droit humanitaire, op. cit., p. 13.

${ }^{129}$ DELOOZ, François et KOLANOWSKI, Stéphane, «Introduction au droit international humanitaire », in Actualité du droit international humanitaire, éd. La Charte, Bruxelles, 2001, p. 8.
} 
A la suite de leur définition, ces auteurs précités font part de la distinction opérée au sein du DIH entre ses deux branches constitutives : le droit de Genève et le droit de La Haye:

«- Le droit de Genève : il s'agit du droit international humanitaire proprement dit qui contient les règles relatives au traitement des personnes au pouvoir de l'ennemi. Ces règles figurent dans les quatre Conventions de Genève de 1949 qui protègent les militaires blessés et malades dans les opérations terrestres, les militaires blessés et les malades dans les opérations maritimes, les prisonniers de guerre et les civils. - Le droit de La Haye: il s'agit du droit de la guerre en tant que tel qui contient les règles relatives à la conduite des hostilités. La plupart de ces règles se trouvent dans des conventions internationales conclues à la Haye (cf. infra) $\gg^{130}$.

A propos du droit de La Haye, Eric DAVID enseigne que celui-ci peut se résumer en trois principes: On ne peut pas attaquer n'importe qui: principe de discrimination quant aux personnes, les attaques doivent se limiter aux combattants. On ne peut pas attaquer n'importe quoi: principe de discrimination quant aux biens, les attaques se limitent aux objectifs militaires. Il s'agit alors de pouvoir déterminer ce qu'est un objectif militaire! On ne peut pas attaquer n'importe comment: les moyens utilisés doivent respecter les principes de limitation et de proportionnalité ; interdiction spécifique de certaines armes: gaz, bactéries, poison, mines, armes incendiaires et nucléaires, interdiction générique des armes qui causent des maux superflus, interdiction de certaines méthodes de combat : destruction non justifiées, attaques indiscriminées, perfidie, etc ${ }^{131}$.

A la suite de la définition fournie par François DELOOZ et Stéphane KOLANOWSKI, il faudrait indiquer que c'est celle généralement admise et partagée par la plupart d'auteurs ${ }^{132}$ et publications du $\mathrm{CICR}^{133}$. Et d'ailleurs la doctrine s'accorde à considérer que le DIH stricto

\footnotetext{
130 Ibid.

${ }^{131}$ DAVID, Eric, «Introduction au droit international humanitaire », in Stéphane KOLANOWSKI (dir.), Défis contemporains en droit international humanitaire, Actes du Colloque de Bruges, 27-28 octobre 2000. Current Challenges in international Humanitarian Law, CICR et Collège d'Europe, Proceeding of the Bruges Colloquium 27-28 october 2000, Bruxelles, mai 2001, p. 17.

${ }^{132}$ A titre illustratif, pour Patricia BUIRETTE et Philippe LAGRANGE, le DIH est « [...] un ensemble de règles internationales destinées à régler les questions humanitaires découlant des conflits armés. Ce droit a un double objet : d'une part, alléger les souffrances engendrées par la guerre en réglementant les opérations militaires ou les moyens de combat et, d'autre part, protéger les personnes - blessés, prisonniers et populations civiles - ainsi que les biens affectés par le conflit. », Voy. BUIRETTE, Patricia et LAGRANGE, Philippe, Le droit international humanitaire, éd. La découverte, Paris 2008, pp. 3-4. ; Mario BETTATI enseigne pour sa part que «Le droit international humanitaire (DIH) est constitué des règles destinées à restreindre la faculté des parties à un conflit d'utiliser les méthodes et moyens de guerre de leur choix. Il tend à protéger les personnes et les biens affectés par la guerre. ", Voy. BETTATI Mario, Droit humanitaire. Textes commentés et introduits, op.cit., p. 13.; Isabelle KÜNTZIGER et Renaud GALAND écrivent dans leur article Quels règles et mécanismes internationaux pour protéger les enfants dans la guerre? que «Le droit international humanitaire est l'ensemble des règles qui cherchent à limiter les effets des conflits armés. D’une part, il protège les personnes qui ne participent pas ou ne participent plus au combat, d'autre part, il restreint les méthodes et moyens de combat »., Voy. KÜNTZIGER, Isabelle et GALAND, Renaud, « art.cit », p. 128. ; etc.

${ }^{133}$ Suivant, par exemple, le manuel Découvrez le CICR, publié à Genève en mai 2002, élaboré par le CICR en sa page 14, «le droit international humanitaire également appelé "droit des conflits armés » ou "droit de la guerre " est l'ensemble des règles qui, en temps de guerre, protègent les personnes qui ne participent pas, ou ne participent plus aux hostilités. Ce droit, continue le CICR, stipule que le choix des méthodes et moyens de guerre "n'est pas illimité ». Son but essentiel est de limiter et de prévenir les souffrances humaines en temps de conflit armé ».
} 
sensu a pour objet principal la protection de la personne en temps de conflit armé ${ }^{134}$. Cette définition a également le mérite de présenter les deux composantes essentielles du DIH qui, comme le reconnaissent ces auteurs, ne sont toutefois pas totalement séparées dans la mesure où certaines règles du droit de la Haye ${ }^{135}$ ont pour effet de protéger les victimes des conflits, et certaines règles du droit de Genève ${ }^{136} \mathrm{de}$ limiter l'action des belligérants au cours des hostilités ${ }^{137}$. C'est ce qu'atteste la CIJ dans son avis consultatif sur la Licéité de la menace ou de l'emploi d'armes nucléaire, lorsqu'elle dispose : «Ces deux branches du droit applicable dans les conflits armés ont développé des rapports si étroits qu'elles sont regardées comme ayant fondé graduellement un seul système complexe, qu'on appelle aujourd'hui droit international humanitaire. Les dispositions des protocoles de 1977 expriment et attestent l'unité et la complexité de ce droit ${ }^{138}$. Signifions en outre que depuis les années 1990, on parle de droit de New-York comme une autre partie du DIH. Les Conventions se rapportant à ce droit concernent les crimes contre l'humanité, le génocide, la torture et les traitements inhumains ou dégradant ${ }^{139}$. Et pour Paul TAVERNIER, un élément essentiel du droit de NewYork «serait le fameux droit d'ingérence introduit à l'initiative du doyen Bettati et du docteur Kouchner et consacré dans de nombreuses résolutions des Nations Unies » ${ }^{140}$. Le droit de NewYork se rapporterait donc à la mise en œuvre de deux précédents notamment en ce qui concerne sa réponse aux crimes du DIH ${ }^{141}$ (droit de Genève et droit de la Haye).

Par ailleurs, le commentaire fourni par les auteurs de la définition initiale donnerait l'impression que le DIH, notamment le droit de Genève se limiterait aux CG comme sources alors que celles-ci se trouvent complétées par les PA. Ces derniers associent les règles du droit de Genève et du droit de La Haye. Et comme l'exprime si bien la CIJ dans son avis précité : «Les dispositions des protocoles de 1977 expriment et attestent l'unité et la complexité de ce droit ${ }^{142}$. Et même alors, comme l'indique bien René KOSIRNIK, «Le droit international humanitaire ne se limite pas à ces traités. Il faut en particulier ne pas oublier les règles coutumières universellement reconnues ainsi que les principes fondamentaux qui sous-tendent

134 GNAMOU-PETAUTON, Dandi, «Les Etats africains et le droit international humanitaire », in TAVERNIER, Paul (dir.), Recueil juridique des droits de l'Homme en Afrique, Tome I, vol. 2, 2000-2004, Bruylant, Bruxelles, 2005, p. 358.

${ }^{135}$ Signifions avec Eric DAVID que l'on désigne par expression de « droit de la Haye » eu égard à la ville (La Haye) où bon nombre de ses règles on été adoptées (DAVID, Eric, Principes de droit de conflits armés, $5^{\mathrm{e}}$ édition, op.cit., p. 41).

${ }^{136}$ C'est aussi par allusion à la ville (Genève) où la plupart de ses règles ont été adoptées qu'on l'appelle « droit de Genève ». (Voy. DAVID, Eric, Principes de droit de conflits armés, $5^{\mathrm{e}}$ édition, op.cit., p. 41). Cependant, dans la mesure où les délimitations de ces différentes branches du DIH tendent à s'atténuer, la production actuelle fait entrer dans chaque catégorie des textes adoptés dans une ville autre que celle qui la qualifie sur le plan du contenu. Ainsi, par leur contenu, les protocoles de 1977 appartiennent à la fois au droit de la Haye et à celui de Genève, bien que signé dans cette seule seconde ville. Voy. BETTATI, Mario, Droit humanitaire. Textes commentés et introduits, op.cit., p. 45.

${ }^{137}$ DELOOZ François et KOLANOWSKI Stéphane, « art.cit. », p. 8.

${ }^{138}$ CIJ, Affaire de Licéité de la menace ou de l'emploi d'armes nucléaire, avis consultatif du 8 juillet 1996, Recueil 1996, p. 256, §75.

139 BETTATI, Mario, Droit humanitaire. Textes commentés et introduits, op.cit., p. 16 et FIERENS, Jacques, Droit humanitaire pénal, cours destiné aux Etudiants de Master Complémentaire en Droits de l'Homme, Académie Universitaire «Louvain », Bruxelles 2010-2011, p. 47.

140 TAVERNIER, Paul, «De 1899 à 1999: Eclatement ou approfondissement du droit international humanitaire », « art. cit. », p. 6.

${ }_{141}$ BETTATI, Mario, Droit humanitaire. Textes commentés et introduits, op.cit., p. 45.

142 CIJ, Affaire de Licéité de la menace ou de l'emploi d'armes nucléaire, avis consultatif du 8 juillet 1996, Recueil 1996, p. 256, §75. 
tout ce « corpus » juridique ${ }^{143}$. Il faudrait également penser à d'autres sources du DI dérivées dont les résolutions des organisations internationales qui indiquent des règles à observer en situations des hostilités, ou renforcent les règles existant dans ce domaine (cf. infra).

En outre, au regard de la définition ci-haut avancée, le DIH serait synonyme de «droit de la guerre ». Il y a moyen d'atténuer une telle affirmation. Le DIH, en sa forme actuelle, n'est plus à confondre avec le droit de la guerre et même avec le droit de Genève. Le terme « droit de la guerre » était employé jadis pour symboliser le DIH. Toutefois, à l'heure actuelle où le DIH ne s'applique pas seulement aux conflits armés surgissant entre Etats qualifiés de " guerre », mais également aux conflits armés internes à un Etat, l'emploi de «droit de la guerre » semble restreindre le DIH de son champ d'application. Bien plus, la prohibition de la «guerre » entre nations en droit international et la préférence en lieu et place du terme «conflit armé » ${ }^{144}$ seraient plus favorables à l'emploi de «droit des conflits armés» (cf. infra). Notons tout de même que cette dénomination demeure d'utilisation dans des centres de formation militaire et les organes d'expression de ces derniers (revues, manuels, etc.) ${ }^{145}$ voire dans des ouvrages actuels (cf. infra). Cette utilisation vaut donc notamment «pour des besoins pédagogiques et didactiques afin de rendre compte de la distinction entre le droit du recours à la guerre (à la force)/Ius ad bellum et le droit dans la guerre/ius in bello ${ }^{146}$. Bien plus, sous certains égards, le terme «guerre» se trouverait simplement utilisé dans un sens générique englobant ainsi différents types de conflits armés.

En résumé, étant donné que le DIH comprend à la fois le droit de Genève et le droit de la Haye, affirmer qu'il serait simplement synonyme de «droit de la guerre » équivalent lui aussi du droit de la Haye serait l'amputer de l'autre branche, le droit de Genève.

C'est pourquoi de manière claire, Hans Peter GASSER indique que « le droit international humanitaire - à savoir le droit applicable dans les situations des conflits armés autrefois également appelé droit de la guerre - est un droit spécial, élaboré pour les situations des conflits armés (habituellement qualifiés, sans détour de «guerre»). [Il poursuit que] le droit international humanitaire s'efforce d'atténuer les effets de guerre, c'est-à-dire au choix des moyens et des méthodes employés pour la conduite des hostilités, et ensuite en imposant aux belligérants d'épargner et de protéger les personnes qui ne participent pas ou plus, aux conflits $\gg{ }^{147}$.

\footnotetext{
${ }^{143}$ KOSIRNIK, René, «Droit international humanitaire et protection de réfugiés », in SWINARSKI Christophe (Réd.), Etudes et essais sur le droit international humanitaire et sur les principes de la Croix-Rouge en l'Honneur de Jean PICTET - Studies and essays on international humanitarian law and Red Cross principles in honour of Jean PICTET, CICR-Martinus Nijhoff Publishers, Genève, 1984, pp. 388-389.

${ }^{144}$ MATTEI, Jean-Matthieu, Histoire du droit de la guerre (1700-1819). Introduction à l'histoire du droit international, Tome I, Presses Universitaires d'Aix-Marseille, Aix-en-Provence, 2006, p. 79.

${ }^{145}$ BULA-BULA, Sayeman, Droit international humanitaire, Academia-Bruylant s.a, Louvain-La-Neuve, 2010, p. 52. Voy. par exemple, la Revue de Droit Militaire et de Droit de la Guerre (http://www.ismllwbe.org/publications_FR.php ) de la Société Internationale de Droit Militaire et de Droit de la Guerre (http://www.ismllw.org/index_FR.php ).

${ }^{146}$ MEJRI, Khaled, Le droit international humanitaire dans la jurisprudence internationale, éd. L'Harmattan, Paris, p. 23.

${ }^{147}$ GASSER, Hans Peter, Le droit International Humanitaire : Introduction, édition Paul Haupt Berne, Stuttgart Vienne, 1993, p. 3.
} 
Eric DAVID quant à lui, préfère le terme «droit des conflits armés ${ }^{148}$ et écrit à ce sujet : «Appelé jadis ${ }^{149}$ «droit de la guerre», plus fréquemment aujourd'hui «droit international humanitaire », le droit des conflits armés recouvre ces deux aspects - haine et fraternité (supposée...) - de la guerre, d'une part en régissant la manière dont les hommes peuvent se détruire, d'autre part en les obligeant à respecter ou secourir ceux qu'ils viennent d'abattre et qui tombent en leur pouvoir » ${ }^{150}$. Le terme «droit des conflits armés » est aussi utilisé par «les institutions politiques (Assemblée générale, Conseil de sécurité de l'ONU, alliances militaires...) ou lorsque les instances délibérantes entendent se dérober face à la qualification d'une guerre [...] La majorité des Etats issus de la colonisation européenne, adoptent aussi cette dernière dénomination [...] ${ }^{151}$. L'article $2 b$ du PA I consacre pour sa part l'expression «Règles du droit international applicable dans les conflits armés ». Et suivant cet article, cette expression "s'entend des règles énoncées dans les accords internationaux auxquels participent les parties au conflit ainsi que des principes et règles du droit international généralement reconnus qui sont applicables aux conflits armés ». Le terme droit des conflits armés est employé par différents ouvrages d'expression française ou anglaise (The law of armed conflict ${ }^{152}$. Celui-ci traduit mieux le progrès accompli par les CG qui rattachent dorénavant automatiquement et objectivement des conséquences juridiques à l'affrontement armé entre parties. Et ce sans faire dépendre les victimes de la qualification ou de l'appréciation discrétionnaire des parties ${ }^{153}$ (cf. infra). Robert KOLB fait remarquer qu'à strictement parler, le droit international humanitaire est la principale branche du «droit des conflits armés ». Celui-ci est un terme plus englobant. Ainsi, certaines institutions telles que les prises ou la contrebande ou encore le droit de neutralité dans le droit de la guerre maritime ne conviennent pas au DIH. C'est donc « une perte de nuance regrettable», selon cet auteur, de considérer le «droit international humanitaire » comme synonyme de droit des conflits armés ${ }^{154}$.

Et le «droit de la guerre » d'usage notamment dans des ouvrages anciens ${ }^{155}$ reste non moins

\footnotetext{
${ }^{148}$ Il consacre d'ailleurs comme titre de son ouvrage Principes de Droit des conflits armés.

149 BULA-BULA, Sayeman mentionne dans le même sens que Hans Peter GASSER et Eric DAVID que : «Historiquement, le droit international humanitaire, alors droit de la guerre, forme l'une des trois pierres d'angle du droit des gens, [...] » (nous soulignons). Voy. Sayeman BULA Bula, Droit international humanitaire, op. cit., p. 49

${ }^{149}$ GASSER, Hans Peter, Le Droit International Humanitaire : Introduction, op. cit., p. 3.

${ }^{150}$ DAVID, Eric, Principes de droit des conflits armés, $5^{\mathrm{e}}$ édition op. cit., pp. 40-41.

${ }^{151}$ BULA-BULA, Sayeman, Droit international humanitaire, op.cit., p. 52.

${ }^{152}$ Voy. par exemple, DAVID, Eric, Principes de droit des conflits armés, op. cit., 1151 p. ; ROUSSEAU, Charles, Le droit des conflits armés, A. Pedone, Paris, 1983, 629 p. ; DEYRA, Michel, L'essentiel du droit des conflits armés, éd. Gualino Lextenso, Paris 2002, 130 p.; GREEN, L.C., The contemporary law of armed conflict, Manchester University Press, Manchester - New-York, 1993, 374 p. ; HENSEL, Howard M. (ed.), The law of armed conflict. Constraints on the contemporary use of military force, Ashgate Publishing Limited Ashgate Publishing Company, Hampshire - Burlington, 2006, 266 p. ; CHETAIL, Vincent (dir.), Permanence et mutation du droit des conflits armés, Bruylant, Bruxelles, 2013, 683 p. ; etc.

${ }^{153} \mathrm{KOLB}$, Robert, Ius in bello. Le droit international des conflits armés, $2^{\mathrm{e}}$ édition, op. cit., p. 13.

${ }^{154}$ Ibid., p. 15.

${ }^{155}$ Voy. par exemple, Le droit de la guerre et de la paix (1625) de Hugo GROTIUS traduit par P. PRADIERFODERE, et édité par D. ALLAND, et S. GOYARD-FABRE, $2^{\mathrm{e}}$ édition, PUF, 2012, 868 p. ; ROLIN, Albéric, Le droit moderne de la guerre. Les Principes. - Les Conventions. Les usages et les abus, Tome $1^{\mathrm{er}}$, Albert Dewit, Librairie-éditeur, Bruxelles, 1920, 586 p. ; ROLIN, Albéric, Le droit moderne de la guerre. Principes. Les conventions. Les usages et les abus, Tome $1^{\mathrm{er}}$, Albert Dewit, Librairie-éditeur, Bruxelles, 1921, 455 p. ; DEJONGH, Charles et YSEUX, Victor, Le droit et la guerre, Tome I, L.G.D.J, Paris, 1917, 418 p. ; DEJONGH, Charles et YSEUX, Victor, Le droit et la guerre, Tome II, L.G.D.J, Paris, 1918, 944 p. ; DEJONGH, Charles et YSEUX, Victor, Le droit et la guerre, Tome III, L.G.D.J - Bruylant, Paris- Bruxelles, 1919, 801 p. ; M. H.
} 
d'actualité ${ }^{156}$ pour désigner également le DIH. D'autres préfèrent encore l'expression latine «jus in bello » ou «Ius in bello ${ }^{157}$. Et nombreux sont encore les ouvrages qui portent l'intitulé de droit international humanitaire ou international humanitarian law ${ }^{158}$. Cette expression est également utilisée par la $\mathrm{CIJ}^{159}$ et par des juridictions pénales internationales ${ }^{160}$. Elle est aussi adoptée et reprise notamment dans différentes résolutions du CS/NU face à des violations des règles relatives à la conduite des hostilités ou à la protection des civils en conflits

KEEN, The laws of war in the late middle ages, Routledge \& Kegan Paul - University of Toronto Press, London-Toronto, 1965, 291 p. ; MEYROWITZ, Henri, Le principe de l'égalité des belligérants devant le droit de la guerre, A. Pédone, Paris, 1970, 418 p. ; etc.

156 Voy. par exemple, CUMIN, David, Manuel de droit de la guerre, éd. Larcier, Bruxelles, 2014,534 p. ; CUMIN, David, Le droit de la guerre. Traité sur l'emploi de la force armée en droit international, 3 Vol., L'Harmattan, Paris, 2015, 1681 p. ; DEYRA, Michel, Le droit dans la guerre, éd. Gualino Lextenso, Paris 2009, 283 p. ; etc.

${ }^{157}$ Voy. par exemple, KOLB, Robert, Ius in bello. Le droit international des conflits armés, $2^{\mathrm{e}}$ édition, Helbing Lichtenhahn, Bruylant, 2009, 551 p.

${ }^{158}$ Voy. par exemple, THÜRER, Daniel, International humanitarian law: Theory, practice, context, Hague Academy of International Law, The Hague, 2011, 500 p. ; EMMANUELLI, Claude, International humanitarian Law, Bruylant - éd. Yvon Blais, Bruxelles - Québec, 2009, 425 p. ; FLECK, Dieter (ed.), The Handbook of humanitarian law in armed conflicts, Oxford University Press, op. cit., 589 p. ; ARNOLD, Roberta et HILDBRAND, Pierre-Antoine (ed.), International humanitarian law and the 21st century's conflicts. Changes and challenges, Editions Universitaires suisses -Edis, Lausane-Berne-Lugano, 2005, 253 p. ; McCOUBREY, Hilaire, International humanitarian law. The regulation of armed conflicts, Dartmouth Publishing Company limited - Gower Publishing Company, Hants-Vermont, 1990, 227 p. ; ROSENBLAD, Esbjörn, International humanitarian law of armed conflict. Some aspects of the principle of distinction and related problems, Henry Dunant Institute, Geneva, 1979, 200 p. ; BULA-BULA, Sayeman, Droit international humanitaire, op. cit., 402 p.; BELANGER, Michel, Droit international humanitaire, op. cit., 150 p.; BELANGER, Michel, Droit international humanitaire général, op. cit.,, 156 p. ; BETTATI, Mario, Droit humanitaire, $1^{\mathrm{er}}$ édition, Dalloz, Paris, 2012, 321 p. ; ASPREMONT, Jean d' et HEMPTINE, Jérôme de, Droit innternational humanitaire, A. Pedone, Paris, 2012, 508 p. ; STEENBERGHE, De Raphaël Van (dir.), Droit international humanitaire : un régime spécial de droit international?, Bruylant, Bruxelles, 2013, 352 p.; BIAD, Abdelwahab, Droit international humanitaire, $2^{\mathrm{e}}$ édition, Ellipses, Paris, 2006, 139 p. ; HAROUEL-BURELOUP, Véronique, Traité de droit humanitaire, $1^{\mathrm{er}}$ édition, PUF, Paris, 2005, 556 p. ; PICTET, Jean, Les principes du droit international humanitaire, CICR, Genève, 1966, 66 p. ; etc.

${ }^{159}$ Voy., par exemple, CIJ, Affaire des Activités militaires et paramilitaires au Nicaragua et contre celui-ci (Nicaragua c. Etats-Unis d'Amérique), arrêt du 27 juin 1986, Recueil 1986, pp.14, 15 ; p. 65, §116 ; p. 66, §118 ; p. 112, §216; p. 114, §220, etc.; CIJ, Conséquences juridiques de l'édification d'un mur dans le territoire palestinien occupé, Avis consultatif du 9 juillet 2004, Recueil 2004, p. 137 ; p. 172, §89 ; p. 177, §§ 103 , 104 ; p. 178, §106, etc. ; CIJ, Affaire des Activités armées sur le territoire du Congo (République Démocratique du Congo c. Ouganda), arrêt du 19 décembre 2005, Recueil 2005, voir plus particulièrement la partie réservée aux «Violations du droit international relatif aux droits de l'homme et du droit international humanitaire : Appréciation de la Cour », p. 239, §§ 205 et ss. ; etc.

${ }^{160}$ Les dénominations officielles des juridictions pénales ad hoc en disent déjà plus. En effet, l'article $1^{\text {er }}$ de la Résolution S/808/1993 du CS/NU du 22 février 1993 porte création d' « un tribunal international pour juger les personnes présumées responsables de violations graves du droit humanitaire international commises sur le territoire de l'ex-Yougoslavie depuis $1991 »$ (nous soulignons) (Voy. http://www.un.org/fr/documents/view doc.asp?symbol=S/RES/808(1993) (Source consultée le 11 septembre 2016), Voy. aussi l'article 2 de la résolution $\mathrm{S} / \mathrm{RES} / 827$ (1993) in http://www.un.org/fr/documents/view doc.asp?symbol=S/RES/827(1993) (Source consultée le 11 septembre 2016) . Pour le cas du Rwanda, il est créé un «tribunal criminel international chargé de juger les personnes présumées responsables d'actes de génocide ou d'autres violations graves $d u$ droit international humanitaire commis sur le territoire du Rwanda et les citoyens rwandais présumés responsables de tels actes ou violations commis sur le territoire d'États voisins entre le ler janvier et le 31 décembre 1994 ». Voy. le préambule du Statut du Tribunal international pour le Rwanda en annexe de la Résolution S/RES/955 (1994) http://www.un.org/fr/documents/view_doc.asp?symbol=S/RES/955(1994)\&TYPE=\&referer=http://www.un.org/ fr/sc/documents/resolutions/1994.shtml\&Lang=F (Source consultée le 11 septembre 2016). La CPI fait également usage de «droit international humanitaire » en reprenant la jurisprudence du TPIY ou du TPIR (Voy. par exemple, CPI, Le Procureur c Thomas Lubanga Dyilo, affaire $\mathrm{N}^{\circ}$ ICC-01/04-01/06, jugement du 14 mars 2012 , p. 264, § 533 ou p. 267, §538). Elle utilise aussi l'expression «droit international des conflits armés » (Voy. la même décision pp. 267-268, §538). 
armés ${ }^{161}$. «Droit international humanitaire » est aussi l'expression de plus en plus utilisée actuellement par l'Institut de droit International (IDI) ${ }^{162}$. Lequel n'hésite tout de même pas à employer le terme «droit de conflits armés » ${ }^{163}$ en abandonnant «droit de la guerre »d'usage jadis ${ }^{164}$. Il est arrivé aussi à cette institution savante de faire usage de la combinaison d'expression "Règles de caractère humanitaire résultant du droit relatif aux conflits armés 》 ou «Règles humanitaires relatives aux conflits armés ${ }^{165}$ ou d'employer simplement l'expression globale de «droit international en vigueur » ${ }^{166}$ pour désigner les règles équivalent au DIH. Toutefois, aucune justification particulière n'est offerte pour telle ou telle préférence. Celle-ci est simplement relative aux thèmes faisant l'objet d'examen.

De ces expressions - «jus in bello », «droit de la guerre », «droit ou droit international des conflits armés », et «droit international humanitaire »-, il y a lieu d'observer avec David CUMIN une certaine «mutation sémantique ». Laquelle est perçue dès le moment (1864) où les Etats invoquent «les exigences humanitaires » associées et soumises aux «nécessités militaires ». Ces exigences sont dès lors perçues par la Croix-Rouge comme le noyau du jus in bello, nommé $« \mathrm{DIH}{ }^{167}$. En effet, cet auteur fait remarquer que de cette mutation sémantique, «1) Le terme «guerre » est devenu suspect en raison de la mutation du jus ad bellum en jus contra bellum. 2) Il est également devenu trop étroit en raison de l'apparition de conflits armés autres qu'interétatiques [...] 3) Par rapport à «jus in bello», expression latine donc ésotérique, ancienne, dépourvue de sigles, sévère, « droit international humanitaire », expression française, récente, utilisable en sigles, sympathique, apparaît nettement plus attractif. 4) « DIH » a l'immense avantage, du point de vue de «l'impérialisme des droits de l'homme », de suggérer l'association avec « DIDH » ... ${ }^{168}$.

A la lumière de ce qui précède, s'il est vrai que le DIH «s'inspire du sentiment

\footnotetext{
${ }^{161}$ L'expression «droit international humanitaire » est utilisée dans des nombreuses résolutions du CS/NU concernant les conflits armés en RDC. Voy. par exemple les résolutions 1565 (2004) §19; 1649 (2005) $4^{\mathrm{e}}$ considérant, $\S \S 3$ et $18 ; 1635$ (2005) $7^{\mathrm{e}}$ considérant ; 1736 (2006), $6^{\mathrm{e}}$ considérant ; 1794 (2007) $5^{\mathrm{e}}$ considérant ; 1856 (2008) $3^{\mathrm{e}}$ considérant, $\S 3 ; 1906$ (2009) $3^{\mathrm{e}}$ considérant, $\S 17 ; 1952$ (2010) $10^{\mathrm{e}}$ considérant ; etc.

${ }_{162}$ Voy. IDI, Session de Rhodes, Problèmes actuels du recours à la force en droit international, $10^{\mathrm{e}}$ Commission, Sous-groupe D, L'autorisation du recours à la force par les Nations unies, Résolution du 9 septembre 2011, art. 6 et 9; IDI, Session de Santiago, Problèmes actuels du recours à la force en droit international - Action humanitaire -, $10^{\mathrm{e}}$ Commission, Sous-groupe B, Résolution du 27 octobre 2007, § V ; IDI, Session de Bruges, L'Assistance humanitaire, $16^{\mathrm{e}}$ Commission, Résolution du 2 septembre 2003, $8^{\mathrm{e}}$ et $9^{\mathrm{e}}$ considérants.

${ }^{163}$ Voy. IDI, Session de Tallinn, Régime juridique des épaves des navires de guerre et des épaves des autres navires d'Etat en droit international, $9^{\mathrm{e}}$ Commission, Résolution du 29 août $2015,7^{\mathrm{e}}$ considérant ; L'expression «Règles relatives aux conflits armés», allusion faite au «droit des conflits armés» a été utilisée. Voy. IDI, Session de Wiesbaden, Les Conditions d'application des règles autres que les règles humanitaires, relatives aux conflits armés aux hostilités dans lesquelles les forces des Nations Unies peuvent être engagées, $1^{\text {ère }}$ Commission, Résolution du 13 août 1975, articles 2 et 6.

${ }^{164}$ Voy. IDI, Session de Venise, Règles sur le bombardement des villes ouvertes par des forces navales, Résolution du 29 septembre 1896, article $1^{\text {er }}$; IDI, Session de Gand, Régime de la neutralité, Résolution des 21, 22, 24 et 25 septembre 1906, article 9 ; etc.

${ }^{165}$ Voy. IDI, Session de Zagreb, Les Conditions d'application des règles humanitaires relatives aux conflits armés aux hostilités dans lesquelles les forces des Nations Unies peuvent être engagées, ${ }^{\text {ère }}$ Commission, Résolution du 3 septembre 1971, articles 2 et 4 à 8.

${ }^{166}$ Voy. IDI, Session d'Edimbourg, La distinction entre les objets militaires et non militaires en général et notamment les problèmes que pose l'existence des armes de destruction massive, $5^{\mathrm{e}}$ Commission, Résolution du 9 septembre 1969, articles 4 à 8.

${ }^{167}$ CUMIN, David, Le droit de la guerre. Traité sur l'emploi de la force armée en droit international, Vol. 2, L'Harmattan, Paris, 2015, p. 487.

${ }^{168}$ Ibid. pp. 487-488.
} 
d'humanité » ${ }^{169}$, il sied de reconnaître en même temps que l'expression «droit international humanitaire » laisse la fausse impression que toutes les règles qu'elle contient sont vraiment de nature humanitaire alors qu'en réalité ce n'est toujours pas le cas ${ }^{170}$. S'il existe différentes expressions utilisées pour désigner le terme $\mathrm{DIH}$, cependant la doctrine tend généralement à ne pas accorder d'importance ou d'intérêt aux choix d'expression opérés par des auteurs à ce sujet $^{171}$. L'importance est réservée plutôt au contenu que l'on attribuerait à l'expression que l'on voudrait équivaloir au terme «DIH ». Il est également important de signifier que de nos jours, la distinction entre le «droit de La Haye » et le «droit de Genève » est moins marquée et moins visible. L'évolution des conflits armés, la conclusion des PA qui fait « une mixture »de ces deux rameaux mais également de nombreux instruments juridiques sans égard des noms des villes précitées ont joué pour cela. Mais pour Jean PICTET cette distinction traditionnelle doit être maintenue car reposant sur « une différence de nature ${ }^{172}$.

Par ailleurs, au regard de la définition sous-examen, la question serait celle de savoir si le DIH se limiterait uniquement aux situations de conflits armés - internationaux ou internes ? En d'autres termes, ce droit n'est-il pas finalement revêtu d'un caractère évolutif pour étendre son champ d'application au-delà des hostilités?

En effet, MOVA Sakanyi affirme que le DIH ne s'est pas contenté de ne régir que les situations de conflits armés : il s'est préoccupé aussi des situations autre que les conflits armés mais qui n'en appellent pas moins au respect des règles humanitaires ${ }^{173}$. A ce sujet, d'aucuns estiment qu'il suffit, en substance, de bien qualifier ces événements pour déclencher les actions humanitaires et créer des obligations pour les Etats ${ }^{174}$. Mario BETTATI abonde dans le même sens en indiquant que «longtemps limité aux conflits armés, le DIH a progressivement été étendu, au moins en partie, aux catastrophes naturelles et/ou industrielles - à l'initiative de la France, en 1988, sur un terrain diplomatique préparé quelques années auparavant par la Jordanie, qui avait lancé l'idée d'un nouvel ordre humanitaire international ${ }^{175}$.

${ }^{169}$ PICTET, Jean, Les principes du droit international humanitaire, op. cit., p. 7.
${ }^{170}$ DINSTEIN, Yoram, The Conduct of Hostilities under the Law of international Armed Conflict, op. cit. p. 13.
${ }^{171}$ Pour en savoir plus, lire DAVID Eric, Principes de droit des conflits armés, $5^{\mathrm{e}}$ édition, op.cit., p. $92 ;$
DEYRA, Michel, Le droit dans la guerre, op. cit., p. 5 ; BULA Bula Sayeman, Droit international humanitaire,
op.cit., p. 52. ; etc.
${ }_{172}$ PICTET, Jean, « Le droit international humanitaire : définition », «art. cit. », p. 14.
${ }_{173}$ MOVA, Sakanyi H., Le droit International Humanitaire : protection des Victimes ou droit d'Ingérence
Humanitaire?, éd. Safari, Lubumbashi, 1998, p. 8.
${ }_{174}$ ANDENDE, Apindia, «art cit. », p. 22. Droit humanitaire, $1^{\mathrm{e}}$ édition, Dalloz, 2012, op. cit., p. 88. Avec BALLALOUD, Jacques, il sied de retenir que l'expression "Nouvel ordre humanitaire international" est apparue pour la première fois dans une lettre adressée aux Nations Unies le 28 octobre 1981 (A/36/245) par le représentant de la Jordanie afin que soit inscrit ce thème à l'ordre du jour de la 36è session de l'Assemblée générale. Le représentant de ce pays insistait sur la nécessité "d'élaborer un cadre international reconnu de principes humanitaires devant régir les relations entre les peuples et les nations en temps de guerre et de paix”. De manière plus concrète le représentant jordanien estimait nécessaire de renforcer la réaction internationale face aux catastrophes naturelles ou provoquées par l'homme. L'Assemblée générale dans sa résolution du 14 décembre 1981 (Rés. 36/136) notait avec intérêt la proposition et l'élargissait notablement en reconnaissant "qu'il importe d'améliorer encore un cadre international global tenant pleinement compte des instruments existant relatifs aux questions humanitaires ». L'Assemblée générale priait le Secrétaire général de recueillir sur la question l'opinion des gouvernements. Environ vingt-cinq Etats ont fait connaître leurs vues et insistent sur la nécessité de renforcer les instruments juridiques existant qui constituent, selon certains, de considérables progrès dans le domaine humanitaire. Parallèlement aux travaux des Nations unies, se constituait à Genève le 5 juillet 1983 une 
En effet, cet argument se fonde sur la résolution $43 / 131^{176}$ de l'AG/NU adoptée le 8 décembre 1988 à l'initiative de Bernard KOUCHNER pour la France. Cette résolution rappelle l'importance de l'assistance humanitaire ${ }^{177}$ face aux catastrophes naturelles et situations d'urgence du même ordre (cf. $5^{\mathrm{e}}$ considérant). En cela, elle convie la "Communauté internationale » à agir rapidement et efficacement au profit des victimes en observant particulièrement les principes d'humanité, de neutralité et d'impartialité ( $12^{\mathrm{e}}$ considérant). Si la souveraineté étatique est réaffirmée (\$2), l'importante contribution à l'assistance humanitaire des $\mathrm{OI}$ et ONG est également reconnue (§3). Les Etats sont donc invités à faciliter la mise en œuvre de l'assistance humanitaire à ces organisations (§4) et leur apporter un appui (§5). Pour Mario BETTATI, «[1]e texte innove puisque, pour la première fois, l'organisation véritable sanctuaire de la souveraineté, pose dans un même document des principes destinés à une application concrète et qu'on peut résumer ainsi : l'urgence impose le libre accès aux victimes, notamment pour les organisations humanitaires internationales ${ }^{178}$.

A l'appui de cet argument, Michel BELANGER constate d'abord que de nombreux auteurs retiennent encore la définition «étroite » du DIH comme un droit des conflits armés et indique ensuite qu'une définition «large » et «moderne» semble préférable ${ }^{179}$. A ce titre, il définit le DIH qu'il appelle «droit international humanitaire général » comme «l'ensemble des règles juridiques qui concernent, au plan international, la protection de la personne humaine en situation de crise ${ }^{180}$. En ce sens, la notion de «crise » qui se situe au centre de cette définition est envisagée dans sa globalité. Elle incorpore notamment des situations telles que les conflits armés (guerres, guerres civiles), les troubles intérieurs, les catastrophes naturelles et industrielles majeures. Selon Michel BELANGER, la notion de «victime » initialement prévue pour des personnes ayant subi des préjudices d'un fait illicite se trouve élargie aux personnes ayant subi des préjudices résultant des situations similaires aux conflits armés (ex : troubles intérieurs, catastrophes naturelles ou industrielles majeures, etc. $)^{181}$.

Si cette définition a le mérite de révéler un aspect du DIH tant «ignoré » ou «négligé »par de nombreux auteurs, cependant, en ne cherchant qu'à placer en piédestal la protection des personnes en des circonstances sus-indiquées, c'est seul le "droit de Genève » ou "droit humanitaire proprement dit» qui se trouve privilégié. Cela ignore donc d'autres aspects

\footnotetext{
"Commission indépendante sur les questions humanitaires", formée de 26 personnalités pour "favoriser un nouvel ordre humanitaire mondial ». En annonçant la création de cette commission, le prince Sadruddin Aga Khan en définissait sa mission dans les grandes lignes : "L La commission, qui devra se réunir deux ou trois fois l'an, cherchera à définir les domaines du droit humanitaire où il y a des vides à combler, des améliorations à apporter en liaison avec les organismes existants. » (nous soulignons). Voy. BALLALOUD, Jacques, Droits de l'homme et organisations internationales. Vers un nouvel ordre humanitaire mondial, éd. Montchrestien, Paris 1984, pp. 11-12.

${ }^{176}$ Voy. AG/NU, Résolution A/RES/43/131, Assistance humanitaire aux victimes des catastrophes naturelles et situations d'urgence $d u$ même ordre, 8 décembre 1988, disponible sur http://www.un.org/french/documents/ga/res/43/fres43.htm (Source consultée le 5 août 2016).

${ }^{177}$ Selon l'IDI, «[1]'expression " assistance humanitaire » désigne l'ensemble des actes, activités et moyens humains et matériels relatifs à la fourniture de biens et de services d'ordre exclusivement humanitaire, indispensables à la survie et à la satisfaction des besoins essentiels des victimes de catastrophes ». Voy. IDI, Session de Bruges, L'Assistance humanitaire, $16^{\mathrm{e}}$ Commission, Résolution du 2 septembre 2003, §I, 1.

${ }^{178}$ BETTATI, Mario, Droit humanitaire. Textes introduits et commentés, op.cit., p. 42. BETTATI, Mario, Droit humanitaire, $1^{\mathrm{e}}$ édition, Dalloz, 2012, op. cit., pp. 90-91.

${ }^{179}$ BELANGER, Michel, Droit international humanitaire général, $2^{\mathrm{e}}$ édition, Gualino éditeur, EJA, Paris, 2007, p. 16.

${ }_{180}$ Ibid.

181 Ibid.
} 
importants composant le DIH dont le «droit de La Haye ». Bien plus, cette définition présente un sérieux problème de juridicité. Rappelons que le DIH, comme le DIP, « est plus un droit de coordination que de subordination; un droit sans véritable législateur «supranational»; l'accord constitue sa source première, quelle que soit la manière dont il s'exprime : traité, coutume, acte des organisations internationales [...] ${ }^{182}$. A travers l'accord, les Etats doivent avoir exprimé clairement leur intention de s'engager ou de contracter des obligations juridiques. Un seuil de juridicité requis doit donc être observable. Ce qui n'est donc pas le cas $\mathrm{du}$ texte principal sur lequel se fondent la plupart de ses défenseurs : une résolution de l'AG/NU (Résolution 43/131 de l'AG/NU du 8 décembre 1988). Celle-ci ne fait que part des recommandations. Bien plus, on est encore loin d'observer la pratique générale des Etats en ce sens. Lesquelles doivent, en plus, être revêtues d'opinio juris pour donner lieu à la «coutume internationale ».

Il est vrai que la définition précitée va dans le même sens que le vœu exprimé par l'Institut de droit international qui considérait qu'il était souhaitable « que le droit international des droits de l'homme et le droit international humanitaire continuent à être développés, afin de prévenir ou d'atténuer les souffrances humaines qu'engendrent les catastrophes en temps de paix et en temps de guerre ${ }^{183}$. Un tel vœu vient également en appui du vif souhait exprimé, dans ce sens, vingt ans plutôt par le Prince Sadruddin Aga Khan (cf. supra) ${ }^{184}$. Dès lors, la prévention ou la gestion des catastrophes en rapport avec les conflits armés sont justifiables de l'application du DIH (voire du DIDH). A ce propos, l'article $61 a$ du PA I définissant « la protection civile », est clair : «L'expression «protection civile»s'entend de l'accomplissement de toutes les tâches humanitaires, ou de plusieurs d'entre elles [...] destinées à protéger la population civile contre les dangers des hostilités ou des catastrophes et à l'aider à surmonter leurs effets immédiats [...]» (nous soulignons). Et en temps de paix, la prévention ou la gestion des catastrophes devraient être justifiables de l'application du DIDH. Ce qui paraît logique car «[1]e fait de laisser les victimes de catastrophes sans assistance humanitaire constitue une menace à la vie et une atteinte à la dignité humaine et, par conséquent, une violation des droits humains fondamentaux $»^{185}$.

En réalité, la définition large du DIH présentée ci-dessus est celle qui incorpore ce qu'il convient d'appeler «le droit international de l'action humanitaire », «établi et appliqué par la communauté internationale, $[\ldots]$ droit « moderne » $[. .$.$] en voie de formalisation depuis la fin$ des années $1980 »{ }^{186}$. Michel BELANGER distingue deux approches du DIH : le «droit humanitaire interétatique » (le DIH «classique ») et le «droit humanitaire international» (le $\mathrm{DIH}$ «moderne »). Et c'est en cette dernière approche (dite aussi droit international de l'action humanitaire ou droit de New-York) qu'il situe cette définition. A notre avis, il s'agirait d'un aspect problématique du droit de New-York.

Toutefois, d'aucuns estiment que le caractère évolutif du DIH reste admis. Ainsi, par exemple, le DIH apparaît plus large que le droit des conflits armés notamment par rapport à la finalité

\footnotetext{
${ }^{182}$ DAVID, Eric, Principes de droit des conflits armés, $5^{\mathrm{e}}$ édition, Bruylant, 2012, p. 38.

${ }^{183}$ IDI, Session de Bruges, L'Assistance humanitaire, $16^{\mathrm{e}}$ Commission, Résolution du 2 septembre 2003, $9^{\mathrm{e}}$ considérant.

184 BALLALOUD, Jacques, Droits de l'homme et organisations internationales. Vers un nouvel ordre humanitaire mondial, op. cit., p. 12.

${ }^{185}$ IDI, Session de Bruges, L'Assistance humanitaire, $16^{\mathrm{e}}$ Commission, Résolution du 2 septembre $2003, \S \mathrm{II}, 1$.

${ }^{186}$ BELANGER, Michel, Droit international humanitaire général, op. cit., p. 27.
} 
« humanitaire » qu'il poursuit ${ }^{187}$. Dans le même sens, Jacques FIERENS fait savoir que «le droit humanitaire a longtemps été synonyme de droit des conflits armés, mais il peut aujourd'hui trouver à s'appliquer en dehors de ceux-ci ${ }^{188}$. Longtemps considéré comme branche du «DIP», «[d]epuis qu'il s'est pénalisé, le droit humanitaire constitue plus particulièrement une partie du droit international pénal, qui désigne la branche du droit international relative à la répression des infractions internationales, même si elle englobe des infractions étrangères au droit humanitaire $[\ldots]{ }^{189}$.

Au regard des arguments précédents, en ce qui concerne spécialement cette dissertation, il y a lieu de définir, avec le CICR, le «DIH» comme «des règles internationales, d'origine conventionnelle ou coutumière, qui sont spécifiquement destinées à régler les problèmes humanitaires découlant directement des conflits armés, internationaux ou non, et restreignent, pour des raisons humanitaires, le droit des Parties au conflit d'utiliser les méthodes et moyens de guerre de leur choix ou protègent les personnes et les biens affectés, ou pouvant être affectés, par le conflit ${ }^{190}$.

En dépit de la tendance doctrinale de l'extension des règles du DIH à des situations autres que les conflits armés dont les «catastrophes naturelles» et «situations d'urgences du même ordre », la doctrine reconnaît quasi-unanimement cette dernière définition comme celle du DIH (cf. supra). Cette tendance d'extension du DIH relayant notamment le droit à l'assistance humanitaire, en dépit de certaines de ses règles établies sur le plan coutumier telles que l'accès libre des personnes civiles aux secours humanitaires ou la liberté de déplacement du personnel de secours, revêt tout de même un caractère juridique ambigu ${ }^{191}$. Ainsi sans s'en tenir aux spéculations d'ordre académique et pour des raisons pratiques, cette dernière définition constituera la référence pour la présente réflexion.

\section{\$2. Aperçu historique du droit international humanitaire}

«Il est admis aujourd'hui que le droit suit les faits plus qu'il ne les précède. C'est pourquoi l'histoire tient une place si importante dans l'étude des disciplines juridiques ${ }^{192}$. Pour tout dire, l'analyse préalable du contexte culturel, politique, économique, social, philosophique de la naissance d'une règle ou d'une discipline juridique s'avère plus que nécessaire dans une étude liée à l'examen de la mise en œuvre de celle-ci. Cette analyse permet une compréhension aisée du contenu et de la portée, sinon de l'état actuel de la norme. Compréhension qui se fondera également sur les arguments et attitudes des parties créatrices de la norme, hormis le contexte

\footnotetext{
${ }^{187}$ MEJRI, Khaled, Le droit international humanitaire dans la jurisprudence internationale, op. cit., p. 24.

${ }^{188}$ FIERENS, Jacques, Droit humanitaire pénal, éd. Larcier, op. cit., p. 23.

${ }^{189}$ Ibid.

${ }^{190}$ PICTET, Jean, «Le droit international humanitaire : définition », «art.cit. », p. 13. Voy. aussi SANDOZ, Yves, SWINARSKI, Christophe et ZIMMERMANN, Bruno (éd. et Coord.), Commentaire des Protocoles additionnels du 8 juin 1977 aux Conventions de Genève du 12 août 1949, CICR, Martinus Nijhoff Publishers, Genève, 1986, p. XXVII, disponible en ligne https://ihldatabases.icrc.org/applic/ihl/dih.nsf/Comment.xsp?action=openDocument\&documentId=46D8B672E858EDB3 C12563BD002D361A (Source consultée le 05 août 2016).

${ }^{191}$ PERRAKIS, Stelios, «Le droit international humanitaire et ses relations avec les droits de l'homme. Quelques considérations », in TAVERNIER, Paul et HENCKAERTS, Jean-Marie (dir.), Droit international humanitaire coutumier : enjeux et défis contemporains, Bruylant, Bruxelles, 2008, p. 135.

${ }^{192}$ DJIENA Wembou, Michel-Cyr, «Le Droit Humanitaire Africain : sources, contenu et portée », in Revue Africaine de Droit International et Comparé, éd. Sociétés Africaines de Droit International et Comparé, mars 2001, p. 1.
} 
sous étude. Ainsi, l'on ne saurait mieux cerner et comprendre le contenu et l'état actuel d'une règle ou d'une branche du droit sans référence au contexte dans lequel elle trouve naissance. En $\mathrm{DIH}$, il est nécessaire d'interroger l'histoire, à travers diverses civilisations et traditions, afin de comprendre la forme actuelle de ce droit et surtout sa situation de mise en œuvre.

Et d'ailleurs «nos civilisations se sont notamment construites sur le récit de guerres et de génocides, dont la littérature donnera d'ailleurs des versions splendides ${ }^{193}$. Ainsi, « lorsqu'on scripte d'un regard rétrospectif l'histoire humaine, on se rend sans peine compte que celle-ci est, d'une manière générale caractérisée par des frictions entre les hommes et entre les peuples par des actes de violence, de vandalisme et d'oppression et par la réification de l'homme par l'homme. Une histoire émaillée de sang, de larmes, de grincements des dents et des cris de détresse ${ }^{194}$. En clair, « la guerre est incontestablement le plus spectaculaire des phénomènes sociaux. C'est par la guerre qu'ont péri presque toutes les civilisations connues. C'est par la guerre qu'ont fait leur entrée presque toutes les civilisations nouvelles. C'est par la guerre que s'établissent ou se sanctionnent les primautés qui mettent pour un temps plus ou moins long un certain type de société à la tête de l'humanité ${ }^{195}$.

Par ailleurs, au-delà de la présence quasi-permanente des violences, des conflits et de leurs conséquences néfastes, l'histoire de l'humanité se trouve également marquée par des tentatives de réglementation du «phénomène-guerre ». C'est donc la présence des règles humanitaires à l'état embryonnaire.

En effet, il existe, dès les civilisations les plus anciennes, des règles relatives au comportement des combattants. En Occident, les idées humanitaires ont été énoncées dès le $\mathrm{V}^{\mathrm{e}}$ siècle par Saint Augustin et reprises et développées ${ }^{196}$ dès 1260 par Saint Thomas d'Aquin dans sa Summa totius theologiae ${ }^{197}$, avant que Vitoria, Ayala, Suarez, Gentili ou Grotius ne posassent les fondements doctrinaux de la réglementation des guerres. C'est ainsi que Grotius dénonça ceux qui, pendant la guerre, se croyaient autorisés à fouler aux pieds «tout droit humain et divin et à commettre toutes sortes de crimes sans retenue ». Pour Emeric de Vattel, le châtiment du coupable, le refus qu'on lui fait de la vie, ne devait pas être retenu pour une suite de la guerre mais pour une punition de son crime. Fénelon l'affirma encore, en 1711, dans l'examen de conscience sur les devoirs de la royauté : "Il y a des lois de la guerre qu'il ne faut pas regarder moins religieusement que celles de la paix, autrement la guerre ne serait plus qu'un brigandage inhumain, qu'une série perpétuelle d'assassinats, d'abominations et de barbaries ${ }^{198}$.

En d'autres termes, comme le relève à juste titre Jean PICTET «le droit humanitaire a des racines plus profondes que l'ont cru longtemps des auteurs européens aux vues étroites, qui en plaçaient la naissance à la fin du Moyen Age. En réalité, les lois de la guerre sont aussi

193 FIERENS, Jacques, Droit humanitaire pénal international, cours destiné aux Etudiants de Master complémentaire en droits de l'homme, Académie Universitaire «Louvain », Bruxelles 2010-2011, op.cit., p. 13.

194 KAMUNDU Yawara, «L'homme, un animal conflictuel », in Conflits et identités, Actes des Journées philosophiques de CANISIUS, avril 1997, éditions LOYOLA, Kinshasa, 1998, p. 27.

${ }^{195}$ BOUTHOUL, Gaston, op.cit., p. 5.

${ }^{196}$ COURSIER, Henri, Etudes sur la formation du droit humanitaire, CICR, Genève, 1952, p. 25.

${ }^{197}$ NAHLIK, Stanislaw E., Précis abrégé de droit international humanitaire, extrait de la RICR, Genève, JuilletAoût 1984, p. 8.

${ }^{198}$ CURRAT, Philippe, Les crimes contre l'humanité dans le statut de la Cour pénale internationale, Bruylant, L.G.D.J, Schulthess, Bruxelles, Genève-Zurich-Bâle, Paris, 2006, p. 27. 
anciennes que la guerre elle-même et la guerre aussi ancienne que la vie sur terre ${ }^{199}$. Et suivant cette ère très ancienne, renseigne Hans Peter GASSER, chaque fois que des différends entre tribus, habitants de vallées ou partisans de chefs rivaux ou d'autres formes primitives de l'Etat n'ont pas dégénéré en guerres d'extermination, on a assisté à la formation (souvent constante) des règles dont le but était de freiner l'explosion de la violence ${ }^{200}$. Il convient de souligner que ces règles (coutumières) avaient des caractéristiques et des buts très similaires partout dans le monde et dans la plupart des cultures ${ }^{201}$. «Sans parler d'une progression de l'humanitaire dans le temps - car son évolution s'est faite en dents de scie -, on constate, si l'on prend l'exemple de l'occident, que ses racines remontent à l'Antiquité, même si son véritable essor date du XIXe siècle ${ }^{202}$.

L' « humanisation » de l'activité guerrière date dès l'Antiquité. Nombreux sont des textes qui ont eu pour mission de réglementer la guerre. Parmi lesquels, des textes anciens comme le Mahâbhârata, ou le code Hammourabi, des livres saints comme la Bible et le Coran, certaines règles comme le Code de Manou - fondement du droit et de la morale des peuples de l'Inde (élaboré entre 200 avant Jésus-Christ et 200 ans après Jésus-Christ ${ }^{203}$ ), etc. Ces différents textes prônent des règles de respect de l'adversaire et ont émergé à côté d'une barbarie incessante à cet égard ${ }^{204}$. «Des pratiques qui paraissent aujourd'hui barbares étaient admises à l'époque, telles que l'exécution des combattants ennemis capturés ou leur réduction en esclavage et la déportation de la population civile. Les captifs de guerre, femmes ou enfants, faisaient partie du butin que des vainqueurs se partageaient ${ }^{205}$. «Dans certaines situations toutefois, l'attitude des vainqueurs à l'égard des vaincus pouvait être différente : la crainte de représailles, la nécessité de préserver leur potentiel humain ou encore la prise de conscience du caractère irrationnel de tels comportements leur ont fait progressivement adopter des normes de conduite. Même si elles n'étaient pas toujours respectées, elles ont constitué les premiers jalons des règles de l'humanitaire ${ }^{206}$. C'est dans le même sens que Marco SASSÒLI et Antoine A. BOUVIER renseignent dans leur ouvrage collectif que ces coutumes anciennes n'ont pas été adoptées dans un but prioritairement humanitaire sinon avec un objectif tactique ou économique. Mais elles ont non moins eu des effets humanitaires. Par exemple, expliquent-ils, l'interdiction d'empoisonner les puits - très répandue dans le droit traditionnel africain (cf. infra) et réaffirmée dans les traités modernes - avait probablement pour principal objectif de permettre l'exploitation des territoires conquis et non d'épargner les vies de la population locale. Dans le même sens, l'interdiction de tuer les prisonniers (de guerre), qu'on retrouve dans beaucoup de cultures et religions, avait peut-être pour but principal d'assurer la disponibilité de futurs esclaves, plutôt que de sauver les vies des anciens combattants ${ }^{207}$.

Toutefois, une étude fouillée et consacrée spécialement sur la question ne partage pas le point de vue ci-dessus. En effet, dans son étude dédiée à L'eau et la guerre. Eléments pour un régime juridique, Mara TIGNINO fait remarquer que la prohibition d'empoisonnement d'eau, - admise

\footnotetext{
${ }^{199}$ Ibid; SASSÒLI, Marco et BOUVIER Antoine A., Un droit dans la guerre, Genève, CICR, Juin 2003, p. 127.

${ }^{200}$ GASSER, Hans Peter, Le Droit International Humanitaire : Introduction, op.cit., p. 7.

${ }^{201}$ SASSÒLI, Marco et BOUVIER Antoine A., Un droit dans la guerre, op.cit., 127.

${ }^{202}$ BUIRETTE, Patricia et LAGRANGE Philippe, op.cit., 8.

${ }^{203}$ Lire BULA-BULA, Sayeman, op.cit., 33.

${ }^{204}$ BIAD, Abdelwahab, Droit international humanitaire, 2è édition, Ed. Ellipses, Paris 2006, p. 7.

${ }^{205}$ Ibid.

${ }^{206}$ BUIRETTE, Patricia et LAGRANGE, Philippe, op.cit., p. 8.

${ }^{207}$ SASSÒLI, Marco et BOUVIER Antoine A., Un droit dans la guerre, op.cit., p.127.
} 
dans plusieurs cultures, notamment islamique ou chrétienne, et reprise dans de nombreux ouvrages du moyen-âge et de la renaissance - repose sur plusieurs fondements ${ }^{208}$. Grotius y voyait une pratique contraire à la coutume des ancêtres et aux préceptes de dieux. Vattel, faisant référence à quelques auteurs, estimait que cela était dans le but d'éviter de donner la mort à des innocents ${ }^{209}$. Et dans un sens actuel, Mara TIGNINO conclut que «[c]ette prohibition est liée à l'interdiction d'utiliser un moyen de combat perfide qui trompe la bonne foi de l'adversaire. Elle repose également sur le fait que cette arme frappe indistinctement la population et les combattants. Ainsi, l'empoisonnement de l'eau est lié à l'interdiction des armes qui présentent par nature un caractère indiscriminé $»^{210}$.

Sous l'antiquité donc, vers l'an 2000 avant notre ère, on assista au développement des cités et des relations entre les peuples. Ce phénomène fut favorable à la naissance des règles applicables pendant la guerre et à la conclusion de traités de paix. Chez les Sumériens, par exemple, la guerre fut une institution organisée : déclaration de guerre avant le début des hostilités, recours à l'arbitrage en vue de résoudre les différends, immunités parlementaires, conclusion de traités de paix après les hostilités ${ }^{211}$. C'est justement à propos des cités que Platon dans La République proposait un programme d'humanisation de la guerre. Mais ce programme ne concernait que les conflits armés entre les cités grecques, et non la lutte contre les barbares $^{212}$. Il n'avait donc aucun caractère universel. "Platon, dans la ligne d'une différence de traitement entre les citoyens et les autres individus, estime inacceptable l'asservissement des Grecs. Ses recommandations visent à tempérer une nouvelle conduite de la guerre qui autoriserait sans restriction la mise à mort, le pillage et la réduction en esclavage $»^{213}$.

Sous le Moyen Age, le christianisme ${ }^{214}$, l'islam $^{215}$ et la chevalerie contribuèrent à l'émergence

${ }^{208}$ Lire TIGNINO, Mara, L'eau et la guerre. Eléments pour un régime juridique, Bruylant, Bruxelles, 2011, pp. $128-131$.

${ }^{209}$ Ibid., p. 128.

${ }^{210}$ Ibid., p. 131

${ }^{211}$ MAVUNGU, Jean Pierre, «Les Rapports entre les droits de l'homme et le droit international humanitaire », in Droits de l'Homme et droit international humanitaire, Séminaire de Formation Cinquantenaire de la DUDH du 18 novembre au 10 décembre 1999, P.U.K., Kinshasa, 1999, p. 186.

${ }^{212}$ BIAD, Abdelwahab, Droit international humanitaire, 2è édition, Ed. Ellipses, op.cit., pp. 7 - 8.

213 FIERENS, Jacques, Droit humanitaire pénal international, cours destiné aux Etudiants de Master complémentaire en droits de l'homme, Académie Universitaire « Louvain», Bruxelles 2010-2011, op.cit., p.16.

${ }^{214}$ "le christianisme primitif a eu vis-à-vis de la guerre une attitude puissamment originale; il l'a maudite et rejetée en bloc : "Qui a frappé par l'épée périra par l'épée ». Par ailleurs l'Eglise se trouva(nt) rapidement dans l'obligation de composer avec le pouvoir (...), les théologiens les plus éminents élaborent une doctrine de compromis. Saint Augustin, très conscient de la contradiction entre l'Ancien et le Nouveau Testament, développe une théodicée qui justifie la guerre dans la mesure où elle peut être l'expression de la volonté divine : "Si Dieu, par une prescription spéciale, ordonne de tuer, l'homicide devient une vertu». Saint Thomas, dans sa célèbre théorie de la guerre juste, formule les conditions qui peuvent faire de l'activité guerrière une entreprise agréée de Dieu ». Ce sont : $1^{\circ}$ L'autorité du prince ; $2^{\circ}$ Une cause juste ; $3^{\circ} \mathrm{L}^{\prime}$ intention droite (Lire BOUTHOUL, Gaston, op.cit., 12-13). Il faudrait reconnaître cependant que la doctrine catholique de la guerre juste a été rarement appliquée. En effet, les chrétiens ont été de toutes les guerres. Les deux guerres mondiales, par exemple, ont vu les centaines de milliers de chrétiens des pays adversaires s'affronter les armes à la main! Il est pourtant évident qu'au moins un de deux camps ne menait pas la guerre juste, seule permise par la doctrine catholique. A partir du moment où l'Eglise catholique a autorisé ses fidèles à participer aux guerres sous certaines conditions, les controverses n'ont pas manqué entre les théologiens : les uns admettant les guerres sous certaines conditions, les autres affirmant que le commandement "Tu ne tueras pas » ne souffre pas de restriction. Ce différend très important n'a jamais été tranché catégoriquement et le chef de l'Eglise n'a jamais utilisé à ce sujet le pouvoir d'infaillibilité qui lui est conféré » nous renseigne BRENU, Henri bien que lui même prend position dans son ouvrage en affirmant qu'un chrétien doit refuser de participer à la guerre et à sa 
du sentiment d'humanité et à la gestation du droit humanitaire ${ }^{216}$. On parle aujourd'hui encore d'esprit chevaleresque (cf. infra). Régulièrement des conventions ont été établies entre belligérants pour réglementer le sort des personnes ; ce sont là des origines des conventions multilatérales actuelles. Mais de telles règles ont existé aussi dans des cultures qui ne laissaient pas des traces écrites ${ }^{217}$. C'est le cas du continent africain.

L'Afrique ne reste pas en marge. Elle se trouve marquée par des traces des règles humanitaires. Ces dernières, autant pour d'innombrables questions de droit, sont appréhendées dans un contexte collectif $^{218}$. Un «droit de la guerre » était connu et appliqué dans les conflits armés entre tribus et royaumes ${ }^{219}$, compte tenu notamment des coutumes, du niveau de développement, des moyens de combat et de la mentalité propre à chaque peuple ${ }^{220}$. Selon Sayeman BULA-BULA, il s'agissait des « règles humanitaires archaïques, rudimentaires et fragmentaires. Les normes en question s'appliquaient vraisemblablement de manière relative, à l'aune des cultures ${ }^{221}$. Ainsi, «dans les sociétés traditionnelles et préindustrielles dont certaines ne connaissent pas l'écriture, le proverbe s'était révélé comme un mode utile d'instruction dans la mesure où il permettait de véhiculer, de manière prescriptive et répétitive une vision du monde dans laquelle l'expérience humaine y est jugée assez stable, assez définitive pour être mise en formules susceptibles de fixer les comportements individuels dans la société, aussi bien en même temps de paix que lors des conflits armés » ${ }^{222}$. Les proverbes de l'Afrique ancienne contiennent une multitude de règles qui énoncent les obligations d'ordre humanitaire à la charge des chefs traditionnels, des combattants et des citoyens. Mais au dessus de ces règles particulières, il existe trois principes fondamentaux qui constituent l'essence du droit humanitaire africain. Ces principes expriment la coutume des peuples africains ${ }^{223}$. Il s'agit du principe du respect de la vie ou principe d'humanité; du principe de protection et $d u$ principe fondamental du droit de la guerre. Le premier principe se résume comme suit : « La personne humaine est sacrée ; l'on ne peut tuer un homme que lorsque de graves circonstances l'exigent. Dans tous les cas, les morts doivent être entourés de respect ${ }^{224}$. A cet égard, « [1]a locution traditionnelle du Bantou [...] affirme : «Vous frappez, mais vous ne tuez pas !»» ${ }^{225}$.

préparation », (Lire BRENU, Henri, Guerre « juste » et Guerre mondiale, Sogédipresse, Bruxelles (sans année), $1-2)$.

${ }^{215}$ «Les lois de la guerre selon l'Islam sont résumées dans les instructions données par Abou Bekhr, premier successeur de Mahomet, aux généraux chargés de conquérir la Syrie [...] Lorsque vous combattez pour la gloire de Dieu, conduisez-vous comme des hommes, sans tourner le dos, mais que le sang des femmes, des enfants et des vieillards ne souille pas votre victoire. Ne détruisez pas les palmiers, ne brûlez pas les habitations, les champs de blé, n'abattez jamais les arbres fruitiers et ne tuez le bétail que lorsque vous serez contraints de le manger (...)». Voy. COURSIER, Henri, Etudes sur la formation du droit humanitaire, op. cit., pp. 30-31.

${ }^{216}$ MAVUNGU, Jean Pierre, « art. cit. », p.186.

${ }^{217}$ GASSER, Hans Peter, Le Droit International Humanitaire : Introduction, op.cit., p. 7.

218 NDAM NJOYA, Adamou, «La Conception africaine», in Les dimensions internationales du droit humanitaire, Institut Henry Dunant-UNESCO -Pedone, Genève-Paris, 1986, p. 22.

219 Lire avec intérêt BELLO, Emmanuel G., African customary humanitarian law, CICR, Genève, 1980, pp. 1924.

${ }^{220}$ DJIENA Wembou, Michel-Cyr, « art. cit. », p. 1

${ }^{221}$ BULA-BULA, Sayeman, op.cit., p.31.

222 DJIENA Wembou, Michel-Cyr et FALL Daouda, Droit international humanitaire. Théories générales et réalités africaines, éd. L'Harmattan, Paris 2000, p. 172. Voy. aussi BELLO, Emmanuel G., African customary humanitarian law, op.cit., p. 3.

223 DJIENA Wembou, Michel-Cyr et FALL Daouda, Droit international humanitaire. Théories générales et réalités africaines, op. cit., p. 174.

${ }^{224}$ Ibid.

${ }^{225}$ NDAM NJOYA, Adamou, « La Conception africaine », « art. cit. », p. 23. 
Concernant le principe de protection, il est dit que les personnes restées au village et qui ne participent pas aux combats, de même que les moyens nécessaires à leur vie, doivent être protégés $^{226}$. Le principe fondamental du droit de la guerre énonce trois règles principales régissant la conduite des hostilités : l'obligation de déclarer la guerre, l'interdiction de mener les combats au sein de village; la distinction entre combattants et non combattants ${ }^{227}$. Ainsi, pour ce dernier principe, la solution pacifique était toujours privilégiée avant l'éclatement du conflit. La tâche était dévolue aux nobles des entités opposées (Togo), aux gardes impériales (Burkina-Faso), aux notables (Burundi, Rwanda) ou aux sages (Ouganda, Kenya), etc. L'échec des négociations conduisait à l'ouverture des hostilités obéissant à certaines règles (ex : annonce par le son des tambours, par le soufflement dans les cornes d'animaux ou par un tir de flèches, etc. $)^{228}$. En termes de traitement des non-combattants, il est important de faire remarquer que dans la société africaine traditionnelle en général, l' "enfant», symbole d'innocence, était un être vulnérable à protéger (cf. infra). La procréation ou la « source » de la vie qu'incarne la «femme» militait également pour sa protection spéciale. Le «vieillard», proche des esprits des ancêtres, au-delà de sa vulnérabilité physique due au poids de l'âge, méritait aussi une protection spéciale du fait de la pérennisation de la culture, de la tradition qu'il reflétait $^{229}$. Dans la même optique, les féticheurs ou prêtres, en raison de leur mission sacrée, devaient être préservés des effets des hostilités. Ce qui vaut de même pour leurs lieux rituels $^{230}$. Cependant, de telles règles ne sont pas propres à la culture africaine. Elles sont également observables ailleurs ${ }^{231}$.

La protection en période de conflits armés en Afrique traditionnelle ne se limitait point aux personnes. Les biens à caractère civil, servant notamment à la vie ou à la survie des civils, ne devaient pas constituer des cibles pour l'ennemi. Ainsi, par exemple, chez les peuples lacustres de l'Afrique de l'Est, il était interdit aux belligérants de considérer le bétail, les récoltes et les puits d'eau comme cibles de guerre ${ }^{232}$. Tout de même, de telles règles étaient également connues ailleurs. Par exemple, chez Abu Bakr, successeur du Prophète Mahomet, dès le VII ${ }^{\mathrm{e}}$ siècle, face à ses armées, il instruisait: «Ne détruisez pas les palmiers, ne brûlez pas les habitants ni les champs de blé, ne coupez jamais les arbres frutiers et ne tuez le bétail que lorsque vous serez contraints de le manger $»^{233}$.

En revanche, l'existence de règles humanitaires et leur application n'étaient pas uniformes partout en Afrique ${ }^{234}$. On note par exemple que dans des pays de forêts, la «tradition de clémence » - interdisant notamment d'achever un ennemi à terre ou désarmé - n'avait pas sa place. L'ennemi est un sujet à massacrer. Tout comme dans certaines tribus, les civils - non-

${ }^{226}$ DJIENA Wembou, Michel-Cyr et FALL Daouda, Droit international humanitaire. Théories générales et réalités africaines, éd. L'harmattan, Paris 2000, p. 180.

${ }^{227}$ Ibid., p. 177.

${ }^{228}$ NDAM NJOYA, Adamou, « La Conception africaine », « art. cit. », p. 24.

229 Voy. NDAM NJOYA, Adamou, «La Conception africaine », «art. cit. », p. 24. Voy. aussi MUTOY, Mubiala, «Les Etats africains et la promotion des principes humanitaires », in RICR, $\mathrm{n}^{\circ} 776$, CICR, mars-avril 1989, p. 101.

${ }^{230}$ MUTOY, Mubiala, « Les Etats africains et la promotion des principes humanitaires », « art. cit. », p. 101.

${ }^{231}$ Lire par exemple le Chapitre XI-Tempérament par rapport au droit de tuer dans une guerre juste in GROTIUS, Hugo, Le droit de la guerre et de la paix, PUF, Paris, 2012, p. 862. (Ouvrage traduit par P.PRADIER-FODERE et édité par D. ALLAND et S. GOYARD-FABRE).

${ }^{232}$ MUTOY, Mubiala, «Les Etats africains et la promotion des principes humanitaires », « art. cit. », p. 101.

${ }^{233}$ MOMTAZ, Djamchid, «Les règles relatives à la protection de l'environnement au cours des conflits armés à l'épreuve du conflit entre l'Irak et le Koweit », in AFDI, vol. XXXVII, 1991, p. 206.

${ }^{234}$ NDAM NJOYA, Adamou, «La Conception africaine », « art. cit. », p. 25. 
combattants - étaient laissés sans protection avec un traitement similaire aux prisonniers de guerre $^{235}$.

Par ailleurs, l'analyse du contenu essentiel du droit humanitaire africain atteste que la guerre, autant que la mort qui en est son produit, étaient considérées comme ultima ratio. Ainsi, on ne pouvait recourir à la guerre qu'après échec des tentatives diplomatiques où les négociateurs étaient revêtus d'immunités. De même, dans la mesure où la personne humaine est sacrée dans la société africaine traditionnelle, on ne pouvait recourir à la mort qu'après s'être assuré des circonstances graves exigeant une telle situation. Même rudimentaires et fragmentaires, les principes développés ci-avant ont été d'une précieuse valeur dans cette société et prouvent bien à suffisance son organisation avant l'arrivée du colonisateur. Ils ont évité à l'Afrique traditionnelle une jungle et confirmé la pensée inscrite dans la vieille maxime latine $u b i$ societas ubi jus est (là où il y a la société, il y a le droit). Ces principes seront également observables dans le DIH moderne où ils seront fort développés et complétés. (cf. infra).

L'évolution actuelle du DIH atteste d'un apport significatif du continent africain. La montée des «Etats nouveaux » sur la scène internationale a permis de booster la juridicisation de différentes questions les préoccupant. C'est notamment le cas de la reconnaissance des «guerres de libération nationale » au rang de CAI (art. $1^{\mathrm{er}} \S 4$ du PA I). On note par exemple que si les Mouvements de Libération Nationale ont pris part à la Conférence diplomatique de Genève sur la réaffirmation et le développement du droit international humanitaire (19741977), c'est sur proposition de Cuba soutenue notamment par les Etats africains ${ }^{236}$ qui y ont été d'une « brillante participation ${ }^{237}$.

De tout ce qui précède, à quelques exceptions près, et dans la sphère occidentale surtout, la réglementation des hostilités résulte jusqu'ici des arrangements bilatéraux entre belligérants en présence. Les conventions internationales au sens actuel ne sont pas encore connues. Le DIH demeure un droit coutumier. Bien plus, il sied de préciser que ce sont les actes juridiques internes que les Etats émettaient qui par la suite ou mieux par habitude formeront une coutume de guerre qui sera à la base de codification du DIH dans la seconde moitié du XIX ${ }^{\mathrm{e}}$ siècle.

Par ailleurs, comme on peut bien le remarquer à la lecture des lignes précédentes et suivantes, ces pratiques des sociétés ou Etats se trouvaient être facilitées à la base par des conceptions humanitaires véhiculées sur le plan doctrinal ${ }^{238}$. Ainsi, l'on note que les auteurs médiévaux se limitent presque exclusivement à l'étude du jus ad bellum, méditant sur les circonstances dans lesquelles une guerre peut être considérée comme «juste». A part quelques soucis concernant

\footnotetext{
${ }^{235}$ Ibid., p. 24.

${ }^{236}$ WODIE, Vangah Francis, «L'Afrique et le droit humanitaire », in RICR, $\mathrm{n}^{\circ} 761$, CICR, septembre-octobre 1986, p. 270. Lire avec intérêt les pages 271-277 de cette étude.

${ }^{237}$ MUTOY, Mubiala, «Les Etats africains et la promotion des principes humanitaires », « art. cit. », pp. 105106.

${ }^{238}$ «En effet, le premier ouvrage sur le droit de la guerre et de la paix donc sur le droit international dans son ensemble, ne date que du XVIIe Siècle (H. GROTIUS (de GROOT) : De jure belli ac pacis libri tres, $1^{\text {re } e ́ d ., ~}$ Paris, 1625.), alors que des monographies vouées au droit de la guerre commencent à apparaître dès le XIVe (Bartolo de SASSOFERRATO : Tractatus represaliarum, 1354; Giovanni de LEGNANO : De bello, de represaliis et de duello, 1360.), et que des chapitres, ou tout au moins des paragraphes, traitant de certains aspects de ce sujet, peuvent être retrouvés, dans des ouvrages théologiques surtout, beaucoup plus tôt (Pour ne citer que les plus importants, voir surtout : Saint Augustin: De civitate Dei, Livre XXII, chapitre 6 ; Saint Isidore de Séville : Etymologiarum vel originum libri viginti, livre II, chapitre 1, et livre XVIII, chapitre 1 ; Saint Thomas d'Aquin; Summa totius theologiae, Secunda Secundae, Quaestio XL; etc.) (nous soulignons) ». Voy. Stanislaw E. NAHLIK, op.cit., 8.
} 
les personnes et les objets sacrés, donc ecclésiastiques, on pense rarement à restreindre la liberté d'action du belligérant dans une guerre déjà entamée. Il fallut attendre la Renaissance pour qu'on s'intéressât davantage au sort des personnes frappées par les maux de la guerre. Mais les vrais protagonistes de ce qui sera appelé plus tard le droit humanitaire n'apparaissent qu'au Siècle des lumières. Ce sont eux qui vont formuler une doctrine foncièrement humanitaire, selon laquelle la guerre devrait se limiter au combat entre militaires, sans causer du mal ni à la population civile, ni à des biens n'ayant pas un caractère militaire. Les principaux artisans de cette conception furent surtout Jean-Jacques Rousseau, dans un chapitre remarquable de son Contrat social, et Emeric de Vattel, traitant plus spécifiquement des problèmes du droit de la guerre dans son droit des gens ${ }^{239}$.

Toutefois, le DIH tel qu'il existe aujourd'hui, universel et en grande partie codifié, nous le devons directement à deux personnes qui ont été, toutes deux, marquées par des expériences traumatisantes dues à la guerre : Henry DUNANT et Francis LIEBER. Pratiquement en même temps mais chacun ignorant apparemment l'existence de l'autre, DUNANT et LIEBER ont apporté des contributions essentielles à la conception et au contenu du DIH actuel. Mais ce n'est pas porter atteinte à la mémoire de ces deux grandes figures que d'affirmer qu'ils ne sont pas les initiateurs de la protection juridique des victimes de la guerre. Ils ont donc plutôt exprimé cette idée d'une manière nouvelle et plus moderne ${ }^{240}$.

En effet, témoin des souffrances de blessés lors de la guerre d'Italie, qui opposa les français et les italiens aux autrichiens, en 1859 Henry Dunant, un citoyen suisse, émit un double vœu (Un souvenir de Solferino, 1862) : d'une part la constitution dans chaque pays d'une société de secours volontaires susceptible de prêter main-forte au service de santé de l'armée, en cas de guerre ; d'autre part, l'acceptation par les Etats d'un « principe conventionnel et sacré » devant assurer une protection juridique aux hôpitaux militaires et au personnel sanitaire ${ }^{241}$.

Avec l'appui tenace de quatre autres citoyens genevois ${ }^{242}$ à savoir MM. Gustave Moynier, avocat, le général Guillaume-Henri Dufour, les médecins Louis Appia et Théodore Maunoir, et sous l'égide de la Société d'utilité publique de Genève, le premier vœu de DUNANT se réalisera avec la création du Comité international de Secours aux blessés en 1863. Celui-ci deviendra en 1882 le Comité international de la Croix Rouge (CICR).

A l'initiative dudit Comité, le Conseil fédéral suisse convoqua une conférence internationale à

\footnotetext{
${ }^{239}$ Stanislaw E. NAHLIK, op.cit., 8.

${ }^{240}$ GASSER, Hans Peter, Le Droit International Humanitaire : Introduction, op. cit., p. 7.

${ }^{241}$ MAVUNGU, Jean Pierre, « art. cit. », p.186.

${ }^{242}$ Il est important de faire remarquer seul, Henry Dunant n'aurait pas pu matérialiser ses idées humanitaires jugées d'une grande importance. En effet, l'on note que Gustave Moynier avec son talent de juriste et d'organisateur a permis que Dunant puisse exprimer ses idées contenues dans Un souvenir de Solferino en organisant notamment une conférence à ce sujet. Ceci a permis d'attirer l'attention du public sur la question. Il décidera de la mise en place d'une Commission de cinq membres dont l'objet sera d'étudier la matérialisation des idées humanitaires émises par Dunant. Le Général Guillaume Henri Dufour, membre de la Société genevoise d'utilité publique que présidait Gustave Moynier, prendra également part à cette Commission qu'il présidera d'ailleurs. Sa position dans l'armée a été jugée notamment d'une grande importance pour attirer l'attention d'un grand public. Louis Appia et Théodore Maunoir, tous deux médecins, mettront également à profit leur sagesse et intelligence. (Lire BUIRETTE, Patricia et LAGRANGE Philippe, Le droit international humanitaire, éd. La Découverte, Paris, 2008, p.11.) Pour plus d'approfondissement de cette partie, lire utilement Hans G. KNITEL, Les Délégations du Comité International de la Croix-Rouge, Presses de Savoie, Genève, 1967, 2-29. ; PICTET, Jean, Une institution unique en son genre : Le Comité international de la Croix-Rouge, Genève-Paris, Institut Henry-Dunant, éd.A.Pedone, 1985, 111 p. ; COURSIER, Henri, La Croix-Rouge Internationale, PUF, Paris, 1962, 128 p., etc.
} 
Genève qui adopta le 22 août 1864, la Convention pour l'amélioration du sort des militaires blessés dans les armées en campagne. Laquelle sera d'application deux ans après sa signature au cours de la guerre entre l'Autriche et la Prusse. L'adoption de cette convention marqua la première étape dans la codification du $\mathrm{DIH}^{243}$. C'est cette convention qui marque véritablement la naissance du droit international humanitaire (moderne) ${ }^{244}$ qualifié aussi de droit de la CroixRouge $^{245}$. C'est ici donc que se concrétise le second vœu de DUNANT.

Dans son ensemble, la CG du 22 août 1864 indique des conditions juridiques relatives à l'accomplissement des missions des services sanitaires en situation d'hostilités. Ces services doivent remplir leur mission en toute impartialité, neutralité et indépendance dans l'intérêt des militaires blessés dans les armées en campagne. Ils ont pour ce faire à arborer l'emblème de la croix rouge sur fond blanc.

Par la suite, cette première convention est restée inchangée pendant plus de 40 ans, pour être ensuite remaniée en 1906 sur proposition du CICR, en fonction des expériences acquises au cours de plusieurs guerres. La Première Guerre mondiale a mis le «droit de Genève » à rude épreuve, ce qui a conduit à une nouvelle révision en 1929. Quatre ans après la fin de la Seconde Guerre mondiale, ont ensuite été adoptées les quatre CG (12 août 1949). Jean PICTET fait remarquer que le DIH « a pris une ampleur et un élan extraordinaire au cours des années 1948 à 1950, trois années mémorables qui marqueront, à coup sûr, une étape décisive dans la lutte menée pour la défense de la personne humaine ${ }^{246}$. Successivement, la Déclaration universelle des droits de l'homme est proclamée le 10 décembre 1948, les CG sont adoptées le 12 août 1949 et la Convention européenne de sauvegarde des droits de l'homme et des libertés fondamentales est adoptée le 4 novembre $1950^{247}$. De la même manière que ces deux textes relatifs aux droits de l'homme seront développés par de nombreux instruments subséquents, les CG de leur côté connaîtront un développement avec les PA I et II du 8 juin 1977, puis le PA III du 8 décembre 2005. Elles sont également complétées et renforcées par de nombreuses conventions internationales et résolutions des organisations internationales relatives au DIH.

Pour tout dire, «ce ne sont ni les mauvais traitements infligés aux blessés ni la mort d'individus sans défense qui ont le plus frappé Henry DUNANT. Ce qui l'a bouleversé, c'est le manque absolu d'assistance aux blessés et aux mourants ${ }^{248}$ C'est ce qui justifie naturellement l'émission de tels vœux. Lesquels ont pu être concrétisés pour tenter de trouver tant bien que mal remèdes aux problèmes qui se posent.

Par ailleurs, une autre figure a également contribué à la maturation du DIH à savoir Francis LIEBER juriste, émigrant allemand, installé aux Etats Unis d'Amérique et professeur à l'Université de Columbia. Il recevra la demande du Président Abraham LINCOLN celle de rassembler des règles relatives à la conduite des hostilités, singulièrement dans la guerre de Sécession. Ceci aboutira aux Instructions for the Governement of armies of the United States

\footnotetext{
${ }^{243}$ BUIRETTE, Patricia et LAGRANGE Philippe, Le Droit international humanitaire, op. cit., pp. 12-13

244 PICTET, Jean, «Le droit international humanitaire : définition », « art. cit. », p. 15. ; ANDENDE, Apindia, «art. cit.», p. 16.; DELOOZ, François et KOLANOWSKI, Stéphane, «Introduction au droit international humanitaire », « art. cit. », p. 8.

${ }^{245}$ BIAD, Abdelwahab, BIAD, Abdelwahab, Droit international humanitaire, 2è édition, op. cit.,p.17.

${ }^{246}$ PICTET, Jean, Les principes du droit international humanitaire, op. cit., p. 7.

${ }^{247}$ Ibid.

${ }^{248}$ GASSER, Hans Peter, Le Droit International Humanitaire : Introduction, op.cit., p. 8.
} 
in the Field ${ }^{249}$ (instructions pour le comportement des armées des Etats Unis d'Amérique en Campagne) «proclamé le 24 avril 1863 par le Président Abraham LINCOLN dans le contexte de la guerre civile américaine (la guerre de Sécession), en tant qu'ordre général n ${ }^{\circ} 100$ à l'armée nordiste $[. ..] \gg{ }^{250}$. Ces instructions connues sous le nom de «Code LIEBER » préparées par le professeur Francis LIEBER ont été révisées par un groupe d'officiers : le préambule de ce texte indiquait par exemple que «... les progrès de la civilisation doivent avoir pour effet d'atténuer autant que possible les calamités de la guerre... ${ }^{251}$.

«L'œuvre de Francis LIEBER est à l'origine de deux développements importants. Tout d'abord, le Code Lieber a servi d'exemple pour de futurs manuels militaires et instructions relatives au droit de la guerre. Ensuite, les écrits de ce juriste, sont également à l'origine de la seconde évolution du DIH moderne qui a conduit à l'élaboration d'un corps des règles sur la conduite de la guerre. Le premier résultat de cette approche a été un court traité interdisant l'utilisation de projectiles explosifs de moins de 400 grammes: la Déclaration de Saint Petersbourgs de $1868 »^{252}$

«En 1874, c'est la Déclaration de Bruxelles qui établit la distinction entre combattants et noncombattants. Mais les résultats prodigieux vont sortir du développement du droit des conflits armés avec la Conférence de la Haye sur la paix en 1899 et 1907. Ces conférences réglementent l'ouverture des hostilités, le statut de neutralité, le recours au gaz asphyxiant, le largage de ballons et étoffent les lois et coutumes de la guerre maritime et de la guerre sur terre. En 1911, l'utilisation de l'aviation dans la guerre sera également réglementée, fort de l'évolution de la guerre entre la Turquie et l'Italie ${ }^{253}$. L'humanisation de la guerre se poursuit avec les Conventions de Londres qui adoptées successivement en 1923, 1925 et 1929, améliorent le contenu des règles sur la guerre dans ce qu'elles préviennent que ces règles ne sont d'application entre parties au conflit que lorsqu'elles les ont ratifiées ${ }^{254}$. Par ailleurs, «le sort des prisonniers de guerre fera l'objet d'une convention séparée en 1929 (complétant les dispositions de la II ${ }^{\mathrm{e}}$ Convention de La Haye de 1899 et de la IV ${ }^{\mathrm{e}}$ Convention de 1907). Quant au sort des populations civiles, il a fallu attendre la CG IV pour qu'il fasse, lui aussi, l'objet d'un instrument conventionnel propre ${ }^{255}$.

En clair, «le DIH moderne a évolué positivement depuis la première convention de 1864. Les conférences de la Paix de 1899 et 1907 et les quatre Conventions de Genève de 1949 ont marqué un moment important pour la codification du droit humanitaire, et même plus généralement du droit international. Ce mouvement était lié à l'origine à l'idée qu'il fallait développer la paix par le droit ${ }^{256}$. Et les CG qui comptent plus de 400 articles constituent un véritable monument juridique qui assure la protection d'innombrables victimes ${ }^{257}$. Mais cette

\footnotetext{
${ }^{249}$ Lire ce texte in https://ihl-databases.icrc.org/ihl/INTRO/110 (Source consultée le 14 août 2016).

${ }^{250}$ BELANGER, Michel, Droit international humanitaire général, 2è édition, op. cit., p. 30.

${ }^{251}$ GASSER, Hans Peter, Le Droit International Humanitaire : Introduction, op.cit., 8. Voy. aussi le Code Lieber disponible sur https://ihl-databases.icrc.org/dih-traites/INTRO/110 (Source consultée le 14 août 2016).

${ }^{252}$ GASSER, Hans Peter, Le Droit International Humanitaire : Introduction, op.cit., p. 8

${ }^{253}$ ANDENDE Apindia, « art. cit. », p. 16.

${ }^{254}$ Ibid.

255 TAVERNIER, Paul, «De 1899 à 1999: Eclatement ou approfondissement du droit international humanitaire ?», « art. cit »., p. 13.

${ }^{256} \mathrm{Ibid}$.

${ }^{257}$ Voy. M. BUHEDMA, Abdulaziz Contribution à l'étude de la réaffirmation et du développement du droit international humanitaire applicable dans les conflits armés internationaux: Des projets du C.I.C.R aux protocoles additionnels adoptés en 1977, Thèse de doctorat d'Etat en Droit, Université d'Orléans, 1985, p. 6.
} 
codification restait malgré tout limitée. Le grand mérite du CICR a été de sensibiliser la communauté internationale et les Etats afin de développer ce corpus juridique. Cependant, une des faiblesses des codifications du XIX ${ }^{\mathrm{e}}$ siècle, que l'on retrouve dans celles du $\mathrm{XX}^{\mathrm{e}}$ siècle, réside dans l'insuffisance des dispositions prévues en cas de violation des règles posées ${ }^{258}$. Alors que dès 1895, une des sessions de l'Institut de droit international - où siégeait d'ailleurs Gustave Moynier comme un des rapporteurs - se consacrait sur la question en estimant que «[c]hacune des parties contractantes s'engage à élaborer une loi pénale visant toutes les infractions possibles à la Convention de Genève ${ }^{259}$. Les progrès en ce domaine, notamment en ce qui concerne les juridictions pénales internationales, sont spectaculaires, mais encore très récents et toujours fragiles ${ }^{260}$.

Par ailleurs, en tentant de comparer Henry DUNANT et Francis LIEBER, il nous parait intéressant de dire que le premier a joué un rôle considérable dans la maturation du DIH sous l'angle de droit de Genève alors que le second l'a fait également pour le compte du droit de la guerre ou droit de la Haye.

Actuellement, toutes les règles sont élaborées et vues sous les quatre CG du 12 août 1949 et leurs PA I et II, voire le PA III. Ceux-ci constituent les principales sources et donc la toile de fonds du DIH. Ils sont, par ailleurs, complétés et renforcés par d'importants développements juridiques intervenus notamment ces dernières décennies (cf. infra).

\section{§3. Sources du droit international humanitaire}

En termes de sources (sources formelles), « le DIH est constitué d'un ensemble de normes de droit international public primaires, conventionnelles et coutumières, et d'une série de règles de droit international dérivées issues d'actes des Organisations internationales, notamment des Nations Unies ${ }^{261}$. Pour tout dire, le DIH comme branche du droit international public reste influencé par les caractéristiques et sources de celui-ci. Ainsi à côté du droit international conventionnel et du droit international coutumier, le DIH reste également influencé par le «moyen auxiliaire de détermination des règles de droit ${ }^{262}$.

En effet, à l'heure des juridictions pénales internationales, la jurisprudence joue un rôle considérable dans la mise en œuvre et l'évolution des règles du DIH. Rôle que joue aussi la $\mathrm{CIJ}^{263}$. Il faudrait cependant préciser ici que la CIJ « se prononce assez rarement sur le droit international humanitaire et ne peut pas, de ce fait, s'appuyer sur une jurisprudence fournie ${ }^{264}$. A ce sujet, Robert KOLB renseigne que la CIJ «n'a eu à traiter des questions de

258 TAVERNIER, Paul, «De 1899 à 1999: Eclatement ou approfondissement du droit international humanitaire ?», « art.cit. », p. 12.

${ }^{259}$ IDI, Session de Cambridge, «La sanction pénale à donner à la Convention de Genève du 22 août 1864 », Résolution du 12 août 1895, article $1^{\mathrm{er}}$.

260 TAVERNIER, Paul, «De 1899 à 1999: Eclatement ou approfondissement du droit international humanitaire ? », « art.cit. », p.12.

${ }^{261}$ BETTATI, Mario, op.cit.,15. Voy. aussi EMMANUELLI, Claude, International humanitarian Law, op. cit., pp. 29-53.

${ }_{262}$ Voy. l'article 38, 1 d, du Statut de la Cour internationale justice, in http://www.icjcij.org/documents/index.php?p1=4\&p2=2\&p3=0\&lang=fr (Source consultée le 18 janvier 2016).

${ }^{263}$ Lire à ce propos l'ouvrage intéressant de BIAD Abdelwahab, La Cour internationale de justice et le droit international humanitaire. Une lex specialis revisitée par le juge, Bruylant, Bruxelles 2011, 210 p.

${ }^{264}$ SANDOZ, Yves (dir.), Les Moyens de mise en $2 u v r e ~ d u$ droit international humanitaire. Etat des lieux, 
droit international humanitaire que dans quatre affaires contentieuses ou consultatives : celles des activités militaires et paramilitaires au Nicaragua et contre celui-ci (1986), de la Licéité de la menace ou de l'emploi d'armes nucléaires (1996), des conséquences juridiques de l'édification d'un mur dans le territoire palestinien occupé (2004) et des Activités armées sur le territoire du Congo (2005). De manière subordonnée, elle a effleuré des questions de droit des conflits armés dans l'affaire du Détroit de Corfou (1949) et dans celle relative aux prisonniers de guerre Pakistanais (1973), discontinuée après la phase des mesures conservatoires ${ }^{265}$.

Par ailleurs, en dépit de la remarque d'un débat et d'un développement judiciaire peu avancé $^{266}$, différents arrêts des juridictions pénales internationales d'hier et d'aujourd'hui voire de la CIJ sont d'une contribution importante pour faire avancer le DIH. Sans ces arrêts ou décisions nous ne serions pas là où nous sommes. A côté de ceux-ci, la montée croissante des ONG spécialisées dans le secteur humanitaire, rédigeant et publiant des rapports sur différentes situations de conflits armés, est un facteur non négligeable à la formation et à la maturation des règles du DIH. Les activités de ces ONG sont généralement, en amont, d'un apport important dans le processus d'élaboration des règles et constituent, en aval, un facteur influant au niveau de la mise en œuvre des règles du DIH. Elles représentent donc une opinion publique importante. Cette dernière englobe également les écrits d'éminents experts sur de DIH. La doctrine - comme les activités des ONG- n'oblige pas les Etats à se comporter d'une manière ou d'une autre mais influe non moins sur leur comportement. Car aucun Etat sur la scène internationale n'accepte que son image soit ternie. La doctrine émet des interprétations et critiques pour le développement du DIH comme toute autre discipline juridique, d'où le terme même de «source interprétative et incitative » de droit qui lui est attribué (de même pour la jurisprudence).

Ainsi en somme, «[1]es sources du droit international humanitaire correspondent aux sources traditionnelles du droit international public: traités internationaux, coutumes, principes généraux de droit, jurisprudence internationale, doctrine des publicistes les plus qualifiés, résolutions des organisations internationales ${ }^{267}$. Tout en accordant de l'intérêt à l'analyse des sources conventionnelles et coutumières et des principes du DIH, il est important de mentionner que «la doctrine et la jurisprudence occupent une place importante parmi les sources du droit international humanitaire. La doctrine sur le sujet est abondante. La réglementation de la guerre est, en effet, l'un des premiers sujets sur lequel la doctrine s'est penchée ${ }^{268}$ (cf. supra).

Par ailleurs, il importe de souligner dorénavant que les sources principales du DIH conventionnelles et coutumières- qui seront examinées ci-dessous ne sont donc pas contradictoires mais plutôt complémentaires ${ }^{269}$. Pour preuve « [1]a coutume demeure dans la

Analyse des problèmes et éléments de réflexion. Institut International de Droit humanitaire, Sanremo, juillet 2006, p. 87.

${ }^{265}$ KOLB, Robert, Ius in bello. Le droit international des conflits armés, $2^{\mathrm{e}}$ édition, op. cit., p. 472.

266 Ibid.

${ }^{267}$ EMANUELLI, Claude, Droit international public, Montréal, Wilson \& Lafleur Ltée, 1998, p. 512.

${ }^{268}$ Ibid., p. 514.

${ }^{269}$ BETTATI, Mario, Droit humanitaire. Textes introduits et commentés, op.cit., p. 17. 
mesure où le droit écrit ne peut pas tout prévoir et renvoie lui-même à la coutume en cas de lacune » (cf. clause Martens) ${ }^{270}$. La CIJ reconnaît également la complémentarité voire la perméabilité des sources conventionnelles et coutumières en droit international, notamment lorsqu'elle estime que «[...] les conventions multilatérales peuvent avoir un rôle important à jouer en enregistrant et définissant les règles dérivées de la coutume ou même en les développant $»^{271}$.

\section{A.Sources conventionnelles}

A propos des sources conventionnelles, Paul REUTER affirmait que «le traité apparait comme un instrument universel, partout et toujours encore [...] nécessaire $»^{272}$. L'organisation même de la société internationale dépend pour beaucoup de cet instrument. "Autrement dit [...], si le droit international s'édifie sur la volonté des Etats, la théorie des traités est l'expression la plus constructive et la plus rationalisée de cette volonté ${ }^{273}$.

En effet, les Conférences de la Paix de 1899 et 1907 et les CG ont marqué un moment important pour la codification du $\mathrm{DIH}$, et même plus généralement du droit international. Comparativement au droit coutumier, le droit conventionnel présente de nombreux avantages notamment d'être plus précis, d'adapter les règles à l'évolution du monde, des mœurs et des techniques. Il contribue, par là, à une meilleure efficacité et à une effectivité accrue des règles posées $^{274}$.

En revanche, le développement du droit conventionnel présente aussi des inconvénients. Jean PICTET, lors de sa conférence prononcée à l'Université de Genève, le 16 novembre 1984, à l'occasion de son jubilé, relevait les désavantages liés à une codification très détaillée en se préférant des principes souples. A ce titre, il affirmait que «vouloir tout régler c'est limiter, vu que l'on tombe dans le formalisme, qui est rigide. Codifier, c'est figer. Comme il y a toujours des cas non prévus, ils resteront en dehors du droit, tandis que, si l'on s'en tient à des principes simples, clairs et concis, ils permettront de régler les cas nouveaux par extrapolation, c'est-à-dire en prolongeant les lignes des normes de base $»^{275}$. En d'autres termes, une codification très détaillée aura logiquement pour conséquence d'entrainer une protection plus faible, une moindre efficacité, car excluant des cas non clairement définis ou répertoriés. Des règles très précises ou très techniques créeront plus d'échappatoires qu'une formulation générale. L'entreprise de codification ne constitue donc pas toujours un progrès. Le cas de la précision apportée autour de la distinction entre «combattants » et «noncombattants », ou celle entre «biens civils» et «objectifs militaires» en sont des

\footnotetext{
${ }^{270}$ DAVID, Eric, Principes de droit des conflits armés, $5^{\mathrm{e}}$ édition, op.cit., p. 62.

${ }^{271}$ CIJ, Affaire du Plateau continental (Jamahiriya arabe libyenne c. Malte), arrêt du 3 juin 1985, Recueil 1985, pp. 29-30, §27.

${ }^{272}$ REUTER, Paul, Introduction au droit des traité, Librairie Armand Colin, Paris, 1972, p. 38.

${ }^{273}$ Ibid.

274 TAVERNIER, Paul, «De 1899 à 1999: Eclatement ou approfondissement du droit international humanitaire? », in TAVERNIER, Paul et L. BURGORGUE Larsen (dir.), op.cit, pp. 3-4.

${ }^{275}$ PICTET, Jean, « La formation du droit international humanitaire », « art.cit. », p. 330.
} 
exemples $^{276}$.

Dans le domaine du DIH, les traités ont eu un succès considérable, en ce qui concerne leur développement, leur contenu et leur acceptation. Les CG et leurs deux PA représentent une codification extrêmement importante qui a été acceptée par un très grand nombre d'Etats. La mise au point, la ratification et la mise en œuvre de ces traités ont été et sont les principaux objectifs du CICR. L'institution ayant généralement donné la priorité au droit conventionnel, elle n'avait jusqu'à une certaine période jamais essayé de clarifier le droit coutumier (cf. infra $)^{277}$.

Ainsi, le DIH se trouve être reparti dans différentes conventions internationales dont les CG et leurs PA en constituent la toile de fond. Ces CG sont :

- Convention de Genève (I) pour l'amélioration du sort des blessés et des malades dans les forces armées en campagne du 12 août 1949

- Convention de Genève (II) pour l'amélioration du sort des blessés, des malades et des naufragés des forces armées sur mer du 12 août 1949

- Convention de Genève (III) relative au traitement des prisonniers de guerre du 12 août 1949

- Convention de Genève (IV) relative à la protection des personnes civiles du 12 août 1949

Trois Protocoles additionnels complètent et étayent les Conventions de Genève ci-dessus présentées. Pour reprendre les termes expressément utilisés, le PA I «complète » les CG pour la protection des victimes de la guerre (art. 2 \$ du PA I), le PA II «développe et complète » 1'article 3 commun aux CG (art. $1^{\mathrm{er}} \S 1$ du PA II) et le PA III « réaffirme et complète » les CG et PA I et II (art. $1^{\text {er }} \S 2$ du PA III). En réalité, et de manière générale, tout ce processus de codification constitue donc la réaffirmation et le développement des lois et coutumes applicables dans les conflits armés ${ }^{278}$. Ces trois PA sont :

- Le Protocole additionnel (I) aux Conventions de Genève du 12 août 1949 relatif à la protection des victimes des conflits armés internationaux du 8 juin 1977

- Le Protocole additionnel (II) aux Conventions de Genève du 12 août 1949 relatif à la protection des victimes des conflits armés non internationaux du 8 juin 1977

- Le Protocole additionnel (III) aux Conventions de Genève du 12 août 1949 relatif à l'adoption d'un signe distinctif additionnel du 8 décembre 2005 (entré en vigueur le 14 janvier 2007)

\footnotetext{
276 TAVERNIER, Paul, «De 1899 à 1999: Eclatement ou approfondissement du droit international humanitaire? », in P. Tavernier et L. BURGORGUE Larsen (dir.), op.cit, pp. 3-4.

277 HENCKAERTS, Jean-Marie, "Importance actuelle du droit coutumier», in Paul TAVERNIER et BURGORGUE- LARSEN Laurence (dir.), op.cit., pp. 21-22.

${ }^{278}$ Voy. ARRASSEN, Mohamed, Conduite des hostilités. Droit des conflits armés et désarmement, Bruylant, Bruxelles, 1986, pp. 13-14.
} 
En termes du droit conventionnel, il existe de nombreux instruments juridiques se rapportant au DIH en dehors de ceux précités qui constituent sa base essentielle. L'expression « règle du droit international applicable dans les conflits armés» défini par l'article $2 b$ du PA I comme «des règles énoncées dans les accords internationaux auxquels participent les parties au conflit ainsi que des principes et règles du droit international généralement reconnus qui sont applicables aux conflits armés »- parait plus éloquente à cet égard.

Ainsi, en dehors du Recueil des Traités des Nations Unies ${ }^{279}$, de nombreuses conventions sont répertoriées dans le domaine des conflits armés et présentées sous différentes thématiques dans la base de données du $\mathrm{CICR}^{280}$. Bien que non officiel, le Code de droit international Humanitaire $2012^{281}$ élaboré par Eric DAVID, Françoise TULKENS et Damien VANDERMEERSCH épinglent différentes conventions internationales et les repartissent selon différents domaines qui touchent au DIH. Ces domaines qui nous intéressent sont les suivants : armes et méthodes de guerre ; biens culturels ; compagnies militaires et de sécurités privées ; Convention de La Haye ; Conventions de Genève ; Croix-Rouge internationale, droit pénal international humanitaire; Forces des Nations Unies et guerre sur mer. Une partie importante de leur œuvre est également réservée au droit pénal international où différents instruments juridiques instituant les juridictions internationales et mixtes (justice pénale internationale) sont présentés.

Il y a également lieu de répertorier ces différentes conventions internationales formant le DIH sous trois sous-ensembles : droit de La Haye; droit de Genève et droit de New-York, modèle qui se trouve d'ailleurs adopté par Mario BETTATI ${ }^{282}$. En effet, le DIH se trouve dispersé dans une quinzaine de conventions et déclarations formant le droit de La Haye. Celui-ci est composé des textes adoptés de 1864 à 1907, auxquels se rattache la dizaine de textes subséquents, qui vont du Protocole de 1925 sur les gaz asphyxiants à la Convention sur les armes chimiques de 1993. Il faut y ajouter la dizaine de textes qui établissent le droit de Genève, c'est-à-dire les CG de 1949 et les trois PA de 1977 et de 2005. On devrait y joindre également diverses conventions qui forment ce qu'on appelle le droit de New York, relatives aux crimes contre l'humanité, au génocide, à la torture et aux traitements inhumains et dégradants.

\section{B. Sources coutumières}

«A côté du droit conventionnel, qui ne lie que les parties qui ont ratifié ou ont adhéré aux textes, il existe, comme en toute branche du droit international, le droit coutumier général, qui lie l'ensemble des Etats et autres sujets de droit international ${ }^{283}$. En droit international général, Paul REUTER enseigne que si le droit des traités est central (cf. supra), « la coutume

\footnotetext{
${ }^{279}$ https://treaties.un.org/pages/UNTSOnline.aspx?id=3\&clang= fr (Source consultée le 10 août 2016).

280 https://ihl-databases.icrc.org/dih-traites (Source consultée le 10 août 2016).

281 DAVID, Eric TULKENS, Françoise et VANDERMEERSCH, Damien Code de droit international humanitaire 2012, 5è édition à jour au $1^{\mathrm{er}}$ janvier 2012, Bruylant, Bruxelles 2012, 844p.

${ }^{282}$ BETTATI Mario, Droit humanitaire. Textes introduits et commentés, op.cit., pp. 15-16.

${ }^{283}$ KOLB, Robert, Ius in bello. Le droit international des conflits armés, Helbing \& Lichtenhahn, Bruylant, Bâle-Genève-Munich, Bruxelles, 2003, p. 53.
} 
est encore plus centrale que le traité puisque c'est elle qui porte le traité ${ }^{284}$.

Partant de la «définition traditionnelle ${ }^{285}$ de la coutume internationale formulée par l'article $38, \S 1$ b, du Statut de la CIJ, selon laquelle « la coutume internationale [est entendue] comme preuve d'une pratique générale acceptée comme étant le droit ${ }^{286}$, deux éléments essentiels se dégagent: «un élément matériel et un élément psychologique ou opinio juris ce qui consiste d'une part dans la répétition de certaines actions ou attitudes de manière persistante et prolongée et d'autre part dans le sentiment qu'en accomplissant ces actes, on a le sentiment de se conformer à une règle juridique obligatoire ${ }^{287}$. Et c'est dans un même processus que s'effectue la réunion de ces deux éléments formant règle coutumière ${ }^{288}$.

En effet, « la coutume internationale résulte d'une attitude prise par un Etat dans ses rapports avec un autre Etat, attitude déterminée par une conviction de droit et acceptée dans le même esprit par l'Etat à l'égard duquel elle est prise. C'est l'expression d'une ligne de conduite que la pratique internationale révèle comme étant suivie dans la conviction qu'elle répond au respect d'un droit ou à l'accomplissement d'une obligation ${ }^{289}$. En clair, « la pratique n'est, dans la grande majorité des cas, qu'abstraitement et artificiellement distinguable de l'opinio juris parce qu'elle en est elle-même la manifestation tangible. Dès lors, « la coutume est l'expression d'une opinio juris manifestée dans et par une pratique » et «ne résulte pas de l'adjonction de deux éléments mais de la révélation de l'un par l'autre $» »^{290}$. Cependant, il convient de remarquer que dans l'appréciation des moyens permettant d'établir ces deux éléments, les récents travaux de la CDI précisent que chacun de ces éléments doit être établi séparément ${ }^{291}$. Et pour souligner le caractère important de l'opinio juris sive necessitatis, la CIJ fait remarquer : « [1] es Etats intéressés doivent avoir le sentiment de se conformer à ce qui équivaut à une obligation juridique. Ni la fréquence ni même le caractère habituel des actes ne suffisent. Il existe un nombre d'actes internationaux [...] qui sont accomplis presque invariablement mais sont motivés par de simples considérations de courtoisie, d'opportunité ou de la tradition et non par le sentiment d'une obligation juridique $»^{292}$. Position que partage également la $\mathrm{CDI}^{293}$. «Ce n'est [donc] que l'opinio juris sive necessitatis qui marquera le passage d'un état de fait à un état de droit ${ }^{294}$.

\footnotetext{
${ }^{284}$ REUTER, Paul, Introduction au droit des traité, op. cit., p. 38.

${ }^{285}$ SALMON, Jean, (dir.), Dictionnaire de droit international public, Bruylant, Bruxelles, 2001, p. 283.

${ }^{286}$ Voy. l'article 38, $\$ 1$ b, du Statut de la Cour internationale de justice, disponible http://www.icjcij.org/documents/index.php?p1=4\&p2=2\&p3=0\&lang=fr (Source consultée le 22 juillet 2016).

${ }^{287}$ KDHIR, Moncef, Dictionnaire juridique de la Cour internationale de justice, $2^{\mathrm{e}}$ édition, Bruylant, Bruxelles, 2000, p. 92.

${ }^{288}$ Ibid., p. 93.

${ }^{289}$ ROUSSEAU, Charles, Droit international public, éd. Sirey, Paris, 1970, p. 309.

${ }^{290}$ BIAD, Abdelwahab, La Cour internationale de justice et le droit international humanitaire. Une lex specialis revisitée par le juge, op. cit., p. 36

${ }^{291}$ CDI, Détermination du droit international coutumier. Textes des projets de conclusion provisoirement adoptés par le Comité de rédaction, Soixante-septième session, Genève, 4 mai-5 juin et 6 juillet-7 août 2015, p. 1 , §2, Projet de conclusion 3 [4].

${ }^{292}$ CIJ, Affaire du Plateau continental de la mer du Nord, arrêt du 20 février 1969, Recueil 1969, p. 44, § 77.

${ }^{293}$ Voy. CDI, Détermination du droit international coutumier. Textes des projets de conclusion provisoirement adoptés par le Comité de rédaction, Soixante-septième session, Genève, 4 mai-5 juin et 6 juillet-7 août 2015, op. cit., p. 3, Projet de conclusion 9 [10], §§1-2.

${ }^{294}$ CORTEN, Olivier, Méthodologie du droit international public, op. cit., p. 155.
} 
En définissant la coutume internationale comme étant la preuve d'une pratique générale acceptée comme étant le droit, il y a lieu de s'interroger sur le sens à accorder à cette «pratique générale » en DIH ou en DIDH, domaines du droit caractérisés par des violations quotidiennes des Etats. A cet effet, pour identifier la coutume dans ces cadres, la jurisprudence et la doctrine mettent davantage l'accent sur l'opinio juris sive necessitatis des Etats (et sur les principes généraux de droit) que sur leur pratique effective ${ }^{295}$. On rappelera que l'effectivité d'un comportement est déterminante en coutume internationale en général ${ }^{296}$. Ceci n'est donc pas le cas dans ce cadre. L'affirmation de l'opinio juris sive necessitatis est plus remarquable quand les Etats, même auteurs des violations du DIH ou DIDH ne les assument pas, les nient ou les regrettent en réaffirmant leur attachement au droit existant. C'est ce que Robert KOLB nomme « une hypocrisie juridiquement utile » ${ }^{297}$. Logiquement, une telle attitude n'a pas pour conséquence d'affaiblir ou de remettre en cause les règles existantes mais plutôt de renforcer le caractère obligatoire de ces règles ${ }^{298}$. La CIJ le suggère en ces termes :

«La Cour ne pense pas que, pour qu'une règle soit coutumièrement établie, la pratique correspondante doive être rigoureusement conforme à cette règle. Il lui paraît suffisant, pour déduire l'existence de règles coutumières, que les Etats y conforment leur conduite d'une manière générale et qu'ils traitent eux-mêmes les comportements non conformes à la règle en question comme des violations de celle-ci et non pas comme des manifestations de la reconnaissance d'une règle nouvelle. Si un Etat agit d'une manière apparemment inconciliable avec une règle reconnue, mais défend sa conduite en invoquant des exceptions ou justifications contenues dans la règle elle-même, il en résulte une confirmation plutôt qu'un affaiblissement de la règle, et cela que l'attitude de cet Etat puisse ou non se justifier en fait sur cette base ${ }^{299}$.

Par ailleurs, en dépit de l'allusion constamment faite aux Etats, la coutume internationale concerne également d'autres «sujets aptes à générer la création de nouvelles règles de droit international ${ }^{300}$ dont les $\mathrm{OI}^{301}$. A ce propos, sont prises en compte les activités que déploient celles-ci sur le plan international, lesquelles peuvent aboutir à des normes coutumières. Leurs activités internes, pouvant également donner lieu à des règles coutumières respectives, ne sont

\footnotetext{
${ }^{295}$ KOLB, Robert, Ius in Bello. Le droit international des conflits armés, $2^{\mathrm{e}}$ édition, Helbing Lichtenhahn, Bruylant, Bâle-Bruxelles, 2009, op. cit., p. 111.

${ }^{296}$ STERN, Brigitte, «La Coutume au cœur du droit international. Quelques réflexions », in Mélanges offerts à PAUL REUTER. Le droit international : Unité et diversité, Pedone, Paris, 1981, p. 480.

${ }^{297}$ KOLB, Robert, Ius in Bello. Le droit international des conflits armés, $2^{\mathrm{e}}$ édition, Helbing Lichtenhahn, Bruylant, Bâle-Bruxelles, 2009, op. cit., p. 111.

${ }^{298}$ CORTEN, Olivier, Méthodologie du droit international public, op. cit., p. 156.

${ }^{299}$ CIJ, Affaire des Activités militaires et paramilitaires au Nicaragua et contre celui-ci (Nicaragua c. EtatsUnis d'Amérique), fond, arrêt, Recueil 1986, p.98, § 186.

${ }^{300}$ CORTEN, Olivier, Méthodologie du droit international public, op. cit., p. 153. On range également des entités telles que «les entités fédérées actives dans les relations internationales ». Voy. CORTEN, Olivier, Méthodologie du droit international public, op. cit., p. 153.

${ }^{301}$ Voy. CDI, Détermination du droit international coutumier. Textes des projets de conclusion provisoirement adoptés par le Comité de rédaction, Soixante-septième session, Genève, 4 mai-5 juin et 6 juillet-7 août 2015, op. cit., p. 2, Projet de conclusion 4 [5], §2. Lire à ce sujet CAHIN, Gérard, La Coutume internationale et les Organisations internationales. L'incidence de la dimension institutionnelle sur le processus coutumier, Pedone, Paris, 2001.
} 
donc pas concernées ${ }^{302}$. Ainsi, par exemple, sur le plan international, une OI «peut, moyennant une pratique constante, élargir ou, d'une manière générale, modifier la compétence conférée dans le traité qui l'a créée» ${ }^{303}$.

Une coutume internationale peut être d'origine jurisprudentielle. C'est notamment le cas de la règle, d'origine arbitrale (sentences arbitrales sur le Betsey (1797) et de Salley (1797)), qui veut qu'un juge soit le juge de sa propre compétence connue sous le nom de la « règle de la compétence de la compétence ${ }^{304}$. Les traités internationaux peuvent également être à la base de la coutume internationale. C'est le cas des reprises de certaines clauses conventionnelles souvent effectuées dans des traités ultérieurs portant sur le même domaine ${ }^{305}$.

Bien plus, dans l'établissement de l'existence des normes coutumières internationales, les traités demeurent pertinents. En cela, il faut prendre en considération la ratification (nombre de ratifications important mais pas suffisant ${ }^{306}$ ), l'interprétation et l'application des traités, les réserves et déclarations interprétatives effectuées mais aussi les pratiques nationales ${ }^{307}$.

Au regard des récents travaux de la CDI, chaque élément de la coutume - pratique général et opinio juris - doit être établi séparément. «Cela exige d'apprécier pour chaque élément les moyens permettant d'en établir l'existence ${ }^{308}$. La CDI fait ainsi indication de différentes formes de lignes de conduite ou d'attitudes qu'il convient de considérer comme "pratique générale » et de différentes formes d'attestation d'acceptation du droit qu'il convient de considérer comme « opinio juris ».

En effet, pour la pratique générale, suivant la CDI, celle-ci peut revêtir une large variété de formes à savoir des actes matériels et verbaux, voire l'inaction dans certaines circonstances. A titre indicatif et sans aucune hiérarchie prédéterminée entre elles, «les formes de pratiques étatiques comprennent : les actes et la correspondance diplomatiques; la conduite relative aux résolutions adoptées par une organisation internationale ou lors d'une conférence intergouvernementale; la conduite relative aux traités; la conduite exécutive, y compris la conduite opérationnelle « sur le terrain »; les actes législatifs et administratifs; et les décisions des juridictions internes ${ }^{309}$.

Dans le même ordre d'idées, l'opinio juris peut revêtir une large variété de formes. A titre indicatif, celles-ci «comprennent : les déclarations publiques faites au nom des États; les publications officielles; les avis juridiques gouvernementaux; la correspondance diplomatique;

\footnotetext{
302 BARBERIS, Julio A., « Réflexions sur la coutume internationale », in AFDI, XXXVI - 1990, p. 33.

${ }^{303}$ Ibid., pp. 33-34.

${ }^{304}$ Ibid., p. 34.

305 Ibid., p. 35.

${ }^{306}$ Lire CIJ, Affaire du Plateau continental de la mer du Nord, arrêt du 20 février 1969, op. cit., p. 42 , § 73.

${ }^{307}$ MAYSTRE, Magali, op. cit., pp. 69-70.

308 CDI, Détermination du droit international coutumier. Textes des projets de conclusion provisoirement adoptés par le Comité de rédaction, Soixante-septième session, Genève, 4 mai-5 juin et 6 juillet-7 août 2015, op. cit., p. 1, §2, Projet de conclusion 3 [4].

309 CDI, Détermination du droit international coutumier. Textes des projets de conclusion provisoirement adoptés par le Comité de rédaction, Soixante-septième session, Genève, 4 mai-5 juin et 6 juillet-7 août 2015, op. cit., p. 2, Projet de conclusion 6 [7], §§1-3.
} 
les décisions des juridictions nationales; les dispositions de traités; ainsi que la conduite en relation avec les résolutions adoptées par une organisation internationale ou lors d'une conférence intergouvernementale ». Et dans certaines circonstances, l'absence de réaction s'étendant dans le temps à une pratique peut constituer l'opinio juris ${ }^{310}$.

En pratique, la jurisprudence et la doctrine procèdent à l'établissement de la coutume internationale en s'appuyant sur des éléments objectifs et complets tels que les résolutions d'OI, les traités non applicables à titre conventionnel, les travaux de la CDI, les autres documents établissant les positions officielles des Etats, la jurisprudence, la doctrine ${ }^{311}$, etc.

En termes des matières même qui se distinguent de la procédure de formation de la coutume internationale (cf. supra), en DIH « [d] e nombreuses règles coutumières se sont développées, de par la pratique des Etats, et font partie intégrante du droit international pertinent en l'espèce. Il s'agit des «lois et coutumes de la guerre» - selon l'expression traditionnelle - qui furent l'objet des efforts de codification entrepris à La Haye (Conventions de 1899 et de 1907 notamment) et se fondaient partiellement sur la Déclaration de Saint-Pétersbourg de 1868 ainsi que sur les résultats de la Conférence de Bruxelles de $1874 »^{312}$. Il s'agit là essentiellement du droit de La Haye- relatif à la conduite des hostilités - à côté duquel se développera également le « droit de Genève » - consacré à la protection des personnes qui ne participent pas ou plus aux hostilités par des Conventions de 1864, 1906, 1929 et 1949, etc. ${ }^{313}$. En clair, trois grands domaines de «l'activité de guerre » se trouvent concernées par la coutume : les comportements relatifs à la protection des personnes; les moyens ou actes de guerres et la protection des biens ${ }^{314}$.

Alors qu'à l'époque de la Conférence de la Paix de 1899, on était persuadé des bienfaits de la codification et de la supériorité des règles conventionnelles sur les règles coutumières, il n'en est plus tout à fait de même actuellement. On souligne, au contraire, très volontiers les vertus de la règle coutumière qui permet de dépasser les limites de la règle conventionnelle ${ }^{315}$. « [L]a coutume est actuellement plus que jamais, la solution la plus appropriée pour garantir l'applicabilité et l'application des traités dans les conflits armés » ${ }^{316}$. L'acceptation générale de certaines grandes conventions multilatérales, comme les CG, ou d'autres textes comme la CDE, permettrait de considérer les normes qu'elles formulent, ou du moins quelques-unes d'entre elles, comme appartenant désormais au droit coutumier. On estime que les dispositions des Protocoles de 1977, ou plusieurs articles du Statut de Rome de la CPI, reflètent le droit

\footnotetext{
${ }^{310}$ Ibid., p. 3, Projet de conclusion 10 [11], $\$ 1-3$.

${ }^{311}$ Lire CORTEN, Olivier, Méthodologie du droit international public, op. cit., pp. 161-178. Pour le TPIY « [1]orsqu'on évalue la formation de règles coutumières ou de principes généraux, il convient par conséquent d'être conscient que, du fait du caractère intrinsèque de ce domaine, on doit s'appuyer essentiellement sur des éléments comme les déclarations officielles des Etats, les manuels militaires et les décisions judiciaires ». Voy. TPIY, Le Procureur c/ Dusco TADIC alias «DULE», Chambre d'Appel, Arrêt relatif à l'appel de la défense $\begin{array}{lllll}\text { concernant l'exception } & \text { préjudicielle, } & 2 & \text { octobre } & 1995,\end{array}$ http://www.icty.org/x/cases/tadic/acdec/fr/51002JN3.htm (Source consultée le 08 août 2016).

312 CIJ, Affaire de Licéité de la menace ou de l'emploi d'armes nucléaire, avis consultatif du 8 juillet 1996, Recueil 1996, p. 256, §75.

313 Ibid.

${ }^{314}$ MATTEI, Jean-Matthieu, Histoire du droit de la guerre (1700-1819). Introduction à l'histoire du droit international, Tome I, op. cit., pp. 274-275.

315 TAVERNIER, Paul, « art.cit. », in TAVERNIER, Paul et L. BURGORGUE Larsen (dir.), op.cit, pp. 4-5.

${ }^{316}$ EL HAJI, Hamid, L'applicabilité de la coutume dans les conflits armés, L'Harmattan, Paris, 2015, p. 17.
} 
coutumier $^{317}$. A ce sujet, la CIJ renseigne :

«La large codification du droit humanitaire et l'étendue de l'adhésion aux traités qui en ont résulté, ainsi que le fait que les clauses de dénonciation contenues dans les instruments de codification n'ont jamais été utilisées, ont permis à la communauté internationale de disposer d'un corps de règles conventionnelles qui étaient déjà devenues coutumières dans leur grande majorité et qui correspondaient aux principes humanitaires les plus universellement reconnus. Ces règles indiquent ce que sont les conduites et comportements normalement attendus des Etats $»^{318}$.

Plus précisément au sujet du PA II, le TPIY affirmait : «[d]e nombreuses dispositions dudit Protocole peuvent maintenant être considérées comme déclaratives de règles existantes ou comme ayant cristallisé des règles naissantes du droit coutumier [...] ${ }^{319}$. Au sujet du PA I, la Commission arbitrale des réclamations entre l'Erythrée et l'Ethiopie considérait également que cet instrument reflétait le droit coutumier dans un grand nombre de ses dispositions (dont celles sur la conduite des hostilités) mais pas toutes ${ }^{320}$. Pour cette Commission, concernant les textes codificateurs du droit des conflits armés, il est établi une présomption en droit moderne selon laquelle les dispositions substantielles du droit conventionnel correspondent au droit coutumier. Il appartient à la partie qui le conteste d'en apporter la preuve ${ }^{321}$.

On rappellera tout de même, en dépit des affirmations ci-avant, que le traité et la coutume ont la même force juridique, par conséquent ils ont une valeur dérogatoire réciproque. En d'autres termes, un traité peut abroger une coutume ou la modifier (ex : abolition de la traite des noirs par la Déclaration de Vienne du 8 février 1890). De la même manière, une coutume peut abroger un traité ou le modifier en dehors de toute procédure écrite (ex : l'interdiction d'attaquer sans préavis des navires de commerce par les sous-marins belligérants) ${ }^{322}$. Pour ce dernier cas, Robert KOLB enseigne qu' «[i]l faudrait alors procéder à une nouvelle codification, en ligne avec la pratique nouvelle. On ne peut donc guère imaginer que les Etats puissent appliquer les conventions multilatérales par hypothèse contraires au droit coutumier, car la pratique de la guerre est une et elle s'impose toujours $[\ldots] »^{323}$.

A propos des CG et des Conventions de La Haye, Jean PICTET expliquait qu'« en raison de

\footnotetext{
317 TAVERNIER, Paul, « art.cit. », in TAVERNIER, Paul et L. BURGORGUE Larsen (dir.), op.cit, pp. 4-5.

${ }^{318}$ CIJ, Affaire de Licéité de la menace ou de l'emploi d'armes nucléaires, avis consultatif du 8 juillet 1996, Recueil 1996, p. 258, §82.

${ }^{319}$ TPIY, Le Procureur c/ Dusco TADIC alias «DULE », Chambre d'Appel, Arrêt relatif à l'appel de la défense $\begin{array}{lllll}\text { concernant l'exception } & \text { préjudicielle, } & 2 & \text { octobre } & 1995,\end{array} 117$ http://www.icty.org/x/cases/tadic/acdec/fr/51002JN3.htm (Source consultée le 08 août 2016). Voy. aussi TPIR, Le Procureur c. Jean-Paul AKAYESU, Affaire n ${ }^{\circ}$ ICTR-96-4-T, jugement, Chambre de première instance I, 2 septembre 1998, p. 247, \$609. (Jugement également disponible sur http://ictrarchive09.library.cornell.edu/FRENCH/cases/Akayesu/judgement/contents.html (Source consultée le 21 août 2016).

${ }^{320}$ KOLB, Robert, Ius in Bello. Le droit international des conflits armés, $2^{\mathrm{e}}$ édition, Helbing Lichtenhahn, Bruylant, Bâle-Bruxelles, 2009, op. cit., p. 110.

321 Ibid.

${ }^{322}$ EL HAJI, Hamid, L'applicabilité de la coutume dans les conflits armés, op. cit., pp. 15-16.

${ }^{323}$ KOLB, Robert, Ius in Bello. Le droit international des conflits armés, $2^{\mathrm{e}}$ édition, Helbing Lichtenhahn, Bruylant, Bâle-Bruxelles, 2009, op. cit., p. 109.
} 
leur caractère désintéressé et des valeurs supérieures qu'elles défendent, en raison aussi de leur ancienneté et de leur extension dans le monde, on peut aujourd'hui affirmer que les Conventions de Genève et les Conventions de La Haye ont, dans une large mesure, perdu leur aspect de traités réciproques, et limités au cadre des relations étatiques, pour devenir des engagements absolus » (nous soulignons). Il constatait ainsi que le DIH n'était « en somme, que la réaffirmation de règles coutumières plus anciennes, développées et complétées au moment de la codification », ce qui permet de «considérer ces grandes chartes de l'humanité comme déclaratoires $\gg$ du droit coutumier ${ }^{324}$.

De ces propos, il se dégage comme conséquence que « [s]i les Etats restent liés de jure par le droit coutumier, ils ne peuvent par conséquent se prévaloir du fait qu'ils ne sont pas parties à des instruments du DIH pour évacuer totalement leurs obligations dans ce domaine. La coutume devient ici à la fois complément et substitut du droit conventionnel ${ }^{325}$.

Bien que reprise plus tard, la coutume internationale, en particulier, est la grande absente des travaux du CICR ; son nom même n'apparaît pratiquement jamais. Cette absence quasi totale de référence aux règles coutumières du DIH dans le travail du CICR a pendant très longtemps attiré des critiques pertinentes. Toutefois, des facteurs expliquent le silence prolongé du CICR sur la question ${ }^{326}$. L'on note, par exemple, « la précarité des bases juridiques »: « le CICR n'a cessé d'opposer la précision du DIH consacré par les CG du 12 août 1949, à l'état chaotique du droit de la guerre, bafoué depuis des décennies par les grandes puissances, et qui présentait d'inquiétantes lacunes. Tout se passe comme si le CICR s'était convaincu qu'il ne disposait pas d'une base juridique suffisamment ferme pour pouvoir fonder ses interventions $»^{327}$. A propos de son refus de prise de position au regard des bombardements aériens massifs contre des civils, l'institution ne s'était pas demandée si elle pouvait trouver dans le droit international coutumier une argumentation relative à la protection de la population civile contre les bombardements aériens ${ }^{328}$.

Face à cette lacune, la XXVI ${ }^{\mathrm{e}}$ Conférence internationale de la Croix-Rouge et du CroissantRouge, réunie à Genève du 3 au 7 décembre 1995, confiera au CICR le mandat de: préparer, avec l'assistance d'experts $d u$ droit international humanitaire représentant diverses régions géographiques et différents systèmes juridiques, ainsi qu'en consultation avec des experts de gouvernements et d'organisations internationales, un rapport sur les règles coutumières du droit international humanitaire applicables aux conflits armés internationaux et non internationaux, et (...) faire parvenir ce rapport aux États et aux organismes internationaux compétents $^{329}$.

Ce mandat qu'a accepté avec reconnaissance et humilité le CICR ressort initialement des

\footnotetext{
${ }^{324}$ BIAD, Abdelwahab, La Cour internationale de justice et le droit international humanitaire. Une lex specialis revisitée par le juge, op.cit., p. 36.

${ }^{325}$ BIAD, Abdelwahab, Droit international humanitaire, Paris, Ellipses, 2è édition, 2006, p. 35.

${ }^{326}$ HENCKAERTS, Jean-Marie, «Importance actuelle du droit coutumier», in Paul TAVERNIER et BURGORGUE- LARSEN Laurence (dir.), op.cit., p. 22.

${ }^{327}$ Ibid.

328 Ibid.

${ }^{329}$ HENCKAERTS, Jean-Marie et DOSWALD-BECK, Droit international humanitaire coutumier, Volume I : Règles, op. cit., 878 p. Préface de Jakob KELLENBERGER, pp. XIX.
} 
propositions du Groupe d'experts pour la protection des victimes de guerre (de janvier 1995) envue d'améliorer la mise en œuvre du DIH. Ceci se révèle une réaction aux nombreuses graves violations du DIH commises au Rwanda et en ex-Yougoslavie. Cette recommandation sera adoptée en décembre 1995 par la Conférence internationale précitée, laquelle confia au CICR la réalisation de cette étude ${ }^{330}$. A son tour, le CICR confia cette mission à deux membres de sa Division juridique et procéda à de larges consultations : "plus de cent experts éminents ont contribué à l'étude, sous la direction d'un comité directeur qui regroupait douze experts de réputation internationale. Le CICR a tenu à respecter la liberté académique des auteurs, comme celle des experts consultés, puisqu'il s'agissait avant tout d'un travail scientifique : établir une photographie aussi rigoureuse que possible de l'état actuel du droit international humanitaire coutumier ${ }^{331}$. Les conclusions de l'étude ont été publiées ${ }^{332}$ et reflètent bien l'état actuel du droit international humanitaire coutumier. 161 règles coutumières assurant la protection des personnes en période de conflits armés ont pu être décelées. Au sens du CICR, cette étude a mis en évidence l'universalité du droit international humanitaire : toutes les traditions et toutes les civilisations ont contribué au développement de ce droit. Cette étude permettra d'étayer la mise en œuvre des règles du DIH sans perdre de vue le fait que la coutume est un processus dynamique et évolutif ${ }^{333}$. Et depuis lors, une mise à jour du droit international humanitaire coutumier est régulièrement effectuée et conservée dans la base des données du $\mathrm{CICR}^{334}$.

\section{§4. Principes du droit international humanitaire}

«Tout comme les autres branches du droit international, le droit applicable lors des conflits armés contient également un ensemble de principes sur lesquels se base le système de cette branche. [...] les principes du droit applicable pendant les conflits armés, ont comme les autres principes du droit international, un caractère universel de jus cogens à partir du moment où ce caractère leur est reconnu, et qu'ainsi ils deviennent obligatoires $[\ldots]{ }^{335}$. C'est dans ce sens qu'il a été soutenu dans la procédure de l'avis consultatif de la CIJ de juillet 1996 «que ces principes et règles du droit humanitaire font partie du jus cogens tel que le définit l'article 53 de la Convention de Vienne sur le droit des traités du 23 mai 1969. La question de savoir si une règle fait partie du jus cogens a trait à la nature juridique de cette règle ${ }^{336}$. Un grand nombre de règles du $\mathrm{DIH}$, «si fondamentales pour le respect de la personne humaine et pour des

\footnotetext{
${ }^{330}$ HENCKAERTS, Jean-Marie, «Etude du CICR sur le droit international humanitaire coutumier: objet, caractéristique, conclusions et pertinence », in TAVERNIER, Paul et HENCKAERTS, Jean-Marie (dir.), Droit international humanitaire coutumier : enjeux et défis contemporains, op. cit., pp. 31-32.

${ }^{331}$ HENCKAERTS, Jean-Marie et DOSWALD-BECK, Louise, Droit international humanitaire coutumier, Volume I : Règles, op. cit., p. XIX

332 Voy. Customary International Humanitarian Law (Cambridge University Press, 2005), volume I (Rules) et volume II (Practice) qui compte au total plus de 4000 pages. Le premier volume a été traduit en français HENCKAERTS, Jean-Marie et DOSWALD-BECK, Louise, Droit international humanitaire coutumier, Volume I : Règles, Bruxelles, Bruylant-CICR, 2006, 878 p.

${ }^{333}$ HENCKAERTS, Jean-Marie et DOSWALD-BECK, Louise, Droit international humanitaire coutumier, Volume I : Règles, op. cit., p. XX.

${ }^{334}$ Voy. https://ihl-databases.icrc.org/customary-ihl/eng/docs/v1 (Source consultée le 18 août 2016).

${ }^{335}$ BLISHCHENKO, Igor P., «Les principes du droit international humanitaire » in SWINARSKI, Christophe (Réd.), op.cit., 291. (291-300).

${ }^{336}$ CIJ, Affaire de Licéité de la menace ou de l'emploi d'armes nucléaire, avis consultatif du 8 juillet 1996, Recueil 1996, p. 258, §83.
} 
considérations élémentaires d'humanité » constituent des principes intransgressibles du droit international coutumier suivant la $\mathrm{CIJ}^{337}$. Le TPIY partage également cette position et estime que « la plupart des normes du droit international humanitaire, notamment celles qui prohibent les crimes de guerre, les crimes contre l'humanité et le génocide, sont des normes impératives du droit international ou jus cogens, c'est-à-dire qu'elles sont impérieuses et qu'on ne saurait y déroger ${ }^{338}$. Au plan doctrinal, Eric DAVID soutient également que «l'ensemble du droit des conflits armés (à part peut-être quelques rares règles mineures, telles que l'avance de solde aux prisonniers de guerre - CGIII, art. 60) appartient au jus cogens puisque ce droit ne s'élève que sur les ruines du respect de cette autre règle de jus cogens qu'est l'interdiction du recours à la force $[\ldots] »{ }^{339}$.

Ainsi, lorsque les règles conventionnelles et coutumières sont inapplicables, l'application de certaines règles de DIH en tant que principes généraux de droit viennent les compléter. Ces principes trouvent leur source dans «les lois de l'humanité et les exigences de la conscience publique » dont l'importance était déjà affirmée dans le préambule de la Convention II de La Haye de 1899 et à la Convention IV de la guerre sur terre (Clause Martens) et affirmée par les CG (art.63 CG I, art.62 CG II ; art.142 CG III, art.158 CG IV et les PA I et II (art.1(2) et préambule $)^{340}$.

Il est très incertain de vouloir dégager une liste exhaustive des principes du DIH. Tout de même, les principes qui régissent la conduite des hostilités ou la protection des personnes qui ne participent pas ou plus aux hostilités trouvent leur fondement aux plans conventionnel et coutumier. La jurisprudence en formalise. C'est notamment l'exercice que fait la CIJ dans son avis consultatif sur la Licéité de la menace ou de l'emploi d'armes nucléaires, lorsqu'elle énumère «les principes cardinaux contenus dans le texte formant le tissu du droit international humanitaire ${ }^{341}$. Elle en dégage deux principes fondamentaux que l'on peut nommer respectivement «principe de distinction » et «principe de limitation du choix des moyens et méthodes à disposition des belligérants ». La doctrine, à travers de nombreux ouvrages, se prête également à l'exercice en privilégiant différemment les principes. Si, par exemple, avec Robert KOLB, l'on retiendra les principes de «nécessité militaire », d' « humanité et de limitation » et de «proportionalité au sens étroit » comme «principes constitutionnels du droit des conflits armés ${ }^{342}$, chez Catherine BERGEAL, dans la conduite des hostilités trois principes fondamentaux sont utilisés : le principe de distinction ou principe de discrimination, le principe de proportionnalité et le principe de précaution dans l'attaque ${ }^{343}$. Il y a lieu de comprendre

\footnotetext{
${ }^{337}$ Ibid., p. 257, $\$ 79$.

338 TPIY, Le Procureur c. Zoran KUPRE[KI], Mirjan KUPRE[KI], Vlatko KUPRE[KI], Drago JOSIPOVI], Dragan PAPI], Vladimir [ANTI], alias "VLADO », Affaire $\mathrm{N}^{\circ} \mathrm{IT}-95-16-\mathrm{T}$, La Chambre de première instance, Jugement rendu le 14 janvier 2000, p. 212, §520.

${ }^{339}$ DAVID, Eric, Principes de droit des conflits armés, $5^{\mathrm{e}}$ édition, op. cit., p. 113.

${ }^{340}$ Lire EMANUELLI, Claude, Droit international public. Contribution à l'étude du droit international selon la perspective canadienne, Montréal, Wilson \& Lafleur Ltée, 1998, p. 513. et JASICA, Roman, « Protection de la population civile et ses contraintes », in Le Droit international humanitaire. Problèmes actuels et perspectives d'avenir, Les Cahiers du Droit public, Université de Clermont I, Bordeaux, 1987, p. 57.

${ }^{341}$ Voy. CIJ, Affaire de Licéité de la menace ou de l'emploi d'armes nucléaire, avis consultatif du 8 juillet 1996, Recueil 1996, p. 257, §78.

${ }^{342}$ Voy. KOLB, Robert, Ius in Bello. Le droit international des conflits armés, $2^{\mathrm{e}}$ édition, Helbing Lichtenhahn, Bruylant, Bâle-Bruxelles, 2009, op. cit., pp. 116-122.

343 BERGEAL, Catherine, «La Coutume et la conduite des hostilités », in TAVERNIER, Paul et HENCKAERTS, Jean-Marie (dir.), Droit international humanitaire coutumier : enjeux et défis contemporains,
} 
qu'il existe plus de principes du DIH formalisés en jurisprudence et en doctrine. Tous ces principes concourent au sens de l' «humanisation» des conflits armés (principe d'humanité). D'où, l'intérêt d'examiner quelques uns en commençant par le principe fondateur, principe d'humanité.

\section{A. Principe d'humanité}

«Il faut reconnaître que le principal et le plus ancien des principes du droit international humanitaire est le principe traditionnellement appelé principe d'humanité. Le rôle de ce principe pour les autres principes du droit international humanitaire, ainsi que son importance dans ce système juridique, sont reconnus par presque tous les courants doctrinaux du droit international ${ }^{344}$. Le principe d'humanité incarne le sens et l'essence du DIH. Il est considéré comme le principe fondateur même du DIH qui guide toute son action. "Tous les autres principes du droit international humanitaire se sont formés sur la base du principe d'humanité et sont donc sa concrétisation ${ }^{345}$. Le principe d'humanité, qui trouve son fondement juridique dans la coutume internationale et dans différents instruments juridiques relatifs à la protection de l'être humain en toutes circonstances, dont spécialement ceux liés au DIH, a pour but d'humaniser la conduite des hostilités. L'on remarquera donc par ce principe que différentes interdictions sont imposées aux belligérants afin d'assurer à la personne humaine et à son entourage, une vie plus ou moins humaine en périodes exceptionnelles. Ce principe évite de la barbarie et du traitement inhumain et dégradant dans les opérations militaires.

Par ailleurs, s'il faut limiter strictement le «principe d'humanité » au droit de Genève, il équivaut à la valeur de ce que représente le «principe de limitation du choix des moyens et méthodes à disposition des belligérants » dit aussi «principe de limitation » en droit de La Haye. Ces deux principes «génèrent une série de règles limitatives de la violence armée » ${ }^{346}$. Robert KOLB les analyse indistinctement sous un même point ${ }^{347}$.

\section{A. Le principe de limitation du choix des moyens et méthodes à disposition des belligérants}

Le principe de limitation est énuméré par la CIJ au rang des «principes cardinaux contenus dans le texte formant le tissu du droit international humanitaire » (cf. supra). Suivant la CIJ, par ce principe, «il ne faut pas causer des maux superflus aux combattants: il est donc interdit d'utiliser des armes leur causant de tels maux ou aggravant inutilement leurs souffrances; en application de ce second principe, les Etats n'ont pas un choix illimité quant aux armes qu'ils emploient $»^{348}$.

En effet, le droit de la Haye s'est longtemps penché sur l'emploi des armes dans le théâtre des

\footnotetext{
op. cit.,p. 104.

${ }^{344}$ BLISHCHENKO, Igor P., « art.cit. » in SWINARSKI, Christophe (Réd.), op.cit., 291.

345 Ibid., p. 293.

${ }^{346}$ KOLB, Robert, Ius in Bello. Le droit international des conflits armés, $2^{\mathrm{e}}$ édition, Helbing Lichtenhahn, Bruylant, Bâle-Bruxelles, 2009, op. cit., p.121.

${ }^{347}$ Voy. Ibid.

348 CIJ, Affaire de Licéité de la menace ou de l'emploi d'armes nucléaire, avis consultatif du 8 juillet 1996, Recueil 1996, p. 257, §78.
} 
hostilités. Les parties aux conflits n'ont donc pas un droit illimité quant au choix des méthodes et moyens de combats. Différents textes conventionnels et déclaratoires traitent de cette question. L'on citera, à titre d'exemple, la Convention de La Haye sur les lois et coutumes de la guerre terrestre de 1907 ; la Déclaration à l'effet d'interdire l'usage de certains projectiles en temps de guerre du 11 décembre 1868, dite «Déclaration de Saint-Pétersbourg »; le Protocole concernant la prohibition d'emploi à la guerre de gaz asphyxiants, toxiques ou similaires et de moyens bactériologiques signé à Genève le 17 juin 1925 ; la Convention sur l'interdiction de la mise au point, de la fabrication et du stockage des armes bactériologiques (biologiques) ou à toxines et sur leur destruction du 16 décembre 1971; le Protocole relatif aux éclats non localisables du 10 octobre 1980 (Protocole I); le Protocole sur l'interdiction ou limitation de l'emploi des mines, pièges et autres dispositifs du 10 octobre 1980 (Protocole II); le Protocole relatif aux armes à laser aveuglantes du 13 octobre 1995 (Protocole IV) ${ }^{349}$, etc. Les 4 CG et leurs PA traitent également de cette question de l'utilisation des moyens et méthodes de combat.

De ces instruments juridiques précités, l'on épingle « deux formes d'interdiction de l'usage d'armes: normes spéciales et normes générales. Font partie des normes spéciales les interdictions conventionnelles de certains types d'armes. Certains chercheurs les appellent à juste titre «Les moyens de guerre absolument interdits » [...] et soulignent que leur usage est interdit même s'il répond à une nécessité militaire ${ }^{350}$. Les normes générales sont celles qui formulent une interdiction d'ordre général sans identifier spécifiquement un type d'armes susceptibles de causer inévitablement des maux superflus et/ou de manière non-discriminatoire, etc. Elles posent tout de même des principes très importants qui comblent également les normes spéciales. Ainsi, l'article 35 du PA I pose des règles fondamentales à observer notamment dans les conflits armés internationaux : «[d]ans tout conflit armé, le droit des parties au conflit de choisir des méthodes ou moyens de guerre n'est pas illimité. 2. Il est interdit d'employer des armes, des projectiles et des matières ainsi que des méthodes de guerre de nature à causer des maux superflus. 3. Il est interdit d'utiliser des méthodes ou moyens de guerre qui sont conçus pour causer, ou dont on peut attendre qu'ils causeront, des dommages étendus, durables et graves à l'environnement naturel ». Le principe de limitation du choix des moyens et méthodes à disposition des belligérants va dans le même sens qu'un autre principe aussi intéressant à savoir le principe de distinction (ou principe de discrimination).

\section{B. Principe de distinction ou principe de discrimination}

Appréhendé par la CIJ comme le premier principe des «principes cardinaux contenus dans le texte formant le tissu du droit international humanitaire » (cf. supra), ou par le TPIY comme «principe fondamental $\mathrm{du}$ droit international humanitaire ${ }^{351}$ et par l'Institut de droit international comme «principe fondamental du droit international en vigueur ${ }^{352}$, le principe

\footnotetext{
349 Voy. la liste des textes conventionnels et déclaratoires disponibles dans la base de données du CICR : https://ihl-databases.icrc.org/dih-traites (Source consultée le 18 août 2016).

${ }^{350}$ BLISHCHENKO, Igor P., «art.cit.» in SWINARSKI Christophe (Réd.), op.cit., p. 294.

${ }^{351}$ TPIY, Le Procureur c. Stanislav Galic, Affaire N${ }^{\circ}$ T-98-29-T, la Chambre de première instance I, jugement rendu le 5 décembre 2003, p. 24, $\$ 45$.

${ }^{352}$ Voy. IDI, Session d'Edimbourg, La distinction entre les objets militaires et non militaires en général et notamment les problèmes que pose l'existence des armes de destruction massive, $5^{\mathrm{e}}$ Commission, Résolution du
} 
de distinction est une règle très ancienne du DIH coutumier. Ce principe est déductible du préambule de la Déclaration de Saint-Pétersbourg de 1868 qui indique notamment « [q]ue le seul but légitime que les Etats doivent se proposer, durant la guerre, est l'affaiblissement des forces militaires de l'ennemi ». L'article 25 du Règlement de La Haye qui interdit expressément « d'attaquer ou de bombarder, [...] des villes, villages, habitations ou bâtiments qui ne sont pas défendus» fait non moins part de ce principe. Lequel sera peaufiné par des instruments juridiques subséquents.

En effet, le contenu du principe de distinction peut être lu à l'article 48 du PA I comme suit : «En vue d'assurer le respect et la protection de la population civile et des biens de caractère civil, les parties au conflit doivent en tout temps faire la distinction entre la population civile et les combattants ainsi qu'entre les biens de caractère civil et les objectifs militaires et, par conséquent, ne diriger leurs opérations que contre des objectifs militaires ». Il se dégage de cette disposition deux autres principes : le principe de distinction entre civils et combattants et le principe de distinction entre biens de caractère civil et les objectifs militaires. Bien que les statuts de combattants et de civils ne sont pas définis dans le PA II, établissant par là la difficulté d'appréhender le principe de distinction en CANI, il est néanmoins admis que le principe de distinction existe non moins en $\mathrm{CANI}^{353}$ et établi coutumièrement ${ }^{354}$. L'article 13 $\$ 2$ du PA II qui renseigne que «[n]i la population civile en tant que telle ni les personnes civiles ne devront être l'objet d'attaques. Sont interdits les actes ou menaces de violence dont le but principal est de répandre la terreur parmi la population civile» «constitue une application directe de ce principe ${ }^{355}$ en CANI. Il va sans dire que l'article $13 \S 2$ du PA II reconduit textuellement en CANI l'article $51 \S 2$ du PA I (à l'exception de «ne devront » en lieu et place de «ne doivent» de l'art. 51, $\$ 2$ du PA I) qui renforce davantage le contenu du principe de distinction dégagé de l'article 48 du PA I. Ce principe établit en CAI comme en CANI des règles bien fondées sur le plan coutumier ${ }^{356}$ selon lesquelles les personnes qui combattent peuvent être combattues alors que celles qui ne combattent pas ne doivent pas être combattues. En ce sens, les belligérants prendront toutes les dispositions ou mesures pour faire en sorte que la population civile ou les personnes civiles ne soient pas les cibles des attaques militaires. Pour donner davantage effet au principe de distinction, le Statut de Rome de la CPI érige expressément en crimes de guerre «le fait de diriger intentionnellement des attaques contre la population civile en tant que telle ou contre les civils qui ne participent pas directement aux hostilités » en CAI (art. 8 §2-b-i) ou en CANI (art. 8 §2-e-i). La même logique est à observer pour des biens de caractère civil vis-à-vis des objectifs militaires en CAI (art. 8 §2-b-ii) ou en CANI (art. 8 §2-e-iii-iv-v).

\footnotetext{
9 septembre 1969 , article $1^{\text {er }}$.

${ }^{353}$ GAGGIOLI, Gloria, L'influence mutuelle entre les droits de l'homme et le droit international humanitaire à la lumière du droit à la vie, op.cit., p. 261.

${ }^{354}$ Lire également HENCKAERTS, Jean-Marie et DOSWALD-BECK, Louise, Droit international humanitaire coutumier, Volume I : Règles, op.cit., pp. 6-8.

355 GAGGIOLI, Gloria, L'influence mutuelle entre les droits de l'homme et le droit international humanitaire à la lumière du droit à la vie, op. cit., p. 261.

${ }^{356}$ Lire les deux premiers chapitres de l'ouvrage de HENCKAERTS, Jean-Marie et DOSWALD-BECK, Louise, Droit international humanitaire coutumier, Volume I : Règles, op.cit., pp.3 et ss., et pp.34 et ss.
} 


\section{Principe de proportionnalité}

A côté des principes précités, existe également le principe de proportionnalité. Ce principe est lisible notamment dans l'article $51 \S 5 b$ du PA I et également repris dans l'étude du CICR à titre du DIH coutumier applicable en CAI et en CANI (Règle 14) ${ }^{357}$. Ce principe «signifie qu'un belligérant doit employer la force jusqu'à concurrence de ce qui est nécessaire pour réaliser le but de la guerre : la soumission complète de l'ennemi, le plus rapidement possible et avec un minimum de pertes humaines et matérielles. Il faudra donc que les avantages militaires concrets et directs attendus d'une opération militaire soient évalués en comparaison directe avec les dommages collatéraux qui pourraient en résulter : ces derniers ne doivent pas être plus importants que les avantages militaires ${ }^{358}$. Ainsi, si dans le lancement d'une opération militaire on peut s'attendre à des pertes et des dommages incidents qui seraient excessifs par rapport à l'avantage militaire concret et direct attendu, ceux qui préparent ou décident de cette attaque doivent s'abstenir de la lancer. Et suivant le TPIY «même si les attaques sont dirigées contre des cibles militaires légitimes, elles sont illégales si elles emploient des moyens ou des méthodes de guerres aveugles, ou si elles sont menées de manière à causer sans discernement des dommages aux civils ${ }^{359}$. Le principe de proportionnalité propose une balance plus ou moins en équilibre entre la nécessité militaire et les exigences humanitaires.

Par ailleurs, dans la pratique, ce principe renvoie à des problèmes d'appréciation notamment d' «avantage militaire concret et direct» face aux dommages éventuels excessifs. Le test de proportionnalité mal effectué reste non moins sans incidence sur la protection des civils. Ceci pourrait éventuellement laisser place à une action judiciaire.

\section{Principe de précaution}

Le principe de précaution, se présente comme le moyen d'expression du principe de distinction et reste très attaché au principe de proportionnalité (cf. infra). Ce principe, comme le dispose l'article 57 du PA I, exige d'épargner les civils et les biens à caractère civil des conséquences des opérations militaires. L'article 58 (Précaution contre les effets des attaques) du PA I abonde dans le même sens. Ainsi, comme l'étaye le TPIY, ce principe veut que «l'on prenne des précautions raisonnables lors de l'attaque d'objectifs militaires pour éviter que les civils pâtissent inutilement d'une imprudence ${ }^{360}$. Cette attitude vaut également pour des biens à caractère civil. La règle 15 de l'étude du droit international humanitaire coutumier du CICR le reprend également ${ }^{361}$. En même temps, il impose donc des obligations pendant et après le

\footnotetext{
${ }^{357}$ Voy. HENCKAERTS, Jean-Marie et DOSWALD-BECK, Louise, Droit international humanitaire coutumier, Volume I : Règles, op. cit., pp. 62-68.

${ }^{358}$ DEYRA, Michel, Le droit dans la guerre, op.cit., p. 146.

359 TPIY, Le Procureur c. Zoran KUPRE[KI], Mirjan KUPRE[KI], Vlatko KUPRE[KI], Drago JOSIPOVI], Dragan PAPI], Vladimir [ANTI], alias "VLADO », Affaire $\mathrm{N}^{\circ} \mathrm{IT}-95-16-\mathrm{T}$, La Chambre de première instance, Jugement rendu le 14 janvier 2000, p. 214, §524.

360 TPIY, Le Procureur c. Zoran KUPRE[KI], Mirjan KUPRE[KI], Vlatko KUPRE[KI], Drago JOSIPOVI], Dragan PAPI], Vladimir [ANTI], alias "VLADO », Affaire N ${ }^{\circ}$ IT-95-16-T, La Chambre de première instance, Jugement rendu le 14 janvier 2000, p. 213, §524.

${ }^{361}$ Voy. HENCKAERTS, Jean-Marie et DOSWALD-BECK, Louise, Droit international humanitaire coutumier, Volume I : Règles, op. cit., pp. 69-74
} 
combat, par exemple les dangers qui résulteraient des armes à sous-munitions. Bien plus, comme le principe de proportionnalité, cette règle impose une action de renseignement. Et lors de l'attaque, il faudrait disposer d'armes de précision ${ }^{362}$.

Ainsi, s'abstenir d'attaquer pour éviter des dommages incidents excessifs par rapport à l'avantage militaire concret et direct attendu fait penser à une parfaite combinaison de principes de précaution (art. $57 \S 2$ a-iii du PA I) et de proportionnalité (art. $51 \S 5 b$ du PA I). Et comme le rappelait bien le TPIY, le principe de précaution est toujours appliqué avec le principe de proportionnalité $^{363}$. Il en sera de même si l'attaque a déjà été lancée et qu'en pleine opération, les combattants se rendent compte de l'apparition d'un élément nouveau par exemple une population civile massée. En pareilles circonstances, afin d'éviter des dommages incidents excessifs, l'opération doit être annulée ou suspendue. C'est ce qui ressort également du TPIY dans l'affaire Le Procureur c. Stanislaw Galic ${ }^{364}$.

Il faudrait également attacher à ces principes précédents, «le principe d'honnêteté et de bonne foi dans les choix des moyens et méthodes de guerre souvent appelé dans la littérature occidentale "principe de la chevalerie » ${ }^{365}$. Ici, il est recommandé aux belligérants de faire preuve de bonne foi dans le choix des méthodes et moyens de nuire à l'ennemi. Ainsi, par exemple, l'article 36 du PA I dispose que «[d]ans l'étude, la mise au point, l'acquisition ou l'adoption d'une nouvelle arme, de nouveaux moyens ou d'une nouvelle méthode de guerre, une Haute Partie contractante a l'obligation de déterminer si l'emploi en serait interdit, dans certaines circonstances ou en toutes circonstances, par les dispositions du présent protocole ou par toute autre règle du droit international applicable à cette Haute Partie contractante ». Ici, la partie concernée fera preuve de bonne foi dans ce processus. La bonne foi relève, on le sait, d'un principe de droit international connu sous le nom «Pacta sunt servanda». Principe important qui sert de base dans la mise en œuvre des conventions internationales notamment (article 26 de la Convention de Vienne sur le droit des traités du 23 mai 1969).

Il se dégage que tous les principes évoqués précédemment, lesquels consacrent la mise en œuvre du principe d'humanité, ne sont pas érigés dans le but de s'écarter les uns des autres mais plutôt de se compléter afin de réserver à l'être humain une meilleure protection en temps de conflits armés. En dehors de ces principes précités, il existe également différents autres principes évoqués en doctrine qui assurent la protection de la personne humaine en période des hostilités dont spécialement celle de l'« enfant» et de l'« enfant soldat ».

\footnotetext{
${ }^{362}$ BERGEAL, Catherine, « La Coutume et la conduite des hostilités », « art. cit. », p. 104. .

${ }^{363}$ TPIY, Le Procureur c. Zoran KUPRE[KI], Mirjan KUPRE[KI], Vlatko KUPRE[KI], Drago JOSIPOVI], Dragan PAPI], Vladimir [ANTI], alias «VLADO», Affaire $\mathrm{N}^{\circ} \mathrm{IT}-95-16-\mathrm{T}$, La Chambre de première instance, Jugement rendu le 14 janvier 2000, pp. 213-214, §524.

${ }^{364}$ TPIY, Le Procureur c. Stanislav Galic, Affaire NIT-98-29-T, la Chambre de première instance I, jugement rendu le 5 décembre 2003, p. 32, §58.

${ }^{365}$ Lire les deux premiers chapitres de l'ouvrage de HENCKAERTS, Jean-Marie et DOSWALD-BECK, Louise, Droit international humanitaire coutumier, Volume I : Règles, op.cit., pp. 3 et ss., et pp. 34 et ss.
} 


\section{Section II Notions d'enfant et d'enfant soldat et aperçu historique de la protection et des droits de l'enfant ${ }^{366}$}

La présente section examine les notions d'enfant en droit international (§1) et d'enfant soldat ou d'enfant associé aux forces ou groupes armés (EAFGA) (§2) avant d'étudier l'aperçu historique de la protection et des droits de l'enfant (§3).

\section{§1 Définition de l'enfant en droit international}

L'article $1^{\mathrm{er}}$ de la CDE donne la définition de l'enfant en ces termes : «Au sens de la présente Convention, un enfant s'entend de tout être humain âgé de moins de dix-huit ans, sauf si la majorité est atteinte plus tôt en vertu de la législation qui lui est applicable. ». "Une telle définition s'abstient délibérément de fixer un point de départ à l'enfance - conception, naissance ou un moment quelconque entre les deux. La Convention laisse donc à chaque Etat le soin de trouver une solution équilibrée aux conflits de droits et d'intérêts que soulèvent les questions comme celles de l'avortement ou de la planification familiale. L'intention des rédacteurs était certainement d'éviter de prendre sur l'avortement et les autres problèmes avant la naissance une position qui aurait pu compromettre l'acceptation universelle de la Convention. Cependant, il apparaît que la plupart des articles de la Convention ne peuvent s'appliquer à l'enfant qu'après sa naissance ${ }^{367}$. Bien plus, concernant l'âge limite de dix-huit ans, suivant Françoise DEKEUWER-DEFOSSEZ, « le seuil d'âge n'a rien d'absolu : à certains égards, on cesse d'être enfant plus tôt (par exemple, si l'on est émancipé). Mais on peut aussi le rester plus tard (par exemple, certaines mesures d'assistance éducative peuvent durer jusqu'à l'âge de vingt et un ans) ${ }^{368}$. Bien plus, au sens de cette Convention, il n'existe pas de différence entre «enfant », terme à connotation biologique et «mineur », expression à tendance juridique. Les deux termes sont perçus comme étant synonymes ${ }^{369}$. Au-delà de la fixation de l'âge limite de l'enfant à dix-huit ans, la confirmation est fournie également par la suite de la phrase de l'article $1^{\text {er }}$ de la CDE : «[...] sauf si la majorité est atteinte plus tôt en vertu de la législation qui lui est applicable »(nous soulignons).

Par ailleurs, cette définition de l'enfant semble problématique. Elle accorde largement la possibilité aux législations nationales de reculer ou d'avancer l'âge de dix-huit ans conventionnellement admis. Ce qui pourrait s'avérer compromettant pour le bien-être de l'enfant. En même temps, il importe de signifier que «[c]ette flexibilité offerte par le traité reflète l'absence d'accord au niveau international sur une définition de la majorité. En effet, celle-ci peut varier d'un pays à un autre ou selon des critères différents. L'âge de la majorité

\footnotetext{
${ }^{366}$ Pour l'historique des droits de l'enfant, veuillez lire notamment : MEUNIER, Guillemette, L'application de la Convention des Nations Unies relatives aux droits de l'enfant dans le droit interne des Etats parties, L'Harmattan, Paris, 2002, pp. 15-26 ; GEANITON, Thierry, Aspects récents de l'Action du fonds des Nations unies pour l'enfance (UNICEF) en matière de protection internationale de l'enfant, Thèse de doctorat en droit, Université Paris 1, 1995, 7-11 ; Riad DAOUDI, «La codification des droits de l'enfant : analyse des prises de position gouvernementales », in Maurice TORRELLI (éd.), La protection internationale des droits de l'enfant, Paris, P.U.F, 1983, p. 30.

${ }^{367}$ MEUNIER, Guillemette, op.cit., 51.

${ }^{368}$ DEKEUWER-DEFOSSEZ, Françoise, Le droit de l'enfant, P.U.F, Paris, 2010, p.3.

369 Lire également FURAHA MWAGALWA, Thomas, L'interdiction de la participation aux hostilités, la démobilisation et la réinsertion des enfants soldats en République démocratique du Congo, op.cit., pp. 20-21.
} 
peut différer selon qu'il s'agit de la majorité civile, pénale ou politique. Enfin, cette majorité peut, à diverses fins, répondre à des critères autres que l'âge ; tel en est le cas pour le mariage pour lequel la législation peut se limiter à exiger simplement «une compréhension suffisante $»^{370}$. Cette possibilité de fluctuation entre législations nationales en termes de l'âge de l'enfant a été aussi observée dans la première définition conventionnelle de l'enfant qu'offrait l'OIT. Il s'agit de la Convention $\left(n^{\circ} 130\right)$ concernant les soins médicaux et les indemnités de maladie, adoptée à Genève par la $53^{\mathrm{e}}$ session de la Conférence générale de l'Organisation internationale du travail le 25 juin 1969 et entrée en vigueur le 27 mai 1972. Aux fins de cet instrument qui est actuellement en vigueur entre les 15 Etats ${ }^{371}$ qui l'ont ratifié, par « enfant», il faut entendre « un enfant qui est au-dessous de l'âge auquel la scolarité obligatoire prend fin ou enfant de moins de quinze ans [...] ${ }^{372}$ (art. $1^{\text {er }}$, alinéa $i$ ). Or la fin de la scolarité obligatoire peut varier d'un pays à un autre ${ }^{373}$.

Il importe de dire avec Thierry GEANITON que « définissant communément l'être dans sa période allant de la naissance à l'adolescence, force est toutefois de constater qu'il n'en existe pas de définition universellement admise, celle-ci variant de façon plus ou moins sensible au gré des cultures et des civilisations. Quoique l'on retienne plus généralement comme limite de l'enfance l'âge de dix-huit ans, celle-ci oscille de douze à quinze ans selon les pays. Dès lors, l'on comprend aisément que la détermination de cet âge constitua un obstacle sérieux à l'élaboration de la Convention des Nations unies de 1989 relative aux droits de l'enfant qui retint finalement la définition reprise ci-haut $»^{374}$.

Cependant, d'autres instruments juridiques internationaux ultérieurs ont incorporé ce critère d'âge de dix-huit ans sans laisser de marges de manœuvre aux Etats. C'est notamment le cas de la Charte africaine des droits et du bien-être de l'enfant en son article 2 qui «entend par «enfant» tout être humain âgé de moins de 18 ans $»^{375}$. La Convention ( $\left.{ }^{\circ} 182\right)$ concernant l'interdiction des pires formes de travail des enfants et l'action immédiate en vue de leur élimination abonde dans le même sens. Celle-ci appréhende l' «enfant» comme «l'ensemble des personnes de moins de 18 ans ${ }^{376}$.

\footnotetext{
${ }^{370}$ MEUNIER, Guillemette, op.cit., p. 51.

${ }^{371}$ Allemagne, Bolivie, Costa Rica, Danemark, Equateur, Finlande, Libye, Luxembourg, Norvège, Pays-Bas, Slovaquie, Suède, République Tchèque, Uruguay et Venezuela. Voy. la liste disponible sur http://www.ilo.org/dyn/normlex/fr/f?p=1000:11300:0::NO:11300:P11300_INSTRUMENT_ID:312275 (Source consultée le 25 juillet 2016).

${ }^{372}$ Article $1^{\text {er }}$, alinéa $i$, de la Convention $\left(n^{\circ} 130\right)$ concernant les soins médicaux et les indemnités de maladie disponible

http://www.ilo.org/dyn/normlex/fr/f?p=1000:11300:0::NO:11300:P11300_INSTRUMENT_ID:312275 $\quad$ (Source consultée le 25 juillet 2016).

${ }^{373}$ Lire également FURAHA MWAGALWA, Thomas, L'interdiction de la participation aux hostilités, la démobilisation et la réinsertion des enfants soldats en République démocratique du Congo, op.cit., p. 16.

${ }^{374}$ GEANITON, Thierry, op.cit., p. 7.

375 Article de la Charte africaine des droits et du bien-être de l'enfant, adoptée à Addis-Abeba (Ethiopie) par la $26^{\text {e }}$ Conférence des Chefs d'»Etat et de Gouvernements de l'OUA, le 11 juillet 1990 http://www.achpr.org/fr/instruments/child/ (Source consultée le 24 juillet 2016)

${ }^{376}$ Article 2 de la Convention ( $\left.n^{\circ} 182\right)$ concernant l'interdiction des pires formes de travail des enfants et l'action immédiate en vue de leur élimination, adoptée par la Conférence générale de l'Organisation internationale du

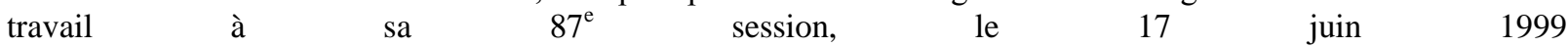
http://www.ilo.org/dyn/normlex/fr/f?p=NORMLEXPUB:12100:0::NO::P12100_ILO_CODE:C182 ～(Source consultée le 24 juillet 2016).
} 
Au plan national, différentes législations ont relayé ces définitions conventionnelles de l'enfant avec pour critère de base, l'âge de dix-huit ans.

Ainsi, par exemple, au Rwanda, suivant la loi $n^{\circ} 27 / 2001$ du 28 avril 2001 relative aux droits et à la protection de l'enfant contre les violences, l' « enfant» est appréhendé comme tout être humain âgé de moins de dix-huit ans sauf dispositions contraires (art. $\left.1^{\mathrm{er}}\right)$. Cette définition sera reprise également par la loi $n^{\circ} 13 / 2009$ portant réglementation du travail au Rwanda. Celle-ci définit 1 ' «enfant» comme tout être humain âgé de moins de dix-huit ans et interdit à son article $4, \S 1$, d'employer un enfant dans une entreprise, même en tant qu'apprenti, avant l'âge de seize ans ${ }^{377}$. L'âge de l'enfant tel que défini diffère de celui du «mineur ». Au sens du Code civil rwandais, celui-ci est entendu comme l'individu de l'un ou de l'autre sexe qui n'a pas encore atteint vingt-et-un ans (art. 360). Le «mineur» peut-être émancipé de plein droit par voie maritale (art. 426) ${ }^{378}$ ou sur demande personnelle d'un de ses parents ou de son tuteur à partir de l'âge de dix-huit ans (art. 427 et 428$)^{379}$. Bien plus, de nombreux autres instruments juridiques règlent sans distinction de sexe des questions de majorité notamment en matière électorale (dix-huit ans), commerciale (seize ans) ou pénale (quatorze ans) ${ }^{380}$.

Pour la République d'Ouganda, son Rapport initial adressé au Comité des droits de l'enfant le $1^{\text {er }}$ février 1996 attestait que la définition de l'enfant variait suivant le texte législatif en présence, et ce en dépit de la majorité atteinte à dix-huit ans ${ }^{381}$. Par exemple, « [a]ux termes de la loi sur les écoles agréées, toute personne âgée de moins de 12 ans est un enfant, toute personne dont l'âge est compris entre 7 et 16 ans étant un mineur » (nous soulignons) ${ }^{382}$. «Au sens de la loi sur le divorce qui règle la situation des enfants issus du mariage, le terme "mineur" s'entend d'un garçon de moins de 15 ans et d'une fille de moins de 13 ans ${ }^{383}$. Pour

\footnotetext{
${ }^{377}$ Comité des droits de l'enfant, Examen des Rapports soumis par les Etats parties en application de l'article 44 de la Convention, Troisième et quatrième rapports périodiques des Etats parties devant être soumis en 2008, RWANDA, CRC/C/RWA/3-4, 01 mars 2012, pp. 20-21, $\S \S$ 93-94 disponible sur http://tbinternet.ohchr.org/_layouts/treatybodyexternal/TBSearch.aspx?Lang=en\&TreatyID=5\&TreatyID=10\&T reatyID=11\&DocTypeID=29\&DocTypeCategoryID=4 (Source consultée le 22 juillet 2016).

${ }^{378}$ Comité des droits de l'enfant, Examen des Rapports présentés par les Etats parties en application de l'article 44 de la Convention, deuxième rappor périodique des Etats parties devant être soumis en 1998, RWANDA, CRC/C/70/Add.22, 8 octobre 2003, p. 27, $\$ \$ 73-74, \quad$ disponible sur http://tbinternet.ohchr.org/_layouts/treatybodyexternal/Download.aspx?symbolno=CRC $\% 2 \mathrm{fC} \% 2 \mathrm{f} 70 \% 2 \mathrm{fAdd} .22$ \&Lang=en (Source consultée le 22 juillet 2016).

379379 Comité des droits de l'enfant, Examen des Rapports présentés par les Etats parties en application de l'article 44 de la Convention, deuxième rappor périodique des Etats parties devant être soumis en 1998, RWANDA, CRC/C/70/Add.22, 8 octobre 2003, op. cit., p. 28, §75.

${ }^{380}$ Lire pour plus d'approfondissement les $3^{\mathrm{e}}$ et $4^{\mathrm{e}}$ Rapports périodiques du Rwanda au Comité des droits de l'enfant in Comité des droits de l'enfant, Examen des Rapports soumis par les Etats parties en application de l'article 44 de la Convention, Troisième et quatrième rapports périodiques des Etats parties devant être soumis en 2008, RWANDA, CRC/C/RWA/ 3-4, op. cit., p. 21, §§ 96-97.

${ }^{381}$ Comité des droits de l'enfant, Examen des Rapports présentés par les Etats parties en application de l'article 44 de la Convention, Rapports initiaux des Etats parties devant être soumis en 1992, OUGANDA, CRC/C/3/Add.40, 17 juin $1996, \quad$ p. $13, \quad \$ 38$ disponible http://tbinternet.ohchr.org/ layouts/treatybodyexternal/Download.aspx?symbolno=CRC $\% 2 \mathrm{fC} \% 2 \mathrm{f} 3 \% 2 \mathrm{fAdd} .40 \&$ Lang=en (Source consultée le 22 juillet 2016).

${ }^{382}$ Comité des droits de l'enfant, Examen des Rapports présentés par les Etats parties en application de l'article 44 de la Convention, Rapports initiaux des Etats parties devant être soumis en 1992, OUGANDA, CRC/C/3/Add.40, 17 juin 1996, op.cit., p. 13, §38, a.

${ }^{383}$ Comité des droits de l'enfant, Examen des Rapports présentés par les Etats parties en application de l'article 44 de la Convention, Rapports initiaux des Etats parties devant être soumis en 1992, OUGANDA, CRC/C/3/Add.40, 17 juin 1996, op.cit., p. 13, §38, c.
} 
mettre fin à cette ambigüité, la loi sur l'enfance de 1996 appréhendera l'enfant comme « toute personne âgée de moins de 18 ans ${ }^{384}$.

En RDC, cette question est réglée par la Constitution. En effet, le terme "enfant » s'y trouve défini pour la première fois avec la Constitution du 18 février 2006. C'est exactement l'expression «enfant mineur» qui est employée par cette dernière. Ce qui sous-entend l'existence d' «enfant majeur ». C'est ici la possibilité d'émancipation de l'enfant mineur de plein droit par le mariage (art. 288 du Code de la Famille) - disposition qui se trouve abrogée par l'article $48^{385}$ de la Loi $n^{\circ} 09 / 001$ du 10 janvier 2009 portant protection de l'enfant en vertu $\mathrm{du}$ principe lex posterior derogat priori, estimons-nous. Position que ne partagent pas cependant la majorité des praticiens du droit congolais qui pensent à la coexistence de ces deux dispositions en dépit de leur contradiction ${ }^{386}$. L'émancipation peut avoir lieu aussi par une décision judiciaire (art. 292, alinéa 2, du Code de la Famille).

En effet, suivant l'article 41, alinéa 1, de la Constitution de la RDC du 18 février 2006, "L'enfant mineur est toute personne, sans distinction de sexe, qui n'a pas encore atteint 18 ans révolus ${ }^{387}$. Cette définition rejoint et renforce celle du «mineur » fournie par la Loi $n^{\circ} 87-010$ portant Code de la Famille du $1^{\mathrm{er}}$ août 1987 en son article 219 en ces termes : " [1]e mineur est l'individu de l'un ou de l'autre sexe qui n'a pas encore l'âge de dix-huit ans accomplis ${ }^{388}$. La loi $n^{\circ} 09 / 001$ du 10 janvier 2009 portant protection de l'enfant, en son article 2, §1, appréhende à son tour l' «enfant» dans le même sens. Suivant cette disposition, l' "enfant [est] toute personne âgée de moins de dix-huit ans ${ }^{389}$.

« La définition portée par la Constitution s'applique dès lors à tous les secteurs où des flottements persistaient encore, s'agissant de l'âge à prendre en compte ${ }^{390}$. C'est notamment le cas « de l'article ter du décret du 6 décembre 1950 sur l'enfance délinquante, tel que modifié par l'ordonnance-loi du 4 juillet 1978 qui dispose: «Est mineur au sens du présent décret

\footnotetext{
${ }^{384}$ Comité des droits de l'enfant, Examen des Rapports présentés par les Etats parties en application de l'article 44 de la Convention, Deuxième Rapport périodiques des Etats parties devant être soumis en 1997, OUGANDA, CRC/C/65/Add.33, 5 novembre 2004, p. $34, \quad \S 83 \quad$ disponible sur http://tbinternet.ohchr.org/ layouts/treatybodyexternal/Download.aspx?symbolno=CRC\%2fC\%2f65\%2fAdd. 33 \&Lang=en (Source consultée le 22 juillet 2016).

${ }^{385}$ Article 48 de la Loi $n^{\circ} 09 / 001$ du 10 janvier 2009 portant protection de l'enfant : « Les fiançailles et le mariage d'enfants sont interdits » disponible sur http://www.leganet.cd/Legislation/JO/2009/L.09.001.10.01.09.htm (Source consultée le 25 juillet 2016).

${ }^{386}$ Voy. FURAHA MWAGALWA, Thomas, L'interdiction de la participation aux hostilités, la démobilisation et la réinsertion des enfants soldats en République démocratique du Congo, op.cit., p. 21, note 55.

387 Article 41, alinéa 1, de la Constitution de la République Démocratique du Congo du 18 février 2006 in Journal Officiel de la République Démocratique du Congo, $47^{\mathrm{e}}$ année, numéro spécial, Kinshasa 18 février 2006, p. 21.

388 Article 219 de la Loi n87-010 portant Code de la Famille du $1^{\text {er }}$ août 1987 disponible sur http://www.leganet.cd/Legislation/Code\%20de\%20la\%20famille/Table.htm (Source consultée le 24 juillet 2016).

389 Article 2, §1, de la Loi $n^{\circ} 09 / 001$ du 10 janvier 2009 portant protection de l'enfant disponible sur http://www.leganet.cd/Legislation/JO/2009/L.09.001.10.01.09.htm\#TIICISII (Source consultée le 24 juillet 2016).

${ }^{390}$ Comité des droits de l'enfant, Examen des Rapports présentés par les Etats parties en application de l'article 44 de la Convention, Rapports périodiques des Etats parties devant être soumis en 1997, République Démocratique $d u \quad$ Congo, $\quad \mathrm{CRC} / \mathrm{C} / \mathrm{COD} / 2, \quad 24$ juillet 2008, p. 18, \$66, in http://tbinternet.ohchr.org/_layouts/treatybodyexternal/TBSearch.aspx?Lang=en\&TreatyID $=5 \&$ TreatyID=10\&T reatyID=11\&DocTypeID=29\&DocTypeCategoryID=4 (Source consultée le 20 décembre 2015).
} 
l'enfant apparemment âgé de moins de 16 ans accomplis au moment du fait ${ }^{391}$. Cependant, en dépit de l'âge de dix-huit ans retenu dans la définition de l' "enfant » et de la protection qui en résulte, suivant la Loi $n^{\circ} 015 / 2002$ du 16 octobre 2002 portant Code du travail (art. 6, alinéa 2 et sauf exceptions prévues par cet article ${ }^{392}$ ) et la Loi $n^{\circ} 09 / 001$ du 10 janvier 2009 portant protection de l'enfant (art. 50), il est admis d'employer un enfant à l'âge minimum de seize ans.

\section{\$2 Notions d'enfant soldat ou d'enfant associé à une force ou à un groupe armé (EAFGA)}

L'expression «enfant soldat», habituellement d'usage, est définie par des instruments de softlaw. Les instruments juridiques contraignants se sont attelés quant à eux à régir le recrutement et la participation des enfants dans les conflits armés.

Ainsi, suivant les Principes du Cap, le terme « «enfant soldat» désigne toute personne âgée de moins de 18 ans enrôlée dans une force armée ou un groupe armé régulier ou irrégulier, quelle que soit la fonction qu'elle exerce, notamment mais pas exclusivement celle de cuisinier, porteur, messager, et toute personne accompagnant de tels groupes qui n'est pas un membre de leur famille. Cette définition englobe les filles recrutées à des fins sexuelles et pour des mariages forcés. Elle ne concerne donc pas uniquement les enfants qui sont armés ou qui ont porté des armes ${ }^{393}$. Les Principes de Paris adoptés en 2007, soit dix ans après les Principes de Cap, n'utilise pas le terme " enfant soldat » au profit d' " enfant associé à une force armée ou à un groupe armé »(EAFGA). Les Principes de Paris veulent être plus détaillés sur un certain nombre de questions, et larges en tenant compte des diversités du monde contrairement aux Principes de Cap limités aux situations africaines bien que s'inspirant de la sphère internationale. L'expérience de dix ans après le Cap avec de nombreuses situations nouvelles justifie leur adoption. "Enfant associé à une force armée ou à un groupe armé », qui remplace désormais "enfant soldat», est appréhendé comme "toute personne âgée de moins de 18 ans qui est ou a été recrutée ou employée par une force ou un groupe armé, quelque soit la fonction qu'elle y exerce. Il peut s'agir, notamment mais pas exclusivement, d'enfants, filles ou garçons, utilisés comme combattants, cuisiniers, porteurs, messagers, espions ou à des fins sexuelles. Le terme ne désigne pas seulement un enfant qui participe ou a participé directement à des hostilités ${ }^{394}$.

A dire vrai, si le contenu de ces deux termes se présente comme étant identique, l'intérêt réside

\footnotetext{
${ }^{391}$ Ibid., § 67.

${ }^{392}$ Lire l'article 6, alinéa 2, de la Loi $n^{\circ} 015 / 2002$ du 16 octobre 2002 portant Code du travail, Journal Officiel de la République Démocratique du Congo, $43^{\mathrm{e}}$ année, Numéro spécial, 25 octobre 2002, p. 7.

${ }^{393}$ Voy. la partie de définitions dans les Principes du Cap et meilleures pratiques Concernant le recrutement d'enfants dans les forces armées et la démobilisation et la réinsertion sociale des enfants soldats en Afrique adoptés au Symposium sur la Prévention du recrutement d'enfants dans les forces armées et sur la démobilisation et la réinsertion sociale des enfants-soldats en Afrique, entre les 27 et 30 avril 1997, (Document disponible sur http://www2.unicef.org:60090/french/emerg/index childsoldiers.html (Source consultée le 15 mai 2016).

${ }^{394}$ Voy. la partie de définitions dans Les Principes et lignes directrices sur les enfants associés aux forces armées ou gux groupes armés, février 2007 , http://www.unicef.org/french/protection/files/ParisPrincipesFrench310107.pdf (Source consultée le 18 juillet 2016).
} 
plutôt au niveau terminologique. La terminologie d' "enfant associé à une force armée ou à un groupe armé » semble plus proche de la réalité, globale et permet ainsi de couvrir la notion de participation directe ou indirecte des enfants aux conflits armés, alors que le concept d'enfants soldats est moins englobant ${ }^{395}$, laissant plus l'impression d'un enfant porteur d'armes uniquement et prenant directement part aux hostilités. Ainsi, l'expression «enfant associé à une force armée ou à un groupe armé » viserait une plus grande protection de l'enfant ${ }^{396}$.

De ce qui précède, l'âge retenu dans ces textes se fonde sur la CDE. Et en dépit de l'idée que soutiennent certains de préserver un système de défense militaire en recourant aux enfants de moins de dix-huit ans dans les conflits armés, la pratique des Etats, des OI et des ONG, à travers les législations internationales notamment, atteste la reconnaissance de l'interdiction d'utilisation des personnes de moins de dix-huit ans dans ce contexte ${ }^{397}$. Ce n'est donc pas un hasard de fixer cet âge à dix-huit ans affirme HONWANA. « Le service militaire, le fait d'être soldat et de combattre sont habituellement vécus comme une sorte d'introduction aux activités des «grands» $[\ldots]{ }^{398}$. «Dans les armées régulières, les soldats sont vus comme les défenseurs de la nation et du peuple, et en cela, ils sont associés aux notions de vigueur, de force, d'agressivité, de responsabilité, de masculinité et de maturité. La transition du civil au militaire constitue un processus de reconfiguration identitaire ${ }^{399}$. Exercice auquel les enfants ne sont pas encore physiquement et moralement prêts à s'engager. Bien plus, l'âge limite de dix-huit ans était appréhendé avec raison par l'Union internationale de protection de l'Enfance, lors de sa proposition sur l'interdiction de la peine de mort contre les personnes de moins de dix-huit ans à la XVII ${ }^{\mathrm{e}}$ Conférence internationale de la Croix-Rouge, comme une limite absolue, un âge de discernement. Ce qui est très valable jusqu'à ce jour. Avant cet âge, «l'individu n'est pas entièrement capable de discernement, [...] il ne mesure pas toujours la portée de ses actes et agit souvent sous l'influence d'autrui, si ce n'est sous la contrainte ${ }^{400}$.

\section{§3. Aperçu historique de la protection et des droits de l'enfant : de l'objet des droits à sujet des droits}

Etymologiquement, «enfant» vient du latin infans signifiant « qui ne parle pas ». L'infans latin était ce que nous appelons un enfant en bas âge ${ }^{401}$. Et la culture dite « occidentale » et le droit distinguaient pendant longtemps l'infans du puer. C'est autour de sept ans que s'établissait cette limite. Le puer, l'équivalent de jeune actuellement, est dans l'âge qui précède la maturité

\footnotetext{
${ }^{395}$ Lire RAMASY, Juvence F., «La protection juridique et politique des enfants dans les conflits armés en Afrique. Inventaire des dispositions légales et politiques », in BABIKER, Mohamed Abdelsalam, DAUBLAIN, Maxense et VAHLAS, Alexis (dir.), Enfants-soldats et droits des enfants en situation de conflit et post-conflit. Réalités et enjeux, L'Harmattan, Paris, 2013, p. 264.

${ }^{396}$ MARTIN CHENUT, Kathia, «art.cit » in SOREL, Jean-Marc et POPESCU, op.cit., p. 206. ; LAVALLEE, Carmen, La Protection internationale des droits de l'enfant. Entre idéalisme et pragmatisme, Bruylant, Bruxelles, 2015, p. 301.

${ }^{397}$ Lire ALFREDSON, Lisa, «Enfants soldats, déplacement et sécurité humaine », in Forum du désarmement, Trois, 2002, pp. 19-20.; LAVALLEE, Carmen, La Protection internationale des droits de l'enfant. Entre idéalisme et pragmatisme, op.cit., p. 301.

${ }^{398}$ HONWANA, Alcinda, «Innocents et coupables. Les enfants-soldats comme acteurs tactiques », in Enfants, jeunes et politiques, Le Dossier, Politique africaine n80, décembre 2000, p. 62.

399 Ibid.

${ }^{400}$ PICTET, Jean S. (dir.), Commentaire IV, La Convention de Genève relative à la protection des personnes civiles en temps de guerre, op. cit., p. 372.

${ }^{401}$ DEKEUWER-DEFOSSEZ, Françoise, Le droit de l'enfant, op. cit., p. 3.
} 
d'adulte. Sa responsabilité est variable suivant des domaines de la vie sociale (majorité pénale, majorité civile, majorité politique, etc. ${ }^{402}$. Différentes représentations culturelles de l'enfant jalonent l'histoire occidentale ${ }^{403}$.

Parlant d'infans, l'étymologie, ici, suggère qu'on fit pendant des siècles peu de cas de la parole de l'enfant et, plus largement, de cet âge de la vie. Sans voix, sans poids, sans droits ${ }^{404}$. Et d'ailleurs, il est bien connu qu'historiquement les enfants étaient perçus et souvent traités comme une propriété personnelle vivant sous l'autorité puissante du père. Des écrits de Hugo Grotius en 1625, l'on sait bien comprendre l'influence de la puissance paternelle ou parentale sur l'enfant jusqu'à une certaine époque. L'auteur précité note que :

«Ce n'est pas seulement sur les choses, mais encore sur les personnes que l'on acquiert un droit; et on l'acquiert originairement par la génération, par le consentement, à cause d'un délit. Par la génération un droit est acquis aux parents sur les enfants [...]. Il faut distinguer trois époques dans les enfants : la première, celle du jugement imparfait, de l'absence de discernement [...]; la seconde, celle du jugement parfait, mais pendant laquelle le fils fait encore partie de la famille de ses père et mère [...]; la troisième, lorsque l'enfant est sorti de cette famille. Dans la première époque, toutes les actions des enfants sont soumises à la direction de leurs père et mère : il est juste, en effet, que celui qui ne peut se gouverner lui-même, soit gouverné par autrui. [...] «Dans la seconde époque, lorsque l'âge a mûri le jugement, l'autorité des parents ne s'exerce que sur celles des actions de leurs enfants qui sont de quelque importance pour la position de la famille paternelle ou maternelle. [...] Quant aux autres actions, les enfants, ont une puissance, c'est-à-dire une faculté morale d'agir ; mais ils sont tenus néanmoins, même dans l'accomplissement de ces actes, de s'efforcer toujours de plaire aux parents. [...] Dans la troisième époque, le fils est absolument maître de lui-même et indépendant du droit d'autrui, sauf toutefois le devoir de piété filiale et de respect, qui subsiste toujours, et dont la cause est perpétuelle. Il suit de là que les actes des rois ne peuvent être censés annulés pour la raison que ces rois ont des parents ${ }^{405}$.

La période connue sous le nom d'«enfance »n'était pas reconnue jusqu'à récemment parce que les enfants étaient considérés comme invisibles dans la plupart des sociétés. Ces attitudes ont prévalu pendant des siècles ${ }^{406}$. Pourtant, l'idée d'une protection de l'enfant n'est pas exclue dans les civilisations ${ }^{407}$ même en temps de guerre. En schématisant toutefois, on peut affirmer

\footnotetext{
402 FIERENS, Jacques, «Responsable de quoi ? », in Actes du Colloque, Responsabilité individuelle versus déresponsabilisation collective - jeune et responsable?, JDJ, n³06, juin 2011, p. 4.

${ }^{403}$ FIERENS, Jacques, « Responsable de quoi ? », « art. cit. », pp. 4-7.

${ }^{404}$ ROYAL, Ségolène, Les droits des enfants, Dalloz, Paris, 2007, p. 4.

${ }^{405}$ Voy. GROTIUS, Hugo Le droit de la guerre et de la paix, Paris, P.U.F, 1999, pp. 222, 223 et 224. (Ouvrage traduit par P.PRADIER-FODERE et édité par D. ALLAND et S. GOYARD-FABRE).

${ }^{406}$ MEUNIER, Guillemette, op.cit., 15.

407 Ibid., p.16. "L'histoire nous révèle quelques mesures de protection sociale. Chez les hébreux, la fécondité est une bénédiction de Dieu, l'orphelin est entouré d'une protection spéciale et il existe un statut de l'enfant trouvé. A Thèbes, peuvent être adoptés les enfants dont les parents sont trop pauvres pour les élever. Il existe aussi quelques dispositions relatives à l'éducation de l'enfant ; ainsi en Grèce, l'intervention de l'Etat est très importante dans la relation parents-enfants. Si le Chef de famille maltraitait ses enfants, tout citoyen pouvait se porter leur défenseur et faire entendre leur plainte devant la justice criminelle », voy. Guillemette MEUNIER,
} 
que jusqu'à la fin du Moyen Age, il n'existait aucune conscience sociale de l'existence des enfants en tant que groupe au sein de la société. Les enfants n'étaient donc pas identifiés comme une catégorie sociale distincte. ${ }^{408}$ Les lois médiévales reflètent cette situation : l'enfant n'existait pas. Si l'on y fait référence dans un texte de loi, c'est tout à fait exceptionnellement et c'est pour le considérer comme la possession du père ou comme une propriété quelconque ${ }^{409}$.

Cette perception de l'enfant est aussi accrue dans les milieux traditionnels africains et reste non sans influence sur certains milieux urbains. Ainsi, «dans plusieurs sociétés africaines traditionnelles, l'âge reste un critère relatif. En milieu traditionnel, en effet, on parle moins d' «âge» que de «classe d'âge ${ }^{410}$. En culture traditionnelle moaga au Burkina Faso, par exemple, il n'est pas autorisé à un homme de prendre la parole en public, aussi longtemps que son père est en vie. De même, dans la culture mandingue (Afrique de l'Ouest), un homme ne peut se voir confier une responsabilité sociale, avant d'avoir atteint un certain statut social ou familial, correspondant, environ, à l'âge de 40 ans. Dans la société traditionnelle massaï (Kenya et Tanzanie) aussi, la passation des rites d'initiation ne suffisait pas, à elle seule, pour que l'enfant intègre le rang des adultes. Au sortir des rites d'initiation, le sujet mâle acquérait le statut de guerrier, mais pour être reconnu adulte, il devait soit participer à une expédition et en revenir, soit tuer un lion. Au Rwanda, un dicton populaire dit : «umuruho uzana n'insya », ce qui signifie que «la responsabilité s'assume dès l'apparition des poils pubiens ». Cela veut dire que lorsque les poils pubiens apparaissaient chez un enfant, la fille pouvait être demandée en mariage, tout comme le garçon pouvait aider ses aînés dans les tâches communautaires, à savoir entre autres, aller à la chasse et relever son père au front ${ }^{411}$.

Le siècle des lumières sera d'un apport positif sur la situation des droits de l'enfant. Kant écrira : «Les enfants comme personnes ont aussi originairement comme avantage inné droit aux soins de leurs parents, jusqu'à ce qu'ils soient capables de se conserver eux-mêmes ${ }^{412}$. A ce propos, « [u]ne nouvelle avancée en faveur de l'enfance aura lieu en France le 9 août 1793, lorsque la Convention présentera un code affirmant, pour la première fois, que les parents ont des devoirs envers les enfants, particulièrement un devoir de protection ${ }^{413}$. Ceci doit être vu nettement comme une avancée par rapport à la Déclaration des droits de l'homme et du citoyen du 26 août 1789 critiquée pour avoir promu les droits des «bourgeois victorieux » et écrasé ceux des plus faibles dont les enfants ${ }^{414}$.

Néanmoins, sur le plan des faits, la situation de l'enfant devient de plus en plus catastrophique. Malgré les réflexions philosophiques relayées par les mouvements et revendications en faveur des droits de l'homme - droits qui incluent indirectement les droits de l'enfant - l'enfant est

\footnotetext{
op.cit., 16.

408 Ibid.

${ }^{409}$ Ibid. 17.

${ }^{410}$ BIRUKA, Innocent, «la classe d'âge réunissait ceux avec lesquels on avait été initiée et qui avaient subi les mêmes épreuves et accompli ensemble les différents rituels préparant l'entrée dans la société ». Voy. Innocent BIRUKA, op.cit., 30.

${ }^{411}$ MEUNIER, Guillemette, op.cit., p. 17.

412 Ibid.

${ }^{413}$ GEANITON, Thierry, Aspects récents de l'Action du fonds des Nations unies pour l'enfance (UNICEF) en matière de protection internationale de l'enfant, Thèse de doctorat en droit, Université Paris 1, op. cit., p. 8.

${ }^{414}$ ROUVILLOS, Frédéric, Libertés fondamentales, éd. Flammarion/Champs Université, Roubaix, p. 311.
} 
exploité de façon intensive au profit du développement économique. La révolution industrielle au XIXème siècle prendra une bonne part d'enfants. Il n'était donc pas rare qu'un enfant travaillât jusqu'à seize heures par jour pour un salaire dérisoire et sans aucune protection sanitaire ou sociale ${ }^{415}$.

La condition de l'enfant n'évoluera concrètement qu'au début du XXème siècle, avec notamment les progrès réalisés dans le domaine de la médecine, la psychiatrie infantile et les sciences humaines. En 1919, l'idée de la création d'une Association internationale pour la protection de l'enfance voit le jour, à l'initiative privée d'Eglantyne Jebb. « C'est aux Balkans qu'elle découvre l'extrême détresse des populations civiles déplacées et des enfants pris dans les violences de la guerre, Serbes victorieux comme Albanais vaincus. Elle décide de ne pas choisir son camp et de soigner les enfants qui souffrent de deux côtés de la barrière ${ }^{416}$. Lui vient ainsi l'idée de créer Save the Children Fund en 1919 à Londres avec l'aide de sa sœur Dorothy Buxton pour l'assistance et la protection des enfants victimes de guerre ${ }^{417}$. Et c'est Save the Children Fund de Londres et le Comité International de Secours aux enfants de Berne (fondé à Berne le 28 mars 1919) ${ }^{418}$ qui créeront à Genève, sous le patronage du CICR, l'Union Internationale de Secours aux Enfants ${ }^{419}$. Cette dernière aura pour mission d'intervenir partout où des enfants sont réfugiés, affamés par les guerres, privés de protection, et développera, après l'Europe, ses activités en direction de l'Afrique ${ }^{420}$. Au plan institutionnel, «c'est à l'époque de la Société des Nations que l'on commence à protéger l'enfance sur un plan international, notamment contre les formes modernes de l'esclavage et de la traite » ${ }^{421}$. Déjà en 1919 avec la Société des Nations (SdN), un Comité de protection de l'enfance a été créé. Le 26 septembre 1924, la SdN adopte la Déclaration de Genève sur les droits de l'enfant, texte en cinq articles $^{422}$. Lequel texte a été adopté et ratifié auparavant, respectivement lors du $\mathrm{IV}^{\mathrm{e}}$ et du $\mathrm{V}^{\mathrm{e}}$ Congrès général de l'Union Internationale de Secours aux Enfants tenus respectivement le 23 février 1923 et le 28 février $1924^{423}$. Eglantyne Jebb rédigea en grande partie ce premier texte $^{424}$.

L’adoption par la SdN de ce texte, inspiré des travaux du médecin polonais Janusz KORCZAK

${ }^{415}$ GEANITON, Thierry, op.cit., p. 9.

${ }^{416}$ ROYAL, Ségolène, Les droits de l'enfant, op.cit., p. 22.

417 Lire «Déclaration de Genève sur les droits de l'enfant, 1924 » in http://www.humanium.org/fr/normes/declaration-de-geneve-1924/ (Source consultée le 18 juillet 2015)

${ }^{418}$ Le «Comité International de Secours aux enfants de Berne » continuera ses activités sous la dénomination du «Comité suisse de Secours aux Enfants » après la création de l’Union Internationale de Secours aux Enfants (Save the Children Fund: Central Union) (Voy. Diplomatic documents of Switzerland 1945-1972, Union Internationale de Secours aux Enfants in http://db.dodis.ch/organization/22141 (Source consultée le 18 juillet 2015).

${ }^{419}$ Lire l'Acte portant création de l'Union Internationale de Secours aux Enfants (Save the Children Fund : Central Union) $\quad \mathrm{du}$ 06-08 janvier 1920, Archives $\mathrm{d}^{\prime}$ Etat in http://etat.geneve.ch/dt/archives/union_internationale_secours_aux_enfants-66-2193-1069.html (Source consultée le 18 juillet 2015).

${ }^{420}$ ROYAL, Ségolène, Les droits de l'enfant, op.cit., p. 22.

${ }^{421}$ REUTER, Paul, Préface de l'ouvrage Le Fonds des Nations Unies pour l'enfance (F.I.S.E -U.N.I.C.E.F.), Paris, A. Pedone, 1967, 7(319 p.) ouvrage de Kesera KARUNATILLEKE.

422 Voy. le texte intégral in http://www.humanium.org/fr/normes/declaration-de-geneve-1924/texte-integraldeclaration-de-geneve/ (Source consultée le 18 juillet 2015).

423 Lire «Déclaration de Genève sur les droits de l'enfant, 1924 » in http://www.humanium.org/fr/normes/declaration-de-geneve-1924/ (Source consultée le 18 juillet 2015)

${ }^{424}$ KUPER, Jenny, International law concerning child civilians in Armed conflict, op. cit., p. 41. 
sur le respect de l'identité de l'enfant et de sa dignité ${ }^{425}$, constitue «la première manifestation de la communauté internationale en faveur de l'enfance et [de] la première déclaration des droits de l'homme adoptée par une organisation intergouvernementale, précédant de vingtquatre ans la Déclaration universelle des droits de l'homme ${ }^{426}$. «C'est la guerre qui va susciter sur ce plan, par son horreur même, une prise de conscience de l'opinion internationale ${ }^{427}$ sur la question. Il s'agit là d'un texte déclaratoire destiné à s'appliquer également en temps de paix ${ }^{428}$, cependant, la conjoncture ne permettra pas qu'il soit appliqué.

De la lecture de la Déclaration de Genève de 1924, il y a lieu d'affirmer que ce texte a la particularité de ne faire nullement allusion à l' « Etat » ni expressément aux «droits ». Ce texte déclaratoire met à la disposition des adultes «les hommes et les femmes de toutes les nations», comme le précise son préambule, des devoirs ${ }^{429}$ à accomplir au profit de l'enfant. Lesquels devoirs sont vus néanmoins comme des droits de l'enfant. Les Etats ne se sont obligés à rien en dépit de l'adoption de ce texte. Les promesses de transcription dans leurs législations nationales faites dix ans plus tard, soit en 1934, lors de l'approbation de nouveau de ce texte à l'Assemblée générale de la SdN n'ont pas été suivies d'effet ${ }^{430}$. Cependant, la Déclaration de Genève «n'en constitue pas moins le ferment qui abouti à une protection internationale » ${ }^{431}$.

Toutefois, au lendemain de la Seconde Guerre mondiale, en 1946, l'ECOSOC/NU recommandera en effet que soit reprise la déclaration de 1924. Une fois de plus, la situation de souffrance des enfants durant le second conflit mondial n'était pas innoncente à cette initiative $^{432}$. Des droits et libertés seront implicitement reconnus aux enfants le 10 décembre

\footnotetext{
425 «Histoire des droits de l'enfant» in http://www.humanium.org/fr/histoire-des-droits-de-l-enfant/ (Source consultée le 18 juillet 2015). Janusz KORCZAK est présenté comme celui qui réclama à la SdN dès sa création de se doter d'un instrument juridique de protection de l'enfant. Suivant Ségolène ROYAL, au sujet du droit au respect de l'enfant, Janusz KORCZAK «s'insurge contre la propension des adultes à ne voir les enfants que comme la surface projective de leurs désirs. Il s'oppose à ces deux formes jumelles du déni de l'enfance que sont, d'une part, l'infantilisation, qui ne comprend pas que l'enfant est doué de raison même si sa raison n'est pas celle des adultes, et, d'autre part, la réduction de l'enfant à un brouillon d'adulte, qui fait de son éducation une marche forcée vers un âge qu'il n'a pas à atteindre avant l'heure. Il conteste une éducation qui refuse à l'enfant le droit de vouloir et de progresser, le restreint « à ne pas faire de bruit, ne pas traîner ses souliers, écouter et exécuter les ordres, ne pas critiquer et croire que tous n'ont en vue que son bien » ». "Pour Janusz Korczak, le premier droit de l'enfant est le droit à l'enfance ». Voy. ROYAL, Ségolène, Les droits de l'enfant, op.cit., pp. 25-26.

${ }^{426}$ MARTIN CHENUT, Kathia, « art.cit » in SOREL, Jean-Marc et POPESCU, op.cit., p. 166.

${ }^{427}$ ROUVILLOS, Frédéric, Libertés fondamentales, op.cit., p. 311. Voy. aussi KUPER, Jenny, International law concerning child civilians in Armed conflict, op. cit., p. 41.

${ }^{428}$ KUPER, Jenny, International law concerning child civilians in Armed conflict, op. cit., p. 41.

${ }^{429}$ En termes des devoirs vis-à-vis des «hommes et femmes de toutes les nations », il s'agit de : devoir de développer l'enfant de façon normale matériellement et spirituellement (art. $1^{\mathrm{er}}$ ); devoirs de l'alimentation, de soin et d'encouragement, de recueillir et de secourir l'enfant (art. 2); devoir de privilégier le secours de l'enfant en cas de détresse (art. 3) ; devoir de protection de l'enfant contre l'exploitation (art. 4) et devoir d'élever l'enfant dans des meilleures conditions (art. 5)).

${ }^{430}$ ROUVILLOS, Frédéric, Libertés fondamentales, op.cit., p. 312.

${ }^{431}$ CHAGNOLLAUD, Dominique et DRAGO, Guillaume, Dictionnaire des droits fondamentaux, Dalloz, Paris, 2010 , p. 402.

432 KUPER, Jenny, International law concerning child civilians in Armed conflict, op. cit., p. 41. Kesera KARUNATILLEKE écrit à ce sujet dans sa thèse de doctorat: «Ces problèmes (problèmes de l'enfance), jusqu'alors inaperçus, cachés et ignorés, sont apparus tout soudainement sur la scène mondiale par le déclenchement de la seconde guerre mondiale. Celle-ci, par ses méthodes psychologiques de combat, n'eut pas de précédent dans l'histoire. La peur engendrée par la présence de l'ennemi sur les territoires sous occupation hitlérienne, les moyens psychologique employés pour écraser la résistance de l'adversaire, les massacres des civils, l'élimination entière des peuples et les formes scientifiques de torture qui marquèrent cette guerre, ne furent pas
} 
1948 par la proclamation de la Déclaration universelle des droits de l'homme. Celle-ci reconnaît à l'enfant spécifiquement le droit à une aide et à une assistance spéciales (article 25 $\S 2)$, voire le droit à l'éducation indistinctement de l'adulte (article 26). Cependant, consciente des besoins spécifiques de l'enfant et de son droit à une protection spéciale eu égard à sa vulnérabilité, sa fragilité physique et intellectuelle et sa dépendance, et ne souhaitant pas se contenter d'une déclaration d'ordre général des droits de l'homme, la Commission des questions sociales, estimait que «les besoins de l'enfance justifiaient l'existence d'un instrument qui vienne compléter la Déclaration universelle des droits de l'homme ». C'est dans ce sens que ladite Commission chargera, en 1950, un Comité composé des représentants de l'Australie, du Brésil, de la France, de l'Irak et de la Yougoslavie de préparer un projet de Déclaration des Nations Unies sur les droits de l'enfant, à soumettre au Conseil économique et social qui, après consultation de la Commission des droits de l'homme, le transmettra à 1 'AG/NU ${ }^{433}$

C'est ainsi que, dans ce laborieux jalonnement juridique des droits de l'enfant, une étape particulièrement décisive sera franchie le 20 novembre 1959 avec l'adoption à l'unanimité par l'AG/NU de la Déclaration des droits de l'enfant (résolution 1386 (XIV)) ${ }^{434}$. Il s'agira ici d'un texte proclamant des droits de l'enfant que des règles juridiques qui lui sont applicables par les adultes comme c'est le cas du texte de 1924. Dès l'adoption de cette déclaration, l'AG/NU reconnut que le moyen le plus indiqué pour encourager les nations à réaliser les fins de la Déclaration était le Fonds des Nations unies pour l'Enfance (UNICEF) ${ }^{435}$.

Il est important de préciser que la Déclaration des droits de l'enfant des Nations Unies de 1959,

sans laisser un effet profond sur les esprits des jeunes et des enfants, en particulier. Ayant perdu des millions d'adultes au cours des six années de guerre, le monde a pris conscience de l'importance de la génération à venir pour sauver l'humanité de la dégradation. A la suite de la carence de la génération de guerre, l'enfant est devenu le centre d'attention et l'espoir du monde. Le Préambule de la Charte des Nations Unies déclare solennellement que les peuples des Nations Unies, afin de préserver les générations futures du fléau de la guerre [...] ». Voy. Kesera KARUNATILLEKE, Le Fonds des Nations Unies pour l'enfance (F.I.S.E-U.N.I.C.E.F.), Paris, A. Pedone, 1967, p. 13.

${ }^{433}$ GEANITON, Thierry, op.cit., pp. 9-10.

434 Voy. la Résolution 1386 (XIV) du 20 novembre 1959 «Déclaration des droits de l'enfant» in http://www.un.org/french/documents/ga/res/14/fres14.shtml (Source consultée le 18 juillet 2015).

${ }^{435}$ KARUNATILLEKE Kesera, op.cit., p. 14. L'UNICEF fut créé le 11 décembre 1946 par une résolution adoptée à l'unanimité par l'AG/NU (résolution 57(1)) sous l'appellation de Fonds International de Secours à l'Enfance (FISE) qui venait remplacer l'Administration des Nations Unies pour le Secours et la Reconstruction pour reprendre certaines de ses fonctions. Le FISE s'occupait de la situation des millions d'enfants d'Europe victimes des effets de guerre en leurs distribuant des vivres, médicaments et vêtements. Une fois cette mission terminée, il fut jugé important de recadrer la mission d'un tel organisme sous un angle permanent. Ceci entre autre par le fait que la situation de l'enfant s'est avérée particulièrement choquante dans les conflits extraeuropéens, d'où l'élargissement du champ d'activité de l'UNICEF par l'ONU. Dès 1950, l'UNICEF orientera ses activités vers l'assistance économique et sociale des enfants et mères d'enfants (femmes allaitantes ou enceintes) issus principalement des pays pauvres dits pays en développement. Il réitère cette mission au changement de sa dénomination du Fonds International de Secours à l'Enfance au Fonds des Nations Unies pour l'Enfance par la résolution 802 (VIII) adoptée le 6 octobre 1953 (Voy. \$\$2-3). Alors que Fonds des Nations Unies pour l'Enfance est largement connu par l'acronyme anglais « UNICEF », c'est plutôt le symbole «FISE » qui a été maintenu par la résolution 802 (VIII) (\$3). Actuellement, rien de ce qui touche à l'enfance ne lui est étranger. Lire pour approfondissement KARUNATILLEKE, Kesera, op. cit., pp. 13-18 et GEANITON, Thierry, op.cit., pp. 13-17.; HERMANT, Daniel, «L'espace problématique de la violence politique des enfants », in La violence politique des enfants, Cultures et Conflits, $\mathrm{n}^{\circ} 18$, Paris, L’Harmattan, 1995, p. 181 ou voy. http://www.unicef.org/french/about/history/index_milestones_46_55.html (Source consultée le 31 janvier 2016). 
bien que reconnaissant «que la nécessité de protection spéciale de l'enfant a été énoncée dans la Déclaration de Genève de 1924 sur les droits de l'enfant et reconnue dans la Déclaration universelle des droits de l'homme ainsi que dans les statuts des institutions spécialisées et des organisations internationales qui se consacrent au bien-être de l'enfance » ${ }^{436}$, a le grand avantage de préciser le sens du principe de protection spéciale de l'enfant que l'on ne retrouve pas d'autres textes antérieurs. Comme le feraient d'ailleurs pour le cas des conflits armés, les PA contrairement aux CG (cf. infra). Elle le spécifie en ces termes « [c]onsidérant que l'enfant, en raison de son manque de maturité physique et intellectuelle, a besoin d'une protection spéciale et de soins spéciaux, notamment d'une protection juridique appropriée, avant comme après la naissance $»^{437}$.

On rappellera tout de même que la Déclaration de 1959 se fonde sur la philosophie des droits de l'enfant développée par Locke trois siècles plus tôt. Celle-ci considère l'enfant comme titulaire de droits mais il doit rester sous la tutelle et la protection des parents en raison de son manque de maturité. Cette conception négative de l'enfant n'est pas partagée par Rousseau qui estime que l'enfant est pourvu de raison et des capacités spécifiques liées à son état ${ }^{438}$.

Parallèlement à cette protection s'appliquant généralement en temps de paix, l'idée était aussi celle d'assurer la protection de l'enfance spécifiquement en temps de conflits armés. C'est ainsi qu'en 1939, le CICR et l'Union internationale de Secours aux Enfants vont élaborer un projet de convention pour la protection de l'enfance en temps de conflits armés. Texte dont l'adoption sera empêchée du fait de la Seconde Guerre mondiale. Toutefois, au lendemain de cette guerre, avec l'adoption des CG en 1949 notamment la CG IV sur la protection des personnes civiles, les dispositions de ce projet de 1939 seront reprises par le CICR pour servir la protection spéciale des enfants en temps de guerre ${ }^{439}$ à côté de celle générale qui leur est accordée comme personne civile. La pire expérience vécue par l'enfant durant la Seconde Guerre mondiale ( $c$ f. infra) servira pour beaucoup à la reprise de ce texte en 1949. Il faudra cependant attendre 1977 pour que la protection de l'enfant-combattant soit prise en compte, avec les deux PA.

Par ailleurs, 1974 sera également une année bénéfique pour l'enfant, où son statut en période d'urgence et de conflit armé sera pris en compte. Sur recommandation de l'ECOSOC/NU, l'AG/NU adoptera la Déclaration sur la protection des femmes et des enfants en période d'urgence et de conflit armé en sa résolution 3318 (XXIX) du 14 décembre 1974. Cette déclaration rappelle aux Etats membres des Nations Unies de veiller à observer les CG et autres instruments relatifs aux droits de l'homme applicables en période de conflit armé, lesquels instruments préservent la population civile, particulièrement les femmes et enfants des effets des guerres ${ }^{440}$.

\footnotetext{
${ }^{436}$ Lire le $4^{\mathrm{e}}$ considérant du Préambule de la Déclaration des droits de l'enfant du 20 novembre 1959 la Résolution 1386 (XIV) du 20 novembre 1959 in http://www.un.org/french/documents/ga/res/14/fres14.shtml (Source consultée le 18 juillet 2015).

${ }^{437}$ Lire le $3^{\text {e }}$ considérant du Préambule de la Déclaration des droits de l'enfant du 20 novembre 1959 la Résolution 1386 (XIV) du 20 novembre 1959 in http://www.un.org/french/documents/ga/res/14/fres14.shtml (Source consultée le 18 juillet 2015).

${ }^{438}$ Lire YOUF, Dominique, Penser les droits de l'enfant, P.U.F, 2002, pp. 93-97.

${ }^{439}$ Lire MARTIN CHENUT, Kathia, «art.cit », in SOREL, Jean-Marc et POPESCU, op.cit., 2010, p. 167 et MAYSTRE Magali, op.cit., p. 31.

${ }_{440}$ Voy. les points 1 à 6 de AG/NU, Résolution 3318 (XXIX) du 14 décembre 1974, Déclaration sur la protection
} 
Par ailleurs, la «Déclaration des droits de l'enfant des Nations Unies de 1959 eut peu d'efficacité sur la communauté internationale et fit sentir la nécessité d'un traité plus contraignant $»^{441}$. Afin de marquer le vingtième anniversaire de la Déclaration des droits de l'enfant du 20 novembre 1959 et sensibiliser davantage l'opinion publique sur les questions des droits de l'enfant, l'AG/NU a décidé de désigner l'année 1979 comme étant l'année internationale de l'enfance. « Durant les préparatifs de cette commémoration, le gouvernement polonais prit l'initiative de proposer l'élaboration d'un projet de Convention relative aux droits de l'enfant. Le premier projet a été présenté à la Commission des droits de l'homme en 1978 et une version modifiée le 5 octobre 1979. De sa trente-cinquième (1979) à sa quarantedeuxième session (1986), la Commission des droits de l'homme examina la question ${ }^{442}$. Et 10 ans plus tard, soit 30 ans exactement après l'adoption de la Déclaration de droits de l'enfant de 1959, la Convention des Nations Unies relatives aux droits de l'enfant sera adoptée par la résolution 44/25 de l'AG/NU le 20 novembre 1989, signée à New-York le 26 janvier 1990 et entrée en vigueur le 2 septembre 1990 au regard de son article 49 §1. Pour Mohamed BENNOUNA, il est certain que l'attachement de l'ONU à la célébration des « anniversaires » a joué un rôle non négligeable dans l'accélération de ce processus ${ }^{443}$. Ainsi, « [c]omme pour la Déclaration universelle des droits de l'homme, il appartenait en conséquence aux Nations Unies de traduire en termes contraignants ${ }^{444}$ les "droits" solennellement proclamés par 1'Assemblée générale en $1959 »^{445}$. La Convention relative aux droits de l'enfant se présente à ce jour comme celle la plus ratifiée des Nations Unies à l'exception des Etats-Unis d'Amérique. Le Soudan du Sud, 193è Etat membre de l'ONU depuis le 9 juillet 2011, est devenu le $195^{\mathrm{e}}$ Etat a adhéré à la Convention relative aux droits de l'enfant, le 23 janvier 2015, après l'Etat de Palestine qui l'a fait le 02 avril 2014. La Somalie, qui traînait encore le pas, a finalement ratifié cet instrument le $1^{\mathrm{er}}$ octobre $2015^{446}$.

des femmes et des enfants en période d'urgence et de conflit armé disponible http://www.un.org/french/documents/view_doc.asp?symbol=A/RES/3318(XXIX)\&Lang=F (Source consultée le 22 juillet 2016).

${ }_{441}$ CHAGNOLLAUD, Dominique et DRAGO, Guillaume, Dictionnaire des droits fondamentaux, op.cit., 402.

${ }^{442}$ SCHINDLER, Dietrich et TOMAN, Jiri, Droit des conflits armés, Genève, CICR \& Institut Henry-Dunant, 1996, p. 1023. L'on note qu' «[e]n 1979, un groupe de travail à composition non limitée a été constitué. Ce groupe s'est réuni chaque année durant une semaine précédent les sessions de la Commission des droits de l'homme. Afin d'accélérer les travaux d'élaboration de la nouvelle Convention, des sessions complémentaires ont été organisées en coopération avec des organisations non gouvernementales »., Voir SCHINDLER, Dietrich et TOMAN, Jiri, op.cit.,p. 1023.

${ }^{443}$ BENNOUNA, Mohamed, «La Convention des Nations Unies relative aux droits de l'enfant», in AFDI, XXXV, 1989, p. 433.

${ }_{444}$ Pour l'analyse sur la portée contraignante de la convention relative aux droits de l'enfant, Voy. notamment GRANET, Frédérique, «La Convention de New York sur les droits de l'enfant et sa mise en œuvre en France », in RUBELLIN-DEVICHI, Jacqueline et FRANK, Rainer (dir.), L'Enfant et les Conventions internationales, Presses Universitaires de Lyon, Lyon, 1996, pp. 105-107 ; ou VERHOEVEN, Joe, «La mise en œuvre de la Convention des Nations Unies sur les droits de l'enfant. Observations en droit des gens » in MEULDERSKLEIN, M.T. (dir.), La Convention sur les droits de l'enfant et la Belgique, Kluwer éditions juridiques Belgique, E. Story-scientia, Bruxelles, 1992, p. 62.

${ }_{445}$ VERHOEVEN, Joe, «La mise en œuvre de la Convention des Nations Unies sur les droits de l'enfant. Observations en droit des gens », in MEULDERS-KLEIN, M.T. (dir.), La Convention sur les droits de l'enfant et la Belgique, op.cit., p. 61.

${ }^{446}$ Voy. état de signature, ratification, acceptation, adhésion et succession de la Convention relative aux droits de l'enfant in https://treaties.un.org/Pages/ViewDetails.aspx?src=IND\&mtdsg no=IV-11\&chapter=4\&clang= fr (Source consultée le 13 novembre 2016) 
«A rebours des textes antérieurs axés sur les parents et sur l'Etat, la Convention de New-York choisit l'enfant en dressant un statut juridique de quarante et un articles regroupés ${ }^{447}$ autour des droits civils, des libertés publiques et des droits économiques et sociaux (cf. infra) ${ }^{448}$. « Ainsi, [la $\mathrm{CDE}$ ] constitue une avancée considérable dans l'édification d'un droit de l'enfance, en accordant de véritables droits catégoriels allant à la fois dans le sens de la protection que de l'autodétermination ${ }^{449}$. La CDE consacre donc avec une force juridique contraignante une conception révolutionnaire de l'enfant ${ }^{450}$. Celle qui considère désormais l'enfant comme titulaire des droits ou sujet des droits indépendamment de ses parents. Car depuis toujours les droits de l'enfant ne sont pas envisagés en dehors de ceux de ses parents (objet des droits). L'enfant ne devenait donc titulaire des droits qu'à son accession à la majorité ${ }^{451}$. Et avec la CDE, l'enfant est dorénavant une personne qui «doit se voir reconnaître tous les droits de la personne : [...] la liberté de pensée et de conscience, la liberté d'expression individuelle et collective. L'enfant a une pensée, des affects et des sentiments; il prend part à l'orientation de sa vie et peut prendre des décisions le concernant même s'il ne jouit pas d'une pleine capacité de décision ${ }^{452}$. Ainsi, donc en apportant à l'enfant de moins de dix-huit ans ce qui lui avait toujours fait défaut : des droits et en premier lieu, "le droit à n'être plus un objet » dévolu à l'autorité de ses parents mais un sujet de droit $[\ldots] »{ }^{453}$, la « $[\mathrm{CDE}]$ est apparue extrêmement novatrice ${ }^{454}$.

En dépit de cette réussite, cette conception de l'autonomie de l'enfant n'a non moins suscité de vive polémique. Ainsi, d'aucuns suggéraient la dissolution du système de protection de l'enfant car celui-ci était désormais identifié à l'adulte ${ }^{455}$. Cependant, il y a lieu d'affirmer à la suite de cette pensée qu'élever l'enfant, longtemps considéré comme objet des droits, au rang de sujet des droits est une démarche qui s'inscrit dans le sens « de rechercher le juste équilibre entre les droits dont l'enfant est titulaire et la protection qui lui est due en tant qu'être faible et biodépendant ${ }^{456}$.

Enfin, le fait que ces droits - nouveaux et existants - soient rassemblés dans un seul instrument, au lieu de faire l'objet d'instruments distincts, constitue en outre une originalité ${ }^{457}$.

\section{Section III Notions de recrutement et de participation aux hostilités}

A travers la présente section, essentiellement deux notions seront abordées à savoir la notion de recrutement $(\S 1)$ et celle de participation aux hostilités $(\S 2)$.

\footnotetext{
${ }^{447}$ CHABERT, Cyril « Applicabilité directe et réception de la Convention de New-York », LEBORGNE, Anne, et al. (dir.), La Convention de New-York sur les droits de l'enfant. Vingt ans d'incidences théoriques et pratiques, Presses Universitaires d'Aix-Marseille, 2012, p. 9.

448 Ibid.

${ }^{449}$ ATTAL-GALY, Yaël, Droits de l'homme et catégories d'individus, L.G.D.J-EJA, Paris, 2003, p. 137.

${ }^{450}$ ROSENCZVEIG, Jean-Pierre, Le droit des enfants, éd. Bayard, Paris, 2011, p. 19.

451 PAUVERT, Bertrand et LATOUR, Xavier, Libertés publiques et droits fondamentaux, éd. Studyrama, Levallois-Perret, 2011, p. 56.

${ }^{452}$ ROSENCZVEIG, Jean-Pierre, Le droit des enfants, op. cit., pp.19-20.

${ }^{453}$ ATTAL-GALY, Yaël, Droits de l'homme et catégories d'individus, op. cit. p. 136.

${ }^{454}$ Ibid.

${ }^{455}$ YOUF, Dominique, Penser les droits de l'enfant, op. cit., p. 93 ; ATTAL-GALY, Yaël, Droits de l'homme et catégories d'individus, op. cit., pp. 137-138.

${ }^{456}$ ATTAL-GALY, Yaël, Droits de l'homme et catégories d'individus, op. cit., p. 138.

${ }^{457}$ ERGEC, Rusen et HAPPOLD, Matthew, Protection européenne et internationale des droits de l'homme, $3^{\mathrm{e}}$ éditions, Larcier, Bruxelles, 2014, p. 78.
} 


\section{§1. Notion de recrutement}

Le « recrutement» des enfants de moins de quinze ans par les parties au conflit est interdit par les deux PA (art. 77 §2 du PA I et art. 4 §3-c du PA II). Erigé dans un même esprit que l'article 77 $\S 2$ du PA I au regard notamment des termes utilisés, l'article $38 \S 3$ de la CDE oblige les Etats à s'abstenir d' «enrôler» des enfants de moins de quinze ans dans leurs forces armées. Encore plus précis, le Protocole facultatif se rapportant à la Convention relative aux droits de l'enfant, concernant l'implication d'enfants dans les conflits armés du 25 mai 2000 exige des Etats parties de veiller à ce que les enfants de moins de dix-huit ans ne fassent pas l'objet d' "enrôlement obligatoire » (art. 2). Si son article 3 traite du relèvement de l'âge minimum de l'«engagement volontaire », en revanche son article $4 \S 1$, interdit de manière absolue 1' "enrôlement» des personnes de moins de dix-huit ans aux groupes armés distincts des forces armés. L'interdiction d' "enrôlement » est également repris dans l'article $22 \$ 2$ de la Charte africaine des droits et du bien-être de l'enfant. L'article 3 (a) de la Convention ( $n^{\circ} 182$ ) concernant l'interdiction des pires formes de travail des enfants et l'action immédiate en vue de leur élimination du 17 juin 1999 utilise l'expression "recrutement forcé ou obligatoire » des enfants en vue de leur utilisation dans les conflits armés comme une des pires formes de travail des enfants. Enfin, le Statut de Rome érige en crimes de guerre la «conscription » ou l'«enrôlement» des enfants de moins de quinze ans dans les forces armées nationales ou dans les groupes armés pour une participation active aux hostilités (cf. art. 8-2-b-xxvi et art. 8-2-e-vii).

Il y a lieu de se demander si tous ces termes utilisés dans ces différents instruments revêtent la même signification. D'où l'intérêt de les analyser.

Dorénavant, il est important de rappeler l'article $31 \S 1^{\text {er }}$ de la Convention de Vienne sur le droit des traités selon lequel « $[\mathrm{u}] \mathrm{n}$ traité doit être interprété de bonne foi suivant le sens ordinaire à attribuer aux termes du traité dans leur contexte et à la lumière de son objet et de son but ». Il s'agit donc d'interprétation textuelle (sens ordinaire des termes du traité), contextuelle (contexte) et téléologique (objet et but du traité). Ainsi, au regard de la CIJ, chaque fois que cela est possible, «les mots doivent être interprétés de manière à avoir un effet utile ${ }^{458}$. En d'autres termes, l'interprétation ne doit pas vider la disposition conventionnelle concernée de toute sa substance ou de toute son utilité. En revanche, elle doit viser à la rendre effective. C'est dans ce sens que la CIJ indiquait que «[1]e principe d'interprétation exprimé par la maxime ut res magis valeat quam pereat, principe souvent désigné sous le nom de principe de l'effet utile, ne saurait autoriser la Cour à entendre la clause de règlement des différends insérée dans les traités de paix dans un sens qui [...] contredirait sa lettre et son esprit ${ }^{459}$. En même temps, il est plus qu'important de tenir compte des conditions actuelles. C'est l'essence même de l'interprétation évolutive.

En effet, au sujet du « recrutement » utilisé dans l'article $77 \S 2$ du PA I, la Commission III de la

\footnotetext{
${ }^{458} \mathrm{CIJ}$, Affaire relative à l'Application de la Convention internationale sur l'élimination de toutes les formes de

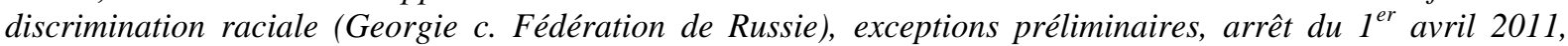
Recueil 2011, p. 126, § 134.

${ }^{459}$ CIJ, Affaire relative à l'Interprétation des traités de paix conclu avec la Bulgarie, la Hongrie et la Roumanie (deuxième phase), Avis consultatif du 18 juillet 1950, Recueil 1950, p. 229.
} 
Conférence diplomatique de 1974-1977, à ce propos, renseignait que l'interdiction d' «engagements volontaires » des enfants de moins de quinze n'est plus expressément mentionnée car cela ne serait pas réaliste ${ }^{460}$. Le «recrutement» en ce sens équivaudrait au « recrutement forcé » et non à l'«engagement volontaire ». Le commentaire précise tout de même à cet égard que «[1]es autorités militaires ou civiles trouveront dans la présente disposition un motif très valable de refuser les engagements volontaires des mineurs de moins de quinze ans $[\ldots]{ }^{461}$. En revanche, le terme « recrutement» utilisé dans l'article 4 \$3-c du PA II se fonde, suivant le commentaire, sur le "principe de non-recrutement dans les forces armées », lequel comprend outre le recrutement forcé ou obligatoire, l' «enrôlement volontaire». Cette interdiction s'étend également à l'« autorisation à prendre part aux hostilités » ${ }^{462}$ (cf. infra).

Par ailleurs, au sujet de nombreuses conventions internationales adoptées depuis les PA, interdisant le recrutement des enfants, la Chambre préliminaire I de la Cour pénale internationale (CPI) indique que «[1]'étude de ces instruments internationaux et des deux Protocoles additionnels révèle qu'une distinction peut être faite quant à la nature même du recrutement, ce dernier pouvant être forcé ou volontaire ${ }^{463}$.

Ainsi, quand la CDE indique que les Etats s'abstiennent d' «enrôler » des enfants de moins de quinze ans, l'enrôlement dans ce cadre est synonyme du terme générique «recrutement». L'expression «recruiting » employée dans la version anglaise de cet article est encore plus significative. L'historique de la rédaction de la $\mathrm{CDE}$ atteste que certaines délégations suggéraient de remplacer «enrôlement » ou «recrutement» par « recrutement obligatoire» ou «conscription» et de faire la différence entre «engagement volontaire» par l'école militaire et «recrutement obligatoire» - comme cela a été fait plus tard dans le Protocole facultatif se rapportant à la Convention relative aux droits de l'enfant, concernant l'implication d'enfants dans les conflits armés. Comme ces idées n'ont pas été suivies, le Commentateur conclut que le terme " recrutement » au sens de l'article $38 \S 3$ de la $\mathrm{CDE}$ est perçu comme terme générique censé englober à la fois le «recrutement obligatoire et volontaire », ou à la fois la «conscription » et l' « enrôlement ${ }^{464}$ comme dans le cadre du Statut de Rome (cf. infra). Ce qui est d'ailleurs conforme au sens ordinaire de ce terme ${ }^{465}$. Cette interprétation est suivie par le Comité des droits

\footnotetext{
${ }^{460}$ PILLOUD, Claude et DE PREUX, Jean, Commentaire de l'article 77 du Protocole I Protection des enfants, paragraphe 3, in SANDOZ, Yves, SWINARSKI, Christophe et ZIMMERMANN, Bruno (éd. et Coord.), Commentaire des Protocoles additionnels du 8 juin 1977 aux Conventions de Genève du 12 août 1949, op. cit.,pp. 924-925.

${ }^{461}$ Ibid., p. 925.

462 JUNOD, Sylvie-S., Commentaire de l'article 4 du Protocole II -Garanties fondamentales, paragraphe 3, alinéa c, in SANDOZ, Yves, SWINARSKI, Christophe et ZIMMERMANN, Bruno (éd. et Coord.), Commentaire des Protocoles additionnels du 8 juin 1977 aux Conventions de Genève du 12 août 1949, op.cit., p. 1404.

${ }^{463}$ CPI, Le Procureur c. Thomas Lubanga Dyilo, Chambre préliminaire I, décision sur la confirmation des charges $\mathrm{N}^{\circ}$ ICC-01/04-01/06, 29 janvier 2007, p. 71, § 245.

${ }^{464}$ ANG, Fiona, «Article 38. Children in Armed Conflicts », in ALEN, André, et al., (éd.), A commentary on the United Nations Convention on the Rights of the Child, Martinus Nijhoff Publishers, Leiden, 2005, pp. 48-49. Lire aussi la page 50.

465 Suivant son sens ordinaire, le recrutement est appréhendé comme l' « [a]ction de recruter des hommes de troupe; [1]'ensemble des opérations destinées à fournir à l'armée son personnel ». Voy. http://www.cnrtl.fr/definition/recrutement (Source consultée le 12 septembre 2016).
} 
de l'enfant ${ }^{466}$. Le Tribunal spécial pour la Sierra Leone (TSSL) va également dans le même sens et considère d'ailleurs la distinction entre ces deux formes de recrutement - «enrôlement volontaire » et «enrôlement forcé »- comme artificielle ${ }^{467}$. L'interprétation du Protocole facultatif se rapportant à la Convention relative aux droits de l'enfant, concernant l'implication d'enfants dans les conflits armés, sous cet aspect, s'alignera dans le même sens.

En effet, le terme «enrôlement» employé au niveau de l'article $4 \S 1$ du Protocole facultatif se rapportant à la Convention relative aux droits de l'enfant, concernant l'implication d'enfants dans les conflits armés inclut l'«enrôlement obligatoire » et l' "enrôlement volontaire ». On imagine mal que les Etats s'interdisent l'«enrôlement obligatoire » et l'autorisent aux groupes armés. Ainsi, l' «enrôlement» dans ce sens n'est donc pas synonyme d' «enrôlement » tel que formulé par le Statut de Rome. Lequel voudrait simplement dire « recrutement volontaire » (cf. infra). Ce terme «enrôlement» est donc synonyme de «recrutement» tel qu'employé par l'article 4 §3-c du PA I, c'est-à-dire recrutement obligatoire ou forcé, et recrutement volontaire $^{468}$. Le commentaire sur cette disposition mentionne clairement : « [a]rticle 4 does not distinguish between voluntary and compulsory recruitment, thus covering both. It also include cross-border recruitment, which is often practised by rebel groups ${ }^{469}$. Dans cette même optique, Joël MERMET écrit que «[1]'article 4 du Protocole facultatif, quand bien même il utilise une formule au conditionnel, soumet les groupes armés à des obligations plus fortes que celles imposées aux Etats parties. En effet, les groupes armés ne sont pas autorisés à recruter des personnes de moins de 18 ans que ce soit par conscription ou de manière volontaire et ne doivent pas les utiliser dans les hostilités que ce soit de manière directe ou indirecte ${ }^{470}$.

Que dire de l'article $22 \S 2$ de la Charte africaine des droits et du bien-être de l'enfant qui utilise ce même terme?

L' «enrôlement» des enfants qu'interdit l'article $22 \S 2$ de la Charte africaine des droits et du bien-être de l'enfant sous-entend également « recrutement» au sens générique. L'obligation formulée par cette disposition s'impose de manière absolue. Il nous paraît insoutenable d'une part que cette disposition soit comprise comme se limitant à interdire le «recrutement volontaire » des enfants en exigeant des Etats des mesures nécessaires et d'autre part que soit autorisé le « recrutement obligatoire ». Bien plus, en prenant en considération le fait que les Etats parties à cette convention réaffirment « leur adhésion aux principes des droits et de la protection de l'enfant consacrés [...] notamment à la $[\mathrm{CDE}]{ }^{471}{ }^{4}$, il y a lieu de penser que sont pris en

\footnotetext{
${ }^{466}$ ANG, Fiona, «Article 38. Children in Armed Conflicts », in ALEN, André, et al., (éd.), A commentary on the United Nations Convention on the Rights of the Child, Martinus Nijhoff Publishers, Leiden, 2005, pp. 47-48.

${ }^{467}$ Voy. TSSL, Prosecutor against Moinina Fofana, Allieu Kondewa, Case n ${ }^{\circ}$ SCSL-04-14-T, Trial Chamber I, judgement, 2 août 2007, p. 58, § 192 .

${ }_{468}$ Lire Coalition contre l'utilisation d'enfants soldats et UNICEF, Guide du Protocole facultatif concernant l'implication d'enfants dans les conflits armés, UNICEF, New-York, mai 2004, p. 17.

469 VANDEWIELE, Tiny, «Optional Protocol: The involvement of Children in Armed conflicts », in ALEN, André, et al., (éd.), A commentary on the United Nations Convention on the Rights of the Child, Martinus Nijhoff Publishers, Leiden, 2006, p. 41.

${ }^{470}$ MERMET, Joel, «Protocole facultatif à la Convention relative aux droits de l'enfant concernant l'implication d'enfants dans les conflits armés : quel progrès pour la protection des droits de l'enfant ? », in Actualité et droit international. Revue d'analyse juridique de l'actualité internationale, Juin 2002, p. 6, disponible sur http://www.ridi.org/adi/articles/2002/200206mer.htm (Source consultée le 12 avril 2015).

${ }^{471}$ Lire le $9^{\text {e }}$ considérant du Préambule de la Charte africaine des droits et du bien-être de l'enfant du 11 juillet
} 
compte sous cet article le «recrutement obligatoire (ou forcé) et volontaire ». Et comme le mentionne le Commentateur de l'article 38 de la CDE, l'article 22 précité est dans une large mesure similaire à l'article $38^{472}$. Ce qui pousse davantage à penser à la reconduction de l'interprétation du terme «enrôlement » développée ci-dessus.

Enfin, concernant les expressions employées par le Statut de Rome, la Chambre préliminaire « est d'avis que la « conscription » et « l'enrôlement» sont deux formes du recrutement, la « conscription » constituant un recrutement forcé tandis que «l'enrôlement » se réfère davantage à un recrutement volontaire. La Chambre souligne à cet égard qu'il s'agit là d'une distinction qui a également été opérée par le juge Robertson dans son opinion individuelle jointe à l'arrêt rendu par la Chambre d'appel du Tribunal spécial pour la Sierra Leone le 31 mai 2004 dans l'affaire Le Procureur c. Sam Hinga Norman ${ }^{473}$. Il est également dit que la conscription incorpore le recrutement obligatoire - entendu comme recrutement forcé par la loi - et le recrutement forcé - vu comme recrutement lié à la contrainte (ex : enlèvement $)^{474}$. Ceci résout également la question de l'article 3 (a) de la Convention ( ${ }^{\circ} 182$ ) concernant l'interdiction des pires formes de travail des enfants et l'action immédiate en vue de leur élimination du 17 juin 1999 qui utilise l'expression « recrutement forcé ou obligatoire».

Pour tout dire, en dépit des divergences des termes employés, il y a lieu de dire que les clauses de sauvegarde ${ }^{475}$ insérées dans ces différents instruments juridiques permettront de laisser place à des instruments utilisant des termes plus protecteurs d'enfants.

Par ailleurs, si la différence entre « recrutement volontaire » et « recrutement forcé » semble clairement établie en théorie, elle est réellement et fréquemment moins perceptible en situation de conflits armés ${ }^{476}$. La deuxième partie de ce travail tentera de le démontrer.

Un enfant « recruté » est appelé à prendre part aux hostilités. Que comprendre de la participation aux hostilités?

\section{§2. Notion de participation aux hostilités}

Avant d'aborder la question proprement dite de participation aux hostilités (B) sous les angles de participation directe, indirecte ou active, le présent paragraphe définira de prime abord le terme « hostilités » (A).

\footnotetext{
1990.

${ }^{472}$ ANG, Fiona, « Article 38. Children in Armed Conflicts », « art. cit. », p. 5.

${ }^{473}$ CPI, Le Procureur c. Thomas Lubanga Dyilo, Chambre préliminaire I, décision sur la confirmation des charges $\mathrm{N}^{\circ}$ ICC-01/04-01/06, 29 janvier 2007, p. 71, § 246.

${ }^{474}$ Lire MAYSTRE, Magali, pp. 25 et 153.

${ }^{475}$ Voy. par exemple, les articles 41 de la CDE, 5 du Protocole facultatif à la Convention relative aux droits de l'enfant concernant l'implication d'enfants dans les conflits armés, $1^{\text {er }} \S 2$ de la Charte africaine des droits et du bien-être de l'enfant, etc.

${ }^{476}$ BUGNION, François, «Les enfants soldats, le droit international humanitaire et la Charte africaine des droits et du bien-être de l'enfant », in Revue Africaine de droit international et comparé, « art. cit. », p. 262.
} 


\section{A. Notion d'hostilités}

Une des expressions de base du DIH, le terme «hostilités» est utilisé dans différents instruments juridiques qui se préoccupent de la réglementation des conflits armés ${ }^{477}$ sans y être toutefois défini. «[S]ouvent employé pour désigner le conflit lui-même (ouverture des hostilités, suspension des hostilités, etc.) ${ }^{478}$, il est appréhendé par le Dictionnaire de droit international public comme un «[e]nsemble des actes offensifs ou défensifs et des opérations militaires accomplis par un belligérant dans le cadre d'un conflit armé ${ }^{479}$. Cette définition rejoint en partie celle d' « attaques » que fournit l'article 49 §1, du PA I. Ce dernier entend par «attaques », « des actes de violence contre l'adversaire, que ces actes soient offensif ou défensifs ». Et le terme « opérations militaires », compris dans cette définition désigne, pour sa part, "tous les mouvements et actions en rapport avec les hostilités accomplis par les forces armées ${ }^{480}$. Cette dernière définition vaut également pour le mot «opération» qui doit être compris comme « opération militaire ». Il s'est agi d'une omission du qualificatif « militaire » dans le cadre de l'article 48 du PA I qui l'utilise ${ }^{481}$. Ainsi, partant de la définition du Dictionnaire de droit international public, il est clair que les «attaques» et «opérations militaires» font partie des

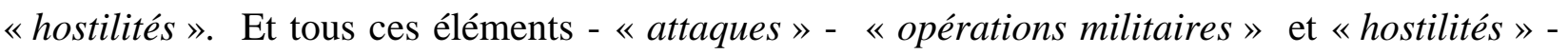
sont compris dans un cadre plus large qui est le «conflit armé » (cf. infra). Le terme «hostilités » n'est donc pas synonyme de « conflit armé ».

Dans le même ordre d'idées, pour le CICR, par "hostilités», il faut entendre le «recours (collectif) par les parties au conflit à des méthodes et moyens de nuire à l'ennemi ${ }^{482}$. Se référant au recours collectif à l'opposé du caractère individuel que revêt la participation aux hostilités, le concept «hostilités » se présente donc comme l'ensemble de tous les actes hostiles des personnes participant directement aux hostilités ${ }^{483}$. Et c'est dans cette même logique que le Commentaire des PA du CICR appréhende le terme «actes d'hostilités » comme des « actes qui, par leur nature et leur but, sont destinés à frapper concrètement le personnel et le matériel des forces armées ${ }^{484}$. D'ailleurs, différentes décisions du TPIR, ci-dessous reprises, sur la participation directe aux hostilités confirment ce dernier point de vue (cf. point B).

\footnotetext{
${ }^{477}$ Voy. par exemple, le titre même de la Convention III de La Haye du 18 octobre 1907 - Convention (III) relative à l'ouverture des hostilités (nous soulignons) -, son article $1^{\mathrm{er}}$; la Section II Des hostilités de la Convention (IV) de La Haye ; les articles 67 et 118 de la CG III de même que l'intitulé de la Section II du titre IV de ladite Convention; les articles 49 (alinéa 2), 130 (alinéa 3), 133 (alinéas 1 et 3 ) et 134 de la CG IV ; les articles $31 \S 4,33,34,40,43 \S 2,44 \S 3,45,47 \S 1 b$ et $c, 49 \S 4 ; 51 \S 3,53 a, 56 \S 5,59 \S 2 c, 60 \S \S 2$ et $3 c ; 61 a$, $67 \S 1 e, 73,77 \S 2$ du PA I ; les articles 4-\$§1, $2 c, d$ et $e, 6 \S 5,13 \S 3,16$ du PA II, etc.

${ }^{478}$ SALMON, Jean, (dir.), Dictionnaire de droit international public, op. cit., p. 550.

${ }^{479}$ Ibid.

480 Commentaire de l'article 51, 11 , du PA I, p. 631, $\$ 1936$ disponible sur https://ihldatabases.icrc.org/applic/ihl/dih.nsf/Comment.xsp?action=openDocument\&documentId=F18532328D8075E0C1 2563BD002D9397 (Source consultée le 29 juillet 2016).

${ }_{481}$ Voy. Le Commentaire de l'article 48 du PA I, p. 611, $\$ 1875$ disponible sur https://ihldatabases.icrc.org/applic/ihl/dih.nsf/Comment. $x$ sp? action=openDocument \&documentId=3589F184685802A4C1 2563BD002D9141 (Source consultée le 29 juillet 2016).

${ }^{482}$ MELZER, Nils, Guide interprétatif sur la notion de participation directe aux hostilités en droit international humanitaire, CICR, Genève, octobre 2010, p. 45.

${ }^{483}$ Ibid., p. 46.

484 Commentaire de l'article 51, $\$ 3$, du PA I, p. 633, $\$ 1942$ disponible sur https://ihldatabases.icrc.org/applic/ihl/dih.nsf/Comment.xsp?action=openDocument\&documentId=F18532328D8075E0C1 2563BD002D9397 (Source consultée le 29 juillet 2016).
} 
Au cours des débats, pour différentes délégations à la conférence diplomatique de 1974-1977, l'expression «hostilités» «couvrait les préparatifs du combat et le retour du combat » ${ }^{485}$ (cf. infra, point B). A la suite des débats sur la participation individuelle aux hostilités (cf. infra), il s'est révélé « que le mot «hostilités» ne couvre pas seulement le temps où le civil se sert d'une arme, mais aussi, par exemple, le temps pendant lequel il la porte, ainsi que les situations où le civil se livre à des actes hostiles sans se servir d'une arme ${ }^{486}$.

\section{B. Notion de participation directe aux hostilités}

Chercher à analyser le contenu de «participation directe aux hostilités » permet par ricochet de comprendre différentes autres notions qui s'y rattachent. En effet, l'étude de la notion de «participation directe aux hostilités » que se propose cette partie permet également de saisir la portée des notions de participation indirecte ou de participation active aux hostilités voire de participation aux hostilités simplement. Ainsi, cette question principale sera abordée successivement sous l'angle de la position conventionnelle et doctrinale, jurisprudentielle et étatique.

\section{Position conventionnelle et doctrinale}

«La notion de participation directe aux hostilités découle de la formule «qui ne participent pas directement aux hostilités » utilisée à l'article 3 commun aux Conventions de Genève » ${ }^{487}$. Si l'on reconnaît qu'il n'existe aucune définition précise en DIH de l'expression «participation directe aux hostilités », cependant il y a lieu de déterminer avec plus de certitude, les éléments constitutifs de cette expression ${ }^{488}$. Ainsi, suivant l'étude du CICR sur la question, la «participation directe aux hostilités » est constituée du seuil de nuisance, de la causation directe ou lien direct de causalité et du lien de belligérance ${ }^{489}$. Le seuil de nuisance se traduit par des dommages affectant les opérations ou capacités militaires d'une partie au conflit, par des pertes en vies humaines, des blessures et des destructions des biens protégés $^{490}$. La causation directe ou le lien direct de causalité, comme le mot l'indique, explique le lien entre les actes hostiles ci-haut énumérés et les dommages occasionnés ${ }^{491}$. Enfin, le lien de belligérance « requiert que l'acte en cause vise à préjudicier une partie et à avantager l'autre ${ }^{492}$.

\footnotetext{
485 Commentaire de l'article 51, $\$ 3, \quad$ du $\quad$ PA I, p. 633, $\S 1943$ disponible sur https://ihldatabases.icrc.org/applic/ihl/dih.nsf/Comment.xsp?action=openDocument\&documentId=F18532328D8075E0C1 2563BD002D9397 (Source consultée le 29 juillet 2016).

486 Commentaire de l'article 51, $33, \quad$ du PA I, p. 633, § 1943 disponible sur https://ihldatabases.icrc.org/applic/ihl/dih.nsf/Comment.xsp?action=openDocument \&documentId=F18532328D8075E0C1 2563BD002D9397 (Source consultée le 29 juillet 2016).

${ }^{487}$ MELZER, Nils, Guide interprétatif sur la notion de participation directe aux hostilités en droit international humanitaire, op. cit., p. 45.

${ }^{488}$ MOMTAZ, Djamchid, «La participation directe des personnes civiles aux hostilités », « art.cit. », p. 493.

${ }^{489}$ MELZER, Nils, Guide interprétatif sur la notion de participation directe aux hostilités en droit international humanitaire, op.cit., 48.

${ }^{490}$ Voy. DAVID, Eric, Principes de droit des conflits armés, 5è édition, op.cit., pp. 285-286.

${ }^{491}$ Voy. Ibid., p. 286.

${ }^{492}$ Voy. Ibid.
} 
Il y a lieu d'ajouter au-delà de ce qui précède que l'accent se trouve mis sur la nature hostile de l'acte accompli par le civil. Les actes constitutifs de participation directe aux hostilités sont des véritables actes de guerre, lesquels visent à frapper concrètement, à causer des dommages réels au personnel ou aux matériels des forces armées ennemies. Ce qui exclut les actes contribuant à l'effort de guerre généralement apportés de différentes manières par la population civile ou les personnes civiles vis-à-vis d'une partie au conflit. Ainsi, l'intérêt accordé à la nature hostile de l'acte, le lieu et le moment de la commission de l'acte en question importent peu ${ }^{493}$. Et ce quand bien même il soit dit que la participation directe « implique un lien direct de cause à effet entre l'activité exercée et les coups portés à l'ennemi au moment où cette activité se produit et là où elle s'exerce ${ }^{494}$. Par ailleurs, si l'on s'en tient à la nature de l'acte, c'est notamment par le fait de la participation intermittente du civil aux hostilités. Ainsi, le civil ne sera donc attaqué que pendant le moment de sa participation aux hostilités, période qui couvre celle de la préparation au combat et celle de chemin de retour après la commission de l'acte hostile ${ }^{495}$. Le civil ne se trouve donc pas dans l'hypothèse d'une "fonction continue » au sein d'une force armée ou d'un groupe armé pour être attaqué à tout moment aussi longtemps que son appartenance à cette force ou ce groupe armé ${ }^{496}$. Il ne bénéficiera donc pas du statut de prisonnier de guerre s'il tombe au pouvoir d'une partie ennemie dans le cadre d'un CAI car ne répondant pas aux critères de combattant ${ }^{497}$. Toutefois, le droit international rejetant complètement le droit de disposer arbitrairement du sort des simples particuliers et n'autorisant contre eux ni mauvais traitements ni violences ${ }^{498}$, le civil participant directement aux hostilités dans le cadre d'un CAI bénéficiera des garanties fondamentales qu'impose notamment l'article $75 \mathrm{du}$ PA I. Il y est fait obligation aux parties au conflit de les «traiter avec humanité en toutes circonstances». Il sied de signifier en passant qu'en dépit de l'incertitude quant au champ d'application rationae personae de cette disposition, on s'accorde d'affirmer que sur base de l'article 72 du PA I, l'article 75 s'interprétera de «façon à inclure également les ressortissants de la partie contractante appliquant les dispositions de l'article en question » voire d'autres ${ }^{499}$. Position que défend la Finlande $^{500}$. Il s'agit là d'un ensemble de garanties que l'on retrouve également dans le cadre d'un CANI dont l'article 3 commun aux quatre CG. Il va sans dire également que les droits de l'homme et le droit national concerné s'appliqueront à l'endroit d'une telle personne qui participerait directement aux hostilités. Ce qui n'exclurait toutefois pas l'hypothèse d'infraction pénale à l'ordre public national dans le cadre notamment du CANI en application du droit national.

\footnotetext{
${ }^{493}$ MOMTAZ, Djamchid, « La participation directe des personnes civiles aux hostilités », « art.cit. », p. 494.

${ }^{494}$ Voy. HAROUEL-BURELOUP, Véronique, op.cit., 304. ; LARRALDE, Jean-Manuel, « Les réponses du droit international à la question des enfants soldats », « art.cit. », pp. 70-71.

${ }^{495}$ MOMTAZ, Djamchid, « La participation directe des personnes civiles aux hostilités », « art.cit. », p. 495.

${ }^{496}$ DAVID, Eric, Principes de droit des conflits armés, 5è édition, op.cit., p. 287.; MOMTAZ Djamchid, « La participation directe des personnes civiles aux hostilités », «art.cit. », p. 494.

${ }^{497}$ Voy. l'article 4 de la CG III.

${ }^{498}$ PICTET, Jean, Les Principes du droit international humanitaire, op.cit., p. 29.

499 GAUDREAU, Julie, «Les réserves aux Protocoles additionnels aux Conventions de Genève pour la protection des victimes de la guerre », in RICR, n ${ }^{\circ} 849$, mars 2003, p.176.

${ }^{500}$ Ibid.
} 


\section{Position jurisprudentielle}

Les statuts des juridictions pénales internationales sont évolutifs sur la question de protection de l'enfant. C'est la notion la plus protectrice de «participation active» qui s'y trouve développée. Celle-ci inclut la notion de «participation directe». Le Statut de Rome consacre cette notion en son article $8 b$ (xxvi) et $e$ (vii). Au regard de ces deux dispositions, « le fait de procéder à la conscription ou à l'enrôlement d'enfants de moins de 15 ans dans les forces armées ou dans des groupes armés ou de les faire participer activement à des hostilités » est constitutif de crimes de guerre en CAI et en CANI (nous soulignons). Le Statut du Tribunal Spécial pour la Sierra Léone reprend cette notion en son article $4 c$ en ces termes : «[1]e Tribunal spécial est habilité à juger les personnes accusées d'avoir commis les violations graves ci-après du droit international humanitaire: [...] c) recrutement et enrôlement d'enfants âgés de moins de 15 ans dans des forces ou groupes armés en vue de les faire participer activement aux hostilités $»^{501}$ (nous soulignons). Il va sans dire que ces deux textes sont identiques sur ce point ${ }^{502}$. Cette notion de «participation active» est encore plus explicite dans le premier jugement de la CPI dans l'affaire le Procureur contre Thomas Lubanga Dyilo.

En effet, si la défense dans l'affaire Le Procureur c. Thomas Lubanga Dyilo devant la CPI soutenait que la notion de participation active est synonyme à la participation $\operatorname{directe}^{503}$, la Chambre préliminaire a jugé que :

«participer activement » à des hostilités signifie non seulement une participation directe aux hostilités, c'est-à-dire aux combats, mais couvre également le fait de participer activement à des activités en rapport avec les combats, telles que la reconnaissance, l'espionnage, le sabotage, ainsi que l'utilisation d'enfants comme leurres ou messagers ou leur utilisation aux postes de contrôle militaire. Selon la Chambre préliminaire, le fait de garder des objectifs militaires ou d'exercer les fonctions de garde du corps sont également des activités en rapport avec les hostilités, notamment lorsqu' « elles ont un impact direct sur le niveau de ressources logistiques et sur l'organisation des opérations nécessaires pour l'autre partie au conflit» ${ }^{504}$.

«En outre, la Chambre préliminaire a considéré que les enfants affectés à des activités qui sont « manifestement sans lien avec les hostilités», telles que « la livraison de denrées alimentaires à une base aérienne ou l'emploi de personnel domestique dans les quartiers réservés aux officiers mariés », ne participent pas activement aux hostilités $»^{505}$.

Rappelons que 1'expression "participation active aux hostilités » a fait, depuis 1969, l'objet de débats dans de multiples réunions d'experts du $\mathrm{CICR}^{506}$. En 1970, la résolution 2675 de l'AG/NU

$501 \quad$ Article 4 c $\quad \mathrm{du}$ Statut du Tribunal Spécial pour la Sierra Léone in https://www.icrc.org/applic/ihl/dih.nsf/Treaty.xsp?documentId=0D909D3998AA71A9C1256BAD0027E08F\&a ction=openDocument (Source consultée le 14 juillet 2015).

${ }^{502}$ CPI, Le Procureur c Thomas Lubanga Dyilo, affaire N ${ }^{\circ}$ ICC-01/04-01/06, jugement du 14 mars 2012, p. 311, $\S 624$.

${ }_{503}^{50 y . ~ I b i d ., ~ p . ~ 293, ~} \$ 584$.

504 Ibid., p. 311, §622.

${ }^{505}$ Ibid., $\$ 623$.

${ }^{506}$ MALLEIN, Jean, La Situation juridique des combattants dans les conflits armés non internationaux, Thèse 
a substitué cette expression à celle de participation directe ${ }^{507}$. Au regard du TPIR, ces formules sont tellement identiques qu'elles sont utilisées comme synonymes ${ }^{508}$. C'est dans cette logique qu'il affirme dans l'affaire Le Procureur c. Ignace Bagilishema que «participer directement ou activement aux hostilités, c'est commettre des actes qui, par leur nature ou objectif, sont susceptibles de causer des préjudices au personnel et au matériel des forces armées ${ }^{509}$ (nous soulignons). Toutefois, dans d'autres décisions ${ }^{510}$, le TPIR se limiterait à définir la «participation directe » sans faire allusion à la participation active. C'est notamment dans l'affaire Le Procureur c. Laurent Semanza qu'il décide que « participer directement aux hostilités [...], c'est commettre des actes de nature à frapper concrètement le personnel ou le matériel des forces armées de l'adversaire $»^{511}$.

Par ailleurs, dans le même ordre que la position adoptée par la CPI, il est affirmé que la «participation active » est à considérer comme la conception extensive du caractère direct de la participation aux hostilités. Et la «participation directe» elle-même doit être prise comme la conception restrictive dudit caractère ${ }^{512}$. Suivant la conception restrictive, motivée par des raisons humanitaires, l'engagement physique dans les combats est le seul critère déterminant. En cela, seuls les enfants (civils) qui participent directement aux hostilités perdent leur immunité de protection. La «participation active », quant à elle, supposerait « une attitude active, par rapport à une attitude passive ${ }^{513}$. Ce qui engloberait un nombre important des civils ${ }^{514}$. En clair, «[a]lors que l'expression «les personnes ne participant pas directement aux hostilités » fixe [...] le rapport de causalité adéquate entre l'acte de participation et son résultat immédiat dans les opérations militaires, le terme «activement» établirait le rapport de causalité entre l'acte de participation et son effet sur le déroulement du conflit dans son ensemble. C'est-à-dire son issue, et non pas sur celle de tel ou tel engagement armé » ${ }^{515}$.

de doctorat d'Etat en Droit, Université de Grenoble, 1978, p. 74.

${ }^{507}$ Ibid., L'article 2 de la Résolution 2675 (XXV) du 9 décembre 1970 de l'AG/NU dispose : « Dans la conduite des opérations militaires en période de conflit armé, une distinction doit toujours être faite entre les personnes qui prennent part activement aux hostilités et les populations civiles» (Nous soulignons). Voir cette résolution sur http://www.un.org/french/documents/ga/res/25/fres25.shtml (Source consultée le 16 avril 2016).

508 TPIR, Le Procureur c. Jean-Paul AKAYESU, Affaire n' ${ }^{\circ}$ CTR-96-4-T, jugement, Chambre de première instance I, 2 septembre 1998, p. 255, \$629. (Jugement également disponible sur http://ictrarchive09.library.cornell.edu/FRENCH/cases/Akayesu/judgement/contents.html (Source consultée le 9 mai 2016).

${ }_{509}$ TPIR, Le Procureur c. Ignace BAGILISHEMA, Affaire n ${ }^{\circ}$ ICTR-95-1A-T, jugement, Chambre de première Instance I, 7 juin 2001, $\$ 104 \quad$ disponible $\quad$ sur http://ictrarchive09.library.cornell.edu/FRENCH/cases/Bagilishema/judgement/index.html (Source consultée le 9 mai 2016).

510 Voy. TPIR, Le Procureur c. Laurent SEMANZA, Affaire n ${ }^{\circ}$ ICTR-97-20-T, jugement et sentence, Chambre de première Instance III, 15 mai 2003, p. 101, §366 ; TPIR, Le Procureur c. Georges Anderson NDERUBUMWE RUTAGANDA, Affaire n ${ }^{\circ}$ ICTR-96-3-T, jugement et sentence, Chambre de première instance I, 6 décembre 1999, $\$ 100$ et TPIR, Le Procureur c. Alfred MUSEMA, n ${ }^{\circ}$ ICTR-96-13-T, jugement et sentence, Chambre de première instance I, 27 janvier 2000, \$279.

511 TPIR, Le Procureur c. Laurent SEMANZA, Affaire ${ }^{\circ}$ ICTR-97-20-T, jugement et sentence, Chambre de première Instance III, 15 mai 2003, p. 101, §366.

512 Voy. MALLEIN, Jean, La Situation juridique des combattants dans les conflits armés non internationaux, op.cit., 70-76.

${ }^{513}$ MALLEIN, Jean, La Situation juridique des combattants dans les conflits armés non internationaux, op.cit., 73.

${ }^{514}$ Ibid.

${ }^{515}$ Ibid., pp. 74-75. 
De là, il y a lieu d'arguer que toute "participation directe aux hostilités » est «participation active » mais toute «participation active » n'est pas nécessairement «participation directe » aux hostilités. La position des Etats développée ci-dessous va d'ailleurs dans ce même sens.

\section{Position des Etats}

La «participation directe aux hostilités » se trouve définie au plan législatif et en pratique par les Etats précisément dans leurs rapports soumis au Comité des droits de l'enfant. Lesquels rapports font état de mise en œuvre par les Etats du Protocole facultatif à la Convention relative aux droits de l'enfant concernant l'implication d'enfants dans les conflits armés du 25 mai 2000.

En effet, faisant référence à l'article 2, alinéa 15, de la loi $n^{\circ} 04 / 023$ du 12 novembre 2004 portant organisation générale de la défense et des forces armées, la RDC appréhende la participation directe comme « la mise en œuvre qui s'entend par le déploiement et l'engagement des unités en particulier dans un théâtre opérationnel ${ }^{516}$. En réalité, ce texte précité ne définit pas la participation directe aux hostilités mais plutôt le concept «mise en œuvre ». C'est donc la définition de ce dernier concept qui est repris dans le Rapport initial de la RDC sur le protocole précité. En pratique, les auteurs dudit Rapport situent l'origine de «participation directe » au discours du Président de la République du 14 juin 2001 sur le lancement de la campagne du processus de démobilisation et de réinsertion des groupes vulnérables présents dans les forces armées. Ainsi la participation directe des enfants précisément aux hostilités est appréhendée en pratique comme «étant l'envoi sur les lignes de front et l'utilisation des enfants à des tâches purement militaires, notamment le maniement d'armes ${ }^{517}$.

Pour la République d'Ouganda, « [1]a participation directe d'un enfant aux hostilités s'entend de l'implication d'un enfant, de gré ou de force, dans des combats ou d'autres formes d'hostilités conduites par des forces armées, qu'il s'agisse de l'armée nationale, de milices ou de groupes rebelles. [...] Ainsi, en Ouganda, on entend par participation directe le fait de prendre part activement $\grave{a}$ un combat militaire, ce qui implique parfois l'affrontement en première ligne avec les forces ennemies » (nous soulignons) ${ }^{518}$.

La République du Rwanda, pour sa part, ne conçoit pas définir la «participation directe » des enfants aux hostilités estimant qu'elle est déjà interdite dans sa législation ${ }^{519}$. Toutefois, dans

\footnotetext{
516 Comité des droits de l'enfant, Examen des Rapports présentés par les Etats parties en application du paragraphe 1 de l'article 8 du Protocole facultatif à la Convention relative aux droits de l'enfant, concernant l'implication d'enfants dans les conflits armés, Rapports initiaux des Etats parties attendus en 2004, République Démocratique du Congo, CRC/C/OPAC/COD/1, 18 avril 2011, p. 13, $\quad$ \& 47. http://tbinternet.ohchr.org/ layouts/treatybodyexternal/TBSearch.aspx?Lang=en\&TreatyID=5\&TreatyID=10\&T reatyID=11\&DocTypeID=29\&DocTypeCategoryID=4 (Source consultée le 10 janvier 2016). ${ }^{517}$ Ibid., p. 14, § 48 .

518 Comité des droits de l'enfant, Examen des Rapports présentés par les Etats parties en application du paragraphe 1 de l'article 8 du Protocole facultatif à la Convention relative aux droits de l'enfant, concernant l'implication d'enfants dans les conflits armés, Rapports initiaux des Etats parties attendus en 2004, Ouganda, $\begin{array}{llllllll}\mathrm{CRC} / \mathrm{C} / \mathrm{OPAC} / \mathrm{UGA} / 1, & 7 & \text { juillet } & 2008, & \text { p. } & 8, & \S & 13 .\end{array}$ http://tbinternet.ohchr.org/_layouts/treatybodyexternal/TBSearch.aspx?Lang=en\&TreatyID=5\&TreatyID=10\&T reatyID=11\&DocTypeID=29\&DocTypeCategoryID=4 (Source consultée le 11 janvier 2016).

519 Comité des droits de l'enfant, Examen des Rapports présentés par les Etats parties en application du paragraphe 1 de l'article 8 du Protocole facultatif à la Convention relative aux droits de l'enfant, concernant
} 
le cadre du processus de démobilisation et de réinsertion des anciens enfants soldats rwandais, la République du Rwanda appréhende ce concept comme faisant partie de « l'implication [des enfants] dans les conflits armés ${ }^{520}$. En ce sens, ce dernier concept s'apparente à la participation active telle que développée notamment par la CPI.

Il ressort de la conception de ces Etats que la participation directe des enfants aux hostilités concerne des «tâches purement militaires» en ligne de front impliquant des enfants, lesquelles sont étroitement liées aux combats. Cette conception n'entend pas comprendre différentes palettes d'activités comme le veut bien « la participation active » (cf. supra).

En conclusion, il va sans dire que la criminalisation de la «participation active » des enfants aux hostilités semble plus protectrice car englobant même les questions liées à la participation indirecte des enfants aux hostilités. Elle s'avère donc extensive contrairement à l'interdiction de la «participation directe ». Cependant, en termes du déroulement des hostilités, seuls les enfants qui participent directement aux hostilités perdraient leur immunité de protection. Ce qui n'est nullement le cas des enfants dans le cadre de participation active dont la participation indirecte, sans lien direct avec le combat. Tout ceci forme donc ce qu'il convient de nommer «participation aux hostilités », différent de contribution à l'effort de guerre.

l'implication d'enfants dans les conflits armés, Rapports initiaux des Etats parties attendus en 2004, Rwanda,

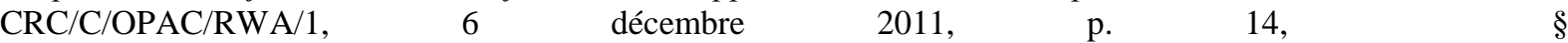
71.http://tbinternet.ohchr.org/ layouts/treatybodyexternal/TBSearch.aspx?Lang=en\&TreatyID=5\&TreatyID=10 \&TreatyID=11\&DocTypeID=29\&DocTypeCategoryID=4 (Source consultée le 11 janvier 2016).

${ }^{520}$ Comité des droits de l'enfant, Examen des Rapports présentés par les Etats parties en application du paragraphe 1 de l'article 8 du Protocole facultatif à la Convention relative aux droits de l'enfant, concernant l'implication d'enfants dans les conflits armés, Rapports initiaux des Etats parties attendus en 2004, Rwanda, CRC/C/OPAC/RWA/1, 6 décembre $2011, \quad$ p. $\quad 14, \quad$ \& http://tbinternet.ohchr.org/ layouts/treatybodyexternal/TBSearch.aspx?Lang=en\&TreatyID=5\&TreatyID=10\&T reatyID=11\&DocTypeID=29\&DocTypeCategoryID=4 (Source consultée le 11 janvier 2016). 


\section{Conclusion du Chapitre premier}

Les mots sont polysémiques. Permettre une lecture aisée d'une œuvre scientifique oblige logiquement l'auteur, mieux le chercheur, d'éclairer l'opinion sur des concepts utilisés. C'est donc la mission que s'est fixée naturellement ce premier chapitre.

En effet, le présent chapitre s'est préoccupé d'élucider le contenu du DIH sous différentes rubriques (Section I); les notions de l'enfant et de l'enfant soldat, y compris l'aperçu historique de la protection et des droits de l'enfant (Section II) et les questions de « recrutement » et de «participation aux hostilités » (Section III).

Il ressort de ce qui précède que le DIH reste essentiellement un droit applicable en période de conflits armés à travers ses rameaux - droit de La Haye et droit de Genève. Lesquels ne sont nullement étanches l'un vis-à-vis de l'autre. La tendance à leur unification est d'ailleurs très marquée. Et au-delà de tout, ils tendent à la réalisation d'une mission : «humaniser » les conflits armés. A cela s'ajoute également ce qu'il convient de nommer «droit de Newyork ». Bien plus, une conception « extensionniste » ou « évolutionniste » du DIH est de plus en plus présente. C'est celle qui considère que le DIH devrait être d'application en dehors des situations conflictuelles à savoir les catastrophes naturelles ou «situation d'urgence du même ordre ». Tout de même, la juridicité d'une telle tendance reste encore ambiguë.

Le DIH est un droit vieux comme la guerre sur terre mais dont la «naissance moderne » est située en 1864. Il s'est vu évoluer au plan conventionnel et coutumier. Il se trouve également étoffé des principes fondamentaux.

Concernant l' «enfant » et l' «enfant soldat », s'il existe une définition conventionnelle pour le premier terme, le second bénéficie en revanche seulement d'un apport de soft-law. Il n'existe donc pas une définition juridique pour ce dernier terme. Suivant l'article $1^{\mathrm{er}}$ de la $\mathrm{CDE}, l^{\prime}$ « enfant » est appréhendé comme toute personne de moins de dix-huit ans sauf, si la majorité est atteinte plus tôt en vertu d'une législation. Cette définition relative, laissant une large marge de manœuvre aux Etats en termes d'appréciation d'âge d'enfant, est corrigée par des instruments juridiques subséquents au plan régional (africain) et national (ex : R.D congolais). Bien que critiquable, elle est toutefois appréciable face au silence éloquent d'une telle définition observé en DIH. Le plus intéressant dans le cadre de la CDE est la révolution opérée qui consiste à considérer désormais l'enfant comme un « sujet des droits » non plus comme « un objet des droits » vis-à-vis de ses parents.

Pour sa part, l' « enfant soldat», est entendu brièvement comme toute personne de moins de dix-huit ans enrôlée par des forces ou groupes armés aux fins de tâches non exclusivement militaires. «Enrôler » ou «recruter » un enfant pour en faire un soldat revêt de sens variés suivant les instruments en présence. Et sa «participation directe aux hostilités» s'appréhende, au regard de la position des Etats, comme des « tâches purement militaires » en ligne de front. Cette participation peut être également «indirecte » et ne se confond tout de même pas avec un simple effort de guerre. Les conventions internationales protègent différemment les enfants à cet égard. Ces deux formes de participation (directe ou indirecte) constituent la «participation active », criminalisée par le Statut de Rome de la CPI. 


\section{CHAPITRE II DROIT INTERNATIONAL HUMANITAIRE : REGLES ET MECANISMES DE PROTECTION : QUELLE MISE EN GEUVRE ?}

Après avoir déterminé le contenu du DIH au chapitre lié au cadre conceptuel de cette dissertation, le présent chapitre s'interroge sur l'efficacité de la mise en œuvre du DIH en situation de conflits armés. Il sera d'abord question du champ d'application du DIH sous différents aspects de ses règles (Section I). Ensuite, la préoccupation sera celle d'étudier les mécanismes qui assurent la mise en œuvre des règles examinées (Section II). Enfin, l'analyse de ces règles et mécanismes conduira à réfléchir sur les limites extra-juridiques liées à l'application desdites règles et au fonctionnement desdits mécanismes (Section III). Il va sans dire que les analyses qui se dégageront dans ce cadre se présentent d'ores et déjà comme se rapportant à la protection générale de l'enfant en période de conflits armés. Question dont le chapitre suivant se préoccupera.

\section{Section I Champ d'application du droit international humanitaire}

Le DIH demeure fort marqué par son caractère évolutif comme l'ont si bien attesté les lignes précédentes. Appelé à régir au départ l'exercice du droit de souveraineté des Etats de mener la guerre, le DIH est resté pendant longtemps un droit régissant la guerre ou mieux un droit de la guerre ou des conflits armés internationaux. Cependant, l'évolution de la physionomie du système international a pu démontrer une montée grandissante des guerres civiles ou conflits armés internes au point qu'il existe actuellement plus de conflits armés internes que de conflits armés internationaux. Pour réagir et s'adapter à cette évolution, le DIH a pu consacrer quelques dispositions conventionnelles sur ce nouveau domaine, bien que de manière moindre et non comparable aux règles consacrées aux conflits armés internationaux. Bien plus, une certaine tendance doctrinale suggérant l'extension du DIH aux situations autres que les conflits armés - à savoir les catastrophes ou les situations urgentes du même ordre - est présente mais reste encore très discutable en droit. Des limites liées au champ d'application du DIH s'y trouvent aussi épinglées notamment pour des situations qui ne correspondent pas du tout à la nomenclature classique préalablement établie par les instruments juridiques du DIH. Ainsi, cette section se propose d'examiner le champ d'application du DIH sur les plans matériel $(\S 1)$, personnel $(\S 2)$, territorial et temporel $(\S 3)$.

\section{§1. Champ d'application ratione materiae}

Le DIH s'applique très largement voire exclusivement ${ }^{521}$ aux situations de conflits armés, que ceux-ci soient internationaux ou non internationaux. Ce champ d'application ratione materiae fait appel à deux régimes juridiques distincts, l'un applicable aux CAI et l'autre aux CANI bien que la tendance actuelle est celle de l'unification ou de l'uniformisation de ces règles de droit ou régimes juridiques (cf. infra). Ce sont donc les CG et leur PA I qui s'appliquent aux CAI. L'article 3 commun aux CG qualifié selon la désormais célèbre formule de R. PINTO de «Convention en miniature ${ }^{522}$, ou encore de «Convention dans la convention » et le PA II se

\footnotetext{
${ }^{521}$ Voy. BIAD, Abdelwahab, Droit international humanitaire, 2è édition, op. cit., 2006, p. 23 et BUIRETTE, Patricia et LAGRANGE, Philippe, op.cit., p. 37.

${ }^{522}$ FURET, Marie Françoise, MARTINEZ, Jean Claude et DORANDEU, Henri, op.cit., p. 164.
} 
concentrent de régir la situation de CANI ou conflits armés internes. Pour ce second régime, il se pose une sorte de deux sous-régimes distincts étant donné la formulation différente de leurs dispositions. L'un s'avère plus large que l'autre (cf. infra).

Par ailleurs, ces instruments juridiques précités ne fournissent pas à proprement parler une définition précise des termes «conflits armés » et «conflits armés internationaux ou non internationaux». Ils invoquent cependant des conditions ou mieux des critères pouvant amener à qualifier une situation de conflits armés, internationaux ou non internationaux, afin de permettre ou non l'application du DIH, critères dont le champ d'application ne tient pas compte de plusieurs situations possibles (cf. infra). La pratique et la jurisprudence semblent combler cette carence. Ainsi, les lignes suivantes permettront de comprendre les contours et contenus de ces différents concepts.

Dorénavant, il est d'une importance capitale de rappeler que « depuis la nuit des temps, les relations internationales sont fortement marquées du sceau du conflit sous toutes ses formes et, tout particulièrement du conflit armé. Malgré tous les progrès dont se targue l'humanité, les conflits armés n'ont jamais été aussi violents, étendus et meurtriers qu'au cours du XX siècle $\gg^{523}$ (cf. supra).

Par ailleurs, «la notion du conflit est récente. En effet, jusqu'à la fin des années 1950, c'est le vocable «guerre » qui prévalait. Il était entendu comme un instrument devant permettre de trancher les différends politiques entre Etats souverains $»^{524}$.

Suivant Charles ROUSSEAU, la guerre, phénomène de pathologie sociale et facteur de transformation politique, constitue d'abord une lutte armée entre Etats. Que ceux-ci soient constitués en coalition ou de manière individuelle. Elle est un fait interétatique, mieux « un fait international », pour reprendre l'expression de la Cour Permanente d'Arbitrage (sentence du 11 novembre 1912, affaire de l'indemnité de guerre turque). A la différence de la guerre civile ou d'une action armée contre les insurgés ou les pirates, elle implique une lutte des forces publiques et s'analyse dès lors comme une relation d'Etat à Etat ${ }^{525}$.

Cependant, des faits nouveaux vinrent donner une autre connotation à ce concept, notamment la guerre de décolonisation ou guerre de libération nationale. Les affrontements ont laissé voir qu'il n'y avait pas que des Etats souverains qui intervenaient dans la guerre. L'expression «développement des arsenaux nucléaires » va dans le même sens. Ceci a permis de ne plus se limiter aux actions strictement opérationnelles mais d'envisager d'autres formes de violence organisée en vue de ne pas tomber dans un affrontement interétatique entre puissances nucléaires $^{526}$.

En d'autres termes, la configuration du système international atteste que les Etats ne sont pas les seuls acteurs dans les rapports belliqueux. Interviennent ici également des acteurs

\footnotetext{
${ }^{523}$ BRAILLARD, P. et DJALILI, M.-R. ; Les Relations Internationales, 6 e édition P.U.F., Paris, 2002, p. 102.

${ }^{524}$ LABANA Lasay'Abar, Le conflit en relations internationales, Analyse des concepts de base, Maison édition Sirices, Kinshasa, 2004, p. 7.

${ }_{525}$ ROUSSEAU, Charles, Droit international public, op.cit., p. 7.

${ }^{526}$ LABANA, Lasay'Abar, op. cit., p. 7.
} 
internationaux, non-étatiques. A ce titre, le terme «guerre» devient de plus en plus étroit voire suranné. Il est plus aisé et recommandé d'utiliser le concept «conflit armé » qui se veut terminologiquement plus extensif ou global et reflétant par conséquent la réalité du système international. Et les CG de 1949 en font usage officiellement. L'article 2 commun aux CG dispose que «[...] la présente convention s'appliquera en cas de guerre déclarée ou de tout autre conflit armé $[\ldots] »$ (nous soulignons). Ainsi, ces deux raisons - terminologique et juridique - , confirmées par de nombreux instruments juridiques et autres textes ultérieurs, attestent du choix de ce terme ${ }^{527}$.

En effet, le conflit est entendu comme un désaccord sur un point de droit ou de fait, une contradiction de thèses juridiques ou d'intérêts entre sujets de droit (national ou international); dans le cadre des relations internationales entre les acteurs du système international $^{528}$. S'il est certes vrai que le terme « différend » ou « conflit » est plus général au point même d'incorporer le concept «conflit armé », il importe de préciser avec un regard scrutateur qu'est qualifié en général de «conflit armé » tout conflit dont les acteurs étatiques ou non étatiques - recourent à la force ou mieux aux armes pour trancher les litiges qui les opposent.

Au-delà de toutes ces réflexions précédentes, que dit concrètement le $\mathrm{DIH}$ au sujet des CAI et CANI?

Avant de tenter de formuler une réponse à cette question, il est temps d'affirmer que la détermination du champ d'application du DIH n'est pas chose aisée comme l'ont si bien démontré d'ailleurs les intervenants au $13^{\mathrm{e}}$ Colloque de Bruges sur le «Scope of Application of International Humanitarian Law ${ }^{529}$ auquel nous avions pris part. L'on retrouve de «surqualification» ou de «sous-qualification» des situations par rapport au DIH. La détermination du seuil d'intensité de conflit armé, par exemple, pour faire ainsi appel à l'application du DIH semble poser problème. D'autres problèmes se trouvent liés notamment à l'absence d'une instance de qualification des conflits armés en DIH; à l'apparition de nouveaux éléments autant que de nouvelles notions en DIH telles que « combattants illégaux », «combattants ennemis » ou «belligérants non-privilégiés», etc. La jurisprudence des juridictions pénales relayées par la pratique des Etats en ce domaine semble aussi ne pas simplifier la situation au regard des textes initiaux.

Il est important de rappeler préalablement que le DIH se caractérise également, comme sa branche mère - le droit international public -, par le principe de souveraineté des Etats $^{530}$ (auteurs des CG et PA) en dépit du caractère de jus cogens reconnu pour la plupart de ses règles. A ce titre, l'auto-appréciation ou l'auto-interprétation étatique des dispositions conventionnelles reste centrale. Ceci influe non moins sur la qualification des conflits armés. Tout de même, en DIH, «on s'achemine vers la remise en cause du droit exclusif et

\footnotetext{
${ }^{527}$ DAVID, Eric, Principe de droit des conflits armés, $5^{\mathrm{e}}$ édition, op. cit., p. 116.

${ }^{528}$ LABANA, Lasay'Abar, op. cit., p. 7.

${ }^{529}$ College of Europe and ICRC, 13th Bruges Colloquium - October 18 and 19, 2012 « Scope of Application of International humanitarian Law ».

${ }^{530}$ Lire avec intérêt NIYUNGEKO, Gérard, « La mise en œuvre du droit international humanitaire et le principe de la souveraineté des Etats », in RICR, nº788, mars-avril 1991, op.cit., pp. 113-141.
} 
discrétionnaire des Etats de qualifier les situations conflictuelles qui prévalent sur leur territoire ${ }^{531}$. A ce sujet, dans le cadre des commentaires de l'article $1^{\text {er }}$ du PA II, le CICR estimait déjà que "[1]'application [des critères de cette disposition] ne doit pas dépendre de l'appréciation des parties. Le Protocole entre en vigueur automatiquement dès que les conditions matérielles, telles que définies par l'article, sont remplies. Ce système, qui a pour but de ne pas faire dépendre la protection des victimes des conflits armés d'une décision arbitraire des autorités concernées, est l'un des fondements du droit international humanitaire et vaut déjà aux articles 2 et 3 communs aux Conventions de $1949 »^{532}$. Le TPIR confirme ce point de vue dans l'affaire Le Procureur c. Jean-Paul AKAYESU. Il précise que le soin de déterminer le seuil d'intensité d'un conflit armé n'est pas laissé à l'appréciation subjective des parties. Sinon, elles auraient tendance à en minimiser l'intensité. Ainsi, l'article 3 commun aux CG et le PA II trouvent application dès lors que les critères objectifs préétablis sont satisfaits par un conflit armés ${ }^{533}$. Dans le même ordre d'idées, le rôle prépondérant des Etats ou des parties au conflit pour la qualification de conflit armé est également désapprouvé par le TPIY. Celui-ci estime, à travers sa Chambre de première instance, que « les parties au conflit ne peuvent pas s'accorder entre elles pour changer la nature du conflit, laquelle est établie par les faits dont l'interprétation relève, le cas échéant, du juge ${ }^{534}$. Il appartient donc à celui-ci «d'évaluer les faits dont [il] dispose et de déterminer la nature véritable du conflit $»^{535}$.

Par ailleurs, s'il est vrai que le conflit armé s'appréhende donc comme un fait objectif ne dépendant pas de la qualification officielle d'une des parties ${ }^{536}$, il est tout aussi vrai qu'en réalité les Etats, autant que les autres parties (groupes armés), détiennent un rôle prépondérant dans la qualification des conflits armés et l'application du DIH. Et surtout qu'il n'existe pas un « organe supranational » attitré de qualication ou de contrôle concomitant du déroulement des conflits armés. En réalité, les parties appliquent le DIH comme l'entendent les qualifications qu'elles accordent aux conflits armés concernés, voire au-delà des règles concernées (Cas notamment des accords spéciaux). Le point de vue selon lequel les CG et PA entrent «en vigueur automatiquement » dès que les conditions matérielles, telles que définies par lesdits traités, sont remplies (cf. supra), bien que objectif, paraît tout de même «théorique ». Non seulement il n'est pas évident d'appréhender factuellement ces critères - le travail que réalisent les juridictions internationales sur la qualification de conflits armés l'atteste d'ailleurs - mais il y a lieu de se demander comment faire dépendre une partie au conflit armé, dont un Etat, d'une qualification émanant d'un organe extérieur auquel il n'a pas

531 MOMTAZ, Djamchid, «Les défis des conflits armés asymétriques et identitaires au droit international humanitaire », in MATHESON, J. Michael et MOMTAZ, Djamchid, op.cit., p. 16.

532 SANDOZ Yves, SWINARSKI, Christophe et ZIMMERMANN, Bruno, (éd.), Commentaire des protocoles additionnels de 1977 aux conventions de Genève de 1949, CICR/Martinus Nijhoff Publishers, Genève/Dordrecht, $\quad 1986, \quad$ $\quad$ S 4459, $\quad$ disponible $\quad$ sur $\quad \underline{\text { https://ihl- }}$ databases.icrc.org/applic/ihl/dih.nsf/Comment.xsp?action=openDocument \&documentId=26144B48AA09DF15C 12563BD002DF215 (Source consultée le 21 août 2016).

${ }^{533}$ TPIR, Le Procureur c. Jean-Paul AKAYESU, Affaire n ${ }^{\circ}$ ICTR-96-4-T, Chambre I, jugement du 2 septembre 1998, pp. 243-244, §603. Voy. aussi p. 253, § 624.

${ }^{534}$ TPIY, Le Procureur c. Tihomir BLASKIC, Affaire $\mathrm{n}^{\circ}$ IT-95-14-T, Chambre de première instance, jugement du 3 mars 2000, p. 31, $\$ 82$.

${ }^{535}$ Ibid. ; voy. aussi MOMTAZ, Djamchid, «Les défis des conflits armés asymétriques et identitaires au droit international humanitaire », in MATHESON, J. Michael et MOMTAZ, Djamchid, op.cit., p. 16.

${ }^{536}$ DAVID, Eric, Principes de droit des conflits armés, $5^{\mathrm{e}}$ édition, op. cit., p. 120. Lire aussi avec intérêt les pages 144 à 146 . 
préalablement consenti. Un tel point de vue, qui à dire vrai constitue le progrès accompli à travers les CG allant notamment du subjectif vers l'objectif ${ }^{537}$, a davantage de pertinence devant des instances juridictionnelles. D'où l'intérêt des parties d'apprécier objectivement les situations afin d'éviter l'établissement de leur responsabilité. Mais même dans ce cas, la protection des victimes reste moins efficace. Relevons d'abord que le tribunal ne se saisit pas d'office. Face aux conflits armés, le juge est généralement saisi à la fin du conflit armé ou après l'écoulement d'un temps important du déroulement du conflit armé. Bien plus, la problématique de la reconnaissance de sa juridiction voire la lenteur de sa procédure ne se prêtent pas toujours mieux à l'exercice. Ceci n'apparaît donc pas efficace pour assurer la protection des victimes des conflits armés dont les plus vulnérables sont les enfants. Et si l'intervention du juge doit s'avérer nécessaire, l'efficacité en termes de protection des victimes suggérerait que la qualification se fasse de manière a priori c'est-à-dire dès l'instant (ou après quelques instants) du déclenchement du conflit afin de déterminer préalablement le droit applicable. Chose qui n'est pas évidente ou aisée car il faut généralement du temps pour mieux identifier les (vrais) belligérants. Ainsi, le point de vue jurisprudentiel ci-dessus exprimé ne résout pas non plus la question en termes d'efficacité de protection des victimes si ce n'est que de manière a posteriori en termes d'établissement de responsabilité.

Or le DIH est appelé à s'appliquer effectivement «au cours même du combat et non après coup devant les cours et tribunaux ${ }^{538}$. Lesquels ne changent en rien la tragédie irréparable occasionnée par l'entreprise de désolation, le conflit armé ${ }^{539}$.

Dès lors, il paraît intéressant qu'un organisme impartial tel que le CICR soit habilité, par les Etats, à qualifier les conflits armés. Un tel processus juridique ne semblerait pas poser de sérieux problèmes en termes de matérialisation si l'on sait déjà que les Etats n'ont pas de monopole de qualification de conflits armés. Et donc confier une telle mission à un organisme extérieur impartial paraît rassurant et sauvegardant même les intérêts des Etats. Pour l'instant, la pratique onusienne, voire du CICR, qui consiste généralement à ne pas qualifier expressément les conflits armés mais de recommander l'application du DIH (cf. infra), autant aux forces armées des Etats qu'aux groupes armés, est une attitude bénéfique et protectrice à l'égard des victimes.

\section{A. Les conflits armés internationaux (CAI)}

En effet, l'article 2 commun aux CG du 12 août 1949 dispose que «[...] la présente convention s'appliquera en cas de guerre déclarée ou de tout autre conflit armé surgissant entre deux ou plusieurs des Hautes Parties contractantes, même si l'état de guerre n'est pas reconnu par l'une d'elles. La convention s'appliquera également dans tous les cas d'occupation de tout ou partie du territoire d'une Haute Partie contractante, même si cette occupation ne rencontre aucune résistance militaire [...]». Cette disposition doit être

\footnotetext{
${ }^{537}$ Lire KOLB, Robert, Ius in bello. Le droit international des conflits armés, $2^{\mathrm{e}}$ édition, op. cit., p. 13.

${ }^{538}$ DAVID, Eric, Principes de droit des conflits armés, $5^{\mathrm{e}}$ édition, op. cit., p. 120. Lire aussi avec intérêt les pages 144 à 146.

${ }_{539}$ Voy. NIYUNGEKO, Gérard, «La mise en œuvre du droit international humanitaire et le principe de la souveraineté des Etats », «art. cit.», p.114.
} 
interprétée largement. L'expression «conflit armé international» vise : tout différend surgissant entre Etats et provoquant l'intervention de forces armées ou assimilées et ce quels que soient la durée du conflit ou de l'affrontement, l'importance des forces en présence ${ }^{540}$, le nombre de victimes ou personnes capturées, l'extension et l'intensité des conflits ${ }^{541}$. «Il peut même ne pas avoir de combat: il suffit qu'il y ait détention de personnes visées par la Convention ${ }^{542}$. Le caractère transfrontalier ${ }^{543}$ reste un élément déterminant dans ce type de conflit, lequel caractère sera également épinglé au niveau du conflit armé interne internationalisé (cf. infra).

C'est ainsi que "se fondant sur l'article 2 commun aux Conventions de Genève, le commentaire du CICR y relatif et l'Arrêt Tadic du TPIY, la Chambre préliminaire I [CPI] a conclu qu'un conflit armé est international : s'il oppose deux ou plusieurs États, et que cette notion couvre les cas d'occupation de tout ou partie du territoire d'un État tiers, que cette occupation, de tout ou partie du territoire, rencontre ou non une résistance militaire. De plus, un conflit armé interne qui éclate sur le territoire d'un État peut devenir international —ou, selon les circonstances, présenter parallèlement un caractère international - si i) les troupes d'un autre État interviennent dans le conflit (intervention directe) ou si ii) certains participants au conflit armé interne agissent au nom de cet autre État (intervention indirecte) ${ }^{544}$.

Par ailleurs, bien que s'agissant de CAI, les instruments du DIH ne se réfèrent qu'aux affrontements armés entre Etats (ou de leurs représentants), les OI sont également des sujets majeurs de DI dont l'intervention qualifie un conflit armé d'international. Les opérations de maintien de la paix dans le cadre onusien se trouvent assimilées aux $\mathrm{CAI}^{545}$ (cf. infra).

Bien au-delà, il est important de mentionner qu'au regard d'une diplomatie agissante entreprise notamment par les «nouveaux Etats » sur la scène internationale dont beaucoup avaient expérimenté les guerres de libération nationale (GLN), différentes résolutions au niveau de l'AG/NU ont été adoptées en faveur des mouvements de libération nationale (MLN). Ces derniers ont pu apporter leur contribution à la Conférence diplomatique qui a abouti à l'adoption des PA I et II, après être invités et avoir participé pleinement à ces débats et à ceux des commissions principales. Ils ont même pu signer l'Acte final de la Conférence $^{546}$. Tout ce processus aboutira finalement par la reconnaissance de ce type de conflits (GLN) en «CAI» par le PA I. Il s'agit d'une innovation qui trouve son fondement au niveau de la Charte des Nations unies qui consacre en son article $1^{\mathrm{er}} \S 2^{547}$ le principe de

\footnotetext{
${ }^{540}$ Il importe peu également que les forces en présence soient composées de nationaux des Etats belligérants ou des volontaires étrangers, car il s'agit dans les deux cas d'unités combattant officiellement pour le compte de ces Etats.

541 Voy. DAVID, Eric, Principes de droit de conflits armés, pp. 120-129; DAVID, Eric, Mercenaires et Volontaires Internationaux en Droit des gens, Ed. de l'Université de Bruxelles, Bruxelles 1978, p. 370. Et DEYRA Michel, Droit dans la guerre, op.cit., p. 170.

542 DAVID, Eric, Principes de droit de conflits armés, op. cit., p. 126.

${ }^{543}$ BETTATI, Mario, Droit humanitaire. Textes introduits et commentés, op.cit., p. 37.

${ }^{544}$ CPI, Le Procureur c. Thomas Lubanga Dyilo, affaire $N^{\circ}$ : ICC-01/04-01/06, Chambre de première instance, jugement, $\quad 14$ mars 2012, p. 269, $\quad$ $\quad 541, \quad$ in $\underline{\text { https://www.icc- }}$ cpi.int/fr_menus/icc/situations\%20and\%20cases/situations/situation\%20icc\%200104/related\%20cases/icc\%2001 04\%200106/court\%20records/chambers/trial\%20chamber\%20i/Pages/2842.aspx (Source consultée le 22 mars 2015)

${ }^{545}$ Lire avec intérêt DAVID, Eric, Principes de droit de conflits armés, pp. 127 et 129.

${ }^{546}$ Lire VEUTHEY, Michel, Guérilla et Droit humanitaire, Genève, CICR, 1983, pp. XIX-XX.

${ }^{547}$ Charte des Nations unies, Article $1^{\mathrm{er}}$ : «Les Buts des Nations unies sont les suivants : (...) 2. Développer
} 
l'égalité de droits des peuples et de leur droit à disposer d'eux-mêmes ${ }^{548}$. Il s'agit en même temps d'un moyen de matérialisation de ce principe.

Ainsi, l'article $1^{\mathrm{er}}$ du PA I relatif aux Principes généraux et champ d'application dispose en son quatrième paragraphe : «[d]ans les situations visées au paragraphe précédent sont compris les conflits armés dans lesquels les peuples luttent contre la domination coloniale et l'occupation étrangère et contre les régimes racistes dans l'exercice du droit des peuples à disposer d'eux-mêmes, consacré dans la Charte des Nations unies et dans la déclaration relative aux principes $d u$ droit international touchant les relations amicales et la coopération entre les Etats conformément à la Charte des Nations Unies ».

Il ressort de cette disposition qu'elle élargit - bien que très étroitement ${ }^{549}$ - la notion de conflit armé international telle qu'exprimée par l'article 2 commun aux quatre CG (cf. supra) aux guerres de libération nationale (GLN). Chose qui s'avère aussi très compréhensible si l'on sait que le MLN, comme le dit si bien Abdelwahab BIAD, « est un substitut de l'Etat, un Etat en devenir ${ }^{550}$. Il s'agit des conflits armés qui s'inscrivent dans le cas de lutte des peuples contre une domination coloniale, une occupation étrangère et un régime raciste.

Pour les commentaires du CICR, l'expression de «domination coloniale » couvre le cas le plus fréquent dans les années récentes où un peuple ait dû prendre les armes pour se libérer de la domination d'un autre peuple. L'expression « occupation étrangère » au sens de ce paragraphe - contrairement à l'occupation au sens classique de tout ou partie du territoire d'un Etat par un autre Etat - couvre les cas d'occupation partielle ou totale d'un territoire qui n'est pas encore pleinement érigé en Etat. L'expression « régime raciste », enfin, vise les cas de régimes fondés sur des critères raciaux. Les deux premières hypothèses impliquent l'existence de peuples distincts. La troisième implique, à défaut de deux peuples toujours distincts, au moins un clivage qui, au sein d'un peuple, assure l'hégémonie d'une partie de celui-ci selon une conception raciale. Bien plus, une situation concrète peut correspondre à la fois à deux des hypothèses énumérées ou même aux trois ${ }^{551}$.

Ainsi, « la première hypothèse se vérifie de manière résiduelle en Afrique, dans les Caraïbes, en Guyane et dans le Pacifique. La seconde apparaît de manière éclatante à Gibraltar, en Palestine et au Sahara Occidental. Quant au régime raciste, la chute de l'empire de l'apartheid paraît épuiser cette catégorie ${ }^{552}$.

entre les nations des relations amicales fondées sur le respect du principe de l'égalité de droits des peuples et de leur droit à disposer d'eux-mêmes, et prendre toutes autres mesures propres à consolider la paix du monde », document disponible sur https://treaties.un.org/Pages/ViewDetails.aspx?src=TREATY\&mtdsg_no=I$1 \&$ chapter=1\&clang= fr $\quad$ (Source consultée le 14 août 2016).

${ }^{548}$ Lire par exemple les articles ci-après parus dans Le droit des peuples à disposer d'eux-mêmes. Méthodes d'analyse du droit international. Mélanges offerts à Charles CHAUMONT, éd. A. Pedone, Paris, 1984 : BASTID, Suzanne, «Les droits des peuples dans les plans à moyen-terme (1984-1989) de l'U.N.E.S.C.O. », pp. 11-22 ; BATAILLER-DERMICHEL, Francine, «Droits de l'homme et droits des peuples dans l'ordre international », pp. 23-34; CHARPENTIER, Jean, «Autodétermination et décolonisation », pp. 117-133; CHEMILLIER-GENDREAU, Monique, « Droit des peuples à disposer d'eux-mêmes et réfugiés », pp. 161-177; S. CALOGEROPOULOS-STRATIS, Le droit des peuples à disposer d'eux-mêmes, Bruylant, Bruxelles, 1973, $388 \mathrm{p} ;$ etc.

${ }^{549}$ DAVID, Eric, Principes de droit des conflits armés, $5^{\mathrm{e}}$ édition, op. cit., p. 130.

${ }^{550}$ BIAD, Abdelwahab, Droit international humanitaire, $2^{\mathrm{e}}$ édition, op.cit., p. 26.

${ }^{551}$ Les Commentaires du CICR de l'article $1^{\text {er }}$ paragraphe $4 \mathrm{du}$ Protocole additionnel http://www.icrc.org/dih.nsf/COM/470-750004?OpenDocument, point 112. (Source consultée le 20 juillet 2015).

${ }_{552}$ BULA-BULA, Sayeman, Droit international humanitaire, op.cit., p. 93. 
Par ailleurs, en pratique de conflits armés, pour attirer l'attention de l'opinion publique internationale, différents mouvements ou groupes armés rebelles qualifient très facilement leurs luttes de «libération nationale ». Ceci afin de bénéficier notamment de l'appui de la Communauté internationale, d'un Etat étranger ou encore légitimer leurs luttes à ce juste titre. Les deux conflits armés majeurs (1996-1997 et 1998-2002) qui ont eu lieu en RDC ont été qualifiés de «Guerre de libération nationale » par leurs acteurs notamment l'AFDL ou le MLC, le RCD et autres mouvements rebelles. Cependant, l'on se demandera si ces luttes ou conflits armés répondent réellement aux critères énumérés ci-avant.

Au départ, hormis les hypothèses ci-dessus énumérées, il doit s'agir de luttes qui s'opèrent dans le cadre de l'exercice du droit de peuple à l'autodétermination ou mieux le droit des peuples à disposer d'eux-mêmes. Ceci mérite quelques commentaires.

En clair, les titulaires du «droit des peuples à disposer d'eux-mêmes » tels qu'énumérés cidessus sont les «peuples ». Il s'agit donc de «tous les peuples» comme l'affirment d'ailleurs si bien la Résolution 2625 (XXV) du 24 octobre 1970 portant Déclaration relative aux Principes du Droit international touchant les relations amicales et la coopération entre les Etats conformément à la Charte des Nations Unies; les articles $1^{\mathrm{er}}$ respectifs du Pacte international relatif aux droits civils et politiques et du Pacte international relatif aux droits économiques sociaux et culturels et la jurisprudence ${ }^{553}$. Il ne s'agirait pas seulement, comme on pourrait bien le croire, du peuple colonisé. Cependant, la difficulté majeure demeure celle du contenu à attribuer au terme «peuple ».

En effet, si dans le contexte de la colonisation, les Nations unies ont fait l'économie de controverses conceptuelles en empruntant une démarche pragmatique, évacuant la dimension humaine au profit d'un critère territorial pour définir le terme «peuples » (Ont été réputés «peuple » pour les besoins de la décolonisation, les populations regroupées à l'intérieur des territoires coloniaux, tels que les ont souverainement délimités les colonisateurs) ${ }^{554}$, il n'existe pas, en droit international, de définition de ce qu'est un peuple. Seuls existent des instruments qui énumèrent les droits reconnus à tout peuple. Il n'y a pas non plus de critère objectif ou infaillible qui permette de reconnaître qu'un groupe de population est un peuple ${ }^{555}$. Pour la Cour Suprême du Canada, tout en admettant que le contenu du terme «peuple » reste incertain, elle affirme qu'il est évident qu'un peuple peut s'entendre d'une partie seulement de la population d'un Etat existant. Ce terme ne vise pas nécessairement, selon elle, l'entière population d'un Etat. La Cour reconnaît tout de même que restreindre le terme «peuple » à la

\footnotetext{
${ }^{553}$ La Cour Suprême du Canada affirme que «C'est aux «peuples » que le droit international accorde le droit à l'autodétermination ». in Cour Suprême du Canada, Renvoi relatif à la Sécession du Québec (1998)2 R.S.C (217), lire VAN DROOGHENBROECK, Sébastien, Dimensions collectives des droits de l'Homme-Le droit des peuples à disposer d'eux-mêmes - Documents, Mastère Complémentaire en Droits de l'Homme, Faculté de droit, Académie Universitaire 'Louvain', 2010-2011, p. 4.

${ }^{554}$ Ibid., p. 6.

555 Lire les commentaires du CICR de l'article $1^{\text {er }} \S 4$ du PA I au point 103 in http://www.icrc.org/dih.nsf/COM/470-750004?OpenDocument. (Source consultée le 20 juillet 2015). Ces commentaires précisent au sujet du «peuple » qu' «en plus d'un territoire défini, une communauté de langue, de culture ou d'ethnie sont certes des indices, mais le territoire peut ne pas être d'un seul tenant, géographiquement ou politiquement, et un peuple peut comporter divers groupes linguistiques, culturels ou ethniques. L'essentiel est un sentiment commun de former un peuple et une volonté politique de vivre ensemble comme tel, résultant d'un ou plusieurs des critères indiqués, généralement démontrés et confortés par une histoire commune; cela comprend à la fois un lien entre les personnes appartenant à ce peuple et une distinction d'avec les autres peuples: communauté et différence ».
} 
population d'Etats existants rendrait superflue la reconnaissance $\mathrm{du}$ droit à l'autodétermination notamment eu égard aux instruments juridiques qui le consacrent. Lesquels insistent sur la nécessité d'intégrité territoriale. ${ }^{556}$ L'affirmation de la Cour Suprême du Canada rejoint celle de la Commission Africaine des droits de l'Homme et des Peuples dans l'affaire Congrès du Peuple Katangais $c$. Zaïre.

En effet, il s'agit d'une Communication introduite en 1992 par le Président du Congrès du Peuple Katangais demandant à la Commission Africaine des Droits de l'Homme et des peuples la reconnaissance de cette association comme «MLN» devant aider le Katanga à acquérir son indépendance ; la reconnaissance de l'indépendance du Katanga et l'aide en sa faveur afin d'obtenir l'évacuation du Zaïre de son territoire. En réponse, la Commission a estimé que «[t]ous les peuples ont droit à l'autodétermination. Toutefois, il pourrait y avoir une controverse au sujet de la définition des peuples et du contenu de ce droit. Le problème qui se pose dans cette affaire est l'autodétermination non pas de tous les Zaïrois en qualité de peuple mais les Katangais spécifiquement. Que les Katangais comptent un ou plusieurs groupes ethniques, la question est irrelevante dans ce cas d'espèce, et aucune preuve n'en a été donnée ${ }^{557}$. En clair, avant de dire finalement que cette plainte ne contient aucune preuve de violation d'un quelconque droit prévu par la Charte africaine, la Commission ne fournit pas la définition du terme "peuples » ni le contenu du droit à l'autodétermination. Elle indique tout de même les canaux devant permettre aux peuples d'accéder à l'autodétermination dont l'indépendance, auto gouvernement, gouvernement local, fédéralisme, confédéralisme, unitarisme ou toute autre forme de relations conforme aux aspirations du peuple mais tout en reconnaissant les autres principes établis tels que la souveraineté et l'intégrité territoriale. En d'autres termes, ces canaux doivent être conformes aux principes de souveraineté et d'intégrité territoriale pour qu'ils soient valides. C'est dans ce sens même que «la Commission maintient que le Katanga est tenu d'user d'une forme d'autodétermination qui soit compatible avec la souveraineté et l'intégrité territoriale du Zaïre ${ }^{558}$.

Par ailleurs, suivant les commentaires du CICR, précisons que seuls les peuples bénéficient du droit de disposer d'eux-mêmes défini par des instruments précités. Ce n'est donc pas le cas des minorités ethniques, religieuses ou linguistiques, auxquelles, par exemple, le Pacte relatif aux droits civils et politiques se contente de reconnaître le droit d'avoir leur propre vie culturelle, de professer et de pratiquer leur propre religion, ou d'employer leur propre langue (article 27). Ainsi, par exemple, la lutte que mènent de manière intermittente certains groupes ou mouvements armés au nom des «Banyamulenge », une minorité ethnique dite tutsi-congolais habitant l'Est de la RDC, ne rentrerait point dans ce cadre. Ainsi qu'on peut le constater, toute la difficulté réside au point de la qualification de peuples bénéficiant de ce droit ${ }^{559}$.

Bien plus, dans ses commentaires de l'article $1^{\text {er }}$ du PA I, le CICR posait une importante

\footnotetext{
${ }^{556}$ Cour Suprême du Canada, Renvoi relatif à la Sécession du Québec (1998)2 R.S.C (217), lire VAN DROOGHENBROECK, Sébastien, Dimensions collectives des droits de l'Homme- Le droit des peuples à disposer d'eux-mêmes - Documents, Mastère Complémentaire en Droits de l'Homme, Faculté de droit, Académie Universitaire 'Louvain', 2010-2011, p. 4.

${ }^{557}$ Commission africaine des droits de l'homme et des peuples, Congrès du Peuple Katangais $c$. Zaïre (2000), RADDH 298 (CADHP 1995), in Sélection de documents-clé de l'Union Africaine relatifs aux droits de l'Homme, Pretoria University Law Press, PULP 2006, p. 129.

${ }_{558}^{5}$ Ibid.

559 Point 106 des Commentaires du CICR de l'article $1^{\text {er }} \S 4$ du PA I http://www.icrc.org/dih.nsf/COM/470750004? OpenDocument (Source consultée le 20 juillet 2015).
} 
question qui était celle de savoir si quant au fond, les cas énumérés dans cet article (domination coloniale, occupation étrangère et régime raciste) couvraient-ils toutes les hypothèses de peuples en lutte dans l'exercice de leur droit à disposer d'eux-mêmes. En réponse, il faut conclure que la liste est limitative et exhaustive. Ceci pour dire que les critères de qualification sont très étroits. Ceci recouvre bien tous les cas où un peuple doit, pour exercer son droit à disposer de lui-même, recourir à la force armée contre les ingérences d'un autre peuple ou contre un régime raciste. Sont exclus, en revanche, les cas où, sans l'un de ces éléments, un peuple prend les armes contre des autorités qu'il conteste - cette hypothèse n'étant pas considérée comme internationale ${ }^{560}$. Ceci concorde le mieux avec la situation des guerres dites de «libération nationale » (AFDL, MLC ou RCD) connues en RDC. Situations qui se trouvent exclues des critères précités pour être qualifiées de «GLN ».

Ceci est aussi observable en droit international général. En effet, suivant la logique précédente, la Cour Suprême du Canada conclut qu'"en résumé, le droit à l'autodétermination en droit international donne tout au plus ouverture au droit à l'autodétermination externe (indépendance) dans le cas des anciennes colonies; dans le cas des peuples opprimés, comme les peuples soumis à une occupation militaire étrangère; ou encore dans le cas où un groupe défini se voit refuser un accès réel au gouvernement pour assurer son développement politique, économique, social et culturel. Dans ces trois situations, le peuple en cause jouit du droit à l'autodétermination externe parce qu'on lui refuse la faculté d'exercer, à l'interne (droit à la démocratie), son droit à l'autodétermination ${ }^{561}$. C'est d'ailleurs la position que partage la CIJ. Ainsi, elle affirme dans son avis consultatif sur la Conformité au droit international de la déclaration unilatérale d'indépendance relative au Kosovo que «...Au cours de la seconde moitié du XXe siècle, le droit international, en matière d'autodétermination, a évolué pour donner naissance à un droit à l'indépendance au bénéfice des peuples de territoire occupé non autonomes et de ceux qui étaient soumis à la subjugation, à la domination ou à l'exploitation étrangères » ${ }^{562}$. Toutefois, si de nombreux Etats sont nés par la suite de l'exercice de ce droit, la CIJ renseigne que la pratique des Etats ne révèle pas l'existence d'interdiction, en droit international, des déclarations d'indépendance effectuée en dehors du contexte précité ${ }^{563}$.

Pour les dispositions de l'article $1^{\text {er }} \S 4$ du PA I seules comptent pour application du DIH l'existence d'un MLN suffisamment organisé, structuré et représentatif du peuple au nom duquel est menée sa lutte armée; la ratification ou l'adhésion préalable de l'Etat sur le territoire duquel se déroulent les affrontements et l'obligation pour l'autorité représentant un peuple engagé dans un tel conflit de souscrire à la procédure d'acceptation particulière prévue par l'article 96-3 ${ }^{564}$ du PA I ${ }^{565}$. De cette souscription prévue à l'article 96-3 se dégage le

560 Lire les commentaires du CICR de l'article $1^{\text {er }} \S 4$ du PA I aux points 112 et 113 http://www.icrc.org/dih.nsf/COM/470-750004?OpenDocument (Source consultée le 20 juillet 2015).

561 DAILLIER, Patrick, FORTEAU, Mathias et PELLET, Alain, Droit international public, Paris, L.G.D.J Lextenso éditions, 8è édition, 2009, p. 579.

${ }^{562}$ CIJ, Conformité au droit international de la déclaration unilatérale d'indépendance relative au Kosovo, avis consultatif, Recueil 2010, p. 436, \$79.

563 Ibid.

${ }^{564}$ Art. $96 \$ 3$ : «L'autorité représentant un peuple engagé contre une Haute Partie contractante dans un conflit armé du caractère mentionné à l'article premier, paragraphe 4, peut s'engager à appliquer les Conventions et le Protocole relativement à ce conflit en adressant une déclaration unilatérale au dépositaire. Après réception par le dépositaire, cette déclaration aura, en relation avec ce conflit, les effets suivants : a) les Conventions et le présent Protocole prennent immédiatement effet pour ladite autorité en sa qualité de partie au conflit ; $b$ ) ladite 
principe de l'égalité des belligérants ${ }^{566}$ vis-à-vis des droits et obligations découlant des CG et du PA I.

Concrètement, il y a conflit armé international et application des règles idoines dans les hypothèses suivantes : conflit opposant directement deux Etats ou plus, guerre de libération nationale, conflit armé interne mais qui devient international du fait qu'il a fait l'objet d'une reconnaissance de belligérance, qu'il y a intervention d'un ou plusieurs Etats, qu'il y a une action coercitive des Nations Unies sur la base des articles 43 et suivants de la Charte des Nations Unies.

\section{B. Les conflits armés non-internationaux (CANI)}

Les conflits armés de caractère non international constituent vraisemblablement les plus anciens et les plus nombreux des conflits ${ }^{567}$. Prenant en considération le degré d'intensité, les conflits armés internes se trouvent être répartis en deux catégories en DIH. Ce dernier les classe suivant l'article 3 commun aux 4 CG, «CANI de basse intensité » (B.1) et selon l'article $1^{\mathrm{er}}$ du PA II, «CANI de haute intensité » (B.2). Une troisième catégorie des CANI tend à être créée par le Statut de Rome, qui s'inspire en réalité sur un point précis de la jurisprudence du TPIY (cf. infra) ${ }^{568}$. Toutefois, cette «nouvelle catégorie » - si créée «n'aurait pas d'incidence sur le champ d'application du droit humanitaire mais uniquement sur la compétence de cette juridiction ${ }^{569}$.

Pour le reste, les lignes suivantes démontreront que suivant les seuils d'application, on distingue les CANI qui tombent sous le coup de l'article 3 commun et du PA II et ceux qui relèvent du seul article 3 commun $^{570}$.

\section{B. 1. Les CANI suivant l'article 3 commun aux CG : «CANI de basse intensité »}

L'article 3 commun aux $4 \mathrm{CG}$ dispose : «En cas de conflit armé ne présentant pas un caractère international et surgissant sur le territoire de l'une des Hautes Parties contractantes, chacune des parties au conflit sera tenue d'appliquer au moins les dispositions suivantes : 1) Les personnes qui ne participent pas directement aux hostilités, y compris les membres de forces armées qui ont déposé les armes et les personnes qui ont été mises hors de

autorité exerce les mêmes droits et s'acquitte des mêmes obligations qu'une Haute Partie contractante aux Conventions et au présent Protocole; et c) les Conventions et le présent Protocole lient d'une manière égale toutes les parties au conflit ».

${ }^{565}$ DEYRA, Michel, Le droit dans la guerre, op.cit., p. 171.

${ }^{566}$ Lire MEYROWITZ, Henri, Le principe de l'égalité des belligérants devant le droit de la guerre, A. Pédone, Paris, 1970, 418 p.

${ }^{567}$ BULA-BULA, Sayeman, Droit international humanitaire, op.cit., p. 165.

568 ASPREMONT, Jean d' et HEMPTINE, Jérôme de, Droit international humanitaire, Pedone, Paris, 2012, p. 64 ; DAVID, Eric, Principes de droit des conflits armés, $2^{\mathrm{e}}$ édition, op. cit., p. 133.

${ }_{570}^{5}$ ASPREMONT Jean d' et HEMPTINNE Jérôme de, op.cit., p. 71.

570 TPIR, Le Procureur c. Jean-Paul AKAYESU, Affaire n ${ }^{\circ}$ ICTR-96-4-T, jugement, Chambre de première instance I, 2 septembre 1998, p. 241, §601. (Jugement également disponible sur http://ictrarchive09.library.cornell.edu/FRENCH/cases/Akayesu/judgement/contents.html (Source consultée le 21 août 2016).; Voy. aussi CICR, «Comment le terme «conflit armé » est-il défini en droit international humanitaire?», Prise de position, mars 2008, disponible sur https://www.icrc.org/fre/resources/documents/article/other/armed-conflict-article-170308.htm (Source consultée le 27 août 2016). 
combat par maladie, blessure, détention, ou pour toute autre cause, seront, en toutes circonstances, traitées avec humanité, sans aucune distinction de caractère défavorable basée sur la race, la couleur, la religion ou la croyance, le sexe, la naissance ou la fortune, ou tout autre critère analogue. A cet effet, sont et demeurent prohibés, en tout temps et en tout lieu, à l'égard des personnes mentionnées ci-dessus :

a) les atteintes portées à la vie et à l'intégrité corporelle, notamment le meurtre sous toutes ses formes, les mutilations, les traitements cruels, tortures et supplices ;

b) les prises d'otage;

c) les atteintes à la dignité des personnes, notamment des traitements humiliants et dégradants ;

d) les condamnations prononcées et les exécutions effectuées sans un jugement préalable rendu par un tribunal régulièrement constitué, assorti des garanties judiciaires reconnues comme indispensable par les peuples civilisés.

2) Les blessés et malades seront recueillis et soignés. Un organisme humanitaire impartial, tel que le Comité international de la Croix-Rouge pourra offrir ses services aux parties au conflit.

Les parties au conflit s'efforceront, d'autre part, de mettre en vigueur par voie d'accords spéciaux tout ou partie des autres dispositions de la présente convention.

L'application des dispositions qui précèdent n'aura pas d'effet sur le statut juridique des parties au conflit. »

Ceci suscite quelques commentaires.

En effet, en l'absence de toute précision de l'article 3 commun au CG sur l'expression «conflit armé ne présentant pas un caractère international », celle-ci est appréhendée au plan doctrinal et jurisprudentiel comme tout conflit armé opposant des forces armées gouvernementales et des groupes armés non gouvernementaux ou ces derniers entre eux ${ }^{571}$. Et s'agissant du territoire sur lequel doit surgir le conflit armé à savoir «le territoire de l'une des Hautes Parties contractantes » (c'est-à-dire territoire d'un Etat partie aux CG), il ne se pose aucun problème car non seulement les CG sont actuellement ratifiés universellement ${ }^{572}$ mais de plus l'article 3 commun aux CG a acquis une valeur coutumière ${ }^{573}$ et considéré comme jus cogens. Ceci permet ainsi de régir la situation des conflits armés opposant « un Etat tiers à un

\footnotetext{
${ }^{571}$ Voy. ASPREMONT, Jean d' et HEMPTINE, Jérôme de, Droit international humanitaire, Pedone, Paris, 2012, p. 66 ; CICR, «Comment le terme «conflit armé » est-il défini en droit international humanitaire ? », Prise de position, mars 2008, disponible sur https://www.icrc.org/fre/resources/documents/article/other/armedconflict-article-170308.htm (Source consultée le 27 août 2016) ; TPIY, Le Procureur c/ Tadic, affaire n ${ }^{\circ}$ IT-941-AR72, Chambre d'appel, Arrêt relatif à l'appel de la Défense concernant l'exception préjudicielle d'incompétence, 2 octobre 1995, § 70 in http://www.icty.org/x/cases/tadic/acdec/fr/51002JN3.htm (Source consultée le 23 mars 2015) ; Lire CPI, Le Procureur c. Thomas Lubanga Dyilo, affaire $\mathrm{N}^{\circ}$ : ICC-01/04-01/06, Chambre de première instance, jugement, 14 mars 2012, in http://www.icc-cpi.int/iccdocs/doc/doc1462060.pdf (Source consultée le 22 mars 2015) notamment l'argument de la défense au § 512 (p. 256) et la conclusion de la Chambre de première instance au $\S 533$ reprenant d'ailleurs le $\S 70$ de l'arrêt précité du TPIY et ses paragraphes $534-539$.

572 CICR, «Comment le terme «conflit armé » est-il défini en droit international humanitaire ? », Prise de position, mars 2008, disponible sur https://www.icrc.org/fre/resources/documents/article/other/armed-conflictarticle-170308.htm (Source consultée le 27 août 2016).

${ }^{573}$ ASPREMONT, Jean d' et HEMPTINE, Jérôme de, Droit international humanitaire, op. cit., p. 66.
} 
groupement armé séjournant sur le territoire d'un autre Etat», conflits armés dits $\ll$ transnationaux ${ }^{574}$.

De cette disposition et du développement qui s'en suivra au PA II, les Etats ont finalement concédé, que - même souverains - ils étaient néanmoins soumis à certaines obligations dans le cadre d'un conflit armé qui les opposerait aux groupes armés non étatiques agissant sur leur territoire, lesquels se sont rebellés contre eux. Les Etats gardent néanmoins le pouvoir de faire application de leur droit national à cet égard (cf. infra). Ces groupes armés sont eux aussi sujets aux mêmes impératifs découlant du DIH. En réalité, c'est au profit des «personnes qui ne participent pas [ou plus] directement aux hostilités » que les parties au conflit s'obligent.

L'application de l'article 3 commun est sans effet sur le statut juridique des parties au conflit (art. $3 \S 2$, alinéa 2 commun aux CG). Pour Michel DEYRA, cela ne constitue pas, de la part d'un gouvernement légal, une reconnaissance de la partie adverse, et ne limite en aucune manière son droit de réprimer la rébellion et son droit de poursuivre, de juger et de condamner les rebelles pour leurs crimes conformément à sa législation nationale ${ }^{575}$. Par ailleurs, BULABULA Sayeman estime pour sa part que dans l'hypothèse où l'organisation rebelle négocierait avec le gouvernement en place en vue par exemple d'échanger des prisonniers directement ou par l'intermédiaire du CICR, il y a là de la part du pouvoir en place la reconnaissance d'un nouveau sujet de droit international doté d'une mini-personnalité internationale $^{576}$. Ceci viendrait bien à propos. Cet article - qualifié de «convention en miniature » ou de «convention dans la convention» dans la mesure où c'est l'unique disposition qui s'applique à une situation (CANI) autre que les CAI pour lesquels les CG ont été adoptées - a le grand avantage de prévoir la possibilité d'appliquer les autres dispositions des CG (en intégralité ou en partie) notamment par voie d'accords spéciaux qui pourraient être conclus entre parties au conflit.

Bien plus, l'article 3 commun permet d'inclure toute catégorie de conflit armé de caractère non international avec un seuil de basse intensité. Comparativement au PA II (cf. infra), il érige ainsi un champ d'application large, « attrape-tout » et donc efficacement protecteur en DIH. En ce sens, «le critère appliqué par la Chambre d'appel du TPIY quant à l'existence d'un conflit armé aux fins des dispositions de l'article 3 commun se concentre sur deux aspects d'un conflit : son intensité et l'organisation des parties à ce conflit. Dans un conflit armé de caractère interne ou mixte, ces critères étroitement liés servent, au minimum, uniquement aux fins de distinguer un conflit armé du banditisme, d'insurrections inorganisées et de courte durée ou d'activités terroristes, qui ne relèvent pas du droit international humanitaire $»^{577}$.

La jurisprudence a donc permis de préciser les critères d'applicabilité des dispositions de l'article 3 commun. Elle conduit à exiger des conditions que l'on retrouvera à propos du PA

\footnotetext{
574 Ibid.

${ }^{575}$ DEYRA, Michel, Le droit dans la guerre, op.cit., p. 173.

${ }_{577}^{576}$ BULA-BULA, Sayeman, Droit international humanitaire, op.cit., p. 165.

577 TPIY, Le Procureur c/ Dusco TADIC alias «DULE», Chambre de première instance Affaire n ${ }^{\circ}$ IT-94-1-T, jugement du 07 mai 1997 http://www.icty.org/x/cases/tadic/tjug/fr/tad-tj970507f.pdf (Source consultée le 15 juillet 2015); Voy. aussi TPIR, Le Procureur c. Jean-Paul AKAYESU, Affaire n ${ }^{\circ}$ ICTR-96-4-T, jugement, Chambre de première instance I, 2 septembre 1998, pp. 243-247, §§601-610. (Jugement également disponible sur http://ictr-archive09.library.cornell.edu/FRENCH/cases/Akayesu/judgement/contents.html (Source consultée le 21 août 2016).
} 
II ; à savoir le degré suffisant d'organisation des parties en présence et un niveau d'hostilités ouvertes et collectives, distinctes des simples coups de mains ou attentats ${ }^{578}$. En d'autres termes, «les hostilités doivent atteindre un niveau minimal d'intensité. Ce peut être le cas, par ex. lorsque les hostilités ont un caractère collectif ou lorsque le gouvernement est obligé d'avoir recours à la force militaire contre les insurgés, plutôt qu'aux simples forces de police » (critère d'intensité $^{579}$. En outre, « les groupes non gouvernementaux impliqués dans le conflit doivent être considérés comme des " parties au conflit », c'est-à-dire qu'ils doivent disposer de forces armées organisées. Ce qui signifie, par ex., que ces forces doivent être soumises à une certaine structure de commandement et qu'elles doivent avoir la capacité de mener des opérations militaires durables ${ }^{580}$. Ce qui relève dans leur chef d'une certaine organisation (critère d'organisation) (cf. infra). Bien que celle-ci ne doit pas être à la hauteur de celle des armées régulières où l'on voit une Administration bien structurée. La jurisprudence retient, pour sa part, un niveau minimal d'organisation pour les cas de CANI (cf. infra).

Par ailleurs, cet article insiste sur le traitement avec humanité à l'endroit des personnes qui ne participent pas directement aux hostilités, ou de toute personne qui ne participe pas ou plus aux hostilités. L'expression "traiter avec humanité » tire son origine de l'article 4 du Règlement de La Haye et a été reprise par les Conventions de 1929 et $1949^{581}$. Pris dans son sens le plus général, le terme «traitement» s'applique à toutes les conditions d'existence humaine $^{582}$. La jurisprudence renseigne que «toutes les [trois] chambres du TPIR ont eu à décider, souvent à l'unanimité, que l'une des conséquences de la règle de traitement humain réside dans la nécessité de fournir une protection renforcée aux catégories de personnes civiles qui subissent, d'une façon particulièrement grave, les effets des conflits armés et qui se retrouvent, de ce fait, dans une situation de grande détresse ${ }^{583}$. En même temps, il faudrait souligner que les règles fondamentales posées dans cet article ont valeur de normes coutumières et représentent un minimum auquel les belligérants ne devraient jamais déroger ${ }^{584}$.

Au-delà de ses avantages d'être un article ouvrant un champ d'application plus étendu à la notion de conflit armé, il est considéré lui-même comme «noyau dur de la protection des personnes en situation des conflits armés internes» avec une possibilité de protection maximale par voie d'accords spéciaux (art.3 $\$ 2$ alinéa 2). Et d'ailleurs suivant le prescrit de l'article 3 «[...] chacune des parties au conflit sera tenue d'appliquer au moins les dispositions suivantes [...]» (nous soulignons), il n'est donc pas exclu aux parties d'appliquer les dispositions qui se rapportent aux conflits armés internationaux.

\footnotetext{
${ }^{578}$ BETTATI, Mario, Droit humanitaire. Textes introduits et commentés, op.cit., p. 40.

579 CICR, «Comment le terme « conflit armé » est-il défini en droit international humanitaire ? », Prise de position, mars 2008, disponible sur https://www.icrc.org/fre/resources/documents/article/other/armed-conflictarticle-170308.htm (Source consultée le 27 août 2016).

${ }^{580}$ Ibid.

581 JUNOD, Sylvie-S., Commentaire de l'article 4 du Protocole II Garanties fondamentales, paragraphe 1, in SANDOZ, Yves, SWINARSKI, Christophe et ZIMMERMANN, Bruno (éd. et Coord.), Commentaire des Protocoles additionnels du 8 juin 1977 aux Conventions de Genève du 12 août 1949, Comité international de la Croix-Rouge, Martinus Nijhoff Publishers, Genève 1986, p. 1394.

582 Ibid.

${ }^{583}$ BIRUKA Innocent, op.cit., p. 217.

${ }^{584}$ BIAD, Abdelwahab, Droit international humanitaire, $2^{\mathrm{e}}$ édition, op.cit., p. 28.
} 
Cependant, l'article 3 commun comporte plusieurs inconvénients.

En termes d'inconvénients, BULA-BULA Sayeman retient que les CG ne définissent pas à proprement parler le type de conflits auxquels elles font référence. Elles les envisagent de manière négative et créent une confusion au sujet du seuil minimum à partir duquel la clause s'applique et du seuil maximum au-delà duquel la stipulation ne vaut plus demeurer entière. Ainsi, les critères de distinction avec d'autres atteintes à l'ordre public ne sont guère précis. L'auteur épingle également l'imprécision sur la portée de la protection humanitaire. Ici, la clause conventionnelle est fortement condensée laissant une marge trop large d'interprétation pour les parties en présence. D'où les risques de controverses sur l'étendue de la protection prévue. Enfin, il y a lieu d'ajouter l'inadéquation de la clause à la nature spécifique du conflit interne et l'absence d'un mécanisme de contrôle institutionnel ${ }^{585}$.

A propos du seuil, disons que l'établissement d'un seuil n'a jamais été possible et les interprétations sont divergentes ${ }^{586}$, le $13^{\mathrm{e}}$ Colloque international de Bruges sur le Droit international humanitaire tenu du 18 au 19 octobre 2012 a su également le démontrer. Ainsi, l'on se demandera face à certaines situations s'il faut appliquer les règles du DIH ou continuer à appliquer les normes des droits de l'homme. Toutefois, la jurisprudence de la CPI qui confirme celle du TPIY ou encore du TPIR ${ }^{587}$ fait part d'une piste exploitable en s'attelant sur l'intensité du conflit. « Le TPIY a conclu que l'intensité du conflit devrait « servir seulement à distinguer un conflit armé du banditisme, des insurrections inorganisées et de courte durée ou des activités terroristes, qui ne relèvent pas du droit international humanitaire » (cf. supra ${ }^{588}$. Et pour apprécier l'intensité d'un conflit potentiel, le TPIY indique de «prendre en considération la gravité des attaques et la multiplication possible des affrontements armés, leur extension dans le temps et dans l'espace, le renforcement des effectifs des forces gouvernementales, la mobilisation et la répartition des armes entre les deux parties au conflit, la question de savoir si le conflit a attiré l'attention du Conseil de sécurité de l'ONU et, dans l'affirmative, si ce dernier a adopté des résolutions à son sujet ${ }^{589}$.

Hormis ces inconvénients retenus au sujet de l'article 3 commun aux CG, Abdelwahab BIAD retient que «cet article ne contient aucune règle qui régisse spécifiquement la conduite des hostilités ${ }^{590}$. Toutefois, une lecture en filigrane de cette disposition permettrait de croire que les règles relatives au droit de la Haye n'y sont pas totalement absentes. En clair, du moment où l'article 3 commun insiste sur le traitement avec humanité des personnes qui ne prennent pas ou plus directement part aux hostilités, l'on pourrait très bien comprendre que les personnes qui combattent ne sont pas libres d'utiliser les moyens ou méthodes de combat de leur choix. Ceci risque d'être nuisible aux personnes civiles ou autres qui ne prennent pas

\footnotetext{
${ }^{585}$ Lire BULA-BULA, Sayeman, Droit international humanitaire, op.cit., p. 172.

${ }_{586}^{58}$ BETTATI, Mario, Droit humanitaire. Textes introduits et commentés, op.cit., p. 41.

${ }^{587}$ Voy., par exemple, TPIR, Le Procureur c. Jean-Paul AKAYESU, Affaire n'ICTR-96-4-T, jugement, Chambre de première instance I, 2 septembre 1998, pp. 251-252, §620. (Jugement également disponible sur http://ictrarchive09.library.cornell.edu/FRENCH/cases/Akayesu/judgement/contents.html (Source consultée le 21 août 2016).

${ }_{588}$ CPI, Le Procureur c. Thomas Lubanga Dyilo, affaire $\mathrm{N}^{\circ}$ : ICC-01/04-01/06, Chambre de première instance, jugement, 14 mars 2012, p. 267, § 537, in http://www.icc-cpi.int/iccdocs/doc/doc1462060.pdf (Source consultée le 22 mars 2015).

${ }^{589}$ Ibid.

${ }^{590}$ BIAD, Abdelwahab, Droit international humanitaire, $2^{\mathrm{e}}$ édition, op.cit., p. 28.
} 
directement part ou ne prennent plus part aux hostilités et de violer ainsi le principe du «traitement avec humanité » qui caractérise cette disposition. En appui à cet argument, Gloria GAGGIOLI précise que ces règles, qui ont acquis une valeur coutumière, bien que conçues initialement comme ne comprenant pas les règles relatives à la conduite des hostilités, ont par la suite été interprétées par le TPIY de façon à inclure les règles relatives à la conduite des hostilités. Ainsi, l'interdiction des «atteintes portées à la vie et à l'intégrité corporelle » comprend l'interdiction d'attaquer des civils qui ne participent pas directement aux hostilités ainsi que les membres des forces armées qui ont déposées les armes et les personnes mises hors combat ${ }^{591}$.

\section{B. 2. Les CANI suivant l'article $1^{\text {er }}$ du PA II : «CANI de haute intensité »}

Par ailleurs, un autre type de conflits armés internes qui apparaît plus restrictif par rapport à celui évoqué ci-dessus sera défini par l'article $1^{\mathrm{er}}$ du PA II : «1. Le présent Protocole, qui développe et complète l'article 3 commun aux Conventions de Genève du 12 août 1949 sans modifier ses conditions d'application actuelles, s'applique à tous les conflits armés qui ne sont pas couverts par l'article premier du Protocole additionnel aux Conventions de Genève du 12 août 1949 relatif à la protection des victimes des conflits armés internationaux (Protocole I), et qui se déroulent sur le territoire d'une Haute Partie contractante entre ses forces armées et des forces armées dissidentes ou des groupes armés organisés qui, sous la conduite d'un commandement responsable, exercent sur une partie de son territoire un contrôle tel qu'il leur permette de mener des opérations militaires continues et concertées et d'appliquer le présent Protocole». Le paragraphe 2 de cet article limite son champ d'application en ces termes : «2. Le présent Protocole ne s'applique pas aux situations de tensions internes, de troubles intérieurs, comme les émeutes, les actes isolés et sporadiques de violence et autres actes analogues, qui ne sont pas considérés comme des conflits armés».

«C'est une définition alambiquée que la Conférence diplomatique de Genève (1974 -1977), conciliant des points de vue contradictoires des Etats qui a été retenue ${ }^{592}$. Aux yeux des doctrinaires avertis du $\mathrm{DIH}$, elle pose des conditions parfois difficiles à reconnaître ou appliquer sur le champ de combat.

«Le seuil d'applicabilité du Protocole est donc plus élevé que celui des Conventions, et si l'article 3 commun s'applique obligatoirement à toute situation envisagée par le Protocole II, l'inverse n'est pas vrai ${ }^{593}$. Le PA II n'envisage pas les conflits armés qui opposeraient des forces armées dissidentes ou des groupes armés non étatiques entre eux, aussi organisés soient-ils. «Le CICR, dans son projet, avait prévu l'applicabilité du PA II dans le cas où plusieurs factions viendraient à s'affronter sans l'intervention des forces armées gouvernementales, si le gouvernement établi avait par exemple disparu ou était trop faible pour intervenir. Cette hypothèse est apparue comme un « cas d'école », purement théorique et n'a pas été retenue, $[\ldots] »^{594}$. Apparue comme un cas d'école, cette hypothèse était pourtant

\footnotetext{
${ }^{591}$ GAGGIOLI, Gloria, L'influence mutuelle entre les droits de l'homme et le droit international humanitaire à la lumière du droit à la vie, éd. A. Pedone, Paris, p. 265.

${ }_{592}$ BULA-BULA, Sayeman, Droit international humanitaire, op.cit., p. 177.

${ }^{593}$ DEYRA, Michel, Le droit dans la guerre, op.cit., p. 173.

594 Commentaires du PA II $\S 4461$ in http://www.icrc.org/dih.nsf/COM/475-760004?OpenDocument (Source consultée le 22 mars 2015).
} 
observable à l'époque en Angola et au Liban ${ }^{595}$. Les différentes situations actuelles de conflits armés intermittents qui se déroulent sur le territoire de la RDC attestent également ce point de vue (cf. infra). L'on comprend mieux par là que c'est une conception classique de la guerre civile qui reste prévalante ${ }^{596}$. Bien plus, d'autres conditions rendent l'application du PA II difficile. L'article $1^{\text {er }}$ précité exige des forces armées dissidentes ou groupes armés non étatiques une certaine organisation, une conduite sous un commandement responsable, un contrôle d'une partie du territoire pour mener des opérations militaires continues et concertées et appliquer les règles du $\mathrm{DIH}$.

En clair, pour le CICR dans ses commentaires du PA II, l'existence d'un commandement responsable implique une certaine organisation des groupes armés insurgés ou des forces armées dissidentes, mais cela ne signifie pas forcément la mise en place d'un système d'organisation militaire hiérarchique similaire à celui de forces armées régulières. Il s'agit d'une organisation suffisante, d'une part, pour concevoir et mener des opérations militaires continues et concertées, de l'autre, pour imposer une discipline au nom d'une autorité de fait $^{597}$. Au sens de la Chambre de première instance de la CPI, « [1]orsqu'il s'agit de décider si l'on est en présence d'un groupe armé organisé (pour déterminer si un conflit armé ne présentait pas un caractère international), les éléments de fait suivants, dont la liste n'est pas exhaustive, peuvent être pertinents : la hiérarchie interne de la force ou du groupe en cause ; la structure de commandement et les règles appliquées; la capacité de se procurer des équipements militaires, notamment des armes à feu; la capacité de la force ou du groupe en cause de planifier et de mener des opérations militaires; et l'étendue, la gravité et l'intensité de toute intervention militaire. Aucun de ces éléments de fait n'est déterminant à lui seul ${ }^{598}$. Et concernant le contrôle suffisant du territoire qui n'est donc plus appréciable quantitativement sinon qualitativement, il existe aujourd'hui une tendance à interpréter la notion de «contrôle territorial » de manière libérale aussi bien de la part du CICR que des tribunaux pénaux internationaux. Ainsi, la Chambre préliminaire I de la CPI dans l'affaire Lubanga, en interprétation de l'article 8-2-f, a récemment confirmé cette pratique en indiquant qu'il est suffisant que « les groupes armés en question aient la capacité de concevoir et mener des opérations militaires pendant une période prolongée » et que cette capacité n'est plus liée au contrôle d'un territoire ${ }^{599}$. «Reprenant cette conclusion à son compte, la Chambre de première instance fait observer que l'article 8-2-f du Statut exige seulement l'existence d'un conflit opposant « de manière prolongée » des «groupes armés organisés». À la différence du Protocole additionnel II, il n'exige pas que les groupes armés « exercent sur une partie $\mathrm{d}[\mathrm{u}]$ territoire un contrôle tel qu'il leur permette de mener des opérations militaires continues et concertées ${ }^{600}$.

\footnotetext{
595 ASPREMONT, Jean d' et HEMPTINE, Jérôme de, Droit international humanitaire, op. cit., , p. 64

596 Lire BULA-BULA Sayeman, op.cit., 177., DEYRA Michel, op.cit., 174., BETTATI Mario, Droit humanitaire. Textes introduits et commentés, op.cit., 41.

${ }^{597}$ Commentaires du PA II $§ 4463$, in http://www.icrc.org/dih.nsf/COM/475-760004?OpenDocument (Source consultée le 22 mars 2015).

${ }^{598}$ CPI, Le Procureur c. Thomas Lubanga Dyilo, affaire $N^{\circ}$ : ICC-01/04-01/06, Chambre de première instance, jugement, 14 mars 2012, p. 266, § 537, in http://www.icc-cpi.int/iccdocs/doc/doc1462060.pdf (Source consultée le 22 mars 2015).

599 MAYSTRE, Magali, op.cit., pp. 49-50 ; CPI, Le Procureur c. Thomas Lubanga Dyilo, affaire $\mathrm{N}^{\circ}$ : ICC01/04-01/06, Chambre de première instance, jugement, 14 mars 2012, § 537, 266 in http://www.icccpi.int/iccdocs/doc/doc1462060.pdf (Source consultée le 22 mars 2015).

${ }^{600}$ CPI, Le Procureur c. Thomas Lubanga Dyilo, affaire N ${ }^{\circ}$ : ICC-01/04-01/06, Chambre de première instance,
} 
S'agissant des opérations militaires continues et concertées, il y a lieu là d'exclure les attaques isolées ou sporadiques. Suivant le CICR, il s'agit donc d'opérations militaires conçues et préparées par des groupes armés organisés. Les critères de durée et d'intensité n'ont pas été retenus comme tels dans la définition parce qu'ils auraient introduit un élément subjectif. Le CICR précise tout de même que le critère du caractère continu et concerté des opérations militaires, tout en sous-entendant l'élément de durée et d'intensité, répond, en revanche, à une constatation objective de la situation ${ }^{601}$. Enfin, les groupes armés doivent assurer le respect des règles du DIH contenues dans ce protocole. Ce dernier critère est appréhendé par le CICR comme le critère fondamental qui justifie les autres éléments de la définition ${ }^{602}$.

Par ailleurs, bien qu'initialement le PA II ne soit pas destiné à s'appliquer aux conflits armés qui opposeraient les forces ou groupes armés qui se battraient entre eux, Mario BETTATI estime que des commentateurs n'excluent pas une telle possibilité ${ }^{603}$. Toutefois, le commentaire du CICR à ce sujet ne l'atteste pas ${ }^{604}$. L'hypothèse d'affrontement armé entre groupes armés organisés reste sous l'empire de l'article 3 commun, voire de l'article 19 de la Convention pour la protection des biens culturels en cas de conflit armé du 14 mai 1954 et de l'article 8-2-f du Statut de Rome.

Pour la jurisprudence des juridictions pénales internationales, le CANI est appréhendé comme « un conflit armé prolongé entre les autorités gouvernementales et des groupes armés organisés ou entre de tels groupes au sein d'un Etat ${ }^{605}$. Cette définition dégagée dès 1995 par le TPIY sera donc reprise en 1998 par l'article 8-2-f du Statut de Rome de la CPI. En appréhendant, en partie, les CANI comme des conflits armés opposant de «manière prolongée » sur le territoire d'un Etat «des groupes armés organisés entre eux », la jurisprudence et le Statut de Rome laissent sous-entendre une troisième catégorie de CANI ${ }^{606}$ et ignorent la distinction entre les CANI de haute ou de basse intensité ${ }^{607}$.

Ainsi l'introduction dans le DIH du PA II qui vise en principe à mieux protéger les victimes des conflits armés non internationaux, a pour conséquence de faire coexister deux notions de conflits armés à caractère non international : celle du Protocole et celle de l'article 3 commun aux 4 CG. Le conflit armé visé par le PA II est en effet, envisagé plus restrictivement que celui auquel s'applique l'article 3 commun. Alors que ce dernier vise tous les conflits armés

jugement, 14 mars 2012, p. 266, §536, in http://www.icc-cpi.int/iccdocs/doc/doc1462060.pdf (Source consultée le 22 mars 2015).

${ }^{601}$ Commentaires du PA II $\S 4469$, in http://www.icrc.org/dih.nsf/COM/475-760004?OpenDocument (Source consultée le 22 mars 2015).

${ }^{602}$ Ibid., $\$ 4470$.

${ }^{603}$ BETTATI, Mario, Droit humanitaire. Textes introduits et commentés, op.cit., p. 41.

${ }^{604}$ Voy. Commentaires du PA II $\S$ 4461, in http://www.icrc.org/dih.nsf/COM/475-760004?OpenDocument (Source consultée le 22 mars 2015).

${ }^{605}$ Lire TPIY, Le Procureur c/ Tadic, affaire ${ }^{\circ}$ IT-94-1-AR72, Chambre d'appel, Arrêt relatif à l'appel de la Défense concernant l'exception préjudicielle d'incompétence, 2 octobre 1995, $\S 70$, in http://www.icty.org/x/cases/tadic/acdec/fr/51002JN3.htm (Source consultée le 23 mars 2015); Lire CPI, Le Procureur c. Thomas Lubanga Dyilo, affaire $\mathrm{N}^{\circ}$ : ICC-01/04-01/06, Chambre de première instance, jugement, 14 mars 2012, in http://www.icc-cpi.int/iccdocs/doc/doc1462060.pdf (Source consultée le 22 mars 2015) notamment l'argument de la défense au $\S 512$ (p. 256) et la conclusion de la Chambre de première instance au $\S$ 533 reprenant d'ailleurs le $\S 70$ de l'arrêt précité du TPIY et ses paragraphes 534 - 539 .

${ }^{606}$ ASPREMONT, Jean d' et HEMPTINE, Jérôme de, Droit international humanitaire, op. cit.,p. 64 ; DAVID, Eric, Principes de droit des conflits armés, $2^{\mathrm{e}}$ édition, op. cit., p. 133.

${ }^{607}$ ASPREMONT, Jean d' et HEMPTINE, Jérôme de, Droit international humanitaire, op. cit., p. 64. Lire avec intérêt la page 70 de cet ouvrage. 
non internationaux, seuls ceux d'une certaine intensité sont soumis au PA II. Les termes de l'article $1 \S 1$ du PA II ${ }^{608}$ ne laissent aucun doute à ce sujet ${ }^{609}$. Cette situation est peu satisfaisante car elle complique la qualification juridique des conflits armés internes et devient ainsi inévitablement source de problèmes. Toutefois, la pratique et la jurisprudence tentent de s'y pencher pour y remédier.

Par ailleurs, l'article 1er $\S 2$ du PA II a précisé que les «tensions internes », «troubles internes », «émeutes », « actes isolés et sporadiques de violence » et autres actes analogues ne constituent pas des conflits armés et ne sont de ce fait pas soumis au DIH. Ces notions ne sont pas toujours aisées à distinguer, en pratique, de conflits armés ${ }^{610}$. Il importe, tout de même, de préciser d'ores et déjà que les notions de «tensions internes » et de «troubles internes » recouvrent un ensemble de situations caractérisées toutes par des phénomènes de violences liées à des violations des droits de l'homme. C'est notamment les cas des affrontements directs entre les forces de l'ordre et des opposants au régime, de tensions de caractère ethnique ou racial, religieux ou idéologique, économique ou social, etc. Les forces de 1 'ordre peuvent intervenir à titre préventif ou curatif ${ }^{611}$.

AKELE Adau précise que juridiquement, quoi qu'il en soit, toutes ces situations critiques ou conflictuelles [tensions internes, troubles intérieurs ou conflits armés non internationaux] sont perçues comme des violations de l'ordre public ou comme des actes violentant l'ordre établi. C'est donc une matière qui relève de la pleine souveraineté et par conséquent de la pleine responsabilité de l'Etat comme le rappelle l'article $3 \mathrm{du}$ PA II, qui dispose dans son alinéa $1^{\text {er }}$ que «[a]ucune disposition du présent protocole ne sera invoquée en vue de porter atteinte à la souveraineté d'un Etat ou à la responsabilité du gouvernement de maintenir ou de rétablir l'ordre public dans l'Etat ou de défendre l'unité nationale et l'intégrité territoriale de l'Etat par tous les moyens légitimes ${ }^{612}$. Même dans des situations des troubles internes ou tensions internes, il n'est pas interdit à l'Etat en cause de faire application de dispositions du DIH bien qu'il n'y soit pas obligé. C'est l'application du DIH par analogie ${ }^{613}$.

Bien plus, dans la mesure où les normes internationales qui protègent l'individu contre l'abus du pouvoir en période de troubles et tensions internes ne sont pas entièrement aptes à assurer une telle protection, notamment par la suspension de certains droits de l'homme en pareilles situations, la doctrine a fait part des textes déclaratoires et des codes de conduite ${ }^{614}$. Lesquels

\footnotetext{
${ }^{608}$ Art. 1er $\$ 1$ : «Le présent Protocole qui complète et développe l'article 3 commun aux Convention de Genève du 12 août 1949 sans modifier ses conditions d'application actuelles, s'applique à tous les conflits armés qui ne sont pas couverts par l'article premier du [...] Protocole I et qui se déroulent sur le territoire d'une Haute Partie contractante entre ses forces armées et des forces dissidentes ou des groupes armés organisés qui sous la conduite d'un commandement responsable exercent sur une partie de son territoire un contrôle tel qu'il leur permette de mener des opérationss militaires continues et concertées et d'appliquer le présent Protocole ».

${ }^{609}$ Lire DAVID, Eric, Principes de droit des conflits armés, $5^{\mathrm{e}}$ édition, op. cit., p. 131.

${ }^{610}$ Ibid, p. 147.

${ }^{611}$ RICR « Troubles et tensions internes : pour une nouvelle approche humanitaire ?», in RICR, $\mathrm{n}^{\circ} 769$, janvier - février 1988, p. 3.

${ }^{612}$ AKELE Adau, «Droit International Humanitaire, les Droits de l'Homme et les situations des troubles Internes », in Zaïre Afrique, ${ }^{\circ} 216, \mathrm{XXXV}^{\mathrm{e}}$ année juin 1995, p. 347.

${ }^{613}$ Lire KOLB, Robert, Ius in bello. Le droit international des conflits armés, 2 édition, op. cit., p. 231.

${ }^{614}$ Lire MERON, Theodor, «Projet de déclaration type sur les troubles et tensions internes », in RICR, $\mathrm{n}^{\circ} 769$, janvier - février 1988, pp. 62-80.; GASSER, Hans-Peter, «Un minimum d'humanité dans les situations de troubles et tensions internes : proposition d'un Code de conduite », in RICR, $\mathrm{n}^{\circ} 769$, janvier - février 1988, op. cit., pp. 39 - 60. Dans son article «Les normes humanitaires pour les situations de troubles et tensions internes. Aperçu des derniers développements », in RICR, n801, mai-juin 1993, pp. 238-244 ; GASSER, Hans-Peter fait
} 
s'inspirent à la fois des règles et principes du DIDH et du DIH afin de s'adapter et de régler les situations découlant des troubles ou tensions internes. L'idée est de faire en sorte que « les principes d'humanité et les principes humanitaires minimaux » soient pris en compte en situation de troubles intérieurs, tensions internes et de violence ${ }^{615}$. Toutefois, il n'existe pas à ce stade des obligations internationales découlant du DIH s'imposant aux Etats en temps des troubles et tensions internes.

\section{Les conflits armés internes internationalisés}

Les conflits armés internes internationalisés, appelés aussi conflits mixtes, relèvent du régime juridique du CAI bien que traités distinctement.

En effet, suivant la Chambre préliminaire I de la CPI se fondant sur l'article 2 commun aux CG, le commentaire du CICR à ce sujet et l'Arrêt Tadic du TPIY, «[...] un conflit armé interne qui éclate sur le territoire d'un État peut devenir international — ou, selon les circonstances, présenter parallèlement un caractère international - si i) les troupes d'un autre État interviennent dans le conflit (intervention directe) ou si ii) certains participants au conflit armé interne agissent au nom de cet autre État (intervention indirecte) ${ }^{616}$.

Il s'agit d'une guerre civile ou d'un conflit armé interne qui bénéficie de l'aide ou de l'appui de l'extérieur au profit de l'une des parties. Le sujet extérieur qui intervient pour décolorer cet aspect de guerre civile en conflit armé internationalisé doit être un sujet «majeur» de DI. L'«intervention est, comme l'agression, toujours le fait d'un Etat, d'un groupe d'Etats, voire, par conséquent, d'une organisation internationale ${ }^{617}$. C'est dans ce sens que l'aide apportée par des rebelles ou groupes armés existant au sein d'un Etat donné au profit d'un autre Etat en lutte de conflit armé interne ne conduira pas à qualifier celui-ci de conflit armé interne internationalisé. De même si cette aide était apportée aux autres rebelles. Ceci est nettement le cas de l'intervention du Mouvement de Libération du Congo (MLC) de Jean Pierre BEMBA sollicitée par le président centrafricain Ange Felix PATASSE entre octobre 2002 et mars 2003 pour mater une rébellion interne. Cette position n'est toutefois pas partagée par certains auteurs. David CUMIN estime que le conflit armé s'internationalise également «lorsqu'un groupe ou entité non étatique sur le territoire d'un Etat B se livre à des attaques d'une certaine

allusion notamment à la «Déclaration d'Oslo sur les normes et les procédures à respecter en cas de danger public exceptionnel ou de troubles et tensions internes » de juin 1987 et la Déclaration de Turku/Abo (Finlande) sur les normes humanitaires minimales rédigée par des universitaires et des membres des organisations internationales en 1990 (Voy. p. 241). Résultat d'une approche normative, cette dernière déclaration sera introduite dans le système des Nations unies notamment à la session de 1991 de la Sous - commission de la lutte contre les mesures discriminatoires et de la protection des minorités pour être présenté finalement comme un des rapports de ladite Sous-commission à l'AG/NU via le Secrétariat. Cette Sous-commission fera allusion également à cette déclaration lorsqu'il s'agira de se prononcer sur la situation des droits de l'homme en Irak en 1992 par sa décision 1992/106 ( Voy. GASSER, Hans-Peter, pp. 242 -243).

${ }^{615}$ GASSER, Hans-Peter, «Les normes humanitaires pour les situations de troubles et tensions internes. Aperçu des derniers développements », in RICR, n801, mai-juin 1993, p. 240.

${ }^{616}$ CPI, Le Procureur c. Thomas Lubanga Dyilo, affaire $\mathrm{N}^{\circ}$ : ICC-01/04-01/06, Chambre de première instance, jugement, 14 mars 2012, p. 269, $\quad$ $\quad$ 2 541, in https://www.icccpi.int/fr_menus/icc/situations\%20and\%20cases/situations/situation\%20icc\%200104/related\%20cases/icc\%2001 04\%200106/court\%20records/chambers/trial\%20chamber\%20i/Pages/2842.aspx (Source consultée le 22 mars 2015)

${ }^{617}$ DAVID, Eric, Principes de droit des conflits armés, 5 édition, op.cit., p. 161. 
gravité à l'encontre d'un Etat $\mathrm{A}$, avec ou sans imputation à l'Etat $\mathrm{B} »^{618}$.

Un autre problème délicat réside au sujet de l'internationalisation des conflits armés suite à l'intervention d'une organisation internationale, notamment l'ONU. La doctrine reconnaît moyennant l'application de certaines dispositions de la Charte de l'ONU l'internationalisation du conflit armé au sein d'un Etat par l'intervention de l'ONU. En effet, « [i]l est généralement reconnu que l'intervention des Nations unies internationalise le conflit lorsque les forces armées de l'Organisation des Nations Unies interviennent dans le cadre des articles 43 et suivants de la Charte. En effet, ces dispositions prévoient que les Etats Membres mettent des forces armées à la disposition du Conseil de Sécurité sur la base d'accords à conclure avec celui-ci. Ces dispositions n'ont jamais été appliquées, la guerre froide rendant impossible toute entente à ce sujet. Mais elles restent valides puisqu'elles n'ont pas été abrogées. Donc si ces forces étaient constituées et si elles étaient opposées à un Etat tiers, le conflit serait international ${ }^{619}$. Tout de même pour assurer sa mission de maintien de la paix et la sécurité internationales lui confiée par les Etats membres (art. 24 de la Charte de 1'ONU) et répondre à ce qui pourrait en constituer une menace ou une rupture, des opérations de paix sont menées et obligent parfois les forces des Nations Unies à prendre part aux hostilités et donc aux conflits armés. Ainsi pour David CUMIN, une action militaire non coercitive comme c'est le cas d'opération de maintien de la paix et/ou d'assistance humanitaire armée n'internationalise pas le conflit armé. En revanche, le conflit armé s'internationalise dans le cas d'une action militaire coercitive où les forces onusiennes font face à une partie au conflit, gouvernementale ou insurgée ${ }^{620}$. Précisons avec Eric DAVID que les missions de maintien de la paix ne sont pas en principe envoyées pour prendre part au conflit armé, interne ou international. Il arrive toutefois que sur base de leur mandat elles prennent part aux hostilités. C'est notamment le cas de l'ONU au Congo (ONUC) qui a été autorisée à prendre toutes mesures -dont l'usage de la force - pour empêcher la survenance de la guerre civile. L'ONUC utilisa la force le 28 décembre 1962 pour réduire la sécession katangaise et obtenir la reddition de Moïse Tshombe le 14 janvier $1963^{621}$. Toujours dans cette logique d'idées, l'on se rappellera que l'intervention de l'OTAN en Lybie a été vue aux yeux de l'ensemble de la doctrine et du CICR en particulier comme un conflit armé interne internationalisé. Et le fait pour l'OTAN d'être aux prises avec les forces gouvernementales a été vu comme conflit armé international.

Au regard de ce qui précède, Mario BETTATI avance, pour sa part, un argument qui aurait logiquement pour conséquence de ne pas admettre l'internationalisation d'un conflit armé interne par l'ONU. Ainsi pour lui, le concept «conflit armé » exclut de son champ de définition «toute action armée de l'ONU, laquelle, en vertu du chapitre VII de la Charte, n'est pas un acte de guerre mais une opération de police, en ce qu'elle poursuit un but de contrainte collective sur injonction d'un organe international ${ }^{622}$.

Par ailleurs, s'il est vrai qu' «un conflit interne s'internationalise à partir du moment où un

\footnotetext{
${ }^{618}$ CUMIN, David, Manuel de droit de la guerre, éd. Larcier, Bruxelles, 2014, op.cit., p.151.

619 SOUMAORO, Souleymane, «La qualification des conflits armés », in MATHESON, Michael J. et MOMTAZ, Djamchid, op.cit., 211. DAVID, Eric, Principes de droit des conflits armés, 5è édition, op.cit., p. 179.

${ }^{620}$ CUMIN, David, Manuel de droit de la guerre, op.cit., p.151.

621 DAVID, Eric, Principes de droit des conflits armés, 5è édition, op.cit., pp.179- 181.

${ }^{622}$ BETTATI, Mario, Droit humanitaire. Textes introduits et commentés, op.cit., 36. BETTATI, Mario, Droit humanitaire, $1^{\text {re }}$ édition, Dalloz, op.cit., p. 30.
} 
Etat tiers intervient en laissant ses agents participer aux hostilités ${ }^{623}$, la différence, en termes de fait générateur du droit applicable, avec le conflit armé interne réside dans l'opposition armée entre Etats ou acteurs agissant pour leur compte. C'est justement dans ce sens qu'il faudrait bien comprendre qu' «[u]n conflit armé initialement non international peut, par un appui croissant de l'extérieur [...], devenir un «conflit armé interne internationalisé » ou entièrement international, si les forces armées de différents Etats s'opposent les unes aux autres ${ }^{624}$. La Chambre préliminaire II de la CPI concluait d'ailleurs à ce propos qu' « un conflit armé international existe dès lors que des hostilités armées opposent des États à travers leurs armées respectives ou à travers d'autres acteurs agissant en leur nom ${ }^{625}$ (nous soulignons).

L'internationalisation de conflits armés a fait objet d'examen au niveau des juridictions internationales où différents critères d'appréciation ont été appliqués afin de rattacher à un Etat les actes des groupes armés ne relevant pas directement de lui, et établir par là sa responsabilité internationale. Mais également, par ricochet, voir dans quelle mesure l'intervention de l'Etat - via notamment de tels groupes - pourrait internationaliser un conflit armé non international.

En effet, dans l'examen de l'affaire des activités militaires et paramilitaires au Nicaragua et contre celui-ci (Nicaragua c. Etats-Unis d'Amérique), la CIJ a été amenée à chercher à établir la responsabilité internationale des Etats-Unis d'Amérique pour des actes de violations des règles du DIH commis par des insurgés dits Contras du fait de leur intervention au Nicaragua. Ainsi dans son arrêt du 27 juin 1986 quant au fond ${ }^{626}$, pour que soient attribués à un Etat des actes perpétrés par un groupe qui ne relève pas directement de lui, la CIJ a retenu le critère de contrôle effectif - critère dégagé pour la première fois par elle à l'occasion de la présente affaire $^{627}$. Ce type de contrôle doit être exercé notamment sur des opérations militaires ou paramilitaires du groupe concerné ayant conduit à la perpétration de tels actes. En clair, audelà de «la participation des Etats-Unis à l'organisation, à la formation, à l'équipement, au financement et à l'approvisionnement des contras, à la sélection de leurs objectifs militaires ou paramilitaires et à la planification de toutes leurs opérations » (\$115),- modalités qualifiées de «contrôle général » (ou contrôle global) (\$115) -, il faudrait dans le cas d'espèce que « les Etats-Unis aient ordonné ou imposé la perpétration des actes [en question] [...]»(§ 115). Chose qui n'a pas été démontrée.

Le critère de «contrôle effectif » a été repris par la suite par la Chambre de première instance du TPIY $^{628}$ au sujet des violations du DIH commises par les factions serbes opérant en territoire de Bosnie-Herzégovine avec le soutien présumé de la République fédérale de

\footnotetext{
${ }^{623}$ DEYRA, Michel, Le droit dans la guerre, op.cit., p. 171.

${ }^{624}$ MULINEN, Fréderic De, Manuel sur le droit de la guerre pour les forces armées, CICR, Genève, 2012, $\mathrm{p}$. 32.

${ }^{625}$ CPI, Le Procureur c. Thomas Lubanga Dyilo, affaire $N^{\circ}$ : ICC-01/04-01/06, Chambre de première instance, jugement, 14 mars 2012, p. 270, § 541, in http://www.icc-cpi.int/iccdocs/doc/doc1462060.pdf (Source consultée le 22 mars 2015).

${ }^{626}$ CIJ, Affaire des Activités militaires et paramilitaires au Nicaragua et contre celui-ci (Nicaragua c. Etats Unis d'Amérique), arrêt du 27 juin 1986, Recueil 1986, pp. 54-55, §115.

${ }^{627}$ MOMTAZ Djamchid, «Les défis des conflits armés asymétriques et identitaires au droit international humanitaire », in MATHESON Michael J. et MOMTAZ, Djamchid, (dir.) op.cit., p. 13.

${ }^{628}$ Voy. par exemple, TPIY, Le Procureur c. Dusko Tadic, Affaire N ${ }^{\circ}$ IT-94-1-T, Chambre de première instance, jugement du 7 mai 1997, pp. 230-232, § 585.
} 
Yougoslavie (jugement du 7 mai 1997). Cette juridiction a jugé qu'il n'existe aucun élément de preuve lui permettant de conclure que la République fédérale de Yougoslavie ait « jamais dirigé ou, [...] jamais ressenti la nécessité d'essayer de diriger les opérations militaires effectives ${ }^{629}$. Cette décision, qui occasionnera une opinion dissidente du Président de cette chambre, sera rejetée plus tard par la Chambre d'appel au profit du critère de «contrôle global » en son arrêt du 15 juillet 1999.

En effet, selon ce dernier arrêt, le « contrôle effectif » est qualifié de critère « très étroit » ${ }^{630}$. Cet arrêt retient dans un tel cas le critère de contrôle global (ou contrôle général). Suivant ce dernier critère du TPIY, pour que les actes commis par des organes ou agents de facto (groupes militaires ou paramilitaires) soient imputés à un Etat, celui-ci doit donc exercer un contrôle global sur le groupe en question «non seulement en l'équipant et le finançant, mais également en coordonnant ou en prêtant son concours à la planification d'ensemble de ses activités militaires ${ }^{631}$. «Il n'est cependant pas nécessaire d'exiger de plus que l'État ait donné, soit au chef du groupe soit à ses membres, des instructions ou directives pour commettre certains actes spécifiques contraires au droit international ${ }^{632}$.

Toutefois, si le «contrôle global » est jugé suffisant pour le cas de groupes organisés, ceci n'est pas le cas pour des individus ou des groupes qui ne sont pas organisés en structure militaire. Dans le cas d'espèce, il est «exigé la preuve d'instructions ou de directives spécifiques pour commettre des actes précis ou d'une approbation publique de ces actes après leur perpétration $\gg{ }^{633}$.

De tout ce qui précède, si le critère de «contrôle général » ou «contrôle global», au sens de la CIJ, n'est pas capable d'établir la responsabilité internationale, il est toutefois suffisant pour internationaliser un conflit armé. Dès lors, les actions susmentionnées entreprises par les Etats-Unis d'Amérique sont donc suffisantes pour l'internationalisation de ce conflit armé. La Cour conclura ainsi dans cet arrêt que «[1]e conflit entre les forces contras et celles du Gouvernement du Nicaragua est un conflit armé "ne présentant pas un caractère international ». Les actes des contras à l'égard du Gouvernement du Nicaragua relèvent du droit applicable à de tels conflits, cependant que les actions des Etats-Unis au Nicaragua et contre lui relèvent des règles juridiques intéressant les conflits armés internationaux ${ }^{634}$.

Dans le même ordre d'idées, dans son arrêt du 27 février 2007, tout en refusant d'adhérer « à la doctrine » du TPIY, notamment au motif que celui-ci devrait se préoccuper de se prononcer sur des questions de responsabilité pénale (à l'égard des individus) et non de responsabilité internationale $^{635}$, la CIJ ne conteste néanmoins pas que le critère de contrôle global tel qu'utilisé par le TPIY « soit pertinent et adéquat » à la qualification du caractère international

\footnotetext{
${ }^{629}$ TPIY, Le Procureur c. Dusko Tadic, Affaire N ${ }^{\circ}$ IT-94-1-T, Chambre de première instance, jugement du 7 mai 1997, p. 243, §605 ; MOMTAZ Djamchid, «Les défis des conflits armés asymétriques et identitaires au droit international humanitaire », in MATHESON Michael J. et MOMTAZ, Djamchid, (dir.) op.cit., p. 13.

${ }^{630}$ TPIY, Le Procureur c. Dusko Tadic, Affaire N'IT-94-1-A, Chambre d’Appel, Arrêt du 15 juillet 1999, p. 41, $\S \S 99-100$.

${ }_{631}$ Ibid., $\$ 131$.

632 Ibid.

${ }^{633}$ Ibid., $§ 132$.

634 CIJ, Activités militaires et paramilitaires au Nicaragua et contre celui-ci (Nicaragua c. Etats-Unis d'Amérique), fond, arrêt du 27 juin 1986, Recueil 1986, p. 114, § 219.

${ }^{635}$ CIJ, Affaire de l'Application de la Convention pour la prévention et la répression du crime de génocide (Bosnie-Herzégovine c. Serbie-et-Monténégro), arrêt du 27 février 2007, Recueil 2007, p. 209, § 403.
} 
ou non international d'un conflit armé ${ }^{636}$. En clair, elle rejette le critère de contrôle global pour déterminer la responsabilité internationale d'un Etat. Elle confirme son arrêt précédent et retient donc que des actes des organes et agents de facto sont attribuables à l'Etat s'ils résultent des instructions, de la direction ou du contrôle effectif de l'Etat concerné sur les opérations en question. Au regard de la CIJ, le « critère du «contrôle global» [que retient le TPIY] est inadapté, car il distend trop, jusqu'à le rompre presque, le lien qui doit exister entre le comportement des organes de l'Etat et la responsabilité internationale de ce dernier » ${ }^{637}$.

Ainsi, partant de la thèse que le «contrôle global » est «pertinent et adéquat »à la qualification du caractère international ou non international d'un conflit, un Etat peut être responsable de l'internationalisation d'un conflit armé interne (critère de contrôle global), sans pour autant que sa responsabilité internationale soit forcément reconnue (critère de contrôle effectif) ${ }^{638}$. Il se dégage que le niveau d'intervention requis pour qu'il y ait internationalisation du conflit est peu élevé : l'envoi de fonds, d'équipements ou de conseillers suffit ${ }^{639}$.

Cette conclusion n'est pas partagée par toute la doctrine notamment Eric DAVID. Celui-ci estime qu'il est vrai que la CIJ n'a pas hésité à parler d'un conflit armé international entre ces deux Etats alors qu'il n'y avait cependant pas des troupes américaines aux côtés des Contras. Mais la CIJ faisait allusion sans doute aux actions telles que le minage des ports du Nicaragua par les Etats Unis d'Amérique. Et Eric DAVID de conclure qu'il est difficile d'admettre que l'intervention sous forme d'envois de fonds et d'équipements militaires puisse suffire à internationaliser un conflit armé interne. Ceci semble d'ailleurs excessif, poursuit-il, au regard de la pratique internationale de concevoir qu'une intervention non armée dans un conflit armé non international internationalise celui-ci ${ }^{640}$. Ainsi seule l'intervention militaire étrangère (c'est-à-dire l'emploi de la force armée) en cas d'envoi de troupes régulières ou irrégulières, y compris à titre de conseillers, experts, volontaires ou mercenaires, pourrait internationaliser le conflit armé ${ }^{641}$. Bien plus, il faudrait, pour des experts et des conseillers, qu'ils prennent effectivement part aux hostilités sous l'autorité exclusive de leur Etat d'origine. Des volontaires ou mercenaires apparaissant comme agents de facto des Etats étrangers peuvent également internationaliser le conflit armé que les conseillers et experts face à la partie adverse qu'ils combattent ${ }^{642}$.

De ce qui précède, le critère adopté par la CIJ paraît de faible exigence et par conséquent plus protecteur en DIH. L'internationalisation d'un conflit armé dans des telles circonstances ferait appel pour certains cas à des règles du DIH applicables à des CAI, plus protectrices que celles

\footnotetext{
${ }^{636}$ Ibid., § 404. Lire aussi les analyses de MOMTAZ, Djamchid, « Les défis des conflits armés asymétriques et identitaires au droit international humanitaire », in MATHESON, Michael J. et MOMTAZ, Djamchid, (dir.) op.cit., p. 15. ; SOUMAORO, Souleymane, «art.cit.», in MATHESON Michael J. et MOMTAZ, Djamchid (dir.), op.cit., p. 210

${ }^{637}$ CIJ, Affaire de l'Application de la Convention pour la prévention et la répression du crime de génocide (Bosnie-Herzégovine c. Serbie-et-Monténégro), arrêt du 27 février 2007, Recueil 2007, p. 210, § 406.

${ }^{638}$ SOUMAORO, Souleymane, «art.cit.», in MATHESON Michael J. et MOMTAZ, Djamchid (dir.), op.cit., p. 210.

${ }^{639}$ DEYRA, Michel, Le droit dans la guerre, op.cit., pp. 171-172.

${ }^{640}$ DAVID, Eric, Principes de droit des conflits armés, 5è édition, op.cit., pp. 166- 167.

${ }^{641}$ CUMIN, David, Manuel de droit de la guerre, op.cit., p.151 et Lire DAVID, Eric, Principes de droit des conflits armés, 5è édition, op.cit., pp. 161- 167.

${ }^{642}$ DAVID, Eric, Principes de droit des conflits armés, 5è édition, op.cit., p. 165.
} 
qui ne s'appliqueraient que dans les CANI. Ainsi, les combattants ainsi que les personnes civiles pourraient bénéficier de règles plus protectrices en période d'hostilités. Il n'est point ignoré toutefois que la présence des règles de CANI subsisteront notamment pour l'opposition armée entre groupes armés et forces armées étatiques. Bien plus, la position développée par la jurisprudence de la CIJ sera également suivie au sujet du litige opposant la RDC à l'Ouganda (cf. infra). En même temps, il sied d'admettre que la position d'Eric DAVID nous paraît plus pratique quand il s'agira d'établir notamment le droit applicable face aux parties au conflit en cause.

A la lumière de ce qui précède, le DIH applicable aux conflits armés internationaux ou celui applicable aux conflits armés non internationaux sera respectivement d'application selon la nature des protagonistes. Lorsqu'on est en face des Etats, peu importe leur côté d'intervention, c'est le DIH relatif aux conflits armés internationaux qui s'applique. En revanche, c'est le DIH des conflits armés non internationaux qui sera d'application lorsque le conflit armé oppose un Etat (gouvernement légitime ou Etat intervenant) aux insurgés. C'est la «théorie du fractionnement des régimes » ou "théorie de la décomposition du conflit " ${ }^{643}$ dite aussi des «faisceaux bilatéraux» admise par la CIJ (cf. supra) ${ }^{644}$ ou encore par le $\mathrm{TPIY}^{645}$. Le fractionnement consiste à décomposer le conflit en ses différents rapports binaires, et appliquer le régime juridique propre à chacun d'eux ${ }^{646}$. C'est la thèse qui est également suivie par les instances judiciaires pour les situations concernant la RDC. Toutefois, l'ONU et le CICR font largement la demande d'application de l'ensemble de règles du DIH (cf. infra).

Cependant, à vrai dire, l'application du DIH aux conflits armés internes internationalisés connaît des difficultés. La décomposition des régimes juridiques en droit des conflits armés internationaux et en droit des conflits armés non internationaux conduit à des conséquences illogiques et inégalitaires dans la protection des personnes ${ }^{647}$. Ainsi, par exemple, des enfants victimes «tous » des effets des hostilités, se trouvant «tous » dans une même sphère géographique de combat peuvent néanmoins faire l'objet de règles de protection différentes en fonction de la partie au pouvoir de laquelle ils se retrouvent. Ce qui paraît clairement absurde ! Cette discrimination est également observable dans le chef des combattants. Alors que les insurgés participent aux hostilités avec leurs compagnons d'armes de la puissance étrangère, ils ne bénéficieront néanmoins pas du statut de prisonnier de guerre en cas de capture contrairement à leurs compagnons étrangers ${ }^{648}$. Bien plus, cette théorie reste difficilement envisageable dans les cas d'interventions étrangères multiples ${ }^{649}$. Dans de tels cas, le CICR fait généralement recommandation d'application du droit des $\mathrm{CAI}^{650}$. Toutefois, Michel DEYRA estime qu'en dépit de son inconvénient de complexité et d'inégalité, ce

\footnotetext{
${ }^{643}$ CUMIN, David, Manuel de droit de la guerre, op.cit., p. 151.

${ }^{644}$ Voy. CIJ, Activités militaires et paramilitaires au Nicaragua et contre celui-ci (Nicaragua c. Etats-Unis d'Amérique), fond, arrêt du 27 juin 1986 Recueil 1986, p. 114, § 219.

${ }^{645}$ Voy. TPIY, Le Procureur c.Dario Kordic et Mario Cerkez, Affaire NoIT-95-14/2-A, Chambre d'Appel, arrêt du 17 décembre 2004, p. 106, $\$ 320$.

${ }^{646}$ SOUMAORO, Souleymane, «art.cit.», in MATHESON Michael J. et MOMTAZ, Djamchid (dir.), op.cit., p. 213.

${ }^{647}$ Ibid.

${ }^{648}$ ASPREMONT, Jean d' et HEMPTINNE, Jérôme de, Droit international humanitaire, op. cit., p. 59.

${ }^{649}$ Lire DAVID, Eric, Principes de droit des conflits armés, 5è édition, op.cit., p. 174 et ASPREMONT, Jean d' et HEMPTINNE, Jérôme de, op. cit., p. 59.

${ }^{650}$ DAVID, Eric, Principes de droit des conflits armés, 5è édition, op.cit., pp. 174-175.
} 
fractionnement juridique offre la plus grande protection possible et politiquement acceptable par des Etats souverains ${ }^{651}$.

Si le fractionnement apparaît comme une approche médiane, d'aucuns plaident soit pour une approche minimale, soit pour celle maximale. L'approche minimale est celle qui pense que le conflit armé demeure interne en dépit de l'intervention étrangère ${ }^{652}$ et fait appel au droit des CANI. Suivant l'approche maximale dite théorie des conflits armés internationalisés globalisés, «l'intervention massive -c'est-à-dire celle qui influe de façon décisive sur le cours des hostilités - d'une ou plusieurs puissance(s) étrangère(s) internationalise le conflit dans son ensemble ${ }^{653}$ et fait application du DIH dans son ensemble aux parties, y compris les insurgés. C'est la thèse qualifiée aussi de l' « unité » du conflit ou de l'internationalisation objective et obligatoire ${ }^{654}$. Cette théorie paraît très protectrice des victimes car faisant application d'un droit approfondi et plus protecteur, le droit des CAI. Tout de même, cette théorie pourrait constituer un motif d'encouragement des insurgés à recourir régulièrement à l'aide extérieure afin de bénéficier d'une protection plus favorable. C'est l'idée de " prime à l'insurrection », évoquée par certains Etats lors de la conférence diplomatique sur les PA et qui a conduit notamment à la non réglementation de cette question ${ }^{655}$.

A la lumière des arguments ci-dessus avancés, la position de la doctrine en faveur de l'application intégrale des règles du droit des conflits armés internationaux paraît souhaitable ${ }^{656}$ car plus protectrice. Position que partage le $\mathrm{CICR}^{657}$. Et ce, en dépit du fait que la CIJ, le TPIY et un certain nombre de doctrinaires se prononcent en faveur des «faisceaux bilatéraux ${ }^{658}$. En effet, de plus en plus, les voix plaident en faveur de d'un ensemble unique de règles du $\mathrm{DIH}$. La dichotomie CAI/CANI s'avère inappropriée pour les conflits armés présentant des caractéristiques mixtes (notamment les guerres dans l'ex-Yougoslavie et en Afghanistan) et peut faire l'objet d'incroyables manipulations politiques en défaveur de la protection humanitaire $^{659}$.

\footnotetext{
${ }^{651}$ DEYRA, Michel, Le droit dans la guerre, op.cit., p. 172

${ }^{652}$ DAVID, Eric, Principes de droit des conflits armés, 5è édition, op.cit., p. 171; DEYRA, Michel, Le droit dans la guerre, op.cit., p. 172.

${ }^{653}$ ASPREMONT, Jean d' et HEMPTINNE, Jérôme de, Droit international humanitaire, op. cit., p. 58; DAVID, Eric, Principes de droit des conflits armés, 5è édition, op.cit., pp. 174-175, voy. aussi les pages 162-163 de ce dernier ouvrage.

${ }^{654}$ C'est ce que DAVID Cumin qualifie de «thèse de l'internationalisation objective et obligatoire », ou de la «thèse de l'Unité ». En effet, «la thèse de l'internationalisation objective et obligatoire » affirme que toute intervention étrangère aboutit à l'internationalisation et rend applicable le droit des conflits armés internationaux même à l'égard des insurgés. Une thèse qui s'oppose à celle dite de "l'internationalisation subjective et facultative ». Laquelle contient «la thèse de l' «Unité » et celle de la «décomposition» (ou thèse de fractionnement). La thèse de "l'internationalisation subjective et facultative » établit la distinction selon que l'intervention étrangère est effectuée à la demande du gouvernement ou à son encontre. Ce qui entraînerait l'application, pour l'hypothèse de l'intervention sollicitée, soit du droit des conflits armés internationaux pour l'ensemble du conflit armé (thèse de l'Unité), soit d'une application différenciée - droit des conflits armés internationaux (forces gouvernementales locales et étrangères, ou forces étrangères entre elles) et droit des conflits armés non internationaux (forces gouvernementales locales et/ou étrangères contre les insurgés) - suivant les sujets en présence (thèse de la décomposition). Lire DAVID, Cumin, Manuel de droit de la guerre, op. cit., p. 151.

${ }^{655}$ ASPREMONT, Jean d' et HEMPTINNE, Jérôme de, Droit international humanitaire, op. cit., p. 59.

${ }^{656}$ SOUMAORO, Souleymane, « Art.cit.», in MATHESON Michael J. et MOMTAZ, Djamchid, op.cit., p.214.

${ }^{657}$ Lire DAVID, Eric, Principes de droit des conflits armés, $5^{\mathrm{e}}$ édition, pp. 171-172.

${ }^{658}$ SOUMAORO, Souleymane, « Art.cit.», in MATHESON Michael J. et MOMTAZ, Djamchid, op.cit., p.214.

${ }^{659}$ BIAD, Abdelwahab, Droit international humanitaire, 2 édition, op.cit., pp. 29-30.
} 
Il se dégage de tout ceci que la «question des conflits armés internes internationalisés n'ayant jamais donné lieu à codification, la doctrine et la jurisprudence jouent un rôle important dans l'établissement des critères de qualification objectifs de ces types de conflit ${ }^{660}$. Il importe d'affirmer que la théorisation au plan doctrinal, accompagnée des thèses contradictoires, sur la question de l'internationalisation des conflits armés dépasse largement l'ébauche abordée à travers ces quelques lignes.

De tout ce qui précède, il est important de mentionner que la tendance à l'uniformisation des règles du DIH sur le champ d'application est de plus en plus en vigueur. Soumettre les CANI à l'ensemble des règles du DIH plutôt qu'au article 3 commun ou PA II tend à devenir la règle ${ }^{661}$. Il s'agit donc $d^{\prime}$ ' un effacement progressif [qui] n'implique pas une disparition totale ${ }^{662}$. Ceci est d'ailleurs remarquable notamment au niveau de l'ONU. Laquelle se préoccupe d'ailleurs moins de la qualification du conflit armé au regard du DIH que du respect de celui-ci. Disons que dans ses résolutions, le CS/NU ne s'appuie pas sur la distinction entre conflits armés internationaux et conflits armés non internationaux, pour apprécier l'applicabilité du droit des conflits armés. Il se borne à rappeler aux parties le droit applicable en période de conflits armés ou les appelle à respecter les règles du DIH (cf. infra). Cette position reste partagée également par l'ensemble des organes des Nations Unies dont le Secrétariat. Ce dernier ne se soucie pas de la qualification juridique à donner à un conflit armé auquel prennent part les forces des Nations Unies ni de trancher la question de l'internationalisation du conflit du fait de l'intervention de l'ONU. Pour le Secrétaire général, que le conflit existant sur le terrain soit interne ou international, que les casques bleus soient aux prises avec des forces armées régulières ou rebelles, les règles du DIH applicables sont les mêmes. Ceci ressort d'ailleurs de sa circulaire du 6 août 1999 intitulée « Respect du droit international humanitaire $»(\text { cf. infra })^{663}$. L'AG/NU abonde pour sa part dans le même sens. Ainsi, dans une série de résolutions relatives au « respect des droits de l'homme en période de conflit armé », elle (AG/NU) a confirmé que le champ d'application des principales règles humanitaires n'est pas limité aux conflits armés internationaux. Le fait même pour elle d'indiquer de par l'intitulé « respect des droits de l'homme en période de conflits armés » atteste son intention de montrer qu'un tel devoir ne dépend pas de la qualification des conflits armés. «En effet, par le moyen de ces résolutions, l'Assemblée générale montre l'indépendance de l'applicabilité des règles humanitaires à une telle qualification, puisqu'elle a reconnu «la nécessité d'appliquer les principes humanitaires fondamentaux dans tous les conflits armés » ${ }^{664}$.

\footnotetext{
${ }^{660}$ SOUMAORO, Souleymane, « Art.cit.», in MATHESON Michael J. et MOMTAZ, Djamchid, op.cit., p. 197.

${ }^{661}$ DAVID, Eric, Principes de droit de conflits armés, op. cit., p. 132 ; DAVID, Eric, «La qualification des conflits dans le cadre de lutte contre l'Etat islamique", in Le jihadisme et la lutte contre EI : aspect de droit international, Journée d'Etude du 21 mars 2016 du Centre d'Etude de Droit Militaire et Droit de la guerre (http://www.ismllw-be.org/session/2016.htm (Source consultée le 24 août 2016).

${ }_{662}$ DAVID, Eric, Principes de droit de conflits armés, op. cit., p. 118 ; ASPREMONT, Jean d' et HEMPTINNE, Jérôme de, op. cit, p. 72.

${ }^{663}$ SOUMAORO, Souleymane, « art.cit.», in MATHESON Michael J. et MOMTAZ Djamchid, op.cit., 212.

${ }^{664}$ HOSSEIN RANJBARIAN, Amir, La criminalisation des violations graves du droit international humanitaire commises au cours de conflits armés non internationaux, Thèse de doctorat en droit, discipline : Droit public, Université Paris 13, 2001, p. 62.
} 


\section{§2. Champ d'application ratione personae}

«Le DIH, dont le champ d'application était au départ limité à la seule protection des militaires blessés dans les armées en campagne, s'est considérablement élargi au fur et à mesure que s'élargissait le cercle des victimes des violences ». ${ }^{665}$ Ainsi, « les quatre CG et leur PA I visent à protéger les victimes des conflits armés internationaux, c'est-à-dire tout individu ou groupe d'individus ne prenant pas ou plus part aux hostilités: les militaires blessés, malades ou naufragés, les prisonniers de guerre, les personnes civiles, les membres des services sanitaires des armées ainsi que les personnels des organismes de secours et de protection civile ${ }^{666}$. A côté, l'article 3 commun aux quatre CG et le PA II accordent une protection aux victimes des conflits armés non internationaux.

En clair, la notion de protection est donc apparue dans le DIH dès sa naissance. Cette notion se trouve généralement placée à côté de celle de respect. Celle-ci doit être comprise comme signifiant «épargner, ne point attaquer » et celle-là comme le fait de prendre la défense de quelqu'un, prêter secours et appui ${ }^{667}$. Il s'agit là pour le respect d'une obligation négative imposée aux parties et pour la protection d'une obligation positive. A côté de cette signification originelle de la protection prévue par le DIH, celui-ci utilise ensuite la notion de protection dans une acception beaucoup plus large quand il parle précisément de «personnes protégées ». Il s'agit essentiellement des personnes « au pouvoir d'une partie au conflit ou d'une Puissance occupante dont elles ne sont pas ressortissantes » (cf. article 4, alinéa 1er de la CG IV). La protection dans ce sens tend tout d'abord à prévenir les atteintes physiques ou psychiques, mais elle a également l'ambition, plus étendue, de préserver une certaine qualité de vie. C'est dans cette optique que cette deuxième signification rejoint la première mais va plus loin par rapport à la qualité de vie des «personnes protégées » qu'elle tente d'assurer pendant la période exceptionnelle que traversent celles-ci. Enfin, l'on trouve au titre II de la CG IV la notion de «protection générale des populations civiles contre certains effets de la guerre». Il s'agit de la possibilité de mettre au profit de la population civile des zones sanitaires ou neutralisées et de l'obligation de ne pas attaquer les établissements sanitaires portant l'emblème de protection. Le PA I aborde également cette question au niveau de son titre IV en sa Section I "protection générale contre les effets des hostilités ». En réalité ici, c'est davantage le respect (épargner) que la protection qui est abordé ${ }^{668}$.Il existe également la question de protection spéciale pour les personnes les plus vulnérables dont les enfants, les femmes, les vieillards, les journalistes, etc.

A dire vrai, le DIH envisage, en s'occupant de la protection des victimes des conflits armés des types d'actions et de comportements très divers ${ }^{669}$. De manière évolutive, l'on comprendra que quand bien même la notion de respect implique une obligation négative, une abstention, c'est-à-dire l'obligation de «ne point attaquer, d'épargner » à l'endroit des parties en conflit, elle ne se limite pas à cela. Les Etats, autant que les autres parties concernées, se trouvent également obligés de déployer d'autres mécanismes afin de rendre cette obligation

\footnotetext{
${ }^{665}$ DEYRA, Michel, Le droit dans la guerre, op.cit., p. 37.

${ }^{666}$ BIAD, Abdelwahab, Droit international humanitaire, 2e édition, op.cit., p. 24.

${ }^{667}$ SANDOZ, Yves, « art.cit.» in SWINARSKI Christophe (éd.), op.cit., p. 976.

${ }^{668}$ Ibid.

${ }^{669}$ Ibid. p. 981
} 
de «respect» opérationnelle. C'est d'ailleurs le sens qu'il faudrait aussi comprendre de l'obligation faite aux Etats « de respecter et de faire respecter » le DIH contenu dans les CG et le PA I (cf. infra). Il s'agit là d'une obligation à deux degrés interdépendants. "Respecter » impliquerait en même temps «faire respecter » et vice-versa. Le respect implique donc une obligation positive de la part de l'Etat. Ainsi sur cette même lancée, assurer la «protection » des victimes au-delà de l'obligation positive qu'elle représente, intériorise en même temps une obligation négative.

On l'a vu, la portée du DIH a connu une certaine extension en 1977. D'autres personnes, combattants ou civils, se voient nouvellement protégées ou mieux protégées ${ }^{670}$. Fondé sur le principe de distinction entre les personnes qui combattent et celles qui ne combattent pas ou plus (cf. supra), le système de protection du DIH se déploie en faveur de différents sujets. En ce sens, les personnes qui combattent peuvent également être combattues par contre celles qui ne combattent pas ou plus ont logiquement le droit de ne pas être combattues. C'est cela même la «protection conditionnelle » qui caractérise le DIH. Ce qui reviendrait à dire que le fait pour les personnes civiles de prendre part aux hostilités leur enlèverait le privilège de ne point être combattues.

Ainsi, ces différents sujets qui méritent protection en situations exceptionnelles au nom du DIH sont donc à élucider dans les lignes suivantes. Si pour certains (blessés, malades, naufragés, prisonniers de guerre, etc) la protection semble être assurée sans énormes difficultés cependant pour d'autres (espions, mercenaires par exemple), elle semble être hypothétique.

\section{A. Les blessés, les malades et les naufragés}

Apporter secours aux blessés est le vœu premier exprimé par Henri Dunant. Celui-ci a été témoin privilégié des souffrances indescriptibles de plus de 40.000 militaires autrichiens, français et italiens abandonnés sans soins sur le champ de bataille à Solferino. Il participa luimême à une opération de secours très difficile à coté de la population civile de cette région au profit de ceux-là. Ce premier vœu de secourir les blessés militaires en pleine situation de conflit armé s'accompagnera d'un second lié à l'adoption d'une convention internationale en date du 22 août 1864. Cette dernière sera donc intitulée "Convention de Genève pour l'amélioration du sort des militaires blessés dans les armées en campagne». Les préoccupations de cet instrument juridique de dix articles concernent essentiellement les «militaires blessés » et non les civils. Chose qui peut bien paraître compréhensible au regard de l'expérience vécue par son initiateur, Henri Dunant et de la dénomination même de l'institution à la base, le Comité international de secours aux militaires blessés .

«La Convention de 1864 instaure une protection pour les blessés et malades militaires, catégorie à laquelle la Convention de 1929 ajoute «les autres personnes officiellement attachées aux armées ». S'agissant des Conventions de 1949, les articles 13 des Conventions I et II, visent, outre les membres des forces armées, des personnes suivant ces forces mais n'en

\footnotetext{
${ }^{670}$ FURET, Marie-Françoise, MARTINEZ, Jean-Claude et DORANDEU, Henri, op.cit., p. 125.
} 
faisant pas directement partie ; les membres des équipages, y compris aériens et civils, des parties en conflit et même la population d'un territoire non-occupé ayant pris spontanément les armes pour se défendre contre les troupes d'invasion ${ }^{671}$. Toutefois, ces conventions ne définissent aucunement les blessés, malades et naufragés. Ce qui renvoie à une compréhension habituelle. Et suivant Jean Pictet : «[i]l est heureux qu'aucune définition constituant par sa nature même un cadre plus ou moins rigide et limitatif, n'ait été envisagée à l'origine ${ }^{672}$. Cependant, en 1977 le PA I définira en détails toutes ces terminologies ${ }^{673}$. Chose dont le Protocole additionnel II ne fait pas mention même s'il traite à son Titre III des «Blessés, malades et naufragés».

Par ailleurs, il est important de retenir que la protection des blessés, malades et naufragés a évolué conformément au développement du DIH. De la protection réservée uniquement aux militaires blessés (1864), l'on est passé d'une protection distinctement réservée aux militaires et aux civils blessés, malades et naufragés (1949) pour arriver à celle réservée sans égard au statut de l'infortuné (militaire ou civil, ou encore mieux les personnes ayant pris part ou non au conflit armé) et basée essentiellement sur la nécessité des soins médicaux à prodiguer (1977). Le critère de nécessité des soins médicaux, affirmé par les PA I et II, constitue le fondement même de la priorité des soins à prodiguer. "Aucune distinction fondée sur des critères autres que médicaux ${ }^{674}$ n'est admise ici. Ces infortunés doivent s'abstenir de tout acte d'hostilité pour voir leur protection ainsi assurée. Il s'agit là, une fois de plus, de la protection conditionnelle qui caractérise les règles de $\mathrm{DIH}$.

En clair, «il convient donc de souligner que les notions ci-dessus considérées ne se confondent pas nécessairement avec celle de «personne hors de combat». Puisque celle-ci peut être valide d'une part et, d'autre part, le blessé et autre peut continuer à poser des actes hostiles nonobstant son état ${ }^{675}$.

Par ailleurs, «[1]e système normatif s'articule autour de deux types d'obligations complémentaires. Les premières, générales, imposent aux Parties en conflit de respecter, protéger, traiter avec humanité et soigner les personnes souffrantes ; les secondes étendent la protection aux moyens destinés à assurer ces soins, c'est-à-dire aux personnels et matériels sanitaires ${ }^{676}$. Il se dégage ainsi les principes d'inviolabilité des blessés, malades et

\footnotetext{
${ }^{671}$ BETTATI, Mario, Droit humanitaire. Textes introduits et commentés, op.cit., p. 158.

672 Ibid., p. 157.

${ }^{673}$ Suivant l'article 8 du PA I, a) les termes «blessés » et «malades » s'entendent des personnes, militaires ou civiles, qui, en raison d'un traumatisme, d'une maladie ou d'autres incapacités ou troubles physiques ou mentaux, ont besoin de soins médicaux et qui s'abstiennent de tout acte d'hostilité. Ces termes visent aussi les femmes en couches, les nouveau-né et les autres personnes qui pourraient avoir besoin de soins médicaux immédiats, telles que les infirmes et les femmes enceintes, et qui s'abstiennent de tout acte d'hostilité ; b) le terme "naufragé "s'entend des personnes, militaires ou civiles, se trouvant dans une situation périlleuse en mer ou en d'autres eaux par suite de l'infortune qui les frappe ou qui frappe le navire ou l'aéronef les transportant, et qui s'abstiennent de tout acte d'hostilité, continueront d'être considérés comme des naufragés pendant leur sauvetage jusqu'à ce qu'elles aient acquis un autre statut en vertu des Conventions ou du présent Protocole; $[\ldots]$

${ }^{674}$ Article $7 \S 2$ du PA II, voir également l'article $10 \S 2$ du PA II.

${ }^{675}$ BULA-BULA, Sayeman, Droit international humanitaire, op.cit., p.110.

${ }^{676}$ BETTATI, Mario, Droit humanitaire. Textes introduits et commentés, op.cit., p. 157.
} 
naufragés ; d'immunité du personnel et des installations sanitaires et du droit d'accès à ces victimes.

En effet, l'inviolabilité des blessés, malades et naufragés interdit les actes de violence ou toute attaque à l'endroit de ceux-là. Leur état d'incapacité exige «d'une part le respect et la protection, d'autre part le traitement et les soins » ${ }^{677}$ pourvu qu'ils cessent eux-mêmes de faire preuve d'acte de violence ou d'acte d'hostilité. "Ce principe fondamental [...] s'applique aussi bien aux conflits internationaux qu'aux conflits non internationaux ${ }^{678}$. Le traitement humain comme l'exprime si bien Michel DEYRA «ne s'applique pas qu'au traitement médical mais à toutes les conditions de l'existence d'une personne ${ }^{679}$, ce qui implique la reconnaissance et l'application de certains instruments qui relèvent du domaine de DIDH. Le traitement humain et les soins doivent être dispensés sans aucune discrimination. Il est tout de même prévu ce que l'on pourrait qualifier de «discrimination positive » pour répondre aux besoins des blessés, malades et naufragés dont l'état de santé exige une certaine urgence. Ce qui pourrait fonder une priorité de soins. L'on note en outre, de par l'obligation de recueillement, de recherche, d'enlèvement, d'évacuation des blessés, des malades et des naufragés incombant aux parties, la population civile et les sociétés de secours «seront autorisées à recueillir les blessés, malades et naufragés et leur prodiguer des soins, même de leur propre initiative » (cf. article $17 \S 1$ du PA I). De la même manière que les parties pourront faire appel à la population civile et aux sociétés de secours pour une telle entreprise, et leur accorder la protection et les facilités nécessaires (art. 17 §2 du PA I).

Pour sa part, l'immunité du personnel et des installations sanitaires se rapporte aux «personnel sanitaire », « unités sanitaires », «transport sanitaire », «moyen de transport sanitaire», «véhicule sanitaire», «navire et embarcation sanitaire», «aéronef sanitaire ${ }^{680}$. Elle leur permet de bien remplir leur mission de venir au secours des personnes

\footnotetext{
${ }^{677}$ DEYRA, Michel, Le droit dans la guerre, op.cit., p. 112.

${ }^{678}$ Ibid., p. 108.

${ }^{679}$ Ibid., p. 112.

680 Suivant l'article 8 du PA II, «[... c) l'expression "personnel sanitaire » s'entend des personnes exclusivement affectées par une partie au conflit soit aux fins sanitaires énumérées à l'alinéa e, soit à l'administration d'unités sanitaires, soit encore au fonctionnement ou à l'administration de moyens de transport sanitaires. Ces affectations peuvent être permanentes ou temporaires. L'expression couvre : i)le personnel sanitaire, militaire ou civil, d'une part au conflit, y compris celui qui est mentionné dans les Ire et Ile Conventions, et celui qui est affecté à des organismes de protection civile; ii)le personnel sanitaire des Sociétés nationales de la Croix-Rouge (Croissant-Rouge, Lion-et-Soleil-Rouge) et autres sociétés nationales de secours volontaires dûment reconnues et autorisées par une partie au conflit; iii) le personnel sanitaire des unités ou moyens de transport sanitaire visé à l'article 9, paragraphe 2. e) l'expression " unités sanitaires "s'entend des établissements et autres formations, militaires ou civils, organisés à des fins sanitaires, à savoir la recherche, l'évacuation, le transport, le diagnostic ou le traitement - y compris les premiers secours - des blessés, des malades et des naufragés, ainsi que la prévention des maladies. Elle couvre entre autres les hôpitaux et autres unités similaires, les centres d'approvisionnement sanitaire, ainsi que les dépôts de matériel sanitaire et de produits pharmaceutiques de ces unités. Les unités sanitaires peuvent être fixes ou mobiles, permanentes ou temporaires; f) l'expression "transport sanitaire " s'entend du transport par terre, par eau ou par air des blessés, des malades et des naufragés, du personnel sanitaire et religieux et du matériel sanitaire protégés par les Conventions et le présent Protocole; g) l'expression "moyen de transport sanitaire "s'entend de tout moyen de transport, militaires ou civils, permanent ou temporaire, affecté exclusivement au transport sanitaire et placé sous la direction d'une autorité compétente d'une partie au conflit ; h) l'expression 》véhicule sanitaire " s'entend de tout moyen de transport sanitaire par terre ; i) l'expression "navire et embarcation sanitaires » $s$ 'entend de tout moyen de transport sanitaires par eau; j) l'expression " aéronef sanitaire " s'entend de tout moyen de transport sanitaire par air ;k) sont «permanents »le personnel sanitaire, les unités sanitaires et les
} 
blessées, malades et naufragées. Le personnel sanitaire est composé des personnes -militaires ou civiles - affectées exclusivement de manière permanente ou temporaire aux services sanitaires dans les situations de conflits armés internationaux. Les matériels qu'il utilise se trouvent aussi protégés. Les dispositions liées à l'immunité du personnel et des installations sont également développées - de manière peu approfondie - au niveau du titre III du PA II. Le PA I à travers son article $17 \S 1$ étend l'obligation de respect, voire de protection, de traitement humain et de soins des blessés, malades et naufragés, même si appartenant à la partie adverse, à l'endroit de la population civile expressément sous l'intitulé "Rôle de la population civile et des sociétés de secours ». Mention qui n'existe pas au niveau du PA II. «Or, dans des situations, où la population est souvent divisée par des haines farouches, ce silence sur des comportements particulièrement nécessaire, est une grave lacune » enseignent FURET Marie-Françoise, MARTINEZ Jean-Claude et DORANDEU Henri ${ }^{681}$. Toutefois, il importe de tempérer en arguant qu'une telle disposition n'est pas totalement absente du PA II. Ainsi, l'on peut lire à son article 18 relatif aux «Sociétés de secours et actions de secours » : que «[...] [1] a population civile peut, même de son propre chef, offrir de recueillir et soigner les blessés, les malades et les naufragés ». Il paraît dès lors juridiquement inconcevable que cette population se livre à des actes inhumains à l'encontre de ces infortunés.

Enfin, concernant le droit d'accès aux victimes, il est important de signifier que les CG et leurs PA « ont toujours fondé cet accès, non pas sur un droit à aider, mais sur un droit à être aidé : droit à être aidé au nom d'un principe évident d'humanité pour toute personne en situation périlleuse; droit à être aidé à la seule initiative des organisations non gouvernementales, neutres et impartiales ${ }^{682}$.

\section{B. Les prisonniers de guerre}

«L'admission au statut de prisonnier de guerre est conditionnée par la nature du conflit et la situation de la personne tombée au pouvoir de l'ennemi ${ }^{683}$. En effet, comme l'on peut bien comprendre de l'article 2 de la CG III relative au traitement des prisonniers de guerre, le statut de prisonnier de guerre se trouve précisément réservé aux personnes concernées qui se retrouveraient dans des situations de CAI. Ce qui n'est donc pas le cas pour les CANI ou des situations de troubles ou tensions internes. Ici, la protection des personnes se trouvant matériellement dans de situations semblables à celle de «prisonniers de guerre» est assurée par l'article 3 commun aux CG et le PA II. Lesquels ne traitent pas expressément des «combattants » ou des «prisonniers de guerre ». Et pour les personnes se retrouvant dans les filets du pouvoir public en situation de troubles ou tensions internes, les dispositions des CG

moyens de transport sanitaires affectés exclusivement à des fins sanitaires pour une durée indéterminée. Sont «temporaires»le personnel sanitaire, les unités sanitaires et les moyens de transport sanitaire utilisé exclusivement à des fins sanitaires pour des périodes limitées, pendant toute la durée de ces périodes. A moins qu'elles ne se soient autrement qualifiées, les expressions "personnel sanitaire », " unités sanitaires » et " moyen de transport sanitaire » couvrent un personnel, des unités ou des moyens de transport qui peuvent être soit permanents soit temporaires [...]»

${ }^{681}$ FURET, Marie-Françoise, MARTINEZ, Jean-Claude et DORANDEU Henri, op.cit., p.168.

${ }^{682}$ DEYRA Michel, Le droit dans la guerre, op.cit., p. 117.

${ }^{683}$ Ibid. 
et de PA II ne leur sont pas d'application en principe. Le pouvoir fait appel à sa législation nationale et aux règles de droit des droits de l'Homme (cf. supra). "Cependant, le CICR s'intéresse à cette catégorie de personnes privées de liberté que sont les détenus politiques et les détenus de sécurité. Les délégués du CICR peuvent donc visiter toute personne qui lutte pour faire valoir ses opinions ou pour accomplir ce qu'elle considère comme son devoir et qui, une fois arrêtée et détenue dans ces circonstances, se trouve aux mains d'un pouvoir qui la traite comme une personne ennemie. De nos jours, la grande majorité des visites effectuées par les délégués du CICR se situe dans des situations de troubles intérieurs et de tensions internes (Cachemire, Guatemala, Irak, Israël, Ossétie du Sud, Pérou) ${ }^{684}$. Il faudrait avouer que la situation de troubles ou tensions internes occupe également une place de choix dans des pays où la situation de droits de l'homme est chaotique. La situation de la RDC, par exemple, est à placer dans ce lot. Un pays qui sort des élections entachées des fraudes massives reconnues aux plans interne et international (élections présidentielles et législatives du 28 novembre 2011). Un processus électoral dont les résultats sont à la base des tensions, oppositions ou troubles aux niveaux interne et externe. Lesquels phénomènes aboutissent à différents cas d'assassinats et d'arrestations des personnes impliquées. Il s'avère indéniable qu'en pareilles circonstances un organisme impartial, du genre CICR, puisse se pencher sur les dossiers notamment en assurant ne serait-ce que des visites des prisonniers politiques, des detenus. Ces derniers attendent parfois pendant longtemps l'issue de la justice dont l'indépendance et d'autres garanties judiciaires demeurent problématiques (cf. le dernier chapitre de cette étude).

Bien plus, pour bénéficier de ce statut de prisonnier de guerre, il doit s'agir de « «personne tombée au pouvoir de l'ennemi » et non plus [...] de «personne capturée ». Il s'agit là d'un progrès car cette nouvelle approche permet d'admettre au bénéfice du statut tous ceux qui sont faits prisonniers sans combattre, notamment en cas de reddition ou de capitulation en masse ${ }^{685}$. Ainsi au sens de l'article 4 de la CG III, bénéficient du statut de prisonnier de guerre les personnes y énumérées appartenant à des catégories bien indiquées et tombées au pouvoir de l'ennemi. C'est le cas notamment : des membres des forces armées d'une partie au conflit, des milices et des corps des volontaires faisant partie de ces forces armées. Il s'agit aussi des membres des autres milices, corps de volontaires et des mouvements de résistance organisés répondant aux critères bien établis par le paragraphe 2 de l'article 4 en question. Ils doivent avoir à leur tête une personne responsable; arborer des signes distinctifs et reconnaissables à distance; porter les armes ouvertement et se conformer aux lois et coutumes de guerre. Disons que ces conditions qui matériellement s'avèrent souvent difficiles à rassembler seront appréhendées au regard de la pratique et de la jurisprudence actuellement en vigueur qui en simplifient d'ailleurs (cf. supra). Bénéficieront également de ce statut sur base de l'article 4 de la CG III, les membres des forces armées régulières se réclamant d'un pouvoir ou d'une autorité non reconnue par le pouvoir occupant ; les personnes qui suivent les forces armées sans en faire directement partie ; les membres d'équipages ne bénéficiant pas d'une protection plus favorable en vertu du DI ; la population d'un territoire non occupé qui prend spontanément les armes à l'approche de l'ennemi pour faire face à ses troupes («levée en masse »). D'autres personnes encore moyennant des conditions précises se trouvent être

\footnotetext{
${ }^{684}$ DEYRA, Michel, Le droit dans la guerre, op.cit., p.124.

${ }^{685}$ Ibid., p.125.
} 
protégées par cette disposition en qualité de prisonnier de guerre. Ce statut de prisonnier de guerre est nettement un privilège si l'on sait très bien que combattre au rang de l'ennemi dans un conflit armé international n'est donc pas une infraction. Et la personne qui tombe au pouvoir de l'ennemi ne serait donc pas jugée ou punie pour un tel fait. Et la puissance détentrice se trouve dans l'obligation de libérer les prisonniers de guerre à l'issue de la guerre $^{686}$. Ce qui ne serait probablement pas le cas dans les situations d'insurrection interne où l'Etat pourrait faire prévaloir son droit constitutionnel ou mieux son droit national afin d'évoquer des violations telles que «troubles à l'ordre public», "atteintes à la sûreté de l'Etat », « haute trahison », « rébellion », «insurrection » et punir ainsi l'auteur d'un tel acte. Concernant la libération des prisonniers, mentionnons à titre historique que «le traité de Munster (1648) qui mit fin à la guerre de Trente Ans constitua un précédent pour l'époque en ce qu'il prévoyait en son article 43 la libération des prisonniers de guerre sans exception, ni réserves, ni contre rançon qui était alors une pratique courante ${ }^{687}$.

Admise à ce statut de prisonnier de guerre, la personne concernée bénéficie d'un certain nombre de droits que prévoit le DIH au-delà de ce que prévoit naturellement les droits de l'homme. « D'une façon générale, le prisonnier de guerre a droit à un traitement humain et au respect de sa personne et de son honneur. Les articles 12 à 14 de la troisième Convention le protègent notamment contre les actes dangereux pour la santé, contre toute expérience médicale ou scientifique non justifiée par un traitement médical, toute mesure de représailles, tout acte de violence ou d'intimidation. De façon plus précise, près d'une centaine d'articles réglementent les conditions de l'internement à la fois sur un plan matériel, intellectuel, moral et juridique ${ }^{688}$.

Par ailleurs, «toute personne ne répondant pas aux catégories définies dans la IIIe Convention et le protocole I ne peut pas bénéficier du statut du combattant et par voie de conséquence de celui de prisonniers de guerre [...]. Si elle participe aux hostilités, elle sera considérée comme franc-tireur et punie pour acte de violence ou de terrorisme. Ainsi, les habitants d'un territoire occupé n'appartenant pas aux forces armées mais qui résistent militairement à l'occupant ne peuvent bénéficier du statut de combattant. Il en est de même pour les espions et les mercenaires $\gg$ ${ }^{689}$.

En effet, le terme espion contrairement au terme mercenaire n'est pas à proprement parlé défini par le PA I. Cependant, il découle des énumérations de l'article 46 du PA I, qu'un espion est une personne membre d'une partie au conflit c'est-à-dire de ses forces armées, qui de manière clandestine ou sous de fallacieux prétextes, recueille ou cherche à recueillir des

\footnotetext{
${ }^{686} \mathrm{Il}$ est important de faire remarquer qu' «une règle très ancienne d'origine coutumière admettait que les captifs de guerre soient réduits en esclaves. On ne manquera pas de mentionner la position très en avance de Rousseau pour qui "La fin de la guerre étant la destruction de l'Etat ennemi, on a le droit d'en tuer les défenseurs tant qu'ils ont les armes à la main, mais sitôt qu'ils les déposent et se rendent, ils redeviennent simplement hommes et l'on n'a plus droit sur leur vie ". Il conclut qu'on ne peut pour autant les réduire en esclavage en contrepartie de leur salut. Pour le philosophe, ces principes " dérivent de la nature des choses et sont fondés sur la raison ». BIAD, Abdelwahab, Droit international humanitaire, $2^{\mathrm{e}}$ édition, op.cit., p. 57.

687 BIAD, Abdelwahab, Droit international humanitaire, 2 édition, op.cit., p. 57.

688 DEYRA, Michel, Le droit dans la guerre, op.cit., p. 127. Pour approfondissement de cet aspect voir également les pages 127 à 140 de l'ouvrage précité de DEYRA, Michel et les pages 158-163 de Droit international humanitaire de BULA-BULA, Sayeman.

${ }^{689}$ BIAD, Abdelwahab, Droit international humanitaire, $2^{\mathrm{e}}$ édition, op.cit., p. 61.
} 
renseignements sur un territoire sous contrôle de la partie adverse au profit de la partie à laquelle elle appartient. En cas de détention d'espion, sa condamnation n'interviendra qu'à l'issue d'un procès dont les garanties judiciaires doivent être assurées. Pour être qualifié comme espion, la clandestinité exigée veut notamment que cette personne ne soit pas revêtue de son uniforme militaire. Ainsi, se livrant à recueillir des renseignements pour le compte de ses forces armées tout en étant revêtu de l'uniforme militaire, une fois tombé au pouvoir de la partie adverse, le sujet en question ne sera pas qualifié d'espion mais bénéficiera du statut de prisonnier de guerre.

Le mercenaire $e^{690}$ n'étant pas combattant, une fois capturé, il ne bénéficiera pas du statut de prisonnier de guerre. Il s'entend au sens de l'article 47 du PA I, de toute personne qui à titre individuel, volontaire et pour des raisons de profits personnels, se fait recruter par une partie en conflit pour combattre à ses côtés. Il n'est donc pas membre des forces armées en question Il ne doit être ni ressortissant d'une partie au conflit, ni encore résident du territoire sous contrôle d'une partie. Il reçoit à ce titre une rémunération nettement supérieure à celle réservée à ses collègues ayant un grade et une fonction équivalents dans les forces armées où il preste. «Le mercenariat s'est essentiellement développé en Afrique dans les années 1960 et 1970 lorsque les «chiens de guerre» (surnoms des mercenaires), essentiellement des Européens, menaient des actions militaires, instruisaient les forces armées locales, quand ils ne fomentaient pas des coups d'Etats. Aujourd'hui, le recrutement, l'utilisation, le financement et l'instruction de mercenaires sont prohibés à la fois par une convention de l'OUA (1977) et une convention des Nations unies (1989) » ${ }^{691}$.

De tout ce qui ce précède, il est important de relever que toute personne qui combat sur le champ de bataille et qui tombe au pouvoir d'une partie adverse bénéficie d'une présomption du statut de prisonnier de guerre. La personne combattante est donc présumée prisonnier de guerre en pareille situation. Seul un jugement issu d'un tribunal garantissant la loyauté du combat judiciaire (c'est-à-dire tous les droits judiciaires reconnus en pareilles circonstances) établira le statut exact de ce présumé prisonnier de guerre. Bien plus, l'article 45 alinéa 2 précise d'ailleurs qu'au cas où une personne tombée au pouvoir de la partie adverse est détenue sans bénéfice du statut de prisonnier de guerre et suite à une infraction devant être tranchée par le tribunal judiciaire, celui-ci se prononcera d'abord par rapport à la demande du statut de prisonnier de guerre. Laquelle demande se présente comme un droit reconnu à ce détenu en vertu donc de cet article. Il s'agit là d'une sorte d'exception in limine litis pour laquelle le tribunal judiciaire est appelé à se prononcer avant de statuer sur l'infraction commise par ce présumé prisonnier de guerre. «Toutefois, si cette personne est exclue du régime des prisonniers de guerre et ne bénéficie pas d'un traitement plus favorable, conformément à la IVe Convention de Genève, l'article 45 (du PAI), alinéa 3 lui accorde la protection minimale de l'article $75 \gg{ }^{692}$ du PA I intitulé d'ailleurs «Les garanties fondamentales ».

\footnotetext{
${ }^{690}$ Lire la thèse de doctorat d'Eric DAVID, Mercenaires et Volontaires Internationaux en Droit des gens, édition de l'Université de Bruxelles, Bruxelles, 1977.

${ }^{691}$ BIAD, Abdelwahab, Droit international humanitaire, $2^{\mathrm{e}}$ édition, op.cit., pp. 61-62.

${ }^{692}$ FURET, Marie-Françoise, MARTINEZ, Jean-Claude et DORANDEU, Henri, op.cit., p. 155.
} 


\section{La population civile}

«Une des caractéristiques des règles du droit de Genève antérieures à la Seconde Guerre mondiale est de ne viser que la protection des militaires. Il faut attendre l'adoption de la quatrième convention de Genève, en 1949, complétée par le protocole I, pour que soit prise en compte la protection des civils en temps de guerre, alors pourtant que la pratique avait démontré que ce sont souvent eux qui souffrent le plus des conséquences des hostilités» ${ }^{693}$. Cette léthargie du DIH sur la question de protection des civils pourrait se justifier notamment et surtout par la préoccupation des puissances étatiques qui était plus celle de vouloir réglementer leurs «relations belliqueuses » que de s'occuper des «individus ». L'expérience vécue par Henri Dunant de l'abandon sans soins sur le champ de bataille des militaires, et non des civils, - expérience qui a occasionné la naissance de la "Convention de Genève sur l'amélioration $d u$ sort des militaires blessés dans les armées en campagne » - influe également de manière non-négligeable sur la suite. Cette convention «ne vise la protection des civils que dans la mesure où ceux-ci portent secours aux militaires ${ }^{694}$. Et la perte des civils estimée à $65 \%$ des victimes durant la Seconde Guerre mondiale est nul doute une des raisons de consacrer à leur profit une protection conventionnelle appropriée. Une autre raison qui justifie la léthargie épinglée ci-dessus est le fait que « [1]e respect de la population civile en temps de guerre était un principe tellement indiscutable, qu'on n'avait pas considéré nécessaire de l'introduire explicitement dans les accords internationaux sur le droit de guerre. On peut le déduire de la Déclaration de Saint-Pétersbourg du 29 novembre/11 décembre 1868 à l'effet d'interdire l'usage de certains projectiles en temps de guerre, constatant que « le seul but légitime que les Etats doivent se proposer durant la guerre est l'affaiblissement des forces militaires de l'ennemi $»{ }^{695}$. Les personnes civiles ne devraient donc faire l'objet d'aucun affaiblissement, pour ne point dire d'attaque.

Qu'entendre par personnes civiles et population civile?

$\mathrm{Au}$ regard de l'article $50 \mathrm{du}$ PA I «1. Est considérée comme civile toute personne n'appartenant pas à l'une des catégories visées à l'article 4 A. 1), 2), 3), et 6) de la IIIe Convention et à l'article $43 \mathrm{du}$ présent protocole. En cas de doute, ladite personne sera considérée comme civile. 2. La population civile comprend toutes les personnes civiles. 3. La présence au sein de la population civile de personnes isolées ne répondant pas à la définition de personne civile ne prive pas cette population de sa qualité ». L'article 4 A dont mention est

\footnotetext{
${ }^{693}$ BUIRETTE, Patricia et LAGRANGE, Philippe, op.cit., p. 49. Lire également Claude EMANUELLI, op.cit., p. 516. Il nous paraît très indispensable d'indiquer qu'essentiellement en droit de la Haye : «Pendant longtemps la population eut peu à souffrir de l'emploi des armes, sauf si elle était, dans la zone même des combats : l'interdiction d'attaquer les localités non défendues et la protection de la population civile dans les zones occupées semblaient des règles suffisantes avec les Conventions de La Haye en 1899 et en 1907 ». Voir DEYRA, Michel, op.cit., p.145. Sous ce même angle, il sied de noter la «clause de Martens » insérée dans les Conventions de La Haye de 1899 et de 1907. Cette clause prévoyait que dans des cas non-réglementés par les Conventions, la population et les combattants resteraient sous la protection et la sauvegarde des principes du droit international issus de la coutume, des principes d'humanité et des consciences sociale et exigences des nations civilisées. Cette clause qui reste d'application à ce jour s'inscrit dans la droite ligne de la protection de la population civile.

${ }^{694}$ EMMANUELLI, Claude, op.cit., p. 516.

${ }^{695}$ JASICA, Roman, « art.cit. », p. 57.
} 
faite ici traite des membres des forces armées, des milices, des corps de volontaires, des mouvements de résistance organisés et des populations d'un territoire non occupé se retrouvant dans une situation de «levée en masse ». Lesquels seront qualifiés de prisonniers de guerre s'ils tombent au pouvoir de l'ennemi (cf. supra). Il s'agit là des personnes protégées contre l'arbitraire de l'ennemi. L'article 43 du PA I pour sa part traite de la question de la composition des forces armées. Bref, il est question dans toutes ces dispositions conventionnelles des personnes qui ont droit de prendre part aux hostilités c'est-à-dire des combattants.

Il ressort que «[1]a définition de la population civile est négative en ce que l'on dit ce qu'elle n'est pas, et non ce qu'elle est. On en déduit donc, en résumé, qu'est personne civile tout noncombattant. Les auteurs anciens parlaient des «sujets paisibles de l'adversaire $»{ }^{696}$. Cette définition par exclusion ne varietur a pour avantage d'écarter tout risque de vide juridique entre les statuts de civil et de combattant ${ }^{697}$. Elle prévoit en même temps une présomption du statut de personne civile qui profite à toute personne non combattante dont on ne sait pas clairement déterminer son statut. Il y a lieu également de comprendre déjà de par cette disposition que les règles du $\mathrm{DIH}$ fondent leur protection sur l'ensemble de la population tout comme sur chaque personne prise individuellement.

«Pour autant, cette simplicité ne suffit-elle pas à résoudre les problèmes que la définition comporte dans la pratique. La jurisprudence interne et internationale a permis de préciser ces notions $»^{698}$.

En effet, dans l'arrêt Martic - et dans la lignée de la jurisprudence Blaskic, Galic et Kordic le TPIY, en sa chambre d'appel, a affirmé que la notion de population civile devait être définie de façon stricte. Ainsi, suivant cette juridiction, cette notion ne recouvre que les individus n'appartenant ni aux forces armées d'un Etat ni aux milices ou corps de volontaires qui en font partie. Cette notion exclut donc de son champ d'application les prisonniers de guerre, malades, blessés de guerre, et ceux qui, bien que membres des forces armées d'un Etat, se sont volontairement retirés des hostilités, de même que les corps de volontaires, milices et mouvement de résistances répondant aux critères posés à l'article $4 \S \mathrm{A}$ alinéa 2 de la CGIII ${ }^{699}$. Toutefois, le TPIY a pu tempérer cette conception stricte de la notion de la population civile. Ainsi, se fondant sur l'article 50, paragraphe 3 du PA I cité ci-dessus, le TPIY a estimé que la présence au sein de la population civile de résistants, de militaires ayant déposé les armes, voire même de combattants, ne privait pas nécessairement celle-ci de sa nature civile. Il suffit donc que cette population soit «essentiellement civile ». Il faudrait donc tenir compte du nombre de «non-civils » par rapport aux civils et des raisons de leur présence (Il se peut, par exemple, qu'il s'agisse de soldats en permission dans leur famille). ${ }^{700}$ La conséquence d'une telle conception est à situer notamment au niveau de la répression du

\footnotetext{
${ }^{696}$ BETTATI, Mario, Droit humanitaire. Textes introduits et commentés, op.cit., p. 57.

${ }^{697}$ DEYRA, Michel, Le droit dans la guerre, op.cit., p. 142.

${ }^{698}$ BETTATI, Mario, Droit humanitaire. Textes introduits et commentés, op.cit., p. 57.

${ }^{699}$ HEMPTINNE, Jérôme de, «La définition de la notion de «population civile » dans le cadre du crime contre l'humanité. Commentaire critique de l'arrêt Martic », in RGDIP, 2010/1, p. 95.

${ }^{700}$ HEMPTINNE, Jérôme de, «La définition de la notion de «population civile » dans le cadre du crime contre l'humanité. Commentaire critique de l'arrêt Martic », « art. cit. », p. 97.
} 
crime contre l'humanité comme cela était d'ailleurs le cas dans l'arrêt sous examen. Cela permet d'étendre la qualité des victimes de crime contre l'humanité à ces personnes mises hors combat ou combattantes suite à leurs liens avec un groupe constitué essentiellement de civils. C'est plus avantageux en termes de protection des droits humains. Tout de même, le TPIY ajoute, toujours sous l'angle de l'interprétation de la notion de la population civile conformément au crime contre l'humanité, non seulement que cette population doit être «essentiellement civile», elle doit être également la «cible principale ». L'on comprendra tout logiquement que ces résistants, militaires ayant déposé les armes ou combattants, etc. sont considérés comme victimes de crime contre l'humanité de manière incidente ou accessoire suite à une attaque massive ou systématique visant la population civile avec qui ils ont eu des liens. Il n'a donc pas été dit qu'une attaque massive ou systématique lancée contre de tels groupes des résistants ou militaires ou des combattants sans lien avec la population civile comme décrit ci-dessus serait constitutif de crime contre l'humanité. ${ }^{701} \mathrm{C}$ 'est dans ce sens que Jérôme de HEMPTINE formule des critiques à l'endroit de cet arrêt. Il le dit brièvement en ces termes : «La conception retenue dans l'arrêt Martic nous paraît critiquable qu'un large consensus semble désormais émerger en droit international coutumier pour affirmer que quiconque commet des exactions massives ou systématiques contre des résistants peut être reconnu coupable de crimes contre l'humanité. S'inscrivant dans une tendance progressiste du droit de la guerre visant à étendre au maximun la protection qu'il confère à des individus - et ce indépendamment de leur statut - de plus en plus de voix s'élèvent également pour dire qu'un tel crime pourrait, dans certaines conditions, être perpétré contre des milices ou des paramilitaires ${ }^{702}$.

Ainsi définies, les personnes civiles sont régies par une protection générale et une protection spéciale. Il existe une protection générale accordée aux personnes civiles qui se retrouvent au pouvoir d'une partie au conflit. Il s'agit là des «personnes protégées ». Il faudrait en cela qu'elles ne puissent pas être ressortissantes de cette partie au conflit ou de la puissance occupante sous le pouvoir de laquelle elles tombent (cf. article 4 CG IV et infra). Face à ce « critère de nationalité », une interprétation large et téléologique est donc souhaitée qu'étroite et technique ${ }^{703}$. Ainsi, le critère d'allégeance effective ${ }^{704}$ a été favorisé envue d'assurer plus de protection aux civils dans un conflit armé interne internationalisé que n'accordait «le critère de nationalité ${ }^{705}$. Robert KOLB précise que ce critère d'allégeance ne reste valable que dans le cadre d'un conflit armé interne internationalisé et non dans le cadre d'un CAI classique $^{706}$. Tout de même, le «critère de nationalité » est, sous l'influence de la jurisprudence internationale et de la doctrine des droits de l'homme, progressivement supplanté par une version tendant à n'exclure personne ${ }^{707}$.

\footnotetext{
701 Ibid.

702 Ibid., p.101.

${ }^{703}$ KOLB, Robert, Ius in bello. Le droit international des conflits armés, $2^{\mathrm{e}}$ édition, op. cit., p. 364.

${ }^{704}$ TPIY, Le Procureur c. Zejnil Delalic et al., Affaire $\mathrm{N}^{\circ} \mathrm{IT}-96-21$, Chambre de première instance, jugement du 16 novembre 1998, p.108, § 263. Lire l'extrait de ce jugement repris au Chapitre suivant, Section II, §1, A, A.1.

${ }^{705} \mathrm{KOLB}$, Robert, Ius in bello. Le droit international des conflits armés, $2^{\mathrm{e}}$ édition, op. cit., p. 365.

${ }^{706}$ Ibid., p. 366.

${ }^{707}$ Lire MOMTAZ Djamchid, «Les défis des conflits armés asymétriques et identitaires au droit international humanitaire », in MATHESON Michael J. et MOMTAZ Djamchid, op.cit., pp. 17-20
} 
Une autre protection générale concerne les personnes civiles des parties en conflit sans prise en compte d'un quelconque critère discriminatoire. Il s'agit là de la protection contre les effets des hostilités. En clair, si pour des «personnes protégées », la protection exige qu'elles ne soient pas ressortissantes des pays au pouvoir desquels elles se retrouvent cependant pour la protection accordée au titre II de la CG IV intitulée «Protection générale des populations civiles contre certains effets de la guerre » aucun critère n'est retenu. Et cette dernière protection s'adresse à tout le monde autant qu'aux personnes protégées une fois de plus.

A côté de cette protection générale décrite, il existe également une protection spéciale accordée aux personnes vulnérables notamment les enfants, les femmes, et aussi le personnel religieux et les journalistes compte tenu de la particularité de leur mission en pareilles circonstances. Ces personnes qui méritent une protection spécifique ou spéciale suite à leur vulnérabilité ou leurs activités particulières en situation de conflits armés ne sont pas moins couvertes par la protection générale ci-haut détaillée. Elles ne sont donc pas moins personnes civiles au même titre que les autres. Cependant, leur vulnérabilité ou la particularité de leur activité exigent un regard spécifique de la part des parties au conflit.

Eu égard à ce qui précède, «le droit de la guerre repose sur un principe de base selon lequel les hostilités doivent se dérouler exclusivement entre les forces armées des parties en conflit ${ }^{708}$. «La population civile doit être soustraite à tout acte de violence, à toute attaque, y compris à toute pose de mines. L'immunité dont est couverte la population civile vaut pour toutes les opérations militaires, aériennes, terrestres et navales (art. 49, protocole I). Elle s'étend aussi à leurs biens divers (art. 52 s. ibid. et art. 3 bis de la Convention de Chicago du 7 décembre 1944 adoptée après la destruction de l'aéronef de Korean Airlines suspecté d'espionnage par l'Union soviétique, au-dessus d'une portion de son territoire aérien jugée stratégique par elle, en octobre 1983) ${ }^{709}$. Sans formuler une définition quelconque des termes «populations civiles» ou «personnes civiles» comme l'a fait le PA I, le titre IV du PA II consacré à la «Population civile » assure tout de même la protection des populations et personnes civiles; des biens indispensables à leur survie; des ouvrages et des installations contenant des forces dangereuses dont l'attaque peut s'avérer néfaste sur la population civile.

De ce qui précède, il est important de mentionner que la protection de la population et des personnes civiles est assurée par de nombreuses dispositions conventionnelles, règles et principes (cf. supra Principes du droit international humanitaire) qui ne relèvent pas nécessairement de la CG IV ou des PA. Toutefois, ces règles, même avec le mécanisme de contrôle exercé par les puissances protectrices ou par le CICR et avec l'obligation des Parties au conflit de fixer les sanctions pénales à appliquer aux auteurs des infractions graves, ne constituent pas un système de protection absolue de la population civile contre les effets des hostilités $^{710}$.

\footnotetext{
${ }^{708}$ BUIRETTE, Patricia et LAGRANGE, Philippe, op.cit., p. 49.

${ }^{709}$ BULA-BULA, Sayeman, op.cit., p. 114.

${ }^{710}$ Lire JASICA, Roman, « art.cit.», p. 59.
} 


\section{\$3. Champ d'application ratione temporis et ratione loci}

L'article 3 du PA I dispose : «Sans préjudice des dispositions applicables en tout temps : a) les Conventions et le présent Protocole s'appliquent dès le début de toute situation visée à l'article premier du présent protocole; b) l'application des Conventions et du présent Protocole cesse, sur le territoire des parties au conflit, à la fin générale des opérations militaires et, dans le cas des territoires occupés ${ }^{711}$, à la fin de l'occupation, sauf, dans les deux cas, pour les catégories de personnes dont la libération définitive, le rapatriement ou l'établissement ont lieu ultérieurement. Ces personnes continuent à bénéficier des dispositions pertinentes des Conventions et du présent Protocole jusqu'à leur libération définitive, leur rapatriement ou leur établissement ». La situation visée par le PA I, précisément en son article $1^{\mathrm{er}}$, concerne les conflits armés internationaux (cf. supra). Par ailleurs, l'alinéa $b$ de l'article 3 reprend les éléments de fin d'application des CG et ne fait pas mention du délai d'application que prévoit l'article 6 de la CG IV en son alinéa 3 lorsqu'il dispose : «En territoire occupé, l'application de la présente convention cessera un an après la fin générale des opérations militaires; [...] ». En d'autres termes, de deux seuils de la fin du droit de l'occupation de la CG IV - «seuil d'un an » et «seuil de la fin d'occupation » - érigés par l'article 6 (alinéa 3) précité, seul ce dernier seuil est pertinent et retenu par l'article $3 b$ du PA I ${ }^{712}$. Le « seuil de la fin de l'occupation » applicable à certains articles de la CG IV expressément énumérés par l'article 6 alinéa 3, est appréhendé comme la fin de l'exercice des fonctions gouvernementales et administratives de la puissance occupante ${ }^{713}$. L'article $3 b$ du PA I a donc pour effet de le remplacer et de prévoir une application prolongée des CG et du PA I en territoire occupé jusqu'à la fin de l'«occupation» et non un an après «la fin des opérations militaires ». Et «[1]a fin de l'occupation, qui peut intervenir longtemps après le début de cette occupation, résultera de divers éléments de fait ou de droit, selon que l'issue en sera la libération du territoire ou son incorporation dans un ou plusieurs Etats conformément au droit du peuple ou des peuples de ce territoire à disposer d'eux-mêmes ${ }^{714}$. Il s'agit là de la reprise d'une idée du projet de la Conférence diplomatique de 1949 non adoptée. S'agissant de cette idée, au cours des travaux préparatoires, «[p]lusieurs délégations à la Conférence diplomatique firent valoir [...] que si l'occupation devait être maintenue durant un temps très long après la fin générale des hostilités, le moment viendrait sans doute où l'application de la Convention ne se justifierait plus, spécialement lorsque la plupart des fonctions gouvernementales et administratives, exercées précédemment par la Puissance occupante, auraient été remises aux autorités du territoire occupé. En 1949, les délégués avaient naturellement présents à l'esprit les cas de l'Allemagne et du Japon. C'est ainsi qu'on est arrivé à prévoir qu'en territoire occupé

\footnotetext{
711 «Un territoire qui se trouve placé de fait sous l'autorité de l'armée ennemie est considéré comme un territoire occupé par le droit international ». (BOUCHET-SAULNIER, Françoise, Dictionnaire pratique du droit humanitaire, ... 2013, op. cit., p. 755). «Il est possible que l'autorité des forces d'occupation ne parvienne pas à s'établir ni à s'exercer, du fait des actes de violence commis par les combattants adverses contre les forces d'occupation. Le droit humanitaire ne parle plus alors de territoire occupé, mais de territoire envahi. Les règles qui lui sont applicables sont celles du champ de bataille, c'est-à-dire les règles générales du droit des conflits armés » (BOUCHET-SAULNIER, Françoise, Dictionnaire pratique du droit humanitaire,...2013, op. cit., p. 756).

${ }^{712}$ KOUTROULIS, Vaios, Le début et la fin de l'application du droit de l'occupation, éd. Pedone, Paris, 2010, p. 163.

${ }_{713}$ Ibid., p. 164.

714 Points 155 et 156 des Commentaires de l'article 3 alinéa $b$ du PA I, in http://www.icrc.org/dih.nsf/COM/470-750006?OpenDocument (Source consultée le 23 mars 2015).
} 
la Convention serait applicable entièrement pendant une période d'un an, après quoi la Puissance occupante ne serait liée que dans la mesure où elle continue à exercer des fonctions gouvernementales. $[\ldots] \gg^{715}$.

Par ailleurs, il découle de la jurisprudence que «le champ temporel et géographique des conflits armés internationaux et internes s'étend au-delà de la date et du lieu exact des hostilités $\gg^{716}$.

Concernant, l'application territoriale des règles du DIH, par exemple, « La chambre d'appel (du TPIY) affirme: «[1]es Conventions de Genève restent silencieuses sur le champ géographique des "conflits armés" internationaux mais les dispositions suggèrent qu'au moins certaines des clauses desdites Conventions s'appliquent à l'ensemble du territoire des parties au conflit et pas simplement au voisinage des hostilités effectives. Indéniablement, certaines des dispositions sont clairement liées aux hostilités et le champ géographique de ces dispositions devrait y être limité. D'autres, en particulier celles se rapportant à la protection des prisonniers de guerre et des civils, ne sont pas restreintes de la même façon. S'agissant des prisonniers de guerre, la Convention s'applique aux combattants aux mains de l'ennemi ; il ne fait aucune différence qu'ils soient internés à proximité des hostilités ou non. Dans le même esprit, la CG IV protège les civils sur tout le territoire des parties. Cette interprétation est implicite à l'article 6, paragraphe 2 de la Convention, qui stipule que : «Sur le territoire des parties au conflit, l'application de la Convention cessera à la fin générale des opérations militaires ${ }^{717}$. Ainsi donc, «le droit international humanitaire continue de s'appliquer sur l'ensemble du territoire des Etats belligérants ou, dans les cas de conflits internes, sur l'ensemble du territoire sous le contrôle d'une partie, que des combats effectifs s'y déroulent ou non ${ }^{718}$.

\section{Section II Mise en œuvre du droit international humanitaire}

Le souci le plus ardent de tout législateur, national ou international soit-il, est celui de voir sa loi mise en application et respectée. La loi qui n'est qu'un texte ou mieux des mots sur papier, doit réguler les modes de vie des individus en société. Et pour la faire respecter, des mécanismes doivent être envisagés par son auteur.

Ainsi, «tout système de droit n'est efficace que s'il permet l'application effective des normes établies par l'ordre juridique qui l'organise. C'est à cette condition qu'il remplit sa fonction sociale qui est de régulation des rapports entre ses différents sujets $\gg^{719}$.

En effet, si au plan national ou étatique, le pouvoir public arrive à imposer facilement sa loi

\footnotetext{
715 Commentaires de l'article 6, alinéa 3 de la CG IV, in http://www.icrc.org/dih.nsf/COM/380600009? OpenDocument (Source consultée le 23 mars 2015).

716 TPIY, Le Procureur c/ Tadic, affaire n IT-94-1-AR72, Chambre d'appel, Arrêt relatif à l'appel de la Défense concernant l'exception préjudicielle d'incompétence, 2 octobre 1995, § 67, in http://www.icty.org/x/cases/tadic/acdec/fr/51002JN3.htm (Source consultée le 23 mars 2015); BETTATI Mario, Droit humanitaire. Textes introduits et commentés, op.cit., p. 44.

${ }^{717}$ TPIY, Le Procureur c/ Tadic, affaire n IT-94-1-AR72, Chambre d'appel, Arrêt relatif à l'appel de la Défense concernant l'exception préjudicielle d'incompétence, 2 octobre $1995, \quad \S \quad 68$, in http://www.icty.org/x/cases/tadic/acdec/fr/51002JN3.htm (Source consultée le 23 mars 2015).

718 BETTATI, Mario, Droit humanitaire. Textes introduits et commentés, op.cit., p. 43.

${ }^{719}$ DUPUY, Pierre-Marie, Droit International Public, édition Dalloz, Paris, 1992, p. 293.
} 
ou plus mieux son droit par différents mécanismes à sa portée (Administration publique, cours et tribunaux, armée et police, etc.), cependant le problème est tout autre en droit international. Ici règne la souveraineté des Etats qui sont à la fois auteurs et sujets dudit droit. Bien plus, contrairement au droit national, le droit international dispose de moyens limités pour la mise en œuvre de ses dispositions. Que dire de la mise en œuvre du DIH à proprement parler ?

En effet, de même qu'en DIH, il ne suffit pas pour les Etats de ratifier les CG ou leurs PA, comme cela pourrait bien être le cas pour tout autre instrument juridique international. L'important est d'assurer leur mise en œuvre au profit des bénéficiaires. Ce qui concorde le mieux avec le principe pacta sunt servanda (cf. infra).

L'effectivité du droit dans la guerre dépend, d'une part, de son champ d'application qui est à géométrie variable (cf. supra), et d'autre part, des mesures d'exécution prises par les Etats qui ont une responsabilité individuelle et collective dans la mise en œuvre du $\mathrm{DIH}^{720}$.

«Or, là où le bât blesse, en droit international humanitaire, c'est bien surtout du côté de la mise en œuvre ${ }^{721}$ estime Luigi CONDORELLI. «Le DIH existant refuse d'organiser efficacement sa propre mise en œuvre » insiste l'auteur précité et réitère Paul TAVERNIER $^{722}$. Et à Mario BETTATI d'ajouter que «non seulement ces traités sont dépourvus de moyens suffisants de mise en œuvre, mais ils comportent diverses lacunes qui ont justifié l'adoption de toute une série de textes conventionnels ou unilatéraux [...] en vue de renforcer la protection des victimes ${ }^{723}$. Bien plus, le DIH s'applique différemment selon qu'il s'agit de CAI ou selon qu'il s'agit de CANI (cf. supra). Le premier se rapporte au droit des CAI, plus élaboré avec des mécanismes de mise en œuvre appropriés. Les CG dans leur entièreté s'y consacrent. Le second concerne le droit des CANI avec des règles et moyens de mise en œuvre très limités. Le PA II et l'article 3 commun aux CG, pour leur part, se préoccupent de la question. Le PA II ne contient que peu de dispositions (28 articles au total dont 18 substantiels) pour réglementer les CANI.

Par ailleurs, l'analyse des mécanismes existants - à retrouver plus dans les conflits armés internationaux - permet de les classer en trois grandes catégories à savoir : les mécanismes de prévention $(\S 1)$, les mécanismes de contrôle $(\S 2)$ et les mécanismes de sanction (§3). Ce qui paraît très logique dans la succession des évènements. En d'autres termes, les premiers sont à développer en temps de paix ; les deuxièmes sont à instituer en temps de conflit et les derniers sont à organiser plus à l'issue des hostilités.

Toutefois, un intérêt sera réservé au rôle joué par l'ONU dans l'émergence du DIH (§4) avant d'examiner en dernier lieu des facteurs non-juridiques liés à la mise en œuvre du DIH (§5).

\footnotetext{
${ }^{720}$ DEYRA, Michel, Le droit dans la guerre, op.cit., p. 169.

${ }^{721}$ Lire la Préface de CONDORELLI, Luigi in S. VITE, Les Procédures internationales d'établissement des faits dans la mise en ouvre du droit international humanitaire, éditions Bruylant et éditions de l'Université de Bruxelles, Bruxelles 1999, p. XIII.

${ }^{722}$ CONDORELLI, Luigi cité par TAVERNIER, Paul, « Réflexion sur les mécanismes assurant le respect du Droit International Humanitaire conformément aux Conventions de Genève et aux Protocoles additionnels », in Actualités et Droit International, Revue d'analyse juridique et d'actualités internationales http://www.ridi.org/adi/200004 (Source consultée le 25 novembre 2015).

${ }_{723}$ BETTATI, Mario, Droit humanitaire. Textes commentés et introduits, op.cit., p. 65.
} 


\section{\$1 Les mécanismes de prévention}

L'article $1^{\text {er }}$ commun aux CG et l'article $1^{\text {er }} \S 1$ du PA I imposent aux Etats non seulement de respecter ces instruments internationaux mais aussi de les faire respecter en toutes circonstances. « [A] première vue, cette disposition peut paraître superfétatoire en ce qu'elle n'ajoute rien au principe général du droit des traités, pacta sunt servanda $[\ldots]^{724}$ En réalité, il semble que les auteurs de ces textes aient voulu à la fois rappeler la règle et y insister $[\ldots]{ }^{725}$. Cette disposition est interprétée comme visant non seulement le respect du DIH dans l'ordre interne mais aussi dans l'ordre international ${ }^{726}$. Suivant la CIJ dans son avis consultatif sur les «Conséquences juridiques de l'édification d'un mur dans le territoire palestinien occupé », «[i]l résulte de cette disposition l'obligation de chaque Etat partie à cette convention, qu'il soit partie ou non à un conflit déterminé, de faire respecter les prescriptions des instruments concernés $\gg^{727}$.

Dans «une étude attentive et bien documentée ${ }^{728}$ telle que qualifiée par Robert KOLB, François DUBUISSON renseigne que la portée de l'article $1^{\mathrm{er}}$ commun aux CG fait l'objet de débat. Le problème se situe au niveau d'admettre ou non s'il existe un devoir d'agir des Etats parties aux CG afin d'amener un Etat à respecter ses engagements au regard de la convention, en cas de violation. En réponse, si certains reconnaissent l'inexistence d'une telle obligation dans l'interprétation de cette disposition ${ }^{729}$, en revanche la conception largement dominante que partage François DUBUISSON et que nous partageons d'ailleurs - reconnaît l'existence d'une telle obligation ${ }^{730}$. Laquelle se trouve confortée par le commentaire du CICR et attestée dans la pratique étatique à travers les résolutions et avis des organes onusiens dont le CS/NU, l'AG/NU et la $\mathrm{CIJ}^{731}$. Bien plus, différentes approches - bilatérales ou multilatérales, régionales ou universelles - sont adoptées dans la pratique des Etats pour remplir cette obligation de «faire respecter » le DIH dont des démarches discrètes ou des protestations, des dénonciations publiques, des pressions diplomatiques, des mesures coercitives, des mesures de rétorsion, etc. ${ }^{732} \mathrm{Il}$ ressort donc de l'étude de François DUBUISSON que l'article $1^{\text {er }}$ commun aux CG (et l'article $1^{\mathrm{er}}, \S 1$, du PA I) «implique une obligation positive pour les Etats parties de faire respecter [...] le droit humanitaire ${ }^{733}$ mais aussi une obligation négative (nous soulignons). Car comme l'indique l'auteur, «[i]l est a fortiori exigé que les

\footnotetext{
${ }^{724}$ cf. article 26 de la Convention de Vienne sur le droit des traités

725 NIYUNGEKO, Gérard, «La mise en œuvre du droit international humanitaire et le principe de la souveraineté des Etats », « art.cit. », pp.114-115.

${ }^{726}$ BULA-BULA, Sayeman « art.cit. », p. 169.

${ }^{727}$ CIJ, Conséquences juridiques de l'édification d'un mur dans le territoire palestinien occupé, avis consultatif, Recueil 2004, pp. 199-200, §158.

${ }^{728}$ Voy. KOLB, Robert, «Commentaires iconoclastes sur l'obligation de faire respecter le droit international humanitaire selon l'article 1 commun des Conventions de Genève de 1949 », in RBDI, 2013/2, pp. 513-520.

${ }^{729}$ Lire Ibid.

${ }^{730}$ DUBUISSON, François, «Les obligations internationales de l'Union européenne et de ses Etats membres concernant les relations économiques avec les colonies israéliennes », in RBDI, 2013/2, p. 428.

${ }^{731}$ Lire Ibid., pp. 429-432.

732 VEUTHEY, Michel, «L'Union européenne et l'obligation de faire respecter le droit international humanitaire », in MILLET-DEVALLE, Anne-Sophie (dir.), L'Union européenne et le droit international humanitaire, Paris, Pedone, 2010, pp. 196-197.

${ }^{733}$ DUBUISSON, François, «Les obligations internationales de l'Union européenne et de ses Etats membres concernant les relations économiques avec les colonies israéliennes », « art. cit. », p. 432.
} 
Etats s'abstiennent d'actes qui iraient à l'encontre de l'objectif d'incitation au respect du droit humanitaire ${ }^{734}$. En clair, cet article «n'offre lui-même aucune indication quant aux mesures qui peuvent être prises pour le mettre en œuvre ${ }^{735}$. Ainsi, l'identification de telles mesures devrait être guidée par leur licéité en droit international et surtout «par le souci d'efficacité c'est-à-dire celui d'améliorer réellement le sort des victimes $»^{736}$.

Jean PICTET, dans son commentaire au regard de cet article, écrivait que « les mots «en toutes circonstances » signifient qu'[...] une Puissance liée ne peut se donner aucun prétexte valable, d'ordre juridique ou autre, pour ne pas respecter la Convention dans son ensemble. «En toutes circonstances », cela signifie encore que l'application de la Convention ne dépend pas du caractère du conflit. Qu'il s'agisse d'une guerre « juste » ou « injuste », d'une agression ou d'une résistance à l'agression, cela ne saurait affecter en rien la protection et les soins dus aux blessés et aux malades» ${ }^{737}$.

La CIJ a bien montré, dans l'affaire Nicaragua, que l'article premier commun n'est pas « une simple clause de style ${ }^{738}$ dépourvue de toute force juridique, mais une norme fermement ancrée dans le droit international général entraînant des obligations pour chaque Etat, qu'il ait ratifié ou non les traités en question. La Cour affirme que : " Les Etats-Unis ont l'obligation, selon les termes de l'article premier des quatre Conventions de Genève, de « respecter » et même de «faire respecter» ces Conventions «en toutes circonstances », car une telle obligation ne découle pas seulement des Conventions elles-mêmes, mais des principes généraux du droit humanitaire dont les Conventions ne sont que l'expression concrète ${ }^{739}$. Et Faridey SHAYGAN n'hésite pas à affirmer que les obligations du DIH vont au delà de celles relevant du droit international coutumier ${ }^{740}$.

Ainsi il découle de ce qui vient d'être dit, comme l'estime Hans Peter GASSER, un certain nombre de mesures doivent être prises si l'on veut assurer le respect des obligations découlant du DIH tant au plan interne qu'international ${ }^{741}$. En clair, les Etats parties devront prendre des mesures diverses parmi lesquelles : la traduction et la diffusion des traités de DIH dans les langues nationales; l'adoption des dispositions législatives ou réglementaires (législation pénale réprimant les crimes de guerre et les autres violations du DIH ); la protection des emblèmes de la croix rouge, du croissant rouge et du cristal rouge; l'élaboration des programmes d'éducation; le recrutement et la formation du personnel, l'identification et la

\footnotetext{
${ }_{734}^{734}$ Lire Ibid.,p. 433.

735 CICR, «Protection des victimes de la guerre », Préparation de la Réunion du Groupe d'experts intergouvernemental pour la protection des victimes de la guerre, Genève 23-27 janvier 1995, Suggestions du CICR, Genève, op.cit., p. 478.

${ }^{736}$ Ibid.

737 PICTET, Jean, Commentaire I. La Convention de Genève pour l'amélioration du sort des blessés et des malades dans les forces armées en campagne, CICR, Genève, 1952, p. 28. Voy. aussi SHAYGAN, Farideh, La Compatibilité des sanctions économiques du Conseil de sécurité avec les droits de l'Homme et le droit international humanitaire, Bruxelles, Bruylant, 2008, p. 70.

${ }^{738}$ Jean PICTET le signifiait déjà en 1952 dans son commentaire à ce sujet. Voy. PICTET, Jean, Commentaire I. La Convention de Genève pour l'amélioration du sort des blessés et des malades dans les forces armées en campagne, op.cit., p. 28.

${ }^{739}$ CIJ, Affaire des Activités militaires et paramilitaires au Nicaragua et contre celui-ci (Nicaragua c. EtatsUnis), Recueil 1986, p. 114, §220. ; SHAYGAN, Farideh, op.cit., p. 71.

${ }^{740}$ Ibid., p. 70.

${ }^{741}$ GASSER, Hans Peter, op.cit., pp. 88-89.
} 
signalisation des personnes, des lieux et des biens protégés; la nomination des conseillers juridiques auprès des forces armées ; etc. ${ }^{742}$ Même sur le champ de bataille, plusieurs phases devraient caractériser la préparation et la conduite d'une opération militaire : la mission, la collecte des renseignements, l'analyse des facteurs, l'appréciation, la prise de décision, la communication de la décision, l'exécution et son contrôle ${ }^{743}$. La phase d'analyse devra comporter une étude de vulnérabilité des personnes et des biens civils. ${ }^{744}$

Toujours en temps de paix, la pratique des Etats actuellement consiste en l'institution de commissions nationales de mise en œuvre du DIH. Citons à cet effet, la Commission nationale de mise en œuvre du droit international humanitaire du Kenya créée le 5 octobre 2001 regroupant en son sein les représentants de Ministères des Affaires Etrangères, de la Défense, de la Justice, de l'Intérieur, de la Santé, les représentants du Procureur Général, des milieux académiques et de la Croix-Rouge. Elle se charge de promouvoir le respect du DIH par l'adoption des mesures législatives et de programmes de diffusion. Une telle commission, on la retrouve également à Lituanie (depuis le 22 mai 2001), à l'Ile Maurice (créée le 21 décembre 2001) ${ }^{745}$ ou au Madagascar. En Amérique latine, il existe par exemple en Argentine la Comisión de Aplicación del Derecho internacional humanitario (Commission d'application du droit international humanitaire) créée par le décret $n^{\circ} 933 / 94$ du 16 juin 1994. Elle a pour mission de proposer aux autorités des lois et règlements d'application du DIH et de coordonner les activités de diffusion de ce droit. En Bolivie, il y a une telle commission sous l'appelation de la Comisión Nacional permanente para la aplicación del Derecho internacional humanitario (Commission nationale permanente pour l'application du droit international humanitaire). De même qu'en Uruguay où est instituée la Comisión Nacional de Derecho internacional humanitario par le décret $n^{\circ} 191 / 92$ du 12 mai $1992^{746}$. Il va sans dire que la création de ces commissions « est une mesure essentielle pour faire appliquer le droit international humanitaire ${ }^{747}$. En RDC, pays où sont dénombrés de multiples cas récurrents de violations du DIH en général et de la protection des enfants en situation de conflits armés en particulier, il n'existe pas en revanche de commission nationale de mise en œuvre du DIH. C'est dans cet ordre d'idées que nous suggérons sa création (cf. infra).

Par ailleurs, spécialement à la situation de l'enfant, il revient également à l'Etat d'envisager, en période de paix, des mesures à prendre pour assurer sa protection en temps de conflits armés. Ainsi, la diffusion ou l'enseignement des règles du DIH relatives à la protection des enfants dans les conflits armés reste d'une grande importance. Ceci relève d'ailleurs d'une

\footnotetext{
${ }^{742}$ DEYRA, Michel, Le droit dans la guerre, op.cit., p. 163.

743 REMACLE, Robert, «La conduite des opérations militaires au regard du droit des conflits armés », in Actualité du Droit international humanitaire, Bruxelles, éd. La Charte 2001, p. 34.

${ }^{744}$ Ibid., p. 36.

${ }^{745}$ Lire CICR. « Mise en œuvre du Droit International Humanitaire », Chronique semestrielle de législation et de jurisprudences nationales, juillet-décembre 2001 RICR, nº 845, CICR. Genève_mars 2002,

${ }_{746}$ DUTLI, Maria Teresa, «Mise en œuvre du droit international humanitaire - Mesures nationales informations reçues par le Comité international de la Croix-Rouge sur les mesures nationales de mise en œuvre adoptées par les Etats », in RICR, n 809, CICR. Genève, septembre - octobre 1994, pp. 508-510.

747 CICR, «Protection des victimes de la guerre », Préparation de la Réunion du Groupe d'experts intergouvernemental pour la protection des victimes de la guerre, Genève 23-27 janvier 1995, Suggestions du CICR, op.cit., p. 469.
} 
obligation internationale ${ }^{748}$ (cf. infra) voire constitutionnelle pour certains Etats dont la $\mathrm{RDC}^{749}$ (cf. infra). A cet égard, il faudrait, par exemple, intégrer les règles élémentaires du DIH en général et celles liées à la protection des enfants en particulier dans les programmes scolaires voire universitaire. Au regard de l'implication accrue de la jeunesse dans les conflits armés, il s'avère d'une grande utilité d'inclure ces enseignements dès le bas âge scolaire ${ }^{750}$.

En outre, des lois spécifiquement liées à la protection de la vulnérabilité de l'enfant doivent être promulguées et diffusées largement dans les langues nationales et locales ${ }^{751}$. Elles iront dans le sens de pénaliser les auteurs des violations des droits de l'enfant et d'ériger des tribunaux spéciaux (pas d'exceptions) pour traiter de tels litiges. D'autres mesures pratiques seront également prises dans le sens d'envisager la protection spéciale à assurer aux enfants à la survenance des hostilités. Elles auront également pour mission de préciser, par rapport au contexte, les différents instruments internationaux ratifiés relatifs à l'enfant.

La pratique démontre plutôt que ces mesures ne sont pas toujours prises par les Etats, surtout ceux dits «faibles ». Ces derniers ne les placent pas en priorité, et ne disposent d'ailleurs pas de ressources conséquentes pour répondre à de telles attentes. Même si elles sont disponibles, ces ressources seront affectées à d'autres secteurs jugés «plus importants » simplement parce que «protecteurs du pouvoir». Il faudrait voir ici les budgets affectés à la police et à la défense dans ces pays pour s'en convaincre (cf. infra).

Il y a lieu d'admettre, pour l'accomplissement de l'obligation de «faire respecter le DIH » au plan national et international - que les mesures à déployer ne sont pas prédéfinies et dépendent des moyens à la disposition des Etats. Ainsi, il sera requis des Etats d'adopter, dans le respect du droit international, des mesures raisonnablement envisageables de nature à inciter effectivement l'Etat concerné à respecter le $\mathrm{DIH}^{752}$.

\section{\$2 Les mécanismes de contrôle}

Afin d'assurer le respect des CG et du PA I, les parties au conflit doivent s'assurer du concours et admettre le contrôle des puissances protectrices, c'est-à-dire d'Etats neutres chargés de sauvegarder les intérêts des puissances belligérantes en pays ennemi. Si celles-ci

\footnotetext{
${ }^{748}$ L'article commun 47 de la CG I ; 48 de la CG II ; 127 de la CG III et 144 de la CG IV CG dispose clairement que les Etats «s'engagent à diffuser le plus largement possible, en temps de paix et en temps de guerre [...]» les textes de ces instruments, «notamment à en incorporer l'étude dans les programmes d'instruction militaire et, si possible, civile, de telle manière que les principes en soient connus [...]».

${ }^{749}$ Voy. l'article 45, alinéa 6, de la Constitution du 18 février 2006 qui dispose : «Les pouvoirs publics ont le devoir d'assurer la diffusion et l'enseignement de la Constitution, de la Déclaration universelle des droits de l'homme, de la Charte africaine des droits de l'homme et des peuples, ainsi que de toutes les conventions régionales et internationales relatives aux droits de l'homme et au droit international humanitaire dûment ratifiées » in http://www.droitcongolais.info/etat_autorites_rdc.html (Source consultée le 15 décembre 2015).

750 CICR, «Protection des victimes de la guerre» Préparation de la Réunion du Groupe d'experts intergouvernemental pour la protection des victimes de la guerre, Genève 23-27 janvier 1995, Suggestions du CICR, op.cit., p. 472.

${ }^{751}$ Lire également l'article 42 de la Convention relative aux droits de l'enfant qui va dans ce sens.

752 DUBUISSON, François, «Les obligations internationales de l'Union européenne et de ses Etats membres concernant les relations économiques avec les colonies israéliennes », « art. cit. », p. 433.
} 
n'ont pas été désignées, le CICR offrira ses bons offices aux parties au conflit en vue de cette désignation ${ }^{753}$. Les parties au conflit peuvent également solliciter au CICR d'agir en tant que «substitut des puissances protectrices » ou à toute organisation présentant les garanties d'impartialité et d'efficacité. Les puissances protectrices ou le substitut des puissances protectrices assurent les visites aux prisonniers de guerre et aux lieux d'internement et interviennent en faveur de la population civile au pouvoir de l'ennemi.

Cependant, il s'est avéré que depuis la Seconde Guerre mondiale, les parties au conflit ne sont aujourd'hui plus prêtes à nommer des puissances protectrices comme leur prescrit le DI ${ }^{754}$. En effet, depuis l'adoption des CG de 1949, ce mécanisme " n'a été mis en œuvre qu'à quatre reprises (lors des conflits de Suez en 1956, de Goa en 1961, indo-pakistanais de 1971 et des Malouines en 1982) «et même dans ces cas le fonctionnement de l'institution était soit incomplet, soit le résultat du hasard, soit sujet à controverse $»{ }^{755}$. Bien plus, dans les divers conflits qui ont eu lieu depuis 1945, c'est toujours le CICR qui a comblé la lacune, sans toutefois n'avoir jamais été expressément nommé comme Substitut d'une puissance protectrice. A la différence de celle-ci, le CICR n'agit cependant jamais comme mandataire d'une partie au conflit (à laquelle il devrait alors rendre des comptes) mais il a toujours agi en son nom propre ${ }^{756}$. «Il est évident que si la puissance protectrice représente les intérêts d'une partie au conflit, le CICR en revanche agit pour assurer la bonne application de la Convention, en tant que représentant de l'intérêt de la communauté conventionnelle et, par extension, de la communauté internationale; car depuis peu, les Conventions de Genève ont atteint l'universalité absolue, en devenant les premiers et, pour le moment, les seuls instruments acceptés par la totalité des Etats existants ${ }^{757}$. Cependant, la lecture des dispositions des CG concernant la puissance protectrice, sans le dire expressément, laisse apparaître un rôle plus large et plus objectif reconnu à cette institution que la simple représentation des intérêts des Etats mandants. La puissance protectrice s'occupe donc des intérêts de la communauté conventionnelle qui est désormais la communauté internationale $\mathrm{e}^{758}$. «Concrètement, elles (puissances protectrices) sont censées assurer trois fonctions principales, à savoir : i) rétablir le dialogue entre les parties en conflit ; ii) garantir le bien-être des victimes et leurs secours ; et iii) veiller à la bonne application des Conventions de Genève et du $1^{\text {er }}$ Protocole additionnel, notamment en matière de traitement des blessés, malades, naufragés, prisonniers de guerre et civils ${ }^{759}$.

Par ailleurs, le refus par les hautes parties contractantes, ou mieux les Etats parties au conflit, de désigner les puissances protectrices est dû à diverses raisons. Sur le plan politique, la

\footnotetext{
${ }^{753}$ CICR, comprendre le Droit Humanitaire, Règles essentielles des Conventions de Genève et leurs Protocoles additionnels, Genève, CICR 1990, p. 9. Voy. les articles 8 à 11 de CG I, II et III ; 9 à 12 de la CG IV et 5 du PA I.

${ }^{754}$ GASSER, Hans Peter, op.cit., p. 90.

755 ASPREMONT, Jean d' et HEMPTINNE, Jérôme de, op. cit., p. 373. Voy. aussi ABI SAAB, Georges, «Vers un mécanisme global de protection de la population civile en temps de conflit armé ? », in SOREL, Jean Marc et FOUCHARD Isabelle, Les tiers aux conflits armés et la protection des populations civiles, éd. A.Pedone, Paris, 2010 , p. 224.

${ }^{756}$ GASSER, Hans Peter op.cit., p. 90.

757 ABI SAAB, Georges, «Vers un mécanisme global de protection de la population civile en temps de conflit armé ? », op.cit., p. 222.

${ }^{758}$ Ibid.

${ }^{759}$ ASPREMONT, Jean d' et HEMPTINNE, Jérôme de, op.cit., p. 373.
} 
neutralité et l'impartialité de l'Etat désigné comme puissance protectrice pose toujours problème. L'Etat accréditaire potentiel se méfierait du mandataire (puissance protectrice) de l'Etat accréditant qui du reste est pris pour «espion » dont on ne sait déterminer les intérêts politiques au-delà de «l'humanitaire ». Du point de vue juridique, disons que les Etats parties au conflit, par la désignation des puissances protectrices, voient en cela la reconnaissance de la partie adverse qui automatiquement donne au conflit un caractère international avec toutes les conséquences qui en découleront. C'est dans le même sens que Robert KOLB, tout en épinglant aussi les motifs que nous relevons ci-dessous, décèle le coût non négligeable de ce mécanisme dont les bénéfices réels seraient peu prometteurs d'autant plus que le CICR interviendra comme substitut. Enfin, il évoque la tâche lourde, ardue et politiquement sensible d'un tel mécanisme ${ }^{760}$. Pour Georges ABI SAAB, «C'est peut-être en raison du rôle écrasant conféré par les Conventions de 1949 aux puissances protectrices, que cette institution, qui avait très bien fonctionné avant même d'être codifié, a été presque abandonnée dans la pratique ${ }^{761}$. Jean d'ASPREMONT et Jérôme de HEMPTINNE ajoutent aussi que les Etats ne sont pas prêts à accepter de jouer le rôle de puissance protectrice car cela occasionne des coûts importants au-delà de son caractère particulièrement délicat et lourd à fonctionner en période conflictuelle ${ }^{762}$.

Il importe de signifier, en passant, que l'institution des puissances protectrices résulte du droit diplomatique. Ainsi, en cas d'absence ou de rupture des relations diplomatiques, ou encore en cas de guerre déclarée, chaque Etat en conflit devrait donc désigner un Etat tiers représentant ses intérêts auprès de son adversaire. D'ailleurs, cette pratique dite de «représentation internationale » existe actuellement en droit diplomatique et consulaire. C'est dans ce sens que lors de la Première Guerre mondiale, les Etats tiers représentant les intérêts de différentes parties belligérantes ont considéré que la Convention et les Règlements de La Haye faisaient parties des traités qui continuaient à s'appliquer en temps de guerre. Ces Etats devaient par conséquent veiller à leur application, et notamment entreprendre la visite des prisonniers de guerre $^{763}$.

Par ailleurs, la mise en œuvre du DIH, y compris la protection de l'enfant, passe également par la Commission internationale d'établissement des faits ${ }^{764}$ telle qu'instituée par l'article 90 du PA I. Cette Commission a pour tâches d'enquêter sur tout fait prétendu être une infraction grave au sens des CG et du PA I ou toute autre violation grave des CG ou du PA I, d'une part et de faciliter, en prêtant ses bons offices, le retour à l'observation des dispositions des CG et du PA, d'autre part. Elle ne peut qualifier juridiquement les faits sinon établir les faits, ou mieux constater l'illégalité. Elle n'exercera sa compétence qu'à l'égard des parties ayant

\footnotetext{
${ }^{760} \mathrm{KOLB}$, Robert, Ius in bello. Le droit international des conflits armés, $2^{\mathrm{e}}$ édition, op.cit., p. 479.

761 ABI SAAB Georges, «Vers un mécanisme global de protection de la population civile en temps de conflit armé ? », « art. cit. », p. 224.

${ }^{762}$ ASPREMONT Jean d' et HEMPTINNE Jérôme de, op.cit., p. 373.

${ }^{763}$ ABI SAAB Georges, «Vers un mécanisme global de protection de la population civile en temps de conflit armé ? », « art. cit. », p. 222.

${ }^{764}$ Pour un approfondissement de cette question lire CONDORELLI, Luigi, « La Commission internationale humanitaire d'établissement des faits : un outil obsolète ou un moyen utile de mise en œuvre du droit international humanitaire ? », in TAVERNIER, Paul et BURGORGUE LARSEN, Laurence (dir.), Un siècle de droit international humanitaire. Centenaire des Conventions de la Haye et cinquantenaire des Conventions de Genève, Bruxelles, Bruylant 2001, pp. 87-99 et VITE, Sylvain, Les procédures internationales d'établissement des faits dans la mise en ouvre du droit international humanitaire, Bruxelles, Bruylant 1999, 485 p.
} 
accepté la clause facultative contenue dans l'article 90, §2 a. L'acceptation de la compétence de la Commission peut se faire par déclaration (au moment de la signature, de la ratification ou de l'adhésion au PA I, ou à tout autre moment par la suite ou de manière ad hoc au moment de la saisine de la Commission). La Commission se compose de 15 membres de « haute moralité et d'une impartialité reconnue et désignées par les parties contractantes » ${ }^{765}$. Toutefois, conditionner le fonctionnement de la Commission internationale d'établissement des faits à l'acceptation préalable des Etats serait la rendre obsolète et par conséquent empêcher une mise en œuvre importante du DIH. Dans un domaine aussi internationalisé que le DIH, qualifié de jus cogens, il est plus que normal que les Etats puissent renoncer à certains aspects de leur souveraineté. Pour ce faire, l'acceptation de la clause contenue dans l'article 90 devrait être comprise comme partie essentielle des Conventions (ou du PA) pour qu'aucune réserve ne soit émise par les parties contractantes. Cette commission n'est entrée en fonction qu'en 1991, après que le $20^{\mathrm{e}}$ Etat a reconnu sa compétence ${ }^{766}$. Pour sa part, la RDC a fait la déclaration d'acceptation de la compétence de ladite Commission, sur la base de l'article 90 du PA I, le 12 décembre $2002^{767}$ (cf. infra).

\section{\$3 Les mécanismes de sanction}

«La protection de toutes les victimes des conflits armés, qui est l'objet essentiel du DIH, n'exclut pas la mise en cause, soit des entités étatiques, soit des groupements interétatiques, soit encore des groupements internationaux, soit des organisations infra-étatiques, lorsqu'ils violent le $\mathrm{DIH} \gg^{768}$.

Par ailleurs, le DIH gouverne essentiellement les relations interétatiques. Ce sont donc des personnes morales qui sont principalement concernées, y compris les mouvements de libération nationale (Polisario, OLP, etc.). La règle générale traditionnelle veut qu'il n'y ait pas de sanctions pénales contre ces entités. L'exception admise depuis la fin de la Seconde Guerre mondiale est la répression pénale des organes ou agents de l'Etat, personnes physiques. Mais le Tribunal de Nuremberg est allé au-delà des organes de l'Etat. Il a aussi châtié des personnes privées ${ }^{769}$.

Bien que les Etats, sujets primaires et principaux du DI, ne soient pas concernés par une responsabilité pénale internationale du fait de violation du $\mathrm{DIH}$, si ce ne sont que leurs organes ou agents, cependant la responsabilité internationale pour des violations des obligations internationales commises par eux au moyens de leurs organes ou agents peut néanmoins être reconnue par une juridiction internationale telle que la CIJ. Cette dernière, par ses avis consultatifs et ses arrêts, assure tant soit peu des avancées des règles du DIH et constitue un mécanisme de sanction du $\mathrm{DIH}^{770}$. Cependant, contrairement aux droits de

\footnotetext{
${ }^{765}$ GASSER, Hans Peter, op. cit., p. 95.

${ }^{766}$ BARBIER, S., «Les Commissions d'enquête et d'établissement des faits », in ASCENCIO, Hervé. Ascencio, ${ }_{767}$ DEAUX, Emmanuel et PELLET Alain, Droit international Pénal, Paris, éd. A. Pedone, 2000, p.700. 767 Voy. https://ihldatabases.icrc.org/applic/ihl/dih.nsf/vwTreatiesByCountrySelected.xsp?xp countrySelected=CD\&nv=4 (Source consultée le 04 septembre 2016).

768 BULA BULA, Sayeman, op.cit., p. 225.

${ }^{769}$ Ibid., p. 260.

${ }^{770}$ Pour comprendre le rôle de la CIJ vis-à-vis du DIH, veuillez bien lire BIAD, Abdelwahab, La Cour
} 
l'homme, plus souvent reconnus dans la jurisprudence de la CIJ depuis $1945^{771}$, il faudrait préciser que celle-ci «se prononce assez rarement sur le droit international humanitaire et ne peut pas, de ce fait, s'appuyer sur une jurisprudence fournie ${ }^{772}$. A ce sujet, Robert Kolb renseigne que la CIJ «n'a eu à traiter des questions de droit international humanitaire que dans quatre affaires contentieuses ou consultatives $[\ldots] \gg{ }^{773}$.

L'obligation de respecter et de faire respecter les règles du DIH telle que formulée par les CG et le PA I implique également pour l'Etat d'ériger en infractions certains comportements offensant ces règles. Au plan international, ceci est marqué par la création des juridictions pénales internationales dont les Tribunaux pénaux internationaux pour l'ex-Yougoslavie et pour le Rwanda, la Cour pénale internationale, les tribunaux dits internationalisés ou mixtes (Sierra Leone, Timor-Leste, Cambodge, Kosovo, Liban, Bosnie-Herzégovine). Toutes ces juridictions, entendues comme mécanismes de sanction du DIH, tentent de jouer un rôle efficace dans la mise en œuvre des règles du DIH.

Ainsi, « la [CPI] a été créée pour assurer la répression de certaines violations graves du jus contra bellum et du DIH ${ }^{774}$ En effet, le DIH accuse différentes faiblesses dès la CG du 22 août 1864 pour l'amélioration du sort des militaires blessés dans les armées en campagne qui marque le début de sa codification. Une de ses faiblesses importantes réside dans l'absence des sanctions en cas de violation de ses dispositions. Les CG et leur PA I se limitent à confier aux Etats parties la mission de prendre les mesures adéquates pour réprimer les infractions graves expressément énumérées ${ }^{775}$. Et également de prendre des mesures pour assurer la mise en œuvre des autres dispositions.

Toutefois, l'expérience prouve que les gouvernements ne sont pas très diligents en ce domaine. Dans ces conditions, il est normal que l'on ait songé à organiser une répression internationale devant une juridiction internationale ${ }^{776}$. D'où l'importance de la CPI.

internationale de justice et le droit international humanitaire. Une lex specialis revisitée par le juge, éd. Bruylant, Bruxelles, 2011, 210 p.

${ }^{771}$ GOY, Raymond, La Cour internationale de justice et les droits de l'homme, Nemesis - Bruylant, Bruxelles, 2002 , p. 7.

772 SANDOZ, Yves (dir.), Les Moyens de mise en auvre du droit international humanitaire. Etat des lieux, Analyse des problèmes et éléments de réflexion. Institut International de Droit humanitaire, Sanremo, juillet 2006, p. 87.

${ }^{773}$ KOLB, Robert, Ius in bello. Le droit international des conflits armés, $2^{\mathrm{e}}$ édition, op.cit., p. 472 . Il s'agit des affaires «des activités militaires et paramilitaires au Nicaragua et contre celui-ci (1986), de la Licéité de la menace ou de l'emploi d'armes nucléaires (1996), des conséquences juridiques de l'édification d'un mur dans le territoire palestinien occupé (2004) et des Activités armées sur le territoire du Congo (2005). De manière subordonnée, elle a effleuré des questions de droit des conflits armés dans l'affaire du Détroit de Corfou (1949) et dans celle relative aux prisonniers de guerre Pakistanais (1973), discontinuée après la phase des mesures conservatoires ».Voy. KOLB, Robert, Ius in bello. Le droit international des conflits armés, 2 édition, op.cit., p. 472.

${ }^{774}$ DAVID, Eric, «L'avenir de la Cour Pénale Internationale », in TAVERNIER, Paul et BURGORGUE LARSEN, Laurence (dir.), Un siècle de droit international humanitaire. Centenaire des Conventions de La Haye. Cinquantenaire des Conventions de Genève, op. cit., p. 185.

${ }^{775}$ Les articles 49(1), 50(1), 129(1) et 146 respectivement des I ère ${ }^{\mathrm{e}} \mathrm{II}^{\mathrm{e}}$, III ${ }^{\mathrm{e}}$ et $\mathrm{IV}^{\mathrm{e}}$ Convention de Genève du 12 août 1949 disposent: «Les Hautes Parties contractantes s'engagent à prendre toute mesure législative nécessaire pour fixer les sanctions pénales adéquates à appliquer aux personnes ayant commis, ou donné l'ordre de commettre, l'une ou l'autre des infractions graves à la présente Convention définie à l'article suivant. ». Voy. 1'article $86 \mathrm{du} 1^{\mathrm{er}}$ Protocole additionnel aux Conventions de Genève.

776 TAVERNIER, Paul, «De 1899 à 1999: Eclatement ou approfondissement du droit international 
La CPI se charge de la répression des crimes les plus graves qui touchent l'ensemble de la communauté internationale (cf. le préambule et l'art. 5 du Statut de la CPI). Il s'agit du crime de génocide, des crimes contre l'humanité, des crimes de guerre et du crime d'agression (cf. Art.5 du statut de la CPI). Sa compétence se rapporte donc aux crimes ci-dessus commis sur le territoire d'un Etat membre ou par un ressortissant d'un Etat membre sur le territoire d'un Etat tiers, conditions non cumulatives. Le CS/NU peut tout de même demander à la CPI d'enquêter sur toute situation analogue survenue sur le territoire d'un Etat tiers. Ce qui étend davantage la compétence de la CPI. Et contrairement aux autres juridictions pénales internationales ad hoc créées par des résolutions du CS/NU pour des circonstances spécifiques, la CPI est une juridiction permanente créée par une convention internationale, le Statut de la CPI adoptée à Rome le 17 juillet 1998. Cet instrument juridique est entré en vigueur le $1^{\mathrm{er}}$ juillet 2002, soixantième jour après le dépôt du soixantième instrument de ratification par la RDC. Toutefois, contrairement aux autres juridictions pénales internationales dont le TPIY ou le TPIR qui ont une préséance sur les juridictions pénales nationales, la CPI a, quant à elle, une compétence complémentaire vis-à-vis des juridictions pénales nationales. Elle «ne se substitue pas et ne prime pas les juridictions pénales nationales ${ }^{777}$. «Cette complémentarité s'apparente plutôt à une subsidiarité, puisque la préférence est, dans tous les cas, accordée aux juridictions nationales ${ }^{778}$. Cette complémentarité, mentionnée au dixième considérant du préambule du Statut de Rome, ainsi qu'aux articles $1^{\text {er }}$ et 17 du même texte conventionnel, voudrait que «la Cour déclare irrecevable toute affaire dont est saisie une juridiction nationale, au stade de l'enquête ou des poursuites, ou sur laquelle une telle juridiction a déjà statué ${ }^{779}$ (cf. Principe Non bis in idem, art 20). Ceci n'empêche cependant pas la CPI d'intervenir dans des situations où les Etats n'ont pas engagé leurs juridictions pénales ou qu'elles se sont engagées de manière fantaisiste ou moins crédibles. A travers cette répression, la CPI représente un mécanisme de sanction indubitablement important de mise en œuvre des règles du DIH. Au-delà de lutte contre l'impunité des crimes les plus odieux à l'endroit de l'humanité voire également de l'expression de vœu de non-renouvellement de ces crimes, la CPI, de par son statut, réactualise le droit international humanitaire ${ }^{780}$. Ceci est attesté notamment au niveau des articles 7 et 8 du Statut de la CPI.

En effet, l'article 7 du Statut de la CPI offre une nouvelle version du crime contre l'humanité dont le mobile n'est pas défini avec précision et qui peut être commis dans un contexte hors conflit armé mais dans le cadre d'une attaque généralisée ou systématique dirigée contre une population civile et en connaissance de l'attaque ${ }^{781}$. Et l'article 8 du statut comprend une liste impressionnante de crimes de guerre, liste qui non seulement couvre à peu près toutes les incriminations figurant dans les CG de 1949, le PA I de 1977 et les statuts des TPI, mais qui

\footnotetext{
humanitaire? », in TAVERNIER, Paul et Laurence BURGORGUE, Larsen (dir.), op.cit., p. 16.

${ }_{777}^{778}$ REBUT, Didier, Droit pénal international, $2^{\mathrm{e}}$ édition, Dalloz, Paris, 2014, p. 629.

${ }^{778}$ Ibid.

779 BERKOVICZ, Grégory, La place de la Cour pénale internationale dans la Société des Etats, L’Harmattan, Paris, 2005, p. 194.

${ }^{780}$ DAVID, Eric, «L'avenir de la Cour Pénale Internationale », «art. cit. », p. 200.

${ }^{781}$ Pour plus de détails, lire CURAT, Philippe, Les Crimes contre l'humanité dans le statut de la Cour pénale internationale, Bruylant, L.G.D.J, Schulthess, Bruxelles, Genève-Zurich-Paris, 2006, pp. 95-113.
} 
en outre énonce de nouvelles infractions. Le Statut de la CPI distingue les crimes de guerre commis dans deux types de conflit armé interne et élargit la notion de conflit armé interne notamment en l'absence des critères de territorialité et d'opposition gouvernements/insurgés

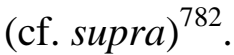

Par ailleurs, sur le terrain des conflits armés, bien que l'on ne sait pas encore visualiser l'effet dissuasif de cette jeune juridiction qui vient de rendre son premier jugement intéressant la question de l'implication des enfants dans les conflits armés le 14 mars 2012 dans l'affaire Le Procureur c. Thomas Lubanga Dyilo (cf. le dernier chapitre de la thèse), il sied de dire que la CPI marque un pas non moins décisif dans le processus de codification du DIH. Son statut complète par là quelques insuffisances des CG et de leurs PA qui constituent la toile de fond du DIH. Elle agit là où les puissances étatiques sont hésitantes. Elle répare tant soit peu les préjudices, surtout moraux, causés aux victimes notamment lors des conflits armés. Elle est donc un premier mécanisme universel et permanent de sanction pénale à l'endroit des individus ou personnes physiques, à côté de la CIJ qui juge les Etats. En conclusion, à travers la CPI, les mécanismes de sanction du DIH se renforcent et complètent ceux de prévention et de contrôle.

En dehors des juridictions internationales décrites ci-haut, une nouvelle catégorie d'institutions judiciaires est apparue plus récemment: ce sont les six tribunaux dits internationalisés (Tribunal spécial pour la Sierra Leone, les Chambres spéciales créées au Timor Leste, les Chambres extraordinaires pour le Cambodge, les Chambres mixtes kosovares, le Tribunal spécial pour le Liban et la Section pour les crimes de guerre de Bosnie-Herzégovine). Ceux-ci sont variés. Tout en ayant une composante internationale, ces tribunaux gardent un ancrage national prononcé. Deux tribunaux (Tribunal spécial pour la Sierra Leone et Tribunal spécial pour le Liban) sont construits davantage sur le modèle d'une juridiction supranationale tandis que les quatre autres s'inscrivent résolument dans le paysage judiciaire national des pays concernés et appliquent, pour partie, les règles de droit matériel et procédural de ces Etats. Ces six juridictions internationalisées ou mixtes sont imprégnées des caractéristiques suivantes $^{783}$ :

- Elles exercent toutes une fonction judiciaire et restent soumises aux principes fondamentaux régissant le fonctionnement des juridictions pénales ;

- Elles se fixent l'objectif de rétablissement de l'Etat de droit et la répression des crimes internationaux;

- L'organisation des Nations Unies a joué un rôle déterminant dans leur création ;

- Elles revêtent toutes une dimension internationale qui varie d'une institution à l'autre ;

\footnotetext{
${ }^{782}$ Lire DAVID, Eric, «L’avenir de la Cour pénale internationale », «art. cit., », pp. 196-200.

${ }^{783}$ BOSLY, Henri D., et VANDERMEERSCH, Damien, Génocide, crimes contre l'humanité et crimes de guerre face à la justice. Les juridictions internationales et les tribunaux nationaux, éd. Bruylant, Bruxelles-Paris, 2012, pp. 146-147.
} 
- Comme les Tribunaux pénaux internationaux pour l'ex-Yougoslavie et pour le Rwanda, ces juridictions ont été créées pour faire face à des situations particulières et pour une mission ou pour une période déterminée.

Par ailleurs, sous ce registre, signifions qu'à la suite des négociations finalisées par la signature (le 22 août 2012) d'un accord entre la Commission de l'Union Africaine et le gouvernement du Sénégal, ont été créées les Chambres africaines extraordinaires au sein des juridictions sénégalaises pour la poursuite des crimes internationaux - les crimes de génocide, les crimes contre l'humanité, les crimes de guerre et la torture ${ }^{784}$ - commis au Tchad durant la période du 7 juin 1982 au $1^{\text {er }}$ décembre 1990. Cette création est aussi le fait de l'arrêt de la Cour de la CEDEAO exigeant la création d' « une juridiction spéciale ad hoc à caractère international » à la suite de la plainte de Hissène Habré de violation du principe de nonrétroactivité par les changements législatifs au Sénégal ${ }^{785}$. Des pressions des ONG, association des victimes voire l'arrêt de la CIJ instruisant au Sénégal de déférer Hissène Habré devant les autorités compétentes ou de 1 'extrader ${ }^{786}$ ne sont pas innocents quant à la création de ces institutions. Le préambule de l'Accord entre la Commission de l'Union africaine et la République du Sénégal créant ces chambres le rappelle également. Le procès entamé le 20 juillet 2015 connaîtra son verdict le 30 mai 2016. La Chambre africaine extraordinaire d'assises condamne Hissène Habré à perpétuité pour crimes contre l'humanité, torture et crimes de guerre ${ }^{787}$.

De tout ce qui précède, il importe de mentionner qu'à l'exception du Tribunal spécial pour le Liban qui ne s'occupe pas de crimes de masse et dont la compétence concerne les auteurs responsables de l'attentat terroriste contre le premier ministre libanais Rafik Hariri et d'autres attentats connexes, les autres juridictions dites internationalisées se préoccupent de réprimer les crimes de masse commis dans des contextes aussi particuliers. Il est certes vrai qu'au regard du nombre de cas à traiter dans les différentes situations sous examen, ces tribunaux dits internationalisés ne sauront pas apporter solution à tout problème et il leur faudrait une contribution énorme de la part des institutions judiciaires ordinaires voire des institutions de justice transitionnelle. Cependant, leur rôle comme mécanisme de sanction de violations des règles du DIH reste incontournable. De manière générale, ces tribunaux mixtes ont une compétence matérielle centrée sur des crimes de génocides, crimes de guerres, et des crimes

\footnotetext{
${ }^{784}$ Article $4 \mathrm{du}$ Statut des Chambres africaines extraordinaires au sein des juridictions sénégalaises pour la poursuite des crimes internationaux commis au Tchad durant la période du 7 juin 1982 au $1^{\text {er }}$ décembre $1990 \mathrm{du}$ 22 août 2012 in http://www.chambresafricaines.org/index.php/presentation-des-chambres/contexte-decreation.html (Source consultée le 18 mars 2016).

${ }_{785}$ http://www.chambresafricaines.org/index.php/presentation-des-chambres/contexte-de-creation.html (Source consultée le 18 mars 2016). Cette position de la Cour de la CEDEAO a été unanimement critiquée par la doctrine estimant que le principe de non-rétroactivité reste inopérant pour des actes qui au moment de leur commission sont interdits par le droit international conventionnel et coutumier (Voy. le lien ci-dessus).

${ }^{786}$ CIJ, Questions concernant l'obligation de poursuivre ou d'extrader (Belgique c Sénégal), arrêt du 20 juillet 2012, Recueil 2012, p. 463, §122, point 6.

${ }^{787}$ Lire Chambres Africaines Extraordinaires, Prononcé et résumé du jugement dans l'affaire le Parquet Général contre Hissein Habré, Chambre Africaine Extraordinaire d'Assises, 30 mai 2016, Point 4, $\S$ E et F, disponible sur http://www.chambresafricaines.org/index.php/le-coin-des-medias/communiqué-de-presse/639-documentprononce-et-resume-du-jugement-dans-l'affaire-le-parquet-general-contre-hissein-habre-30-mai-2016.html (Source consultée le 19 juillet 2016).
} 
contre l'humanité.

En effet, l'on note par exemple que le Tribunal spécial pour la Sierra Leone connait : 1. des crimes de guerre et des crimes contre l'humanité et notamment des attaques contre la population civile, l'enrôlement d'enfants de moins de quinze ans dans des groupes armés et des attaques contre les personnes en charge des opérations d'assistance humanitaires ou de maintien de la paix et 2 . des crimes de droit sierra-léonais consistant dans des sévices commis contre des fillettes ou des incendies volontaires et des destructions de biens ${ }^{788}$. Le Tribunal spécial pour la Sierra Leone est la seule juridiction dite internationalisée à avoir une compétence personnelle à l'égard des personnes de moins de dix-huit ans ou mieux des mineurs. Il faudrait rappeler que face aux effectifs du R.U.F (Revolutionary United Front) constitués de 50 à $80 \%$ d'enfants âgés de moins de quinze ans dont nombreux étaient auteurs de graves violations du DIH, se posait dès lors la question de la responsabilité de ces enfants (bourreaux) qui sont en même temps victimes. Malgré la réponse unanimement négative des ONG, sous la pression du Gouvernement de Freetown et des représentants de la société civile sierra-léonaise, le Tribunal spécial pour la Sierra Leone a été déclaré compétent pour poursuivre des mineurs de quinze ans au moment la commission de l'infraction ${ }^{789}$. L'article 7 $\S 1$ du Statut du Tribunal spécial pour la Sierra Leone à cet effet qui dispose: «Le tribunal spécial n'est pas compétent pour juger les mineurs âgés de 15 ans au moment où l'infraction alléguée a été commise. Si le Tribunal est appelé à juger une personne âgée de 15 à 18 ans au moment où l'infraction alléguée a été commise, cette personne doit être traitée avec dignité et respect, en tenant compte de son jeune âge et de la nécessité de faciliter sa réinsertion et son reclassement pour lui permettre de jouer un rôle constructif dans la société, et conformément aux normes internationales relatives aux droits de l'homme, en particulier les droits de l'enfants ». Pareille disposition ne s'avère pas contraire au DIH voire aux droits de l'homme dont la Convention relative aux droits de l'enfant de 1989, ratifiée par la Sierra Leone, qui ne s'oppose pas à l'action en responsabilité d'enfants mineurs ${ }^{790}$ (article 40 §3, a). Le DIH interdit simplement l'application de la peine capitale aux personnes de moins de 18 ans (cf. art. $77 \S 5$ du PA I ou art. $6 \S 4$ du PA II). «Par contre, le Procureur du Tribunal [TSSL] a annoncé que, en accord avec le mandat du Tribunal de poursuivre les individus portant «la responsabilité la plus lourde», pour les violations commises, il ne poursuivrait pas des individus pour des crimes commis avant l'âge de 18 ans ${ }^{791}$.

Pour leur part, les Chambres spéciales créées au Timor Leste ont une compétence matérielle centrée sur les crimes de guerre, les crimes contre l'humanité et les crimes de génocide, des meurtres, des violences sexuelles et de torture. Les Chambres extraordinaires pour le Cambodge en dehors des trois crimes précités, ont une compétence matérielle élargie aux crimes et délits de destruction de biens culturels durant un conflit armé (art.7), aux crimes contre les personnes internationalement protégées (art.8) et aux crimes relevant du droit

\footnotetext{
${ }^{788}$ BOSLY, Henri D. et VANDERMEERSCH, Damien, op.cit., p. 151.

${ }^{789}$ LOMBART, Laurent, Le Tribunal pénal spécial sierra-léonais, éd. Publibook, Paris, 2003, pp. 33-34.

790 Ibid., p. 34. Voy. aussi HUYBRECHTS, Pierre, «Quels règles et mécanismes internationaux pour protéger les enfants dans la guerre ? », in LORIAUX, G., Les enfants soldats, Kindsoldaten, Journée d'études du 20 janvier 2005, Centre d'Etudes de Droit Militaire et de Droit de la guerre, a.s.b.1, Bruxelles, 2005, pp. 28-29.

791 TRAHAN, Anne-Marie, «Les enfants et les conflits armés », in Liber Amicorum Peter Leuprecht, Bruylant, Bruxelles, 2012, p. 159.
} 
commun cambodgien (art.3- homicide, torture et persécution religieuse). Les chambres mixtes Kosovares s'occupent quant à elles des crimes de guerre, des crimes ayant une motivation ethnique, des crimes dits organisés et des crimes susceptibles de compromettre le processus de paix. Et la Section pour crime de guerre de Bosnie Herzégovine s'occupe de réprimer les crimes de guerre ${ }^{792}$.

Par rapport à la protection spécifique des enfants en situation de conflits armés, exception faite au Statut de la CPI, bien que les traités - tels que le PA II et la CDE - obligent les États parties à s'abstenir de recruter et d'utiliser des enfants dans les hostilités, ils n'érigent cependant pas ces actes en crimes portant responsabilité pénale individuelle. Les États parties à ces traités sont obligés pourtant de prendre les mesures nécessaires pour prévenir ces actes, ce qui est un appel implicite à sanctionner le recrutement d'enfants comme infraction, afin d'enquêter et de poursuivre de tels actes (cf. supra) ${ }^{793}$.

C'est dans ce sens que dans l'affaire Hinga Norman, la défense a contesté la compétence du Tribunal spécial pour la Sierra Leone pour poursuivre des personnes pour crime de recrutement d'enfants de moins de quinze ans. Selon elle, l'article 4 du statut du Tribunal viole le principe nullum crimen sine lege. Elle souligne que bien que le PA II aux Conventions de Genève de 1977 et la Convention des droits de l'enfant de 1990 créent une obligation à la charge des Etats parties pour qu'ils s'abstiennent de recruter des enfants soldats, ces instruments ne criminalisent pas cette activité, et par ailleurs si le Statut de Rome l'érige en crime, il ne codifie pas une règle coutumière. En se référant à diverses sources de droit international et de droit interne, la Cour d'appel a rejeté cet argument et a conclu que le recrutement d'enfant était incriminé bien avant novembre $1996 .^{794}$ Disons en gros que ce phénomène de pénalisation marque le droit international depuis quelques années : le poids de la répression pénale paraît déplacer l'attention portée au droit vers la sanction, alors que le dispositif juridique initial semblait plutôt orienté vers une perspective préventive ${ }^{795}$.

\section{§4. L'ONU et l'émergence du DIH}

«A leurs débuts, les Nations Unies ne voulurent pas se préoccuper du droit applicable en période de conflits armés. L'Organisation ne pouvait se résoudre à traiter de cette question alors que la Charte énonçait le principe fondamental de l'interdiction du recours à la force et que l'une de ses missions était d'assurer le maintien de la paix (Ainsi, la Commission du droit international avait exclu de ses travaux, la question du droit de la guerre [...] ) ${ }^{796}$. En toute

\footnotetext{
${ }^{792}$ Lire BOSLY, Henri D., et VANDERMEERSCH, Damien, op.cit., pp. 158,164, 171 et 184.

${ }^{793}$ Nations Unies, Haut Commissariat des Nations Unies aux droits de l'homme, Rapport du Projet Mapping concernant les violations les plus graves des droits de l'homme et du droit international humanitaire commises entre mars 1993 et juin 2003 sur le territoire de la République démocratique du Congo, Août 2010, p. 338.

${ }^{794}$ YEYONGNON, M., «Les juridictions internationales ou internationalisées compétentes pour connaître des violations les plus graves du droit international humanitaire commises en Afrique», in TAVERNIER, Paul, (dir.) Regards sur les droits de l'homme en Afrique, L'harmattan, Paris, 2008, p. 292.

${ }^{795}$ DEYRA, Michel, Droit dans la guerre, op.cit., p. 178.

${ }^{796}$ BOISSON DE CHAZOURNES, Laurence, « Les résolutions des organes des Nations Unies, et en particulier celles du Conseil de sécurité, en tant que source de droit international humanitaire », in CONDORELLI, Luigi et LA ROSA SYLVIE SCHERRER, Anne-Marie, (dir.), Les Nations Unies et le droit international humanitaire. The United Nations and international humanitarian law. Acte du Colloque international à l'occasion du cinquantième anniversaire de l'ONU (Genève - 19, 20, 21 octobre 1995), Paris, éd. A. Pedone, p. 151. Lire aussi
} 
logique, l'ONU devrait se préoccuper de développer le droit de la paix. Car se préoccuper du droit de la guerre pouvait bien apparaître comme une manière de légitimer ce qui est au départ interdit : «Le recours à la force ». Patrick DAILLIER, Mathias FORTEAU et Alain PELLET n'hésitent pas d'écrire clairement à ce propos que «[m]algré tout, on ne peut nier la contradiction entre l'interdiction du recours à la force et la réglementation juridique de son exercice. Plus que l'aveu de l'impuissance du droit préventif, cette réglementation d'une activité interdite équivaut à une véritable organisation de l'illicite " ${ }^{797}$. Une telle réglementation, au-delà du caractère d'impuissance qu'elle atteste, s'interpréterait également au sens de Mario BETTATI comme un manque de confiance dans l'organisation pour régler les différends par des moyens pacifiques. C'est ainsi qu'il est d'emblée apparu que la CDI chargée de préparer la codification et le développement progressif du DI devait s'abstenir de s'occuper du $\mathrm{DIH}^{798}$.

Cette position de l'ONU sera déjà favorisée, dans la doctrine, par des points de vues opposés à l'idée de développer le droit de la guerre. «L'un des plus violents réquisitoires contre le droit de la guerre a été dressé dans un article anonyme paru dans le B.Y.I.L 1920-21, p.109, intitulé « The League of Nations and the Law of War ». L'auteur faisait valoir d'une part qu'il est inutile et impossible de codifier le droit de la guerre en raison du perfectionnement des techniques militaires, d'autre part que la trop grande place donnée au droit de la guerre depuis Grotius a rendu le droit international impopulaire et empêché le progrès du droit de la paix [...] » ${ }^{799}$.

En clair, deux arguments principaux remettent en cause l'existence du droit de la guerre. Il serait en premier lieu inutile parce qu'il est toujours en retard d'un conflit, non adapté aux progrès rapides accomplis par les techniques de combat. En second lieu, ce droit serait vain et inefficace, n'impressionnant pas les belligérants. "Ce droit est donc relatif, « anarchique », faiblement institutionnalisé, et la jurisprudence y a longtemps joué un rôle réduit même s'il est qualitativement important ${ }^{800}$. Disons qu'au départ, en lui-même, le droit de la guerre exprimerait une certaine confusion et tente de faire rallier deux situations paradoxales : le droit et la guerre. Le droit de la guerre tente donc de réglementer, de placer la justice dans une situation où la raison n'a pas lieu. C'est justement dans cette logique qu'Eric DAVID soulève des questions pertinentes dans l'introduction de son ouvrage : «N'y a-t-il pas de contradiction dans les termes mêmes de l'expression « droit des conflits armés »? Est-il pensable d'associer au droit un comportement qui en paraît la négation ? ${ }^{801}$. Et à Philippe BRETTON d'arguer que le droit de la guerre «empêche de jamais réussir à justifier par le droit le prétendu principe que la raison du plus fort est toujours la meilleure ${ }^{802}$. Cependant, il s'avère, quelque part en pratique, que vouloir soumettre la guerre par le droit, une situation quasi incontrôlée par nature, serait ainsi à la base même de l'irrespect de ce droit.

THÜRER, Daniel, International humanitarian law : Theory, practice, context, Ail-Pocket, Hague Academy of International Law, The Hague, 2011, p. 299.

${ }^{797}$ DAILLIER, Patrick, FORTEAU, Mathias et PELLET, Alain, op.cit., p. 1067.

${ }^{798}$ BETTATI, Mario Droit humanitaire, $1^{\text {re }}$ édition, Dalloz, op. cit., p. 65.

${ }^{799}$ BRETTON, Philippe op.cit., p. 6.

${ }^{800}$ DAVID, Eric, Principes de droit des conflits armés, $5^{\mathrm{e}}$ édition, op.cit., p. 38.

${ }^{801}$ Ibid., p. 37.

${ }^{802}$ BRETTON, Philippe, Le droit de la guerre, Librairie Armand Collin, Paris, 1970, p. 5. 
Par ailleurs, les faits eux-mêmes se sont chargés de répondre à ces critiques : le recours à la force armée n'étant pas définitivement éliminé de la vie internationale, il est nécessaire de continuer à soumettre son déroulement au droit afin de limiter, autant que faire se peut, ses dangers et ses dommages ${ }^{803}$. Et comme le dirait Eric DAVID, en réponse aux questions précédemment posées, la guerre, à l'instar de toute activité humaine, peut donner lieu à une réglementation ${ }^{804}$.

Ainsi pour appuyer la réponse à ces critiques, Philippe BRETTON surenchérit que : «[n]ul ne suggère d'abolir le droit pénal parce qu'il y aura toujours des assassins. [...] Chaque conflit révèle davantage les lacunes du droit de la guerre, et loin de renoncer à vouloir codifier le droit de la guerre, il paraît plus opportun de le renforcer, tout en ayant conscience des limites du droit devant la guerre. [...] « Héraclite d'Ephèse disait que la guerre est la mère du droit des gens. Rien n'est plus vrai : la guerre est, hélas, la plus importante des relations entre les peuples. Sur trois mille quatre cents ans d'histoire connue, il n'y a eu que deux cent cinquante ans de paix générale» ${ }^{805}$.

Toutefois, « [1]'incursion véritable du « droit de l'ONU » dans la sphère humanitaire du « droit du CICR » fut entamée par la conférence de Téhéran de 1968, qui englobait dans une même dynamique le DIDH et le DIH. L'ONU enfanta ainsi une nouvelle perspective de sécurité collective dominée par des considérations humanitaires ${ }^{806}$. Le DIH fit son entrée dans l'arène des Nations Unies. Les organes onusiens allaient alors, chacun dans son champ de compétence respectif, se préoccuper du développement normatif et de l'application de ce droit ${ }^{807}$. Ainsi, «[d]ans sa résolution 2444 (XXIII) du 19 décembre 1968, « relative au respect des droits de l'homme en période de conflit armé », elle $[\mathrm{AG} / \mathrm{NU}]$ ne s'est pas limitée à énoncer des principes à observer dans ce genre de situations ; elle a ouvert la voie à des résolutions appelant au respect du droit international humanitaire dans des situations générales aussi bien que spécifiques. ${ }^{808}{ }$ Bien plus, si lors de la Conférence diplomatique sur la réaffirmation et le développement du DIH applicable aux conflits armés tenue à Genève de 1974 à 1977, le projet d'article 5 du PA I proposé par la Norvège attribuant certaines compétences à l'ONU en matière d'enquête sur les violations des CG a été rejeté, l'ONU demeure tout de même importante dans la mise en œuvre de ces instruments ${ }^{809}$. Le rejet de cette proposition se fondait sur le caractère politique de l'institution (ONU) devant s'occuper du contrôle d'application des instruments du DIH. Cependant, le même protocole reconnaît l'importance de l'ONU en faveur du DIH comme l'atteste bien l'article 89 du PA ${ }^{810}$. Cet article dispose que «[d]ans les cas de violations graves

\footnotetext{
${ }^{803}$ DAILLIER, Patrick, FORTEAU, Mathias et PELLET, Alain, op.cit., p. 1067.

${ }^{804}$ DAVID, Eric, Principes de droit des conflits armés, 5 édition, op.cit., p. 38.

${ }^{805}$ BRETTON, Philippe, op.cit., p. 6.

${ }^{806}$ REYNAUD, Oriane, Les droits de l'enfant soldat. Contribution de l'Union européenne aux efforts de la communauté internationale, Séminaire de Droit International Public, Master I - Secteur Affaires Internationales Parcours Relations Internationales Contemporaines Diplôme Universitaire d'Etudes Européennes (DUEE), Université de Lyon, Université de Lyon 2 , 2008-2009, p. 26.
}

\footnotetext{
${ }^{807}$ BOISSON DE CHAZOURNES, Laurence, « Les résolutions des organes des Nations Unies, et en particulier celles du Conseil de sécurité, en tant que source de droit international humanitaire », «art.cit.», p. 150.

${ }^{808}$ BETTATI, Mario, Droit humanitaire, $1^{\mathrm{re}}$ édition, Dalloz, op.cit., p. 248.

${ }^{809}$ Voy. par exemple EMMANUELLI, Claude, International humanitarian Law, op.cit., p. 52.

${ }^{810}$ ROSAS, Allan, «International monitoring mechanisms in situations of armed conflict », in BLOED, Arie, et al., (ed.), Monitoring human rights in Europe. Comparing international procedures and mechanisms, Martinus Nijhoff Publishers, The Netherlands, 1993, p. 234.
} 
des conventions ou du présent Protocole, les Hautes parties contractantes s'engagent à agir tant conjointement que séparément, en coopération avec l'Organisation des Nations Unies et conformément à la Charte des Nations unies ». Cette disposition serait également à la base de la juridictionnalisation du DIH (cf. infra).

Les années récentes ont vu les Nations Unies jouer un rôle sans cesse plus grand dans le champ humanitaire ${ }^{811}$. Nombreuses sont notamment les résolutions du CS/NU qui font référence au DIH (cf. infra). Le regard du CS/NU est attiré par ce droit élaboré, négocié et adopté en grande partie en dehors de l'arène des Nations Unies et il se montre de plus en plus soucieux d'en assurer le respect. Qu'il mène son action dans le cadre du Chapitre VI ou du Chapitre VII de la Charte, s'il fait face à un conflit armé, il a de plus en plus tendance à rappeler aux parties la nécessité de respecter le $\mathrm{DIH}^{812}$. A ce titre, le CS/NU s'adresse indistinctement ${ }^{813}$ aux parties aux conflits, forces armées étatiques et acteurs non étatiques. Ses résolutions visent ainsi toutes les Parties aux conflits $^{814}$.

Le DIH est devenu donc l'objet des préoccupations de l'ONU qui, non seulement se montre très soucieuse de son respect ${ }^{815}$, mais contribue à faire émerger de nouvelles normes. L'intervention de l'ONU par exemple pour des cas de «menace contre la paix », de « rupture de la paix » ou d' « acte d'agression » contribue au renforcement et à l'émergence des instruments du DIH. Dans le cas où l'ONU interviendrait dans le cadre d'un conflit interne à un Etat ${ }^{816}$, il serait ici fait appel à diverses obligations internationales d'ordre humanitaire sans nécessairement que celles-ci émanent du PA II. Ce qui serait une bonne façon de renforcer ou de développer les 18 articles substantiels de cet instrument. Et, Désormais, la protection des civils fait partie intégrante de toute mission de maintien de la paix en plus de ses tâches purement militaires ${ }^{817}$. Toujours au sujet de l'émergence de nouvelles normes, on pense notamment sur ce second point à l'assistance humanitaire. Sans épiloguer sur la nature juridique de ce concept qui a soulevé tant de controverses, rappelons simplement que le mérite revient à l'ONU, notamment l'AG/NU, de l'avoir formalisé dans sa résolution $\mathrm{n}^{\circ} 43 / 181$ du 8 décembre 1988 intitulée Assistance humanitaire aux victimes des catastrophes naturelles ou autres situations du même ordre ${ }^{818}$. De même, on ne saurait oublier de mettre à l'actif de l'ONU et principalement du CS/NU, la

\footnotetext{
${ }^{811}$ BOISSON DE CHAZOURNES, Laurence, « Les résolutions des organes des Nations Unies, et en particulier celles du Conseil de sécurité, en tant que source de droit international humanitaire », «art.cit.», p. 150.

${ }^{812}$ Ibid. pp. 153 -154.; Voy. BETTATI, Mario, Droit humanitaire, $1^{\text {re }}$ édition, op.cit., 245 ; EMMANUELLI, Claude, International humanitarian Law, op.cit., p. 52.

813 Dans de nombreuses résolutions au sujet de l'application du DIH ou du DIDH, le CS/NU s'adresse indistinctement aux parties. C'est le cas par exemple de sa Résolution 1355 (2001) du 15 juin 2001, §15, sur la situation de la RDC, le CS/NU «condamne les massacres et atrocités commis sur le territoire de la République démocratique du Congo, exige une fois de plus que toutes les parties au conflit mettent immédiatement fin aux violations des droits de l'homme et du droit international humanitaire, et souligne que les responsables devront répondre de leurs actes ; », ou encore des Résolution 1291 (2000) du 24 février 2000, §15; 1304 (2000) du 16 juin $2000, \S 15$; 1332 (2000) du 14 décembre 2000, $\$ 14$; ou de nombreuses résolutions subséquentes sur la situation de la RDC dont la Résolution 2198 (2015) du 29 janvier 2015, etc.

${ }^{814}$ REYNAUD, Oriane, op.cit., p. 27 ; voy. infra

${ }^{815}$ Lire SCHINDLER, Dietrich, «United Nations forces and international humanitarian law », in SWINARSKI, Christophe (éd.), op.cit., pp. 521-530.

${ }^{816}$ MOIR, Lindsay, The Law of internal armed conflict, Cambridge University Press, op.cit., pp. 251-252.

${ }^{817}$ BETTATI, Mario, Droit humanitaire, $1^{\text {re }}$ édition, op. cit., pp. 246-247.

${ }^{818}$ Lire à ce sujet, BELANGER, Michel, Droit international humanitaire général, op.cit., pp. 85-149.
} 
juridictionnalisation du DIH à travers la création des juridictions pénales internationales ${ }^{819}$.

\section{§5. Les facteurs non-juridiques liés à la mise en œuvre du droit international humanitaire ${ }^{820}$}

L'expérience de différents déroulements des hostilités permet d'affirmer que les mécanismes ou facteurs juridiques seuls ne sauraient point assurer une mise en œuvre efficace et efficiente des règles du DIH. « Il convient de combiner les mécanismes juridiques à des éléments de fait lorsque l'on veut à tout prix sauver les victimes de l'entreprise la plus bestiale que l'humanité mène depuis la nuit des temps : la guerre ${ }^{821}$. De ces éléments de facto, sont épinglés ${ }^{822}$ : la réciprocité; l'action de l'opinion publique; les impératifs de l'efficacité militaire ; une certaine éthique humanitaire et les nécessités de la reconstruction de la paix à l'issue du conflit armé.

\section{A. La réciprocité}

«La réciprocité, si elle n'est pas une condition d'application du DIH, anime souvent l'effort de retenue que manifestent les combattants. Une partie à un conflit international peut toujours espérer que le respect du DIH, en faveur des civils ou des personnes hors de combat, est de nature à inciter la Partie adverse à adopter la même attitude à l'égard de ses ressortissants. ${ }^{823}$. Ce qui peut être également le cas pour le traitement réservé aux personnes tombées au pouvoir de l'ennemi. C'est ainsi que dans le conflit franco-algérien, bien que le pouvoir public français refusait de considérer ce conflit comme conflit armé international (position que défendait le gouvernement provisoire de la République algérienne dont la création fut annoncée le 18 septembre 1958), les rebelles capturés ont été cependant généralement traités comme des prisonniers de guerre vers la fin du conflit. Et ce dans le but d'éviter que les soldats français capturés ne soient maltraités et faciliter ainsi les négociations avec les organes de la rébellion ${ }^{824}$.

\section{B. L'opinion publique}

L'opinion publique détient toujours un rôle à jouer face à l'organisation ou au fonctionnement des institutions politiques nationales ou internationales. Sans elle, l'on parlerait d'une organisation ou d'un fonctionnement des institutions sans garde-fous factuels.

Dans le cas des conflits armés -internationaux ou non internationaux-, l'opinion publique nationale ou internationale peut influer positivement sur le déroulement voire l'issue des

\footnotetext{
${ }^{819}$ KEMFOUET KENGNY, Emile Derlin, «Etats et acteurs non étatiques en Droit international humanitaire », in Revue québécoise de droit international (2008) 21.2, pp. 74-75.

${ }^{820}$ Pour la rédaction de cette partie, nous nous sommes référé à l'étude de VEUTHEY, Michel, Guérilla et Droit humanitaire, op.cit., 338-347. Ces facteurs tels qu'analysés par Michel VEUTHEY sont également repris par BULA-BULA, Sayeman, Droit international humanitaire, op. cit., pp. 215-223.

${ }^{821}$ BULA-BULA, Sayeman, Droit international humanitaire, op.cit., p. 215.

${ }^{822}$ Voy. VEUTHEY, Michel, Guérilla et Droit humanitaire, op.cit., pp. 338-347 et BULA Bula, Sayeman, Droit international humanitaire, op. cit., pp. 215-223

${ }^{823}$ BETTATI, Mario, Droit humanitaire. Textes introduits et commentés, op.cit., p. 57.

${ }^{824}$ Lire BRETTON, Philippe, Le droit de la guerre, op. cit., pp. 9-10.
} 
hostilités. Ainsi, faire respecter le DIH. A ce titre, se fondant sur l'expérience de son pays, la République démocratique du Viêt-Nam, l'ambassadeur Nguyen Van Luu a déclaré lors de la deuxième session de la conférence diplomatique sur le droit humanitaire que «l'opinion publique est la source même du droit humanitaire ${ }^{825}$. Toutefois, sans considérer exagérément «l'opinion publique comme une panacée, un substitut universel de tous les autres facteurs d'application, juridiques ou non ${ }^{826}$, il y a lieu de reconnaître à juste titre son rôle efficace à la mise en œuvre du DIH ou des droits de l'homme. Comme l'attestera d'ailleurs l'adoption de différents instruments relatifs à la protection de l'enfant.

En effet, aucun sujet de droit international «responsable» ne pourrait souhaiter que son image soit ternie par des propos maladroits. D'où, l'obligation de veiller sur ses attitudes ou agissements sur les champs des hostilités et sur les personnes qu'on est censé protéger. L'opinion publique reste perçue comme une force qui rappelle à l'ordre tout contrevenant éventuel. "Grâce à la technologie moderne, les médias peuvent rendre compte de faits tragiques sinon barbares presque en temps réel à l'échelle planétaire. Plus d'un acteur de la guerre se trouverait mal en point devant ses (futurs) électeurs ${ }^{827}$. En même temps, une telle attitude des médias n'est pas toujours bien perçue par toutes les parties au conflit et pourrait avoir pour conséquence d'accorder un avantage matériel à une partie au conflit. Il s'agirait là de dévoiler les stratégies ou tactiques de conduite des hostilités qu'utilise une partie. Il est donc à remarquer que «l'exclusion des médias sur le théâtre des opérations au Congo, en Angola, au Soudan, etc., ou la sélection de certains d'entre [eux] en Afghanistan et en Irak, vise à éviter la sensibilisation du public ${ }^{828}$. Le rôle positif de l'opinion publique peut s'avérer aussi dans le sens de rappel des règles du DIH à mettre en application sur les champs de batailles. Le professionnalisme de la presse, par exemple, qui la conduirait à faire appel aux spécialistes des questions de DIH serait d'un effet positif et surtout si l'audimat de celleci s'étend même au champ ou zone de conflit. A contrario, le manque de professionnalisme pourrait s'avérer catastrophique comme source de désinformation.

Le rôle positif de l'opinion publique est aussi assuré par les ONG nationales ou internationales des droits de l'homme (cf. infra). Ces dernières jouent une influence remarquable en amont, lors de l'adoption des instruments juridiques internationaux et en aval, au moment de l'application de ces instruments ${ }^{829}$ (cf. infra). Leurs rapports sur des situations données - marqués d'une certaine objectivité - constituent un mécanisme non négligeable de mise en œuvre de DIH. Cependant, la présence des ONG dites «ONG étatiques » ou «GONGOS» (Governement Organized Non-governemental organization, « dans le jargon onusien, de fausses Organisations non gouvernementales en réalités contrôlées par des

\footnotetext{
${ }^{825}$ VEUTHEY, Michel, Guérilla et Droit humanitaire, op.cit., p. 342.

${ }^{826}$ Ibid., p. 343.

827 BULA-BULA, Sayeman, Droit international humanitaire, op.cit., p. 219.

828 Ibid.

829 Lire avec intérêt G. COHEN-JONATHAN et J.F. FLAUSS, (éd.), Les Organisations non gouvernementales et le droit international des droits de l'homme. International human rights law and non governemental organization, Bruylant, Bruxelles, 2005, 258 p. ; BRETON-LE GOLF, Gaëlle, L'influence des Organisations non gouvernementales (ONG) sur la négociation de quelques instruments internationaux, Bruylant, éditions Yvon Blais, Bruxelles, 2001, 263 p.; BEIGBEDER, Yves, Le Rôle international des organisations non gouvernementales, Bruylant, L.G.D.J, Bruxelles, Paris, 1992, 195 p.
} 
gouvernements $\left.{ }^{830}{ }\right)$, dans les forums des ONG sur la scène internationale voire nationale, qui représentent et défendent les causes et faits de certains gouvernements sur des questions de droits de 1 'homme, ne clarifie pas toujours la situation au bon sens ${ }^{831}$. Ceci n'est point à confondre avec la CONGO, à savoir la «Conférence des ONG jouissant du statut consultatif auprès du Conseil économique et social des Nations Unies » ${ }^{832}$, créée en 1948 par les ONG.

Par ailleurs, l'opinion publique notamment les médias ne jouent pas toujours un rôle positif vis-à-vis du DIH. Différents faits leurs sont reprochés fustigeant ainsi le rôle négatif qu'ils jouent. «D'où le caractère de couteau à double tranchant de ces moyens. Les médias peuvent informer aussi bien désinformer la population sur la conduite des hostilités ${ }^{833}$. On le sait, la question de l'indépendance, de l'objectivité ou de la neutralité axiologique des médias face à certaines situations belliqueuses pose des problèmes sérieux. Il est facile de remarquer la tendance de certains médias de par leur prise de positions face à des situations données. Un auditeur ou téléspectateur moins ou non averti serait ainsi facilement manipulé. L'histoire des conflits récents atteste les rôles négatifs qu'ont joué certaines presses qui ont même servi d'instrument de violations des règles du DIH. L'on citera «Radio des Milles Collines » de triste mémoire qui a joué un rôle très néfaste dans la mise en exécution du génocide tutsi.

De tout ce qui précède, l'opinion publique appréhendée comme facteur extra-juridique de mise en œuvre des règles du DIH peut tout de même jouer un rôle positif voire négatif en ce sens. Il sied d'être circonspect afin d'analyser à bon escient le sens et la nature de son intervention pour mieux la saisir.

\section{L'efficacité militaire, l'éthique humanitaire et la reconstruction de la paix post- conflit}

L'efficacité militaire «coïncide avec le respect des principes humanitaire ${ }^{834}$. Ainsi, «le professionnalisme d'une armée régulière l'empêche[rait] de se livrer au pillage des biens de caractère civil, au viol des femmes et des enfants ${ }^{835}$.

L'éthique militaire «rappelle qu'on est ennemi pour un temps, mais qu'on demeure à jamais membre du genre humain. D'où la nécessité d'une retenue dans la conduite des hostilités qui laisse place à l'application du droit au nom de la solidarité humaine ${ }^{836}$. Ceci n'est rien d'autre que le rappel des sages conseils de Jean-Jacques Rousseau qui avait tenté d'humaniser la guerre (cf. supra). L'éthique permettrait d'éviter la perpétration des crimes innommables au

\footnotetext{
${ }^{830}$ MEGRET, Frédéric, «La diversification des acteurs impliqués dans les conflits armés : vers un dépassement de la «participation directe aux hostilités », in SOREL, Jean-Marc et FOUCHARD, Isabelle (dir.), Les tiers aux conflits armés et la protection des populations civiles, éd. Pedone, Paris, 2010, p. 60. Voy. aussi RYFMAN, Philippe, Les ONG, op.cit., pp. 5-6.

${ }^{831}$ OLIVIER, Clémentine, «Les Organisations non gouvernementales et la répression pénale internationale » in COHEN-JONATHAN et J.F. FLAUSS, (éd.), Les Organisations non gouvernementales et le droit international des droits de l'homme. International human rights law and non governemental organization, op.cit., pp.120 121.

${ }^{832}$ BEIGBEDER, Yves, Le Rôle international des organisations non gouvernementales, op.cit., p. 36.

${ }^{833}$ BULA-BULA, Sayeman, Droit international humanitaire, op.cit., p. 217.

${ }^{834}$ VEUTHEY, Michel, Guérilla et Droit humanitaire, op.cit., p. 344.

${ }^{835}$ BULA-BULA, Sayeman, Droit international humanitaire, op.cit., p 220.

${ }^{836}$ Ibid., p. 221.
} 
cours des hostilités. Ainsi, « [o]n ne saurait oublier, en effet, que le droit humanitaire est avant tout la transposition dans le droit de règles morales et que, pendant longtemps, le sens de l'honneur militaire avant d'être quelque peu dévalorisé par les techniques de la guerre moderne était une des plus sûres limitations des méfaits du combat ${ }^{837}$. Et c'est donc dans les consciences des combattants que le principe humanitaire doit s'enraciner pour lutter contre l'animus belligerandi ${ }^{838}$.

Enfin, la reconstruction de la paix post-conflit peut jouer aussi un rôle positif dans le sens d'application du $\mathrm{DIH}^{839}$. «De même que le respect du droit humanitaire facilite le maintien de la paix intérieure, de même, le retour de la paix entre les belligérants sera grandement facilité par des gestes humanitaires, semences de paix qui maintiennent, si restreinte soit-elle, la place du dialogue et de la réconciliation ${ }^{840}$.

L'analyse de ces facteurs non-juridiques liés à la mise en application du DIH attestent que celui-ci reste matériellement non dépendant des facteurs juridiquement institués par des convention voire la coutume internationales. Il sied d'affirmer en conclusion que la réussite à l'application du DIH réside dans la combinaison des «intelligences » dégagées dans différentes disciplines.

\section{Section III Les limites relatives à l'application du droit international humanitaire}

L'application des règles du DIH n'est point tributaire uniquement d'un aménagement juridique. Il existe un grand nombre de facteurs sans lesquels celles-là ne sauront être mises en application (cf. supra).

Au-delà des obstacles ou écueils d'ordre juridique qui seront développés tout au long de cette dissertation, il existe des limites diverses d'ordre pratique qui font que l'application des règles de DIH demeure problématique sur le champ de bataille. Trois d'entre elles sont retenues : les limites d'ordre politiques $(\S 1)$, les limites d'ordre économique $(§ 2)$ et celles d'ordre idéologique (§3).

\section{§1. Les limites d'ordre politique}

«La politique dirige tout! » dit-on. Il n'est point un secret que les budgets des Etats en proie à des confits armés accordent un grand intérêt aux secteurs de défense et de sécurité nationales ${ }^{841}$. Une telle mesure qui relève de la politique nationale d'un Etat ne veut pas

\footnotetext{
${ }^{837}$ TORRELLI, Maurice, Le droit international humanitaire, P.U.F, 1985, p. 23.

${ }^{838}$ Ibid.

${ }^{839}$ BULA-BULA, Sayeman, Droit international humanitaire, op.cit., pp. 221-223.

${ }^{840}$ VEUTHEY, Michel, Guérilla et droit humanitaire, op.cit., p. 346.

${ }^{841}$ L'Afrique est très peu équipée militairement et y consacre très peu de moyens financiers par rapport à d'autres régions géographiques ou Etats étrangers (par exemple: Etats Unis d'Amérique, France, Inde, etc.).(Voy. BOUTEMEUR, Famila, et al., «L'Afrique demain développement et sécurité », in Association des auditeurs et cadres des hautes études de l'armement, Géostratégie et armement au XXI siècle, La Documentation française, Paris, 2014, pp. 89-90) Mais les moyens financiers alloués à ce secteur comparativement à d'autres au plan interne de chaque Etat africain n'est pas moindre. Il n'existe tout de même pas de lien entre ces dépenses et la force militaire. Certaines armes, par exemple, peuvent être d'efficacité nulle sur le terrain (FONTANEL, Jacques, Les dépenses militaires et le désarmement, Publisud, Paris, 1995, p. 23.)
} 
nécessairement pas refléter les intérêts du peuple. «Souvent les forces armées sont, de fait, l'" assurance vie $» d u$ pouvoir en place ${ }^{842}$. D'où l'intérêt du pouvoir de leur accorder attention. Il arrive donc que les autorités étatiques, surtout celles des Etats en guerre civile ou en conflit armé international, prennent des options ou stratégies non dans le sens d'assurer la protection de la population civile mais simplement pour protéger ou conserver leurs pouvoirs. Lesquels pouvoirs sont souvent acquis par des voies antidémocratiques.

Il va sans dire que des mesures prises pour protéger ou conserver le pouvoir politique face aux rebelles, opposants armés ou autres parties au conflit n'iront pas prioritairement dans le sens de répondre aux attentes du peuple en termes du DIH. Il arrive donc que les Etats utilisent tous les moyens possibles pour atteindre leurs objectifs même ceux les plus illicites ou indicibles. L'on ne cesse d'apprendre que les armées nationales participent aux viols et massacres de population civile, aux violations des droits fondamentaux, au pillage des ressources naturelles et des biens appartenant aux populations civiles qu'elles sont censées protéger.

Bien plus, l'expérience sur différentes situations belliqueuses démontre que les parties aux conflits armés notamment les Etats n'agissent qu'en fonction de leurs intérêts conformément à l'adage "pas d'action sans intérêt! ». Et s'il est certes vrai que sur la scène internationale aucun Etat ne souhaite que son image soit ternie ou qu'il soit vu comme un mauvais élève en termes de mise en œuvre des droits humains ou DIH, cependant ils ne sont pas aussi diligents dans l'application de ces droits au bénéfice de leurs populations comme l'attestent des arguments précédents.

Par ailleurs, il est important de mentionner que les règles du DIH restent tributaires de la politique nationale. Le DIH ne serait rien sans l'Etat qui demeure malgré tout sujet ou acteur principal de sa mise en application. Les autres acteurs qui interviennent (ONG, OI, etc.) ne sont que secondaires. Les Etats ont reçu mandat de par les traités ou conventions internationales d'assurer la mise en œuvre du DIH, respectant ainsi le principe pacta sunt servanda. Toutefois, le DIH ne serait aussi rien sans l'intervention des ONG nationales ou internationales qui agissent de manière croissante pour l'application de ses règles. Les actions que mène le $\mathrm{CICR}^{843}$ qui a été à la base du DIH moderne et qui demeure l'organe clé ou

Pour illustration, pour les exercices budgétaires 2015 et 2016, la RDC réservait pour les secteurs de défense et sécurité des parts respectives de $11,85 \%$ et 13,86\% (Voy. Tableau de «Synthèse de dépenses par Administration » in Ministère du budget (RDC), Loi de finances $n^{\circ} 14 / 027$ du 31 décembre 2014 pour l'exercice 2015 -Vol. II Dépenses, Kinshasa, Janvier 2015 ; Tableau de «Synthèse de dépenses par grandes fonctions » in Ministère du budget (RDC), Loi de finances $n^{\circ} 15 / 021$ du 31 décembre 2015 pour l'exercice 2016 -Vol. II Dépenses, Kinshasa, Janvier 2016). Par ailleurs, en termes d'analyses comparatives, une étude publiée en 2015 atteste, par exemple, que le budget alloué au secteur de la défense en RDC n'avoisine même pas le 5\% du budget de la République de l'Angola. Celle-ci consacre un budget de 5,7 milliards de dollars américains à la défense alors que la RDC n'y réserve que 247 millions de dollars américains. Voy. MUSAVULI, Boniface, « RD Congo - Armée : Une bombe à retardement », article disponible sur http://desc-wondo.org/fr/exclusif-rd-congo-armeeune-bombe-a-retardement-boniface-musavuli/ (Source consultée le 11 septembre 2016). Tout de même, à nous aussi de constater - sans entrer dans le détail - qu'en termes de parts représentatives comparativement aux budgets de ces deux Etats, il n'y aurait pas grande différence.

${ }^{842}$ BOUTEMEUR, Famila, et al., «L'Afrique demain développement et sécurité », « art. cit. », p. 80.

${ }^{843}$ Voy. par exemple FREYMOND, Jacques, Guerres, Révolutions, Croix-Rouge. Réflexions sur le rôle du Comité international de la Croix-Rouge, Institut universitaire de Hautes études internationales, Genève, 1976, pp. 145-184; MOIR, Lindsay, The Law of internal armed conflict, Cambridge University Press, Cambridge 
mieux la «sentinelle permanente» du $\mathrm{DIH}$, sont à épingler dans ce sens. L'ONU dont les principaux organes et autres organes subsidiaires sont également appréhendés comme véritables mécanismes d'application du DIH joue un rôle très considérable. La création de différentes juridictions internationales ou internationalisées soit par voie de traités (CPI, Tribunal spécial pour la Sierra-Leone,) sous l'instigation de l'ONU ou par voie résolutoire de l'ONU (les Chambres spéciales créées au Timor-leste, les Chambres mixtes kosovares; le Tribunal spécial pour le Liban ${ }^{844}$ ) ou par une loi nationale (les Chambres extraordinaires pour le Cambodge ${ }^{845}$ ) constitue une mise en application non négligeable du DIH. Car on le sait, les crimes du DIH sont le plus souvent commis soit par ceux qui occupent le pouvoir, soit simplement par des personnalités hautement placées. Se rabattre ainsi sur les juridictions nationales - avec des moyens matériels, humains et financiers limités - pour des procès à forte dose politique risquerait à coup sûr d'aboutir à un simulacre de procès, par conséquent à une impunité grandissante. L'intervention de la «communauté internationale » par le biais de $1^{\prime} \mathrm{ONU}{ }^{846}$ par la création notamment de ces juridictions constitue un signal fort de mise en œuvre des règles du DIH. Les Etats qui ont cédé une partie de leur souveraineté à l'ONU pour assurer la paix et la sécurité internationales se voient l'obligation notamment de coopérer avec les différentes juridictions qu'elle crée. Et pour les juridictions créées par voie de traité ou lois nationales, les Etats non parties ou non concernés n'ont aucune obligation de coopérer. Mais, ils peuvent décider unilatéralement d'apporter leur aide et ne peuvent pas se permettre d'agir dans le sens d'obstruer le bon fonctionnement de ces juridictions en vertu $\mathrm{du}$ principe d'opposabilité des traités.

Ainsi, les organisations non gouvernementales et intergouvernementales font généralement de pressions sur les Etats qui adoptent des politiques non ou peu efficaces au bénéfice du DIH ou encore des Etats simplement auteurs de violations du DIH. Ceci constitue une opinion publique internationale très considérable et très influente qu'aucun Etat, même le plus dictatorial, n'arrive à supporter facilement. Il s'en suit toujours des «justifications » de la part de ces Etats.

En conclusion, la politique qui influe sur la mise en application des règles du DIH dans la mesure où elle constitue des options fondamentales que prennent les Etats relativement au $\mathrm{DIH}$, est également un facteur de déstabilisation. Ceci reste fort remarqué notamment dans la conservation du pouvoir où les Etats (Gouvernements) ne voient que leurs intérêts au détriment de l'intérêt du peuple. Tout de même, le DIH demeurerait « un mot dans le livre », « un slogan creux » sans l'action des Etats, sujets originaires et principaux du DI.

2002, 250-251 ou HUBER, Max, La pensée et l'action de la Croix-Rouge, édition du C.I.C.R, Genève, 1954, $376 \mathrm{p}$.

${ }^{844}$ Il sied de dire que dans un premier temps, le Tribunal spécial pour le Liban a été créé aux termes d'un Accord conclu entre le Secrétaire général des Nations Unies et la République libanaise. Suite aux lenteurs de la procédure de ratification de cet Accord par les autorités libanaises compétentes, le Conseil de sécurité a décidé d'entériner l'Accord au terme d'une résolution prise sur base du Chapitre VII de la Charte des Nations Unies. Autrement dit, la résolution du Conseil de Sécurité est venue donner un caractère exécutoire à un Accord conclu entre l'ONU et le Liban, dont l'absence de ratification nationale en retardait l'exécution. Voy. BOSLY, Henri D. et VANDERMEERSCH, Damien, op.cit., p. 176.

${ }^{845}$ Les Chambres extraordinaires pour le Cambodge n'ont pas été créés par une résolution du Conseil de Sécurité basée sur le chapitre VII de la Charte des Nations unies, ni par un traité multilatéral mais par une loi cambodgienne. Voy. BOSLY, Henri D. et VANDERMEERSCH, Damien, op.cit., p. 166.

${ }^{846}$ MOIR, Lindsay, The Law of internal armed conflict, op.cit., p. 251. 


\section{§2. Les limites d'ordre économique}

Il ressort de ce qui précède que la mise en œuvre des règles du DIH nécessite également l'institution des mécanismes appropriés. Et la concrétisation de ces mécanismes engage pour leur part des moyens humains, matériels et surtout financiers conséquents.

S'il est certes vrai que la plupart des Etats notamment ceux en proie à des conflits armés allouent des budgets conséquents aux secteurs de la défense et de la sécurité nationale, il est aussi paradoxalement vrai que cela ne concerne pas nécessairement la mise en application des règles du DIH.

En clair, la concrétisation de différentes structures analysées ci-dessus qui doivent rentrer dans le cadre des mécanismes de prévention, de contrôle et de sanction veut que les moyens financiers conséquents leur soient également alloués.

En effet, différentes mesures devant être prises par l'Etat en temps de paix pour mieux assurer la mise en œuvre des règles de DIH en temps de conflit armé obligent les Etats à engager des moyens conséquents. A titre exemplatif, la traduction des traités de DIH dans les langues nationales; l'adoption des dispositions législatives ou réglementaires (législation pénale réprimant les crimes de guerre et les autres violations du $\mathrm{DIH}$ ) ; la protection des emblèmes de la croix rouge, du Croissant rouge et du cristal rouge; l'élaboration des programmes d'éducation; le recrutement et la formation du personnel, l'identification et la signalisation des personnes, des lieux et des biens protégés ; la nomination des conseillers juridiques auprès des forces armées ; etc. (cf. supra) ne peuvent être valablement assurés qu'avec des moyens financiers importants sans lesquels rien ne sera fait.

Par ailleurs, mener une guerre nécessite des moyens financiers énormes et mener une bonne guerre, respectueuse des règles de $\mathrm{DIH}$, contraint les parties aux conflits armés à engager plus que des moyens ${ }^{847}$ en termes notamment de prises en charge des combattants capturés, blessés ou tués; de recrutement et de la formation du personnel; de l'identification et de la signalisation des personnes vulnérables ; de l'institutions des puissances protectrices, de mesures relatives aux restrictions des méthodes ou moyens de combat ; etc. L'on pourra peutêtre se demander, par exemple, comment un Etat peut répondre aux attentes des prisonniers de guerres alors qu'il ne sait pas assurer habituellement les droits de ses propres prisonniers ordinaires. Ces derniers y traversent des situations plus que pénibles. Bref, les Etats faibles

\footnotetext{
${ }^{847}$ Cette réflexion est appuyée par la Banque Mondiale. Traitant spécifiquement de la guerre civile dans son étude sur Briser la spirale des conflits. Guerre civile et politique de développement, Editions De Boeck Université, Bruxelles 2005, 95-96., la Banque Mondiale fait remarquer que la «La rébellion coûte cher (sic). Plusieurs milliers de gens vont devoir travailler à plein temps pour l'organisation, et ce, pendant plusieurs années. Il faudra les nourrir, les habiller et les loger, ainsi que les personnes à leur charge. Il faudra aussi les équiper en matériel. Selon son degré de sophistication, l'équipement militaire peut atteindre des prix très élevés et, en période de combat. Il demande à être fréquemment remplacé. Or, les activités militaires ne génèrent aucun revenu direct, de sorte que l'organisation rebelle est confrontée à un difficile problème financier. Si elle ne parvient pas à y faire face, elle ne pourra pas survivre. Tel est peut-être le sort qu'ont connu beaucoup de mouvements rebelles avortés. Pour parvenir à donner à l'action violente la dimension d'une guerre civile, un groupe rebelle doit donc, au moins pour partie, prendre la forme d'une entreprise commerciale. »
} 
économiquement sont généralement ceux les plus confrontés à des situations des conflits armés $^{848}$. Et ils n'arrivent généralement pas à allouer des moyens conséquents au respect du DIH suite à leurs différentes difficultés d'ordre économique. Ou ils ne sont simplement guère intéressés à fournir d'énormes efforts pour une mise en œuvre efficace et efficiente des règles du DIH.

L'une des grandes difficultés liées à la mise en œuvre des règles de DIH se rapporte notamment à la création des juridictions pénales internationales ou internationalisées (ou mixtes). En effet, la création de ces juridictions autant que leur fonctionnement emploient d'énormes moyens notamment financiers supportés par la «communauté internationale ${ }^{849}$. Et l'expérience démontre que ces juridictions sont coûteuses aux yeux de la «communauté internationale » qui généralement n'agit pas aussi sans intérêt. Ainsi, les Etats membres de cette communauté ne regardent pas tous toujours dans la même direction même face aux crimes indicibles à l'endroit de l'humanité. Certaines prises de position ne facilitent pas toujours la tache à ces juridictions. Ce qui pourrait porter quelque part atteinte à leur indépendance fonctionnelle.

Ainsi, comme l'expliquent Henri D. BOSLY et Damien VANDERMEERSCH, "les juridictions internationales nourrissent l'ambition d'offrir un standard de justice exemplaire, notamment en termes de garanties et de droits de la défense. Tout cela a un coût non négligeable, ainsi qu'en témoignent les budgets de fonctionnement des juridictions internationales (TPIY, TPIR et CPI) ${ }^{850}$. A bon droit, des moyens importants sont octroyés à la défense mais on peut se poser la question de l'efficacité de ces juridictions en terme de rapport «coût-efficacité » ${ }^{851}$. Ceci vaut de même pour les juridictions internationalisées ou mixtes ${ }^{852}$.

Mais aussi au niveau national, vouloir que les juridictions nationales compétentes en matière des crimes internationaux puissent réellement remplir leurs missions et aboutir à des enquêtes sérieuses nécessite absolument des moyens sérieux tant au plan humain, matériel que financier. Déjà on le sait, les magistrats, juges et avocats nationaux, surtout ceux des pays en voie de développement, sont dans la plupart de cas mieux outillés pour affronter les branches dites classiques du droit dans la mesure où c'est là où naissent quotidiennement des litiges. Cependant, ils manifestent peu d'engouement à l'égard des branches dites spécialisées du

\footnotetext{
${ }^{848}$ Banque Mondiale, Briser la spirale des conflits. Guerre civile et politique de développement, Editions De Boeck Université, Bruxelles 2005, p. 74.

${ }^{849}$ Exceptionnellement le budget du Tribunal spécial pour le Liban est supporté à $51 \%$ par la communauté internationale et à $49 \%$ par le gouvernement Libanais.

${ }^{850}$ A titre d'exemple, le budget du TPIR pour les années 2008 et 2009 s'est élevé à 298 millions de dollars US (Soit environ 150 millions par an). Le budget de l'ensemble de l'équipe de la défense de trois accusés dans le procès dit des médias devant le TPIR s'est élevé à 4.871.590.94 US dollars tandis que celui octroyé à la défense de Bagosora et dans le dossier « Militaire I» du TPIR, qui concernait 4 accusés s'est élevé à 8.536.590.79 US dollars (Document préparatoire pour le colloque international «Tribunal pénal international pour le Rwanda Modèle ou contre-modèle pour la justice pénale internationale ? Le point de vue des acteurs », juillet 2009, p.72). D. BOSLY, Henri et VANDERMEERSCH, Damien, op.cit., p. 191

${ }^{851}$ Ibid., pp. 190-191.

${ }^{852}$ A titre illustratif, l'on note en fin 2010 que le Tribunal spécial pour le Liban comptait plus de 300 membres du personnel et son budget annuel pour l'année 2010 s'élevait à 55 millions de dollars. Voy. D. BOSLY, Henri et VANDERMEERSCH, Damien, op.cit., p. 181.
} 
droit telles que le DIH ou droit international pénal où des litiges ne sont toujours pas réguliers. Bien plus, ces branches qui traitent spécialement des questions des crimes internationaux nécessitent aussi un intérêt et une formation particuliers de la part des Etats. Or, la plupart d'Etats notamment africains se trouvent au départ en butte à de sérieuses difficultés notamment un sérieux problème de formation des magistrats dont le recyclage est quasi inexistant, laissant ainsi place à une certaine routine. Les bibliothèques des cours et tribunaux accusent de carences en termes d'ouvrages (cf. le cas de la RDC). La justice reste éloignée des justiciables. Les infrastructures de justice demeurent délabrées autant que les opérateurs judiciaires sont dans des situations peu confortables au plan financier. Le tout influe sur le climat de travail et pèse sérieusement sur l'indépendance de la justice ${ }^{853}$. Ainsi, l'on se demandera également si ces magistrats qui ne sont au départ pas indépendants pourront mieux se comporter face aux procès qui concernent généralement de gros poissons et et qui sont souvent hautement politisés.

Par ailleurs, la communauté internationale à travers notamment des OI et des ONG vient généralement au chevet des Etats en matière d'administration de la justice. Ceci est attesté par le financement et l'organisation des recyclages et séminaires sur certaines questions spécifiques de justice (cf. infra).

\section{§3. Les limites d'ordre idéologique}

La mise en œuvre des règles du DIH demeure tributaire de la considération que l'on accorde aux personnes bénéficiant de cette réglementation. Une partie au conflit ne saurait point assurer le respect des règles du DIH à partir du moment où elle n'accorde aucune considération à la partie adverse. Des termes tels que: «cancrelats, vermines, cafard, racaille, parasites, gredin, populace...» véhiculés dans certains conflits armés contre certaines parties ou populations ont le plus souvent pour objectif de ne réserver aucun respect à ces personnes tout au long du déroulement des hostilités. Ceci aboutit généralement à des exactions indicibles nommées génocides, crimes contre l'humanité, etc. Et d'ailleurs, l'histoire des différents génocides atteste ce point de vue. En clair, en partant de la définition du «génocide » qui est demeurée inchangée depuis l'adoption de la Convention pour la prévention et la répression du crime de génocide le 9 décembre 1948, l'on peut mieux comprendre l'intention qui caractérise les présumés responsables d'un tel crime. Ainsi, le TPIR dans l'affaire Akayesu rappelle que le crime de génocide est caractérisé par «une intention spéciale» ou dolus specialis et l'article 2(2) de son statut le définit comme: «l'intention de détruire, en tout ou en partie, un groupe national, ethnique, racial ou religieux $»^{854}$.

En effet, le plus souvent dans des conflits armés qui opposent certaines ethnies, tribus ou « races », l'idée est celle d'éliminer ou d'exterminer la partie adverse. Au-delà de l'absence

\footnotetext{
${ }^{853}$ Lire MUMBALA ABELUNGU, Junior « La question de l'indépendance du pouvoir judiciaire en RDC », in YAV Katshung, Joseph (dir.), La justice congolaise au banc des accusés?, Presses Universitaires de Lubumbashi, Lubumbashi, juin 2010, pp. 91-113.

${ }^{854}$ SCHABAS, William A., «L'affaire Akayesu et ses enseignements sur le droit du génocide», in BOUSTANY, Katia et DORMOY, Daniel, (dir.), Génocide(s), éditions Bruylant, éditions de l'Université de Bruxelles, 1999, p. 125.
} 
remarquée des structures devant s'occuper des questions humanitaires, le déroulement des hostilités dans de tels conflits reste caractérisé par l'ignorance quasi-totale des règles humanitaires. Deux exemples parmi tant d'autres nous permettent de mieux comprendre.

Premièrement, «[é]crivant à Hannah Arendt en 1960, quelques mois avant l'ouverture du procès Eichmann, le philosophe Karl Jaspers soulignait que l'ampleur des événements pour lesquels Eichmann étais mis en accusation n'avait «rien à voir avec ce que l'on peut comprendre en termes humains et moraux » et que «quelque chose d'autre que le droit (était) ici en jeu - et le fait d'y répondre en termes juridiques (était) une erreur ${ }^{855}$.

En second lieu, le témoignage de Révérien RURANGWA victime du génocide rwandais qu'il voudrait bien qu'on qualifie de «génocide tutsi » contenu dans son ouvrage Génocidé est très poignant :

«Je n'oublierai jamais les prunelles noires de Simon Sibomana au moment où il abat sa lame sur mon crâne. Elles sont gravées en moi pour toujours [...] Sibomana vient de hacher Valens qui se pelotonnait contre moi. Le sang de mon cousin germain m'asperge. Le cabaretier dresse à nouveau sa machette. Je lève le bras gauche, devant ma tête, par réflexe, à hauteur du front, comme lorsque mon père voulait me porter une taloche. Il frappe. La lame s'abat et tranche mon poignet. La main et mon avant-bras tombent derrière moi. Un liquide chaud et épais gicle. Je m'effondre dedans. Crois-il qu'il m'a tué, ou préfère-t-il m'achever plus tard ? ( J'ai déjà souligné la méthode pratiquée : les Hutu blessent lors d'une première tournée ; laissent la victime mariner dans son «jus » et sa douleur; puis terminent le «travail », comme ils disent, lors d'une seconde tournée.) Sibomana passe au suivant. C'est mon père. [...] Il y a quelques centaines de secondes, ils étaient vivants. Je suis pétrifié. Je viens de voir assassiner mon père, ma mère, mes frères, mes sœurs, mes cousins, mes cousines, mes oncles, mes tantes et ma grand-mère. Celle-ci, comme ma mère, a été dénudée. Les Hutu lui ont arraché son pagne. Un carnage, en une minute. Quarante-trois personnes abattues en moins d'une centaine de secondes. Toute ma famille. Suis-je mort ? Hélas, pas encore. [...] J'ai encore la conscience suffisamment éveillée pour voir les tueurs attraper une femme qui court, un bébé sur son dos. Ils la couchent, lui tranchent les chevilles, puis la tête (comme ils reprochent aux Tutsi d'être plus grands qu'eux, les Hutus prennent un malin plaisir à les « raccourcir » ou à les « ramener au format standard»). Quant au bébé, un homme le saisit, s'approche de la cabane où je suis caché et lui fait exploser le crâne en le projetant contre le mur de brique ${ }^{856}$.

Quels mots placés à la suite de ce récit hautement tragique ?

L'on retiendra qu'avant les événements d'avril 1994, la Radio Télévision Libre des Milles Collines avait diffusé des messages de haine ethnique préparant les populations hutues à participer au massacre généralisé qui allait se dérouler. Un mouvement extrémiste hutu lança déjà d'ores et déjà un message d'appel au meurtre des Tutsis : "Supprimez-les et surtout qu'ils ne partent pas et leur peine c'est la mort et pas moins». Ainsi, les tueries furent exécutées d'une façon horrible très souvent avec des machettes. Des blessés étaient achevés dans des hôpitaux. Des enfants furent tués dans des écoles par leurs maîtres ${ }^{857}$.

\footnotetext{
${ }^{855}$ BUIRETTE, Patricia et LAGRANGE, Philippe, op.cit., p. 103.

${ }^{856}$ RURANGWA, Révérien, Génocidé, éd. Presses de la Renaissance, Paris, 2006, pp. 61,62 et 67.

${ }^{857}$ ZANG, Laurent, MEYE, Lydie Ella et ZOCK, Françis, «Conflits intraétatiques et génocide défaillance de
} 
De ce qui précède, comme l'on peut très bien le comprendre, l'idéologie généralement inculquée aux combattants voire aux populations consistant à ne réserver aucune considération à l'ennemi ne permettront point à coup sûr d'observer ne fût-ce que les règles élémentaires du DIH. L'idée ancrée dans leurs têtes est celle d'un traitement inhumain et dégradant avec des méthodes et moyens de combat inacceptables en DIH. C'est ce qui s'est remarqué dans certaines guerres civiles basées le plus souvent sur des disputes des terres ou de suprématie à la tête du pouvoir. Le DIH ne trouve par là aucune chance de voir son application assurée à bon droit. Dans certains conflits armés impliquant certaines communautés, pour ce qui concerne les enfants, dans un schéma de démarche idéologique, leur participation n'est pas seulement approuvée mais carrément encouragée ${ }^{858}$, en marge des règles en la matière (cf. infra).

l'Etat et du système international au Rwanda », in BOUSTANY, Katia et DORMOY, Daniel, (dir.), op.cit., pp. 468 et 470 .

858 SCHMITZ, Marc, «Les enfants-soldats, un phénomène universel de plus en plus préoccupant », in SCHMITZ, Marc, La guerre admis, op.cit., pp. 31-32. 


\section{Conclusion du Chapitre II}

Le présent chapitre portant sur le Droit international humanitaire : Règles et mécanismes de protection : quelle mise en ouvre? s'est interrogé sur l'efficacité de la mise en œuvre du DIH en situation de conflits armés. Il s'est préoccupé d'abord d'étudier le champ d'application matériel, personnel, territorial et temporel - du DIH (Section I). Ensuite, il a analysé la problématique de la mise en œuvre du DIH à travers ses mécanismes de prévention, de contrôle et de sanction mais également des facteurs non juriques y relatifs (Section II). Enfin, il s'est efforcé d'examiner des limites extra-juriques de mise en œuvre du DIH à savoir : les limites d'ordres politique, économique et idéologique (Section III). Ce chapitre se présente aussi dans son ensemble comme un cadre de protection générale de l'enfant en période de conflits armés.

Il se dégage de son contenu que la mise en œuvre du DIH reste problématique. En effet, analysant le contenu de cette branche du DIH, des doctrinaires affirment carrément que le DIH refuse d'organiser efficacement sa mise en œuvre.

Limité au départ à la protection des militaires aux hostilités, le DIH conventionel s'est considérablement étendu à toutes les victimes des conflits armés (CAI et CANI) dont les civils. L'ensemble du territoire (des territoires) étatique(s) sur lequel survient le conflit armé, - CANI et CAI - et non seulement les zones géographiques proches ou voisines des hostilités, se trouve concerné par l'application du DIH. Celle-ci est observable jusqu'à la « fin générale des opérations militaires » ou «à la fin de l'occupation». Et pour des personnes privées de liberté en rapport avec les conflits armés, par exemple, cette application leur reste valable jusqu'à leur «libération définitive » ou «rapatriement». Cette protection accordée demeure tout de même «conditionnelle ». Ainsi, pour différentes catégories de personnes concernées (ex : combattants, prisonniers de guerre, civils, etc.), des conditions sont respectivement exigées par les CG et PA pour bénéficier de la protection. Celle-ci vaut de même pour des biens.

Par ailleurs, il n'existe point de mise en œuvre du droit sans l'institution des mécanismes indiqués. En DIH, des mécanismes de prévention, de contrôle et de sanction (voire de réparation) sont envisagés pour assurer le respect de ses règles. Toutefois, il s'avère que ces mécanismes ne sont pas toujours effectifs ou efficaces en conflits armés. De nombreux efforts restent fournis par des Etats au plan de la réglementation (ex : législations nationales sur le $\mathrm{DIH}$ ) et des mécanismes (ex : des commissions nationales du DIH) sans un lendemain meilleur sur le champ de bataille. En dépit donc de quelques facteurs extra-juridiques qui devraient faciliter le fonctionnement de ces mécanismes, des limites ou écueils notamment d'ordre politique, économique ou idéologique demeurent remarquables dans le chef des Etats ou des parties en conflit.

De tout ce qui précède, si la protection au plan général en DIH pose de sérieux problèmes d'effectivité et d'efficacité, il y a lieu de s'interroger sur le sort réservé à la protection exigeante, celle dite «spéciale » des personnes vulnérables dont les enfants. 


\section{CHAPITRE III LES REGLES DE PROTECTION DES ENFANTS DANS LES CONFLITS ARMES EN DROIT INTERNATIONAL HUMANITAIRE}

A côté de la protection générale, bénéficiant à toute personne qui ne participe pas aux hostilités, le DIH a établi une protection spéciale profitant directement ou indirectement à l'enfant ${ }^{859} \mathrm{au}$ regard de ses vulnérabilités. Cette logique de protection vaut également pour l'enfant soldat mais avec une protection spéciale très limitée. Ce système de protection est le fruit d'une certaine évolution. Laquelle est due notamment aux nouvelles méthodes de combat, nouvelles formes des conflits armés et à la mutation des enjeux du système international. Et bien que soucieux de l'amélioration de la situation de l'enfant sur le champ de bataille, le régime de protection de l'enfant en telle situation particulière ne peut se satisfaire d'avoir mieux assuré sa mission. De ce fait, différents écueils liés à la formulation de certaines obligations conventionnelles et aux mécanismes de mise en œuvre du DIH sont à cerner (cf. infra).

C'est dans cette optique que le présent chapitre se préoccupe d'analyser «théoriquement» la «protection générale » et «spéciale» des enfants en situation de conflits armés (Section II). Il procède préalablement à l'examen succinct de la situation des enfants - « civils » ou « soldats » dans les conflits armés en général (Section I).

\section{Section I Les enfants dans les conflits armés}

La présente section se propose d'examiner spécifiquement la question de la victimisation des enfants $(\S 1)$ et celle relative à leur utilisation dans les conflits armés $(\S 2)$ avant de laisser place à l'étude des instruments juridiques applicables à la seconde section.

\section{§1. La victimisation des enfants dans les conflits armés}

Dans son rapport sur l'impact des conflits armés sur les enfants présenté en forme de résolution par l'AG/NU, Graça Machel indiquait que des «millions d'enfants sont impliqués dans des conflits non seulement comme spectateurs, mais comme cibles. Si certains tombent victimes de l'assaut général lancé contre les civils, d'autres meurent à la suite d'un génocide délibéré. D'autres encore subissent les effets de violences sexuelles ou des multiples privations résultant des conflits armés, qui les exposent à la faim ou à la maladie. Tout aussi déplorable est le fait que des milliers de jeunes sont cyniquement exploités comme combattants ${ }^{860}$. [...] Au cours des dix dernières années [ précédant 1996 ], on estime que les conflits armés ont fait parmi les enfants 2 millions de morts, et trois fois plus de blessés graves ou d'invalides, souvent par l'explosion de mines. D'innombrables autres ont été forcés d'être le témoin d'horribles actes de violence, voire d'y participer ${ }^{861}$.

Plus de quinze ans après le rapport d'expert Graça Machel transmis par le SG/NU à l'AG/NU,

\footnotetext{
${ }^{859}$ DEYRA, Michel, Le droit dans la guerre, op. cit., p. 155.

${ }^{860} \S 1^{\text {er }}$ de la Résolution A/51/306 du 26 août 1996 de l'AG/NU, Promotion et protection des droits des enfants . Impact des conflits armés sur les enfants », p. 7, http://www.unicef.org/french/emerg/files/Garca-Machel_fr.pdf (Recherche menée le 06 décembre 2013).

${ }^{861}$ Ibid, $\$ 2$.
} 
un autre rapport établi en mai 2013 par le SG/NU couvrant la période de janvier à décembre 2012 atteste que la situation des enfants en conflits armés n'a pas évolué comme souhaité. Il peut donc y être lu ce qui suit : «Ces dernières années, les représentants des structures de protection de l'enfant des Nations Unies ont noté avec préoccupation que la nature changeante des conflits armés et des tactiques employées dans ce cadre créaient des menaces sans précédent pour les enfants. L'absence de lignes de front clairement définies et d'opposants identifiables, l'utilisation croissante de stratégies de terreur par des groupes armés et certaines méthodes utilisées par les forces de sécurité ont accru la vulnérabilité des enfants. Des enfants sont utilisés comme auteurs d'attentats-suicides à la bombe ou comme boucliers humains, tandis que des écoles continuent d'être utilisées à des fins militaires et de subir des attaques, ce qui affecte particulièrement l'éducation des filles. Des enfants sont aussi détenus pour des raisons de sécurité pour association présumée avec des groupes armés. Enfin, des enfants ont trouvé la mort lors de frappes de drones qui ont également entraîné de graves conséquences psychologiques et sociales dans la population enfantine ${ }^{862}$. Le rapport du SG/NU du 20 avril 2016 argumente dans le même sens que celui de $2013^{863}$.

Comme l'on peut bien remarquer depuis le début des années 90, l'évolution du système international a eu des incidences négatives sur la progression des conflits armés, notamment les guerres civiles. Il y a plus des CANI que des CAI. Présents dans la plupart des régions ou sous régions en voie de développement, ces conflits armés internes dits aussi «nouvelles guerres » 864 ont vu le développement des méthodes et moyens de combats. Chose qui aurait logiquement un effet fatal voire catastrophique sur les personnes civiles dont les plus vulnérables. Les enfants sont donc les plus touchés. Leur état de vulnérabilité physique et mentale ne leur permet pas de se mettre à l'abri des conflits comme pourrait être le cas pour des personnes adultes. Ils sont pris pour cibles dans des nombreuses zones de conflits sous contrôle des groupes armés voire des armées régulières. Dans des nombreux cas de violations des règles du DIH qui concernent la population civile, les enfants occupent une place non négligeable. Ils se passent pour l'image même des déplacés ou des réfugiés. "On estime aujourd'hui que la moitié des personnes réfugiées et déplacées dans le monde a moins de 20 ans ${ }^{865}$. Génocides, massacres, violences sexuelles, déportations, prises d'otage, traitements cruels, inhumains et dégradants, tortures,... font donc partie de nombreuses formes d'abus indicibles dont ils sont victimes dans les conflits armés. Machines à tuer, main d'œuvre facile dans la conduite des hostilités, les enfants sont aussi utilisés par les parties belligérantes comme soldats (cf. infra). Une atteinte à leur dignité ! Tout ceci est donc de la «civilianisation des conflits armés ${ }^{866}$ que caractérisent les conflits armés actuels.

\footnotetext{
$862 \$ 9$ de la Résolution AG/NU et CS/NU A/67/845- S/2013/245 Le sort des enfants en temps de conflits armé, Rapport du Secrétaire général, in http://www.un.org/fr/sc/documents/sgreports/2013.shtml (Recherche menée le 06 décembre 2013).

${ }^{863}$ Voy. les paragraphes 4-12 de la Résolution AG/NU et CS/NU A/70/836-S/2016/360, Le sort des enfants en temps de conflit armé, Rapport du Secrétaire général, in http://www.un.org/fr/sc/documents/sgreports/2016.shtml (Source consultée le 5 juillet 2016).

${ }^{864}$ JEANGENE VILMER, Jean-Baptiste, «L'éthique de la guerre », in JEANGENE VILMER, Jean-Baptiste et CHUNG, Ryoa, (dir.), Ethique des relations internationales, Paris, PUF, 2013, p.157.

${ }^{865}$ BETTATI, Mario, Droit humanitaire, $1^{\mathrm{e}}$ édition, Dalloz, op.cit., p. 189.

${ }^{866}$ « «Civilianisation des conflits armés » : les civils sont les principales victimes des guerres contemporaines. » Voy. JEANGENE VILMER, Jean-Baptiste, «art.cit», in JEANGENE VILMER, Jean-Baptiste et CHUNG, Ryoa (dir.), op.cit.,p.157.
} 


\section{§2. L'utilisation des enfants dans les conflits armés : un phénomène omniprésent}

Un bref rappel historique de la situation des enfants soldats ${ }^{867}$ s'impose afin de mieux appréhender la manière dont le DIH, principalement, s'est préoccupé de la question.

En effet, l'histoire des enfants soldats n'est ni contemporaine ni propre à l'Afrique. Elle remonte à l'Antiquité et s'étend dans l'espace. Au IVème siècle avant Jésus Christ à Sparte dans la Grèce Antique, les enfants étaient éduqués dès l'âge de 7 ans aux disciplines militaires. Il s'agissait d'un système éducatif très spécial devant transformer les garçons en robustes guerriers. Cette éducation au métier des armes du jeune spartiate serait due notamment à l'Etat guerrier instauré constitutionnellement par Lycurgue dès le VII ${ }^{\mathrm{e}}$ avant Jesus Christ ${ }^{868}$. Subissant donc un entraînement très exigeant, dès l'âge de 11-12 ans, ces enfants étaient parés pour le combat, prêts à défendre la cité ${ }^{869}$. Au XVème siècle dans l'Empire aztèque, l'enfant devait prouver sa virilité en ramenant du combat son premier prisonnier. D'ailleurs, l'histoire renseigne que la naissance d'un fils était saluée par ce discours : «Ta mission sera de donner à boire au Soleil avec le sang de tes ennemis ». A 6 ans, l'enfant Aztèque commençait à apprendre toutes les techniques de combat, et à 12 ans il devait capturer son premier prisonnier pour prouver sa maturité. Au Moyen-âge de nombreux enfants étaient utilisés comme écuyers par les chevaliers. Si accéder au titre de chévalier nécessitait une longue formation, l'histoire renseigne que Louis IX s'est fait chévalier dès l'âge de 11 ans, la veille de son sacre ${ }^{870}$. Pendant la guerre de trente ans (16181648), on estime que plusieurs dizaines de milliers d'enfants avaient rejoint les armées de mercenaires avec comme tâche principale le pillage ${ }^{871}$. Au XVIII ${ }^{\mathrm{e}}$ siècle, les enfants étaient engagés comme mousses sur les bâtiments militaires dans les batailles navales notamment en raison de leurs petites tailles. Leur nombre serait plus important dans ce type de bataille que dans les armées en campagne ${ }^{872}$. En France après cent cinquante quatre ans de fonctionnement, l'Ecole des mousses fermera ses portes en $1988^{873}$. Sous la période du XVIII ${ }^{\mathrm{e}}$ siècle , précisément en 1764, l'on note que Louis XV avait ordonné l'ouverture d'une école militaire à la Flèche où l'on a dénombré deux cent cinquante enfants âgés d'entre 8 et 11 ans destinés à la carrière d'officier. Napoléon, issu de ce genre d'institution, n'hésita pas non plus à faire appel aux adolescents, avec l'idée de les envoyer au feu. Les deux grandes guerres ont vu la participation massive des enfants notamment au côté des Soviétiques, à Stalingrad et au côté des Allemands où de nombreux enfants, faisant partie de la «jeunesse hitlérienne»(Hitlerjugend) ont été utilisés dans des combats en Normandie et à Berlin ${ }^{874}$.

\footnotetext{
${ }^{867}$ Pour ce bref rappel historique, nous nous référons principalement et largement aux écrits de SCHMITZ, Marc, «Les enfants-soldats, un phénomène universel de plus en plus préoccupant », «art. cit. », pp. 20-26 et de CHAPLEAU, Philippe, Enfants-soldats. Victimes ou criminels de guerre?, op.cit., pp. 21-62. Pour approfondissement sur cette partie, veuillez bien lire ces auteurs.

${ }^{868}$ CHAPLEAU, Philippe, Enfants-soldats. Victimes ou criminels de guerre?, op.cit., pp. 20-21.

${ }^{869}$ SCHMITZ, Marc, «Les enfants-soldats, un phénomène universel de plus en plus préoccupant », «art. cit. », p. 20.

${ }_{870}$ CHAPLEAU, Philippe, Enfants-soldats. Victimes ou criminels de guerre ?, op.cit., p. 29.

${ }^{871}$ SCHMITZ, Marc, «Les enfants-soldats, un phénomène universel de plus en plus préoccupant », « art. cit. », pp. 20-21.

${ }^{872}$ CHAPLEAU, Philippe, Enfants-soldats. Victimes ou criminels de guerre?, op.cit., p. 34.

${ }^{873}$ Ibid. p. 35

${ }^{874}$ SCHMITZ, Marc, «Les enfants-soldats, un phénomène universel de plus en plus préoccupant », « art. cit. », p. 21 ; Voy. aussi HABIBU, Jean Bosco, HABIBU, Jean Bosco, L'effectivité du Statut de la Cour Pénale Internationale: Référence spéciale à la situation concernant la République Démocratique du Congo, édition de l'ACAT, Bukavu, 2007, p. 53.
} 
Dans un passé récent, on a retrouvé également les enfants sur différents champs de bataille. Sur tous les théâtres d'opération en Indochine, au Vietnam ou au Cambodge du temps des Khmers rouges, en Irak, de Beyrouth à Soweto, de la Birmanie à l'Erythrée, des maquis mozambicains aux camps de réfugiés palestiniens, en passant par l'Afghanistan, le Guatemala, les Philippines..., partout, les enfants sont dans les rangs. En Amérique centrale, on les appelle muchachos; bassidji en Iran ou kadogo en RDC. Au Nicaragua, c'est d'abord eux qui ont chassé le dictateur Somoza en fin des années 70. A 10 ans, ils construisaient les barricades dans les rues de Managua, à 13-14 ans, ils tiraient au fusil d'assaut, à 16 ans, ils faisaient déjà figure d'anciens combattants. Ils ont résisté par la suite à la guerre d'agression de Ronald Reagan. Au Salvador, on les a également retrouvés ${ }^{875}$. Il s'agit donc d'un phénomène global et ominiprésent auquel aucune région du monde n'échappe ${ }^{876}$.

Ainsi, « [d]e tous les temps, des enfants ont donc pris part à la guerre. Comme espions, guetteurs, messagers... ou dans un autre rôle de soutien aux troupes, plus rarement comme combattants. Le tableau a fort changé - et les enfants sont de plus en plus impliqués - depuis la fin de la Deuxième Guerre mondiale $[. ..]{ }^{877}$. C'est donc au cours de dernières décennies du siècle dernier que ce phénomène a atteint une ampleur jusqu'alors inconnue ${ }^{878}$. Ceci se justifie notamment en raison de la «nature des conflits ${ }^{879}$ avec toutes les conséquences que cela implique. Nature des conflits qui sont devenus plus des guerres civiles que des simples guerres classiques opposant des Etats. Guerres civiles appelées aussi «nouvelles guerres » causées par des facteurs économiques et sociaux (tels que l'ethnicité et la religion, devenus plus importants que les facteurs politiques tels que l'idéologie), la privatisation de la violence (c'est-à-dire la perte par l'Etat du monopole de la violence légitime) ou des violations graves des droits humains ${ }^{880}$. Ces conflits font massivement recours aux enfants au point que «[c]hercheurs, militaires et humanitaires s'accordent sur un chiffre terrifiant ${ }^{881}: 300.000$ enfants impliqués actuellement dans les conflits armés.

Une autre explication du tableau présenté ci-dessus réside dans le «développement et la prolifération des armes légères ${ }^{882}$. «Tout en étant de redoutables engins de mort, les armes

\footnotetext{
${ }^{875}$ SCHMITZ, Marc, «Les enfants-soldats, un phénomène universel de plus en plus préoccupant », «art. cit. », p. 23. Voy. aussi LOUYOT, Alain, Les enfants soldats, op.cit., p. 11.

${ }^{876}$ MAYSTRE, Magali, op. cit., p. 22.

877 SCHMITZ, Marc, «Les enfants-soldats, un phénomène universel de plus en plus préoccupant » in SCHMITZ, Marc, (coord.), La guerre. Enfants admis. 300.000 enfants-soldats dans le monde: comment combattre ce fléau? Grip éditions Complexe, Bruxelles, 2001, pp. 24-25; Voy. LOUYOT, Alain, Les enfants soldats, éd. Perrin, Paris, 2007, pp. 10-11; KALONJI, Anne, « La protection des enfants au cœur des premières poursuites intentées devant la Cour pénale internationale et le tribunal spécial pour la Sierra Leone », in Sociétés et jeunesses en difficulté, n ${ }^{\circ} 6 / 2008$, p. 2 (disponible sur http://sejed.revues.org/index4933.htmlp (Source consultée le 26 mai 2016) ); HABIBU, Jean Bosco, L'effectivité du Statut de la Cour Pénale Internationale: Référence spéciale à la situation concernant la République Démocratique du Congo, op. cit., p. 53.

${ }^{878}$ CHAPLEAU, Philippe, Enfants-soldats. Victimes ou criminels de guerre ?, op.cit., p. 20.

${ }^{879}$ SCHMITZ, Marc, « art.cit. », in Marc SCHMITZ (coord.), op.cit., p. 25.

${ }^{880}$ JEANGENE VILMER, Jean-Baptiste, «art.cit », in JEANGENE VILMER, Jean-Baptiste et CHUNG, Ryoa, (dir.), op.cit., p. 157.
}

${ }^{881}$ CHAPLEAU, Philippe, Enfants-soldats. Victimes ou criminels de guerre ?, op.cit., p. 19.

${ }^{882}$ SCHMITZ, Marc, «art.cit. », in Marc SCHMITZ (coord.), op.cit., p. 25. Une analyse des données de COMTRADE révèle qu'en 2008, par exemple, la valeur totale des exportations d'armes légères et de petit calibre, de leurs munitions et des pièces et accessoires connexes était de 4,3 milliards USD. Les pays tels que 
légères sont faciles à manipuler et à transporter. Mitrailleuses, revolvers ou grenades sont donc à la portée des enfants...et on peut même affirmer que la majorité des enfants-soldats - en tous les cas tous ceux qui ont un rôle offensif - ne seraient pas soldats sans ces armes. Une partie de celles-ci est par ailleurs utilisée dans toute une série d'autres violations des droits humains ou du droit international humanitaire ${ }^{883}$. Bien plus, la présence des enfants soldats sur le champ de bataille est justifiée aussi par la pauvreté, cause qui justifie même la présence des «nouvelles guerres ». Pauvreté qui se trouve exacerbée par la destruction des structures existantes en période de guerre. Et pour de raison de survie, et par manque d'occupation notamment l'école, les enfants s'engagent «volontairement» aux forces ou groupes armés. Ils le font pour défendre leurs familles ; leur communauté, pour raison d'estime personnelle vis-à-vis de la société ; par vengeance ; par pression des membres de famille voire pour des raisons idéologiques (cf. infra).

Les forces ou groupes armés ont grand avantage de recourir aux enfants, par force notamment, dans la mesure où ces enfants constituent une main d'œuvre nettement moins chère que des soldats adultes. Dociles, manipulables et moins exigeants, les enfants ont davantage de résistance et savent mieux survivre dans la brousse. Pervers et pouvant commettre les crimes les plus odieux, les enfants sont moins craintifs face aux opérations risquées et s'adaptent mieux au nouvel environnement. Toutefois, certains doutent de leur efficacité et stigmatisent notamment l'absence de discipline militaire dans leur chef, par le fait qu'ils ralentissent les troupes en mouvement par leurs forfaits qu'il faut réprimander. Ils manquent de prudence et ne savent pas se débrouiller sur le champ de bataille ${ }^{884}$.

Les situations ci-haut décrites ne devaient pas laisser le DIH indifférent. Toutefois, si d'aucuns estiment que « la prise en compte de la situation des enfants pendant les conflits armés date des temps immémoriaux ${ }^{885}$, il importe de préciser que le DIH s'est préoccupé des questions de recrutement et de participation des enfants aux conflits armés récemment (cf. infra).

\footnotetext{
Etats-Unis, Italie, Allemagne, Brésil, Suisse, Israël, Autriche, Corée du Sud, Belgique, Russie, Espagne, Turquie, Norvège et Canada sont catégorisés comme principaux exportateurs. Lire à ce sujet Groupe de Recherche et d'information sur la Paix et la Sécurité et Institut de Hautes internationales et du développement, Genève, Annuaire sur les armes légères 2011, Bruxelles, GRIP, 2011. Lire aussi, à ce titre, ALI ABDOU, Daoud, Réguler le commerce des armes. Utopie d'un monde sans violence, Couleurs-Livre, Charleroi 2012, 60 p. et WERY, Michel et ADAM, Bernard, Armes légères. Destructions massives. 640 millions d'armes légères dans le monde, 500000 morts par an, Bruxelles, GRIP - éd. Complexe, 111 p.

${ }^{883}$ WERY, Michel, «Lutter contre les armes légères : un moyen de prévention », in SCHMITZ, Marc (coord.), La guerre. Enfants admis, Grip -éditions Complexe, Bruxelles 2001, p. 175.

${ }^{884}$ Lire SCHMITZ, Marc, « art.cit. », in SCHMITZ, Marc (coord.), op.cit., p. 23.

${ }^{885}$ HABIBU, Jean Bosco op.cit, p. 62.
} 


\section{LES ENFANTS SOLDATS DANS LE MONDE}

\section{- Pays où des personnes de moins de 18 ans sont utilisées illégalement par des groupes et des forces armés quelle que soit la fonction qu'elles}

\section{y exercent}

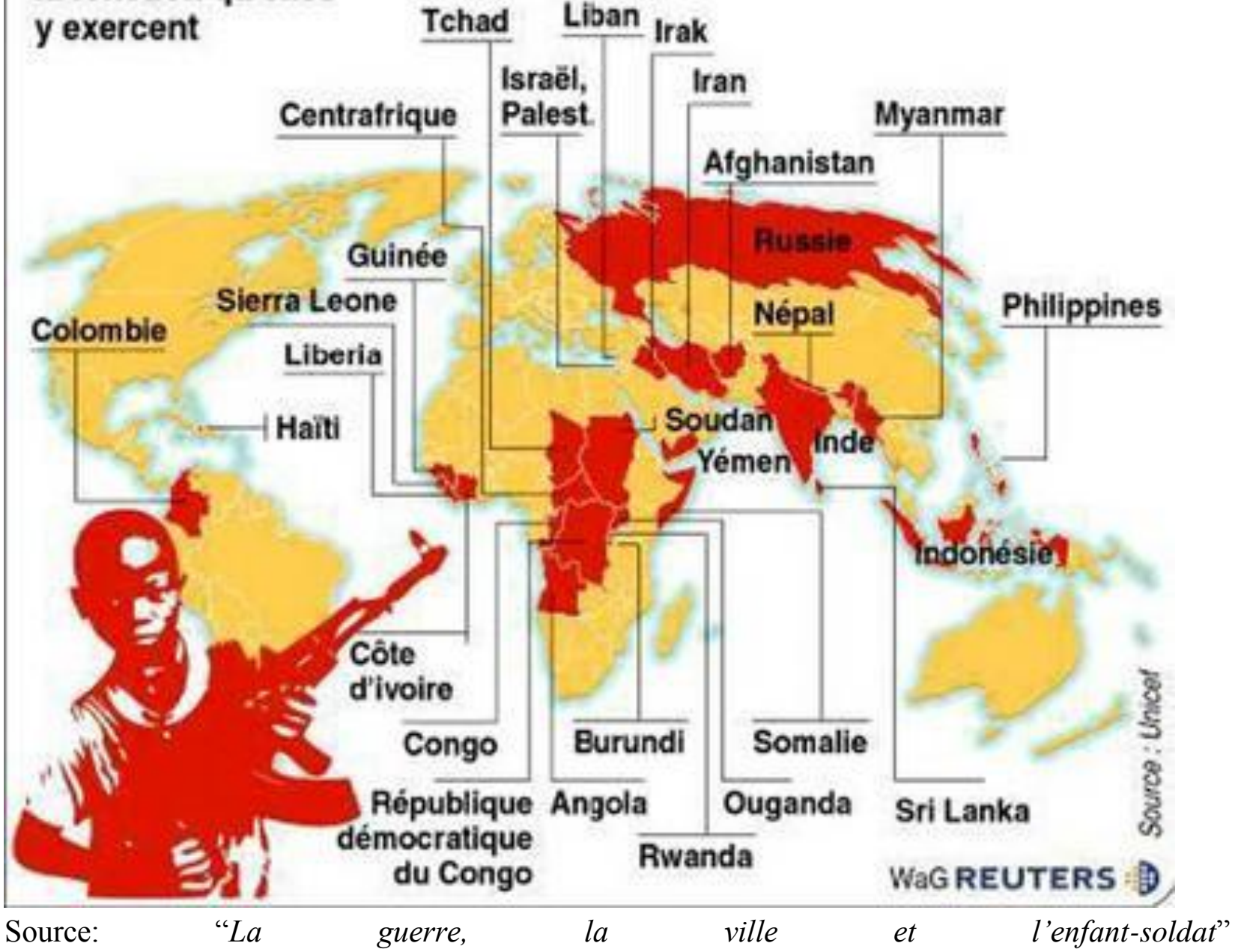

https://sites.google.com/site/geographievilleenguerre/la-guerre-la-ville-et/la-guerre-la-ville-et-lenfant-soldat (Source consultée le 22 décembre 2013).

\section{Section II Les instruments juridiques applicables}

Seuls les instruments juridiques du DIH $(\S 1)$ ne sauraient assurer une protection efficace des enfants en situation de conflits armés. Un complément important leur est assuré par le DIDH.

Ainsi, point n'est besoin de rappeler que le DIDH assure la protection de l'être humain en toutes circonstances, c'est-à-dire en temps de paix comme en temps de conflits armés, de troubles ou tensions internes, ou autres circonstances similaires ${ }^{886}$. Par conséquent, la présente section intégrera des instruments juridiques pertinents du DIDH relatifs à la protection de l'enfant. D'autres branches du droit international public, dont le DIPé et le droit onusien et le DIH

\footnotetext{
${ }^{886}$ CIJ, Avis consultatif sur la licéité de la menace ou de l'emploi de l'arme nucléaire, 8 juillet 1996, Recueil
} $1996, \S 25$. 
coutumier, se préoccupant également des questions de protection des enfants en conflits armés n’y seront point écartées.

En effet, de même que le DIH accorde une protection générale relayée de celle spéciale à l'enfant en situation de conflits armés, le DIDH offre également une protection générale à l'enfant en tant qu'être humain et une protection particulière ou spéciale en raison de sa vulnérabilité au plan physique, mental ou psychique. C'est donc le bien-être de l'enfant qui doit être recherché par ses protecteurs. C'est justement dans cette optique que différents instruments juridiques ont été adoptés pour assurer une protection approriée ou spécifique à l'enfant dans différentes situations dans lesquelles il se retrouve à côté de nombreux instruments juridiques généraux des droits de l'Homme. Une raison de plus pour rendre les droits de l'enfant plus visibles que disparates dans différents instruments généraux. C'est ici l'importance d'examiner la CDE, son Protocole facultatif sur l'implication d'enfants dans les conflits armés $(\$ 2)$ et la Charte africaine des droits et du bien-être de l'enfant ( $\$ 4)$ dans l'optique de la protection des enfants en situation de conflits armés. Sans oublier la Convention de l'OIT $\left(\mathrm{N}^{\circ} 182\right)$ concernant l'interdiction des pires formes de travail des enfants et l'action immédiate en vue de leur élimination (§3). Dans le même ordre d'idées, le Statut de Rome portant création de la CPI sera également étudié (\$5) mais également les résolutions de l'ONU (§6) se rapportant aux enfants et le DI coutumier applicable (§7). Enfin, un intérêt sera réservé au Soft-Law dans ce domaine (\$8).

Soucieux de vouloir éradiquer le «phénomène enfants soldats », ces instruments se préocupent de protèger l'enfant de ce fléau. En outre, ils rappellent aux Etats parties l'obligation de respecter et de faire respecter les règles du DIH applicables aux enfants en situation de conflits armés et d'assurer leur protection par des mesures appropriées (voy. notamment la CDE, art.38, §§ 1 et 4). Une manière de renforcer la protection de l'enfant en situation de conflits armés amorcée par les $\mathrm{CG}$ et leurs PA.

\section{§1. Les Conventions de Genève du 12 août 1949 et leurs protocoles additionnels du 08 juin 1977}

Le $X^{\mathrm{e}}$ siècle demeure d'un apport très significatif dans l'histoire de la protection de l'enfant. Avant d'être appréhendée par des règles contraignantes du droit, la protection de l'enfant a été l'objet du soft-law. Ainsi, l'histoire (cf. supra) rappelle différentes déclarations qui ont eu pour champ d'intérêt la protection de l'enfant. L'on cite notamment la déclaration des ONG britannique «Save the Children » et suédoise «Rädda Barnen » qui aboutit à la «Déclaration de Genève » adoptée par l'Assemblée générale de la SdN le 26 septembre 1924. Avec l'ONU, il y a eu la "Déclaration des droits de l'enfant» du 20 novembre 1959 adoptée à l'unanimité par l'AG/NU dans sa résolution 1386 (XIV). D'autres textes de l'AG/NU ont été par la suite adoptés dont la «Déclaration sur la protection des femmes et des enfants en période d'urgence et de conflit armé » du 14 décembre 1974. Ces instruments ont le mérite d'insister sur la protection spéciale de l'enfant. En revanche, ils demeurent sans valeur juridique contraignante. Ils insistent sur la protection de l'enfant sous l'angle de droit des droits de l'homme et se préoccupent plus de l'enfant non-combattant et non de l'enfant combattant ou enfant soldat.

Les instruments à valeurs juridiques contraignantes qui vont marquer davantage l'histoire de la 
protection de l'enfant sont d'abord l'œuvre du DIH. Ceux-ci se préoccupent, comme l'on peut bien s'attendre, à la protection de l'enfant en période des hostilités. Il s'agit d'une protection générale (A) pour l'enfant qui ne prend pas ou plus part aux hostilités. Donc de l'enfant considéré comme membre de la population civile. Et de la protection spéciale au regard de la vulnérabilité particulière de l'enfant en temps de conflits armés (B). Suivant ces deux types de protection, sera également prise en compte la question de l'enfant qui participe aux hostilités car il ne demeure pas moins enfant malgré le fait d'être combattant. Les instruments juridiques contraignants de droits de l'Homme viendront également s'insérer dans cette logique de protection générale et spéciale de l'enfant en temps de paix et en temps de conflits armés (cf. infra).

\section{A. La protection générale de l'enfant en situation de conflits armés dans les Conventions de Genève du 12 août 1949 et leurs Protocoles additionnels du 08 juin 1977}

La protection générale de l'enfant sera abordée en fonction de l'enfant civil (A.1) et de l'enfant « combattant » ou enfant soldat (A.2).

\section{A. 1. - Enfant civil}

«Lors d'un conflit armé - qu'il soit international ou non - l'enfant bénéficie de la protection générale accordée par le DIH aux personnes civiles qui ne participent pas aux hostilités ${ }^{887}$ ». Ceci s'avère tout à fait logique et légitime car avant d'être vu sous l'angle de ses situations particulières - vulnérabilité d'ordre physique, psychique ou mental - l'enfant est d'abord à classifier parmi les personnes, et dans le cadre de conflits armés, parmi les personnes civiles. Il pourrait éventuellement être perçu comme combattant, lorsqu'il prend part aux hostilités. Même là, il lui sera au départ accordé une protection générale au même titre que tous les autres combattants avant de s'atteler sur ce qui lui est spécifique en pareilles circonstances afin de lui faire bénéficier de la protection spéciale (cf. infra). Cette protection générale de l'enfant comme personne civile est l'œuvre de la CG IV.

En effet, le champ d'application rationae personae de la CG IV se rapporte essentiellement aux «personnes protégées » telles que définies par l'article 4 de cet instrument : "Sont protégés par la convention les personnes qui, à un moment quelconque et de quelque manière que ce soit, se trouvent, en cas de conflit ou d'occupation, au pouvoir d'une partie au conflit ou d'une Puissance occupante dont elles ne sont pas ressortissantes. Les ressortissants d'un Etat qui n'est pas lié par la convention ne sont pas protégés par elle. Les ressortissants d'un Etat neutre se trouvant sur le territoire d'un Etat belligérant et les ressortissants d'un Etat co-belligérant ne seront pas considérés comme des personnes protégées aussi longtemps que l'Etat dont ils sont ressortissants aura une représentation diplomatique normale auprès de l'Etat au pouvoir duquel ils se trouvent. $[\ldots] »$.

La définition des «personnes protégées » fournie par cet article se diffère de celle qui figure dans d'autres CG. Elle vise essentiellement les personnes qui se trouvent «au pouvoir d'une partie au conflit ou d'une Puissance occupante dont elles ne sont pas ressortissantes » (article 4, alinéa $1^{\mathrm{er}}$

\footnotetext{
${ }^{887}$ MARTIN CHENUT, Kathia, «art.cit», in SOREL, Jean-Marc et POPESCU, Corneliu-Liviu (dir.), op.cit., p.173.
} 
de la CG IV). Ainsi, au regard du titre III de la CG IV, deux catégories de personnes s'y trouvent concernées: les ressortissants ennemis sur le territoire de chacune des parties au conflit et l'ensemble des personnes se trouvant dans les territoires occupés, à l'exception de celles ayant la nationalité de la puissante occupante ${ }^{888}$. Ce critère de nationalité a été appréhendé de manière non exclusive et plus souple par la jurisprudence notamment du TPIY. Ce dernier envisageait le critère d'allégeance qui rendait la situation «des personnes protégées » moins absurde ou chaotique en cas d'internationalisation des conflits armés internes. A ce titre, la Chambre de première instance du TPIY conclura :

\begin{abstract}
«En tenant compte du bien-fondé relatif des approches basées sur les notions de "lien effectif' et d'"agent", la présente Chambre de première instance souhaite insister sur la nécessité d'envisager de façon plus souple les conditions posées par l'article 4 de la IVe Convention de Genève. En cas de succession d'États violente, le droit interne de la nationalité ne peut décider si les personnes happées dans des conflits découlant de tels événements sont protégées ou non. Le Commentaire de la IVe Convention de Genève nous impose de garder à l'esprit que "les Conventions sont faites avant tout pour protéger des individus et non pas pour servir les intérêts des États; la présente Chambre de première instance est donc d'avis que les Conventions devraient couvrir le plus grand nombre de personnes possible. Il serait en effet contraire à l'intention du Conseil de sécurité, dont le souci était de faire face effectivement à une situation qui, estimait-il, constituait une menace pour la paix et la sécurité internationales, et de mettre un terme aux souffrances de toutes les personnes prises dans le conflit, que le Tribunal international refuse à un groupe de personnes le bénéfice de la IVe Convention de Genève uniquement sur la base du droit interne de la nationalité ${ }^{889}$.
\end{abstract}

Ainsi, l'application du critère de nationalité en situation notamment de CANI internationalisé aura pour conséquence un traitement discriminatoire. En d'autres termes, une inégalité de traitement pour des personnes civiles se trouvant dans une situation identique. Ces conséquences fâcheuses pourront être évitées en envisageant un critère plus englobant et plus protecteur : critère d'allégeance ${ }^{890}$. Le critère de nationalité n'étant finalement plus exclusif en pareilles circonstances, celui d'allégeance permettra d'étendre la protection aux personnes civiles pour des violations qui pourraient être commises par les parties dont elles sont originaires.

Il est important de faire observer, de ce qui précède, que l'article 4 de la CG IV atteste de l'empreinte de la «conception souverainiste» des Etats. Et ce, en dépit du fait que les instruments du DIH servent primordialement de la protection des victimes et non des intéréts propres des Etats. Une telle conception tendrait à considérer que l'Etat est libre de traiter ses ressortissants comme il entend. Et logiquement cependant, il ne se permettrait pas de tout à l'égard des ressortissants ennemis (ou étrangers) à son pouvoir. Ressortissants auxquels il doit protection. Cette tendance qui a prévalu au moment de l'adoption des CG, a été progressivement abandonnée. En effet, sous l'influence de ratification des conventions des droits de l'homme, notamment le pacte international relatif aux droits civils et politiques et de la jurisprudence

\footnotetext{
${ }^{888}$ Lire MOMTAZ, Djamchid, «Les défis des conflits armés asymétriques et identitaires au droit international humanitaire », in MATHESON, Michael J. et MOMTAZ, Djamchid, op.cit., 17. Voy. aussi KOLB, Robert, Ius in bello. Le droit international des conflits armés, $2^{\mathrm{e}}$ édition, op. cit., pp. 365-366.

${ }^{889}$ TPIY, Le Procureur c. Zejnil Delalic et al., Affaire $\mathrm{N}^{\circ} \mathrm{IT}-96-21$, Chambre de première instance, jugement du 16 novembre 1998, p.108, § 263.

${ }^{890}$ Lire MOMTAZ Djamchid, «Les défis des conflits armés asymétriques et identitaires au droit international humanitaire », in MATHESON, Michael J. et MOMTAZ, Djamchid, op.cit., pp. 22-23.
} 
internationale qui en résultait, le principe de non-discrimination en termes de protection des personnes en temps de paix et de conflits armés a eu de l'ascendance ${ }^{891}$. C'est dans ce sens que les rédacteurs du PA I se sont efforcés d'étendre l'applicabilité de certaines dispositions protectrices aux propres ressortissants des parties au conflit armé ainsi qu'aux personnes relevant de leur juridiction. Les exceptions à ce sujet sont expressément énumérées (cf. par exemple, l'article 78 du PA I consacré à l'évacuation des enfants.) ${ }^{892}$.

Toutefois, il sied de retenir que la CG IV pose un régime de protection essentiellement réservé aux «personnes protégées » telles que définies par l'article 4. Ce qui pourrait être considéré comme une sorte de droit restreint ou spécial à côté d'un régime général ou de droit commun institué au titre II de ladite Convention et profitable à la fois aux personnes protégées au sens de l'article 4 qu'à l'ensemble de la population civile sans aucune distinction de caractère défavorable fondée notamment sur la nationalité. Ce qui reste d'ailleurs développé par le PA comme signifié ci-avant et entrepris dans le cadre du PA II pour ce qui est de CANI.

De ce qui précède, considéré comme une personne qui ne prend pas part aux hostilités et se trouvant au pouvoir d'une partie au conflit ou d'une Puissance occupante, l'enfant bénéficie d'un ensemble de dispositions des CG et des PA. Lesquelles dispositions imposent généralement aux parties de réserver à l'enfant, à l'instar d'autres personnes civiles, un traitement humain. Traitement humain, concept pour lequel d'ailleurs «Toutes les 3 chambres du TPIR ont eu à décider, souvent à l'unanimité, que l'une des conséquences de la règle de traitement humain réside dans la nécessité de fournir une protection renforcée aux catégories de personnes civiles qui subissent, d'une façon particulièrement grave, les effets des conflits armés et qui se retrouvent, de ce fait, dans une situation de grande détresse ${ }^{893}$.

Le traitement humain en faveur de l'enfant doit être entrepris en toutes circonstances. L'enfant doit être protégé contre tout acte pouvant porter atteinte à sa vie et à son intégrité physique et morale. L'article 27 de la CG IV s'exprime très clairement à ce sujet de la manière suivante :"Les personnes protégées ont droit, en toutes circonstances, au respect de leur personne, de leur honneur, de leurs droits familiaux, de leurs convictions et pratiques religieuses, de leurs habitudes et de leurs coutumes. Elles seront traitées, en tout temps, avec humanité et protégées notamment contre tout acte de violence ou d'intimidation, contre les insultes et la curiosité publique. [...] Compte tenu des dispositions relatives à l'état de santé, à l'âge et au sexe, les personnes protégées seront toutes traitées par la partie au conflit au pouvoir de laquelle elles se trouvent, avec les mêmes égards, sans aucune distinction défavorable, notamment de race, de religion ou d'opinions politiques. [...]." L'hypothèse de renonciation partielle ou totale des droits reconnus aux personnes civiles est absolument exclue au régard de l'article 8 de la Convention sous examen.

La CG IV contient de nombreuses dispositions assurant la protection des personnes civiles notamment le titre II qui se rapporte à la Protection générale des populations contre certains

\footnotetext{
891 MOMTAZ Djamchid, «Les défis des conflits armés asymétriques et identitaires au droit international humanitaire », in MATHESON, Michael J. et MOMTAZ, Djamchid, op.cit., pp. 17-20.

892 Ibid., p. 18.

${ }^{893}$ BIRUKA, Innocent, op.cit., p. 217.
} 
effets de la guerre où des mesures de protection de l'ensemble des populations des pays en conflit sont envisagées (De l'art. 13 à l'art. 26 de la CG IV). Il y a également le troisième titre de la CG IV qui traite de Statut et traitement des personnes protégées (De l'art. 27 à l'art.141 de la CG IV). Dans cette grande partie de la Convetion, sont examinés notamment les situations des étrangers sur le territoire d'une partie au conflit; les cas des personnes protégées qui se trouvent dans un territoire occupé; les règles relatives au traitement des internés, etc. L'on retrouve dans ces règles qui traitent des situations des personnes civiles celles spécifiquement liées à la situation des enfants qui feront objet d'examen ultérieurement. Cette protection générale des personnes est complétée au niveau des PA. C'est ainsi par exemple que le PA I assure la protection des bléssés, malades et naufragés et renforce la CG IV au sujet de la protection générale de la population civile contre les effets des hostilités. L'on retrouve pour la première fois ce que l'on peut entendre par "personne civile" ou "population civile". Des précisions sont données par rapport aux biens de caractère civil qui ne doivent pas faire objet d'attaques. Lesquelles doivent être limitées aux objectifs militaires. Des mesures de précaution sont également prévues à l'endroit des civils (Chapitre 4). Il est demandé aux belligérants de veiller à épargner la population civile, les personnes civiles et les biens civils dans la conduite des opérations militaires. Il est consacré également un chapitre (Chapitre 6) entier à la Protection civile qui s'entend de l'accomplissement de toutes les tâches humanitaires, ou de plusieurs d'entre elles [...] destinées à protéger la population civile contre les dangers des hostilités ou des catastrophes et à l'aider à surmonter leurs effets immédiats ainsi qu'à assurer les conditions nécéssaires à sa survie. [...].” Tant bien d'autres dispositions se rapportent à la protection des civils. Tout ceci reste donc profitable à l'enfant en tant que personne civile.

La protection des civils n'est point un appanage des CAI. Dans le cadre des CANI, l'article 3 commun aux CG se préoccupe également d'une protection minimale à l'endroit des personnes qui ne participent pas directement aux hostilités dont les membres des forces armées qui ont déposées les armes et les personnes mises hors combat pour de raison de maladie, blessure ou détention ou pour toute autre cause. Ces personnes seront donc traitées avec humanité (cf. supra). Le PA II qui complète l'article 3 précité, réserve un titre relatif au traitement humain, un autre en rapport avec la protection et les soins à administrer aux blessés, malades et auffragés et un autre titre lié à la protection de la population civile.

En conclusion, dans le conflit armé international ou non international, les enfants comme personnes civiles seront protégés contre des atteintes à la vie, à la santé, au bien-être physique ou psychique et à la dignité humaine - par l'interdiction de l'assassinat, de la torture, de la mutilation des personnes ou encore de tout acte de brutalité ou traitement humiliant ou dégradant ${ }^{894}$ et par l'assurance de diverses garanties pénales ${ }^{895}$.

\section{A. 2. Enfant soldat}

Au sujet de la protection générale des enfants « combattants » ou enfants soldats, « [d]ans un conflit armé international, lorsque les enfants sont enrôlés et participent aux hostilités, ils

\footnotetext{
${ }^{894}$ Voy. GASSER, Hans-Peter, « Protection of the civilian population », « art. cit.», pp. 216-217.

${ }^{895}$ MARTIN CHENUT, Kathia, « art.cit », in SOREL, Jean-Marc et POPESCU, Corneliu-Liviu (dir.), op.cit., p. 168.
} 
bénéficient au moins des mêmes droits que les autres membres des forces armées : le droit au statut de combattant et son corollaire, le droit au statut de prisonnier de guerre ${ }^{896}$. «En revanche, s'ils sont membres des milices ou groupes armés, ils doivent respecter les conditions définies par l'article 4 de la Convention III de Genève ${ }^{897}$, ou au moins celles consacrées par l'article $44 \mathrm{du}$ Protocole $\mathrm{I}^{898}{ }_{\gg}^{899}$ afin de bénéficier de ces droits. Statuts inexistants en conflit armé non international mais signifiant nullement l'absence totale de traitement équivalent. Bien plus, toutes les règles liées à la conduite des hostilités applicables tant en CAI qu'en CANI leur seront également d'application. Ainsi, des principes tels que nécessité militaire, proportionnalité, interdiction des maux superflus applicables en DIH limiteraient certains dégâts à l'encontre de l'enfant participant directement aux hostilités, à l'instar de tout combattant. Il ne pourrait donc pas être tué n'importe comment ${ }^{900}$. «Dès lors, il faudrait selon les dires de Jean PICTET, capturer plutôt que blesser les combattants, blesser plutôt que tuer ${ }^{901}$. Que dire alors de la protection spéciale de l'enfant en situation de conflits armés?

\section{B. La Protection spéciale de l'enfant en situation de conflits armés dans les Conventions de Genève du 12 aout 1949 et leurs Protocoles additionnels du 08 juin 1977 : enfant civil et enfant soldat}

Préalablement à l'examen de la protection spéciale de l'enfant civil (B.2) et de l'enfant soldat (B.3) en situation de conflits armés, le présent point traitera du fondement même de cette protection spéciale (B.1).

\footnotetext{
${ }^{896}$ AIVO, Gérard, AIVO, Gérard, Le Statut de combattant dans les conflits armés non internationaux, Bruylant, Bruxelles, 2013, p. 240.

${ }^{897}$ Art. 4 de la CG III: «A. Sont prisonniers de guerre, au sens de la présente convention, les personnes qui, appartenant à l'une des catégories suivantes, sont tombées au pouvoir de l'ennemi :

1) les membres des forces armées d'une partie au conflit, de même que les membres des milices et des corps de volontaires faisant partie de ces forces armées ;

2) les membres des autres milices et les membres des autres corps de volontaires, y compris ceux des mouvements de résistance organisés, appartenant à une partie au conflit et agissant en dehors ou à l'intérieur de leur propre territoire, même si ce territoire est occupé, pourvu que ces milices ou corps de volontaires, y compris ces mouvements de résistance organisés, remplissent les conditions suivantes :
}

a) d'avoir à leur tête une personne responsable pour ses subordonnés ;

b) d'avoir un signe distinctif fixe et reconnaissable à distance ;

c) de porter ouvertement les armes

d) de se conformer, dans leurs opérations, aux lois et coutumes de la guerre ; (..)»

${ }^{898}$ Art.44 \$3 du PA I : «Pour que la protection de la population civile contre les effets des hostilités soit renforcée, les combattants sont tenus de se distinguer de la population civile lorsqu'ils prennent part à une attaque ou à une opération militaire préparatoire d'une attaque. Etant donné toutefois, qu'il y a des situations dans les conflits armés où, en raison de la nature des hostilités, un combattant armé ne peut se distinguer de la population civile, il conserve son statut de combattant à condition que, dans de telles situations, il porte ses armes ouvertement :

a) pendant chaque engagement militaire; et

b) pendant le temps où il est exposé à la vue de l'adversaire alors qu'il prend part à un déploiement militaire qui précède le lancement d'une attaque à laquelle il doit participer. (...) »

${ }^{899}$ AIVO, Gérard, Le Statut de combattant dans les conflits armés non internationaux, op.cit., pp. 236-237.

${ }^{900}$ Lire GAGGIOLI, Gloria, L'influence mutuelle entre les droits de l'homme et le droit international humanitaire à la lumière du droit à la vie, éd. A. Pedone, Paris, 2013, pp. 253-255.

${ }^{901}$ Ibid., p. 254. 


\section{B. 1. Fondement de la Protection spéciale de l'enfant}

«L'expérience de la [seconde Guerre Mondiale] avait tragiquement souligné le besoin de règles conventionnelles pour la protection de l'enfance. Des dizaines de milliers d'enfants ont été séparés de leurs parents, déportés, astreints au travail forcé, enrôlés dans les armées, faits prisonniers de guerre. Cette situation est particulièrement douloureuse pour l'enfant qui est irresponsable et «neutre »du fait de son âge ${ }^{902}$. Et compte tenu de cette pire expérience de la guerre, il était temps d'insérer différents principes et règles de protection de l'enfance en période de conflits armés dans la Convention sur la protection des civils ${ }^{903}$.

Le projet de Convention pour la protection des enfants en situation de conflit armé élaboré en 1939 par le CICR et l'Union Internationale de Secours aux Enfants est la source de la protection spéciale des enfants. L'échec d'adoption de ce texte du fait de la survenance de la seconde guerre mondiale a occasionné que ses dispositions soient reprises par le CICR pour servir de la protection spéciale des enfants dans la CG IV. Par ailleurs, s'il est vrai que la CG IV contient différentes dispositions relatives à la protection spéciale des enfants en période de conflits armés, toutefois, cet instrument conventionnel n'énonce nullement le principe fondant une telle protection spéciale en faveur des enfants ${ }^{904}$. Cette lacune est comblée par les deux PA. Le PA I consacre ce principe en son article $77 \S 1$ en ces termes : «Les enfants doivent faire l'objet d'un respect particulier et doivent être protégés contre toute forme d'attentat à la pudeur. Les parties au conflit leur apporteront les soins et l'aide dont ils ont besoin du fait de leur âge ou pour toute autre raison ». Pour sa part, le PA II l'énonce en son article $4 \S 3$ de manière suivante : «Les enfants recevront les soins et l'aide dont ils ont besoin [...]». Ceci s'apparente également à la précision qu'apportait la Déclaration des droits de l'enfant du 20 novembre 1959 au sujet du sens de la protection spéciale de l'enfant en son préambule ${ }^{905}$ (cf. supra). Rappelons qu'en DIDH en général, la reconnaissance des droits spécifiques à l'enfant se fonde également sur son manque de maturité physique et psychique. Et comme l'exprime mieux Dominique YOUF, « [1]'enfant est différent de nous, il est vulnérable et inachevé, c'est la raison pour laquelle il doit bénéficier du statut protecteur de mineur ${ }^{906}$.

Ainsi, outre la protection de l'enfant en général en tant que civil en CAI ou comme personne ne prenant pas part aux hostilités dans le cadre des CANI contre les atteintes à la vie, à la santé, au bien-être physique ou psychique et à la dignité humaine - par l'interdiction de l'assassinat, de la torture, de la mutilation des personnes ou encore de tout acte de brutalité ou traitement humiliant

\footnotetext{
902 LA PRADELLE, Paul de, La conférence diplomatique et les Nouvelles Conventions de Genève du 12 août 1949, Les éditions internationales, Paris, 1951, pp. 82-83.

${ }^{903}$ Ibid., p. 83.

${ }^{904}$ PLATTNER, Denise, « La protection de l'enfant dans le droit international humanitaire », « art.cit », p. 150; SINGER, Sandra, «La protection des enfants dans les conflits armés », « art.cit. », p. 145 ; MARTIN CHENUT, Kathia, « art.cit», in SOREL, Jean-Marc et POPESCU, Corneliu-Liviu (dir.), op.cit., p. 172.

905 Le troisième considérant du préambule de la Déclaration des droits de l'enfant du 20 novembre 1959 indiquait : «Considérant que l'enfant, en raison de son manque de maturité physique et intellectuelle, a besoin d'une protection spéciale et de soins spéciaux, notamment d'une protection juridique appropriée, avant comme après la naissance ». Voy. la Déclaration des droits de l'enfant du 20 novembre 1959, la Résolution 1386 (XIV) du 20 novembre 1959, in http://www.un.org/french/documents/ga/res/14/fres14.shtml (Source consultée le 15 juillet 2016). ${ }^{906}$ YOUF, Dominique, Penser les droits de l'enfant, op. cit., pp. 94-95.
} 
ou dégradant et par l'assurance de diverses garanties pénales - les enfants bénéficient du régime de protection spéciale en raison de leur vulnérabilité particulière ${ }^{907}$. A ce titre, le DIH se réfère «à plusieurs reprises à l'âge de quinze ans comme âge limite au dessous duquel l'enfant doit jouir d'une protection spéciale. Il est généralement admis qu'au-dessus de quinze ans le développement des facultés de l'enfant sont telles que des mesures spéciales ne s'imposent pas systématiquement avec la même nécessité ${ }^{908}$.

Ainsi de ce qui précède, accorder une protection spéciale aux enfants ne s'avère nullement discriminatoire d'autant que cette protection spéciale se justifie face à une situation de vulnérabilité particulière dans laquelle se trouve l'enfant. «La prise en considération des vulnérabilités est [donc] susceptible d'introduire soit une différenciation [...], soit une hiérarchie dans la protection ${ }^{909}$. Des juridictions des droits de 1'homme le justifient d'ailleurs. Dans son avis consultatif $n^{\circ} 17$ de 2002 sur la « condition juridique et les droits humains de l'enfant », la Cour interaméricaine des droits de l'homme a admis que le principe d'égalité reconnu par l'article 24 de la Convention américaine des droits de l'homme ${ }^{910}$ n'empêche pas l'adoption des règles et mesures spécifiques aux enfants. Le traitement différent dont ils bénéficient n'est pas per se discriminatoire. Certaines inégalités de fait peuvent légitimement se traduire dans les inégalités de traitement ${ }^{911}$. Ce qui s'avère donc logique.

En revanche, vouloir traiter identiquement un enfant, personne se trouvant en situation de vulnérabilité particulière, qu'un adulte n'est rien d'autre que de la discrimination. Cette logique de raisonnement est non moins admissible en DIH. Ce dernier reconnaît d'ailleurs le principe de non-discrimination tel que formulé par les instruments de droits de l'homme ${ }^{912}$.

Le DIH tend, par un tissus de règles très dense, à assurer à l'individu placé, par les circonstances de la guerre, au pouvoir de son ennemi, une vie aussi normale que possible compte tenu des impératifs militaires. La protection, là, tend tout d'abord, bien sûr, à prévenir les atteintes physiques ou psychiques, mais elle a également l'ambition, plus étendue, de préserver une certaine qualité de la vie ${ }^{913}$. Différentes dispositions des CG et PA consacrent la protection spéciale à l'enfant civil ou soldat.

\section{B. 2. Protection spéciale de l'enfant civil}

Différentes dispositions conventionnelles, ici analysées, obligent les parties au conflit armé d'assurer une protection spéciale à l'enfant civil. Celui-ci est considéré comme un élément le plus « innocent » de la population civile ${ }^{914}$, une des « catégories de civils les plus vulnérables et les

\footnotetext{
${ }^{907}$ MARTIN CHENUT, Kathia, « art.cit», p. 168.

${ }^{908}$ DUTLI, Maria Teresa, «Enfant-combattants prisonniers », « art. cit. », p. 458.

909 RUET, Céline, «La vulnérabilité dans la jurisprudence de la Cour européenne des droits de l'homme », in $R T D H(102 / 2015)$, p. 338.

910 Article 24 : «Toutes les personnes sont égales devant la loi. Par conséquent elles ont toutes droit à une protection égale de la loi, sans discrimination d'aucune sorte ».

${ }_{911}$ MARTIN CHENUT, Kathia, « art.cit», p.173.

${ }^{912}$ Lire TIGNINO, Maria, L'eau et la guerre. Eléments pour un régime juridique, op. cit., pp. 216 et 294. Lire par exemple à ce sujet les articles 3 \$1 commun aux CG, 27 alinéa 3 de la CG IV ou 75 \$1 du PA I.

913 SANDOZ, Yves, «La notion de protection dans le droit international humanitaire et au sein du Mouvement de la Croix-Rouge », « art. cit. », p. 977.

${ }^{914}$ LA PRADELLE, Paul de, La conférence diplomatique et les Nouvelles Conventions de Genève du 12 août
} 
plus dignes de protection et d'assistance ${ }^{915}$. Il est donc plus civil que d'autres et devrait par conséquent mériter plus d'attention ${ }^{916}$. En termes d'obligations pour assurer cette protection spéciale, il incombe aux parties au conflit de créer sur leurs propres territoires ou sur les territoires occupés des zones et localités sanitaires et de sécurité afin de mettre les enfants de moins de quinze ans à l'abri des effets de la guerre ${ }^{917}$; d'entreprendre l'évacuation des enfants d'une zone assiégée ou encerclée ${ }^{918}$; de créer le libre passage de tout envoi des vivres indispensables, des vêtements et des fortifiants réservés aux enfants de moins de quinze ans ${ }^{919}$; de prendre les mesures nécessaires au profit des enfants de moins de quinze ans, orphelins ou séparés des familles du fait de la guerre, pour que soient facilités leur entretien, la pratique de leur religion et leur éducation ${ }^{920}$; d'accueillir les enfants en pays neutre pendant la durée du conflit ${ }^{921}$; de procéder à l'identification des enfants de moins de douze ans ${ }^{922}$, etc. Ajoutons à cette liste, l'intangibilté du statut personnel de l'enfant qui interdit à la Puissance occupante de modifier sa situation de famille, son état civil et sa nationalité (art. 50 §2 de la CG IV).

A propos de zones et localités sanitaires et de sécurité afin de mettre les enfants de moins de quinze ans à l'abri des effets de la guerre, celles-ci combinent les formules de zones et localités sanitaires et de zones et localités de sécurité ${ }^{923}$. En effet, les zones et localités sanitaires sont organisées de manière durable hors de la zone des hostilités pour mettre les blessés et malades (militaires et civils) à l'abri des armes de longue portée et bombardements. Les zones et localités de sécurité servent à la sécurisation des certaines personnes civiles dont la vulnérabilité requiert une protection spéciale (ex : les enfants, les femmes enceintes, les mères d'enfants de moins de sept ans, les vieillards, etc. $)^{924}$. Ces zones précitées diffèrent de zones neutralisées. Ces dernières sont de caractère temporaire, créées non hors de zone de combat mais dans celle-ci pour mettre à l'abri un grand nombre de personnes (Blessés et malades militaires et civils, l'ensemble de la population civile étrangère aux hostilités se trouvant dans cette région) des opérations militaires $^{925}$. Les dispositions consacrant ces zones et localités « sont assez souples pour laisser la voie ouverte à différentes combinaisons possibles » ${ }^{926}$. Cependant, «[1]a création de zones et localités sanitaires et de sécurité ne fait pas l'objet d'une obligation formelle. L'article 14 n'a qu'un caractère facultatif. Toutefois les auteurs de la Convention ont voulu souligner l'importance humanitaire d'un tel système et en préconiser l'adoption pratique ${ }^{927}$. Bien plus, leur « existence juridique » au plan international et «leur protection conventionnelle » dépendent de leur reconnaissance par la partie adverse. D'où, l'importance d'un accord portant

1949, op. cit., p. 186.

915 PICTET, Jean S. (dir.), Commentaire IV, La Convention de Genève relative à la protection des personnes civiles en temps de guerre, op. cit., p. 193.

${ }^{916}$ DAVID, Eric, Principes de droit des conflits armés, $5^{\mathrm{e}}$ édition, op. cit., p. 301

${ }^{917}$ Lire art. 14 de la CG IV.

${ }^{918}$ Lire art. 17 de la CG IV.

${ }^{919}$ Lire art. 23 de la CG IV.

${ }^{920}$ Lire art. $24 \S 1$ de la CG IV.

${ }^{921}$ Lire art. 24 §2 de la CG IV.

${ }^{922}$ Lire art. $24 \S 3$ de la CG IV.

${ }^{923}$ PICTET, Jean S. (dir.), Commentaire IV, La Convention de Genève relative à la protection des personnes civiles en temps de guerre, op. cit., p. 130.

${ }_{924}$ Ibid., p. 129.

${ }^{925}$ Ibid., p. 130.

926 Ibid., p. 135.

${ }^{927}$ Ibid., p. 134. Voy. aussi SANDOZ, Yves, « La notion de protection dans le droit international humanitaire et au sein du Mouvement de la Croix-Rouge », « art. cit. », p. 978. 
reconnaissance de ces zones entre parties $^{928}$.

Portant leur choix sur les enfants de moins de quinze ans et mères d'enfants de moins de sept ans, les auteurs de la CG IV ont estimé que ceci était approprié, raisonnable et généralement en accord avec le développement physique et moral de l'enfance. En dépit de ces raisons, cette limitation révèle non moins «quelque chose d'arbitraire » ${ }^{929}$. C'est également pour ces mêmes raisons que les enfants seront concernés par d'autres dispositions similaires telles que celle en rapport avec l'évacuation d'une zone assiégée ou encerclée (art.17 de la CG IV). Mais la différence est que pour cette dernière disposition, par exemple, il n'y a pas de limite d'âge pour les enfants. Pour le commentaire de la CG IV, «[1]es belligérants intéressés sont libres de se mettre d'accord sur l'âge limite ; toutefois la limite supérieure de 15 ans, retenue pour l'accès à une zone de sécurité, paraît raisonnable et mérite d'être également retenue dans le cas présent ${ }^{930}$. Mais, la tendance actuelle suggérant la protection de l'enfant de moins de dix-huit ans en conflits armés, face à une telle disposition laissant une ouverture, va prévaloir et prise en considération, à notre avis.

La limite d'âge sera encore remarquable au niveau de l'article 24 de la CG IV. Les deux premiers alinéas de cet article se réfèrent à l'âge de moins quinze ans pour l'entretien et l'éducation des enfants orphelins ou séparés de leur famille du fait de la guerre, et leur accueil en pays neutre. Son dernier alinéa se rapporte à l'âge de douze ans pour l'identification de tous les enfants. La décision d'adoption de l'âge limite de douze ans « a été préconisée à Stockholm lors de la XVII Conférence internationale de la Croix-Rouge, qui a estimé qu'à partir de douze ans les enfants étaient généralement capables de témoigner eux-mêmes de leur identité ${ }^{931}$. Suivant la même logique, la référence à l'âge de quinze ans dans différentes dispositions du DIH se justifie par le fait qu'il a été admis que « le développement des facultés, à partir de cet âge, est généralement tel que des mesures spéciales ne s'imposent plus avec la même nécessité » ${ }^{932}$.

S'agissant de vivres indispensables destinés aux enfants de moins de quinze ans méritant le droit au libre passage (art. 23 de la CG IV), il faudrait entendre par là les denrées de première nécessité telles que le lait, la farine, le sucre, le sel, etc. Il s'agit des «aliments de base, nécessaires à la santé et au développement normal physique et psychique ${ }^{933}$ des enfants de moins de quinze ans. Et les fortifiants se composent de «tous les produits pharmaceutiques destinés à rendre à l'organisme humain affaibli sa vitalité normale ${ }^{934}$. Ce droit au libre passage s'appréhende également comme une exception humanitaire face au rapport de blocus pouvant exister notamment entre parties en conflit. Chaque Etat autorisant ce libre passage détient néanmoins un droit de regard sur celui-ci. Il a droit notamment de fixer les modalités techniques de passage, de contrôler les convois, etc. (cf. dernier alinéa de l'art. 23 de la CG IV).

\footnotetext{
${ }^{928}$ PICTET, Jean S. (dir.), Commentaire IV, La Convention de Genève relative à la protection des personnes civiles en temps de guerre, op. cit., p. 137.

${ }^{9} 9$ Ibid., p. 135.

${ }^{930}$ PICTET, Jean S. (dir.), Commentaire IV, La Convention de Genève relative à la protection des personnes civiles en temps de guerre, op. cit., p. 149.

931 Ibid., p. 203.

${ }_{932}$ Ibid., p. 201. Voy. aussi DUTLI, Maria Teresa, «Enfant-combattants prisonniers », « art. cit. », p. 458.

${ }^{933}$ PICTET, Jean S. (dir.), Commentaire IV, La Convention de Genève relative à la protection des personnes civiles en temps de guerre, op. cit., p. 194

${ }^{934}$ Ibid., p. 195.
} 
Toutefois, ce droit au libre passage de vivres indispensables, vêtements et fortifiants, élargi précisément par le PA I (art. 70) notamment sans égard d'âge d'enfants (art. 70 §1) et consacré en DIH coutumier ${ }^{935}$, se trouve fort développé globalement sous les auspices de l'ONU particulièrement de l'AG/NU et du CS/NU à travers le droit à l'assistance humanitaire (cf. supra). Ainsi, différentes résolutions sont adoptées par ces organes demandant aux Etats - parties ou non aux conflits armés - d'accorder un libre passage de secours humanitaires en faveur des civils en général et des enfants en particulier, sans égard de leur âge (cf. infra).

Pour sa part le PA I traite en ce qui concerne les enfants: 1'appartenance à la catégorie des blessés et malades des femmes en couches, des nouveaux nés, les femmes enceintes ( $\operatorname{art.} 8 a$ ) du PA I); la priorité d'accès au secours et le traitement de faveur aux enfants, femmes enceintes ou en couches et les mères qui allaitent (art. $70 § 1$ du PA I); le regroupement des familles dispersées (art. 74 du PA I); la préservation de l'unité familiale en cas d'arrestation, détention ou internement des familles (art.75 §5) voire des garanties fondamentales prévues dans la même disposition dans son ensemble. Il existe également des garanties spécifiques pour les enfants détenus, arrêtés ou internés notamment l'interdiction de l'éxécution d'une condamnation à mort (cf. art. $75 \S 5$ et $77 \S 4$ du PA I; art. $94 \$ 3$ de la CG IV et art. $6 \S 4$ du Protocole II) ${ }^{936}$ et la réglementation d'évacuation des enfants (art. 78).

Enfin, le PA II accorde des garanties fondamentales en son article 4 (équivalent de l'article $75 \mathrm{du}$ PA I ou de l'article 3 commun aux CG) et précise au paragraphe 3 alinéa 3 que la protection spéciale que prévoit ledit article restera applicable aux enfants s'ils prennent directement part aux hostilités et sont capturés. Il s'agit donc d'un traitement humain qui doit leur être réservé.

A propos de l'interdiction de la peine de mort contre des enfants, l'article $77 \S 5 \mathrm{du}$ PA I dispose qu' "une condamnation à mort pour une infraction liée au conflit armé ne sera pas exécutée contre les personnes qui n'avaient pas dix-huit ans au moment de l'infraction». Son équivalent au niveau du PA II qui est l'article $6 \S 4$ indique que « [1] a peine de mort ne sera pas prononcée contre les personnes âgées de moins de dix-huit ans au moment de l'infraction et elle ne sera pas exécutée contre les femmes enceintes et les mères d'enfants en bas âge ». Les deux articles cidessus présentés qui tendent à régir la situation identique de l'enfant bien que dans deux contextes de conflits armés différents se divergent. Le premier retient - en cas de CAI - la condamnation de l'enfant à la peine de mort et exclut en revanche l'exécution d'une telle peine. Le second exclut - dans le cadre d'un CANI - le prononcé de la peine de mort à l'endroit d'un enfant, donc la condamnation, et par conséquent son exécution. En principe, ces deux textes devaient être de la même teneur. Le projet du CICR en lien avec l'article 77 §5 excluait effectivement de «prononcer» la peine de mort contre des personnes âgées de moins de 18 ans au moment de l'infraction. Mais la suggestion d'un délégué, faisant valoir que la législation de

\footnotetext{
${ }^{935}$ Lire avec beaucoup d'intérêt la règle 55, in HENCKAERTS, Jean-Marie et DOSWALD-BECK, Louise, Droit international humanitaire coutumier, Vol. I : Règles, op. cit., pp. 258-267. Voy. aussi PERRAKIS, Stelios, «Le droit international humanitaire et ses relations avec les droits de l'homme. Quelques considérations », in TAVERNIER, Paul et HENCKAERTS, Jean-Marie (dir.), Droit international humanitaire coutumier : enjeux et défis contemporains, «artr. cit. », p. 135. Le PA II ne contient pas une disposition spécifique sur l'accès des organismes de secours humanitaires. Néanmoins, elle exige que des actions de secours humanitaires soient entreprises en faveur de la population civile souffrant de privations excessives, avec le consentement de la Haute Partie contractante concernée (cf. art. 18 \$2 du PA II).

${ }^{936}$ DEYRA, Michel, op.cit., p. 155.
} 
son pays ne permettait pas d'interdire le prononcé de la peine de mort si ce n'est que son exécution, avait été acceptée par la Commission III et la Conférence. Elle sera ainsi prise en compte en texte final ${ }^{937}$.

Une chose est sûre et certaine, tous ces articles se rapportent aux infractions qui sont en lien avec le conflit armé. Ce qui revient à dire que la condamnation ou l'exécution de la peine de mort contre l'enfant pour les types d'infractions qui n'ont aucun lien avec le conflit armé ne sont donc logiquement pas exclues. Elles restent du ressort de l'ordre pénal applicable.

Toutefois, on retrouve également une telle disposition pour les «personnes protégées». Il est dit à l'alinéa 4 de l'article 68 de la CG IV qu' «[e]n aucun cas la peine de mort ne pourra être prononcée contre une personne protégée âgée de moins de dix-huit ans au moment de l'infraction ». Les lettres de cette disposition accordent une protection plus large que celles précédentes. Il s'agit de l'interdiction du prononcé de la peine de mort et par conséquent de son exécution à l'égard des "personnes protégées » âgées de moins de dix-huit ans dans tous les cas. En effet, cette interdiction ne spécifie pas que l'infraction commise soit en lien avec le conflit armé. Ceci est symbolisé par les termes «[e]n aucun cas ». L'on pourrait donc dire qu'en période de CAI, l'infraction commise par la personne protégée âgée de moins de dix-huit ans, en lien ou non avec le conflit armé, ne pourra être punie de la peine de mort. Suivant l'Union internationale de protection de 1'Enfance, auteure de cette proposition à la XVII ${ }^{\mathrm{e}}$ Conférence internationale de la Croix-Rouge, l'âge limite de 18 ans était une limite absolue, un âge de discernement en dessous duquel «l'individu [...] ne mesure pas toujours la portée de ses actes et agi souvent sous l'influence d'autrui, si ce n'est sous la contrainte ${ }^{938}$. Ce qui est du reste valable à ce séjour.

Et il se dégage qu'en dépit de la protection accordée par le PA I qui s'étend aux «personnes protégées » de manière non discriminatoire, sans tenir compte des critères défavorables dont la nationalité, la CG IV paraît plus avantageuse sous cet angle.

Par ailleurs, poursuivant l'article $6 \S 4$ du PA II, il y a interdiction d'exécution de la peine de mort contre des femmes enceintes et des mères d'enfants en bas âge et non la condamnation. « Le but de l'interdiction d'exécuter la peine de mort prononcée contre une femme enceinte est de protéger l'enfant à naître, non pas la femme elle-même; c'est pourquoi l'interdiction de prononcer la peine de mort [contre la femme] n'a été prévue ${ }^{939}$. L'on retrouve également au niveau du PA I une disposition similaire. Il s'agit du paragraphe 3 de l'article 76. Cet article dispose: « [d]ans toute la mesure du possible, les parties au conflit s'efforceront d'éviter que la peine de mort soit prononcée contre les femmes enceintes ou les mères d'enfants en bas âge dépendant d'elles pour une infraction commise en relation avec le conflit armé. Une condamnation à mort contre ces femmes pour une telle infraction ne sera pas exécutée ». Cette dernière disposition vient suppléer l'absence d'interdiction d'exécution de la peine de mort contre les femmes enceintes constatée

\footnotetext{
${ }^{937}$ PILLOUD, Claude et DE PREUX, Jean, Commentaire de l'article 77 du Protocole I Protection des enfants, paragraphe 5, in SANDOZ, Yves, SWINARSKI, Christophe et ZIMMERMANN, Bruno (éd. et Coord.), Commentaire des Protocoles additionnels du 8 juin 1977 aux Conventions de Genève du 12 août 1949, op. cit., p. 928.

${ }_{938}$ PICTET, Jean S. (dir.), Commentaire IV, La Convention de Genève relative à la protection des personnes civiles en temps de guerre, op. cit., p. 372.

${ }^{939}$ M.BUHEDMA, Abdulaziz, op.cit., p. 92.
} 
aux CG III et $\mathrm{IV}^{940}$. En outre, la présente disposition qui s'applique aux CAI ne s'exprime pas exactement de la même manière que son correspondant au niveau du PA II. L'on comprend qu'il y a ici une obligation de moyen en ce qui concerne le prononcé de la peine de mort contre des femmes enceintes ou mères d'enfants en bas âge dépendant d'elles. Les termes «Dans toute la mesure du possible », «s'efforceront d'éviter » l'attestent. En clair, la possibilité de prononcer une condamnation à la peine de mort contre des femmes enceintes ou des mères d'enfants en bas âge n'est donc pas totalement exclue. En revanche, il existe une obligation de résultat en ce qui concerne l'exécution d'une telle condamnation. Pour le PA II, seule l'exécution de la peine de mort contre les femmes enceintes et mères d'enfants en bas âge est interdite. Leur condamnation à cette peine reste donc possible.

Toutefois, au regard de cette question de la peine de mort, il est important de mentionner que l'influence des instruments des droits de l'homme qui tendent de plus en plus à faire du «droit à la vie » un droit absolu et indérogeable ${ }^{941}$ ne reste pas en pratique sans conséquence en DIH. L'abolition de la peine de mort en toutes circonstances prend de plus en plus de pas sur sa rétention. «Aujourd'hui, plus des deux tiers des pays du monde ont aboli la peine de mort en droit ou en pratique. On constate une baisse tendancielle du nombre de condamnations à mort et des exécutions dans le monde. En 20 ans, plus de cinquante États sont devenus abolitionnistes en droit ${ }^{942}$. On rappelera d'ailleurs que différents instruments du DIDH prévoient l'interdiction de prononcer la peine de mort contre les enfants de moins de 18 ans et de l'exécuter contre les femmes enceintes (art. $6 \S 5$ du PIDCP ; art. $4 \S 5$ de la Convention américaine des droits de l'homme et l'art. 37 alinéa 1 de la CDE ). Si le droit à la vie est un droit relatif à l'égard des adultes dont seule la privation arbitraire est interdite, il se révèle que tel n'est pas le cas pour les enfants. En effet, la lecture des dispositions précitées accompagnées d'autres telles que celles liées aux mesures de dérogation ou de suspension des droits garantis (ex : article 4, alinéa 2, du PIDCP ; art. 27 \$2 de la Convention américaine relativer aux droits de l'homme) - atteste que le droit à la vie à l'endroit de l'enfant, notamment l'interdiction de la peine de mort, est un droit absolu et indérogeable. Ceci vaut de même pour la Charte africaine des droits et du bien-être de l'enfant qui fait du droit à la vie un droit imprescritible (art. $5 \S 1$ ) et interdit de prononcer la peine de la mort pour des crimes commis par des enfants (art. $5 \S 3$ ).

Que dire de cette présentation du régime de protection spéciale réservé à l'enfant comme personne qui ne prend pas part aux hostilités?

En réponse, il va sans dire que le régime de protection spéciale de l'enfant suivant les CG et leurs

\footnotetext{
${ }^{940} \mathrm{El}$ KOUHENE, Mohamed, Les garanties fondamentales de la personne en droit humanitaire et droits de l'homme, Dordrecht, Martinus Nijhoff Publishers, 1986, p. 114.

${ }^{941}$ Lire par exemple le Protocole $\mathrm{n}^{\circ} 13$ à la Convention de sauvegarde des droits de l'homme et des libertés fondamentales, relatif à l'abolition de la peine de mort en toutes circonstances, Vilnius, 3 mai 2002. Son article $1^{\text {er }}$ dispose : «La peine de mort est abolie. Nul ne peut être condamné à une telle peine ni exécuté ». Et l'article 2 précise : «Aucune dérogation n'est autorisée aux dispositions du présent protocole au titre de l'article 15 de la convention ». Au regard de ces deux dispositions, le droit à la vie se présente comme un droit absolu c'est-à-dire non susceptible de restriction et un droit indérogeable c'est-à-dire non susceptible de dérogation ou de suspension en période de guerres, dangers publics, ou autres situations de crise.

942 «La peine de mort dans le monde », in http://www.diplomatie.gouv.fr/fr/politique-etrangere-de-lafrance/droits-de-l-homme/peine-de-mort/la-peine-de-mort-dans-le-monde/ (Source consultée le 26 septembre 2016).
} 
PA pose problèmes. En effet, ces instruments juridiques ne définissent pas le terme «enfant » et utilisent différents termes semblables tels que «mineurs » ${ }^{943}$, «adolescent ${ }^{944}$ sans toutefois les définir également. Comme le souligne le commentaire des PA au sujet de l'absence de définition du terme «enfant», il s'agit d' "une omission intentionnelle». Il a été retenu que ce terme (enfant) n'avait pas d'acception généralement admise. D'où la difficulté même de fixer la limite d'âge d' «enfant» au sujet du premier paragraphe de l'article 77 du PA I ${ }^{945}$. L'on pourrait se demander, en ce sens, comment prétendre assurer une meilleure protection d'un sujet dont on ne connaît pas les contours et les qualités. Toutefois, le CICR note, pour sa part, que l'absence de toute définition de la notion de l'enfant dans les CG et dans leurs PA facilitera leur application universelle, indépendamment des particularités locales ${ }^{946}$. Cette absence de définition du terme « enfant » sera par ailleurs comblée par le droit international à travers la CDE (cf. supra).

Bien plus, de sérieuses difficultés sont à identifier au niveau de la formulation de leurs dispositions, de distinction d'âges de l'enfant qu'ils entretiennent et de mécanimes (cf. infra) devant assurer la protection spéciale de l'enfant en situations de conflits armés.

En effet, l'interprétation des instruments juridiques précités permet de croire qu'ils accordent une large marge d'appréciation aux parties au conflit. Celles-ci sont donc invitées à assurer leur mise en oeuvre en fonction notamment de leurs moyens disponibles. Cette affirmation peut-être observée dans différentes dispositions. Il est important de citer, à ce titre, l'article 14 de la 4è Convention de Genève qui indique que «[...] les parties au conflit pourront créer sur leur propre térritoire et, s'il en est besoin, sur le territoire occupé, des zones et localités sanitaires et de sécurité organisées de manière à mettre à l'abri des effets de la guerre [...] les enfants de moins de 15 ans [...] ». L'article 17 de la même Convention dispose que «les parties au conflit s'éfforceront de conclure des arrangements locaux pour l'évacuation d'une zone assiégée ou encerclée [...] des enfants». Pour le commentaire, cette expression fait de l'évacuation « une mesure facultative ${ }^{947}$ et non obligatoire. Ce dernier terme souligné est repris également au niveau de l'article $24 \$ 3$ de la CG IV pour des mesures nécessaires d'identification des enfants de moins de 12 ans. L'article $77 \S 2$ du PA I indique que « les parties au conflit prendront toutes les mesures possibles dans la pratique pour que les enfants de moins de quinze ans ne participent pas directement aux hostilités [...]. Au niveau de l'article $78 \S 2$ et 3 du PA I, l'on peut bien remarquer in fine le terme «possible » qui traduit une possibilité et non une nécessité. L'on retrouve également une disposition similaire au sujet de la protection des femmes. Chose qui s'avère une protection par ricochet des enfants. Il s'agit notamment du paragraphe 3 de l'article $76 \mathrm{du}$ PA I. Cet article dispose «[d]ans toute la mesure du possible, les parties au conflit s'efforceront d'éviter que la peine de mort soit prononcée contre les femmes enceintes ou les mères d'enfants en bas âge dépendant d'elles pour une infraction commise en relation avec le

\footnotetext{
${ }^{943}$ Lire art. $76 \S 5$ de la CG IV.

${ }^{944}$ Lire art. $94 \$ 2$ de la CG IV.

${ }^{945}$ PILLOUD, Claude et DE PREUX, Jean, Commentaire de l'article 77 du Protocole I Protection des enfants, paragraphe 1, in SANDOZ, Yves, SWINARSKI, Christophe et ZIMMERMANN, Bruno (éd. et Coord.), Commentaire des Protocoles additionnels du 8 juin 1977 aux Conventions de Genève du 12 août 1949, op. cit., p. 923.

946 DAOUDI, Riad, «La codification des droits de l'enfant : analyse des prises de position gouvernementales », in TORRELLI, Maurice (éd.), La protection internationale des droits de l'enfant, PUF, Paris, 1983, p. 30.

947 PICTET, Jean S. (dir.), Commentaire IV, La Convention de Genève relative à la protection des personnes civiles en temps de guerre, op. cit., p. 149.
} 
conflit armé. Une condamnation à mort contre ces femmes pour une telle infraction ne sera pas exécutée ». La liste n'est donc pas exhaustive.

Les termes ainsi soulignés s'avèrent réducteurs de la protection ${ }^{948}$. Il ressort de cette «prudence stylistique » utilisée, que le DIH relatif à la protection des enfants en temps de conflits armés réserverait une sorte de "pouvoir discrétionnaire» très important et plus d'obligations de moyens aux belligérants. L'on pourrait donc imaginer que ces derniers, étant généralement préoccupés par la poursuite des intérêts occultes et la victoire sur l'ennemi, trouveront par là l'opportunité de justifier à tout prix leurs abus. Ceux-ci peuvent se manifester par un manque d'intérêt délibéré aux dispositions liées à la protection de l'enfant voire des violations manifestes. Ce qui pourrait logiquement fragiliser le système de protection spéciale des enfants en zones de combat. La situation des guerres en Afrique centrale atteste ce point de vue (cf. la seconde partie de la thèse).

Tout de même, au plan doctrinal, Eric DAVID soutient que «le fait que l'obligation soit énoncée en termes d'obligation de moyen plutôt que de résultat n'affaiblit donc pas la portée de l'obligation [...] simplement, elle en élargit la portée ${ }^{949}$. C'est dans cette optique qu'un Etat devant agir afin d'éviter la survenance d'un événement ne devrait pas lui-même provoquer l'événement en cause $^{950}$. Ainsi, l'auteur indique d'ailleurs, à ce propos, que l'obligation de moyen devrait inclure une obligation de résultat ${ }^{951}$. Mais une telle interprétation, bénéfique soit-elle, ne saurait tout de même pas englober tous les cas et faire perdre l'obligation de moyen de ses conséquences juridiques notammment en termes d'établissement de responsabilité internationale.

Bien plus, l'absence des termes clairs limitant les ambiguïtés éventuelles ne devrait logiquement pas favoriser une application efficace des règles de protection des victimes par les parties. La « conception souverainiste », présente sur différentes lignes des CG et des PA, affaiblit ainsi davantage la protection générale et spéciale des civils principalement des enfants.

Par ailleurs, il sied de remarquer, à titre illustratif, des formulations impératives des articles tels que : $77 \S 1$ du PA I qui indique que «[1]es enfants doivent faire l'objet d'un respect particulier et doivent être protégés contre toute forme d'attentat à la pudeur [...]»; 78 §1 du même PA qui dispose qu' «aucune partie au conflit ne doit procéder...à l'évacuation d'enfants autres que ses propres ressortissants [...]» (nous soulignons) ; $68 \S 4$ de la CG IV indiquant qu' "[e]n aucun cas, la peine de mort ne pourra être prononcée contre une personne protégée âgée de moins de dix-huit ans au moment de l'infraction » (nous soulignons). Quelques dispositions dans ce sens sont décelables au niveau du second PA. Par exemple, son article $4 \$ 1$ prévoit que «[t]outes les personnes qui ne participent pas directement ou ne participent plus aux hostilités [...] seront en toutes circonstances traitées avec humanité, sans aucune distinction de caractère défavorable. Il est interdit d'ordonner qu'il'y ait pas de survivants » (nous soulignons). Du moins, dans ces dernières dispositions épinglées à titre d'exemple, l'on sait bien remarquer l'expression des obligations impératives et non permissives vis-à-vis des parties au conflit.

\footnotetext{
${ }^{948}$ Lire DEYRA, Michel, Le droit dans la guerre, op.cit., p. 45.

${ }^{949}$ DAVID, Eric, Principes de droit des conflits armés, $5^{\mathrm{e}}$ édition, op.cit., p. 568.

${ }^{950}$ Ibid.

${ }^{951}$ Ibid.
} 
Dans l'ensemble, l'absence d' « uniformisation terminologique » et la «présence fragmentaire » des conventions en la matière, comme l'on pourrait bien remarquer, ne sont pas toujours favorables à une protection spéciale efficace des enfants.

En substance, les CG et les PA contiennent en effet des dispositions, certes limitées, mais qui ont le mérite d'exister ${ }^{952}$. En rapport avec la protection spéciale de l'enfant, ces limites sont liées à la «formulation peu satisfaisante des obligations» (voy. supra) et aux mécanismes de mise en cuvre (voy. infra). Les obligations exprimées de manière relative laisseraient entrevoir des «justifications » éventuelles des violations par les belligérants. Et ce, malgré le fait qu'il soit dit dans la jurisprudence internationale que « le besoin militaire ou rationnel ne peut pas justifier la non-observation des normes positives du droit international ${ }^{953}$.

En effet, le DIH est marqué par la doctrine de nécessité militaire appelée aussi la doctrine de la «Kriegsraison» selon laquelle, un commandant pouvait-il s'affranchir du respect du droit humanitaire du moment où les exigences militaires le nécessitaient. Bien qu'encore appliquée durant la seconde guerre mondiale, cette doctrine a été l'objet de condamnation jurisprudentielle (notamment à Nuremberg) et doctrinale. D'aucuns ont invoqué «l'état de nécessité militaire » comme «un authentique droit de conservation de l'Etat». C'est-à-dire les autorités étatiques suprêmes pourraient se prévaloir de ce droit à titre exceptionnel pour justifier des violations des règles essentielles du DIH. Cependant, pour la $\mathrm{CDI}$, dans le domaine de responsabilité, cette exception ne saurait être invoquée pour contourner les règles impératives du droit international ${ }^{954}$.C'est dans cette optique que suivant le CICR, «[a]ujourd'hui, le principe de nécessité militaire est généralement reconnu comme autorisant «seulement le degré et le type de force, non interdits par ailleurs par le droit des conflits armés, qui sont requis pour atteindre le but légitime du conflit, à savoir la soumission complète ou partielle de l'ennemi le plus tôt possible avec le coût minimum en vies humaines et en moyens engagés » ${ }^{955}$ (nous soulignons). Ainsi, les considérations militaires sont expressément prises en compte conventionnellement dans certaines circonstances précises pour déroger à certaines règles ${ }^{956}$. Dès lors, lorsque les parties en conflit se heurtent à une interdiction formelle, elles ne peuvent plus invoquer la nécessité militaire pour y

\footnotetext{
${ }^{952}$ TAVERNIER, Paul, «Réflexion sur les mécanismes assurant le respect du droit international humanitaire conformément aux Conventions de Genève et aux Protocoles additionnels », in Actualités et Droit International, Revue d'analyse juridique et d'actualités internationales http://www.ridi.org/adi/200004 (Source consultée le 20 juillet 2014).

${ }_{953}$ I.P.BLISHCHENKO, « Les principes du droit international humanitaire », in C. SWINARSKI (éd.), Etudes et essais sur le droit international humanitaire et sur les principes de la Croix-Rouge en l'honneur de Jean PICTET - Studies and essays on international Humanitarian law and Red Cross principles in honour of Jean PICTET, op. cit., p. 299.

${ }_{954}$ ASPREMONT, Jean d' et HEMPTINE, Jérôme de, Droit international humanitaire, op.cit., p. 221.

${ }^{955}$ MELZER, Nils, Guide interprétatif sur la notion de participation directe aux hostilités en droit international humanitaire, op. cit., p. 82.

956 «Tel est le sens de l'expression « pour autant que les exigences militaires ou les considérations d'ordre militaires le permettront » utilisée, par exemple, aux articles 12 et 42 de la CG I, 23 de la CG III ainsi que 16 et 18 de la Convention de Genève IV. Telle est également la signification des expressions plus restrictives - quoique imprécises - de «nécessités militaires urgentes » prévues aux articles 33 de la Convention de Genève I et 28 de la Convention de Genève II, de «nécessités militaires absolues » utilisées aux articles 42 et 53 de la Convention de Genève IV ou de «nécessités militaires impérieuses » figurant aux articles 126 de la Convention de Genève III et 49 de la Convention de Genève IV ainsi que 54, paragraphe 4), 62, paragraphe 1) et 67, paragraphe 4) du $1^{\text {er }}$ Protocole additionnel ». Lire ASPREMONT, Jean d' et HEMPTINE, Jérôme de, Droit international humanitaire, op.cit., p. 222.
} 
déroger. Lorsqu'une telle possibilité est expressément prévue, elles peuvent l'invoquer seulement dans la mesure où elle est prévue ${ }^{957}$.

Spécialement à la situation de l'enfant, les limites liées à la formulation des obligations sont également remarquables au niveau de distinction d'âges qu'entretiennent les CG et PA. En dehors de la protection spéciale accordée aux «personnes âgées de moins de 18 ans », ou aux « enfants »- sans limite d'âge précise - (ex : l'évacuation d'une zone assiégée ou encerclée - art. 17 de la CG IV-; l'interdiction de la peine de mort - art. 68, alinéa 4 de la CG IV, art. 77 §5 du PA I, art. $6 \S 4$; le principe du droit à un respect et à une protection particuliers - art. $77 \S 1 \mathrm{du}$ PA I, art. 4 §3), il existe une protection spécifique réservée aux enfants de moins de 15 ans en majeure partie et encore plus spécifique pour ceux de moins de 12 ans (cf. supra). Ainsi, malgré l'absence de définition de l'enfant en DIH, cette limite d'âge de 15 ans s'attache à l'enfant au point d'apparaître comme «une base raisonnable de définition » ${ }^{958}$. Ainsi, les CG et PA emploient expressément le terme «personnes » s'agissant de limite de 18 ans ${ }^{959}$. Ainsi, par exemple, la création des zones et localités sanitaires et de sécurité ne sont expressément profitables qu'aux enfants de moins de 15 ans (art. 14 de la CG IV). De même pour le droit au libre passage de vivres indispensables, de vêtements et de fortifiants (art. 23, alinéa 1, de la CG IV) ou encore des mesures nécessaires pour faciliter en toutes circonstances l'entretien des enfants, la pratique de leur religion et leur éducation (art. $24 \$ 1$ de la CG IV). L'interdiction de recrutement et de participation des enfants aux conflits armés vont également dans le même sens (cf. infra). Les enfants de moins de 12 ans, quant à eux, seront identifiés par le port d'une plaque d'identité ou par tout autre moyen (art. $24 \$ 3$ de la CG IV). Les enfants de bas âges se trouvent également protégés par ricochet à travers l'interdiction de l'exécution de la peine de mort contre leurs mères (cf. supra).

Au regard de ce qui précède, en dépit des raisons évoquées précédemment, l'on est en droit de se demander si une telle distinction serait de nature à assurer une protection spéciale efficace de l'enfant sur le champ de bataille. Ou encore n'est-ce pas là une «insécurité juridique » dans laquelle l'enfant se trouve placé ?

En effet, la question de la sélectivité de la protection de l'enfance ainsi que celle de la multiplication des catégories ${ }^{960}$ ne rendent pas toujours aisé la protection spéciale de l'enfant en situation de conflits armés. Le fait pour ces instruments juridiques précités de se préoccuper en majeure partie d'un âge déterminé de l'enfant (moins de quinze ans) et de catégoriser davantage les enfants au sein de cet âge rend la protection de l'enfant discriminatoire. Les enfants étant tous particulièrement vulnérables se retrouveraient les uns plus protégés que les autres. Ce qui pourrait éventuellement créer sur le plan psychologique des effets néfastes pour des enfants issus d'une même famille voire vis-à-vis de leurs parents. Ceci violerait donc le principe d'égalité et de nondiscrimination applicable autant en DIDH qu'en DIH. Par ailleurs, il s'avère matériellement

\footnotetext{
957 Ibid.

${ }^{958}$ PILLOUD, Claude et DE PREUX, Jean, Commentaire de l'article 77 Protection des enfants, paragraphe 1, in SANDOZ, Yves, SWINARSKI, Christophe et ZIMMERMANN, Bruno (éd. et Coord.), Commentaire des Protocoles additionnels du 8 juin 1977 aux Conventions de Genève du 12 août 1949, op. cit., p. 923. 959 Ibid.

960 MARTIN CHENUT, Kathia, «art.cit.», in SOREL, Jean-Marc et POPESCU, Corneliu-Liviu (dir.), op.cit.,172 ; DAOUDI, Riad, « art.cit. », in TORRELLI, Maurice (éd.), op.cit,. p. 30.
} 
difficile d'établir cette catégorisation sur terrain faute des pièces justificatives - carte d'identité ou attestation de naissance - à présenter en pareilles situations de trouble. La situation est d'ailleurs précaire en temps de paix dans la plupart des pays en développement - bastion des guerres civiles ou interétatiques - où l'enregistrement ou le recensement d'enfants demeure un sujet très délicat. Ainsi, il y a risque que les parties, suivant les enjeux des conflits armés, profitent de cette catégorisation pour effectuer des sélectivités basées sur des aspects physiques non profitables toujours à l'enfant.

Pour tout dire, « [1]a confusion qui peut découler de cette référence à différentes tranches d'âge et, par conséquent, à différentes catégories d'enfants soulève la question de l'opportunité ou de la pertinence d'une telle distinction, de même que celle de l'intérêt qu'elle présente en tant que critère objectif d'établissement du niveau de protection. Il va de soi que l'instauration d'un régime homogène serait plus facile avec une uniformisation de l'âge de référence et, dans ce domaine, l'âge de dix-huit ans constitue sans doute la limite idéale. Toutefois, la réglementation de l'âge est en soi une question complexe et la diversité des solutions retenues dans les différents ordres juridiques nationaux ne facilite pas l'adoption d'une référence unique en la matière ${ }^{961}$.

En conclusion, l'exigence de respecter et de protéger les enfants dans les conflits armés figure dans de nombreuses législations nationales, dans de nombreux manuels militaires. Les déclarations officielles et d'autres types de pratique étayent davantage cette régle ${ }^{962}$. C'est en cela qu'elle est d'ailleurs appréhendée au rang du DIH coutumier (cf. infra). Que dire de recrutement et participation des enfants aux conflits armés?

\section{B. 3. Protection spéciale de l'enfant soldat}

En termes de prévention du phénomène «enfant soldat », le recrutement et la participation des enfants aux hostilités ont été réglementés expressément bien après. Les CG ne régissent pas le recrutement et l'utilisation d'enfants en limitant notamment leur âge de recrutement ou de participation aux conflits armés. Ainsi, l'on retrouve l'article $51 \S 1$ de la CG IV qui dispose : «La Puissance occupante ne pourra pas astreindre des personnes protégées à servir dans ses forces armées ou auxiliaires. Toute pression ou propagande tendant à des engagements volontaires est prohibée. ${ }^{963}$ ». Cette disposition fait partie de règles de protection générale à l'endroit des «personnes protégées » dont l'enfant. Il ne s'agit pas d'une disposition qui vise expressément la protection spéciale de l'enfant. Bien plus, la question de la protection, à travers cet article, n'est réglée que partiellement. En clair, cet article régit la situation d' «occupation». En d'autres termes, il n'existe pas, sous cet angle, une prohibition faite à l'Etat concernant le recrutement et la participation des enfants issus de son propre territoire national. Ainsi donc, à proprement parler, les CG ne régissent pas la question de recrutement et d'utilisation d'enfants

\footnotetext{
${ }^{961}$ KANE, Ameth Fadel, La protection des droits de l'enfant pendant les conflits armés en droit international, op. cit., pp. 60-61.

962 HENCKAERTS, Jean-Marie et DOSWALD-BECK, Louise, Droit international humanitaire coutumier, Vol.I : Règles, op. cit., pp. 632-633.

${ }^{963}$ Le libellé de l'article 51 de la CG n'est pas nouveau. On le retrouve dans le Règlement concernant les lois et coutumes de la guerre sur terre annexé à la Convention (IV) de La Haye du 18 octobre 1907 concernant les lois et coutumes de la guerre sur terre, en son article $23 \S 2$. Cet article renseigne : "Il est également interdit à un belligérant de forcer les nationaux de la partie adverse à prendre part aux opérations de guerre dirigées contre leurs pays, même dans le cas où ils auraient été à son service avant le commencement de la guerre ».
} 
aux conflits armés.

Deux raisons majeures tentent d'expliquer l'absence de règles relatives au recrutement et à la participation des enfants aux hostilités dans les CG. "Premièrement, au lendemain de la Seconde Guerre mondiale, régir le recrutement d'enfants soldats n'était pas une priorité du fait que ce phénomène était resté une exception lors des atrocités de la guerre. Deuxièmement, les CG régissent des conflits armés internationaux, c'est-à-dire des rapports interétatiques. A l'époque des négociations des CG, en 1948-1949, il était considéré que le droit international humanitaire ne devrait pas s'interposer entre un Etat et ses propres ressortissants et que l'âge limite pour pourvoir incorporer des enfants dans les forces armées d'un Etat était du ressort de la compétence nationale exclusive ${ }^{964}$. Tout cela par souci de ne pas heurter la souveraineté des Etats. Il est d'ailleurs remarqué que les CG se préoccupent de régir la protection de l'enfant comme civil que comme combattant. C'est justement à ce titre que Gérard AIVO estime que les enfants étant des « civils purs », comme le qualifiait le CICR dans son rapport sur La participation directe aux hostilités en droit international humanitaire, n'ayant donc pas vocation à faire la guerre, les CG ne devaient donc pas consacrer la question de leur recrutement ou utilisation ${ }^{965}$. Il faudrait donc attendre que cette problématique soit prise en charge par les PA de 1977 au cours des conférences diplomatiques de 1974-1977 qui avait conduit à leur adoption. Le DIDH, devant également s'appliquer en circonstances des conflits armés, s'est également préoccupé de la question. Différents instruments contraignants voire de soft-law s'y sont penchés (cf. infra).

En effet, les rédacteurs des PA ont pris finalement en compte l'aspect de l'utilisation des enfants dans les conflits armés et complété la CG IV qui n'avait pas abordé cette question afin de protéger davantage les enfant soldats ${ }^{966}$. Par ailleurs, même dans les années 70 , l'adoption des dispositions relatives au recrutement et à la participation des enfants aux conflits armés n'a pas été aisée. Elles sont le résultat d'un compromis difficile lors des conférences diplomatiques tenues de 1974 à 1977. Ce qui peut expliquer le caractère non absolu de certaines interdictions ${ }^{967}$.

Le PA I applicable aux conflits armés internationaux, en son article $77 \S 2$, fait obligation aux belligérants de prendre «toutes les mesures possibles dans la pratique pour que les enfants de moins de quinze ans ne participent pas directement aux hostilités, notamment en s'abstenant de les recruter dans leurs forces armées... » (nous soulignons).

En ce sens, le projet d'article initialement proposé par le CICR stipulait que «[1]es parties au conflit prendront toutes les mesures nécessaires pour que les enfants âgés de moins de quinze ans ne prennent aucune part aux hostilités, notamment en s'abstenant de les recruter dans les forces armées ou d'accepter leur enrôlement volontaire ${ }^{968}$ (nous soulignons). Ainsi, il y a lieu de comprendre que les «mesures possibles » dépendent entièrement des moyens disponibles chez les puissances belligérantes. Celles-ci ne se trouvent pas, par là, contraintes d'agir à tout prix. Par

\footnotetext{
${ }^{964}$ MAYSTRE, Magali, op.cit., p. 41.

965 AIVO, Gérard, Le Statut de combattant dans les conflits armés non internationaux, op. cit., p. 240.

${ }^{966}$ HAROUEL-BURELOUP, Véronique, Traité de droit humanitaire, P.U.F, Paris, 2005, p. 304.

${ }^{967}$ MARTIN-CHENUT, Kathia, « art.cit. », pp. 174-175.

${ }^{968}$ Lire l'article $68 \S 2$ du Projet de Protocole additionnel aux Conventions de Genève du 12 août 1949 relatif à la protection des victimes des conflits armés internationaux in CICR., Projets de Protocoles additionnels aux Conventions de Genève du 12 août 1949. Commentaires, Genève, octobre 1973, p. 89.
} 
contre, en parlant des «mesures nécessaires », il sied de penser non pas aux moyens disponibles chez les parties au conflit pour atteindre le but mais au but ou résultat visé d'abord. En d'autres termes, c'est le but qui conditionne ou nécessite ces mesures adéquates. La formule de «mesures nécessaires» n'a pourtant pas été adoptée par les gouvernements, qui «n'ont pas voulu contracter des obligations absolues en ce qui concerne la participation spontanée des enfants aux hostilités ${ }^{969}$. «Il n'aurait été ni réaliste, ni même possible, d'interdire de façon absolue la participation des enfants aux hostilités ${ }^{970}$. Une participation volontaire des enfants de moins de 15 ans reste donc possible au regard de l'article $77 \S 2 \mathrm{du}$ PA I.

«Pourtant cette disposition contient une obligation absolue, de résultat, en ce qui concerne le recrutement: les parties au conflit ne peuvent pas recruter d'enfants de moins de 15 ans dans leurs forces armées ». Leur responsabilité sera donc engagée en cas de recrutement d'enfants de moins de 15 ans et non en cas de participation directe de ces enfants aux hostilités per se si les mesures prises à cet égard se sont révélées inefficaces ${ }^{971}$.

En outre, ce texte laisse entendre que la participation indirecte des enfants de moins de quinze ans dans les conflits armés internationaux n'est pas interdite. Une absence dommageable que «regrette» Eric DAVID ${ }^{972}$. Aussi, le recrutement et la participation directe ou indirecte des enfants d'au moins quinze ans ou plus aux CAI ne sont pas interdits.

En référence au projet du CICR tel que décrit ci-dessus concernant la réglementation de la participation des enfants dans les CAI, il était disposé «[...] que les enfants de moins de quinze ans ne prennent aucune part aux hostilités [...] ». Comme l'indique bien le commentaire de ce projet d'article «sont ainsi interdites non seulement la participation directe aux hostilités, mais aussi tout autre acte en relation avec ces dernières : transmission d'informations militaires, transport d'armes, de munitions et de matériel de guerre, sabotage, etc. ${ }^{973}$. Mais cette proposition a été rejetée par les conférences diplomatiques de 1974-1977 pour retenir au niveau du paragraphe 2 de l'art.77 du PA I « [...] que les enfants de moins de quinze ans ne participent pas directement aux hostilités, [...] ». Disposition qui occasionne des conséquences déplorables ci-dessous.

Pour Michael J. MATHESON et Djamchid MOMTAZ, les parties au conflit auront toujours la possibilité de recourir aux activités telles que la collecte des renseignements, la transmission d'ordres ou transport des munitions et des biens nécessaires aux combattants, toutes activités non couvertes par cette disposition visant uniquement la participation directe aux hostilités ${ }^{974}$.

\footnotetext{
${ }^{969}$ MAYSTRE, Magali, op.cit., p. 175.

970 PLATTNER, Denise, « La protection de l'enfant dans le droit international humanitaire », «art.cit.», p.159; Voy. aussi HAROUEL-BURELOUP, Véronique, Traité de droit humanitaire, op. cit., pp. 304-305.

971 MARTIN-CHENUT, Kathia, « art.cit. », p. 175.

${ }^{972}$ DAVID, Eric, Principes de droit des conflits armés, $5^{\mathrm{e}}$ édition, op.cit., p. 568.

${ }^{973}$ Lire le commentaire de l'article $68 \S 2$ du Projet de Protocole additionnel aux Conventions de Genève du 12 août 1949 relatif à la protection des victimes des conflits armés internationaux in CICR., Projets de Protocoles additionnels aux Conventions de Genève du 12 août 1949. Commentaires, op.cit., p. 90.

${ }^{974}$ MOMTAZ, Djamchid (dir.), «Les défis des conflits armés asymétriques et identitaires au droit international humanitaire », in M.J MATHESON et D. MOMTAZ (dir.), op. cit., p. 26. ; voy. aussi HAROUEL-BURELOUP, Véronique, op.cit., p. 304. ; LARRALDE, Jean-Manuel, « Les réponses du droit international à la question des enfants soldats », in $C R D F, \mathrm{n}^{\circ} 5,2006$, pp. 70-71.
} 
Par ailleurs, le PA II semble plus avancé que le PA I. Il dispose en son article $4 \S 3 \mathrm{c}$ que «les enfants de moins de quinze ans ne devront pas être recrutés dans les forces ou groupes armés, ni autorisés à prendre part aux hostilités». Comparativement à l'article $77 \S 2 \mathrm{du}$ PA I qui impose deux obligations distinctes (obligation de moyen concernant la participation d'enfants de moins de quinze ans et obligation de résultat concernant le recrutement d'enfants de moins de quinze ans), le présent article impose deux obligations de nature identique concernant le recrutement et la participation des enfants de moins de quinze ans à savoir l'obligation de résultat. Un autre grand avantage qu'accorde cet article est qu'il s'applique autant pour la participation directe que pour la participation indirecte. Ceci est exprimé par « [...] ni autorisés à prendre part aux hostilités » (nous soulignons). Cet article a un autre point fort de s'adresser expressément aux groupes armés qui se voient par là l'obligation négative de recruter et de faire participer les enfants de moins de quinze ans aux conflits armés moyennant certains critères qu'ils doivent remplir (cf. supra). Mais le problème ne demeure point réglé à propos de recrutement et de participation des enfants de quinze ans et plus dans les conflits armés.

Il importe de préciser que contrairement à l'article 3 commun aux CG qui n'accorde pas une protection spéciale à l'enfant qui ne participe pas ou plus directement aux hostilités et le traite identiquement comme des adultes, le PA II lui réserve tout de même une protection spéciale. Il se dégage que seuls les enfants se trouvant au pouvoir de l'ennemi sont concernés par l'article 3 commun aux CG et non ceux qui prennent part directement aux hostilités ${ }^{975}$.

De ce qui précède, à dire vrai, la question abordée jusque là est celle de la protection spéciale de l'enfant contre sa participation aux hostilités notamment sa participation directe. Ce qui laisse perplexe d'ailleurs la question de participation indirecte de l'enfant (cf. supra). Bien plus, il y a lieu de se demander ce que prévoit le DIH au sujet de la protection spéciale de l'enfant qui prend directement part aux hostilités. Ce qui est le cas de nombreux enfants en RDC (cf. infra).

En règle générale, on rappelera dès lors qu'ils participent directement aux hostilités malgré les interdictions ci-haut soulignées, les enfants bénéficient d'abord de la protection générale accordée à tous les combattants pourvu qu'ils répondent aux conditions fixées (cf. le point $\mathrm{A}$. 2 supra). En outre, une protection spéciale leur est également réservée s'ils tombent au pouvoir de la partie adverse. Ainsi, pour le cas de CAI, l'article $77 \S 3$ du PA I dispose: «Si, dans des cas exceptionnels et malgré les dispositions du paragraphe 2, des enfants qui n'ont pas quinze ans révolus participent directement aux hostilités et tombent au pouvoir d'une partie adverse, ils continueront à bénéficier de la protection spéciale accordée par le présent article, qu'ils soient ou non prisonniers de guerre » (nous soulignons). La protection spéciale qu'accorde le présent article se rapporte au respect particulier et à la protection des enfants contre toute forme d'attentat à la pudeur. Il est fait obligation aux parties au conflit d'accorder les soins et de l'aide aux enfants suivant leur besoin en fonction de leur âge ou autre raison.

\footnotetext{
${ }^{975}$ DAVID, Eric « La Protection juridique de l'enfant contre les effets directs des hostilités » in Commission communautaire française, La Guerre et l'enfant, Actes du Colloque organisé par l'Association internationale des journées universitaires de la paix à l'Institut de Sociologie de l'Université Libre de Bruxelles le mercredi 2 mars 1983. Centre bruxellois de Recherche et de Documentation pédagogique, Service Enseignement, Bruxelles, 1990, p. 7.
} 
Cet article insiste également sur la séparation des enfants des adultes en cas de leur arrestation, détention ou internement pour des raisons liées au conflit armé sauf pour de raisons d'unité familiale. Enfin, il est interdit l'exécution mais pas la condamnation à mort pour des infractions liées au conflit armé pour des personnes de moins de dix-huit ans (article $77 \S 5$ (cf. supra).

Ainsi, la protection spéciale abordée par l'article $77 \S 3$ du PA I (voy. également l'article $4 \S 3$ d du PA II pour les CANI) se limite en principe dans le cadre de cet article. Rien n'est expressément affirmé qu'elle s'étend aux enfants qui participeraient directement aux hostilités sans être tombé au pouvoir de la partie adverse. Cette protection concerne donc l'enfant qui prend directement part aux hostilités et tombe au pouvoir d'une partie au conflit. Qu'il soit ou non revêtu du statut de prisonnier de guerre comme pourrait être le cas dans le cadre d'un CAI. «Or avec cette participation, ils perdent la protection générale accordée aux civils ainsi que la protection spéciale dont ils bénéficient en vertu des traités, mais conservent la protection assurée par l'article 77 du PI [PA I] et l'article 4 du P II [PA II] [...]. S'ils sont prisonniers de guerre les articles 16 et 49 de la CG III s'appliquent ${ }^{976}$. En d'autres termes, en tant que combattant, les enfants - de moins de quinze ou de quinze à dix-huit ans - recrutés peuvent être abattus comme n'importe quel autre combattant ${ }^{977}$. Il n'existe donc pas une protection spéciale liée à leur statut. Une telle interprétation, reconnaît Magali MAYSTRE, n'est toutefois par partagée par certains ${ }^{978}$ qui estiment qu'en dépit de sa participation directe aux hostilités, l'enfant doit être traité comme civil. En même temps, au sens du DIH, un tel point de vue ne semble pas correctement soutenable. Il irait à l'encontre du principe sacrosaint de distinction entre combattants et civils ${ }^{979}$ et encouragerait le recrutement et la participation d'enfants car le droit applicable ici interdirait de les attaquer au cours des hostilités $^{980}$. D'où, cette interprétation en dépit de la désolation qu'elle suscite demeure correcte au regard du DIH.

En même temps, il importe de rappeler, encore une fois, que vouloir traiter identiquement un enfant, personne se trouvant en situation de vulnérabilité particulière, qu'un adulte n'est rien d'autre que de la discrimination. Cette logique de raisonnement est admissible en DIH qui reconnait le principe de non-discrimination ${ }^{981}$.

Ainsi, de ce qui précède, il se dégage que le DIH assure faiblement la protection spéciale de l'enfant incorporé au sein des forces ou groupes armés et qui participe directement aux hostilités en CAI comme en CANI (cf. infra). Cette faible protection nous amène à considérer l'enfant comme «doublement victime ». Victime d'abord du fait de son recrutement et de sa participation aux hostilités surtout par de nombreux groupes armés opérant sur le terrain

\footnotetext{
${ }_{976}^{97}$ BETTATI, Mario, Droit humanitaire, $1^{\text {re }}$ édition, op.cit., p.191., MAYSTRE, Magali, op.cit., p. 77.

${ }^{977}$ MAYSTRE, Magali, op.cit., p. 77. Voy. aussi CUMIN, David, Le droit de la guerre. Traité sur l'emploi de la force armée en droit international, Vol. 2, L'Harmattan, Paris, 2015, p. 631.

${ }^{978}$ SINGER, Sandra, « La protection des enfants dans les conflits armés », « art. cit. », p. 157.

${ }^{979}$ Bien qu'il soit dit que la pratique d'enrôlement et de participation des enfants aux hostilités brouille la démarcation entre combattants et civils. Ce qui viole d'ores et déjà le principe de distinction entre combattants et civils.

${ }^{980}$ MAYSTRE, Magali, op.cit., pp. 77-78.

${ }^{981}$ Lire TIGNINO, Maria , L'eau et la guerre. Eléments pour un régime juridique, op. cit., pp. 216 et 294. Lire par exemple à ce sujet les articles $3 \S 1$ commun aux CG, 27, alinéa 3 de la CG IVou $75 \S 1$ du PA I.
} 
notamment. Victime, ensuite, d'un droit qui assure faiblement sa protection en pleines hostilités en tant que participant. Toutefois, le DIH ne tolèrant pas l'arbitraire, le «vide juridique » n'est donc pas concevable. Ainsi, en participant directement aux hostilités, l'enfant restera sous la protection générale réservée aux combattants (cf. supra), sous la protection de la clause Martens, voire des règles de droits de l'Homme applicables en période des hostilités, etc. L'usage plus des principes de précaution ou d'un test rigoureux de proportionnalité face à une troupe composée d'enfants de moins de quinze ans reste vivement recommandé ${ }^{982}$.

De manière générale, la pratique sur terrain tendrait à une certaine amélioration. Il est affirmé que l'utilisation des enfants soldats dans les combats proprement dits n'est pas forcément systématique $^{983}$ ou encore rarement recourue ${ }^{984}$. Toutefois, leur recrutement par les forces ou groupes armés pour assurer différents rôles- cuisiniers, guetteurs ou sentinelles, informateurs, porteurs, agents de liaison ou de renseignement - demeure d'usage fréquent. Ce qui pourrait par ailleurs tomber éventuellement sous le coup de la participation active. La jurisprudence sur la question de protection de l'enfant est plus protectrice à travers la notion de «participation active» (cf. supra). Celle-ci inclut la question de participation indirecte et contribue à l'efficacité de l'interdiction de la participation des enfants aux hostilités à travers la répression. Ce qui est plus considérable est le fait que, suivant l'étude du CICR, « rien dans la pratique recueillie à l'appui de l'interdiction de la participation des enfants aux hostilités n'indique qu'ils devraient être privés de leur protection spéciale s'ils participent effectivement aux hostilités $»^{985}$.

Une autre question - au-delà de l'enfant soldat- lui qui assure « une fonction continue », est celle de s'interroger sur le sort de l'enfant civil, qui sans être incorporé dans une force ou un groupe armé participerait tout de même aux hostilités.

L'enfant qui prend volontairement les armes sans être recruté par les forces ou groupes armés « devrait être traité comme personne civile protégée, compte tenu de circonstances atténuantes qui excluent sa culpabilité, notamment en raison de son jeune âge ou de son manque de discernement ${ }^{986}$. En effet, la question de la participation directe de l'enfant civil aux hostilités est à appréhender au rang d'un civil qui participerait volontairement aux hostilités. Ainsi, l'enfant est donc une personne civile et bénéficie de ce fait des règles du DIH applicables aux personnes civiles ou populations civiles. Dans le cadre d'un CAI, au sens de la protection générale accordée aux personnes civiles dont bénéficie notamment l'enfant, 1'article $51 \S 3$ du PA I dispose: «[1]es personnes civiles jouissent de la protection accordée par la présente section, sauf si elles participent directement aux hostilités et pendant la durée

\footnotetext{
${ }^{982}$ MAYSTRE, Magali, op.cit., p. 77. Voy. aussi CUMIN, David, Le droit de la guerre. Traité sur l'emploi de la force armée en droit international, Vol. 2, op. cit., p. 631.

983 BAILLON, Thierry, "A l'écoute des enfants-soldats », in Marc SCHMITZ (coord.), La guerre. Enfants admis. 300.000 enfants-soldats dans le monde:comment combattre ce fléau?, op.cit., p. 10.; Voy. également CHAPLEAU, Philippe, Enfants-soldats. Victimes ou criminels de guerre?, op.cit., p. 152.

984 THONIER, Jean-Paul, «Le militaire en opération multinationale face aux enfants-soldats », in BABIKER, Mohamed Abdelsalam, DAUBLAIN Maxence et VAHLAS Alexis (dir), Enfants-soldats et droits des enfants en situation de conflit et poste-conflitr. Réalités et enjeux, op. cit., p. 192.

${ }^{985}$ HENCKAERTS, Jean-Marie et DOSWALD-BECK, Louise, Droit international humanitaire coutumier, Volume I : Règles, Bruxelles - Genève, éd. Bruylant - CICR, 2006, p. 643.

${ }^{986}$ SINGER, Sandra, « art.cit. », p. 157
} 
de cette participation ». La protection générale des personnes civiles prises individuellement ou de la population civile prise globalement dont se préoccupent ces dispositions conventionnelles se rapporte à l'interdiction des attaques, « des actes ou menaces de violence dont le but est de répandre la terreur parmi la population civile ${ }^{987}$. En d'autres termes, le traitement humain des personnes civiles ou de la population civile reste de mise. Cette protection générale se rapportant au statut de civil de l'enfant n'exclut cependant pas qu'il puisse bénéficier de la protection spéciale liée à sa situation. Toutefois, comme pour l'ensemble du DIH, il s'agit de «protection conditionnelle ». Cette protection reste accordée « sauf si [...] ». Ainsi, au regard des dispositions précitées, lorsqu'un enfant civil, à l'instar de tout civil, participe directement aux hostilités et durant cette participation, il perd son immunité de protection contre les attaques ${ }^{988}$. L'enfant civil ne se trouve donc pas dans l'hypothèse d'une «fonction continue » au sein d'une force armée ou d'un groupe armé pour être attaqué à tout moment aussi longtemps que son appartenance à ces force ou groupe armés $^{989}$. Ainsi, l'enfant civil ne sera donc attaqué que pendant le moment de sa participation directe aux hostilités. Période qui couvre celle de préparation au combat et celle de chemin de retour après la commission de l'acte hostile ${ }^{990}$. Il ne bénéficiera donc pas du statut de prisonnier de guerre s'il tombe au pouvoir d'une partie ennemie dans le cadre d'un CAI car ne répondant pas aux critères de combattant ${ }^{991}$.

Toutefois, le droit international rejetant complètement le droit de disposer arbitrairement du sort des simples particuliers et n'autorisant contre eux ni mauvais traitements ni violences ${ }^{992}$, le civil ayant participé directement aux hostilités dans le cadre d'un CAI bénéficiera au minimum des garanties fondamentales qu'impose l'article 75 du PA I. Il est fait obligation aux parties au conflit de «traiter avec humanité en toutes circonstances » ces personnes se trouvant à leur pouvoir et ne bénéficiant pas d'une protection plus favorable (cf. article 75 $\S 1)$. Il sied de signifier en passant qu'en dépit de l'incertitude quant au champ d'application rationae personae de cette disposition, on s'accorde d'affirmer que sur base de l'article $72 \mathrm{du}$ PA I ${ }^{993}$, l'article 75 s'interprétera de « façon à inclure également les ressortissants de la partie contractante appliquant les dispositions de l'article en question » voire d'autres ${ }^{994}$. Position que défend la Finlande ${ }^{995}$. Il s'agit là d'un ensemble de garanties semblables à celles de l'article 3 commun aux quatre CG ou de l'article 4 du PA II pour les CANI.

\footnotetext{
${ }^{987}$ Voy. l'article $51 \S 2$ du PA I et l'article $13 \S 2$ du PA II

988 THÜRER, Daniel, International humanitarian law : Theory, practice, context, op. cit., p. 91 ; DAVID, Eric, Principes de droit des conflits armés, $5^{\mathrm{e}}$ édition, op.cit., p. 287

${ }^{989}$ DAVID, Eric, Principes de droit des conflits armés, $5^{\mathrm{e}}$ édition, op.cit., p. 287 ; MOMTAZ Djamchid, « La participation directe des personnes civiles aux hostilités », « art.cit. », p. 494.

${ }_{990}$ MOMTAZ, Djamchid, « La participation directe des personnes civiles aux hostilités », « art.cit. », p. 495.

${ }^{991}$ Voy. l'article 4 de la $3^{\text {e }}$ Convention de Genève du 12 août 1949 relative au traitement des prisonniers de guerre.

992 PICTET, Jean, Les principes du Droit international humanitaire, op.cit., p. 29.

993 L'article 72 du PA I dispose : «Les dispositions de la présente section complètent les normes relatives à la protection humanitaire des personnes civiles et des biens de caractère civil au pouvoir d'une partie au conflit énoncées dans la IVè Convention, en particulier aux titres I et III, ainsi que les autres normes applicables du droit international qui régissent la protection des droits fondamentaux de l'homme pendant un conflit armé de caractère international » (nous soulignons).

994 GAUDREAU, Julie, «Les réserves aux Protocoles additionnels aux Conventions de Genève pour la protection des victimes de la guerre », in RICR, n849, mars 2003, p. 176.

${ }^{995}$ Ibid.
} 


\section{§2. La Convention relative aux droits de l'enfant et le Protocole facultatif se rapportant à la Convention relative aux droits de l'enfant, concernant l'implication d'enfants dans les conflits armés}

Avant d'aborder à proprement parler la question de la protection de l'enfant en situation de conflits armés sous l'angle de la CDE et de son protocole facultatif concernant l'implication d'enfants dans les conflits armés (B), un examen laconique du contenu de la CDE est d'importance (A).

\section{A. Contenu global de la CDE}

Il importe de rappeler que « [la CDE] exigea dix années d'une élaboration minutieuse. Ce fut en effet au cours de l'année internationale de l'enfant, en 1979, que ce travail de rédaction particulièrement ardu fut entrepris, à l'instigation de la Pologne. Un groupe de travail s'attela à la tâche sur la base des dix articles de la Déclaration de 1959 [cf. supra]. Ledit groupe se composait de 43 Etats membres de la Commission des Nations unies et de nombreuses organisations des Nations Unies et de nombreuses organisations non gouvernementales, qui jouèrent un rôle capital dans la rédaction de nombreux articles de la Convention ${ }^{996}$. «Le 20 novembre 1989, sur recommandation de sa Troisième commission (Affaires sociales et humanitaires) l'Assemblée Générale des Nations Unies a adopté et ouvert à la signature, à la ratification et à l'adhésion des Etats, la [CDE] ${ }^{997}$. Cette dernière apparaît aux yeux de l'UNICEF comme un « document qui rend le mieux compte des aspirations de la Communauté internationale en ce qui concerne le bien-être des enfants $\gg{ }^{998}$. C'est donc un produit des compromis ${ }^{999}$.

Les droits énoncés dans cette Convention se regroupent en quatre principales catégories : le droit à la survie; le droit au développement; le droit à la protection; le droit à la participation, appréhendant dans sa globalité la condition de l'enfant. ${ }^{1000}$ Ces droits ne sont, par ailleurs, pas classés par importance; la Convention cherche au contraire à souligner que tous les droits se renforcent mutuellement ${ }^{1001}$.

Toutefois, pour des raisons pédagogiques, on décrit parfois la gamme des droits garantis par la Convention comme les trois $« \mathrm{P} »$ : prestation, protection et participation. Les enfants ont le droit d'obtenir la prestation d'un nombre d'éléments et de services, allant du droit à un nom et à une nationalité, à des soins de santé et à une éducation. Ils ont le droit d'être protégés d'actes tels que la torture, l'exploitation, la détention arbitraire ou le retrait injustifié de la garde des parents. Enfin, les enfants ont le droit de participer aux décisions concernant leur vie ainsi que celles de leur communauté ${ }^{1002}$. Plusieurs Etats, comme c'est le cas de la RDC, instituent ce qu'on appelle « les Parlements d'enfants » pour faire entendre leurs voix.

\footnotetext{
${ }^{996}$ GEANITON, Thierry, op.cit., p. 20.

997 BENNOUNA, Mohamed, «La Convention des Nations Unies relative aux droits de l'enfant », « art.cit. », p. 433.

${ }_{998}$ KEBA Mbaye, Les droits de l’homme en Afrique, 2è édition, éd. A.Pedone, Paris, 2002, p. 120.

999 VILJOEN, Frans, International Human Rights Law in Africa, Oxford University Press, New-York, 2007, pp. 261-262.

${ }^{1000}$ GEANITON, Thierry, op.cit., p. 21.

${ }^{1001}$ MEUNIER, Guillemette, op.cit., p. 43.

${ }^{1002}$ Ibid.
} 
Au regard de ce qui précède, le Comité des droits de l'enfant - qui n'a pas retenu l'approche holistique défendue par la CDE - groupe les droits mentionnés dans cette convention en thèmes principaux, tout en réaffirmant leur étroite relation. Dans différentes directives générales concernant la forme et le contenu des rapports étatiques à lui soumettre sur l'effectivité de la CDE, il identifie 8 domaines thématiques : «1) Mesures d'application générale (articles 4, 42, et 44 paragraphe 6) ; 2) Définition de l'enfant (article 1) ; 3) Principes généraux (articles 2, 3, 6, 12) ; 4) Libertés et droits civils (articles 7, 8, 13, 14, 15, 16, 17, 37 a) ; 5) Milieu familial et protection de remplacement (article 5, 9, 10, 11, 18, 19, 20, 21, 25, 27, para 4, 39) ; 6) Santé et Bien-être (articles 6, 23, 24, 26, 27, paras 4, 39) ; 7) Education, loisirs et activités culturelles (articles 28, 29, 31) ; 8) Mesures spéciales de protection de l'enfance (article 22, 30, 32, 33, 34, $35,36,37,38,39,40) » 1003$.

\section{B. Protection spéciale de l'enfant en conflit armé}

Deux points distincts et complémentaires consacrent cette partie : l'angle de la CDE (B.1) et celui du protocole facultatif se rapportant à la Convention relative aux droits de l'enfant, concernant l'implication d'enfants dans les conflits armés (B. 2).

\section{B. 1. Suivant la CDE}

En termes des mesures spéciales de protection de l'enfant à la participation aux conflits armés, la $\mathrm{CDE}$ indique en son article 38 que «1. Les Etats parties s'engagent à respecter et à faire respecter les règles du droit humanitaire international qui leur sont applicables en cas de conflit armé et dont la protection s'étend aux enfants. 2. Les Etats parties prennent toutes les mesures possibles dans la pratique pour veiller à ce que les personnes n'ayant pas atteint l'âge de quinze ans ne participent pas directement aux hostilités. 3. Les Etats parties s'abstiennent d'enrôler dans leurs forces armées toute personne n'ayant pas atteint l'âge de quinze ans. Lorsqu'ils incorporent les personnes de plus de quinze ans mais de moins de dix-huit ans, les Etats parties s'efforcent d'enrôler en priorité les plus âgées. 4. Conformément à l'obligation qui leur incombe en vertu du droit humanitaire international de protéger la population civile en cas de conflit armé, les Etats parties prennent toutes les mesures possibles dans la pratique pour que les enfants qui sont touchés par un conflit armé bénéficient d'une protection et de soins ». "Il s'agit de la première Convention des Nations Unies sur les droits de l'Homme à introduire, part le biais de son article 38, une disposition de droit international humanitaire sur le recrutement et la participation des enfants soldats aux hostilités ${ }^{1004}$.

L'article 38 est une importante illustration des dispositions de la CDE dont les travaux préparatoires révèlent un assez faible consensus. L'on note au départ que cette disposition n'existait pas dans l'avant-projet de cette Convention. C'est en 1980 que cette lacune - l'absence d'une disposition comme celles contenues dans les PA - a été remarquée. C'est ainsi que la question de l'insertion d'un nouvel article a été soulevée par les ONG en 1982 et qu'une proposition émise par le groupe ad hoc d'ONG et soutenue par les délégations des Pays-Bas, Belgique, Suède, Finlande, Pérou et Sénégal a été présentée en 1985 précisément au cours de la

\footnotetext{
1003 Ibid., pp. 43-44.

${ }^{1004}$ MAYSTRE, Magali, op.cit., p. 51.
} 
réunion du groupe de travail du 28 janvier au $1^{\mathrm{er}}$ février 1985 . Réunion qui a précédé la $41^{\mathrm{e}}$ session de la Commission des droits de $1^{\prime}$ 'homme ${ }^{1005}$. La disposition proposée concernait d'une part, le respect des normes de DIH importantes pour les enfants dans les conflits armés et, d'autre part, l'abstention de recrutement d'enfants (sans aucune référence à un seuil d'âge) ainsi que la prise de mesures possibles pour éviter la participation des enfants aux hostilités ${ }^{1006}$.

L'historique de cet article révèle qu'il a été adopté dans un climat tendu. Le débat tournait notamment autour du seuil d'âge. Le seuil d'âge de 15 ans n'existait pas dans le texte initial qui disposait :

«1. Les Etats parties à la présente Convention s'engagent à respecter et à faire respecter les règles du droit humanitaire international applicables en cas de conflit armé dont la protection s'étend aux enfants.

2. En cas d'exécution de ces obligations, les Etats parties à la présente Convention s'abstiennent notamment, en conformité avec les règles pertinentes du droit international d'enrôler les enfants dans les forces armées et prennent toutes les mesures possibles dans la pratique pour que les enfants ne participent pas aux hostilités ${ }^{1007}{ }$ (

Ce seuil d'âge a été suggéré par le Royaume-Uni soutenu par le Bangladesh et le Canada. Lors des discussions à la suite de cette proposition, la majorité était pour le seuil d'âge de dix-huit ans, question d'être conforme avec l'article premier du projet de la convention sous examen. D'un autre côté, certains estimaient que le groupe de travail sur la Convention devrait maintenir la position du PA qui est une lex specialis et donc une référence en DIH applicable aux enfants. Il ne lui revenait donc pas de remettre en cause le travail finement ouvragé abattu par la Conférence diplomatique de 1974-1977 (Position des Etats-Unis). Un autre argument était de dire que le groupe de travail n'était pas tenu au respect de ce standard minimal et qu'il pouvait bien offrir à l'enfant une protection plus favorable ${ }^{1008}$. «Toutefois, face au risque de suppression pure et simple de la disposition entière en cas d'absence de consensus (opinion de l'Allemagne et des Etats-Unis) et surtout la ferme opposition des Etats-Unis à la version du texte adoptant le même seuil prévu pour l'article $1^{\text {er }}$ du projet de convention (dix-huit ans), la disposition finalement adoptée par le groupe de travail s'est alignée sur le texte du Protocole I, standard le plus faible ${ }^{1009}$. De l'avis de différents représentants ${ }^{1010}$ au forum des discussions, à la suite de l'adoption de ce texte, la formule choisie était moins protectrice que le standard international existant. Il s'agit donc d'une disposition conventionnelle qui fait apparaître clairement un compromis des Etats sacrifiant l'intérêt supérieur de l'enfant ${ }^{1011}$. Pour réagir face à ce standard minimal de protection de l'enfant, six Etats -Allemagne, Argentine, Colombie, Equateur, Espagne et Venezuela - ont fait des déclarations unilatérales allant dans le sens de respecter la

\footnotetext{
${ }^{1005}$ SCHINDLER, Dietrich et TOMAN, Jiri, op.cit., p. 1023.

${ }^{1006}$ MARTIN-CHENUT, Kathia, « art.cit. », p. 178.

1007 COUTURIER-BOURDINIERE, Lucile, La protection internationale des droits de l'enfant, Thèse de doctorat en Droit, discipline : Droit international, droit européen, relations internationales, op.cit., p. 455.

${ }^{1008}$ MARTIN-CHENUT, Kathia, « art.cit. », pp. 179-180.

1009 Ibid., p. 180.

${ }^{1010}$ Australie, Autriche, Belgique, Finlande, Italie, Pays-Bas, Nouvelle-Zélande, Suède, Suisse, Venezuela

1011 COUTURIER-BOURDINIERE, Lucile, La protection internationale des droits de l'enfant, Thèse de doctorat en Droit, discipline : Droit international, droit européen, relations internationales, Université PanthéonAssas (Paris II), juillet 1999, op.cit., p. 445.
} 
limite d'âge de dix-huit ans conformément à leurs législations nationales. ${ }^{1012}$ Chose d'ailleurs suggérée à d'autres Etats ${ }^{1013}$. Ce qui paraît très bénéfique pour la protection de l'enfant. Ces déclarations n'ont donc rien de contradictoire avec le droit international général et plus particulièrement le droit international de protection de l'enfant qui n'excluent pas la possibilité pour les Etats de faire application d'une protection meilleure (cf. infra).

Par ailleurs, il est remarquable que l'article 38 est la seule disposition de la CDE qui ne s'applique pas à toutes personnes de moins de dix-huit ans (enfants) ${ }^{1014}$. En clair, la reconduction de l'article 77 \$2 du PA I de 1977, «le maintien de ce statu quo est regrettable à plusieurs égards ${ }^{1015}$ au dire d'Arianne ACKE. Comment tolérer, en effet, qu'un enfant de quinze ans soit envoyé au carnage sur des champs de bataille ? Et pourtant, un Etat qui se livre à pareille abjection peut se considérer comme parfaitement en règle avec les exigences de la Convention ${ }^{1016}$. Nul doute que cela peut paraître contradictoire aux préoccupations de la CDE qui visent entre autres à élever l'enfant dans un esprit de paix et à lui accorder une protection spéciale en raison de son insuffisance de maturité physique et intellectuelle ${ }^{1017}$.

L'article 38 en ses paragraphes 2 et 3 contiennent respectivement une obligation de moyen concernant la participation directe des enfants de moins de quinze ans aux hostilités et une obligation de résultat à propos de recrutement ou d'enrôlement de ces enfants. L'obligation de moyen, au départ faible, ne concerne que la participation directe et non indirecte des enfants de moins de quinze ans. En d'autres termes, la participation indirecte à cet égard n'est pas interdite. Et comme pour les autres instruments, la question de la protection des enfants d'au moins quinze ans mais de moins de 18 ans demeure hypothétique. Pour les enfants de moins de quinze ans participants aux CANI, la protection tel qu'accordée par l'article 38 s'avère plus faible par rapport à celle accordée par l'article $4 \S 3 c$ qui interdit toute participation - directe et indirecte de ces enfants aux hostilités. Cette dernière disposition introduit une interdiction absolue $\mathrm{e}^{1018}$ autant pour le recrutement que pour la participation des enfants de moins de quinze ans aux hostilités. A ce titre, l'article 38 ne constitue donc pas une avancée pour la protection des enfants. Toutefois, l'article 38 a l'avantage d'être d'application en temps de paix et de conflits armés. Contrairement aux dispositions de PA limitées aux seules situations de conflits armés.

En outre, d'aucuns estiment que ne s'adressant qu'aux Etats parties et non expressément aux insurgés, la CDE serait d'application limitée aux seuls parties étatiques l'ayant ratifiée ${ }^{1019}$. Ce qui

\footnotetext{
1012 Ibid., p. 463

1013 Ibid.

1014 Bureau international des droits des enfants, Les enfants et les conflits armés. Un guide en matière de droit international humanitaire et de droit des droits de la personne, Bureau international des droits des enfants, Montréal, Québec, 2010, p. 111.

1015 ACKE, Arianne, «La perspective des droits de l'enfant. Conventions et instruments juridiques internationaux», in Enfants en guerre, Rapport de Conférence de la Commission Femmes et Développement, (S. éd), Bruxelles, p. 25.

1016 PREUMONT, Marc, Mémento du droit de la jeunesse 2014, éd. Wolters Kluwer Belgium SA, Waterloo, 2014, p. 20.

${ }^{1017}$ KALINDYE Byanjira D. et al., «Les enfants soldats face au Droit international humanitaire en République Démocratique du Congo », in Nouvelle Tribune Internationale des Droits de l'enfant, « art.cit. », p. 12.

1018 LARRALDE, Jean-Manuel, «Les réponses du droit international à la question des enfants soldats », « art.cit. », p. 69.

${ }^{1019}$ MAYSTRE, Magali, op.cit., p. 53.
} 
n'est donc pas le cas précisément de l'article $4 \S 3 c$ du PA II qui s'adresse indistinctement et expressément aux forces armées et aux groupes armés (cf. supra). A titre illustratif, «lors d'un conflit armé non international, si un Etat est uniquement partie à la [CDE] et non pas au PA II, les groupes armés contre lesquels il lutte ne sont pas liés par l'obligation de ne pas recruter ni d'utiliser des enfants de moins de quinze ans dans les hostilités ${ }^{1020}$. Ce point de vue n'est pas admissible si l'on sait d'abord que l'interdiction de recrutement et de participation aux hostilités des enfants de moins de 15 ans, tant en CAI qu'en CANI, relève également du DIH coutumier (cf. infra). Bien plus, les insurgés faisant non moins partie de l'Etat, il se trouve par là dans l'obligation d'appliquer les instruments conventionnels ratifiés par l'Etat sur le territoire duquel il se trouve. En d'autres termes, sauf application du droit international coutumier « [1]'applicabilité des dispositions conventionnelles par des collectivités non étatiques depend donc de l'adhésion des Etats à la convention, autrement dit, les dispositions conventionnelles ne lient que les collectivités non étatiques se trouvant sur le territoire ou sous la juridiction des Etats parties ${ }^{1021}$.

En même temps, il revient aux Etats parties suivant le premier paragraphe de l'article 38 de faire respecter les règles du DIH notamment par les insurgés se trouvant sur leurs territoires.

S'il est certes vrai que la disposition de l'article 38 accorde une protection faible au regard du droit international existant, cependant une lecture de celui-ci associé à d'autres dispositions conventionnelles permettrait une certaine amélioration. D’abord, en son paragraphe premier, l'article 38 contient une clause de renvoi aux règles de DIH applicables aux enfants en situation de conflits armés. Il faudrait comprendre par là, les règles issues des instruments juridiques dont les Etats concernés sont parties voire même les règles coutumières. Cette clause, qui constitue en même temps le rappel du Principe pacta sunt et bonne foi en droit international, permettrait d'accorder une protection plus favorable aux enfants en application notamment des dispositions du PA II pour les CANI. Le DIH s'appliquera ici en lex specialis vis-à-vis des règles issues de la CDE. Par conséquent «Lex specialis derogat legi generali » (Les règles spéciales dérogent aux règles générales). Toutefois, cette hypothèse n'est valable que si les Etats concernés par l'application des règles du DIH plus favorables aux enfants s'y trouvent liées ${ }^{1022}$. Il sied de préciser la lex specialis du DIH vis-à-vis des règles des droits de l'Homme.

En effet, la jurisprudence des organes de contrôle des droits de l'homme permet de mesurer la différence à la fois méthodologique et structurelle qui existe entre les deux ensembles normatifs (DIH et DIDH). Il est notoire que le DIDH a pour point de départ une idée abstraite et presque absolue de l'être humain, doté de certains droits inhérents à sa nature propre, donc, par définition, des droits universels et intemporels. Ces droits peuvent cependant être limités ou dérogés suivant certaines circonstances. Le DIH part, quant à lui, de la situation concrète dans le cadre du conflit armé. Il assure la réglementation d'une manière assez précise et détaillée des comportements des belligérants et la protection des personnes hors des zones de combat. C'est d'ailleurs largement dans cette mesure qu'on l'a qualifié de lex specialis. De prime abord, notamment pour les conflits armés internationaux, le DIH semble ainsi plus détaillé que les droits de l'homme. Cependant,

\footnotetext{
${ }^{1020}$ Ibid., p. 55.

1021 CUMIN, David, Le droit de la guerre. Traité sur l'emploi de la force armée en droit international, vol. 2, op. cit., p. 634.

${ }^{1022}$ Lire également dans ce sens Jaap DOEK, « Le cadre juridique international pour protéger les enfants dans les conflits armés », « art. cit. », p. 10.
} 
ceci ne signifie nullement que la protection accordée à l'individu soit meilleure sous le régime humanitaire. La vision catégorielle du DIH n'est pas nécessairement meilleure que la vision unitaire des droits de l'homme ${ }^{1023}$. D'où dans certains cas, au lieu d'affirmer le DIH comme lex specialis, il est suggéré une application simultanée du DIDH et du DIH ${ }^{1024}$.

Ainsi, rappelons que les garanties fondamentales des droits de l'homme ont une vocation universelle dans la mesure où elles s'appliquent en toutes circonstances, en temps de paix comme en temps de guerre. De ce fait les droits de l'homme comblent utilement les «zones d'ombre »du DIH. En outre à la différence du DIH, les droits de l'homme soumettent la marge d'appréciation des Etats à une supervision internationale qui, bien qu'insuffisante, leur donne une base plus objective $^{1025}$. S'appliquant en temps de paix et de conflits armés, l'article 38 de la CDE « dissipe les doutes éventuels quant aux obligations des Etats qui ne sont pas parties à un conflit armé » ${ }^{1026}$. Une portée qui s'avère plus large par conséquent plus avantageuse par rapport à la protection accordée par les PA. Et cette Convention institue un Comité des droits de l'enfant ( $c$ f. infra) auprès duquel les Etats membres soumettront leurs rapports sur des mesures prises relativement à la mise en œuvre des droits de l'enfant.

Par ailleurs, l'idée que l'article 38 affaiblirait la protection instituée par le droit international existant ne doit finalement pas être admissible. Ainsi comme l'affirme Eric DAVID, «cette crainte d'affaiblissement est d'autant moins fondée qu'il existe une clause de sauvegarde à l'article 41 qui prévoit que

«[a]ucune des dispositions de la présente convention ne porte atteinte aux dispositions plus propices à la réalisation des droits de l'enfant qui peuvent figurer :

a) dans la législation d'un Etat partie, ou

b) dans le droit international en vigueur pour cet Etat» (Dans le même sens, Protocole facultatif de 2000, art.5) ${ }^{1027}$.

A la suite d'Eric DAVID, il importe d'affirmer que l'article 41 précité vient en renfort à l'article 38. Il procède de la philosophie du système de protection des droits de l'homme tel qu'admis d'ailleurs en droit international général qui consiste pour un Etat partie à différentes conventions internationales d'accorder la meilleure protection qu'il soit conformément en son engagement sur le plan international. D'ailleurs, cette clause de sauvegarde se trouve contenue dans la plupart d'instruments juridiques internationaux (cf. infra). Il va ainsi au-delà du paragraphe premier de l'article 38 qui se limite aux règles du DIH. Sont ici prises en compte les règles issues du droit international général et du droit national de l'Etat.

Toutefois, les normes de disposition de l'article 38 ont été améliorées dans le Protocole facultatif

\footnotetext{
${ }^{1023}$ GUELLALI, Amna, «Lex specialis, droit international humanitaire et droits de l'Homme : Leur interaction dans les nouveaux conflits armés » « art.cit. », pp. 557-558.

${ }^{1024}$ FRUMER, Philippe, «Quand droits de l'homme et droit international humanitaire s'emmêlent - Un regard critique sur l'arrêt Hassan c. Royaume-Uni », in RTDH (102/2015), p. 490.

1025 El KOUHENE, Mohamed, Les garanties fondamentales de la personne en droit humanitaire et droits de l'homme, op. cit., pp. 97-98.

1026 ARZOUMANIAN, Naïri et PIZZUTELLI, Francesca, «Victimes et bourreaux : questions de responsabilité liées à la problématique des enfants-soldats en Afrique », in RICR, n 852 , « art.cit. », p. 834.

${ }^{1027}$ DAVID, Eric, Principes de droit des conflits armés, $5^{\mathrm{e}}$ édition, op. cit., p. 570.
} 
concernant l'implication d'enfants dans les conflits armés ${ }^{1028}$.

\section{B. 2. Suivant le Protocole facultatif se rapportant à la Convention relative aux droits de l'enfant, concernant l'implication d'enfants dans les conflits armés du 25 mai 2000}

Dès qu'il fut opérationnel, le Comité des droits de l'enfant consacra sa première journée de débat général aux enfants dans les conflits armés. Suite à sa recommandation, une étude globale de l'ONU sur la question sera effectuée et aboutira au Rapport de Graça Machel (cf. infra) et à la nomination du Représentant spécial du Secrétaire général pour les enfants et les conflits armés (cf. infra). Ce Comité rédigea un avant-projet du Protocole facultatif sur l'implication d'enfants dans les conflits armés. Avant-projet qu'il transmettra au groupe de travail - composé des délégués d'Etats, d'ONG, d'organismes de l'ONU et d'experts indépendants ${ }^{1029}$ - chargé de la question et mis en place par la Commission des droits de l'homme de l'ONU par sa résolution 1994/91. Le texte final dudit Protocole facultatif sera adopté par l'AG/NU le 25 mai 2000 et entré en vigueur le 12 février $2002^{1030}$.

L'article $2 \mathrm{du}$ Protocole sous examen interdit l'« enrôlement obligatoire » des personnes de moins de dix-huit ans dans les forces armées en demandant aux Etats de «veiller» que ces personnes n'en fassent pas l'objet (obligation de moyen). Cela implique également qu'ils ne peuvent imposer des obligations militaires à des personnes de moins de dix-huit ans (obligation de résultat). La règle est énoncée sur un mode général et s'applique même en dehors de tout conflit armé ${ }^{1031}$. Et au regard de l'article 3 de ce texte, l' «engagement volontaire » des enfants reste non encore protégé de manière absolue (cf. infra). Et on le sait, dans des Etats à situations économiques de précarité caractérisés par des guerres civiles ou conflits armés quasi-permanents, les enfants sont souvent attirés par les modiques sommes ou biens matériels que proposent certains groupes ou forces armés en présence. Ainsi qu'on peut bien le remarquer, une possibilité reste offerte aux Etats à employer les enfants qui s'engagent volontairement. S'il est tout de même vrai que juridiquement l'autorisation d'engagement volontaire ne rime pas nécessairement avec la participation directe aux hostilités (cf. infra), cependant, sur le terrain de combat, il n'est pas toujours évident face à certaines situations délicates des hostilités de ne point recourir aux « ressources humaines disponibles » dont les enfants recrutés qui font d'ailleurs partie ce qu'on désigne sous l'expression de «réservistes». Cette critique doit ainsi être formulée à l'endroit de l'exception développée au paragraphe 5 du même article 3 du Protocole facultatif à la CDE (cf. infra). Ce paragraphe soulève une exception à l'obligation de relever l'âge minimum d'engagement volontaire à 18 ans instituée par le paragraphe premier de l'article 3 pour les établissements scolaires placés sous l'administration ou le contrôle des forces armées des Etats parties. Ceci pourrait entraîner la participation spontannée ou volontaire des enfants. Laquelle ne se trouve réglée que de manière relative (cf. articles $1^{\text {er }}$ ou 4 du Protocole). La participation spontanée ou volontaire des enfants aux hostilités demeure une problématique que les Etats ne sont pas enthousiasmés à vouloir résoudre (cf. infra). Déjà on le sait, dès la tentative de réglementation de la participation des enfants aux hostilités, interdire la participation spontanée des enfants de moins de quinze ans notamment aux CAI «paraissait en effet irréaliste pour

\footnotetext{
${ }^{1028}$ DOEK, Jaap, « art.cit. », p.11.

${ }^{1029}$ MARTIN-CHENUT, Kathia, « art. cit. », p. 187.

${ }^{1030}$ DOEK, Jaap, « art.cit. », p.15.

${ }^{1031}$ DAVID, Eric, Les Principes de droit des conflits armés, $5^{\mathrm{e}}$ édition, op. cit., p. 568.
} 
certains, notamment dans les territoires occupés et en cas des guerres de libération nationale ${ }^{1032}$. Il serait donc préalablement prudent d'empêcher au départ tout recrutement (obligatoire ou volontaire) qui pourrait occasionner par la suite la tentative de participation.

Toujours conformément au même Protocole facultatif, l'âge d' « enrôlement obligatoire » (art. 2) et de «participation directe » aux hostilités est relevé à moins dix-huit ans (art. $\left.1^{\mathrm{er}}\right)$. La «participation indirecte» des enfants demeure cependant non protégée. Même pour cette participation directe prohibée, ou l'enrôlement obligatoire, l'obligation qui incombe aux Etats en cette matière est celle de moyen (mesures possibles) et non de résultat comme c'est le cas du PA II. Ici donc, en dehors de l'aspect d'âge de moins de dix-huit ans, le Protocole facultatif rejoint l'article 77 (2) du PA I et ne constitue aucunement une avancée par rapport à l'article 38 de la CDE qu'il est censé améliorer. Tout comme dans ces textes précités, une large marge d'appréciation est réservée aux Etats parties sur la question de protection des enfants participants aux hostilités suivant le Protocole facultatif.

En effet, « [s]i les instruments pertinents n'interdisent pas directement aux enfants de participer aux hostilités, les belligérants, eux, doivent veiller à ce que les moins de quinze ans ne participent pas aux hostilités (PA 1, art .77, §2). Pour les enfants âgés d'au moins quinze ans et n'ayant pas encore atteint dix-huit ans, il n'est pas interdit aux Etats d'accepter qu'ils s'engagent volontairement [cf. supra]. Le texte, inutilement alambiqué, du Protocole facultatif de 2000 relève cet âge à seize ans (art. 3, §1); il oblige, en outre, les Etats parties à prévoir des garanties sur le caractère réellement volontaire de l'engagement d'un enfant de moins de dix-huit ans, le consentement des parents ou tuteurs légaux, l'information des enfants concernés $(\operatorname{art} .3, \S 3){ }^{1033}$. Les tentatives du CICR et de certains Etats visant l'interdiction en CAI et en CANI de toute forme de recrutement des enfants de moins de quinze ans et de participation aux hostilités de ceux de moins dix-huit ans ont donc échoué ${ }^{1034}$.

Par ailleurs, l'article $4 \S 1$ dudit Protocole constitue une avancée significative par rapport à la CDE. Ce paragraphe dispose « [1] es groupes armés qui sont distincts des forces armées d'un Etat ne devraient en aucune circonstance enrôler ni utiliser dans les hostilités des personnes âgées de moins de 18 ans. »

A première vue, il importe de saluer cette disposition qui institue une obligation absolue concernant le recrutement (enrôlement obligatoire ou volontaire) et la participation - directe ou indirecte - des enfants de moins de dix-huit ans dans les hostilités. Contrairement à la CDE, le Protocole s'adresse ici directement aux groupes armés. Et ce bien qu'au conditionnel. Ainsi, cette disposition semble plus protectrice que les autres dispositions antérieurement examinées. Cependant, elle est d'une réglementation sélective car se limitant uniquement aux groupes armés. Les Etats ne se trouvent pas concernés par cette obligation. Les Etats ont la seule obligation de moyen c'est-à-dire de prendre toutes les mesures possibles dans la pratique pour empêcher l'enrôlement et l'utilisation de ces enfants. Si la volonté des Etats était réellement de résoudre

\footnotetext{
${ }^{1032}$ HAROUEL-BURELOUP, Véronique, op.cit., p. 305. Voy. également DEYRA, Michel, Le Droit dans la guerre, op. cit., p. 45.

${ }^{1033}$ DAVID, Eric, Principes des conflits armés, $5^{\mathrm{e}}$ édition, op.cit., p. 569.

${ }^{1034}$ Ibid.
} 
complètement ce fléau, ils devraient normalement commencer par donner l'exemple en s'interdisant eux-mêmes cette pratique. Mais ce n'est donc pas le cas.

Imposer deux types d'obligations aux Etats et aux Groupes armés, lesquels se retrouveraient sur un même champ de bataille constitue une violation du principe d'égalité des belligérants ${ }^{1035} \mathrm{ou}$ principe de non-discrimination entre belligérants. Lequel voudrait que le DIH «s'applique de manière égale aux belligérants et sans tenir compte de la légitimité des causes qu'ils poursuivent ${ }^{1036}$. Suivant ce principe, les belligérants sont tous placés sur un pied d'égalité et soumis tous aux mêmes règles. Ainsi, «cette distinction opérée selon les acteurs à un conflit armé pourrait bien amener les groupe armés à ne pas se considérer liés par un texte qui les place de jure dans une situation plus contraignante que leur adversaire et par là même discriminatoire ${ }^{1037}$. Par conséquent, cet article pose problème de l'efficacité de sa mise en œuvre.

Un autre avantage du Protocole est de prôner la pénalisation des pratiques d'enrôlement et d'utilisation d'enfants aux hostilités (art. 4 §). Ce qui parait un avantage certain par rapport aux instruments précédents. On rappellera que la violation de l'art. $77 \S 2$ ne figure pas sur la liste des infractions graves répertoriées par l'article 85 du PA I ${ }^{1038}$.

Pour tout dire, l'apport du Protocole à la protection spéciale de l'enfant en situation de conflits armés reste mitigé.

\section{§3. La Convention de l'OIT $\left(n^{\circ} 182\right)$ concernant l'interdiction des pires formes de travail des enfants et l'action immédiate en vue de leur élimination du 17 juin 1999}

Renforçant encore ce mouvement de rejet de l'utilisation d'enfants lors des conflits armés, en $1999^{1039}$, la Convention de l'Organisation Internationale du Travail ( $\left.\mathrm{N}^{\circ} 182\right)$ concernant l'interdiction des pires formes de travail des enfants et l'action immédiate en vue de leur élimination a été adoptée. Cette convention interdit quatre formes de travail des enfants, parmi lesquelles «le recrutement forcé ou obligatoire des enfants en vue de leur utilisation dans les conflits armés » qu'elle entend comme l'une des pires formes de travail des enfants et assimile à une forme de l'esclavage ${ }^{1040}$. Il s'agit du premier instrument conventionnel à vocation universelle à consacrer de manière contraignante le seuil d'âge de dix-huit ans pour le recrutement

\footnotetext{
${ }^{1035}$ Lire CUMIN, David, Le droit de la guerre. Traité sur l'emploi de la force armée en droit international, vol. 2, op. cit., p. 637 ; MARTIN-CHENUT, Kathia, « art. cit. », p. 188 ; Lire avec intérêt MEYROWITZ, Henri, Le principe de l'égalité des belligérants devant le droit de la guerre, A. Pédone, Paris, 1970, 418 p.

${ }^{1036}$ DAVID, Eric, Principes des conflits armés, $5^{\mathrm{e}}$ édition, op.cit., p. 401.

1037 MERMET, Joel, «Protocole facultatif à la Convention relative aux droits de l'enfant concernant l'implication d'enfants dans les conflits armés : quel progrès pour la protection des droits de l'enfant ? in Actualité et droit international. Revue d'analyse juridique de l'actualité internationale, Juin 2002, p. 6. http://www.ridi.org/adi/articles/2002/200206mer.htm (Source consultée le 12 avril 2015). Voy. aussi MARTINCHENUT, Kathia, « art. cit. », p. 189.

1038 CUMIN, David, Le droit de la guerre. Traité sur l'emploi de la force armée en droit international, vol. 2, op. cit., p. 633.

${ }^{1039}$ MARTIN CHENUT, Kathia, « art.cit.», p. 186

1040 «Aux fins de la présente Convention, l'expression "pires formes de travail des enfants » comprend: a) toutes les formes d'esclavage ou pratiques analogues, telles que la vente et la traite des enfants, la servitude pour dettes et le servage ainsi que le travail forcé ou obligatoire, y compris le recrutement forcé ou obligatoire des enfants en vue de leur utilisation dans les conflits armés ».
} 
d'enfants ${ }^{1041}$. Elle en donne même la définition sans ambigüité. L'élargissement du champ de protection des enfants en englobant les enfants de moins de dix-huit ans est son apport principal $^{1042}$. Toutefois, cette convention n'interdit pas l'enrôlement volontaire, ce qui est toutefois compréhensible du fait que son but premier vise à interdire l'esclavage et que celui-ci comprend un élément de contrainte ${ }^{1043}$.

\section{\$4. La protection de l'enfant en situation de conflits armés dans le système africain de protection des droits de l'homme}

Ce paragraphe se propose d'analyser les instruments juridiques adoptés sur le plan africain relatifs à la protection de l'enfant en situation de conflits armés. Il sera question d'étudier précisément la Charte africaine des droits et du bien-être de l'enfant du 11 juillet 1990 (A), le Protocole à la Charte africaine des droits de l'Homme et des peuples relatif aux droits des femmes (Protocole de Maputo) (B) et la Convention de l'Union africaine sur la protection et l'assistance aux personnes déplacées en Afrique (Convention de Kampala) adoptée par le Sommet spécial de l’Union africaine tenu le 22 octobre 2009 (C).

\section{A. La Charte africaine des droits et du bien-être de l'enfant adoptée à Addis-Abéba (Ethiopie) le 11 juillet 1990}

La protection de l'enfant par la Charte africaine des droits et du bien-être de l'enfant fait, bien entendu, partie intégrante du système africain de protection des droits de l'Homme. En d'autres termes, une protection générale des droits de l'homme dont bénéficie également l'enfant, est assurée par la Charte africaine des droits de l'Homme et des peuples adoptée le 26 juin 1981 par la Conférence des Chefs d'Etat et de gouvernement de l'OUA et entrée en vigueur le 21 octobre 1986. Cette charte est perçue d'ailleurs comme un « instrument principal et général de protection des droits de l'Homme en Afrique ${ }^{1044}$. Et à l'instar du système universel de protection des droits de l'homme, cette protection se trouve être complétée et soutenue par une protection spéciale à des catégories des êtres particulièrement vulnérables dont les enfants.

Partant de cette logique, la rédaction de cette convention régionale si peu de temps après l'adoption d'une convention universelle (CDE), symbolise d'une part le ferme soutien des Etats africains à la cause universelle des droits de l'enfant et d'autre part, le fait qu'ils pensent qu'une convention régionale peut mieux prendre en considération les problèmes spécifiques auxquels sont confrontés les enfants sur le continent africain ${ }^{1045}$. Ainsi, la Charte africaine des droits et du bien-être de l'enfant a été adoptée à la suite de «la non prise en compte dans la [CDE] de certaines questions particulières touchant des aspects spécifiques aux droits de l'enfant

\footnotetext{
${ }^{1041}$ MAYSTRE, Magali, op.cit., p. 66.

1042 MOMTAZ, Djamchid, «Les défis des conflits armés asymétriques et identitaires au droit international humanitaire », in MATHESON, Michael J., et MOMTAZ, Djamchid (dir.), op.cit., p. 48.

${ }^{1043}$ MAYSTRE, Magali, op.cit, p. 67.

1044 BOUKONGOU, Jean-Didier, «Le Système africain de protection des droits de l'enfant. Exigences universelles et prétentions africaines », in CRDF, n5, 2006, p. 100.

${ }^{1045}$ BREMS, Eva, Human Rights : Universality and Diversity, Martinus Nijhoff publishers, The Hague - Boston - London, 2001, p. 137.
} 
africain ${ }^{1046}$. Toutefois, il ne s'agit pas d'un premier texte sous cet angle régional. A la suite de l'année internationale de l'enfant en 1979, l'Organisation de l'Unité Africaine (OUA) adopta le 20 juillet 1979, la Déclaration africaine des droits de l'enfant ${ }^{1047}$. Ainsi, «face au refus de la communauté internationale de créer un déséquilibre au profit des particularismes régionaux, la communauté africaine se trouvait devant un problème juridique et moral majeur, qui ne pouvait demeurer en l'état, sans porter préjudice à l'amélioration de la condition juridique de l'enfant en Afrique ${ }^{1048}$. De ce fait, «les Etats africains ont choisi de renforcer les droits de l'enfant, en «prenant en considération les vertus de leur héritage culturel, leur passé historique et les valeurs de la civilisation africaine ${ }^{1049}$. La Charte africaine des droits et du bien-être de l'enfant qui s'inspire de la CDE, en termes des droits, principes fondamentaux et mécanisme de mise en œuvre des droits garantis, est donc un instrument juridique régional qui s'applique dans le sens de compléter la CDE sous cet angle régional ${ }^{1050}$. Suivant cette logique, la Charte africaine des droits et du bien-être de l'enfant s'inspire aussi largement du système africain de protection des droits de l'homme. Lequel «se démarque principalement à travers l'inspiration communautaire des droits de la personne, par la protection égalitaire des droits civils et des droits sociaux et par le lien établi entre les notions de droit et de devoir. L'inspiration communautaire se traduit également par la place accordée à l'enfant et à la famille au sein de la collectivité ${ }^{1051}$. De ce fait la «Charte africaine des droits de l'enfant va dans le même sens. De plus, elle n'assortit pas la reconnaissance des droits sociaux à une réalisation progressive de la part des États, et cela contrairement à la [CDE] (art. 4). Cet aspect novateur favorise l'avancement des droits de l'enfant en reconnaissant le caractère immédiat des droits sociaux $»^{1052}$.

Par ailleurs, sous l'angle essentiellement juridique, face à ces deux instruments conventionnels qui ne se veulent pas a priori contradictoires sinon complémentaires, voire tant d'autres, les Etats parties devront privilégier les dispositions législatives ou conventionnelles plus favorables à l'enfant, en vertu d'ailleurs de l'article $1^{\text {er }} \S 2^{1053}$ (clause de

1046 BOUKONGOU, Jean-Didier, «Le Système africain de protection des droits de l'enfant. Exigences universelles et prétentions africaines », in CRDF, n5, 2006, p.101; Voy. aussi LAVALLEE, Carmen, La Protection internationale des droits de l'enfant. Entre idéalisme et pragmatisme, op.cit., p.146.

${ }^{1047}$ LAVALLEE, Carmen, La Protection internationale des droits de l'enfant. Entre idéalisme et pragmatisme, op.cit., p. 146. En 12 points, les Etats africains s'invitent à accorder plus d'attention à différentes situations de l'enfant dont la situation d'inégalités des enfants de sexe féminin, l'héritage culturel et les pratiques nocifs à la croissance et au développement de l'enfant dont le mariage et «circoncision féminine » (l'excision). Ils exhortent les Organisations internationales et les ONG à agir dans ce sens. Les Etats s'invitent, par ailleurs, à mettre en place (si ce n'est pas encore fait) le programme de santé, de nutrition, d'éducation avec une priorité accordée aux enfants les plus démunis et plus vulnérables dont les handicapés physiques. Par rapport aux conflits armés, une attention particulière devant être réservée aux besoins des enfants réfugiés et déplacés. Pour plus voy. Doc. AHG/ST.4(XVI) Rev.1 (1979) in http://www.au.int/ (Source consultée le 15 juillet 2015). Voy. aussi VILJOEN, Frans, International Human Rights Law in Africa, op.cit., p. 261.

1048 BOUKONGOU, Jean-Didier, «Le Système africain de protection des droits de l'enfant. Exigences universelles et prétentions africaines », «art. cit. », p. 101. Voy. aussi VILJOEN, Frans, International Human Rights Law in Africa, op.cit., p. 262.

${ }^{1049}$ Ibid., p. 98 . Voy. aussi LAVALLEE, Carmen, La Protection internationale des droits de l'enfant. Entre idéalisme et pragmatisme, op.cit., p. 147

${ }^{1050}$ Pour une analyse comparative des droits consacrés par les deux instruments, lire avec intérêt BREMS, Eva, Human Rights : Universality and Diversity, op. cit., pp. 138-146.

${ }^{1051}$ LAVALLEE, Carmen, La Protection internationale des droits de l'enfant. Entre idéalisme et pragmatisme, op.cit., p. 147.

${ }^{1052}$ Ibid., p. 148.

1053 Article $1^{\text {er }} \S 2$ de la Charte africaine des droits et du bien-être de l'enfant: «Aucune disposition de la présente Charte n'a d'effet sur une quelconque disposition plus favorable à la réalisation des droits et de la 
sauvegarde) de la Charte africaine des droits et du bien-être de l'enfant ${ }^{1054}$.

La Charte africaine des droits et du bien-être de l'enfant a été adoptée par la $26^{\mathrm{e}}$ session de la Conférence des Chefs d'Etat et de gouvernement de l'OUA à Addis-Abeba le 11 juillet 1990 et entrée en vigueur le 29 novembre 1999. Sans entrer dans les détails, il convient de retenir que «la Charte comporte, ratione materiae, une double architecture. La première repose sur l'existence des devoirs aux côtés des droits de l'enfant. La deuxième se caractérise par la consécration des droits immédiatement applicables et des garanties de nature programmatoire ${ }^{1055}$.

En ce qui concerne particulièrement la protection de l'enfant en période de conflits armés, la Charte africaine des droits et du bien-être de l'enfant s'exprime de la manière ci-après en son article 22 portant le titre de «Conflits armés » :

«1. Les Etats parties à la présente Charte s'engagent à respecter, et à faire respecter les règles du droit international humanitaire applicables en cas de conflits armés qui affectent particulièrement les enfants.

2. Les Etats parties à la présente Charte prennent toutes les mesures nécessaires pour veiller à ce qu'aucun enfant ne prenne directement part aux hostilités et en particulier, à ce qu'aucun enfant ne soit enrôlé sous les drapeaux.

3. Les Etats parties à la présente Charte doivent, conformément aux obligations qui leur incombent en vertu du droit international humanitaire, protéger la population civile en cas de conflit armé et prendre toutes les mesures possibles pour assurer la protection et le soin des enfants qui sont affectés par un conflit armé. Ces dispositions s'appliquent aussi aux enfants dans des situations de conflits armés internes, de tension ou de troubles civils. »

En effet, la Charte africaine des droits et du bien-être de l'enfant se présente ainsi comme le rare instrument conventionnel régional régissant la protection de l'enfant en termes de prohibition de son recrutement et de sa participation aux conflits armés ${ }^{1056}$.

L'article 22 de la Charte africaine des droits et du bien-être de l'enfant se présente comme une porte ouverte à l'application des règles du DIH relatives aux enfants émanant de la coutume, des conventions internationales, des principes généraux du DIH, des résolutions, etc. Comme c'est d'ailleurs le cas pour l'article $38 \S 1$ de la CDE (cf. supra). Ainsi, il est rappelé aux Etats l'obligation de « respecter » et de « faire respecter » les règles du DIH applicables aux enfants en cas de conflits armés. Cette disposition se rapporte, on le sait déjà, à l'article $1^{\mathrm{er}}$ commun aux CG et l'article $1^{\text {er }}$ du PA I. Chose que l'on ne retrouve pas dans le PA II mais y est non moins sousentendu (cf. infra).

Analysant ci-haut les dispositions de l'article 38 de la CDE, il a été affirmé que cet article, en ses paragraphes 2 et 3 , contient respectivement une obligation de moyen concernant l'interdiction de

protection de l'enfant figurant dans la législation d'un Etat partie ou dans toute autre convention ou accord international en vigueur dans ledit Etat ».

${ }^{1054}$ Voy. BREMS, Eva, Human Rights : Universality and Diversity, op. cit., p. 137.

1055 MUTOY MUBIALA, Le système régional africain de protection des droits de l'Homme, Bruylant, Bruxelles, 2005, p. 120.

${ }^{1056}$ Voy. MAYSTRE, Magali, op.cit., p. 64. 
la «participation directe » des enfants de moins de quinze ans aux hostilités et une obligation de résultat à propos de l'interdiction de recrutement ou d'enrôlement de ces enfants. Comparativement à l'article 22 de la Charte africaine des droits et du bien-être de l'enfant, celuici institue une obligation de résultat en qui concerne l'interdiction de la «participation directe » des enfants aux hostilités. En clair, si la CDE s'exprime en termes de «Toutes les mesures possibles » que doivent prendre les Etats parties, la Charte africaine des droits et du bien-être de l'enfant s'exprime en termes de «Toutes les mesures nécessaires ». Cette obligation de résultat vaut également pour le recrutement ou l'enrôlement de ces enfants. Au sens de Jaap DOEK cette disposition «qui ne s'applique qu'aux États africains, est la plus radicale car elle interdit, sans exception, l'enrôlement obligatoire, l'engagement volontaire et l'utilisation d'enfants dans les conflits armés »1057.

Il s'avère important de signifier que contrairement à l'article 38 de la CDE, l'article 22 de la Charte demeure en parfaite harmonie avec le reste du texte entier. En ce sens, il n'existe point ici une différence d'âges d'enfants en termes de protection. Non seulement que le texte donne une définition de l'enfant sans exception - en sens qu' "[a]ux termes de la présente Charte, on entend par "enfant» tout être humain âgé de moins de 18 ans »- mais également cet âge se trouve être reconduit au niveau de la protection en période des hostilités. En d'autres termes, l'âge de la protection de l'enfant sur le plan d'enrôlement obligatoire, d'engagement volontaire et de participation directe aux conflits armés est fixé à dix-huit ans dans le cadre africain et non à quinze ans comme dans le cadre universel à travers la CDE. Il s'agit ici d'une avancée en droit international. "Il est remarquable et encourageant de penser que cette norme est celle d'un continent qui a été, et continue d'être, touché par les conflits armés ${ }^{1058}$. Ainsi, en interdisant expressément seule la participation directe et non la participation indirecte, contrairement au Protocole de Maputo par exemple (cf. infra), ce texte n'est tout de même pas la norme la plus élevée comme le pensait Jaap Doek ${ }^{1059}$.

Un autre avantage de la Charte africaine des droits et du bien-être de l'enfant, comparativement à la CDE, est notamment la protection qu'elle accorde à la population civile et aux enfants. Laquelle protection ne se limite pas seulement aux CAI et CANI mais s'étend également aux situations de tensions ou de troubles. Il s'agit ici de l'extension des règles du DIH en des situations autres que les conflits armés tels que plaident certains auteurs progressistes ou évolutionnistes. Nous pensons notamment aux écrits de Michel BELANGER (cf. supra) ${ }^{1060}$.

Par ailleurs, le fait pour la Charte africaine des droits et du bien-être de l'enfant de s'appliquer aux CAI et CANI mais aussi aux situations de tensions ou de troubles civils pour assurer la protection de l'enfant est fort apprécié. Bien que cette protection accordée au niveau du paragraphe 3 de l'article 22 de la Charte africaine des droits et du bien-être de l'enfant soit vue comme une obligation des moyens, toutefois certains pensent que «[1]es Etats africains ont ainsi fait preuve de sagesse en admettant que la protection due aux enfants ne pouvait pas être divisée, et que l'on ne pouvait pas tolérer et laisser subsister dans le cadre de certains conflits armés des

\footnotetext{
${ }^{1057}$ DOEK, Jaap, «art.cit. », 16. ; Voy. aussi McCONNAN, Isobel et UPPARD, Sarah, Des enfants Pas des soldats, Londres, The Save the Children, 2002, p. 24.

${ }^{1058}$ Jaap DOEK, « art.cit. », p. 16.

${ }^{1059}$ Ibid.

${ }^{1060}$ Lire son ouvrage Droit international humanitaire général, op.cit., 156 p.
} 
comportements que l'on interdisait dans d'autres ${ }^{1061}$.

La Charte reste tout de même sur un même plan que la CDE dans la mesure où elles interdisent toutes «la participation directe » et non la «participation indirecte » contrairement au PA II qui interdit les deux. Mais qu'il soit dit que malgré que la Charte africaine des droits et du bien-être de l'enfant ne prohibe que la «participation directe » aux hostilités et non pas la participation per $s e$, le fait qu'elle interdise totalement le recrutement rend la participation des enfants aux conflits armés moins probable ${ }^{1062}$. Une évolution très bénéfique pour la protection de l'enfant en droit international principalement en DIH. Cette protection spéciale au plan africain sera davantage renforcée, cette fois-ci, par un instrument assurant la protection de la femme, sous l'angle plus spécial de la jeune fille : le Protocole à la Charte africaine des droits de l'Homme et des peuples relatifs aux droits des femmes (Protocole de Maputo).

\section{B. Le Protocole à la Charte africaine des droits de l'Homme et des peuples relatifs aux droits des femmes adopté à Maputo (Mozambique) le 11 juillet 2003}

Le Protocole de Maputo, adopté le 11 juillet 2003 et entré en vigueur le 25 novembre 2005, contient une disposition très importante pour la protection spéciale de la jeune fille, et de l'enfant en général. Il s'agit de son article $11^{1063}$, qui à son paragraphe 4 dispose : « [1] es États prennent toutes les mesures nécessaires pour qu'aucun enfant, surtout les filles de moins de 18 ans, ne prenne part aux hostilités et, en particulier, à ce qu'aucun enfant ne soit enrôlé dans l'armée ${ }^{1064}$. Cet article est une nette avancée par rapport à l'état actuel du droit international relatif à la protection de l'enfant en période de conflits armés. Il impose aux Etats non des «mesures possibles » (obligation de moyen) mais des «mesures nécessaires » (obligation de résultat) pour empêcher toute participation - directe et indirecte- de l'enfant, particulièrement de la jeune fille, aux hostilités. A cet égard, cette disposition va encore plus loin que le texte plus protecteur existant - l'article 22 de la Charte africaine des droits et du bien-être de l'enfant - qui n'oblige que des mesures nécessaires pour la participation directe. Le présent article fixe en même temps à dix-huit ans l'âge d'enrôlement (obligatoire et facultatif) et de participation directe et indirecte de l'enfant en général, et de la jeune fille en particulier, aux hostilités. Le même âge que fixe aussi la Charte africaine des droits et du bien-être de l'enfant pour l'enrôlement (obligatoire et facultatif) et la participation directe aux

\footnotetext{
${ }^{1061}$ MAYSTRE, Magali , op.cit., p. 65.

1062 Ibid.

1063 Article 11 : Protection des femmes dans les conflits armés «1. Les États partis s'engagent à respecter et à faire respecter, les règles du droit international humanitaire applicables dans les situations de conflits armés qui touchent la population, particulièrement les femmes.

2. Les États doivent conformément aux obligations qui leur incombent en vertu du droit international humanitaire, protéger en cas de conflit armé les civils, y compris les femmes, quelle que soit la population à laquelle elles appartiennent;

3. Les États s'engagent à protéger les femmes demandeurs d'asile, réfugiées, rapatriées ou déplacées, contre toutes les formes de violence, le viol et autres formes d'exploitation sexuelle et à s'assurer que de telles violences sont considérées comme des crimes de guerre, de génocide et/ou de crimes contre l'humanité et que les auteurs de tels crimes sont traduits en justice devant des juridictions compétentes;

4. Les États prennent toutes les mesures nécessaires pour qu'aucun enfant, surtout les filles de moins de 18 ans, ne prenne part aux hostilités et, en particulier, à ce qu'aucun enfant ne soit enrôlé dans l'armée ».

${ }^{1064}$ Lire l'article 11, $\$ 4 \mathrm{du}$ Protocole à la Charte africaine des droits de l'homme et des peuples relatif aux droits des femmes, in http://www.achpr.org/fr/instruments/women-protocol/\#14 (Source consultée le 14 octobre 2015).
} 
hostilités. Et ce, contrairement au Protocole facultatif se rapportant à la CDE concernant l'implication d'enfants dans les conflits armés qui réserve une telle disposition uniquement pour des groupes armés et non pour les Etats (cf. article $4 \S 1^{\mathrm{er}}$ ). Pour leur part, sur la base de ce dernier instrument, les Etats ne doivent que veiller que les personnes de moins de 18 ans ne fassent pas l'objet d'enrôlement obligatoire dans leurs forces armées (cf. article 2). En bref, cet instrument sera préféré sous ses angles plus protecteurs notamment vis-à-vis de la Charte africaine des droits et du bien-être de l'enfant et d'autres autres instruments applicables qui d'ailleurs suggèrent l'application des instruments plus propices aux enfants ${ }^{1065}$.

\section{Convention de l'Union africaine sur la protection et l'assistance aux personnes déplacées en Afrique (Convention de Kampala) adoptée par le Sommet spécial de l'Union tenu le 22 octobre 2009}

L'Union africaine a adopté lors de son Sommet spécial tenu à Kampala (Ouganda) le 22 octobre 2009 la Convention de l'Union africaine sur la protection et l'assistance aux personnes déplacées en Afrique (Convention de Kampala), entrée en vigueur le 06 décembre 2012. Celle-ci réitère dans son ensemble les obligations internationales des Etats applicables et interdit expressément aux groupes armés de «[r]ecruter, en quelque circonstance que ce soit, des enfants, de leur demander ou de leur permettre de participer aux hostilités ${ }^{1066}$ (article $7 \S 5$ e). Cette obligation telle que formulée permet de réitérer les mêmes critiques adressées au Protocole facultatif de la CDE sur l'implication d'enfants dans les conflits armés. Cette convention a été critiquée d'imposer aux groupes armés une obligation distincte des forces armés étatiques. Ce qui portait d'office atteinte au principe d'égalité des belligérants régissant le DIH. Une conséquence néfaste était attendue quant au sort qui devrait être réservé à son application par les groupes armés.

De tout ce qui précède, la Charte africaine des droits et du bien-être de l'enfant, le Protocole à la Charte africaine des droits de l'Homme et des peuples relatifs aux droits des femmes et la Convention de l'Union africaine sur la protection et l'assistance aux personnes déplacées en Afrique sont des instruments à promouvoir en Afrique. Cette dernière est présentée comme le continent qui regorge plus de conflits armés dans le monde. Lesquels conflits armés sont plus des guerres civiles que des conflits interétatiques. La promotion et surtout la mise en œuvre de ces instruments, par les Etats parties et par les mécanismes africains de promotion et de protection des droits de l'Homme, pourrait tempérer tant soit peu le phénomène d'enfants soldats et le ciblage d'enfants dans le conflits armés. Mais hélas ! le combat est très loin d'être gagné. Il ressort donc que «la complexité du système africain, les difficultés de son institutionnalisation, la multiplication des acteurs, les capacités limitées du système et les défis titanesques sur la situation de l'enfant en Afrique indiquent que ce progrès est incertain ${ }^{1067}$.

\footnotetext{
1065 Lire par exemple l'article 41 de la Convention relative aux droits de l'enfant ou l'article 5 du Protocole facultatif se rapportant à la Convention relative aux droits de l'enfant concernant l'implication d'enfants dans les conflits armés du 25 mai 2000.

1066 Convention de l'Union africaine sur la protection et l'assistance aux personnes déplacées en Afrique (Convention de Kampala) adoptée par le Sommet spécial de l'Union tenu le 22 octobre 2009 in http://www.refworld.org/pdfid/4ae825fb2.pdf (Source consultée le 07 mai 2015).

1067 BOUKONGOU, Jean-Didier, «Le Système africain de protection des droits de l'enfant. Exigences universelles et prétentions africaines », « art. cit. », p. 104.
} 


\section{§5. Le Statut de Rome portant création de la CPI}

Concernant l'implication des enfants dans les conflits armés, les statuts des tribunaux pénaux internationaux et internationalisés (TPIY, TPIR, Tribunal Spécial pour la Sierra Leone) créés pour traiter les cas de différents pays ne mentionnent pas l'enrôlement et l'utilisation d'enfants comme constituant des crimes de guerre, contrairement au Statut de Rome de la CPI qui considère «[1]e fait de procéder à la conscription ou à l'enrôlement d'enfants de moins de 15 ans dans les forces armées nationales ou de les faire participer activement à des hostilités ${ }^{1068}$ (article 8-\$2-b-xxvi) dans le cadre des conflits armés internationaux ou «le fait de procéder à la conscription ou à l'enrôlement d'enfants de moins de 15 ans dans les forces armées ou dans les groupes armés ou de les faire participer activement à des hostilités» (article 8-§2-e-vii) en conflits armés internes comme crimes de guerre. Cette disposition est identique à l'article 4-c du Statut du TSSL ${ }^{1069}$ qui qualifie cependant ces faits expressément de «violations graves» du droit international humanitaire et non des «crimes de guerre » comme le Statut de Rome. A titre indicatif, on signalera pour l'OUA, à travers la résolution 1659 (LXIV) issue de son Conseil des Ministres tenu à Yaoundé (Cameroun) du $1^{\text {er }}$ au 5 juillet 1996, que l'utilisation des enfants dans les conflits armés « devrait être assimilée à un crime de guerre ${ }^{1070}$ (cf. infra).

Rappelons que l'expression «participation active aux hostilités 》 a fait, depuis 1969, l'objet de débats dans multiples réunions d'experts du CICR $^{1071}$. En 1970, la résolution 2675 de 1'AG/NU a substitué cette expression à celle de participation directe ${ }^{1072}$. Sa consécration actuelle dans un traité universel est perçue comme une avancée significative. Cette expression a l'avantage de couvrir « une palette beaucoup plus grande d'actes que les parties considèrent comme des actes d'hostilités ; non seulement l'engagement physique dans les combats, mais aussi des activités en relation étroite avec ceux-ci et les membres des diverses forces armées des parties ${ }^{1073}$. En d'autres termes, au regard du Statut de Rome, l'expression «participation active aux hostilités » s'entend à la fois de la participation directe et indirecte des enfants de moins de quinze ans dans les conflits armés. Le jugement dans l'affaire Thomas Lubanga Dyilo l'explique davantage (cf. supra, définition de la participation directe au Chapitre Premier). Ainsi, le Statut de Rome consacre donc l'interdiction et la criminalisation du recrutement, de la participation à la fois directe et indirecte des enfants de moins de quinze ans aux hostilités. Chose qui n'existe pas sur la liste des infractions graves établie par le PA I (cf. art. 85). Cependant, les enfants de quinze ans et plus ne se trouvent pas concernés par cette disposition. Il importe de signifier que cette limitation d'âge d'enfants

\footnotetext{
${ }^{1068}$ DOEK, Jaap, « art.cit. », p. 19.

1069 CPI, Le Procureur c Thomas Lubanga Dyilo, jugement No ICC-01/04-01/06 du 14 mars 2012, § 624, p. 311.

1070 OUA, Conseil des Ministres, Rés. 1659 (LXIV), Résolution sur la condition des enfants africains en situation de conflits armés, p. 2, § 6.

${ }^{1071}$ MALLEIN, Jean, La Situation juridique des combattants dans les conflits armés non internationaux, Thèse de doctorat d'Etat en Droit, Université de Grenoble, 1978, p. 74.

${ }^{1072}$ Ibid. L'article 2 de la Résolution 2675 (XXV) du 9 décembre 1970 de l'AG/NU dispose : « Dans la conduite des opérations militaires en période de conflit armé, une distinction doit toujours être faite entre les personnes qui prennent part activement aux hostilités et les populations civiles » (nous soulignons). Voy. cette résolution sur http://www.un.org/french/documents/ga/res/25/fres25.shtml (Source consultée le 16 avril 2016).

1073 MALLEIN, Jean, La Situation juridique des combattants dans les conflits armés non internationaux, op.cit., p. 74.
} 
n'apparaît pas dans les travaux préparatoires relatifs à la création de la CPI. A ce titre, pour les CAI, la version du Projet du Statut de Rome de 1996 mentionne en son article 20 c) 1 e) qu'on entend par (crimes de guerre) : [...] d) Le fait de contraindre un prisonnier de guerre ou un civil à servir dans les forces d'une puissance ennemie $;^{1074}$. Formulation générale, rappelant l'article 51 de la CG IV, qui vise également le cas de l'enfant à considérer comme personne civile. Concernant les CANI, une fois de plus aussi pour les conflits armés internationaux, ce Projet du Statut de Rome mentionne en son article 20 c) 2 p) qu'on entend par (crimes de guerre): [...] e) Le fait de contraindre des civils, y compris des enfants, à prendre part aux hostilités ou à accomplir des travaux forcés ou des travaux liés à des fins militaires: ${ }^{1075}$. La limite d'âge n'y est donc pas inscrite. En effet, l'inscription d'âge dans la version finale du Statut de Rome « [...] limite fortement la protection des enfants et leur droit à un recours effectif. Les chefs de groupes armés peuvent éviter d'être traduits devant la CPI s'ils n'enrôlent et n'utilisent que des enfants de 16 ans ou plus. Il est, par conséquent particulièrement important que des poursuites soient possibles au niveau national en cas d'enrôlement ou d'utilisation de toute personne âgée de moins de 18 ans ». ${ }^{1076}$

Toutefois, le Statut de Rome est une convention internationale. Il ne s'impose que dans le cadre du principe pacta sunt servanda. De nombreux Etats dont les Etats Unis d'Amérique en têtes s'opposent à l'application de cet instrument juridique sur leurs territoires et ressortissants (cf. infra).

Par ailleurs, le Statut de la CPI distingue les crimes de guerre commis dans deux types de conflits armés (CANI et CAI) et soutient l'élargissement de la notion de CANI notamment en l'absence des critères de territorialité et d'opposition gouvernements/insurgés ${ }^{1077}$ (cf. supra). «L'inclusion de crimes de guerre pouvant être commis dans le cadre de [CANI] dans le Statut de Rome est toutefois une étape importante dans la criminalisation des violations graves des lois et coutumes applicables aux $[\mathrm{CANI}]$ et mérite donc d'être soulignée ${ }^{1078}$. S'inscrivant dans le cadre des CAI, certains enfants de plus de quinze ans ne se trouvent pas totalement non protégés. Du moment où ils répondent aux critères des «personnes protégées », ils se trouveront par là sous la protection de la disposition de l'article 8 \& a) v selon laquelle « on entend par "crimes de guerre» : [...] le fait de contraindre un prisonnier de guerre ou une personne protégée à servir dans les forces d'une puissance ennemie ».

\section{§6. Les résolutions de l'ONU}

En dépit de l'absence de traitement des questions liées au DIH en son sein dès ses premières périodes (cf. supra), l'ONU n'est cependant pas nonchalante à l'égard de la situation de l'enfant en temps des conflits armés autant pour la population civile en général. S'il est certes vrai que la protection de l'enfant en période des hostilités fait preuve d'hésitation voire de léthargie déjà au

\footnotetext{
1074 Nations Unies, Assemblée générale, Rapport du Comité préparatoire pour la création d'une Cour Criminelle internationale, Volume II (Compilation des propositions), Documents officiels. Cinquante et unième session supplément $\mathrm{n}^{\circ} 22 \mathrm{~A}(\mathrm{~A} / 51 / 22)$, pp. 63 et 61 .

1075 Ibid., p. 62.

${ }^{1076}$ DOEK, Jaap, « art.cit. », p. 19

1077 Lire DAVID, Eric, «La répression pénale internationale: l'avenir de la Cour Pénale Internationale », «art. cit. », pp. 196-200.

${ }^{1078}$ MAYSTRE, Magali, op.cit., p. 151.
} 
niveau des Etats (cf. supra), l'ONU s'était déjà préoccupé de cette situation.

Bien qu'en retard, l'ONU s'intéressa à la question des droits de l'enfant à partir de 1959, soit 14 ans après sa création, par la résolution 1386 (xiv) de l'AG/NU, dite «Déclaration des droits de l'enfant » (cf. supra). Énonçant 10 principes à valeur non contraignante, elle rappelle dès son préambule la nécessité d'accorder une protection spéciale à l'enfant du fait de son manque de maturité physique et intellectuelle. Ces droits incluent notamment l'éducation et les soins, ainsi que la protection et les secours. La lecture en filigrane du dixième principe présage l'intérêt majeur que l'ONU accordera par la suite aux enfants soldats. Celui-ci dispose que: « [1]'enfant doit être protégé contre toute forme de négligence, de cruauté et d'exploitation, il ne doit pas être soumis à la traite, sous quelque forme que ce soit. L'enfant ne doit pas être admis à l'emploi avant d'avoir atteint un âge minimum approprié; il ne doit en aucun cas être astreint ou autorisé à prendre une occupation ou un emploi qui nuise à sa santé ou à son éducation, ou qui entrave son développement physique, mental ou moral ${ }^{1079}$.

Quinze ans plus tard, l'ONU se penchera de nouveau sur cette question d'enfants en situation de conflits armés notamment à travers une importante déclaration proclamée par l'AG/NU en résolution 3318 (XXIX) le 14 décembre 1974 à savoir la «Déclaration sur la protection des femmes et des enfants en période d'urgence et de conflit armé ». Cette déclaration contextualise au départ la situation sous examen. Elle se préoccupe d'assurer la protection des femmes et enfants se retrouvant dans les situations d'urgences ou des conflits armés dans le cadre de lutte pour la paix, l'autodétermination, la libération nationale et l'indépendance. Il s'agit des situations où une des parties au conflit lutte contre le colonialisme, le racisme, la domination ou la sujétion étrangère ou l'agression. Situations que condamne l'ONU notamment l'AG/NU à travers différentes résolutions des années 60 et 70 . En ces situations, les femmes et enfants sont victimes de nombreux préjudices issus des violations des règles de DIH devant les protéger et des droits fondamentaux et de la dignité humaine. Des mesures importantes devraient être adoptées et les Etats devraient veiller à leur mise en application. La présente résolution interdit des attaques et bombardements contre la population civile notamment les femmes et enfants qui sont les plus vulnérables. L'interdiction des armes biologiques et bactériologique au cours des opérations militaires comme le prescrivent bien les règles du DIH y est formulée. Il est fait rappel aux Etats d'assurer les obligations qui leur incombent conformément au DIH et au DIDH à l'endroit des femmes et enfants en période des hostilités. Les Etats, notamment les parties au conflit, devraient prendre des mesures importantes pour épargner aux femmes et enfants des ravages de la guerre en les préservant notamment de persécution, représailles, tortures, traitements dégradant ou violences. Ainsi toutes les dispositions inscrites dans les instruments internationaux relatifs aux droits de l'Homme en pareilles circonstances seront donc appliquées en vue d'assurer leur survie. Tous ces actes contraires seront donc condamnés.

Cette importante déclaration fait suite à la recommandation du Conseil économique et social de l'ONU, contenue dans sa résolution 1861 (LVI) du 16 mai 1974, préoccupé par la situation des femmes et enfants en des temps d'urgences et des conflits armés décrits ci-dessus. La déclaration rappelle en même temps ses importantes résolutions adoptées dans le cadre de l'ONU qui

$\overline{{ }^{1079} \text { REYNAUD, Oriane, op.cit., p. } 13 .}$ 
tiennent au respect des droits de l'Homme et des principes fondamentaux touchant au respect de la population civile en période de conflits armés. La résolution 1515 (XLVIII) du Conseil économique et social du 28 mai 1970, dans laquelle le Conseil a prié l'AG/NU de considérer la possibilité d'élaborer un projet de déclaration sur la protection des femmes et des enfants en période d'urgence ou en temps de guerre, a été également rappelée.

De tout ce qui précède, en dépit de la haute valeur morale qu'elle représente, la déclaration décrite ci-dessus est dépourvue de force obligatoire comme recommandation au sens formel. Toutefois, «[1]'absence de force obligatoire des recommandations ne signifie pas qu'elles n'ont aucune portée. Si tel était le cas, on s'expliquerait mal l'acharnement des débats conduisant à leur adoption. Comme l'a rappelé la CIJ dans son avis consultatif de 1996 sur la Liceité de la menace ou de l'emploi d'armes nucléaires, "les résolutions de l'Assemblée générale, même si elles n'ont pas de force obligatoire, peuvent parfois avoir une valeur normative ». Leur impact politique est souvent fondamental et même leur valeur juridique n'est pas négligeable ${ }^{1080}$. Ainsi, dans le cas de la présente déclaration, il faudrait bien dire qu'elle recense et fait rappel des instruments internationaux pertinents relatifs au DIH et au DIDH devant assurer la protection de la population civile, plus particulièrement celle la plus vulnérable - femmes et enfants - en périodes des hostilités. Ces instruments précités cristallisent dans la plupart le droit international coutumier voire le jus cogens (cf. supra). En définitive, la «Déclaration sur la protection des femmes et des enfants en période d'urgence et de conflit armé »n'est point à considérer comme un simple instrument de soft law qui pourrait être violé comme l'on voudrait bien. Il mérite donc observance ne serait-ce que du fait qu'il fait mention des textes qui font référence au droit international coutumier. Cette situation s'étendra également pour les autres déclarations ou résolutions issues de l'AG/NU qui feront références précisément aux règles de DIH et de DIDH.

De nombreuses résolutions encore plus importantes seront adoptées au sein de l'AG/NU pour assurer de manière toute particulière la protection de l'enfant en période de conflit armé.

En effet, l'AG/NU a adopté la résolution 48/157, en date du 20 décembre 1993, intitulée «Protection des enfants touchés par les conflits armés». l'AG/NU rappelant les différents instruments juridiques assurant la protection spéciale de l'enfant en période de conflits armés (dont les CG, PA et l'art. 38 de la CDE), s'est déclarée profondément préoccupée de la situation tragique dans laquelle se trouvent les enfants de nombreuses régions du monde du fait de conflits armé. Elle a prié tous les États membres de poursuivre leurs efforts pour une amélioration notable de cette situation avec des mesures concrètes appropriées. En même temps, elle a recommandé la coopération des organismes de l'ONU ainsi que des organisations intergouvernementales et non gouvernementales, dans le cadre de leurs mandats respectifs, pour s'attaquer avec plus d'efficacité à ce fléau ${ }^{1081}$.

Ce n'est donc que le 20 décembre 1993 que la thématique des enfants touchés par les conflits armés fut inscrite spécifiquement à l'ordre du jour des débats de l'AG/NU ${ }^{1082}$.

\footnotetext{
${ }^{1080}$ DAILLIER, Patrick, FORTEAU, Mathias et PELLET, Alain op.cit., p. 417.

${ }^{1081}$ Lire la Résolution A/RES/48/157, in http://www.un.org/fr/documents/view doc.asp?symbol=A/RES/48/157 ( Source consultée le 10 août 2013).

1082 REYNAUD, Oriane, op.cit., p. 26.
} 
Pour matérialiser ses vœux, l'AG/NU a prié le SG/NU de désigner un expert qui, en collaboration avec le Centre pour les droits de l'homme du Secrétariat et l'UNICEF, entreprendrait une étude approfondie de la question, portant notamment sur la participation des enfants à des conflits armés et le point de savoir si les normes en vigueur sont suffisantes et bien adaptées ${ }^{1083}$. Cette étude, première du genre dans les annales de l'ONU, formulera des recommandations spécifiques sur les moyens d'empêcher les enfants d'être touchés par les conflits armés et de mieux les protéger en pareilles situations. Ces recommandations se préoccuperont également sur les mesures propres à assurer la protection effective des enfants, notamment contre l'emploi aveugle de toutes les armes de guerre, spécialement les mines antipersonnel, leur réadaptation physique et psychologique et leur réinsertion sociale, etc ${ }^{1084}$. Et le 8 juin 1994, Mme Graça Machel (Mozambique) sera désignée par le SG/NU comme expert pour entreprendre une telle étude. Conformément à la résolution précitée $(\$ 8)$, pour faire bénéficier à cette étude des plus hautes qualités d'exactitude et de professionnalisme, l'expert aura recours aux conseils et avis d'un groupe formé de personnalités d'une intégrité et d'une réputation d'envergure internationale, provenant de divers horizons. Une assistance technique et administrative sera également mise à sa disposition $^{1085}$. Ainsi comme mentionné dans la résolution A/51/306 du 26 août 1996 de l'AG/NU, le SG/NU communiquera à l'AG/NU, le Rapport de l'expert, une centaine de pages.

«Dans cette étude, l'expert propose aux États Membres et à la communauté internationale les éléments d'un programme d'action détaillé en vue d'améliorer la protection et la prise en charge des enfants dans les conflits et d'empêcher l'apparition de ces conflits. L'étude montre l'importance fondamentale de ces questions pour le respect des droits de l'homme à l'échelon international, pour la paix et la sécurité et pour le développement. Elle doit inciter la communauté internationale à agir d'urgence et avec détermination afin d'améliorer le sort des enfants touchés par les conflits armés ${ }^{1086}$. En ce qui concerne 1'ONU dans son ensemble, l'étude réserve un titre important sur sa responsabilité dans la mise en œuvre de la protection des enfants notamment en situation de conflits armés du paragraphe 281 à 306. Un rappel important de la Déclaration et du Programme d'action de Vienne adoptés par la Conférence mondiale sur les droits de l'homme le 25 juin 1993 (A/CONF.157/24, Partie I, chapitre III) a été fait. Ces documents contiennent une recommandation d'une ultime nécessité tendant à ce que les questions touchant les droits des enfants soient périodiquement revues et suivies par tous les organes et mécanismes intéressés du système des Nations Unies ainsi que par les organes directeurs des institutions spécialisées, conformément à leurs mandats respectifs. La protection de l'enfance doit en effet être l'un des principaux éléments des politiques humanitaires et des politiques d'instauration et de maintien de la paix des Nations Unies et devrait recevoir la priorité dans toute action entreprise pour défendre les droits de l'homme et les considérations humanitaires ${ }^{1087}$. Il a été ainsi encouragé aux différents mécanismes onusiens de protection des droits de l'homme de

$1083 \quad \S 7 \quad$ de $\quad$ la $\quad$ Résolution $\quad$ A/RES/48/157,

http://www.un.org/fr/documents/view_doc.asp?symbol=A/RES/48/157 ( Source consultée le 10 août 2013). 1084 Ibid

${ }^{1085} \mathrm{AG} / \mathrm{NU}, \quad \mathrm{A} / 49 / 643 \quad 4 \quad$ novembre $\quad 4994 \quad$ http://www.refworld.org/cgibin/texis/vtx/rwmain/opendocpdf.pdf?reldoc=y\&docid=4a38d1e22 (recherche menée le 10 août 2013).

${ }^{1086}$ Paragraphe 2 de la résolution A/51/306 du 26 août 1996 http://www.unicef.org/french/emerg/files/GarcaMachel_fr.pdf (recherche menée le 10 août 2013).

$\begin{array}{llllll}1087 & \mathrm{AG} / \mathrm{NU}, & \mathrm{A} / 49 / 643 & 4 & \text { novembre } & 1994 \quad \mathrm{http} / / / \mathrm{www} . \text { refworld.org/cgi- }\end{array}$ bin/texis/vtx/rwmain/opendocpdf.pdf?reldoc=y\&docid=4a38d1e22 (recherche menée le 10 août 2013).

${ }^{1087}$ Paragraphe 2 de la résolution A/51/306 du 26 août 1996 http://www.unicef.org/french/emerg/files/GarcaMachel fr.pdf (recherche menée le 10 août 2013). 
travailler en collaboration sur ce sujet et surtout de prendre spécialement en considération la situation des enfants affectés par les conflits armés dans l'examen des rapports périodiques des droits de l'homme qui leur sont soumis (voy. paragraphe 287).

Par ailleurs, faisons remarquer que « ces recommandations ont abouti dès 1996 à la désignation d'un représentant spécial du Secrétaire général pour les enfants et les conflits armés ${ }^{1088}$.

En dehors des textes précités, il existe d'innombrables résolutions et déclarations adoptées par l'AG/NU en rapport avec la situation des enfants en général et sur la situation des enfants dans conflits armés en particulier. L'on citera notamment la résolution 62/293 du 12 août 2012 relative au Plan d'action mondial des Nations unies pour la lutte contre la traite des personnes; la résolution 62/141 sur les droits de l'enfant du 22 février 2008 ; la résolution 61/146 du 19 décembre 2006 ; la résolution 60/141 du 16 décembre 2005 ; le document final de sa vingtseptième session extraordinaire consacrée aux enfants intitulé «Un monde digne des enfants » de mai 2002 ; la Déclaration du Millénaire adoptée à New-York le 8 septembre 2000 ; la résolution 51/77 ; la Déclaration et le Programme d'action de Vienne du 25 juin 1993 ; etc.

Concernant le CS/NU, c'est depuis 1998, année à partir de laquelle la préoccupation des enfants touchés par les conflits armées a été officiellement inscrite à son ordre du jour. A eu lieu donc le premier débat sur les enfants et les conflits armés au sein du CS/NU ${ }^{1089}$. La volonté de ce dernier d'agir contre ce fléau s'est concrétisée par l'adoption d'importantes mesures. C'est ainsi que non seulement des débats et un examen sur cette question sont désormais organisés chaque année ${ }^{1090}$, mais aussi, d'importantes résolutions sont adoptées régulièrement pour réguler ce fléau ${ }^{1091}$. On citera notamment les résolutions 1261(1999), 1314 (2000), 1379 (2001), 1460 (2003), 1539 (2004), 1612 (2005), 1882 (2009), 1998 (2011), 2068 (2012), 2143 (2014), 2225 (2015) du $\mathrm{CS} / \mathrm{NU}$, etc.... Il s'agit là du cadre général de protection spéciale des enfants en période de conflits armés.

Ainsi pour l'application de ces résolutions notamment par les Etats, leur interprétation suggère l'analyse de leurs libellés ou des termes utilisés et de leur contexte d'adoption ${ }^{1092}$. Question de préciser leurs conséquences juridiques, savoir ainsi s'il s'agit d'exhortation ou d'injonction ${ }^{1093}$. Et en cas d'injonction, les Etats se trouvent obligés d'assurer leur application en vertu

\footnotetext{
${ }^{1088}$ LARRALDE, Jean-Manuel, « art.cit. », p. 72.

${ }^{1089}$ Voy. https://childrenandarmedconflict.un.org/fr/qui-sommes-nous/historique/ (Source consultée le 22 février 2016).

${ }^{1090}$ AYISSI, Anatole et MAIA, Catherine, «La lutte contre le drame des enfants soldats ou le conseil de sécurité contre le terrorisme à venir... », in $R T D H,(58 / 2004)$, p. 342.

${ }^{1091}$ Voy. HAPPOLD, Matthew, «Protecting children in Armed conflict: harnessing the Security Council's "Soft power" », « art. cit. », p. 363.

1092 CEDH, affaire Al-Jedda c. Royaume-Uni, arrêt 07 juillet $2011, \quad \S \quad 76$ http://hudoc.echr.coe.int/sites/eng/pages/search.aspx?i=001-105613\#\{"itemid":["001-105613 (Source consultée le 18 février 2016). Par contexte d'adoption de résolution, il faudrait comprendre « les débats qui ont précédé son adoption, des dispositions de la Charte invoquées et en général de tous les éléments qui pourraient aider à préciser les conséquences juridiques de la résolution du Conseil de sécurité ». Voy. CIJ, Conséquences juridiques pour les Etats de la présence continue de l'Afrique du Sud en Namibie (Sud-ouest africain) nonobstant la résolution 276 (1970) du Conseil de sécurité, avis consultatif, Recueil 1971, p. 53, § 114.

1093 CIJ, Conséquences juridiques pour les Etats de la présence continue de l'Afrique du Sud en Namibie (Sudouest africain) nonobstant la résolution 276 (1970) du Conseil de sécurité, avis consultatif, Recueil 1971, p. 53, $\S 114$.
} 
notamment de l'article 25 de la Charte des Nations Unies ${ }^{1094}$.

En effet, pour l'analyse de quelques unes d'entre elles, la résolution 1261 (1999) est celle adoptée par le CS/NU à sa 4037e séance, le 25 août 1999. Elle note avec satisfaction en son préambule les efforts fournis au niveau de la Communauté internationale pour lutter contre le phénomène enfant soldat notamment avec la Convention $\mathrm{n}^{\circ} 182$ de l'OIT et le Statut de Rome portant création de la CPI. Par la suite, elle « [c]ondamne énergiquement le fait de prendre pour cible les enfants dans des situations de conflit armé, notamment les assassinats et les mutilations, les violences sexuelles, les enlèvements et le déplacement forcé, le recrutement et l'utilisation d'enfants dans les conflits armés en violation du droit international, ainsi que les attaques contre des objets protégés en vertu du droit international, y compris les lieux où des enfants se trouvent généralement en nombre, tels que les écoles et les hôpitaux, et enjoint à toutes les parties concernées de mettre fin à de telles pratiques ${ }^{1095}$. Elle «exhorte » à ce sujet toutes les parties concernées de respecter scrupuleusement leurs obligations internationales particulièrement en vertu des CG, PA et la CDE, et souligne leur obligation de poursuivre les responsables de ces violations graves ${ }^{1096}$.

Pour rendre effectifs les droits de l'enfant, à travers cette résolution, le CS/NU appuie les mécanismes institués dans le cadre du système onusien relatif à la protection des enfants de même que d'autres organisations internationales compétentes en la matière. C'est dans ce sens qu'il appuie les actions que mènent le Représentant spécial du secrétaire général des Nations Unies pour les enfants et les conflits armés, l'UNICEF et le HCR (cf. \$4 de la résolution 1261). Afin de réduire au minimum les souffrances infligées aux enfants, il demande aux parties aux conflits armés de prendre des mesures concrètes telles que des «jours de tranquillité » afin de permettre la prestation de service de première nécessité à l'endroit des enfants. Les parties devront tenir à ces engagements ou mesures concrets (cf. $\$ 8$ et 9 de la résolution 1261). Des mesures spéciales doivent être prises en faveur des enfants en particulier des petites filles notamment «contre le viol et les autres formes de violence sexuelle et fondée sur le sexe dans les situations de conflit armé » (cf. $\$ 10$ de la résolution 1261).

Tout de même, les mesures à prendre en faveur de la protection de l'enfant ne devront pas se limiter en situation des hostilités mais aussi en temps de paix ou mieux après les conflits armés. La protection de l'enfant doit ainsi servir à l'édifice d'un environnement protecteur pour tous les enfants. En cela, la protection des enfants ne se limiterait pas seulement aux situations d'urgence mais aussi au contexte politique, social, économique, ou familial où vivent ces enfants ${ }^{1097}$. Le CS/NU encourage, par ce fait, les parties aux conflits armés de prendre en considération la protection, les droits et le bien-être de l'enfant dans leurs différentes négociations de paix ou dans processus de paix auquel elles sont engagées. Ainsi, le CS/NU «[e]xhorte les États et les organismes des Nations Unies à faciliter le désarmement, la démobilisation, la réhabilitation et

\footnotetext{
1094 Art. 25 de la Charte des Nations Unies: "Les Membres de l'Organisation conviennent d'accepter et d'appliquer les décisions du Conseil de sécurité conformément à la présente Charte".

1095 \$2 de la résolution 1261 (1999) http://www.un.org/fr/documents/scres.shtml (Source consultée le 14 février 2015).

1096 Ibid., §3.

1097 BODINEAU, Sylvie, Figures d'enfants soldats. Puissance et vulnérabilité. Regard anthropologique sur l'intervention humanitaire de protection des « enfants soldats » en République démocratique du Congo entre 1996 et 2011, op.cit., p. 9.
} 
la réintégration des enfants utilisés comme soldats en violation du droit international, et demande en particulier au Représentant spécial du Secrétaire général pour les enfants et les conflits armés, à l'UNICEF, au HCR et aux autres organismes compétents des Nations Unies de redoubler d'efforts à cet effet ${ }^{1098}$.

La résolution suivante du CS/NU en faveur des enfants en période des hostilités est celle 1314 (2000) adoptée le 11 août 2000 à la $4185^{\mathrm{e}}$ séance du CS/NU. Celle-ci reprend dans la plupart de ses dispositions les acquis de la résolution 1261. Le CS/NU se félicite tout de même de l'adoption le 25 mai 2000 du Protocole facultatif à la CDE concernant l'implication d'enfants dans les conflits armés. Elle demande par conséquent aux Etats membres de le signer et de le ratifier ( $\$ 4$ de la résolution 1314).

Bien plus, le fait pour le CS/NU à travers sa résolution 1314 (1999) d'épingler les pratiques consistant à prendre délibérément pour cible, en conflits armés, les populations civiles ou autres personnes protégées, y compris les enfants, et commettre ainsi des violations du DIH et DIDH comme pouvant constituer une menace contre la paix et la sécurité internationales ${ }^{1099}$ s'avère très capital. Ceci lui permettra d'agir en bon escient sous chapitre VII de la Charte des Nations Unies et déployer par conséquent tous les mécanismes prévus. Situation qui pourrait permettre de jouer un rôle très considérable face à ce fléau d'enfants soldats.

Cette résolution veut également bien faire entendre la voix de l'enfant. C'est justement dans ce sens qu'elle demande aux Etats et aux organisations notamment celles de la société civile s'occupant des questions des enfants d'encourager la participation des jeunes aux programmes de consolidation et renforcement de paix (cf. $\$ 19$ de la résolution 1314). Et pour se rendre compte de la mise en application de deux résolutions adoptées, le CS/NU priera au SG/NU de lui présenter le 31 juillet 2001 au plus tard un rapport à ce sujet. Il le fera également pour le reste de ses résolutions.

Et sur base du rapport du SG/NU qui sera présenté finalement en date du 7 septembre 2001, la résolution 1379 (2001) sera adoptée le 20 novembre 2001 par le CS/NU à sa 4423e séance. Cette résolution reprend en majeure partie certaines dispositions de ses prédécesseurs. Le CS/NU «se déclare résolu par conséquent à accorder à la protection des enfants dans les conflits armés la plus grande attention lorsqu'il examine les questions dont il est saisi ${ }^{1100}$. Il se déclare en outre " disposé à prévoir explicitement des dispositions assurant la protection des enfants lorsqu'il examine le mandat des opérations de maintien de la paix et, à cet égard, se déclare à nouveau prêt, le cas échéant, à continuer de doter les opérations de maintien de la paix de conseillers en matière de protection des enfants $\gg{ }^{1101}$. Comme dans la résolution 1261 (\$3) mais également dans d'autres résolutions subséquentes, le $\mathrm{CS} / \mathrm{NU}$ réitère, par la présente résolution, aux Etats leur obligation de poursuivre les auteurs des graves violations du DIH et du DIDH notamment celles commises sur les enfants (cf. §9).

\footnotetext{
$1098 \S 15$ de la résolution 1261 (1999) du CS/NU http://www.un.org/fr/documents/scres.shtml (Source consultée le 10 août 2013).

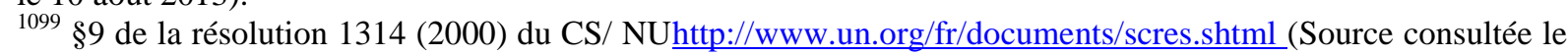
10 août 2013).

${ }^{1100} \S 1$ de la résolution 1379 (2001) du CS/NU http://www.un.org/fr/documents/scres.shtml (Source consultée le 11 août 2013).

${ }^{1101}$ Ibid., $\$ 2$.
} 
Faisant suite à la demande du rapport de l'application de la résolution 1379 (2001) (cf. § 15), le SG/NU «remettait au CS/NU, le 26 novembre 2002, un rapport officiel faisant le point sur les progrès accomplis dans l'application du corpus juridique visant à protéger les jeunes des souffrances de la guerre. Ce rapport est extrêmement novateur en ce qu'il met clairement en évidence la distance qui sépare les normes posées au niveau international de leur respect effectif sur le terrain, et ce, afin que cette prise de conscience s'ouvre enfin sur une « phase de mise en œuvre ». Mais surtout, il fournit en annexe une liste où sont recensés et explicitement mentionnés ceux qui violent les lois de protection des enfants victimes des guerres ${ }^{1102}$. Cette méthode s'avère d'une certaine efficacité dans la mesure où elle pourra avoir un effet dissuasif à l'égard des parties qui recourent à la pratique des violations des droits reconnus aux enfants et aux règles du DIH devant s'appliquer aux enfants en pareilles circonstances. La rédaction des rapports du $\mathrm{SG} / \mathrm{NU}$ avec des annexes désignant les auteurs ou parties violant les règles du droit international relatif à la protection des enfants sera de mise pour les autres résolutions qui suivront. Il sera établi par la suite un mécanisme de surveillance et de communication des informations à la résolution 1612 (2005) mais déjà réclamé à la résolution 1539 (2004) (cf. infra). La résolution 1460 (2003) qui sera adoptée par le CS/NU à sa 4695e séance, le 30 janvier 2003, assurera la continuité de la résolution précédente. C'est dans ce sens qu'il sera demandé au SG/NU de soumettre au CS/NU, avant le 31 octobre 2003, un rapport sur l'application de la résolution 1379 (2001) et de cette résolution elle-même ${ }^{1103}$.

Tout en réitérant les dispositions des résolutions précédentes sur les questions des enfants sur le champ de bataille, la résolution $1460 \mathrm{du}$ CS/NU note avec préoccupation en son paragraphe 10 les cas où des femmes et des enfants, en particulier des filles, ont été victimes d'exploitation et de sévices sexuels dans le cadre d'une crise humanitaire, en particulier ceux qui sont le fait de soldats de la paix et d'agents humanitaires. Il recommande aux Etats fournisseurs de ces contingents à cet effet le respect de codes de conduite destinés à ce personnel et la mise sur pied des mécanismes devant établir leur responsabilité et de sanction disciplinaire appropriée.

La résolution 1460 du CS/NU sera suivie de celle 1539 (2004) adoptée par le CS/NU à sa séance 4948, le 22 avril 2004. Si à travers cette dernière résolution, le CS/NU se satisfait des progrès accomplis dans les domaines de la sensibilisation du public et de l'élaboration de règles de protection des enfants touchés par les conflits armés (cf. préambule), il reste tout de même profondément préoccupé par l'absence des progrès sur le terrain. Car les parties aux conflits continuent de violer impunément le droit international relatif à la protection des enfants dans les conflits armés. Le CS/NU souligne ainsi sa détermination de faire respecter ses résolutions et règles internationales pour la protection des enfants touchés par les conflits armés.

Ayant examiné le rapport du SG/NU en date du 10 novembre 2003, conformément à la résolution 1460 (2003) sans pourtant tirer des conclusions juridiques sur les situations visées dans ce rapport et sur le statut juridique des parties non étatiques, le CS/NU prend un certain nombre de mesures. Il prie le SG/NU, «compte tenu des propositions contenues dans son rapport ainsi que de tous autres éléments pertinents, de mettre au point d'urgence et de préférence d'ici à trois mois, un plan d'action pour un mécanisme systématique et global de surveillance et de communication de

1102 AYISSI, Anatole et MAIA, Catherine, « art.cit », pp. 349-350.

1103 Lire le $\$ 16$ de la Résolution 1460 (2003) du CS/NU http://www.unicef.org/french/emerg/files/S-RES1460 fr.pdf (Source consultée le 10 août 2013). 
l'information faisant appel aux compétences du système des Nations Unies et aux contributions des gouvernements nationaux, des organisations régionales, des organisations non gouvernementales à titre consultatif et des divers acteurs de la société civile, afin de disposer en temps voulu d'informations objectives, exactes et fiables sur le recrutement et l'utilisation d'enfants soldats en violation $d u$ droit international applicable et sur d'autres violations et sévices commis contre les enfants touchés par les conflits armés, pour examen dans le cadre d'une action appropriée ${ }^{1104}$. Entretemps, le CS/NU ne cesse de condamner de par cette résolution le recrutement et l'utilisation d'enfants soldats par les parties aux conflits armés en violations des obligations qui leur incombent au plan international. Il se résout entre autre à prendre «des mesures appropriées, en particulier en envisageant des activités sous régionales et transfrontières, pour s'attaquer aux liens entre le commerce illicite de ressources naturelles et autres, le trafic d'armes légères et l'enlèvement et le recrutement transfrontières d'enfants, d'une part, et les conflits armés, de l'autre, et qui peuvent prolonger ces conflits et en aggraver l'effet sur les enfants, et prie donc le Secrétaire général de proposer des mesures effectives pour réprimer ce commerce et ce trafic illicites ${ }^{1105}$.

Après lecture du rapport présenté par le $\mathrm{SG} / \mathrm{NU}$, le $\mathrm{CS} / \mathrm{NU}$ demande aux parties aux conflits de préparer en collaboration avec les missions de paix des Nations Unies de leurs pays respectifs, dans les trois mois, des plans d'action concrets et à délais pour arrêter le recrutement et l'utilisation d'enfants en violation des obligations internationales qui leur sont applicables. Il envisage de prendre des mesures ciblées et progressives à l'endroit des parties qui ne respecteraient pas ces engagements ou qui refuseraient le dialogue. Le CS/NU réitère, comme d'habitude, les dispositions arrêtées dans les résolutions précédentes, encourage et assure son soutien à la coopération entre les mécanismes onusiens, organisations internationales ou régionales ou sous régionales, et les parties aux conflits armés afin d'assurer la protection de l'enfant. Le rôle important de l'éducation dans les zones de conflits a été reconnu et rappelé aux parties aux conflits armés. Un accent particulier a été mis sur l'éducation au VIH/Sida. Enfin, au paragraphe 15, il a été prié au SG/NU de soumettre au CS/NU un rapport sur l'application de la présente résolution et des résolutions précédentes. Il lui reviendra notamment d'incorporer dans son rapport des informations sur le respect des engagements et les progrès des parties mentionnées dans son rapport. Il devra fournir également des informations sur les progrès accomplis concernant le plan d'action demandé au paragraphe 2 de la présente résolution et l'incorporation des meilleures pratiques pour les programmes de désarmement, de démobilisation et de réinsertion évoqués également dans son rapport.

Il sera par la suite adopté par le CS/NU à sa 5235e séance la résolution 1612 (2005), le 26 juillet 2005. A travers cette résolution, le CS/NU prendra note du plan d'action présenté par le SG/NU pour la mise en place du mécanisme de surveillance et de communication de l'information sur les enfants et les conflits armés ${ }^{1106}$ tel que demandé au paragraphe 2 de sa résolution $1539(2004)^{1107}$

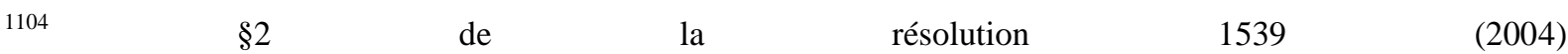

http://www.un.org/french/documents/view_doc.asp?symbol=S/RES/1539\%20(2004) (Source consultée le 04 novembre 2013).

1105 Ibid., $\$ 3$.

1106 Pour le contexte d'adoption de cette résolution, Voy. Bureau du Représentant Spécial du Secrétaire général pour les enfants et les conflits armés, Examen stratégique décennal de l'Etude Machel : les enfants et les conflits armés dans un monde en mutation, UNICEF, New-York, 2009, p. 47.

$\begin{array}{lllllllll}1107 & \$ 2 & \text { de } & \text { la } & \text { résolution } & 1612 & \text { (2005) } & \text { du } & \text { CS/NU }\end{array}$
} 
(Lire le paragraphe $1^{\mathrm{er}}$ de la Section III du Chapitre III de la seconde partie).

La résolution 1612 sera suivie de la résolution 1882 (2009) adoptée à la 6176e séance du CS/NU, le 4 août 2009. La présente résolution constate en son préambule «que l'application de [1]a résolution 1612 (2005) a permis de réaliser des progrès, aboutissant à la libération et à la réinsertion d'enfants dans leur famille et leur collectivité et à un dialogue plus systématique entre les équipes spéciales des Nations Unies au niveau des pays et les parties aux conflits armés concernant l'exécution de plans d'action assortis d'échéances ». En même temps, elle regrette profondément l'absence des progrès dans certaines situations de conflits armés où les enfants demeurent des victimes de meurtres et de mutilations à la suite de leur ciblage, voire de viols et violences commis avec brutalité, etc.

Le CS/NU condamne de nouveau cette situation et réaffirme que le mécanisme de surveillance et d'information établi par la résolution précédente continuera à être mis en place conformément aux rapports du SG/NU dans ce domaine. Une interaction entre le SG/NU, par l'intermédiaire de sa Représentante pour les enfants et les conflits armés, et les gouvernements concernés par des violations à l'encontre des enfants dans les conflits armés a été recommandée (cf. \$4). Il a été demandé aux autres parties impliquées dans les violations sur les enfants, qui ne l'ont pas encore fait, de mettre en place un plan d'action assortis d'échéances devant mettre fin à ces situations. Les Etats membres devraient collaborer activement en déployant les moyens, en étroite collaboration avec les équipes des Nations Unies de surveillance et de communication des informations pour permettre l'élaboration des plans d'action et leur mise en œuvre (cf. §6). Ces équipes sont également là pour assurer la mise en œuvre des résolutions des Nations Unies sur les enfants et les conflits armés (cf. §8). Elles doivent faire des rapports au SG/NU qui à son tour devrait inclure les informations concernant l'application de recommandations de ces équipes (cf. $\S 9)$.

Rappelons que le CS/NU fait de la question des enfants un des éléments essentiels dans le système onusien. C'est dans ce sens qu'il a été prié au "Secrétaire général de veiller à ce que la question des enfants et des conflits armés soit traitée expressément dans tous ses rapports consacrés à la situation dans un pays» (cf. §10). Le CS/ NU «se félicite des efforts déployés par le Département des opérations de maintien de la paix pour intégrer la protection des enfants dans les missions de maintien de la paix, conformément à la directive adoptée [...] par le Département sur la protection des enfants ».

Les Etats ont été encouragés à prendre des mesures de répression à l'endroit des auteurs persistants des violations des règles protégeant les enfants en situation de conflits armés. Le CS/NU demande un appui administratif et technique du SG/NU au Groupe de travail sur les enfants et les conflits qu'il a créé (cf. §18). Enfin, le SG/NU devrait fournir un rapport relatif à l'évolution de la mise en œuvre du cadre général pour la protection des enfants touchés par les conflits armés.

$\mathrm{Au}$ regard de ce qui précède, il est important de signifier que le CS/NU joue un rôle très considérable dans la mise en œuvre des règles du DIH applicable aux enfants affectés par les

http://www.un.org/fr/documents/view_doc.asp?symbol=S/RES/1612\%20(2005)(Source consultée le 04 novembre 2013). 
conflits armés de même pour le DIDH. Ses résolutions développent de manière pragmatique la portée de certaines règles du DIH et du DIDH. A titre d'exemple, à chaque fois qu'il insiste sur la protection des enfants en conflits armés, il ne fait nullement allusion à la catégorie d'âges comme c'est le cas des instruments juridiques ci-dessus analysés. Ce qui est également le cas de l'AG/NU. Bien plus, le CS/NU ne cesse de souligner dans ses différentes résolutions sur les enfants dans les conflits armés (notamment celles précédemment examinées) «qu'il est déterminé à faire respecter ses résolutions et les autres obligations et normes applicables à la protection des enfants en période de conflit armé ». Ces Règles assurent la protection de l'enfant comme victime ou soldat.

Toutefois, le rôle du CS/NU, bien que garant de la paix et de la sécurité internationales, ne vient que soutenir ou compléter le rôle des Etats dans ce sens. Ce qui vaut également pour l'ensemble du système onusien et d'autres organisations régionales, sous régionales voire la Communauté internationale. Ceci pour dire qu'il incombe au premier chef aux Etats qui ont ratifiés les différents instruments juridiques relatifs à la protection des enfants en situation de conflits armés d'assurer leur protection. Il leur revient également, comme le précisent d'ailleurs les résolutions du CS/NU sur les enfants et les conflits armés, de déployer de par leur arsenal législatif des mécanismes afin de punir les auteurs de ces crimes internationaux notamment au niveau des juridictions nationales, mixtes ou internationales.

Les résolutions ci-avant mentionnées ne concernent que les enfants et les conflits armés en général. Il existe, par ailleurs, des résolutions adoptées par le CS/NU pour de nombreuses situations particulières en vertu de son mandat d'assurer la paix et la sécurité internationales. Lesquelles, non mentionnées ici, concernent différentes situations qui impliquent les enfants. Il s'agit, à titre d'exemple, des situations en Afghanistan, Burundi, Côte d'ivoire, Libéria, Lybie, Mali, République Centrafricaine, Sierra-Leone, Soudan, etc. Ces situations affectent gravement l'état des droits des enfants. Tout comme, à côté de ses résolutions qui se rapportent particulièrement aux enfants et les conflits armés, le CS/NU a adopté des résolutions assurant la protection des civils dans les conflits armés de manière générale. Il s'agit notamment des résolutions 1738 (2006), 1674 (2006), 1894 (2009), etc.

Enfin, la protection spéciale de l'enfant par les organes onusiens - tout comme par d'autres - , reste un processus dont les objectifs ne sont pas encore atteints sur terrain. En d'autres termes, les violations graves du DIH ou du DIDH font partie des charges qui pèsent quotidiennement sur les parties aux conflits - Etats ou collectivités non étatiques. Le CS/NU n'est tout de même pas d'un apport moindre dans cet édifice. Son rôle, à travers la mise en place d'un système de protection de l'enfant en période de conflits armés, reste appréciable. Et ce notamment du fait du pouvoir des sanctions qu'il détient à l'endroit des Etats ou entités pouvant perturber la paix et la sécurité internationales. Et surtout que le fait de procéder au recrutement et à l'utilisation des enfants dans les conflits armés peut être constitutif de menace à la paix et à la sécurité internationales. 


\section{§7. Le droit international humanitaire coutumier}

\section{A. Au plan universel ${ }^{1108}$}

La protection de l'enfant en situation de conflits armés n'est donc pas absente du DIH coutumier. Au-delà des garanties fondamentales reconnues également aux enfants en DIH coutumier $^{1109}$, l'enfant bénéficie des règles spécifiques au plan coutumier. Lesquelles règles se trouvent d'ailleurs renforcée au plan des conventions, résolutions de l'ONU, des législations nationales, etc. En effet, suivant l'étude du CICR sur le DIH coutumier ${ }^{1110}$, les enfants touchés par les conflits armés (CAI et CANI) ont droit à un respect et à une protection particuliers (Règle 135). Cette règle générale inclut en pratique notamment la protection des enfants contre toutes les formes de violence sexuelle; le fait d'être séparé des détenus adultes en cas de privation de liberté, sauf s'il s'agit de membres d'une même famille, l'accès à l'éducation, aux vivres et aux soins de santé; l'évacuation des zones de combat pour raisons de sécurité ; la réunification des enfants non accompagnés avec leur famille ${ }^{1111}$. L'interdiction de la peine de mort à l'égard des enfants (cf. supra) appréhendée également comme rélevant du DIH coutumier s'analyse sous cet angle ${ }^{1112}$.

D'autres règles d'ordre coutumier liées spécifiquement à l'enfant sont retenues dans les travaux du CICR en CAI et en CANI: c'est le cas de la règle 136 qui indique que les enfants ne doivent pas être recrutés dans les forces armées ni dans les groupes armés ou de la règle 137. Selon cette dernière, les enfants ne doivent pas être autorisés à participer aux hostilités. Le seuil d'âge minimal reconnu dans la pratique des Etats de recrutement et de participation des enfants aux hostilités au regard notamment des instruments juridiques internationaux et nationaux, voire des déclarations nationales et internationales, est de quinze ans. L'on ne peut donc pas admettre le recrutement et la participation des enfants de moins de quinze ans aux hostilités ${ }^{1113}$. Ceci se trouve être reconnu d'ailleurs par le Tribunal spécial pour la Sierra Leone (cf. supra).

\section{B. Au plan régional africain}

Existe t-il un droit international coutumier régional africain qui serait plus protecteur que les normes coutumières précitées ?

Préalablement, il convient d'affirmer avec la CDI qu'une règle de droit international coutumier particulier, qu'elle soit régionale ou locale, est une règle de droit international coutumier ${ }^{114}$. Par conséquent, pour déterminer son existence et son contenu, il importe de procéder mutatis mutandis à la méthode d'établissement du droit international coutumier universel. Il faudrait donc rechercher l'existence de la pratique générale et de l'opinio juris ${ }^{115}$.

\footnotetext{
1108 Cette partie est encore plus développée au paragraphe 3 de la Section II du Chapitre III de la seconde partie.

${ }^{1109}$ Lire HENCKAERTS, Jean-Marie et DOSWAL-BECK, Louise, Droit international humanitaire coutumier,

Vol. I : Règles, op. cit., pp. 395-503.

${ }^{1110}$ Ibid.

${ }^{1111}$ Ibid., pp. 634-635.

1112 Ibid., p. 636.

${ }^{1113}$ Ibid., pp. 631-640.

1114 CDI, Détermination du droit international coutumier. Textes des projets de conclusion provisoirement adoptés par le Comité de rédaction, Soixante-septième session, Genève, 4 mai-5 juin et 6 juillet-7 août 2015, op. cit., p. 5, Projet de conclusion 16 [15], §§1-2.

${ }^{1115}$ Ibid.
} 
En rapport avec le processus d'établissement de l'existence des normes coutumières internationales, rappelons que les traités sont perçus comme étant pertinents en dépit de l'inexistence de la hiérarchie entre les différentes formes de preuve d'établissement de pratique générale telle qu'affirmée par la CDI (cf. Chapitre premier, Section I, §3). En ce sens, sont donc pris en considération : la ratification (nombre de ratification important mais pas suffisant ${ }^{116}$ ), l'interprétation et l'application des traités, les réserves et déclarations interprétatives effectuées mais aussi les pratiques nationales ${ }^{1117}$. Servent également d'utilité, en termes des sources documentaires, dans le processus d'établissement des règles coutumières, des éléments objectifs et complets tels que les moyens indiquant directement la position des Etats - moyens directs - : les résolutions d'OI, les traités non applicables à titre conventionnel, les travaux de la CDI, les autres documents établissant les positions officielles des Etats, et les moyens indirects : la jurisprudence, la doctrine ${ }^{1118}$, etc.

En effet, le standard africain de protection de l'enfant contre le recrutement et la participation aux hostilités est plus élévé que celui observé au niveau des instruments universels. L'article 22 de la Charte africaine des droits et du bien-être de l'enfant du 11 juillet 1990 interdit sans « réserve » le recrutement (enrôlement obligatoire ou volontaire) et la participation directe aux hostilités des personnes de moins de dix-huit ans (cf. article $22 \S 2$ ) et non de moins de quinze ans et de manière relative comme dans certains instruments universels. Le fait que cette disposition conventionnelle ne prohibe que la «participation directe » ne pose pas problème l'avons-nous indiqué. Car le fait qu'elle interdise totalement le recrutement rend la participation - directe et indirecte - des enfants aux hostilités moins probable ${ }^{1119}$. Cette protection spéciale au plan africain sera davantage renforcée, notamment par un instrument assurant la protection de la femme, spécialement la jeune fille : le Protocole à la Charte africaine des droits de l'Homme et des peuples relatif aux droits des femmes (Protocole de Maputo) du 11 juillet 2003.

Pour la CDI, «[1]e fait qu'une règle soit énoncée dans plusieurs traités peut signifier, sans toutefois que cela soit nécessairement le cas, que la règle conventionnelle reflète une règle de droit international coutumier ${ }^{1120}$.

Suivant l'état de ratification de la la Charte africaine des droits et du bien-être de l'enfant, il ressort qu'au moins 51 Etats ont signé cet instrument dont 42 ratifications ${ }^{121}$. En juillet 2012,

\footnotetext{
${ }^{1116}$ Lire CIJ, Affaire du Plateau continental de la mer du Nord, arrêt du 20 février 1969, op. cit., p. 42 , § 73.

${ }^{1117}$ MAYSTRE, Magali, op. cit., pp. 69-70.

1118 Lire CORTEN, Olivier, Méthodologie du droit international public, op. cit., pp. 161-178. Pour le TPIY « [1]orsqu'on évalue la formation de règles coutumières ou de principes généraux, il convient par conséquent d'être conscient que, du fait du caractère intrinsèque de ce domaine, on doit s'appuyer essentiellement sur des éléments comme les déclarations officielles des Etats, les manuels militaires et les décisions judiciaires ». Voy. TPIY, Le Procureur c/ Dusco TADIC alias «DULE », Chambre d'Appel, Arrêt relatif à l'appel de la défense $\begin{array}{llllll}\text { concernant l'exception } & \text { préjudicielle, } & 2 & \text { octobre } & 1995, & \$ 99\end{array}$ http://www.icty.org/x/cases/tadic/acdec/fr/51002JN3.htm (Source consultée le 08 août 2016).

${ }^{1119}$ MAYSTRE, Magali, op.cit., p. 65.

${ }^{1120}$ CDI, Détermination du droit international coutumier. Textes des projets de conclusion provisoirement adoptés par le Comité de rédaction, Soixante-septième session, Genève, 4 mai-5 juin et 6 juillet-7 août 2015, op. cit., p. 3, Projet de conclusion 11 [12], §2.

${ }^{1121}$ Le site non actualisé de la Commission africaines des droits de l'homme et des peuples fait mention de 41 Etats ayant ratifié cet instrument et 9 Etats ayant signé sans ratification. Cependant, 4 ne l'ont ni signé ni ratifié. Il faudrait préciser que depuis la scission du Soudan, l'Afrique compte actuellement 55 Etats. La RDC est partie
} 
le Comité africain d'Experts sur les droits et le bien-être de l'enfant déplorait la ratification non parachevée de cet instrument - plus de dix ans après son entrée en vigueur - et la lenteur dans la soumission des rapports étatiques de sa mise en œuvre ${ }^{1122}$. Il est tout de même remarqué qu'aucune réserve n'a été soulevée au sujet de l'article 22 précité $^{1123}$. Il n'existe pas également une position officielle étatique, d'une manière quelconque, remettant en question cette disposition conventionnelle. De la même manière qu'aucune Observation générale instrument d'interprétation du sens et de la portée d'une disposition conventionnelle - au sujet de l'article 22 précité n'est encore effectuée de la part du Comité africain d'Experts sur les droits et le bien-être de l'enfant. Tout de même au plan des pratiques nationales, différentes mesures législatives et administratives sont prises par des Etats pour assurer la mise en œuvre d'interdiction de recrutement et de participation (non seulement la participation directe) des personnes de moins de dix-huit ans aux hostilités ${ }^{1124}$. Pour les Etats de la région des Grands lacs tels que les Républiques d'Ouganda, Démocratique du Congo, du Rwanda (cf. Seconde partie, Chapitre III, Section III, §2 A), Unie de Tanzanie ${ }^{1125}$, le standard de protection contre le recrutement et la participation des enfants aux hostilités est de dix huit ans. Rien n'atteste que la non ratification par d'autres Etats africains soit motivée par leur «désaprobation active ${ }^{1126}$ de l'article 22 de cet instrument. Ainsi, par exemple, un Etat, non partie à cette convention, tel que la République de Tunisie interdit strictement le recrutement dans le service militaire des personnes âgées de moins de 18 ans et leur participation aux

à cet instrument mais ne s'y trouve pas indiquée. Ce qui qui donne un effectif d'au moins 42 Etats ayant ratifié. Voy. http://www.achpr.org/fr/instruments/child/ (Source consultée le 16 août 2016). Le site du Comité africain d'Experts sur les droits et le bien-être de l'enfant mentionne pour sa part 6 Etats (dont le Sud-Soudan) n'ayant pas signé ni ratifié la Charte africaine des droits et du bien-être de l'enfant dont la RDC. Voy. http://www.acerwc.org/ratification-data/ (Source consultée le 16 août 2016). Néanmoins, le journal officiel de l'Etat congolais confirme qu'elle est bien partie à cet instrument (cf. infra).

${ }^{1122}$ Union africaine, Conseil exécutif, Vingt et unième session ordinaire (9-12 juillet 2012) EX.CL/744(XXI), Rapport du Comité africain d'Experts sur les droits et le bien-être de l'enfant (ACERWC), p. 1.

${ }_{1123}$ Voy. http://www.acerwc.org/reservations/ (Source consultée le 16 août 2016).

${ }^{1124}$ Lire les différents rapports initiaux soumis au Comité africain d'Experts sur les droits et le bien-être de l'enfant par les Etats suivants: Algérie, Angola, Burkina Faso, Cameroun, Comores, Congo, Côte d'Ivoire, Erythrée, Ethiopie, Gabon, Ghana, Guinée, Kenya, Lesotho, Liberia, Madagascar, Malawi, Mauritanie, Mali, Maurice, Mozambique, Namibie, Niger, Nigeria, Ouganda, Rwanda, République Sud africaine, Sénégal, Sierra Leone, Soudan, Tanzanie, Tchad, Togo et Zimbabwe disponibles sur http://www.acerwc.org/initial-reports/ (Source consultée le 19 septembre 2016). Lire aussi, à ce sujet, les différents rapports initiaux sur la mise en œuvre du Protocole facultatif à la CDE, concernant l'implication d'enfants dans les conflits armés adressés au Comité des droits de l'enfant par des Etats tels que : Egypte, Burkina Faso, Congo, Guinée, Madagascar, Malawi, Ouganda, RDC, Rwanda, Sierra Leone, Soudan, Tanzanie, Tunisie, voire d'autres rapports soumis au Comité des droits de l'enfant par les Etats africains principalement au sujet de la mise en œuvre de l'article 38 de la CDE, disponibles sur http://tbinternet.ohchr.org/ layouts/treatybodyexternal/TBSearch.aspx?Lang=en\&TreatyID=5\&TreatyID=10\&T

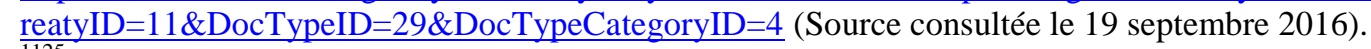

${ }^{1125}$ On signalera pour la République-Unie de Tanzanie que, bien que le recrutement des personnes âgées de moins de dix-huit ans soit autorisé, dans la pratique aucun membre des Forces de défense populaire de Tanzanie n'a moins de dix-huit ans. Voy. Comité des droits de l'enfant, Examen des rapports présentés par les Etats parties conformément au paragraphe 1 de l'article 8 du Protocole facultatif à la Convention relative aux droits de l'enfant, concernant l'implication d'enfants dans les conflits armés, Rapports internationaux des Etats parties attendus en 2006, République-Unie de Tanzanie, CRC/C/OPAC/TZA/1, 19 octobre 2007, pp. 6-7, Rapport disponible

sur http://tbinternet.ohchr.org/ layouts/treatybodyexternal/TBSearch.aspx?Lang=en\&TreatyID=5\&TreatyID=10\&T reatyID=11\&DocTypeID=29\&DocTypeCategoryID=4 (Source consultée le 19 septembre 2016).

${ }^{1126}$ Expression utilisée par CIJ, affaire du Plateau continental de la Mer du Nord, Recueil 1969, op. cit., p. 42, § 73. 
hostilités ${ }^{1127}$. On signalera également que le Maroc, alors Etat non membre de l'UA, allait largement au-delà du standard de la Charte africaine des droits et du bien-être de l'enfant en interdisant initialement le recrutement et la participation aux hostilités des personnes âgées de moins de vingt ans avec sa la loi $n^{\circ} 4-99$ relative au service militaire promulguée par le dahir 1-99-194 du 25 août 1999. Celle-ci sera abrogée par la loi $n^{\circ}$ 48-06 promulguée par dahir $n^{\circ}$ 1-06233 du 28 rabii I 1428 (17 avril 2007, Bulletin officiel $n^{\circ} 5522$ du 3 mai 2007, p. 581) qui interdira la conscription sous toutes ses formes et autorisera l'engagement volontaire à 18 ans $^{1128}$.

En tant qu'organisation régionale, l'OUA va dans le même sens que la Charte précitée. En effet, dans la résolution 1659 (LXIV) issue de son Conseil des Ministres tenu à Yaoundé (Cameroun) du $1^{\mathrm{er}}$ au 5 juillet 1996, elle lançait un appel à la signature et à la ratification de la Charte pour les Etats ne l'ayant pas encore fait ${ }^{1129}$. Elle exhortait en même temps tous les pays africains à «s'abstenir de recruter les enfants de moins de 18 ans dans des conflits armés ou des activités violentes de quelque nature que ce soit ${ }^{1130}$. Dans le même ordre, et ce bien avant le Statut de Rome portant création de la CPI, l'OUA estimait à travers cette résolution que l'utilisation des enfants dans les conflits armés devrait être appréhendée comme crime de guerre $^{1131}$.

Par ailleurs, s'il est certes vrai que, sur le champ de bataille, le recrutement et la participation des enfants aux hostilités constituent des pratiques quotidiennes, aucun Etat ne les justificient. Ces pratiques sont non seulement niées mais également condamnées par ces Etats ou par des OI dont ils sont parties (cf. infra).

De ce qui précède, il paraît là « une participation très large et représentative » au sens de la $\mathrm{CIJ}^{1132}$, ou encore une pratique «suffisamment répandue et représentative, ainsi que constante ${ }^{1133}$ suivant la formule de la CDI, au-delà de laquelle se dégage l'opinio juris sive necessitatis. Chose qui s'avère logique car l'opinio juris doit en principe «pouvoir être déduite des positions de l'ensemble des Etats concernés par la règle coutumière ${ }^{1134}$.

\footnotetext{
${ }^{1127}$ Voy. Comité des droits de l'enfant, Examen des rapports présentés par les Etats parties conformément au paragraphe 1 de l'article 8 du Protocole facultatif à la Convention relative aux droits de l'enfant, concernant l'implication d'enfants dans les conflits armés, Rapports internationaux des Etats parties attendus en 2005, Tunisie, CRC/C/OPAC/TUN/1, 30 août 2007, p. 5, Rapport disponible sur http://tbinternet.ohchr.org/_layouts/treatybodyexternal/TBSearch.aspx?Lang=en\&TreatyID=5\&TreatyID=10\&T reatyID=11\&DocTypeID=29\&DocTypeCategoryID=4 (Source consultée le 19 septembre 2016).

${ }^{1128}$ Lire Comité des droits de l'enfant, Examen des rapports présentés par les Etats parties conformément au paragraphe 1 de l'article 8 du Protocole facultatif à la Convention relative aux droits de l'enfant, concernant l'implication d'enfants dans les conflits armés, Rapports internationaux des Etats parties attendus en 2004, Maroc, CRC/C/OPAC/MAR/1, 19 juin 2012, pp. 3-4, disponible sur http://tbinternet.ohchr.org/_layouts/treatybodyexternal/TBSearch.aspx?Lang=en\&TreatyID=5\&TreatyID=10\&T reatyID=11\&DocTypeID=29\&DocTypeCategoryID=4 (Source consultée le 19 septembre 2016).

1129 OUA, Conseil des Ministres, Rés. 1659 (LXIV), Résolution sur la condition des enfants africains en situation de conflits armés, op. cit., p. $1, \S 2$.

${ }^{1130}$ Ibid., p. $2, \S 5$.

${ }^{1131}$ Ibid., p. $2, \S 6$.

${ }^{1132}$ CIJ, Affaire du Plateau continental de la Mer du Nord, Recueil 1969, op. cit., p. 42 , § 73.

${ }^{1133}$ CDI, Détermination du droit international coutumier. Textes des projets de conclusion provisoirement adoptés par le Comité de rédaction, Soixante-septième session, Genève, 4 mai-5 juin et 6 juillet-7 août 2015, op. cit., p. 2, Projet de conclusion 8 [9], §1.

${ }^{1134}$ CORTEN, Olivier, Méthodologie du droit international public, op. cit., p. 159.
} 
Bien plus, la protection de l'enfant en Afrique est encore renforcée par le Protocole à la Charte africaine des droits de l'Homme et des peuples relatif aux droits des femmes (Protocole de Maputo) du 11 juillet 2003. A travers cet instrument, les Etats africains ont réitéré leur vœu d'éradiquer le phénomène enfant soldat du continent. L'article 11, paragraphe 4, de cet instrument dispose : «[1]es États prennent toutes les mesures nécessaires pour qu'aucun enfant, surtout les filles de moins de 18 ans, ne prenne part aux hostilités et, en particulier, à ce qu'aucun enfant ne soit enrôlé dans l'armée »" ${ }^{135}$. Cet article est une nette avancée par rapport à l'état actuel du droit international relatif à la protection de l'enfant en période de conflits armés (cf. supra). Une obligation ferme (obligation de résultat) s'impose aux Etats au sujet d'interdiction de recrutement (enrôlement obligatoire et volontaire) et de participation (directe, indirecte ou active) des enfants (personnes de moins de dix-huit ans) aux hostilités. Cette convention qui intervient douze ans après la Charte précitée confirme non moins la pratique des Etats africains observée en cette matière. Elle est ratifiée par 36 Etats présentement. 15 autres Etats l'ont jusque là signé ${ }^{1136}$.

Il existe également dans le cadre africain, la Convention de l'Union africaine sur la protection et l'assistance aux personnes déplacées en Afrique (Convention de Kampala) adoptée par le Sommet spécial de l'Union tenu le 22 octobre 2009 et entrée en vigueur le 06 décembre 2013. Celle-ci réitère dans son ensemble les obligations internationales des Etats applicables et interdit expressément aux groupes armés de « [r]ecruter, en quelque circonstance que ce soit, des enfants, de leur demander ou de leur permettre de participer aux hostilités ${ }^{1137}$ (article 7 $\S 5 \mathrm{e})$.

$\mathrm{Au}$ regard de tous ces éléments, à défaut d'admettre l'existence d'un droit international coutumier régional africain interdisant le recrutement et la participation - directe et indirecte des enfants aux hostilités, il ne serait pas exagéré d'affirmer qu'il existe un droit international coutumier régional africain interdisant au moins le recrutement et la participation directe des personnes de moins dix-huit ans aux hostilités (suivant le standard même de la Charte). Cette dernière attitude est déjà démontrée par la majorité des Etats au plan universel notamment lors de négociation de la CDE. La pratique de l'ONU ou même du CICR, voire d'autres organismes de protection de l'enfant, va également dans le sens d'interdire le recrutement et la participation aux hostilités des enfants de moins de dix-huit ans ${ }^{1138}$.

Il s'avère que l'interdiction au moins d'enrôlement et de participation directe d'enfants de moins de dix-huit ans aux hostilités reste une mesure en parfaite harmonie avec les pratiques sociales.

En effet, «dans la plupart des pays, des enfants de moins de dix-huit ans n'ont pas la

\footnotetext{
${ }^{1135}$ Lire l'article 11, $\$ 4$ du Protocole à la Charte africaine des droits de l'homme et des peuples relatif aux droits des femmes in http://www.achpr.org/fr/instruments/women-protocol/\#14 (Source consultée le 14 octobre 2015).

${ }^{1136}$ Voy. l'Etat de ratification de cet instrument disponible sur http://www.achpr.org/fr/instruments/womenprotocol/ (Source consultée le 19 septembre 2016).

1137 Convention de l'Union africaine sur la protection et l'assistance aux personnes déplacées en Afrique (Convention de Kampala) adoptée par le Sommet spécial de l'Union tenu le 22 octobre 2009 in http://www.refworld.org/pdfid/4ae825fb2.pdf (Source consultée le 07 mai 2015).

${ }^{1138}$ Lire BUGNION, François, « Les enfants soldats, le droit international humanitaire et la Charte africaine des droits et du bien-être de l'enfant », « art. cit. », pp. 269-273.
} 
possibilité de prendre part à la vie politique ; ils n'ont pas le droit de conduire un véhicule à moteur, même s'ils ont les moyens de s'en procurer un, ils ne sont pas autorisés à entrer dans un bar, dans un débit de boissons alcoolisées ou dans un cabaret. Pourquoi devraient-ils être autorisés à prendre part à la guerre, s'ils ne sont pas autorisés à participer à la vie politique de leur pays ? Pourquoi devraient-il[s] être autorisés à manier une arme automatique ou à conduire un tank, alors qu'ils ne sont pas autorisés à conduire une auto ? Pourquoi devraientils connaître l'horreur du champ de bataille si on leur interdit de fréquenter certains établissements publics ? ${ }^{1139}$.

Bien plus, l'âge limite de dix-huit ans était appréhendé avec raison par l'Union internationale de protection de l'Enfance, lors de sa proposition sur l'interdiction de la peine de mort contre les personnes de moins de dix-huit ans à la XVII Conférence internationale de la Croix-Rouge, comme une limite absolue, un âge de discernement. Ce qui est très valable jusqu'à ce jour. Avant cet âge, «l'individu n'est pas entièrement capable de discernement, [...] il ne mesure pas toujours la portée de ses actes et agi souvent sous l'influence d'autrui, si ce n'est sous la contrainte ${ }^{1140}$.C'est également l'âge que retenaient déjà plusieurs législations pénales nationales $^{1141}$.

\section{§8. Le soft-law}

«On a constaté au cours de la décennie (1990-2000) l'émergence d'une volonté nouvelle de reconnaître et de s'attaquer aux problèmes de l'exploitation des enfants autrefois occultés, à savoir notamment le travail des enfants, la vente et la traite des enfants et des femmes, la prostitution des enfants, leur enrôlement dans les forces armées, la violence sexiste, la maltraitance, la justice pour mineurs, l'abus de drogues, l'exploitation et le meurtre des femme et des enfants dans les conflits. Après une longue tradition de silence, ces problèmes ont en effet été exposés à une publicité croissante et ils occupent aujourd'hui une place de plus en plus éminente sur la scène publique et politique tant au niveau international qu'au niveau national ${ }^{1142}$.

De nombreuses conférences au plan international et régional, en marge d'importantes activités de l'ONU liées à l'adoption d'instruments relatifs à la protection ou aux droits de l'enfant, ont été tenues. Ces conférences internationales qui ont abouti à des déclarations des règles consacrants des droits ou mécanismes de protection de l'enfant ont joui également d'une grande influence visà-vis des instruments juridiques contraignants dans ce sens notamment au niveau de leurs ratifications et de leurs mises en œuvre. La Coalition pour mettre fin à l'utilisation d'enfants soldats composée de ses membres tels que Amnesty international, Terres des hommes, Human Rights Watch, l'Alliance internationale Save the Children, le Service jésuite pour les réfugiés et le Bureau Quaker ont organisé de multiples conférences régionales dans ce domaine et occasionné l'adoption de différentes déclarations en faveur du relèvement du standard de protection des enfants soldats. On citera la Déclaration de Maputo du 22 avril 1999 résultant de la Conférence africaine sur l'utilisation d'enfants en tant que soldats ; la Déclaration de Montevideo

\footnotetext{
${ }^{1139}$ Ibid., pp. 269-270.

${ }^{1140}$ PICTET, Jean S. (dir.), Commentaire IV, La Convention de Genève relative à la protection des personnes civiles en temps de guerre, op. cit., p. 372.

1141 Ibid.

1142 MEUNIER, Guillemette, op.cit., p. 84.
} 
du 8 juillet 1999 issue de la Conférence Latino-américaine et des Caraïbes sur 1'utilisation des enfants comme soldats ; la Déclaration de Berlin du 20 octobre 1999 qui ressort de la Conférence européenne sur l'utilisation des enfants comme soldats et la Déclaration de Katmandu du 18 mai 2000 adoptée après la Conférence de l'Asie et du Pacifique pour mettre un terme à la pratique de l'utilisation des enfants soldats. Sur cette liste des textes déclaratoires de valeur morale non négligeable, l'on citera la déclaration de N'djamena de juin 2010 signée par le Cameroun, le Niger, le Nigeria et la République Centrafricaine, le Soudan et le Tchad. Il s'agit d'une déclaration pour «[m]ettre fin au recrutement et à l'utilisation des enfants par les forces et groupes armées - contribution à la paix, à la justice et au développement ${ }^{1143}{ }^{143}$ Il sied de souligner également sous cet angle que les «Principes de Cap »adopté en 1997 l'a été également grâce aux $\mathrm{ONG}^{1144}$. Les Principes de Cap qui définissent ce qu'il faudrait entendre par «Enfant soldat » (cf. supra), se focalisent sur la prévention du recrutement d'enfants, leur démobilisation et leur réinsertion sociale (en famille et en communauté). En ce qui concerne spécialement la prévention de recrutement d'enfants, ils recommandent aux forces ou groupes armés d'élever l'âge légal minimum de recrutement de toute personne sous quelque forme que ce soit et de participation aux conflits armés à dix-huit ans. Ils recommandent aux gouvernements la ratification et l'applications des conventions régionales et internationales relatives à la protection des enfants notamment les CG et leurs PA, la CDE et la Charte africaine des droits et du bienêtre de l'enfant. L'adoption et la ratification du Protocole facultatif à la CDE, concernant l'implication d'enfants dans les conflits armés ont été recommandées aux Etats. Par des législations précises et des procédures bien établies, les gouvernements devraient incorporer ces instruments juridiques au plan national. Ils devraient en outre prévoir des sanctions à l'encontre des auteurs des violations des droits de l'enfant précisément ceux qui pratiquent de tel recrutement. Les parties aux conflits devraient signer des accords respectant des principes détaillés dans cette déclaration du Cap. Une attention particulière et des mesures de protection spéciale devraient être prises à l'endroit des enfants à plus grand risque d'être recrutés, par exemple les enfants se retrouvant dans les zones de conflits, les enfants réfugiés ou déplacés, etc. Un contrôle devrait être exercé sur la production et le transfert d'armes, précisément les armes légères qui, comme on le sait (cf. supra), est un facteur important d'exacerbation du phénomène « enfant soldat ». C'est dans cette optique qu'il est recommandé de ne pas fournir les armes aux parties qui font recours aux enfants soldats.

Les Principes de Cap, limités à la sphère africaine ont en revanche inspiré plus d'un instrument international, régional ou national de protection des enfants. Dix ans après leur adoption, l'apparition d'éléments nouveaux notamment l'accumulation des nouvelles expériences résultant des conflits dans le monde avec différentes formes d'implications sur les enfants, etc, ont amené les Etats à revoir les Principes de Cap et les étendre sur la sphère mondiale sous «Les Engagements de Paris relatifs à la protection des enfants contre le recrutement ou l'utilisation illicites par les forces armées ou les groupes armés » dits «les Engagement de Paris ». Ceux-ci sont complétés par «Les Principes de Paris relatifs aux enfants associés aux forces armées et aux groupes armés» dits «Les Principes de Paris». «Les Principes de Paris sont un ensemble

\footnotetext{
${ }^{1143}$ RAMASY, Juvence F., « La protection juridique et politique des enfants dans les conflits armés en Afrique. Inventaire des dispositions légales et politiques », in BABIKER, Mohamed Abdelsalam, DAUBLAIN, Maxense et VAHLAS, Alexis (dir.), Enfants-soldats et droits des enfants en situation de conflit et post-conflit. Réalités et enjeux, op. cit., p. 275.

${ }^{1144}$ Lire MARTIN CHENUT, Kathia, « art.cit. », pp. 184-185.
} 
de principes détaillés, non-contraignants, largement appuyés par les États et qui permettent de guider et de renforcer les actions entreprises par les gouvernements et les enfants eux-mêmes pour veiller au succès de la réinsertion des enfants touchés par les conflits armés. Les Engagements de Paris sont un complément aux mécanismes juridiques et politiques déjà existants ${ }^{1145}$. Précisons que «les Engagements de Paris » se veulent être un instrument d'appui au respect et à l'application des Principes de Paris, chaque fois que cela est possible et conforme aux des obligations internationales. En ce sens, aucun effort ne devrait être épargné pour mettre fin au recrutement et à l'utilisation illégaux des enfants par les forces ou groupes armés. Les Etats sont, une fois de plus, recommandés de ratifier les instruments pertinents et d'assurer leur mise en œuvre (cf. le point 1 des Engagement de Paris). Ainsi, au regard des Engagements de Paris, les Etats doivent veiller à ce que les procédures de recrutement et de conscription aux forces armées répondent aux normes internationales. Les mesures réalisables doivent être prises à l'endroit des groupes armés afin d'empêcher qu'ils puissent recruter les enfants de moins de 18 ans dans les conflits armés (cf. Point 4). Ils doivent lutter contre l'impunité des auteurs de recrutement ou d'utilisation des enfants de moins de dix-huit ans dans les conflits et ne pas leur faire bénéficier des mesures d'amnistie (cf. Point 6). Très réaliste de ce qu'est la question de recrutement et d'utilisation des enfants par les parties aux conflits armés, «les Engagements de Paris » recommandent aux Etats de prendre des mesures nécessaires face aux enfants de moins de dixhuit ans recrutés ou utilisés dans les conflits armés par les parties adverses afin que le DIH et DIDH soient respectés (Point 9). Les enfants qui commettraient des crimes dans les conflits armés à la suite de leur recrutement ou participation seraient considérés en premier lieu comme victimes de violation du droit international et non seulement comme présumés coupables (Point 11). Les Etats devraient coopérer pour assurer la mise en œuvre des recommandations contenues dans ce document. Lesquelles doivent guider leurs actions. C'est au tour des Principes de Paris de développer les Engagements de Paris à travers : Définitions; Principes fondamentaux; Principes concernant spécifiquement les filles; Enfants réfugiés et enfants déplacés; Prévention du recrutement et de l'utilisation illégaux; Libération et réinsertion des enfants associés aux forces armées ou aux groupes armés; Justice; Surveillance et suivi et Surveillance et évaluation des interventions au titre des Programmes.

Les présents Principes entendent inspirer toutes les interventions concernant la protection et le bien-être de ces enfants et contribuer à la prise de décisions de politique générale et de programmation. Ils visent à guider les interventions avec les objectifs de prévenir le recrutement et l'usage illégaux des enfants; de faciliter la libération des enfants associés aux forces armées et aux groupes armés; de faciliter la réinsertion de tous les enfants associés aux forces armées et aux groupes armés et d'assurer l'environnement le plus protecteur possible pour tous les enfants $^{1146}$.

Il existe d'autres instruments, non repris ici, qui tentent également de renforcer, au niveau de la sphère régionale ou internationale, la protection de l'enfant en temps de conflits armés ou de manière générale.

Pour tout dire, les instruments ci-haut cités n'obligent juridiquement pas les Etats. Ces derniers ne

${ }^{1145}$ Bureau International des droits des enfants, op.cit., p. 314.

${ }^{1146}$ Lire « Les Principes de Paris », Point 1.11, Portées et destinataires 
sont donc pas contraints d'en observer. Toutefois, il est important de souligner que du moment où certains instruments juridiques au niveau international, régional ou national s'inspirent ou font clairement mention de ces textes de soft-law, il y a là une force non négligeable qui leur est accordée. Et le fait pour eux de reprendre certains éléments retenus dans des instruments juridiques contraignants relayé surtout de la grande valeur morale qu'incarnent ces textes, doit être compris comme un message de circonspection. En clair, il ne s'agit pas de chiffon de papier qu'on peut violer à tout moment. 


\section{Conclusion du Chapitre III}

Les présent chapitre s'est proposé d'étudier les règles du DIH relatives à la protection des enfants en situation de conflits armés. Ces règles sont, en réalité, complétées par celles issues des instruments du DIDH. Lesquels font expressément référence au DIH dans ce cas précis. Elles se trouvent en outre renforcées par celle du DIPé mais également par différentes résolutions des OI dont particulièrement celles de l'ONU. Le soft-law, bien que non revêtu du caractère obligatoire, reste d'un apport non moins important à cet égard.

En effet, la protection de l'enfant en situation de conflits armés varie suivant que l'enfant est civil ou soldat. Elle est générale ou spéciale au regard de chacun de ces statuts. Elle varie également suivant l'âge de l'enfant.

Enfant de moins de quinze ans - en tant que civil - ne prenant pas part aux hostilités bénéficie d'une protection générale en vertu notamment des règles de la CG IV, de l'article 3 commun aux CG, des PA I et II suivant qu'il se retrouve en CAI ou en CANI (Sans oublier les instruments du DIDH). Cette protection conditionnelle en DIH cesse dès lors qu'il prend part directement aux hostilités et pendant le temps de cette participation. Il perd par là son immunité de protection et devient une cible légitime. Cette protection générale est doublée de protection spéciale afin de répondre à ses vulnérabilités physique, mentale ou psychique. Ces vulnérabilités qui ne disparaissent pas avec la participation directe de l'enfant aux hostilités cessent cependant de bénéficier de la protection spéciale dès lors que l'enfant participe directement aux hostilités.

Enfant de moins de quinze ans - en tant que soldat - participant directement aux hostilités, et revêtu du statut de combattant, bénéficie de la protection générale réservée aux «combattants» au regard notamment des principes et règles régissant la conduite des hostilités. Ses vulnérabilités ne sont plus prises en compte en DIH. Lequel le traite au même rang que des combattants adultes. Chose qui paraît non moins discrimatoire. Car vouloir traiter identiquement un enfant, personne se trouvant en situation de vulnérabilité particulière, qu'un adulte n'est rien d'autre que de la discrimination.

Néanmoins, une protection spéciale est réservée à l'enfant qui participe directement aux hostilités et tombe au pouvoir d'une partie adverse, qu'il soit ou non prisonnier de guerre (cf. articles $77 \S 3$ du PA I ; $4 \S 3 d$ du PA II). En outre, des garanties fondamentales liées au traitement humain reste de mise dans toutes circonstances.

Bien plus, l'âge de moins de quinze ans est donc celui ancré en DIH conventionnel et coutumier. Mais de plus en plus présente, la tendance générale du DIDH d'interdiction d'enrôlement obligatoire et de participation directe des personnes de moins de dix-huit ans aux hostilités notamment. Ce droit est encore très avancé au plan régional africain en interdisant de manière absolue le recrutement -obligatoire et volontaire - et la participation directe et indirecte - des enfants (moins de dix-huit ans) aux hostilités (cf. Protocole de Maputo). Dans ce cadre, les présentes recherches attestent l'existence d'un droit international coutumier régional africain fixant un standard de protection de l'enfant équivalent à l'article 
22 de la Charte africaine des droits et du bien-être de l'enfant - interdisant le recrutement et la participation directe des enfants (personnes de moins de 18 ans) aux hostilités.

Il se dégage que le DIH en général accorde une faible protection spéciale aux enfants qui participent directement aux hostilités. Situation qui rend de tels enfants, à notre humble avis «doublement victimes » - . Victimes généralement de recrutement et de leur utilisation par des forces ou groupes armés d'une part et d'un droit qui assure faiblement leur protection entant qu'enfants - sujets à vulnérabilités - d'autre part. Il va sans dire que les Etats n'ont pas souhaité s'engager inconditionnellement avec des règles plus protectrices de l'enfance en conflits armés.

Toutefois, la coutume ne démontrerait pas que l'enfant combattant ou civil qui prend part aux hostilités est généralement attaqué par les parties au combat.

Au regard de ce qui précède, il n'est pas exagéré de suggérer l'adoption (conventionnelle) d'un statut spécial de l'enfant qui prendrait directement part aux hostilités. Lequel statut viserait notamment l'observation des mesures (non létales) nécessaires pour neutraliser les enfants qui prennent part directement aux hostilités dans les rangs des forces ou groupes armés adverses. En clair, il y a lieu de suggérer aux Etats de «prendre des mesures nécessaires pour rendre les enfants moins nuisibles et moins victimes ». La doctrine (cf. supra) suggère déjà dans ce cas précis une remarquable appréciation du principe de proportionnalité dans l'attaque et un test rigoureux entre nécessités militaires et considérations humanitaires. Enfin, tout ceci ne devrait nullement traduire un quelconque encouragement au phénomène enfants soldats alors que la philosophie ici véhiculée demeure celle de le combattre. 


\section{CHAPITRE IV LES MECANISMES DE PROTECTION DES ENFANTS EN SITUATION DE CONFLITS ARMES}

«Vu la nature de la communauté internationale et du droit international, l'expérience montre que l'un des moyens les plus efficaces pour faire respecter le droit international est de doter les traités d'un solide mécanisme de contrôle et de mise en ouvre ayant un effet multiplicateur sur le respect des règles convenues. Le droit international sur la protection des droits de l'enfant doit encore tirer toutes les conséquences de cette importante leçon. Comme l'a reconnu, voilà déjà quelques années le Représentant spécial pour les enfants et les conflits armés, la principale difficulté que nous rencontrons lorsque nous faisons face à la détresse des enfants dans les conflits armés est peut-être la mise en œuvre, sur le terrain, des instruments internationaux et des normes locales ${ }^{1147}$.

«Ces dernières années, toute une série de programmes ont été définis par des institutions gouvernementales et non gouvernementales pour la protection des enfants dans les situations de conflit armé. Citons, entre autres, le Programme antiguerre de l'UNICEF, les « dix recommandations » du Secrétaire général de l'ONU et [...] l'« agenda pour la paix et la sécurité » de Graça Machel. L'on peut aussi mentionner d'autres contributions importantes comme celles de l'Organisation pour la sécurité et la coopération en Europe ou du Comité international de la Croix-Rouge ${ }^{1148}$.

Ce Chapitre se préoccupe donc d'étudier les différents mécanismes conventionnels prévus par les instruments juridiques internationaux et régionaux (section I) et ceux non conventionnels (Section ii) qui assurent la protection de l'enfant en période de conflits armés.

\section{Section I. Les Mécanismes conventionnels de protection de l'enfant en situation de conflits armés}

Sous cette section, l'étude accordera son intérêt à l'examen des mécanismes de protection de l'enfant en conflits armés institués par les CG et PA (\$1), la CDE (Comité des droits de l'enfant) (§2), la Charte africaine des droits et du bien-être de l'enfant (Comité africain d'experts sur les droits et le bien-être de l'enfant) (§4) et le Statut de Rome (CPI). La mise en œuvre de la Convention de l'OIT $\mathrm{n}^{\circ} 182$ fera également l'objet d'analyse $(\S 3)$.

Qu'il soit précisé dorénavant que l'étude qu'effectue la présente section sur ces différents mécanismes demeure théorique par rapport à celle qui sera entreprise au dernier chapitre de cette thèse sur les mêmes mécanismes (cf. Section II du Chapitre III de la deuxième partie). Là, il sera concrètement examiné la manière dont ces différents mécanismes s'occupent de la question de la protection de l'enfant en situation de conflits armés en RDC.

\footnotetext{
1147 AYISSI, Anatole, «Protéger les enfants dans les conflits armés : concrétiser les engagements pris » in Forum $d u$ désarmement. Les enfants et la sécurité, Trois, 2002, pp. 12-13, in http://www.unidir.org/files/publications/pdfs/les-enfants-et-la-securite-en-582.pdf (Source consultée le 12 avril 2015).

${ }^{1148}$ Ibid., p. 13.
} 


\section{§1. Les Mécanismes de protection de l'enfant dans les Conventions de Genève du 12 août 1949 et leurs Protocoles additionnels du 08 juin 1977}

La responsabilité première de mise en œuvre des règles du DIH revient aux Etats qui ont élaboré et souscrit aux quatre CG et à leurs PA qui constituent la toile de fond de cette branche du droit international. Ils ont donc l'obligation de «respecter» et de «faire respecter » «n toutes circonstances » les CG et leur $1^{\mathrm{er}}$ PA. Cette obligation n'est pas, suivant la CIJ, « une simple clause de style » dépourvue de toute force juridique, mais une norme fermement ancrée dans le droit international général entraînant les obligations pour tout Etat, qu'il ait ratifié ou non les traités en question (cf. supra). Cette obligation, autant pour d'autres règles du DIH, s'impose même en l'absence de réciprocité, comme le précise d'ailleurs la $140^{\mathrm{e}}$ règle coutumière ${ }^{1149}$. Les Etats se trouvent donc obligés de prendre différentes mesures pour rendre concrète cette obligation. C'est dans ce sens qu'au plan interne ou international, les Etats prennent des mesures de prévention, de contrôle et de sanction afin de tenter de faire du DIH un droit effectif.

Cependant, cette mission étant lourde et délicate, il serait absurde de penser que seuls les Etats sont habilités à assurer la mise en œuvre des règles du DIH. Bien plus, attachés à leur « souveraineté », les Etats ne sont pas toujours diligents à assurer de bon aloi la mise en œuvre des règles du DIH. En clair, «la « souveraineté » des Etats demeure un obstacle majeur à la mise en œuvre du droit humanitaire ${ }^{1150}$. Différentes autres institutions sont apparues pour accompagner les Etats dans cette tâche au nom de l'humanité.

En effet, rappelons qu'il est d'un constat que le DIH existant souffre d'un sérieux problème de mise en œuvre (cf. supra). Les mécanismes établis au niveau conventionnel ou résolutoire souffrent d'un sérieux problème de dysfonctionnement sur terrain. Il a été démontré, par exemple, que des «puissances protectrices », qui sont des institutions devant veiller à l'application des CG et de leur $1^{\mathrm{er}} \mathrm{PA}$ au-delà des intérêts des parties belligérantes qu'elles sont censées représenter, n'ont pas fonctionné comme souhaité par ces traités. En lieu et place, c'est le CICR qui a joué plus ce rôle à titre autonome sur base de son droit d'initiative. Les puissances protectrices devraient en principe donc veiller au bien-être et à la protection des victimes de conflits armés notamment les blessés, malades, naufragés, prisonniers de guerres et civils.

En rapport avec la protection des personnes civiles qui nous préoccupe, les puissances protectrices, dans le cadre des conflits armés internationaux, devraient donc veiller à la protection générale de toutes les personnes civiles et à la protection spéciale des personnes vulnérables dont les enfants. Ces derniers bénéficient d'une double protection. En effet, considéré comme une personne qui ne prend pas part aux hostilités et se trouvant au pouvoir d'une partie au conflit, l'enfant bénéficie d'un ensemble de dispositions des CG et des PA. Lesquelles dispositions imposent généralement aux parties de réserver à l'enfant, à l'instar d'autres personnes civiles, un traitement humain en toutes circonstances et de le protéger contre tout acte pouvant porter atteinte à sa vie et à son intégrité physique et morale. Ces dispositions se trouvent être relayées

\footnotetext{
1149 Voy. HENCKAERTS, Jean-Marie et DOSWALD-BECK, Louise, Droit international humanitaire coutumier, Volume I : Règles, op. cit., pp. 655-657.

${ }^{1150}$ ASPREMONT, Jean d' et HEMPTINE, Jérôme de, op.cit., p. 371.
} 
par celles spécifiquement liées à l'état d'enfance notament à sa vulnérabilité physique, psychique ou morale. En outre, pris comme acteur dans un conflit armé international, l'enfant n'est non moins un sujet protégé. Il se verra donc reconnaître la qualité de combattant, par opposition à une personne civile. Cette protectionn s'étend aussi à l'enfant prenant part aux conflits armés non internationaux.

De ce qui précède, il est à remarquer que la protection spéciale de l'enfant entamée au niveau des CG sera complétée et développée au niveau des PA. Toutefois, les articles qui assurent la protection spéciale de l'enfant directement ou indirectement ${ }^{151}$ ne représentent pas aussi grand chose par rapport à l'ensemble des CG et des PA I et II. Bien plus la protection de l'enfantsoldat reste encore plus précaire par rapport à celle de l'enfant qui ne prend pas part aux hostilités suivant ces instruments juridiques. Ce constat a une implication considérable sur les mécanismes de protection des enfants en situation de conflits armés.

En effet, il est clair que l'on ne peut pas parler de la protection spéciale des enfants en période d'hostilités sans l'institution des mécanismes aussi appropriés ou mieux spécialisés ou spécifiques. L'institution des "puissances protectrices" qui ont brillé par un dysfonctionnement quasi total est à percevoir comme institution de protection d'ordre général. Et ce, en dépit du fait que la tâche de la protection spéciale des personnes vulnérables dont les enfants leur était également reconnue.

Par ailleurs, les CG voire les PA se limitent à obliger les puissances belligérantes les "mesures" à prendre pour assurer leur application. Lesquelles "mesures" sont plus "possibles" que "nécessaires". Chose qui paraît réductrice de certaines interdictions ${ }^{1152}$. En ce sens, l'on rappelera certaines mesures expressément énumérées par ces instruments: le droit des parties au conflit de créer sur leurs propres territoires ou sur les territoires occupés des zones et localités sanitaires et de sécurité afin de mettre les enfants de moins de quinze ans à l'abri des effets de la guerre (art.14 de la CG IV) ou la création de zones neutralisées dans les régions des combats destinées à mettre à l'abri des dangers des combats des personnes civiles en général (article 15 de la CG IV); l'évacuation des enfants d'une zone assiégée ou encerclée (art.17 de la CG IV); le libre passage de tout envoi des vivres indispensables, des vêtements et des fortifiants réservés aux enfants de moins de quinze ans (art.23 de la CG IV); les mesures nécessaires à prendre par les parties au conflit au profit des enfants de moins de quinze ans, orphelins ou séparés des familles du fait de la guerre, pour que soient facilités leur entretien, la pratique de leur religion et leur éducation (art.24 §1 de la CG IV); accueil des enfants en pays neutres (art.24 §2 de la CG IV); identification des enfants de moins de 12 ans (art.24 $\$ 3$ de la CG IV); etc.

De ces mesures, il nous paraît intéressant de dire un mot sur les zones et localités sanitaires et de sécurité; zones neutralisées et les zones démilitarisées qui rentrent dans le cadre de "protection civile" profitable aux enfants. Disons qu'au sens de l'article $61 \mathrm{du}$ PA I, la "protection civile" est appréhendée comme l'accomplissement des tâches humanitaires destinées à protéger la population civile contre les dangers des hostilités ou des catastrophes et à l'aider à surmonter leurs effets immédiats ainsi qu'à assurer les conditions nécessaires à sa survie. Ces tâches sont

${ }_{1152}^{1151}$ DEYRA, Michel, Le droit dans la guerre, op.cit., p. 155.

1152 Ibid., p. 45. 
énumérées à l'article précité et comporte notamment "la mise à disposition et organisation d'abris". En effet, les zones et localités sanitaires et de sécurité, au sens de l'article 14 de la CG $\mathrm{IV}$, sont instituées de manière à mettre à l'abri des effets de la guerre différentes personnes vulnérables de par leur état physique, à savoir les blessés et les malades, les infirmes, les personnes âgées, les femmes enceintes, les mères d'enfants de moins de sept ans et les enfants de moins quinze ans. Ces zones sont donc créées sur les territoires occupés, sur base d'un accord entre parties au conflit, "s'il en est besoin". La CG I distingue, d'une part, les "zones et localités sanitaires", de caractère généralement durable, organisées hors de la région des combats pour mettre à l'abri des armes à longue portée, et surtout des bombardements aériens, les blessés et malades, militaires ou civils, et d'autre part, les "zones et localités de sécurité" destinées à certains éléments de la population civile dont la faiblesse requiert une protection particulière notamment les enfants, vieillards, femmes enceintes. Les zones et localités sanitaires et de sécurité étant la combinaison de ces deux formules ${ }^{1153}$. Les zones neutralisées sont créées provisoirement, sur base d'un accord entre parties belligérantes dans les régions où se déroulent les combats pour mettre à l'abris les blessés, malades civils et militaires et les civils qui ne prennent pas ou plus part aux combats. Elles diffèrent des zones sanitaires et de sécurité de par leur caractère provisoire et de leur proximité des zones de combat; de l'accueil accordé à la population civile en général voire aux victimes militaires qui ne prennent plus part aux combats. Ce sont des lieux de réfuge d'urgence. Elles peuvent être créées directement par une partie ou de manière négociée par l'entremise d'un tiers (Organisme humanitaire ou puissance protectrice) ${ }^{1154}$. Les zones démilitarisées (cf. art. 60 du PA I), peuvent être instituées par accord exprès, verbal ou écrit entre parties. En ces zones, il est interdit aux parties au conflit d'étendre leurs opérations militaires, si cette extension est contraire à l'accord conclu. Ces zones doivent répondre aux conditions suivantes (cf. art. $60 \S 3$ du PA I): les combattants, les armes et matériels militaires mobiles devront être évacués; il n'y sera pas fait un usage hostile des installations ou établissements militaires fixes; les actes hostiles sont interdits à l'endroit des autorités et de la population en général; et toute activité liée à l'effort militaire devra avoir cessé. Les parties se voient le droit de donner une interprétation à ce qu'il faut entendre par "toute activité liée à l'effort militaire devra avoir cessé". Il faudrait ajouter que "[1] a violation substantielle par l'une des parties libérera l'autre partie de ses obligations et mettra fin au statut de la zone"1155. Les enfants en conflits armés se trouvent être protégés sous ces "mesures" qui, pour certaines, dont les “zones sanitaires et de sécurité principalement, s'avèrent spécifiques. Cependant, une fois de plus, aucun caractère obligatoire n'est marqué. Tout reste du domaine de l'appréciation des parties au confli armé.

En revanche, il n'existe pas un ou des "mécanismes conventionnels spécifiques" devant ainsi veiller à ce que les mesures liées à la protection spéciale des enfants en situation de conflits armés soient bel et bien mises en oeuvre. Qu'il soit dit aussi que ces mesures, nécessitant de coûts importants de la part des parties aux conflits armés qui au départ généralement peu soucieux de l'importance de leur mise en oeuvre et préoccupées plus par la victoire sur l'ennemi, ne sont pas toujours concrétisées sur le champ de bataille. Analysons, à juste titre, les mesures d'évacuation des enfants pour des raisons tenant à leur santé ou traitement médical ou pour des raisons de

\footnotetext{
${ }^{1153}$ DEYRA, Michel, Le droit dans la guerre, op.cit., 64-65.

${ }^{1154} \mathrm{Ibid}$.

${ }^{1155} \mathrm{Ibid}$
} 
sécurité pour lesquelles insistent d'ailleurs les PA I (article 78) et II (article $4 \S 3$ e). Ces mesures nécessitent pour leur concrétisation des ressources financières importantes que l'on ne peut imaginer. Déjà, beaucoup d'Etats, notamment en développement (cadre où se passent actuellement les grands lots des conflits armés), accusent de défaillances croissantes dans le domaine de transport. L'exemple d'un pays comme la RDC qui n'a aucun aéronef (depuis tous les temps des conflits armés) national n'est pas isolé ${ }^{156}$. Ce qui vaut de même pour d'autres moyens tels que des bateaux ou bâtiments de mer. Ces évacuations peuvent s'effectuer sur des longues distances, d'un pays à un autre dans le cadre d'un CAI ou d'une zone à une autre d'un même pays dans le cadre d'un CANI. Les ressources financières, humaines et logistiques importantes seront donc attendues. Et les Etats ne sont toujours pas prêts à de tels "sacrifices" alors qu'il s'agit là de leur responsabilité.

La problématique des mécanismes de mise en oeuvre des règles du DIH demeure généralisée. Les mécanismes de prévention autant de sanction sont aussi concernés. Suivant, les CG et leurs PA, les Etats parties s'engagent à diffuser le plus largement possible les dispositions contenues dans ces instruments juridiques sur leurs territoires respectifs. Ils doivent notamment l'incorporer dans le programme d'instruction militaire voire dans l'enseignement civil afin que ceux-ci soient compris. Ceci s'avère même une obligation coutumière (cf. Règle $142^{1157}$ ). Car l'on ne peut mieux appliquer que quelque chose qui au départ est bien connue et maîtrisée. Il est donc demandé aux autorités civiles, militaires et autres devant assumer en temps de guerre une responsabilité sur des personnes protégées d'avoir une certaine maîtrise de ces instruments et de les détenir (cf. Par exemple, l'article 144 de la CG IV; article 127 de la CG III; article 48 de la CG II, article 47 de la CG I). Le PA I en son article 6 demande aux Hautes Parties contractantes de s'efforcer, avec l'aide des sociétés nationales de la Croix-Rouge (Croissant-Rouge, Lion-etSoleil-Rouge) de former un personnel qualifié en vue de faciliter l'application des CG et du PA I. Et le CICR pour sa part tiendra la liste des personnes ainsi formées que les Etats lui auraient communiquées. Au-delà de cela, des mesures repressives sont prévues à l'égard des infractions graves établies par ces instruments (cf. Article 147 de la CG IV; article 130 de la CG III; article 51 de la CG II; article 50 de la CG I). A ce titre, les Etats sont appelés à prendre des mesures législatives nécessaires pour reprimer ce genre d'infractions. Ce qui vaut de même pour les autres violations de DIH bien que cela ne soit pas expressément mentionné.

Les Etats devraient pour prévenir les cas liés aux violations des droits des enfants en période des hostilités prendre toutes les mesures nécessaires dans ce sens (cf. Supra). Ce qui sera le cas pour la prise en compte des règles élémentaires liées au DIH et aux droits de l'homme dans le programme scolaire dès l'école fondamentale. L'éducation à ces notions autant pour celles de la paix est plus que nécessaire si l'on veut bien atteindre un monde des esprits épris de paix et d'humanisme.

Pour tout dire, aux termes des CG et de leurs PA, la protection spéciale de l'enfant ne s'accompagne pas avec des "mécanismes spéciaux de respect ou de protection". L'on comprend

${ }^{1156}$ Depuis fin juillet 2015, la RDC s'est dotée d'une compagnie aérienne Congo Airways avec deux Airbus A320.

${ }^{1157}$ Voy. DAVID, Eric, TULKENS, Françoise et VANDERMEERSCH, Damien, Code de droit international humanitaire, op.cit., p. 373. 
parfaitement que la maladie qui ronge déjà le DIH en termes des mécanismes de protection générale des personnes civiles n'épargnent pas le secteur de la vulnérabilité où se retrouve l'enfant. Ainsi, la protection spéciale de l'enfant demeure donc problématique d'autant plus que les mécanismes spéciaux ou spécifiques devant tenir compte de certaines de ses réalités propres et distinctes d'autres catégories des personnes civiles sont inexistants.

\section{§2. Le Comité des droits de l'enfant}

Il n'existe pas de mise en œuvre des droits de l'homme efficace sans l'institution des mécanismes appropriés. Etant donné que la mise en œuvre des droits de l'homme revient principalement aux Etats qui sont parties aux traités, en même temps leurs auteurs, ceux-ci instituent par conséquent, au plan interne ou international des mécanismes indiqués. Et dans le cadre de la Convention relative aux droits de l'enfant, «l'application et le respect de ces droits reposent sur l'action du gouvernement dont dépend l'enfant et sur l'adoption dans ce pays de lois conformes à la convention ${ }^{1158}$. Il est mis, par ailleurs, en place le Comité des droits de l'enfant. Ce dernier se charge de veiller aux progrès accomplis par les Etats parties à la Convention relative aux droits de l'enfant concernant l'application des droits contenus dans cet instrument. En clair, « [e]n ce qui concerne le respect des droits de l'enfant, le rôle du Comité des droits de l'enfant est de donner des indications aux États parties en formulant des recommandations dans les Observations finales sur les différents pays et diverses Observations générales ${ }^{1159}$.

Pour remplir sa mission qui consiste globalement à la protection et à la promotion des droits de l'enfant, le Comité des droits de l'enfant se compose des dix huit membres au 18 décembre $2002^{1160}$, experts de haute moralité et d'une compétence reconnue dans le domaine des droits de l'enfant. Agissant non comme diplomates représentant leurs Etats d'origine respectifs mais plutôt à titre personnel, ces experts sont élus au scrutin secret par les Etats parties parmi leurs ressortissants pour un mandat de quatre ans. Et ce sur base d'une liste qu'établissent ces Etats. Il est donc de droit reconnu à tout Etat partie qui le souhaite de désigner un candidat. Tout comme, sur base des usages diplomatiques, un Etat quelconque pourra se contenter à appuyer la candidature d'un de ses partenaires. Il est tenu compte d'une représentation équilibrée des principaux systèmes juridiques en présence et d'une répartition géographique équitable. Les membres du Comité institué reçoivent des émoluments prélevés sur les ressources de l'ONU avec approbation de l'AG/NU. Ce qui contribue tant soit peu à leur indépendance (cf. art. 43 de la CDE).

Pour les cas d'empêchement d'exercice de leurs fonction, ce qui peut-être le décès, la démission ou toute autre raison, il revient à l'Etat partie qui avait présenté la candidature du cas concerné de nommer un autre expert pour terminer le mandat restant sous réserve de l'approbation du Comité (§7 de l'art.43).

Le Comité, comme toute institution des droits de l'Homme, adopte un règlement intérieur devant

\footnotetext{
${ }^{1158}$ BOUCHET-SAULNIER, Françoise, Dictionnaire pratique du droit humanitaire, Paris, éd. La Découverte, 2013, p. 349.

1159 Jaap DOEK, « art.cit. », p.17.

${ }^{1160}$ Voy. De SCHUTTER, Olivier, TULKENS, Françoise et VAN DROOGHENBROECK, Sébastien, op.cit., p. 211.
} 
régir ses activités et élit le Bureau devant le conduire pour un mandat de deux ans. Le SG/NU demeure la plaque tournante pour l'organisation et le fonctionnement du Comité des droits de l'enfant. Il assure l'organisation matérielle des élections des membres du Comité des droits de l'enfant ( $\$ 4$ et $\$ 5$ de l'art.43 de la Convention relative aux droits de l'enfant) et lui facilite la tâche pour son bon fonctionnement. A ce titre, le SG/NU met à la disposition du Comité le personnel et les matériels nécessaires pour lui permettre de s'acquitter efficacement de ses missions ( $\$ 12$ de l'art.43 de la Convention relative aux droits de l'enfant). Le SG/NU sert des relais pour faire parvenir les rapports étatiques sur des situations des droits de l'enfant au Comité ( $\$ 1$ de l'art.44 de la Convention relative aux droits de l'enfant). Lesquels rapports doivent être soumis périodiquement tous les cinq ans après un rapport initial de deux ans après l'entrée en vigueur de la Convention. Un délai qui laisse souffrir différentes situations des droits de l'enfant. En d'autres termes, ce système «ne permet pas au Comité de prendre en compte des situations ou des cas urgents puisque les rapports des Etats et leur examen ont lieu seulement tous les cinq ans $^{1161}$ ». A ce titre, le même problème est constaté dans le système africain qui réduit, toutefois, ce délai à trois ans (cf. infra).

Par ailleurs, une double mission, de protection et de promotion des droits de l'enfant, est attribuée au Comité des droits de l'enfant, l'avions-nous dit. Il s'agit d'une mission qui nécessité le concours de différents organismes autant gouvernementaux, intergouvernementaux que nongouvernementaux. Pour tout dire, si le SG/NU reste la plaque tournante devant permettre au Comité des droits de l'enfant de mieux remplir sa double mission, il est important de mentionner que d'autres institutions de Nations unies appuient efficacement le Comité des droits de l'enfant dans cette œuvre. L'AG/NU, par exemple, a un pouvoir d'approbation notamment sur la modification de la durée des sessions, les émoluments à allouer aux membres du Comité. Le rapport des activités du Comité des droits de l'enfant lui est soumis par l'intermédiaire du Conseil économique et social des Nations Unies ( $\$ 5$ de l'art.44 de la Convention relative aux droits de l'enfant). Le Comité peut recommander des études sur des questions des enfants au SG/NU par l'entremise de l'AG/NU (point c, art. 45 de la Convention relative aux droits de l'enfant).

Ainsi donc, dans la poursuite de ces objectifs, le Comité peut demander et recevoir des informations ou des conseils de tout organe compétent du système des Nations Unies (ex : Fonds des Nations Unies pour l'enfance, Organisation Internationale du Travail, voire les autres Institutions spécialisées) ou de toute autre organisation qu'il jugera appropriée, telle qu'une ONG (art. 45 de la Convention relative aux droits de l'enfant).

Il peut en outre formuler des suggestions et de recommandations générales qui ne sont pas obligatoires. Le Comité remet tous les deux ans un rapport d'activités à l'AG/NU ${ }^{1162}$. De l'avis de Jaap DOEK, Président du Comité des droits de l'enfant de 2001 à 2007, « [1]a façon dont chaque État partie applique ces recommandations varie et dépend souvent non seulement des priorités et de la volonté politique mais aussi des actions des [ONG] et d'autres organisations de la société civile. Le système des droits de l'homme tente de voir comment améliorer le suivi des observations finales ; le Haut Commissariat des Nations Unies aux droits de l'homme joue un

\footnotetext{
${ }^{1161}$ BOUCHET-SAULNIER, Françoise, Dictionnaire pratique du droit humanitaire, Paris, éd. La Découverte, 2013, op.cit., p. 105.

${ }^{1162}$ Lire Idem, Dictionnaire pratique du Droit humanitaire, Paris, éd.La Découverte \& Syros, 1998, p. 60,
} 
rôle important dans ces discussions $»^{1163}$.

De tout ce qui précède, concernant spécialement la situation des enfants dans les conflits armés, le Comité des droits de l'enfant, dans ses études sur l'application du protocole facultatif, note avec inquiétude que l'enrôlement et l'utilisation des enfants en violation des dispositions du protocole figurent souvent uniquement dans des dispositions du droit militaire sans que ces violations soient explicitement érigées en infraction par la législation. Par conséquent, en se fondant sur les dispositions du Protocole facultatif à la Convention relative aux droits de l'enfant concernant la vente d'enfants, la prostitution des enfants et la pornographie mettant en scène des enfants, le Comité a recommandé aux États parties ${ }^{1164}$ :

- de préciser en droit que les violations des règles concernant l'enrôlement et l'utilisation d'enfants dans les conflits armés sont des crimes et qu'elles doivent être sanctionnées par des peines sévères appropriées ;

- d'établir leur compétence extraterritoriale pour ces crimes - en tout cas pour ceux qui sont commis par ou contre une personne qui est ressortissant de l'État concerné ;

- d'instaurer des règles d'extradition effectives similaires à celles énoncées à l'article 5 du Protocole facultatif à la Convention relative aux droits de l'enfant concernant la vente d'enfants, la prostitution des enfants et la pornographie mettant en scène des enfants .

Tout comme dans le cadre global des droits reconnus par la Convention, le Comité des droits de l'enfant a systématiquement recommandé aux États parties d'élaborer une stratégie globale avec des politiques ou plans d'action nationaux pour mettre en œuvre la Convention. Pour des situations post-conflits, ces plans devront concerner tous les enfants impliqués dans les conflits afin que leurs points de vue soient entendus dans le processus de réintégration. C'est ici que les enfants doivent influer sur des mesures qui sont ou devront être prises pour assurer ou garantir leurs droits. Ces plans ou stratégies devront inclure de mesures de réadaptation et de réinsertion de ces enfants impliqués d'une manière ou d'une autre au conflit, assurer l'accès à l'éducation et aux services de santé de qualité ; prendre des mesures devant favoriser le regroupement familial ainsi qu'instituer un processus de justice transitionnelle pour de nombreux cas de crimes internationaux commis à l'endroit des enfants ${ }^{1165}$.

Enfin, au regard de la configuration ci-haut présentée, il y a lieu de se demander si le Comité des droits de l'enfant peut valablement assurer la protection des droits de l'enfant plus précisément en situation de conflits armés. En réponse, le Comité hérite d'un défaut général de différents systèmes de protection des droits de l'homme. C'est notamment le fait d'être des organes dépendant trop des Etats représentés au sein de différents organes tels que la Conférence des Chefs d'Etats et de Gouvernement, l'AG/NU, etc. Ses rapports sont d'ailleurs remis tous les deux ans à l'AG/NU. De ce point de vue là, il se présente comme un organe politisé dont les recommandations pourraient souffrir de la bonne foi des Etats qui ne sont pas toujours impressionnés de mettre en œuvre les recommandations ou résolutions adoptées. Mais la présence

\footnotetext{
${ }^{1163}$ DOEK, Jaap, « art.cit. », p. 17.

${ }^{1164}$ Ibid.

${ }^{1165}$ Ibid., p. 13.
} 
d'un organe des Nations Unies tel que le Secrétariat pour soutenir le Comité dans ses diverses taches n'est pas à minimiser. Celui-ci autant que d'autres organes de l'ONU constitue un véritable organe de mise en œuvre des droits de l'homme. Il a institué un Représentant spécial sur les enfants et les conflits armés dont le rapport sur la situation des enfants établi en 1996 est un fruit appréciable. Des résolutions importantes condamnant le recrutement et l'utilisation des enfants dans les conflits armés sont prises au sein des Nations Unies (cf. supra). Et sur la scène internationale, aucun Etat, puissant soit-il, ne souhaiterait que son identité soit affichée sur la liste des Etats dont la situation des droits de l'enfant reste précaire.

Un autre désavantage lié au Comité des droits de l'enfant est le fait qu'il n'admette pas des communications individuelles émanant des particuliers, des ONG et se contente uniquement des rapports émanant des Etats. Alors que par le système de communication individuelle, le Comité se comporterait comme une juridiction devant établir des responsabilités des Etats auteurs de violations s'il y a lieu.

C'est justement dans ce sens que concernant le droit à un recours effectif, le nouveau protocole facultatif à la Convention relative aux droits de l'enfant, le Protocole facultatif à la Convention relative aux droits de l'enfant établissant une procédure de présentation de communications ${ }^{1166}$, représente une avancée importante car il instaure une procédure de présentation de communications individuelles ${ }^{1167}$. «En vertu de ce protocole, les enfants à titre individuel ou en groupe pourront déposer des plaintes concernant des violations spécifiques de leurs droits, en regard de l'application de la $[\mathrm{CDE}]$ et de ses deux protocoles additionnels ${ }^{1168}$. Ainsi, si en droit national, la capacité juridique du mineur d'ester en justice est drastiquement limitée, « [e]n droit international, l'enfant peut, au contraire, agir lui-même, la condition de capacité d'ester en justice étant inexistante ${ }^{1169}$. Et en dépit d'une mise en œuvre particulièrement difficile d'un tel droit, certains enfants ont réussi à saisir notamment le Comité des droits de l'homme et la Cour européenne à cet effet ${ }^{1170}$. Ce troisième protocole facultatif permettra ainsi aux enfants touchés par une guerre de porter plainte et revendiquer leur droit à la réadaptation et à la réinsertion. Il sera aussi possible de porter plainte pour l'enrôlement et l'utilisation d'enfants de quinze ans ou plus, ce que ne permet pas le Protocole facultatif concernant l'implication d'enfants dans les conflits armés. La faille du Statut de Rome est ainsi comblée, même si c'est de manière limitée ${ }^{1171}$. Ainsi, le 14 janvier 2014, le Costa Rica a déposé son instrument de ratification qui permet à ce protocole d'entrer en vigueur le 14 avril 2014. Ce qui revient répondre bien à propos

\footnotetext{
${ }^{1166}$ Lire A/RES/66/138, Protocole facultatif à la Convention relative aux droits de l'enfant établissant une procédure de présentation de communications du 19 décembre 2011, in http://research.un.org/fr/docs/ga/quick/regular/66 (Source consultée le 25 novembre 2016). Lire également pour approfondissement RASSON, Anne-Catherine, «La protection juridictionnelle des droits fondamentaux de l'enfant : une utopie ? », in RTDH (106/2016), pp. 498-520.

${ }^{1167}$ Lire DOEK, Jaap, «art.cit. », pp. 20-21.

1168 «L'UNICEF France se réjouit que les enfants puissent déposer plainte auprès de l'ONU et appelle le gouvernement français à ratifier ce nouvel instrument juridique», Information de Presse in http://www.unicef.fr/sites/default/files/cp_protocole_cide_140113_0.pdf (Source consultée le 13 juillet 2014). Voy. aussi GRAZIANI, Laurene et SERSTE, Nastassia, «Children and war : past and présent », in J.D.J, n 358 -octobre 2016, p. 30.

${ }^{1169}$ RASSON, Anne-Catherine, « La protection juridictionnelle des droits fondamentaux de l'enfant : une utopie ? », « art.cit. », pp. 488-489.

${ }^{1170}$ Voy. Ibid., pp. 490-494.

${ }^{1171}$ Lire DOEK, Jaap, « art.cit. », pp. 20-21.
} 
aux attentes du Comité des droits de l'enfant de l'ONU qui affirmait : « [p]our que les droits aient un sens, il faut qu'il existe des voies de recours efficaces en cas de violation ${ }^{1172}$.

\section{§3. La mise en ouvre de la Convention de l'OIT $\mathbf{n}^{\circ} 182$ concernant l'interdiction des pires formes de travail des enfants et l'action immédiate en vue de leur élimination}

Comme tout instrument conventionnel, principalement dans les domaines du DIH et du DIDH, la Convention de l'OIT $n^{\circ} 182$ nécessite pour sa mise en œuvre un certain nombre d'attitudes de la part des Etats qui sont parties. Ceux-ci se trouvent liés par des obligations positives et négatives exigées par cet instrument.

Ainsi, au regard de l'article $1^{\text {er }}$ de cette convention, les Etats doivent prendre des mesures immédiates et efficaces pour assurer l'interdiction et l'élimination de recrutement forcé ou obligatoire et ce, de toute urgence. Dans le même sens, l'article 7 renforce les dispositions de l'article précédent en indiquant aux Etats parties de prendre des «mesures nécessaires » pour assurer la mise en œuvre effective et le «respect» des dispositions donnant effet à cette convention. En clair, ces dispositions instruisent aux Etats d'avoir des attitudes, positives et négatives. D'ailleurs, cette Convention s'appréhende comme « action-oriented ${ }^{1173}$ qui nécessite des mesures appropriées de la part de ses parties.

En termes d'attitudes positives, ou mieux des obligations positives qui y ressortent, les Etats parties devraient mettre en place des mécanismes appropriés pour assurer l'effectivité des dispositions du présent instrument. Ils prendront des mesures qu'ils jugeront nécessaires au regard de la situation sur terrain. C'est ici qu'il faut souligner l'expression de la convention qui mentionne des «mesures nécessaires » et non des «mesures possibles ». La première expression semble contraignante et ne laisse pas une certaine latitude aux Etats comme c'est le cas pour la seconde (cf. supra). Les Etats iront jusqu'à aménager leurs législations, dans l'objectif de mettre fin au recrutement forcé ou obligatoire des enfants, pour intégrer différents types de sanctions (pénales, administratives, etc.) à l'endroit des auteurs éventuels de cette pratique. Indirectement, l'on peut remarquer l'obligation de « respecter et de faire respecter » dans le domaine des droits de l'Homme à travers ces dispositions.

Par ailleurs, les Etats ont une obligation de collaboration ou de coopération avec d'autres organes pour mettre fin à la pratique de recrutement obligatoire ou forcé des enfants. Les Etats sont donc appelés à collaborer avec des institutions publiques compétentes et les organisations d'employeurs et de travailleurs voire des groupes intéressés sur ce sujet (cf. les articles 5 et 6). La coopération entre Etats est également exigée en vue de mesures appropriées (cf. art. 8).

Au-delà de cela, les Etats eux-mêmes ont l'obligation de respecter des obligations émises par ledit instrument. C'est ici qu'il faut appréhender les obligations négatives qui leur incombent. En d'autres termes, les Etats ne doivent pas être des auteurs de violations des obligations formulées

1172 «L'UNICEF France se réjouit que les enfants puissent déposer plainte auprès de l'ONU et appelle le gouvernement français à ratifier ce nouvel instrument juridique », Information de Presse in http://www.unicef.fr/sites/default/files/cp_protocole_cide_140113 0.pdf (Source consultée le 13 juillet 2014)

${ }^{1173}$ MAYSTRE, Magali, op.cit., p. 66. 
par ce instrument. L'interdiction de la pratique de recrutement forcé des enfants impose aux Etats de ne point y recourir.

En bref, les obligations positives et négatives se trouvent intimement liées dans différentes dispositions. Pour être plus explicite, par exemple, l'obligation de coopération entre Etats (obligation positive) implique également de la part des Etats de rien faire qui pourrait porter atteinte à l'effectivité de cette coopération (obligation négative); Le respect de cet instrument (obligation négative) implique également aux Etats de déployer tout mécanisme nécessaire pour que ce respect soit assuré (obligation positive). Il revient finalement au Conseil d'administration du Bureau international du travail de présenter, si nécessaire, le rapport sur l'application de cette convention à la conférence générale.

\section{§4. Le Comité africain d'experts sur les droits et le bien-être de l'enfant}

La Charte africaine des droits et du bien-être de l'enfant a institué en son article 32 un Comité africain d'experts sur les droits et le bien-être de l'enfant dont la mission est d'assurer la promotion et la protection des droits et du bien-être de l'enfant. Mis en place en juillet 2001 à l'occasion de la $37^{\mathrm{e}}$ session de la Conférence des chefs d'Etats et de gouvernements de l'OUA (actuelle UA) à Lusaka (Zambie) ${ }^{1174}$, le Comité africain d'experts sur les droits et le bien-être de se compose de onze membres siégeant à titre personnel (art.33) et se réunit deux fois par an, généralement en mai et en novembre à Addis-Abeba, en Ethiopie ${ }^{1175}$. Ces membres sont élus au scrutin secret pour un mandat de cinq ans par la Conférence des Chefs d'Etats et de gouvernement sur une liste présentée par les Etats parties à cette charte (art.34). Ils ne sont donc pas rééligibles contrairement aux membres du Comité des droits de l'enfant (cf. supra) qui sont rééligibles après un mandat de quatre ans si leur candidature venait d'être présentée à nouveau. Il est de droit reconnu aux Etats parties à ladite charte de présenter tout au plus deux candidats dont l'un ne devrait pas être son ressortissant mais d'un autre Etat partie à la présente charte. Cela peut sous-entendre le souci de préserver une répartition géographique équitable. Et d'ailleurs ce comité ne peut comprendre plus d'un ressortissant du même Etat. Sur base des usages en la matière, il sera également tenu compte d'une représentation équilibrée des principaux systèmes juridiques africains. Et sur base des usages diplomatiques, un Etat quelconque pourra se contenter à appuyer la candidature d'un de ses partenaires. Si rien n'est expressément dit dans la Charte à propos des émoluments des membres du Comité, il sied de comprendre par ailleurs qu'ils ne travaillent pas en bénévolat. Autant pour leurs privilèges et immunités comme fonctionnaires internationaux, ils dépendent de l'Union Africaine.

Pour les cas d'empêchement d'exercice de leurs fonction, ce qui peut-être le décès, la démission ou toute autre raison, il revient à l'Etat partie qui avait présenté la candidature du cas concerné de nommer un autre expert pour terminer le mandat restant, sous réserve de l'approbation de la Conférence des Chefs d'Etat et de gouvernement (art.39). Disons que faire dépendre la nomination du candidat concerné de la Conférence des Chefs d'Etats et de gouvernement s'avère

\footnotetext{
${ }^{1174}$ Union africaine, Conseil exécutif, Vingt et unième session ordinaire (9-12 juillet 2012) EX.CL/744(XXI), Rapport du Comité africain d'Experts sur les droits et le bien-être de l'enfant (ACERWC), op. cit., p. 1.

1175 BOUCHET-SAULNIER, Françoise, Dictionnaire pratique du droit humanitaire, Paris, éd. La Découverte, 2013, op.cit., p. 351.
} 
logique sur base du parallélisme des formes d'autant plus que c'est cette conférence qui avait élu les membres du Comité. En même temps, c'est accrôitre davantage la politisation de cet organe de protection des droits et du bien-être de l'enfant. Rappelons en ce sens que suivant le système adopté par le Comité des droits de l'enfant, l'approbation en pareilles circonstances n'émane pas de 1'AG/NU mais de membres du Comité eux-mêmes. Ce qui est aussi une manière de préserver leur indépendance et leur manière de travailler.

Le Comité africain d'experts sur les droits et le bien-être de l'enfant, comme toute institution des droits de l'Homme, adopte un règlement intérieur devant régir ses activités et élit le Bureau devant le conduire pour un mandat de deux ans. Le Secrétaire général de l'Union africaine demeure la plaque tournante pour l'organisation et le fonctionnement dudit Comité. Il assure l'organisation matérielle des élections des membres du Comité africain d'experts sur les droits et le bien-être de l'enfant et lui facilite la tâche pour son bon fonctionnement. A ce titre, c'est lui qui convoque la première réunion du Comité après l'élection de ses membres. Mission qui sera entreprise par la suite par le Président du Comité. Son pouvoir se trouve encore plus élargi lorsqu'il doit désigner le Secrétaire du Comité. Ne devrait-on pas laisser ce privilège au Comité lui-même ? Cette manière atteste à coup sûr les écueils dont sont victimes différents organes régionaux de protection des droits de l'homme notamment la Cour et la Commission africaines des droits de l'homme et des peuples. Le Secrétaire général de l'Union africaine sert également des relais, comme c'est le cas pour le Secrétaire général de l'ONU à propos du Comité des droits de l'enfant, pour faire parvenir les rapports étatiques sur des situations des droits de l'enfant au Comité (art.43). Lesquels rapports doivent être soumis tous les trois ans. A ce titre, le système africain paraît tout de même plus avantageux par rapport au système onusien de la Convention relative aux droits de l'enfant qui laisse un délai de cinq ans pour la soumission des rapports étatiques. Il serait, par ailleurs, plus souhaitable que ce délai soit ramené à un an pour une promotion et une protection très progressive, par conséquent très efficace des droits et du bienêtre de l'enfant. Mais, dans tous les cas, il ne paraît pas possible d'examiner des cas urgents.

Suivant son mandat (cf. art .42), le Comité africain d'experts sur les droits et le bien-être de l'enfant assure la promotion et la protection des droits de l'enfant consacrés par ladite Charte notamment en réunissant des documents et informations importants concernant la situation de l'enfant sous la sphère africaine ; en élaborant et formulant des principes et règles visant la protection et le bien-être de l'enfant en Afrique; coopérant avec toute institution africaine œuvrant dans le domaine des droits et du bien-être de l'enfant; interprétant et veillant à l'application de la présente Charte et en s'acquittant des tâches qui peuvent lui être confiées par tout organe de l'Union africaine. A ce titre comme tout organe de protection des droits de l'homme, le Comité africain d'experts sur les droits et le bien-être de l'enfant n'agit pas de manière solitaire. Car il participe non moins au respect des droits de l'homme au niveau universel. C'est justement dans ce sens que pour mieux remplir sa double mission de promotion et de protection des droits et du bien-être de l'enfant sous la sphère africaine, le Comité s'inspire de tout instrument pertinent relatifs au DIDH (art. 46) ${ }^{1176}$. L'on peut donc dire qu'il se sert de jurisprudence de différents organes de protection des droits autant au plan universel que régional.

Par ailleurs, la Charte africaine des droits et du bien-être de l'enfant apporte une innovation non

${ }^{1176}$ VILJOEN, Frans, International Human Rights Law in Africa, op.cit., p. 263. 
moins de taille comparativement à la $\mathrm{CDE}$. Ce qui est très profitable pour la situation des enfants touchés par les conflits armés. En effet, «[1]a Convention relative aux droits de l'enfant et le Protocole facultatif concernant l'implication d'enfants dans les conflits armés ne comprennent aucune disposition sur les possibilités de recours en cas de violation des droits de l'enfant. Néanmoins, d'après l'article 44 de la Charte africaine des droits et du bien-être de l'enfant, le Comité africain d'experts sur les droits et le bien-être de l'enfant " est habilité à recevoir des communications concernant toute question traitée par la présente Charte, de tout individu, groupe ou organisation non gouvernementale reconnue par l'Organisation de l'unité africaine, par un État membre, ou par l'Organisation des Nations unies ». La communication peut donc être déposée en violation de l'article 22 de la Charte africaine des droits et du bien-être de l'enfant concernant l'interdiction d'enrôler et d'utiliser des enfants dans les conflits armés » ${ }^{1177}$. «Les premières communications ont été examinées tardivement ${ }^{1178}$ et le Comité africain a traité la première plainte concernant l'utilisation d'enfants dans un conflit en $2013 »^{1179}$. Il va sans dire que la mise en œuvre d'un tel processus se trouve limité notamment par la complexité du système africain, la multiplication des acteurs et des textes, les ressources et les capacités limitées, etc. $^{1180}$

De tout de ce qui précède, l'on se permettra de dire que le Comité des droits et du bien-être de l'enfant demeure un organe dépendant de l'Union Africaine. Ce qui est le cas pour ses homologues qui sont la Cour et la Commission africaines des droits de l'homme et des peuples. La Conférence des Chefs d'Etats et de gouvernement reste un organe central devant donner suite au travail de ce Comité. Les rapports d'activités du Comité lui sont donc adressés après chacune de ses sessions. Le Comité publie ses rapports seulement après l'examen de la Conférence. Et les Etats parties devront assurer par la suite une large diffusion dans leurs propres pays (art. 45). Le Secrétaire général de l'Union Africaine reste également un organe qui joue pleinement son rôle pouvant aller jusqu'à toucher l'indépendance du Comité. Celui-ci détient le droit de désigner le Secrétaire du Comité (art. 40). Rôle que nous estimons devrait être joué par le Comité lui-même à qui il revient le droit d'élire son Bureau pour une période deux ans.

Pour tout dire, en dépit du privilège que détient le Comité de recevoir les requêtes individuelles, il ne s'agit pas d'un organe «juridictionnel» de protection des droits de l'Homme avec tous les atouts y relatifs. Ce qui vaut d'ailleurs pour la Commission africaine des droits de l'homme et de peuples, laquelle reste fort pénétrée par la tradition africaine «des modes consensuels de règlement des différends ${ }^{1181}$.

\section{§5. La Cour pénale internationale comme mécanisme de protection de l'enfant en situation de conflits armés}

La CPI a été créée pour assurer la répression de certaines violations graves du jus contra bellum

\footnotetext{
${ }^{1177}$ DOEK, Jaap, « art.cit. », p. 18.

${ }_{1178}$ Voy. http://national-cases.acerwc.org/ (Source consultée le 25 novembre 2016).

1179 GRAZIANI, Laurene et SERSTE, Nastassia, «Children and war : past and présent », « art. cit. », p. 30 . Il s'agit de l'Affaire Michelo Husungule et autres (au nom des enfants du Nord de l'Ouganda) c. Ouganda, 2013 non retrouvée sur le site internet dudit Comité en date du 25 novembre 2016.

${ }^{1180}$ RASSON, Anne-Catherine, «La protection juridictionnelle des droits fondamentaux de l'enfant : une utopie ? », « art.cit. », p. 497.

1181 GNAMOU-PETAUTON, Dandi, «Les mécanismes régionaux africains de protection des droits de l'homme », in TAVERNIER, Paul (dir.), Regards sur les droits de l'homme en Afrique, L'Harmattan, Paris, 2008, p. 257.
} 
et du droit international humanitaire ${ }^{1182}$. En effet, le DIH accuse différentes faiblesses dès la Convention de Genève du 22 août 1864 pour l'amélioration du sort des militaires blessés dans les armées en campagne qui marque le début de sa codification (cf. supra). Une de ses faiblesses importantes réside dans l'absence des sanctions en cas de violation de ses dispositions. Les CG et leur premier PA se limitent à confier aux Etats parties la mission de prendre des mesures adéquates pour réprimer les infractions graves expressément énumérées ${ }^{1183}$. Et également prendre des mesures pour assurer la mise en œuvre des autres dispositions.

Toutefois, l'expérience prouve que les gouvernements ne sont pas très diligents en ce domaine. Dans ces conditions, il est normal que l'on ait songé à organiser une répression internationale devant une juridiction internationale ${ }^{1184}$. D'où l'importance de la CPI. Nicolas MICHEL n'hésite pas d'épingler la création de cette juridiction comme la plus spectaculaire des réussites du DIH de ces dernières années. Elle suscite d'attentes parfois mêlées d'incertitudes. L'avènement de cette juridiction viendra, au sens de l'auteur, renforcer le respect du DIH en tirant parti de l'expérience des tribunaux internationaux ad hoc. Elle aura donc un rôle répressif mais aussi préventif par répercussion poursuit l'auteur précité. ${ }^{1185}$

La CPI se charge de la répression des crimes les plus graves qui touchent l'ensemble de la communauté internationale (cf. le préambule et l'art. 5 du Statut de la CPI). Il s'agit du crime de génocide, des crimes contre l'humanité, des crimes de guerre et du crime d'agression non (cf. art. $5 \mathrm{du}$ statut de la CPI). Sa compétence se rapporte donc aux crimes ci-dessus commis sur le territoire d'un Etat membre ou par un ressortissant d'un Etat membre sur le territoire d'un Etat tiers. Conditions non cumulatives. Le CS/NU peut tout de même demander à la CPI d'enquêter sur toute situation analogue survenue sur le territoire d'un Etat tiers. Ce qui étend davantage la compétence de la CPI. En clair, cette dernière peut donc « être saisie par l'Etat concerné (art.13 et 14), c'est-à-dire l'Etat partie sur le territoire duquel le crime a été commis ou dont l'auteur [présumé] du crime a la nationalité («renvoi »), par le Conseil de sécurité des Nations Unies agissant au titre du chapitre VII de la Charte (art.13) ou par le Procureur agissant de sa propre initiative (art.13 et 15). ${ }^{1186} \gg$

Et contrairement aux autres juridictions pénales internationales ad hoc créées par résolutions du CS/NU pour des circonstances spécifiques, la CPI est une juridiction permanente créée par une convention internationale, le Statut de la CPI, adoptée à Rome le 17 juillet 1998. «Parce qu'elle est permanente, la recevabilité des requêtes devant elle ne connaît pas de limitation temporelle ou

1182 DAVID, Eric, « La répression pénale internationale: l'avenir de la Cour Pénale Internationale », in TAVERNIER, Paul, et L. Burgorgue Larsen (dir.), Un siècle de droit international humanitaire. Centenaire des Conventions de La Haye. Cinquantenaire des Conventions de Genève, Bruylant, Bruxelles, 2001, p. 185.

1183 Les articles 49(1), 50(1), 129(1) et 146 respectivement de la Ière, IIè, IIIè et IVè CG du 12 août 1949 disposent: «Les Hautes parties contractantes s'engagent à prendre toute mesure législative nécessaire pour fixer les sanctions pénales adéquates à appliquer aux personnes ayant commis, ou donné l'ordre de commettre, l'une ou l'autre des infractions graves à la présente Convention définie à l'article suivant. ». Voy. l'article $86 \mathrm{du}$ PA I.

1184 TAVERNIER, Paul, «De 1899 à 1999: Eclatement ou approfondissement du droit international humanitaire? », « art. cit. », p. 16.

1185 MICHEL, Nicolas, «Le droit international humanitaire entre frustrations, réussites et interrogations », in FLAUSS, Jean-François, (dir.), Les Nouvelles Frontières du Droit international humanitaire, Bruxelles, Bruylant, 2003, p. 12.

${ }^{1186}$ DAILLIER, Patrick, FORTEAU, Mathias et PELLET, Alain, op.cit., p. 805. 
géographique, sauf application du principe de non-rétroactivité et effets d'une immunité décidée par le Conseil de sécurité ${ }^{1187} \gg$. Le Statut de Rome est entré en vigueur depuis le $1^{\text {er }}$ juillet 2002, soixantième jour après le dépôt du soixantième instrument de ratification par la République Démocratique du Congo (RDC). Toutefois, contrairement aux autres juridictions pénales internationales dont le TPIY ou le TPIR qui ont une préséance sur les juridictions pénales nationales, la CPI a, quant à elle, une compétence complémentaire vis-à-vis des juridictions pénales nationales. Ceci ne l'empêche cependant pas d'intervenir pour des situations où les Etats n'ont pas engagé leurs juridictions pénales ou qu'elles se sont engagées de manière fantaisiste ou moins crédibles. A travers cette répression, la CPI représente un mécanisme de sanction important de mise en œuvre des règles du DIH. Au-delà de lutte contre l'impunité des crimes les plus odieux à l'endroit de l'humanité dont les enfants en particulier voire également de l'expression de vœu de non-renouvellement de ces crimes, la CPI, de par son statut, réactualise le droit international humanitaire ${ }^{1188}$. Ceci est attesté notamment au niveau des articles 7 et 8 du Statut de la CPI.

En effet, l'article 7 Statut de la CPI offre une nouvelle version du crime contre l'humanité dont le mobile n'est pas défini avec précision et pouvant être commis dans un contexte hors conflit armé mais dans le cadre d'une attaque généralisée ou systématique dirigée contre une population civile et en connaissance de l'attaque ${ }^{1189}$. Et l'article $8 \mathrm{du}$ statut comprend une liste impressionnante de crimes de guerre, liste qui non seulement couvre à peu près toutes les incriminations figurant dans les CG de 1949, le $1^{\mathrm{er}}$ PA de 1977 et les Statuts des TPI, mais qui en outre énonce des nouvelles infractions. Les enfants se trouvent donc concernés (cf. infra). Le Statut de la CPI distingue les crimes de guerre commis dans deux types de conflits armés (conflit armé interne et international) et soutient l'élargissement de la notion de conflit armé interne notamment en l'absence des critères de territorialité et d'opposition gouvernements/insurgés ${ }^{190}$ (cf. supra).

A ce sujet, la CPI venait de rendre le 14 mars 2012 son arrêt déclarant coupable Sieur Thomas Lubanga Dyilo, sujet congolais, notamment de crime de guerre consistant à procéder à l'enrôlement, à la conscription et à faire participer activement les enfants de moins de quinze ans à des hostilités ${ }^{1191}$. Celui-ci a été condamné à une peine d'emprisonnement de 14 ans le 10 juillet 2012 par la même juridiction. L'arrêt ci-haut énoncé a été suivi également de la décision des principes liés à la réparation pour les victimes, décision prise le 07 août 2012. Ceci est donc une avancée significative dans la protection de l'enfant en situation de conflits armés sur la scène internationale et particulièrement en $\mathrm{RDC}^{1192}$ (cf. infra).

«Toutefois, de sérieux handicaps dérivant de sa propre convention et de son fonctionnement

\footnotetext{
${ }^{1187}$ Ibid.

1188 DAVID, Eric, « La répression pénale internationale: l'avenir de la Cour Pénale Internationale », « art.cit. », p. 200.

${ }^{1189}$ Pour plus de détails, lire CURAT, Philippe, Les Crimes contre l'humanité dans le statut de la Cour pénale internationale, Bruxelles, Genève-Zurich, Bruylant, L.G.D.J, Schulthess, Paris 2006, pp. 95-113.

${ }^{1190}$ Lire DAVID, Eric, « L'avenir de la Cour Pénale Internationale » « art.cit. », pp. 196-200.

${ }^{1191}$ Lire HABIBU Jean Bosco, L'effectivité du statut de la Cour pénale internationale : Référence spéciale à la situation concernant la République Démocratique du Congo, op. cit., p.52.

1192 Lire MUMBALA ABELUNGU, Junior, «Regard critique sur la protection des enfants en situation de conflits armés en Droit international humanitaire et en Droit congolais », in YAV Katshung (dir.) Mélanges à l'Hommage de Me KALALA MBUYI (Sous presses).
} 
jusqu'aujourd'hui font que la CPI, pour un certain nombre d'observateurs, soit perçu comme un tribunal pour «petits » ${ }^{1193}$. D'où la critique fondamentale de l'UA par son ancien Président Jean PING qui « regrette que la justice internationale ne semble appliquer les règles de la lutte contre l'impunité qu'en Afrique comme si rien ne se passait ailleurs, en Irak, à Gaza, en Colombie ou dans la Caucase $[\ldots]{ }^{1194}$. C'est également dans le même élan que la République du Burundi se lance depuis le 12 octobre 2016 dans le processus du retrait de la CPI par un vote positif de son parlement ${ }^{1195}$ suivi de la promulgation par le Président de la République de la Loi $n^{\circ} 14$ du 18 octobre 2016 portant retrait de la République du Burundi du Statut de Rome de la Cour pénale internationale adopté à Rome le 17 juillet 1998. Et ce après ouverture d'examen préliminaire du Bureau du procureur de la CPI sur les violences ayant émaillé la crise politique dans ce pays ${ }^{1196}$. La République Sud-africaine se lance également dans cette procédure de retrait ${ }^{1197}$.

L'UA au cour du sommet extraordinaire du 11 au 12 octobre 2013 avait pris une décision, critiquable, selon laquelle les Chefs d'Etat et de gouvernement en exercice ne devraient pas être poursuivis par la CPI. En son entendement ces poursuites porteraient atteinte à la souveraineté et à la paix des Etats membres ${ }^{1198}$. Cette décision fait suite aux mandats d'arrêt lancés contre les Président et Vice-Président kenyans. Au-delà des discours, il sera remarqué des violations concrètes des obligations de coopération lorsqu'il s'agira, par exemple, de déférer le Président du Soudan, Omar El Béchir, à la CPI sur pied du mandat d'arrêt qui pèse sur lui. Ceci est « un fait sans précédent, puisque pour la première fois dans l'histoire du droit humanitaire international, un mandat d'arrêt est décerné contre un président effectivement en exercice ${ }^{1199}$. Béchir effectuera différents déplacements en Afrique sans être arrêté ${ }^{1200}$. Le second dans ce sens concernera le Président Kenyan.

Si des critiques d'impartialités s'avèrent vraies, dès lors, il sera affirmé que cette situation discrédite davantage cette jeune juridiction internationale qui est censée jouer pleinement son rôle en toute neutralité et indépendance et faire sentir réellement sa dissuasion vis-à-vis des criminels potentiels. Devons-nous croire, comme l'affirment certaines langues, que la CPI est un instrument créé par les puissances mondiales dans le cadre de processus néocolonial de l'Afrique ? Ou s'agit-il simplement d'une simple coïncidence d'autant plus que l'Afrique se présente à l'heure actuelle comme un champ de conflits armés multiples ?

\footnotetext{
${ }^{1193}$ OWONA, Joseph, Droit international Humanitaire, Paris, L’Harmattan, 2012, p. 106.

1194 Ibid., p. 109. Discours disponible sur (Version audio) : https://www.youtube.com/watch?v=U7B3FNSjJaQ (Source consultée le 27 février 2016).

1195 Lire «Le Burundi se retire de la Cour pénale internationale », in http://tempsreel.nouvelobs.com/monde/20161012.REU9436/le-burundi-se-retire-de-la-cour-penale-

internationale.html (Source consultée le 13 octobre 2016).

${ }^{1196}$ Lire «Déclaration du Procureur de la Cour pénale internationale, Mme Fatou Bensouda, à propos de l'examen préliminaire entamé dans le cadre de la situation au Burundi », in https://www.icccpi.int//Pages/item.aspx?name=otp-stat-25-04-2016\&ln=fr (Source consultée le 13 octobre 2016).

${ }^{1197}$ Lire «L'Afrique du Sud va se retirer de la CPI », in http://www.lemonde.fr/afrique/article/2016/10/21/1afrique-du-sud-va-se-retirer-de-la-cpi 5017929 3212.html (Source ce 21 octobre 2016).

${ }^{1198}$ FIDH, « Sommet de l'Union africaine sur la Cour pénale internationale : La protection des dirigeants au détriment des victimes et de la paix » in http://www.fidh.org/fr/afrique/union-africaine/14151-sommet-de-1union-africaine-sur-la-cour-penale-internationale-la (Source consultée le 27 février 2016).

${ }^{1199}$ FIERENS, Jacques, Droit humanitaire pénal, op. cit., p. 241.

1200 DAVID, Eric, « La Cour pénale internationale fait-elle preuve de partialité à l'encontre de l'Afrique ? in Justice en ligne. Comprendre et communiquer http://www.justice-en-ligne.be/article596.html (Source consultée le 27 février 2016).
} 
Dans son ouvrage Droit humanitaire pénal, Jacques Fierens, se demandant si la CPI était une juridiction des «petits», estime que celle-ci ne doit être perçue comme un tribunal des vainqueurs, de par son histoire et sa composition. Tout de même, il pense que le fait que cette juridiction s'occupe actuellement plus des «petits poissons », situations toutes localisées en Afrique, et se trouve loin des plus puissants de la planète, le risque des critiques reste présent. A cela s'ajoute le refus des plus puissants Etats de ne pas ratifier son texte constitutif ${ }^{1201}$. « La Cour pourrait ainsi être avant tout un tribunal de vaincus, comme le TPIY ou le TPIR, quand l'on considère par exemple que sa situation en Lybie n'est examiné qu'après la chute du colonel Kadhafi et de son régime ${ }^{1202}$.

Dans une étude sur la question, Eric DAVID relativise les critiques portées à la CPI. Il estime que la partialité mise en cause n'a pas lieu. Ainsi, de huit situations déférées à la CPI (actuellement 9 dont deux en Centrafrique) ${ }^{1203}$, analyse l'auteur, quatre émanent directement des Etats (africains) eux-mêmes (RDC, Ouganda, République Centrafricaine et Mali) ${ }^{1204}$, deux de l'initiative du CS/NU (Libye et Soudan) et deux autres du seul procureur (Kenya et Côte d'Ivoire) ${ }^{1205}$. « Ceci est moins le fait d'une prétendue partialité de la cour que du système actuel des relations internationales fondées sur l'essentiel sur l'accord des Etats». «L'accord des Etats est sous jacent à ces situations : accord des Etats pour devenir parties au statut, accord des membres du Conseil de sécurité pour saisir la Cour pénale internationale ${ }^{1206}$. Il reconnaît tout de même qu'il existe pas moins des décisions du Procureur politiquement teintées. C'est notamment le cas de son refus de donner suite à la reconnaissance de la compétence de la CPI par la Palestine (21 janvier 2009) estimant qu'il revient au CS/NU ou à l'AG/NU de décider en droit si la Palestine était un Etat. Argument qui paraît non défendable en droit international ${ }^{1207}$.

A l'issue de cette étude d'Eric David, il importe de dire que la problématique de la partialité mise en cause de la CPI ne se trouve pas pour autant définitivement résolue si l'on sait que « [1]a plupart des dossiers pendants devant la CPI pour lesquels les Etats africains ont collaboré sont tous relatifs à des adversaires politiques ou militaires des pouvoirs en place dans ces Etats ${ }^{1208}$. Dès lors, la CPI serait perçue par certains comme instrument d'élimination d'adversaires politiques dont les pouvoirs en place se serviraient. Lesquels seraient généralement soutenus par les puissances occidentales. Les cas Laurent Gbagbo pour la Côte d'Ivoire, Bosco Ntaganda ou

\footnotetext{
${ }^{1201}$ FIERENS, Jacques, Droit humanitaire pénal, op.cit., p. 241. 1202 Ibid.

1203 https://www.icc-cpi.int/fr_menus/icc/situations\%20and\%20cases/Pages/situations\%20and\%20cases.aspx (Source consultée le 27 février 2016).

${ }^{1204}$ Ajoutons aussi la saisine par la République centrafricaine, le 30 mai 2014, du Procureur de la CPI pour connaître des crimes présumés commis sur son territoire depuis le 1er août 2012. Et le 24 septembre 2014, le Bureau du Procureur de la CPI annonçait l'ouverture d'une deuxième enquête en République centrafricaine concernant ces crimes. Voy. Situation en République Centrafricaine II in https://www.icccpi.int/fr menus/icc/situations\%20and\%20cases/Pages/situations\%20and\%20cases.aspx (Source consultée le 27 février 2016).

1205 DAVID, Eric, « La Cour pénale internationale fait-elle preuve de partialité à l'encontre de l'Afrique ? in Justice en ligne. Comprendre et communiquer http://www.justice-en-ligne.be/article596.html (Source consultée le 27 février 2016).

1206 Ibid.

1207 Ibid.

1208 MADI DJABAKATE, Mohamed, Le Rôle de la Cour pénale internationale en Afrique, L’Harmattan, Paris, 2014, p. 72.
} 
Jean-Pierre Bemba vis-à-vis de la RDC - précisément- confirmeraient cette hypothèse ${ }^{1209}$. C'est donc ici que se poserait une autre problématique de partialité de la CPI.

Et c'est «à partir du moment où la Cour a déposé un mandat d'arrêt à l'encontre d'Omar El Béchir, président en exercice du Soudan, [qu']un début de mouvement de fronde s'est organisé » ${ }^{1210}$, envenimée par le mandat d'arrêt contre Uhuru Kenyatta et William Ruto, pour aboutir, le 31 janvier 2016, à l'adoption par l'Union africaine de la proposition du Président kenyan Uhuru Kenyatta de retrait des Etats africains du Statut de Rome.

C'est au regard de toutes ces critiques objectives et subjectives au sujet de la CPI que se profile l'idée de la création d'une Cour pénale africaine, autonome ou au sein de la Cour africaine de justice ou de la Cour africaine des droits de l'homme et des peuples ${ }^{1211}$. A ce sujet «les ministres de la justice et les Procureurs généraux des pays membres de l'Union africaine (UA) se sont réunis à Addis-Abeba, les 15 et 16 mai 2014, pour examiner un projet de protocole visant à étendre l'autorité de la Cour africaine de justice et des droits de l'homme aux crimes de génocide, aux crimes de guerre et crimes contre l'humanité ${ }^{1212}$. Il nous paraît que l'idée demeure bonne si la lutte contre l'impunité - de manière indépendante et impartiale - demeure au centre des préoccupations. En revanche, il s'agirait d'un plus grand recul de créer des juridictions qui serviraient à protéger des « seigneurs des guerres » une fois au pouvoir comme il est actuellement constaté.

Par ailleurs, certaines puissances s'opposent carrément à la ratification du Statut de Rome ou aux effets de cet instrument lorsque leurs intérêts se trouvent en jeu. A ce titre, les Etats Unis d'Amérique ont signé le Statut de Rome sans le ratifier. La signature américaine qualifiée de «drôle de signature ${ }^{1213}$ est donc accompagnée d'un avertissement. Celui-ci « annonce que la signature ne doit nullement être analysée comme une promesse d'une ratification prochaine et que le Statut de Rome, sans modifications substantielles, ne sera pas soumis au Sénat américain ${ }^{1214}$. Bien plus, l'American service member's protection act voté en 2002 soustrait les soldats américains de la compétence de la CPI. Les Etats Unis d'Amérique exercent d'importantes pressions sur différents Etats s'apprêtant à le ratifier par l'interruption de l'aide économique, la fin d'avantages douaniers, etc. Ils ont développé un système d'accords bilatéraux avec les Etats parties au Statut de Rome (Egypte, Maroc, Afghanistan, Bulgarie, Colombie, RD Congo) afin que les américains devant répondre de leurs actes devant cette juridiction soient transférés plutôt devant les instances judiciaires américaines. Ils redoutent que cette juridiction, organisme «incontrôlé » selon le qualificatif du Secrétaire d'Etat américain à la Défense de l'époque, Donald Rumself, accuse « injustement » les soldats américains, des crimes uniquement politiques dans les pays étrangers ${ }^{1215}$. Ceci, devons-nous le comprendre s'inscrit dans la politique de puissance de ne point subir le même traitement que les autres sujets. En d'autres termes, ne pas

\footnotetext{
1209 Ibid., pp. 72-74.

1210 JACQMIN, Denis et RIGO, Emese, Cour pénale internationale. Quelle justice pour les crimes de masse?

éd. Couleur livres, Mons, 2014, p. 54.

1211 DIAKITE, Kemoko, La Justice pénale internationale en Afrique. Aspects juridiques, défis et perspectives, L'Harmattan, Paris, 2014, p. 78.

1212 Ibid.

1213 FERNANDEZ, Julian, La Politique juridique extérieure des Etats-Unis à l'égard de la Cour pénale internationale, Pedone, Paris, 2010, p. 355.

1214 Ibid., p. 356.

${ }^{1215}$ Lire OWONA, Joseph, Droit international Humanitaire, Paris, L’Harmattan, 2012, pp.106-107.
} 
vouloir donc «s'humilier» par la répression pénale internationale et vouloir se considérer comme Princeps legibus solutus est c'est-à-dire délié ou mieux échappant à la loi internationale, par conséquent supérieur aux autres.

Ainsi, sur le terrain des conflits armés, bien que l'on ne sait pas encore visualiser l'effet dissuasif de cette jeune juridiction qui venait de rendre son premier jugement dans l'affaire Le Procureur c. Thomas Lubanga Dyilo, il importe de dire que la CPI marque un pas non moins décisif dans le processus de codification du DIH. Son statut complète par là quelques insuffisances des CG et de leurs PA qui constituent la toile de fond du DIH. Elle agit là où les puissances étatiques sont hésitantes. Elle répare tant soit peu les préjudices, surtout moral, causés aux victimes notamment lors des conflits armés plus principalement les cas des enfants de moins de quinze ans. Elle est donc un premier mécanisme universel et permanent de sanction pénale à l'endroit des individus ou personnes physiques, à côté de la CIJ qui juge les Etats. En conclusion, à travers la CPI, les mécanismes de sanction des violations des règles du DIH à l'endroit des enfants se renforcent et complètent ceux de prévention et de contrôle. Et à défaut d'avoir des juridictions efficaces pour la lutte contre l'impunité - précisément en Afrique -, la CPI paraît tout de même comme l'instance souhaitée.

\section{Section II Les Mécanismes non conventionnels de protection de l'enfant en situation de conflits armés}

La présente section se préoccupe précisément d'étudier l'ONU ( 1 1), les autres Organisations internationales $(\$ 2)$ et les ONG $(\S 3)$ comme mécanismes de protection de l'enfant en situation de conflits armés.

\section{§1. Les mécanismes de l'ONU de protection de l'enfant en situation de conflits armés}

«C'est en vieillissant que l'humanité redécouvre l'enfance. Réintégrée dans la littérature, puis dans la pensée religieuse, l'enfance est devenue depuis [plus d']un siècle un objet d'étude et de connaissance pour toutes les sciences de l'homme. Cette tendance ne pouvait rester étrangère au droit, pas même au droit international qui pendant si longtemps semble s'être désintéressé des êtres dans leur condition humaine. C'est à l'époque de la Société des Nations que l'on commence à protéger l'enfance sur un plan international, notamment contre les formes modernes de l'esclavage et de la traite (cf. supra). Depuis 1945 les initiatives se sont multipliées dans le cadre des Nations Unies et des institutions spécialisées consacrées aux problèmes sociaux, pour aborder les différents aspects d'un problème que l'explosion démographique universelle impose tous les jours avec plus de force à l'esprit ${ }^{1216}$.

Ainsi actuellement, chaque organe de l'ONU se préoccupe au-delà de ses missions classiques d'apporter un édifice, de par ses résolutions, à la mise en œuvre des droits de l'Homme et du DIH. De là, se situe non moins la protection des enfants en situation de conflits armés.

En effet, nous l'avions souligné ci-haut, l'ONU s'était montré indifférente au sujet de

\footnotetext{
${ }^{1216}$ Paul REUTER, Préface de l'ouvrage Le Fonds des Nations Unies pour l'enfance (F.I.S.E-U.N.I.C.E.F.), A. Pedone, Paris, 1967, p. 7 (Ouvrage de Kesera KARUNATILLEKE).
} 
développement du DIH, cette branche ancienne du droit international. Le motif était que vouloir développer un droit applicable à la guerre, guerre dont le recours était prohibé, serait mal vu. Ce serait perçu comme une manière de développer l'illicite et d'attester directement la défaillance de cette institution de mettre réellement fin à ce fléau (cf. supra). Cependant, le réalisme voudrait qu'on puisse voir cela autrement ! La guerre demeure un sujet permanent de la vie internationale. Elle est un moyen dont les Etats pourraient recourir n'importe quand pour régler leurs différents, et ce en dépit de cette prohibition ou réglementation internationale. D'où, l'importance de s'intéresser sur ce que peut être le comportement des combattants sur le champ de bataille. Chose qui pourrait apporter, en cas de respect, une contribution non négligeable au rétablissement de la paix et de la sécurité internationales, objet essentiel de création de l'ONU.

Il sera noté, comme d'ailleurs souligné ci-avant, qu'à la suite de la résolution 2444 (XXIII) du 19 décembre 1968 de l'AG/NU « relative au respect des droits de l'Homme en période de conflit armé », cette institution a ouvert la voie à des résolutions appelant au respect du DIH dans des situations générales aussi bien spécifique ${ }^{1217}$. Dès lors, par le biais des résolutions portant sur des conflits spécifiques, l'AG/NU attire l'attention des Etats et de la Communauté internationale sur leurs responsabilités découlant de l'obligation de «faire respecter» le DIH, conformément à l'article premier commun aux CG et à l'article $1^{\mathrm{er}} \mathrm{du}$ PA I. Ses organes subsidiaires notamment le Conseil des droits de l'Homme et la Commission des affaires sociales, humanitaires et culturelles ne cessent d'invoquer le DIH dans leurs recommandations ${ }^{1218}$. Si hier à la Commission des droits de l'homme, le DIH a graduellement commencé à compléter le droit relatif aux droits de l'homme en tant qu'objet important d'attention, cette tendance s'est poursuivie au sein de l'actuel Conseil des droits de l'homme ${ }^{1219}$. L'important à signifier est l'Examen périodique universel (EPU) permettant d'évaluer l'état de mise en œuvre des droits de l'homme dans chacun des Etats membres de l'ONU, procédure introduite par le Conseil des droits de l'Homme ${ }^{1220}$. Puisque les droits de $1^{\prime}$ homme et le DIH se chevauchent ${ }^{1221}$, la résolution $5 / 1$ donne expressément le pouvoir à cette procédure d'Examen périodique universel de s'assurer également de l'état de mise en œuvre du DIH dans les pays membres de l'ONU ${ }^{1222}$. Ainsi, l'ex-Commission des droits de l'homme et l'actuel Conseil des droits de l'homme se sont référés à plusieurs reprises au DIH, surtout pendant les conflits en Afghanistan, en Irak, au Liban et à Gaza ${ }^{1223}$.

Dans le cadre des instruments internationaux relatifs aux droits de l'homme ratifiés sous l'égide de l'ONU, il existe des mécanismes devant veiller à la mise des droits der l'Homme y consacrés respectivement. C'est le cas du Comité des droits de l'Homme institué par le pacte international relatif aux droits civils et politique du 16 décembre 1966. D'autres mécanismes similaires sont à retrouver notamment au niveau de la Convention contre la torture et autres peines ou traitements cruels, inhumains ou dégradant (art.17) ; la Convention internationale sur l'élimination de toutes les formes de discrimination raciale (article 8); la Convention sur l'élimination de toutes les

\footnotetext{
${ }^{1217}$ BETTATI, Mario, Droit humanitaire, 1ère édition, Dalloz, op.cit., 248.

1218 Ibid.

1219 THÜRER, Daniel, International humanitarian law: theory, practice, context, op. cit., p. 318.

${ }^{1220}$ BETTATI, Mario, Droit humanitaire, 1ère édition, Dalloz, op.cit., 248.

${ }^{1221}$ THÜRER, Daniel, International humanitarian law: theory, practice, context, op. cit., p. 318.

${ }^{1222}$ BETTATI, Mario, Droit humanitaire, 1ère édition, Dalloz, op.cit., 248.

${ }^{1223}$ THÜRER, Daniel, International humanitarian law: theory, practice, context, op. cit., p. 318.
} 
formes de discrimination à l'égard des femmes (article 17); la Convention relative aux droits de l'enfant (article 43), etc. Ces Comités, qui assurent la protection des droits de l'Homme tels que consacrés respectivement par ces instruments, examinent les situations des droits en tout temps notamment en période des hostilités. Ce qui fait profiter non moins au DIH d'une protection par ricochet. Par là, Il sied de comprendre que le DIH bénéficie de l'appui des organes traditionnellement reconnus des droits de l'Homme pour se promouvoir.

Ainsi, bien que différents du CICR dans la protection et assistance aux victimes des conflits armés, tous les organes de l'ONU ont affaire, d'une façon ou d'une autre, aux situations de conflit et ils peuvent et doivent s'intéresser aux victimes de la guerre dans le cadre de leur mandat. Diverses agences agissent en faveur des victimes de conflits armés : le Haut-Commissariat des Nations Unies pour les réfugiés (HCR), le Programme alimentaire mondial (PAM), le Fonds des Nations Unies pour l'enfance (UNICEF), le Programme des Nations unies pour le développement (PNUD) et l'Organisation des Nations Unies pour l'éducation, la science et la culture (UNESCO) ${ }^{1224}$. Il y a également le Bureau de la Coordination des affaires humanitaires (OCHA : Office for the Coordination of Humanitarian Affairs) établi en 1998 en remplacement du département des affaires humanitaires (DAH). Celui intervient notamment en situation de crises humanitaires $^{1225}$. Egalement, il existe d'autres mécanismes juridictionnels et non juridictionnels régionaux de promotion et de protection des droits de l'Homme qui s'intéressent non moins au $\mathrm{DIH}^{1226}$.

Particulièrement en matière de protection de l'enfant, ces organes jouent un rôle qui n'est donc pas le moindre vis-à-vis du Comité des droits de l'enfant. A ce titre, l'article 45 de la Convention relative aux droits de l'enfant dispose: "Pour promouvoir l'application effective de la Convention et encourager la coopération internationale dans le domaine visé par la Convention : a) Les institutions spécialisées, le Fonds des Nations Unies pour l'enfance et d'autres organes des Nations Unies ont le droit de se représenter lors de l'examen de l'application des dispositions de la présente Convention qui relèvent de leur mandat. Le Comité peut inviter les institutions spécialisées, le Fonds des Nations Unies pour l'enfance et tous autres organismes qu'il jugera appropriés à donner des avis spécialisés sur l'application de la Convention dans les domaines qui relèvent de leurs mandats respectifs. Il peut inviter les institutions spécialisées, le Fonds des Nations Unies pour l'enfance et d'autres organes des Nations Unies à lui présenter des rapports sur l'application de la Convention dans les secteurs qui relèvent de leur domaine d'activité ; $[\ldots] »$.

Il y a lieu de comprendre que la protection de l'enfant, au tant de l'être humain en général, reste un champ multisectoriel. Elle nécessité des interactions de différents organes en même temps une coordination. Elle ne doit pas être une chasse gardée au seul Comité des droits de l'enfant. Ce dernier doit s'assurer des avis des uns et des autres pour se fonder une excellente idée sur l'état de

\footnotetext{
${ }^{1224}$ BETTATI, Mario, Droit humanitaire, 1ère édition, Dalloz, op.cit., 248. pp. 249-250.

${ }_{1225}$ Lire BELANGER, Michel, op.cit., p. 106.

${ }^{1226}$ Lire MARTIN, Fanny, «Le droit international humanitaire devant les organes de contrôle des droits de l'Homme », in Droits fondamentaux, $\mathrm{n}^{\circ}$ 1, juillet - décembre 2001, www.droits-fondamentaux.org, pp 119-148 (Source consultée le 22 avril 2014) ; lire également BETTATI, Mario, op.cit., pp. 253-254.
} 
mise en œuvre ou mieux de la protection des enfants. Il ne saura donc par exemple donner des réponses appropriées en matière de violation des droits de santé des enfants sans consulter l'Organisation Mondiale de la Santé. Tout comme il pourra également travailler en collaboration avec le PAM (organe subsidiaire créée conjointement par le Organisation pour l'Alimentation et l'Agriculture (FAO) et l'ONU) ou le FAO, institution spécialisée de l'ONU en ce qui concerne l'aide alimentaire aux enfants.

Revenons aux principaux organes onusiens pour faire remarquer, des lignes précédentes, que l'AG/NU joue un rôle capital dans le système onusien de protection des droits de l'homme pour assurer la promotion et la protection des droits et du bien-être des enfants touchés par les conflits armés autant pour tous les enfants. Ceci se trouve même réaffirmé par différentes résolutions qu'elle adopte dont la résolution 62/141 citée ci-avant. La promotion faite par elle pour l'adoption et la ratification notamment de la Convention relative aux droits de l'enfant voire de son protocole facultatif sur l'implication d'enfants dans les conflits armés s'inscrit sous ce registre. L'on remarquera par exemple que le Comité des droits de l'enfant soumet tous les deux ans les rapports de ses activités à l'AG/NU via le Conseil économique et social. Ses membres sont d'ailleurs élus par elle (cf. article 44 point 5).

L'AG/NU demeure, pour tout dire, un épicentre dans le système onusien, organe ouvert où tous les Etats membres s'expriment souverainement sur différentes questions d'ordre international. Sur base de l'article $10^{1227}$ de la Charte de l'ONU combiné avec l'article 11 alinéa $1^{1228}$ de la même Charte, il importe de dire que l'AG/NU s'avère un organe important dans le développement de différentes questions de droit international relevant du domaine de protection de l'enfant ou autre. Ses règles dépourvues du caractère obligatoire jouent une fonction incitative très importante ${ }^{1229}$. L'AG/NU se trouve d'ailleurs appuyée par la Commission de Droit international $(\mathrm{CDI})$. Cette dernière contribue à l'avancée progressive et à la codification du droit international. Elle a initié d'importants textes dont le Statut de Rome de la CPI qui constitue à ce jour une avancée significative notamment dans la répression des violations des règles du DIH (cf. infra et supra).

Tout de même, le doute doit demeurer sur l'espoir que peut apporter un organe politique dans la mise en œuvre d'un instrument juridique d'ordre humanitaire. Les Etats appelés à voter les résolutions de différents organes des Nations Unies sont plus guidés par leurs intérêts qui ne prennent pas toujours en compte le bien-être de l'humanité prôné par les conventions humanitaires. A ce juste titre, il est dès lors prudent de ne pas trop espérer sur l'AG/NU autant sur d'autres organes des Nations Unies pour la mise en œuvre efficace et efficiente des règles du

\footnotetext{
1227 «L'Assemblée générale peut discuter toutes questions ou affaires rentrant dans le cadre de la présente Charte ou se rapportant aux pouvoirs et fonctions de l'un quelconque des organes prévus dans la présente Charte, et, sous réserve des dispositions de l'article 12, (...)». Et à son niveau, l'article $12 \S 1$ dispose que «Tant que le Conseil de sécurité remplit, à l'égard d'un différent ou d'une situation quelconque, les fonctions qui lui sont attribuées par la présente Charte, l'Assemblée générale ne doit faire aucune recommandation sur ce différend ou cette situation, à moins que le Conseil de sécurité ne le lui demande ».

1228 «L'Assemblée générale peut étudier les principes généraux de coopération pour le maintien de la paix et de la sécurité internationales, y compris les principes régissant le désarmement et la réglementation des armements, et faire, sur ces principes, des recommandations soit aux Membres de l'Organisation, soit au Conseil de sécurité, soit aux Membres de l'Organisation et au Conseil de sécurité.»

${ }^{1229}$ BETTATI, Mario, op.cit., p. 248.
} 
DIH.

Le CS/NU joue également un rôle très efficace dans la mise en œuvre du DIH en général et dans la protection de l'enfant en situation de conflits armés en particulier, l'avions-nous souligné précédemment. «Organe politique par nature, le Conseil de sécurité fait application du droit international à des fins politiques. Prenant en compte les normes de DIH, il les interprète pour y puiser toutes les vertus lors de son application aux différents conflits dont il est saisi. Ce rôle ambitieux peut toutefois le conduire sur d'autres chemins. Au gré de ses résolutions et décisions, l'organe principal des Nations Unies, chargé du maintien de la paix et de la sécurité internationales, participe à la reconnaissance et au développement du DIH. Quelques-unes de ses décisions peuvent même aller jusqu'à modifier la portée de telle ou telle règle de ce droit ou peuvent mettre en lumière certaines insuffisances. De telles actions ont très certainement une incidence sur l'évolution de ce dernier (cf. supra) ». ${ }^{1230}$ Les Missions de paix créées par le $\mathrm{CS} / \mathrm{NU}$ en terme d'organes subsidiaires pour répondre aux conflits armés réservent généralement des bureaux s'occupant des questions des droits de l'Homme, plus spécialement des enfants ${ }^{1231}$ (Cas de la MONUSCO en RDC, cf. infra).

Par ailleurs, d'autres organes de l'ONU tels que le Conseil économique et social, la Cour internationale de Justice et le Secrétariat s'occupent également de la question de protection des enfants en situations de conflits armés. En effet, conformément à la Charte des Nations Unies à son article 62 notamment, le Conseil économique et social peut faire ou provoquer des études et des rapports sur des questions internationales dans les domaines économiques, sociales (...). Il peut faire des recommandations en vue d'assurer le respect effectif des droits de l'homme et des libertés fondamentales pour tous. La question des droits de l'enfant rentre effectivement dans son champ de compétence. L'on lira par exemple au préambule de la résolution 48/141 adoptée à New-York par l'AG/NU du 20 décembre 1993 portant création du poste de Haut Commissaire aux droits de l'Homme que l'Assemblée générale, le Conseil économique et la commission des droits de l'Homme, l'actuel Conseil des droits de l'Homme, sont des organes chargés de la définition des orientations et de la prise de décisions en matière de promotion et de protection des droits de l'Homme. Le Secrétariat des Nations Unies pour sa part reste un organe très déterminant dans la protection de l'enfant en situations de conflits armés. Il a travaillé en collaboration avec l'AG/NU et le CS/NU pour l'amélioration de la situation des enfants. Il détient d'ailleurs à ce titre un Représentant spécial du SG/NU pour les enfants et les conflits armés. Différents rapports sur la situation des enfants en conflits armés ont été établi sur demande du CS/NU notamment (cf. supra). L'on se rappellera à juste titre de l'étude menée par Graça Machel, expert désigné par le Secrétaire général de l'ONU, sur la situation des enfants. Première étude du genre dans les annales de l'ONU qui formulera des recommandations spécifiques sur les moyens d'empêcher les enfants d'être touchés par les conflits armés et de mieux protéger les enfants dans les conflits armés (cf. supra).

\footnotetext{
${ }^{1230}$ BOISSON DE CHAZOURNES, Laurence, « Les résolutions des organes des Nations Unies, et en particulier celles du Conseil de sécurité, en tant que source de droit international humanitaire », in CONDORELLI, Luigi et LA ROSA SYLVIE SCHERRER, Anne-Marie (dir.), Les Nations Unies et le droit international humanitaire. The United Nations and international humanitarian law. Acte du Colloque international à l'occasion du cinquantième anniversaire de l'ONU (Genève - 19, 20, 21 octobre 1995), Paris, éd. A Pedone, pp. 150-151.

1231 Voy. §2 de la Résolution 1379 (2001) du CS/NU http://www.un.org/fr/documents/scres.shtml (Source consultée le 11 août 2013).
} 
Le travail en synergie de ces organes - dont le SG/NU et le CS/NU - sont notamment à la base de la crétion du mécanisme de surveillance et de communication de l'information sur les enfants et les conflits armés. En effet, par la résolution 1612 (2005), le 26 juillet 2005, le CS/NU prendra note du plan d'action présenté par le SG/NU pour la mise en place du mécanisme de surveillance et de communication de l'information sur les enfants et les conflits armés ${ }^{1232}$ tel que demandé au paragraphe 2 de sa résolution 1539 (2004) ${ }^{1233}$. Il priera le SG/NU de mettre en place sans tarder ce mécanisme et de l'appliquer dans un premier temps, dans la limite des ressources disponibles et en étroite consultation avec les pays concernés, aux parties aux conflits armés mentionnées sur la liste annexée au rapport du Secrétaire général ${ }^{1234}$. Un Groupe de travail sera créé à cet effet pour l'examen des rapports dudit mécanisme et faire des recommandations. Par ce mécanisme, le CS/NU disposera des informations objectives concernant les enfants touchés par les conflits armés en temps voulu ${ }^{1235}$ (Pour plus d'approfondissement, lire la Section III, §1, du Chapitre III de la seconde partie).

La CIJ reste l'organe qui a rendu des décisions liées au DIH qui ont non moins apporté un édifice dans l'amélioration de la situation des enfants en conflits armés. Cette question est davantage renforcée par différentes juridictions créées sous les auspices de l'ONU.

Par ailleurs, la lecture de la CDE permet de bien voir comment les différentes instances des Nations Unies interviennent pour assurer la mise en œuvre des droits de l'enfant notamment sa protection en situation de conflits armés. L'on remarquera, par exemple, que les Etats parties à cet instrument soumettent leurs rapports au Comité des droits de l'enfant via le Secrétaire général des Nations Unies. Le Comité à son tour soumet ses rapports d'activités à l'AG/NU par l'intermédiaire du Conseil économique et social. Pour le reste, comme détaillé ci-haut, les autres institutions comme celles spécialisées peuvent intervenir pour donner leurs avis à l'effectivités des droits de l'enfant (cf. les articles 44 et 45 de la Convention relative aux droits de l'enfant) ${ }^{1236}$.

Par ailleurs, traiter de la mise en œuvre du DIH par l'ONU conduit également à évoquer la question de la Responsabilité de protéger (R2P), une notion qui trouve soubassement sur des éléments déjà consolidés en droit international dont le DIH en particulier ${ }^{1237}$. Ce concept reste au cœur des préoccupations liées à la protection de population civile en général, victime de violation

1232 Pour le contexte d'adoption de cette résolution, Voy. Bureau du Représentant Spécial du Secrétaire général pour les enfants et les conflits armés, Examen stratégique décennal de l'Etude Machel : les enfants et les conflits armés dans un monde en mutation, UNICEF, New-York, 2009, p. 47. Lire également avec beaucoup d'intérêt HAPPOLD, Matthew, «Protecting children in Armed conflict: harnessing the Security Council's "Soft power" », « art. cit. », pp. 373-375.

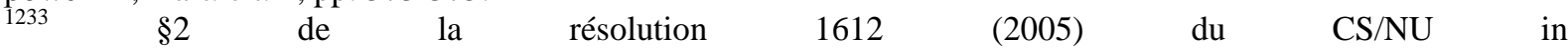
http://www.un.org/fr/documents/view_doc.asp?symbol=S/RES/1612\%20(2005)(Source consultée le 04 novembre 2013).

$1234 \quad \$ 2 \quad$ de $\quad$ la $\quad$ résolution $1612 \quad$ (2005) du $\quad$ CS/NU $\quad$ in http://www.un.org/fr/documents/view_doc.asp?symbol=S/RES/1612\%20(2005)(Source consultée le 04 novembre 2013).

${ }^{1235}$ Ibid., §2. a . Voy. aussi Bureau du Représentant Spécial du Secrétaire général pour les enfants et les conflits armés, Examen stratégique décennal de l'Etude Machel: les enfants et les conflits armés dans un monde en mutation, op.cit., p. 47.

${ }^{1236}$ Voy. aussi KEBA Mbaye, op.cit., p. 122.

1237 Lire BOISSON DE CHAZOURNES, Laurence et CONDORELLI, Luigi, «De la responsabilité de protéger » ou d'une nouvelle parure pour une notion déjà bien établie », in R.G.D.I.P, 2006-1, pp. 11-18. 
des droits fondamentaux notamment en situations de conflits armés. Ce qui nous permet de les analyser en tant que mécanisme de protection générale de l'enfant.

\section{- La Responsabilité de protéger comme mécanisme de protection générale de l'enfant}

Il est certes vrai que le «concept de « responsabilité de protéger» $(\mathrm{R} 2 \mathrm{P})$ est indépendant du droit international humanitaire mais il est devenu récemment un sujet de débat dans les sphères humanitaire et politique. Sa raison d'être est finalement d'améliorer la protection des individus face aux crimes les plus odieux ${ }^{1238}$. Chose qui concoure aux vœux du DIH.

En effet, la R2P découle de la notion d' « intervention humanitaire » et s'inspire amplement du «droit d'ingérence humanitaire ${ }^{1239}$. La notion d' «intervention humanitaire » quant à elle peut être appréhendée en droit international comme une action humanitaire entreprise, conduite ou acceptée par la communauté internationale en faveur d'une population dont les droits fondamentaux sont violés. Il existe à ce sujet différents types d'interventions humanitaires à savoir la protection des nationaux de l'Etat intervenant; la protection des nationaux de l'Etat où se situe l'intervention et la protection «mixte»: la protection des minorités par exemple ${ }^{1240}$. Cette notion d'《intervention humanitaire » diffère de l' « intervention d'humanité » qui s'analyse comme une action unilatérale étatique (un Etat ou un groupe d'Etats) pour la protection des nationaux de l'Etat ou des Etats intervenant à l'extérieur de leurs frontières ${ }^{1241}$. Emmanuel SPIRY tient à différencier ces deux termes en se focalisant surtout sur les qualificatifs «humanitaire » et «d'humanité ». Le premier qualificatif renvoie à un soutien logistique et militaire pour assurer la sécurité de convoi ou d'aide humanitaire généralement organisée par les ONG ou les OI. Lesquelles feront de l'assistance humanitaire. Pour le second qualificatif, il ne sera plus question d'aide médicale ou sanitaire effectuée par des organismes précités mais plus question de soustraire les victimes de massacres des griffes de leurs oppresseurs ${ }^{1242}$. C'est le cas notamment de l'intervention de la Belgique au Congo en 1960 pour la protection des sujets belges lors des insurrections de ce temps. De même que l'intervention française en 1978 à Kolwezi (ExZaïre, l'actuelle RDC) lors de la guerre civile qui y régnait. Ainsi, en dépit de la présence du système de la Charte de l'ONU, la doctrine d'intervention d'humanité qui date du XIX ${ }^{\mathrm{e}}$ Siècle n'allait donc cesser de trouver d'ardents défenseurs continuant à affirmer la substance dans certaines circonstances d'un droit d'intervention unilatérale ${ }^{1243}$.

\footnotetext{
${ }^{1238}$ BETTATI, Mario, op.cit., p. 244.

1239 Ibid.

${ }^{1240}$ BELANGER, Michel, op.cit., 90.

${ }^{1241}$ Ibid., p. 87. Lire J. L., HOLZGREFE, «The humanitarian intervention debate », in J. L., HOLZGREFE et Robert O. KEOHANE (éd.), Humanitarian intervention. Ethical, legal, and political dilemmas, Cambridge, Cambridge University Press, 2004, p. 18. Pour cette question lire aussi Alan J. KUPERMAN, The limits of humanitarian intervention. Genocide in Rwanda, Washington, Brookings Institutions Press, 2001, 162 p. et KOFFI ANNAN et MOUSAVIZADEH, Nader, Interventions a life in war and peace, USA, Penguin Press, 2013, 383 p.; DINSTEIN, Yoram, War Aggression and self-defence, Cambridge, fith edition, Cambridge University Press, pp. 73-75., ORFORD, Anne, Reading Humanitarian intervention. Human Rights and the use of force in international law, Cambridge, Cambridge University Press, 2003, 243 p.

1242 SPIRY, Emmanuel, «Interventions humanitaires et interventions d'humanité : la pratique française face au droit international in RGDIP 1998-2, pp. 408-409.

${ }^{1243}$ CORTEN, Olivier et KLEIN, Pierre, Droit d'ingérence ou obligation de réaction?, éd. Bruylant, Bruxelles, 1992, p. 2.
} 
Que dire à présent au sujet du «droit d'ingérence humanitaire »? En effet, comme l'affirme un de ses promoteurs, souvent évoqué, rarement expliqué, fréquemment reprouvé, le «droit d'ingérence humanitaire » est l'objet de critiques générées par la confusion des concepts et l'absence d'une claire maîtrise de son contenu ${ }^{1244}$. Il faudrait au départ dire que 1' «expression de «devoir d'ingérence humanitaire » semble due à Eugène IONESCO. La première tentative de construction juridique axée sur la notion d' «ingérence humanitaire » ${ }^{1245}$, qui est celle de Mario BETTATI (M. BETTATI et B. Kouchner (dir.), Le devoir d'ingérence : peut-on les laisser mourir ?, Denoël, Paris, 1987, 300 p.) s'est orientée dans cette voie. Elle traduit l'orientation morale du droit d'ingérence humanitaire, et trouve un certain fondement dans l'article 24 de la charte de l'ONU [...] ${ }^{1246}$. Le «droit d'ingérence humanitaire » se résume comme une nécessité d'intervenir à l'intérieur d'un Etat en guerre civile pour mettre fin aux violations graves des droits humains qu'endure la population civile. «Cette construction juridique portant mise en application de la notion d' «ingérence humanitaire » a comme fondement spécifique la protection du droit à la vie, et plus généralement, la défense de l'ensemble des droits fondamentaux de la personne humaine ${ }^{1247}$. Des critères semblent être posés au niveau doctrinal pour légitimer une telle intervention. Comme critères, la doctrine est unanime que le but exclusivement humanitaire nécessite une telle intervention et que les droits de la personne soient gravement violés. En ce sens, l'Etat qui interviendrait devrait donc être désintéressé. Si la majorité soutient qu'une telle intervention soit effectuée sous la bannière d'une organisation internationale, un autre point de vue est de ne point accorder d'importance aux types d'interventions individuelles ou conjointes. Il s'agirait donc d'un droit reconnu à tout Etat. ${ }^{1248}$ Selon Bernard KOUCHNER et Mario BETTATI, promoteurs de ce concept au sein de l'ONU, une intervention armée à l'intérieur d'un Etat souverain est légitime, si elle a pour objectif de mettre fin à des violations massives des droits de l'Homme. Dans la foulée, deux résolutions de l'AG/NU abordent cette question. Il s'agit de la résolution 43/131 relative à l'assistance humanitaire aux victimes des catastrophes naturelles et situations d'urgence du même ordre (1988) et la résolution 45/100 qui autorise l'établissement de couloirs d'urgence (1990). Le droit d'ingérence humanitaire cédera place à la notion de la R2P. Disons que nombre d'Etats de toutes les régions du monde n'appréciaient guère l'expression «droit d'ingérence humanitaire », la ressentant comme hautement dangereuse notamment du fait qu'elle apparaissait visiblement contradictoire vis-à-vis du principe de souveraineté des Etats et de l'un de ses principaux corollaires, le principe de non intervention ${ }^{1249}$. Dans le même sens, Olivier Corten et Pierre Klein qualifiaient la proposition autrichienne d'amendement de 1991 de la Charte des Nations Unies tendant à la reconnaissance du «droit d'ingérence pour motifs humanitaires » de dangereux, car introduisant un droit unilatéral

\footnotetext{
${ }^{1244}$ BETTATI, Mario, Allocution d'ouverture au colloque de Nanterre sur la responsabilité de protéger, Société française pour le Droit international, La responsabilité de protéger, éditions A. Pedone, Paris, p. 13.

${ }^{1245}$ L' "Ingérence humanitaire» semble avoir été inventée en 1979 par Jean François Revel (article publié en juin dans l'Express). On peut définir l'ingérence humanitaire comme une assistance humanitaire non sollicitée. L'ingérence peut être matérielle ou immatérielle. Il s'agit en réalité d'une notion particulièrement complexe. (Voy. BELANGER, Michel, op.cit., p. 91.). Au sens de BETTATI, Mario, l'ingérence ne traduit pas un concept juridique déterminé. La référence au droit international permet de cerner deux éléments de ce concept : L'atteinte à la compétence nationale des Etats et la contrainte (voy. Michel BELANGER, op.cit., p. 91.).

${ }^{1246}$ BELANGER, Michel op.cit., p. 94.

1247 Ibid.

${ }^{1248}$ Lire TSAGARIS Konstantinos, Le droit d'ingérence humanitaire, Université de Lille, Mémoire de DEA en Droit international et communautaire, septembre 2001, pp. 25-30.

1249 Lire BOISSON DE CHAZOURNES, Laurence et CONDORELLI, Luigi, « De la responsabilité de protéger » ou d'une nouvelle parure pour une notion déjà bien établie », «art.cit. », pp. 12-13.
} 
d'intervention armée, et d'inutile, dans la mesure où les possibilités de réactions non-armées aux violations existent déjà en droit international ${ }^{1250}$. La R2P semble apaiser les esprits ${ }^{1251}$ et recueillir ainsi une large acceptation des Etats bien que toujours réticents de tout ce qui touche à leur souveraineté (cf. infra).

En effet, la R2P trouve son fondement juridique sur différents textes et faits juridiques. Au départ, elle reconnaît que la responsabilité première de protection de peuple ou de la population civile incombe aux Etats. En d'autres termes, au nom de la souveraineté des Etats, il leur revient en premier lieu d'assurer la protection de leurs populations contre le génocide, le crime de guerre, le nettoyage ethnique et le crime contre l'humanité. La Communauté internationale est donc appelée à accompagner les Etats dans cette mission. Ce n'est que si l'Etat n'est pas lui-même en mesure d'assurer cette responsabilité c'est-à-dire de mettre fin à ces souffrances qu'endure le peuple, souffrance qui peut d'ailleurs être le fait de lui-même l'Etat en question, qu'une action collective peut être menée. Cette responsabilité de la communauté internationale est donc subsidiaire à celle de l'Etat. Cette action collective menée par la Communauté internationale se fixera l'objectif de mettre fin à cette situation. Ainsi, la R2P procède de par sa démarche de trois phases graduelles à savoir d'abord la Responsabilité de prévenir, ensuite la Responsabilité de réagir et enfin la Responsabilité de reconstruire.

En effet, la Responsabilité de prévenir permet d'éliminer à la fois les causes profondes et celles directes des conflits internes et des autres crises qui mettent en danger la population civile. Pour sa part, la Responsabilité de réagir consiste en la réaction devant des situations où la protection des êtres humains est une impérieuse nécessité, en utilisant des mesures appropriées pouvant prendre la forme de mesures coercitives telles que des sanctions et des poursuites internationales et, dans les cas extrêmes, en ayant recours à l'intervention militaire ${ }^{1252}$. «Il s'agit, dans un premier temps, de privilégier des actions qui n'engagent pas d'intervention armée ; que ce soit aux niveaux militaire (embargo sur les armes), économique (sanctions financières) ou politico diplomatique (exclusion de certaines organisations internationales), de nombreuses alternatives à l'emploi de la force armée existent. L'intervention militaire proprement dite n'est envisagée qu'en dernier recours ${ }^{1253}$. Ceci trouve fondement notamment au niveau des articles 41 et 42 de la Charte des Nations Unies qui reconnaissent au CS/NU, la compétence de prendre respectivement des mesures n'impliquant pas l'emploi de la force armée pour donner effet à ses décisions ou au cas où ces mesures prises seraient inadéquates d'entreprendre au moyen des forces militaires toute action qu'il juge nécessaire au maintien de la paix et de la sécurité internationales. Enfin, la Responsabilité de reconstruire implique l'obligation qui revient à l'ONU de soutenir les populations après la mise en œuvre de la responsabilité de protéger, notamment en favorisant la paix, le développement durable, la démocratie et la bonne gouvernance $^{1254}$. Cette phase dite aussi de consolidation de la paix permet, après une intervention militaire, de fournir une assistance à tous les niveaux afin de permettre que la vie reprenne son cours normal. En cette phase, on agit sur les causes qui ont occasionné une telle situation afin

\footnotetext{
${ }^{1250}$ CORTEN, Olivier et KLEIN, Pierre, Droit d'ingérence ou obligation de réaction?, op. cit., p. 272.

${ }^{1251}$ HAJJAMI, Nabil, La Responsabilité de protéger, éd. Bruylant, Bruxelles, 2013, p. 251.

1252 Lire BUIRETTE, Patricia et LAGRANGE, Philippe, op.cit., p. 86.

${ }^{1253}$ ROUSSEAU, Nicolas, Peut-on empêcher les crimes de masses ? La responsabilité de protéger à l'épreuve de la réalité, Bruxelles, éditions Couleur livres Asbl, 2012, p. 31.

${ }^{1254}$ Ibid.
} 
d'éviter le renouvellement des crimes. C'est également ici où l'on s'engage dans le processus de réconciliation. L'on peut donc trouver certains mécanismes de justice transitionnelle opérés (par exemple les Commissions Vérité et Réconciliation). La phase de prévention demeure la principale dimension de la R2P. Il est donc recommander d'épuiser tous les moyens disponibles avant de passer à l'intervention.

En 2011, pour la première fois, le CS/NU a expressément visé la R2P à propos de la situation en Côte d'Ivoire, dans la résolution 1975 (2011), et l'a mise en œuvre en Libye, par des résolutions 1970(2011) et 1973(2011). Ce passage de l'abstrait au concret semble montrer que la R2P est une notion opérationnelle ${ }^{1255}$.

De ce qui précède, la R2P tire son fondement de la Charte des Nations Unies, notamment son article 24 qui confère au CS/NU la responsabilité du maintien de la paix et de la sécurité internationales; de différents textes d'ordre international et national qui assurent la protection de la population civile; des pratiques des Etats et des Organisations régionales voire du CS/NU en ce sens... ${ }^{1256}$

A la lumière des arguments ci-haut avancés, la R2P va au-delà du système du DIH. Elle n'a pas encore acquis le statut de règle internationale, bien qu'elle découle de normes internationales telles que les CG, PA ou la Convention pour la prévention et la répression du crime de génocide $^{1257}$ et soit décrite comme une «nouvelle norme prescrivant une obligation collective internationale de protection ». Ainsi, bien que presque tous les Etats l'aient acceptée et qu'elle ait été utilisée à différentes reprises comme références par le CS/NU, la R2P fait toutefois l'objet d'un consensus encore fragile. Certains Etats, particulièrement attachés à leur souveraineté, craignent en effet qu'elle ne fasse l'objet d'une interprétation abusive et ne serve que la propension des grandes puissances à intervenir dans les affaires d'Etats plus faibles ${ }^{1258}$. La crainte ou l'inquiétude de ces Etats s'avère quelque peu légitime. Les Etats qui interviennent sous la bannière de la R2P afin d'assurer la protection de la population civile ne sont donc pas purement désintéressés. Leur intervention trouve au départ motivation sur des raisons ou intérêts politicodiplomatiques pourquoi pas économiques. Et autour de cette intervention, chaque Etat intervenant arrive avec son agenda caché qu'il compte réaliser sur le territoire de l'Etat où il intervient. «C'est dans ce sens que dans son étude Rougier parle de l'impossibilité pratique de séparer les mobiles humains de l'intervention des mobiles politiques. Il estime qu'à partir du moment où les Etats intervenants sont les seuls à juger de l'opportunité de leur action, ils vont le faire en fonction de leurs intérêts ${ }^{1259}$. La situation de la Lybie reste un exemple éloquent ${ }^{1260}$. Encore ici, l'un des membres influents de la Commission internationale de l'intervention et de la souveraineté (CIISE), M. Cornelio SOMMARUGA avait déclaré que «la responsabilité de

1255 CHAUMETTE, Anne-Laure, «La responsabilité de protéger, interrogations sémantiques» in CHAUMETTE, Anne-Laure et THOUVENIN, Jean-Marc (dir.), La responsabilité de protéger, dix ans après. The Responsability to protect, ten years on, Actes du colloque du 14 novembre 2011, Paris, éd. Pedone, 2013, p. 8.

${ }^{1256}$ Lire BUIRETTE, Patricia et LAGRANGE, Philippe, op.cit., p. 86.

${ }^{1257}$ HAJJAMI, Nabil, La Responsabilité de protéger, op. cit., pp. 219-220.

${ }^{1258}$ ROUSSEAU, Nicolas, op.cit., p. 31.

1259 ROUGIER, A., «La théorie de l'intervention d'humanité », in RGDIP, 1910, pp.468-526 cité par TSAGARIS Konstantinos, op.cit., p. 30.

${ }^{1260}$ Lire à ce sujet ROUSSEAU, Nicolas, op.cit., pp. 37-48. 
protéger a été assassinée en Lybie. Elle est morte en Lybie à travers l'usage que la Communauté internationale en a fait dans le cas Lybien, dans une logique qui n'était pas celle vraiment de la protection de la population, mais de faire autre chose $»^{1261}$.

Toutefois, il importe de dire à l'issue des arguments précédents qu'il n'y a aucune obligation systématique d'agir collectivement pour empêcher que les crimes les plus odieux ne se produisent, mais le $\mathrm{CS} / \mathrm{NU}$ - organe essentiellement politique - a toute la liberté de choisir comment et quand il peut agir ${ }^{1262}$.

Enfin, certains Etats - Mexique, Guatemala - ont suggéré d'étendre le concept aux catastrophes naturelles, aux pandémies et à la lutte contre le crime organisé. Leurs propositions ont reçu peu d'échos, les autres Etats jugeant qu'une extension de cet ordre de la R2P risquait d'en affaiblir la portée car l'intérêt du concept est de porter sur les « atrocités de masse » et de lier clairement ce concept à la lutte contre l'impunité de l'Etat. ${ }^{1263}$ Dans le même ordre idées, Luigi CONDORELLI ajoute ce qui suit : «[i]l conviendrait - nous dit-on - de se limiter aux quatre grandes catégories de crimes sans chercher dans d'autres directions, ce qui alourdirait trop le bateau. Et bien ça, c'est une décision politique. Mais elle ne doit pas faire oublier qu'au-delà de ces quatre types de situations gravissimes, il y a bien d'autres situations graves, d'autres cas de violations massives des droits de l'homme, qui déclenchent elles aussi une obligation de chaque Etat et de l'ensemble des Etats d'agir pour obtenir le respect des règles : en somme, la responsabilité de protéger n'est pas exigible seulement en cas de génocide, de crimes de guerre, de crimes contre l'humanité et de nettoyage ethnique. Il est donc vain de s'opposer à un élargissement du champ d'application de la responsabilité de protéger. ${ }^{1264}$

Comparant la R2P à la notion de «droit d'ingérence humanitaire » et à l'obligation de « respecter et de faire respecter le droit international humanitaire », Laurence BOISSON DE CHAZOURNES et Luigi CONDORELLI affirment que la R2P est « indéniablement une brillante invention diplomatique ${ }^{1265}$ mais est loin d'être une innovation en droit international. En clair, « il n'a pas fallu attendre la consécration, en 2005, de la responsabilité de protéger pour savoir que chaque Etat avait l'obligation juridique de prévenir et réprimer le crime de génocide, le crime de guerre, le crime contre l'humanité et le nettoyage ethnique ${ }^{1266}$. Une telle obligation est bien ancrée en droit international conventionnel (les CG, PA ou la Convention pour la prévention et la répression du crime de génocide) et coutumier ${ }^{1267}$. Le document final du Sommet mondial de 2005 qui consacre la R2P ne fait rien de plus, pour ce qui est de la R2P, qu'assembler une série d'acquis juridiques dans un cadre unitaire ${ }^{1268}$. «En somme, le système international n'a

\footnotetext{
1261 CONDORELLI, Luigi, «La responsabilité de protéger, nouvelle norme du droit international ?», in CHAUMETTE, Anne-Laure et THOUVENIN, Jean-Marc (dir.), op.cit., p. 167.

${ }^{1262}$ BETTATI, Mario, Droit humanitaire, $1^{\text {re }}$ édition, op.cit., p. 245.

${ }^{1263}$ ROUSSEAU, Nicolas, op.cit., p. 55.

1264 CONDORELLI, Luigi, «La responsabilité de protéger, nouvelle norme du droit international ?», in CHAUMETTE, Anne-Laure et THOUVENIN, Jean-Marc (dir.), op.cit., p. 164.

${ }^{1265}$ BOISSON DE CHAZOURNES, Laurence et CONDORELLI, « De la responsabilité de protéger » ou d'une nouvelle parure pour une notion déjà bien établie », « art.cit.», p. 12.

${ }^{1266}$ Voy. aussi HAJJAMI, Nabil, La Responsabilité de protéger, op. cit., pp. 219-220.

${ }^{1267}$ HAJJAMI, Nabil, La Responsabilité de protéger, op. cit., p. 219.

1268 BOISSON DE CHAZOURNES, Laurence et CONDORELLI, « De la responsabilité de protéger » ou d'une nouvelle parure pour une notion déjà bien établie », « art.cit.», p. 13.
} 
réellement progressé du fait de la proclamation solennelle de la « responsabilité de protéger » ${ }^{1269}$.

\section{§2. Les Organisations internationales comme mécanismes de protection de l'enfant en situation de conflits armés}

Les situations conflictuelles qui dominent la scène internationale ne laissent pas les Organisations internationales indifférentes. Ces organisations interviennent, diplomatiquement ou militairement, dans la gestion ou la résolution de ces conflits armés. Ces interventions les obligent, quelle que soit leur nature - politique, diplomatique, économique, sociale ou militaire - à s'intéresser aux questions de DIH. Elles sont ainsi amenées à interpréter ce droit et à contribuer à sa mise en œuvre soit par l'utilisation de moyens prévus expressément par celui-ci, soit par d'autres moyens néanmoins conformes à ce droit. ${ }^{1270}$ Ainsi donc, ces organisations expriment souvent leurs préoccupations relatives à l'application et au respect du DIH. Leur rôle en faveur du respect du DIH est donc marqué d'un activisme croissant ${ }^{1271}$.

Bien plus, l'IDI, dans sa Résolution de Berlin du 25 août 1999, va d'ailleurs dans le sens d'instituer une obligation de respect de DIH aux organisations internationales, y compris 1'ONU ${ }^{1272}$. Cette résolution vient soutenir la Circulaire ST/SGB/1999 du SG/NU signée le 6 août 1999 et entrée en vigueur le 12 août 1999. Laquelle énonçait, de manière non exhaustive, l'application des «principes et règles fondamentaux du DIH » aux forces des Nations Unies durant leur participation aux interventions de contrainte et opération de maintien de la paix ${ }^{1273}$. Tout ceci rejoint Michael Bothe qui indiquait déjà que « [1]'ONU, agissant avec une force armée propre, peut-être destinataire du jus in bello ${ }^{1274}$, doctrine qui représente actuellement l'unanimité $^{1275}$.

Par ailleurs, l'Organisation des Etats Américains (OEA), l'Union africaine (UA), l'Union

\footnotetext{
${ }^{1269}$ Ibid., p. 16.

1270 SANDOZ, Yves (dir.), Les Moyens de mise en ouvre du droit international humanitaire. Etat des lieux, Analyse des problèmes et éléments de réflexion, op.cit., pp. 90-91.

1271 ZASOVA, Svetiana, «Le rôle des organisations internationales dans l'incitation des groupes armés au respect du droit international humanitaire : Quo vadimus ? », in SOREL, Jean-Marc et FOUCHARD, Isabelle Les tiers aux conflits armés et la protection des populations civiles, éd. A. Pedone, Paris, 2010, p. 133.

1272 «Toutes les parties aux conflits armés auxquels prennent part des entités non étatiques, indépendamment de leur statut juridique, de même que les Nations-unies et les organisations régionales et autres organisations internationales compétentes, ont l'obligation de respecter le droit international humanitaire de même que les droits fondamentaux de l'homme. L'application des principes et des règles pertinents n'affecte pas le statut juridique des parties au conflit et ne dépend pas de la reconnaissance de belligérance ou du statut d'insurgés ». Voy. IDI, L'application du droit international humanitaire et des droits fondamentaux de l'homme dans les conflits armés auxquels prennent part des entités non étatiques, Résolution de Berlin du 25 août 1999, in http://justitiaetpace.org/resolutions_chrono.php?start=1993\&end=1999 (Source consultée le 24 avril 2013).

1273 Nations Unies, Secrétariat, Respect du droit international humanitaire par les forces des Nations Unies, Circulaire du Secrétaire général, ST/SGB/1999/13, 6 août 1999, article I, in http://www.un.org/french/documents/view_doc.asp?symbol=ST/SGB/1999/13 (Source consultée le 24 avril 2013).

${ }^{1274}$ BOTHE, Michael, «Le droit de la guerre et les Nations Unies. A propos des incidents armés au Congo » in Etudes et travaux de l'Institut universitaires des hautes études internationales, n 5, éd. Droz, Genève, 1967, p. 208. Voy. aussi la page 211 de cette étude. Voy. également TAUBENFELD, Howard J., « The Applicability of the laws of war in civil war », in NORTON MOORE, John (ed.), Law and civil war in the modern world, The Johns Hopkins University Press, Baltimore-London, p. 514.

1275 Lire avec intérêt LAGRANGE, Philippe, «Forces des Nations Unies et respect du droit international humanitaire. De l'importance de la notion de participation aux hostilités », in BIAD, Abdelwahab et TAVERNIER, Paul (dir.), Le Droit international humanitaire face aux défis du XXIe Siècle, op.cit., pp. 297-298.
} 
européenne (UE) et l'Organisation pour la Sécurité et la Coopération en Europe (OSCE), notamment, ont toutes fait des déclarations relatives à ces normes ${ }^{1276}$.

Ces organisations sont fréquemment présentes dans des missions de paix avec l'aval de l'ONU et instituent des missions d'enquêtes pour établir des faits face à certaines situations graves ${ }^{1277}$. Certaines, parmi elles, sont à la base des conventions des droits de l'Homme créant ainsi des organes de surveillance ou de mise en œuvre des droits consacrés. Tout ceci ne les empêche pas d'avoir une attention sur des questions de DIH. Ce qui vaut pour les organisations régionales vaut également pour des institutions spécialisées de l'ONU.

Concernant les organisations régionales, quelques faits sont à mentionner. On note par exemple pour l'Organisation pour la Sécurité et la Coopération en Europe, l'adoption du Document de Helsinki de 1992 où les Etats membres rappelaient leur engagement de respecter et de faire respecter les règles du DIH dont les violations pourront donner lieu à des missions d'experts ou des rapporteurs ${ }^{1278}$. La reconnaissance de l'importance du DIH se trouve mentionnée par l'article 2 de la Charte de l'Association des Nations de l'Asie du Sud-est (ASEAN ou ANASE) ${ }^{1279}$. L'Organisation du Traité de l'Atlantique Nord (OTAN) de par son caractère militaire et en dépit des critiques formulées au sujet de ses interventions n'est non moins à l'abri des règles du DIH. «La présence des conseillers juridiques au sein de ses forces intégrées l'aide à cet effet ${ }^{1280}$ ». En Afrique, la Communauté Economique des Etats d'Afrique de l'Ouest (CEDEAO) a institué au début des années 90 une force d'intervention, ECOMOG (Economic Community of West African States Cease-fire Monitoring Group), qui doit de se référer au DIH dans ses interventions.

Au niveau des institutions spécialisées analysées déjà précédemment sous l'ONU, il convient d'épingler le rôle que joue l'UNESCO. Celle-ci joue, dans le domaine des biens culturels, un rôle similaire à celui du CICR pour l'ensemble du DIH ${ }^{1281}$. L'UNESCO joue un rôle essentiel dans la mise en œuvre de la Convention pour la protection des biens culturels en cas de conflit armé du 14 mai 1954 et ses protocoles.

Que dire alors de la situation de l'enfant face aux organisations internationales ? Il importe ici de s'atteler particulièrement sur les cas de l'UA et de l'UE. Lesquelles jouent non moins un rôle dans la mise en œuvre du DIH en général ${ }^{1282}$.

Bien avant nos propos sur la question des enfants au regard de ces institutions internationales, il sied de dire que l'UE est un acteur indispensable dans la mise en œuvre du $\mathrm{DIH}^{1283}$. Comme pour

\footnotetext{
${ }^{1276}$ BETTATI, Mario, , Droit humanitaire, $1^{\text {re }}$ édition, op.cit., p. 251.

${ }^{1277}$ Rappelons à cet égard que l'article 89 du PA I engage les Etats à agir en coopération avec l'ONU en cas de violations graves des $\mathrm{CG}$ et du présent $\mathrm{PA}$.

1278 SANDOZ, Yves, (dir.), Les Moyens de mise en æuvre du droit international humanitaire. Etat des lieux, Analyse des problèmes et éléments de réflexion, op.cit., p. 92.

${ }^{1279}$ BETTATI, Mario, Droit humanitaire, $1^{\text {re }}$ édition, op. cit., p. 251.

1280 SANDOZ, Yves, (dir.), Les Moyens de mise en æuvre du droit international humanitaire. Etat des lieux, Analyse des problèmes et éléments de réflexion, op.cit., p. 93.

1281 Ibid., p. 81.

${ }^{1282}$ Lire par exemple MEDJOUBA, Faria et STEFANELLI, Justine, «La prise en considération du droit international humanitaire par l'Union européenne- Une introduction », in SOREL, Jean-Marc et POPESCU, Corneliu-Liviu (dir.), op.cit., pp. 87-130.

${ }^{1283}$ Lire avec intérêt à ce sujet, MILLET-DEVALLE, Anne-Sophie (dir.), L'Union européenne et le droit
} 
les Nations Unies, la référence aux règles du DIH par l'UE - alors Communauté européenne s'est faite progressivement. Le DIH y sera d'abord pris en considération par les actes déclaratoires (déclarations communes) avant sa consécration par les actes contraignants (Actions et Positions communes) ${ }^{1284}$. Initialement, sur base de la compétence générale de l'UE dans le domaine des droits de l'homme, seules les références aux droits de l'homme - « vocable plus générique et plus englobant »- étaient présentes dans ses instruments de politique étrangère et de sécurité commune (PESC) ${ }^{1285}$. Le DIH n’y trouvait pas place. «Une telle attitude reflétait sans doute de la retenue dans l'invocation du respect de ce droit attaché à une fonction essentiellement

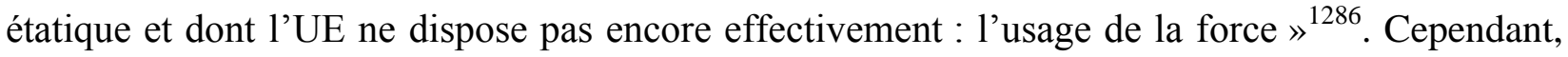
par le rapprochement progressif des Etats membres sur le DIH, par la montée du DIH coutumier fédérant les points de vue étatiques et, surtout par l'interdépendance des instruments des droits de l'homme et du DIH sur la question de protection de la personne, les règles du DIH seront finalement prises en compte dans la $\operatorname{PESC}^{1287}$ et utilisées dans le langage diplomatique européen $^{1288}$.

Dès 1990, dans le cadre du conflit au Libéria, le respect des règles les plus élémentaires du DIH relatives à la protection des civils se trouvant aux ambassades et lieux de refuge (églises, hôpitaux, etc.) a été référencé et recommandé par l'UE (Communauté européenne) aux parties au conflit $^{1289}$. Et depuis cette année, des références aux CG et PA essentiellement lorsque l'Union doit se prononcer face à un CAI ou à un CANI sont de plus en plus fréquentes. Il n'est donc point rare pour l'UE de solliciter l'engagement de la responsabilité des auteurs d'infractions graves ; d'indiquer le respect de la proportionnalité dans l'attaque ou le respect du principe de distinction ; de rappeler la prohibition des représailles des civils; de rappeler le respect en toutes circonstances des civils et l'application de la CG IV pour une meilleure protection de ces civils $^{1290}$. La mise en œuvre du DIH par l'Union européenne est également remarquable en ce qui concerne l'aide humanitaire.

En effet, l'UE est perçue comme le principal contributeur mondial en matière d'aide humanitaire. Elle intervient notamment en tant que bailleur institutionnel en faveur d'ONG humanitaires (finançant par exemple quelques $25 \%$ des dépenses de Médecin du Monde) ${ }^{1291}$. L'on note que cette action humanitaire a commencé depuis 1970 d'abord avec l'aide humanitaire, puis avec l'aide aux réfugiés et l'aide d'urgence. Le $1^{\mathrm{er}}$ mars 1992, il sera créé l'Office d'aide humanitaire de la Communauté européenne ou ECHO (European Community Humanitarian Office) qui s'occupera d'acheminer l'aide humanitaire aux victimes des conflits armés ou des catastrophes des pays de l'ACP (ECHO 1), de l'ex-Union soviétique, d'Europe centrale et orientale, d'Asie

\footnotetext{
international humanitaire, op. cit., 302 p.

${ }^{1284}$ FERRARO, Tristan, «Le droit international humanitaire dans la politique étrangère et de sécurité commune de l'Union européenne », in RICR, Vol. 84, n846, pp. 436 et 437.

${ }^{1285}$ Ibid., p. 435.

1286 Ibid.

${ }^{1287}$ Lire AUVRET-FINCK, Josiane, « L'utilisation du DIH dans les instruments de la PESC » in MILLETDEVALLE, Anne-Sophie (dir.), L'Union européenne et le droit international humanitaire, op. cit., pp. 46-50.

${ }^{1288}$ FERRARO, Tristan, «Le droit international humanitaire dans la politique étrangère et de sécurité commune de l'Union européenne », « art. cit. », p. 436.

${ }^{1289}$ Ibid., p. 446.

${ }^{1290}$ Lire MEDJOUBA, Faria et STEFANELLI, Justine « art.cit. » in SOREL, Jean-Marc et POPESCU, CorneliuLiviu (dir.), op.cit., pp. 105-106.

${ }^{1291}$ BELANGER, Michel, op.cit., p. 107.
} 
centrale, du Moyen-Orient, du bassin méditerranéen (ECHO 2) et des pays de l'Asie, du MoyenOrient, Amérique latine (ECHO 3) ${ }^{1292}$. En 2006, la contribution en faveur d'aide humanitaire a dépassé les 2 milliards d'euros d'aide. Ce qui représente à cette époque là $40 \%$ de l'assistance humanitaire internationale globale ${ }^{1293}$.

Particulièrement à la situation des enfants, il est important de signifier que dans la promotion et la protection des droits de l'homme dans l'espace européen, l'UE tient compte des droits des personnes vulnérables dont les enfants. Le Traité sur l'Union Européenne mentionne en son article $3 \S 3$ que l'Union assure la promotion et la protection des droits de l'enfant ${ }^{1294}$. Et comme le précise la CJUE, « [1]a protection de l'enfant est [...] consacrée dans des instruments élaborés dans le cadre de l'Union européenne, tels que la Charte des droits fondamentaux de l'Union européenne, proclamée le 7 décembre 2000 à Nice [...], dont l'article 24, paragraphe 1, dispose que les enfants ont droit à la protection et aux soins nécessaires à leur bien-être [...]. Par ailleurs, le droit des États membres de prendre les mesures nécessaires pour des raisons relatives à la protection des mineurs est reconnu par certains instruments du droit communautaire, tels que la directive 2000/31 ${ }^{1295}$. Rappelons que bien avant que la Charte des droits fondamentaux de l'Union européenne n'acquiert une force juridique contraignante ${ }^{1296}$, avec l'entrée en vigueur du Traité de Lisbonne ( $1^{\text {er }}$ décembre 2009), la CJUE faisait expressément référence à différents instruments juridiques relatifs à la protection des droits de l'enfant, dont la CDE, dans l'application des principes généraux du droit communautaire ${ }^{1297}$. Depuis lors, la CJUE fonde sa jurisprudence sur le seul article 24 de la Charte précitée. L'arrêt Deticek c. Sgueglia du 23 décembre 2009 est une illustration de cette démarche. Toutefois, cette autonomie des droits de l'enfant au sein de l'Union n'exclut pas une certaine harmonisation des jurisprudences européennes et internes sur la question ${ }^{1298}$. Pour sa part, la CEDH privilégie la CDE.

\footnotetext{
1292 Ibid.

1293 Lire MEDJOUBA, Faria et STEFANELLI, Justine «art.cit. » in Jean-Marc SOREL et Corneliu-Liviu POPESCU (dir.), op.cit., p. 100.

1294 Article $3 \S 3$ alinéa 2 du Traité sur l’Union européenne (revisé par le Traité de Lisbonne) :«Elle combat l'exclusion sociale et les discriminations, et promeut la justice et la protection sociales, l'égalité entre les femmes et les hommes, la solidarité entre les générations et la protection des droits de l'enfant. » (Nous soulignons). Voy. Traité de Lisbonne modifiant le Traité sur l'Union européenne et le Traité instituant la Communauté européenne, Journal Officiel de l'Union européenne, 2007/C 306/01, 17.12.2007 disponible sur http://eurlex.europa.eu/legal-content/fr/TXT/?uri=CELEX\%3A12007L\%2FTXT (Source consultée le 18 juillet 2016).

${ }^{1295}$ CJCE, Affaire C-244/06, Dynamique Medien Vertriels GmbH c/ Avides Media AG, arrêt du 14 février 2008, Rec., I-548, § 41.

${ }^{1296}$ La force juridique contraignante de la Charte des droits fondamentaux de l'Union européenne est reconnue à l'article 6, §1, alinéa 1, du Traité sur 1'Union européenne (revisé par le Traité de Lisbonne) en ces termes : «L'Union reconnaît les droits, les libertés et les principes énoncés dans la Charte des droits fondamentaux de l'Union européenne du 7 décembre 2000, telle qu'adaptée le 12 décembre 2007 à Strasbourg, laquelle a la même valeur juridique que les traités ». Voy. Traité de Lisbonne modifiant le Traité sur l'Union européenne et le Traité instituant la Communauté européenne, Journal Officiel de l'Union européenne, 2007/C 306/01, 17.12.2007 disponible sur http://eur-lex.europa.eu/legal-content/fr/TXT/?uri=CELEX\%3A12007L\%2FTXT (Source consultée le 18 juillet 2016).

${ }^{1297}$ Voy. CJCE, Affaire C-244/06, Dynamique Medien Vertriels GmbH c/ Avides Media AG, arrêt du 14 février 2008, Rec., I-547, § 39. ; CJCE, Affaire C-540/03, Parlement européen c/ Conseil de l'Union européenne, arrêt de la Cour (grande chambre) du 27 juin 2006, Rec., I-5822, §37.

1298 GOUTTENOIRE, Adeline, « La consécration de l'intérêt supérieur de l'enfant dans l'Union européenne », in TINIERE, Romain et VIAL, Claire (dir.), La Protection des droits fondamentaux dans l'Union européenne. Entre évolution et permanence, Bruylant, Bruxelles, 2015, pp. 240-241.
} 
En outre, l'Union fait mention de la protection de l'enfant et de ses droits dans des déclarations liées au DIH ou aux droits de l'Homme. Elle appuie notamment, à ce juste titre, les juridictions pénales internationales principalement la CPI afin que les auteurs des crimes portés sur les enfants ne demeurent point impunis. Ceci rentre d'ailleurs dans le cadre de sa politique fondée sur le respect des droits de l'homme, de la démocratie et l'Etat de droit. Cette attitude est remarquable en ce qui concerne des mesures prises par l'UE contre les auteurs des violations de règles de protection des enfants en temps de conflits armés en RDC (cf. Le dernier chapitre). Elle appuie d'ailleurs le système onusien de protection de l'enfant constitué notamment de l'ensemble des organes principaux de l'ONU, de l'ensemble des mécanismes onusiens de protection des droits de l'Homme, et particulièrement du Représentant spécial du SG/NU pour les enfants et les conflits armés, le groupe de travail du CS/NU sur les enfants et les conflits armés, UNICEF, etc. (cf. infra). Et vis-à-vis des Etats membres de l'Union, à titre de compétence d'appui, et conformément à l'article 6 du Traité sur le Fonctionnement de l'Union européenne, l'Union dispose d'une compétence pour mener des actions pour appuyer, coordonner ou compléter l'action des Etats membres dans le domaine de protection civile ${ }^{1299}$.

L’Union africaine, pour sa part, est aussi un acteur régional de mise en œuvre du DIH et de protection des enfants en situation de conflits armés. Elle travaille en collaboration avec le CICR pour assurer le respect du DIH, et les autres agences internationales de protection de l'enfance dont l'UNICEF, ou le Bureau du Représentant Spécial du Secrétaire Général pour les enfants et les conflits armés. Le Conseil de Paix et de Sécurité de 1'Union africaine qui « est un organe permanent de décision pour la prévention, la gestion et le règlement des conflits ${ }^{1300}$ a pour objectifs entre autres de promouvoir et d'encourager le respect du DIH conformément à l'article $3 \mathrm{du}$ Protocole portant sa création ${ }^{1301}$. L'Union africaine en collaboration avec le CICR organise différentes séances de formation des officiers d'armées aux règles du DIH. L'on citera le séminaire organisé à l'endroit de 59 officiers somaliens pour améliorer leur compréhension du DIH et promouvoir ainsi le respect de ce droit ${ }^{1302}$. Dans un communiqué de presse ce «Conseil [de paix et de sécurité] a exprimé sa gratitude au CICR pour ses efforts et l'assistance humanitaire qu'il apporte aux populations victimes des conflits armés en Afrique, en particulier les enfants et les autres groupes vulnérables ${ }^{1303}{ }^{»}$.

Pour ce qui est de la protection des enfants en période de conflits armés, l'UA a notamment joué un rôle important dans le processus de signature et de ratification de la Charte africaine

\footnotetext{
${ }^{1299}$ Lire l'article 6 du Traité sur le Fonctionnement de l'Union Européenne (revisé par le traité de Lisbonne). Voy. Traité de Lisbonne modifiant le Traité sur l'Union européenne et le Traité instituant la Communauté européenne, Journal Officiel de l'Union européenne, 2007/C 306/01, 17.12.2007 disponible sur http://eurlex.europa.eu/legal-content/fr/TXT/?uri=CELEX\%3A12007L\%2FTXT (Source consultée le 18 juillet 2016).

${ }^{1300}$ Voy. l'article 2 du Protocole relatif à la création du Conseil de paix et de sécurité de l'Union africaine du 09 juillet 2002.

${ }_{1301}$ Ibid., article 3.

${ }^{1302}$ Communiqué de presse «L'Union Africaine termine un atelier de deux semaines sur le Droit International Humanitaire en faveur de l'Armée Nationale Somalienne », in http://amisom-au.org/fr/2013/08/the-africanunion-concludes-a-two-week-long-workshop-on-international-humanitarian-law-for-the-somalia-national-army $/$ (Recherche menée le 24 novembre 2013).

1303 Communiqué de presse de la $276^{e}$ Réunion du Conseil de paix et de sécurité (du 28 avril 2011)http://www.ausitroompsd.org/Documents/PSC2011/276th/PRESSSTATEMENT/276emecOMMUNIQUE.pdf (Recherche menée le 24 novembre 2013 ).
} 
des droits et du bien-être de l'enfant dont l'article 22 reste de grande valeur à cet égard (cf. supra). En effet, dans la résolution 1659 (LXIV) issue de son Conseil des Ministres tenu à Yaoundé (Cameroun) du $1^{\mathrm{er}}$ au 5 juillet 1996, l'OUA lançait un appel à la signature et à la ratification de la Charte pour les Etats ne l'ayant pas encore fait ${ }^{1304}$. Elle exhortait en même temps tous les pays africains «à placer les enfants hors des zones de guerre et à s'abstenir de recruter les enfants de moins de 18 ans dans des conflits armés ou des activités violentes de quelque nature que ce soit $»^{1305}$. Dans le même ordre, et ce bien avant le Statut de Rome portant création de la CPI, elle estimait à travers cette résolution que l'utilisation des enfants dans les conflits armés devrait être appréhendée comme crime de guerre ${ }^{1306}$. D'importantes mesures sont également prises sur ces questions par elle. Ainsi, par exemple, il est à signaler des mesures liées au déploiement d'effectifs spécialisés dans la protection de l'enfance au sein de la Mission de l'Union africaine en Somalie et de la Division des opérations d'appui à la paix de l'Union africaine ${ }^{1307}$ comme c'est le cas actuellement pour certaines missions onusiennes. A ce titre, le 17 septembre 2013, le Conseil de Paix et sécurité de l'Union africaine ensemble avec le Bureau du Représentant Spécial du Secrétaire Général pour les enfants et les conflits armés signait un accord de collaboration, impliquant le soutien de l'UNICEF, en vue de mieux protéger les enfants touchés par les conflits armés en Afrique et de renforcer les mécanismes présents ${ }^{1308}$. Par cet acte, la protection des enfants devrait être au centre de toutes les activités de paix et de sécurité sur le continent. Ainsi cinq domaines de collaboration se trouvent concernés :

«. l'inclusion de la protection des enfants dans toutes les activités de paix et de sécurité de l'UA;

- le détachement de spécialistes de la protection de l'enfance au sein du Département Paix et Sécurité de l'UA;

. l'élaboration conjointe d'un programme de travail, notamment pour harmoniser les législations nationales avec les instruments juridiques régionaux et internationaux concernant les droits de l'enfant;

. l'élaboration de directives pour protéger les enfants touchés par les conflits armés ; et

- le développement de programmes de formation améliorés et harmonisés en matière de protection de l'enfance pour les pays contributeurs de troupes aux missions de soutien à la paix de l'Union Africaine ${ }^{1309}$.

\footnotetext{
1304 OUA, Conseil des Ministres, Rés. 1659 (LXIV), Résolution sur la condition des enfants africains en situation de conflits armés, p. $1, \S 2$.

${ }^{1305}$ Ibid., p. $2, \S 5$.

${ }^{1306}$ Ibid., p. 2, § 6 .

1307 RAMASY, Juvence F., « La protection juridique et politique des enfants dans les conflits armés en Afrique. Inventaire des dispositions légales et politiques », «art.cit», in BABIKER, Mohamed Abdelsalam, DAUBLAIN, Maxense et VAHLAS, Alexis (dir.), Enfants-soldats et droits des enfants en situation de conflit et post-conflit. Réalités et enjeux, op.cit., p. 277.

${ }^{1308}$ Bureau du Représentant Spécial du Secrétaire Général pour les Enfants et les conflits armés, Les Nations unies et l'Union africaine s'unissent pour protéger les enfants affectés par les conflits armés, Communiqué de Presse du 19 septembre 2013 in https://childrenandarmedconflict.un.org/fr/press-release/onu-et-ua-sunissentpour-proteger-les-enfants/ (Source consultée le 31 janvier 2016).

${ }^{1309}$ Bureau du Représentant Spécial du Secrétaire Général pour les Enfants et les conflits armés, Les Nations unies et l'Union africaine s'unissent pour protéger les enfants affectés par les conflits armés, Communiqué de Presse du 19 septembre 2013 in https://childrenandarmedconflict.un.org/fr/press-release/onu-et-ua-sunissent-
} 
Toutefois, les ressources financières, matérielles et humaines allouées aux instances africaines ne leur permettent pas toujours de répondre aux objectifs assignés d'où la question de leur efficacité. Il sera remarquable de constater, par exemple, pour ce qui est de la protection spéciale des enfants, certaines agences internationales (ex: UNICEF) ou des ONG (ex: Save The Children Suède) venir en aide à ces institutions (ex: le Comité africain d'experts sur les droits et le bien-être de l'enfant) pour leur fonctionnement (cf. infra $)^{1310}$. Ce qui atteste de la faiblesse de la protection des droits de l'enfant en Afrique ${ }^{1311}$.

Par ailleurs, dans le cadre de coopération entre l'UA et l'UE, il y a lieu de mentionner la déclaration commune faite à Addis-Abeba et à Bruxelles le 12 février 2011 à l'occasion de la célébration de la journée internationale contre l'utilisation d'enfants soldats. Ces deux organisations internationales soulignent la nécessité de redoubler d'efforts à tous les niveaux pour prévenir les conflits et protéger les enfants des effets des conflits armés, notamment lorsqu'ils sont enrôlés de force comme combattants, esclaves sexuels ou domestiques. Elles soutiennent la campagne lancée en mai 2010 par le Bureau du Représentant spécial du Secrétaire général des Nations unies pour les enfants et les conflits armés, en coopération avec d'autres partenaires, en vue de parvenir à la ratification universelle du Protocole facultatif concernant l'implication d'enfants dans les conflits armés. Ces institutions régionales réaffirment leurs appuis sans réserve à la lutte contre l'impunité en cas de recrutement et d'utilisation d'enfants soldats et la nécessité de traduire les auteurs de ces crimes en justice ${ }^{1312}$.

Pour tout dire, en matière de respect des règles du DIH particulièrement de la protection des enfants en conflits armés, il sied de mentionner le dialogue institutionnel entre ces organisations régionales. Ces dernières, autant pour les $\mathrm{ONG}$, ont joué un rôle très considérable dans la rédaction et l'adoption de nombreux instruments contraignant ou de soft-law comme c'est le cas pour les Principes et Engagements de Paris (cf. supra). A travers leur dialogue institutionnel, ces organisations condamnent toutes de la même tonalité les violations graves liées aux règles du DIH de protection des enfants. Ce dialogue sera même remarqué notamment par la lecture en filigrane de la jurisprudence issue des organes de protection des droits de l'Homme se rapportant à la protection de l'enfant. Ceci fait donc évoluer tant bien que mal la protection de l'enfant en conflits armés.

\section{§3. Les ONG comme mécanismes de promotion de protection de l'enfant en situation de conflits armés.}

L'émergence des droits et de la protection de l'enfant ainsi que l'évolution du DIH moderne restent marquées de la présence des Organisations Non gouvernementales. L'adoption de la déclaration de Genève de 1924 a été l'œuvre des ONG (cf. supra). L'adoption et la mise en

\footnotetext{
pour-proteger-les-enfants/ (Source consultée le 31 janvier 2016).

${ }^{1310}$ Voir AFFA'A MINDZIE, Mireille, « Protection régionale des droits de l'enfant en Afrique » in Pambazuka News http://www.pambazuka.net/fr/category.php/comment/44469 (Source consultée le 31 janvier 2016).

1311 MARTIN CHENUT, Kathia, «La protection des enfants en temps de conflit armé et le phénomène des enfants-soldats », op.cit., p. 200.

1312 Journée internationale contre l'utilisation d'enfants soldats, Déclaration commune de l'Union Africaine et de l'Union Européenne (Addis-Abeba - Bruxelles, 12 février 2011) in http://www.ambafranceau.org/spip.php?page=mobile_art\&art=4054 (Recherche menée le 26 novembre 2013).
} 
œuvre des instruments juridiques ultérieurs se rapportant à la protection des enfants autant dans le champ du DIDH que dans celui du DIH ont bénéficié des contributions inestimables des ONG. Pour rappel, la Déclaration universelle des droits de l'homme bénéficia d'un apport important des ONG pour l'amélioration de son texte ${ }^{1313}$. Ce qui vaut de même pour la Convention relatives aux droits de l'enfant ${ }^{1314}$. On se souviendra par exemple du rôle des ONG dans l'insertion de l'article 38 de ladite convention (cf. supra). Dans le cadre du DIH, les CG et leurs PA doivent beaucoup au CICR. Ce dernier est qualifié de "gardien et protecteur du droit humanitaire ${ }^{1315}$. On ne parlerait point du DIH sans faire allusion au CICR. Le DIH se trouve d'ailleurs nommé "Droit de la Croix-Rouge ». "Le CICR apparaît comme le pilier institutionnel de ce droit, même s'il n'est pas, historiquement, la première ONG humanitaire (qui est l'Ordre de Malte ${ }^{1316}$ ) ${ }^{1317}$. Le CICR constitue sans doute l'un des acteurs non étatiques les plus importants dans l'application du DIH dont la personnalité juridique est largement reconnue au niveau doctrinal et au niveau jurisprudentiel. La Chambre de première instance du TPIY, dans l'affaire Simic et consorts le reconnait en ces termes : «It is widely aknowldeged that the ICRC, an independant humanitarian organization, enjoys a special status in international law, based on the mandate confered upon it by the international community (and that it) is generally aknowldeged that the ICRC (...) has an international legal personality $(. . .)^{1318} \gg$

« Il n'existe aucune définition générale de l'ONG car chaque ordre juridique est compétent pour dire ce qu'il considère comme $\mathrm{ONG}{ }^{1319}{ }^{13}$. Bien plus, il est difficile d'en trouver une définition universellement acceptée, notamment avec l'émergence des «GONGOS » ${ }^{1320}$ (cf. supra). Tout de même, sur pied des critères formels dégagés par l'ordre juridique de création $^{1321}$, l'ONG serait «formellement, tout groupement privé à but non lucratif » ${ }^{1322}$. En cela, cette notion inclura notamment les groupements à but caritatif, les syndicats, les lobbies industriels, les organisations religieuses, les sociétés savantes, les institutions sportives, etc. Les mouvements de libération nationale, par exemple, n'y feront pas partie au regard de leur

1313 YACOUB, Joseph, Les droits de l'homme sont-ils exportables? Géopolitique d'un universalisme, Ellipses Editions Marketing S.A., Paris, 2005, p. 37.

1314 ZANI, Mamoud, La Convention internationale des droits de l'enfant : portées et limites, op.cit., p. 97.

1315 ASPREMONT, Jean d' et HEMPTINE, Jérôme de, op.cit., p. 30.

${ }^{1316}$ L'Ordre de Malte (Ordre souverain, militaire et hospitalier de Saint Jean de Jérusalem) a été crée en 1099.

Son siège social a été établi à Rome en 1834. Voy. BELANGER, Michel, op.cit., p. 108.

1317 BELANGER, Michel, op.cit., p. 19.

1318 Lire VAN STEENBERGHE, Raphaël, «Théorie des sujets », in VAN STEENBERGHE, Raphaël, (dir.), Droit international humanitaire : un régime spécial de droit international ?, Bruylant, Bruxelles, 2013, p. 24.

1319 LEROUX, Nicolas, La Condition juridique des O.N.G internationales, éditions Bruylant, éditions Yvon Blais, Bruxelles, Québec, 2009, p. 6.

${ }^{1320}$ OLIVIER, Clémentine, «Les Organisations non gouvernementales et la répression pénale internationale », «art.cit », in COHEN-JONATHAN et J.F. FLAUSS, (éd.), Les Organisations non gouvernementales et le droit international des droits de l'homme. International human rights law and non governemental organization, op.cit., p. 120.

${ }^{1321}$ Par exemple en RDC, la Loi $n^{\circ} 004 / 2001$ du 20 juillet 2001 portant dispositions générales applicables aux Associations sans but lucratif et aux établissements d'utilité publique appréhende en son article 2 une ONG comme une Association sans but lucratif. Cette dernière est définie au niveau d'article $1^{\text {er }}$ de la même loi comme une entité «qui ne se livre pas à des opérations industrielles ou commerciales, si ce n'est à titre accessoire, et qui ne cherche pas à procurer à ses membres un gain matériel » voir http://www.leganet.cd/Legislation/Droit\%20Public/loi0042001.20.07.2001.asbl.htm (Source consultée le 02 décembre 2015). L'article 5, alinéa 3 de la Loi belge du 2 mai 2002 sur les associations sans but lucratif, les associations internationales sans but lucratif et les fondations va également dans le même sens. Voir http://www.loiasbl.be/texte nouvelle_loi.php (Source consultée le 02 décembre 2015).

${ }^{1322}$ LEROUX, Nicolas, La Condition juridique des O.N.G internationales, op.cit., p. 6. 
but final d'érection d'une institution publique, l'Etat ${ }^{1323}$. Au regard du champ géographique d'activités, une ONG peut être nationale ou internationale. C'est dans ce sens que de manière encore plus complète que the "NGO" as private organizations:... not established by governement or by intergovernmental agreement, which are capable of playing a role in international affairs by virtue of their activities, and whose members enjoy independent voting rights. The members of an NGO may be individuals (private) or bodies corporate. Where the organization's membership or activity is limited to a specific state, one speaks of a national $N G O$ and where they go beyond, of an international NGO ${ }^{1324}$. Il s'agirait donc d'une structure privée de droit interne regroupant des personnes physique ou morales, originaires de plusieurs pays, œuvrant sans esprit de lucre à la réalisation d'un but d'intérêt général international dans des pays autres que celui de sa création, parlant d'ONG internationale ${ }^{1325}$. Ce qui ne serait pas le cas d'ONG nationale poursuivant un but d'intérêt général national. C'est ce qui ressort d'ailleurs de l'article 2 de la résolution de l'Institut de droit international du 11 septembre 1950 sur les Conditions d'attribution d'un statut international à des associations d'initiative privée :

«Les associations internationales visées à l'article ler sont des groupements de personnes ou de collectivités, librement créés par l'initiative privée, qui exercent, sans esprit de lucre, une activité internationale d'intérêt général, en dehors de toute préoccupation d'ordre exclusivement national ${ }^{1326}{ }$.

L'article 2 de la Résolution de l'IDI du 12 août 1923 sur le Projet de convention relative à la condition juridique des associations internationales s'était inscrit également dans ce sens ${ }^{1327}$. Les ONG - nationales ou internationales- se trouvent donc toutes en principe sous l'empire du droit privé. Toutefois, elles peuvent se voir appliquer les règles exorbitantes de droit commun (droit public) au regard de la mission d'intérêt général qu'elle poursuit.

Il importe de signifier que des efforts ont été fournis par l'IDI pour reconnaître un statut minimal aux ONG avec des prérogatives de droit international public (en 1923) ${ }^{1328}$ ou un traitement national plus favorable (en 1950) ${ }^{1329}$. Toutefois, au sens du droit international

\footnotetext{
1323 Ibid.

${ }^{1324}$ SUNGA, Lyal S., « NGO Insolvement in international human rights monitoring », in COHEN-JONATHAN et J.F. FLAUSS, (éd.), Les Organisations non gouvernementales et le droit international des droits de l'homme. International human rights law and non governemental organization, Bruylant, Bruxelles, 2005, p. 43.

1325 BRETON-LE GOLF, Gaëlle, L'influence des Organisations non gouvernementales (ONG) sur la négociation de quelques instruments internationaux, op.cit., p. 14.

1326 Article 2 de la Résolution du 11 septembre 1950 de l'IDI, les Conditions d'attribution d'un statut international à des associations d'initiative privée, Session de Bath, in http://justitiaetpace.org/resolutions_chrono.php?start=1947\&end=1952 , p. 2. (Source consultée le 02 décembre 2015).

${ }^{1327}$ L'article 2, §2, du Projet de convention relative à la condition juridique des associations internationales, Résolution du 12 août 1923, Session de Bruxelles, dispose : "Sont considérées comme internationales, au sens de la présente convention, les associations de caractère privé qui sont accessibles, dans les conditions fixées par leurs statuts, aux sujets et aux collectivités de plusieurs pays et poursuivent, sans esprit de lucre, un but d'intérêt international », in http://justitiaetpace.org/resolutions_chrono.php?start=1922\&end=1925 , p. 2. (Source consultée le 02 décembre 2015).

${ }^{1328}$ Lire IDI, Projet de convention relative à la condition juridique des associations internationales, Résolution du 12 août 1923, Session de Bruxelles, in http://justitiaetpace.org/resolutions chrono.php?start=1922\&end=1925 (Source consultée le 02 décembre 2015).

${ }^{1329}$ Lire IDI, les Conditions d'attribution d'un statut international à des associations d'initiative privée,
} 
positif, aucun statut international n'est reconnu aux ONG en dépit de la présence de la Convention européenne sur la reconnaissance de la personnalité juridique des organisations non gouvernementales du 24 avril 1986. Laquelle permet aux ONG de se prévaloir de leur personnalité et capacité juridiques acquises dans un Etat partie auprès des autres Etats parties $^{1330}$. «La pratique tend plutôt à un principe de reconnaissance des O.N.G., reconnaissance par les organisations intergouvernementales et reconnaissance mutuelle dans un cadre européen ${ }^{1331}$. En ce sens, son article 2 Convention européenne sur la reconnaissance de la personnalité juridique des organisations non gouvernementales du 24 avril 1986 dispose expressément ce qui suit :

«1. La personnalité et la capacité juridiques d'une ONG telles qu'elles sont acquises dans la Partie dans laquelle elle a son siège statutaire sont reconnues de plein droit dans les autres Parties.

2. Lorsqu'elles sont dictées par un intérêt public essentiel, les restrictions, limitations ou procédures spéciales prévues pour l'exercice des droits découlant de la capacité juridique par la législation de la Partie dans laquelle la reconnaissance a lieu, sont applicables aux ONG établies dans une autre Partie ${ }^{1332}{ }_{\gg .}$

Par ailleurs, essentiellement sur des questions des droits de l'homme, il existe donc des nombreuses $\mathrm{ONG}^{1333}$ qui œuvrent dans les domaines de droits de l'homme et du DIH. Elles sont parfois appelées organisation de solidarité internationale (OSI), afin de dépasser la distinction entre les « urgentistes » (ONG urgentistes ou ONG d'urgence) et les «développementalistes » (ONG de développement). Elles sont classées en trois générations. La première génération est constituée du CICR, la deuxième génération est composée des «ONG urgentistes (Comme Médecins sans frontières) et la troisième génération avec des ONG comme Amnesty International ou Human Rights Watch ${ }^{1334}$.

Ainsi, grâce à l'expérience et l'expertise qu'ils ont acquises dans leurs domaines de compétences respectives, ces organismes peuvent convaincre les Etats de se conformer aux recommandations qu'ils estiment conformes aux principes qu'ils entendent faire respecter ${ }^{1335}$.

Il faudrait signifier que «[s]i, initialement, elles (ONG) étaient d'abord tournées vers la protection des droits fondamentaux de l'homme, elles s'orientent désormais également vers la promotion du respect des principes de droit humanitaire. Et leur contribution dans ce domaine est

\footnotetext{
Résolution $\quad \mathrm{du} \quad 11 \quad$ septembre $1950, \quad$ Session $\quad$ de $\quad$ Bath in http://justitiaetpace.org/resolutions_chrono.php?start=1947\&end=1952 (Source consultée le 02 décembre 2015).

${ }^{1330}$ LATTY, Franck, La lex sportiva. Recherche sur le droit international, éd. Martinus Nijhoff Publishers, Leiden Boston, 2007, p. 627. Voy. aussi BEIGBEDER, Yves, Le Rôle international des organisations non gouvernementales, op.cit., pp. 9 -10.

1331 AUDEOUD, Olivier, "Le Statut de la société civile internationale, un statut pour les O.N.G »? in GHERARI, Habib et SZUREK, Sandra (dir.), L'Emergence de la société civile internationale. Vers la privatisation du droit international, CEDIN Paris X, Cahiers internationaux, éd. Pedone, Paris, 2003, p. 27.

${ }^{1332}$ Article 2 de la Convention européenne sur la reconnaissance de la personnalité juridique des organisations non gouvernementales du 24 avril 1986 in http://www.coe.int/fr/web/conventions/full-list//conventions/treaty/124 (Source consultée le 02 décembre 2015).

${ }^{1333}$ Lire avec intérêt G. COHEN-JONATHAN et J.F. FLAUSS, (éd.), Les Organisations non gouvernementales et le droit international des droits de l'homme. International human rights law and non governemental organization, Bruylant, Bruxelles, 2005, 258 p.

${ }^{1334}$ BELANGER, Michel, op.cit., p. 108.

1335 ASPREMONT, Jean d' et HEMPTINE, Jérôme de, op.cit., p. 30.
} 
essentielle et sans précédent ${ }^{1336}$. Ainsi, des organisations comme Human Rights Watch, Amnesty International ou la Commission internationale de Juristes défendent principalement le respect des droits de l'homme en dénonçant leurs violations, mais elles introduisent aussi de plus en plus le droit humanitaire dans leur argumentation, pour attirer l'attention sur les transgressions des normes fondamentales dans les situations de conflit armé. ${ }^{1337}$ Comme, on peut le remarquer, bien que bénéficiant d'un statut spécial au regard des CG et de leurs PA et de la pratique, le CICR n'est plus le seul à œuvrer durement dans le domaine humanitaire. Il se trouve accompagné sinon relayé d'un grand nombre d'ONG nationales et internationales.

En ce qui concerne spécialement la protection des enfants en situation de conflits armés, les ONG n'ont cessé de marquer leur présence dans toutes les instances et à tous les niveaux. L'adoption de la Convention relative aux droits de l'enfant et plus précisément l'insertion de l'article 38 de cette convention l'a été grâce à la pression des ONG (cf. supra). On rappellera à ce sujet que les ONG avaient mis sur pied dès 1983 «un groupe spécial des ONG sur l'élaboration de la convention $[\mathrm{CDE}]$ chargé, après consultation de ses membres de faire des propositions au groupe de travail des Nations Unies ${ }^{1338}$. Les ONG ont également euvré en collaboration avec l'UNICEF pour l'adoption et la ratification par les Etats du protocole facultatif à la Convention relative aux droits de l'enfant sur l'implication des enfants dans les conflits armés et de différents instruments de soft-law en la matière. Lesquels contribuent positivement au droit international de l'enfant.

Les ONG sont également pour beaucoup dans la mise en œuvre des instruments précités. L'on note que dans sa double mission de protection et de promotion des droits de l'enfant, le Comité des droits de l'enfant, sur pied de l'article 45 de la Convention relative aux droits de l'enfant, peut recourir à tout organisme qu'il jugera approprié à lui fournir des avis spécialisés sur l'application de la convention. C'est ici que ce Comité fait appel aux ONG. En ce sens, «[u]n groupe présessionnel du Comité, réuni deux à trois mois avant la session du Comité, commence l'étude des rapports pour identifier les problèmes qui mériteront une discussion approfondie lors de la réunion officielle du Comité. C'est à ce stade que les ONG sont les plus actives car elles sont souvent invitées à participer au groupe présessionnel. C'est en outre la seule étape dans l'examen des rapports pendant laquelle elles sont autorisées à prendre la parole ${ }^{1339}$. Bien plus, les ONG jouent également un rôle important en aval notamment en ce qui concerne la mise en œuvre des recommandations du Comité des droits de l'enfant. Ainsi dit précédemment, l'application des suggestions et recommandations du Comité des droits de l'enfant dépend non seulement de la volonté politique des Etats mais également des actions que mènent les ONG sur terrain. La pression exercée par les ONG peuvent inciter les Etats à aller dans le sens des vœux du Comité. Il faudrait rappeler qu'elles constituent une opinion publique Et l' «opinion publique joue un rôle indéniable aujourd'hui [...] par rapport à certains problèmes de droit international humanitaire $»^{1340}$ (cf. infra).

\footnotetext{
1336 Ibid., p. 397.

${ }^{1337}$ BETTATI, Mario, op.cit., p. 255.

1338 BENNOUNA, Mohamed, «La Convention des Nations Unies relative aux droits de l'enfant », « art.cit », p. 434.

${ }^{1339}$ BOUCHET - SAULNIER, Françoise, Dictionnaire pratique du droit humanitaire, 1998, op.cit., p. 59. Lire Idem, Dictionnaire pratique du droit humanitaire, 2013, op.cit., p. 349.

1340 SANDOZ, Yves (dir.), Les Moyens de mise en cuvre du droit international humanitaire. Etat des lieux,
} 
Ainsi, la lutte des ONG pour la protection de l'enfant en situation de conflits armés est fort remarquable également pour l'éradication du phénomène enfant-soldat.

En effet, en 1998, a été constituée la Coalition pour mettre fin à l'utilisation d'enfants soldats par les membres fondateurs qui sont les ONG que voici : Amnesty international, Terres des hommes, Human Rights Watch, l'Alliance internationale Save the Children, le Service jésuite pour les réfugiés et le Bureau Quaker auprès des Nations unies. Cette Coalition a organisé de multiples conférences régionales dans ce domaine et occasionné l'adoption de différentes déclarations en faveur du relèvement du standard de protection des enfants soldats (cf. supra) ${ }^{1341}$.

Par ailleurs, dans les zones de combat, la présence des ONG permet de soulager, tant bien que mal, les personnes les plus vulnérables, dont les enfants, des conséquences des conflits armés. Elles sont dans tous les fronts même dans les zones les plus reculées ${ }^{1342}$ (cf. le dernier chapitre de la thèse $)^{1343}$. Elles utilisent différents moyens pour accéder à certains territoires dès qu'elles estiment nécessaire en cas de refus étatique. Elles sensibilisent et tentent d'impliquer les communautés internationales, nationales et locales aux questions humanitaires. «D'émergent, les ONG sont par conséquent devenues un acteur incontournable ${ }^{1344} \gg$.

Concernant le CICR vis-à-vis de la protection des enfants dans les conflits armés, il y a lieu de rappeler ce qui suit. En 1995, il y a eu adoption par le Conseil des déléguées du Plan d'action du Mouvement relatif aux enfants dans les conflits armés (Children Affected by Armed Conflict CABAC) avec deux objectifs principaux : promouvoir le principe de non-enrôlement et de nonparticipation des enfants de moins de 18 ans aux conflits armés et prendre des mesures spécifiques pour fournir protection et assistance aux enfants victimes de conflits armés. En 1999, toutes les Sociétés nationales seront encouragés par ledit Conseil à appuyer l'adoption d'instruments internationaux mettant en œuvre les principes ci-haut évoqués. Le résultat observé est que 41 Sociétés nationales et 33 gouvernements vont s'engager, lors de la XXVIIe Conférence internationale de la Croix-Rouge et du Croissant-Rouge, à fournir protection et assistance aux enfants touchés par les conflits armés, et à empêcher que les enfants ne soient pris pour cibles en s'assurant que leurs droits soient respectés et en favorisant leur bien-être ; etc. En 2001, il sera établi que très peu d'informations étaient disponibles sur les activités des Sociétés nationales destinées aux enfants. Ce qui pousse au début 2003, le CICR a envoyé à toutes les Sociétés nationales un questionnaire visant à évaluer la mise en œuvre du Plan d'action CABAC de 1995. Cependant, aucune action de suivi concrète n'a été observé suite aux réponses relativement peu nombreuses. ${ }^{1345}$ « Depuis l'adoption du Plan d'action en 1995, les composantes du Mouvement ont beaucoup progressé, protégeant les enfants touchés par les conflits armés et empêchant d'autres enfants de rejoindre des groupes armés ou des gangs dans de nombreuses régions du

Analyse des problèmes et éléments de réflexion, op.cit., p. 100.

${ }^{1341}$ Lire MARTIN CHENUT, Kathia, «La protection des enfants en temps de conflit armé et le phénomène des enfants-soldats », op.cit., pp. 184-185.

${ }_{1342}$ Lire RYFMAN, Philippe, Les $O N G$, éditions La Découverte, Paris, 2004, p. 3.

1343 Lire idem, La Question humanitaire. Histoire, problématique, acteurs et enjeux de l'aide humanitaire internationale, Ellipses Editions Marketing S.A., Paris, 1999, pp. 95-96.

1344 Ibid., p. 112.

1345 CICR, Les enfants touchés par les conflits armés ou d'autres situations de violence, Genève, Atelier du 1416 mars 2011, Genève, Rapport d'octobre 2011, 2011, pp. 9-10. 
monde. $^{1346} \gg$

De tout temps le CICR a été préoccupé par le sort des enfants dans les conflits. Ils sont doublement victimes : soit ils souffrent des attaques comme le reste de la population civile, soit ils sont recruté, souvent de force, et entraînés voir drogués pour aller combattre. Les actions du CICR sur le terrain cherchent à leur assurer un minimum de sécurité et de bien-être. Comme exemples concrets d'activités en leur faveur, on peut mentionner l'identification et l'enregistrement des enfants non accompagnés afin de pouvoir les réunir avec leurs parents dès que possible: au Rwanda après le retour massif d'ex-Zaïre en 1996, les délégués ont photographiés les très jeunes enfants incapables de s'identifier et ont largement diffusé ces photos afin de retrouver des membres de famille. ${ }^{1347}$ D'innombrables exemples au sujet de la protection de l'enfant en conflit armé en RDC par le CICR seront relevés dans la partie suivante.

Il est à noter que depuis la fin de la guerre froide, avec l'avènement de nouvelles formes d'hostilités et face à l'insuffisance des mécanismes traditionnels de résolution des conflits, les ONG se sont également organisées de façon à apporter une contribution cruciale aux entreprises d'établissement et de consolidation de la paix engagées par l'ONU, comme en a d'ailleurs pris note la résolution 1645 du 20 décembre 2005 du CS/NU ${ }^{1348}$.

De tout ce qui précède, n'étant pas formellement liées par une Convention comme c'est le cas des Etats soucieux de préserver et défendre leurs intérêts, les ONG jouissent d'une grande autonomie pour délimiter leurs champ et moyens d'action. Et n'étant pas soumises à des contraintes administratives et politiques comme les organisations internationales et les Etats, les ONG peuvent, à ce titre, agir avec plus de flexibilité et de rapidité. Ainsi, fortes de leur connaissance de terrain et des liens étroits qu'elles entretiennent avec les entités locales impliquées dans les conflits armés, elles peuvent exercer avec pragmatisme et efficacité des fonctions dans les domaines variés ${ }^{1349}$. Cependant, pour l'exercice de leur mission, les ONG dépendent des Etats. Ainsi, elles ont besoin d'agrément des Etats pour exercer leurs fonctions. Sans lequel elles ne sont donc pas libres de tout exercice. C'est ici où certaines contraintes d'ordre administratifs et politiques sont à déceler. Les Etats ne sont pas toujours prêt à accorder leur agrément à des ONG qui pourront par la suite de leurs fonctions dénoncer des violations des droits fondamentaux ou des règles du DIH dues à l'Etat. Lesquelles dénonciations seraient de nature à porter atteinte à l'image de l'Etat concerné. Toutefois, les Etats se sentent aussi dans l'obligation de coopérer avec des ONG qui ont une grande influence sur la scène internationale afin de soigner leur image.

Par ailleurs, sur le terrain d'activités, tout ne marche pas bon train pour les $\mathrm{ONG}^{1350}$. Certaines souffrent d'un problème de moyens financiers, logistiques et humains. Le recours aux financements étatiques dont bénéficient certaines d'entre elles influe non moins sur leur neutralité ou indépendance. La présence des ONG dites «gombo » atteste cela. Pour y échapper, certaines

\footnotetext{
${ }^{1346}$ Ibid., p. 11.

1347 RINIKER, Anne, «Le Comité International de la Croix-Rouge et les conflits armés », in BENCHIKH, Madjid, (dir.), Les Organisations internationales et les conflits armés, L’Harmattan, Paris, 2001, p. 162.

1348 ASPREMONT, Jean d' et HEMPTINE, Jérôme de, op.cit., p. 382.

${ }^{1349}$ Lire Ibid.

${ }^{1350}$ Lire POULIGNY, Béatrice, «L'Humanitaire non gouvernemental face à la guerre. Evolution et enjeux », in HASSNER, Pierre et MARCHAL, Roland, Guerres et sociétés. Etat et violence après la guerre froide, éd. Karthala, Paris, 2003, pp. 545-569.
} 
ont une préférence des fonds privés que des fonds publics ou institutionnels. Philippe RYFMAN indique que «(l)e niveau des ressources financières demeure un problème permanent et angoissant, pouvant conduire à la disparition pure et simple ${ }^{1351} \gg$ des ONG. Il se pose également un problème d'expertise pour des ONG. Le manque d'expertise retombe sur les rapports publiés qui parfois voire souvent sont remis en cause par les Etats concernés ou les instances internationales. Ce qui porte atteinte à leur crédibilité. Des critiques sont également formulées vis-à-vis de leurs attitudes - neutralité ou prise de position - face à certaines crises ${ }^{1352}$.

Dans un article consacré à l'ONG Human Rights Watch, l'hebdomadaire international Jeune Afrique écrit ce qui suit au sujet d'Amnesty International : «L'organisation fondée en 1961, Prix Nobel de la paix 1977, ne fait plus trembler les satrapies. Alors qu'Amnesty a longtemps été seule à défendre les droits de l'Homme, elle est désormais dévancée par Human Rights Watch(HRW). [...] Ces dernières années, plusieurs de ses publications ont été contestées par des gouvernements... et même par l'Organisation mondiale de la santé, qui s'est insurgée contre un rapport consacré au système de santé en Corée du Nord. [...] En élargissant ses missions (droits des femmes, droits économiques et sociaux...), Amnesty a marché sur les plates-bandes d'ONG parfois plus légitimes, à l'instar d'Oxfam. [...] » ${ }^{1353}$.

Bien plus, les ONG sont confrontées à deux défis majeurs. Premièrement, contrairement à la politique défendue par le CICR, elles cherchent souvent à s'affranchir de la « souveraineté »de l'Etat en menant des actions à vocation transnationale avec le plus d'indépendance possible. Les tenants du droit d'ingérence vont même jusqu'à ériger en principe la nécessité que l'intervention des ONG se passe du consentement étatique. La prolifération d'ONG en concurrence les unes par rapport aux autres sur un même terrain suscite un second enjeu considérable en matière de coordination des activités de ces ONG entre elles ainsi qu'avec les Etats et les Organisations internationales concernées ${ }^{1354}$.

Tant bien que mal, la présence des ONG demeure d'une grande importante pour l'émergence des droits de l'enfant et surtout pour la protection de celui-ci en période de conflits armés. La ratification de certaines conventions, l'adoption de certains textes législatifs voire leur mise en œuvre dépendent pour beaucoup d'ONG (Voy. à ce sujet pour le cas de la RDC au dernier chapitre).

\footnotetext{
${ }^{1351}$ RYFMAN, Philippe, La Question humanitaire. Histoire, problématique, acteurs et enjeux de l'aide humanitaire internationale, op.cit., p. 112.

1352 BRICMONT, Jean, critique par exemple l'attitude des ONG des droits de l'Homme - dont Human Rights Watch mis en exergue - par rapport à la guerre en Irak. Il estime que ces ONG sont prêtes à y dénoncer les violations des droits de l'homme et gardent une certaine neutralité sur les fauteurs des « guerres d'agression». D'où, il suggère un «Observatoire de l'impérialisme » qu'il nomme impérialisme Watch qui dénoncerait ces guerres et leurs propagandes. Voy. BRICMONT, Jean, Impérialisme humanitaire. Droits de l'homme, droit d'ingérence, droit du plus fort ? Edition revue et augmentée, Editions Aden, Bruxelles, 2009, pp. 225-228.

${ }^{1353}$ DOUGUELI, Georges, «Human Rights Watch. Une armée en campagne », in Jeune Afrique. Hebdomadaire international indépendant, $\mathrm{n}^{\circ} 2747$, du $1^{\mathrm{er}}$ au 7 septembre 2013, p. 26.

${ }^{1354}$ ASPREMONT, Jean d' et HEMPTINE, Jérôme de, op.cit., pp. 383-384. Lire aussi BADIE, Bertrand, La diplomatie des droits de l'Homme. Entre éthique et volonté de puissance, Paris, éd. Fayard, 2002, p. 248.
} 


\section{Conclusion du Chapitre IV}

Il n'existe point de mise en œuvre des règles de droit sans l'institution des mécanismes indiqués. A travers ce Chapitre, il était question d'étudier les mécanismes de mise en œuvre des règles de protection de l'enfant en période de conflits armés.

En effet, il ressort de cette analyse qu'en période de conflits armés seuls les mécanismes conventionnels du DIH, complétés de ceux du DIDH ou du DIPé, n'assurent point la protection de l'enfant en période de conflits armés. Il existe d'autres mécanismes non conventionnels qui sont d'une contribution importante à ce sujet.

En rapport avec les mécanismes issus des instruments du DIH, en déhors du CICR, ils sont généralement quasi non opérationnels. Il n'existe pas à proprement parler un mécanisme spécifiquement dédié à l'enfant en période de conflits armés. L'enfant bénéficie simplement de la protection assurée dans un cadre général par le CICR mais également par les mécanismes qu'instituent les Etats pour répondre à leurs obligations conventionnelles.

Par ailleurs, les mécanismes du DIDH s'avèrent opérationnels mais demeurent «bureaucratiques ». Ils examinent des rapports périodiques des Etats sur la mise en œuvre de la protection de l'enfant notamment en période de conflits armés mais avec un pouvoir limité en termes de recommandations. Et la CPI qui se montre très préoccupée au sujet de la protection spéciale de l'enfant au niveau à la fois de son acte créateur (Statut de Rome) et de son fonctionnement même, à travers ses premières affaires, a beaucoup à prouver en termes de dissuasion.

Il va sans dire que ces mécanismes ne sont nullement de nature à assurer une réelle protection de l'enfant en pleine période des hostilités.

Ainsi, l'ONU, à travers ses organes et multiples mécanismes, s'est avérée d'une grande importance pour la mise en œuvre du DIH, singulièrement de la protection de l'enfant en conflits armés. On ne parlerait, par exemple, point de la protection de l'enfant sans faire allusion à 1'UNICEF. Ce dernier est à la base d'adoption et de ratification de différents instruments juridiques contraignants voire de soft-law s'intéressant aux problèmes d'enfants en conflits armés. Il travaille en collaboration avec des ONG. Celles-ci ne sont donc point à négliger dans la promotion et la protection de l'enfant et de ses droits.

La protection des enfants en période des hostilités est également appréhendée par les organisations régionales dont l'UE et l'UA. Celles-ci, à l'instar d'autres, adoptent d'importantes résolutions et déclarations qui assurent la protection des enfants, au-delà de leur droit primaire,

En conclusion, la rédynamisation des mécanismes de protection de l'enfant en période de conflit armé relayée de leur franche collaboration servirait à l'efficacité de la protection spéciale de l'enfant. 


\section{Conclusion de la première partie}

La première partie de cette thèse portant sur le droit international humanitaire et la protection des enfants en situation de conflits armés, a examiné successivement le cadre conceptuel de cette thèse (Chapitre I), la mise en œuvre du DIH en général (Chapitre II) avant de s'appesantir spécifiquement sur les règles (Chapitre III) et les mécanismes (Chapitre IV) du DIH relatifs à la protection des enfants en situation de conflits armés. En réalité, seul le DIH n'est pas examiné. Des règles et mécanismes qu'offrent notamment le DIDH et le DIPé - en appui au DIH - ont été également examinés.

En effet, complexe, le DIH est fort marqué par le caractère évolutif. Appelé à régir au départ l'exercice du droit de souveraineté des Etats de mener la guerre, le DIH est resté pendant longtemps un droit régissant la guerre (ou les CAI) pour se préoccuper ensuite des CANI. Une certaine tendance doctrinale suggérant l'extension du DIH aux situations autres que les conflits armés - à savoir de catastrophes ou de situations urgentes du même ordre - est présente mais sa juridicité reste encore très discutable.

En situation de conflits armés, l'enfant est la victime la plus vulnérable. Il se trouve différemment appréhendé selon qu'il est civil (enfant) ou qu'il est soldat (enfant soldat). Ainsi, s'il existe une définition conventionnelle pour le premier terme, le second bénéficie en revanche seulement d'un apport de soft-law.

En effet, la définition relative que donne l'article $1^{\mathrm{er}}$ de la CDE au sujet de l'enfant laisse une large marge d'appréciation de l'âge de l'enfant aux Etats. Elle se trouve tout de même corrigée par des instruments juridiques subséquents au plan régional et national. Pour sa part, 1'«enfant soldat», est entendu comme toute personne de moins de dix-huit ans enrôlée par des forces ou groupes armés aux fins des tâches non exclusivement militaires. «Enrôler » ou « recruter » un enfant pour en faire un soldat revêt de sens variés suivant les instruments en présence. Et sa «participation directe aux hostilités » s'appréhende, au regard de la position des Etats, comme des «tâches purement militaires » en ligne de front. Cette participation peut être également «indirecte» et ne se confond tout de même pas avec un simple effort de guerre. Elle peut aussi être active.

$\mathrm{Au}$ sujet de la mise en cuvre du DIH, des mécanismes de prévention, de contrôle et de sanction (voire de réparation) sont envisagés pour assurer le respect de ses règles. Toutefois, il s'avère que ces mécanismes ne sont pas toujours effectifs ou efficaces en conflits armés. De nombreux efforts étatiques fournis au plan de la réglementation et des mécanismes sont sans un lendemain meilleur sur les champs de bataille. Des limites ou écueils d'ordre politique, économique ou idéologique demeurent remarquables dans le chef des Etats ou des parties en conflit.

Il ressort de ce qui précède que le régime de protection de l'enfant en temps de conflits armés n'est point à mesure de lui assurer une protection efficace. Des sérieux écueils sont à épingler au niveau de la formulation de certaines obligations conventionnelles. Les termes utilisés pour assurer la protection de l'enfant en période de conflits armés s'avèrent plus «permissifs » et « réducteurs » de cette protection. A la base, les Etats, auteurs de ces instruments juridiques, «au 
nom de leur souveraineté », se refusent de souscrire des «obligations inconditionnelles ». Ils ont donc des larges marges de manœuvres dans la mise en œuvre des obligations souscrites. Si l'enfant est appréhendé comme toute personne ayant moins de dix-huit ans, cependant sa protection contre son utilisation aux hostilités - sauf exception notamment de la Charte africaine des droits et du bien-être de l'enfant ou du Protocole de Maputo - reste opérée en dessous de cet âge (moins de quinze ans). Et ce, malgré l'objectif final, soutenu notamment par le mouvement des ONG, d'atteindre l'âge de dix-huit ans. En ce sens, les instruments se divergent et créent une certaine fragmentation des règles notamment au sujet de la répression de l'enrôlement, de la participation directe, indirecte ou volontaire des enfants aux conflits armés. La protection est encore plus problématique lors de sa participation directe aux hostilités. Il est traité comme tout combattant alors que sa vulnérabilité physique et morale demeure présente.

En dehors des écueils décelables au niveau même des règles en question, il importe de remarquer que le DIH n'institue pas à proprement parler des mécanismes qui s'occuperaient de «la protection spéciale» de l'enfant en période de conflits armés. Déjà les mécanismes institués conventionnellement en DIH pour assurer la protection générale des personnes civiles dont les Puissances protectrices ou Commission internationale d'établissement des faits posent des sérieux problèmes de dysfonctionnement. Le DIDH apporte pour sa part une contribution énorme à travers le Comité des droits de l'enfant et tant d'autres mécanismes. Mais ces derniers ne sont donc pas des mécanismes de terrain. Il s'agit des instances - non juridictionnelles - devant se prononcer sur des rapports étatiques leur soumis et ne formulent que des recommandations.

Au rang des mécanismes non-conventionnels, l'ONU, à travers ses multiples mécanismes, s'est avérée d'une grande importance pour la mise en œuvre du DIH, singulièrement de la protection de l'enfant en conflits armés. L'ONU s'est appropriée le DIH, droit qui s'est plus développé en dehors de ses enceintes. L'enfant se trouve au centre des multiples activités de ses organes (AG/NU, CS/NU, Secrétariat, ECOSOC/NU, CIJ, etc.). On ne parlerait point de protection de l'enfant sans faire allusion à l'UNICEF. Ce dernier est à la base d'adoption et de ratification de différents instruments juridiques contraignants voire de soft-law s'intéressant aux problèmes d'enfants en conflits armés. Il travaille en collaboration avec des ONG. Celles-ci ne sont donc point à négliger dans la promotion et la protection de l'enfant et de ses droits.

La protection des enfants en période des hostilités est également appréhendée par les organisations régionales dont l'UE et l'UA. Celles-ci, à l'instar d'autres, adoptent d'importantes résolutions et déclarations qui assurent la protection des enfants, au-delà de leur droit primaire,

Par ailleurs, de tout ce qui précède, la protection de l'enfant en période des hostilités a encore du pain sur la planche. L'on ne peut donc pas se permettre d'arguer que la protection de l'enfant actuellement est satisfaisante à tous égards. Beaucoup reste à faire ! 
LE DROIT INTERNATIONAL HUMANITAIRE ET LA PROTECTION DES ENFANTS EN SITUATION DE CONFLITS ARMES EN REPUBLIQUE DEMOCRATIQUE DU CONGO 
La seconde partie de cette thèse traite du Droit international humanitaire et la protection des enfants en situation de conflits armés en République Démocratique du Congo. Elle se préoccupera de l'examen de la mise en œuvre des règles et mécanismes, étudiés en première partie, en conflits armés en RDC au profit des enfants.

En clair, la présente partie se propose d'examiner d'abord l'évolution des conflits armés en RDC. Ceux-ci se présentent à priori comme les causes de recrudescence de violations de l'enfance, de recrutement et d'utilisation des enfants dans les hostilités. C'est ainsi que cette partie s'efforcera de comprendre les causes et méthodes de recrutement et de participation des enfants à ces conflits armés. Elle s'engage en outre à l'examen de l'implication de ces conflits armés sur les enfants civils (Chapitre I)

Ces éléments, une fois éclairés, seront d'une grande utilité dans la qualification des conflits armés en RDC de 1996 à ce jour sous l'angle du DIH. De cette qualification découleront les règles du droit applicable en DIH. Lequelles se trouvent complétées par les règles du DIDH, DIpé mais également de nombreuses règles issues des accords spéciaux sans compter le droit national. Un rappel important de ces règles sera fréquemment effectué par le droit international dérivé (ONU, UE, UA) (Chapitre II).

Bien plus, une analyse de mécanismes hétéroclites de protection de l'enfant en période de conflits armés en RDC permettrait de déceler leur efficacité. Ces mécanismes sont conventionnels et non conventionnels. Ils sont non seulement d'ordre du DIH mais également du DIDH, du DIpé, du droit national, voire surtout du droit international dérivé (Chapitre III). 


\section{CHAPITRE PREMIER}

\section{CONFLITS ARMES ET ENFANTS EN REPUBLIQUE DEMOCRATIQUE DU CONGO}

L'Histoire politique de la RDC, dès la veille de son indépendance et durant chaque décennie, est marquée par des situations de crises politiques ou de conflits armés. Ceux-ci sont davantage les faits de rébellions ${ }^{1355}$ voire d' «agressions » des Etats voisins. De ces disputes des acteurs politiques ou des batailles menées entre parties aux conflits armées, la population civile est la plus grande victime.

Ainsi, les premiers moments d'indépendance sont à appréhender comme le temps de rébellions, de révoltes, d'insurrections ou de mutineries. Cette période, autant pour la suite, est émaillée des sang de nombreux civils. A titre exemplatif, il sied d'épingler le massacre du 27 août 1960 des populations villageoises du Sud-Kasaï en réaction à la proclamation par Albert KALONJI de l'indépendance de cette entité le 09 août 1960. Massacre qui a été commis par le pouvoir central. Lequel a été qualifié de génocide par les Nations Unies ${ }^{1356}$. Au Kwilu, avec la rébellion dirigée par Pierre MULELE, l'on rapportait l'existence de ce qui a été nommé «Boucherie nationale de Kikwit» où plus de trois milles assassinats ne concernaient pas seulement les rebelles mais aussi la population civile. Ainsi, à la perte d'un policier, cinq cents civils devraient être tués. Et pour un militaire tué, c'est tout un village qui devrait être exécuté ${ }^{1357}$. Les guerres de Shaba I et II respectivement de 1977 et 1978 ont fait de nombreuses victimes parmi lesquelles les villageois de Lufupa dont les cases ont été incendiées par l'offensive zaïro-marocaine (1977) sans oublier les tueries exercées sur la population d'origine européenne par les Forces Armées Zaïroises (FAZ) et les rebelles katangais du Front National pour la libération du Congo (FNLC) à Kolwezi $(1978)^{1358}$. Toujours sous ce lot, l'on comptera les représailles dont était victime la population de Moba au Katanga en novembre 1984 par le fait de l'armée régulière Zaïroise à la suite d'une rébellion déclenchée dans cette cité ${ }^{1359}$.

La décennie 90 est sillonnée d'une succession d'importants événements ${ }^{1360}$ qui seront d'une influence remarquable sur l'avenir politique de ce pays. Le début de cette décennie accuse le «Massacre » des étudiants de Lubumbashi dit «Lititi mboka» (cf. infra), suivi des pillages du 23 septembre 1991 répétés du 28 au 30 janvier 1993 ; des massacres des chrétiens du 16 février 1992 à la suite d'une marche de réclamation de réouverture de la Conférence

\footnotetext{
1355 Lire VERHAEGEN, Benoit, Rébellions au Congo, Tome I, Léopoldville-Bruxelles, I.R.E.S-LovaniumLéopoldville, I.N.E.P-Léopoldville et C.R.I.S.P-Bruxelles, 1966, 568 p. VERHAEGEN, Benoit, Rébellions au Congo. Maniema, Tome II, Bruxelles-Kinshasa, C.R.I.S.P - Bruxelles, I.R.E.S -Kinshasa, 1969, 830 p.

${ }_{1356}^{136}$ BRAECKMAN, Colette, Le Dinosaure. Le Zaïre de Mobutu, Paris, Librairie Arthème Fayard, 1992 , p. 34.

${ }^{1357}$ Ibid., p. 40.

${ }^{1358}$ Ibid., p. 65.

1359 Ibid., p. 50.

${ }^{1360}$ Lire à ce sujet MUKENDI, Germain et KASONGA, Bruno, Kabila. Le retour du Congo, éd. Quorum SPRL, Ottignies, 1997, pp. 127-180. Ces auteurs retracent de manière chronologique les grands événements sur le plan socio-politique qui ont eu lieu dès la veille de la «démocratisation des institutions » au Zaïre à la veille de la prise du pouvoir à Kinshasa par l'AFDL.
} 
Nationale Souveraine (CNS). L'on dénombre plusieurs actes de répression de la population civile manifestant contre le pouvoir en place notamment par les soldats de la Division Spéciale Présidentielle (DSP) en particulier. C'est en octobre 1996 que la rébellion du Kivu éclate avec l'Alliance des Forces Démocratiques pour la Libération du Congo-Zaïre (AFDL). Une rébellion qui arrive deux ans après le génocide rwandais et portera au pouvoir Laurent Désiré KABILA.

Depuis 1996, la situation politique de la République Démocratique du Congo (RDC) est scellée, près de deux décennies, des conflits armés intermittents et enchevêtrés avec des conséquences les plus meurtrières après la Seconde Guerre Mondiale.

Les enfants font partie des civils les plus victimes de ces conflits armés notamment en raison de leur vulnérabilité manifeste. Ils sont les cibles des belligérants. Ils sont recrutés par les parties en conflits armés afin d'être transformés soit en «machine à tuer » soit en «chair à canon ». Leurs droits fondamentaux se trouvent bafoués. Ils subissent des massacres, tueries, viols, etc. Bref, des atrocités indicibles de divers ordres. C'est dans ce contexte d'étude que le présent chapitre s'inscrit.

Ainsi, il paraît très utile d'examiner, sous un chapitre, l'évolution des conflits armés en RDC. Lesquels se présentent à priori comme les causes de recrudescence de violations de l'enfance, de recrutement et d'utilisation des enfants dans les hostilités en marge du DIH. Ce chapitre se préoccupera de l'étude des conflits armés qui se déroulent sur le territoire de la RDC, près de deux décennies (Section I), avant de se focaliser sur l'analyse du processus de recrutement et de participation des enfants à ces conflits armés (Section II). Ne point se limiter à voir les enfants comme «machines à tuer », «acteurs » ou «combattants », nous permettra de nous engager dans l'examen de l'implication de ces conflits armés sur les enfants (Section III) eu égard à la vulnérabilité psychique ou morale et physique dont ils font preuve.

\section{Section I Les Conflits armés en République Démocratique du Congo}

L'Afrique est généralement présentée comme le continent où «la seule certitude est l'impossibilité de la paix ${ }^{1361}$. Différentes régions africaines sont touchées par les conflits ou leurs effets, pour le moins qu'on puisse dire. La Région des Grands-Lacs est une partie distinguée de cette rage de la guerre. Elle est donc une région de l'Afrique à hauts risques : guerres civiles et violences se succèdent depuis plusieurs décennies. L'imbrication des pays de la région, de par leurs intérêts communs, leurs alliances ou leurs antagonismes, fait en sorte qu'un conflit éclatant dans un Etat peut, par effet de domino, déclencher un véritable cataclysme dans toute la région ${ }^{1362}$.

Aujourd'hui, cette sous-région et ses environs passent pour l'une des zones les plus instables et les plus risquées d'Afrique et même du monde. Elle souffre de plusieurs maux : guerre, insécurité, pauvreté extrême, intolérance ethnique et politique, faiblesse de la gouvernance, non-respect des droits de l'homme, etc. dont la solution requiert une approche simultanée,

${ }^{1361}$ GERE, François, Pourquoi les guerres? Un siècle de géopolitique, Paris, éd. Courrier International Larousse, 2002, p. 149.

${ }_{1362}$ Commission Justice et Paix, Ruanda, Burundi et République Démocratique du Congo : Analyse de la situation et perspectives, Bruxelles, édition Commission Justice et Paix, 1998, p. 5. 
fondée sur la solidarité des problèmes de la sécurité et du développement ${ }^{1363}$.

La RDC, au cœur de cette Région, n'est point exemptée de ce cycle d'extrêmes violences. Il est d'ailleurs impossible d'examiner la situation des conflits armés qui règnent sur son territoire en l'écartant de la situation globale de la région. La RDC fait l'objet depuis plusieurs années de conflits enchevêtrés. Lesquels sont intimement liés aux conflits des pays voisins au point d'être vus d'ailleurs comme l' « exportation du conflit rwandais ${ }^{1364}$. Les causes de tels conflits s'avèrent donc multidimensionnelles et interdépendantes. Dans le cadre de cette étude, elles seront appréhendées sous deux angles - lointain et immédiat (\$2). Par la suite, l'intérêt de cette analyse sera consacré à l'examen de la situation conflictuelle congolaise dans les arènes de l'ONU, principalement du $\mathrm{CS} / \mathrm{NU}(\S 3)$. Enfin, il sera souhaitable d'examiner le processus de paix y entrepris $(\$ 4)$. Ces réflexions, ainsi reparties, nécessiteront au départ la présentation socio-économique même de ce pays, la RDC $(\S 1)$.

\section{§1. Situations socio-économiques de la République démocratique du Congo}

${ }^{1363}$ KITIMA, Kasendwe, « La crise dans les Grands-Lacs et ses conséquences sécuritaires pour les pays de la sous-région », in Les Mélanges de la pléiade congolaise, Vol I (juin 2003 - mars 2005), Kinshasa, éditions La pléiade Congolaise 2005, p. 97.

1364 LANOTTE, Olivier, République Démocratique du Congo. Guerres sans frontières. De Joseph-Désiré Mobutu à Joseph Kabila, Bruxelles, Grip-éditions Complexe, p. 35. 
Carte $\boldsymbol{n}^{\circ} 2$ : Vue de la RDC au centre de l'Afrique

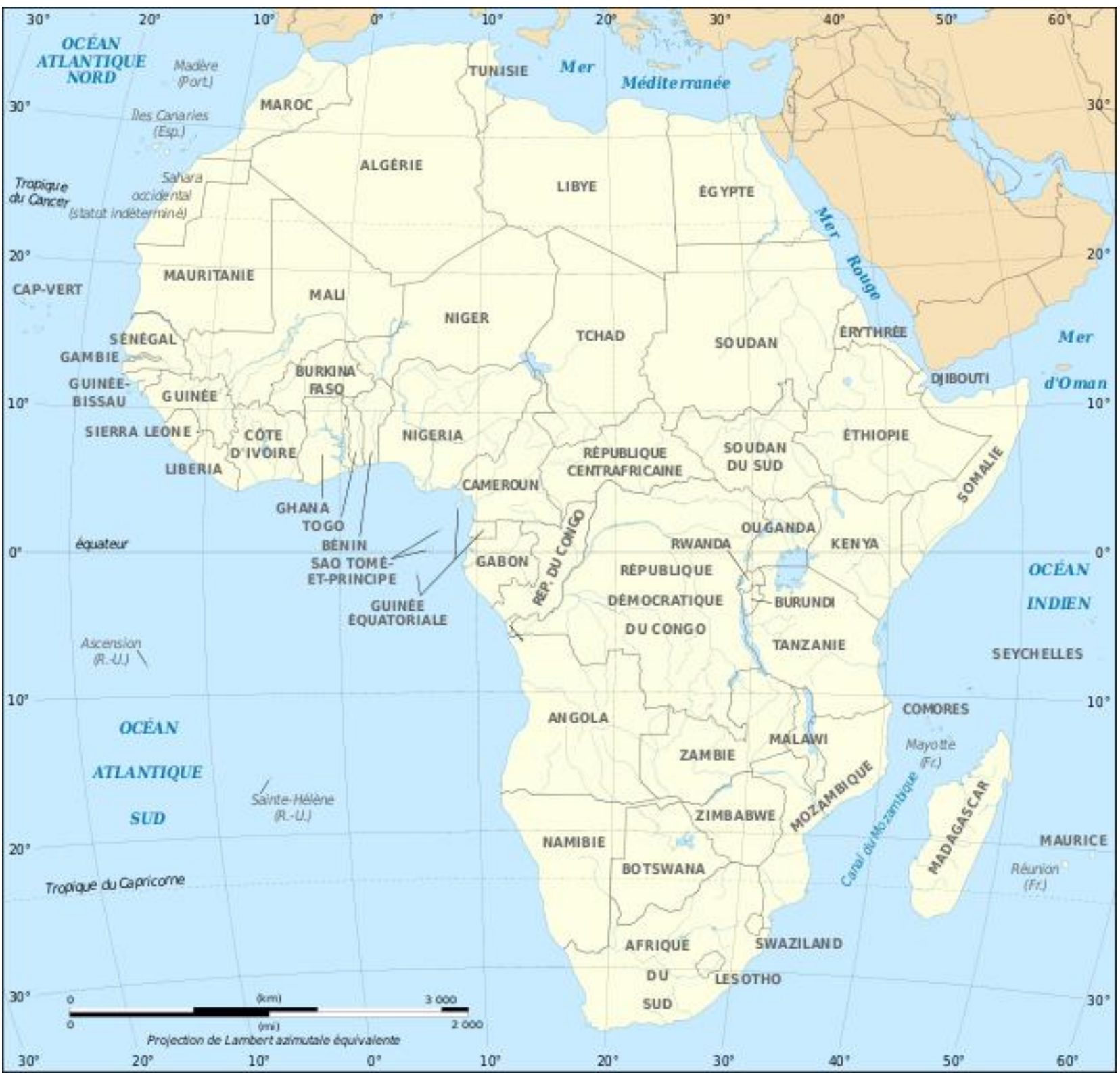

source : http://commons.wikimedia.org/wiki/File:African_continent-fr.svg (Source consultée le 12 mars 2014). 
Carte $^{\circ} \mathbf{3}$ : Carte géographique de la RDC (Provinces avec Capitales des Provinces dites Chefs-lieux )

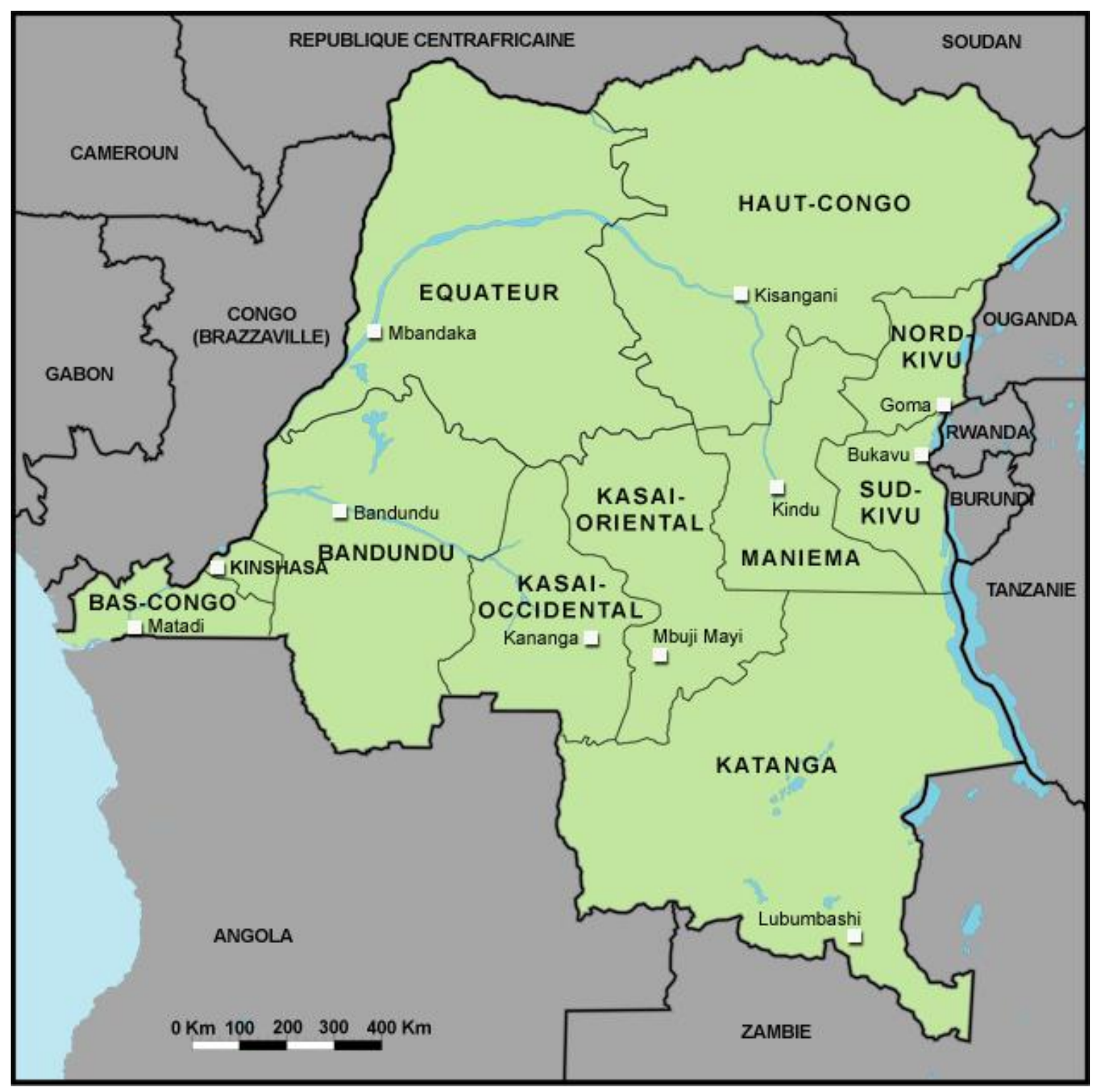

Source: RFI in http://www1.rfi.fr/actufr/articles/079/article 45035.asp (source consultée le 12 mars 2014 ). Il est important de préciser que la présente carte géographique est présentée à titre illustratif aur regard du déroulement des conflits armés en RDC depuis 1996. Actuellement, avec la constitution du 18 février 2006, la RDC est dotée de 26 provinces. Ces dernières ne sont devenues effectives qu'en second semestre de l'année 2015.

La RDC apparaît comme l'une des dernières réserves mondiales de ressources stratégiques. Un véritable condensé géologique: deux tiers de réserves mondiales de cobalt, le tiers de réserves de chrome et de manganèse, la deuxième réserve du cuivre du monde, des réserves insoupçonnées en hydrocarbures et gaz, une des dernières réserves forestières du monde, le quart des réserves mondiales d'or... La RDC produit le 4/5 du coltan mondial (...) Ce qui la prédestine, selon les estimations du savant égyptologue Cheikh Anta Diop, à devenir "la première région industrielle de l'Afrique", le centre principal de son industrie ${ }^{1365}$. Bref,

1365 NTUMBA Luaba Lumu, «Grandes puissances et avenir de la République Démocratique du Congo », in 
l'expression "scandale géologique" dite par le géologue Belge Jules Cornet en février 1892 traduit la mesure de ses potentialités ${ }^{1366}$.

Cependant, la RDC est un pays de paradoxe. Alors que les réserves de son potentiel minier seraient estimées à 34.000 milliards de dollars américains ${ }^{1367}$, une grande partie de sa population vit dans une misère indescriptible: un taux de pauvreté de $71 \%$ et $14 \%$ des pauvres $\mathrm{du}$ continent. La RDC se trouve "considérée par plusieurs de ses partenaires au développement comme un pays très pauvre en raison des indicateurs économiques catastrophiques"1368. Le Rapport National sur le Développement Humain 2008 sur la RDC initié par le Programme des Nations Unies pour le Développement (PNUD) indique que ce pays figure parmi les trois derniers pays du classement mondial sur la base du PIB par tête $\mathrm{d}^{\prime}$ habitant ${ }^{1369}$. Lors de la conférence sur la bonne gouvernance et la transparence dans le secteur minier de la RDC tenue à Lubumbashi (RDC) les 30 et 31 janvier 2013, Monsieur Eustache OUAYORO, Directeur des opérations de la Banque Mondiale en RDC a affirmé qu'en RDC, l'on retrouve 2/3 d'enfants de 12 à 14 ans non scolarisés et la moitié des décès chez les enfants de moins de 5 ans reste liée à la malnutrition ${ }^{1370}$. En termes d'indice du développement humain, la RDC se classe 186 è sur 186 pays en $2013^{1371}$. Et du classement Doing Business 2014 de la Banque mondiale et de la Société financière internationale (classement des pays en fonction de la facilité d'y faire des affaires), la RDC occupe la 183è place sur $189^{1372}$. Ainsi, pour dire que le climat des affaires s'y porte encore très mal.

Bien plus, différents Rapports d'Experts de l'ONU épinglent la persistance des «microconflits alimentés par la convoitise des minerais, des produits agricoles, de la terre et

SABAKINU Kivulu (dir.), Démocratie et paix en République Démocratique du Congo, P.U.K, Kinshasa, 1999, p. 222.

${ }^{1366}$ NGOIE Tshibambe, «La politique de bon voisinage: analyse d'un principe de la politique étrangère de la RDC », in Congo-Afrique, n 412-413, Kinshasa, éd. Cepas, février-mars 2007, p. 158. Lire également Termes de références. La conférence sur la bonne gouvernance et la transparence dans le secteur minier de la RDC tenue à $\begin{array}{lllllll}\text { Lubumbashi } & \text { les } & 30 & \text { et } & 31 & \text { janvier } & 2013\end{array}$ :http://7sur7.cd/apa/TDRs_Conference bonne_gouvernance_secteur_minier.pdf (Source consultée le 28 août 2013).

${ }^{1367}$ E. OUAYORO, «Les Ressources minérales de la RDC, bénédiction ou malédiction ? Comment peuventelles contribuer au développement durable de la RDC ? », in Ministère des Mines de la RDC, Rapport final des travaux de la conférence sur la bonne gouvernance et la transparence dans le secteur minier de la RDC tenue à Lubumbashi les 30 et 31 janvier 2013, in http://mines-rdc.cd/fr/documents/Rapport_final_conference lushi.pdf (Source consultée le 28 août 2013).

${ }^{1368}$ MULUMA, Munanga Tizi, A., « Corruption et pauvreté. Que faire pour la relance socio-économique en RD Congo » in Congo-Afrique $\mathrm{N}^{\circ} 430$, Kinshasa, éd.Cepas, décembre 2008, p. 819. Lire également K. HARMON SNOW et D.BAROUSKI, «Derrière les chiffres: la souffrance indicible au Congo », in http://www.droitcongolais.info/files/derriere_les_chiffres_la_souffrance.pdf (Source consultée le 28 août 2013). ${ }^{1369}$ RDC, Rapport National sur le Développement Humain 2008, Restauration de la paix et Reconstruction, PNUD 2008, p.17, in http://www.undp.org.cd (Source consultée le 28 août 2013).

${ }^{1370}$ E. OUAYORO, «art.cit.» in Ministère des Mines de la RDC, Rapport final des travaux de la conférence sur la bonne gouvernance et la transparence dans le secteur minier de la RDC tenue à Lubumbashi les 30 et 31 janvier 2013 http://mines-rdc.cd/fr/documents/Rapport_final_conference lushi.pdf (Source consultée le 28 août 2013).

${ }^{1371}$ PNUD, « Rapport sur le Développement humain 2013 : L'essor du Sud Le progrès humain dans un monde diversifié », in http://hdr.undp.org/en/media/HDR_2013_FR.pdf, p. 162 (Source consultée le 28 août 2013).

1372 Doing Business 2014 http://francais.doingbusiness.org/reports/global-reports/doing-business-2014 (Source consultée le 12 mars 2014). 
même des recettes fiscales $»^{1373}$ (cf. infra). Ce qui appauvrit davantage ce pays. Des autorités politico-administratives et officiers militaires, à différents échelons, se trouvent impliqués ${ }^{1374}$. Le peuple se trouve donc loin de bénéficier de ces richesses sinon quelques groupes ou classes.

\section{§2. Genèse et évolution des conflits armés en République Démocratique du Congo}

\section{A. De Mobutu à Laurent Désiré KABILA}

Pour une analyse aisée du point du passage de pouvoir de Mobutu à Laurent-Désiré KABILA, par les conflits armés dits «Guerre de libération» ou encore "première guerre de libération », il nous paraît judicieux d'examiner cette question sous deux angles (a. causes lointaines et $\mathrm{b}$. causes immédiates) intrinsèquement liés. Lesquels incorporent à la fois des causes internes et externes du départ de Mobutu du pouvoir.

\section{a. Des causes lointaines}

Les guerres, le plus souvent internes aux Etats qui ensanglantent aujourd'hui le monde sont souvent présentées comme étant les conséquences inéluctables de haine, de clivage ou d'antagonisme quasi-immémoriaux ${ }^{1375}$. Et lorsqu'on analyse les conflits infra-étatiques contemporains, on constate tout d'abord que dans la plupart des cas, ils se déroulent au sein d' «Etats importés » où la greffe de l'Etat n'a pas ou a mal pris et ce parce qu'ils sont nés d'une décolonisation octroyée et/ou qu'ils résultent d'un découpage frontalier artificiel. Il peut s'agir aussi de «quasi-Etats » en situation d'échec faute de ressources suffisantes pour assurer la continuité des pouvoirs publics et satisfaire les demandes sociales... ${ }^{1376}$ En RDC, ces critères d'analyse s'y retrouvent. C'est dans cette logique qu'il sera ici question de tenter de cerner les causes d'échec de politique interne qui, associées aux causes liées à la politique régionale ou internationale, occasionneront le cycle des conflits armés dans ce pays.

En effet, la démocratisation manquée avec ses effets directs sur la survenance de la guerre de l'AFDL ne constitue que la résultante d'une politique d'un régime oppresseur de son peuple datant d'un quart de siècle. La décennie 90 sera donc l'étape finale où tout sera mis en branle pour mettre un terme au « système mobutiste ». Une pénible et longue période de transition!

Lorsqu'il prend le pouvoir par coup d'Etat le 24 novembre 1965, Joseph-Désiré Mobutu se présente comme le plus soucieux du sort de son peuple. C'est dans cette optique qu'il constate, avec ses compagnons, dans son acte de prise de pouvoir ${ }^{1377}$ que l'armée se préoccupe, dès l'indépendance, à un sort meilleur de la population civile. Ce qui n'est pas, en revanche, le cas de la classe politique plus préoccupée par la course au pouvoir. Ces autorités

\footnotetext{
${ }^{1373}$ Rapport final du Groupe d'experts sur l'exploitation illégale des ressources naturelles et autres formes de richesse de la République Démocratique du Congo, in http://www.grip.org/bdg/g2004.html (Source consultée 28 août 2013).

${ }^{1374}$ Ibid.

1375 DARIO, Battistella, «Les facteurs de conflits : vers de nouveaux types de conflits ? », in Les conflits dans le monde, Cahier français $\mathrm{N}^{\circ} 290$, Paris, 1998, p. 43.

${ }^{1376}$ Ibid.

1377 Lire la Proclamation du Haut Commandement militaire des Forces armés (24 novembre 1965) in MUKENDI, Germain et KASONGA, Bruno, op.cit., pp. 245-248.
} 
politiques, constatent Mobutu et ses compagnons, ne fournissent aucun effort pour venir en aide à la population civile éprouvée des conflits armés. Par conséquent, leur course au pouvoir risque de peser lourdement sur cette population déjà meurtrie par les effets des rébellions. Il est donc temps, selon le haut Commandement de l'armée que dirige Mobutu, de mettre fin à ces ambitions par la destitution du Président Joseph Kasa-Vubu. Et lors d'un discours prononcé la même période au stade Roi Baudoin, l'actuel Stade Tata Raphaël, ex-stade du 20 mai, le Président Mobutu promettra la prospérité à son peuple. Cette compassion ou ce souci manifesté par le Président vis-à-vis de son peuple, et au regard de la pratique constatée quelques temps après, ne serait qu'un leurre pour s'attirer la sympathie populaire afin d'asseoir son pouvoir.

Pendant le premier «quinquennat présidentiel», l'on dénombre plusieurs mesures arbitraires que peu de démocraties occidentales osent dénoncer. Pendaisons publiques, enlèvements, disparitions, exécutions sommaires, etc. A côté de ces atteintes aux droits fondamentaux, l'on relève la gabegie financière, la mégalomanie, l'impunité des «fidèles » du régime accompagnée de la corruption institutionnalisée. L'économie productive léguée par le colon n'est pas suivie d'une croissance. Le Président, pour sa part, est au dessus des lois et renforce davantage son pouvoir au point d'ériger un «parti-Etat», le Mouvement Populaire de la Révolution (M.P.R) ${ }^{1378}$. Cette situation s'empire de plus en plus au point que personne n'avait droit d'aller dans le sens contraire à la politique du régime en place. Déjà avec un parti unique, parti Etat, décrété, il n'y avait pas un autre son de cloche possible à entendre. Toute tentative dans ce sens écoperait des mesures ci-haut décrites.

Par ailleurs, l'orgueil démesuré du « Guide de la nation » le conduira à prendre une mesure économique drastique et impardonnable. Laquelle aura des conséquences néfastes sur la politique économique du pays dont le peuple souffrira pendant longtemps des effets : La «Zaïrianisation ». Elle s'inscrit dans le prolongement de mouvement politique de Mobutu de recours à l'authenticité congolaise décrété le 21 octobre 1971. Différentes villes de noms occidentaux furent rebaptisées de noms puisés dans le patrimoine culturel zaïrois. Ce qui vaut de même pour des citoyens zaïrois dont les noms chrétiens et occidentaux devraient être supprimés au profit des noms zaïrois.

Par la zaïrianisation, il s'est agi d'un processus de nationalisation entrepris par Mobutu entre 1973 et 1974 pour la plupart des entreprises détenues par des étrangers. Il s'agit d'une tentative de dégager l'économie zaïroise des influences extérieures dont essentiellement celles de la domination coloniale. Les secteurs concernés étaient les plus divers : construction, construction métallique, pétrole, mines, plantations, élevage... Ces actifs furent d'abord repris par l'État ou par des organismes étatiques pour être ensuite attribués à des personnes privées zaïroises - des proches du président, membres de sa famille ou fidèles soutiens politiques ${ }^{1379}$.

\footnotetext{
1378 Lire MUKENDI, Germain et KASONGA, Bruno, op.cit., 30. L'Histoire de la RDC renseigne «qu'en mai 1970, le Congrès extraordinaire proclama le Mouvement Populaire de la Révolution institution suprême du pays à laquelle toutes les autres sont subordonnées. Cette institutionnalisation du parti fut consignée dans la constitution modifiée vers la fin de la même année». Elle sera reconduite et renforcée lors de la révision constitutionnelle du 15 août 1974 après que le Congrès ordinaire de mai 1972 ait suggéré la concrétisation de l'institutionnalisation et de la suprématie du MPR. Lire MPINGA Kasenda et D.J GOULD, Les Réformes administratives (1972-1973), Kinshasa, Presses Universitaires du Zaïre, 1975, pp. 10 et 25.

${ }^{1379}$ MOREAU, Jean-Louis, « De la décolonisation à la zaïrianisation. Le sort des capitaux belges au Congo », in IRIC-UMR 8138, http://irice.univ-paris1.fr/spip.php?article594 (Recherchée le 23 février 2014). Lire également YABILI YALALA, Asan, Code de la Zaïrianisation. Recueil de textes et règlements des décisions du 30
} 
Insuffisamment préparés pour assurer de tels types de gestion, les nouveaux propriétaires, occasionneront, seulement quelques mois après, la faillite de ces entreprises pour la plupart. Ceci poussera le Président Mobutu à revenir sur sa décision pour reprendre ces entreprises. Cette mesure n'aura rien résolu car l'économie zaïroise entrait en récession. Dans un discours prononcé le 25 novembre 1975, le président Mobutu annonça son intention de restituer aux anciens propriétaires $40 \%$ des entreprises zaïrianisées. Cette annonce ne suscita que peu d'enthousiasme chez les anciens propriétaires. Le 17 septembre 1976, le Comité de stabilisation porta de $40 \%$ à $60 \%$ le niveau de restitution. Et dans les mois qui suivirent, d'autres mesures d'assouplissement firent que dans certains cas, les propriétaires récupérèrent l'intégralité de leurs avoirs ${ }^{1380}$. Mais, la crainte des investisseurs étrangers de penser à une nouvelle mesure de nationalisation une fois les entreprises redressées était permanente. La confiance n'existait donc plus. Le désastre occasionné par cette mesure via ces «administrateurs » seront ressentis durant tout le régime à multiples niveaux.

D’un lien direct avec les conflits armés qui seront observés plus tard, cette mesure de «zaïrianisation », conjuguée ensemble avec la nationalité zaïroise accordée aux ressortissants rwandais établis au Kivu, permet à des hommes d'affaires, des acteurs politiques et des notables tutsis de récupérer des terres, notamment d'anciennes plantations coloniales, redistribuées par l'Etat. Ces acquisitions de terre vont conférer un caractère légal aux implantations foncières des paysanneries tutsies dans le Kivu, et cela en totale opposition aux usages coutumiers locaux qui gèrent la terre en régime de propriété clanique ou villageoise. Cette situation provoque l'indignation des populations autochtones qui s'estiment expropriées pour la seconde fois (la première fois par les colons belges) d'une partie de leur territoire par des tutsis. Lesquels sont considérés comme envahisseurs dans l'inconscient collectif ${ }^{1381}$. La mauvaise gestion de ce litige sera d'ailleurs d'une grande influence pour la guerre de l'AFDL, et donc pour la fin du régime de Mobutu.

A côté de la politique économique désastreuse, les rébellions ou mouvements insurrectionnels resurgiront de temps en temps pour lutter contre le régime en place. En face de ces rébellions, les Forces Armées Zaïroises (FAZ) pour les contrer. Toutefois, les FAZ se trouvent dans un état de décomposition avancé, à l'image de l'Etat Zaïrois lui-même. Abandonnées à ellesmêmes, sous-payées, mal formées, sous-équipées et sous armées, les FAZ, principale source d'insécurité et de désordre dans le pays ${ }^{1382}$, ne seront pas, dans la plupart des cas, en mesure de contrer ou de mettre fin à ces différentes rébellions qui s'y déclenchent. Les FAZ, doit-on le rappeler, ont fait la fierté du pays notamment par leurs diverses missions interafricaines de maintien de la paix et leur participation à l'instruction de nombreux parachutistes et commandos africains (burundais, rwandais, centrafricains, togolais et tchadiens) ${ }^{1383}$. Mais par souci de conservation du pouvoir, Mobutu a été amené à faire de l'armée une chasse gardée.

\footnotetext{
novembre 1973 et du 30 novembre 1974, éd. Mwanga-Hebdo, Lubumbashi, 145 p.

${ }^{1380}$ MOREAU, Jean-Louis, « De la décolonisation à la zaïrianisation. Le sort des capitaux belges au Congo », in IRIC-UMR 8138, http://irice.univ-paris1.fr/spip.php?article594 (Recherchée le 23 février 2014).

1381 NTUMBA BUKASA, Eric, La RDC et le processus d'intégration des pays des Grands Lacs comme voie de sortie de la crise sécuritaire régionale, Master en Administration Publique, ENA, 2008 in http://www.memoireonline.com/12/08/1724/m La-RDC-et-le-processus-dintegration-des-pays-des-GrandsLacs-comme-voie-de-sortie-de-la-crise-secur9.html (Recherche menée le 23 février 2014).

1382 LANOTTE, Olivier, République Démocratique du Congo. Guerres sans frontières. De Joseph-Désiré Mobutu à Joseph Kabila, op.cit., p. 22.

1383 Ibid.
} 
C'est dans sens qu'il devrait placer à la tête des unités des personnes qu'il maîtrisait bien des profils et qui ne devraient pas avoir des visées putschistes. Ainsi, il lui était donc facile de nommer des personnes relevant de sa tribu ou de son ethnie, ou ses proches. L'armée était tribalisée ou régionalisée au point qu'il était perceptible au niveau même de la rémunération des soldats. Par exemple, les soldats de la DSP recrutés pour la plus part, si pas tous, dans les sous-régions du Nord- et du Sud-Ubangi et dans la Mongala (Province de l'Equateur, Province du Président Mobutu) et les Services de renseignements militaires de l'Armée (SARM) touchaient régulièrement leur solde et d'autres avantages sociaux. La «tribalisation ou la régionalisation de l'armée » a été observée graduellement en écartant d'abord la plus part d'officiers issus de l'ethnie tetela après une « tentative » de coup d'Etat militaire en 1975 par le colonel Omba Pene, secrétaire particulier du Président Mobutu, originaire de l'ethnie tetela. En 1978, de nouveau, le Président va devoir éjecter les officiers originaires du Bandundu, du Bas-Congo, du Kasaï et du Katanga toujours sous prétexte de «tentative de coup d'Etat ». Après avoir fait de la DSP et de la Garde Civile des chasses gardées à ses proches à la fin des années 80, le Président Mobutu écartera le Général Mahele pour laisser place au Général Eluki, en janvier 1993, après la destruction observée par les pillages militaires et populaires. On parlera ainsi de «quarteron des généraux » pour désigner le clan formé par les généraux Nzimbi, Baramoto et Eluki et l'amiral Mavua ${ }^{1384}$. A propos du tribalisme, le Général MUKOBO, ex-Chef d'Etat-Major Général adjoint des FAZ, l'épingle comme le mal qui a gangrené l'armée Zaïro-congolaise et toutes les armées africaines. Le tribalisme a joué un rôle primordial dans la destruction considérable des FAZ, poursuit-il. Il situe son début dans les FAZ à la création de l'unité spéciale chargée de la sécurité personnelle du Président de la République. Cette unité, dirigée par le Général BUMBA Moaso Djogi n'était composée en majorité que des ressortissants de l'Equateur, Province de Mobutu. Les officiers n'avaient aucune formation requise sauf le seul mérite de parler la même langue du Village. Sous les FAZ, le tribalisme a joué également au niveau du commandement où les combattants n'obéissent qu'aux ordres relevant des Commandants issus de leur tribu ou ethnie. C'est ce qui a été constaté à l'Est du Congo lors de la guerre de l'AFDL. où les soldats de la DSP n'attendaient que les ordres de Kinshasa pour agir en dépit des ordres donnés par des officiers d'opération sur place ${ }^{1385}$. Chose qui a joué en faveur de la partie ennemie.

Du tribalisme régné au sein de l'armée Zaïroise, il va sans dire que seuls les officiers de l'Equateur et de la Province du Haut-Zaïre, l'actuelle Province-orientale avaient la bénédiction du «Guide ». Le souci de Mobutu d'être au contrôle permanent de son pouvoir le conduira également à ne point équiper les FAZ craignant de subir un coup d'Etat. L'armement que détenait les FAZ, sera mis en vente, au fur et à mesure de l'évolution du chaos du régime, par les Généraux- hommes d'affaires aux groupes rebelles étrangers. On ne pouvait donc pas s'attendre à plus de résultats positifs. Cette pratique est actuellement observable dans les Forces Armées de la République Démocratique du Congo (FARDC).

Ainsi, les FAZ se sont montrées généralement incompétentes, peu efficaces face aux adversaires équipés dans différents conflits armés qui les opposaient au plan national. Elles

\footnotetext{
${ }^{1384}$ Lire LANOTTE, Olivier, République Démocratique du Congo. Guerres sans frontières. De Joseph-Désiré Mobutu à Joseph Kabila, op.cit., pp. 23-25.

${ }^{1385}$ Lire l'entretien du Général MUKOBO « Général MUKOBO : « Il faut un changement à la tête du pays », in Ingeta Le Journal http://www.ingeta.com/general-mukobo-il-faut-un-changement-a-la-tete-du-pays/ (Recherche menée le 10 mars 2014).
} 
n'ont donc pas remporté des guerres sans l'intervention des forces étrangères. Ainsi comme le note bien Colette BRAECKMAN «[...] lorsqu'elle (l'armée zaïroise) se trouve en face d'opposants réels, décidés à se battre, elle s'effondre et abandonne le combat. Par contre, les soldats retrouvent tout leur savoir-faire lorsqu'il s'agit de trafiquer, de piller et de s'en prendre aux populations civiles ${ }^{1386}$. Elles remportent comme butins de guerres les biens pillés aux pauvres populations. Au final, pour mater les rebelles, le recours est fait aux alliés étrangers, mercenaires ou Etats. Ceci est attesté notamment par les rébellions de Kwilu avec Pierre Mulele et de l'est du Congo avec Gbenye et Gaston Soumialot ${ }^{1387}$, les Guerres de Shaba I et II $^{1388}$.

De ce qui précède, si certains reconnaissent le début du régime Mobutu comme meilleur au plan économique avec un taux de croissance de 7,5\% par an à partir de 1967, un taux de progression industrielle de $12,5 \%$, sans compter le cour du cuivre haut et favorable au Congo, c'est également en cette période que la dégringolade faisait ses débuts car pour le régime en place, tout était permis ${ }^{1389}$. Sous cette période, la RDC jouissait d'un prestige au plan africain. L'on note par exemple que ces universités accueillaient la grande communauté africaine. L'emploi était à la portée des diplômés qui sortaient des universités, instituts supérieurs et écoles. Les hôpitaux congolais étaient une référence pour de nombreux patients africains. Au plan sportif, le Congo venait de remporter la Coupe d'Afrique des Nations de football (1968). Et après avoir remporté sa seconde coupe d'Afrique en 1974, le Zaïre de Mobutu s'offrira un ticket pour la Coupe du monde de football. Il sera à ce titre, la première nation d'Afrique noire à le faire. Le 30 octobre 1974, les projecteurs du monde entier seront braqués sur l'exZaïre pour «le combat du siècle » qui opposa deux poids lourds de boxe, Mohammed Ali et George Foreman. L'on n'oubliera pas de mentionner sur le plan culturel, le concert musical historique joué par TABU LEY dans la salle mythique de l'Olympia de Paris en 1972 pendant plus d'une semaine. Tout ceci met en avant plan la culture sur la scène mondiale.

Cependant, la situation politique du pays devenait de plus en plus chaotique. Le système de parti Etat renforçait davantage ses stratégies. Les étudiants qui avaient tenté de manifester contre le pouvoir s'étaient retrouvés incorporés dans l'armée et leur Université fermée (Université de Louvanium, 1969). Ceci vaut de même pour les religieux. Il était clair pour le Guide éclairé, Mobutu, : «A César, ce qui est à César; à Dieu, ce qui est à Dieu». Les religieux ne devraient donc pas se mêler de la politique. Pour y avoir tenté, le Cardinal MALULA, alors Monseigneur, s'est retrouvé en exil, à Rome. Les Acteurs politiques qui tentaient de s'y mêler se retrouvaient soit en prison, soit exécutés, soit en exil. A Nimy MAYIDIKA, Chef de services de sécurité, de reconnaître : "Sur le plan intérieur, si au Zaïre de Mobutu, il y a une chose qui marche, c'est au moins le Service de sécurité. (...) C'est une machine, c'est un appareil qui fonctionnait parfaitement. Et que par conséquent qui tenait les gens $[\ldots] »^{1390}$.

« Le point sur lequel tous les Zaïrois sont d'accord est le bilan du quart de siècle de règne de

\footnotetext{
${ }^{1386}$ BRAECKMAN, Colette, Le Dinosaure. Le Zaïre de Mobutu, op.cit., p. 51.

${ }^{1387}$ Lire Ibid., pp. 40-41.

${ }^{1388}$ Lire Ibid., pp. 63-69.

1389 Suivre l'entretien de LECLERCQ, Hugues, President Economic Advisor dans le film Mobutu, Roi du Zä̈re 2 Le Maître du Jeu (20': 03' '̀̀ 20':33') in You Tube

${ }^{1390}$ Entretien de NIMY Mayidika, Chef de service de sécurité sous Mobutu, in Mobutu, Roi du Zä̈re 2 Le Maître du Jeu (09': 16' à 09':30', in You Tube
} 
Mobutu pendant la période dite de la $\mathrm{II}^{\mathrm{e}}$ République. Il est nul. Certes, il y en a qui préfèrent ne pas parler: les fanatiques ou les sympathisants. Ou d'autres qui osent parler timidement, dans un cadre restreint ${ }^{1391}$. Ainsi, il est estimé que Mobutu s'est inspiré du Roi Léopold II pour gérer le Zaïre comme sa propriété personnelle à la manière qu'avait fait ce dernier de 1885 à 1908. C'est ici d'ailleurs qu'on situerait même les origines de la crise congolaise ${ }^{1392}$.

Conscient de cette situation, dès le début de la décennie 90, Mobutu manifestera les signes d'ouverture en annonçant une «consultation populaire » où le peuple devrait, cette fois-ci, s'exprimer par rapport à la situation du pays. «Ce périple tourne à l'humiliation pour le président, peu préparé à se voir littéralement injurié par son peuple ${ }^{1393}$. Les mécontentements exprimés par le peuple se sont traduits notamment par le rejet du parti unique MPR, l'exécration des forces de sécurité, la dénonciation de la concentration des pouvoirs, la détresse économique ${ }^{1394}$, etc. Ceci conduit au discours historique du 24 avril 1990, le fameux «Comprenez mon émotion ». Ce discours d'ouverture politique, où le pluralisme politique sera lancé, fait suite non seulement aux pressions internes mais également aux grandes mutations observées sur la scène internationale notamment la fin de la guerre froide avec toutes ses conséquences. Précisons qu' « [e]n raison de la guerre froide, l'Occident l'a soutenu inconditionnellement en dépit de graves atteintes aux droits de l'homme. Lorsque l'Union Soviétique s'est effondrée, Mobutu a perdu sa raison d'être stratégique et a été contraint d'accepter le principe de transition démocratique ${ }^{1395}$ L'occident s'est avéré favorable aux gouvernements respectueux des droits fondamentaux. Les mutations observées sur la scène internationale seront reconnues par Mobutu lui même en ces termes « (...) Face aux grandes mutations qui tourmentent le monde en ce vingtième siècle finissant, j'ai estimé, seul devant ma conscience de tenter de nouveau l'expérience du pluralisme politique dans notre pays avec à la base, le principe de liberté pour chaque citoyen d'adhérer à la formation politique de son choix (...) ${ }^{1396}$. Dès lors, il sera lancé une « transition démocratique » qui verra sa fin avec les élections organisées en 2006 sous Joseph KABILA.

«L'enlisement et l'échec de cette transition, dont l'objectif final est l'avènement de la Troisième République à travers l'instauration de la démocratie et d'un Etat de droit, est sans conteste l'une des principales causes de la prise violente du pouvoir à l'issue de la guerre victorieuse menée par Laurent-Désiré KABILA et ses soutiens extérieurs, d'octobre 1996 à mai $1997 »^{1397}$.

En effet, la transition démocratique entreprise par Mobutu ne serait que de façade. L'intention manifestée par le «Guide éclairé » sera encore loin d'être réelle. Du multipartisme à trois formations politique, il cédera après pressions internes et internationales en faveur du

\footnotetext{
${ }^{1391}$ MUKENDI, Germain et KASONGA, Bruno, op.cit., p. 39.

1392 Lire TREFON, Theodore, Congo, la mascarade de l'aide au développement, , Academia-L'Harmattan, Louvain-La-neuve, 2013, p. 35.

${ }^{1393}$ LANOTTE, Olivier, République Démocratique du Congo, Guerres sans frontières. De Joseph-Désiré Mobutu à Joseph Kabila, op.cit., p. 17.

${ }^{1394}$ Ibid.

1395 TREFON, Theodore, op.cit., p. 35

${ }^{1396}$ Discours de Mobutu du 24 avril 1990 in Mobutu, in Mobutu, Roi du Zaïre 3/3 La fin d'un règne (17': 34' à 18':04'') in You Tube

1397 LANOTTE, Olivier, République Démocratique du Congo, Guerres sans frontières. De Joseph-Désiré Mobutu à Joseph Kabila, op.cit., p. 15.
} 
multipartisme intégral. En «fin politicien», Mobutu utilisera différentes stratégies pour éluder ses promesses et prendre contrôle, d'une manière ou d'une autre des formations politiques en place en les soudoyant, ou en tentant leurs dislocations. D'où l'expression du «multimobutisme» employée par certains en lieu et place du multipartisme ${ }^{1398}$. La Conférence Nationale Souveraine sera tumultueusement organisée, sans considération pour sa part mais toujours dans ses collimateurs. «Mais, en reprenant d'une main ce qu'il avait accordé de l'autre, Mobutu a tout bouleversé. La partie s'est déroulée dans la confusion, il n'y avait plus ni chef ni arbitre ${ }^{1399}$ explique un de ses conseillers en cette matière, Monsieur Nkema Liloo.

La transition démocratique connaîtra sous Mobutu des événements de grandes ampleurs sur 1'histoire socio-politique du pays. Seulement, quelques semaines après le discours du 24 avril 1990, la ville de Lubumbashi vit au rythme des «massacres » des étudiants de l'Université de Lubumbashi. Ce dossier va ternir davantage l'image de la République du Zaïre et de son «Guide éclairé» au point d'être à la base de la rupture de la coopération structurelle avec la Belgique. Pour leur part, « la France gela les relations, les Etats-Unis n'avaient plus besoin de Mobutu ${ }^{1400}$. A la base, entre autre, la récupération politique de l'opposition, dont la déclaration de Monsieur Jean de Dieu NGUZ-A-KARL-I-BOND affirmant l'existence des «massacres» et du «charnier» ayant servi d'ensevelissement des corps d'étudiants tués. Cette déclaration sera d'une grande influence au niveau des instances internationales eu égard à la personnalité que représente cet opposant qui a été une figure de proue de la politique interne et étrangère du Zaïre ${ }^{1401}$. Certains auteurs penchent à l'idée des massacres en avançant des grands chiffres des disparus ${ }^{1402}$. En revanche, au regard des enquêtes et des études scientifiques menées ${ }^{1403}$, cette hypothèse semble à rejeter. En effet, des rapports d'enquêtes nationales - Rapport de la commission de l'Assemblée provinciale du Shaba, Rapport du Parquet général de la République, Rapport de la Commission parlementaire - attestent l'existence d'un seul cas d'étudiant décédé (Ilombe Ilombe) ${ }^{1404}$ voire également d'un autre cas de décès, celui de l'étudiant Mudisi Munasi décédé à la Clinique Ngaliema à Kinshasa ${ }^{1405}$. Pour sa part, le Rapport de la Commission des droits de l'Homme des nations Unies annonce les chiffres de dix à douze cas de décès ${ }^{1406}$. De nombreux cas de disparus sont également épinglés ci et là. Il ressort de ce qui précède qu'il y ait donc eu autre chose que le «massacre » des étudiants de Lubumbashi.

\footnotetext{
${ }^{1398}$ VAN REYBROUCK, David, Congo. Une histoire, éd. Actes Sud, Paris, 2012, p. 427.

${ }^{1399}$ BRAECKMAN, Colette, Le Dinosaure. Le Zaïre de Mobutu, op.cit., p. 347.

${ }^{1400}$ VAN REYBROUCK, David, Congo. Une histoire, op.cit., p. 426.

1401 KOYAGIALO Ngbase Te Gerengbo, Louis Alphonse, Massacre de Lubumbashi (11-12 mai 1990), L'Harmattan, Paris, 2012, p. 76.

${ }^{1402}$ Lire BRAECKMAN, Colette, op.cit., pp. 13-27, principalement la page 23 ; VAN REYBROUCK, David, Congo. Une histoire, op.cit., p. 426.

1403 Contrairement à l'expression «massacre » employée et véhiculée dans l'opinion, dans le Chapitre Premier intitulé «Le rôle social de l'Université de Lubumbashi» de l'ouvrage collectif Université de Lubumbashi 1990-2002. Société en détresse, pari sur l'avenir, le Professeur Donatien Dibwe dia Mwembu titre un des points «les incidents sanglants au campus de Lubumbashi et la division». Il récolte, sous ce titre, différents témoignages concordants qui n'affirment pas l'existence d'un massacre mais confirment le seul cas de décès de l'étudiant Ilombe Ilombe. Lire JEWSIEWICKI, Bogumil, et KLAUBER, Véronique, (éd.), Université de Lubumbashi 1990-2002. Société en détresse, pari sur l'avenir, L'Harmattan, Paris, 2003, pp. 30-36.

${ }^{1404}$ LUNDA BULULU, Vincent de Paul, Conduire la première transition au Congo-Zaïre, L'Harmattan, Paris, 2003, pp. 39-43.

${ }^{1405}$ MUKENDI, Germain et KASONGA, Bruno, op.cit., p. 128.

${ }^{1406}$ LUNDA BULULU, Vincent de Paul, Conduire la première transition au Congo-Zaïre, op.cit., p. 55.
} 
Sous cette transition, les mécontentements des populations, entraîneront différentes manifestations dont les pillages du 23 septembre 1991 et du 28 au 30 janvier 1993 sans oublier celui généralisé dans le pays le 20 décembre 1992. Lesquels mettront par terre l'économie congolaise. D'un autre côté, les revendications politiciennes entrainent des sérieuses répressions de la population de la part du pouvoir. C'est le cas notamment de «massacre » des chrétiens du 16 février 1992 à la suite de la marche pour la réouverture de la Conférence Nationale Souveraine ${ }^{1407}$, de la répression des manifestants du Parti Lumumbiste Unifié (PALU). Le dossier le plus sombre sera celui de l'épuration ethnique observée au Katanga, alors Shaba, où différents ressortissants du Kasaï seront refoulés vers leurs province d'origine (Kasaï occidental et Kasaï oriental) par les katangais. 50.000 morts seront comptabilisés dont les enfants pour la plupart ${ }^{1408}$. Le tout sous la bénédiction du «Guide éclairé ».

La situation des libertés et des droits fondamentaux devenait donc intenable. Les effets des génocides rwandais ressentis dans l'ex-Zaïre seront quant à eux plus déterminants pour le départ de Mobutu.

\section{b.Des causes directement liées à « la première guerre de libération » ${ }^{1409}$}

En effet, en RDC, des multiples tensions ont préparé le terrain à la violence puis aux affrontements militaires en radicalisant chaque fois davantage les positions partisanes ${ }^{1410}$. L'on dénombre ici, des tensions démographiques et foncières croissantes, des tensions ethniques exacerbées et l'internationalisation des tensions politico-ethniques.

En effet, la région des Grands Lacs se distingue tout d'abord par ses fortes densités de population, source d'une pression foncière d'une intensité rare en Afrique. Avec des densités de l'ordre de 225 à 230 habitants par $\mathrm{Km}^{2}$. Ce foyer exceptionnel de peuplement est redevable aux qualités du milieu : climat, d'altitude, sols volcaniques autorisant l'extension parallèle de l'élevage et de l'agriculture ${ }^{1411}$.

Par ailleurs, en rapport avec des tensions ethniques exacerbées, il importe de noter que l'Occident avait appliqué son principe sacro-saint «diviser pour mieux régner ». Ainsi, par exemple au Rwanda seuls les Tutsis avaient accès aux écoles, aux Séminaires, à 1'Administration au détriment des Hutus. Cette pratique non seulement qu'elle a été à la base de la «révolution sociale » de 1959 qui balaya la prééminence politique des Tutsis et mit à bas tout l'édifice sur lequel la Société avait fonctionné. Les empreintes de cette pratique sont décelables jusqu'à ce jour.

\footnotetext{
${ }^{1407}$ Lire VAN REYBROUCK, David, Congo. Une histoire, op.cit., pp. 431- 433.

${ }^{1408}$ MUKENDI, Germain et KASONGA, Bruno, op.cit., p. 130.

1409 Cette partie s'inspire largement des études réalisées par Jean-Claude WILLAME, Olivier LANOTTE, Colette BRAECKMAN et se référent également à d'autres études citées en bas de pages. Pour plus d'approfondissement de la question des conflits armés ou de paix en RDC, il serait souhaitable de lire utilement les auteurs précités et différentes études réalisées dans le cadre du Groupe de Recherche et d'information sur la paix et la Sécurité (GRIP) basé à Bruxelles (www.grip.org)

${ }^{1410}$ POURTIER, Roland, «Conflits en cours et zone de Tension : la guerre des Grands Lacs », in ROUGNOY, Philippe (dir.), Les conflits dans le monde, Cahier français, n²90, Paris 1998, p. 71.

${ }^{1411}$ Ibid.
} 
Les chercheurs soulignent d'ailleurs que des conflits de ce genre, intensément destructeurs trouvent souvent leur origine dans la structure sociale confectionnée et entretenue par le colonisateur et dans le mode de fonctionnement du système politique, emprunté certes à l'Occident mais reconverti en Afrique soit aux affinités des tribus soit aux caprices des ethnies, jamais investi dans le bien-être d'une démocratie réelle ou dans les bienfaits d'une tolérance sincère ou dans les exigences d'une justice sociale égalitaire ${ }^{1412}$.

L'internationalisation des tensions politico-ethniques, pour sa part, se manifeste par le fait que chaque paroxysme d'une crise désormais installée dans la longue durée dans un pays se répercute sur les pays voisins. C'est véritablement le cas du Rwanda vis-à-vis de la RDC.

Entre 800.000 et 1000.000 de Tutsis et de Hutus modérés furent massacrés au Rwanda en 1994. Au moins 1,2 millions de réfugiés se sont déplacés vers les Kivus, dont cent mille Interahamwe (milices hutues du Rwanda et du Burundi) ${ }^{1413}$ en août-septembre 1994. Cette installation sur les frontières d'un million et demi des réfugiés Hutus a achevé de déstabiliser la région.

Les effets de génocide rwandais sont à appréhender préalablement au niveau de la province du Nord-Kivu avec les Banyarwanda ${ }^{1414}$ et au Sud-Kivu avec les Banyamulenge ${ }^{1415}$. Le génocide rwandais et ses effets ne viendront qu'envenimer une situation des crises ethniques préexistant au Nord et au Sud-Kivu.

En effet, des Banyarwanda du Nord-Kivu, il y a ceux qui sont des congolais de souche (Rutshuru et Bwisha) et d'autres qui se sont implantés au Kivu au fil du temps ${ }^{1416}$. Les Banyarwanda du Nord-Kivu sont rejoints par les réfugiés tutsi -estimés entre 50.000 et 60.000 - dès le lendemain immédiat de l'indépendance du Congo à la suite du pogrom de 1959-1960 (cf. supra) au Rwanda dont ceux-ci sont victimes. Majoritaires principalement dans les hautes terres du Nord-Kivu, les représentants des Banyarwanda adhèrent au Centre de regroupement africain (CEREA) qui remporte les élections de 1960 dans les hautes

${ }^{1412}$ HADDAD, Adnan, Pistes de réflexion sur les causes externes et internes de conflits dans la région des Grands-Lacs (Cas de la Guerre de la République Démocratique du Congo), P.U.L. Lubumbashi, septembre $1999,57$.

1413 TREFON, Theodore, op.cit., 36.

1414 Le Banyarwanda désigne la population d'origine rwandaise habitant particulièrement le Kivu. Cette population rwandophone n'est cependant aucunement homogène dans la mesure où ses origines sont multiples. Tandis que certains Banyarwanda du Nord-Kivu sont des congolais de souche (Rutshuru et Bwisha), d'autres communautés Banyarwanda se sont implantées au Kivu au fil du temps. Voy. LANOTTE, Olivier, République Démocratique du Congo, Guerres sans frontières. De Joseph-Désiré Mobutu à Joseph Kabila, op.cit., 27. Pour plus d'approfondissement de cette question, lire utilement WILLAME, Jean-Claude, Banyarwanda et Banyamulenge. Violences ethniques et gestion de l'identitaire au Kivu, L'Harmattan, Paris, 1997.

${ }^{1415}$ Le terme "Banyamulenge », utilisé aujourd'hui pour qualifier les populations d'origine rwandaise du SudKivu méridional pratiquant depuis longtemps des activités de type pastoral, est totalement inconnu pendant la période coloniale. Les cartes ethniques du sud de Bukavu ne font référence qu'à quatre " tribus »: les Babembe, les Bavira, les Bafulero et les Barundi.(...) Littéralement, l'appellation Banyamulenge ne renvoie d'ailleurs pas à un nom ethnique mais bien à "ceux qui sont de Mulenge », une petite bourgade située au sud d'Uvira et qui, selon certaines traditions, aurait été un village important construit par les pasteurs rwandais qui menaient leurs troupeaux vers le plateau de l'Itombwe dans les années 1850. Voy. WILLAME, Jean-Claude, Banyarwanda et Banyamulenge. Violences ethniques et gestion de l'identitaire au Kivu, Paris, L'Harmattan, 1997, p. 78. D'autre part, des recherches admettent que les Banyamulenge se sont installés dans la région d'Uvira au Sud-Kivu à la fin du XVIIIe siècle en provenance du Rwanda d'où ils auraient été exilés à la suite d'une révolution [...]. Voy. LANOTTE, Olivier, République Démocratique du Congo, Guerres sans frontières. De Joseph-Désiré Mobutu à Joseph Kabila, op.cit., p. 32.

1416 LANOTTE, Olivier, République Démocratique du Congo, Guerres sans frontières. De Joseph-Désiré Mobutu à Joseph Kabila, op.cit., p. 27. 
montagnes du Nord-Kivu. Ces élites installées au Congo avant ledit pogrom aspirent à s'installer dans la «territorialité » au niveau national que provincial. La scission de la province du Kivu-Maniema en trois entités provinciales en 1962-1963 menacera cet « opportunisme politique » de Banyarwanda. L'ostracisme à l'égard des Banyarwanda se révélera dans leur refus de souscrire au projet de création d'une province autonome du NordKivu que défendent les autochtones (Bahunde, Batembo et Banyanga). Ce refus au démembrement du Kivu se trouve être justifié par la crainte d'une perte d'influence des élites Banyarwanda sur l'ensemble du pouvoir. Ils craignent d'être exclus à la suite de ce démembrement. Une autre raison tient à la rivalité qui les oppose aux Banande, tous deux tenant au «contrôle des espaces politiques et commerciaux dans la région et au-delà. » N'étant pas sûr de l'alliance qu'ils pouvaient nouer avec des politiciens Banyanga et Bahunde pour faire face à leurs adversaires Banande dans la future province du Nord-Kivu, les Banyarwanda préféraient s'accrocher à Bukavu qui gérait un ensemble ethniquement hétérogène où ils occupaient une place de choix et où leurs adversaires Banande étaient moins présents et moins influents. Toutes ces raisons sont donc de nature stratégique ${ }^{1417}$.

Tout de même, ils plaidaient pour le rattachement de Goma et de Rutshuru, entités où ils sont majoritaires à la province du Kivu-central et exigeaient un référendum pour les territoires de Masisi et Walikale. La nouvelle province du Kivu-Central constituée se dotera d'une Assemblée provinciale dominée par des anciens conseillers provinciaux d'origine rwandaise. L'indétermination politique réservée au sort des territoires de Goma et de Rutshuru à la suite du démembrement laissera libre cours à l'idée d'un «plan diabolique » de création d'un «hutuland» qui regrouperait les territoires de Goma, Rutshuru et Walikale ${ }^{1418}$.

Par ailleurs, pour avoir participé du côté des rebelles «mulélistes» qui occupaient le Maniema et une partie du Sud-Kivu en 1964 et être à la base notamment de différentes violences, les Banyarwanda seront punis d'une mesure d'expulsion décrétée par le pouvoir central en octobre 1965. Des leaders seront transférés à Kinshasa et sévèrement réprimés, soit pour incitation à la désobéissance civile dans une période électorale, soit pour création des milices en vue de sabotage du référendum sur Goma et Rutshuru ${ }^{1419}$. Il va sans dire que la gestion des crises du Nord-Kivu s'inscrira en droite ligne des stratégies politiques du régime de Mobutu et servira d'un grand enjeu. Comme pour les Forces Armées Zaïroises (FAZ) (cf. infra), Mobutu fera la promotion socio-économique et politique de la communauté « rwandophone » du Kivu estimant qu'elle ne représentait pas un danger pour son pouvoir du fait de sa dispersion politique, de sa minorité numérique et de l'ambiguïté de son statut national et politique. C'est ainsi que les Banyarwanda occuperont différentes fonctions au niveau des grandes Entreprises publiques et privées dans différentes provinces du pays et sur le plan politique. Le plus remarquable sera Barthélemy Bisengimana qui sera directeur de cabinet de Mobutu de 1969 pour être déchargé de ses fonctions en 1977 à la suite d'accusations de malversations financières. Celui-ci jouera un rôle essentiel dans la promotion et l'intégration des «rwandais » au Zaïre pour lequel il sera d'ailleurs considéré comme « Parrain ».

\footnotetext{
${ }^{1417}$ WILLAME, Jean-Claude, La guerre du Kivu. Vues de la salle climatisée et de la véranda, Bruxelles, GRIP, pp. 31-33.

1418 Ibid., p. 33.

${ }^{1419}$ Ibid., p. 34.
} 
En effet, la présence massive des Banyarwanda estimée à près de $60 \%$ de la population du Nord-Kivu sera à l'origine de la question de leur nationalité zaïroise ${ }^{1420}$. De «l'initiative » d'un de leurs qui est Directeur du cabinet du Président Mobutu, Barthelemy Bisengimana, une première loi accorde au terme de son article 15 la citoyenneté zaïroise "aux personnes originaires du Ruanda-Urundi qui (étaient) établies dans la province du Kivu avant le $1^{\text {er }}$ janvier 1950 et qui ont continué à résider depuis lors dans la République du Zaïre ». "Cette décision concernait 300.000 personnes qualifiées d' «étrangers» dans les chiffres du recensement de 1970 et qui étaient disséminées surtout dans le Masisi et dans une moindre mesure dans les territoires de Rutshuru, Walikale et Goma ${ }^{1421}$. Les Banyarwanda vont acquérir la nationalité congolaise et bénéficieront des mesures de la Zaïrianisation (cf. supra) dont l'acquisition des entreprises et des terres. Chose qui sera très mal vue par les autochtones qui considèrent cela comme un «envahissement ». L'acquisition de la nationalité zaïroise aux Banyarwanda affirmera davantage leur droit à l'exercice du pouvoir politique notamment dans la région au moyen des élections car ils sont majoritaires. Cependant, cette question de nationalité de la population «rwandaise » demeurera finalement non-résolue. Plus d'une année après le départ du « Parrain » Barthélemy BISENGIMANA, précisément en juin 1978, l'épineuse question de la nationalité des Banyarwanda resurgit sur la table du Conseil législatif. Il faudrait donc remettre en cause leur nationalité zaïroise qui, en conséquence, entrainerait la perte de leurs biens acquis de la zaïrianisation et de leur influence politique. Ce qui pourrait donner raison aux autochtones qui «souffrirait» de cet «envahissement ». En novembre 1981, une nouvelle loi annule la loi de 1972. Le prétexte utilisé ici est que les personnes visées par l'article 15 de la loi de 1972 n'ont jamais été déchues de leur qualité de Rwandais (ou Burundais), ce qui instaure une double nationalité dans un pays où la nationalité est une et exclusive ${ }^{1422}$. Suivant l'article 4 de la nouvelle loi de 1981 est Zaïrois «toute personne dont un des ascendants est ou a été membre d'une des tribus établies sur le territoire du Zaïre dans ses limites $d u 1^{\text {er }}$ août $1885{ }^{1423}$. Cette loi soulève l'épineuse question des tribus pour laquelle les rwandais ne rentrent d'ailleurs pas dans les critères tels que le démontrent des cartes ethniques du Congo. Pour le reste, seule une demande expresse et individuelle de nationalité peut donner droit à la nationalité zaïroise. Il s'agit d'une loi rétroactive perçue comme «injuste, arbitraire et inéquitable » car applicable en réalité aux seuls « infiltrés rwandais » entrés clandestinement et qui ne peuvent prétendre à la nationalité zaïroise $^{1424}$.

De facto, cette question non résolue de la nationalité zaïroise des banyarwanda, autant des banyamulenge au Sud-Kivu (cf. infra), sera à la base des graves tensions ou conflits ethniques entre d'une part les autochtones et les immigrés, et d'autre part les immigrés (Hutu-Tutsi) entre eux. Différentes milices tribales vont donc s'affronter. Ces clivages ethniques ainsi formés sera ressenti même au sein de la société civile notamment les confessions religieuses (Eglise catholique, adventiste, Néo-politique, etc) et les ONG locales ${ }^{1425}$. Ces tensions seront

\footnotetext{
${ }^{1420}$ LANOTTE, Olivier, République Démocratique du Congo, Guerres sans frontières. De Joseph-Désiré Mobutu à Joseph Kabila, op.cit., p. 28.

${ }^{1421}$ WILLAME, Jean-Claude, La guerre du Kivu. Vues de la salle climatisée et de la véranda, op.cit., p. 35.

1422 Ibid., p. 36.

1423 Ibid., p. 37.

1424 LANOTTE, Olivier, République Démocratique du Congo, Guerres sans frontières. De Joseph-Désiré Mobutu à Joseph Kabila, op.cit., p. 29.

${ }^{1425}$ WILLAME, Jean-Claude, La guerre du Kivu. Vues de la salle climatisée et de la véranda, op.cit., 38.
} 
exacerbées par la guerre qui commence en octobre 1990 au Rwanda. Ainsi, les Banyarwanda tutsi - qui rejoindront le Rwanda pour participer à la guerre d'octobre 1990 du côté des Forces Patriotiques Rwandaises - seront pris pour des traitres par les Banyarwanda hutus du Nord-Kivu en coalition avec les autochtones. Ils seront ainsi victimes des violences notamment dans le Masisi et Rutshuru (1991). Pour faire face à la répression de cette coalition, les Banyarwanda tutsi feront intervenir les F.A.Z pour assurer leur sécurité. Les représailles dont feront montre les F.A.Z à l'endroit des autochtones et Banyarwanda hutu seront notamment à la base de la création des factions rebelles ou bandes armées (Bangilima, Maï-Maï du Nord-Kivu) ${ }^{1426}$ hostiles aux Banyarwanda. Lesquelles factions seront d'un rôle déterminant pour les conflits armés qui s'en suivront en RDC. On dirait qu'ils ont pris «le goût de la guerre ».

Par ailleurs, le génocide rwandais se prolonge au Zaïre, les éleveurs Tutsi installés dans le Masisi au Nord-Kivu, doivent faire face, dès 1995, à des expéditions meurtrières lancées à partir des camps de réfugiés Hutus. Ayant fait alliance avec leurs «cousins » Hutus du Kivu et d'autres groupes locaux, des réfugiés Hutus, volent leur bétail et provoquent l'exode vers le Rwanda de dizaines de millions des réfugiés tuts ${ }^{1427}$. Il faut signaler que les réfugiés Hutus qui arrivent au Zaïre traversent avec tous les symboles du pouvoir dont l'armée. Numériquement et matériellement, les Banyarwanda Hutus s'avéraient supérieurs à leurs adversaires tutsis. Dès lors, les réfugiés Hutus vont tenter de réaliser leur vieux rêve de s'emparer de leurs terres et de créer surtout dans le Masisi une sorte de «Hutuland» (cf. supra) où ils se seraient repliés et d'où ils auraient attaqué le Rwanda ${ }^{1428}$. La situation demeure de plus en plus confuse. L'on note, après la médiation personnelle du Président Mobutu qui a séjourné durant un mois dans la région, la reprise de la violence avec des attaques de plus en plus meurtrières en janvier 1996. Et en septembre de la même année, des attaques meurtrières des localités de Bunangama, Tshengerero et Kavangi (Rutshuru) seront attribuées à des jeunes tutsis. «Ces attaques meurtrières, accompagnées de destructions «méchantes et gratuites des biens, des maisons, des infrastructures publiques », sont interprétées «comme le prélude à une offensive généralisée du FPR et de la NRA (armée ougandaise) pour occuper le Kivu» et «constituer (ainsi) l'Empire Hima des Grands Lacs ${ }^{1429}$. Il est donc remarquable que les mêmes visées sont de deux côtés avec des mêmes procédés sur un territoire qui leur sont tous étrangers.

Le plus décisifs pour le départ du régime de Mobutu sera observable avec les Banyamulenges au Sud-Kivu.

Au Sud-Kivu, avec les Banyamulenge, la scène se passe de manière similaire à ce qui a été constaté pour les Banyarwanda au Nord-Kivu. Comme leurs frères Banyarwanda du NordKivu, les Banyamulenge bénéficieront des effets de la loi de 1972 et de la Zaïrianisation de 1973. La découverte en 1994 des potentialités aurifères du massif de l'Itombwe où sont

${ }^{1426}$ LANOTTE, Olivier, République Démocratique du Congo, Guerres sans frontières. De Joseph-Désiré Mobutu à Joseph Kabila, op.cit., p. 30

${ }_{1427}$ BRAECKMAN, Colette, L'enjeu Congolais : l'Afrique Centrale après Mobutu, Paris, Arthème Fayard, 1999, 29.

1428 BRAECKMAN, Colette et Alli, KABILA prend le pouvoir, les prémices d'une chute - La campagne Victorieuse de l'A.F.D.L. Le Congo d'aujourd'hui, édition GRIP, Bruxelles, 1998, p. 70.

${ }^{1429}$ LANOTTE, Olivier, République Démocratique du Congo, Guerres sans frontières. De Joseph-Désiré Mobutu à Joseph Kabila, op.cit., pp. 30-31. 
installés les Banyamulenge fera soulever, de nouveau, la question de leur nationalité de la part des autorités locales et des autochtones. Et l'arrivée massive des réfugiés rwandais fera en sorte que les FAZ soient utilisées pour avoir une main mise sur la production aurifères et les troupeaux de bétail et les immenses pâturages acquis par les Banyamulenges à la suite de la zaïrianisation $^{1430}$. Comme leurs frères Banyarwanda tutsis du Nord-Kivu, les Banyamulenge ont combattu aussi dans les rangs de F.P.R avant que certains ne soient démobilisés et retournés au Sud-Kivu. La mauvaise gestion de cette crise par les autorités zaïroises sera à la base de la rébellion de Banyamulenge.

En septembre 1996, les autorités du Kivu demanderont aux Banyamulenge de retourner au Rwanda. Ceci ne fait que relayer des résolutions adoptées par le Haut Conseil de la République - Parlement de Transition assimilant tous les Banyarwanda à des réfugiés rwandais. Le refus des Banyamulenge d'être dépossédés de leurs terres et autres biens sera à la base des violences - «relativement limitées » en comparaison de celles qui ont touché les Banyarwanda au Nord-Kivu ${ }^{1431}$ - dont ils seront victimes. Il faudrait préciser que ce n'est qu'en apparence que la conflictualité du Sud-Kivu ressemble à celle du Nord. Bien que dans les deux cas il s'agit d'un problème d' «occupation » de l'espace par des «immigrés » mais pour le cas du Sud-Kivu l'espace est beaucoup moins «plein» qu'au Nord-Kivu ${ }^{1432}$. L'ethnicité se trouve ici réinventée dans la mesure où le terme « Banyamulenge » est inconnu dans la nomenclature ethnique du pouvoir colonial bien qu'on relève déjà la présence d'une cette population vers la fin du XVIIIè siècle. Connue sous l'appellation des Banyarwanda (fils du Rwanda) comme ceux du Nord-Kivu, cette population rwandophone du Sud-Kivu, installée sur les haut plateaux de l'Itombwe, cherchera à se démarquer des réfugiés rwandais (tutsi) qui arrivent par le terme «Banyamulenge ». Ce terme apparu en 1967 ne renvoie pas à un nom ethnique mais bien à « ceux qui sont de Mulenge », un petit village de l'Itombwe ${ }^{1433}$. Lors de la rébellion du Kivu-Maniema avec l'Armée Populaire de Libération (A.P.L) de Soumialot et Marandura, les Banyamulenge resteraient en écart. Cependant leurs frères réfugiés tutsi- dans l'espoir d'une reconquête du Rwanda, prendront part à la guerre du côté de l'A.P.L. A la défaite des rebelles, les Banyamulenge feront part du loyalisme au pouvoir central dans le processus de pacification des hauts plateaux en traquant les rebelles recrutés parmi les tribus voisines (Bafulero, Babembe et Bavira). De ce fait, ils seront récompensés par différents avantages notamment «désignation comme autorités locales dans la plaine de Ruzizi et même au Nord-Katanga, obtention des terres, autorisation de percevoir des tributs et des taxes dans divers marchés de l'Itombwe ${ }^{1434} \gg$. Tout ceci sera très mal perçu par les tribus autochtones (Bafulero, Babembe et Bavira) qui avaient pris part à la guerre du côté des rebelles. C'est ici donc le point de départ du conflit entre les autochtones et les allochtones. Face à des expéditions meurtrières lancées à partir des camps de réfugiés hutus dès 1995 et des vols des bétails dont ils sont victimes de la part des réfugiés hutus en connivence avec leurs «cousins» hutus congolais et d'autres groupes locaux au Nord-Kivu notamment, de nombreux réfugiés tutsis sont contraints de retourner au Rwanda (cf. supra). Bien plus, la

\footnotetext{
1430 Ibid., p. 30.

1431 Ibid., p. 30.

${ }^{1432}$ WILLAME, Jean-Claude, La guerre du Kivu. Vues de la salle climatisée et de la véranda, op.cit., p. 40.

${ }^{1433}$ Lire LANOTTE, Olivier, République Démocratique du Congo, Guerres sans frontières. De Joseph-Désiré Mobutu à Joseph Kabila, op.cit., pp. 31-32. ; WILLAME, Jean-Claude, La guerre du Kivu. Vues de la salle climatisée et de la véranda, op.cit., pp. 40-41.

${ }^{1434}$ WILLAME, Jean-Claude, La guerre du Kivu. Vues de la salle climatisée et de la véranda, op.cit., p. 42.
} 
décision prise les autorités du Kivu, en septembre 1996, demandant aux Banyamulenge de retourner au Rwanda sera à la base des vives tensions qui engendreront un mois après, soit en octobre 1996, la première guerre de libération avec Laurent-Désiré KABILA.

En effet, par la suite des événements du Nord et du Sud-Kivu, patiemment tous les Tutsis d'origine Zaïroise arrivés récemment ou non au Rwanda, reçurent un entraînement particulier au sein de l'armée Rwandaise afin de constituer une petite force de 200 ou 300 hommes, une force susceptible d'un jour être renvoyée au Kivu afin de démanteler les camps des réfugiés (hutus) et de forcer la plupart de ces derniers à rentrer au pays ${ }^{1435}$ et être aussi « rétablis » dans leurs droits. Ceci est d'autant plus vrai que la présence massive sur les frontières congolo-Rwandaises des ressortissants rwandais, opposants au pouvoir en place, ne serait qu'une menace susceptible de renverser ce pouvoir dont le Guide est Tutsi. Quoi de plus normal pour ce Guide, relayé de ses adeptes, de chercher des voies et moyens pour sauvegarder son pouvoir, de surcroît instaurer une paix même de force. Rétablir de surcroît les tutsis vivant en RDC dans leurs droits.

Finalement pour canaliser leurs revendications, ces Tutsis formeront différents groupuscules qui rejoindront peu après des partis politiques révolutionnaires congolais qui luttaient aussi de leur manière contre le régime zaïrois. Il s'agit de du Conseil National de Résistance pour la démocratie (CNRD) de KISASE Ngandu, du Mouvement Révolutionnaire pour la Libération du Zaïre (MRLZ) de MASASU Nindanga, de l'Alliance Démocratique des Peuples (ADP) de Déogratias BUGERA et du Parti de la Révolution Populaire (P.R.P.) de Laurent-Désiré KABILA.

Toutes les démarches diplomatiques aboutirent à la conclusion d'un accord dit accord de LEMERA par les partis révolutionnaires ci-haut cités, le 18 octobre 1996. Malgré la conclusion de cet accord qui porte officiellement création de l'A.F.D.L par des révolutionnaires congolais, le Burundi, l'Ouganda, surtout le Rwanda sont à considérés comme les parrains de cette rébellion. L'Alliance bénéficiera sur différents plans de l'appui incommensurable de ces pays dont le Rwanda en particulier. C'est dans cette optique qu'il est remarquable que l'accord de LEMERA prévoyait dès que l'alliance aura gagné la victoire, «une rétribution spéciale » sera allouée aux alliés et la détermination spéciale de cette rétribution est de la compétence de l'instance supérieure de l'Alliance ${ }^{1436}$. En outre, l'accord prévoyait l'attribution collective de la nationalité aux camarades Banyamulenge et aux autres populations d'origine Rwandaise établies au pays avant la date de l'indépendance ${ }^{1437}$.

Hormis les prévisions précitées, l'Alliance se proposait la mission de chasser les réfugiés Hutus afin d'éviter qu'ils menacent la sécurité aux frontières du Rwanda, du Burundi et de l'Ouganda. Pour concrétiser cette mission dernière, les camps où se trouvaient ces réfugiés Hutus ont été bombardés avec une aide humanitaire quasi inexistante, après chutes des différentes villes. Ceci devrait les obliger de prendre la voie ouverte vers le Rwanda, leur laissée par les auteurs desdits bombardements. Ainsi, il s'agira là donc d'un retour forcé au pays natal. C'est dans ce contexte que débute une guerre peu sanglante. Certains réfugiés

\footnotetext{
1435 BRAECKMAN, Colette et Alli, KABILA prend le pouvoir, les prémices d'une chute - La campagne Victorieuse de l'A.F.D.L. Le Congo d'aujourd'hui, op.cit., p. 70.

${ }^{1436}$ Lire l'Article 5 de l'accord de LEMERA (Accord Secret in MUKULUMANYA, Wa Ngate Zenda, La guerre de l'Est enjeux, vérités oubliées et perspectives de paix, édition Zenda, Kinshasa 2000).

${ }^{1437}$ Ibid., lire article 7.
} 
Hutus, par contre, prendront la route de l'Intérieur de la RDC que le Rwanda.

Laurent-Désiré KABILA et ses troupes conquièrent le Zaïre en 7 mois, l'armée zaïroise est inexistante : les officiers et les soldats sans solde depuis longtemps se défendent à peine et l'équipement est insuffisant. Fatiguée et écœurée de la dictature mobutiste, la population accueille les rebelles comme le libérateur et facilite l'avance des troupes de l'A.F.D.L., Kabila se proclame Chef de l'Etat de la RDC le 17 mai $1997^{1438}$.

Il ressort de l'analyse précédente qu'avant l'arrivée au pouvoir de Laurent-Désiré KABILA, la RDC a connu des « conflits armés cycliques ». Il s'agit des conflits armés qui revenaient de manière non régulière en chaque décennie. Les différents rebelles, bien qu'en tête, avec un seul objectif qui est la conquête du pouvoir et son exercice, devraient leurs soutiens à différents parrains. Et ce sans un lien direct étendu dans le temps entre eux. Cependant, il sera remarqué par la suite que depuis 1996, le Rwanda demeurera le «Parrain permanent et incontournable» de différentes guerres à l'Est de la RDC simplement avec changement d'acteurs.

\section{B. De Laurent-Désiré KABILA au M23}

C'est donc la non-tenue parfaitement des obligations résultant de l'accord ci-haut nommé tout au long de l'exercice du pouvoir par Laurent-Désiré Kabila qui occasionnera la seconde guerre dite de Libération. C'est ce que Olivier LANOTTE nomme «L'impératif d'ingratitude de Kabila ${ }^{1439}$. D'ailleurs, la non-application de différents accords signés - généralement dans un climat plein d'hypocrisie et d'une insouciance déroutante - est épinglée comme une des causes profondes de résurgence ou de prolongement des conflits armés en RDC ${ }^{1440}$.

En effet, Laurent-Désiré Kabila s'est distingué par la faculté de se mettre à dos les parrains de la rébellion de l'AFDL. La tension n'a cessé de croître entre Laurent-Désiré Kabila et ses alliés rwandais et Ougandais. Le Rwanda lui reproche son incapacité à mettre de l'ordre dans l'Est du pays d'où les rebelles hutus continuent à attaquer le Nord-Ouest du Rwanda. Ce qui vaut de même pour l'Ouganda qui subit toujours les attaques des rebelles de l'Alliance of Democratic Forces (ADF). En même temps, au plan interne, la présence des rwandais et ougandais au pouvoir de Kinshasa n'enchante pas le peuple Congolais. Ainsi, face aux Rwanda et Ouganda qui paraissaient «encombrants » vis-à-vis de Kabila, celui-ci devrait opérer un choix pour se sentir indépendant dans la gestion de son pouvoir. C'est ainsi que le 27 juillet 1998 Kabila annonce publiquement qu'il met fin à la mission de coopération des militaires Rwandais et qu'il les remercie et les prie de regagner leur pays au plus vite. Dans le même ordre, ironiquement, il remercie également le peuple Congolais d'avoir supporté aussi longtemps cette présence ${ }^{1441}$. Instamment le Mouvement anti Kabila s'est dévoilé en déclenchant un mouvement des «Rebelles » cinq jours après, plus précisément le 2 août

\footnotetext{
${ }^{1438}$ Commission Justice et Paix, op.cit., p. 19

${ }^{1439}$ LANOTTE, Olivier, «La guerre en République Démocratique du Congo (1998-2004) », in REMACLE Eric et ROSOUX (dir.), L'Afrique des Grands Lacs. Des conflits à la paix, Bruxelles, P.I.E PETER LANG S.A, 2007, p. 48.

1440 OLLANDET, Jérôme, La Conférence internationale sur la région des Grands Lacs. Une dynamique nouvelle d'intégration en Afrique, L'Harmattan, Paris, 2014, p. 235.

${ }^{1441}$ HADDAD, Adnan, op.cit.,p. 116.
} 
$1998^{1442}$. Cette décision prise urgemment est due aussi au projet d'un coup d'Etat fomenté par le Colonel Kabarebe, Chef d'Etat major général des Forces armées Congolaises, sujet rwandais, coup d'Etat découvert peu de temps avant par la Présidence de la République comme le note la RDC dans ses conclusions devant la CIJ ${ }^{1443}$.

En dehors de l'itinéraire commun aux deux guerres, la seconde guerre quant à elle avait ouvert sans tarder c'est-à-dire quelques jours après le front ouest (Bas-Congo - Kinshasa). Là, le déroulement a été tout autre. Aussitôt que l'avion civil transporteur d'armement et des « insurgés» atterrissait sur la base militaire de Kitona, la population leur adoptée un comportement réticent dans son ensemble, et ce, malgré le contrôle qu'ils assumaient pour différentes villes bas-congolaises. Des catastrophes étaient à observer de ce front dont le délestage électrique causé par la coupure des fils électriques du Barrage Inga alimentant la majorité de provinces voire d'autres pays étrangers. Arrivés à Kinshasa, les «insurgés » ou rebelles ont été déstabilisés par des Forces Armées Congolaises (FAC) avec l'appui de la population de la ville. Ces dernières seront par la suite appuyées par les forces armées de l'Angola, de la Namibie, du Zimbabwe voire du Tchad ou du Soudan ${ }^{1444}$. Signifions, bien que peu connu, qu'après avoir rompu ses alliances avec le Rwanda et l'Ouganda, la RDC établira de nouvelles alliances avec le Tchad et le Soudan voire divers groupes d'insurgés affirmera l'Ouganda devant la C.I.J ${ }^{1445}$. Ce conflit armé sera d'ailleurs qualifié de la «première guerre mondiale africaine» en raison notamment du nombre impressionnant d'acteurs impliqués. De ce nombre d'acteurs impliqués, il «constitue vraisemblablement la plus grande confrontation militaire actuelle (...), après la guerre menée par l'OTAN en ex - Yougoslavie, particulièrement au Kosovo. Néanmoins, l'ampleur des hostilités n'est nullement comparable ${ }^{1446}$.

Malgré le nouvel itinéraire emprunté par les insurgés et l'implication de la population civile, rien n'a cependant pas mis fin à cette seconde guerre de libération qui a ruiné davantage la société congolaise et son économie. Elle prendra fin «officiellement» avec la signature de 1'Accord Global et Inclusif en fin 2002, lequel accord institue le partage équitable et équilibré du pouvoir.

Par ailleurs, différentes causes justifient la présence de ce conflit armé en RDC.

Pour DIUR Katond, il s'agit « d'une guerre par procuration aux petits pays voisins de l'Est de la République Démocratique du Congo qui avec l'appui logistique et financier font la guerre à la République Démocratique du Congo pour le compte de puissances occidentales. Les raisons fondamentales résident dans la recherche du contrôle du pouvoir de Kinshasa en vue de l'accès libre aux immenses ressources naturelles dont regorge la République Démocratique du Congo en dehors des besoins spécifiques d'espace vital des commissionnaires : Ruanda,

\footnotetext{
1442 Ibid.

1443 CIJ Affaire des Activités armées sur le territoire du Congo (République démocratique du Congo c. Ouganda), arrêt du 9 décembre 2005, Recueil 2005, pp. 191-192, §30.

${ }^{1444}$ Le Tchad est intervenu dans ce conflit armé vers la fin du mois de septembre 1998 et s'est retiré du champ de bataille après sa défaite face à l'armée ougandaise. Le Soudan est aussi cité comme ayant participé soit directement soit indirectement par son appui notamment aux groupes armés anti-ougandais.

${ }^{1445}$ CIJ, Affaire des Activités armées sur le territoire du Congo (République démocratique du Congo c. Ouganda), arrêt du 19 décembre 2005, Recueil 2005, p. 194, §37.

1446 BULA BULA, Sayeman, «L'accord de Syrte du 18 avril 1999 pour le règlement des différends dans les Grands Lacs. Note de lecture », in https://sbulabula.wordpress.com/publications/laccord-de-syrte-du-18-avril$\underline{1999 /}$ (source consultée le 10 mai 2015).
} 
Ouganda et Burundi ${ }^{1447}$. Car qui tient la République Démocratique du Congo tient l'Afrique Centrale et pourquoi pas l'ensemble de l'Afrique .... ${ }^{1448}$ Bien plus, aux dires de NTUMBA Luaba, de la naissance de l'Etat indépendant du Congo (EIC) à la RDC, l'ombre de l'occident ne quitte pas le Congo, tant s'en faut. L'occident, en particulier les puissances berlinoises (Belgique, France, Etats-Unis au $1^{\mathrm{er}}$ rang) l'a toujours accompagné tout au long de son existence, tantôt en douceur par des influences subtiles, tantôt brutalement par la présence ostensible de ses canons $^{1449}$. La RDC a soutenu la thèse de l'exploitation de ses ressources naturelles par l'Ouganda et le Rwanda dans ses conclusions devant la CIJ. Pour la RDC, l'Ouganda et le Rwanda ont occupé des positions privilégiées au plan politique, militaire et économique. C'est donc la rupture unilatérale de ce lien, par le Président Laurent-Désiré Kabila, qui sera à la base de ces conflits armés. A ce sujet, l'on lit dans l'arrêt du 19 décembre 2005 de la CIJ que pour la RDC, «après l'accession du président Kabila au pouvoir, l'Ouganda et le Rwanda se sont vu accordé en RDC d'importants avantages dans les domaines économiques et militaire. Elle (RDC) note que le président Kabila s'est toutefois efforcé, par la suite, de réduire progressivement l'influence de ces deux Etats dans les affaires politiques, militaires et économiques du pays. C'est, au dire de la RDC, "cette nouvelle politique d'indépendance et d'émancipation" à l'égard des deux Etats qui a constitué la véritable cause de l'invasion du territoire congolais par les forces armées ougandaises en août $1998{ }^{1450}$.

Dans cette même optique, MALEMBA M. N'Sakila citant M. Dolive estime que les combats ne cesseront en RDC que si les Ougandais et les Rwandais négocient entre eux une stratégie d'exploitation des richesses économiques propres à chacun d'eux ; car ce qui apparait être une guerre ne serait qu'un conflit de personnalité et d'intérêt que se livrent leurs chefs ${ }^{1451}$. Dans le même sens, le Président français, Nicolas Sarkozy, lors de son adresse au Parlement Congolais réuni en Congrès à Kinshasa suggérait, pour la situation de crise de l'Est de la RDC, de susciter des projets qui fédèrent à l'exemple de la Communauté économique des Pays des Grands lacs (Burundi, RDC et Rwanda). Il faudrait, ajoute t-il, inclure d'autres pays de la région (ex: Ouganda, la Tanzanie, Kenya) et travailler ensemble dans des filières agricoles, commerciales et industrielle sur des bases fiables (transparences et règles) ${ }^{1452}$. Suggestion qui opine la réflexion de KITIMA Kasendwe qui affirme que la crise qui secoue la région des Grands Lacs ne pourra trouver des solutions durables que dans le cadre d'une concertation élargie entre les décideurs de la contrée ${ }^{1453}$. Toutefois, à notre humble avis, il faudrait toutefois ne pas oublier que l'on se retrouve dans le cadre d'un «conflit armé par procuration ». En cela, l'approche réaliste voudrait que l'on débatte directement avec les «puissances instigatrices » de ces guerres ou mieux de les impliquer au débat. Ce sont eux les véritables acteurs de ces conflits que d'aucuns nomment «Acteurs invisibles». Ils sont

\footnotetext{
${ }^{1447}$ DIUR, Katond «Coopération Militaire et paix au sein des pays de la SADC », in SABAKIBU, Kivulu (dir.), Démocratie et Paix en République Démocratique du Congo, P.U.K., Kinshasa 1999, p. 207.

1448 NTUMBA Luaba, «Grandes Puissances et avenir de la République Démocratique du Congo », in SABAKIBU, Kivulu (dir.), op.cit., p. 220.

1449 Ibid.

1450 CIJ, Activités armées sur le territoire du Congo (République démocratique du Congo c. Ouganda), arrêt du 19 décembre 2005, Recueil 2005, p. 191, § 29.

${ }^{1451}$ MALEMBA M. N'Sakila, Identité post-tribale au Congo Kinshasa, édition M.E.S., Kinshasa 2003, p. 113.

${ }^{1452}$ Lire Discours du Président Français Nicolas Sarkozy publié par JMV Ndagijimana in http://www.francerwanda.info/article-29684349.html (Source consultée le 12 octobre 2014).

${ }^{1453}$ KITIMA Kasendwe, « art. cit. », p. 105.
} 
constitués à la fois des Etats (grandes puissances) et des Multinationales profitant de ces conflits armés pour exploiter les ressources nationales congolaises.

En outre, il importe de rappeler que la présence massive de Hutus, opposants au gouvernement Rwandais, tout au long des frontières entre les deux pays (Rwanda - R.D.C) créant ainsi une insécurité permanente est une source incontestable de ces conflits armés.

Ainsi, l'objectif des Tutsis est de participer à la formation d'un nouveau gouvernement en RDC acquis à leurs revendications dont la plus intéressante est la sécurisation de leurs frontières à l'est du pays par la neutralisation pure et simple de leurs ennemis Hutus se trouvant en grand nombre en $\mathrm{RDC}^{1454}$.

Le non-octroi de la nationalité Congolaise aux Banyarwanda en général et aux Banyamulenge en particulier semble également être identifié comme cause de ces conflits armés. A ce titre, KAPETA Nzovu Ilunga note que la RDC a une longue frontière commune avec neuf pays (...). Avec chacun de ces neufs pays, la RDC connaît des cas de compénétration des peuples ou tribus pour des raisons diverses ; mais c'est uniquement vers l'Est, principalement dans l'ex-Kivu que l'on connaît avec acuité cette problématique ${ }^{1455}$. C'est ce qui pousse certains auteurs à croire que la question de nationalité en ce conflit est en fait un pseudo-problème. Il y a une raison occulte. A BOSSEKOTA W'atsia, cependant, d'ajouter que si la RDC a connu un dénombrement dramatique de cette question de nationalité dans l'Est de son territoire notamment avec les Banyamulenge et la première guerre dite de libération c'est pour ne pas avoir su régler ce problème lorsque le Zaïre en était encore fort capable ${ }^{1456}$.

Par ailleurs, les scientifiques avertis retiennent comme cause endogène, l'absence d'un Etat de droit où la démocratie, la bonne gouvernance et le respect des droits de l'homme sont les maîtres mots.

La question de sécurité des frontières Rwandaises, perturbée par les rebelles Hutus rwandais se réfugiant en RDC, demeure l'arbre qui cache la forêt. Le Rwanda ne cesse donc de soulever cette question pour justifier certains de ses actes en RDC. L'exploitation des ressources naturelles congolaises le pousse à justifier également sa présence à travers ses sous-traitants.

En clair, le Rwanda est depuis la «première guerre de libération » à l'ombre de toutes les guerres ou rébellions à l'Est de la RDC. Du RCD au M23 en passant par le CNDP, le Rwanda a eu à utiliser quelques officiers rwando-congolais des forces armées (Jules MUTEBUSI, Laurent NKUNDA, Bosco NTANGANDA, Sultani MAKENGA, etc) pour maintenir sa main sur le pouvoir à Kinshasa.

Le Rwanda maintient une présence permanente en RDC mais avec changement d'acteurs à son service. En dehors de l'exploitation des richesses minières (diamant, or, colombotantalite (coltan), étain, tungstène, etc) de l'Est du Congo, le Rwanda veut désormais assurer une la politique désormais de puissance régionale au moyen de contrôle des pouvoirs notamment à Kinshasa. Pour le reste, le Rwanda a toujours nié sa présence ou son implication à la guerre au

\footnotetext{
${ }^{1454}$ HADDAD, Adnan, op. cit., p. 63.

1455 KAPETA, Nzovu Ilunga, «La question de la nationalité et les perspectives de paix en République Démocratique du Congo », in SABAKIBU, Kivulu (dir.), op.cit., p. 119.

${ }^{1456}$ BOSSEKOTA, W'atsia, Rebâtir le Congo Démocratique : De la bonne gouvernance étatique et du rôle clé de P.M.E. - P.M.I. (Tome I), édition P.U. Bel Campus, Kinshasa 1999, pp. 412 - 413.
} 
Kivu. Même s'il a été montré à la presse des véhicules de combat et autres armements, portant drapeau rwandais, abandonnés par les rebelles de M23 en déroute au début du mois de novembre 2013. Sans le nommer expressément, le CS/NU a reconnu cependant dans ses différentes résolutions dont la résolution 2078 (2012) ces appuis en ces termes : le CS/NU, « [r]enouvelant sa ferme condamnation de tout appui extérieur au M23, notamment la fourniture de renforts de personnels militaires, de conseils tactiques et de matériel, et se disant vivement préoccupé par les informations et les allégations faisant état de la poursuite d'un tel appui au M23, » ${ }^{1457}$.

Il est remarquable que ces conflits armés menés par différents groupes armés finissent par des solutions qui consacrent la culture d'impunité notamment par la protection de ceux-là même qui ont été à la base des graves violations des droits de l'Homme et du DIH. Cette protection est entre autre le fait des pouvoirs en place (Rwanda-RDC). Ceci est le cas de Laurent NKUNDA placé en résidence surveillée au Rwanda sans une procédure judiciaire aussi très claire. C'est aussi le cas de Bosco NTANGANDA, protégé par le pouvoir de Kinshasa au nom de «la préservation de la paix fragile » avant d'être transféré à la CPI. D'autres finissent par occuper des postes de responsabilités en RDC après être amnistiés (cf. le dernier chapitre de cette étude).

Les objectifs poursuivis par ces conflits armés, leurs auteurs intellectuels ou parrains voire les méthodes de guerre demeurent les mêmes. Le Rwanda, par ce fait, continue à contrôler le pouvoir en place de Kinshasa au moyen de « la pénétration » et d'une importante partie de son économie. D'ailleurs, «il ressort que ce «contrôle économique » a abouti (entre 1999 et 2000) à créer une valeur ajoutée pour le Rwanda de l'ordre de 238 millions USD, ce qui équivaut à environ 10 à $12 \%$ du PNB, et à plus de $270 \%$ des dépenses militaires ${ }^{1458}$. Depuis près de deux décennies, la RDC vit dans une situation permanente dont on demande toujours : A quand l'issue?

\footnotetext{
${ }^{1457}$ Résolution 2078 (2012) Adoptée par le CS/NU à sa 6873e séance, le 28 novembre 2012 ( $6^{\text {e }}$ considérant) in http://www.un.org/fr/sc/documents/resolutions/2012.shtml (Source consultée le 09 juillet 2015).
}

${ }^{1458}$ WILLAME, Jean-Claude, La Guerre du Kivu. Vues de la salle climatisée et de la véranda, op.cit., pp. 11-12. 
Carte $^{\circ} \mathbf{4}$ : Principales ressources naturelles finançant les conflits armés en RDC

RDC. Principales ressources naturelles:
source de financement du trafic d'armes entre
trafiquants, bandes armées et milices à l'Est du pays
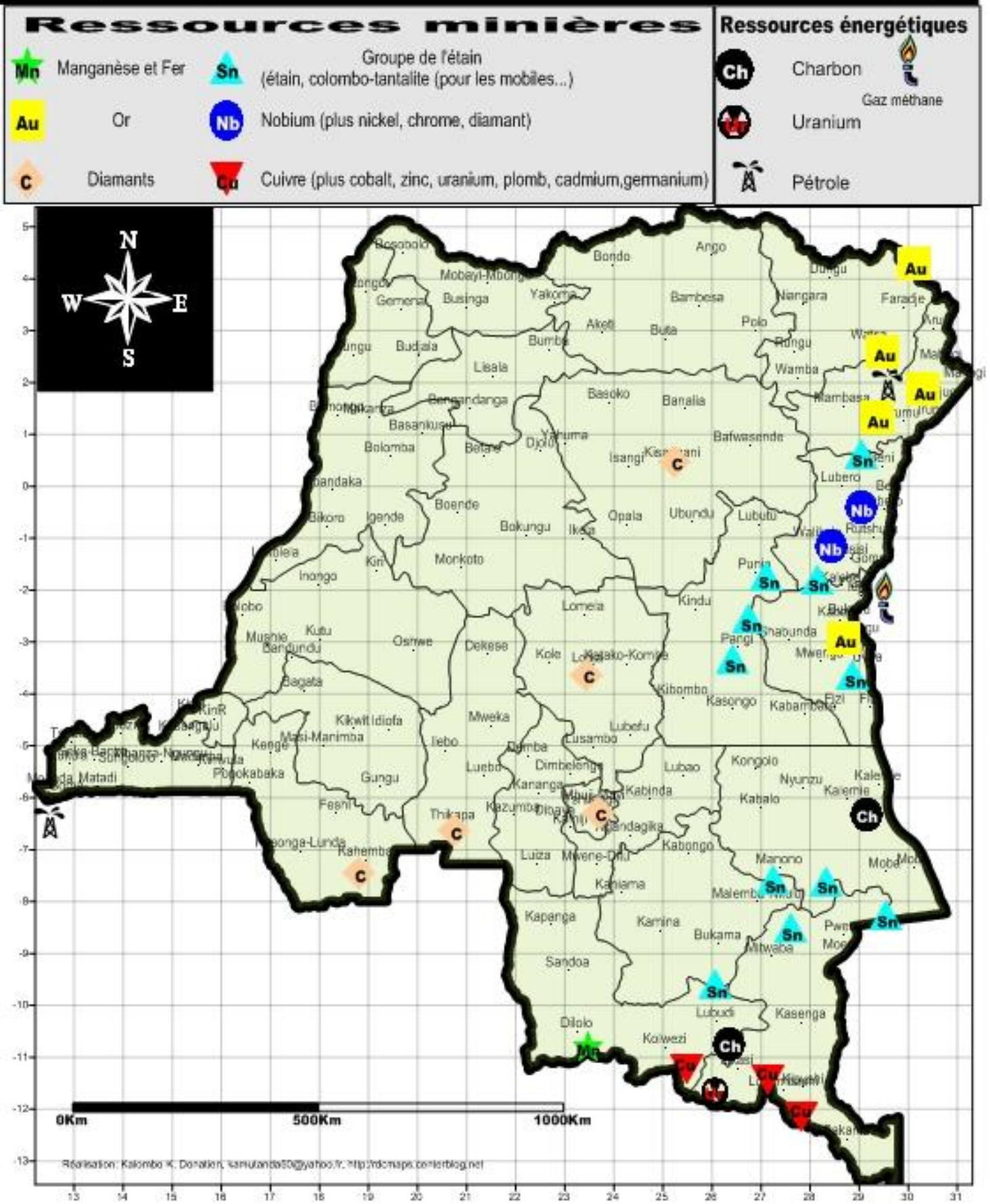

Source: Les Cartes géographiques de la RDC in http://rdcmaps.centerblog.net/ Source consultée le 11 mars 2014). 
Carte $^{\circ} 5$ : La RDC avec les pays impliqués dans les conflits armés sur son territoire de 1998 à 2003.

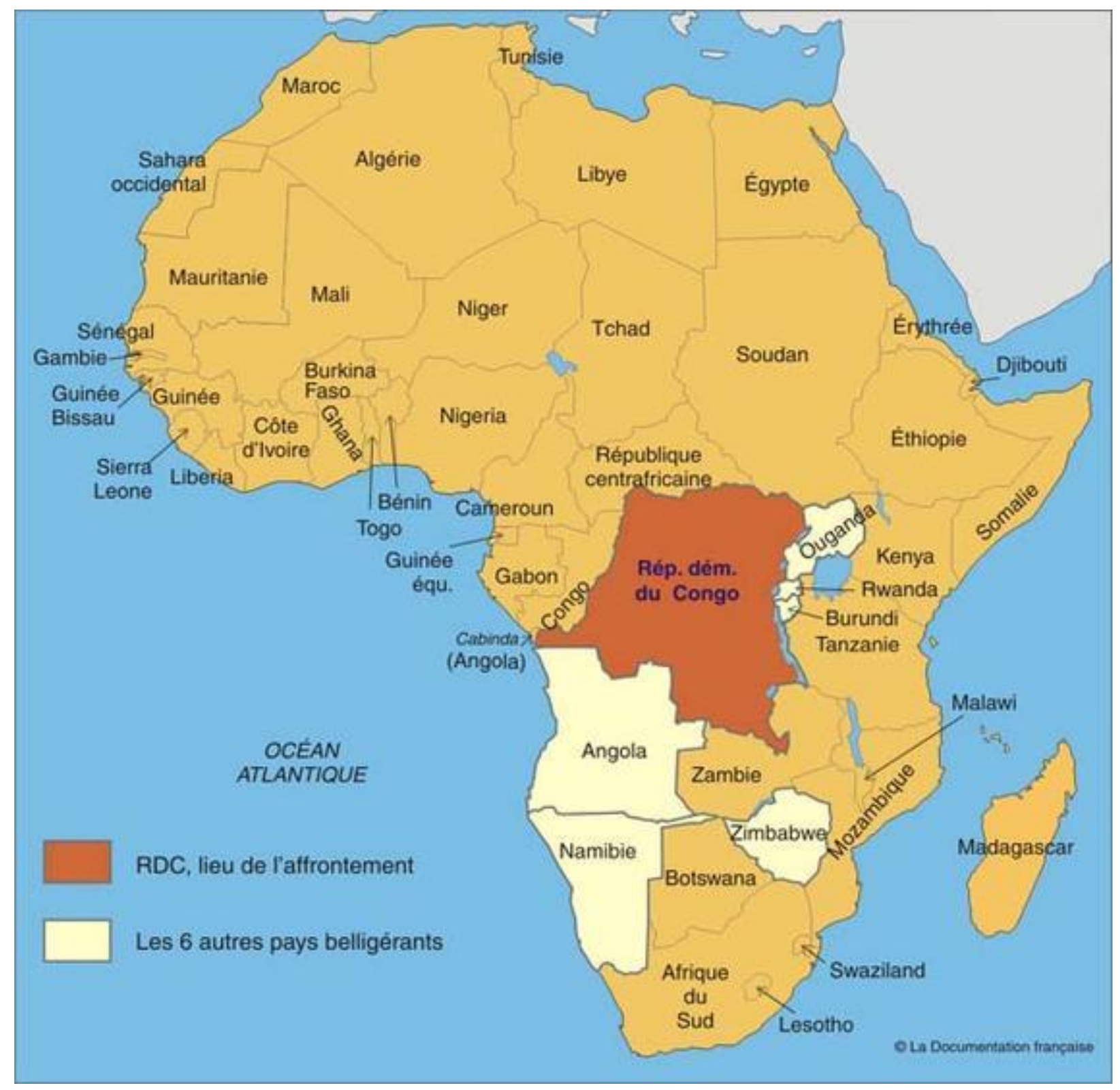

(source: La documentation française in

http://www.ladocumentationfrancaise.fr/dossiers/conflit-grands-lacs/pillage-ressourcesnaturelles-rdc.shtml (Source consultée le 11 mars 2014).

N.B: Le Tchad et le Soudan sont aussi cités parmi les Etats ayant participé au conflit armé en RDC mais généralement ignorés. (cf. CIJ, Affaire des Activités armées sur le territoire du Congo (République démocratique du Congo c. Ouganda), arrêt du 19 décembre 2005, Recueil 2005, 194, §37.)

\section{§3. Le Conseil de sécurité des Nations Unies et les Conflits armés en RDC}

Depuis 1990, crises politiques, guerres civiles, massacres, déplacements massifs de population dans la région des Grands Lacs ont suscité de la part des acteurs internationaux une attention d'une intensité inconnue jusque-là et ont justifié de leur part des engagements 
accrus ou nouveaux ${ }^{1459}$. En dépit de quelques failles décelées ${ }^{1460}$ ci et là, l'ONU à travers son Conseil de Sécurité, en particulier, a dû réagir face à toutes ces situations, question de faire régner un climat de paix et de sécurité. Le cas «République Démocratique du Congo » n'est point donc à exclure.

Rappelons que l'un de principaux objectifs de l'ONU qui est au cœur même de son mandat, est le maintien de la paix et de la sécurité internationales (...). Et au fil des décennies, l'Organisation a contribué à mettre un terme à des nombreux conflits, souvent grâce à l'intervention du CS/NU, principal organe traitant des questions de paix et de sécurité internationales ${ }^{1461}$. Celui-ci a reçu mandat en vertu de 1'article 24 de la Charte, de la part des Etats d'agir en leur nom en ce sens.

A ce titre, sauf exception de l'article 10 de la Charte des Nations Unies ${ }^{1462}$, et précisément de l'article $11 \S 2^{1463}$, le CS/NU demeure le seul organe habilité à constater et à qualifier une situation de menace contre la paix, de rupture de la paix ou d'acte d'agression, et ce malgré l'opinion que peut donner une partie au conflit. Et le plus souvent, sur base des intérêts qui leur sont propres, les parties donnent des qualifications aux conflits qui peuvent ne pas rencontrer l'assentiment du $\mathrm{CS} / \mathrm{NU}$, qui du reste est «indépendant». Lui seul détient les critères d'appréciation. Cependant, tout n'est pas aussi objectif au niveau du CS/NU.

Ainsi, un gouvernement peut qualifier une guerre de simples troubles internes ou tensions

${ }^{1459}$ GUICHAONA A. et Vital C., «Les politiques internationales dans la région des Grands Lacs Africains », in Politiques internationales dans la Région des Grands Lacs, Politiques africains N68, édition Karthala, Paris, décembre 1997, p. 3.

${ }^{1460}$ Il est à remarquer, par exemple, par rapport à la situation de la RDC, comme le note SEGIHOBE BIGIRA Jean-Paul, «la création de la MONUC ne résulte pas d'une inspiration directe du Conseil de Sécurité. Ce dernier a semblé d'ailleurs, pour longtemps, ne pas vouloir envisager cette éventualité, abandonnant par là même sa responsabilité naturelle et principale du maintien de la paix et de la sécurité internationales (article $24 \$ 1$ de la Charte) au système régional et sous régional africain, en l'occurrence à l'Organisation de l'Unité Africaine (OUA) et à la Communauté de Développement de l'Afrique Australe (SADC), auxquelles il a simplement déclaré apporter son appui pour les efforts de médiation régionale, visant à parvenir à un règlement pacifique du conflit ». Voy. SEGIHOBE BIGIRA, Jean-Paul, Le Congo en droit international, Presses Universitaires Ryckmans (PUR), Bruxelles, 2011, p. 234.

${ }^{1461}$ Nations Unies, op.cit., 77.

${ }^{1462}$ L'article 10 de la Charte des Nations Unies dispose que « [1]'Assemblée générale peut discuter de toutes questions ou affaires rentrant dans le cadre de la présente charte ou se rapportant aux pouvoirs et fonctions de l'un quelconque des organes prévus dans la présente Charte, et, sous réserve des dispositions de l'article 12 , formuler sur ces questions ou affaires des recommandations [...]» (nous soulignons). Lire $\S 17$, CIJ, Conséquences juridiques de l'édification d'un mur dans le territoire palestinien occupé, avis consultatif, Recueil 2004 , p. 145.

1463 L'article $11 \S 2$ de la Charte des Nations Unies dispose que « [1]'Assemblée générale peut discuter toutes questions se rattachant au maintien de la paix et de la sécurité internationales, dont elle aura été saisie par l'une quelconque des nations unies [...] et, sous réserve de l'article 12 faire sur toutes questions de ce genre des recommandations [...]» (nous soulignons). Lire $\S 17$, CIJ, Conséquences juridiques de l'édification d'un mur dans le territoire palestinien occupé, avis consultatif, Recueil 2004, p. 145. L'histoire renseigne que l'AG/NU, suite à la paralysie du CS/NU par le véto soviétique, constata la menace contre la paix en Grèce et y envoya une commission d'observation (1948); elle recommanda l'application des mesures coercitives à l'Albanie et à la Bulgarie qui persistaient à méconnaitre ses résolutions (1949). Et dans la guerre de Corée, elle adopta le 3 novembre 1950, la résolution $377(\mathrm{~V})$ intitulée «L'union pour le maintien de la paix ». Lire avec intérêt VAN LANGENHOVE, Fernand, Le Rôle proéminent du Secrétaire général dans l'opération des Nations Unies au Congo, Institut Royal des relations internationales \& Martinus Nijhoff, La Haye, 1964, pp. 13-16. 
internes lorsqu'il se rend compte qu'il contrôle toute la situation, et ce, pour prouver sa capacité ou mieux sa puissance aux autres Etats qui sont prédestinés à le combattre. Dans le même sens, un gouvernement peut donner à une situation directement la qualification de conflits armés non internationaux tout en évoquant un danger pour sa population. Ceci peut lui donner plein droit de faire appel à ses alliés pour légitimer son pouvoir contesté. Cependant, si le doute n'existe nullement pour l'assistance sollicitée d'un Etat victime d'agression armée d'un ou d'autre(s) Etat(s), l'affirmation avancée ci-haut dans le cas d'une guerre civile mérite d'être précisée suivant la doctrine. C'est la problématique de l'intervention sollicitée en cas de guerre civile.

En tant qu'intervention, il s'agit d'un acte manifestement incompatible avec la Charte des Nations unies ${ }^{1464}$. Au sens des résolutions de l'AG/NU, l'interdiction de l'intervention dans les affaires intérieures d'un «Etat» en faveur du gouvernement ou d'une partie de la population est faite sans distinction. Population et gouvernement sont tous des éléments constitutifs de l'Etat. La logique du droit international est celle de ne privilégier aucun de ces éléments. Ainsi, l'Etat tiers qui interviendrait aux côtés du gouvernement contre des insurgés, symbolisant la population, se heurterait donc à un autre Etat, enseigne Eric David. Ce qui vaut de même si l'intervention est faite en faveur des insurgés. Cette analyse n'est pas unanime reconnât-il $^{1465}$. Une telle analyse paraît dévastatrice notamment à l'égard du principe de l'intégrité territoriale de l'Etat. Ainsi, si chaque mouvement ou groupe d'insurgés doit se réveiller un matin pour prétendre représenter l'Etat par conséquent être placé sur un pied d'égalité que le gouvernement légitime vis-à-vis de l'extérieur, la souveraineté et l'intégrité de l'Etat préservées également par la même Charte des Nations unies se trouveraient en mal de fonctionnement. La suite logique des conséquences qui en résulteraient de ces situations porterait à coup sûr atteinte à la paix et sécurité internationales. Ces dernières sont donc dans la plupart de cas liée aux situations internes des Etats.

Pour tout dire, tout dépend du principe à privilégier selon les caractéristiques de la situation : l'intégrité territoriale de l'Etat qui sollicite l'intervention, celle-ci étant alors légitime, ou le principe du droit des peuples à disposer d'eux-mêmes, qui interdit, dans certains cas, aux tiers d'aider le souverain territorial à résister par la force à une tentative d'accession à l'indépendance ou de se débarrasser par la force des opposants au gouvernement en place ${ }^{1466}$.

En effet, pour Patrick Daillier, Mathias Forteau et Alain Pellet «[1] orsque le gouvernement et, a fortiori, une faction politique fait appel à l'aide d'un Etat étranger pour l'emporter dans une guerre civile, l'intervention étrangère se heurte au droit des peuples à disposer d'euxmêmes. Elle doit être tenue pour illicite en dehors des hypothèses de décolonisation (Lutte contre la domination coloniale, l'occupation étrangère ou le régime raciste). Non pas que le droit international consacre le droit à la sécession ou à la rébellion, mais parce que les autres Etats sont tenus par le principe de l'interdiction du recours à la force et celui de non ingérence dans les affaires intérieures ${ }^{1467} »$. Il va sans dire que l'intervention de l'Etat étranger perturberait l'équilibre de force dans le cadre d'une contestation démocratique. La situation sera donc autre dans le cas de l'hypothèse du principe de l'intégrité territoriale qui se

\footnotetext{
${ }^{1464}$ DAILLIER, Patrick, FORTEAU, Mathias et PELLET, Alain, op.cit., p. 1051.

${ }^{1465}$ Lire DAVID, Eric, Principes de droit des conflits armés, $5^{\mathrm{e}}$ édition, op.cit., p. 162.

${ }^{1466}$ DAILLIER, Patrick, FORTEAU, Mathias et PELLET, Alain, op.cit., p. 1051.

${ }^{1467}$ Ibid., pp. 1051-1052.
} 
trouve mobilisé. Ce qui pourrait rendre l'intervention sollicitée valide car l'Etat, étant titulaire de ses compétences, a le droit et devoir de défendre son intégrité territoriale. Ainsi, «rien ne lui interdit de faire appel à des tiers, aussi longtemps qu'il n'aliène pas son indépendance [...] ${ }^{1468}$. Ceci pourrait être entrepris d'ailleurs sans violation du principes de non recours à la force car l'intervention étrangère peut être non militaire.

Par ailleurs, Charles Zorgbibe estime quant à lui que « [1]a licéité d'une intervention sur appel du gouvernement légal attaqué semble aujourd'hui consacré en doctrine et dans la pratique internationale $^{1469}$ ». Quant à la CIJ «Le principe de non-intervention relève du droit international coutumier. Or, il perdrait assurément toute signification réelle comme principe de droit si l'intervention pouvait être justifiée par une simple demande d'assistance formulée par un groupe d'opposants dans un autre Etat (...) On voit mal en effet ce qui resterait du principe de non-intervention en droit international si l'intervention, qui peut déjà être justifiée par la demande d'un gouvernement, devait aussi être admise à la demande de l'opposition à celui-ci. Tout Etat serait ainsi en mesure d'intervenir à tout coup dans les affaires intérieures d'un autre Etat ${ }^{1470}$. Il apparaît dès lors que la CIJ approuve l'intervention sollicitée par le gouvernement en place comme étant licite et condamne en revanche toute intervention sollicitée par des opposants ${ }^{1471}$. Cette position est d'ailleurs affirmée dans l'affaire des activités armées sur le territoire du Congo. La Cour Internationale de Justice a soutenu dans son arrêt « que la République de l'Ouganda, en se livrant à des actions militaires à l'encontre de la République démocratique du Congo sur le territoire de celle-ci, en occupant l'Ituri et en soutenant activement, sur les plans militaires, logistique économique et financier, des forces irrégulières qui opéraient sur le territoire congolais, à violé le principe du non recours à la force dans les relations internationales et le principe de non intervention ${ }^{1472}$.

Enfin, un gouvernement peut qualifier un conflit armé d'agression notamment dans l'hypothèse où ses forces armées sont minimes par rapport à celles de l'ennemi. Voire reporter l'entière responsabilité du conflit sur l'ennemi ${ }^{1473}$. Ou encore, il peut entrer en conflit avec un autre Etat ou intervenir sur le territoire de celui-ci, lorsqu'il estime être en situation de légitime défense. C'est par exemple le cas des frappes françaises en Syrie contre les positions de DAESH du dimanche 27 septembre 2015. L'agression ainsi déclarée pourrait être condamnée - si elle s'est avérée vraie - par la Communauté Internationale et faire bénéficier à ce gouvernement d'aide en équipement militaire voire même d'intervention étrangère ou onusienne pour bouter hors du territoire national concerné l'agresseur. Ainsi la qualification qui au départ est politique peut être approuvée sur le plan juridique.

Par ailleurs, il importe de retenir qu'il n'est pas toujours aisé pour le Conseil de Sécurité de l'ONU de donner l'une des qualifications précitées à une situation belliqueuse. Surtout celle d'agression. En lieu et place des traitements objectifs souhaités, les tendances subjectives ou

\footnotetext{
${ }^{1468}$ DAILLIER, Patrick, FORTEAU, Mathias et PELLET, Alain, op.cit., p. 1051.

1469 ZORGBIBE, Charles, La guerre civile, Paris, P.U.F, p. 105,

${ }^{1470}$ DAILLIER, Patrick, FORTEAU, Mathias et PELLET, Alain, op.cit., p. 1052.

${ }^{1471}$ Ibid.

1472 CIJ, Affaire des Activités armées sur le territoire du congo (République démocratique du Congo c. Ouganda), arrêt du 19 décembre 2005, Recueil 2005, p. 280.

${ }^{1473}$ MORELLI, Anne, Principes élémentaires de propagande de guerre utilisables en cas de guerre froide, chaude ou tiède..., Bruxelles, éd. Labor, 2003, p. 18.
} 
mieux les intérêts politiques des Etats membres permanents dudit Conseil vis-à-vis des parties en cause au conflit ou différend en examen prévalent. "C'est ainsi que pour leurs intérêts nationaux directs (stratégiques, diplomatiques, etc.) ou pour les intérêts croisés des multinationales, les puissances, notamment les membres permanents du Conseil de sécurité, ont pu minimaliser les capacités du Conseil ou le paralyser par leurs rivalités dans la région des Grands Lacs africains (par exemple les rivalités Etats-Unis - Union européenne, EtatsUnis - France, France - Belgique) ${ }^{1474} \gg$. Par ailleurs, l' «agression est lourde de conséquences pour l'auteur de l'acte, et c'est sans doute pour cette raison que les instances habilitées à la constater n'appliquent que rarement cette qualification à des cas de recours à la force armée» $^{1475}$ estime Maurice KAMTO. C'est avec raison que d'aucuns pensent que la qualification des situations internationales et leur objectivité doivent procéder, plutôt que des astuces politiciennes, mais bien d'une démarche juridictionnelle libérée des tendances partisanes mais uniquement mue par les impératifs liés à la paix et à la sécurité internationales $^{1476}$.

Pour bien cerner la qualification que donne le Conseil de Sécurité puis son rôle dans la résolution du conflit en RDC, examinons préalablement les «qualifications » que donnent les belligérants et autres.

En effet, la version de l'ennemi (les insurgés) la plus répandue sur cette guerre est de la qualifier d'une guerre civile c'est-à-dire un conflit Congolo-Congolais marqué par le déclenchement de la rébellion contre le pouvoir de fait du Président Laurent-Désiré KABILA. Lequel ne cherche pas à procéder à une ouverture démocratique, mais tient à perpétuer un régime dictatorial à l'instar de celui de Mobutu (cf. Mouvement de Libération National, Rassemblement Congolais pour la Démocratie $)^{1477}$.

Bien qu'évoluée, quelques fois, par la reconnaissance timide et tardive de leurs troupes en terre congolaise (Situation avant l'accord de Pretoria du 17 décembre 2002), la version des pays ennemis à la RDC continue à être essentiellement fardée sur la thèse de la rébellion congolaise que ces pays ennemis sont appelés à appuyer (sans toutefois reconnaître expressément leur appui), en vue d'imposer au Président Laurent-Désiré KABILA d'accélérer le processus de démocratisation en RDC sinon de le renverser en vue d'imposer un régime favorable à eux ${ }^{1478}$.

Il y a lieu de comprendre, pour un pays comme le Rwanda voire l'Ouganda (cf. infra) que l'argument justificatif de la présence de leurs troupes sur le territoire congolais se base sur la légitime défense. D'ailleurs, c'est l'argument qui a été développé par l'Ouganda devant la CIJ dans les Affaires des activités militaires sur le territoire du Congo. Pour l'Ouganda, la présence de ses troupes sur le territoire du Congo, au-delà du débat sur le consentement de ce

\footnotetext{
${ }^{1474}$ SEGIHOBE BIGIRA, Jean-Paul, op.cit., 235.

${ }_{1475}$ KAMTO, Maurice, L'agression en droit international, Paris, éd. A. Pedone, 2010, p. 91.

1476 Lire KISHIBA Fitula, G., De la "Communauté Internationale» face aux conflits en Afrique Contemporaine. Repères pour l'alternative à la Charte des Nations Unies, Thèse de Doctorat en Droit, Université de Lubumbashi, mars 2005, 487 p. (inédit).

${ }^{1477}$ NDONDOBONI Lubali Esambela, «La redéfinition de la guerre en République Démocratique du Congo », in Economie de guerre, bonne gouvernance et développement en République Démocratique du Congo (Actes des journées scientifiques organisées par la Faculté d'Administration et Sciences Economiques), Revue de la Faculté d'Administration des Affaires et Sciences Economiques de l'Université Protestante au Congo, CEDI, Kinshasa, 1999, p. 50

${ }_{1478}$ NDONDOBONI Lubali Esambela, « art.cit », p. 50.
} 
dernier, trouvait justification sur base de légitime défense afin de traquer les rebelles antiougandais installés sur le territoire de la RDC. Le Rwanda fera de même, mais en dehors de la Cour, via les médias notamment. En réalité, cette thèse semblait s'inscrire dans la fameuse théorie de «légitime défense préventive ${ }^{1479}$. Cette dernière n'est pas à confondre avec la légitime défense individuelle ou collective reconnue par l'article 51 de la Charte de l'ONU dans le cas où un Etat membre des Nations Unies est l'objet d'une agression armée. Ce qui constitue une exception au principe de recours à la force armée.

Dans son sens classique, la légitime défense préventive est entendue comme une notion générique englobant, sans le distinguer, la légitime défense exercée en réaction à une menace d'agression armée imminente et celle visant à prévenir une menace d'agression armée plus éloignée dans le temps. Ce n'est que récemment que ces deux types de légitime défense préventive ont été différenciées ${ }^{1480}$. On parle ainsi de la légitime défense dont l'objectif est de répondre à une (menace d')agression armée (manifestement) imminente ainsi que de celle visant à prévenir de nouvelles attaques/agressions armées (immédiatement) après qu'une agression armée a eu lieu ${ }^{1481}$. D'autres appréhendent restrictivement la notion de légitime défense préventive comme tout simplement une attaque ou mieux une réplique préalable dès lors qu'un Etat se retrouve dans une situation de menace d'agression armée imminente vis-àvis d'un ou (d')autre(s) Etat(s) ${ }^{1482}$.

Ainsi, si l'hypothèse de légitime défense préventive veut l'existence de menace d'agression, en revanche, pour ce qui est de légitime défense, il doit y avoir effectivement agression armée d'un Etat, ou attribuable à celui-ci du fait notamment de son soutien «substantiel»; ou d'agression armée en cours de réalisation. En effet, l'agression est entendue au sens de la Résolution A/Res/3314 (XXIX) du 14 décembre 1974 de l'AG/NU, comme «l'emploi de la force armée par un Etat contre la souveraineté, l'intégrité territoriale ou l'indépendance politique d'un autre Etat, ou de toute autre manière incompatible avec la charte des Nations Unies, (...) ${ }^{1483}$. Cette définition, servant de guide, est admise par la Cour internationale de justice sans contradiction des Etats parties aux litiges faisant son application, voire dans le

\footnotetext{
${ }^{1479}$ Pour plus d'approfondissement de cette notion lire avec intérêt VAN STEENBERGHE, Raphaël, La légitime défense en Droit international public, Bruxelles, Larcier, pp.358 et ss.

${ }^{1480}$ Ibid., p. 358.

1481 Ibid., p.400. «Les Américains font couramment la distinction entre les attaques préemptives et préventives, une différence qui va au-delà des arguties. Une attaque préemptive est menée contre un ennemi sur le point d'attaquer; une attaque préventive est fondée uniquement sur la possibilité que l'ennemi attaque sous peu. La préemption en tant que moyen de défense peut être jugée tout à fait légitime si le danger est imminent, mais il est généralement difficile de justifier une guerre préventive où l'on déploie des ressources militaires pour faire valoir les intérêts de son pays. En pratique, cependant, cette distinction n'est guère pertinente. D'une part, ces définitions sont contestées. De fait, en Europe, certains spécialistes du droit international donnent à ces termes le sens inverse. D'autre part, il serait pratiquement impossible de classer dans l'une de ces catégories des dangers ou des scénarios concrets et spécifiques qui, de toute façon, se prêtent à une certaine interprétation. Le pays usant de la force prétendra toujours qu'il s'agit d'une mesure préemptive, tandis que ceux qui s'opposent à cette mesure la jugeront préventive ou tout simplement agressive»., KARL-HEINZ, Kamp, « La défense préemptive : une nouvelle réalité politique », disponible sur http://www.journal.forces.gc.ca/vo6/no2/viewsvues-fra.asp (Source consultée le 12 mars 2013).

1482 VAN ASSCHE Cédric, «Légitime défense préventive. Légal? » in http://www.lalibre.be/debats/opinions/legitime-defense-preventive-legal-51b87ccbe4b0de6db9a84794 (Source consultée le 12 mars 2013).

1483 http://www.un.org/french/documents/view_doc.asp?symbol=A/RES/3314(XXIX)\&Lang=F (Source consultée le 23 août 2014).
} 
domaine conventionnel, mais elle n'est pas suivie dans la pratique du CS/NU ${ }^{1484}$.

Ainsi, l'hypothèse d'agression armée exclut dorénavant celle d'agression économique ou idéologique, même lorsque l'expression «agression» est employée sans qualificatif ${ }^{1485}$. Toutefois, l'action armée dont est question doit atteindre certaine «gravité » pour être qualifiée d'agression armée afin de bénéficier du droit de légitime défense. Cette gravité est appréciée avec certaine souplesse. Ce qui revient à dire que toute violation de l'article $2 \S 4$ ne donne pas nécessairement lieu à la qualification d'agression donnant ainsi lieu au droit de légitime défense ${ }^{1486}$ (cf. infra).

De ce qui précède, il y a lieu de considérer avec Maurice KAMTO que l'agression « ne peut se déduire simplement de l'intention ou du comportement de son auteur présumé. C'est lorsqu'elle est avérée, qu'elle justifie la légitime défense. Dans cet ordre d'idées, une guerre préventive ne serait pas de la légitime défense ; l'opinion dominante tend à la considérer au contraire comme acte d'agression ${ }^{1487} »$.

Par ailleurs, la légitime défense préventive est soutenue au premier plan par les Etats-Unis d'Amérique dans le cadre de la « doctrine Bush » (d'action préventive ou guerre préventive) consistant à un droit de recourir à la force contre tout Etat ou groupement terroriste qui représenterait une menace pour la sécurité américaine (dans un avenir plus ou moins proche $)^{1488}$, doctrine défendue aussi par l'Australie qui a ainsi affirmé son droit de frapper préventivement des terroristes sur le sol des Etats voisins; de même que le Japon qui a menacé de frapper préventivement la Corée du Nord en février $2003^{1489}$; etc. Cette théorie demeure discutable en droit international d'autant plus que la jurisprudence internationale et la doctrine ne réservent pas des réponses clairement tranchées et unanimes au sujet de sa légalité ${ }^{1490}$. Cette discussion continue même au sein de la communauté internationale au sujet de la pratique des Etats de la légitime défense préventive ${ }^{1491}$. Toutefois, comme le dit si bien Maurice KAMTO, l'opinion dominante tend à la considérer au contraire comme acte d'agression ${ }^{1492}$.

Au regard de cette brève présentation, pour le gouvernement Rwandais, dirigé par un Tutsi, le fait que les Hutus demeurent sur le sol Congolais, en dépit de la chasse entreprise lors de «la première guerre de libération », est un grand danger. Ceux-ci se prépareraient quotidiennement à une éventuelle attaque contre le pouvoir en place au Rwanda (cf. supra).

\footnotetext{
${ }^{1484}$ Lire CORTEN, Olivier, Le droit contre la guerre, $2^{\mathrm{e} e ́ d i t i o n s, ~ e ́ d . ~ A . ~ P e d o n e, ~ P a r i s, ~ 2014, ~ p p . ~ 660-661 . ~}$

1485 Lire KAMTO, Maurice, L'agression en droit international, op.cit., p. 103 et CORTEN, Olivier, Le droit contre la guerre, $2^{\mathrm{e}}$ éditions, op.cit., p. 657.

${ }^{1486}$ CORTEN, Olivier, Le droit contre la guerre, $2^{\mathrm{e}}$ éditions, op.cit., pp. 657- 658.

${ }^{1487}$ KAMTO, Maurice, L'agression en droit international, op.cit., p. 92.

${ }^{1488}$ CHRISTAKIS, Théodore, «Vers une reconnaissance de la notion de guerre préventive », in BANNELIER, Karine, et al. (dir ), L'intervention en Irak et le droit international, Paris, Pedone, 2004, p. 9.

${ }_{1489}$ Ibid., p. 12.

1490 VAN ASSCHE Cédric, «Légitime défense préventive. Légal? », in http://www.lalibre.be/debats/opinions/legitime-defense-preventive-legal-51b87ccbe4b0de6db9a84794 (Source consultée le 12 mars 2013); lire BES, Clélie, «Le Droit international reconnaît-il le concept de Guerre préventive ? », in KHERAD, Rahim, Les Implications de la guerre en Irak, Colloque international, mercredi 12 mai et Jeudi 13 mai 2004, Faculté de droit, d'économie et de gestion de l'Université d'Angers, Paris, Pedone, 2004, pp. 108-110.

${ }^{1491}$ Lire VAN STEENBERGHE, Raphaël, La légitime défense en Droit international public, op.cit., pp. 363 et ss.

${ }_{1492}$ KAMTO, Maurice, L'agression en droit international, op.cit., p. 92.
} 
D'où une « contre attaque » préventive de la part de ce dernier.

Pour sa part, le gouvernement Congolais n'a cessé de démontrer et de défendre la thèse d'agression par la coalition Burundo - Ougando - Rwandaise. Le discours du Chef de l'Etat, Laurent-Désiré Kabila, qualifiant cette situation d'agression, était repris avant chaque édition du journal télévisé à la Radio Télévision Nationale Congolaise (RTNC). Par ailleurs, 1' "agression » dont est l'objet la RDC est fortement soulignée sur différentes lignes du «Livre Blanc sur les violations délibérées de l'accord de cessez-le-feu de Lusaka du 10 juillet 1999, de la Charte internationale des droits de l'Homme, des règles de base du Droit International Humanitaire ainsi que des résolutions pertinentes du Conseil de Sécurité de l'ONU par les "pays agresseurs »(Ouganda, Rwanda, Burundi) et leurs complices congolais du R.C.D. et du M.L.C. dans les territoires occupés de la République Démocratique du Congo » publié par le Ministère des Droits Humains de la RDC voire par différentes déclarations politiques des hautes instances du pays ou acteurs politiques du pays relayées par la presse locale et étrangère. Cette thèse $d$ ' " agression armée » sera plus tard défendue devant la CIJ en dépit de la qualification retenue bien avant (cf. infra) par le Conseil de Sécurité de l'ONU. Ainsi, devant la CIJ, dans son premier chef de conclusion, la RDC prie la Cour de dire et juger: "Que la République de l'Ouganda, en se livrant à des actions militaires et paramilitaires à l'encontre de la République démocratique du Congo, en occupant son territoire, en soutenant activement, sur les plans militaire, logistique, économique et financier des forces irrégulières, qui y opéraient, a violé les principes conventionnels et coutumiers suivants : - le principe de non recours à la force dans les relations internationales y compris l'interdiction d'agression [...] ${ }^{1493}$. A la CIJ de conclure qu'à partir du 7 août 1998, l'Ouganda avait recouru à l'emploi de la force sans aucun consentement de la part de la RDC et que les événements dont a fait état l'Ouganda ne justifiaient pas l'emploi de la force au titre de légitime défense. De son avis, il s'agit là de violations graves du paragraphe 4 de l'article 2 de la Charte des Nations Unies ${ }^{1494}$. La Cour conclut en conséquence que l'Ouganda a violé la souveraineté ainsi que l'intégrité territoriale de la RDC. Les actes de l'Ouganda constituent également une ingérence dans les affaires intérieures de la RDC et dans la guerre civile qui y faisait rage ${ }^{1495}$. Rien n'est dit donc expressément que l'intervention de l'armée ougandaise était une agression. «En refusant de qualifier «d'agression» le recours à la force par l'Ouganda en RDC, elle (CIJ) se fonde sur des résolutions du Conseil de sécurité qui disposaient que la présence de troupes étrangères en RDC constituait une «violation de la souveraineté et de l'intégrité territoriale ${ }^{1496}{ }$ (cf. infra). Pour Abdelwahab BIAD, la Cour a manqué ainsi l'occasion d'enrichir le droit international sur la question d'agression. Droit qui se trouve inachevé sur ce point faute d'une définition consensuelle d'agression permettant notamment à la CPI de poursuivre le crime d'agression ${ }^{1497}$.

Tout de même, Maurice KAMTO estime que l'invocation de la violation de l'article 2

1493 CIJ, Affaire des Activités armées sur le territoire du Congo (République démocratique du Congo c. Burundi; République démocratique du Congo c. Ouganda; République démocratique du Congo c. RwandaArrêt du 19 décembre 2005- R.D. Congo c. Ouganda, in EISEMANN, Pierre Michel et PAZARTZIS, Photini (dir.), La jurisprudence de la Cour internationale de justice, Paris, éd. A. Pedone, p. 643.

1494 Ibid., p. 648.

1495 Ibid.

${ }^{1496}$ BIAD, Abdelwahab, « Affaire des activités armées sur le territoire du Congo, République démocratique du Congo c. Ouganda (Arrêt du 19 décembre 2005) », in Bulletin du CREDHO n 16 -décembre 2006, p. 116. 1497 Ibid. 
paragraphe 4 de la Charte pourrait donner à penser que tout emploi de la force armée par un Etat contre un autre Etat, constitue un acte d'agression au sens du droit international. Or il n'en est rien ${ }^{1498}$. Il s'agit d'une disposition de portée générale, ou de caractère principiel visant toute menace ou tout emploi de la force quels qu'ils soient, incluant donc aussi bien les simples incursions armées transfrontalières que ce que la Charte appelle « rupture de la paix » et «agression ${ }^{1499}$.

D'autres chercheurs ont également soutenu cette thèse d'agression de la RDC. Ainsi, par exemple, BULA Bula Sayeman qualifie ce conflit d' « une guerre d'agression par procuration exécutée à la faveur du désordre international maintes fois décrié. Le badigeonnage par une vraie fausse rébellion ne réussit guère à maquiller la réalité : deux armées étrangères en l'espèce Ruandaise et Ougandaise bourlinguent depuis des semaines sur le territoire de la République Démocratique du Congo, campant ici pour s'accaparer des minerais précieux, bivouaquant là-bas pour massacrer des populations sans défense, et cela au vu et au su de tous, y compris de $1^{\prime} \mathrm{ONU}{ }^{1500} »$. Pour sa part, le Juge Simma affirmera que de toutes les affaires que la Cour a eu à connaître (Détroit de Corfou, Activités militaires et paramilitaires au Nicaragua et contre celui-ci ou Plates-formes pétrolières), si une seule devait être qualifiée d'acte d'agression, ce serait l'invasion de la RDC par l'Ouganda ${ }^{1501}$. C'est la position soutenue antérieurement par le CS/NU qui sera ici suivie ${ }^{1502}$.

Ainsi, pour le CS/NU avec sa plus célèbre résolution 1234 adoptée à sa $3993^{\mathrm{e}}$ séance le 9 avril 1999, et après de longues tergiversations, le conflit en RDC constitue «une menace pour la paix, la sécurité et la stabilité dans la région. ${ }^{1503}$ " Tout de même, sans reconnaître expressément l'agression dont fait l'objet la RDC, au point 2 de la même résolution, le Conseil de Sécurité «déplore que les combats se poursuivent et que des forces d'Etats étrangers demeurent en République Démocratique du Congo dans des conditions incompatibles avec les principes de la Charte des Nations Unies et demande à ces Etats de mettre fin à la présence de ces forces non invitées et de prendre immédiatement des mesures à cet effet ${ }^{1504} »$. Au paragraphe premier de la résolution précitée, le Conseil « [r]éaffirme que tous les Etats ont l'obligation de respecter l'intégrité territoriale, l'indépendance politique et la souveraineté nationale de la République démocratique du Congo et des autres Etats de la région $[\ldots] »^{1505}$. En réaffirmant l'obligation de respecter l'intégrité territoriale et la souveraineté congolaise, le Conseil de sécurité reconnaissait implicitement la violation de

\footnotetext{
${ }^{1498}$ KAMTO, Maurice, L'agression en droit international, op.cit., p. 92.

1499 Ibid.

1500 BULA BULA, Sayeman, cité par Ministère des Droits Humains, Livre blanc sur les violations délibérées de l'accord de cessez-le-feu de Lusaka du 10 juillet 1999, de la Charte Internationale des Droits de l'Homme, des règles de base du Droit International Humanitaire ainsi que des résolutions pertinentes du Conseil de Sécurité de l'ONU par les Agresseurs (Ouganda, Burundi, Ruanda) et leurs complices Congolais du RCD et du MLC dans les territoires occupés de la R.D.C. couvrant la période du 11 juillet 1999 au 31 décembre 1999, 5 ans, édition Kinshasa juin 2000.

${ }^{1501}$ BIAD, Abdelwahab, «Affaire des activités armées sur le territoire du Congo, République démocratique du Congo c. Ouganda (Arrêt du 19 décembre 2005) », « art.cit. », p.116.

1502 Ibid.

${ }^{1503}$ Voy. Résolution S/RES/1234 du 9 avril 1999 in MONUC, Résolutions adoptées par le Conseil de Sécurité 9 avril 1999 - 1 octobre 2004, Kinshasa Division de l'information de la MONUC, 2004, 7.

1504 §2 Résolution S/RES/12334 du 9 avril 1999.

1505 \$1 Résolution S/RES/12334 du 9 avril 1999
} 
cette obligation (qui en était rien autre que par l'agression de la RDC) ${ }^{1506}$.

Ainsi, après avoir reconnu timidement l'agression en RDC et qualifié expressément la situation de menace pour la paix, la sécurité et la stabilité de la région, le CS/NU a pu mettre en place des mécanismes devant faire face à cette situation.

En effet, le CS/NU par la résolution susmentionnée a demandé la signature immédiate d'un accord de cessez-le-feu permettant le retrait ordonné de toutes les forces étrangères, le rétablissement de l'autorité de l'Etat congolais sur tout son territoire et le désarmement des groupes armés non-gouvernementaux. Il souligne que dans le contexte d'un règlement pacifique durable, il est nécessaire que tous les congolais s'engagent dans un dialogue politique ouvert à tous, tendant à la réconciliation nationale et à la tenue à une date rapprochée d'élections démocratiques, libres et équitables. L'adoption des mesures pertinentes de sécurité le long des frontières de la République Démocratique du Congo a été recommandée. En Institution protectrice des droits de l'Homme et de mise en œuvre du DIH, le CS/NU a demandé à toutes les parties au conflit de défendre des droits de l'Homme et de respecter le DIH, en particulier, les dispositions des CG de 1949 et des PA de 1977 et de la Convention sur la prévention et la répression du crime de génocide de 1948 qui leur sont applicables ${ }^{1507}$.

Le vœu de cette résolution sera accueilli par les parties au conflit qui signeront à Lusaka le 10 juillet 1999 un accord de cessez-le-feu qui était en même temps un accord de paix dans la mesure où il planifie le retour définitif de la paix en RDC.

Ainsi, dans le but d'aider la Commission militaire mixte établie par l'Accord de Lusaka, ainsi que les Etats parties à œuvrer pour l'effectivité dudit accord, le CS/NU, par la résolution 1258 du 6 août 1999 de la $4032^{\mathrm{e}}$ séance, autorisait le déploiement de 90 membres du personnel militaire de liaison des Nations Unies au maximum ainsi que du personnel civil, politique, humanitaire et administratif voulu, dans les capitales des Etats signataires dudit accord de cessez-le-feu et au quartier général provisoire de la Commission militaire mixte, et dans les quartiers généraux militaires des principaux belligérants au cas où les conditions sécuritaires les permettaient ${ }^{1508}$. Par la résolution 1279 du 30 novembre 1999 du même Conseil, le Personnel ci-haut énuméré deviendra la Mission de l'Organisation des Nations Unies en République Démocratique du Congo (MONUC) jusqu'au $1^{\text {er }} \operatorname{mars} 2000^{1509}$. Celle-ci s'occupera essentiellement de la mise en œuvre de l'Accord de Lusaka ${ }^{1510}$. Son mandat sera cependant évolutif sur le plan matériel tout comme sur le plan temporel jusqu'à devenir Mission de l'Organisation des Nations Unies pour la Stabilisation en République Démocratique du Congo, MONUSCO en sigle, par la résolution 1925 du Conseil de sécurité du 28 mai 2010. Avant de se voir prolonger par la suite, son mandat couvrira la période du $1^{\mathrm{er}}$

\footnotetext{
${ }^{1506}$ SEGIHOBE BIGIRA, Jean-Paul, op.cit., p. 236.

${ }^{1507}$ Voy. $\$ \S 4$ et 6 de la Résolution S/RES/1234 (1999) adoptée par le CS/NU à sa 3993 e séance, le 9 avril 1999 in http://www.un.org/fr/documents/view_doc.asp?symbol=S/RES/1234(1999) (Source consultée le 14 février 2016).

${ }^{1508} \S 8$ de la Résolution S/RES/1258 (1999) adoptée par le CS/NU à sa $4032^{\mathrm{e}}$ séance, le 06 août 1999, in http://www.un.org/fr/documents/view_doc.asp?symbol=S/RES/1258(1999) (Source consultée le 14 février 2016).

${ }_{1509}$ Voy. § 4 de la Résolution S/RES/1279 (1999) adoptée par le CS/NU à sa $4076^{\mathrm{e}}$ séance, le 30 novembre 1999

http://www.un.org/fr/documents/view_doc.asp?symbol=S/RES/1279(1999)\&TYPE=\&referer=http://www.un.or $\mathrm{g} / \mathrm{fr} / \mathrm{sc} /$ documents/resolutions/1999.shtml\&Lang=F (Source consultée le 14 février 2016).

${ }^{1510}$ Voy. Ibid., § 5.
} 
juillet 2010 au 30 juin 2011.

De tout ce qui précède, l'ONU, en général et le Conseil de Sécurité en particulier, à travers la MONUSCO, demeure un organe pivot au processus de paix en RDC qu'il convient présentement d'examiner.

\section{§4. Aperçu du processus de paix en République Démocratique du Congo}

La paix et la sécurité sont des questions autour desquelles depuis les siècles des sociétaires se mobilisent pour leur quête existentielle étant donné qu'elles constituent la condition requise pour le développement intégral de l'homme. Elles sont par ailleurs l'objet de plusieurs instruments juridiques ${ }^{1511}$.

Les Etats prennent soin de les garantir car leurs réalisations permettent les relations pacifiques ou amicales. A défaut, ce sont des rapports belliqueux qui sont quelque peu institués ; les foyers de tension menacent et rompent la paix dans le monde en général et dans les différentes sous-régions en particulier ${ }^{1512}$. Et même dans ces situations de menace ou de rupture de la paix, différents mécanismes sont souvent envisagés et déployés pour ramener la paix. Aucun Etat n'envisage être dans un rapport belliqueux permanent avec son semblable. Quel que soit le prix, la paix demeure une finalité.

En RDC, afin de tenter de contenir le conflit armé qui a ravagé manifestement sa population et son territoire, différents efforts de paix ont été fournis et les sont actuellement à l'heure de la consolidation.

En effet, la volonté de dialoguer se manifeste à travers les accords de Lusaka (Zambie), de Syrte (Libye), les rencontres de Luanda (Angola), Dar Es-Salam (Tanzanie), Pretoria (Afrique du Sud), Maputo (Mozambique), Windhoek (Namibie), Harare (Zimbabwe), le Caire (Egypte), Khartoum (Soudan), Libreville (Gabon), etc ${ }^{1513}$.

Et pourtant comme le note MUKULUMANYA dans son ouvrage paru en 2000, ni le processus de paix initié dans le cadre de SADC par les sommets de Pretoria, Durban, Victoria Falls, Grand Baie et soutenu par la Communauté Internationale à partir du $20^{\mathrm{e}}$ sommet francoafricain, tenu à Paris au mois de novembre 1998, qui avait choisi Lusaka (Zambie) comme cadre approprié pour toutes les rencontres visant la mise en route des modalités d'un cessezle-feu en RDC, ni la résolution 1234 du Conseil de Sécurité des Nations Unies qui, timidement, reconnait sans la condamner l'agression dont la RDC est victime de la part de ses voisins incriminés en l'occurrence la République du Rwanda et la République de l'Ouganda, ni l'accord de Syrte instituant le cessez-le-feu conclu le 18 avril 1999, entre le Président Youweri MUSEVENI de l'Ouganda et le Président Laurent Désiré KABILA sous la médiation du Président Libyen Moammar El Kadhafi ${ }^{1514}$, ni encore moins le cessez-le-feu unilatéral décrété le vendredi 28 mai 1999 par la République du Rwanda, aucune initiative n'a

\footnotetext{
${ }^{1511}$ KITIMA, Kasendwe, «Les mécanismes de promotion, de maintien et de consolidation de la paix et de la sécurité collective en Afrique subsaharienne », in Les mélanges de la pléiade congolaise, Vol 1, Kinshasa, édition Pléiade Congolaise, 2005, p.182.

${ }^{1512}$ Ibid.

${ }^{1513}$ KITIMA, Kasendwe, « Les relations Internationales post-conflits : cas de la R.D.C. », in Les Mélanges de la pléiade congolaise ? Vol I, Kinshasa, édition de la Pléiade Congolaise, 2005, pp. 72 - 73.

${ }^{1514}$ Lire BULA BULA, Sayeman, «L'accord de Syrte du 18 avril 1999 pour le règlement des différends dans les Grands Lacs. Note de lecture », in https://sbulabula.wordpress.com/publications/laccord-de-syrte-du-18-avril1999/ (source consultée le 10 mai 2015 ).
} 
pu parvenir à faire cesser la guerre en $\mathrm{RDC}^{1515}$.Cette situation est encore observable avec les conflits armés menés, cette fois-ci, par les rebelles de M23 et autres groupes armés à l'Est de la RDC.

Certes, le but ultime poursuivi par tous ces accords et rencontres demeure la paix, la stabilité et la sécurité du pays et de la région des Grands Lacs. En d'autres termes, la RDC ne saurait être en paix véritable si la sous-région dont elle est membre fait l'objet des tensions récurrentes. Ce processus de paix devait donc impliquer en même temps différents acteurs. Et comme l'attestent les lignes précédentes, les conflits armés en RDC actuellement sont en grande partie la «transposition du génocide rwandais » sur le territoire congolais. En d'autres termes, ce sont donc en partie les effets de ce génocide qui sont à comprendre comme source de conflits armés en RDC (cf. supra).

Ainsi, par exemple, suivant l'accord de Lusaka, appréhendé comme un fondement essentiel du processus de paix en RDC par la communauté internationale ${ }^{1516}$, dès son entrée en vigueur, les parties s'engageraient à trouver immédiatement des solutions aux préoccupations de la RDC et des pays voisins en matière de sécurité (lire article II de l'Accord de Lusaka). Chose qui n'a pas été entreprise par la suite. Et la cessation des hostilités souhaitée par ledit accord n'a pas été aussitôt mise en œuvre. Ce qui vaut de même pour la tenue du dialogue national. Plusieurs péripéties ont été observées de la part des acteurs pour que celle-ci soit tenue finalement à Sun City (République Sud Africaine) en 2002.

Certains observateurs notent à ce propos que le changement du régime en RDC semble favorable à la tenue de ce dialogue national. En effet, Joseph KABILA qui a succédé à son père Laurent Désiré KABILA, en prêtant serment, le 26 janvier 2001, s'est solennellement engagé à appliquer l'accord de Lusaka resté lettre morte du fait de la mauvaise volonté des uns et des autres. Il s'est également assigné la tâche de normaliser les relations de son pays avec les Etats Unis d'Amérique, 1'Union Européenne et les Nations Unies ${ }^{1517}$.

En dépit de quelques écueils constatés ci et là, il y a eu ouverture du Dialogue Inter Congolais le 25 février 2002 et un accord politique dit « Accord Global et Inclusif » signé à l'issue de ce dialogue à Pretoria en date du 17 décembre 2002. Il sera "par la suite solennellement adopté par les délégués des composantes et entités au dialogue en date du $1^{\mathrm{er}}$ avril 2003, à Sun City, Afrique du $\operatorname{Sud}^{1518} »$. Cet accord fixe entre autres objectifs l'établissement d'un nouvel ordre politique par la tenue des élections démocratiques, libres et transparentes, gage de l'Etat de Droit; la réconciliation nationale; la formation d'une armée nationale restructurée et intégrée ; etc. Et par la même occasion, la RDC s'est doté d'une Constitution (Constitution de la transition du 04 avril 2003) qui organise le pouvoir pendant la période de la transition.

Par ailleurs, la signature de l'Accord global et inclusif n'a pas réellement mis fin aux conflits armés. Quelques poches des conflits armés notamment à la province du Nord Kivu ont subsistés ou refait surface. Ces poches des conflits armés - œuvre des groupes armés

\footnotetext{
${ }^{1515}$ MUKULUMANYA, Wa Ngate, op.cit., p. 14.

${ }^{1516}$ Lire NGOY, Théodore, L'Accord de Lusaka : la paix piégée, Seconde édition CERBIPAD, Kinshasa, 2002, pp. 2-3.

${ }^{1517}$ Publi Information, « R.D.C. demain la paix », p. IV 20015 ans, S.ed.

1518 MAZYAMBO, Makengo Kisala, André, «Le désarmement, la démobilisation et la réinsertion des combattants en République Démocratique du Congo », in BASUE, Babu Kazadi (dir.), Le droit international à l'épreuve des enjeux sécuritaires en République Démocratique du Congo, P.U.K, Kinshasa, 2002, p. 202.
} 
bénéficiant d'un appui extérieur - feront également objet d' " accords politiques » entre parties en conflits en présence. C'est le cas du Pacte sur la Paix, la Sécurité, la Stabilité et le Développement dans la Région des Grands du 15 décembre 2006 dit «Pacte ou Traité de Nairobi) qui sert de cadre juridique et d'agenda pour la Conférence Internationale de la Région des Grands Lacs (CIRGL) et entré en vigueur en juin $2008^{1519}$. Cette organisation régionale ainsi créée s'attellera notamment au conflit armé du Mouvement M23 et la RDC (cf. infra) notamment par des sommets organisés à Kampala où se retrouvaient sur une même table de négociation les différents protagonistes. C'est aussi le cas d'Acte d'engagement de Goma du 23 janvier 2008. Cet acte est issu d'une concertation convoquée par le Président Joseph Kabila et tenue du 06 au 23 janvier 2008 sur les problèmes de paix, de sécurité et de développement des deux provinces du Kivu ${ }^{1520}$. Différentes couches sociales ont pris part à ces assises dont les groupes armés. D'importantes résolutions liées à la cessation des hostilités, au désengagement des mouvements armés, aux principes humanitaires et respect des droits de l'homme, et aux mesures de garanties politiques et judiciaires ont été adoptées $^{1521}$. Par ailleurs, l'Acte d'engagement de Goma ne sera pas mis en œuvre tel que souhaité. "Ses angéliques professions de foi ne purent ni trouver des solutions aux causes profondes de la crise ni apporter quelques remèdes aux souffrances des populations qui continuèrent de voguer d'un camp de fortune à un autre. La violence sous toutes ses formes avait repris une ampleur effroyable avec plus de vols et de viols, plus d'enrôlement d'enfants dans les milices et de sévices de toute sorte sur les populations ${ }^{1522}$. Cette situation interpellera la l'ONU, l'UA qui envoyaient respectivement Olusegum Obasanjo (ancien Président du Nigeria) et Benjamin Mpaka (ancien Président de la Tanzanie) comme Représentants spéciaux pour la région des Grands Lacs. Conférence Internationale de la Région des Grands Lacs (CIRGL) (cf. infra) était présente dans cette entreprise diplomatique avec son Secrétaire exécutif. Ainsi, ceci finira par donner naissance à l'Accord de paix entre le Gouvernement et le Congrès National pour la Défense du Peuple (CNDP) dit Accord du 23 mars $2009^{1523}$. Celui-ci se base notamment sur les principes fondamentaux consacrés par la Constitution congolaise et sur d'autres accords précédents dont le Pacte sur la Paix, la Sécurité, la stabilité et le développement dans la région des Grands Lacs du 15 décembre 2006 et l'Acte l'Acte d'engagement de Goma du 23 janvier 2008. Le CNDP se trouve entre autres obligé de mettre fin à son existence comme Mouvement politico-militaire et intégrer la police et les forces armées de la RDC. Pour sa part le Gouvernement s'engage à traiter avec célérité la demande du CNDP de se muer en parti politique, libérer les prisonniers politiques, promulguer une loi d'amnistie couvrant des faits datant de juin 2003 à la promulgation de ladite loi. L'administration du territoire et l'administration publique ont été concernées par cet accord à travers quelques suggestions. La réforme de l'armée et des services de sécurité voire celle économique ont été réglementées. Des mécanismes de suivi de cet accord ont été

\footnotetext{
${ }^{1519} \mathrm{http}: / /$ www.icglr.org/index.php/fr/historique ( Source consultée le 22 avril 2015).

${ }^{1520}$ OLLANDET, Jérôme, La conférence internationale sur la région des Grands Lacs. Une dynamique nouvelle d'intégration en Afrique, op. cit., p. 241.

1521 Voy. Acte d'engagement de Goma du 23 janvier 2008, in «Accord de paix signé à Goma » http://www1.rfi.fr/actufr/articles/097/article 61837.asp (Source consultée le 22 avril 2015).

${ }_{1522}$ OLLANDET, Jérôme, La conférence internationale sur la région des Grands Lacs. Une dynamique nouvelle d'intégration en Afrique, op.cit., p. 242.

${ }^{1523}$ Voy. l'Accord de paix entre le Gouvernement et le Congrès National pour la Défense du Peuple (CNDP) du 23 mars 2009, in http://radiookapi.net/files/Accord-CNDP-Gvt-23-mars-2009-pdf.pdf?55c0b5 (Source consultée le 22 avril 2015).
} 
également institués. Alors que la paix durable attendue se rétablissait petit à petit, la crise éclata de nouveau en avril 2012 avec un Mouvement armé nouvellement créé dit «M23». «Ses instigateurs considéraient ce nom comme une donnée symbolique en référence aux Accords signés le 23 mars 2009 entre le gouvernement de Kinshasa et le CNDP ${ }^{1524}$. Ils justifiaient ainsi leur rébellion au non respect de l'accord du 23 mars 2009 par le gouvernement central ${ }^{1525}$.

Pour trouver enfin des solutions durables aux problèmes récurrents des conflits armés en RDC de la période d'après «Accord global et inclusif » il y aura la signature le 24 février 2013 à Addis-Abeba - avec la facilitation de l'ONU, de l'UA, de la CIRGL et de la SADC-par onze pays de la région (Angola, Afrique du Sud, Burundi, République Centrafricaine, République du Congo, RD Congo, Ouganda, Rwanda, Sud - Soudan, Tanzanie et Zambie) d'un accordcadre pour la paix, la sécurité et la coopération pour la RDC et la région ${ }^{1526}$. Cet accord est vu par de nombreux observateurs comme « un tournant dans la recherche des stratégies pour mettre fin aux cycles de conflits et de violence en RDC qui constituent une source d'instabilité pour l'ensemble de toute la région des Grands Lacs » ${ }^{1527}$

Par ailleurs, le processus de paix en RDC a bénéficié non seulement de la contribution des acteurs nationaux ou sous régionaux mais également de ceux internationaux.

En effet, la Communauté Internationale à travers l'ONU a énormément contribué à cet édifice. L'ONU est intervenue après avoir déclaré et laissé son temps à l'appui aux organisations régionales (OUA) et sous régionales (SADC) (cf. supra).

A cet égard, plusieurs résolutions ont été adoptées, singulièrement par le CS/NU, pour faire respecter les droits de 1'Homme et le Droit International Humanitaire, restaurer la paix, la stabilité et la sécurité du pays et de la région des Grands Lacs en général. Ces résolutions avaient pour conséquence logique notamment le retrait définitif des troupes ou forces étrangères non invitées. C'est dans cette optique que La MONUC sera créée par la résolution 1279 du 30 novembre 1999 du CS/NU en sa $4076^{\text {e }}$ séance pour suivre de près cette opération de paix.

En effet, "l'objectif principal de la MONUC en République Démocratique du Congo est que des élections crédibles, se tiennent et qu'une paix stable et durable puisse s'installer » a déclaré le SG/NU, Koffi ANNAN, dans son seizième rapport sur la MONUC. A cette fin, a-til ajouté, la MONUC poursuivra ses efforts pour que l'accord de paix soit appliqué de façon intégrale et équitable et continuera à chercher les moyens d'encourager les ex-belligérants à accepter, pour la période d'après la transition un ordre politique favorable à la sécurité, à des formes des reformes démocratiques et à la bonne gouvernance ${ }^{1528}$.

Cependant, il importe de noter que bien que la MONUC a été placée, suivant l'évolution de son mandat, sous chapitre VII de la Charte des Nations Unies notamment avec la résolution 1493 du 28 juillet 2003 du CS/NU, elle s'est avérée toutefois obsolète face à certaines

\footnotetext{
${ }^{1524}$ OLLANDET, Jérôme, La conférence internationale sur la région des Grands Lacs. Une dynamique nouvelle d'intégration en Afrique, op.cit., 234

1525 Ibid.

1526 Ibid. p. 249.

1527 Ibid.

${ }^{1528}$ TSHIMANGA Joseph, «Les Nations Unies et le maintien de la paix dans le monde », in MONUC Magazine, VOL IV, $\mathrm{N}^{\circ} 30$, p. 6.
} 
attaques. C'est le cas des événements de Laurent NKUNDA et Jules MUTEBUSI et d'autres qui s'en sont suivis vers le mois de juillet 2004, au Sud-Kivu.

Toutefois, ce serait trop dire d'affirmer haut et fort que le mandat de la MONUC, actuellement MONUSCO, est négatif bien qu'il reste tout de même mitigé (cf. Chapitres IV)

Rappelons que l'intérêt que présente la situation congolaise a mobilisé plusieurs acteurs régionaux et internationaux. Parmi lesquels, l'Union européenne (UE). "L'appui au processus de paix, de réconciliation et démocratie est une spécialité de l'Union. ${ }^{1529}$ » En effet, après la présence franco-belge marquée dans la région de Grands Lacs à la suite de la crise humanitaire occasionnée par le génocide rwandais, il était temps pour l'UE de s'intéresser de cette région. La nomination de son Représentant spécial Aldo AJELLO en 1996 l'atteste. Celui-ci a accompli un rôle délicat sur le plan diplomatique ${ }^{1530}$. L'UE a marqué sa présence dans cette région notamment par son appui financier et matériel aux mécanismes de prévention, de gestion et de résolution des conflits armés de l'ONU et de l'UA.

Pour la RDC, l'UE s'est préoccupé du processus de transition démocratique dès la fin de la décennie 90. Son intérêt à la situation politique congolaise est également démontré par son soutien technique et financier à l'OUA et à l'ONU afin d'assurer la mise en œuvre de 1'Accord de Cessez-le-feu de Lusaka de 1999. Le reste du processus le démontre également.

Et pour aller plus loin, l'UE a cessé de se présenter comme un simple «bailleur de fonds » pour s'impliquer directement dans les conflits congolais à travers des missions de sécurité telles que l'opération Artémis et EUFOR Congo. La mission Artémis était une opération militaire d'interposition en RDC dans le secteur de la capitale régionale de Bunia avec 1800 personnes. La population de Bunia, à l'Est de la RDC, ne peut oublier l'opération Artémis du $1^{\text {er }}$ juin 2003 au $1^{\text {er }}$ septembre 2003, première intervention de l'UE en dehors de sa sphère géographique. Il faudrait signifier comme limites, il s'agissait d'une opération de «sauvetage » de la garnison de la MONUC à Bunia menacée par les milices de l'Ituri dont l'une a réussi à se rendre maître de la ville. Les 1800 personnes déployées dans le cadre de cette opération assuraient un renfort de dispositif de la MONUC qui devrait être porté à 2800 personnes. Son mandat étant limité dans le temps (3 mois) et dans l'espace (Bunia), l'opération était revêtue d'un caractère d'urgence afin de contribuer à stabiliser les conditions de sécurité, améliorer la situation humanitaire (...) et à assurer la sécurité de la population civile, du personnel des Nations Unies et des organisations humanitaires de la ville ${ }^{1531}$.

A entendre Aldo AJELLO, après trois mois à Bunia, les troupes européennes ont réussi à sécuriser la ville au point que les organisations humanitaires ont repris normalement leurs activités et la population vaquée à ses occupations. Sur le plan politique, le déploiement de l'opération Artémis a facilité la relance du processus de paix en RDC, en ayant permis notamment la Constitution de l'Etat Major Général Militaire intégré. Toujours selon l'envoyé spécial de l'UE en région des Grands Lacs, c'est grâce à cette opération que les institutions de

\footnotetext{
${ }^{1529}$ WILDE d'ESTMAEL, T. de, «L'Union européenne et la résolution des conflits », in REMACLE E. et al. (dir.), L'Afrique des Grands Lacs. Des conflits à la paix ?, P.I.E. Peter Lang S.A., Bruxelles, 2007, p. 189.

${ }^{1530}$ Lire RICHARD, Pierre-Olivier, Aldo AJELLO, Cavalier de la paix. Quelle politique européenne commune pour l'Afrique. Entretiens avec le Représentant spécial de l'Union européenne pour la région des Grands Lacs, Grip et éditions Complexe, Bruxelles, 2000, pp. 89-104.

${ }^{1531}$ WILLAME, Jean-Claude, La guerre du Kivu, op.cit., 120-121.
} 
la Transition ont pu être installées.

L'opération Artémis était un succès à attribuer à la Politique européenne de sécurité et de défense (PESD). La France y a joué un rôle considérable au point que $40 \%$ de sa composition et sa direction, depuis le Quartier général à Paris, étaient françaises. Des forces supplétives émanaient d'autres pays européens, à l'exception de la Suède. L'Afrique du Sud et le Brésil ont participé à cette opération respectivement de l'ordre de 150 et 50 hommes de troupe. Ceci fait dire aux observateurs que cette opération était une «intervention française qui a été européanisée $^{1532} \gg$. Bien plus, il est affirmé que les uniformes français exercèrent un effet de dissuasion incomparablement plus évident que les «Casques bleus » de l'ONU. Le succès recueilli par l'opération Artémis avait permis de recommander l'opération Artémis bis au Kivu notamment à la suite de la tentative de la prise de la ville de Bukavu par Jules Mutebusi et Laurent Nkunda. L'offensive spectaculaire qu'avait lancée Laurent Nkunda contre les FARDC au Nord-Kivu exigeait également une force européenne afin de renforcer notamment la capacité de la MONUC de protéger la population civile. Cependant, les réticences ou l'absence des motivations des Etats européens de prendre part à cette seconde opération fera que celle-ci ne puisse pas voir le jour ${ }^{1533}$.

EUFOR Congo était, pour sa part, une mission militaire de soutien des casques bleus de la MONUC durant la période des élections de 2006 avec 2000 personnes ${ }^{1534}$. Il s'agit là des plus importantes missions militaires réalisées par l'UE en Afrique centrale. Relativement appréciées, ces opérations occupent une place non moins la moindre dans le cadre d'intervention des acteurs étrangers dans le processus de pacification de la $\mathrm{RDC}^{1535}$. D'autres missions civiles, de moindre envergure en termes de personnel déployé, ont été également accomplies avec d'effets bénéfiques pour le pays. Il y a lieu de mentionner ici EUPOL Kinshasa effectuée d'avril 2005 à juin 2007 (30 personnes); EUSEC RD Congo et EUPOL RD Congo déployées respectivement en juin 2005 et en juillet 2007 avec 40 personnes chacune.

Par ailleurs, l'UE reste omniprésente dans la sphère politique congolaise. Il est à noter, à titre d'exemple, que les élections présidentielles et législatives organisées en ce pays, en 2006 et en 2011, ont vu l'UE jouer un rôle non le moindre. Avec un montant final de 242 millions d'euros sur un coût total de 430 millions, l'UE venait largement en tête de tous les bailleurs de fonds ${ }^{1536}$ pour les élections législatives, présidentielles et provinciales de 2006. Le gouvernement congolais n'avait quant à lui injecté que 5,6 millions d'euros sur les 20,7 millions annoncés. S'il est attesté que pour des pays se trouvant dans une situation d'après guerre, les dépenses liées à l'organisation des élections se chiffrent à 20-30\% du budget, pour la RDC, elles étaient inférieures à $1 \%{ }^{1537}$. Le rôle de l'UE dans la consolidation de la paix reste donc remarquable dans le maintien ou imposition de la paix proprement dits dans l'Est

\footnotetext{
1532 Ibid., p. 120.

${ }^{1533}$ Lire Ibid., pp. 122, 123, 128, 129 et 130

1534 FRANCK, Christian, Action extérieure de l'Union Européenne. L'UE dans les relations internationales, Collège d'Europe, Natolin, Diplomatische Akademie Wien, p. 76. Inédit.

${ }^{1535}$ Lire REYCHLER, Luc et MIGABO KALERE, Jean (éd.), RDC Congo. Pays de l'avenir. Construisons ensemble une paix durable pour un meilleur destin, Livre Ouvert, vol.87, UNIRDCONGO \& IPRA, Leuven, 2010, pp. 126-127.

${ }^{1536}$ WILLAME, Jean-Claude, La guerre du Kivu. Vues de la salle climatisée et de la véranda op.cit., p. 112. ${ }^{1537}$ Ibid.
} 
de la RDC.

Qu'il soit signifié que ce rôle de l'UE s'inscrit dans le cadre de la Politique étrangère et de sécurité (PESC) de l'UE, consacrée lors de l'entrée en vigueur du Traité de Maastricht (1993), à la suite d'une évolution historique ${ }^{1538}$ et développée avec des innovations de tailles au niveau du Traité de Nice (2001) dont la création des organes tels que le COPS (Comité politique et de sécurité), le CMUE (Comité militaire de l'Union Européenne) et l'EMUE (Etat-major de l'Union européenne) ${ }^{1539}$. Lesquels organes sont d'une grande importance pour des missions de sécurités comme celles décrites ci-dessus. Le moins qu'on puisse dire est qu'il s'agit là «des moyens permettant à l'UE d'affirmer son identité sur la scène internationale ${ }^{1540}{ }_{\gg}$

Un autre organe regroupant les Représentants de l'extérieur à joué un rôle important dans le cadre du processus de paix en RDC: le Comité international d'accompagnement de la Transition (CIAT). Celui-ci est créé en application de l'Accord global et inclusif signé à Pretoria le 17 décembre 2002. Le CIAT regroupait les représentants en RDC des membres permanents du CS/NU (Chine, Etats-Unis d'Amérique, France, Royaume-Uni et Russie), de l'Afrique du Sud, de l'Angola, de la Belgique, du Canada, du Mozambique, de la Zambie, de l'Union Africaine, de l'Union européenne et de la MONUC. Ce Comité apportait son appui au processus de transition et jouait la médiation dans des crises politiques qui pouvaient se déclarer.

Pour tout dire, beaucoup d'acteurs nationaux, sous régionaux, régionaux et internationaux ont participé à l'édification de la paix en RDC. Certains objectifs assignés à cette période de transition ont été atteints. Ce qui n'est pas le cas d'autres tels que la formation de l'armée nationale restructurée et intégrée. Le moins que l'on puisse dire est que la paix retrouvée en RDC est encore relative et différents acteurs s'emploient tout de même à la consolider. Il ne s'agit donc pas d'une paix durable mais fragilement acquise et à tout moment remise en question. Il nous paraît que les vrais acteurs concernés par cette « guerre par procuration » ne sont pas toujours clairement identifiés et présents sur la table de négociation. Les négociations se passent entre les pseudo-acteurs ou les mandataires et non entre les vrais mandants. Un autre problème réside dans l'identification du nerf de la guerre. Il s'agit d'une guerre essentiellement économique, en dépit de quelques raisons d'ordre socio-politiques relevées cihaut. Mais, cette raison économique semble éluder par les parties à la table de négociation pour s'atteler sur des fausses bases d'ordre essentiellement politique. A ces conditions, devrons-nous nous attendre à une paix durable?

\footnotetext{
${ }^{1538}$ MEDJOUBA, Faria et STEFANELLI, Justine, « La prise en considération du Droit international humanitaire par l'Union européenne - Introduction », in Jean-Marc SOREL et Corneliu-Liviu Popescu (dir.), La Protection des personnes vulnérables en temps de conflits armés, op. cit., , p. 88.

${ }^{1539}$ FRANCK, Christian, Action extérieure de l'Union Européenne. L'UE dans les relations internationales, op. cit., p. 76. Inédit.

${ }^{1540}$ MEDJOUBA, Faria, et Justine STEFANELLI, «art.cit.», in Jean-Marc SOREL et Corneliu-Liviu Popescu (dir.), op.cit., p. 89.
} 


\section{Section II Recrutement et participation des enfants aux conflits armés en République Démocratique du Congo}

Comme l'indique son intitulé, cette section analysera préalablement et brièvement le contexte de recrutement et de participation des enfants dans ces conflits armés en RDC (\$1) avant de s'étendre proprement sur les méthodes et raisons de ce recrutement - conscription et enrôlement (§2).Enfin, elle se penchera à identifier des forces et groupes armés procédant à ce recrutement et les méthodes de participation des enfants aux hostilités (§3).

\section{§1. Cadre contextuel de recrutement et de participation des enfants aux hostilités}

Dans certaines régions du monde, l'Europe de l'Ouest, par exemple, la population se sent en sécurité depuis plusieurs décennies. La plupart des gens ressentent les violations des droits de l'Homme et les guerres dans les autres pays, non comme une réalité existentielle mais comme une réalité virtuelle. Pour les enfants, la guerre est un jeu vidéo, pour la plupart des adultes, la guerre est inimaginable et peut être réduite à un événement télévisuel que l'on peut allumer ou éteindre à son gré ${ }^{1541}$. En revanche, l'Afrique, dite «berceau de l'humanité », se présente comme le «champ de prédilection » de nombreux conflits qui ont engendré des conséquences désastreuses. L'Afrique est à l'heure actuelle, « la zone stratégique la plus déstabilisée de la planète », plongée dans une instabilité et dans une insécurité grandissantes, ralentissant et fragilisant ainsi son développement économique ${ }^{1542}$. La Région des Grands Lacs africains, sphère la plus insécurisée de ce continent, connaît plus de deux décennies consécutives des crises politiques et des conflits armés les plus meurtriers. Le génocide rwandais, avec son bilan estimé entre 800.000 à 1000.000 de morts, a entraîné, par effet de contagion (cf. supra), des conflits armés enchevêtrés et intermittents en RDC que d'aucuns dénombrent « à près de 10.000.000 de morts » dès leur début à ce jour. « Ce n'est pas une guerre dans laquelle les civils sont les victimes malheureuses de dégâts collatéraux, mais une guerre dans laquelle ils ont été inlassablement et impitoyablement pris pour cibles ${ }^{1543}$. «Le bilan est extrêmement lourd chez les enfants congolais. [...] chaque année, il meurt plus d'enfants de moins de cinq ans en RDC qu'en Chine (dont la population est 23 fois plus nombreuse) ou que dans tous les pays d'Amérique latine pris ensemble ${ }^{1544}$ notait Martin BELL, Ambassadeur d'UNICEFRoyaume-Uni, à l'issue de sa visite en 2006 dans la partie orientale de la RDC. L'enfant en désolation et sans espoir est l'image fortement symbolique qu'on peut mieux retenir de ces conflits armés. Il se trouve être victime à plusieurs degrés.

Comme l'on peut bien le remarquer, la RDC n'offre donc pas à l'enfant un environnement propice à son épanouissement tant physique, psychique, moral qu'intellectuel. La RDC est, suivant les différents classements des organismes internationaux, un des pays où la pauvreté a

\footnotetext{
${ }^{1541}$ REYCHLER, Luc, « Les crises et leurs fondements. La prévention des conflits violents », in Fondations Roi Baudoin et Médecins Sans Frontières, Conflits en Afrique. Analyse des crises et pistes pour une prévention. La communauté internationale : quelle responsabilité ?, GRIP-Ed. Complexe, Bruxelles, 1997, p. 40.

${ }^{1542}$ KIKI SONAGNON, Lydie, Les Organisations internationales dans le règlement des conflits en Afrique de l'Ouest, Thèse de doctorat en Droit international public, Université Paris 1 Panthéon-Sorbonne, Université de Cocody-Abidjan, 2012, p. 18.

${ }^{1543}$ Amnesty international, République Démocratique du Congo - Enfants en guerre, AI index :Afr 62/034/2003. Secrétariat international, document public, p. 3, in http://www.kongokinshasa.de/dokumente/ngo/ai_enfants_0903.pdf(Source consultée le 29 mars 2014).

${ }^{1544}$ UNICEF, SOS, République Démocratique du Congo. Reportage de Martin Bell sur les enfants piégés par la guerre, Juillet 2006, p. 3. Voy. http://www.unicef.org/childalert/drc/ (Source consultée le 29 mars 2014).
} 
atteint son paroxysme. Cette situation s'avère paradoxale pour ce pays qui regorge de nombreuses ressources naturelles ${ }^{1545}$. Celles-ci servent les intérêts privés de certains individus à la tête de différentes institutions étatiques et certaines puissances étrangères comme l'attestent bien divers rapports (cf. supra). Cette situation de pauvreté se trouve être exacerbée par la destruction des infrastructures sociales dont celles scolaires et sanitaires, le développement d'une économie informelle de subsistance, l'enclavement de régions par le non entretien du réseau routier, l'affaiblissement des structures familiales, la transformation de valeurs sociales, etc. Structures et valeurs qui auraient éventuellement pu freiner l'engagement « volontaire » de nombreux enfants ${ }^{1546}$.

En clair, cette situation chaotique du pays occasionnant le taux élevé de chômage dans la population active et de nombreux cas $\mathrm{d}^{\prime}$ '《impaiement» des salariés -terme régulièrement employé dans le jargon des agents ou travailleurs congolais- ou de «sous paiement » dans le cadre des entreprises publiques, se répercute négativement sur les enfants. Les parents se trouvent, par la suite, être déserteurs de leur responsabilité d'assurer le financement des études de leurs enfants. Tout est pénible dès l'enseignement fondamental sensé être gratuit conformément à l'article 26 de la déclaration universelle des droits de l'Homme. C'est dans ce contexte qu'en 2009 renseignait Marie Rose MBIMBA, directrice de l'école primaire (EP1) d'Inkisi à Kinshasa, qu'au début de l'année scolaire, son école avait 754 élèves. A peine trois mois plus tard, seulement 516 d'entre eux étaient encore inscrits. A elle de conclure que « [1]e problème vient des difficultés financières auxquelles sont confrontés les parents [...] Ils ne peuvent faire face aux frais de scolarité alors que beaucoup d'entre eux sont sans emploi» ${ }^{1547}$. Il ne s'agit pas là d'un cas isolé en dépit de l'amélioration de la situation de scolarisation des enfants tel qu'annonce l'UNICEF pour la $\mathrm{RDC}^{1548}$. D'après les estimations, 7,6 millions d'enfants ne vont pas à l'école, dont 34 pour cent se trouvent dans les zones affectées par le conflit ${ }^{1549}$.

Face à l'incertitude que représente leur avenir en RDC, les enfants n'ont d'autre choix que de se prendre en charge et répondre ainsi un tant soit peu à leurs besoins et à ceux de leurs familles (cf. infra). Ils se retrouvent là à la solde des forces ou groupes armés. C'est ce que constate d'ailleurs Lucie COUTURIER-BOURDINIERE dans sa thèse de doctorat où elle affirme que lorsque les conflits armés se prolongent pendant des années, voire des décennies, les conditions qui étaient à l'origine du déclenchement des hostilités (la pauvreté et la répression, notamment) s'aggravent encore, poussant les populations civiles à s'enrôler dans des groupes armés ${ }^{1550}$.

\footnotetext{
${ }^{1545}$ Lire l'Enquête nationale sur la situation des enfants et adolescent en dehors de l'école, 2012, pp. 18-19, in http://www.kongo-kinshasa.de/dokumente/uno/unicef-2013-03-01_fr.pdf ( Source consultée le 27 mars 2014).

${ }^{1546}$ BAILLON, Thierry, «A l'écoute des enfants-soldats congolais », in SCHMITZ Marc, La Guerre. Enfants admis, op.cit., p. 97.

${ }^{1547}$ BLOEMAN, Shantha, «La faiblesse des taux de scolarisation incitent à investir davantage dans l'éducation en République démocratique du Congo », in http://www.unicef.org/french/infobycountry/drcongo_51031.html ( Source consultée le 27 mars 2014).

${ }_{1548}$ «Augmentation de $23 \%$ de taux de scolarisation des enfants en RDC », in http://french.news.cn/afrique/2010-11/21/c 13615774.htm (source consultée le 27 mars 2014).

${ }^{1549}$ UNICEF, 2012 Action humanitaire de l'UNICEF pour les enfants, p. 33, in www.unicef.org/french/hac2012 (Source consultée le 29 mars 2014).

1550 COUTURIER-BOURDINIERE, Lucile, La protection internationale des droits de l'enfant, Thèse de
} 
Dans cette situation de précarité prononcée relayée de l'impunité manifeste à la suite du dysfonctionnement croissant des institutions étatiques, les forces ou groupes armés n'hésitent point d'employer toutes les méthodes à leurs portées (cf. infra) pour parvenir à leur objectif avec dans leurs rangs un nombre consistant de combattants. Le Président de l'UNICEF Canada de retour d'une visite en RDC (26 juin 2003) fait cette déclaration : «En RDC, les enfants vivent constamment dans l'instabilité et la peur, et ils subissent des traumatismes. La crise a forcé le déplacement d'environ 300.000 personnes, ce qui augmente le risque que les enfants soient enlevés et forcés de devenir des enfants soldats. Dans la province d'Ituri, les groupes armés comptent de 12.000 à 15.000 enfants (certains n'ont pas 10 ans) qui constituent 40 à $50 \%$ des combattants. Beaucoup d'enfants ont été forcés de commettre des actes d'une grande violence, beaucoup d'enfants ont été blessés ou tués. [...] ils (les enfantssoldats) sont entre 23.000 (Selon UNICEF) et 30.000 (selon Amnesty International) sur tout le territoire congolais $\gg{ }^{1551}$.

Ainsi qu'on peut bien comprendre, la précarité des institutions étatiques en RDC, la pauvreté extrême accompagnée de certains impératifs socio-culturels de différentes communautés en présence, sont des facteurs incitateurs et explicatifs de recrutement (conscription ou enrôlement) d'enfants dans les forces ou groupes armés.

\section{§2. Recrutement des enfants aux conflits armés en République Démocratique du Congo}

\section{A. Méthodes de recrutement}

Devant leurs objectifs à atteindre dans le cadre des conflits armés en RDC, les forces ou groupes armés ne résignent pas sur les moyens. Tous les moyens qui s'offrent à eux pour remporter la bataille ou la guerre sont donc exploitables. Les enfants vus comme «des instruments de guerre bon marché, faciles à armer, à diriger et à motiver ${ }^{1552}$ » sont donc les bienvenus. Pour leur recrutement, les belligérants font usage des méthodes diverses.

\section{A. 1. Recrutement forcé ou conscription}

En réalité, en grande partie, le recrutement des enfants pour incorporer les forces ou groupes armés se fait par la force ou contrainte. Cette dernière est directement effectuée sur l'enfant concerné ou son entourage, soit sous forme de menaces. Elle peut aussi être précédée des ruses, tromperies ou manipulations.

En effet, les parties au conflit armé en RDC, Maîtres du lieu, sans se soucier de l'avenir des enfants, font usage de terreur à l'endroit de ceux-ci voire de leurs responsables afin que leurs enfants soient incorporés dans les rangs. Le refus d'obtempérer à leur ordre dans ce sens peut

doctorat en Droit, discipline : Droit international, droit européen, relations internationales, Université PanthéonAssas (Paris II), juillet 1999, op.cit., pp. 446-447. ; Voy. RAMASY, Juvence F., « La protection juridique et politique des enfants dans les conflits armés en Afrique. Inventaire des dispositions légales et politiques », «art.cit», in BABIKER, Mohamed Abdelsalam, DAUBLAIN, Maxense et VAHLAS, Alexis (dir.), Enfantssoldats et droits des enfants en situation de conflit et post-conflit. Réalités et enjeux, op.cit., pp. 264-265.

${ }^{1551}$ HABIBU, Jean Bosco, op.cit., 60. Ces estimations sont variables suivant les organismes et les différents rapports d'enquêtes présentés (cf. infra).

${ }^{1552}$ Voy. RAMASY, Juvence F., « La protection juridique et politique des enfants dans les conflits armés en Afrique. Inventaire des dispositions légales et politiques », «art.cit. », in BABIKER, Mohamed Abdelsalam, DAUBLAIN, Maxense et VAHLAS, Alexis (dir.), Enfants-soldats et droits des enfants en situation de conflit et post-conflit. Réalités et enjeux, op.cit., p. 265. 
engendrer des mesures sévères dont les tortures, l'assassinat ou le meurtre. Les parents assistent donc impuissamment au recrutement forcé de leurs enfants et ne peuvent s'y opposer au risque d'être abattus. Pour aboutir à ce recrutement forcé dont certains enfants tentent d'échapper au risque de leur vie aussi, les différentes parties au conflit armé en RDC ciblent les milieux les plus fréquentés par les enfants. A titre illustratif, dans son rapport du 28 mars 2010 intitulé «Le chemin de la mort», Human Rights Watch indiquait que «[L]es combattants de la LRA (Lord's Resistance Army, ou Armée de Résistance du Seigneur) ont spécifiquement recherché les endroits dans lesquels les gens auraient tendance à se rassembler - tels que les marchés, les églises et les points d'eau - et ont à plusieurs reprises demandé à ceux qu'ils rencontraient la localisation des écoles [...] ${ }^{1553}$. Les nombreux enfants enlevés âgés de dix à quinze ans étaient attachés avec des cordes ou du fil métallique à la taille, formant ainsi des chaînes humaines de plus ou moins quinze personnes au service de la LRA $^{1554}$. En effet, les écoles, les marchés, les sources d'eau, les camps de réfugiés et de déplacés, les camps et bases militaires, les champs agricoles voire des forêts, les mines, les rues et autres places publiques sont des cibles privilégiés et font objet d'irruption surprise des soldats qui viennent kidnapper les enfants. Il arrive même que certaines écoles voient simplement une grande partie de ses élèves vidés aux vues des enseignants impuissants. L'enlèvement considéré comme «la prise de l'enfant contre son gré » ${ }^{1555}$ est donc une méthode privilégiée qui s'inscrit dans le cadre de recours ou recrutement forcé des enfants par les forces ou groupes armés. A ce titre, une étude réalisée sur les zones de conflits armés en RDC par un groupe d'ONG internationales s'occupant de la protection des enfants, indique, à propos des filles, qu'à «travers tous les villages et les grandes villes des provinces de l'Est, des milliers de filles ont été enlevées de force alors qu'elles travaillaient dans les champs ou lors de l'attaque d'un village tout entier ${ }^{1556}$.

Par ailleurs, de leur côté, les parents prennent souvent précautions en ces périodes de conflits armés de ne point envoyer leurs enfants à l'école au risque d'être victimes d'enrôlement forcé. C'est dans ce sens que l'utilisation de la contrainte par les forces ou groupes armés se trouve généralement accompagnée par des guet-apens tendus aux enfants sur leurs chemins habituels. Il arrive aussi que les parents livrent leurs enfants aux groupes armés pour faire la paix avec ceux-ci ${ }^{1557}$.

La contrainte n'est toutefois pas la seule méthode employée par les parties au conflit armé en RDC pour recruter les enfants et les utiliser dans les hostilités qui s'y déclenchent. Les belligérants font usage d'appel d'enfants par voies de campagnes en utilisant plusieurs ruses ou manipulations d'ordre psychologique. Se retrouvant dans les milieux pauvres et appauvris, les enfants ont certains besoins fondamentaux auxquels ils doivent répondre dont se nourrir,

\footnotetext{
${ }^{1553}$ MEYER, Antoine, «La protection de l'enfance dans les conflits armés : perspectives de mise en œuvre des normes du droit international humanitaire et du droit international des droits de l'homme » « art.cit », p. 221.

${ }^{1554}$ Ibid.

1555 WHITMAN, Shelly, ZAYED, Tanya et CONRADI, Carl, Enfants soldats : Un guide pour les intervenants du secteur de la sécurité, 2è édition, The Roméo Dallaire, Child Soldiers initiative et Dalhousie University, octobre 2013, p. 35.

1556 VERHEY, Beth, Atteindre les filles. Etudes sur les filles associées aux groupes et forces armées en République Démocratique du Congo, Save the Children UK et le groupe des ONG: CARE, IFESH et IRC, Novembre 2004, p. 11.

1557 Lire KAGANDA MULUMEODERWA, Philippe, «Analyse des modèles de réinsertion des enfants exsoldats filles à l'Est de la R.D. Congo », in RDPC, Vol. 93, N², 2013, p. 89.
} 
se vêtir et satisfaire à d'autres besoins spécifiques. Connaissant très bien ces réalités macabres du terrain, les parties aux conflits reprennent habilement dans leurs propos tous ces besoins auxquels ils se disent prêts à répondre. Ces traquenards retiennent l'attention de certains responsables, qui n'hésitent même pas à encourager leurs enfants à s'y rendre (cf. supra). Il sied d'être très prudent pour placer ces astuces dans le lot d'enrôlement ou recrutement volontaire. Ainsi, nous estimons que si la volonté y est, elle doit être libre des circonstances, conditions ou pression d'ordre social ou autre. Il s'avère que les enfants se trouvent être contraints socialement de s'incorporer dans les forces ou groupes armés pour satisfaire dans l'ensemble à leurs besoins.

\section{A. 2. Engagement « volontaire»}

Des études menées par certains organismes prouvent l'existence de l'aspect « volontaire »du recrutement des enfants dans les forces et groupes armés en RDC.

En effet, Thomas MWAGALWA FURAHA nous révèle une étude menée par le Bureau international du travail (BIT/IPEC) au Burundi, au Congo-Brazzaville, en RDC et au Rwanda qui atteste que «près des $2 / 3$ des enfants enquêtés disent s'être enrôlés "volontairement", c'est-à-dire qu'ils n'ont été ni contraints par la force ou sous la menace ni enlevés, mais ont entrepris une démarche individuelle pour intégrer un groupe armé ${ }^{1558} \gg$. L'auteur poursuit que les analystes du phénomène des enfants soldats s'accordent généralement sur le fait que les recrutements forcés concernent principalement les filles alors que la majorité de garçons s'engagent plutôt volontairement. C'est dans ce sens qu'il cite Milfrid Tonheim qui renseigne qu'un « projet de recherche "Les enfants-soldats, la réintégration et la société civile dans l'Est du Congo" (2009-2011) a [...] constaté que le taux d'enfants recrutés de force parmi les répondants enfants-soldats constituait environ $90 \%$ parmi les filles-soldats et $40 \%$ parmi les garçons soldats ${ }^{1559}$. Une autre étude citée par l'auteur va également dans le sens d'accréditer la thèse d'enrôlement « volontaire » de plus de garçons que de filles dans le groupe Maï-Maï au Sud-Kivu ${ }^{1560}$. Dans une autre enquête limitée aux territoires de Beni et de Lubero au courant de la moitié de la dernière décennie, « il apparaît que le recrutement d'enfants soldats dans les milices Maï-Maï est à $83 \%$ volontaires. Ces jeunes s'engageaient surtout par «goût de l'aventure militaire » et pour le prestige que confère le titre de Kadogo. Beaucoup agissaient cependant par suivisme, n'ayant aucune autre opportunité de se mettre en valeur ${ }^{1561}$. Appréhendé par la communauté comme un acte patriotique, l'adhésion volontaire des filles dans certains groupes armés a été également signifié dans une étude réalisée par un groupe d'ONG internationales sur les provinces de Nord-Kivu, Sud-Kivu, Maniema, Katanga et la Province orientale. Ces filles ont été vues en même temps comme étant difficiles ${ }^{1562}$.

\footnotetext{
1558 FURAHA MWAGALWA, Thomas, L'interdiction de la participation aux hostilités, la démobilisation et la réinsertion des enfants soldats en République démocratique du Congo, op.cit., pp. 77-78.

1559 Ibid., lire aussi KAGANDA MULUMEODERWA, Philippe, «Analyse des modèles de réinsertion des enfants ex-soldats filles à l'Est de la R.D. Congo », « art. cit. », p. 88.

${ }^{1560}$ FURAHA MWAGALWA, Thomas, L'interdiction de la participation aux hostilités, la démobilisation et la réinsertion des enfants soldats en République démocratique du Congo, op.cit., pp. 77-78.

1561 WILLAME, Jean-Claude, Les "Faiseurs de paix » au Congo. Gestion d'une crise internationale dans un Etat sous tutelle, op.cit., pp. 118-119.

${ }^{1562}$ Lire VERHEY, Beth, Atteindre les filles. Etudes sur les filles associées aux groupes et forces armées en
} 
Il est toutefois important d'affirmer que dans tous les cas la question d'enrôlement «volontaire» ne se trouve pas vidée de sens. En effet, «[d]ans les discours, le caractère volontaire du recrutement des enfants est en général atténué, voire réfuté, par bon nombre d'acteurs. On évoque l'incapacité de discernement des enfants manipulés par les adultes du fait de leur immaturité, ou bien on considère que les enfants qui font ce choix peuvent le faire en toute clarté et en pesant raisonnablement les différentes options, mais qu'ils le font par manque d'autres options et seraient dans un certain sens «forcés de se porter volontaires » pour une activité dont ils ne mesureraient pas pleinement les dangers ${ }^{1563}$. L'enrôlement «volontaire » requiert une certaine liberté préalable de la part de l'enrôlé potentiel. Cette liberté d'esprit est certes matériellement difficile à établir dans le chef de l'enfant. C'est donc «l'absence de choix ou de véritable alternative pour l'enfant ${ }^{1564}$ qui l'amène à s'engager «volontairement» dans l'armée. C'est avec raison qu'une étude, menée dans le cadre d'une Université associée à des ONG œuvrant dans le secteur d'enfants soldats, conclue qu' " il n'y a pas d'engagement véritablement volontaire, surtout en ce qui concerne les enfants. Les garçons et les filles qui «choisissent » de se joindre à une force armée ou un groupe armé le font seulement en situation de contrainte extrême, en ayant une compréhension naïve et imparfaite des conséquences de leurs actions $»{ }^{1565}$.

Ainsi, l'enfant en situation des conflits armés en RDC se trouve être contraint par des pressions d'ordre socio-économique, culturel, idéologique, etc. (cf. infra) et n'a nullement d'autre choix que de s'engager dans les forces et groupes armés. Ce qui revient à dire que le fait pour un enfant de ne pas être forcé ou obligé d'intégrer les forces ou groupes armés ne renvoie pas ipso facto à un aspect réellement volontaire de son engagement dans les forces ou groupes armés. Comme le dit si bien François BUGNION : «[i]l n'y a pas de libre choix sans alternative ${ }^{1566}$. Et c'est avec raison que Marc SCHMITZ conclut sur une partie de son étude liée à la question du volontariat de l'engagement des enfants dans les forces et groupes armés que «[d]ans la plupart des cas, les jeunes recrues n'ont probablement été ni forcées ni obligées de prendre les armes, et de tremper dans les horreurs de la guerre. En attendant, les gosses sont l'objet de moult manipulations subtiles et de pressions diverses qu'il sera plus compliqué d'éliminer que le recrutement forcé ${ }^{1567}$. Il est trompeur, affirmait Graça MACHEL de considérer ce comportement d'enfants comme volontaire ${ }^{1568}$.

Dans un entretien du 26 octobre 2006 avec Philippe CHAPLEAU, Lucien Badjoko, kadogo

République Démocratique du Congo, op.cit., p. 12.

1563 BODINEAU, Sylvie, Figures d'enfants soldats. Puissance et vulnérabilité. Regard anthropologique sur l'intervention humanitaire de protection des «enfants soldats » en République démocratique du Congo entre 1996 et 2011, op.cit., p. 44.

1564 RAMASY, Juvence F., « La protection juridique et politique des enfants dans les conflits armés en Afrique. Inventaire des dispositions légales et politiques », « art.cit », p. 267.

${ }^{1565}$ WHITMAN, Shelly, ZAYED, Tanya et CONRADI, Carl, Enfants soldats : Un guide pour les intervenants du secteur de la sécurité, op.cit., p. 37.

1566 BUGNION, François, «Les enfants soldats, le droit international humanitaire et la Charte africaine des droits et du bien-être de l'enfant », in Revue Africaine de droit international et comparé, « art. cit. », p. 262.

${ }^{1567}$ SCHMITZ, Marc, «Les enfants-soldats, un phénomène universel de plus en plus préoccupant » «art.cit », 33.

${ }^{1568}$ Rapport de Graça Machel, «Impact des conflits armés sur les enfants », Nations Unies, New-York, 26 août 1996, p. 15, §38 http://www.unicef.org/french/emerg/files/Garca-Machel_fr.pdf (Source consultée le 20 juillet 2014). 
âgé de douze ans au moment de son recrutement en octobre 1996 sous 1'A.F.D.L, affirme : «Moi, je n'ai pas été pris de force. Mais beaucoup de mes amis avaient été forcés, influencés d'une manière ou d'une autre. Certains sont venus de leur propre volonté, enfin...volonté entre guillemets $\gg$ (nous soulignons) ${ }^{1569}$. La lecture en filigrane des propos de ce Kadogo atteste de «l'absence de choix ou de véritable alternative» dans laquelle se retrouvent de nombreux enfants en RDC pour s'offrir aux forces ou groupes armés. Marc SCHMITZ n'a t-il pas raison lorsqu'il s'interroge : «Que penser en effet de la notion «volontaire » lorsque la misère et l'angoisse poussent les enfants dans les mains de groupes militaires, ou quand le service dans l'armée ou la guérilla paraît plus sûr que la vie dans son environnement familial ? ${ }^{1570}$. La réponse se trouve clairement dans la question !

Bien plus, Colette BRAECKMAN, citant des études menées par Human Rights Watch sous la période de la « deuxième guerre de libération » en RDC (1998-2003), n'hésite d'ailleurs point d'affirmer que « [d] ans les provinces de l'Est, le recrutement n'a rien de volontaire ${ }^{1571}$. Ce qui vaut de même pour la province de l'Equateur selon l'auteure ${ }^{1572}$. Souvent par méconnaissance des conséquences qui les attendent durant les hostilités et par contraintes ou pressions énumérées ci-haut, les enfants adhèrent «volontairement » aux forces ou groupes armés. Ceci est d'ailleurs prouvé par le Procureur de la CPI dans ses accusations contre Thomas Lubanga lorsqu'il affirme: «[1]es enfants qui se montraient réticents, par crainte d'être tués pendant les combats, étaient contraints de prendre part aux hostilités sous peine d'être exécutés. Craignant pour leur vie, ils obéissaient aux ordres et ont tué à maintes reprises des Lendu, civils et militaires ${ }^{1573}$. Le moins qu'on puisse dire est que les enfants ne sont pas autant libres que leur volonté. C'est dans ce sens que la Chambre de première instance de la CPI, dans la même affaire, conclut «que les filles et les garçons de moins de quinze ans ne sont souvent pas à même de donner un consentement véritable et éclairé lorsqu'ils s'enrôlent dans une force ou un groupe armé ${ }^{1574}$.

Différentes pressions entourant l'enfant dans son milieu le pousse donc à agir dans le sens d'un enrôlement « volontaire ». En réalité, ce n'est que «l'absence de choix ou de véritable alternative ». Lucile COUTURIER-BOURDINIERE, pour confirmer ainsi l'argument de conclusion avancé précédemment par Marc SCHMITZ sur l'aspect du volontariat, explique clairement dans sa thèse de doctorat que «[d]ans les cas où les jeunes soldats n'ont pas été contraints de participer aux hostilités, ils sont néanmoins soumis à toutes sortes de pressions et d'influences souvent masquées et «sournoises» plus difficiles à éliminer que le recrutement forcé manifeste. Mais les véritables raisons de la participation volontaire sont très difficiles à apprécier car il existe une infinité de motivation ${ }^{1575}$.

\footnotetext{
1569 CHAPLEAU Philippe, Enfants-soldats. Victimes ou criminels de guerre ?, op.cit., p. 16.

${ }^{1570}$ SCHMITZ, Marc, «Les enfants-soldats, un phénomène universel de plus en plus préoccupant » «art.cit », p. 33.

1571 BRAECKMAN, Colette, «Le rêve brisé des enfants-soldats en République Démocratique », « art.cit. », pp. 50 et 49

1572 Ibid., p. 49.

1573 BODINEAU, Sylvie, Figures d'enfants soldats. Puissance et vulnérabilité. [...], op. cit., p. 40.

1574 CPI, Le Procureur c. Thomas Lubanga Dyilo, affaire N ${ }^{\circ}$ : ICC-01/04-01/06, Chambre de première instance, jugement, 14 mars 2012, http://www.icc-cpi.int/iccdocs/doc/doc1462060.pdf p. 307, § 613 (Source consultée le 22 mars 2015).

1575 COUTURIER-BOURDINIERE, Lucile, La protection internationale des droits de l'enfant, Thèse de doctorat en Droit, discipline : Droit international, droit européen, relations internationales, Université Panthéon-
} 


\section{B. Raisons ou motivations de recrutement}

«Le recrutement des enfants est généralement décrit comme le résultat d'une combinaison de facteurs. Ainsi, le besoin pressant de recrues et la malléabilité des enfants capables d'obéir aveuglement en feraient des proies privilégiées des forces et groupes armés ${ }^{1576}$.

Ainsi, il existe de nombreuses raisons ou motivations qui poussent les enfants à intégrer les forces ou groupes armés ou ceux-ci à recourir à ceux-là pour mener la guerre. En dépit de la généralisation, certaines zones de conflits pourraient présenter certaines spécificités comparativement à d'autres. Tout est fonction des réalités du milieu sous examen.

En effet, de nombreux facteurs justifient la présence des enfants sur le champ de bataille. D'une part, la recrudescence de recrutement et la participation des enfants dans les conflits reste généralement attribuée à l'augmentation du nombre de guerres civiles ; la profusion des armes légères qui atteste, par exemple pour la RDC, que « le flux massif d'armes légères [...] a rendu plus viable l'utilisation d'enfants soldats, car ces armes légères peuvent être facilement portées par les garçons et les filles âgés de moins de 10 ans ${ }^{1577}$. Le coût moins cher d'usage des enfants en conflits armés, etc. (cf. supra), voire d'autres facteurs particuliers suivant les milieux sont à épingler. D'autre part, des raisons ou motivations d'ordre socio-économique, culturel, idéologique et sécuritaire justifient l'engagement « volontaire » des enfants dans les forces ou groupes armés. S'inspirant des articles publiés sous la coordination de Marc SCHMITZ $^{1578}$, l'étude des raisons ou motivations à la base de recrutement (conscription ou enrôlement (volontaire)) des enfants dans les forces ou groupes armés abordera ces raisons sous les angles socio-économique, culturel, idéologique, sécuritaire et de tactique de guerre.

\section{B. 1. Raisons d'engagement « volontaire » des enfants}

\section{a. Raisons d'ordre socio-économique}

La situation socio-économique catastrophique de la RDC telle que présentée ci-dessus demeure d'une grande influence sur le recrutement massif des enfants. De nombreuses études attestent que les enfants soldats proviennent en quasi-totalité des milieux pauvres. A titre illustratif, dans une étude limitée aux seuls territoires de l'extrême nord de la province du Nord-Kivu, Beni et Lubero, il est révélé que «les enfants soldats se recrutaient principalement dans le milieu rural : ils étaient à près de $90 \%$ des enfants d'agriculteurs ou de travailleurs saisonniers dans un territoire où existaient de nombreux litiges fonciers. Leur niveau d'études était peu élevé puisqu'ils étaient 33\% à n'avoir fait aucune étude et $44 \%$ n'avoir terminé que le niveau primaire ${ }^{1579}$.

Ainsi, sans un avenir certain relayé par une absence d'alternative ou de choix, de nombreux enfants désœuvrés notamment les enfants de la rue, réfugiés, orphelins n'ont comme unique salut qu'adhérer aux forces ou groupes armés ${ }^{1580}$. Suivant plusieurs études de cas, les enfants

Assas (Paris II), juillet 1999, op.cit., p. 449.

1576 BODINEAU, Sylvie, Figures d'enfants soldats. Puissance et vulnérabilité. [...], op. cit., p. 42.

1577 Amnesty international, République Démocratique du Congo - Enfants en guerre, AI index: Afr 62/034/2003. Secrétariat international, document public, p. 4, in http://www.kongokinshasa.de/dokumente/ngo/ai_enfants_0903.pdf(Source consultée le 29 mars 2014).

1578 Lire SCHMITZ, Marc (coord.), La guerre. Enfants admis, op.cit,

1579 WILLAME, Jean-Claude, Les "Faiseurs de paix» au Congo. Gestion d'une crise internationale dans un Etat sous tutelle, op.cit., p. 119.

${ }^{1580}$ SCHMITZ, Marc, «Les enfants-soldats, un phénomène universel de plus en plus préoccupant », « art.cit. », 
sont encouragés dans ce sens par leurs parents surtout si la solde est directement versée à la famille ${ }^{1581}$.

En RDC, ce constat d'adhésion des enfants aux forces et groupes armés à la suite des situations socio-économiques désastreuses est établi dans différentes situations de rébellions. Une situation qui ne date pas des guerres contemporaines. L'on note, par exemple à Kasongo, dans le Maniema, sous la rébellion de Simba en 1964, que le désœuvrement et les conditions misérables de nombreux jeunes âgés de 12 à 20 ans les ont poussés à s'engager dans n'importe quel mouvement qui leur garantissait un changement d'existence ou la poursuite de leurs études ${ }^{1582}$. Au Kivu, lors de la rébellion menée par l'AFDL (octobre 1996- mai 1997), les enfants assuraient que, de toutes manières, dans le système mobutiste ils n'avaient pas d'avenir et qu'avant de faire des projets d'avenir, il leur fallait d'abord abattre la dictature ${ }^{1583}$. D'où leur adhésion aux forces et groupes armés. Cette situation est encore observable actuellement où de nombreux enfants s'enrôlent pour rechercher de quoi se nourrir, satisfaire à leurs besoins et surtout à leur sécurité (cf. infra $)^{1584}$.

\section{b. Raisons d'ordre culturel et idéologique}

Le souci de survie manifesté par des enfants dans une société congolaise chaotique est relayé par celui de considérations sociales. Les enfants estiment avoir certaines considérations de leur communauté de par leur statut de militaire. Ceci n'est non moins vrai quand l'on pense aux empressements de certains enfants voire les encouragements de leurs familles lors du périple de l'AFDL sur le vaste territoire de la RDC voire par la suite et actuellement. Situation qui trouve aussi justification, en partie, par les soldes de 100 dollars américains promises aux soldats, notamment pour le cas de l'AFDL.

Ainsi, dans les zones de conflits de l'est de la RDC, il existe une forme de « militarisation des esprits » ${ }^{1585}$. Le port de l'uniforme qui constitue désormais le «rêve de gamins » désœuvrés se situe déjà dans un milieu où adhérer à l'armée, prise comme gardienne de la patrie, acquiert certaine revalorisation ${ }^{1586}$ ou considération sociale.

Par ailleurs, comme il pourrait bien être remarqué, les guerres ethniques que vivent certaines communautés, par exemple les Lendu et les Hema en Ituri, les guerres civiles ou guerres en général, sont à la base d'une croissance de recrutement et d'utilisation des enfants soldats. Les milieux se trouvent quotidiennement occupés par les activités militaires, quoi de plus normal de militariser les esprits faibles des enfants ! Ces derniers se sentent dans l'obligation de défendre leur communauté ou leur terre au risque de la voir être soumise au pouvoir de l'ennemi. C'est ainsi que pour de nombreux enfants et adultes, leur appartenance ethnique

\footnotetext{
32.

1581 Ibid, pp. 32-33.

1582 VERHAEGEN, Benoit, Rébellions au Congo. Maniema, Tome II, Bruxelles-Kinshasa, C.R.I.S.P- Bruxelles, I.R.E.S - Kinshasa, 1969, p. 312.

1583 BRAECKMAN, Colette, «Le rêve brisé des enfants-soldats en République démocratique du Congo », in SCHMITZ, Marc, op.cit., p. 45.

1584 Lire Amnesty international, République Démocratique du Congo - Enfants en guerre, AI index : Afr 62/034/2003. Secrétariat international, document public, op. cit., p. 5, in http://www.kongokinshasa.de/dokumente/ngo/ai_enfants_0903.pdf(Source consultée le 29 mars 2014).

${ }^{1585}$ BRAECKMAN, Colette, «Le rêve brisé des enfants-soldats en République démocratique du Congo », in SCHMITZ, Marc, op.cit., p. 101.

${ }^{1586}$ Ibid.
} 
n'est pas seulement une question d'identité mais implique un devoir actif de défendre et d'affirmer les valeurs de leur groupe contre celles des groupes adverses, par la force si nécessaire ${ }^{1587}$. A ce titre, les enfants acquièrent des «statuts » particuliers vis-à-vis de leurs communautés respectives qui les considèrent comme des véritables défenseurs ou héros. Ceci vaut également pour des conflits qui sont des conflits des territoires ou d'occupation en RDC. Colette BRAECKMAN nous renseigne en ces termes : " [...] alors que, dans d'autres pays d'Afrique, le Sierra Leone, le Liberia, les enfants - soldats sont de petits délinquants, souvent drogués, utilisés par les chefs de guerre locaux, au Congo, les enfants-soldats sont différents. Aux yeux de leur famille, ceux qui ont été enlevés par les forces rebelles sont perçus comme des victimes et seront probablement traités comme tels lorsqu'ils rentreront chez eux. Quant aux autres, engagés aux côtés des Maï-Mä̈, ils sont considérés comme des résistants, ayant accompli un devoir patriotique et il est frappant de constater, à Bukavu par exemple, que tous reconnaissent les Mä̈-Maï comme "leurs enfants » et sont prêts à les traiter en héros lorsque la guerre sera terminée ${ }^{1588}$. Ces conflits ethniques forgent les esprits des générations entières à lutter contre les adversaires. Des membres des communautés se relayent pour ne pas perdre face. S'y trouve perpétré un esprit de «vengeance par le sang » où l'on voit souvent des enfants prendre les armes pour «réparer» la mort de leur proche ${ }^{1589}$. Et dans la région où les hostilités sont la règle, posséder une arme ou intégrer un groupe armé ou une force armée assure une certaine sécurité.

\section{c. Raisons d'ordre sécuritaire}

Bien plus, l'armée se présente pour la plupart d'enfants, orphelins du fait même de ces différentes guerres, comme un cadre d'abri ou de protection aux attaques communautaires ou des parties adverses au combat. Car étant porteurs d'armes à feu, les enfants peuvent en faire usage à titre de «légitime défense ». Ayant perdu les parents dans des guerres déclenchées et ciblées contre certaines communautés ou populations civiles, les enfants se fient donc aux forces ou groupes armés pour se «protéger» des «tracasseries», des «intimidations » ou des attaques des membres des forces armées, groupes armés ou communautés ennemies. Amnesty International appuie cet argument en ce sens « [1]a pauvreté généralisée et l'éclatement des services sociaux de base, comme l'éducation et le centres de soins, ont donc poussé des orphelins et des enfants séparés de leur famille lors de la panique engendrée par une attaque armée, à rechercher la protection d'un groupe armé pour assurer leur propre sécurité, leurs besoins en nourriture et satisfaire leur sentiment d'appartenance à un groupe, même si celui-ci est violent $»^{1590}$.

\footnotetext{
${ }^{1587}$ HABIBU, Jean Bosco, op.cit., p. 62.

${ }^{1588}$ BRAECKMAN, Colette, «Le rêve brisé des enfants-soldats en République démocratique du Congo », in SCHMITZ, Marc, op.cit., pp. 52-53.

${ }_{1589}$ SCHMITZ, Marc, «Les enfants-soldats, un phénomène universel de plus en plus préoccupant », «art.cit », p. 30 .

${ }^{1590}$ Amnesty international, République Démocratique du Congo. Enfants en guerre, AI index : Afr 62/034/2003. Secrétariat international, document public, op. cit., p. 5, in http://www.kongokinshasa.de/dokumente/ngo/ai_enfants_0903.pdf (Source consultée le 29 mars 2014).
} 


\section{B. 2. Raisons de recrutement forcé (conscription) des enfants par les Forces et groupes armés}

Dans l'entretien précité du 26 octobre 2006 avec Philippe CHAPLEAU, Lucien BADJOKO, le kadogo âgé de douze ans au moment de son recrutement en octobre 1996 sous l'AFDL, indiquait :

«Les enfants, ce sont les meilleurs combattants du siècle, mon cher frère. Ils ont plus d'énergie que les vieux. Ils résistent, sans ressentir la douleur physique. Ils ont plus de résistance. J'ai vu des vieux, disons des hommes adultes, qui avaient les pieds qui gonflaient au bout de quelques kilomètres. Et ils geignaient sur le bord de la piste. Nous, on continuait. Au combat, c'était pareil. Quand il y avait des face-à-face, des histoires terribles, les vieux papas commençaient à pleurer ; certains cherchaient à fuir. Et pourtant, c'était des anciens des Faz, les forces armées zaïroises. Nous, les Kadogos, on n'avait pas peur. La peur, c'est ce qui faisait mourir beaucoup de gens. On avait le moral et on appliquait ce qu'on nous avait appris. En fait, on n'avait rien à voir avec les anciens, les déserteurs de l'armée de Mobutu. Eux, ils avaient fait une carrière dans l'armée, des études pour être militaires... Nous, nous étions pas des militaires; nous étions des combattants. La formation qu'on avait reçue, c'était pour aller faire la guerre : monter et démonter les armes, tirer, progresser. Ça n'avait rien à voir avec l'armée, le règlement, la discipline $»^{1591}$.

Ce récit d'enfant soldat vantant les mérites de Kadogo atteste par ailleurs le facteur de motivation pour les belligérants de recourir aux enfants dans les conflits armés. Il traduit en même temps le degré très faible voire quasi-inexistant de formation militaire proprement dite des enfants soldats. Cette absence de formation militaire appropriée aura à coup sûr une incidence négative sur le respect des règles du DIH (cf. infra). Ces enfants sont visiblement considérés comme des «machines à tuer» efficaces. Bien plus, ces enfants «coûtent nettement moins chers que des soldats adultes, explique Ray Torres (UNICEF), ils mangent moins, leur solde est minime et ils n'ont pas d'autres exigences ${ }^{1592}$. Ce qui pourrait également être vu comme une efficience. Au Congo, selon le témoignage d'un officier rebelle qui vantait les mérites des enfants soldats en 1998 : rien ne les tracasse, ils obéissent aux ordres et ne sont pas préoccupés par leur retour en familles, auprès de leurs épouses ${ }^{1593}$. Aux vues des recruteurs, les enfants soldats présentent également d'autres atouts par le fait notamment qu'ils sont plus faciles à motiver ou à manipuler, ne craignent pas des opérations risquées, sont plus vite intimidés, moins enclins à déserter, s'adaptent mieux à un nouvel environnement... ${ }^{1594}$

Cependant, les mérites vantés des enfants soldats sont à tempérer. En effet, on ne mène pas une guerre de n'importe quelle manière pour espérer à une victoire. Ce qui justifie d'ailleurs la présence de nombreuses écoles de guerre pour former les militaires aux stratégies et tactiques de guerre. La guerre n'est pas un simple combat armé. Au-delà des aspects matériels sur terrain, il y a des cellules d'études qui ne cessent d'analyser régulièrement la situation afin de mettre en place des plans de guerre pouvant amener les troupes à une victoire sans faire

\footnotetext{
${ }^{1591}$ CHAPLEAU Philippe, Enfants-soldats. Victimes ou criminels de guerre ?, op.cit., pp. 15-16.

1592 SCHMITZ, Marc, «Les enfants-soldats, un phénomène universel de plus en plus préoccupant », «art.cit », p. 35 .

${ }_{1593}$ Ibid.

${ }^{1594}$ Ibid.
} 
trop des victimes ou des dégâts collatéraux. C'est l'intelligence au service de la guerre.

La guerre reste donc subordonnée à certains nombres de facteurs que Sun Tzu énumère à cinq (la vertu, le climat, la topographie, le commandement et l'organisation). Lesquels facteurs doivent être pris en considération afin de déterminer avec exactitude la balance des forces ${ }^{1595}$. Les combattants se retrouvent au centre de ces facteurs. Ainsi, la conduite de la guerre dépend de comportement de beaucoup d'entre eux. Le commandant peut avoir un meilleur plan de guerre mais celui-ci doit pour son exécution la coopération qualitative des combattants. Bien qu'il soit dit qu' «il n'y a pas de mauvaises troupes mais de mauvais commandants », les troupes composées des soldats sans expériences, sans maîtrises de certaines stratégies ou tactiques de combat seront plus vouées à l'échec. C'est dans ce sens que certains doutent de l'efficacité des enfants soldats : ils ralentissent les troupes en mouvement, en raison de leurs bêtises il faut souvent les réprimander, durant les hostilités ils ne sont guère prudents, puis ils ne savent pas se débrouiller (se laver, cuisiner, prendre soin de soin)... ${ }^{1596}$

De ce qui précède, la recrutement des enfants soldats en RDC tend généralement à se « normaliser » et à s'accroître dans des zones de conflits armés. Les forces et groupes armés recourent aux enfants en suivant notamment le comportement des parties ennemies qui ne trouvent «aucun inconvénient» à en recourir. Il est à noter que, pendant la guerre d'« agression » déclenchée le 2 août 1998, à l'exception des forces armées de l'Angola, de la Namibie et du Zimbabwe, venues à la rescousse des FAC sous Laurent-Désiré KABILA, toutes les parties ont recouru à l'utilisation des enfants soldats. Laurent-Désiré KABILA, alors Président de la République, face à la guerre éclatée le 02 août 1998, n'a point hésité de recourir à une de ses anciennes méthodes rebelles consistant à battre campagne pour le recrutement d'enfants-soldats. Ceci sera fait le 07 août 1998 par voie d'un communiqué officiel. Plus de 5000 adolescents répondront présents. Bon nombre d'enfants qui s'étaient engagés "volontairement" l'ont fait dans l'espoir de recevoir un salaire, de la nourriture et un statut social ${ }^{1597}$. De leurs côtés, les groupes armés présents n'ont cessé de sillonner notamment les zones fréquentées régulièrement par les enfants, les écoles, marchés, etc., pour les kidnapper et les enrôler de force ou battre campagne à ce sujet (cf. supra). Actuellement, le Mécanisme de surveillance et de communication de l'information du Conseil de sécurité des Nations Unies liste différentes parties recourant aux enfants pour faire la guerre (cf. le dernier chapitre de cette étude).

\section{§3. Participation des enfants aux conflits armés}

\section{A. Identification des Recruteurs et des enfants participants aux conflits armés}

Depuis près de deux décennies, la RDC connaît des conflits armés où différentes parties recourent aux enfants (notamment de moins de quinze ans) pour en faire des soldats. Si les preuves ne sont pas rapportées au sujet des forces étrangères intervenues sur invitation du gouvernement congolais -Angola, Zimbabwe et Namibie- toutes les parties sont unanimement

\footnotetext{
1595 SUN TZU, L'art de la guerre. Traduit du chinois et commenté par Jean Levi, Librairie Arthème Fayard/Pluriel, Paris, 2010, p. 53.

${ }^{1596}$ SCHMITZ, Marc, «Les enfants-soldats, un phénomène universel de plus en plus préoccupant », «art.cit », p. 36.

${ }_{1597}$ BRAECKMAN, Colette, «Le rêve brisé des enfants-soldats en République démocratique du Congo », in SCHMITZ, Marc, op.cit., p. 48.
} 
citées comme ayant fait recours aux enfants (notamment de moins de quinze ans) dans les conflits armés. Les forces et groupes armés présents ont recouru impunément aux enfants (notamment de moins de quinze ans) pour faire la guerre à leurs adversaires. Les enfants, pour différentes raisons, sont présentés sur le champ de bataille comme les «instruments » offrant plus des résultats attendus.

En effet, « en RDC, la pratique du recrutement de jeunes s'est quasi-institutionnalisé avec le lancement de l'offensive de Laurent-Désiré Kabila et son AFDL en 1996. C'est durant cette année en effet que l'on vit apparaître dans la ville de Bukavu le phénomène de recrutement et de formation militaire dispensée à plusieurs milliers d'enfants soldats appelés Kadogo $[\ldots]^{1598}$ ». Depuis lors, ce phénomène, qui était également connu sous les rébellions des premières heures d'indépendances (rébellions mulélistes surtout voire de Kalonji Ditunga), mais non signalé sous les FAZ de Mobutu, est devenue une pratique admise dans différents groupes et forces armés.

Les forces régulières congolaises, FAC, dès le déclenchement de la guerre du 02 août 1998, avaient lancé une campagne de recrutement des volontaires dont nombreux étaient des enfants poussés par la promesse de cent dollars américains à titre de solde. Malgré le processus de démobilisation massive entreprise dès 2004 après un début timide en décembre 2001 à la suite de la promulgation d'un décret-loi sur la démobilisation une année plus tôt (Décret-loi du 09 juin 2000 portant sur la démobilisation et la réinsertion des groupes vulnérables), les FAC ne sont pas totalement détachés des enfants soldats (notamment de moins de quinze ans) comme l'attesteront différents rapports ultérieurs. A l'instar de ses adversaires, les autres forces ou groupes armés, l'armée régulière assure la pratique de « recrutement » qui est généralement suivie de celle de « re-recrutement » lorsque le besoin se présente. Les estimations des enfants soldats dans les rangs des forces régulières étaient de l'ordre de $10 \%{ }^{1599}$. Les efforts du gouvernement congolais dans la mise en œuvre de son plan d'action ne permettrait tout de même pas de maintenir un tel chiffre à ce jour.

Recrutés pour être utilisés dans les conflits armés, les enfants (notamment de moins de quinze ans) y participent par différentes méthodes ${ }^{1600}$. Les autres forces armées étrangères dont l'Ouganda et le Rwanda sont également réputées d'avoir directement et indirectement fait usage des enfants (notamment de moins de quinze ans) dans les conflits armés en RDC. Indirectement via leurs alliés congolais, des groupes armés ou milices opérant sur le territoire congolais. L'Ouganda par exemple appuyait de différentes formes (stratégiquement, militairement, logistiquement, etc.) le MLC de Jean Pierre BEMBA qui n'est non moins cité dans le recrutement des enfants dans les conflits armés. Différentes milices opérant en Ituri avec un grand nombre de mineurs dans leurs rangs ont bénéficié du soutien de l'Ouganda pour mener la guerre en passant par le contrôle des ressources naturelles présentes dans la région. C'est le cas notamment des Forces armées pour le Congo (FAPC), milice regroupant des ethnies Lugbara, Alur et Kabwa qui ont repoussé l'Union des Patriotes Congolais de Thomas LUBANGA (milice de tendance de l'ethnie Hema) hors de Bunia en mars 2003. L'armée ougandaise « rapprocha ensuite les FAPC et deux autres milices le PUSIC (Parti

1598 WILLAME, Jean-Claude, Les «Faiseurs de paix » au Congo. Gestion d'une crise internationale dans un Etat sous tutelle, op.cit., p. 118.

${ }^{1599}$ Ibid.,p. 119.

${ }^{1600}$ A/70/836 - S/2016/360 le sort des enfants en temps de conflits armés, op. cit., p. $3, \S 11$. 
pour l'unité et la sauvegarde de l'intégrité du Congo) composé de Hema du sud, et le FNI (Front nationaliste et intégrationniste) lendu, afin qu'ils contrôlent la ville, avec l'aide d'armement lourds, notamment des mortiers, qu'elle leur fournit ${ }^{1601}$. Il s'agit là des groupes et milices réputés des grands recruteurs d'enfants soldats. La moitié de leur rang est généralement composée des enfants soldats. D'autre part, un autre grand groupe armé qui a bénéficié du soutien inlassable de l'Ouganda est le RCD-ML de Mbusa Nyamwisi avec sa branche militaire -Armée populaire congolaise- indexé également comme recruteur des enfants soldats. Pour le Rwanda, des enfants soldats du RCD-Goma allaient subir même des entraînements ou formations au sein de son armée régulière. Le RCD-Goma qui a eu des accointances avec l'ex Congrès National pour la Défense du Peuple (CNDP) devenu luimême « M23 » n'ont pas épargné les enfants dans leurs troupes. Les Maï-Maï, connus pour la plupart de défenseurs des autochtones de l'allochtonie ne sont pas en marge de cette pratique dans le Kivu ${ }^{1602}$.

Par ailleurs, le district d'Ituri dans la Province orientale est épinglée dans différents rapports et écrits comme une des parties du territoire qui a subi le plus le drame des enfants soldats. Cela n'est donc pas étonnant que le cas déféré devant la CPI au sujet de conscription des enfants dans les conflits armés concerne cette partie du territoire national avec l'UPC de Thomas LUBANGA.

Le district d'Ituri a connu entre 1997 et 2003 des conflits récurrents d'ordre tribal ou ethnique. A la base une douzaine de milices se réclamant de différentes tribus ou ethnies de la région. Soutenus par différents parrains qui sont notamment l'Ouganda, le Rwanda, le MLC ou le gouvernement congolais, nombre de ces milices incluaient des enfants soldats, parfois jusqu'à $60 \%{ }^{1603}$. Suivant le rapport du Président de 1'UNICEF Canada (cf. supra), dans le district d'Ituri, les groupes armés comptent de 10.000 à 15.000 enfants dont certains n'ont même pas dix ans ${ }^{1604}$. Parmi ces groupes armés opérant dans la région, les plus importants cités sont l'Armée populaire congolaise, branche armée du RCD-ML, le Front Nationaliste et Intégrationniste (FNI) de tendance Lendu, la Force des Résistances Patriotiques d'Ituri (FRPI) de tendance Ngiti, l'Union des Patriotes Congolais (UPC). D'autres également épinglés (FAPC, PUSIC) sont sur la liste. Tous ces mouvements rebelles, au-delà de lutte de suprématie dans la région, se battent pour le contrôle des ressources naturelles pour lesquelles d'ailleurs leurs parrains extérieurs restent très attachés.

Par ailleurs, le nombre d'enfants se trouvant sur le champ de bataille varie d'un organisme à un autre, d'une période à une autre, au regard des mouvements de recrutement, de démobilisation et de re-recrutement des enfants. En 2003, 23.000 enfants étaient le nombre estimé par l'UNICEF contre 30.000, nombre rapporté par Amnesty international sur tout le territoire national en la même année. Toujours pour cette même année, dans un article intitulé La RD Congo: les groupes armés intensifient l'utilisation d'enfants, l'auteur avance le

1601 REMACLE, Eric et MARTINELLI, Marta, «La RDC, laboratoire des actions militaires et de police européenne », in REMACLE, Eric et al. (dir.), L'Afrique des Grands Lacs. Des Conflits à la paix ? Bruxelles, P.I.E. Peter Lang, 2007, p. 214.

${ }^{1602}$ Voy. KAGANDA MULUMEODERWA, Philippe, «Analyse des modèles de réinsertion des enfants exsoldats filles à l'Est de la R.D. Congo », « art. cit. », pp. 86-87.

${ }^{1603}$ REMACLE, Eric et MARTINELLI, Marta, «La RDC, laboratoire des actions militaires et de police européenne », in REMACLE, Eric et al. (dir.), L'Afrique des Grands Lacs. Des Conflits à la paix ? Bruxelles, op. cit., p. 214.

${ }^{1604}$ HABIBU, Jean Bosco, op.cit., p. 66. 
nombre de la moitié des 130.000 d'enfants soldats d'Afrique pour la RDC ${ }^{1605}$. Pour les Nations unies, entre 2010 et 2013, 4.200 cas de recrutement et utilisation d'enfants (garçons et filles) ont été recensés ${ }^{1606}$. Suivant l'Association le BVES ${ }^{1607}$ dans un communiqué publié sur le site de l'ONG Child Soldiers International à l'occasion de la célébration en RDC de la journée mondiale contre le recrutement et l'utilisation d'enfants, en 2013, les enfants soldats étaient estimés entre 33.000 et 100.000 sur toute l'étendue de la RDC. En 2014, suivant cette même association, ils sont estimés à près de 4.000 enfants utilisés essentiellement par les groupes armés (étrangers et congolais) ${ }^{1608}$. Il y a lieu tout de même lieu de prendre du recul par rapport aux derniers chiffres avancés et s'interroger sur le justificatif de la spectaculaire démobilisation des enfants entreprise en une année. Peut-être le fonctionnement positif du plan d'action signé le 04 octobre 2012 par le gouvernement congolais contre le recrutement et l'utilisation d'enfants soldats. Ce qui semble encore très aléatoire dans sa mise en œuvre (cf. infra). Tout de même, pour ladite ONG, il y a lieu d'espérer que la RDC se dirige vers une victoire finale contre ce crime de guerre, moyennant la mise en œuvre du programme actuel de DDR enfants en gestation, la réussite du processus de pacification et l'appui continu de la communauté internationale vers une paix durable et la lutte contre l'impunité vis-à-vis des crimes contre l'humanité et des crimes de guerre ${ }^{1609}$.

De ce qui précède, l'on peut comprendre que ces enfants se recrutaient par milliers dans des milieux ruraux, pauvres, afin de faire face à leurs survies personnelles et celles de leurs communautés respectives. Bien plus, «[d]ans la plupart de cas, le recrutement d'enfants est directement lié à l'évolution du conflit en cours et augmente lorsque de nouvelles hostilités éclatent $»^{1610}$.

D'un autre côté, il y a un mouvement de désarmement, démobilisation et réintégration (DDR) sociale des ex-enfant soldats ${ }^{1611}$. «Jusqu'en 2006, la commission gouvernementale chargée du DDR en RDC n'avait démobilisé que 19.000 ex-enfants soldats avant de connaître des difficultés, selon l'UNICEF ${ }^{1612}$. Depuis 2004 avec le commencement du programme DDR, les acteurs de la protection de l'enfance ont facilité la sortie et la prise en charge de plus de 36.000 enfants associés aux forces et groupes armés. Un problème se pose tout de même pour

1605 TOEKA KAKALA Taylor, «RD CONGO: Les groupes armés intensifient l'utilisation d'enfants », in http://www.ips.org/fr/rd-congo-les-groupes-armes-intensifient-lutilisation-denfants/ (source consultée le 05 mai 2014).

1606 Centre régional d'information des Nations unies pour l'Europe occidentale, Enfants de la République démocratique $d u$ Congo, http://www.unric.org/fr/actualite/2727-enfants-de-la-republique-democratique-ducongo (Source consultée le 31 octobre 2015).

${ }_{1607}$ BVES est une association sans but lucratif basée à Bukavu (Sud-Kivu) qui ouvre depuis 1992 pour la promotion, la protection et la défense des droits fondamentaux des enfants victimes de la marginalisation économique et sociale ainsi que des enfants victimes des conflits armés en RDC.

${ }^{1608}$ Lire «L'organisation partenaire BVES-RDC appelle à plus de bruit dans les communautés pour dire NON au recrutement et à l'utilisation d'enfants soldats en République Démocratique du Congo », in http://www.childsoldiers.org/francais_report_reader.php?id=741 (Source consultée le 04 mai 2014).

${ }^{1609}$ Lire Ibid.

1610 \$19 Rapport du Secrétaire général sur les enfants et les conflits armés en République Démocratique du Congo, S/2008/693, in http://www.un.org/fr/documents/view doc.asp?symbol=S/2008/693 (Source consultée le 20 février 2016).

${ }^{1611}$ Lire utilement la thèse de doctorat en Droit de FURAHA MWAGALWA, Thomas, L'interdiction de la participation aux hostilités, la démobilisation et la réinsertion des enfants soldats en République Démocratique du Congo, op.cit., 533 p.

1612 TOEKA KAKALA Taylor, «RD CONGO: Les groupes armés intensifient l'utilisation d'enfants », «art. cit. », in http://www.ips.org/fr/rd-congo-les-groupes-armes-intensifient-lutilisation-denfants/ (source consultée le 05 mai 2014). 
les filles qui ont très peu d'accès aux programmes DDR. Devenues épouses des combattants voire mères, les enfants soldats filles sont très difficilement relâchées par les forces et groupes armés. Au demeurant, elles ne sont pas si facilement identifiables notamment pour crainte personnelle de stigmatisation mais également par le fait que leur présence est généralement niée par leurs bourreaux ${ }^{1613}$. Bien avant 2009 , seuls $20 \%$ des filles enfants soldats étaient soutenus dans ce processus par l'UNICEF et ses partenaires. Des efforts ont été fournis notamment au courant de l'année 2009. Un total de 5.930 enfants a été démobilisé, dont 1.222 filles, lors du processus d'intégration rapide des groupes armés dans les FAC - devenues Forces Armées de la République Démocratique du Congo (FARDC) à l'issue de l'Accord global et inclusif qui exigeait une armée nationale, restructurée et intégrée - au début de l'année 2009 à l'est du pays ${ }^{1614}$. Des efforts restent encore à fournir. Toutefois, les risques de réintégration au sein des forces et groupes armés restent permanents pour des enfants qui hier étaient démobilisés.

En effet, sous la pression de la Communauté internationale, le régime de Laurent Désiré Kabila au pouvoir à Kinshasa devrait mettre fin à la présence des enfants soldats, Kadogo, au sein des Forces Armées Congolaises (FAC). C'est dans ce sens qu'en décembre 2001, une année et six mois après la promulgation du décret-loi du 09 juin 2000 sur la démobilisation que les enfants furent cantonnés dans un centre de démobilisation où on ne s'occupa pas d'eux. L'espoir d'une vie meilleure au sein de l'armée s'est donc envolé. Certains d'entre eux réussirent à regagner leurs provinces d'origines où ils reprirent service avec les groupes ou forces armées opérant dans la région ${ }^{1615}$. Il ne s'agit pas d'un cas isolé. Un autre cas illustratif parmi tant d'autres est celui d'un ex- enfant soldat nommé Maurice. Cet ex-enfant soldat âgé de 16 ans associé aux forces et groupes armés a été retiré de nouveau d'une milice du NordKivu et accueilli au Centre de transit et d'orientation pour ex-enfants soldats (CTO) de Nyakariba, dans la province du Nord-Kivu, afin de réintégrer dans la vie civile. Son seul espoir reposait sur une chèvre que 'Caritas Goma' lui avait offerte pour reprendre la vie civile. Chèvre qui sera consommée par sa famille à son absence. Il dira par la suite : "Contraint par des difficultés économiques après ma première réunification familiale..., j'ai donc pris la décision de retourner aux armes". Il a rejoint la milice Nyatura, après avoir été démobilisé du groupe des Patriotes Résistants Congolais (PARECO). Le processus de démobilisation recevra une véritable désapprobation avec la création de M23 en avril 2012. Ceci a «entraîné une forte augmentation du nombre de violations graves des droits de l'enfant ${ }^{1616}$. comme l'épingle le Rapport du Secrétaire Général de l'ONU du 15 mai 2013. « Le M23 s'est livré au recrutement et à l'utilisation systématiques d'enfants ${ }^{1617}$. Sous cette vague, de nombreux groupes armés se sont livrés au recrutement et à l'utilisation des enfants soldats. Un plan d'action sera signé le 04 octobre 2012 entre le gouvernement de la RDC et l'ONU visant à faire cesser et à empêcher le recrutement et l'utilisation d'enfants ainsi que les violences

\footnotetext{
${ }^{1613}$ Voy. BODINEAU, Sylvie, Figures d'enfants soldats. Puissance et vulnérabilité...op. cit., pp. 48 et 91. 1614 «UNICEF: Le recrutement forcé des enfants soldats en RDC doit cesser», in http://www.un.org/apps/newsFr/storyF.asp?NewsID=21215\&Cr=Congo\&Cr1=\#.U2eBhmAVe1s $\quad$ (source consultée le 5 mai 2014).

${ }^{1615}$ WILLAME, Jean-Claude, Les «Faiseurs de paix » au Congo. Gestion d'une crise internationale dans un Etat sous tutelle, op.cit., p. 118.

1616 AG/NU et CS/NU, A/67/845-S/2013/245, Le sort des enfants en temps de conflit armé Rapport du Secrétaire Général, p. 16, \$56 http://www.un.org/fr/sc/documents/sgreports/2013.shtml (source consultée le 05 mai 2014 ).

${ }^{1617}$ Ibid., p. 17, \$59.
} 
sexuelles commises contre ces derniers par les forces armées et les forces de sécurité. Ainsi en cette année 2012, 1.497 enfants (1.334 garçons et 163 filles) ont été démobilisés ou ont fui les rangs des forces et des groupes armés ${ }^{1618}$.

De ce qui précède, au-delà du problème de coordination des chiffres à constater, il importe d'affirmer avec Amnesty International qu« aucun des groupes armés opérant dans l'est du pays n'est sérieusement impliqué dans des initiatives de démobilisation. Au contraire, ils continuent même à recruter de nouveaux enfants. (Ou alors) ils sont surveillés de près par leurs «commandants» après leur démobilisation et sont à nouveau recrutés lorsque ces commandants ont besoin de regarnir leur effectifs en prévision de nouveaux combats ${ }^{1619}$.

A ce propos, le dernier rapport (à la conclusion de cette thèse) du SG/NU dont l'étude couvre la période de janvier à décembre 2015, publié le 20 avril 2016, confirme cette continuité par «l'enrôlement de 488 enfants (parmi lesquels 26 filles), dont $30 \%$ étaient âgés de moins de quinze ans au moment du recrutement. C'est plus du double des cas recensés en 2014. Dans $89 \%$ des cas, le recrutement et l'exploitation de ces enfants se sont produits dans le Nord-Kivu, et ils sont imputables pour près de la moitié aux FDLR (219), suivis par les Raïa Mutomboki (89), les Nyatura (69) et d'autres groupes (111) » ${ }^{1620}$. Rien n'atteste que les FARDC n'ont pas procédé à cette pratique. A ce sujet, ce rapport atteste qu' « [e]n juillet [2015], 10 garçons recrutés en 2013 et 2014 ont échappé aux FARDC et ont indiqué qu'ils avaient participé, l'année de leur recrutement, à des opérations militaires dans le Nord-Kivu. L'ONU s'est mise en relation avec les FARDC qui lui ont déclaré avoir suspendu les commandants présumés responsables et ouvert une enquête $[\ldots] \gg^{1621}$.

Recrutés pour être utilisés dans les conflits armés, les enfants y participent par différentes méthodes.

\section{B. Méthodes de participation des enfants aux hostilités}

«Entraînés, équipés et asservis, les enfants soldats n'ont plus qu'à remplir leurs missions. Ils n'occupent, certes, aucune des fonctions militaires qui requièrent une connaissance technologique poussée : ils ne pilotent pas d'aéronefs, ne travaillent pas dans les bases de détections ou de transmissions ou ne mettent pas en œuvre des batteries de missiles ${ }^{1622}$. Cependant, les enfants soldats jouent un rôle indubitablement important dans l'avancée des troupes auxquelles ils appartiennent. Si d'aucuns admettent que dans la pratique des conflits actuels l'utilisation des enfants soldats dans le combat proprement dit n'est pas forcément systématique ${ }^{1623}$ ou encore rarement recourue ${ }^{1624}$, toutefois, il sied de dire que les enfants assument des rôles non moins négligeables. En raison de leurs tailles et poids notamment, ils sont de plus en plus utilisés comme espions, messagers, informateurs, ou agents de liaison et

\footnotetext{
1618 Ibid., p. 19, §65.

1619 WILLAME, Jean-Claude, Les «Faiseurs de paix » au Congo. Gestion d'une crise internationale dans un Etat sous tutelle, op.cit., p. 119.

${ }^{1620} \mathrm{~A} / 70 / 836$ - S/2016/360 le sort des enfants en temps de conflits armés, op. cit., pp. 11, §45.

${ }^{1621}$ Ibid., pp.10-11.

1622 CHAPLEAU Philippe, Enfants-soldats. Victimes ou criminels de guerre ?, op.cit., pp. 151-152.

${ }^{1623}$ BAILLON, Thierry, «A l'écoute des enfants-soldats », in SCHMITZ, Marc (coord.), op.cit., p. 103.

1624 Lire THONIER, Jean-Paul, «Le militaire en opération multinationale face aux enfants-soldats », in BABIKER, Mohamed Abdelsalam, DAUBLAIN, Maxence et VAHLAS, Alexis (dir.), Enfants-soldats et droits des enfants en situation de conflit et post-conflit. Réalités et enjeux, op.cit., p. 192.
} 
de renseignement, guetteurs ou sentinelles, voire comme porteurs, cuisiniers, ou en groupe pour contrôler un bâtiment ou un check point, gardes du corps, boucliers humains, kamikaze ou démineurs, pourvoyeurs de munitions ou de drogue, intendant des troupes, domestiques ou esclaves sexuels, etc. ${ }^{1625}$ Positions qui ne les dispensent tout de même pas d'être envoyés aux fronts pour un combat actif lorsque le besoin se fait sentir. Une étude réalisée sur les enfants soldats filles sur les territoires de Bukavu, Kalehe, Kabare, Uvira, Walungu et Mwenga (SudKivu) atteste ce point de vue. Ainsi, bien que leurs activités principales soient les travaux domestiques, l'exploitation sexuelle, l'espionage et le déplacement des armes et munitions, les enfants soldats filles ne sont pas exclues de combats bien que faiblement ${ }^{1626}$.

En clair, il existe une multitude de fonctions ou missions qui sont confiées aux enfants en période des hostilités.

$\mathrm{Au}$ combat proprement dit, ils jouent le rôle d'éclaireurs. D'où le nom de "songa-mbele" (troupes avancées) attribués à des kadogo en RDC. Un kadogo en témoigne d'ailleurs sous la plume de Thierry BAILLON : "Un jour, nous avons attaqué l'ennemi qui occupait une petite colline. Le commandant a d'abord envoyé une petite troupe. Tous les enfants du bataillon en faisaient partie. On devait avancer vers le sommet de la colline, l'autre groupe plus important nous suivait à une certaine distance. Il fallait être visible pour que les ennemis nous tirent dessus ; ainsi l'autre groupe savait où ils étaient et pouvait les attaquer ${ }^{1627}$. A ce kadogo de conclure que c'était une tactique utilisée également par les parties adverses. Laquelle pouvait marcher ou pas. C'est ainsi qu'il a été observé qu'au combat les enfants soldats opèrent principalement dans des unités d'infanterie ou des commandos de reconnaissance, rarement équipés d'armes lourdes au regard de leurs poids afin de faciliter leur mobilité, leur discrétion ou camouflage. Ils s'avèrent très utiles dans les combats de basse et de moyenne intensité ${ }^{1628}$. Plus concrètement, sur différents fronts de combat, lors de la chute de Mobutu par l'AFDL de Laurent Désiré KABILA par exemple, les troupes alliées rwandaises s'occupaient de l'armement lourd alors que les Kadogo jouaient véritablement le rôle d'éclaireurs ci-haut décrit.

Par ailleurs, des enfants soldats sont aussi utilisés par des commandants pour de différents types de missions suicidaires. Des massacres non seulement du côté de leurs adversaires mais aussi des paisibles civils, sans oublier des viols ou violences sexuelles, agressions, brutalités qu'ils font subir à ceux-ci, sont autant d'actes que commettent ces enfants, souvent, sur ordre de leurs commandants. Il a été dit précédemment que pour avoir un sang froid et surtout dans l'optique de ne plus permettre leur retour dans leurs communautés, les enfants devraient accomplir des missions de tueries. C'est dans ce sens qu'ils devraient tuer ou violer un membre de leurs communautés d'origine voire de leurs propres familles. Ainsi, rejetés par les communautés ou familles, ces enfants ne pouvaient plus y retourner surtout à la suite de

${ }^{1625}$ Lire THONIER, Jean-Paul, « Le militaire en opération multinationale face aux enfants-soldats » in BABIKER, Mohamed Abdelsalam, DAUBLAIN, Maxence et VAHLAS, Alexis (dir.), Enfants-soldats et droits des enfants en situation de conflit et post-conflit. Réalités et enjeux, op.cit., p. 192; CHAPLEAU Philippe, Enfants-soldats. Victimes ou criminels de guerre?, op.cit., 153. ; BAILLON, Thierry, « A l'écoute des enfantssoldats » in SCHMITZ, Marc (coord.), op.cit., p. 103 et WHITMAN, Shelly, ZAYED, Tanya et CONRADI, Carl, Enfants soldats : Un guide pour les intervenants du secteur de la sécurité, op.cit., pp. 29-31.

${ }^{1626}$ KAGANDA MULUMEODERWA, Philippe, « Analyse des modèles de réinsertion des enfants ex-soldats filles à l'Est de la R.D. Congo », « art. cit. », pp. 89-90.

${ }^{1627}$ BAILLON, Thierry, « A l'écoute des enfants-soldats » in SCHMITZ, Marc (coord.), op.cit., p. 103.

${ }^{1628}$ CHAPLEAU Philippe, Enfants-soldats. Victimes ou criminels de guerre?, op.cit., p. 152. 
meurtre ou assassinat commis. Cette attitude de «tueur professionnel» devrait également être observable contre leurs collègues. C'est dans ce sens que contre un de leurs camarades qui tenterait de fuir, les enfants étaient obligés de prendre part au meurtre de celui-ci. Ceci vaut de même à l'égard de leur camarade inapte ou défaillant. Les chanvres, drogues et alcools leurs étaient administrés pour avoir du courage de passer à l'acte. Les témoignages de deux enfants soldats rapportés par Amnesty International nous permettront d'être éclairé davantage. Le premier, Albert, recruté à l'âge de quinze ans par le RCD- Goma en 1999 indiquait ce qui suit : «Je peux vous dire par expérience personnelle que nous kadogos [...] nous étions plutôt nombreux. Après la capture d'un village, ce qui arrivait, c'est qu'ils nous donnaient du chanvre [haschich] et nous forçaient à tuer des gens pour nous endurcir. Parfois, ils amenaient des femmes et des filles pour être violées. Les officiers ne justifiaient jamais leurs actes. Chaque fois qu'ils faisaient quelqu'un prisonnier, ils ordonnaient aux kadogos de faire ces choses devant les soldats adultes, comme si c'était un spectacle, pour humilier les villageois. Cela ne nous intéressait pas mais ils nous battaient si nous refusions d'obéir. Avant de faire cela, avant de tuer quelqu'un, vous deviez fumer du haschich (Chanvre) - et une fois que vous l'aviez fumé, cela empêchait l'esprit de la personne que vous avez tuée d'entrer dans votre corps... ${ }^{1629}{ }$ Cette pratique est également confirmée par Olivier, recruté à l'âge de 11 ans par le RCD-Goma et au service de différents groupes armés pendant 7 ans (2003). Celui-ci affirmait qu'à la prise de la ville de Katoye (Nord-Kivu), un ordre leur avait été donné d'attaquer les populations : "Il nous a ordonné de tout piller, de chasser les civils et de détruire leurs maisons. La population a réagi et à essayer de nous en empêcher. Alors le commandant nous a dit de tuer quiconque opposerait une résistance. Il m'a personnellement ordonné de le faire et a demandé à deux autres soldats de me surveiller et de me tuer si je refusais d'obéir. Alors, j'ai tué, j'ai tiré sur ces gens. Ils m'ont amené une femme et ses enfants et j'ai dû les mettre dans un trou pour les enterrer vivants. Ils criaient et me suppliaient de leur épargner la vie. J'ai pris pitié d'eux mais lorsque je me suis retourné, j'ai vu les deux soldats qui m'accompagnaient. Alors je me suis dit: 'si je les laisse partir, ces soldats vont me tuer'. Alors j'ai fait ce qu'on m'avait dit de faire et j'ai enterré la femme et ses enfants vivants pour sauver ma propre vie ${ }^{1630}{ }^{\Perp}$.

En revanche, prenant directement part aux hostilités, ces enfants sont des cibles militaires des parties ennemies qui leur réservent impitoyablement des attaques sur les lignes de fronts. A titre indicatif, Bénédicte, recrutée à l'âge de 11 ans par l'AFDL, a rapporté à Amnesty International ce qu'elle a vécu sur le front : "Plusieurs de mes amis ont été tués au cours des combats. D'autres ont perdu des membres - des bras, des jambes. Je me souviens d'un camarade, un de mes amis, dont le nez avait été arraché. Un autre avait un grand trou dans le visage, autour de ses lèvres et de sa bouche ${ }^{1631} »$.

En effet, la «militarisation de esprits » décrite dans les lignes précédentes relayées de tout type de «bourrages de crâne », expression utilisée par Marc SCHMITZ ${ }^{1632}$ ne peuvent que

${ }^{1629}$ Amnesty international, République Démocratique du Congo - Enfants en guerre, AI index :Afr 62/034/2003. Secrétariat international, document public, op. cit., p. 8 in http://www.kongokinshasa.de/dokumente/ngo/ai_enfants_0903.pdf (Source consultée le 03 août 2014).

${ }^{1630}$ Ibid.

${ }_{1631}$ Ibid., p. 7.

1632 Lire SCHMITZ, Marc, «Les enfants-soldats, un phénomène universel de plus en plus préoccupant », «art.cit », p. 35. 
conduire qu'à un tel résultat.

Au-delà d'être essentiellement recrutés et utilisés comme soldats, les enfants sont naturellement des victimes de différents faits des conflits armés comme civils.

\section{Section II Impacts des conflits armés sur les enfants en République Démocratique du Congo}

Après une étude de l'enfant comme acteur ou combattant dans les conflits armés à la section précédente, il sera question dans la présente section d'appréhender l'enfant comme civil, personne ne prenant pas part aux hostilités. La situation de l'enfant civil en temps de conflits armés est donc l'objet de cette réflexion. Situation qui sera d'ailleurs, autant pour l'enfant combattant, davantage étayée dans le chapitre suivant sous l'angle essentiellement juridique.

Ainsi, cette section a pour objet d'examiner le traitement général de l'enfant pendant cette période des conflits armés $(\S 1)$ et l'impact de ces conflits armés sur sa santé $(\S 2)$ et sur son éducation $(\$ 3)$.

\section{§1. Traitement des enfants}

«L'enfant est l'avenir du monde dit-on; la guerre le rend incertain. Le conflit armé n'épargne personne et les enfants, pas plus que les autres, ne bénéficient d'une immunité ${ }^{1633}$. En effet, d'un regard plus scrutateur de la situation de conflits armés en RDC, les observateurs sont d'avis qu'il s'agit d'une guerre qui vise directement la population civile dont les enfants en particulier. Le bilan établi pour leur compte est extrêmement lourd. En 2006, Martin BELL, Ambassadeur d'UNICEF-Royaume-Uni, notait que chaque année, mourraient plus d'enfants de moins de cinq ans en RDC qu'en Chine (dont la population est 23 fois plus nombreuse) ou que dans tous les pays d'Amérique latine pris ensemble ${ }^{1634}$ (cf. supra).

Autant sur le plan mondial, près de deux décennies après la publication du Rapport Graça Machel, la situation de l'enfant en conflits armés ne s'est vraiment guère améliorée ${ }^{1635}$. On note d'un côté plus de naissances de guerres civiles accompagnées de plus des milices ou groupes armés qui font fréquemment recours aux enfants pour renforcer leurs capacités militaires. D'un autre côté, le développement d'un arsenal juridique au plan international relayé de certains mécanismes qui tentent, un tant soit peu, de résorber la situation. Et pour emprunter l'intitulé du chapitre introductif de l'ouvrage de Alain Louyot sur Les enfants soldats, «Rien n'a vraiment changé » ${ }^{1636}$. Effectivement, rien n'a réellement changé, du

\footnotetext{
${ }^{1633}$ BOUCAUD, Pascale, «Droit des enfants en droit international -Traités régionaux et droit humanitaire », in $R T D H, \mathrm{n}^{\circ} 12$, octobre 1992, p. 462.

${ }^{1634}$ UNICEF, SOS, République Démocratique du Congo. Reportage de Martin Bell sur les enfants piégés par la guerre, p. 3, disponible sur http://www.unicef.org/childalert/drc/ (Source consultée le 11 avril 2015).

${ }^{1635}$ Lire par exemple FOFACK, Eric Wilson, «Les enfants victimes des conflits armés dans le monde : Permanence et mutation d'une préoccupation mondiale », in Note d'analyse du Groupe de Recherche et d'Information sur la Paix et la Sécurité du 21 août 2013 http://www.operationspaix.net/DATA/DOCUMENT/8099 V Les_enfants_victimes_des_conflits_armes_dans 1 e_monde Permanence et_mutation_dune_preoccupation_mondiale.pdf (Source consultée le 11 avril 2015).
}

${ }^{1636}$ LOUYOT, Alain, Les enfants soldats, op. cit.,p. 9. 
Rapport Graça Machel aux différents rapports ou études subséquents ${ }^{1637}$ sur les enfants dans les conflits armés dont les récents rapports du SG/NU sur la question des enfants dans les conflits armés. Devrions-nous rappeler le rapport du SG/NU de mai 2013 (cf. supra) qui indiquait que ces «dernières années, les représentants des structures de protection de l'enfant des Nations Unies ont noté avec préoccupation que la nature changeante des conflits armés et des tactiques employées dans ce cadre créaient des menaces sans précédent pour les enfants ${ }^{1638} \gg$.

Pour mieux comprendre la situation de l'enfant en RDC, il s'avère nécessaire de se questionner préalablement sur la considération qui lui est réservée par les parties aux conflits. Au-delà des aspects des obligations juridiques qui incombent aux belligérants sur le champ de bataille vis-à-vis des enfants, la protection réellement assurée est tributaire de la considération réservée au sujet à protéger. Contrairement au symbole d'innocence et de vulnérabilité que représente l'enfant dans la société moderne, la pratique des parties aux conflits armés en RDC laisse entrevoir l'absence de considération de l'enfant. Les enfants sont pris comme outils devant servir le mieux à leurs intérêts, la conquête du pouvoir et l'exploitation des ressources naturelles par la perpétuation des hostilités. La protection des enfants des effets des conflits armés n'est donc pas prioritaire des parties aux conflits armés.

Ainsi pour se rendre compte de l'absence de considération dans les zones des conflits armés, au-delà des lignes précédentes, il suffit d'examiner la pratique de transformation de l'enfant civil en enfant soldat. Aucun respect de la personne humaine ne correspond à ce qui est infligé à l'enfant. Un traitement simplement inhumain et dégradant.

En effet, il sied d'indiquer préalablement que l'utilisation des enfants sur le champ de bataille, comme ailleurs, requiert préalablement une formation de quelques jours, semaines voire des mois pour certains. Il ne s'agit pas d'une formation militaire professionnelle comme l'on peut bien entendre. Il s'agit d'une formation rudimentaire basée plus sur les maniements d'armes, le positionnement sur le champ de batailles, le camouflage, etc. C'est ici où les enfants venus des milieux différents doivent subir pour leur première fois des rudes épreuves de leurs vies. Dans l'est du pays, des méthodes atypiques d'apprentissage sont donc

1637 Lire par exemple FOFACK, Eric Wilson, «Les enfants victimes des conflits armés dans le monde : Permanence et mutation d'une préoccupation mondiale », in Note d'analyse du Groupe de Recherche et d'Information sur la Paix et la Sécurité du 21 août 2013 http://www.operationspaix.net/DATA/DOCUMENT/8099 V Les_enfants_victimes_des_conflits_armes_dans_1 e monde Permanence et mutation_dune preoccupation_mondiale.pdf (Source consultée le 11 avril 2015); BETTATI, Mario, Droit humanitaire, $1^{\text {re }}$ édition, op. cit., p. 189 ; BOUCHET-SAULNIER, Françoise, Dictionnaire pratique du droit humanitaire, éd. La Découverte, Paris, 2013, op. cit., p. 342 ; RAMASY, Juvence F., «La protection juridique et politique des enfants dans les conflits armés en Afrique. Inventaire des dispositions légales et politiques », «art. cit.», pp. 263-268 ; CHAPLEAU, Enfants-soldats. Victimes ou criminels de guerre ?,op. cit., pp. 7-9; AYISSI, Anatole et MAIA, Catherine, « La lutte contre le drame des enfants soldats ou le conseil de sécurité contre le terrorisme à venir... », in RTDH. , 58/2004, 543- 545 ; AYISSI, Anatole, «Protéger les enfants dans les conflits armés : concrétiser les engagements pris », in Les enfants et la sécurité, Forum du désarmement, 2002, p. 5, pp. 9-10, disponible http://www.unidir.org/files/publications/pdfs/les-enfants-et-la-securite-en-582.pdf (Source consultée le 12 avril 2015).

$1638 \S 9$ de la Résolution AG/NU et CS/NU A/67/845- S/2013/245, Le sort des enfants en temps de conflit armé, Rapport du Secrétaire général, in http://www.ipji.org/fileadmin/data/documents/UN_documents/UNSG_SCReportChildrenArmedConflict_2013_FR.pdf (Source consultée le 06 décembre 2013). 
employées au risque souvent de la vie des enfants. Le traitement réservé à ces enfants au cours de leur formation ou entraînement est généralement d'une dureté extrême au regard de leurs vulnérabilités physique et mentale. Brutalités, viols, violences sexuelles, agressions, souffrances extrêmes, morts, bref traitements inhumains sont autant des techniques utilisées pour militariser ou dompter les esprits de ces gosses. Il va sans dire que ces conditions d'entrainement et d'endoctrinement laissent des séquelles traumatiques sévères et indélébiles chez la plupart des enfants. Et par conséquent engendrer de sérieuses difficultés en santé mentale chez ces derniers. Que comprendre des témoignages de Thomas et Gaston ? Le premier, âgé de 13 ans au moment de son recrutement dans l'armée du RCD-Goma (2000) et envoyé au camp d'entraînement de Mushaki dans le Nord-Kivu pendant 5 mois, raconte : «Les traces que j'ai sur tout mon dos sont dues aux commandants du camp qui m'infligeaient 40 coups de crosses de fusils chaque fois que je ne parvenais pas à faire comme un adulte les exercices quotidiens ou bien si je m'endormais pendant mes tours de garde. En raison des coups, deux de mes amis dans le camp sont morts. Les soldats les ont enterrés dans les toilettes. Je pense toujours à eux ${ }^{1639}$ ». Le second, Gaston, enrôlé à l'âge de 10 ans dans l'AFDL alors qu'il se trouvait dans sa salle de classe, témoigne: "On avait peur parce que nous étions jeunes et on ne savait rien au sujet de l'armée. Même sur les terrains de tirs, lorsqu'ils vous disent de tirer, vous avez toujours peur. Pour que je puisse vaincre ma peur, j'ai dî tuer quelqu'un dans le camp d'entraînement. Une nuit, ils ont emmené quelqu'un alors que je montais la garde de l'entrée du camp. C'était un enfant dont ils avaient caché le visage. Ils m'ont dit que c'était un rebelle, un ennemi et que je devais le tuer. C'est exactement ce que j'ai fait. Sur le champ. Avec mon poignard Cette nuit-là, après l'avoir tué, je n'ai pas fermé $l^{\prime}$ 'oeil ${ }^{1640}{ }$. C'est effectivement de la «barbarie sans frontière ${ }^{1641}$ ». Par ailleurs dans la zone ouest, à Kinshasa, sous l'AFDL notamment, le traitement des jeunes recrues durant leur phase de formation ou d'entraînement n'était pas aussi moins pénible, bien qu'il est ici renseigné que les cas de violence physique ne semblent pas être la règle. Au premier Centre d'entraînement des nouvelles recrues, A Kibomango, précisément, indique un enfant, «la nourriture n'était pas décente. On recevait moins qu'au stade des martyrs, et en plus on ne pouvait plus rentrer chez nous. On recevait du pain deux fois par jour, une boîte de tomate et un peu de riz ${ }^{1642}$. Un autre enfant soulignera que dans le centre la «vie était plutôt pénible, nous étions exposés à des maladies et les soins n'étaient pas suffisants. Certains de mes amis sont morts ${ }^{1643}$. La problématique des nourritures suffisantes, des logements décents voire des soins de santé se posaient dans différents centres pour enfants soldats. Un des cas les plus flagrants est celui des enfants soldats de Kapalata à Kisangani. Casernés à Kapalata pour recevoir des instructions après la chute du régime de Mobutu par Laurent Désiré Kabila, ces enfants affamés, croupissaient dans des conditions d'hygiène épouvantables au point qu'une épidémie de choléra se déclencha pour emporter des centaines d'entre eux ${ }^{1644}$. Des mesures

\footnotetext{
${ }^{1639}$ Amnesty international, République Démocratique du Congo - Enfants en guerre, AI index :Afr 62/034/2003. Secrétariat international, document public, op. cit, p. 7, in http://www.kongokinshasa.de/dokumente/ngo/ai_enfants_0903.pdf(Source consultée le 04 août 2014). 
urgentes ont été prises pour y mettre fin. Sur le champ de bataille, le problème de nourriture décent continuait de se poser. Un enfant dira à ce sujet, durant le combat RDC-Rwanda, il mangeait «tout ce que l'on pouvait trouver dans la forêts ou dans les villages ${ }^{1645}$.

Ce problème se pose de la même manière que celui de solde. La solde allouée à ces jeunes soldats étaient irrégulières autant pour les soldats adultes. Déjà, la corruption et le détournement des deniers publics constituent, depuis belle lurette (cf. supra), les lots quotidiens des forces armées en RDC et des mouvements dissidents. Il s'agit là d'un problème quasi généralisé. A titre d'exemple, «à la fin mars 2006, le versement de la solde des militaires dans les régions troublées du Kivu posait toujours problème. Le Chef de la MONUC évoqua à cette époque le sort d'une armée toujours abandonnée à son sort, «sans nourriture, sans salaire et sans moyens logistiques ${ }^{1646}{ }^{\prime}$. C'est d'ailleurs la raison du déploiement de l'opération EUSEC-RD Congo (cf. supra) qui se fixa la mission de la gestion efficace et efficiente de l'armée congolaise à travers les conseils de réforme du système des paiements. Cependant, il s'est avéré notamment que vouloir séparer la chaîne de paiement de la chaîne de commandement n'était pas bien perçu par la hiérarchie militaire pour qui cela était profitable.

Concernant la fameuse formation militaire, engagés dans la vie de soldat, les enfants devront faire face à des rudes épreuves souvent au risque de leur vie sur différents fronts de bataille. Les champs de batailles leur sera sans merci. Des attaques à leur encontre, considérés comme des cibles militaires légitimes, ne sont pas sporadiques. Ils devront non seulement lutter contre l'ennemi mais aussi avoir une attitude convenable, sur le plan de tactique de combat, comme voulu par leurs commandants pour ne pas être abattus. En dépit de bourrage de crânes à travers des substances alcooliques, la drogue ou autres, une certaine discipline règne dans certains groupes. Le non respect ou la non exécution de certaines consignes par l'enfant pourrait facilement entraîner le meurtre de celui-ci (cf. témoignages de Olivier et de Thomas, supra) dans des circonstances aussi effroyables.

Cette situation macabre ne concerne pas seulement l'enfant qui prend les armes pour combattre. Ceci vaut de même pour les enfants, civils, qui se trouvent traumatisés des tirs d'armes à feu. Pour aborder cela, les angles d'éducation et de santé restent notre préoccupation.

\section{\$2. Impact des conflits armés sur la santé des enfants}

«Les combats - armes blanches, balles, bombes et mines anti-personnelles font chaque année des milliers de morts parmi les enfants, mais bien d'autres meurent de la malnutrition et de la maladie causées ou aggravées par les conflits armés. L’interruption des approvisionnements alimentaires, la destruction des récoltes et de l'infrastructure agricole, la désintégration des familles et des communautés, les déplacements de populations, la destruction des services et des programmes de santé et des systèmes d'approvisionnement en eau et d'assainissement sont autant d'éléments qui compromettent sérieusement la santé des enfants. Nombre d'enfants meurent de malnutrition grave tandis que d'autres, affaiblis par la malnutrition,

${ }_{1646}^{1645}$ BAILLON, Thierry, « A l'écoute des enfants-soldats », in SCHMITZ, Marc (coord.), op.cit., p. 104.

${ }^{1646}$ WILLAME, Jean-Claude, Les « Faiseurs de paix au Congo », op.cit., p. 164. 
n'ont plus la résistance voulue aux maladies et infections communes de l'enfance » ${ }^{1647}$.

La RDC, avec un système détruit préalablement par sa politique, fait face en période de conflits armés à des sérieuses difficultés étayées ci-avant. En effet, hier, dotée d'un système de santé réputé en Afrique attirant des patients de différents horizons, la RDC se retrouve actuellement avec un système de santé très délabré. Sauf quelques rares exceptions, les infrastructures sanitaires ne sont généralement pas en mesure de prendre en charge différents types de maladies. Vétustes, ces établissements hospitaliers, dont la plupart datent d'ailleurs de l'époque coloniale, comme les écoles de ce pays (cf. infra), possèdent un personnel soignant démotivé. Certains membres de ce personnel sont qualifiés mais pas toujours recyclés. D'autres n'ont pas de spécialisation dans les domaines concernés mais y exercent quand même faute de spécialistes attitrés. Les grèves du personnel dans ce secteur pour exprimer ses revendications légitimes ne sont point rares. Les matériels ne sont pas toujours au point de la nouvelle technologie. Les pharmacies de ces établissements hospitaliers ne sont généralement que des noms. Les hôpitaux de référence, les hôpitaux généraux voire des cliniques universitaires qui sont le recours ultime des patients ne sont pas toujours à considérer comme tels. Les soins de santé sont généralement conditionnés par une paie préalable sans laquelle le patient ne peut être pris en charge. Le système de mutuelle de santé, sauf pour certains travailleurs, est quasi inexistant. Des malades meurent souvent à la suite de l'incapacité financière de payer des frais hospitaliers. Le problème demeure plus accentué dans les milieux ruraux. Par exemple, à Kabare au Sud-Kivu, il est indiqué que «les formations sanitaires sont quasiment inexistantes et là où elles existent, elles sont sous équipées et sans médicaments appropriés, située(s) à plusieurs milliers de mètres de la population, avec un personnel peu qualifié et pour un coût qui dépasse la capacité contributive des populations ${ }^{1648}$. Il sied de faire observer dorénavant que dans ce pays, la plupart de spécialistes se trouvent confinés dans des centres urbains. Le cas de maladies graves en milieux ruraux nécessitent l'évacuation vers les centres urbains faute de soins appropriés ou d'un personnel qualifié en milieux ruraux. Ce qui engage des frais conséquents de déplacement pour des villageois déjà pauvres sans compter les frais de soins proprement dits qui les attendent.

En temps de conflits armés, les infrastructures sanitaires en état de délabrement très prononcé connaissent de nouveau de sérieuses difficultés. Ces établissements hospitaliers sont soit détruits par le fait de guerre, soit non opérationnels à la suite de la fuite du personnel en raison des hostilités. On le sait, la guerre diminue l'accès au système de santé adéquat. A travers la guerre, il y a apparition des cas maladies dues notamment à la promiscuité des déplacés, à l'absence des conditions hygiéniques, etc. Les épidémies de type choléra, fièvre typhoïde, se déclenchent très facilement. C'est notamment le cas des enfants dans le territoire de Kabare au Sud-Kivu exposés à ce type de maladies ${ }^{1649}$. Durant la guerre, il y a augmentation

$1647 \S 137$ de la Résolution A/51/306 du 26 août 1996 de l'AG/NU, Promotion et protection des droits des enfants. Impact des conflits armés sur les enfants », 43, http://www.unicef.org/french/emerg/files/GarcaMachel_fr.pdf (Recherche menée le 06 août 2014).

1648 Action des Chrétiens pour l'abolition de la torture, Effectivité des droits des enfants en République Démocratique à l'aune des objectifs du millénaire pour le développement. Regard sur la situation particulière des enfants dans les territoires de Kabare au Sud-Kivu, op.cit., p. 21.

1649 Ibid., p. 22 
notamment des cas des blessés, des filles atteintes des maladies sexuellement transmissibles (MST), VIH/Sida à la suite d'agression et violences sexuelles exercées contre elles. En dépit du taux de prévalence relativement faible pour tout le pays comparativement aux autres pays de la région, la zone sud-est de la RDC est celle dont le taux de prévalence est élevé notamment suite au déplacement des populations, des ressortissants des pays dont le taux de prévalence est élevé en période de guerre. Situation qui affecte des enfants qui sont soit euxmêmes atteints ou devenus orphelins du fait de la perte des parents atteints.

Par ailleurs, les campagnes de vaccination des enfants contres certaines maladies telles que poliomyélite sont en période des hostilités soit interrompues soit carrément interdites. Les grossesses, non désirées des filles dont les corps ne sont pas encore matures pour supporter le fœus, engendrent des conséquences graves sur leur développement. Tout ceci crée des nouveaux besoins de soins de santé que ne sauraient prendre en charge ces hôpitaux déjà débordés ou fermés.

Les enfants qui sont au départ physiquement vulnérables ne résistent pas des situations d'urgence. Ils souffrent de différents problèmes causés directement par la guerre dont la malnutrition. Cette dernière «peut affecter tous les enfants, mais c'est parmi les très jeunes qu'elle compte la mortalité et la morbidité les plus grandes, spécialement lorsque les enfants ont moins de 3 ans. En période d'urgence, les très jeunes enfants risquent de souffrir de malnutrition aiguë ou de "dépérissement", situation qui se manifeste par un poids insuffisant par rapport à la taille ${ }^{1650}$. Laquelle entraîne logiquement un grand nombre de décès et un impact négatif sur le développement cognitif des survivants. «Dans le Sud et l'Est du pays, les enquêtes nutritionnelles ont indiqué à maintes reprises des taux de malnutrition aiguë et de mortalité très élevés. Au Kasaï, dans la province Orientale, une étude réalisée par le Comité permanent de la nutrition du système des Nations Unies en juin 2002 a montré que 75 p. 100 de tous les enfants interrogés avaient été malades au cours des deux semaines précédentes, révélant ainsi la présence de malnutrition et de vulnérabilité à d'autres maladies ${ }^{1651}$. Les résultats de 1'Enquête Démographie-Santé couvrant la période 2002-2007 indiquent que la RDC se trouve dans un contexte de déficit nutritionnel persistant, soit $46 \%$ des enfants de moins de cinq ans souffrent de malnutrition chronique et $8 \%$ de malnutrition aiguë ${ }^{1652}$. Ce qui constitue une des principales causes de la mortalité infanto-juvénile (0-5 ans) estimée à l'ordre de 148 pour mille naissances vivantes. Un des taux les plus élevés en Afrique $^{1653}$. Cinq ans après ces résultats d'enquête, soit en 2012, l'OMS indiquera que le taux de mortalité infanto-juvenille de 146 pour mille naissances vivantes pour la RDC ${ }^{1654}$. L'extrême pauvreté que vivent les adultes dans leurs milieux de refuge n'est pas toujours

\footnotetext{
$1650 \$ 156$ de la Résolution A/51/306 du 26 août 1996 de l'AG/NU, Promotion et protection des droits des enfants. Impact des conflits armés sur les enfants », p. 48, in http://www.unicef.org/french/emerg/files/GarcaMachel_fr.pdf (Source consultée le 06 août 2014).

${ }^{1651}$ Watch List on children and armed conflict, Impact des conflits armés sur les enfants en République démocratique du Congo (RDC), 17, in http://watchlist.org/ (Source consultée le 06 août 2014).

${ }^{1652}$ http://www.congoforum.be/fr/congodetail.asp?subitem=40\&id=160425\&Congofiche=selected consultée le 06 août 2014).

${ }^{1653} \mathrm{http}: / / \mathrm{www}$. congoforum.be/fr/congodetail.asp?subitem=40\&id=160425\&Congofiche=selected consultée le 06 août 2014).

${ }^{1654}$ http://www.who.int/countries/cod/fr/ (Source consultée le 06 août 2014).

(Source

(Source
} 
supportée par les enfants.

Par ailleurs, il se pose un sérieux problème de santé mentale pour les enfants qui ont survécu ces dures épreuves de guerre. Beaucoup sont ces enfants qui ont perdu leurs familles entières du fait de la guerre. Parmi eux, sont également les enfants qui ont été obligés d'assister à des scènes horribles de viol ou de tueries de leurs parents ou membres de famille. Quels traumatismes psychologiques que ressentiraient ces enfants? Certainement, les traces de ces traumatismes demeureront très déterminantes pour la suite de leur vie. Ceci a fait développer l'esprit de vengeance de certains enfants au point d'intégrer les forces ou groupes armés (cf. supra).

\section{§3. Impact des conflits armés sur l'éducation des enfants}

«L'éducation est particulièrement importante en période de conflit armé. Alors que tout l'entourage peut être plongé dans le chaos le plus complet, l'école peut être un havre de normalité. Les enfants des écoles ont la possibilité d'être avec leurs amis et de jouir de leur soutien et de leur encouragement. Ils peuvent avoir des contacts réguliers avec leurs maîtres, qui peuvent surveiller leur santé physique et leur état d'esprit. Les maîtres peuvent également aider les enfants à acquérir les connaissances et les compétences nécessaires pour survivre et faire face, qu'il s'agisse de savoir reconnaître des mines, de négocier et de résoudre des problèmes ou d'en savoir davantage sur le VIH/SIDA et d'autres maladies ${ }^{1655}{ }_{\gg}$. Par sa résolution S/RES/1539 (2004), le CS/NU a demandé aux Etats et au système des Nations Unies de reconnaître le rôle de l'éducation des enfants en période des conflits armés pour arrêter et empêcher leur recrutement ${ }^{1656}$. Dès lors la «protection des écoles et l'éducation dans les situations d'urgence et de conflit devraient être une priorité absolue pour la communauté internationale ${ }^{1657} »$.

En RDC, pays dont une bonne partie d'infrastructures scolaires publiques datent de l'époque coloniale, l'école en pleine période de conflit armé n'est pas à présenter comme un havre de paix sinon une «cible légitime» des forces et groupes armés. Il n'est point un secret que l'enseignement autant son infrastructure en RDC se trouve dans un état de délabrement très avancé. Les enseignants, mal payés, se trouvent dans une situation identique de pauvreté extrême que les parents d'écoliers. Ce qui influe déjà négativement sur la scolarité des enfants. En juin 2003, dans un rapport publié par Watch List on children and Armed conflict, on pouvait lire ce qui suit : «Dans le Nord-Kivu, ils (enseignants) ont reçu leur dernier salaire déclaré de 5,82 \$US par mois en 1995. Depuis, c'est aux écoles de recueillir des fonds pour payer les enseignants et couvrir les autres coûts de fonctionnement. Dans la plupart des régions, si ce n'est toutes, on compte sur les parents pour contribuer aux frais de fonctionnement des écoles. Les salaires des enseignants varient de 1 à 15 \$US par mois dans les zones rurales et de 15 à 30 \$US dans les zones urbaines du district d'Ituri. En raison de

$1655 \$ 185$ de la Résolution A/51/306 du 26 août 1996 de l'AG/NU, Promotion et protection des droits des enfants. Impact des conflits armés sur les enfants", http://www.unicef.org/french/emerg/files/GarcaMachel_fr.pdf (Source consultée le 05 août 2014).

$\begin{array}{llllllll}1656 & \$ 9 & \text { de la } & \text { Résolution } & \text { S/RES/1539 } & \text { (2004) du } & \text { CS/NU }\end{array}$ http://www.un.org/fr/documents/view_doc.asp?symbol=S/RES/1539\%20(2004) (Source consultée le 19 février 2016).

${ }^{1657}$ AG/NU, Rapport de la Représentante spéciale du Secrétaire général pour les enfants et les conflits armés, $\mathrm{A} / 64 / 254$. 
l'inflation galopante, le salaire réel est souvent considérablement inférieur. De nombreuses écoles du pays sont dévastées. Il n'y a plus de livres et souvent, les élèves n'ont pas d'uniforme ${ }^{1658} \gg$.

Les conflits armés viennent de plus porter ses désastres sur le peu qui existe. Grâce aux efforts de la Communauté internationale, quelques avancées sont tout de même signalées. Dans le cadre de la Banque Mondiale, le «Projet d'Urgence de Réhabilitation Urbaine et Sociale (PURUS) et le Projet d'Appui à la Réhabilitation du Secteur de l'Education (PARSE) ont permis la construction de 918 salles de classes ainsi que la distribution de 14 millions de manuels scolaires. Le taux d'enrôlement dans les écoles primaires est passé de 64\% en 2007 à $93 \%$ en 2011, et 43335 enseignants ont officiellement intégré la fonction publique ${ }^{1659}$ ». En revanche, de son côté, l'UNICEF note pour l'année 2012 en RDC, 7,6 millions d'enfants ne vont pas à l'école, dont 34 pour cent se trouvent dans les zones affectées par le conflit ${ }^{1660}$.

En période de conflits armés, les écoles sont considérées comme un des endroits indiqués où le recrutement des enfants s'opèrent le plus souvent. Il arrive que des classes entières soient vidées par le rapt des milices ou groupes armés. Ceci crée un climat d'insécurité généralisée autant chez les enseignants que chez les élèves. Les enseignants, généralement déjà démotivés à la suite de non paiement de leurs salaires ou paiement de salaires insuffisants, se sentent obligés de ne plus se rendre aux lieux de travail. Ce qui vaut de même pour les élèves protégés par leurs parents. Au regard d'enlèvements d'élèves quasi-réguliers sur la route d'écoles, les parents protègent leurs enfants en les interdisant d'aller à l'école. Beaucoup sont donc des élèves qui ont été enlevés en route d'écoles. Celles-ci, en milieux ruraux, sont généralement éloignées des habitations des écoliers. Il faudrait pour ces derniers emprunter des chemins dangereux, tels que les forêts, parfois pour de dizaines de kilomètres. C'est aussi des groupes armés qui rodent au tour de ces écoles. Le témoignage de Jeanne n'est donc point un cas isolé, même pour des groupes armés actuellement. Recrutée de force par l'ADFL à l'âge de 11 ans en 1996, Jeanne explique : "J'ai été recrutée à Goma alors que je rentrais de l'école. Sur la route, il y avait des soldats dont le véhicule avait l'air d'être en panne. C'était en fait un piège. Ils m'ont appelée, moi et d'autres enfants. Quand je me suis approchée d'eux, ils m'ont alors attrapée et mise dans leur véhicule avant de m'emmener dans un camp d'entraînement militaire. C'est là que j'ai été entraînée et c'est de là que nous avons commencé à marcher sur Kinshasa. Parce que nous avons été emmenés de force alors que nous rentrions de l'école, nos parents n'ont pas su ce qui nous était arrivé. A ce jour, je ne sais pas si mes parents sont vivants. Et même s'ils le sont, ils ne savent pas ce qui m'est arrivée $\gg^{1661}$.

Les conflits armés ont généralement d'impact très négatif pour l'unité familiale. Les familles

\footnotetext{
1658 Watch List on children and armed conflict, Impact des conflits armés sur les enfants en République démocratique du Congo (RDC), p. 21, in http://watchlist.org/reports/pdf/dr_congo.report.fr.pdf (Source consultée le 05 août 2014).

${ }^{1659} \mathrm{http} / / / \mathrm{www} \cdot$ banquemondiale.org/fr/country/drc/overview\#3 (Source consultée le 05 août 2013).

1660 UNICEF, 2012 Action humanitaire de l'UNICEF pour les enfants, op. cit., p. 33.

1661 Amnesty international, République Démocratique du Congo - Enfants en guerre, AI index :Afr 62/034/2003. Secrétariat international, document public, op.cit. pp. 5-6 in http://www.kongokinshasa.de/dokumente/ngo/ai_enfants_0903.pdf(Source consultée le 05 août 2014)
} 
font souvent de déplacement à l'intérieur du pays ou à l'extérieur de celui-ci à la recherche du refuge ou de l'abri. Déplacement de fois voire souvent opéré sans certains enfants. Ces enfants se retrouvant à l'abandon, sans protection, sont à la portée des groupes armés. La suite de leur éducation est par là compromise. Les déplacés à leur tour sont casés souvent dans des infrastructures scolaires, en l'absence ou en attente d'un camps de réfugiés ou de déplacés appropriés, obligeant par là les élèves à ne plus y fréquenter.

D'un autre côté, la situation de la jeune fille n'est pas enviable en temps de guerre. Elle est prise comme esclave sexuelle par des groupes armés et victime de violences sexuelles. Elle se trouve par la suite rejetée par la société à sa réintégration, autant pour l'enfant qu'elle mettra au monde à la suite de ses relations avec les membres des milices ou mouvements armés. Elle perd ses valeurs de future femme vis-à-vis de la société. Tout ceci vient consolidés des préjugés dont elle est généralement victime. En milieux ruraux, différentes familles privilégient plus la scolarisation des garçons que celle des jeunes filles ${ }^{1662}$. Ces dernières sont vouées aux travaux ménagers les préparant aux mariages. Elles n'ont pas à faire des études avancées si pas simplement des études. Elles sont bonnes pour les mariages. Lesquels interviennent généralement peu avant leur majorité. A la base des coutumes patriarcales dominantes.

Se soucier de créer des infrastructures scolaires, tout comme celles de santé, en période de guerre ne rentre pas dans les agendas des belligérants. Déjà pour l'Etat congolais, fort préoccupé par l'effort de guerre, son budget alloué à l'éducation ne consacre pas grand-chose. Les groupes armés, pour leur part, restent très attachés à l'exploitation de ressources naturelles ou fiscales de la zone qu'ils contrôlent, la conservation de leur position sur cette zone et la poursuite des hostilités. Il s'avère important pour eux de trouver des voies et moyens leur permettant de conserver davantage cette position. Exploiter les enfants dont la main d'œuvre est moins chère, docile et manipulable constitue un des moyens sûrs pour atteindre ce but. Les drogues, alcools et autres substances de même nature administrées par les milices et groupes armés aux enfants n'ont aucune envie de garder leur intelligence intacte au point qu'ils reprennent la route de l'école. En revanche, construire des écoles pour eux pourrait engager «inutilement » des frais qu'il faudrait plutôt réserver pour l'effort de guerre. C'est le choix estimé judicieux !

Par ailleurs, dans des conflits ethniques, les écoles sont aussi appréhendées comme des lieux où les communautés s'affrontent entre elles. Soit, ce sont les enseignants qui humilient les élèves de la communauté adverse par leurs propos en classe, soit ce sont des élèves qui s'affrontent à leurs tours. Il arrive aussi que les Maîtres soient pointés comme agents d'une milice ou d'un groupe armé devant servir les intérêts de celui-ci au détriment de certains de leurs écoliers. Bien plus, «il est de plus en plus manifeste que les enseignants y exercent un harcèlement sexuel contre les filles ${ }^{1663}$. Des études attestent d'ailleurs que « l'école serait le

\footnotetext{
${ }^{1662}$ Voy. par exemple la situation du territoire de Kabare au Sud-Kivu répertorié dans le rapport de l'ONG Action des Chrétiens pour l'abolition de la torture, Effectivité des droits des enfants en République Démocratique à l'aune des objectifs du millénaires pour le développement. Regard sur la situation particulière des enfants dans les territoires de Kabare au Sud-Kivu, op.cit., p. 41.

${ }^{1663}$ Watchlist on Children and Armed Conflict, Impact des conflits armés sur les enfants en République démocratique du Congo (RDC), op.cit., p. 22, disponible en ligne : http://www.watchlist.org (Source consultée le 05 août 2014).
} 
lieu où la violence sexuelle est la plus répandue $»^{1664}$.

Contrairement aux vœux et affirmations exprimés à cette introduction, à la suite des conflits armés qui y règnent sur une zone, en RDC les écoles ne sont pas toujours des endroits qui favorisent l'épanouissement souhaité de l'écolier. Certains esprits sont froissés et découragés d'y aller. Ceci est remarqué notamment dans les chefs des ex-enfants soldats démobilisés qui souhaitent ou ont repris cette voie. Le Rapport de l'ONG Amnesty International mentionne que quand «ces enfants réussissent à aller à l'école, en raison de leur passé d'enfants soldats, ils sont souvent humiliés par leurs enseignants et leurs camarades de classe pour leurs mauvais résultats scolaires. Dans certains cas, les enseignants et les collégiens ont peur des anciens combattants en raison de leur passé violent ».

De tout ce qui précède, à voir tout ce qui se passe sur le champs de bataille en RDC, la «civilianisation des conflits armés » a atteint l'enfant à un niveau extrême. L'enfant est une «cible légitime » de différentes parties à ces conflits armés qui leur servent de marche pied pour atteindre leurs objectifs. Ce constat vaut donc pour les enfants soldats et des enfants civils. Ainsi, tant que la guerre se prolongera sur ce territoire avec de philosophie non humaniste, pour ne point dire inhumaine, il est très difficile d'espérer à une situation meilleure pour les enfants. L'éducation des enfants se trouvant en désastre, c'est l'avenir de toute une nation qui supportera les lourdes conséquences. Il est plus qu'important que cette situation particulière soit prise en charge conséquemment au niveau national et au niveau de la communauté internationale.

1664 Institut National de la Statistique Kinshasa-RD-Congo, L'épidémiologie du VIH/Sida en RDC. Une analyse secondaire de l'EDS-RDC -2007, XXVIè Congrès Général de la population, Marraketch, Maroc du 26 septe au 02 oct. 2009, 6, in http://iussp2009.princeton.edu/papers/90584 (Source consultée le 06 août 2014). 


\section{Conclusion du Chapitre Premier}

Ce chapitre sur «Les Conflits armés et les enfants en République Démocratique du Congo » s'est préoccupé de l'étude des conflits armés qui se déroulent sur le territoire de la RDC, durant près de deux décennies (Section I), avant de se focaliser sur l'analyse du processus de recrutement et de participation des enfants à ces conflits (Section II). Evitant la vision bornée uniquement sur des enfants comme «machines à tuer», «acteurs » ou «combattants», ce chapitre a analysé également la situation de l'enfant - civil, celui qui ne participe pas aux hostilités. L'intérêt était ici accordé notamment à l'examen des impacts de ces conflits armés sur la santé et l'éducation des enfants sans oublier le traitement généralement réservé à l'enfant par les parties en conflits. (Section III).

En effet, les conflits armés en RDC présentent des causes multidimensionnelles et interdépendantes. Essentiellement présentés comme «guerre par procuration» pour l'exploitation des ressources naturelles de la RDC, les conflits armés en RDC tiennent également pour cause la situation socio-politique de la région et du pays en particulier.

La région des Grands Lacs est généralement présentée comme celle à hauts risques et la plus instable d'Afrique voire du monde. Par effet de contagion, un conflit déclenché dans un pays entraîne d'autres conflits armés et des conséquences souvent néfastes sur d'autres pays de la région. Dès lors, il serait maladroit d'étudier la situation de la RDC en l'écartant de la situation globale de la région. Les conflits armés en RDC sont d'ailleurs perçus comme l'« exportation du conflit rwandais » (cf. supra). Leurs causes sont appréhendées sous l'angle lointain et immédiat.

Des conflits armés sont répertoriés au moins une fois chaque décennie depuis l'indépendance de la RDC notamment à la suite de la gestion calamiteuse du pouvoir sous MOBUTU. A l'heure actuelle, la RDC est passée aux conflits armés symbolisés par l'ombre du «Parrain permanent et incontournable », le Rwanda. Ce dernier ne fait que changer des « acteurs » ou «mains d'œuvre », de l'AFDL au M.23 en passant par le RCD et le CNDP. D'autres Etats, dont l'Ouganda, ne sont pas absents.

Pour atteindre l'objectif de conquête du pouvoir et de contrôle des ressources naturelles de la RDC, le recrutement et l'utilisation des enfants aux hostilités restent le mode opérationnel indiqué. De l'engagement «volontaire » - appréhendé comme «l'absence d'alternative »- et de conscription, différentes raisons expliquent de telles pratiques. L'enfant civil, avec sa vulnérabilité psychique ou morale et physique naturelle, souffre atrocement des effets de ces conflits armés. Le traitement qui lui est réservé ne va pas dans le sens de son intérêt supérieur.

Souvent victime de traitement inhumain et dégradant de la part des forces et groupes armés, l'enfant subit plus les effets des conflits armés sous les angles de santé et d'éducation. Depuis le rapport Graça Machel suivi de différents rapports subséquents des instances onusiennes et des ONG, rien n'a véritablement changé la situation de l'enfant. En RDC, l'enfant demeure la «cible légitime » des parties à ces conflits armés. Il est victime des atrocités indicibles. Sa santé et son éducation sont en péril.

Aux causes multidimensionnelles et interdépendantes liées à ces conflits armés, il faudrait également des suggestions ou solutions de la même hauteur. Pour ces conflits armés, lesquels 
sont essentiellement économiques, dont certains proposent des projets fédératifs de gestion des ressources entre pays de la région (cf. supra), il nous paraît évident d'identifier préalablement les véritables instigateurs ou «Acteurs invisibles» de cette «guerre par procuration » et débattre ainsi sur les véritables causes de ces conflits souvent éludées lors de processus de paix. A ce prix, probablement les solutions véritables sortiront. Au-delà de tout, la volonté politique de mise en œuvre de ces résolutions reste déterminante. 


\section{CHAPITRE II LES REGLES DU DROIT INTERNATIONAL HUMANITAIRE RELATIVES A LA PROTECTION DES ENFANTS EN RDC}

Il sied de rappeler d'emblée que la protection des enfants en situation de conflits armés sous l'angle du DIH complété par le DIDH a été abordée théoriquement dans les chapitres précédents (Première Partie). Il était là question d'analyser en général les règles et mécanismes qui assurent la protection des enfants en temps de conflits armés. Cette importante entreprise a été suivie de l'établissement des faits. Il s'est agi, pour ce dernier cas, d'étudier la genèse et l'évolution des conflits armés en RDC (Chapitre I de la seconde partie) avant de se préoccuper de la situation des enfants dans ces conflits armés (Chapitre II de la seconde partie).

Par ailleurs, le présent Chapitre se propose une mission non moins périlleuse que celle effectuée dans les chapitres précédents. Il s'agit pour l'essentiel d'une mission déterminante pour la suite de cette dissertation. Le travail consiste à confronter les faits établis au regard du DIH. Il s'agit d'un travail concret. La mission est d'une grande importance car c'est de ce chapitre que le fait générateur du processus d'application du DIH relatif à la protection des enfants dans les conflits armés en RDC sera déterminé. Une mission, qui mal accomplie, risquerait de déboucher sur l'identification et l'application des règles autres que celles prévues.

Ainsi, afin de ressortir les règles du DIH relatives à la protection des enfants en situation de conflits armés en RDC, avec un complément du DIDH, il apparaît logique et judicieux de préciser préalablement la nature et les conséquences juridiques de ces conflits armés au regard du DIH même (Section I). Il sera donc question de donner, suivant le DIH, une ou des qualification(s) possible(s) aux conflits armés survenus en RDC depuis 1996. Conflits armés intermittents avec différentes parties. Viendra ensuite le moment d'identifier à la suite de cette ou de ces qualification(s), les règles devant servir à la protection des enfants en temps de conflits armés en RDC. Ces règles seront donc fonction des instruments juridiques du DIH complétés par ceux du DIDH ratifiés par les Etats parties concernées (Section II) sans oublier le droit coutumier, voire le droit dérivé notamment les résolutions onusiennes et autres (Section III).

\section{Section I Nature et conséquences juridiques des conflits armés en RDC au regard du droit international humanitaire}

«La simple citation d'une disposition particulière d'un traité n'a aucun sens si elle n'est pas accompagnée d'une argumentation prouvant que cette disposition est applicable au problème juridique qui fait l'objet de l'étude ${ }^{1665}$. Ainsi, l'application d'une disposition conventionnelle à un problème juridique donné est fonction de son acceptation par les parties concernées. Dans ce sens, après avoir opéré la ou les qualification(s) des conflits armés survenus en RDC depuis 1996 au regard du DIH (§1), cette section déterminera les règles du DIH applicables (§2).

${ }^{1665}$ CORTEN, Olivier, Méthodologie du droit international public, op.cit., p. 142. 


\section{\$1 Nature juridique des conflits armés en RDC en droit international humanitaire}

Il est important d'affirmer d'avance, comme l'a fait l'accusation dans l'affaire Le Procureur c. Thomas Lubanga Dyilo devant la CPI, qu'il peut exister simultanément sur un territoire donné plusieurs conflits armés opposant différentes forces ${ }^{1666}$. Argument de coexistence de conflits armés - internationaux et non internationaux - auquel souscrit la Chambre de première instance de la $\mathrm{CPI}^{1667}$ mais que ne partage pas la Chambre préliminaire de la CPI au regard de la qualification issue de son analyse de la situation en Ituri dans l'affaire précité $^{1668}$. Ainsi, il n'est donc point exclu que différentes natures juridiques des conflits armés soient simultanément dégagées à propos d'une situation se déroulant sur le territoire d'un Etat donné. Le TPIY l'a clairement démontré, avant de conclure « que les conflits dans l'ex-Yougoslavie revêtent les caractères de conflits à la fois internes et internationaux ${ }^{1669}$ », en affirmant : « les conflits dans l'ex-Yougoslavie auraient pu être qualifiés à la fois d'internes et d'internationaux ou d'un conflit interne parallèle à un conflit international, ou d'un conflit interne qui s'est internationalisé du fait d'un soutien extérieur, ou d'un conflit international remplacé ultérieurement par un ou plusieurs conflits internes ou quelque combinaison de ces situations $»^{1670}$.

De ce qui précède, pour le cas de la RDC, différentes qualifications ou natures seront donc possibles et il faudrait, pour ce faire, les circonscrire à travers trois périodes successives. Il s'agira donc de la période d'octobre 1996 à mai 1997 (A), période dite de la " première guerre de libération » ou «guerre de l'AFDL »; suivie de la période d'août 1998 à juin 2003 (B), marquée par la « seconde guerre de libération »; et enfin de la période de juin 2003 à ce jour (C), caractérisée par des conflits armés intermittents juste après le début de la transition politique.

\section{A. D'octobre 1996 à mai 1997}

A partir de 1996, le Congo-Zaïre a connu une longue guerre aussi meurtrière que dévastatrice $^{1671}$. Des acteurs étatiques aux acteurs non étatiques, dont certains invisibles, ils sont multiples à avoir pris part aux conflits armés en RDC suivant différentes périodes.

En effet, le déroulement des conflits armés en RDC se caractérise par des interventions ou des incursions de multiples acteurs suivant différents épisodes comme dans une pièce de théâtre. Dès 1996, c'est au tour du Rwanda et de l'Ouganda voire du Burundi de faire la guerre à la RDC (alors République du Zaïre) par la création et l'instrumentalisation d'une « rébellion »

\footnotetext{
1666 CPI, Le Procureur c. Thomas Lubanga Dyilo, affaire $N^{\circ}$ : ICC-01/04-01/06, Chambre de première instance, jugement, 14 mars 2012, in http://www.icc-cpi.int/iccdocs/doc/doc1462060.pdf p. 254, § 510. (Source consultée le 22 mars 2015).

${ }^{1667}$ Ibid., p. 269, § 540.

1668 Ibid., p. 261, §§524-525.

1669 TPIY, Le Procureur c/ Tadic, affaire n IT-94-1-AR72, Chambre d'appel, Arrêt relatif à l'appel de la Défense concernant l'exception préjudicielle d'incompétence, 2 octobre $1995, \quad \$ 77$ in http://www.icty.org/X/cases/tadic/acdec/fr/51002JN3.htm (Source consultée le 22 mars 2015).

${ }^{1670}$ Ibid.

${ }^{1671}$ MAMPUYA, Auguste, « Responsabilité et réparations dans le conflit des Grands-Lacs au Congo-Zaïre », in RGDIP, 2004-3, p. 679.
} 
conduite par l'AFDL. Ceci pour éviter que leur mission soit directement qualifiée d'agression ou de toute autre violation de l'article $2 \S 4$ de la Charte des Nations Unies (Non-recours à la force) par le CS/NU, voire éventuellement par la CIJ, à la suite d'une ou (des) probable(s) affaire(s) qui pourrai(en)t les concerner devant cette instance judiciaire sur la question.

Cette guerre s'achèvera avec la victoire de l'AFDL sur les FAZ, le 17 mai 1997, portant au pouvoir Laurent-Désiré KABILA. L'armée de l'AFDL reste symbolisée par l'image de l'enfant soldat dit Kadogo. Il s'agit pour cette période d'octobre 1996 à mai 1997 d'une prétendue «rébellion » bénéficiant d'un appui substantiel de la coalition précitée. L'Accord secret de Lemera, dont d'aucuns nient l'existence, déterminait les droits et obligations des parties impliquées dans ce conflit armé (cf. supra). C'est dans ce cadre que «l'Ouganda et le Rwanda se sont vu accorder en RDC d'importants avantages économiques et militaires ${ }^{1672}$. Ceci dit, il n'est point un secret que pour faire la guerre au Zaïre et atteindre leurs objectifs, les Républiques du Rwanda et de l'Ouganda feront appel à Laurent-Désiré KABILA, opposant de longue date au régime zaïrois ${ }^{1673}$ mais «tombé dans l'oubli depuis des décennies ${ }^{1674}$ pour reprendre l'expression de Rik COOLSAET. Ainsi, l'AFDL est donc un pur produit de cette coalition et est demeurée durant toutes ses opérations sous sa totale dépendance.

Il s'agit, à dire vrai, d'un conflit armé conçu et préparé, par cette coalition, contre le régime du Zaïre longtemps favorable à l'ancien régime du Rwanda dirigé par le Général Major Juvénal Habyarimana. Bien plus, le Zaïre servait de refuge aux extrémistes hutu, présumés auteurs du génocide rwandais et hostiles au régime de Kigali en place après le génocide de 1994. Ainsi, le renversement du pouvoir de Mobutu et le démantèlement de ces réfugiés hutu au Zaïre constituaient des éléments du plan de bataille de l'AFDL, dont le Rwanda jouera un rôle moteur, que dévoilera plus tard le Président Paul KAGAME dans un entretien accordé au Washington Post le 9 juillet $1997^{1675}$. Et suivant le Rapport du Projet Mapping, « [1]'implication du Rwanda et de l'Ouganda dans le conflit, dès le début, dans la mise sur pied de l'AFDL et son organisation, la planification des opérations, le support logistique tel que la fourniture d'armes et l'entraînement d'une partie des combattants est aujourd'hui reconnue par les plus hautes autorités des pays concernés ${ }^{1676}$. Il s'en suit que les opérations militaires étaient menées sous le commandement d'un Officier rwandais, le Colonel James KABAREBE, qui deviendra, après victoire de l'AFDL sur les FAZ, le Chef d'état-major ad

${ }^{1672}$ CIJ Affaire des activités armées sur le territoire du Congo (République démocratique du congo c. Ouganda), arrêt du 19 décembre 2005, Recueil 2005, p. 191, \$29.

1673 «Le $1^{\text {er }}$ conflit du Zaïre 1996-1997 », in La Documentation française. La librairie du citoyen, disponible sur http://www.ladocumentationfrancaise.fr/dossiers/conflit-grands-lacs/premier-conflit-zaire.shtml $\quad$ (Source consultée le 10 avril 2016).

${ }^{1674}$ COOLSAET, Rik, La Politique extérieure de la Belgique. Au cœur de l'Europe, le poids d'une petite puissance, éd. De Boeck Université, Bruxelles, 2002, p. 291.

${ }_{1675}$ Suivant le Rapport du Projet Mapping, dans son entretien accordé au Washington Post le 9 juillet 1997, le Président rwandais Paul Kagame (Ministre de la défense à l'époque), reconnaissant le rôle clef joué par le Rwanda dans la campagne AFDL, indiquait que «le plan de bataille était composé de trois éléments: $a$ démanteler les camps de réfugiés, $b$ détruire la structure des ex-FAR et des Interahamwe basés dans les camps et autour des camps et $c$ renverser le régime de Mobutu ». Voy. la note infrapaginale $\mathrm{n}^{\circ} 886 \mathrm{du}$ Rapport du Projet Mapping (...).

${ }^{1676}$ Nations Unies, Haut Commissariat aux droits de l'homme, Rapport du Projet Mapping concernant les violations les plus graves des droits de l'homme et du droit international humanitaire commises entre mars 1993 et juin 2003 sur le territoire de la République démocratique du Congo, Août 2010, pp. 273-274, § 479. 
interim de la nouvelle armée congolaise, les $\mathrm{FAC}^{1677}$.

Tous ces éléments vont largement au-delà de ce qui peut être qualifié de «contrôle global » pour affirmer à suffisance le «contrôle effectif » exercé par ces deux Etats (Rwanda et Ouganda) sur l'AFDL. Laquelle n'est d'ailleurs rien d'autre que leur pure création. Ces éléments seront d'un grand intérêt pour l'établissement de la responsabilité internationale de ces Etats au regard notamment d'innombrables crimes graves du DIH. Ils nous permettent également, dans le cadre de cet examen, de qualifier ces affrontements armés en RDC de conflit armé international (CAI). En d'autres termes, ce sont les forces armées étatiques étrangères qui combattaient, via l'AFDL, les forces armées congolaises sur le territoire de celles-ci.

La question pourrait tout de même se poser pour le cas du soutien des FAZ aux interahamwe pour combattre les forces armées rwandaises au Zaïre et effectuer des incursions sporadiques mais meurtrières au Rwanda. Au départ, il s'agirait d'un conflit armé non-international suivant l'application minimale de l'article 3 commun aux CG. En d'autres termes, il se dégage de l'organisation et de la planification établies pour effectuer ces opérations militaires, qu'il ne s'agirait pas de simples actes de banditisme pour créer des troubles internes. Il s'agirait véritablement de conflit armé en dépit de leur durée. Et le soutien qu'apportent les FAZ, rentrant dans le cadre de «contrôle global » dégagé par jurisprudence internationale, suffit d'internationaliser ce conflit pour se voir qualifier de conflit armé non - international internationalisé.

Par ailleurs, en marge de ce CAI ou CANI internationalisé, il existe encore quatre types d'affrontements, en jeu sous cette période, qui opposent sur le territoire congolais : 1. les forces armées rwandaises (à dominante tutsi) aux anciens génocidaires hutu; 2. les forces armées burundaises (à dominante tutsi) à leurs adversaires extrémistes hutu; 3. le gouvernement ougandais à deux groupes rebelles différents et 4 . un certain nombre d'organisations rebelles au gouvernement zaïrois ${ }^{1678}$. A défaut d'être des simples troubles internes ou des tensions internes, au regard notamment d'intensité d'affrontements armés, ces trois premiers types d'affrontements, dits aussi conflits armés «transnationaux » ou «exportés » devraient, du moins au sens de l'article 3 commun aux CG, être qualifiés de conflit armé non international (CANI). Sont donc pris en considération les types d'acteurs étatiques ou non étatiques - indépendamment du territoire du déroulement des hostilités. Ceci devrait aller dans le même sens pour le dernier cas d'affrontements entre mouvement rebelles et les forces armées congolaises.

Quid de la qualification par les parties étatiques elles-mêmes?

Rappelons préalablement qu'il n'existe pas en DIH, un organe conventionnellement habilité

\footnotetext{
1677 Nations Unies, Haut Commissariat aux droits de l'homme, Rapport du Projet Mapping concernant les violations les plus graves des droits de l'homme et du droit international humanitaire commises entre mars 1993 et juin 2003 sur le territoire de la République démocratique du Congo, Août 2010, pp. 273-274, § 479.

${ }_{1678}$ «Le $1^{\text {er }}$ conflit du Zaïre 1996-1997», in La Documentation française. La librairie du citoyen, disponible sur http://www.ladocumentationfrancaise.fr/dossiers/conflit-grands-lacs/premier-conflit-zaire.shtml consultée le 10 avril 2016).

(Source
} 
pour qualifier les conflits armés, contrairement au jus ad bellum, dans le cadre du système onusien. Ainsi, en application d'un principe général du droit international, « il appartient à chaque Etat d'apprécier, raisonnablement et de bonne foi, les situations [...] ${ }^{1679}$. Cette auto-appréciation ou auto-qualification est valable en DIH. En d'autres termes, en principe, « [1]a qualification n'est pas laissée à l'appréciation partisane des parties en conflit. Le droit humanitaire énonce des critères de qualification factuels et objectifs pour éviter les polémiques ${ }^{1680}$ (nous soulignons). Ainsi, l'auto-appréciation ou l'auto-qualification des parties demeure non moins sans risque de la qualification qui pourrait se dégager éventuellement d'une instance judiciaire ou quasi-judiciaire nationale ou internationale. Laquelle pourrait s'avérer exigeante en termes du droit applicable.

Pour cette première phase des conflits armés, contrairement à la deuxième débouchée par une qualification juridique effectuée par les parties via notamment l'Accord de Lusaka, les parties se sont plus limitées aux arguments de registre politique se rapportant plus au jus ad bellum qu'au jus in bello en soi. Ainsi, pour le Zaïre, il s'agirait d'agression par la coalition Burundooudando-rwandaise. Pour ces trois Etats :

«Ils font essentiellement valoir le caractère sécuritaire de leur engagement auprès de leurs frères tutsi Banyamulenge : "nettoyer" les camps de réfugiés hutu, établis à proximité de la zone frontalière depuis 1994 au Kivu, qui menacent leur tranquillité donc celle du nouvel ordre politique tutsi rwandais. En effet, les camps sont infiltrés par les responsables du génocide de 1994: Hutus extrémistes des ex-Forces armées rwandaises (FAR) [;] Interahamwe soutenus par les Forces armées zaïroises (FAZ) qui franchissent la frontière pour effectuer des incursions meurtrières sur le territoire rwandais ${ }^{1681}$.

De ces arguments politiques, juridiquement problématiques, il y a lieu de déceler toutefois des conséquences probables sur le plan du DIH. Ainsi, affirmer que les forces armées zaïroises font face à une agression reviendrait à admettre indirectement l'existence d'un conflit armé international. Ce qui ne serait probablement pas le cas de l'intervention des forces armées de la coalition en sécurisation de « leurs frères tutsis banyamulenge » contre les extrémistes hutu. Situation qui serait qualifiée de CANI. Mais la situation des interahamwe soutenus par les FAZ faisant face aux forces armées de la coalition, situation dite conflit armé «transnational» ou « exporté » à l'instar de la précédente, pourrait être qualifiée de CANI internationalisé en DIH.

\section{B. D'août 1998 à juin 2003}

La deuxième période à considérer est celle d'août 1998 à juin 2003. «En 1998, à la réouverture des hostilités le 02 août, on annonce une nouvelle «rébellion des

\footnotetext{
${ }^{1679}$ Affaire du Lac Lanoux (Espagne, France), Sentence du 16 novembre 1957, Recueil des Sentences Arbitral des Nations Unies, Vol. XII, p. 310.

${ }_{1680}$ BOUCHET-SAULNIER, Françoise, Dictionnaire pratique du droit humanitaire, op.cit., 547.

1681 «Le $1^{\text {er }}$ conflit du Zaïre 1996-1997 », in La Documentation française. La librairie du citoyen, disponible sur http://www.ladocumentationfrancaise.fr/dossiers/conflit-grands-lacs/premier-conflit-zaire.shtml consultée le 10 avril 2016).

(Source
} 
Banyamulenge » à l'Est du Congo, en fait une rébellion d'unités des Forces Armées Congolaises (FAC) des garnisons de l'Est, coiffées deux semaines plus tard par un mouvement politico-militaire, le Rassemblement Congolais pour la Démocratie (RCD), alors qu'un autre mouvement rebelle verra le jour en novembre 1998 dans la province de l'Equateur (Nord-Ouest du pays), le Mouvement pour la Libération du Congo (MLC) ${ }^{1682}$.

"[Cette] rébellion se mua en une "guerre sans frontières », un cocktail sanglant de guerre civile, de banditisme et de conflit international, qui fit du Congo, en un minimum de temps, un véritable patchwork de territoires contrôlés par des groupes rebelles rivaux, l'armée gouvernementale et des troupes étrangères ${ }^{1683}$.

En effet, il est important de rappeler que c'est à la suite de la décision prise par le Président Laurent-Désiré KABILA de remercier les troupes invitées et de les prier de regagner leurs pays respectifs que cette «deuxième guerre de libération » fut entamée. Elle empruntera un autre itinéraire que la «première guerre de libération », plus rapide, pour atteindre la capitale à savoir la zone ouest du pays. C'est notamment l'opération aéroportée organisée le 04 août 1998 par les Républiques de l'Ouganda et du Rwanda pour acheminer leurs soldats de Goma (Nord-Kivu) à Kitona (Bas-Congo), sur le littoral atlantique à quelque 1800 kilomètres, avec objectif d'atteindre Kinshasa et de renverser Laurent-Désiré Kabila ${ }^{1684}$. Cet argument de la RDC devant la CIJ contre la République de l'Ouganda a été rejeté par celle-ci. La République de l'Ouganda dément formellement sa participation à l'attaque de Kitona du 04 août $1998^{1685}$. Et faute des preuves suffisantes apportées par la RDC, la Cour adhère à la position de l'Ouganda ${ }^{1686}$. Toutefois, cette attaque connue du grand public congolais reste non moins attribuable aux forces armées étrangères. Elle se soldera par une large défaite de ces combattants «étrangers » précisément à Kinshasa par les FAC soutenues par la population kinoise. Il va sans dire que l'internalisation de cette «rébellion» par l'appui extérieur (Ouganda et Rwanda), bien que souvent nié, se manifeste dès le déclenchement des hostilités.

En effet, les Républiques de l'Ouganda et du Rwanda procéderont à la création du RCD et du MLC. «Ainsi, le RCD aurait été créé par l'Ouganda et le Rwanda le 12 août 1998 et, à la fin du mois de septembre 1998, l'Ouganda aurait appuyé la formation du MLC, nouveau groupe rebelle qui n'était pas lié à l'armée rwandaise » ${ }^{1687}$. Et comme nous l'affirmions, cidessus, au sujet de la première phase, Auguste MAMPUYA estime qu' «[e]n réalité, le recours à des Zaïro-Congolais de souche, pour couvrir les Banyamulenge-Tutsi congolais, rwando-type trop facilement reconnaissable, n'a servi qu'à camoufler une opération dont, sans cela, le caractère d'agression aurait éclaté trop brutalement dès le début : d'ailleurs Kagame reconnaît avoir recruté des opposants Zaïrois ${ }^{1688}$.

\footnotetext{
${ }^{1682}$ MAMPUYA, Auguste, «Responsabilité et réparations dans le conflit des Grands-Lacs au Congo-Zaïre », « art.cit. », p. 680.

${ }^{1683}$ COOLSAET, Rik, La Politique extérieure de la Belgique. Au cour de l'Europe, le poids d'une petite puissance, op.cit., p. 291.

${ }^{1684}$ CIJ, Affaire des Activités armées sur le territoire du Congo (République démocratique du Congo c. Ouganda), arrêt du 19 décembre 2005, Recueil 2005, p.191, §31.

1685 Ibid., p. 194, $\$ 38$.

${ }^{1686}$ Ibid., p.205, §41.

${ }^{1687}$ Ibid.,p.191, §32.

${ }^{1688}$ MAMPUYA, Auguste, « Responsabilité et réparations dans le conflit des Grands-Lacs au Congo-Zaïre »,
} 
Le soutien aux mouvements rebelles par ces deux Etats est un des volets de ces conflits armés qui perdura jusqu'à ce jour. Dans l'affaire qui a opposé la RDC à l'Ouganda devant la CIJ, il a été affirmé, par la RDC, que «l'Ouganda a été fortement impliqué dans le recrutement, la formation, l'entraînement, l'équipement et le ravitaillement du MLC et de son aile armée, l'ALC [Armée de libération du Congo, branche Armée du MLC]. Les liens étroits existant entre l'Ouganda et le MLC se sont traduits, au dire de la RDC, par la constitution d'un front militaire unique dans les opérations de combat contre les FAC. La RDC soutient que, dans un certain nombre de cas, les UPDF [Uganda People's Defence Forces] ont apporté un appui tactique, notamment sous la forme d'une couverture d'artillerie, aux forces de l'ALC ${ }^{1689}$. Pour sa part, la République de l'Ouganda reconnaît son appui aux rebelles mais fait part d'une nuance non moins de taille. Ainsi, elle indique que «la nature et l'ampleur de son soutien aux rebelles congolais n'excédaient pas les limites de ce qu'imposaient les exigences de légitime défense ${ }^{1690}$. D'après lui, «il s'était abstenu d'apporter aux rebelles le type ou la quantité d'aide dont ils auraient eu besoin pour parvenir à des fins aussi ambitieuses que la conquête $d u$ territoire ou le renversement $d u$ Gouvernement de la $R D C »^{1691}$. Bien plus, l'Ouganda admet «avoir soutenu le MLC lors de affrontements survenus entre la fin du mois de septembre 1998 et en juillet 1999, tout en insistant sur le fait que son aide à M. Bemba "fut toujours limitée et soumise à de nombreuses conditions $\gg \gg{ }^{1692}$.

A la lumière de ce qui précède, il ressort clairement que la République de l'Ouganda mobilise les arguments du registre de «contrôle global » pour tenter de se disculper lors du processus de l'établissement de sa responsabilité internationale. Celle-ci pourrait donc résulter notamment du lien de « contrôle effectif » établi entre la République de l'Ouganda et le MLC pour des violations graves du DIH matérialisées par ce dernier. En même temps, ces arguments paraissent d'ores et déjà suffisants, dans le cas d'espèce, pour donner qualification à un conflit armé non international internationalisé.

Par ailleurs, il est vrai que la vérité judiciaire n'est pas nécessairement la vérité des faits. Le formalisme judiciaire ne permet pas toujours de parvenir à la réalité vue ou vécue par une population donnée. Il n'est point une nouveauté qu'une partie devant une instance judiciaire, internationale soit-elle, puisse faire part des objections à titre de sa défense même pour des faits qui s'avèrent matériellement établis. Il n'est donc pas toujours évident pour la partie qui détient la vérité d'apporter ses moyens de preuves selon la forme requise. Faute du respect de ce formalisme, on ne peut donc aboutir à la «vérité des faits » mais à la «vérité judiciaire » qui n'est donc pas nécessairement véridique. C'est dans le même ordre d'idées qu'enseigne Olivier CORTEN : «[L]a difficulté de la phase de l'établissement du fait est tout d'abord et fondamentalement, que la réalité ne peut être appréhendée ni communiquée de manière directe. Ce n'est que par l'intermédiaire de «témoignages » ou de «preuves » que la vérité sera établie, mais ces témoignages et ces preuves ne peuvent, par définition, que fournir des

\footnotetext{
« art.cit. », 680.

1689 CIJ, Affaire des Activités armées sur le territoire du Congo (République démocratique du Congo c. Ouganda), arrêt du 19 décembre 2005, Recueil 2005, p.192, §32

1690 Ibid., p. $195, \S 41$.

${ }^{1691}$ Ibid., pp. 195-196, §41.

${ }^{1692}$ Ibid., p. 225, §157.
} 
approximations plus ou moins fiables du réel. La vérité judiciaire ou juridique ne constitue qu'une construction, $[\ldots]{ }^{1693}$. «[...] personne ne peut affirmer que cette vérité (judiciaire) juridique correspond avec une certitude absolue avec la réalité objective ${ }^{1694}$.

C'est peut être ce qu'il faudrait dire à la suite de cette brève analyse.

Ainsi, de tout ce qui précède, de nombreuses recherches scientifiques effectuées sur la situation de la RDC, durant la seconde guerre de libération voire actuellement atteste à suffisance non seulement l'appui continu des Républiques de l'Ouganda ou du Rwanda aux mouvements rebelles ou groupes armés opérant dans la zone Est de la RDC mais aussi leurs nombreuses participations directes aux conflits armés en RDC. Par exemple, «[i]l a été amplement démontré que l'Ouganda avait pris part par la suite, à plusieurs occasions, notamment en août 1999 et en mai et juin 2000, à des combats de grande ampleur, à Kisangani, contre les forces rwandaises, également présentes ${ }^{1695}$. Bien plus, devant la C.I.J, il a été établi que « [du]rant la période pertinente, qui s'étend d'août 1998 à juin 2003, les forces ougandaises étaient présentes dans la partie orientale de la RDC, notamment la province orientale, la province de l'Equateur et une partie de la province du Nord-Kivu. Durant cette même période, des actes constitutifs de violations graves des règles les plus fondamentales des droits de l'homme et du DIH ainsi que des actes d'exploitation illégale des ressources naturelles de la RDC ont été commis ${ }^{1696}$. Il s'agit de ce fait d'un CAI clairement établi. La Cour ne qualifie pas expressément ce conflit armé de CAI mais fait application d'un droit applicable au CAI. Elle qualifie l'Ouganda de puissance occupante ${ }^{1697}$ - notion applicable dans le cas de CAI - et mobilise différents instruments juridiques internationaux relatifs au DIH ${ }^{1698}$ applicables dans le cas de CAI (ex : la CG IV et le PA I) dont les deux Etats (RDC et Ouganda) sont parties. Sans oublier le Règlement concernant les lois et coutumes de la guerre sur terre, annexé à la quatrième convention de La Haye du 18 octobre $1907^{1699}$ qui est considéré par la Cour comme l'expression du droit international coutumier bien que deux Etats ne soient pas parties.

Des analyses effectuées dans les lignes précédentes, il se dégage de manière significative des éléments de l'internationalisation du conflit en RDC, en application notamment du critère admis de contrôle global, le moins exigeant. Cette internationalisation se rapportera également aux conflits ethniques. Ceci est observé à propos du conflit ethnique qui a opposé les Lendu et les Hema dans la région de l'Ituri occasionnant des milliers de victimes civiles.

\footnotetext{
${ }^{1693}$ CORTEN, Olivier, Méthodologie du droit international public, op.cit., p. 252.

${ }^{1694}$ Ibid., p. 253.

1695 CIJ, Affaire des activités armées sur le territoire du Congo (République démocratique du Congo c. Ouganda), arrêt du 19 décembre 2005, Recueil 2005, p. 207, §80.

${ }^{1696}$ KOUTROULIS, Vaios, «L'affaire des activités armées sur le territoire du Congo (Congo c. Ouganda) : Une lecture restrictive du droit de l'occupation? », in RBDI, 2006/2, p. 704.

1697 Voy. CIJ, Affaire des activités armées sur le territoire du Congo (République démocratique du Congo c. Ouganda), arrêt du19 décembre 2005, Recueil 2005, p. 231, §178.

1698 CIJ, Affaires des activités armées sur le territoire du Congo (République démocratique du Congo c. Ouganda), arrêt du 19 décembre 2005, Recueil 2005, pp. 243-244, §§ 217-219.

${ }^{1699}$ Voy. Convention (IV) concernant les lois et coutumes de la guerre sur terre du 18 octobre 1907 et son annexe Règlement concernant les lois et coutumes de la guerre sur terre in Deuxième Conférence internationale de la Paix, La Haye 15 juin - 18 octobre 1907, Actes et documents, Tome I, Séances plénières de la Conférence, Ministère des affaires étrangères, Imprimerie Nationale, La Haye, 1907, pp. 626 - 637. Textes disponibles sur https://www.icrc.org/dih/INTRO/195 (Source consultée le 07 avril 2016).
} 
La République de l'Ouganda s'est rangée derrière les Hema suivant l'argument de la RDC devant la $\mathrm{CIJ}^{1700}$.

Par ailleurs, la complexité de ces conflits armés, que reconnaît d'ailleurs la $\mathrm{CIJ}^{1701}$, fera apparaître, sous cette seconde période également, deux types des conflits armés à savoir les CAI et CANI. Le CAI est remarquable dans les affrontements armés directs qui ont opposé l'Ouganda et le Rwanda (A Kisangani, par exemple) (cf. supra) ou entre eux (ou chacun d'eux) et la RDC. Ou encore des situations d'oppositions armées qui ont impliqué des forces armées étrangères venues à l'appui de la RDC telles que les forces armées des Républiques de l'Angola, de la Namibie, du Zimbabwe voire du Tchad ou du Soudan contre ces deux précédents (Ouganda et Rwanda). C'est d'ailleurs en raison du nombre impressionnant d'acteurs impliqués que ce conflit armé sera qualifié politiquement de la "première guerre mondiale africaine» ou encore de la "guerre sans frontières ${ }^{1702}$. Il s'agira des CANI pour des nombreux cas qui opposent les mouvement rebelles ou groupes armés entre eux ou ceux-ci et les entités étatiques identifiées. Rappelons que la situation de conflits armés s'est complexifiée avec le phénomène "groupes armés ». Le territoire de la RDC est devenu le théâtre de multiples acteurs non étatiques étrangers et locaux. Ces derniers peuvent entrer en affrontements armés entre eux. Tout comme ils peuvent s'opposer à des acteurs étatiques invités ou non sur le territoire congolais. C'est le cas entre autres des groupes armés étrangers luttant contre les pouvoirs en place au Rwanda, en Ouganda voire au Soudan qui se trouvent traqués sur le territoire congolais par ceux-là (conflit armé dit transnational ou exporté). Ces groupes armés étrangers se servent du territoire national congolais comme sièges ou bases arrières. Tout comme ils pourront faire front commun pour contrecarrer des actions conjointes ou unilatérales menées par des forces armées étatiques. La situation de CANI sera observée notamment pour le cas d'affrontement des groupes armés locaux aux forces armées étrangères. Le $\boldsymbol{C A I}$ sera identifié pour le cas d'opposition armée entre les forces armés des Etats engagés dans ce conflit armé. En bref, les CAI et CANI sont fonction d'acteurs ou belligérants en présence indépendamment du territoire où ces conflits armés sont menés.

Il ressort de cette période un conflit armé mixte qui a donc « une dimension à la fois interne et externe ${ }^{1703}$ comme le reconnaissaient d'ailleurs les parties à l'Accord de Lusaka.

\section{De juin 2003 à ce jour (Période des conflits armés intermittents)}

Enfin, la troisième période à prendre en considération est celle d'après le retrait officiel des forces armées étrangères du territoire congolais. C'est aussi la période marquée par l'installation d'un gouvernement de transition avec les chefs rebelles d'hier (1998-2003). Cette période reste caractérisée par la montée en puissances des groupes armés, mouvements rebelles, et milices (cf. supra). La Zone Est de la RDC, du Sud-Est au Nord-Est, est largement

\footnotetext{
1700 CIJ, Affaires des activités armées sur le territoire du Congo (République démocratique du Congo c. Ouganda), arrêt du 19 décembre 2005, Recueil 2005, pp. 233-234, §187.

${ }^{1701}$ Voy. Ibid., p. 245, §221.

1702 COOLSAET, Rik, La Politique extérieure de la Belgique. Au cour de l'Europe, le poids d'une petite puissance, op.cit., p. 291.

${ }^{1703}$ Préambule (16 ${ }^{\mathrm{e}}$ considérant) de l'Accord de cessez-le-feu en République Démocratique du Congo (Accord de Lusaka) du 10 juillet 1999.
} 
dominée par des groupes armés procédant le plus souvent au recrutement des enfants dans leurs rangs. L'opinion congolaise se souviendra par exemple du fameux «triangle de la mort » regroupant les localités de Mitwaba - Pweto - Manono au Katanga. Lesquelles localités sont restées pendant longtemps sous la terreur de Gédéon Kyungu Mutanga à la tête du Mouvement Maï-Maï. Des noms tels que Laurent Kunda, Mutebusi, Bosco Ntaganda, Général Makenga, etc sont repris parmi les Seigneurs de guerre souvent soutenus par l'extérieur. Il existe également de nombreux mouvements rebelles ou groupes armés et milices luttant contre l'envahissement ou le soutien extérieur au Nord-Kivu, au Sud-Kivu, au Maniema, au Katanga et à la Province-Orientale (cf. Supra). Il s'agit pour la plus part des situations de CANI telles que détaillées ci-dessus.

Par ailleurs, depuis la fin officielle de ces conflits armés symbolisée notamment par la mise en place d'un gouvernement de l'Union nationale réunissant les ex - rebelles et la partie gouvernementale avec la formule sui generis de 1+4 (1 Président de la République et 4 VicePrésidents de la République) tel que le suggérait le Dialogue Inter-congolais, la RDC est demeurée un territoire où les incursions étrangères sont fréquentes. Ceci est généralement l'œuvre des acteurs non étatiques et étatiques étrangers. Si ce ne sont pas les groupes armés qui sèment la terreur sur le territoire congolais (ex : F.D.L.R ou L.R.A), ce sont les acteurs étatiques étrangers qui interviennent du côté des mouvements rebelles congolais pour faire face à l'armée gouvernementale. L'appui patent du Rwanda vis-à-vis du C.N.D.P et du M.23 avec des armements aux insignes officiels du Rwanda est très significatif à cet égard. Ceci est un CAI où les rebelles ne sont autres que des représentants de l'Etat rwandais. Ces rebelles sont donc en réalité sous le contrôle effectif du pouvoir rwandais qui les soutient substantiellement. Sans les nommer expressément, le CS/NU a reconnu cependant dans ses différentes résolutions dont la résolution 2078 (2012) ces appuis en ces termes : le CS/NU, «[r]enouvelant sa ferme condamnation de tout appui extérieur au M23, notamment la fourniture de renforts de personnels militaires, de conseils tactiques et de matériel, et se disant vivement préoccupé par les informations et les allégations faisant état de la poursuite d'un tel appui au M23, » (Nous soulignons) ${ }^{1704}$.

\section{§2. Conséquences juridiques de la qualification des conflits armés en RDC au regard du droit international humanitaire : Identification des sources conventionnelles des règles assurant la protection générale des enfants - combattants et civils - en conflits armés}

Il se dégage du paragraphe précédent que les conflits armés qui sévissent en RDC depuis 1996 revêtent différentes qualifications suivant les cas et les périodes. Il s'agit en somme de CANI, de CANI internationalisés et de CAI. Ces qualifications entraînent comme conséquences juridiques l'application des règles du DIH se rapportant respectivement à chaque type de conflits armés sauf application d'accords spéciaux étendant les règles de CAI aux CANI, par exemple. Et s'agissant de la population civile et des personnes civiles, rappelons dorénavant qu'une protection générale leur est accordée contre les dangers résultant d'opérations militaires (art. 51 du PA I et art. 13 du PA II, voire l'art. 3 commun aux CG). Protection

\footnotetext{
${ }^{1704}$ Résolution 2078 (2012) Adoptée par le Conseil de sécurité à sa 6873e séance, le 28 novembre $2012\left(6^{\mathrm{e}}\right.$ considérant), in http://www.un.org/fr/sc/documents/resolutions/2012.shtml (Source consultée le 09 juillet 2015).
} 
générale dont bénéficie également l'enfant au-delà de sa protection spéciale (cf. infra). La question de la protection générale se pose également pour les enfants qui participent directement aux hostilités. Lesquels, pris comme combattants, se retrouveront préalablement sous le régime de la protection des combattants.

Ces règles seront examinées dans le cadre de CAI (et CANI internationalisé) (A) et dans le contexte de CANI (B).

\section{A. Dans le cadre de CAI (et CANI internationalisé) en RDC}

Les règles applicables dans ce cadre seront donc fonction de l'état de ratification ou d'adhésion des Etats parties à ces conflits armés aux instruments relatifs au DIH. Ceci n'exclura pas l'application des instruments relatifs aux droits de l'homme auxquels ils sont également parties. Bien plus, le DIH coutumier, qui se trouve d'ailleurs exprimé par la plupart des instruments précités, sera d'application. Ceci concorde d'ailleurs le mieux avec l'article $51 \S 1$ du PA I qui admet l'élargissement du champ d'application du droit à la protection générale de la population civile et des personnes civiles contre les dangers résultant d'opérations militaires, lorsqu'il affirme «[...] [e]n vue de rendre cette protection effective, les règles suivantes, qui s'ajoutent aux autres règles du droit international applicable, doivent être observées en toutes circonstances» (nous soulignons). Ceci pour dire que la protection de l'enfant à travers la protection générale de la population civile est l'objet non seulement du DIH mais aussi du DIDH voire de toute règle pertinente du Droit international applicable.

Comme nous l'avions examiné ci-dessus, les conflits armés en RDC ont impliqué suivant différentes périodes de nombreux Etats à savoir les Républiques d'Angola, du Burundi, de la Namibie, du Zimbabwe, du Rwanda, de l'Ouganda, du Tchad, du Soudan hormis la RDC elle-même. Ce qui nous amène à examiner sous ce point le contenu du droit applicable suivant les obligations internationales contractées par lesdits Etats.

En effet, les quatre CG du 12 août 1949, entrées en vigueur depuis le 21 octobre 1950, sont d'application à tous ces Etats concernés. Au-delà du fait que les dispositions de ces Conventions sont vues comme du droit coutumier, tous les Etats impliqués dans les conflits armés y ont adhéré.

Ainsi, la situation d'adhésion à ces instruments par ces Etats se présente de la manière ciaprès : la République d'Angola est partie aux CG depuis le 20 septembre 1984 ; la République du Burundi depuis le 27 décembre 1971; la RDC depuis le 24 février 1961 «avec effet rétroactif à compter du 30 juin 1960, date de son indépendance ${ }^{1705}$; la République de la Namibie depuis le 22 août 1991; la République du Rwanda depuis 05 mai 1964, la République de l'Ouganda depuis le 18 mai 1964 ; la République du Soudan depuis le 23 septembre 1957 (la République du Soudan du sud depuis le 25 janvier 2013) ; la République

1705 CIJ, Affaire des Activités armées sur le territoire du Congo (République démocratique du Congo c. Ouganda), arrêt du 19 décembre 2005, Recueil 2005, p. 243, §217. 
du Tchad depuis le 05 août 1970 et la République du Zimbabwe depuis le 07 mars $1983^{1706}$. De tous ces Etats, seule la République d'Angola a formulé une réserve notamment au sujet de l'article 85 de la CG III qui dispose : «Les prisonniers de guerre poursuivis en vertu de la législation de la Puissance détentrice pour des actes qu'ils ont commis avant d'avoir été faits prisonniers resteront, même s'ils sont condamnés, au bénéfice de la présente convention ». Cette réserve se présente de façon suivante : «En adhérant aux Conventions de Genève du 12 août 1949, la République populaire d'Angola se réserve le droit de ne pas mettre au bénéfice découlant de l'article 85 de la Convention relative au traitement des prisonniers de guerre les auteurs de crimes de guerre et crimes contre l'humanité définis à l'article VI des "Principes de Nuremberg", tels que formulés en 1950 par la Commission du droit international, mandatés par l'Assemblée générale des Nations Unies ${ }^{1707}$. Il ressort de cette réserve que la République d'Angola entend poursuivre un prisonnier de guerre pour des crimes de guerre et crimes contre l'humanité commis en vertu de sa législation avant qu'il ne tombe en son pouvoir et ne pas lui faire bénéficier de ce statut de prisonnier de guerre comme le veut bien l'article 85 précité. Aucune objection n'a été signalée à cette réserve.

Le PA I applicable dans le cas de CAI sera d'application car faisant l'objet d'adhésion des Etats ici concernés. La République d'Angola est partie au PAI depuis le 20 septembre 1984 ; la République du Burundi depuis le 10 juin 1993 ; la RDC depuis le 03 juin 1982 ; la République de Namibie depuis le 17 juin 1994 ; la République du Rwanda depuis 19 novembre 1984, la République de l'Ouganda depuis le 13 mars 1991 ; la République du Soudan depuis le 07 mars 2006 (le 25 janvier 2013 pour la République du Soudan du Sud) ; la République du Tchad depuis le 17 janvier 1997 et la République du Zimbabwe depuis le 19 octobre $1992^{1708}$.

De nombreux autres instruments relatifs au DIH auxquels les Etats en conflits armés en RDC sont parties seront également d'application ${ }^{1709}$ suivant les dates de leur entrée en vigueur vis-àvis de ces Etats et en tenant compte de réserves émises à cet effet. A titre illustratif, pour le cas de la RDC, il s'agit de la Convention sur l'interdiction de la mise au point, de la fabrication et du stockage des armes bactériologique (biologiques) ou à toxines et sur leur destruction du 10 avril 1972, en vigueur depuis le 26 mars 1975 (Ratifiée par la RDC le 28 janvier 1977); Convention sur l'interdiction de la mise au point, de la fabrication, du stockage et de l'emploi des armes chimiques et sur leur destruction du 13 janvier 1993 en vigueur depuis le 29 avril 1997 (adhésion de la RDC le 12 octobre 2005); Convention sur l'interdiction de l'emploi, du stockage, de la production et du transfert des mines antipersonnel et sur leur destruction, 18 septembre 1997 en vigueur depuis le $1^{\text {er }}$ mars 1999 (adhésion de la RDC le 02 mai 2002); Convention de La Haye pour la protection des biens culturels en cas de conflit armé du 14 mai 1954 en vigueur depuis le 07 août 1956 (adhésion de la RDC le 18

${ }_{1707}^{1706}$ Voy. https://www.icrc.org/dih (Source consultée le 28 décembre 2014).

https://www.icrc.org/applic/ihl/dih.nsf/Notification.xsp?action=openDocument\&documentId=AC9D48BE76C26 EFDC12563FF0047C167 (Source consultée le 28 décembre 2014)

https://www.icrc.org/applic/ihl/dih.nsf/States.xsp?xp_viewStates=XPages_NORMStatesParties\&xp_treatySelect ed $=470$ (Source consultée le 28 décembre 2014)

${ }^{1709}$ Voy. https://www.icrc.org/dih (Source consultée le 28 décembre 2014). 
avril 1961) ; Protocole pour la protection des biens culturels en cas de conflit armé du 14 mai 1954 en vigueur depuis le 07 août 1956 (adhésion de la RDC le 18 avril 1961) ; Convention de l'OUA sur l'élimination du mercenariat en Afrique du 3 juillet 1977 en vigueur depuis le 22 avril 1985 ratifiée par la RDC le 13 juillet 1979 ; voire le Statut de Rome qui contient des dispositions qui affermissent davantage le DIH. Signalons que la RDC est signataire des instruments suivants : la Convention sur les armes à sous-munitions du 30 mai 2008 en vigueur depuis le $1^{\text {er }}$ août 2010 et signée par la RDC le 18 mars 2009; la Convention sur l'interdiction d'utiliser des techniques de modification de l'environnement à des fins militaires ou toutes autres fins hostiles du 10 décembre 1976 entrée en vigueur le 05 octobre 1978 et signée de la RDC le 28 février 1978 ; la Convention internationale contre le recrutement, l'utilisation, le financement et l'instruction des mercenaires du 4 décembre 1989 en vigueur depuis le 20 octobre 2001 et signée par la RDC le 20 mars 1990. Ces instruments précités n'ont pas encore fait l'objet de ratification par la RDC. Cependant, en vertu de l'article 18 de la Convention de Vienne sur le droit des traités du 23 mai 1969 - auquel la RDC a adhéré depuis le 25 juillet 1977- Un Etat signataire s'oblige de «s'abstenir d'actes qui priveraient un traité de son objet et de son but ${ }^{1710}$. On citera au rang du DIH coutumier le règlement concernant les lois et coutumes de la guerre sur terre, annexé à la quatrième convention de La Haye du 18 octobre 1907 auquel ni la RDC, ni l'Ouganda ne sont parties mais dont les dispositions ont acquis un caractère coutumier ${ }^{1711}$.Tous ces instruments concourent à la protection générale des enfants en tant que personnes civiles voire en tant que combattants en périodes des conflits armés.

Par ailleurs, autant pour les CAI (et CANI internationalisé) que pour les CANI, d'importants instruments relatifs aux droits de l'homme ${ }^{1712}$ auxquels la RDC et les autres Etats sont parties seront également d'application en pareilles circonstances. C'est le cas notamment des instruments ratifiés par la RDC ${ }^{1713}$ - voire des Etats en conflits- tels que le Pacte international relatif aux droits économiques, sociaux et culturels du 16 décembre 1966 (la RDC y a adhéré le $1^{\text {er }}$ novembre 1976); le Pacte international relatif aux droits civils et politiques du 16

1710 Lire l'article 18 de la Convention de Vienne sur le droit des traités du 23 mai 1969 in https://treaties.un.org/doc/Treaties/1980/01/19800127\%2000-52\%20AM/Ch_XXIII_01.pdf $\quad$ p. 9, (Source consultée le 11 mars 2015).

1711 CIJ, Affaire des Activités armées sur le territoire du Congo (République démocratique du Congo c. Ouganda), arrêt du 19 décembre 2005, Recueil 2005, p.243, §217.

${ }^{1712}$ La Section III, §1, du présent chapitre reprend, pour les conventions internationales des droits de l'Homme s'occupant en totalité ou en partie des droits de l'enfant, les dates d'entrée en vigueur, de ratification ou d'adhésion des Etats membres.

${ }^{1713}$ Lire Journal officiel de la République Démocratique du Congo, Instruments internationaux et régionaux relatifs aux droits de l'Homme ratifiés par la République Démocratique du Congo, $43^{\mathrm{e}}$ année, Numéro spécial, 5 décembre 2002, 294 p. Par souci de prudence et de conformité, il est important de signifier que certaines dates mentionnées par le Journal officiel de la RDC précité ne coïncident pas, par exemple, avec celles mentionnées dans les sites des Organisations internationales concernées ou encore avec celles mentionnées dans l'arrêt de la CIJ dans l'affaire des Activités armées sur le territoire de la RDC. C'est le cas notamment de la Convention de l'Organisation de l'Unité Africaine régissant les aspects propres aux problèmes des réfugiés en Afrique du 10 septembre 1969 dont l'UA fait mention du 14 février 1973 (Voy. http://www.droitcongolais.info/files/0.1.23.-1.-Convention-on-Refugees adhesions.pdf) comme date de ratification de cet instrument par la RDC, alors qu'elle même retient la date du 20 juin 1974. Ou encore la non reprise de la RDC comme partie à la Charte africaine des droits et du bien-être de l'enfant du 11 juillet 1990 sur la liste de l'UA (V. http://www.droitcongolais.info/files/0.1.8.3.1.-Adhesions-African-Charter-on-the-Rights_Child.pdf) alors que le Journal officiel de la RDC confirme la ratification de cet instrument par la RDC le 28 mars 2001 voire l'arrêt de la CIJ dans l'affaire des Activités armées sur le territoire de la RDC. 
décembre 1966 (la RDC y a adhéré le $1^{\text {er }}$ novembre 1976); le Protocole facultatif se rapportant au Pacte international relatif aux droits civils et politiques du 16 décembre 1966 (la RDC y a adhéré le $1^{\text {er }}$ novembre 1976); la Convention internationale sur l'élimination de toutes les formes de discrimination raciale du 21 décembre 1965 (à laquelle la RDC a adhéré le 21 août 1976); la Convention internationale sur l'élimination et la répression du crime d'apartheid du 30 novembre 1973 (ratifiée par la RDC le 11 juillet 1978); la Convention pour la prévention et la répression du crime de Génocide du 09 décembre 1948 en vigueur depuis le 12 janvier 1951 (adhésion de la RDC le 31 mai 1962); la Convention contre la torture et autres peines ou traitement cruels inhumains ou dégradants du 10 décembre 1984 (ratifiée par la RDC le 17 février 1989); la Convention relative au statut des réfugiés du 14 décembre 1950 (ratifiée par la RDC le 07 juillet 1965); le Protocole relatif au statut des réfugiés en vigueur le 31 janvier 1967 (ratifié par la RDC le 02 janvier 1968) ; la Convention sur l'élimination de toutes les formes de discrimination à l'égard des femmes du 18 décembre 1979; la Convention relative aux droits de l'enfant du 20 novembre 1989 (ratifiée par la RDC le 27 septembre 1990); le Protocole facultatif à la convention relative aux droits de l'enfant concernant la vente d'enfants, la prostitution des enfants et la pornographie mettant en scène des enfants du 25 mai 2000 (adhésion de la RDC le 11 novembre 2001 et entré en vigueur le 18 janvier 2002, de même pour la RDC); le Protocole facultatif à la convention relative aux droits de l'enfant concernant l'implication d'enfants dans les conflits armés du 25 mai 2000 (ratifié par la RDC le 11 novembre 2001) ; le Statut de Rome de la Cour Pénale internationale du 17 juillet 1998 (ratifié par la RDC le 11 avril 2002); la Charte africaine des droits de l'homme et des peuples du 27 juin 1981 (ratifiée par la RDC le 20 juillet 1987); la Convention de l'Organisation de l'Unité Africaine régissant les aspects propres aux problèmes des réfugiés en Afrique du 10 septembre 1969 (ratifiée par la RDC le 14 février 1973 ) ; la Charte africaine des droits et du bien-être de l'enfant du 11 juillet 1990 (ratifiée par la RDC le 28 mars 2001), le Protocole à la Charte africaine des droits de l'Homme et des peuples relatifs aux droits de la femme (Protocole de Maputo) du 11 juillet 2003 que la RDC a ratifié en 2009; etc.

Par ailleurs, il faudrait signifier que la question de la protection générale des enfants en période de conflits armés n'est pas propre aux enfants civils. Elle se pose également pour le cas des enfants combattants. Dans la mesure où ceux-ci participent directement aux hostilités, perdant par là leur immunité de protection en tant que civils, et/ou membres des forces armées d'une partie étatique, de tels enfants resteront sous le régime des règles gouvernant les combattants ${ }^{1714}$. A titre illustratif, ils ne devront par être victimes «des maux superflus ». Il est donc de règles fondamentales en DIH que dans tout conflit armé le choix des méthodes ou moyens de nuire à l'ennemi n'est pas illimité. Les armes, projectiles et des matières, et les moyens de guerre occasionnant des maux superflus sont donc interdits d'usages (article 35 $\S \S 1-2$ du PA I). Il sera également «interdit de tuer, de blesser ou capturer un [enfant] adversaire en recourant à la perfidie » (article 37, $\S 1$ du PA I). Dès lors qu'un enfant combattant se retrouve hors combat, il ne doit pas faire l'objet d'attaque (article 41 du PA I). De ces quelques règles relatives à la situation des combattants en général, de nombreuses autres se rapportant à la conduite des hostilités, qualifiées autrement de « droit de La Haye »,

${ }^{1714}$ Voy. par exemple Titre III - Méthodes et moyens de guerre. Statut de combattant et de prisonnier de guerre du PA I. 
seront donc d'application. Par exemple, il y a lieu de citer pour la RDC, la Convention sur l'interdiction de la mise au point, de la fabrication, du stockage et de l'emploi des armes chimiques et sur leur destruction du 13 janvier 1993 en vigueur depuis le 29 avril 1997 (adhésion de la RDC le 12 octobre 2005); la Convention sur l'interdiction de l'emploi, du stockage, de la production et du transfert des mines antipersonnel et sur leur destruction, 18 septembre 1997 en vigueur depuis le $1^{\text {er }}$ mars 1999 (adhésion de la RDC le 02 mai 2002) (cf. supra), etc. Il faudrait penser aussi aux règles relatives à la protection des prisonniers de guerre (cf. IIIe CG).

Nonobstant ce qui vient d'être souligné, comme signalé ci - dessus, pour l'intérêt de la présente étude, les efforts seront plus consacrés à l'étude des CG et de leurs PA - base essentielle du DIH - voire d'autres instruments des droits de l'homme ou du droit pénal international relatifs à la protection des enfants de manière plus spécifique en situation de conflits armés (cf. infra).

\section{B. Dans le cadre de CANI en RDC}

Par rapport aux règles du DIH applicables dans le cadre de CANI, il ne fait aucun doute de l'application de l'article 3 commun aux CG d'autant plus que la RDC voire les autres Etats participant à ses côtés contre les groupes armés sont parties aux CG. Il s'en suit par ailleurs que les groupes armés agissant sur le territoire de la RDC dans le cadre de CANI s'obligent tout de même d'observer les règles du DIH applicables en pareilles circonstances pour lesquelles la RDC a ratifié. En d'autres termes, les groupes armés se trouvant en conflit armé contre toute force armée étatique - congolaise ou étrangère - s'obligeraient d'observer les règles du $\mathrm{DIH}$ applicables ratifiées par la $\mathrm{RDC}^{1715}$. Ce qui vaut de même pour les règles de droits de l'homme (cf. supra). Etant entendu que ces groupes armés, mouvements rebelles ou milices sont non moins des entités agissant sur le territoire national congolais, ils doivent donc se conformer au droit y applicable. Ils feront de même s'ils entrent en conflits armés entre eux sur le territoire congolais. Il est nécessaire de rappeler que si l'article 3 commun aux quatre CG reste applicable à tout CANI, le PA II ne l'est pas. «En effet, le Protocole II ne s'applique qu'à des conflits d'une certaine intensité et n'a pas exactement la même portée que l'article 3 commun, qui vaut dans toutes les situations de conflit armé non international ${ }^{1716}{ }$. En ce sens notamment, le PA II «s'applique lorsque les forces armées gouvernementales luttent contre des insurgés qui forment des groupes armés organisés, ce qui est le plus souvent le cas ${ }^{1717}{ }$. La protection dont est question en PA II, sous cet angle, concernera pour l'essentiel l'enfant civil. Les règles proprement dites sur la conduite des hostilités ne sont d'ailleurs pas développées en droit de CANI. Il existe tout de même des garanties fondamentales profitables généralement à toute personne ayant pris part aux hostilités (dont l'enfant) et non aux personnes participant aux hostilités (article 4 du PA II). Ainsi, des règles profitables aux

\footnotetext{
${ }^{1715}$ Lire dans ce sens DABONE, Zakaria, Le Droit international public relatif aux groupes armés non étatiques, Schulthess, L.G.D.J, Genève-Zurich-Bâle - Paris, 2012, pp. 128-129.

${ }^{1716}$ Protocole additionnel aux Conventions de Genève du 12 août 1949 relatif à la protection des victimes des conflits armés non internationaux (Protocole II), 8 juin 1977, Commentaire - Champ d'application matériel, in https://www.icrc.org/applic/ihl/dih.nsf/Comment.xsp?viewComments=LookUpCOMART\&articleUNID=2E657 2BC09B135E8C12563BD002C30B5, point 4447 (Source consultée le 11 mars 2015).

${ }^{\frac{1}{1717}}$ Ibid.
} 
enfants en tant que «personnes privées de liberté pour des motifs en relation avec le conflit armé », internés ou détenus (article $5 \S 1^{\mathrm{er}}$ du PA II), ou des règles applicables aux blessés, malades et naufragés ayant notamment pris part au conflit armé sont détaillées dans le PA II. Il s'agit cependant de règles applicables après les « hostilités ». En cela, ils seront traités avec humanité en toutes circonstances et soignés suivant les exigences de leur état. «Aucune distinction fondée sur des critères autres que médicaux ne sera faite entre eux » (article $7 \mathrm{du}$ PA II).

Etant donné la situation de la RDC, affirmons que le PA II sera tardivement d'application. Car la RDC n'est devenue partie à cet instrument du DIH que le 12 décembre 2002. A la base, les délégués de la RDC (ex-Zaïre) déploraient vis-à-vis de cet instrument le fait que plusieurs de ses dispositions compromettaient dangereusement la souveraineté étatique. Et traiter sur un pied d'égalité un Etat souverain, un gouvernement légal et un groupe de ses ressortissants insurgés, hors la loi était perçu par ces délégués comme la grande erreur de cet instrument ${ }^{1718}$. Toutefois, la pratique subséquente atteste en revanche que l'Etat congolais siège sur pied d'égalité aux côtés des groupes armés pour la résolution des conflits qui les opposent ${ }^{1719}$.

Conformément à l'article $23, \S 2$ du PA II, son entrée en vigueur vis-à-vis de la RDC devrait s'effectuer six mois après le dépôt d'instrument d'adhésion de la RDC, à savoir jusqu'au mois de Juin 2003. Cependant, l'absence d'une disposition d'application immédiate à l'égard d'un nouvel Etat adhérant -partie à un conflit armé- tel que prévoient les $\mathrm{CG}^{1720}$, n'interdit pas au commentateur du PA II d'admettre que «l'existence d'une situation visée à l'article premier du [PA II] donnera effet immédiatement aux ratifications et adhésions des parties au conflit ${ }^{1721}$. Ainsi, les CANI qui se déroulent d'octobre 1996 à mai 1997 - contrairement à certaines affirmations ${ }^{1722}$ - et d'août 1998 à juin 2003 ne verront pas l'application du PA II qu'à partir de décembre 2002, à côté de l'article 3 commun aux CG. C'est ici que les accords spéciaux joueront un grand rôle dans l'élargissement de quelques dispositions du DIH applicables en CAI. A l'exception donc du Soudan (partie au PA II dès le 13 juillet 2006), la RDC se présente ainsi comme le dernier Etat à adhérer au PA II comparativement à d'autres Etats parties au conflit armé sur son territoire - le Rwanda (19 novembre 1984), l'Ouganda (13 mars 1991), le Burundi (10 juin 1993), la Namibie (17 juin 1994), le Tchad (17 janvier 1997) et le Zimbabwe (19 juillet 1991). A ce jour, elle n'est pas encore partie au PA III comme pour les autres Etats précités à l'exception de l'Ouganda (21 mai 2008).

Tout de même, la non adhésion de la RDC au PA II n'a pas empêché son Ministère des droits humains, en octobre 2001, de mobiliser cet instrument contre des Etats parties - Ouganda et Rwanda - afin de dénoncer leur responsabilité pour des cas de recrutements et de transferts

\footnotetext{
${ }^{1718}$ WODIE, Vangah Francis, « L'Afrique et le droit humanitaire » « art. cit. », p. 261.

1719 KAZADI MPIANA, Joseph, La position du droit international dans l'ordre juridique congolais et l'application de ses normes, op.cit., pp. 122-123.

${ }^{1720}$ Voy. les articles 62-61-141-157 respectivement des CG I, CG II, CG III et CG IV.

1721 Commentaire de l'article 23 du PA II renvoyant à celui de l'article 95 du PA I in https://www.icrc.org/applic/ihl/dih.nsf/Comment.xsp?action=openDocument\&documentId=7F437C01A1CCF8 C9C12563BD002DD4A3 (Source consultée le 19 juin 2016).

${ }^{1722}$ Voy. NGOY Walupakah, Providence et MUYA Miyanga, Sandra, Le Droit de la guerre à l'épreuve du conflit armé en République démocratique du Congo, Publibook, Paris, 2015, p. 105.
} 
forcés d'enfants vers Ouganda et Rwanda ${ }^{1723}$. Ce qui paraît d'ailleurs une application non adaptée car cet instrument s'applique en CANI et non en CAI comme c'est ici le cas.

Par ailleurs, signifions également que les instruments relatifs aux droits de l'homme, universels et régionaux, répertoriés ci-dessus, s'y appliqueront suivant leur période d'entrée en vigueur.

En dehors de ces nombreux instruments universels et régionaux identifiés, la résolution des conflits armés en RDC est à la base de nombreux accords régionaux et spéciaux conclus entre parties (cf. infra). Quelques uns de ces accords, variés suivant les périodes, imposent également aux parties certaines obligations du DIH à observer vis-à-vis des personnes civiles. Sous ce registre, il sera épinglé l'Accord de Cessez-le-feu de Lusaka du 10 juillet 1999, le Pacte sur la Paix, la Sécurité, la Stabilité et le Développement dans la Région des Grands Lacs, dit «Pacte ou Traité de Nairobi » du 15 décembre 2006, entré en vigueur en juin $2008^{1724}$, l'Accord cadre pour la paix, la sécurité et la coopération pour la RDC et la région du 24 février 2013 (Accord d'Addis Abeba) ${ }^{1725}$ et différents accords bilatéraux voire des accords entre gouvernement congolais et groupes armés applicables dans le cadre de CANI précisément.

En outre, nombreuses sont également des résolutions onusiennes (cf. infra) qui assurent indistinctement la protection de l'enfant en situation de CAI ou CANI.

\section{Section II Le droit international humanitaire applicable à la protection spéciale des enfants en RDC}

La protection spéciale de l'enfant en situation de conflits armés en RDC se trouve régie par diverses règles du DIH et du DIDH auxquelles les Etats, acteurs de ces conflits armés, sont parties. Les règles qui assurent la protection générale de l'enfant - en tant que personne civile et en tant que combattant - dans ces conflits armés sont répertoriées dans la section précédente.

A propos de la protection proprement dite ou mieux de la protection spéciale de l'enfant personne civile et combattant - durant les conflits armés en RDC, d'importantes règles régissent cette question. Ces règles assurant cette protection spéciale, comme pour la protection générale décrite ci-dessus, sont fonction de l'état de ratification des instruments concernés par les Etats impliqués dans lesdits conflits armés. En effet, s'il est admis que les groupes armés doivent se conformer aux règles du DIH et du DIDH ratifiés par l'Etat sur le territoire duquel ils agissent à l'instar de l'Etat congolais (cf. supra), il est aussi vrai que les Etats étrangers impliqués dans lesdits conflits armés doivent faire application des règles qu'ils ont ratifiées dans le cas d'espèce. Ils doivent en outre étendre - sauf exception expresse l'application des instruments qu'ils ont ratifiés sur le territoire de la RDC, spécialement ceux

\footnotetext{
${ }^{1723}$ République Démocratique du Congo, Ministre des droits humains, La guerre d'agression en République Démocratique du Congo. Trois ans de massacre et de génocide "à huis clos », Livre Blanc, Numéro spécial, Kinshasa, Octobre 2001, p. 34-36.

${ }_{1724}$ Voy. http://www.icglr.org/index.php/fr/le-pacte (source consultée le 11 mai 2015).

1725 Voy. http://www.peaceau.org/uploads/scanned-on-24022013-125543.pdf (source consultée le 11 mai 2015).
} 
des droits de l'homme, au profit des enfants - civils et combattants.

Il est non moins sans intérêt de rappeler à cet égard l'interprétation de la notion de «juridiction» qu'a dégagé la Cour européenne des Droits de l'homme (CEDH) dans différentes affaires. Par exemple dans son arrêt du 07 juillet 1989 dans l'affaire Soering c. Royaume-Uni, la CEDH a indiqué que

«la notion de «juridiction» au sens de l'article 1 de la Convention ne se circonscrit pas nécessairement au seul territoire national des Hautes Parties contractantes ${ }^{1726}$. En effet, la «Cour a admis que, dans des circonstances exceptionnelles, les actes des Etats contractants accomplis ou produisant des effets en dehors de leur territoire peuvent s'analyser en l'exercice par eux de leur juridiction au sens de l'article 1 de la Convention. Ainsi qu'il ressort des principes pertinents du droit international, un Etat contractant peut voir engager sa responsabilité lorsque, par suite d'une action militaire légale ou non, il exerce en pratique le contrôle effectif sur une zone située en dehors de son territoire national. L'obligation d'assurer, dans une telle région, le respect des droits et libertés garantis par la Convention découle du fait de ce contrôle, qu'il s'exerce directement, par l'intermédiaire des forces armées de l'Etat concerné ou par le biais d'une administration locale subordonnée ${ }^{1727}$.

Cette position est confortée par la jurisprudence de la CIJ dans l'affaire des Activités armées sur le territoire du Congo (République démocratique du Congo c. Ouganda) où ladite Cour déclare que « les instruments internationaux relatifs aux droits de l'homme étaient applicables «aux actes d'un Etat agissant dans l'exercice de sa compétence en dehors de son propre territoire », particulièrement dans les territoires occupés ${ }^{1728}$.

Il faudrait rappeler sous cet angle, en DIH, l'obligation de « respecter et de faire respecter le $\mathrm{DIH}$ », dans le cadre de CAI. Obligation qui incombe à toute partie aux CG et au PA I dont les Etats parties aux conflits armés en RDC. Cette obligation se trouve renforcée davantage dans le cadre de l'occupation. C'est ainsi qu'après avoir qualifié l'Ouganda de puissance occupante dans le district de l'Ituri, la CIJ conclut que l'Ouganda

«se trouvait dans l'obligation, énoncée à l'article 43 du règlement de La Haye de 1907, de
prendre toutes les mesures qui dépendaient de lui en vue de rétablir et d'assurer, autant qu'il
était possible, l'ordre public et la sécurité dans le territoire occupé en respectant sauf
empêchement absolu, les lois en vigueur en RDC. Cette obligation comprend le devoir de
veiller au respect des règles applicables du droit international relatifs aux droits de l'homme
et du droit international humanitaire, de protéger les habitants du territoire occupé contre les
actes de violence et de ne pas tolérer de tels actes de la part d'une quelconque tierce
partie »

Il ressort de là que l'Ouganda devrait veiller à ce que le DIH et le DIDH soient respectés

1726 CEDH, affaire Ilascu et autres c. Moldova et Russie, arrêt du 08 juillet 2004, \$314 in http://hudoc.echr.coe.int/sites/fra/pages/search.aspx?i=001-66444\#\{"itemid":["001-66444"]\} (Source consultée le 15 mars 2015).

${ }^{1727}$ Ibid.

${ }^{1728}$ CIJ, Affaire des Activités armées sur le territoire du Congo (République démocratique du Congo c. Ouganda), arrêt du 19 décembre 2005, Recueil 2005, p. 243, §216.

${ }^{1729}$ CIJ, Affaire des Activités armées sur le territoire du Congo (République démocratique du Congo c. Ouganda), arrêt du 19 décembre 2005, Recueil 2005, p. 231, §178. 
autant par les Etats que par les groupes armés ou milices opérant sur le territoire de l'Ituri qu'il occupait.

Cet éclairage nous permet d'examiner les règles assurant la protection spéciale des enfants en situation de conflits armés en RDC dans le cas de CAI (§1) et de CANI (\$2). Enfin, les règles du DIH coutumier feront l'objet d'étude pour l'ensemble de ces conflits armés $(\S 3)$.

\section{§ 1. Règles du DIH assurant la protection spéciale des enfants - combattants et civils - en CAI en RDC}

Il se dégage de la présentation des instruments internationaux relatifs au DIH et au DIDH que seulement certains instruments traitant spécifiquement des enfants dans leur ensemble ou dans certaines de leurs dispositions seront concernés pour la situation des enfants en CAI en RDC. La question sera appréhendée respectivement sous l'angle des enfants civils (A) et enfants « combattants » $(\mathrm{B})$.

\section{A. Règles du DIH assurant la protection spéciale des enfants civils en CAI en RDC}

\section{A. 1. Règles du DIH assurant la protection spéciale des enfants civils en CAI en RDC : Règles issues des instruments juridiques universels}

Aucune réserve pour les règles relatives à la protection spéciale des enfants en situation de conflits armés (CAI ou CANI (cf. infra)) n'a été signalée pour les Etats en conflits armés en RDC. Tout de même, ces règles sont revêtues de valeur coutumière (cf. supra).

Ainsi, les dispositions de la CG IV et du PA I se rapportant à la protection spéciale des enfants en période de conflits armés se verront toutes d'application. Toutefois, partant du principe que ces règles ne sont pas exclusives d'autres dispositions propices à la réalisation de la protection spéciale, en vertu notamment du droit congolais ou du droit international applicables, les dispositions de la CG IV et du PA I pourront donc céder face à celles plus favorables applicables en même temps qu'elles. Ceci sera plus remarquable au niveau du recrutement et de la participation des enfants aux hostilités (cf. infra). Il faudrait pour ce faire tenir compte des dates d'entrée en vigueur de différentes conventions ou législations nationales applicables vis-à-vis des parties en conflits armés en RDC.

En effet, des dispositions suivantes de la CG IV visent la protection spéciale des enfants en RDC: le droit des parties au conflit de créer sur leurs propres territoires ou sur les territoires occupés des zones et localités sanitaires et de sécurité afin de mettre les enfants de moins de quinze ans à l'abri des effets de la guerre (art.14); l'évacuation des enfants d'une zone assiégée ou encerclée (art.17); le libre passage de tout envoi des vivres indispensables, des vêtements et des fortifiants réservés aux enfants de moins de quinze ans (art. 23); les mesures nécessaires à prendre par les parties au conflit au profit des enfants de moins de quinze ans, orphelins ou séparés des familles du fait de la guerre, pour que soient facilités leur entretien, la pratique de leur religion et leur éducation (art.24 §1); l'accueil des enfants en pays neutres (art.24 §2); l'identification des enfants de moins de 12 ans (art.24 §3); le droit de 
correspondance familiale (art. 25); facilitations par les parties au conflit des recherches entreprises par les membres des familles dispersées pour des contacts les uns avec les autres (art. 26); le droit au traitement préferentiel pour les enfants de moins de quinze ans, des femmes enceintes et des mères d'enfants de moins de sept ans (art. 38); l'intangibilté du statut personnel de l'enfant interdisant à la Puissance occupante de modifier sa situation de famille, son état civil et sa nationalité (art. $50 \S 2$ ); les règles encadrant les mesures exceptionnelles de transferts, de déportations ou évacuations (article 49); l'obligation de ne pas astreindre au travail des personnes de moins de dix-huit ans (art. 51 alinéa 2); obligation pour la Puissance occupante de ne pas astreindre des personnes protégées à servir dans ses forces armées ou auxillaires (art. 51 alinéa 1 de la CG IV); 1'interdiction des peines de mort (art. 68 alinéa 4 ); le traitement des détenus (art. 76); l'entretien des personnes dépendant des internés par la Puissance détentrice (art. 81 alinéa 3); le regroupement des internés notamment ceux issus d'une même famille en particulier les parents et leurs enfants (art. 82); le droit à l'alimentation suffisante et saine dont des suppléments - proportinonnés aux besoins physiologiques- pour les femmes enceintes et en couches, et les enfants de moins de quinze ans (art. 89); l'assurance de la pratique des activités intellectuelles, éducatives, recréatives et sportives des enfants (art. 94); possibilité de libération, du rapatriement, du retour au lieu de domicile ou l'hospitalisation en pays neutre des enfants, des femmes enceintes et des mères avec nourrissons et enfants en bas âge pendant la durée des hostilités (art. 132).

Les PA I et II traitent notamment en ce qui concerne les enfants (cf. Section II, §1, B., B.2) : la priorité d'accès au secours et le traitement de faveur aux enfants, femmes enceintes ou en couches et les mères qui allaitent (art. $70 \S 1$ du PA I); le regroupement des familles dispersées (art. 74 du PA I); la préservation de l'unité familiale en cas d'arrestation, détention ou internement des familles (art.75 $\$ 5$ du PA I) voire des garanties spécifiques pour les enfants détenus, arrêtés ou internés notament l'interdiction de l'éxécution d'une condamnation à mort (art. $77 \S 5$ du PA I ou art. $6 \S 4$ du PA II); la réglementation d'évacuation des enfants (art. 78 du PA I). Des garanties fondamentales sont également accordées aux enfants (art. 75 du PA I, art. 4 du PA II (cf. 3 commun aux CG), etc.

Au-delà de certains termes réducteurs - les parties pourront créer [...] ; les parties au conflit s'efforceront [...]; Elles (les personnes protégées inculpées) seront séparées si possible des autres détenus [...]; la puissance occupante groupera dans toute la mesure du possible les internés selon [...], etc. - par lesquels s'expriment de nombreuses dispositions ci-dessus, rendant ainsi préalablement moins aisée la mise en oeuvre du DIH, nombreuses sont également des dispositions liées à la protection spéciale qui se trouveront buter à des sérieux problèmes notamment d'application.

Dans le cadre des conflits armés en RDC, différentes dispositions nécessitent de la part de l'Etat congolais voire d'autres parties en conflits armés en RDC d'importants moyens humains et financiers (cf. infra) au-delà de ceux qui existent. C'est notamment le cas des Règles relatives au traitement des internés ${ }^{1730}$ telles que: 1'entretien des personnes dépendant des internés par la Puissance détentrice (art. 81 alinéa 3 de CG IV); le droit à l'alimentation

\footnotetext{
${ }^{1730}$ Voy. la Section IV (Règles relatives au traitement des internés) du Titre III (Statut et traitement des personnes protégées) de la IV ${ }^{\mathrm{e}} \mathrm{CG}$.
} 
suffisante en quantité, qualité et variété afin d'assurer un équilibre normal de santé et empêcher les troubles de carence chez les femmes enceintes et en couches, et les enfants de moins de quinze ans, voire des suppléments de nourritures proportinonnés à leurs besoins physiologique (art. 89 de la CG IV); l'assurance de la pratique des activités intellectuelles, éducatives, recréatives et sportives des enfants (art. 94 de la CG IV). Il s'agit là donc des dispositions qui nécessiteront des moyens humains et financiers conséquents pour leur application. La situation économique déjà chaotique de la RDC ne devrait pas permettre la mise en oeuvre efficace de telles dispositions. Afin de mieux comprendre les difficultés que susciterait la mise en oeuvre des dispositions ci-dessus épinglées, il y a lieu de voir ce qui se passe déjà pour les cas des obligations notamment des droits de l'homme à assurer en temps de paix. En effet, pour ne prendre que le cas de la gestion de la situation carcérale en RDC, il n'est point un secret que "[1]es prisons du pays sont en état d'abandon matériel et humain: les juges continuent à incacérer des condamnés dans des centres de détention aux murs vacillants, sans sanitaires, sans budget pour l'alimentation des détenus et les salaires du personnel. Environ 15.000 personnes sont emprisonnées dans des lieux insalubres ${ }^{1731}$ et surpeuplés où les morts de faim ne sont pas rares: la prison centrale de Kinshasa accueille plus de 4.000 prisonniers (42\% y sont détenus préventivement) pour une capacité initiale de 1.500 prisonniers et, dans les prisons de provinces, des détenus souffrent régulièrement de la

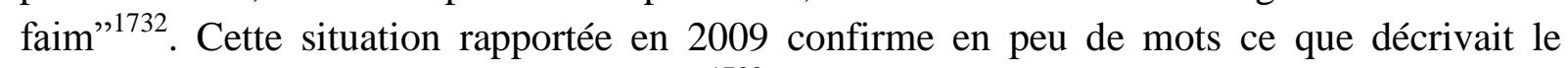
Rapport de la MONUC en octobre $2005^{1733}$ sur la question et n'est donc pas différente de celle actuellement vécue. Il y a lieu d'ajouter le cas d'insécurité grandissante dans des prisons telles qu'à Bunia (Nord-Est de la RDC) où il est rapporté au mois de janvier 2015 le cas de près de 152 prisonniers de la prison de Bunia blessés au cours d'affrontement entre deux groupes de prisonniers ${ }^{1734}$. Ainsi, le surpeuplement, l'évasion, la mort des prisonniers suite à des maladies dues à l'insalubrité ou à la faim sont fréquents. Dans un article intitulé «Conditions carcérales difficiles en RDC » publié le 2 avril 2015, la Radio Okapi rapportait que « [d]es morts, des malades et des évasions massives sont observés dans plusieurs prisons de la RDC. A la prison de Mbanza Ngungu (Province du Bas-Congo), par exemple, 4 prisonniers sont morts cette semaine. A Walikale (Province du Nord Kivu), la prison ne compte plus qu'un seul détenu après l'évasion de 62 prisonniers. Et la prison centrale de Kindu connait une rupture de stock de nourriture ${ }^{1735}$. La rupture de stock de nourriture déjà qualitativement et quantitativement insuffisante - demeure fréquente. C'est notamment le cas des prisons centrales de Munzenze à Goma et de Lubero, toutes au Nord - Kivu, où le 21 avril 2015 les pensionnaires déclenchaient un mouvement de protestation à la suite de rupture de stock de nourriture depuis quatre jours. En termes de capacités d'accueil, la prison

\footnotetext{
${ }^{1731}$ Le Rapport de la MONUC d'octobre 2005 indiquait que «les conditions hygiéniques minimales font particulièrement défaut dans la plupart des prisons en $R D C »$, voy. MONUC, Division des droits de l'homme, Rapport sur les conditions de détention dans les prisons et cachots de la RDC, octobre 2005, p. 10.

${ }^{1732}$ VIRCOULON, Thierry, «Réforme de la justice : réalisations, limites et questionnements », in TREFON, Theodore (dir.), Réforme au Congo (RDC). Attentes et désillusions, Musée royal de l'Afrique centrale L'Harmattan, Paris, 2009, p. 87.

${ }^{1733}$ MONUC, Division des droits de l'homme, Rapport sur les conditions de détention dans les prisons et cachots de la RDC, op.cit.,, $42 \mathrm{p}$.

${ }_{1734}$ http://www.aa.com.tr/fr/afrique/457513--rdc-152-blesses-apres-des-rixes-entre-prisonniers-a-bunia (Source consultée le 20 avril 2015).

${ }_{1735}$ Radio Okapi, «Conditions carcérales difficiles en RDC», in http://radiookapi.net/emissions-2/dialogue-entrecongolais/2015/04/02/conditions-carcerales-difficiles-en-rdc/ (Source consultée le 20 avril 2015)
} 
centrale de Munzenze accueille 1450 pensionnaires actuellement pour une capacité initiale de 150. Pour sa part, la prison centrale de Lubero en accueille quatre-vingt-dix pour une capacité initiale de soixante détenus ${ }^{1736}$.

S'il est aussi vrai qu'ailleurs, en Belgique précisément, la population carcérale se plaint de divers problèmes dont la prise en charge médicale non adéquate, la vétusté, l'exiguïté des locaux, la surpopulation - laquelle atteignait par exemple 21, $4 \%$ en 2007 pour une population de 9.873 détenus et $19,5 \%$ en mars 2009 pour une population de 10.100 détenus ${ }^{1737}$ - le bref tableau ci-dessus dressé sur la situation carcérale en RDC est plus que catastrophique.

Ce bref aperçu sous-tend donc notre doute sur la volonté et la capacité de la RDC - en situation économique chaotique - d'assurer la protection spéciale des enfants dans le cadre des conflits armés tels que le prescrivent notamment les dispositions conventionnelles indexées ci - avant. Laquelle protection nécessitant non moins des moyens humains et financiers importants.

Au-delà de ces instruments à caractère universel, il existe des instruments juridiques régionaux applicables pour la protection spéciale des enfants en situation de conflits armés en RDC - la Charte africaine des droits et du bien-être de l'enfant du 11 juillet 1990 et la Convention de l'Union africaine sur la protection et l'assistance aux personnes déplacées en Afrique (Convention de Kampala) adoptée par le Sommet spécial de l'Union tenu le 22 octobre 2009.

Les lignes suivantes examinent ce que prévoyent ces instruments régionaux et spéciaux au sujet du DIH et plus précisément de la protection spéciale des enfants en conflits armés.

\section{A. 2. Règles du DIH assurant la protection spéciale des enfants civils en CAI en RDC : règles issues des Accords régionaux et spéciaux signés entre parties aux conflits armés}

La résolution des conflits armés atteste généralement de la conclusion de nombreux accords à dénominations variées à côté d'actes unilatéraux des Etats tels que les déclarations unilatérales de cessez-le-feu. A cet égard, la doctrine politique ou juridique épingle des "traités de paix", "peace treaty", "accord de paix" "accord de pacification", "accord de Cessez-le-feu ou Cessez-le-feu”, "accord politique”, "engagement purement politique", "acte ou instrument concerté non conventionnel", etc. A leurs contenus, se trouvent attachées des définitions subtiles qui diffèrencient les uns des autres.

En effet, pour ne reprendre que quelques uns, si certains dictionnaires spécialisés ${ }^{1738}$ ne

1736 Radio Okapi, «Goma : des coups de feu entendus aux prisons de Munzenze et Lubero», in http://radiookapi.net/actualite/2015/04/21/goma-des-coups-de-feu-entendus-aux-prisons-de-munzenze-lubero/ (Source consultée le 22 avril 2015).

${ }^{1737}$ Lire CAPRON, Claire et DELSEMME, Florence, La vie en prison. 80 visiteurs témoignent, éd. Couleur Livres, Charleroi, 2009, p.11, pp. 26-30.

${ }^{1738}$ Voy. par exemple, BATTISTELA, Dario, et al., Dictionnaire des relations internationales, $3^{\mathrm{e}}$ édition, Dalloz, 2012, 572 p. ou BEMBA, Joseph, Dictionnaire de la justice internationale, de la paix et du développement, L'Harmattan, Paris, 20045, 403 p. 
réservent point de définition aux "accords politiques" en général ou "traités ou accords de paix" en particulier, le Dictionnaire de Droit international public précise au sujet d"'Accords politiques" que le mot "politique" est d'un contenu incertain. Néanmoins, il pourrait prendre en compte différentes matières dont la paix et les questions militaires ${ }^{1739}$. Au sujet de "Traité de paix", les Dictionnaires de droit international (version anglaise) appréhendent en "Peace treaty" (Traité de paix), une paix durable, permanente, dans la résolution de conflits armés en ces termes:

"Instrument ending a state of war. Though it is seldom achieved, the primary function of a peace treaty is to succed in gaining lasting reconciliation between former enemies" "1740. Ou encore "A treaty legally terminating the state of war between states.It is the normal mode of restoring a condition of peace betwen warring parties (...) In addition to stipulating termination of the state of war and the restoration of peace, a peace treaty contains provisions on liquidating the effects of war, such as restitution of property, repatriation of the prisoners of war, reparations, the validity of prewar treaties, territorial and military clauses, and the like." ${ }^{, 1741}$.

Le Dictionnaire de Droit international public précité abonde d'ailleurs dans le même sens au sujet de "Traité de paix"1742. Celui-ci diffère donc d'armistice, de Cessez-le-feu qui cherche à mettre fin momentannément aux hostilités et non de manière définitive. Pour leur part, les "accords de paix" (peace agreement) peuvent inclure à la fois les dispositions relatives aux "traités de paix" et celles de cessez-le-feu ${ }^{1743}$ (Cette même logique sera retrouvée pour la catégorisation d'accords spéciaux en DIH (cf. infra)). L'Accord de Lusaka (cf. infra) est d'ailleurs l'exemple bien indiqué à cet égard. D'emblée, il serait circonspect face à ces différents instruments de résolution de conflits de ne point se fier à leurs dénominations mais à leurs contenus afin de les situer.

Au regard du DIH, l'impact de ces accords à dénominations variées réside dans les modalités qu'ils définissent pour la mise en oeuvre de ce droit. Sans s'atteler sur ces différentes dénominations, les Conventions de Genève ne désignent que les "accords spéciaux". Ceux-ci sont donc considérés comme des actes juridiques subjectifs contrairement aux conventions qui sont des actes juridiques objectifs. Ainsi, le non respect d'un accord spécial par une partie peut donner lieu à l'exception d'inexécution vis-à-vis de la partie lesée. Celle-ci peut donc se délier de ses obligations ${ }^{1744}$. Ce qui n'est nullement le cas des CG (cf. supra).

Tout de même, au sens du DIH, deux types d'accords spéciaux existent. Ceux qui définissent les modalités pratiques d'application du DIH voire de son élargissement, et ceux qui closent définitivement les hostilités tout en règlant le sort des civils et des combattants ${ }^{1745}$.

\footnotetext{
${ }^{1739}$ SALMON, Jean, (dir.), Dictionnaire de droit international public, op.cit., p.17.

${ }^{1740}$ FOX, James R., Dictionary of international and comparative law, Third edition, Oceana Publication, Dobbs Ferry, New-York, 2003, p. 252.

${ }^{1741}$ BLEDSOE, Robert L. et BOCZEK, Boleslaw A., The international law dictionary, Santa Barbara, Oxford, California, England, p. 385.

${ }_{1742}$ SALMON, Jean, (dir.), Dictionnaire de droit international public, op.cit., 1091.

${ }^{1743}$ KAZADI MPIANA, Joseph, La position du droit international dans l'ordre juridique congolais et l'application de ses normes, op.cit., p. 117.

1744 AIVO, Gérard, «Le rôle des accords spéciaux dans la rationalisation des conflits armés non internationaux », in RQDI, Vol. 27.1 (2014), p. 2.

1745 Ibid., p. 7.
} 
Les CG prévoient la possibilité de signature des accords spéciaux en CANI ${ }^{1746}$ comme en $\mathrm{CAI}^{1747}$. Si ces accords définissent des modalités pratiques d'application des obligations contenues précisément dans ces Conventions, leur rôle dans la protection des personnes civiles voire des personnes participant aux hostilités est plus que nécessaire. Ils étendent l'application des règles du DIH dans un domaine où elles sont peu développées -le CANI.

En effet, des multiples accords signés durant la "deuxième guerre de libération" et par la suite, il y a lieu de citer: "l'Accord de cessez-le-feu, dit "Accord de Lusaka", conclu entre belligérants, en date du 10 juillet 1999, l'Accord de paix, conclu à Pretoria (Afrique du Sud), le 30 juillet 2002, entre la République Démocratique du Congo et le Rwanda, l'Accord de paix, (conclu à Luanda), le 6 septembre 2002, entre la République Démocratique du Congo et l'Ouganda, l'Accord global et inclusif, signé à Pretoria, le 17 décembre 2002, lors des négociations de paix (dénommées "Dialogue inter-congolais"), par la suite, solennellement adopté par les délégués des composantes et entités au dialogue en date du 1er avril 2003, à Sun City, en Afrique du Sud" ${ }^{1748}$. Sous cette période d'avant juin 2003, il y a lieu de faire également mention de l'Accord de Syrte instituant le cessez-le-feu conclu le 18 avril 1999, entre l'Ouganda et la RDC sous la médiation de la Lybie. D'autres initiatives rentrent dans le cadre du processus de paix. C'est notamment le cas du Cessez-le-feu unilatéral décrété le vendredi 28 mai 1999 par la République du Rwanda et de multiples sommets et rencontres tenus à Luanda (Angola), Dar Es-Salam (Tanzanie), Pretoria (Afrique du Sud), Maputo (Mozambique), Windhoek (Namibie), Harare (Zimbabwe), le Caire (Egypte), Khartoum (Soudan), Libreville (Gabon), etc. ${ }^{1749}$

Par ailleurs, les conflits armés en RDC ne se sont jamais arrêtés avec la signature de l'Accord global et inclusif. Quelques poches de conflits armés notamment à la province du Nord Kivu ont subsistés ou surgi. Ces poches de conflits armés - œuvre généralement des groupes armés opérant dans la région - seront prises en charge et feront également objet d' «accords politiques » entre parties en conflits en présence. C'est le cas du Pacte sur la Paix, la Sécurité, la Stabilité et le Développement dans la Région des Grands Lacs, dit «Pacte ou Traité de Nairobi », du 15 décembre 2006 qui sert de cadre juridique et d'agenda pour la Conférence Internationale de la Région des Grands Lacs (CIRGL) et entré en vigueur en juin $2008^{1750}$. Cette organisation régionale ainsi créée s'attellera notamment sur la question de conflit armé du Mouvement M23 en RDC par des sommets organisés à Kampala où se retrouvaient sur une même table de négociation les différents protagonistes.

Cette période d'après « Accord global et inclusif » verra également la signature le 24 février 2013 à Addis-Abeba - avec la facilitation de l'ONU, de l'UA, de la CIRGL et de la SADCpar onze pays de la région (Angola, Afrique du Sud, Burundi, République Centrafricaine, République du Congo, RD Congo, Ouganda, Rwanda, Sud - Soudan, Tanzanie et Zambie)

\footnotetext{
${ }^{1746}$ Voy. l'article 3, §2, alinéa 2 commun, aux CG

${ }^{1747}$ Voy. les articles $6,10,15,23,28,31,36,37$ et 52 de la CG I ; 6, 10, 18, 31, 38, 39, 40, 43 et 53 de la CG II ; $6,10,23,28,33,60,65,66,67,72,73,75,109,110,118,119,122$ et 132 de la CG III et les articles 7, 11, $14,15,17,36,108,109,132,133$ et 149 de la CG IV.

1748 MAZYAMBO, Makengo Kisala, André, «Le désarmement, la démobilisation et la réinsertion des combattants en République Démocratique du Congo », in BASUE, Babu Kazadi (dir.), Le Droit international à l'épreuve des enjeux sécuritaires en République Démocratique du Congo, op.cit., pp. 201-202

${ }^{1749}$ Lire KITIMA, Kasendwe, «Les relations Internationales post-conflits : cas de la R.D.C. », in Les Mélanges de la pléiade congolaise ? Vol I, Kinshasa, édition de la Pléiade Congolaise, 2005, pp. 72 - 73.

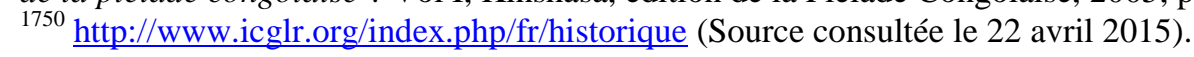


d'un Accord-cadre pour la paix, la sécurité et la coopération pour la République Démocratique du Congo et la région ${ }^{1751}$. Cet accord est vu par de nombreux observateurs comme « un tournant dans la recherche des stratégies pour mettre fin aux cycles de conflits et de violence en RDC qui constituent une source d'instabilité pour l'ensemble de toute la région des Grands Lacs ${ }^{1752}$. En Accord-cadre, il indique des mesures que doivent prendre la RDC, la Région et la Communauté internationale. Il fait «obligation» à la RDC de continuer et d'approfondir la réforme du secteur de sécurité (armée et police); de consolider l'autorité de l'Etat particulièrement à l'est de la RDC en empêchant notamment les groupes armés de déstabiliser le pays ; de promouvoir le développement économique, etc. A la Région, il est demandé de ne pas tolérer, ni fournir une assistance ou soutien quelconque aux groupes armés, ni héberger ou fournir une protection aux personnes accusées de crimes de guerre, des crimes contre l'humanité, d'actes de génocide ou des crimes d'agression. Pour la communauté internationale, un engagement d'appui à la mise en œuvre du Pacte de Nairobi est assuré.

Ces «obligations » telles que formulées nécessitent des mesures importantes pour leur mise en exécution. Indirectement, l'Accord - cadre présenté ci-dessus permettra aux Etats parties de prendre un certain nombre de mesures qui auront une incidence positive sur la protection des enfants précisément dans la lutte contre leur recrutement et leur participation dans les hostilités autant du côté des Etats parties que des groupes armés opérant. Tout de même, la juridicité d'un tel instrument reste problématique.

En effet, le chapitre précédent a démontré que le recrutement et l'utilisation des enfants dans les conflits armés s'expliquaient en partie par la crise économique observée en RDC. La promotion du développement économique pourrait - un tant soit peu - résorber ce fléau. Empêcher les groupes armés à œuvrer librement à travers l'absence d'appui voire des traques, ou encore refuser de fournir une protection internationale aux auteurs des crimes internationaux dans la région serait d'un apport très positif dans la lutte contre le phénomène « enfant soldat». Une fois de plus, il faudrait pour y arriver de la volonté politique.

Faisons valoir à juste titre que la volonté politique est au centre de débat de la mise en œuvre du DIH. C'est ainsi que Helen Durham, Directrice du département du droit international et des politiques humanitaires au CICR, déclarait dans un entretien qu'au-delà des pressions auxquelles est soumis le $\mathrm{DIH}$, le problème est de se demander s'il existe véritablement de la volonté politique de respecter le DIH chez les Etats et les groupes armés non étatiques ${ }^{1753}$.

D'autres accords essentiellement conclus entre le gouvernement congolais et les groupes armés locaux seront également observés (cf. infra).

De ce qui précède, en faisant référence à ces accords, l'intérêt de notre analyse porte sur la recherche des dispositions qui pourraient permettre d'assurer la protection spéciale des enfants en situation de ces conflits armés en RDC. Ainsi, il sera dit que tous ces accords ne consacrent pas des dispositions du DIH ou plus précisément celles relatives à la protection

\footnotetext{
${ }^{1751}$ OLLANDET, Jérôme, La conférence internationale sur la région des Grands Lacs. Une dynamique nouvelle d'intégration en Afrique, op.cit., p. 249.

1752 Ibid.

${ }^{1753}$ Voy. Entretien de Helen Durham présenté par CRAWFORD, Julia, « La Volonté politique de respecter le droit de la guerre existe-t-elle, s'interroge le CICR », in JusticeInfo.Net disponible sur http://www.justiceinfo.net/fr/component/k2/27200-«-le-sommet-humanitaire-mondial-devra-promouvoir-lerespect-du-droit-de-la-guerre-»,-déclare-la-directrice-du-département-du-droit-international-et-des-politiqueshumanitaires-du-cicr.html?Itemid=102 (Source consultée le 17 mai 2016).
} 
spéciale des enfants en conflits armés. Si l'Accord-cadre examiné précédemment touche indirectement à la protection des enfants en situation de conflits armés, certains s'intéressent au retrait des troupes étrangères sur le sol congolais et d'autres voies de sécurisation des frontières sans référence au DIH. C'est le cas de « Peace Agreement » (Accord de Syrte du 18 avril 1999). Celui-ci est signé par l'Ouganda, le Tchad, l'Erythrée, la RDC et la Libye. Il se préoccupait entre autres du cessez-le-feu, du déploiement d'une force internationale neutre, du retrait de toutes les troupes étrangères de la RDC. Sur cette base, les troupes tchadiennes (2.000 soldats) ont pu se retirer de la RDC. Cet accord qui ne sera finalement pas appliqué entre l'Ouganda et la RDC, ne sera pas non plus reconnu par le Rwanda, partie non signataire ${ }^{1754}$. Sous ce registre, il y a le Protocole d'accord signé entre les gouvernements de la R.D.C et du Rwanda sur le retrait des troupes rwandaises du territoire congolais et le désarmement des forces ex-FAR et interahamwe en RDC du 30 juillet 2002 (Accord de Pretoria). Qu'il soit dit que cet accord se préoccupe du processus de traque ${ }^{1755}$ et de démantèlement des ex-FAR et Interahamwe de la RDC. Alors que la RDC réaffirme son droit légitime de voir les forces du gouvernement rwandais se retirer «sans délai » de son territoire $(\S 4)^{1756}$, pour sa part, le gouvernement rwandais conditionne le retrait de ses forces au commencement de la mise en œuvre de ses exigences d'ordre sécuritaire en particulier le démantèlement des ex-FAR et Interahamwe $(\$ 5)^{1757}$. Aucune disposition du DIH n'est donc référencée dans cet accord.

Un autre accord de même type a été conclu entre la RDC et l'Ouganda. Il s'agit de l'Accord entre les gouvernements de la République Démocratique du Congo et de la République de l'Ouganda sur le retrait des troupes ougandaises de la République Démocratique du Congo, sur la coopération et la normalisation des relations bilatérales entre les deux pays ${ }^{1758}$, conclu à Luanda le 06 septembre 2002 sous les auspices de la République d'Angola. Celui-ci, contrairement à son prédécesseur, fait référence aux principes des relations internationales contenues dans les Chartes des Nations unies et de l'Union africaine (respect de la souveraineté nationale, intégrité territoriale, non - recours à la force, règlement pacifique des différends, non ingérence dans les affaires intérieures des Etats). Des résolutions pertinentes du CS/NU se rapportant à la situation de la RDC s'y trouvent également réaffirmées. Ainsi, contrairement au cas du Rwanda dans l'accord précité, l'Ouganda a ordonné unilatéralement le retrait «inconditionnel et immédiat» de ses troupes à Gbado-Lite (Nord - ouest de la RDC), à Beni (Nord - est de la RDC) et ses environs (article $1^{\text {er }} \S 2$ ) sauf dans les versants des

${ }^{1754}$ PARQUE, Véronique, «Le rôle de la communauté internationale dans la gestion du conflit en République Démocratique du Congo », in L'Afrique des Grands Lacs, Annuaire 1999-2000, p. 4, in http://www.ua.ac.be/objs/00111074.pdf (Source consultée le 10 mai 2015). Lire aussi BULA BULA, Sayeman, «L'accord de Syrte du 18 avril 1999 pour le règlement des différends dans les Grands Lacs. Note de lecture », in https://sbulabula.wordpress.com/publications/laccord-de-syrte-du-18-avril-1999/ (source consultée le 10 mai 2015).

${ }^{1755}$ Signifions en passant que l'Accord en question utilise en son $\S 8.1$ le terme «traquage» au lieu de «traque ». Terme utilisé qui n'existe pas en français.

${ }^{1756} \$ 4$ du Protocole d'accord signé entre les gouvernements de la R.D.C et du Rwanda sur le retrait des troupes rwandaises du territoire congolais et le désarmement des forces ex-FAR et interahamwe en RDC du 30 juillet 2002

http://democratie.francophonie.org/IMG/pdf/Protocole_d_Accord_RDC_Rwanda_retrait_troupes_rwandaises.pd f (Source consultée le 10 mai 2015).

${ }^{1757}$ Ibid., $\$ 5$.

1758 Voy. http://www.droitcongolais.info/files/0.4.36.-Accord-du-6-septembre-2002--RDC-Ouganda-_Retraitdes-troupes-ougandaises-de-la-RDC.pdf (Source consultée le 10 mai 2015). 
montagnes de Ruwenzori (Nord - est de la RDC) jusqu' à la mise sur pied d'un mécanisme garantissant la sécurité de l'Ouganda et de la RDC (article $1^{\mathrm{er}} \S 4$ ). Les deux parties conviennent en outre de régler pacifiquement les conflits (article 7), de restaurer les relations diplomatiques (article 3), de coopérer dans le domaine de sécurité (article 5) et de trouver une formule à l'amiable pour résoudre des litiges juridiques (article 4). Il y a lieu de noter l'institution d'une commission de pacification de l'Ituri, zone où se déroulait une partie importante de recrutement et d'utilisation des enfants soldats (Voy. par exemple affaire Thomas Lubanga Dyilo). Cette commission devrait être composée des représentant de différentes couches sociales (forces politiques, militaires, économiques et sociales actives à Bunia et des représentants des communautés locales (article $1^{\text {er }} \S 3$ ) ${ }^{1759}$. Toutefois, aucune référence aux règles du DIH ou celles régissant la protection spéciale des enfants en conflits armés n'est indiquée. Il est à signifier par ailleurs que les deux accords réaffirment dans leurs préambules l'Accord de Lusaka du 10 juillet 1999. Lequel fait référence aux règles du DIH (cf. infra).

Il va sans dire que le fait de s'attarder sur ces accords de paix sans référence expresse au DIH n'est non sans raison. Car le recrutement et l'utilisation des enfants dans les hostilités en RDC demeurent intimement liés à la présence des forces armées étrangères et groupes armés devant s'affronter sur ce territoire. Comme l'atteste d'ailleurs l'interprétation qui résulte de l'Accord de cessez-le-feu de Lusaka du 10 juillet 1999 (cf. infra). Ainsi, ces accords précités s'inscrivent donc en droite ligne de lutte contre le "phénomène enfant soldat » en RDC. Il faudrait tout de même avouer que leur juridicité reste problématique.

De ces accords spéciaux, l'Accord de Lusaka du 10 juillet 1999 parait le plus important. Il se rapporte aux règles du DIH en général voire à la protection de l'enfant en particulier. Il mérite ainsi un examen. De même pour le Pacte sur la Paix, la Sécurité, la Stabilité et le Développement dans la Région des Grands Lacs, dit «Pacte ou Traité de Nairobi », du 15 décembre 2006.

\section{1- Accord de Lusaka du 10 juillet 1999}

«L'Accord de Lusaka, [...], du fait de sa référence à l'article 52 de la Charte se veut un accord de Droit International à caractère régional. Il est né d'une résolution des Nations - Unies adoptée par son Conseil de Sécurité à sa $3993^{\text {è }}$ séance du 09 avril 1999. En tant qu'instrument de mise en œuvre du droit international pour la résolution d'un conflit régional, l'Accord se devait de ne pas être en contradiction avec les buts et les principes des Nations - Unies ${ }^{1760}$. Ainsi, l'Accord de cessez-le-feu en République Démocratique du Congo dit «Accord de Lusaka », qui demeure le texte majeur dans le cadre de conflits armés à la base duquel d'autres accords seront adoptés ${ }^{1761}$, prévoit un certain nombre de dispositions se rapportant au DIH en général et à la protection spéciale des enfants en situation de conflits armés en particulier.

\footnotetext{
1759 Lire l'Accord entre les gouvernements de la République Démocratique du Congo et de la République de l'Ouganda sur le retrait des troupes ougandaises de la République Démocratique du Congo, sur la coopération et la normalisation des relations bilatérales entre les deux pays http://www.droitcongolais.info/files/0.4.36.Accord-du-6-septembre-2002--RDC-Ouganda-_Retrait-des-troupes-ougandaises-de-la-RDC.pdf $\quad$ (Source consultée le 10 mai 2015).

${ }^{1760}$ NGOY, Théodore, L'Accord de Lusaka : la paix piégée, op.cit., pp. 59-60.

${ }^{1761}$ OLLANDET, Jérôme, La conférence internationale sur la région des Grands Lacs. Une dynamique nouvelle d'intégration en Afrique, op.cit., p. 236.
} 
L'Accord de Lusaka dispose dans son préambule de manière impérative que toutes les parties signataires se trouvent «[d]éterminée[s] à assurer le respect, [...] du présent Accord, des Conventions de Genève de 1949 et des Protocoles additionnels de 1977 ainsi que de la Convention sur la prévention et la répression du crime de génocide de 1948, tel que réitéré lors du Sommet régional d'Entebbe du 25 mars $1998 \gg^{1762}$ (nous soulignons). Cette disposition du Préambule est simplement une réaffirmation de l'application des règles du DIH issues des CG et des PA obligeant les parties étatiques - l'Angola, la RDC, la Namibie, l'Ouganda, le Rwanda et le Zimbabwe - et celles non étatiques -RCD et MLC. En d'autres termes, chacune des parties doit respecter ses obligations dans le cadre de ces instruments. Ainsi, par exemple, la RDC devrait respecter ses obligations internationales en vertu des CG et du PA I auxquels elle est partie. Ce qui vaut de même pour les groupes armés -RCD et MLC- qui pourraient se retrouver dans le cadre de CAI ou CANI. Etant donné qu'il s'agit d'accord de cessez-le-feu, ce qui voudrait bien dire cessation effective des hostilités (cf. article I, 2-b), il faudrait moins attendre qu'il légifère à proprement parler la conduite des hostilités. Néanmoins, il détaillera le contenu du « cessez-le-feu » et déterminera la gestion à réserver aux effets occasionnés par des hostilités passées.

En tant qu'accord spécial, le grand avantage que présente l'Accord de Lusaka est notamment de permettre aux groupes armés de s'engager solennellement vis-à-vis de certaines règles du DIH y énoncées. Certaines de ces règles de nature à s'appliquer au CAI s'appliqueront au CANI. C'est par exemple l'interdiction « expresse » de la pose des mines, quel qu'en soit le type (cf. article II, 13). Ainsi, il y a lieu d'affirmer que «les accords spéciaux entre belligérants permettent d'aller au-delà de l'étroitesse du droit applicable aux conflits armés internes en appliquant tout ou partie de l'ensemble du droit des conflits armés. A ce titre, ils jouent un rôle essentiel à la fois de palliatif et de complément dans les conflits armés internes $[\ldots]{ }^{1763}$. Mais, la protection consacrée dans le préambule concourt à la protection générale de l'enfant en période des conflits armés.

Par ailleurs, les dispositifs de cet accord contiennent également des paragraphes d'articles qui cadrent avec le DIH. C'est le cas de l'article $1^{\text {er }} \S 3 c$ de cet accord qui dispose :

«Le Cessez-le-feu implique la cessation de : [...] c. tous les actes de violence contre les populations civiles par le respect et la protection des droits humains. Ces actes de violence incluent les exécutions sommaires, la torture, le harcèlement, la détention et l'exécution des civils basés sur leur origine ethnique, le recrutement et l'utilisation des enfants soldats, la violence sexuelle, le bombardement et le massacre de populations civiles, la propagande et l'incitation à la haine ethnique et tribale, l'armement des civils, la détention et l'exécution des prisonniers d'opinion, les coupures d'eau et d'électricité, la formation et l'utilisation des terroristes $;{ }^{1764} \gg$ (nous soulignons).

A priori, cette disposition n'assure pas véritablement une protection spéciale de l'enfant civil

\footnotetext{
${ }^{1762}$ Lire le $6^{\text {e }}$ considérant du Préambule de l'Accord de cessez-le-feu en République Démocratique du Congo (Accord de Lusaka) du 10 juillet 1999.

${ }^{1763}$ AIVO, Gérard, «Le rôle des accords spéciaux dans la rationalisation des conflits armés non internationaux » «art.cit. », p. 5.

${ }^{1764}$ Voy. http://www.droitcongolais.info/files/0.4.35.-Accord-de-cessez-le-feu-en-Republique-democratique-duCongo.pdf (Source consultée le 14 mars 2015).
} 
en situation de conflit armé en RDC. Il s'agit d'une disposition qui se préoccupe de la protection des civils en général. En même temps, la disposition ci-dessus présentée retrace en quelque sorte la pratique de cette guerre vis-à-vis des civils. Les parties signataires se décident finalement à mettre fin à de telles pratiques qui régnaient sur le champ de bataille. Ces pratiques attestent simplement dans ces conflits armés que les personnes civiles sont des cibles fréquentes des parties au conflit armé. Ces pratiques de violence visent donc indistinctement tous les civils y compris les enfants. C'est à ce titre qu'il réserve dans le lot de cette protection générale, une protection spécifiquement liée aux enfants, une des cibles les plus vulnérables de ces conflits armés.

Puisque l'on ne peut cesser que ce que l'on a entamé, en disposant que le cessez-le-feu implique la cessation de «recrutement et l'utilisation des enfants soldats », cet article confirme la pratique de recrutement et d'utilisation des enfants dans les conflits armés. Il s'agit d'une prévention qui sert théoriquement à stopper des telles pratiques. C'est d'ailleurs la seule disposition où il est fait expressément allusion au sort des enfants dans ces conflits armés.

Dans la partie relative aux «Principes de l'Accord » au Chapitre III, point 10, de l'Accord, il est fait obligation aux Parties de faciliter «l'acheminement de l'aide humanitaire grâce à l'ouverture de couloirs d'aide humanitaire et la création de conditions favorables à la fourniture de l'aide d'urgence aux personnes déplacées, aux réfugiés et autres personnes concernées ». Toutefois, bien qu'elle ne concerne pas expressément l'enfant civil, cette disposition de protection générale constituera un contexte idéal de protection spéciale de l'enfant. En effet, elle concorde à l'article 23 de la IV ${ }^{\mathrm{e}} \mathrm{CG}$ qui traite également du libre passage de tout envoi de médicaments, matériels sanitaires et autres biens indispensables à la population civile en général et en particulier aux enfants de moins de quinze ans, notamment. C'est aussi le cas de l'article 70 du PA I qui traite de la priorité à accorder aux enfants, femmes enceintes ou en couches et mères qui allaitent ${ }^{1765}$. Dans sa mise en œuvre, cette disposition de l'Accord de Lusaka devrait tenir compte des conditions posées dans ces articles précités. Lesquels concourent nettement à la protection spéciale des enfants sur le champ de bataille durant ces conflits armés. Mais les violations répétées quant au cessez-le-feu par les parties amènent à se questionner sur la suite de cet accord spécial qui, comme dit ci-dessus, revêt un caractère subjectif comparativement aux CG et PA.

\section{Pacte sur la Paix, la Sécurité, la Stabilité et le Développement dans la Région des Grands Lacs, dit « Pacte ou Traité de Nairobi », du 15 décembre 2006}

Les Etats parties à cette convention affirment dans son préambule qu'ils sont «[d]éterminés à assurer le respect strict des normes et principes fondamentaux du droit international humanitaire, notamment ceux afférents à la protection et à l'assistance devant être apportées $[\ldots]$ aux enfants ${ }^{1766}$, etc. A ce titre, la présente convention, entrée en vigueur en juin 2008 , institue la prévention et la répression des crimes de génocide, des crimes de guerre et des crimes contre l'humanité et de toute forme de discrimination. Bien plus, de manière directement liée à la protection des enfants, le Pacte de Naïrobi dispose :

\footnotetext{
1765 SINGER, Sandra, « La protection des enfants dans les conflits armés », «art.cit. », p. 152.

${ }^{1766}$ Lire le $\$ 5$ du Pacte sur la Paix, la Sécurité, la Stabilité et le Développement dans la Région des Grands Lacs du 15 décembre 2006 in http://www.icglr.org/index.php/fr/le-pacte (Source consultée le 11 mai 2015).
} 
« [1] es Etats membres s'engagent, conformément au Protocole sur la prévention et la répression de la violence sexuelle à l'égard des femmes et des enfants, à lutter contre ce fléau grâce à des mesures de prévention, dépénalisation et de répression en temps de paix comme en temps de guerre, conformément aux lois nationales et au droit pénal international ${ }^{1767}$.

Il faudrait dire que le présent Pacte se propose de régir les relations juridiques entre les Etats parties notamment sur des questions humanitaires (article 4). Relations qui se trouvent basées sur les principes fondamentaux consacrés par les Chartes des Nations unies et de l'Union africaine. Les Etats parties renoncent donc au recours à la menace ou à la force et s'abtiennent à ce sujet d'envoyer ou de soutenir les groupes armés ou rebelles sur le territoire d'un autre Etat membre ou tolérer de tels groupes sur leurs propres territoires (article 5). Cet instrument encourage l'installation des institutions des droits de l'homme (article 6, b) et la coopération judiciaire entre Etats parties (article 7). Un engagement dans le sens de prévention et de répression des crimes de guerre, des crimes contre l'humanité et des crimes de génocide est assuré (article 8). Spécialement à cet égard, il est institué un mécanisme conventionnel consacré à la prévention de ces crimes en vertu de l'article 38 du Protocole pour la prévention et la répression du crime de génocide, des crimes de guerre et des crimes contre l'humanité ainsi que de toutes les formes de discrimination: le Comité régional pour la prévention du génocide de la Conférence internationale sur la Région des Grands Lacs ${ }^{1768}$. «Son modus operandi comporte trois éléments essentiels à la prévention: la réponse aux causes profondes [...], le recours aux techniques d'alerte précoce et l'implication des acteurs nationaux et locaux ${ }^{1769}$ à travers notamment la constitution des Comités nationaux. Etabli officiellement en septembre 2010, ce Comité régional, en collaboration avec certains Comités nationaux (Kenya, Tanzanie, Congo), est opérationnel dès 2011 à travers des activités organisationnelles et de sensibilisation sur des questions de crimes de guerre, de crimes contre l'humanité et de crimes de génocide ${ }^{1770}$. Sa réussite dépend pour beaucoup de la «volonté politique des Etats ${ }^{1771}$. Signalons que la RDC n'a pas encore établi son Comité national à l'instar d'autres Etats (Angola, Burundi, Soudan, Soudan du sud, la RCA et Zambie).

Ainsi, le Pacte ou Traité de Naïrobi apparaît indubitablement comme un instrument juridique qui jouera un grand rôle notamment dans la lutte contre la violation des droits de l'enfant ou des règles assurant sa protection sur le champ de bataille comme en temps de paix si et seulement si celui-ci est mis en application. La prévention des conflits armés dont il fait la promotion fera en sorte que, une fois appliquée, l'enfant soit épargné d'une grande partie des violations commises généralement en son encontre en pareille circonstance.

Toutefois, ces dispositions liées à la prévention et à la répression des violences sexuelles à l'égard des femmes et enfants, à la prévention et à la répression des crimes de guerre, crimes contre l'humanité et crimes de génocide, qui ressortent des protocoles classés

\footnotetext{
${ }^{1767}$ Ibid., article 11.

${ }^{1768}$ MUTOY, MUBIALA, « Le Comité régional pour la prévention du génocide de la Conférence internationale sur la Région des Grands Lacs », in DECAUX, Emmanuel et TOUZE, Sébastien (dir.), La Prévention des violations des droits de l'homme. Actes du Colloque des 13 et 14 juin 2013, éd. A. Pedone, Paris, 2015, p. 122 1769 Ibid.

${ }^{1770}$ Voy. Ibid.,pp. 117 et 120-121.

1771 Ibid., p.123. Déjà, la première demande de visite de terrain dans le Kordofan (Soudan) adressée par le Comité régional au début de 20 au Soudan n'a pas obtenu une réponse.
} 
contraignants ${ }^{1772}$, nécessitent au niveau des Etats parties l'obligation d'aménager leur arsénal juridique interne afin d'assurer la mise en oeuvre des dispositions décrites ci-dessus. Lesquelles revèlent un caractère général.

Bien plus, contrairement à la plupart d'instruments juridiques régionaux ou spéciaux conclus dans le cadre de conflits armés en RDC, le Pacte ou Traité de Naïrobi présente un avantage certain. C'est celui de désigner la Cour africaine de justice comme instance juridictionnelle habilitée à traiter des litiges pouvant résulter de son interprétation ou de son application (article 29). Ceci n'est cependant possible qu'après échec des voies de règlements pacifiques (articles 29 et 28). Cette judiciarisation qui intervient en ultime recours permettrait de jouer une fonction dissuasive à l'endroit des Etats afin que les dispositions de cet instrument, précisément celles liées à la protection spéciale de l'enfant, trouvent place à leur mise en oeuvre.

Le Pacte ou Traité de Naïrobi trouve par ailleurs un appui de l'Accord cadre pour la paix, la sécurité et la coopération pour la République Démocratique du Congo et la région du 24 février $2013^{1773}$. Celui-ci demande à la Communauté internationale d'appuyer la mise en oeuvre de cet instrument.

\section{B. Règles du DIH assurant la protection spéciale des enfants combattants en CAI en RDC}

La protection spéciale des enfants «combattants » en situation de conflits armés conduit à s'interroger sur les limites, le contenu même de cette protection dite spéciale. En effet, si l'on admet l'existence de la protection spéciale des enfants combattants, ceci revient à dire que ces enfants sont protégés même quand ils participent directement aux hostilités ? Ou encore en dépit de cette qualité de combattant, leur vulnérabilité psychologique et physique subsistera et devrait conduire à leur protection spéciale à tout prix ? Les enfants combattants, en dehors de situation des hostilités, bénéficient-ils de protection spéciale ? Si oui quel est le contenu de celle-ci dans le contexte de la RDC ? Seules les analyses ressorties de différentes règles conventionnelles universelles (B.1) et régionale (B.2), voire législatives ou celles issues du droit international dérivé, permettraient de fournir au final des réponses idoines à ces interrogations.

\section{B. 1. La protection spéciale des enfants combattants en CAI : des règles du DIH issues des instruments juridiques universels applicables en RDC}

Sans assurer à proprement parler la prévention du recrutement et d'utilisation d'enfants dans les hostilités, la CG IV en son article $51 \S 1$, indique que « [1]a Puissance occupante ne pourra pas astreindre des personnes protégées à servir dans ses forces armées ou auxiliaires. Toute pression ou propagande tendant à des engagements volontaires est prohibée ${ }^{1774}$. Régissant

\footnotetext{
${ }^{1772}$ Voy. Présentation du Pacte sur la Paix, la Sécurité, la Stabilité et le Développement dans la Région des Grands Lacs du 15 décembre 2006 in http://www.icglr.org/index.php/fr/le-pacte (Source consultée le 11 mai 2015).

${ }^{1773}$ Voy. http://www.peaceau.org/uploads/scanned-on-24022013-125543.pdf (Source consultée le 12 mai 2015).

${ }^{1774}$ Le libellé de l'article 51 de la CG n'est pas nouveau. On le retrouve dans le Règlement concernant les lois et
} 
donc la situation d' «occupation », la présente disposition n'indique nullement une prohibition faite par exemple à l'Etat congolais concernant le recrutement et la participation des enfants issus de son territoire national. Cette disposition oblige cependant les Etats ennemis de la RDC (Burundi, Ouganda et Rwanda). La question de la protection spéciale de l'enfant en CAI ne se trouve ici que partiellement réglée.

Cette problématique de l'enfant combattant sera prise en charge par les PA de 1977. L'article $77 \S 2$ du PA I fait obligation aux belligérants de prendre «toutes les mesures possibles dans la pratique pour que les enfants de moins de quinze ans ne participent pas directement aux hostilités, notamment en s'abstenant de les recruter dans leurs forces armées [...] » (nous soulignons). La présente «disposition contient une obligation absolue, de résultat, en ce qui concerne le recrutement : les parties au conflit ne peuvent pas recruter d'enfants de moins de [quinze] ans dans leurs forces armées ${ }^{1775}$. Leur responsabilité sera donc engagée en cas de recrutement d'enfants de moins de quinze ans et non en cas de participation directe de ces enfants aux hostilités per se si les mesures prises à cet égard se sont révélées inefficaces ${ }^{1776}$. En outre, la participation indirecte des enfants de moins de quinze ans dans les CAI n'est pas interdite. Aussi, le recrutement et la participation directe ou indirecte des enfants d'au moins quinze ans ou plus aux CAI ne sont pas interdits.

Toutefois, en combinaison avec le Statut de Rome de la CPI d'application en RDC, lequel inclut les termes «participation active », il serait maladroit de penser qu'une telle disposition moins favorable sera d'application, précisément pour des faits qui se sont déroulés après juillet 2002. Rappelons que le Statut de Rome considère comme crimes de guerre notamment « le fait de procéder à la conscription ou à l'enrôlement d'enfants de moins de quinze ans dans les forces armées nationales ou de les faire participer activement à des hostilités ${ }^{1777}$ (article $8 \S 2$ b xxvi) dans le cadre des CAI.

En dehors de la question de la protection spéciale de l'enfant contre sa participation aux hostilité dont sa participation directe, abordée jusque là, il y a lieu de se demander ce que prévoit le DIH, à travers ces instruments juridiques universels, au sujet de la protection spéciale de l'enfant qui prend directement part aux hostilités. Ce qui est le cas de nombreux enfants en RDC.

«Dans un conflit armé international, les enfants-soldats bénéficient du statut de combattant s'ils font partie des forces armées des Etats au conflit. En revanche, s'ils sont membres des milices ou groupes armés, ils doivent respecter les conditions définies par l'article 4 de la

coutumes de la guerre sur terre annexé à la Convention (IV) de La Haye du 18 octobre 1907 concernant les lois et coutumes de la guerre sur terre, en son article $23 \S 2$. Cet article renseigne : " Il est également interdit à un belligérant de forcer les nationaux de la partie adverse à prendre part aux opérations de guerre dirigées contre leurs pays, même dans le cas où ils auraient été à son service avant le commencement de la guerre ». Pour sa part, le Règlement concernant les lois et coutumes de la guerre sur terre annexé à La Convention (II) de La Haye du 29 juillet 1809 concernant les lois et coutumes de la guerre sur terre indiquait déjà aussi en son article 44 : «Il est interdit de forcer la population d'un territoire occupé à prendre part aux opérations militaires contre son propre pays ».

1775 MARTIN-CHENUT, Kathia, « art.cit. », p. 175.

${ }^{1776}$ Ibid., pp.175-176.

1777 DOEK, Jaap «Le cadre juridique international pour protéger les enfants dans les conflits armés », «art. cit. », p. 19. 
Convention III de Genève ${ }^{1778}$, ou au moins celles consacrées par l'article par l'article 44 (paragraphe 3) du Protocole $\mathrm{I}^{1779}{ }_{\gg}{ }^{1780}$.

En effet, dès lors qu'il participe directement aux hostilités malgré les interdictions ci-dessus soulignées et tombe au pouvoir de l'ennemi, l'enfant continue à bénéficier d'une protection spéciale. Pour le cas de CAI, l'article $77 \S 3$ du PA I dispose: « Si, dans des cas exceptionnels et malgré les dispositions du paragraphe 2, des enfants qui n'ont pas quinze ans révolus participent directement aux hostilités et tombent au pouvoir d'une partie adverse, ils continueront à bénéficier de la protection spéciale accordée par le présent article, qu'ils soient ou non prisonniers de guerre » (nous soulignons). En d'autres termes, «[m]ême s'ils sont prisonniers de guerre, les «moins de quinze ans » continueront à bénéficier des dispositions du présent article, en particulier les paragraphes 1,4 et $5 »^{1781}$. Ceci vaut de même en l'absence de ce statut ou traitement équivalent (cf. supra pour des commentaires plus larges). Et la protection spéciale qu'accorde cet article se rapporte au respect particulier et à la protection des enfants contre toute forme d'attentat à la pudeur. Il est fait obligation aux parties au conflit d'accorder les soins et de l'aide aux enfants suivant leur besoin en fonction de leur âge ou autre raison (article $77 \S 1$ ). Cet article insiste également sur la séparation des enfants des adultes en cas d'arrestation, détention ou internement pour des raisons liées au conflit armé sauf raisons d'unité familiale (article 77§4). Enfin, il est interdit l'exécution mais pas la condamnation à mort pour des infractions liées au conflit armé pour des personnes de moins de dix-huit ans (article 77 §5).

L'on retrouve également une telle disposition pour les "personnes protégées" au paragraphe 4 de l'article 68 de la $\mathrm{CG} \mathrm{IV}^{\mathbf{1 7 8 2}}$ dont les lettres accordent une protection plus large que les précédentes (cf. supra).

1778 Art. 4 de la CG III: «A. Sont prisonniers de guerre, au sens de la présente convention, les personnes qui, appartenant à l'une des catégories suivantes, sont tombées au pouvoir de l'ennemi :

1) les membres des forces armées d'une partie au conflit, de même que les membres des milices et des corps de volontaires faisant partie de ces forces armées ;

2) les membres des autres milices et les membres des autres corps de volontaires, y compris ceux des mouvements de résistance organisés, appartenant à une partie au conflit et agissant en dehors ou à l'intérieur de leur propre territoire, même si ce territoire est occupé, pourvu que ces milices ou corps de volontaires, y compris ces mouvements de résistance organisés, remplissent les conditions suivantes :

a) d'avoir à leur tête une personne responsable pour ses subordonnés ;

b) d'avoir un signe distinctif fixe et reconnaissable à distance ;

c) de porter ouvertement les armes

de se conformer, dans leurs opérations, aux lois et coutumes de la guerre $;(\ldots)$ »

1779 Art.44 $\$ 3$ du PA II : «Pour que la protection de la population civile contre les effets des hostilités soit renforcée, les combattants sont tenus de se distinguer de la population civile lorsqu'ils prennent part à une attaque ou à une opération militaire préparatoire d'une attaque. Etant donné toutefois, qu'il y a des situations dans les conflits armés où, en raison de la nature des hostilités, un combattant armé ne peut se distinguer de la population civile, il conserve son statut de combattant à condition que, dans de telles situations, il porte ses armes ouvertement :

a) pendant chaque engagement militaire ; et

b) pendant le temps où il est exposé à la vue de l'adversaire alors qu'il prend part à un déploiement militaire qui précède le lancement d'une attaque à laquelle il doit participer. [...]».

1780 AIVO, Gérard, Le Statut de combattant dans les conflits armés non internationaux, op.cit., 236.

${ }^{1781}$ PILLOUD, Claude et DE PREUX, Jean, Commentaire de l'article 77 Protection des enfants, paragraphe 3, in SANDOZ, Yves, SWINARSKI, Christophe et ZIMMERMANN, Bruno (éd. et Coord.), Commentaire des Protocoles additionnels du 8 juin 1977 aux Conventions de Genève du 12 août 1949, op. cit., pp. 926-927.

${ }^{1782}$ Article 68 4 de la CG IV Il est dit au paragraphe 4 de l'article 68 de la CG IV qu”[E]n aucun cas la peine de mort ne pourra être prononcée contre une personne protégée âgée de moins de dix-huit ans au moment de l'infraction". 
Toutefois, il convient de préciser que la protection spéciale abordée par l'article 77 §3 du PA I - autant pour celle qu'accorde l'article $4 \S 3$ d du PA II dans le cadre du CANI - se limite en principe au cadre de cet article. Il n'est pas expressément affirmé qu'elle s'étend aux enfants qui participeraient directement aux hostilités sans être tombés au pouvoir de la partie adverse. Cette protection concerne donc les enfants qui prennent directement part aux hostilités et tombent au pouvoir d'une partie au conflit. Qu'ils soient ou non revêtus du statut de prisonniers de guerre comme cela pourrait être le cas dans le cadre d'un CAI.

«Or avec cette participation, ils [les enfants] perdent la protection générale accordée aux civils ainsi que la protection spéciale dont ils bénéficient en vertu des traités, mais conservent la protection assurée par l'article 77 du PI [PA I] et l'article 4 du P II [PA II] [...]. S'ils sont prisonniers de guerre les articles 16 et 49 de la CG III s'appliquent ${ }^{1783}$. S'ils ne sont pas prisonniers de guerre, ces enfants pourront se prévaloir de la CG IV s'ils constituent des personnes protégées conformément à cette Convention ${ }^{1784}$. En l'absence du droit au traitement de prisonnier de guerre et de la qualité de personne protégée, sur la base de l'article 45 (Protection des personnes ayant pris part aux hostilités), §3, ils auront finalement droit aux garanties fondamentales qu'accorde l'article 75 du PA I ${ }^{1785}$.

Ceci dit, en tant que combattants, les enfants -de moins de quinze ou de quinze à dix-huit ans - sont des «cibles militaires légitimes ». Ils peuvent être abattus comme n'importe quel combattant.

Ainsi, de ce qui précède, Il se dégage que le DIH assure faiblement la protection spéciale de l'enfant congolais qui participe directement aux hostilités en CAI - comme en CANI d'ailleurs (cf. infra). Cette faible protection amène à considérer l'enfant congolais comme "doublement victime". Victime d'abord du fait de son recrutement et de sa participation aux hostilités par de nombreux groupes armés opérant sur le terrain notamment. Victime, ensuite, d'un droit qui assure faiblement sa protection en pleines hostilités en tant que participant. Toutefois, le DIH ne tolèrant pas l'arbitraire, le « vide juridique » n'est donc pas concevable. En participant directement aux hostilités, l'enfant restera sous la protection des règles du DIH de protection générale des combattants (Voy. par exemple le Titre III du PA I "Méthodes et moyens de guerre. Statut de combattant et de prisonnier de guerre"), des droits de l'Homme applicables en période des hostilités voire d'autres règles du droit international telles que le droit international dérivé, les conventions régionales ou accords spéciaux, et celles issues les lois nationales.

Il est certes vrai que de manière générale, la pratique tend à une certaine amélioration. Il est affirmé que l'utilisation des enfants soldats dans le combat proprement dit n'est pas forcément systématique ${ }^{1786}$ ou encore rarement recourue ${ }^{1787}$. En dehors du recrutement des enfants par les

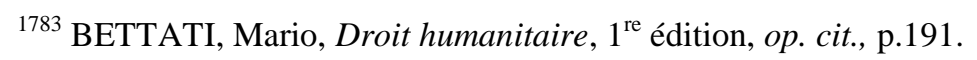

${ }^{1784}$ PILLOUD, Claude et DE PREUX, Jean, Commentaire de l'article 77 Protection des enfants, paragraphe 3 , in SANDOZ, Yves, SWINARSKI, Christophe et ZIMMERMANN, Bruno (éd. et Coord.), Commentaire des Protocoles additionnels du 8 juin 1977 aux Conventions de Genève du 12 août 1949, op. cit., p. 927. 1785 Ibid.

${ }^{1786}$ BAILLON, Thierry, «A l'écoute des enfants-soldats », «art. cit. », p. 10. , Voy. également CHAPLEAU,
} 
forces ou groupes armés pour assurer différents rôles- cuisiniers, guetteurs ou sentinelles, informateurs, porteurs, agents de liaison ou de renseignement demeure d'usage fréquent. Ce qui est encore plus considérable d'arguer, comme l'attestent si bien les recherches du CICR sur le droit international coutumier, que «rien dans la pratique recueillie à l'appui de l'interdiction de la participation des enfants aux hostilités n'indique qu'ils devraient être privés de leur protection spéciale s'ils participent effectivement aux hostilités ${ }^{1788}$.

Cependant, chaque conflit armé à ses réalités propres. L'expérience de la «guerre congolaise » atteste que «l'enfant soldat » est au centre de tous les enjeux. C'est à lui que les forces et groupes armés font recours pour atteindre leurs objectifs politiques et économiques. La «première guerre de libération » menée par l'AFDL de Laurent Désiré Kabila était essentiellement celle de «Kadogo». Ces derniers ont fait face aux soldats des Forces Armées Zaïroise avec tous les risques possibles d'une «guerre». Bien plus, les affaires pendantes devant la CPI (cf. infra) au sujet de la situation en RDC attestent une fois de plus le rôle d'« acteur central » qu'a joué ou que joue l'enfant dans les conflits armés en RDC.

Une autre question - au-delà de l'enfant soldat qui assure " une fonction continue » - est celle de s'interroger sur le sort de l'enfant civil, qui sans être incorporé dans une force ou un groupe armé participerait tout de même aux hostilités.

En effet, la question de la participation directe de l'enfant civil aux hostilités est à appréhender au rang d'un civil qui participerait volontairement aux hostilités. L'enfant est donc une personne civile et bénéficie de ce fait des règles du DIH applicables aux personnes civiles ou populations civiles ${ }^{1789}$. Ce qui n'exclut cependant pas qu'il puisse bénéficier de la protection spéciale liée à sa situation notamment la garantie qu'accorde l'article $77 \S 3$ du PA I. Il faudrait cependant préciser qu'un enfant civil qui participe directement aux hostilités perd son immunité ${ }^{1790}$ de protection comme tout civil. Ce qui veut dire qu'il ne sera attaqué que pendant le moment de sa participation aux hostilités. Période qui couvre celle de préparation au combat et celle de chemin de retour après la commission de l'acte hostile ${ }^{1791}$. Il ne bénéficiera donc pas du statut de prisonnier de guerre s'il tombe au pouvoir d'une partie ennemie dans le cadre d'un CAI car ne répondant pas aux critères de combattant ${ }^{1792}$.

Toutefois, le droit international rejetant complètement le droit de disposer arbitrairement du sort des simples particuliers et n'autorisant contre eux ni mauvais traitements ni violences ${ }^{1793}$, le civil ayant participé directement aux hostilités dans le cadre d'un CAI bénéficiera notamment des garanties fondamentales qu'impose l'article 75 du PA I. Il y est fait obligation aux parties au conflit de les "traiter avec humanité en toutes circonstances". Il sied de

Philippe, Enfants-soldats. Victimes ou criminels de guerre ?, éditions du Rocher, Londres, 2007, p.152.

1787 THONIER, Jean-Paul, «Le militaire en opération multinationale face aux enfants-soldats », in BABIKER Mohamed Abdelsalam, DAUBLAIN, Maxence et VAHLAS, Alexis (dir), Enfants-soldats et droits des enfants en situation de conflit et poste-conflit. Réalités et enjeux, op. cit.,, p.192.

1788 HENCKAERTS, Jean-Marie et DOSWALD-BECK, Louise, Droit international humanitaire coutumier, Volume I : Règles, op. cit., p. 643.

${ }^{1789}$ Voy. par exemple les articles $51 \S 2$ du PA I et $13 \S 2$ du PA II

${ }^{1790}$ DAVID, Eric, Principes de droit des conflits armés, 5è édition, op.cit., p. 287

${ }^{1791}$ MOMTAZ, Djamchid, « La participation directe des personnes civiles aux hostilités », « art.cit. », p. 495.

${ }^{1792}$ Voy. l'article 4 de la CG III.

${ }^{1793}$ PICTET, Jean, Les principes du droit international humanitaire, op.cit., p. 29. 
signifier en passant qu'en dépit de l'incertitude quant au champ d'application rationae personae de cette disposition, on s'accorde que sur base de l'article 72 du PA I ${ }^{1794}$, l'article 75 s'interprétera de "façon à inclure également les ressortissants de la partie contractante appliquant les dispositions de l'article en question" voire d'autres ${ }^{1795}$. D'autres règles seront également d'application dont celles des droits de l'homme, universelles ou régionales, voire des accords régionaux et spéciaux.

\section{B.2 La protection spéciale des enfants combattants en CAI : des règles du DIH issues des Accords régionaux et spéciaux signés entre parties aux conflits armés en RDC}

\section{La Charte africaine des droits et du bien-être de l'enfant du 11 juillet 1990}

La Charte africaine des droits et du bien-être de l'enfant du 11 juillet 1990 (entrée en vigueur le 29 novembre 1999) impose en son article 22 aux Etats parties de prendre "toutes les mesures nécessaires » contre la participation directe des enfants aux hostilités. L'âge de l'enfant retenu est à moins de dix-huit ans.

En clair, rappelons que si la CDE s'exprime en termes de «toutes les mesures possibles » que doivent prendre les Etats parties, distinguant ainsi l'obligation des moyens pour la «participation directe» des enfants de moins de quinze ans aux hostilités et une obligation de résultat à propos de leur «enrôlement », la Charte africaine des droits et du bien-être de l'enfant s'exprime en termes de «toutes les mesures nécessaires ». Il s'agit d'une obligation de résultat identique également pour l'enrôlement et la participation directe de ces enfants. Cette disposition « interdit, sans exception, l'enrôlement obligatoire, l'engagement volontaire et l'utilisation d'enfants dans les conflits armés ${ }^{1796}$. Qu'il soit dit que seule la participation directe est interdite et non la participation indirecte. Toutefois, l'interdiction totale de recrutement rendrait la participation indirecte moins probable ${ }^{1797}$.

Cet instrument prévoit, à l'instar d'autres instruments de droits de l'homme, une clause de sauvegarde contenue en son article $1^{\text {er }}$ et libellée de la manière suivante : «[a]ucune disposition de la présente Charte n'a d'effet sur une quelconque disposition plus favorable à la réalisation des droits et de la protection de l'enfant figurant dans la législation d'un Etat partie ou dans toute autre convention ou accord international en vigueur dans ledit Etat ».

Par conséquent, la RDC et les autres parties aux conflits notamment étatiques s'obligent de privilégier toute disposition - conventionnelle ou législative - qui s'avère plus favorable à la présente. C'est par exemple le cas de l'article 11 du Protocole de Maputo (cf. infra).

\footnotetext{
${ }^{1794}$ L'article 72 du PA I dispose : «Les dispositions de la présente section complètent les normes relatives à la protection humanitaire des personnes civiles et des biens de caractère civil au pouvoir d'une partie au conflit énoncées dans la IVè Convention, en particulier aux titres I et III, ainsi que les autres normes applicables du droit international qui régissent la protection des droits fondamentaux de l'homme pendant un conflit armé de caractère international. » (nous soulignons).

1795 GAUDREAU, Julie, «Les réserves aux Protocoles additionnels aux Conventions de Genève pour la protection des victimes de la guerre », in Revue internationale de la Croix-Rouge/ International Review of The Red Cross, ${ }^{\circ} 849$, mars 2003, p.176.

${ }_{1796}$ DOEK, Jaap, «art.cit.», 16; Voy. aussi I.McCONNAN et S. UPPARD, Des enfants Pas des soldats, Londres, The Save the Children, 2002, 24.

${ }^{1797}$ DOEK, Jaap, « art.cit. », p. 16.
} 


\section{Accord de Lusaka du 10 juillet 1999}

L'on pourrait lire ce qui suit au titre des « Principes de l'Accord » qu'indique l'article 3 :

«7. Dès l'entrée en vigueur de cet Accord, les Parties libéreront les personnes détenues ou prises en otage et leur accorderont la liberté de se réinstaller dans toute province de la République Démocratique du Congo ou dans tout autre pays où leur sécurité pourra être garantie.

8. Les Parties à cet Accord s'engagent à échanger les prisonniers de guerre et à libérer toutes autres personnes détenues en raison de la guerre.

9. Les Parties permettront l'accès immédiat et sans réserve au Comité International de la Croix Rouge (CICR)/Croissant Rouge (CR) afin de permettre les arrangements pour la libération des prisonniers de guerre et autres personnes détenues en raison de la guerre ainsi que l'évacuation et l'inhumation des morts et le soin des blessés.

$[\ldots]$

13. La pose des mines, quel qu'en soit le type, est interdite ».

Dans l'annexe «A » liée aux modalités de mise en œuvre de cet accord de cessez-le-feu, son Chapitre 3 se consacre à la libération des otages et à l'échange des prisonniers de guerre. A cet effet, il revient aux parties signataires dudit accord de coopérer avec le CICR en lui fournissant des renseignements et assistances nécessaires pour rendre des visites, s'assurer de l'état et du statut des prisonniers de guerres et assurer leur libération trois jours après signature. Ce qui vaut de même pour des otages et autres détenus.

Pour un accord de cessez-le-feu, il ne faudrait pas s'attendre à une réglementation proprement dite du déroulement des hostilités. De là, des règles relatives à la protection spéciale des enfants participant directement aux hostilités. Cela paraîtrait illogique. L'une des matières à légiférer sous ce cadre pourrait être les effets de conflits armés sur des enfants notamment ceux ayant pris part aux hostilités. C'est ce que tentent d'entreprendre quelques dispositions épinglées ci-dessus mais dans un sens général et non spécifique. C'est également dans cette optique qu'il faudrait inclure la cessation de recrutement et d'utilisation d'enfants dans les conflits armés dans cet accord (article I, 3-c).

\section{Pacte sur la Paix, la Sécurité, la Stabilité et le Développement dans la Région des} Grands Lacs, dit « Pacte ou Traité de Nairobi », du 15 décembre 2006

Il a été affirmé ci-dessus que les Etats parties à cette convention affirmaient dans son préambule qu'ils sont «[d]éterminés à assurer le respect strict des normes et principes fondamentaux du droit international humanitaire, notamment ceux afférents à la protection et à l'assistance devant être apportées [...] aux enfants ${ }^{1798}$, etc. A ce titre, la présente convention prévoit la prévention et la répression des crimes internationaux dont des crimes de guerre (article 8). Et on le sait, procéder à l'enrôlement ou à la conscription des enfants de moins de quinze ans est appréhendé au regard du Statut Rome, par exemple, comme crimes de guerre, en CANI ou en CAI (cf. supra). En cela, cette convention pourrait jouer un rôle

\footnotetext{
${ }^{1798}$ Lire le $\$ 5$ du Pacte sur la Paix, la Sécurité, la Stabilité et le Développement dans la Région des Grands Lacs du 15 décembre 2006 in http://www.icglr.org/index.php/fr/le-pacte (Source consultée le 11 mai 2015).
} 
important dans la prévention et la répression du phénomène «enfant soldat ». Bien plus, la prévention des conflits armés dont il fait la promotion pourrait limiter le recrutement et l'utilisation des enfants dans les hostilités auxquels font généralement recours des groupes armés voire des forces armées étatiques.

\section{Le Protocole à la Charte africaine des droits de l'Homme et des peuples relatif aux droits des femmes adopté à Maputo (Mozambique) le 11 juillet 2003}

Le Protocole de Maputo contient une disposition très importante pour la protection spéciale de la jeune fille, et de l'enfant en général. Il s'agit de son article $11^{1799}$, qui à son paragraphe 4 indique : «Les États prennent toutes les mesures nécessaires pour qu'aucun enfant, surtout les filles de moins de 18 ans, ne prenne part aux hostilités et, en particulier, à ce qu'aucun enfant ne soit enrôlé dans l'armée ${ }^{1800}$. Cet article est une nette avancée par rapport à l'état actuel du droit international relatif à la protection de l'enfant en période de conflits armés (cf. supra).

En appui de cet instrument, la Résolution (284) sur la répression des violences sexuelles sur les femmes en RDC, adoptée en 55è session ordinaire de la Commission africaine des droits de l'homme et des peuples tenue à Luanda du 28 avril au 12 mai 2014, invite la RDC à prendre des mesures nécessaires pour incorporer en législation nationale cet instrument ${ }^{1801}$.

\section{Convention de l'Union africaine sur la protection et l'assistance aux personnes déplacées en Afrique (Convention de Kampala) adoptée par le Sommet spécial de l'Union tenu le 22 octobre 2009}

La Convention de Kampala réitère dans son ensemble les obligations internationales des Etats applicables et interdit expressément aux groupes armés de «[r]ecruter, en quelque circonstance que ce soit, des enfants, de leur demander ou de leur permettre de participer aux hostilités ${ }^{1802}$ (article $7 \$ 5$ e). A cet égard, les critiques adressées au Protocole facultatif de la convention relative aux droits de l'enfant sur l'implication d'enfants dans les conflits armés sont également à formuler ici (cf. supra).

\footnotetext{
${ }^{1799}$ Article 11 : Protection des femmes dans les conflits armés «1. Les États partis s'engagent à respecter et à faire respecter, les règles du droit international humanitaire applicables dans les situations de conflits armés qui touchent la population, particulièrement les femmes.

2. Les États doivent conformément aux obligations qui leur incombent en vertu du droit international humanitaire, protéger en cas de conflit armé les civils, y compris les femmes, quelle que soit la population à laquelle elles appartiennent;

3. Les États s'engagent à protéger les femmes demandeurs d'asile, réfugiées, rapatriées ou déplacées, contre toutes les formes de violence, le viol et autres formes d'exploitation sexuelle et à s'assurer que de telles violences sont considérées comme des crimes de guerre, de génocide et/ou de crimes contre l'humanité et que les auteurs de tels crimes sont traduits en justice devant des juridictions compétentes;

4. Les États prennent toutes les mesures nécessaires pour qu'aucun enfant, surtout les filles de moins de 18 ans, ne prenne part aux hostilités et, en particulier, à ce qu'aucun enfant ne soit enrôlé dans l'armée ».

${ }^{1800}$ Lire l'article 11, $\$ 4$ du Protocole à la Charte africaine des droits de l'homme et des peuples relatif aux droits de la femme in http://www.achpr.org/fr/instruments/women-protocol/\#14 (Source consultée le 14 octobre 2015).

${ }^{1801}$ Voy. l'avant-dernier considérant de la Résolution (284) sur la répression des violences sexuelles sur les femmes en République Démocratique $d u$ Congo in http://www.achpr.org/fr/sessions/55th/resolutions/284/ (Source consultée le 16 janvier 2016).

1802 Convention de l'Union africaine sur la protection et l'assistance aux personnes déplacées en Afrique (Convention de Kampala) adoptée par le Sommet spécial de l'Union tenu le 22 octobre 2009, in http://www.refworld.org/pdfid/4ae825fb2.pdf (Source consultée le 07 mai 2015).
} 
Cette convention n'est toutefois pas encore ratifiée par la RDC et ne serait pas d'application à son endroit voire pour les différents groupes armés y œuvrant. C'est d'ailleurs dans ce sens que la Résolution 241 de la Commission africaine sur la situation des droits de l'homme en RDC adoptée à Nairobi le 24 juillet 2013 tout en condamnant les actes de violence perpétrées contre les civils dont les enfants, invite la RDC à accélérer le processus de ratification de cette Convention $^{1803}$.

\section{§ 2. Règles du DIH assurant la protection spéciale des enfants - combattants et civils - en CANI en RDC}

Les règles du DIH applicables en CANI par les acteurs non étatiques - groupes armés - se trouvent limitées à l'état de ratification des instruments du DIH par la «Haute Partie contractante » qui est la RDC. Toutefois, par voie d'accords spéciaux, comme le veut bien 1'article $3 \S 2$ commun aux CG, les parties pourront faire application d'autres dispositions des CG relatives à la protection spéciale de l'enfant.

En effet, sous ce paragraphe, l'analyse de la protection spéciale des enfants sera entreprise sous l'angle d'instruments universels et régionaux ratifiés par la RDC et d'accords spéciaux dont sont également parties les groupes armés. Les instruments universels et régionaux (africains) sont ceux qui s'imposent aux groupes armés de par les Etats parties. Alors que les accords spéciaux liés aux conflits armés sont ceux par lesquels les groupes armés expriment clairement leur volonté d'appliquer les règles du DIH voire avec des modalités précises en tant que parties.

Par ailleurs, la question de la protection spéciale d'enfants civils et d'enfants combattants sera donc traitée sous deux angles (instruments universels) (A) et (instruments régionaux et accords spéciaux) (B).

\section{A. Règles du DIH issues des instruments universels assurant la protection spéciale des enfants -combattants et civils - en CANI en RDC}

Il est important de rappeler que la protection spéciale de l'enfant en situation de CANI est régie par le PA II. Aucune protection spéciale n'est réservée aux enfants sous l'angle de 1'article 3 commun aux CG. Lequel se préoccupe d'une protection des enfants au même titre que les adultes (Protection générale). Ces instruments seront d'application dans le cadre des hostilités opposant les parties étatiques et non étatiques ou ces dernières entre elles. L'identification et l'organisation de différents groupes armés œuvrant en RDC permettent de conforter cette affirmation (cf. supra). En CANI, en dépit de quelques avancées notamment en matière de la réglementation du recrutement et de participation des enfants aux hostilités, la protection des enfants reste plus sommaire que celle de $\mathrm{CAI}^{1804}$. Rappelons d'avance que

\footnotetext{
1803 Voy. le dernier considérant de la Résolution (241) sur la situation des droits de l'homme en République Démocratique du Congo http://www.achpr.org/fr/sessions/14th-eo/resolutions/241/ (Source consultée le 16 janvier 2016)

${ }^{1804}$ DAVID, Eric « La Protection juridique de l'enfant contre les effets directs des hostilités », « art. cit. », p. 7.
} 
l'adhésion tardive de la RDC au PA II, le 12 décembre 2002, fera en sorte que cet instrument n'entre en vigueur vis-à-vis d'elle qu'immédiatement après. Ce qui rendra tout de même problématique «la protection spéciale » des enfants en CANI pendant les deux «guerres de libération ».

S'agissant de la protection de l'enfant contre son recrutement et sa participation aux hostilités, il y a lieu de rappeler que le PA II est plus avancé que le PA I. Il dispose en son article $4 \S 3$ c que «les enfants de moins de quinze ans ne devront pas être recrutés dans les forces ou groupes armés, ni autorisés à prendre part aux hostilités ». Comparativement à l'article 77 § du PA I qui impose deux obligations distinctes (obligation de moyens concernant la participation d'enfants de moins de quinze ans et obligation de résultat concernant le recrutement d'enfants de moins de quinze ans), le présent article impose deux obligations de nature identique concernant le recrutement et la participation des enfants de moins de quinze ans à savoir l'obligation de résultat. Un autre grand avantage est qu'il s'applique autant pour la participation directe que pour la participation indirecte. Cet article a un autre point fort qui est de s'adresser expressément aux groupes armés non-étatique qui se voient par là dans l'obligation négative de recruter et de faire participer les enfants de moins de quinze ans aux conflits armés. Mais le problème ne demeure point réglé pour les cas de recrutement et de participation des enfants de quinze ans et plus dans les CANI.

Toujours sous l'angle universel, le Statut de Rome de la CPI entrant en vigueur en RDC précisément à partir de juillet 2002, traite aussi de la question de participation des enfants aux hostilités dans le cadre de CANI. Cette convention considère comme crimes de guerre en CANI ce qui constitue une grande avancée pour le DIH précisément - «le fait de procéder à la conscription ou à l'enrôlement d'enfants de moins de quinze ans dans les forces armées ou dans les groupes armés ou de les faire participer activement à des hostilités » (article 8-§2-e-vii). En traitant de la participation active des enfants de moins de quinze ans aux hostilités, cette disposition consacre d'une manière conventionnelle une question longtemps en débat en doctrine $^{1805}$. L'avantage de cette expression de participation active réside dans l'interdiction et la criminalisation en CANI notamment de la participation directe et indirecte des enfants aux hostilités.

Par ailleurs, le problème demeure identique en CANI comme en CAI au sujet de l'enfant qui prend directement part aux hostilités. L'article $4 \S 3 \mathrm{~d}$ du PA II qui s'apparente à l'article $77 \S 3$ du PA I affirme que «la protection spéciale prévue par le présent article pour les enfants de moins de quinze ans leur restera applicable s'ils prennent directement part aux hostilités en dépit des dispositions de l'alinéa c et sont capturés; ». Cette protection spéciale se limite en principe dans le cadre de ce que prévoit cet article. Rien n'affirme expressément qu'elle s'étend aux enfants qui participeraient directement aux hostilités sans qu'ils ne soient "capturés". Logiquement, à quelques exceptions près, ce qui est dit précédemment à propos de l'article $77 \S 3$ du PA I peut être réitéré ici.

${ }^{1805}$ Voy. MALLEIN, Jean, La Situation juridique des combattants dans les conflits armés non internationaux, op.cit., p. 74. 
Pour sa part, l'enfant civil fait l'objet d'une protection spéciale dense comparativement à l'enfant combattant. A la seule condition qu'il ne participe pas directement aux hostilités. "Protection conditionnelle" qui se limite à la durée de cette participation ${ }^{1806}$. En ce sens, logiquement, la protection réservée à l'enfant qui prendrait indirectement part aux hostilités demeure en principe intacte. En termes de garanties fondamentales réservées aux personnes civiles dont les enfants qui ne prennent pas directement part aux hostilités, l'article $4 \S 1$ du PA II dispose:

"Toutes les personnes qui ne participent pas directement ou ne participent plus aux hostilités, qu'elles soient ou non privées de liberté, ont droit au respect de leur personne, de leur honneur, de leurs convictions et de leurs pratiques religieuses. Elles seront en toutes circonstances traitées avec humanité, sans aucune distinction de caractère défavorable. Il est interdit d'ordonner qu'il n'y ait pas de survivants" 1807 .

La présente disposition qui réitère et renforce l'article 3 commun aux CG ne constitue toutefois pas une disposition de protection spéciale des enfants. Par ailleurs, en son paragraphe 3, l'article 4 précité indique que «les enfants recevront les soins et l'aide dont ils ont besoin ${ }^{1808}$. Il s'agit par exemple de l'éducation telle que désirée par leurs parents ou leurs responsables, des mesures appropriées pour leur regroupement familial, de l'interdiction de leur recrutement et de leur participation aux hostilités, de l'évacuation temporaire des enfants du secteur des hostilités, etc. Cet article reste indicatif (voy. notamment) et non limitatif en termes d'énumération des mesures à prendre pour assurer la protection spéciale de l'enfant aux hostilités. Cette ouverture devrait laisser aux parties étatiques et non étatiques en RDC d'entreprendre des mesures imaginables pour la sécurité et le bien-être de l'enfant sous leur pourvoir.

Bien plus, ces dispositions conventionnelles se trouvent complétées par de nombreux instruments des droits de l'homme ou de droit pénal international ratifiés par la RDC voire les différentes parties étatiques opérant en RDC contre les groupes armés mais également de la législation nationale congolaise. En vertu du droit constitutionnel congolais, les conventions internationales ont supériorité sur les lois nationales (cf. infra). Une application extensive des règles applicables au CAI se fait remarquer par la pratique des accords spéciaux. Ces accords permettent d'étendre donc certaines règles du DIH d'application au CAI au CANI. Ce qui $\mathrm{s}$ 'avère bénéfique tant pour des civils que pour des combattants ${ }^{1809}$.

\section{B. Règles du DIH issues des instruments régionaux et spéciaux assurant la protection spéciale des enfants - combattants et civils - en CANI en RDC}

Dorénavant, il y a lieu de préciser que «c'est dans les conflits armés non internationaux que les accords spéciaux se révèlent particulièrement utiles et produisent des effets juridiques

\footnotetext{
${ }^{1806}$ L'article $13 \S 3$ du PA II au sujet de la protection réservée aux personnes civiles dispose : « Les personnes civiles jouissent de la protection accordée par le présent titre, sauf si elles participent directement aux hostilités et pendant la durée de cette participation $»$.

${ }^{1807}$ Article $4 \S 1$ du PA II

1808 Article 4 § 3 du PA II

1809 AIVO, Gérard, «Le rôle des accords spéciaux dans la rationalisation des conflits armés non internationaux », «art. cit. », p. 6.
} 
considérables tant sur la protection des populations civiles que sur celles des personnes participant directement aux hostilités armées ${ }^{1810}$ ». Ils permettent l'application concrète des règles du DIH, procèdent à leur élargissement suivant le cas et imposent de manière réciproque des obligations aux belligérants ${ }^{1811}$. Ces accords qui, dans le cadre des conflits armés en RDC, ont consacré une part non la moindre à la protection spéciale des enfants en CANI méritent un examen dans les lignes suivantes sous cet angle.

Cependant, des règles du DIH issues notamment des accords régionaux ci - dessus examinés seront également d'application en CANI. Ceci vaut également pour certains accords spéciaux dont l'Accord de Lusaka. Ils ne feront donc pas objet d'examen dans les lignes suivantes. L'on se préoccupera, en revanche, d'étudier les accords politiques conclus entre les différentes parties aux conflits armés en RDC, dans un cadre purement national. Lesquels accords, bien qu'à juridicité douteuse, comportent néanmoins des incidences positives sur le plan de protection spéciale des enfants en conflits armés. Il s'agira de l'Accord global et inclusif sur la transition en RDC du 17 décembre 2002 (B.1), de l'Acte d'engagement de Goma du 23 janvier 2008 (B.2) et de l'Accord de paix entre le gouvernement et le CNDP du 23 mars 2009 (B.3).

\section{B.1 Accord global et inclusif sur la transition en République Démocratique du Congo ${ }^{1812}$}

Le présent accord signé le 17 décembre 2002 et adopté à Sun-City le $1^{\text {er }}$ avril 2003 par différentes parties au CANI en RDC à savoir le gouvernement congolais, le RCD, le MLC, le $\mathrm{RCD} / \mathrm{ML}$, le RCD/N et les Maï-Maï réitère leur engagement vis-à-vis de l'Accord de Lusaka et aux résolutions pertinentes du CS/NU relatives aux conflits armés en $\mathrm{RDC}^{1813}$. Ces parties acceptent de prendre toutes les mesures nécessaires à la sécurisation de la population sur l'ensemble du territoire.

Par ailleurs, cet accord pose un sérieux problème de juridicité. Il se présente comme un simple instrument politique, déclaratoire mais aussi programmatoire. Celui-ci n'est pas comparable à 1'Accord de Lusaka qui au-delà d'être aussi programmatoire, impose un certain nombre d'obligations aux parties faisant référence notamment aux règles du DIH et du DIDH existant. Il se trouve lui même repris par de nombreux instruments juridiques contraignants dont les résolutions du CS/NU qui lui accordent par là une force juridique contraignante.

\section{B.2 Acte d'engagement de Goma du 23 janvier $\mathbf{2 0 0 8}^{1814}$}

L'Acte d'engagement est un des rares accords conclus dans le cadre des conflits armés en RDC à réserver des dispositions spécifiques à la situation de l'enfant. Signé par 9 groupes armés opérant dans la région - CNDP Mouvement politico-militaire, PARECO/FAP, MAI-

\footnotetext{
${ }^{1810}$ Ibid.p. 5.

${ }^{1811}$ Ibid., p. 14.

${ }^{1812}$ Lire l'Accord global et inclusif sur la transition en République Démocratique du Congo du 16 décembre 2002 in http://www.irinnews.org/pdf/in-depth/dial_rdc.pdf (Source consultée le 14 mai 2015).

1813 Ibid., lire le préambule.

1814 Lire l'Acte d'engagement de Goma du 23 janvier 2008, disponible https://www.essex.ac.uk/armedcon/story id/000720.pdf (source consultée le 14 mai 2015).
} 
MAI KASINDIEN, MAI-MAI KIFUAFUA, MAI-MAI VURONDO, MAI-MAI MONGOL, UJPS, MAI-MAI RWENZORI et SIMBA - cet instrument se préoccupe de la situation des enfants en conflits armés.

En effet, au préalable, les parties à cet acte déplorent l'insécurité et les violations de droits de l'homme dont sont victimes les civils. De ces 4 articles, l'Acte d'engagement réserve un article aux principes humanitaires et droits de l'homme. Il s'agit de l'article III intitulé « Des principes humanitaires et du respect des droits de l'homme ». Cet article impose dès son introduction une observation stricte du DIH et du DIDH. En son paragraphe premier, comme l'article $1^{\text {er }} \S 3 c$ de l'Accord de Lusaka précité, il impose un arrêt des actes de violences, d'exaction, de discrimination, sous toutes formes à l'endroit des populations civiles, plus particulièrement à l'égard des enfants. Conscientes des situations que traversent les enfants dans ces conflits armés, les parties signataires de cet acte s'interdisent le recrutement des enfants et se prononcent pour la promotion des droits des enfants. Toutefois, la manière dont ladite disposition est formulée est un peu particulière. Il est ainsi écrit au paragraphe 7 de cet article : "Interdiction de tout recrutement et promotion particulière des droits des enfants en zones des conflits (ou post - conflits) ${ }^{1815}$.

Ce paragraphe 7 de l'article III ne dit pas expressément «Interdiction de tout recrutement des enfant ». Il continue sur la même lancée en traitant de la « promotion particulière des droits des enfants... ». Doit-on comprendre par là que les parties à cet Acte d'engagement voudraient échapper à la reconnaissance de ces genres de pratiques tel que l'avaient fait par ailleurs leurs homologues à l'Accord de Lusaka ? Toutefois, il nous paraît clair en dépit de cet escamotage des mots «des enfants» que cette disposition s'adresse clairement aux « enfants » comme l'atteste d'ailleurs la suite de la phrase. Bien plus, «l'interdiction de tout recrutement » tout court dans cette disposition paraîtrait comme une simple redite dans la mesure où l'article I traitant du cessez-le-feu dispose déjà que celui-ci implique l'arrêt total et immédiat notamment de « tout recrutement ».

Au regard de nombres des parties signataires de cet acte, il y aurait en principe une incidence positive dans le sens de la protection spéciale des enfants si et seulement si ces différentes parties arrivent à intégrer et à mettre les dispositions de cet acte dans leur pratique.

\section{B.3 Accord de paix entre le Gouvernement et le Congrès National pour la Défense du Peuple (CNDP) du 23 mars $2009^{1816}$}

Le présent accord est celui purement politique. En somme, il s'agit d'un accord où un Mouvement politico-militaire fait valoir son cahier de charges au Gouvernement congolais. Ce dernier à son tour s'engage à y répondre. Le CNDP a tout de même certaines obligations dans ce sens. D'ailleurs, rappelons que le non respect de cet accord engendra le mouvement politico-militaire «M23 » à la base de nombreuses violations des règles du DIH sur les

${ }^{1815}$ Ibid., lire l'article III $\S 6$.

${ }^{1816}$ Accord de paix entre le Gouvernement et le Congrès National pour la Défense du peuple, disponible sur http://radiookapi.net/files/Accord-CNDP-Gvt-23-mars-2009-pdf.pdf?55c0b5 (Source consultée le 15 mars 2015). 
enfants.

Quant à ce qui nous concerne, cet accord ne dispose d'aucun article traitant spécifiquement de la protection des enfants en conflits armés. Cependant, dans son préambule, l'Accord du 23 mars 2009 prend en considération le Traité de Naïrobi du 15 décembre 2006 et l'Acte d'engagement de Goma du 23 juin 2008. Lesquels contiennent des dispositions se rapportant à la protection des enfants dans les conflits armés. L'Accord du 23 mars 2009 rappelle toutefois la nécessité du strict respect du DIH en son préambule. Concernant les enfants, il est dit simplement que le CNDP présentera une liste des blessés de guerre dont les orphelins de leurs ex - éléments que le Gouvernement devra prendre en charge (article 12, §12.7).

De ces accords de paix analysés sous l'angle de la protection spéciale des enfants tant en CANI qu'en CAI, la problématique de leur juridicité notamment par rapport aux obligations juridiques qu'ils formulent se pose. En effet, si l'accord spécial est appréhendé comme un acte juridique subjectif qui «confère nommément des droits particuliers dont le non respect par l'un des belligérants permet à l'autre de se libérer de ses obligations contractuelles ${ }^{1817}$, il y a lieu cependant de faire preuve de prudence pour des obligations contenues dans ces accords coïncidant avec les normes du DIH ou du DIDH. Celles-ci diffèrent de nombreux droits spécifiques (généralement d'ordre politique) que conférerait par exemple un Etat aux groupes armés dont l'intégration de leurs agents dans l'armée, la police ou administration publique. Comme c'est d'ailleurs le cas pour les conflits armés $\mathrm{RDC}^{1818}$. Les normes du DIH ou du DIDH sont donc d'une consécration conventionnelle et coutumière que ces belligérants, étant d'ailleurs sujets de droit international, doivent respecter. Une des parties ne peut donc se libérer de telles obligations au motif que l'autre (ou les autres) les a violées. Bien plus, la violation de ces accords par les belligérants entraîne souvent «l'accentuation de la pression de la communauté internationale sur des acteurs du conflit ${ }^{1819}$, dont les Nations Unies. Ces dernières se voient d'ailleurs attribuer le rôle d'organe de suivi de la mise en œuvre de ces accords par les parties ${ }^{1820}$. Celles-ci doivent donc s'y conformer. « Il s'agit d'une obligation de droit international pour les mouvements rebelles qui sont tenus de respecter les engagements qu'ils ont souscrits dans le cadre de ces accords en vue de favoriser le maintien de la paix et de la sécurité internationales ${ }^{1821}$.

\footnotetext{
${ }^{1817}$ AIVO, Gérard, « Le rôle des accords spéciaux dans la rationalisation des conflits armés non internationaux », «art. cit.», p. 2. L'auteur définit un accord spécial « comme un acte juridique subjectif contrairement à une convention qui est un acte juridique objectif. Un accord spécial confère nommément des droits particuliers dont le non respect par l'un des belligérants permet à l'autre de se libérer de ses obligations contractuelles, alors qu'une convention consacre des droits généraux qui s'imposent aux Etats parties et dont la violation par l'un des Etats ne décharge pas nécessairement les autres de leurs obligations. »

${ }^{1818}$ Lire par exemple l'article 12 «Des questions spécifiques » de l'Accord de paix entre le Gouvernement et le Congrès National pour la Défense du Peuple du 23 mars 2009 in http://radiookapi.net/files/Accord-CNDP-Gvt23-mars-2009-pdf.pdf?55c0b5 (Source consultée le 15 mars 2015).

${ }_{1819}$ AIVO, Gérard, «Le rôle des accords spéciaux dans la rationalisation des conflits armés non internationaux », « art. cit. », p. 20.

${ }^{1820}$ L'Accord de paix entre le Gouvernement et le Congrès National pour la Défense du Peuple du 23 mars 2009 institue à son article 15.1, à côté d'un Comité national de suivi (article 14), un Comité international de suivi de la mise en œuvre dudit accord composé de l'Organisation des Nations unies, de l'Union Africaine et de la Conférence Internationale sur la Région des Grands Lacs

${ }^{1821}$ TSHIBANGU, Kalala, Les Résolutions de l'ONU et les destinataires non étatiques, éd. Larcier, Bruxelles, p. 97.
} 


\section{§3. Le DIH coutumier et la protection spéciale des enfants en situation de conflits armés en RDC}

Le droit international humanitaire coutumier apporte un bienfait considérable au profit notamment des personnes qui ne participent pas directement aux hostilités ou ne participent plus, voire même des personnes participant aux hostilités. Ceci est remarquable à travers le standard minimum applicable à tous les Etats ${ }^{1822}$, même à ceux ne faisant pas parties des instruments conventionnels concernés. Ce standard minimum applicable permet de niveler tant soit peu la problématique de la fragmentation du droit international de la protection de l'enfant à travers différents instruments juridiques dont certains ne sont pas ratifiés par certains Etats.

Ce standard minimum applicable est remarquable à plusieurs égards. Il est déjà remarqué que les règles conventionnelles sont plus précises et détaillées en CAI qu'en CANI. Les règles sur la conduite des hostilités, par exemple, étaient quasi-inexistantes en CANI. Ainsi, la majorité des armes ont été interdites en CAI qu'en CANI. L'article 3 commun, très succinct, n'aborde pas cette question de conduite des hostilités. Le PA II à son tour l'aborde de manière générale sous l'angle de la «protection générale » réservée aux civils «contre les dangers résultant d'opérations militaires ». Cependant, avec l'amendement apporté à l'article $1^{\text {er }}$ de la Convention on Prohibitions or Restrictions on the Use of Certain Conventional Weapons Which May be Deemed to be Excessively Injurious or to Have Indiscriminate Effects. Geneva, 10 October $1980^{1823}$ au sujet du champ d'application étendu aux CANI (Amendement du 21 décembre 2001) et l'article 8 du Statut de Rome, voire son amendement ${ }^{1824}$, la majorité des armes sont interdites tant en CAI qu'en CANI. Il en résulte par la suite que le droit international humanitaire coutumier est également porteur des solutions à cet égard. La doctrine et la jurisprudence considèrent que les armes interdites en CAI sont également interdites en CANI dans le cadre du droit international coutumier. Ces règles conventionnelles de l'article 3 commun et du PA II sur le droit à la vie sont donc considérées non seulement comme coutumières mais également interprétées comme incluant les règles relatives à la conduite des hostilités ${ }^{1825}$. Une remarque similaire sera faite au sujet de la responsabilité pénale internationale de l'individu. Il n'existe donc aucune disposition conventionnelle en ce qui concerne les instruments du DIH sur les crimes de guerres. Cependant, au regard de la jurisprudence pénale internationale, le droit international coutumier criminalise des violations graves du DIH en CANI ${ }^{1826}$. Par exemple, les infractions à l'une ou plusieurs des dispositions de l'article 3 commun aux CG (cristallisé en droit international coutumier) ont été reconnues comme équivalant à des crimes de guerre dans les Statuts des juridictions pénales internationales (TPI/Y, TPI/R, TSSL, et CPI $)^{1827}$ Bien plus, différents principes du droit

${ }_{1823}^{1822}$ MAYSTRE, Magali, op.cit., p. 68.

Voy.

https://ihl-

databases.icrc.org/applic/ihl/ihl.nsf/Treaty.xsp?documentId=8CA794BB6F9E0AE2C1256BB30028F98D\&actio $\underline{\mathrm{n}=\text { openDocument }}$ (Source consultée le 19 septembre 2016).

${ }^{1824}$ Lire «Amendements au Statut de Rome de la Cour pénale internationale relatifs au crime d'agression » adopté à Kampala le 11 juin 2010, disponible https://www.admin.ch/ch/f/gg/pc/documents/2381/Statut-deRome Projet fr.pdf (Source consultée le 19 septembre 2016).

${ }_{1825}$ GAGGIOLI, Gloria, L'influence mutuelle entre les droits de l'homme et le droit international humanitaire à la lumière du droit à la vie, op.cit., pp. 262-265.

${ }^{1826}$ Ibidem, pp. 263 et 266.

1827 HENCKAERTS, Jean-Marie et DOSWALD-BECK, Louise, Droit international humanitaire coutumier, 
humanitaire examinés ci-avant en appui au principe d'humanité trouvent fondement au plan du droit international coutumier et sont vus comme tels en CAI comme en CANI (cf. supra). Il ressort de cet argumentaire que ce standard minimum applicable reste profitable à l'enfant en tant que personne civile et combattante dans tout type de conflits armés.

Concernant la protection spéciale de l'enfant civil en CAI Comme en CANI, il se dégage du droit international coutumier la règle selon laquelle les enfants touchés par les conflits armés ont droit à un respect et à une protection particuliers (Règle 135 du Droit international humanitaire coutumier du CICR $)^{1828}$. Il ressort de la pratique que cette règle implique notamment :

« - La protection contre toutes les formes de violence sexuelle (voy. aussi règle 93);

- Le fait d'être séparé des détenus adultes en cas de privation de liberté, sauf s'il s'agit de membres d'une même famille (voy. aussi règle 120);

- L'accès à l'éducation, aux vivres et aux soins de santé (voy. aussi règles 55, 118 et 131);

- L'évacuation des zones de combat pour raisons de sécurité (voy. aussi règle 129);

- La réunification des enfants non accompagnés avec leur famille (voy. aussi règles 105 et 131) ${ }^{1829}$

Relativement à la règle précitée, un nombre considérable de conventions internationales, de législations nationales, de résolutions des Nations unies notamment du CS/NU et de l'AG/NU, de manuels militaires voire des déclarations officielles font référence à cette exigence de respect et de protection particuliers, en d'autres termes de la protection spéciale de l'enfant. Ceci vaut de même pour les CAI que pour les CANI ${ }^{1830}$.

Par ailleurs, en ce qui concerne les enfants en voie de recrutement ou d'utilisation aux hostilités, les travaux du CICR évoquent deux règles de grande importance applicables en CAI comme en CANI. Il s'agit de la règle 136: Les enfants ne doivent pas être recrutés dans des forces armées ni dans des groupes armés et de la règle 137 : Les enfants ne doivent être autorisés à participer aux hostilités.

Comme pour la règle 135 , les règles 136 et 137 sont également référencées par différents instruments juridiques - internationaux et nationaux- voire des manuels militaires. A l'égard de ces deux règles, «[a]ucune pratique officielle contraire n'a été constatée ${ }^{1831}$. Dans ce sens, des cas allégués de recrutement et d'utilisation des enfants dans les conflits armés -CAI et CANI- ont été condamnés par différents Etats - par exemple au Burundi, au Libéria, au Myanmar, en Ouganda et en République démocratique du Congo - et des organisations internationales dont les Nations unies. A ce titre, nombreuses sont également des résolutions des organes des Nations unies, précisément du CS/NU, qui condamnent le recrutement et

\footnotetext{
Volume I : Règles, op.cit., p.631

1828 Ibid.

${ }^{1829}$ Ibid, pp. 634-635.

${ }^{1830}$ Ibid. pp. 632-634.

${ }^{1831}$ Lire HENCKAERTS, Jean-Marie et DOSWALD-BECK, Louise, Droit international humanitaire coutumier, Volume I : Règles, op.cit., pp. 782-783.
} 
l'utilisation des enfants dans les hostilités (cf. supra et infra ${ }^{1832}$.

Des conférences internationales sont organisées à l'issue desquelles des résolutions sont adoptées contre le recrutement et l'utilisation des enfants en conflits armés. C'est le cas de Principes du Cap et meilleures pratiques Concernant le recrutement d'enfants dans les forces armées et la démobilisation et la réinsertion sociale des enfants soldats en Afrique adoptés lors d'un Symposium sur la Prévention du recrutement d'enfants dans les forces armées et sur la démobilisation et la réinsertion sociale des enfants soldats en Afrique organisé en Afrique du Sud (Cap) du 27-30 avril 1997. Ou encore des Conférences internationales de la Croix-Rouge de 1986 et de 1995 ayant abouti à l'adoption des résolutions insistant sur l'interdiction de recrutement d'enfants ${ }^{1833}$.

Ce qui est plus considérable est le fait que le Droit international humanitaire coutumier observe que « rien dans la pratique recueillie à l'appui de l'interdiction de la participation des enfants aux hostilités n'indique qu'ils devraient être privés de leur protection spéciale s'ils participent effectivement aux hostilités ${ }^{1834}$. L'effectivité d'une telle pratique juridique est très loin de la réalisation précisément pour les cas de la RDC.

\section{Section III Des Règles en complément des règles du DIH dans la protection spéciale des enfants en conflits armés en RDC}

Sous cette section, il sera examiné des règles de protection spéciale des enfants qui viennent en renfort des règles conventionnelles établies ci-dessus. C'est le cas des règles de DIDH $(\S 1)$, du droit congolais $(\S 2)$ et de celles issues du droit international dérivé, principalement les résolutions du CS/NU ( $\$ 3)$.

\section{§1. Règles du droit international des droits de l'homme relatives à la protection spéciale des enfants en conflits armés en RDC}

«Les droits de l'homme sont une référence majeure dans l'ordre politique ou juridique ${ }^{1835}$. Ils «ont incontestablement acquis une importance fondamentale dans les sociétés contemporaines ${ }^{1836}$. Cette référence dans nos sociétés contemporaines est sans limite des temps et des circonstances, du moins pour des droits indérogeables. Ainsi, en temps des conflits armés, certains droits demeureront d'application. C'est ainsi que les droits de l'homme se complètent utilement avec le DIH et s'influencent mutuellement ${ }^{1837}$ (cf. supra). Bien qu'il soit dit que le droit international des droits de l'homme place l'individu au rang d'un véritable « sujet » de droit international alors que le DIH le conçoit généralement comme «objet de protection ${ }^{1838}$. Ces deux disciplines sont donc complémentaires. Le DIH fait

\footnotetext{
${ }^{1832}$ Lire Ibid., pp. 637 et 641, 773-774.

${ }^{1833}$ Lire Ibid., p. 638.

${ }^{1834}$ Ibid., p. 643.

${ }^{1835}$ MORANGE, Jean, Manuel des droits de l'homme et libertés publiques, PUF, Paris, 2007, p. 7.

1836 Ibid.

${ }^{1837}$ Lire utilement sur l'influence entre les droits de l'homme et le droit international humanitaire GAGGIOLI, Gloria, L'influence mutuelle entre les droits de l'homme et le droit international humanitaire à la lumière du droit à la vie, op. cit., 614 p.

${ }^{1838}$ ERGEC, Rusen et HAPPOLD, Matthew, Protection européenne et internationale des droits de l'homme, $3^{\mathrm{e}}$
} 
d'ailleurs référence aux droits fondamentaux que doivent respecter les Etats parties en conflits armés. L'article 3 commun aux CG en est d'ailleurs un véritable exemple des pratiques interdites «en tout temps et en tout lieu» au profit des personnes ne participant pas directement aux hostilités ${ }^{1839}$.

La référence aux droits de l'homme tient également compte de certaines personnes à besoin spécifique dont les enfants. Ainsi, «[j]uridiquement, la référence aux droits de l'homme implique d'abord de tirer toutes les conséquences de la spécificité de l'enfance ${ }^{1840}$. «[1]es droits de l'enfant sont ceux d'êtres humains particulièrement vulnérables ${ }^{1841}$

Dans l'affaire des Activités armées sur le territoire du Congo (République démocratique du Congo c. Ouganda) devant la CIJ, après avoir établi l'existence des graves manquements au DIH et des violations massives des droits de l'homme (cf. \$205 - \$213) attribuables à l'Ouganda (cf. \$213 - §214) dont le recrutement et la déportation des enfants congolais dans les zones sous son contrôle en RDC (cf. \$210), la Cour s'est penchée à déterminer si «ce comportement constitue, de la part de l'Ouganda, un manquement à ses obligations internationales $^{1842}{ }^{»}$. Pour ce faire, la Cour a relevé les instruments internationaux relatifs au DIH et aux droits de l'homme auxquels l'Ouganda et la RDC étaient parties (cf. §217) et s'est concentrée sur les règles et principes pertinents applicables $(\$ 218-\$ 219)$ pour aboutir à sa conclusion de l'établissement de la responsabilité internationale de l'Ouganda pour violation de ses obligations internationales (cf. § 220). Il revient de constater que la question de la protection des enfants, au-delà des graves violations du DIH et du DIDH épinglées à l'encontre de la population civile, était au centre du débat (cf. infra).

Se focalisant sur les « règles et principes du droit international relatif aux droits de l'homme et du droit international humanitaire qui sont pertinents ${ }^{1843}$, la Cour n'a pu retenir que 1'article 38, paragraphe 2 et 3 de la Convention relative aux droits de l'enfant et les articles 1 , 2, 3 paragraphe 3, 4, 5 et 6 du protocole facultatif concernant l'implication des enfants dans les conflits armés du 25 mai 2000. En clair, concernant la protection spéciale des enfants en situation de conflits armés en RDC, au sens de la Cour, seuls les instruments relatifs aux droits de l'homme étaient pertinents. Il paraît des lors que la Cour estimait avoir rempli sa mission au sujet de la protection de l'enfant en période de conflits armés en se limitant à épingler, dans le cadre du $\mathrm{DIH}$, des règles assurant la protection générale de la population civile et des personnes civiles notamment les articles 48, 51, 52, 57, 58 et 75, paragraphe 1 et 2, du PA I (cf. supra). Ainsi, la Cour ne fait nullement part, dans le cadre du DIH, de l'article 77 du PA I. Doit-on comprendre par là que ce dernier étant similaire à l'article $38 \S 2$ et 3 de la

\footnotetext{
éditions, op.cit., pp. 31-32.

${ }^{1839}$ BUHRER, Jean-Claude et LEVENSON, Claude B., L'ONU contre les droits de l'homme, Mille et une nuits, Librairie Arthème Fayard, Paris, 2003, p. 89.

1840 THERY, Irène, «Nouveaux droits de l'enfant, la potion magique », in Coordination pédagogique Démocratie ou Barbarie du Ministère de la Communauté française de Belgique, Droits humains : Regards d'aujourd'hui 1948-1998, Ministère de la Communauté française de Belgique, Bruxelles, 1998, p. 124.

1841 Ibid.

1842 CIJ, Affaire des Activités armées sur le territoire du Congo (République démocratique du Congo c. Ouganda), arrêt du 19 décembre 2005, Recueil 2005, op. cit., p. 242, §215.

${ }^{1843}$ CIJ, Affaire des Activités armées sur le territoire du Congo (République démocratique du Congo c. Ouganda), arrêt, Recueil 2005, op. cit., p. 242, §215.
} 
Convention relative aux droits de l'enfant précité, la Cour a préféré prendre en référence celui-ci ? Il nous semble que la réponse est positive. Mais comme il sera remarqué en dernier chapitre, il se pose tout de même un problème d'interprétation sous ce cadre.

Par ailleurs, pour revenir aux instruments des droits de l'homme, il sied de rappeler que la « République Démocratique du Congo [...] est partie à un nombre important de traités relatifs aux droits de l'homme avec ou sans effet « self executing » ${ }^{1844}$ (cf. supra). Ces instruments de droits de l'homme constituent la base générale servant notamment à la reconnaissance des droits de l'enfant en tant que personne humaine en tout temps, voire des droits spécifiques en tant que personne nécessiteuse.

L'intérêt dans les lignes suivantes sera réservé à l'examen d'instruments traitant des droits spécifiques des enfants en situations de conflits armés, précisément en RDC. Instruments d'application dans les cas de CAI ou de CANI.

Au rang de ces instruments applicables en situation de conflits armés en RDC, il y a lieu d'épingler le Pacte international relatif aux droits civils et politiques du 16 décembre $1966^{1845}$ (en ses articles 23 et 24); la Convention relative aux droits de l'enfant du 20 novembre 1989 ${ }^{1846}$; le Protocole facultatif à la convention relative aux droits de l'enfant concernant l'implication d'enfants dans les conflits armés du 25 mai $2000^{1847}$; la Convention $\left(\mathrm{n}^{\circ} 182\right)$ concernant l'interdiction des pires formes de travail des enfants et l'action immédiate en vue de leur élimination du 17 juin $1999^{1848}$; la Charte africaine des droits de l'homme et des

${ }^{1844}$ LUNDA BULULU, Vincent, « Les juridictions congolaises et l'application des conventions internationales relatives aux droits de l'homme », in Droit du pouvoir, Pouvoir du droit. Mélanges offerts à Jean Salmon, Bruylant, Bruxelles, 2007, p. 983.

1845 Le Pacte international relatif aux droits civils et politiques entré en vigueur le 23 mars 1976 est applicable par tous les Etats parties aux conflits armés en RDC qui ont effectué leur adhésion à cet instrument, chronologiquement de manière ci-après : Rwanda (16 avril 1975) ; RDC ( $1^{\mathrm{er}}$ novembre 1976$)$; Soudan (18 mars 1986) ; Zimbabwe (13 mai 1991); Burundi (09 mai 1990); Angola (10 janvier 1992); Namibie (28 novembre 1994); Tchad (09 juin 1995); Ouganda (21 juin 1995) Voy. https://treaties.un.org/Pages/ViewDetails.aspx?src=TREATY\&mtdsg_no=IV-4\&chapter=4\&lang=fr $\quad$ (Source consultée le 19 juillet 2015).

${ }^{1846}$ La Convention relative aux droits de l'enfant entrée en vigueur 02 septembre 1990 est applicable par tous les Etats parties aux conflits armés en RDC qui l'ont ratifiée chronologiquement de manière ci-après : Soudan (03 août 1990) ; Ouganda (17 août 1990) ; Zimbabwe (11 septembre 1990); RDC (27 septembre 1990) ; Namibie (30 septembre 1990); Tchad (02 octobre 1990); Burundi (19 octobre 1990); Angola (05 décembre 1990); Rwanda (24 janvier 1991) voir https://treaties.un.org/pages/viewdetails.aspx?src=treaty\&mtdsg_no=iv-

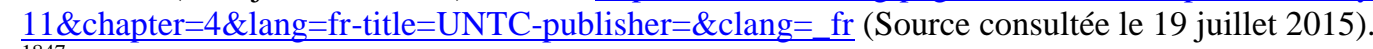

${ }^{1847}$ Le Protocole facultatif se rapportant à la Convention relative aux droits de l'enfant, concernant l'implication d'enfants dans les conflits armés entré en vigueur le 12 février 2002 est applicable aux Etats parties aux conflits armés qui y font parties suivant leurs dates de ratification ou d'adhésion, et surtout de leur présence sur le territoire congolais. Ce qui a pour conséquence que certains Etats ne seront pas concernés de l'application de cette convention. Les dates de ratification ou d'adhésion se présentent comme suit : RDC (ratification le 11 novembre 2001) ; Namibie (ratification le 16 avril 2002); Rwanda (adhésion le 23 avril 2002) ; Ouganda (adhésion le 06 mai 2002) ; Tchad (ratification le 28 août 2002) ; Soudan (ratification le 24 juillet 2005) ; Angola (adhésion le 11 octobre 2007) ; Burundi (ratification 24 juin 2008) ; Zimbabwe (adhésion le 22 mai 2013), voy. https://treaties.un.org/Pages/ViewDetails.aspx?src=TREATY\&mtdsg no=IV-11-b\&chapter=4\&lang=fr （Source consultée le 19 juillet 2015).

${ }^{1848}$ Voy. la Convention ( $\left.{ }^{\circ} 182\right)$ concernant l'interdiction des pires formes de travail des enfants et l'action immédiate en vue de leur élimination du 17 juin 1999 in http://www.ilo.org/public/french/standards/relm/ilc/ilc87/com-chic.htm (Source consultée le 19 juillet 2015). Cet instrument entré en vigueur le 19 novembre 2000 a été ratifié par le Rwanda (23 mai 2000) ; le Tchad (06 novembre 2000) ; la Namibie (15 novembre 2000) ; le Zimbabwe (11 décembre 2000) ; l'Angola (13 juin 2001); 
peuples du 27 juin $1981^{1849}$; la Charte africaine des droits et du bien-être de l'enfant du 11 juillet $1990^{1850}$; le Statut de Rome de la Cour pénale internationale du 17 juillet $1998^{1851}$.

En effet, le Pacte international relatif aux droits civils et politiques traite en son article $23^{1852}$ du droit au mariage et du droit à la protection de la famille par l'Etat. En cela, l'enfant se trouve indirectement concerné. L'article 24 du même instrument dispose directement au profit de l'enfant les droits suivants: «1. Tout enfant, sans discrimination aucune fondée sur la race, la couleur, le sexe, la langue, la religion, l'origine nationale ou sociale, la fortune ou la naissance, a droit, de la part de sa famille, de la société et de l'Etat, aux mesures de protection qu'exige sa condition de mineur. 2. Tout enfant doit être enregistré immédiatement après sa naissance et avoir un nom. 3. Tout enfant a le droit d'acquérir une nationalité». L'enfant mérite donc protection sans aucune forme de discrimination défavorable de la part de sa famille, de la société et de l'Etat.

Par ailleurs, les droits de l'enfant inscrits dans le Pacte international relatif aux droits civils et politiques se trouvent butés à la prescription de l'article 4 du même instrument qui traite de la dérogation. Il ressort de la liste des droits dont aucune dérogation n'est autorisée établie par l'article $4 \$ 2^{1853}$ que les article 23 et 24 ne sont pas repris. Ces deux articles se présentent comme des droits dérogeables. Toutefois, il y a lieu de faire preuve de prudence pour la lecture de l'article $24 \S 1$ (cf. supra) combiné à l'article $4 \S 1^{1854}$. L'article $24 \S 1$ interdit toute

la RDC (20 juin 2001) ; l'Ouganda (21 juin 2001) ; le Burundi (11 juin 2002) et le Soudan (07 mars 2003).

1849 Instrument entré en vigueur le 21 octobre 1986 et ratifié par le Rwanda (15 juillet 1983) ; le Soudan (18 février 1986) ; l'Ouganda (10 mai 1986) ; le Zimbabwe 30 mai 1986) ; le Tchad (09 octobre 1986) ; la RDC (20 juillet 1987) ; le Burundi (28 juillet 1989); l'Angola (02 mars 1990) et la Namibie le 30 juillet 1992, voy. http://www.achpr.org/fr/states/ (Source consultée le 19 juillet 2015).

${ }^{1850}$ En dehors du Soudan, cet instrument, entré en vigueur le 29 novembre 1999, est ratifié par l'Angola (11 juillet 1992) ; l'Ouganda (17 août 1994) ; le Zimbabwe (19 janvier 1995) ; le Tchad (30 mars 2000) ; le Rwanda (11 mai 2001); le Burundi (28 juin 2004) ; la Namibie (23 juillet 2004). Par ailleurs, il est important de mentionner que la RDC n'est pas reprise parmi les Etats parties à la Charte africaine des droits et du bien-être de l'enfant (voy. http://www.achpr.org/fr/states/democratic-republic-of-congo/ratifications/) (Source consultée le 19 juillet 2015). Mais le Journal officiel de la République Démocratique du Congo, Instruments internationaux et régionaux relatifs aux droits de l'Homme ratifiés par la République Démocratique du Congo, $43^{\mathrm{e}}$ année, Numéro spécial, du 5 décembre 2002, précise qu'elle a ratifié le 28 mars 2001 la Charte africaine des droits et du bien-être de l'enfant du 11 juillet 1990 .

${ }^{1851}$ Instrument entré en vigueur le $1^{\text {er }}$ juillet 2002 et par la RDC (11 avril 2002); la Namibie (25 juin 2002); l'Ouganda (14 juin 2002) ; le Burundi (21 septembre 2004) et le Tchad ( $1^{\mathrm{er}}$ novembre 2006) pour lequel le Statut est entré en vigueur le $1^{\text {er }}$ janvier 2007 voir http://www.icccpi.int/fr_menus/asp/states\%20parties/pages/the\%20states\%20parties\%20to\%20the\%20rome\%20statute.aspx

(Source consultée le 19 juillet 2015).

1852 Cet article dispose « 1. La famille est l'élément naturel et fondamental de la société et a droit à la protection de la société et de l'Etat. 2. Le droit de se marier et de fonder une famille est reconnu à l'homme et à la femme à partir de l'âge nubile. 3. Nul mariage ne peut être reconnu sans le libre et plein consentement des futurs époux. 4. Les Etats parties au présent Pacte prendront les mesures appropriées pour assurer l'égalité des droits et de responsabilité des époux au regard du mariage, durant le mariage et lors de sa dissolution. En cas de dissolution, des dispositions seront prises afin d'assurer aux enfants la protection nécessaire ».

${ }^{1853}$ L'article $4 \$ 2$ du PIDCP : « [1]a disposition précédente n'autorise aucune dérogation aux articles 6, 7, 8 (par. $1^{\mathrm{er}}$ et 2$), 11,15,16$ et 18 .

${ }^{1854}$ L'article $4 \S 1$ du PIDCP dispose : « [d]ans le cas où un danger public exceptionnel menace l'existence de la nation et est proclamé par un acte officiel, les Etats parties au présent Pacte peuvent prendre, dans la stricte mesure où la situation l'exige, des mesures dérogeant aux obligations prévues dans le présent Pacte, sous réserve que ces mesures ne soient pas incompatibles avec les autres obligations que leur impose le droit international et qu'elles n'entraînent pas une discrimination fondée uniquement sur la race, la couleur, le sexe, la langue, la religion ou l'origine sociale ». 
forme de discrimination au sujet des mesures de protection de l'enfant, de la part de la famille, la société et de l'Etat. Cette disposition de l'article 24 \$1 est soutenue par l'article 4 $\$ 1$. Ce dernier autorise la dérogation aux obligations contenues dans le Pacte international relatif aux droits civils et politiques sous réserve que les mesures prises à ce sujet ne soient pas incompatibles avec d'autres obligations internationales contractées par l'Etat concerné et n'entraînent pas une discrimination. Il va sans dire qu'il serait matériellement inconcevable de supprimer une disposition qui interdit la discrimination (article 24 §1) sans entraîner par là une discrimination (interdiction faite à l'article $4 \S 1$ ). Sur base de cet article $4 \S 1$, nous considérons l'article $24 \S 1$ du Pacte, bien que non repris expressément par l'article $4 \S 2$, comme une disposition indérogeable érigée d'ailleurs en droit absolu c'est-à-dire non susceptible de restriction comme l'indiquent bien ses termes. En d'autres termes, même en situation de conflits armés en RDC, objet de la présente réflexion, l'article $24 \S 1$ demeure d'application.

Il nous paraît par ailleurs utile d'affirmer que l'article $24 \S 1$ se présente comme une disposition, non indépendante, accompagnant par là le «droit de l'enfant aux mesures de protection » «diverses », « exigées par sa condition de mineur». Lesquelles mesures doivent être assurées «sans discrimination aucune». Cet article pourrait donc venir en appui des dispositions d'autres instruments des droits de l'homme consacrés à l'enfant. Tout ceci confirme ce qu'il convient de dire avec Martine Collin : «L'enfant est vulnérable : sans notre protection, il ne peut survivre. Il est innocent : nouveau venu au monde, il ne peut être tenu pour responsable de la marche de celui-ci ${ }^{1855}$.

De tout ce qui précède, il sied de conclure que la dérogation indiquée par l'article 4 du Pacte n'est donc qu'une «possibilité encadrée » offerte aux Etats de passer outre leurs obligations issues dudit traité face aux situations de « danger public exceptionnel » et non une obligation.

A propos de la Convention relative aux droits de l'enfant, celle-ci se laisse guider par un principe fondamental selon lequel «dans toutes les décisions qui concernent les enfants, de quelque instance qu'elles émanent, «l'intérêt supérieur de l'enfant doit être une considération primordiale ${ }^{1856}$ (cf. article $3 \S 1^{\text {er }}$ de la Convention relative aux droits de l'enfant). Ceci appelle quelques commentaires

En effet, le concept «l'intérêt supérieur de l'enfant» ne naît pas avec la CDE. On le retrouve déjà au Principe 7 de la Déclaration des droits de l'enfant du 20 novembre $1959^{1857}$. Le sens de cette expression se trouve également consacré ou se dégage de l'interprétation de

\footnotetext{
${ }^{1855}$ COLLIN, Martine, «Le droit à l'enfance », in Coordination pédagogique Démocratie ou Barbarie du Ministère de la Communauté française de Belgique, Droits humains: Regards d'aujourd'hui 1948-1998, Ministère de la Communauté française de Belgique, Bruxelles, 1998, p. 127.

${ }^{1856}$ ERGEC, Rusen et HAPPOLD, Matthew, Protection européenne et internationale des droits de l'homme, $3^{\mathrm{e}}$ éditions, op.cit., 78-79.; Voy. également CHAGNOLLAUD, Dominique et DRAGO, Guillaume, Dictionnaire des droits fondamentaux, op. cit., p. 402.

${ }^{1857}$ C'est notamment le cas de l'interprétation qui se dégage de l'art. 8 de la Convention européenne des droits de l'homme du 4 novembre 1950. Voy. par exemple CEDH, Affaire jeunesse c. Pays-Bas (Requête ${ }^{\circ} 12738 / 10$ ), Arrêt du 3 octobre 2014, p. 33, § 109 ; CJCE, affaire C-540/03, Parlement européen c/ Conseil de l'Union européenne, Arrêt de la Cour (grande chambre) du 27 juin 2006, Rec., I-5828, § 56 disponible sur http://curia.europa.eu/juris/liste.jsf?language=fr\&num=C-540/03 (Source consultée le 17 juillet 2016), etc. Voy. aussi l'article 8 de la Convention européenne en matière d'adoption d'enfants du 24 avril 1967, etc. Sur l'historique de l'intérêt supérieur de l'enfant, lire avec intérêt CANTWELL, Nigel, "La genèse de l'intérêt supérieur de l'enfant dans la Convention relative aux droits de l'enfant », in J.D.J, 2013/3, n³23, pp. 8-11.
} 
différentes dispositions conventionnelles ou législatives adoptées avant la $\mathrm{CDE}^{1858}$.

En termes de définition, la doctrine souligne le caractère vague, flou, fuyant ou insaisissable de cette notion ${ }^{1859}$. Il s'agit d'une notion variable ${ }^{1860}$ dont la détermination a priori du contenu est totalement impossible. Tout de même, il est admis que l'intérêt supérieur de l'enfant peut recevoir deux significations. Premièrement, il s'agit d'une «norme générale et abstraite ${ }^{1861}$, d' « un standard idéal-typique ${ }^{1862}$. Lequel concernerait donc tout enfant. Ainsi, l'interdiction de mauvais traitement à l'enfant, par exemple, rentrerait dans ce cadre ${ }^{1863}$. Deuxièmement, la notion d'intérêt supérieur de l'enfant se rapporte à une situation, particulière, concrète de l'enfant ${ }^{1864}$. C'est donc le cas concret. Il va sans dire que cette notion constitue « un principe d'interprétation qui contraint les autorités à respecter les spécificités de l'enfant et à en tenir compte dans l'implémentation des droits de l'enfant ${ }^{1865}$. Ainsi, au sens plus global, par référence au raisonnement tenu par la CJUE, des considérations spécifiques des situations des enfants devraient logiquement conduire à des mesures et de niveau de protection distincts d'un Etat à un autre ${ }^{1866}$.

De tout ce qui précède, la législation congolaise précisément la Loi $n^{\circ} 009 / 01$ du 10 janvier 2009 portant protection de l'enfant, donne une définition au concept "intérêt supérieur de l'enfant ». D'abord, le premier alinéa de son article 6 rappelle l'article $3 \S 1$ de la CDE en affirmant que l'intérêt supérieur de l'enfant doit être «une préoccupation primordiale » dans toutes décisions ou mesures concernant l'enfant. Ensuite, c'est au tour du deuxième alinéa du même article précité de définir cette expression en ce sens :

«Par intérêt supérieur de l'enfant, il faut entendre le souci de sauvegarder et de privilégier à tout prix ses droits ».

1858 OTTEVAERE, Anne, «Adoptions internationales et intérêt supérieur de l'enfant », in J.T, 2008/18, nº6310, pp. 309-312.

${ }^{1859}$ MOREAU, Thierry, « Intérêt et droits de l'enfant ou les deux éléments constitutifs du droit de l'enfant au respect. L'exemple du placement et de la privation de liberté », in MOREAU, Thierry, RASSON-ROLAND, Anne et VERDUSSEN, Marc (dir.), Le droit de l'enfant au respect, éd. Anthemis, Limal, 2013, p.154 ; EGEA, Vincent, «L'intérêt supérieur de l'enfant: menace ou chance pour le droit civil ? ", in PUTMAN, Emmanuel et EGEA, Vincent, La Convention de New-York sur les droits de l'enfant. Vingt ans d'incidences théoriques et pratiques, Presses Universitaires d'Aix-Marseille, Aix-en-Provence, 2012, p. 39; GOUTTENOIRE, Adeline, « La consécration de l'intérêt supérieur de l'enfant dans l'Union européenne », « art.cit. », in TINIERE, Romain et VIAL, Claire (dir.), La Protection des droits fondamentaux dans l'Union européenne. Entre évolution et permanence, op. cit., p. 233.

${ }^{1860}$ MOREAU, Thierry, «Intérêt et droits de l'enfant ou les deux éléments constitutifs du droit de l'enfant au respect. L'exemple du placement et de la privation de liberté », «art.cit.», p. 154. GOUTTENOIRE, Adeline, «La consécration de l'intérêt supérieur de l'enfant dans l'Union européenne », « art. cit. », p. 234.

${ }^{1861}$ GOUTTENOIRE, Adeline, «La consécration de l'intérêt supérieur de l'enfant dans l'Union européenne », « art. cit. », p. 234

${ }^{1862}$ EGEA, Vincent, «L'intérêt supérieur de l'enfant : menace ou chance pour le droit civil ? », « art.cit. », p. 36.

${ }^{1863}$ Ibid. ; GOUTTENOIRE, Adeline, « La consécration de l'intérêt supérieur de l'enfant dans l'Union européenne », « art. cit. », p. 234.

${ }^{1864}$ Ibid.

${ }^{1865}$ MOREAU, Thierry, « Intérêt et droits de l'enfant ou les deux éléments constitutifs du droit de l'enfant au respect. L'exemple du placement et de la privation de liberté », « art.cit. », p. 154.

1866 CJCE, Affaire C-244/06, Dynamic Medien Vertriebs GmbH c/ Avides Media AG, arrêt de la Cour (troisième chambre) du 14 février 2008, Rec., I-549, $\$ 44 . \quad$ Disponible sur http://curia.europa.eu/juris/liste.jsf?language=fr\&num=C-244/06 (Source consultée le 17 juillet 2016). 
Enfin, le troisième alinéa dudit article, en soutien à cette définition, identifie les éléments qui composent cette notion: «[s]ont pris en considération, avec les besoins moraux, affectifs et physiques de l'enfant, son âge, son état de santé, son milieu familial et les différents aspects relatifs à sa situation ».

En dépit de la définition que formule le législateur congolais, il y a lieu de remarquer que le caractère mouvant ou insaisissable de cette notion persiste. Rien n'est donc définitivement arrêté à l'avance. Ainsi, une large marge de manœuvre se trouve réservée aux « autorités » appelées à prendre des «décisions » ou des «mesures» sur des enfants. Elles ont donc un pouvoir discrétionnaire étendu en recourant à différents éléments pour fonder leur appréciation. Pour la CJUE, par exemple, l'« intérêt n'est certes pas déterminant à lui seul, mais il faut assurément lui accorder un poids important ${ }^{1867}$. «Elle rappelle que, pour accorder à l'intérêt supérieur des enfants qui sont directement concernés une protection effective et un poids suffisant, les organes décisionnels nationaux doivent en principe examiner et apprécier les éléments touchant à la commodité, à la faisabilité et à la proportionnalité $[\ldots] »^{1868}$.

Par ailleurs, au-delà des droits civils et politiques, et des droits économiques, sociaux et culturels que reconnaît cette Convention aux enfants (cf. supra), particulièrement à la situation des enfants en situation de conflits armés, il y a l'article 38 qui reste plus préoccupant (cf. supra). Celui-ci n'est donc que la reconduction de l'article 77 du PA I. Reconduction critiquée unanimement par la doctrine en dépit des caractéristiques avantageuses d'un instrument dit des droits de l'homme, applicable en temps de paix et de conflits armés et dissipant par là les doutes éventuels quant aux obligations des Etats non parties au conflit armé ${ }^{1869}$.

Cette Convention est relayée par un Protocole facultatif concernant l'implication d'enfants dans les conflits armés du 25 mai 2000 et entré en vigueur le 12 février 2002. En dépit de ses avantages liés notamment à la fixation d'âge d'enrôlement obligatoire d'enfants dans les forces armées à 18 ans (article 2) et à l'interdiction expresse d'enrôlement (obligatoire et volontaire) et d'utilisation des enfants aux groupes armés (article 4), cet instrument est critiqué pour ne pas avoir pris en compte de manière optimale la question de participation des enfants aux hostilités. Seule la participation directe est interdite (article $1^{\mathrm{er}}$ ). Une autre critique est formulée au sujet de l'âge de recrutement volontaire des enfants (quinze ans) (cf. article 3 $\S 1$ du Protocole renvoyant à l'article $38 \S 3$ de la Convention relative aux droits de l'enfant) et de violation du principe d'égalité des belligérants quant à la portée des obligations imposées aux forces armées et aux groupes armés (cf. articles 2 et 4$)^{1870}$.

\footnotetext{
${ }^{1867}$ CEDH, Affaire jeunesse c. Pays-Bas (Requête n' $12738 / 10$ ), Arrêt du 3 octobre 2014, p. 33, § 109.

${ }^{1868}$ Ibid., p. 33, § 109 et p. 36, § 120.

1869 ARZOUMANIAN, Naïri et PIZZUTELLI, Francesca, «Victimes et bourreaux : questions de responsabilité liées à la problématique des enfants-soldats en Afrique », « art. cit. », p. 834.

${ }^{1870}$ Lire utilement à ce sujet MERMET, Joel, «Protocole facultatif à la Convention relative aux droits de l'enfant concernant l'implication d'enfants dans les conflits armés : quel progrès pour la protection des droits de l'enfant?», in Actualité et droit international. Revue d'analyse juridique de l'actualité internationale, Juin 2002, p. 6, http://www.ridi.org/adi/articles/2002/200206mer.htm (Source consultée le 12 avril 2015).
} 
Toutefois, concernant «l'âge minimum fixé pour l'engagement volontaire dans les forces armées, la RDC en ratifiant le Protocole, le 28 mars 2001, a déposé sa déclaration contraignante auprès du Secrétariat général des Nations Unies indiquant que l'âge minimum de l'engagement volontaire dans les forces armées est de 18 ans. Par conséquent, l'engagement volontaire des personnes âgées de moins de 18 ans tel que prévu à l'article 3 du Protocole n'existe pas ${ }^{1871}$.

Le Statut de Rome de la CPI (relevant du droit international pénal), traite aussi de la question de la participation des enfants aux hostilités. Celui-ci considère comme crimes de guerre « le fait de procéder à la conscription ou à l'enrôlement d'enfants de moins de 15 ans dans les forces armées nationales ou de les faire participer activement à des hostilités » ${ }^{1872}$ (art. 8 \$2 b xxvi) dans le cadre des CAI ou «le fait de procéder à la conscription ou à l'enrôlement d'enfants de moins de 15 ans dans les forces armées ou dans les groupes armés ou de les faire participer activement à des hostilités » (art. 8 §2 d vii) en CANI.

“La Convention de l’Organisation Internationale du Travail ( $\left.\mathrm{N}^{\circ} 182\right)$ concernant l'interdiction des pires formes de travail des enfants et l'action immédiate en vue de leur élimination" du 17 juin 1999 s'inscrit également comme instrument repoussant la participation des enfants aux hostilités. Elle interdit quatre pires formes de travail des enfants, parmi lesquelles «le recrutement forcé ou obligatoire des enfants en vue de leur utilisation dans les conflits armés ${ }^{1873}$.

Au plan régional, il y a d'abord la Charte africaine des droits de l'homme et des peuples qui insiste en son article $18^{1874}$ sur la protection de la famille par l'Etat, notamment de sa santé physique et mentale. En outre cet article réitère sans les citer les droits de l'enfant garantis dans d'autres instruments des droits de l'homme en demandant précisément à l'Etat «d'assurer la protection des droits de la femme et de l'enfant tels que stipulés dans les déclarations et conventions internationales ». Vient ensuite sous cet angle régional, la Charte africaine des droits et du bien-être de l'enfant du 11 juillet 1990 (entrée en vigueur le 29 novembre 1999) qui s'occupe spécialement des droits de l'enfant à l'instar de la Convention relative aux droits de l'enfant au plan international. La Charte africaine des droits et du bien-

\footnotetext{
${ }^{1871}$ Comité des droits de l'enfant, Examen des Rapports présentés par les Etats parties en application du paragraphe 1 de l'article 8 du Protocole facultatif à la Convention relative aux droits de l'enfant, concernant l'implication d'enfants dans les conflits armés, Rapports initiaux des Etats parties attendus en 2004, République Démocratique $d u$ Congo, CRC/C/OPAC/COD/1, 18 avril 2011, p. 16, 865 , http://tbinternet.ohchr.org/_layouts/treatybodyexternal/TBSearch.aspx?Lang=en\&TreatyID=5\&TreatyID=10\&T reatyID=11\&DocTypeID=29\&DocTypeCategoryID=4 (Source consultée le 10 janvier 2016).

1872 Jaap DOEK, «Le cadre juridique international pour protéger les enfants dans les conflits armés », « art. cit. », p. 19.

1873 «Aux fins de la présente Convention, l'expression "pires formes de travail des enfants » comprend: a) toutes les formes d'esclavage ou pratiques analogues, telles que la vente et la traite des enfants, la servitude pour dettes et le servage ainsi que le travail forcé ou obligatoire, y compris le recrutement forcé ou obligatoire des enfants en vue de leur utilisation dans les conflits armés ».

1874 Article 18 de la Charte africaine des droits et du bien-être de l'enfant dispose : «1. La famille est l'élément naturel et la base de la société. Elle doit être protégée par l'Etat qui doit veiller à sa santé physique et morale. 2 . L'Etat a l'obligation d'assister la famille dans sa mission de gardienne de la morale et des valeurs traditionnelles reconnues par la communauté. 3. L'Etat a le devoir de veiller à l'élimination de toute discrimination contre la femme et d'assurer la protection des droits de la femme et de l'enfant tels que stipulés dans les déclarations et conventions internationales. [...]».
} 
être de l'enfant impose une obligation de résultat, en son article 22, aux Etats parties de prendre "toutes les mesures nécessaires" contre l'enrôlement (obligatoire et volontaire) et la participation directe des enfants aux hostilités. L'âge de dix-huit ans est ici retenu. Cette disposition «qui ne s'applique qu'aux États africains, est la plus radicale car elle interdit, sans exception, l'enrôlement obligatoire, l'engagement volontaire et l'utilisation d'enfants dans les conflits armés ${ }^{1875}$. Qu'il soit dit que seule la participation directe est interdite et non la participation indirecte. Toutefois, l'interdiction totale de recrutement rendrait la participation indirecte moins probable ${ }^{1876}$.

Il faudrait également faire mention, sous cet angle, du Protocole à la Charte africaine des droits de l'Homme et des peuples relatif aux droits des femmes (Protocole de Maputo) du 11 juillet 2003 que la RDC a ratifié le 09 juin 2008. Ouganda et Rwanda l'ont fait respectivement le 22 juillet 2010 et le 25 juin 2004. Cette convention contient une disposition très importante pour la protection spéciale de la jeune fille, et de l'enfant en général. Son article 11 ouvre une porte à l'application générale du $\mathrm{DIH}^{1877}$, comme le font d'ailleurs la Convention relative aux droits de l'enfant en son article $38 \S 1$, ou l'article $22 \S 1$ de la Charte africaine des droits et du bien-être de l'enfant. Cet article 11 précise en son paragraphe $4:$ : [l]es États prennent toutes les mesures nécessaires pour qu'aucun enfant, surtout les filles de moins de 18 ans, ne prenne part aux hostilités et, en particulier, à ce qu'aucun enfant ne soit enrôlé dans l'armée ${ }^{1878}$. A plusieurs égards, il s'agit d'une nette avancée du droit international relatif à la protection de l'enfant en période de conflits armés (Voy. les commentaires précédents).

Toujours au plan africain, l'Union africaine a adopté lors de son Sommet spécial tenu à Kampala (Ouganda) le 22 octobre 2009 la Convention de l'Union africaine sur la protection et l'assistance aux personnes déplacées en Afrique (Convention de Kampala). Celle-ci réitère dans son ensemble les obligations internationales des Etats applicables et interdit expressément aux groupes armés de «Recruter, en quelque circonstance que ce soit, des enfants, de leur demander ou de leur permettre de participer aux hostilités » ${ }^{1879}$ (article $7 \S 5$ e).

1875 DOEK, Jaap, «art.cit. », 16; Voy. aussi I.McCONNAN et S. UPPARD, Des enfants Pas des soldats, Londres, The Save the Children, 2002, p. 24.

1876 Ibid.

1877 Article 11 : Protection des femmes dans les conflits armés «1. Les États partis s'engagent à respecter et à faire respecter, les règles du droit international humanitaire applicables dans les situations de conflits armés qui touchent la population, particulièrement les femmes.

2. Les États doivent conformément aux obligations qui leur incombent en vertu du droit international humanitaire, protéger en cas de conflit armé les civils, y compris les femmes, quelle que soit la population à laquelle elles appartiennent;

3. Les États s'engagent à protéger les femmes demandeurs d'asile, réfugiées, rapatriées ou déplacées, contre toutes les formes de violence, le viol et autres formes d'exploitation sexuelle et à s'assurer que de telles violences sont considérées comme des crimes de guerre, de génocide et/ou de crimes contre l'humanité et que les auteurs de tels crimes sont traduits en justice devant des juridictions compétentes;

4. Les États prennent toutes les mesures nécessaires pour qu'aucun enfant, surtout les filles de moins de 18 ans, ne prenne part aux hostilités et, en particulier, à ce qu'aucun enfant ne soit enrôlé dans l'armée ».

${ }^{1878}$ Lire l'article 11, $\$ 4$ du Protocole à la Charte africaine des droits de l'homme et des peuples relatif aux droits de la femme in http://www.achpr.org/fr/instruments/women-protocol/\#14 (Source consultée le 14 octobre 2015).

1879 Convention de l'Union africaine sur la protection et l'assistance aux personnes déplacées en Afrique (Convention de Kampala) adoptée par le Sommet spécial de l'Union tenu le 22 octobre 2009, in http://www.refworld.org/pdfid/4ae825fb2.pdf (Source consultée le 07 mai 2015). 


\section{§2. La protection spéciale des enfants en conflits armés en vertu du droit congolais}

Différentes branches du droit positif congolais assurent la protection de l'enfant, du droit privé au droit public. Cependant, en situations exceptionnelles de conflits armés, la protection de l'enfant reste bien assurée par les règles découlant du DIH, du DIDH, voire du droit international pénal ou droit pénal international. Et en vertu de l'article 215 de la Constitution de la RDC qui dispose : "Les traités et accords internationaux régulièrement conclus ont, dès leur publication, une autorité supérieure à celle des lois, sous réserve pour chaque traité ou accord, de son application par l'autre partie.», tous les instruments juridiques internationaux relatifs aux DIH, DIDH et droit international pénal ou droit pénal international ratifiés par la RDC font partie intégrante de son droit positif. Et s'agissant de ces instruments, étant donné le caractère erga omnes de leurs obligations, l' " Etat dans ce cas ne s'engage plus seulement à l'égard de tel contractant, mais il assume des obligations envers la communauté internationale, envers les particuliers et notamment ses propres ressortissants ${ }^{1880}$. Et la « réserve de réciprocité ${ }^{1881}$ qui se dégage de la disposition constitutionnelle précédente est ici inopérante.

Rappelons que la « réciprocité porte sur l'application de chaque traité par l'autre partie ${ }^{1882}$. En cela, l'inexécution d'une convention par l'autre partie peut être passible de l'exception d'inexécution des traités (Exceptio non adimpleti contractus), conformément d'ailleurs à l'article 60 de la Convention de Vienne sur le droit des traités. En d'autres termes, l'extinction des obligations à la suite de l'inexécution d'un traité par une partie n'est pas automatique. Celle-ci peut, à la suite de l'inexécution initiale (ou de la violation initiale), soit dénoncer ledit traité ou suspendre son application totalement ou partiellement, soit encore observer un silence. Dans ce dernier cas, le traité demeurera d'application. C'est la présomption d'application réciproque ${ }^{1883}$. Seul le pouvoir exécutif est donc habilité à prendre de telles mesures ${ }^{1884}$. Toutefois, il est actuellement admis que le juge - comme démontré en France peut procéder indépendamment du pouvoir exécutif à l'examen de condition de réciprocité afin de régler le litige lui soumis. Indépendant du Ministère des affaires étrangères, le juge français procède depuis peu par un débat contradictoire à l'examen des observations du Ministère des affaires étrangères et de celles de l'Etat en cause pour déterminer si l'accord international en question fait ou non l'objet de réciprocité ${ }^{1885}$.

\footnotetext{
${ }^{1880}$ DECAUX, Emmanuel, La Réciprocité en Droit international, L.G.D.J, Paris, 1980, p. 58.

${ }^{1881}$ ALLAND, Denis, Manuel de droit international public, P.U.F, Paris, p. 205.

${ }^{1882}$ LUNDA Bululu, La conclusion des traités en droit constitutionnel zaïrois. Etude de droit international et de droit interne, éditions Bruylant, éditions de l'Université de Bruxelles, Bruxelles, 1984, p. 234. Sur cette notion de réciprocité, lire avec intérêt DECAUX, Emmanuel, La Réciprocité en Droit international, op. cit., 374 p.

${ }^{1883} \mathrm{La}$ "Cour de Cassation (En France) a déjà considéré qu'il y a présomption d'application réciproque tant que la convention n'est pas officiellement dénoncée (Cass., 6 mars 1984, M. Kryla c/Mme L., n'82-14.008, Bull., $\left.n^{\circ} 85, p .69\right)$ », DUPENDANT, Jeanne «Cour de Cassation. Compétence du juge judiciaire - Contrôle de conventionnalité - Doctrine «Matter»-Hiérarchie des normes -Primauté du droit international - Réciprocité souveraineté -Union européenne (ordre juridique) », in PELLET, Allain et MIRON, Alina (dir.), Les grandes décisions de la jurisprudence française de droit international public, Dalloz, Paris, 2015, p. 95.

${ }^{1884}$ LUNDA Bululu, La conclusion des traités en droit constitutionnel zä̈rois. Etude de droit international et de droit interne, op.cit., pp. 234-235.

${ }^{1885}$ ALLAND, Denis, Manuel de droit international public, op.cit., pp. 207-208. Voy. aussi LOCHAK, Daniel, «Conseil d'Etat. Acte clair - Conventions internationales (interprétation) - Office du juge (interprétation) Question préjudicielle - Réciprocité », in PELLET, Allain et MIRON, Alina (dir.), Les grandes décisions de la jurisprudence française de droit international public, op.cit., p. 198.
} 
En RDC, 1'histoire institutionnelle révèle que le pays s'est inspiré, dès sa constitution du $1^{\mathrm{er}}$ août 1964 (article $9^{1886}$ ), de la constitution française de 1958, précisément de son article $55^{1887}$, en optant ainsi pour le monisme avec primat du droit international sur le droit interne voire sur la constitution ${ }^{1888}$. Mais ceci n'est pas suivi dans la pratique judiciaire congolaise. En effet, prompt à l'application du droit national, le juge congolais a été depuis longtemps très hésitant voire réticent dans l'application même des conventions internationales des droits de l'homme avec effet «self-executing ${ }^{1889}$. A la base, il a été relevé «l'ignorance du droit international des droits de l'homme par les magistrats et les avocats ${ }^{1890}$ congolais, l'absence de l'indépendance des magistrats, etc. ${ }^{1891}$ Toutefois, pour l'heure, « [les juges congolais] ont timidement commencé à se familiariser avec les normes du droit international en général et, de manière particulière, avec celles du droit international pénal et humanitaire, essentiellement celles découlant du Statut de Rome de la CPI ${ }^{1892}$. Et « [1]'application du Statut de Rome par les tribunaux congolais a fait l'objet d'une importante jurisprudence ${ }^{1893}$ (cf. infra). Cependant, il est attesté que la jurisprudence congolaise «a, dans la plupart des affaires analysées, interprété de manière fort douteuse les exigences contextuelles [des crimes internationaux]; et que cette interprétation contestable expose ces tribunaux au risque de confusion entre les crimes de droit international et ceux de droit commun ${ }^{1894}$.

Par ailleurs, la non-application de la réciprocité pour certaines obligations de caractère erga omnes peut bien se lire d'ailleurs dans l'Arrêt du 5 février 1970 de la Cour internationale de

1886 Article 9 de la Constitution de la République Démocratique du Congo du $1^{\text {er }}$ aout 1964 reprend in extenso l'article 55 de la Constitution française du 4 octobre 1955: «Les traités ou accords internationaux régulièrement ratifiés ont, dès leur publication, une autorité supérieure à celles des lois sous réserve, pour chaque traité ou accord, de son application par l'autre partie »Voy. Moniteur congolais, $5^{\mathrm{e}}$ année, numéro spécial du $1^{\mathrm{er}}$ août 1964, pp. 2-3, in http://www.droitcongolais.info/etat autorites_rdc.html (Source consultée le 24 novembre 2015).

1887 Article 55 de la Constitution française du 4 octobre 1958 (Texte originel) : «Les traités ou accords régulièrement ratifiés ou approuvés ont, dès leur publication, une autorité supérieure à celle des lois, sous réserve, pour chaque accord ou traité, de son application par l'autre partie »in http://www.senat.fr/evenement/revision/texte originel.html (Source consultée le 24 novembre 2015).

${ }^{1888}$ LUNDA BULULU, Vincent, « Les juridictions congolaises et l'application des conventions internationales relatives aux droits de l'homme », «art.cit.», pp. 986 et 991. Signifions que cette interprétation de LUNDA Bululu - que nous partageons au regard précisément des éléments résultant du droit international ici étayés par lui et des termes mêmes de l'article 215 précité - n'est tout de même pas admise par certains juristes congolais dont les publicistes internistes. Lesquels estiment que la Constitution a suprématie sur les traités et accords internationaux. Lire avec intérêt KAZADI MPIANA, Joseph, La Position du droit international dans l'ordre juridique congolais et l'application de ses normes, éd. Publibook, Paris, 2013, pp. 159-160. Par ailleurs, si la doctrine et la jurisprudence congolaises demeurent unanimement d'accord au sujet du monisme résultant de l'article 215 précité (Voy. KAZADI MPIANA, Joseph, La Position du droit international dans l'ordre juridique congolais et l'application de ses normes, op.cit., p. 16.), KAZADI MPIANA Joseph s'oriente dans l'approche dualiste en prenant pour cadre de référence notamment les articles 215 et 153, alinéa 4 de la Constitution en vigueur, la pratique et la jurisprudence congolaises de droit international dont essentiellement celle liée au Statut de Rome de la CPI (Voy. toute son étude, ou précisément ses conclusions pp.491-498).

${ }^{1889}$ LUNDA BULULU, Vincent, «Les juridictions congolaises et l'application des conventions internationales relatives aux droits de l'homme », « art.cit. », p. 992. Lire avec intérêt les pages 995-1004 de la même étude.

${ }^{1890}$ Ibid., p. 1002.

${ }^{1891}$ LUNDA BULULU, Vincent, « Les juridictions congolaises et l'application des conventions internationales relatives aux droits de l'homme », « art.cit. », p. 1002.

1892 KAZADI MPIANA, Joseph, La Position du droit international dans l'ordre juridique congolais et l'application de ses normes, op.cit., p. 15. Lire pour plus de détails et précisions à cette attitude, la deuxième partie de cette étude «L'application des normes de droit international en droit congolais », pp. 277- 489.

${ }_{1893}$ MBOKANI, Jacques B., «L'application du Statut de Rome par les Tribunaux congolais. Vers une banalisation de crimes de droit international ? », in RDIDC, 2014/1, p. 115.

${ }^{1894}$ Ibid., p. 113-114. 
justice dans 1'Affaire de la Barcelona Traction, Light and Power Company, Limited (Belgique c. Espagne): «33 (...) Une distinction essentielle doit en particulier être établie entre les obligations des Etats envers la communauté internationale dans son ensemble et celles qui naissent vis-à-vis d'un autre Etat (...). Par leur nature même, les premières concernent tous les Etats. Vu l'importance des droits en cause, tous les Etats peuvent être considérés comme ayant un intérêt juridique à ce que ces droits soient protégés; les obligations dont il s'agit sont des obligations erga omnes. 34. Ces obligations découlent par exemple, dans le droit international contemporain, de la mise hors la loi des actes d'agression et du génocide mais aussi des principes et des règles concernant les droits fondamentaux de la personne humaine, $(. . .)^{1895}$. Bien plus, dans son article 60 relatif à 1' «Extinction d'un traité ou suspension de son application comme conséquence de sa violation ${ }^{1896}$ précisément au paragraphe 5, la Convention de Vienne sur le droit des traités du 23 mai 1969 (entrée en vigueur le 27 janvier 1980) prévoit une non-application de l'exception d'inexécution de traités (Exceptio non adimpleti contractus) pour des dispositions conventionnelles se rapportant à la protection de la personne humaine contenues dans des traités à caractères humanitaires ${ }^{1897}$. Il s'agit des obligations objectives. En ce sens, elles sont absolues, autonomes ou inconditionnelles ${ }^{1898}$. A cet égard, le TPIY, dans l'affaire Le Procureur c. Zoran

${ }^{1895}$ Affaire de la Barcelona Traction, Light and Power Company, Limited (Belgique c. Espagne) du 5 février 1970 in Recueil de Jurisprudence en Droit international public http://www.arpia.be/public/droides/recueil.pdf (Recherches menées le 20 septembre 2012).

1896 Article 60.- Extinction d'un traité ou suspension de son application comme conséquence de sa violation : «1. Une violation substantielle d'un traité bilatéral par l'une des parties autorise l'autre partie à invoquer la violation comme motif pour mettre fin au traité ou suspendre son application en totalité ou en partie. 2. Une violation substantielle d'un traité multilatéral par l'une des parties autorise : a)les autres parties, agissant par accord unanime, à suspendre l'application du traité en totalité ou en partie ou à mette fin à celui-ci: i) soit dans les relations entre elles-mêmes et l'Etat auteur de la violation, ii) soit entre toutes les parties ; $b$ ) une partie spécialement atteinte par la violation à invoquer celle-ci comme motif de suspension de l'application du traité en totalité ou en partie dans les relations entre elle-même et l'Etat auteur de la violation c) toute partie autre que l'Etat auteur de la violation à invoquer la violation comme motif pour suspendre l'application du traité en totalité ou en partie en ce qui la concerne si ce traité est d'une nature telle qu'une violation substantielle de ses dispositions par une partie modifie radicalement la situation de chacune des parties quant à l'exécution ultérieure de ses obligations en vertu du traité. 3. Aux fins du présent article, une violation substantielle d'un traité est constitué par : a) un rejet du traité non autorisé par la présente convention; ou b) la violation d'une disposition essentielle pour la réalisation de l'objet ou du but du traité. 4. Les paragraphes qui précèdent ne portent atteinte à aucune disposition du traité applicable en cas de violation. 5. Les paragraphes 1 à 3 ne s'appliquent pas aux dispositions relatives à la protection de la personne humaine contenues dans des traités de caractère humanitaire, notamment aux dispositions excluant toute forme de représailles à l'égard des personnes protégées par lesdits traités.» https://reaties.un.org/pages/ViewDetailsIII.aspx?src=TREATY\&mtdsg no=XXIII-

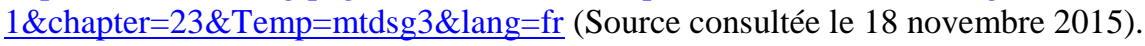

1897 ALLAND, Denis, Manuel de droit international public, op.cit., p. 206. Voy. LUNDA BULULU, Vincent, «Les juridictions congolaises et l'application des conventions internationales relatives aux droits de l'homme » «art.cit. », p. 1001.

1898 RIVIER, Raphaële, Droit international public, 2è édition, P.U.F, Paris, 2013, p. 7. Lire aussi DECAUX, Emmanuel, La Réciprocité en Droit international, op.cit., pp. 58-59. Ces obligations sont vues par Sir Gerald Fitzmaurice comme « obligations « intégrales », « autonomes », « absolues » et «intrinsèques » «pour chaque partie et ne dépendent pas d'une exécution correspondante par les autres parties » (Voy. RIVIER, Raphaële, Droit international public, op. cit., p. 7.) Cette classification de Sir Gerald Fitzmaurice, notamment la catégorie d'obligations intégrales, a été abandonnée par la Commission de Droit international «en raison de son défaut d'homogénéité ». Elle réunissait d'une part les sources internationale de droit interne (ex : conventions du travail ou des droits de l'homme) et d'autre part les textes à ranger dans le jus cogens (ex : onvention sur le génocide) (Voy. DECAUX, Emmanuel, La Réciprocité en Droit international, op. cit., p. 58) 
KUPRE[KI] et autres, déclare ce qui suit :

«[...] la plupart des normes du droit international humanitaire, notamment celles qui prohibent les crimes de guerre, les crimes contre l'humanité et le génocide, sont des normes impératives du droit international ou jus cogens, c'est-à-dire qu'elles sont impérieuses et qu'on ne saurait y déroger. L'une des conséquences de l'appartenance à cette classe est que, si les normes en question sont exprimées dans un traité, contrairement à la règle générale exposée à l'article 60 de la Convention de Vienne sur le droit des traités, la violation substantielle de cette obligation conventionnelle par l'une des parties ne saurait être invoquée par l'autre comme motif d'annulation ou de suspension de l'application du traité. L'article 60 5) précise que les dispositions relatives à la protection de la personne humaine contenues dans les traités de caractère humanitaire, notamment celles qui excluent toute forme de représailles à l'égard des personnes protégées par lesdits traités, font exception à cette réciprocité ou, en d'autres termes, que le principe inadimplenti non est adimplendum ne $s^{\prime}$ applique pas ${ }^{1899}$.

«Bien que n'étant pas une condition juridique d'application des règles humanitaires, depuis les Convention de Genève de 1949 et la Convention de Vienne sur le droit des traités, la réciprocité est un facteur de fait qui a joué un rôle primordial dans l'application du droit humanitaire en général $[\ldots]{ }^{1900}$.

Ainsi qu'on peut bien le comprendre, la RDC hérite du DIH et du DIDH les faiblesses et forces des dispositions étayées ci-avant.

Toutefois, au-delà des dispositions présentées ci-dessus, la RDC tente à sa manière d'assurer la protection des enfants en situation de conflits armés. Ceci répond - tant soit peu - à l'obligation qui lui incombe notamment en vertu de l'article $80 § 1$ du PA I qui dispose : «Les Hautes Parties contractantes et les parties au conflit prendront sans délai toutes les mesures nécessaires pour exécuter les obligations qui leur incombent en vertu des Conventions et du présent Protocole ». Bien plus, ceci rappelle en droit international général le principe «Pacta Sunt Servanda» - expressément consacré par la Convention de Vienne sur le droit des traités du 23 mai 1969 à laquelle les Etats parties aux conflits armés en RDC ont adhéré. Son article 26 consacre ce principe de la manière ci-après : «Tout traité en vigueur lie les parties et doit être exécuté par elles de bonne foi ». Par ailleurs, le fait pour la RDC de prendre des mesures législatives, réglementaires, administratives, ou autres pour assurer la mise en œuvre du DIH concourt le mieux avec les CG (article $1^{\text {er }}$ ) et le PA I (article $1^{\text {er }}$ ) qui obligent les Etats parties à ces conflit armés de respecter et de faire respecter les CG et le PA I en toutes circonstances (cf. supra). Cette obligation leur a été maintes fois rappelée par différentes résolutions du Conseil de Sécurité des Nations Unies (cf. infra) dont la résolution 1234 (1999) adoptée à la $3993^{\mathrm{e}}$ séance du Conseil de Sécurité, le 9 avril 1999 qui, à son paragraphe 6 «[d]emande à toutes les parties au conflit en République démocratique du Congo de défendre les droits de l'Homme et de respecter le DIH, en particulier les dispositions des Conventions de Genève de

1899 TPIY, Le Procureur c. Zoran KUPRE[KI], Mirjan KUPRE[KI], Vlatko KUPRE[KI], Drago JOSIPOVI], Dragan PAPI], Vladimir [ANTI], alias «VLADO », Affaire $\mathrm{N}^{\circ} \mathrm{IT}-95-16-\mathrm{T}$, La Chambre de première instance, Jugement rendu le 14 janvier 2000, p. 212, § 520.

${ }^{1900}$ VEUTHEY, Michel, Guérilla et Droit humanitaire, op.cit., p. 340. «Les Conventions de Genève écartent la réciprocité, sauf à l'article commun 2, alinéa 3, en prévoyant l'inaliénabilité des droits (art. 7 des CGI , CGII et CGIII ; art. 8 de la CG IV) et en interdisant les représailles (art. 46 de la CGI, 47 de la CG II, 13 de la CG III, 33 de la CG IV)»(Voy. VEUTHEY, Michel, Guérilla et Droit humanitaire, op.cit., p. 340). 
1949 et des Protocoles additionnels de 1977 et de la Convention sur la prévention et la répression du crime de génocide de 1948 qui leur sont applicables ${ }^{1901}{ }$.

En effet, il est d'un constat que la protection légale, judiciaire et sociale des enfants est extrêmement faible, voire inexistante en République Démocratique du Congo ${ }^{1902}$. Ce constat établi vis-à-vis des enfants en temps de paix en décembre 2004, vaut de même pour les enfants en période de conflits armés et demeure non moins valable à ce jour. Certes, il y a des tentatives d'amélioration dont la loi de 2009 sur la protection de l'enfant ou le plan d'action signé par la RDC le 04 octobre 2012 pour mettre fin au recrutement et à l'utilisation d'enfants soldats ainsi qu'aux violences sexuelles perpétrées par les FARDC (cf. infra). Toutefois, leur mise en œuvre reste encore problématique.

Différentes textes législatifs et réglementaires assurent la protection de l'enfant en situation de conflits armés en RDC. D'où, l'intérêt d'examiner préalablement l'état de la législation congolaise en matière de recrutement du personnel militaire (A) avant toute analyse sur le contenu même de sa protection de l'enfant en pleine période de conflits armés (B).

\section{A. De la réglementation de recrutement et de participation des enfants aux hostilités en RDC}

La législation en matière de recrutement du personnel militaire fixe différentes conditions dont celle liée à l'âge. Sur le plan constitutionnel, si l'Acte constitutionnel de la transition du 09 avril $1994^{1903}$ et le Décret-loi constitutionnel $n^{\circ} 003$ du 27 mai 1997 relatif à l'organisation et à l'exercice du pouvoir en République Démocratique du Congo ${ }^{1904}$, d'application en cette période d'étude, n'offrent pas un cadre de réglementation expresse de recrutement et de participation des enfants aux conflits armés, la Constitution de la transition du 04 avril 2003 tranche. Signifions au départ pour les deux premiers textes constitutionnels précités qu'il ne s'agit nullement d'un vide juridique car il se dégage du monisme consacré par l'article $112^{1905}$ de l'Acte constitutionnel de la transition du 09 avril 1994 que les instruments internationaux ratifiés par la RDC font partie du droit national congolais. Lesquels instruments dont certaines dispositions pourront être d'applicabilité directe si cellesci s'avèrent notamment complètes et précises ${ }^{1906}$ (ou encore claires, précises et

\footnotetext{
${ }^{1901}$ Résolution 1234 (1999) adoptée par le Conseil de sécurité à sa 3993e séance le 9 avril 1999, in MONUC, Résolutions adoptées par le Conseil de sécurité, 9 avril 1999 - 1 octobre 2004, Division de l'information publique de la MONUC, Kinshasa, 2004, p. 8.

1902 Bureau International Catholique pour l'Enfance, Section Protection de l'Enfant de la MONUC, Save The Children UK et UNICEF, La Protection légale et judiciaire des enfants en RDC. Problèmes centraux et propositions, Documents de discussion, décembre 2004, p. 3.

${ }_{1903}$ Voy. l'Acte constitutionnel de la transition du 09 avril 1994 in http://www.droitcongolais.info/etat autorites_rdc.html (Source consultée le 11 novembre 2015).

${ }^{1904}$ Voy. le Décret-loi constitutionnel $n^{\circ} 003$ du 27 mai 1997 relatif à l'organisation et à l'exercice du pouvoir en République Démocratique du Congo in http://www.droitcongolais.info/etat autorites_rdc.html (Source consultée le 11 novembre 2015).
}

1905 L'article 112 de l'Acte constitutionnel de la transition du 09 avril 1994 dispose : «Les traités et accords internationaux régulièrement ratifiés ou approuvés ont, dès leur publication, une autorité supérieure à celle des lois, sous réserve pour chaque traité ou accord, de son application par l'autre partie ».

${ }^{1906}$ LUNDA BULULU, Vincent, « Les juridictions congolaises et l'application des conventions internationales 
inconditionnelles) $^{1907}$.

Bien plus, comme il sera remarqué dans les lignes suivantes, le Décret-loi 001-2002 du 26 janvier 2002 portant organisation générale de la défense et des forces armées congolaises fixant à «plus de18 ans » l'âge de participation à la défense et à la mobilisation générale - sort ses effets à dater du 27 mai 1997 (cf. article 54).

En effet, suivant l'article 176 de la Constitution de la transition du 04 avril $2003^{1908}$ «Nul ne peut être recruté dans les forces de la Police nationale, ni prendre part à des guerres ou à des hostilités s'il n'a atteint l'âge de dix-huit ans révolus au moment du recrutement ». La même disposition se rapporte aux forces armées au niveau de l'article 184 en ces termes : "Nul ne peut être recruté dans les Forces armées de la République Démocratique du Congo ni prendre part à des guerres ou à des hostilités s'il n'a atteint l'âge de dix-huit ans révolus au moment du recrutement». Ces dispositions constitutionnelles se veulent conformes au Protocole facultatif à la Convention relative aux droits de l'enfant, concernant l'implication d'enfants dans les conflits armés du 25 mai 2000, lequel fixe à 18 ans l'âge d'enrôlement (article 2) et de participation directe aux hostilités (article $1^{\mathrm{er}}$ ). Et « la RDC en ratifiant [c]e Protocole, le 28 mars 2001, a déposé sa déclaration contraignante auprès du Secrétariat [...] des Nations Unies indiquant que l'âge minimum de l'engagement volontaire dans les forces armées est de 18 ans. Par conséquent, l'engagement volontaire des personnes âgées de moins de 18 ans tel que prévu à l'article 3 du Protocole n'existe pas ${ }^{1909}$. Déclaration faite également par d'autres Etats dont la République de l'Ouganda en juin $2002^{1910}$.

Ces dispositions constitutionnelles tirent également leur origine de l'Accord global et inclusif sur la transition en République Démocratique du Congo ${ }^{1911}$. Cet accord a bénéficié de la présence de la société civile (Forces vives), comme partie, lors de sa négociation. Rappelons que la société civile congolaise a été d'un apport positif dans le processus de paix en ce pays dès le début de conflits armés ${ }^{1912}$. Elle a pu organiser plusieurs rencontres et campagnes au plan interne et externe pour plaider la cause des personnes civiles en général et des enfants en particulier. Les parties à l'Accord global ont affirmé leur adhésion aux multiples instruments

relatives aux droits de l'homme », « art.cit. », p. 997.

${ }^{1907}$ Voy. pour plus d'approfondissement le paragraphe sur le Comité des droits de l'enfant, à la deuxième section du chapitre suivant.

1908 Voy. la Constitution de la transition $\mathrm{du} \quad 04 \quad$ avril 2003 http://www.droitcongolais.info/etat_autorites_rdc.html (Source consultée le 11 novembre 2015).

1909 Comité des droits de l'enfant, Examen des Rapports présentés par les Etats parties en application du paragraphe 1 de l'article 8 du Protocole facultatif à la Convention relative aux droits de l'enfant, concernant l'implication d'enfants dans les conflits armés, Rapports initiaux des Etats parties attendus en 2004, République Démocratique du Congo, CRC/C/OPAC/COD/1, 18 avril 2011, op. cit., p. 16, § 65.

${ }^{1910}$ Voy. Comité des droits de l'enfant, Examen des Rapports présentés par les Etats parties en application du paragraphe 1 de l'article 8 du Protocole facultatif à la Convention relative aux droits de l'enfant, concernant l'implication d'enfants dans les conflits armés, Observations finales:Ouganda, Quarante neuvième session,

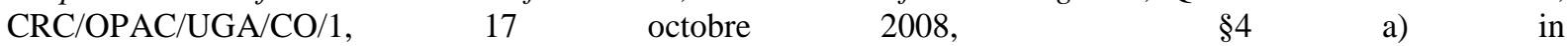
http://tbinternet.ohchr.org/ layouts/treatybodyexternal/Download.aspx?symbolno=CRC $\% 2 \mathrm{fC} \% 2 \mathrm{fOPAC} \% 2 \mathrm{fUG}$ A\%2fCO\%2f1\&Lang=en (Source consultée le 23 janvier 2016).

${ }^{1911}$ Accord global et inclusif sur la transition en République Démocratique du Congo, in Journal Officiel Numéro spécial-5 avril 2003 in http://www.droitcongolais.info/etat_autorites_rdc.html (Source consultée le 12 novembre 2015).

1912 Voy. BADIDIKE, Jean-Pierre (éd.), Guerre et droits de l'homme en République Démocratique du Congo. Regard du Groupe Justice et Libération, L'Harmattan-RDC, Kinshasa, 2009, pp. 110-111. 
des droits de l'homme ${ }^{1913}$ dont ceux protégeant les enfants. En cela, le respect des droits de l'homme devrait être un des principes régissant la transition. Ainsi, dans l'objectif de la «formation d'une armée nationale restructurée et intégrée » ${ }^{1914}$, l'armée congolaise devrait logiquement être respectueuse de nombreuses conventions internationales protégeant notamment les enfants. C'est le sens même de l'armée républicaine que donne la Loi $n^{\circ} 04 / 023$ du 12 novembre 2004 portant organisation générale de la défense et des Forces armées $^{1915}$. Ce qui concorde d'ailleurs le mieux avec 1'article 27 du Décret-loi 001-2002 du 26 janvier 2002 portant organisation générale de la défense et des Forces armées congolaises $^{1916}$ qui présente l'armée congolaise comme mécanisme de mise en œuvre des conventions internationales. Ce qui vaut de même pour l'accomplissement des missions humanitaires comme le veut la Loi $n^{\circ} 04 / 023$ du 12 novembre 2004 portant organisation générale de la défense et des Forces armées (cf. article 42). La consécration constitutionnelle ci-dessus détaillée est donc une manière élevée de mettre définitivement fin aux souffrances dont sont victimes les enfants durant les « deux guerres de libération » en RDC.

En revanche, on ne trouve pas trace des dispositions constitutionnelles précitées dans l'actuelle constitution. Seul son article 190 dispose que « [n]ul ne peut, sous peine de haute trahison [...] entretenir une jeunesse armée ». Pour le reste, ladite constitution se contente d'indiquer que des lois organiques fixeront l'organisation et le fonctionnement de la Police nationale et des Forces armées ${ }^{1917}$.

Il existe en outre des textes législatifs qui traitent de la question de recrutement et de participation des enfants aux conflits armés ou hostilités. Ainsi, se référant à la loi 81-003 du 17 juillet 1981 portant statut du personnel de carrière de services publics de l'Etat, encore en vigueur, en son article $1^{\mathrm{er}}$, "l'ensemble du personnel civil et militaire ouvrant au sein des forces armées zä̈roises et à la gendarmerie nationale ${ }^{1918}$ fait partie des Services publics de l'Etat et se voit appliquer cette loi. Et au regard de l'article $8 \S 4$ de ladite loi, il faudrait un minimum d'âge de 16 ans pour être recruté comme agent de carrière. A côté de cette loi générale d'application, des lois spéciales légifèrent le secteur militaire et fixent là encore des conditions spécifiques dont celle de l'âge.

Ainsi, il importe de reprendre quelques unes à titre historique avant d'aboutir à la situation

\footnotetext{
${ }^{1913}$ Lire le point 3 « II Des objectifs de la transition », in Accord global et inclusif sur la transition en République Démocratique du Congo in Journal Officiel -Numéro spécial-5 avril 2003 in http://www.droitcongolais.info/etat autorites_rdc.html (Source consultée le 12 novembre 2015).

${ }^{1914}$ Ibid., Lire le point 3 « III Des Principes de la transition »

${ }^{1915}$ L'article $3 \$ 21$ de cette loi dispose «L'armée républicaine est celle qui, respectueuse des lois et des institutions de la République, est soumise à l'autorité civile»

${ }^{1916}$ L'article 27 dispose : "Pour la défense de la République et le respect des traités et accords internationaux, il est créé une armée nationale dénommée «Forces armées congolaises», «F.A.C.» en sigle ».
}

1917 Voy. les articles 186 et 191 de la Constitution de la République Démocratique du Congo modifiée par la loi $n^{\circ} 11 / 002$ du 20 janvier 2011 portant révision de certaines articles de la Constitution de la République Démocratique du Congo du 18 février 2006 (Textes coordonnés), in Journal officiel spécial,-5 février 2011, disponible sur http://www.droitcongolais.info/etat_autorites_rdc.html (Source consultée le 12 novembre 2015). ${ }^{1918}$ Article $1^{\text {er }}$ de la Loi 81-003 du 17 juillet 1981 portant statut du personnel de carrière de services publics de l'Etat, in http://www.leganet.cd/Legislation/Droit\%20administratif/Agents/L.81.003.17.07.1981.htm (Source consultée le 11 novembre 2015). 
actuelle. En effet, l'Ordonnance $n^{\circ} 60$ portant création d'une académie militaire du 07 mai 1962 fixe à 18 ans, l'âge minimal pour être admis à l'Académie militaire (article 6) ${ }^{1919}$. Ceci est actuellement d'application. Si l'Ordonnance-loi $n^{\circ} 66-445$ du 16 août 1966 portant création d'un Service civique obligatoire n'indique pas expressément les conditions d'âges, il $\mathrm{y}$ a lieu tout de même de penser à un minimum d'âge de 18 ans au regard des conditions établies en son article 3. Il s'agit d' « une forme spéciale du service militaire » (article $1^{\mathrm{er}}$ ) impliquant obligatoirement les jeunes intellectuels, au niveau d'études supérieures et universitaires $^{1920}$.

Le Décret-loi 001-2002 du 26 janvier 2002 portant organisation générale de la défense et des forces armées congolaises d'application rétroactive dès le 27 mai 1997 fixe à «plus de 18 ans ${ }^{1921}$ l'âge à partir duquel tout congolais peut être réquisitionné pour prendre part à la défense ou à la mobilisation générale. Au sens de l'article $1^{\mathrm{er}}$ de ce Décret-loi «La défense a pour objet d'assurer en tout temps, en toutes circonstances et contre toutes les formes d'agression, la sécurité et l'intégrité du territoire, ainsi que la vie de la population ${ }^{1922}$. Et pour l'article 5 du même Décret-loi «La mobilisation générale consiste dans la mise en ceuvre et l'utilisation de toutes les Forces et ressources du pays ${ }^{1923}$. A l'heure des Forces Armées de la République Démocratique du Congo (FARDC) ${ }^{1924}$, la Loi $n^{\circ} 04 / 023$ du 12 novembre 2004 portant organisation générale de la défense et des Forces armées reconduit le contenu (l'âge de dix-huit ans révolus) de l'article 7 précité en son article $7^{1925}$. Au final, tout ceci devait mener à la Constitution congolaise à définir l'enfant pour la première fois. Ainsi, la Constitution de la RDC du 18 février 2006 en son article 41, alinéa 1, dispose que «L'enfant mineur est toute personne, sans distinction de sexe, qui n'a pas encore atteint 18 ans révolus ${ }^{1926}$. Ce qui va d'ailleurs dans le même sens que le Code de la famille en son

1919 Ordonnance $\mathrm{n}^{\circ} 60$ portant création d'une académie militaire, $3^{\mathrm{e}}$ année, $\mathrm{n}^{\circ} 17$ du 23 juillet 1962 in http://www.leganet.cd/Legislation/Droit\%20administratif/Agents/L.81.003.17.07.1981.htm (Source consultée le 11 novembre 2015).

${ }^{1920}$ Ordonnance-loi $n^{\circ} 66-455$ du 16 août 1966 portant création d'un service civique obligatoire in Moniteur Congolais $\mathrm{n}^{\circ} 23 \mathrm{du}$ 15-12-1966, 855 in http://www.droitcongolais.info/iv.-defense-nationale---securite---ordrepublic.html (Source consultée le 11 novembre 2015).

${ }^{1921}$ L'article 7 du Décret-loi 001-2002 du 26 janvier 2002 portant organisation générale de la défense et des forces armées congolaises dispose : «En cas de mobilisation ou dans les cas prévus par l'article ler du présent décret-loi, les Congolais de deux sexes, âgés, de plus de 18 ans, peuvent être réquisitionnés dans les conditions fixées par la loi ».

${ }^{1922}$ Article $1^{\mathrm{er}}$ du Décret-loi 001-2002 du 26 janvier 2002 portant organisation générale de la défense et des forces armées congolaises in http://www.droitcongolais.info/iv.-defense-nationale---securite---ordre-public.html (Source consultée le 12 novembre 2015).

${ }^{1923}$ Article 5 du Décret-loi 001-2002 du 26 janvier 2002 portant organisation générale de la défense et des forces armées congolaises in http://www.droitcongolais.info/iv.-defense-nationale---securite---ordre-public.html (Source consultée le 12 novembre 2015).

${ }^{1924}$ Pour cette nouvelle dénomination voir l'article 178 de la Constitution de la transition du 04 avril 2003 et l'article 40 de Loi $n^{\circ} 04 / 023$ du 12 novembre 2004 portant organisation générale de la défense et des Forces armées

${ }^{1925}$ L'article 7 de Loi $n^{\circ} 04 / 023$ du 12 novembre 2004 portant organisation générale de la défense et des Forces armées dispose «En cas de mobilisation, les congolais des deux sexes, âgés de 18 ans révolus, peuvent être réquisitionnés dans les conditions fixées par la loi », in http://www.droitcongolais.info/iv.-defense-nationale--securite---ordre-public.html (Source consultée le 12 novembre 2015).

1926 Constitution de la République Démocratique du Congo du 18 février 2006 in http://www.droitcongolais.info/etat autorites_rdc.html (Source consultée le 12 novembre 2015). 
article $219^{1927}$ et le renforce en même temps. L'âge de dix-huit ans est également retenu par des principaux Etats parties aux conflits armés en RDC. Par exemple, la Loi 27/2001 relative aux droits et à la protection de l'enfant contre les violences du 28 avril 2001 de la République du Rwanda dispose en son article 19: "Le Service militaire est interdit pour les enfants de moins de dix huit ans ${ }^{1928}$. Et la Constitution rwandaise du 04 juin 2003 insiste en son article 28 sur des «mesures spéciales de protection » qu'exige la condition d'enfant conformément aux droits national et international ${ }^{1929}$. Pour sa part, la République de l'Ouganda avait adopté en 2005, une loi sur les forces de défenses populaires interdisant l'enrôlement de mineur de moins dix huit ans dans les forces armées ${ }^{1930}$ et une loi relative aux enfants en $2000^{1931}$. Du côté des groupes armés, il y a lieu de noter, par exemple, le décret pris par le RCD Goma en décembre 2001 interdisant le recrutement et l'utilisation des enfants de moins de dix-huit ans dans ses rangs ${ }^{1932}$. Il signera même un plan d'action avec l'UNICEF pour la démobilisation de 2600 enfants de ses rangs. Seuls 104 enfants seront remis à l'UNICEF et agences associées pour être finalement ré-enrôlés ${ }^{1933}$.

Il va sans dire que le standard de protection contre le recrutement et l'utilisation d'enfants en conflits armés en RDC est de dix huit ans pour les Etats parties précités. Toutefois, en dépit de ces interdictions dans leur arsenal juridique interne, ces trois Etats - RDC, Ouganda et Rwanda (et les groupes armés) - ont recouru quotidiennement, voire à ce jour, au recrutement et à l'utilisation d'enfants dans leurs forces armées respectives comme le déplorent les différentes Observations finales leur adressées par le Comité des droits de 1'enfant ${ }^{1934}$.

1927 L'article 219 du Code de la famille : «Le mineur est l'individu de l'un ou de l'autre sexe qui n'a pas encore l'âge de dix-huit ans accomplis». Voy. Loi n॰87-10 portant Code de la famille, $1^{\text {er }}$ août 1987 in http://www.leganet.cd/Legislation/Code\%20de\%20la\%20famille/Table.htm (Source consultée le 21 décembre 2015).

${ }^{1928}$ République du Rwanda, Loi 27/2001 relative aux droits et à la protection de l'enfant contre les violences du 28 avril 2001 disponible

http://www.ilo.org/dyn/natlex/natlex4.detail?p_lang=en\&p isn=71584\&p_country=RWA\&p_count=310

(Source consultée le 23 janvier 2016).

1929 Voy. l'article 28 de la Constitution du Rwanda du 04 juin 2003 in http://www.ilo.org/dyn/natlex/natlex4.detail?p_lang=en\&p_isn=64236 (Source consultée le 23 janvier 2016).

1930 Comité des droits de l'enfant, Examen des Rapports présentés par les Etats parties en application du paragraphe 1 de l'article 8 du Protocole facultatif à la Convention relative aux droits de l'enfant, concernant l'implication d'enfants dans les conflits armés, Observations finales: Ouganda, Quarante neuvième session, CRC/OPAC/UGA/CO/1, 17 octobre 2008, op. cit., \$4 a).

1931 Comité des droits de l'enfant, Examen des Rapports présentés par les Etats parties en application de l'article 44 de la Convention, Observations finales : Ouganda, Quarantième session, Genève, 12-30 septembre 2005, $\quad \mathrm{CRC} / \mathrm{C} / \mathrm{UGA} / \mathrm{CO} / 2, \quad 23 \quad$ novembre $\quad 2005, \quad \S 4, \quad 1, \quad$ in http://tbinternet.ohchr.org/_layouts/treatybodyexternal/Download.aspx?symbolno=CRC $\% 2 \mathrm{fC} \% 2 \mathrm{fUGA} \% 2 \mathrm{fCO} \%$ 2f2\&Lang=en (Source consultée le 22 janvier 2016).

1932 Amnesty international, RDC - Enfants en guerre, AFR 62/034/2003, op. cit., pp. 21-22. Voy. aussi BODINEAU, Sylvie, Rapport d'Evaluation du programme 2007-2011 pour les Enfants associés aux Forces et aux Groupes Armés en RDC, UNICEF RDC, Mai-juin 2011, p. 10.

${ }^{1933}$ Amnesty international, RDC - Enfants en guerre, op.cit., pp. 21-22. Cette « démobilisation » était « tout un exercice des relations publiques visant à renforcer la position du RCD Goma au cours de négociation », Voy. Amnesty international, RDC-Enfants en guerre, op.cit., p. 22.

${ }^{1934}$ Voy. par l'exemple pour la République de l'Ouganda Comité des droits de l'enfant, Examen des Rapports présentés par les Etats parties en application de l'article 44 de la Convention, Observations finales : Ouganda, Quarantième session, Genève, 12-30 septembre 2005, CRC/C/UGA/CO/2, 23 novembre 2005, pp. 13 et 14, 
Par ailleurs, la RDC s'est dotée d'un Code du travail qui s'est inspiré notamment de la Convention ( $\left.n^{\circ} 182\right)$ concernant l'interdiction des pires formes de travail des enfants et l'action immédiate en vue de leur élimination du 17 juin 1999 (entrée en vigueur le 19 novembre 2000). Convention que la RDC a ratifiée le 20 juin 2001. Chose faite également par les Républiques du Rwanda et de l'Ouganda. Ainsi, la Loi $n^{\circ} 015 / 2002$ du 16 octobre 2002 portant Code $d u$ travail en $\mathrm{RDC}^{1935}$ reprend en son article $3 a^{1936}$ les dispositions correspondant à l'article $3 a$ de la Convention $\left(n^{\circ} 182\right)$. En ce sens, «le recrutement forcé ou obligatoire des enfants en vue de leur utilisation dans des conflits armés » est appréhendé comme une des pires formes de travail des enfants qui se trouvent abolies par ladite loi. L'adoption d'une telle disposition qui intervient l'année suivant la ratification par la RDC de la Convention ( $\left.{ }^{\circ} 182\right)$ s'inscrit dans la logique de l'article $1^{\mathrm{er}}$ de celle-ci. Cet article $1^{\mathrm{er}}$ dispose: "Tout membre qui ratifie la présente convention doit prendre des mesures immédiates et efficaces pour assurer l'interdiction et l'élimination des pires formes de travail des enfants et ce, de toute urgence ». C'est encore dans cette optique que la Loi $n^{\circ} 015 / 2002$ du 16 octobre 2002 portant Code du travail institue un Comité National de lutte contre les pires formes de travail des enfants (cf. article 4).

En 2009, il y a eu la promulgation de la loi $\mathrm{n}^{\circ} 09 / 001 \mathrm{du} 10$ janvier 2009 portant protection de l'enfant. Type de loi qu'ont adoptée également les Républiques de l'Ouganda et du Rwanda respectivement en 2000 et en 2001. L'article 71 de cette loi interdit l'enrôlement et la participation des enfants aux hostilités en ces termes : "[1]'enrôlement et l'utilisation des enfants dans les forces et groupes armés ainsi que dans la Police sont interdits. L'Etat assure la sortie de l'enfant enrôlé ou utilisé dans les forces et groupes armés ainsi que dans la Police et sa réinsertion en famille ou en communauté ${ }^{1937}$. Et son article 187, alinéa 2, dispose : «[...] l'enrôlement ou l'utilisation des enfants âgés de moins de dix-huit ans dans les forces et groupes armés et la police sont punis de dix à vingt ans de servitude pénale principale ${ }^{1938}$.

Ceci appelle quelques commentaires. L'article 71 en interdisant l'enrôlement et l'utilisation

$\S \S 65$ et 67 ; Pour la République du Rwanda, Voy. Comité des droits de l'enfant, Examen des Rapports présentés par les Etats parties en application de l'article 44 de la Convention, Observations finales: Rwanda, $\mathrm{CRC} / \mathrm{C} / 15 / A d d .234$, Trente-sixième session, $1^{\text {er }}$ juillet 2004, p. 2, $\$ 5$ et p. 15, 662 , in http://tbinternet.ohchr.org/ layouts/treatybodyexternal/Download.aspx?symbolno=CRC $\% 2 \mathrm{fC} \% 2 \mathrm{f} 15 \% 2 \mathrm{fAdd} .23$ 4\&Lang=en (Source consultée le 22 janvier 2016).

1935 Loi $n^{\circ} 015 / 2002$ du 16 octobre 2002 portant Code du travail in Journal Officiel de la République Démocratique du Congo, numéro spécial, 43 e année, 25 octobre 2002, 95 p.

${ }^{1936}$ Article 3 :

«Toutes les pires formes de travail des enfants sont abolies.

L'expression « les pires formes de travail des enfants » comprend notamment:

a) toutes les formes d'esclavage ou pratiques analogues, telles que la vente et la traite des enfants, la servitude pour dettes et le servage ainsi que le travail forcé ou obligatoire, y compris le recrutement forcé ou obligatoire des enfants en vue de leur utilisation dans des conflits armés; »

1937 Lire l'article 71 la Loi $n^{\circ} 009 / 01$ du 10 janvier 2009 portant Protection de l'enfant in http://www.leganet.cd/Legislation/JO/2009/L.09.001.10.01.09.htm\#TV (Source consultée le 10 janvier 2016).

${ }^{1938}$ Ibid., lire l'article 187. 
des enfants (voire d'autres dispositions similaires) dans les forces et groupes armés ainsi que dans la Police semble offrir une protection plus avantageuse à l'enfant. En effet, il faut au départ signifier qu'est enfant toute personne âgée de moins de 18 ans (cf. son article 2 point 1). En conformité d'ailleurs avec l'article 41, alinéa 1, de la constitution du 18 février 2006 précité. En clair, l'enrôlement et l'utilisation des personnes de moins de 18 ans reste interdite au sein des forces armées régulières tout comme au sein des groupes armés opérant en RDC. Cette interdiction s'étend également à la Police. Cette prescription implique des obligations non seulement négatives mais aussi positives. Il revient donc à l'Etat congolais de s'abstenir à l'enrôlement et à l'utilisation des enfants dans ses forces armées ou sa Police. En même temps, il doit déployer différents mécanismes pour rendre cette disposition applicable notamment en veillant à ce qu'aucun enfant ne soit enrôlé ou utilisé par ses forces armées ou des groupes armés opérant sur son territoire et la Police. Au regard notamment de l'exposé des motifs de ladite loi qui vise notamment à cultiver en l'enfant les valeurs de solidarité, de tolérance, de paix et de respect mutuel $(\ldots)^{1939}$, l'interprétation téléologique ne nous permettrait pas de créer une distinction entre enrôlement qui est un recrutement dit «volontaire » et la conscription -recrutement obligatoire ou forcé ${ }^{1940}$ afin d'arguer que cette dernière ne serait pas interdite (cf. les définitions fournies au chapitre $1^{\mathrm{er}}$ de la $1^{\text {ère }}$ partie de la thèse). Bien plus, cet article fait un rappel de l'article $4 \S 1$ du Protocole facultatif se rapportant à la Convention relative aux droits de l'enfant concernant l'implication d'enfants dans les conflits armés qui dispose : «[1]es groupes armés qui sont distincts des forces armées d'un Etat ne devraient en aucune circonstance enrôler ni utiliser dans les hostilités des personnes âgées de moins de 18 ans » (nous soulignons). Ici, l'obligation est faite aux groupes armés de ne pas effectuer l'enrôlement volontaire et obligatoire (ou forcé). Seul l'enrôlement obligatoire et non volontaire est reconnu aux Etats parties. L'article 2 du même protocole s'exprime comme suit : «Les Etats parties veillent à ce que les personnes n'ayant pas atteint l'âge de 18 ans ne fasse pas l'objet d'un enrôlement obligatoire dans leurs forces armées » (nous soulignons). Ceci pour dire que le terme "enrôler» utilisé dans l'article 71 de la loi $\mathrm{n}^{\circ}$ 09/001 du 10 janvier 2009 portant protection de l'enfant prendrait le sens d'enrôlement obligatoire (ou forcé) et d'enrôlement volontaire. Cet article constitue une avancée par rapport au droit international existant et place finalement sur pied d'égalité - contrairement à ce que prévoyait l'article 4 du Protocole facultatif - les forces armées étatiques et les groupes armés. Et les termes utilisés pour exprimer ces obligations ne sont pas réducteurs comme ceux du Protocole facultatif (cf. supra), et engagent des obligations de résultats à l'endroit de la RDC et des groupes armés.

En outre, l'article 71, contrairement aux enseignements précédents reçus en DIH, interdit l'enrôlement et utilisation des enfants dans les forces ou groupes armés et la police en temps de paix et de conflits armés. Et la participation des enfants aux conflits armés est interdite

\footnotetext{
${ }^{1939}$ Ibid., lire l'exposé de motifs.

${ }^{1940}$ Sur ces notions lire Magali MAYSTRE, op.cit., p.25. S'agissant du débat sur les concepts : conscription, enrôlement et recrutement d'enfants, le statut de Rome a préféré les termes "conscription » et " enrôlement » à celui de "recrutement 》. La Chambre est d'avis que la « conscription » et "l'enrôlement » sont deux formes du recrutement, la "conscription» constituant un recrutement forcé tandis que "l'enrôlement» se réfère davantage à un recrutement volontaire. La Chambre souligne à cet égard qu'il s'agit là d'une distinction qui a également été opérée par le juge Robertson dans son opinion individuelle jointe à l'arrêt rendu par la Chambre d'appel du Tribunal spécial pour la Sierra Leone le 31 mai 2004 dans l'affaire Le Procureur C; Sam Hinga Norman, in HABIBU Jean Bosco, op.cit., pp. 51-52.
} 
sous toutes ses formes - directe ou indirecte. Sur la base de cet article, l'on ne concevrait pas le phénomène des enfants soldats messagers, cuisiniers, espions, etc. Cet article semble encore plus intéressant pour l'enfant-soldat dans la mesure où il prévoit des dispositions relatives à sa démobilisation et à sa réinsertion en famille ou en communauté. Il abroge ainsi différents textes y relatifs dont le Décret-loi $n^{\circ} 066 / 2000$ du 09 juin 2000 portant démobilisation et réinsertion des groupes vulnérables présents au sein des forces combattantes $^{1941}$ par lequel le gouvernement congolais avait manifesté son intention de démobiliser tous les enfants de moins de dix-huit ans se trouvant dans les forces armées congolaises ou dans tout groupe armé (articles $1^{\text {er }}$ et 2 dudit Décret-loi). Ce Décret-loi a été non suivi d'effets pratiques dans différentes zones de combat.

Par ailleurs, au-delà de ces interdictions, le recrutement et l'utilisation d'enfants font l'objet d'incrimination. Celle-ci sera donc analysée notamment sous l'angle de la Loi n024/2002 du 18 novembre 2002 portant Code pénal militaire et de la Loi n ${ }^{\circ} 09 / 001$ du 10 janvier 2009 sur la protection de l'enfant (cf. dernière section du dernier chapitre).

\section{B. Droit congolais protégeant spécialement l'enfant en période de conflits armés : la loi $n^{\circ} 09 / 001$ du 10 janvier 2009 portant protection de l'enfant}

Ainsi, suite aux critiques et pressions faites par des ONG nationales et internationales des droits humains et eu égard au fait que ce pays regorgeait (ou regorge) d'un grand nombre d'enfants soldats, soit une estimation généralement formulée autour de $10 \%$ d'enfants soldats du monde, il a été plus que nécessaire d'adopter une loi spécifique liée à la protection de l'enfant. Il s'agit de la loi n09/001 du 10 janvier 2009 portant protection de l'enfant. Signifions dorénavant que les différentes législations étudiées ci-avant rentrent également dans le cadre de la protection de l'enfant.

Par rapport aux enfants en situation de conflits armés, l'article 2, paragraphe 5, de la loi sous examen, les qualifie d'enfant en situation exceptionnelle. Et celui-ci est entendu au sens de cet article comme «enfant en situation de conflits armés, de tensions ou de troubles civils, de catastrophes naturelles ou de dégradation sensible et prolongée des conditions socioéconomiques ${ }^{1942}$. En cela, l'enfant en situation exceptionnelle mérite une protection aussi exceptionnelle comme il se trouve bien indiqué au Chapitre 3 de ladite loi. Ici, trois articles protègent les enfants en conflits armés à savoir les articles 71, 72 et 73. L'article 71 se présente comme suit : «[...] [1]'Etat assure la sortie de l'enfant enrôlé ou utilisé dans les forces et groupes armés ainsi que dans la Police et sa réinsertion en famille ou en communauté » ${ }^{1943}$. L'article 72 dispose quant à lui que «L'Etat garantit la protection, l'éducation et les soins nécessaires aux enfants affectés par les conflits armés, les tensions ou troubles civils, spécialement à ceux trouvés et non identifiés par rapport à leur milieu famille. Cette disposition s'applique également à l'enfant déplacé par suite d'une catastrophe

\footnotetext{
1941 http://www.leganet.cd/Legislation/Droit\%20Public/Defense/DL.066.09.06.00.htm (Source consultée le 30 octobre 2015).

${ }^{1942}$ Lire l'article 2, paragraphe 5, de la Loi n009/01 du 10 janvier 2009 portant Protection de l'enfant in http://www.leganet.cd/Legislation/JO/2009/L.09.001.10.01.09.htm\#TV (Source consultée le 10 janvier 2016)

${ }^{1943}$ Ibid., lire l'article 71 .
} 
naturelle ou d'une dégradation des conditions socio-économiques ${ }^{1944}$. Cette disposition s'apparente à l'article 23 de la Loi rwandaise $n^{\circ} 27 / 2001$ relative aux droits et à la protection de l'enfant contre les violences du 28 avril 2001 qui dispose en son article 23 que "L'enfant doit être protégé et secouru en premier lieu et spécialement en temps de catastrophe et de guerre ${ }^{1945}$. Il s'agit donc d'une disposition qui prend globalement en compte les enfants dont les «enfants civils » et insiste sur des mesures spéciales «nécessaires » à leur état. Ce qui paraît beaucoup plus exigeant de la part de l'Etat. Enfin, son article 73 renseigne que «[1]'Etat assure la réadaptation et la réinsertion de l'enfant en situation difficile et/ou exceptionnelle ${ }^{1946}$.

Les dispositions ci-dessus présentées appellent quelques commentaires. En effet, l'article 2, paragraphe 5 de la même loi définissant l'enfant en situation exceptionnelle a l'avantage d'être large. Il étend cette notion à des enfants relevant du domaine de DIH et du droit des droits de l'homme. La conséquence logique serait donc de faire appel à d'innombrables instruments juridiques de ces branches respectives pour assurer une protection plus efficace. Toutefois, bien que leurs droits soient violés suivant qu'ils soient enfants en situation de conflits armés, de tensions ou de troubles civils, de catastrophes naturelles ou de dégradation sensible et prolongée des conditions socio-économiques ${ }^{1947}$, il est certain qu'ils ne partagent pas tous les mêmes réalités. D'où l'importance de la spécificité devant être prise en compte en principe par cette loi.

A propos de la partie de l'article 71 ici reprise, des mesures positives doivent être prises par l'Etat congolais pour la rendre effective. C'est le cas notamment du programme DDR assuré - à la suite du Décret-loi $n^{\circ} 066 / 2000$ du 09 juin 2000 portant démobilisation et réinsertion des groupes vulnérables présents au sein des forces combattantes au niveau national- par 1'Unité d'Exécution du Programme National de Désarmement, Démobilisation et Réinsertion (UEPN-DDR), créée par l'Ordonnance n07/057 du 14 juillet 2007 en remplacement de la Commission Nationale de Désarmement, Démobilisation et de Réinsertion (CONADER, créée par décret $n^{\circ}$ 03/042 du 18 décembre 2003). Elle-même remplaçante du Bureau National pour la Démobilisation et la Réinsertion (BUNADER, créé par l'arrêté nº01/2001 du 13 janvier 2001). Cette Unité travaille en étroite collaboration avec l'UNICEF, la MONUSCO et le $\mathrm{CICR}^{1948}$ (cf. infra).

\footnotetext{
1944 Ibid., Lire l'article 72.

1945 Article 23 de Loi 27/2001 relative aux droits et à la protection de l'enfant contre les violences du 28 avril 2001 (Rwanda) disponible sur

http://www.ilo.org/dyn/natlex/natlex4.detail?p_lang=en\&p_isn=71584\&p_country=RWA\&p_count=310 (Source consultée le 23 janvier 2016).

1946 Lire l'article 73 la Loi $n^{\circ} 009 / 01$ du 10 janvier 2009 portant Protection de l'enfant in http://www.leganet.cd/Legislation/JO/2009/L.09.001.10.01.09.htm\#TV (Source consultée le 10 janvier 2016).

${ }^{1947}$ Lire l'article 2, paragraphe 5, de la Loi $n^{\circ} 009 / 01$ du 10 janvier 2009 portant Protection de l'enfant in http://www.leganet.cd/Legislation/JO/2009/L.09.001.10.01.09.htm\#TV (Source consultée le 10 janvier 2016).

${ }^{1948}$ Voy. Comité des droits de l'enfant, Examen des Rapports présentés par les Etats parties en application du paragraphe 1 de l'article 8 du Protocole facultatif à la Convention relative aux droits de l'enfant, concernant l'implication d'enfants dans les conflits armés, Rapports initiaux des Etats parties attendus en 2004, République Démocratique $d u$ Congo, CRC/C/OPAC/COD/1, 18 avril 2011, pp. 22 et 24, §§93-94 et 98, http://tbinternet.ohchr.org/_layouts/treatybodyexternal/TBSearch.aspx?Lang=en\&TreatyID=5\&TreatyID=10\&T reatyID=11\&DocTypeID=29\&DocTypeCategoryID=4 (Source consultée le 20 décembre 2015).
} 
Concernant l'article 72, il revient de constater qu'il indique à l'Etat de prendre des mesures nécessaires et non possibles pour répondre aux besoins des enfants affectés par les conflits armés. Ces mesures sont celles liées au but ou mieux aux besoins de l'enfant et non aux moyens disponibles par le débiteur qui est l'Etat.

Il ressort de ces dispositions une protection plus avantageuse de l'enfant en situation de conflits armés. La loi n09/001 du 10 janvier 2009 évoque des obligations de résultat et non de moyen. Lesquelles sont d'ailleurs absolues. Toutefois, aucun mécanisme adéquat n'est prévu pour assurer la mise en œuvre de cette protection spéciale sur le champ de bataille ou zones de conflit.

En conclusion, la Protection exceptionnelle ou plus précisément la protection de l'enfant en situation de conflits armés assurée par le droit congolais reste problématique. Si la législation semble apporter un éclairage certain par rapport à l'interdiction de l'enrôlement et de l'utilisation des enfants dans les forces, groupes armés ou la police, voire leur criminalisation (article 187 de la loi $n^{\circ} 09 / 001$ du 10 janvier 2009 portant protection de l'enfant), rien ne semble être dit sur les mécanismes ou organes devant veiller sur cette protection (cf. infra). Bien plus, la question de la protection des enfants sur le champs de bataille, mieux en pleines hostilités, ne semble pas être abordée. L'article 72, alinéa 1, de la loi n09/001 du 10 janvier 2009 portant protection de l'enfant dispose simplement que «[1]'Etat garantit la protection, l'éducation et les soins nécessaires aux enfants affectés par les conflits armés, les tensions ou troubles civils, spécialement à ceux trouvés et non identifiés par rapport à leur milieu famille ». Ainsi, le droit congolais de la protection de l'enfant en situation de conflits armés tombe dans les pièges du DIH et du DIDH.

A dire vrai, la logique « réaliste » du DIH consistant à réglementer un comportement et son contraire à la fois n'est pas suivie. Il y a lieu de rappeler par exemple l'article 77 du PA I, comme d'autres dispositions similaires, qui interdit le recrutement et la participation directe des enfants aux hostilités tout en légiférant la situation du non respect de cette interdiction, bien que de manière conditionnelle et limitée. Cette logique n'est pas ici suivie. Ce qui vaut également pour d'autres Etats parties aux conflits armés en RDC. A cet égard, mentionnons à titre illustratif, le cas de la République du Rwanda qui, dans un de ses rapports soumis au Comité des droits de l'enfant, qualifiait de «sans objet» la définition de «participation directe » des enfants aux hostilités au motif que « la législation rwandaise interdit le service militaire pour les enfants (arrêté présidentiel no 72/01 et loi n ${ }^{\circ} 27 / 2001$ susmentionnés) ${ }^{1949}$. Ceci est caractérisé, selon elle, « aussi bien dans la législation que dans la pratique ${ }^{1950}$. Il va sans dire que la RDC et d'autres Etats s'attèlent simplement à l'interdiction de recrutement et de participation des enfants aux hostilités. Ainsi, légiférer les situations de participation des

\footnotetext{
1949 Comité des droits de l'enfant, Examen des Rapports soumis par les Etats parties en application du paragraphe 1 de l'article 8 du Protocole facultatif à la Convention relative aux droits de l'enfant, concernant l'implication d'enfants dans les conflits armés. Rapports initiaux des Etats parties devant être soumis en 2004, Rwanda, $\quad$ CRC/C/OPAC/RWA/1, 6 décembre 2011, p. $14, \quad \$ 71$ disponible sur http://tbinternet.ohchr.org/_layouts/treatybodyexternal/TBSearch.aspx?Lang=en\&TreatyID=5\&TreatyID=10\&T reatyID=11\&DocTypeID=29\&DocTypeCategoryID=4 (Source consultée le 15 avril 2016). ${ }^{1950}$ Ibid.
} 
enfants aux hostilités paraîtrait comme admettre indirectement cette présence. Ce qui nous paraît illogique du point de vue du DIH. D'où, une réglementation sur ce domaine s'avère nécessaire et salvatrice.

De ce qui précède, les enfants soldats, doublement victimes des pratiques des «Seigneurs de guerre » et des forces armées étatiques d'une part et d'un droit des conflits armés assurant très faiblement leur protection d'autre part, méritent mieux en champs de bataille. Leur vulnérabilité physique, leur absence de discernement conduit à affirmer qu'ils ne sont pas «réellement » comme des combattants adultes. D'où un traitement non égalitaire, autrement c'est de la «discrimination ». C'est ainsi qu'en pleines hostilités, nous estimons qu'il revient aux Etats notamment de "prendre des mesures nécessaires pour rendre les enfants moins nuisibles et moins victimes » au plan législatif et administratif. Cette neutralisation des enfants devrait inclure «tout moyen nécessaire » à l'exception de ceux létaux. Et pour qu'une telle mesure ne soit pas à la base de recrutement et d'utilisation massifs des enfants aux rangs de forces armées ou des groupes armés, il faudrait envisager un «système de surveillance mutuelle entre Etats » sur les champs de bataille. Chaque Etat devra signaler «en toute urgence » et à «tout moment» la présence des enfants dans les rangs des forces armées ou groupes armés ennemis au niveau des instances onusiennes habilitées, dont le CS/NU, pour des mesures conséquentes. Ceci devant renforcer le rôle que joue déjà le Mécanisme de surveillance et de communication de l'information sur les enfants et les conflits armés. Tout ceci vient en complément de l'appréciation rigoureuse du principe de proportionnalité lors de l'attaque et d'un test rigoureux entre nécessités militaires et considérations humanitaires que suggèrent la doctrine ${ }^{1951}$.

\section{§3. Les Résolutions du Conseil de sécurité des Nations Unies et la protection spéciale des enfants en situation de conflits armés en RDC}

D'importantes résolutions de l'ONU, notamment de l'AG/NU et principalement du CS/NU ont été adoptées dans le sens de la protection spéciale des enfants en situation des conflits armés. C'est ainsi que quand il mène son action dans le cadre du Chapitre VI ou du Chapitre VII de la Charte, s'il fait face à un conflit armé, le CS/NU a de plus en plus tendance à rappeler aux parties -forces armées ou groupes armés - la nécessité de respecter le DIH ${ }^{1952}$, les droits de l'homme ou des accords de paix qu'ils ont signés dans ce sens. Il renforce par là l'application des règles du DIH par les groupes armés qui posent généralement plus de problèmes que des forces armées étatiques et vise à la base à atteindre la cessation de la menace contre la paix que représentent ces graves violations du DIH ou DIDH ${ }^{1953}$. Cette adresse directe du CS/NU aux groupes armés sans passer par les Etats concernés n'est nullement illégale au sens du droit international. Il s'agit d'une démarche réaliste et pragmatique qui se justifie notamment par rapport au fait que les crimes particulièrement graves que commettent ces groupes armés constituent une menace contre la paix et la sécurité internationales ${ }^{1954}$ au même titre que des Etats. Ainsi, afin d'éviter l'aggravation de la

\footnotetext{
${ }^{1951}$ Voy. MAYSTRE, Magali, op. cit., p. 78.

1952 BOISSON DE CHAZOURNES, Laurence, «art.cit.», 153 -154.; Voy. BETTATI, Mario, Droit humanaitaire, $1^{\text {re }}$ édition, op.cit., 245.

${ }^{1953}$ TSHIBANGU, Kalala, Les Résolutions de l'ONU et les destinataires non étatiques, op.cit., p. 97.

1954 KERBRAT, Yann, La référence au Chapitre VII de la Charte des Nations Unies dans les résolutions à
} 
situation, le CS/NU peut inviter "les parties [étatiques ou non étatiques] intéressées à se conformer aux mesures provisoires qu'il juge nécessaires ${ }^{1955}$. Il s'agit donc des activités des organismes qui sont non moins des sujets de droit international, n'échappant donc pas à la sphère du $\mathrm{CS} / \mathrm{NU}^{1956}$. Ces groupes armés ou mouvements rebelles se trouvent par là obligés de respecter le jus cogens qu'incarne l'essentiel des règles du DIH ou du DIDH et les principes coutumiers du droit international issus du cadre onusien ${ }^{1957}$.

En outre, il importe d'indiquer que les résolutions du CS/NU contribuent également à la réalisation de l'obligation de cessation et de non-répétition ${ }^{1958}$ des violations du droit international (DIH) qui incombe aux Etats.

En rapport avec la situation de conflits armés en RDC, le CS/NU a adopté d'importantes résolutions rappelant les normes du DIH ou du DIDH à respecter par les forces armées ou groupes armés opérant en RDC. S'il est certes vrai que ces règles reposent essentiellement sur «des règles intransgressibles du droit international coutumier » ${ }^{1959}$, le CS/NU n'hésite cependant point à faire allusion à « toutes les violations » du DIH ou du DIDH ${ }^{1960}$.

A propos des enfants qui nous préoccupent, de nombreuses et importantes résolutions du CS/NU «n'ont cessé de stigmatiser les violations des droits de l'enfant en République démocratique du Congo, dont l'enrôlement d'enfants, à l'endroit de toutes les parties belligérantes, sans distinction. Ainsi par exemple, la résolution 1332 (2000) adoptée par le Conseil de sécurité à sa 4247 e séance le 14 décembre 2000 disposait dans l'un de ses paragraphes que «le Conseil de sécurité, profondément préoccupé par la poursuite du recrutement et de l'utilisation d'enfants soldats par des forces et groupes armés, y compris les

caractère humanitaire du Conseil de sécurité, L.G.D.J, Paris, 1995, p. 15. (120 p.)

${ }^{1955}$ L'article 40 de la Charte des Nations Unies : "Afin d'empêcher la situation de s'aggraver, le Conseil de sécurité, avant de faire les recommandations ou de décider des mesures à prendre conformément à l'article 39, peut inviter les parties intéressées à se conformer aux mesures provisoires qu'il juge nécessaires ou souhaitables. Ces mesures provisoires ne préjugent en rien les droits, les prétentions ou la position des parties intéressées. En cas de non-exécution de ces mesures provisoires, le Conseil de sécurité tient dûment compte de cette défaillance ».

${ }^{1956}$ Les justifications légales de l'adresse directe du CS/NU aux groupes armés ici détaillées sont développées dans TSHIBANGU, Kalala, Les Résolutions de l'ONU et les destinataires non étatiques, op.cit., pp. 119-129. L'auteur apprécie la légalité de l'action du CS/NU respectivement sur pied de l'article 40 de la Charte des Nations Unies; de l'absence de protestations des mouvements rebelles (groupes armés) ; de leurs activités rentrant dans le cadre de menace contre la paix et la sécurité internationales; et de la qualité des sujets de droit international autonome leur attribuée.

1957 TSHIBANGU, Kalala, Les Résolutions de l'ONU et les destinataires non étatiques, op.cit., pp. 138-139. L'auteur justifie en quatre points l'obligation des mouvements rebelles de se conformer aux décisions du CS/NU. Il fonde cette obligation par rapport au jus cogens concerné par certaines normes du DIH ou du DIDH qu'ils doivent observer; par le fait que ces mouvements rebelles sont parties aux accords de paix notamment qu'ils doivent respecter; par leur soumission volontaire; et par le respect des buts et principes des Nations Unies devenus principes coutumiers (Voy. pp.137-142).

${ }^{1958}$ Voy. art. 30 du Projet d'articles de la CDI sur la Responsabilité de l'Etat pour fait internationalement illicite, Résolution A/RES/56/83 - 12 décembre 2001.

1959 TSHIBANGU, Kalala, Les Résolutions de l'ONU et les destinataires non étatiques, op.cit., p. 95 et Lire KERBRAT, Yann, La référence au Chapitre VII de la Charte des Nations Unies dans les résolutions à caractère humanitaire du Conseil de sécurité, op.cit., p. 15.

${ }^{1960}$ Lire par exemple le $11^{\mathrm{e}}$ considérant de la Résolution 2021 (2011) Adoptée par le CS/NU à sa 6671e séance, le 29 novembre 2011 concernant la situation en RDC où le CS/NU réitère "sa ferme condamnation de toutes violations des droits de l'homme et du droit international humanitaire commises dans le pays [...]», in http://www.un.org/fr/sc/documents/resolutions/2011.shtml (Source consultée le 10 juillet 2015). 
recrutements à travers les frontières et les enlèvements,...». Ce paragraphe a été repris également par la résolution 1341 (2001) adoptée par le Conseil de Sécurité à sa 4282e séance le 22 février 2001 (voy. également d'autres résolutions ci-dessous dans ce sens). Toujours sous cette optique, par sa résolution 1468 (2003) adoptée à sa 4723e séance le 20 mars 2003, paragraphe 2, le Conseil de sécurité des Nations unies a condamné les massacres et autres violations systématiques du droit international humanitaire et des droits de l'homme perpétrés en RDC, en particulier le recours à la violence sexuelle contre les femmes et filles comme armes de guerre et les atrocités commises dans la région de l'Ituri par les troupes du MLC, du $\mathrm{RCD} / \mathrm{N}$ ainsi que les actes de violence perpétrés par les forces de l'Union des patriotes congolais. Il a réaffirmé que de tels actes ne resteront pas impunis et que leurs auteurs devront en répondre. La même condamnation était réitérée dans la résolution 1493 (2003) adoptée le 28 juillet $2003 »^{1961}$. De 2004 à 2015, il est dénombré au moins 47 résolutions du CS/NU ${ }^{1962}$ sur la situation concernant la RDC. De manière générale, ces résolutions ne cessent d'insister sur le respect du DIH et du DIDH par les parties aux conflits armés en RDC à différentes périodes. La protection des enfants se trouve au centre des préoccupations du CS/NU. Lequel joue donc un rôle non négligeable ${ }^{1963}$. Ces résolutions du CS/NU au sujet de la protection des enfants font suite aux nombreux cas successifs de leur recrutement et de leur utilisation par les parties aux conflits armés en RDC ou encore aux nombreux cas de violations graves de leurs droits en période de conflits armés dont les violences ou massacres.

En effet, à titre indicatif, la résolution 1698 (2006) du 31 juillet 2006 en son paragraphe 13 étend le régime de sanction de la résolution 1596 (2005) en empêchant les mouvements des capitaux et la libre circulation des responsables politiques et militaires ayant procédé au recrutement ou emploi des enfants en violation du droit international applicable, ou de tout individu ayant commis des violations graves dans ce sens. Ces mesures ont été renouvelées dans différentes résolutions ultérieures. Ainsi, la résolution 1807 (2008) du 31 mars 2008 en ses paragraphe 1, 9 et 13, $d$ et $e$, invite tous les États à prendre les mesures nécessaires pour empêcher la liberté des mouvements de capitaux et des acteurs politiques et militaires responsables du recrutement et d'utilisation d'enfants et de tout individu auteur de graves violations du droit international impliquant notamment des actes de violences dirigés contre les enfants. Cette dernière résolution condamne aussi fermement la poursuite du recrutement et de l'emploi d'enfants ainsi que les actes de violence dirigés contre eux ( $5^{\mathrm{e}}$ considérant) comme c'est également le cas de la Résolution 1856 (2008) du 22 décembre 2008 (12 considérant). La résolution 1857 (2008) du 22 décembre 2008 réitère à son tour les mesures

\footnotetext{
${ }^{1961}$ MUMBALA Abelungu Junior, «Le droit international humanitaire et la protection des enfants en situation de conflits armés en République démocratique du Congo », in Droit et cultures. Revue internationale interdisciplinaire 64 (2012),\$76: 207-235.in http://droitcultures.revues.org/2913 (Source consultée le 04 juillet 2015).

${ }_{1962}$ Il s'agit des Résolutions suivantes du CS/NU : 1522 (2004), 1533 (2004), 1552 (2004), 1555 (2004), 1565 (2004), 1592 (2005), 1596 (2005), 1616 (2005), 1621 (2005), 1628 (2005), 1635 (2005), 1649 (2005), 1653 (2006), 1654 (2006), 1669 (2006), 1671 (2006), 1693 (2006), 1698 (2006), 1711 (2006), 1736 (2006), 1742 (2007), 1751(2007), 1756 (2007), 1768 (2007), 1771 (2007), 1794 (2007), 1797 (2008), 1799 (2008), 1804 (2008), 1807 (2008), 1843 (2008), 1856 (2008), 1857 (2008), 1896 (2009), 1906 (2009), 1925 (2010), 1952 (2010), 1991 (2011), 2021 (2011), 2076 (2012), 2078 (2012), 2053 (2012), 2053 (2012), 2098 (2013), 2136 (2014), 2147 (2014), 2198 (2015), 2211 (2015),

${ }^{1963}$ BODINEAU, Sylvie, Figures d'enfants soldats. Puissance et vulnérabilité. Regard anthropologique sur l'intervention humanitaire de protection des "enfants soldats » en République démocratique du Congo entre 1996 et 2011, op.cit., p. 11.
} 
d'obstacles aux libertés des capitaux et des mouvements contenues dans la résolutions 1087 (2008) des «responsables politiques et militaires opérant en République démocratique du Congo et recrutant ou employant des enfants dans les conflits armés en violation du droit international applicable ${ }^{1964}$ et des «personnes opérant en République démocratique du Congo et commettant des violations graves du droit international impliquant des actes de violence dirigés contre des enfants » ${ }^{1965}$ jusqu'au 30 novembre 2009. La résolution 1896 (2009) du 30 novembre 2009 reconduit en ses paragraphes 2 et 3 les mêmes mesures jusqu'au 30 novembre 2010. La résolution 1952 (2010) du 29 novembre 2010 renouvelle en ses paragraphes 2 et 3 lesdites mesures jusqu'au 30 novembre 2011. De cette dernière date jusqu'au 30 novembre 2012, la prorogation desdites mesures a été effectuée par la résolution 2021 (2011) du 29 novembre 2011 en ses paragraphes 2 et 3. La résolution 2078 du 28 novembre 2012 proroge lesdites mesures jusqu'au $1^{\text {er }}$ février 2014 ( $\$ 2$ et 3). Du $1^{\text {er }}$ février 2014 au $1^{\text {er }}$ février 2015 par la résolution 2136 (2014) du 30 janvier 2014, $\S \S 2$ et 3. Et c'est la résolution 2198 (2015) du 29 janvier 2015 qui proroge ces mesures jusqu'au 01 juillet 2016.

En appui aux sanctions prises par le CS/NU à l'encontre des personnes commettant des graves violations contre les enfants, l'Union européenne a adopté à son niveau différents actes contraignants dont les «positions communes ». Au sens de l'article 15 du Traité sur l'Union européenne «[1]e Conseil arrête des positions communes. Celles-ci définissent la position de l'Union sur une question particulière de nature géographique ou thématique $[. ..]{ }^{1966}$. En clair «[1]es positions communes font figure de décisions juridiques obligatoires qui s'imposent en premier lieu aux Etats membres ${ }^{1967}$.

D'abord une position commune (Position commune 2005/440/PESC du Conseil) a été adoptée en appui de la résolution 1596 (2005) du CS/NU qui traite des mesures restrictives à l'encontre des personnes agissant en violation d'embargo. Cette position commune demande aux Etats de prendre des mesures nécessaires pour empêcher l'entrée ou le passage en transit de ces personnes sur leur territoire (art. 4). Ceci vaut de même pour la liberté de leurs capitaux $(\operatorname{art.5})^{1968}$. Elle modifie déjà celle par laquelle l'UE appuyait la mise en œuvre de l'Accord de Lusaka 2002/829/PESC dont le désarmement ${ }^{1969}$. Elle sera elle-même modifiée par les Positions communes 2007/654/PESC du 09 octobre 2007 et 2008/179/PESC du 29 février

\footnotetext{
${ }^{1964}$ Résolution 1857 (2008) adoptée par le conseil de sécurité à sa 6056 ééance, le 28 décembre 2008, § 4, d, in http://www.un.org/fr/sc/documents/resolutions/2008.shtml (Source consultée le 05 juillet 2015).

${ }^{1965}$ Ibid., $\$ 4$, e.

1966 Article 15 du Traité sur l'Union européenne (revisé par le Traité de Lisbonne). Voy. Traité de Lisbonne modifiant le Traité sur l'Union européenne et le Traité instituant la Communauté européenne, Journal Officiel de l'Union européenne, 2007/C 306/01, 17.12.2007 disponible sur http://eur-lex.europa.eu/legalcontent/fr/TXT/?uri=CELEX\%3A12007L\%2FTXT (Source consultée le 18 juillet 2016).

${ }^{1967}$ FERRARO, Tristan, «Le droit international humanitaire dans la politique étrangère et de sécurité commune de l'Union européenne », « art. cit. », p. 451.

${ }^{1968}$ Position commune 2005/440/PESC du Conseil du 13 juin 2005 concernant l'adoption de mesures restrictives à l'encontre de la République Démocratique du Congo et abrogeant la position commune 2002/829/PESC in Journal Officiel de l'Union européenne $\mathrm{n}^{\circ} \mathrm{L} 152 / 22$ du 15 juin 2005, in http://eur-lex.europa.eu/legalcontent/FR/TXT/?uri=uriserv:OJ.L_.2005.152.01.0022.01.FRA\&toc=OJ:L:2005:152:TOC (Source consultée le 21 février 2016).

1969 Position commune 2002/829/PESC du Conseil du 21 octobre 2002 concernant la fourniture de certains équipements à destination de la République Démocratique du Congo, in Journal Officiel de l'Union européenne $\mathrm{n}^{\circ} \mathrm{L} 285 \mathrm{du} \quad 23 \quad$ octobre $2002.2 \mathrm{http}$ ://eur-lex.europa.eu/legalcontent/FR/TXT/?uri=uriserv:OJ.L_.2002.285.01.0001.01.FRA\&toc=OJ:L:2002:285:TOC (Source consultée le 21 février 2016).
} 
2008 à la suite de l'adoption de différentes résolutions par le CS/NU ${ }^{1970}$. Etant donné l'élargissement des mesures prises dans le cadre de la résolution 1596 (2005) aux cas des enfants par la résolution 1698 (2006) du CS/NU, et plus précisément à la suite de la mise à jour de la résolution 1596 (2005) par la résolution 1807 (2008) du CS/NU, l'UE se fera l'obligation d'actualiser sa position commune. Ainsi, sera adoptée par le Conseil, la Position commune 2008/369/PESC du Conseil du 14 mars 2008 concernant l'adoption des mesures restrictives à l'encontre de la République Démocratique du Congo et abrogeant la position commune 2005/440/PESC. Celle-ci instruit aux Etats membres de l'UE « de prendre des mesures nécessaires pour empêcher l'entrée ou le passage en transit sur leur territoire [...] ${ }^{1971}$ notamment des responsables politiques et militaires recrutant ou employant les enfants dans les conflits armés en RDC en violation du droit international applicable; des personnes opérant et commettant des graves violations contre les enfants ${ }^{1972}$. Le gel des fonds, d'autres avoirs financiers et des ressources électroniques en leur possession ou sous leur contrôle a été également décrété ${ }^{1973}$. A la suite de l'actualisation de la liste d'individus et entités faisant objet des mesures restrictives par le Comité de sanction établi par le CS/NU, le Conseil prendra la décision 2010/788/PESC abrogeant la position commune 2008/369/PESC. La présente décision insistera sur le respect de la Charte des droits fondamentaux de l'Union européenne précisément sur le droit à un recours effectif, le droit au procès équitable, le droit à la propriété, le droit à la protection des données à caractère dont bénéficient ces personnes ${ }^{1974}$. Depuis lors différentes mises à jour sont effectuées et de nombreuses décisions d'exécution voire de règlements sont adoptés à cet effet.

Il existe encore d'autres résolutions du CS/NU sur les enfants en RDC. C'est le cas de la résolution du 1771 (2007) du 10 août 2007 qui condamne fermement en son préambule à nouveau la poursuite du recrutement et d'emploi d'enfants dans les hostilités en RDC (Voy. également la résolution 1843 (2008) du 20 novembre 2008 en son préambule, $7^{\mathrm{e}}$ considérant ; la résolution 1896 (2009) du 30 novembre 2009, $9^{\mathrm{e}}$ considérant ; la résolution 1906 (2009) du 23 décembre 2009, $8^{\mathrm{e}}$ considérant; la résolution 1925 (2010) du 28 mai 2010, $11^{\mathrm{e}}$ considérant; la résolution 2021 (2011) du 29 novembre 2011, 11 e considérant; la résolution 2078 (2012) du 28 novembre 2012, $9^{\mathrm{e}}$ considérant; la résolution 2136 (2014) du 30 janvier 2014, $\S \S 11$ et 12 etc.). Il y a également la résolution 1794 (2007) du 21 décembre 2007. Celle-ci demande au paragraphe 15 aux autorités congolaises de lutter contre l'impunité en traduisant en justice notamment les auteurs présumés responsables de recrutement et d'utilisation d'enfants et de

1970 Position commune 2008/179/PESC du Conseil du 29 février 2008 modifiant la position commune 2005/440/PESC concernant l'adoption de mesures restrictives à l'endroit de la République démocratique du Congo in Journal Officiel de l'Union européenne $\mathrm{n}^{\circ} \mathrm{L} 57 / 37 \mathrm{du} 1^{\mathrm{er}}$ mars 2008, in http://eur-lex.europa.eu/legalcontent/FR/TXT/?uri=uriserv:OJ.L_.2008.127.01.0084.01.FRA\&toc=OJ:L:2008:127:TOC (Source consultée le 21 février 2016).

${ }^{1971}$ Article 4 de la Position commune 2008/369/PESC du Conseil du 14 mars 2008 concernant l'adoption des mesures restrictives à l'encontre de la République Démocratique du Congo et abrogeant la position commune 2005/440/PESC, in Journal Officiel de l'Union européenne $\mathrm{n}^{\circ} \mathrm{L} 127 / 84 \mathrm{du} 15$ mai 2008 in http://eurlex.europa.eu/legal-content/FR/TXT/?uri=uriserv:OJ.L_.2008.127.01.0084.01.FRA\&toc=OJ:L:2008:127:TOC

(Source consultée le 21 février 2016).

${ }^{1972}$ Ibid., article 3.

1973 Ibid., article 5

1974 Décision 2010/788/PESC du Conseil du 20 décembre 2010 concernant l'adoption de mesures restrictives à l'encontre de la République Démocratique du Congo et abrogeant la position commune 2008/369/PESC, in Journal officiel de l'Union européenne L 336/30 du 21 décembre 2010 in http://eur-lex.europa.eu/legalcontent/FR/TXT/?uri=celex\%3A32010D0788 (Source consultée le 21 février 2016). 
violation graves en leur encontre dont les violences sexuelles. Chose que feront également la résolution 1856 (2008) du 22 décembre 2008, §4, c, la résolution 2076 (2012) du 20 novembre 2012 et tant d'autres. La résolution du CS/NU du 29 janvier 2015 demandera à son tour, en son préambule, que les personnes responsables des violations du DIH et du DIDH sur des enfants en RDC soient «promptement» appréhendées et traduites en justice. Sous le paragraphe précité de la Résolution 1794 (2007), il est suggéré la création d'un mécanisme de vérification qui prendrait en compte lors de choix des candidats pour des fonctions officielles leurs actions antérieures par rapport au respect du DIH ou du DIDH. D'autres résolutions du $\mathrm{CS} / \mathrm{NU}$ condamnent successivement toutes les violations commises sur des enfants dont leur recrutement et leur participation aux hostilités.

Il ressort de ce qui précède que différentes résolutions adoptées en rapport avec la situation des conflits armés en RDC renvoient les parties - Etats et groupes armés- au respect de leurs engagements notamment les règles du droit international assurant la protection des enfants en périodes des conflits armés. Soit un rappel général est fait au regard du DIH ou du DIDH que doivent observer ces parties, soit encore le CS/NU n'hésite pas à demander directement aux parties d'observer les engagements issus des accords qu'ils ont conclus dans le cadre de ces conflits. C'est par exemple le cas de la résolution du 1906 (2009) du CS/NU du 23 décembre 2009 par laquelle il souligne en son préambule «[...] que les processus de Goma et de Nairobi et les Accords du 23 mars 2009 constituent le cadre approprié pour la stabilisation de la situation dans l'est de la République démocratique du Congo et demande instamment à toutes les parties de respecter et appliquer intégralement ces accords, ${ }^{1975}$. Ceci sera rappelé d'ailleurs par la résolution 1925 (2010) du 28 mai $2010^{1976}$. Et par un ton impératif, le CS/NU n'hésite point à s'adresser directement aux groupes armés qui sèment la désolation dans le chef des enfants. C'est le cas de la résolution 2021 (2011) du 29 novembre 2011 par laquelle le CS /NU « exige de tous les groupes armés, en particulier les FDLR, la LRA, les Maï Maï Yakutumba, les Forces nationales de libération (FNL) et l'Alliance des forces démocratiques (AFD) qu'ils déposent leurs armes, mettent immédiatement fin à toutes formes de violence, violations des droits de l'homme et violations du droit international humanitaire contre la population civile en République démocratique du Congo et dans la région des Grands Lacs, en particulier les violences commises contre des femmes et des enfants, y compris le viol et les autres formes de violence sexuelle, et se démobilisent; » ${ }^{1977}$. Ce qui a été également le cas pour le M23 ${ }^{1978}$.

Il va sans dire que ces résolutions du CS/NU accordent une certaine force exécutoire aux instruments de juridicité douteuse (accords politiques) conclus dans le cadre de gestion et de résolution des conflits armés en RDC. Toutefois, «[i]l faut soigneusement analyser le libellé d'une résolution du Conseil de sécurité avant de pouvoir conclure à son effet obligatoire ${ }^{1979}$.

\footnotetext{
1975 Résolution 1906 (2009) adoptée par le CS/NU à sa $6253^{\text {e }}$ séance, le 23 décembre 2009, $6^{\text {e }}$ considérant, http://www.un.org/fr/sc/documents/resolutions/2009.shtml (Source consultée le 05 juillet 2015).

${ }^{1976}$ Voy. la Résolution 1925 (2010) adoptée par le CS/NU à sa 6324 séance, le 28 mai 2010, $7^{\mathrm{e}}$ considérant, http://www.un.org/fr/sc/documents/resolutions/2010.shtml (Source consultée le 05 juillet 2015).

1977 Résolution 2021(2011) adoptée par le CS/NU à sa 6671e séance, le 29 novembre 2011, \$13 http://www.un.org/fr/sc/documents/resolutions/2011.shtml (Source consultée le 05 juillet 2015).

1978 Résolution 2076 (2012) adoptée par le CS/NU à sa 6866e séance, le 20 novembre 2012, $\S$ 2-3 http://www.un.org/fr/sc/documents/resolutions/2012.shtml (Source consultée le 05 juillet 2015).

${ }^{1979}$ DUPUY, Pierre-Marie et KERBRAT, Yann, Droit international public, $11^{\mathrm{e}}$ édition, op.cit., p. 220.
} 
En réalité, les appels réitérés de cet organe à l'interdiction de recrutement et d'utilisation des enfants aux hostilités ou encore la lutte contre l'impunité des auteurs présumés responsables de ces actes traduisent au-delà de leur importance, leur inefficacité à aboutir à des solutions durables contre ce fléau. C'est donc aujourd'hui, plus ou moins quinze ans après, que le $\mathrm{CS} / \mathrm{NU}$ continue de prendre des résolutions aux termes identiques et connus de tous :"profondément préoccupé... », "exige que...», "demande instamment à toutes les parties... », "réaffirme sa disponibilité..., son importance...», «décide de...», "souligne... », "prend note... », " appelle toutes les partie... », etc.- sans aboutir à des faits mettant durablement à terme ou réduisant très sensiblement le recrutement et l'utilisation des enfants, les violations graves de leurs droits par les parties aux conflits armés en RDC. Cette absence d'efficacité incombe également à l'Etat congolais à qui revient la responsabilité première d'assurer la sécurité de ses enfants en conflits armés. Position d'ailleurs rappelée par le même CS/NU à l'Etat congolais dans ses résolutions.

Par ailleurs, à côté de ces différentes résolutions liées à la situation spécifique des enfants en période de conflits armés en RDC, nombreuses sont également des résolutions concernant les enfants dans les conflits armés en général adoptées par le CS/NU. Lesquelles résolutions ne concernent non moins la situation des enfants en RDC de par leur application. Il s'agit notamment des résolutions 1261(1999), 1314 (2000), 1379 (2001), 1460 (2003), 1539 (2004), 1612 (2005), 1882 (2009), 1998 (2011), 2068 (2012), 2143 (2014), 2225 (2015) du CS/NU. Il y a lieu de rappeler que 1998 est l'année à partir de laquelle la préoccupation des enfants touchés par les hostilités armées a été officiellement inscrite à l'ordre du jour du CS/NU ${ }^{1980}$ (cf. supra). Et depuis cette année, ce sujet «a gravi lentement l'échelle des sanctions possibles : rapports, résolutions demandant aux parties de respecter le droit international et, depuis 2002, liste nominative des groupes armés recrutant des enfants [... ${ }^{1981}$.

\footnotetext{
${ }^{1980}$ AYISSI, Anatole et MAIA, Catherine, «La lutte contre le drame des enfants soldats ou le conseil de sécurité contre le terrorisme à venir... », « art. cit. », p. 342.

${ }^{1981}$ AYISSI, Anatole et MAIA, Catherine, «Les filles-soldats, grandes oubliées des conflits armés en Afrique » in Etudes 2004/7 (Tome 401), disponible sur http://www.cairn.info/revue-etudes-2004-7-page-19.htm (Source consultée le 15 avril 2016).
} 


\section{Conclusion du Chapitre II}

Sous le titre de «Les Règles du droit international humanitaire relatives à la protection des enfants en $R D C$ », le présent chapitre s'est consacré à déterminer la nature des conflits armés en RDC et les conséquences juridiques qui en découlent (Section I) avant de se préoccuper des règles du DIH relatives à la protection spéciale des enfants en pareilles circonstances (Section II). Lesquelles règles se trouvent complétées par d'autres dont le DIDH, lle droit international dérivé ou la législation nationale congolaise (Section III).

Il ressort de cette étude que de 1996 à ce jour, ces conflits armés complexes ont revêtu des qualifications variées en DIH : CANI, CANI internationalisé et CAI. Et pour mieux les circonscrire afin de dégager avec prudence les règles applicables, trois périodes ont été cernées à savoir d'octobre 1996 à mai 1997; d'août 1998 à juin 2003; et de juin 2003 à ce jour. En fonction des acteurs étatiques et non étatiques, les règles applicables en CAI et en CANI, suivant précisément l'état de ratification de nombreux instruments applicables - dont ceux du DIH et du DIDH-, ont été déterminées. Des règles issues des accords régionaux, spéciaux et de la législation nationale congolaises ont été également concernées.

De ce qui précède, s'il est admis qu'il existe - en dépit des critiques formulées- des règles assurant la protection des enfants civils en conflits armés (CANI et CAI), la situation des enfants soldats n'est pas enviable. En somme, ils sont doublement victimes des pratiques des «Seigneurs de guerre » et des forces armées étatiques d'une part et d'un droit des conflits armés assurant très faiblement leur protection d'autre part. Ce qui atteste que les Etats n'ont pas souhaité s'engager inconditionnellement avec des règles plus protectrices de l'enfance en conflits armés.

Les enfants soldats méritent donc mieux sur les champs de bataille. La vulnérabilité physique, et psychique dont ils font preuve, conduit à affirmer qu'ils ne sont pas « réellement » comme des combattants adultes. D'où un traitement non égalitaire, autrement c'est de la «discrimination ». Et d'autant plus qu'ils se retrouvent généralement sur les champs de bataille indépendamment de leur «bonne volonté ». C'est ainsi qu'en pleines hostilités, nous estimons qu'il revient aux Etats principalement à la RDC de "prendre des mesures nécessaires pour rendre les enfants moins nuisibles et moins victimes » au plan législatif et administratif. Seuls les moyens non létaux seraient recommandés. Et pour qu'une telle mesure ne soit pas à la base de recrutement et d'utilisation massifs des enfants par les forces ou des groupes armés, un «système de surveillance mutuelle entre Etats » sur le champ de bataille est envisageable. Chaque Etat devra signaler «en toute urgence» et à «tout moment» la présence des enfants dans les rangs des forces ou groupes armés ennemis au niveau des instances onusiennes habilitées, dont le CS/NU, pour des mesures conséquentes. C'est donc ici qu'il faudrait renforcer le rôle que joue déjà le Mécanisme de surveillance et de communication de l'information sur les enfants et les conflits armés (cf. infra). Tout ceci vient en complément de l'appréciation rigoureuse du principe de proportionnalité lors de l'attaque et d'un test rigoureux entre nécessités militaires et considérations humanitaires que suggère la doctrine ${ }^{1982}$.

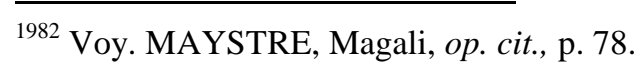




\section{CHAPITRE III LES MECANISMES DE PROTECTION DES ENFANTS EN SITUATION DE CONFLITS ARMES EN RDC}

La mise en œuvre du droit est le point faible du droit international en général et du DIH en particulier ${ }^{1983}$. Ce dernier « refuse d'organiser efficacement sa propre mise en œuvre ${ }^{1984}$. Ses «traités sont dépourvus de moyens suffisants de mise en œuvre ${ }^{1985}$. Les quelques mécanismes institués par les Conventions de Genève de 1949 et leurs PA, par exemple, restent tributaires de la volonté des Etats pour être actionnés. Les analyses précédentes attestent d'ailleurs que les Etats se méfient d'y recourir. Le cas le plus patent est celui de « Puissance protectrice» (cf. supra).

S'il est indubitablement vrai d'arguer que le travail du CICR sur le champ de bataille reste indispensable et incontournable pour la mise en œuvre du DIH, en même temps il est vraisemblablement attesté «l'absence d'organe de contrôle spécialisé propre exclusivement au droit humanitaire : ni une cour de justice pour le droit humanitaire, ni une commission du droit humanitaire, ni un haut commissaire au droit humanitaire ${ }^{1986}$. Et la prise en charge du DIH par des organes de contrôle du droit international des droits de l'homme ou du droit international pénal voire du droit international général, en dépit des avantages qu'elle procure, reste non sans influence sur le contenu du DIH, droit qui se veut aussi spécial ${ }^{1987}$. Soit encore que les membres de ces juridictions sèchent en argumentations approfondies en DIH. L'exemple nous est d'ailleurs fourni par la Commission africaine des droits de l'homme et des peuples dans l'examen des questions du DIH posées dans le cadre de sa première communication interétatique - Communication 227/99 République Démocratique du Congo/Burundi, Rwanda, Ouganda (cf. infra). L'absence d'interprétation quasi permanente des dispositions du DIH laissant place à leurs simples citations y est très remarquable ${ }^{1988}$. Or « [i]l n'y a pas d'application sans interprétation ${ }^{1989}$. Une règle de droit même claire mérite interprétation. Ainsi, la Commission africaine n'offre pas l'occasion de laisser entendre son point de vue sur les contenus de ces différentes dispositions. La question de protection des enfants en DIH dans l'affaire des activités armées (RDC c. Ouganda) devant la Cour internationale de justice subira également les mêmes effets (cf. le dernier paragraphe de la dernière section du chapitre). Ce qui ne semble d'ailleurs pas faire progresser ce droit dans la

${ }^{1983}$ KOLB, Robert, Jus in bello. Le droit international des conflits armés, op.cit., p. 470. Lire aussi la Préface de CONDORELLI, Luigi in S. VITE, Les Procédures internationales d'établissement des faits dans la mise en œuvre du droit international humanitaire, éditions Bruylant et éditions de l'Université de Bruxelles, Bruxelles 1999, p. XIII.

${ }^{1984}$ TAVERNIER, Paul, « Réflexion sur les mécanismes assurant le respect du Droit International Humanitaire conformément aux Conventions de Genève et aux Protocoles additionnels » in Actualités et Droit International, Revue d'analyse juridique et d'actualités internationales http://www.ridi.org/adi/200004 (Source consultée le 24 mai 2015).

${ }^{1985}$ BETTATI, Mario, Droit humanitaire. Textes introduits et commentés, op.cit., p.65.

${ }^{1986}$ KOLB, Robert, Jus in bello. Le droit international des conflits armés, op.cit., p. 473.

1987 Voy. Ibid.

1988 Voy. Commission africaine des droits de l’homme et des peuples, Communication $n^{\circ} 227 / 99$ République Démocratique $d u$ Congo/ Burundi, Rwanda, Ouganda, $\$ \S 71, \quad 79,82,84 \quad 86, \quad$ et 89 in http://www.achpr.org/fr/communications/decision/227.99/ (Source consultée le 16 janvier 2016).

${ }^{1989}$ SOREL, Jean-Marc, «Convention de Vienne de 1969, article 31 Règle générale d'interprétation » in CORTEN, Olivier et KLEIN, Pierre (dir.), Les Conventions de Vienne sur le droit des traités. Commentaire article par article, Vol. II, Bruylant, Bruxelles, 2006, p. 1292. 
sphère africaine voire international.

Il va sans dire que la mise en œuvre est un des plus importants éléments devant faire progresser le $\mathrm{DIH}^{1990}$. Cette question se pose déjà avec acuité en ce qui concerne les mécanismes devant assurer «la protection générale » des personnes civiles. Leur efficacité est donc problématique. Les « hautes parties contractantes » n'ont donc pas souhaité déployer des moyens conséquents. Vraisemblablement, la situation sera encore plus compliquée pour le cas de «protection spéciale» dont doivent bénéficier les enfants. Il n'y aura donc pas de protection spéciale sans l'institution des mécanismes spéciaux, mieux sans une prise en charge spéciale à la hauteur de la vulnérabilité physique et psychique de l'enfant.

Ainsi, le présent chapitre s'emploie à étudier l'opérationnalité des mécanismes institués par les instruments du DIH, du droit international des droits de l'homme, du droit international pénal et du droit international général pour assurer la protection des enfants en situation de conflits armés en RDC. En clair, il sera question d'examiner la prise en charge de la protection spéciale des enfants en situation de conflits par les mécanismes établis par les CG et leurs PA (Section I), par les instruments des droits de l'Homme (Section II), par 1'Organisation des Nations Unies (Section III), par les institutions gouvernementales et non gouvernementales (Section IV). Enfin, un intérêt sera réservé aux mécanismes d'ordre judiciaire, en analysant différentes questions de responsabilité pour violations des règles de protection des enfants en situation de conflits armés en RDC. Lesquelles questions se posent sous l'angle des juridictions pénales nationales, pénales internationales et internationales (Section V).

\section{Section I Mécanismes de protection des enfants en situation de conflits armés institués par les Conventions de Genève et leurs protocoles additionnels}

Il est d'un constat établi dans les lignes précédentes qu'aux termes des CG et de leurs PA, la protection spéciale de l'enfant ne s'accompagne pas des “mécanismes spéciaux de respect ou de protection". Il y a lieu de comprendre parfaitement que le problème déjà soulevé en DIH en ce qui concerne ses mécanismes de protection générale des personnes civiles se poseront avec acuité dans le secteur de protection des personnes présentant une vulnérabilité spécifique dont l'enfant. Ainsi, la protection spéciale de l'enfant demeure donc problématique d'autant plus que les mécanismes spéciaux ou spécifiques devant tenir compte de certaines de ses réalités propres et distinctes d'autres catégories de personnes civiles sont inexistants.

Sous cette section, les mécanismes de prévention $(\S 1)$ et de contrôle du DIH (§2) seront examinés. Quant aux mécanismes de sanction, ils feront l'objet d'étude à la dernière section du présent chapitre.

\section{\$1 Mécanismes de prévention du droit international humanitaire en RDC}

La prévention des violations des règles du DIH de protection de l'enfant, voire du DIH en

${ }^{1990}$ Voy. KOLB, Robert, Jus in bello. Le droit international des conflits armés, op.cit., p. 473. 
général, implique la promotion de ces règles. L'entreprise de promotion du DIH requiert différentes activités possibles au rang desquelles des mesures de «diffusion » sont à classer. Ces dernières sont d'une grande importance bien qu'insuffisantes à elles seules. Les articles 47 de la CG I ; 48 de la CG II ; 127 de la CG III et 144 de la CG IV disposent clairement que les Etats «s'engagent à diffuser le plus largement possible, en temps de paix et en temps de guerre [...] » les textes de ces instruments, «notamment à en incorporer l'étude dans les programmes d'instruction militaire et, si possible, civile, de telle manière que les principes en soient connus [...] ${ }^{1991}$. Le PA I, en son article 83, va plus loin en écartant notamment les termes «si possible », et «principes» au profit d'《instruments» et oblige les Etats à encourager l'étude des CG et PA I par la population civile de sorte que ces instruments soient connus ${ }^{1992}$. Ce qui vaut de même pour l'article 7 du PA III ${ }^{1993}$. Et le PA II indique de manière très concise que «[1]e présent protocole sera diffusé aussi largement possible ${ }^{1994} \gg$. En incluant les «populations civiles », les dispositions précitées paraissent plus étendues que celles de même ordre contenues dans l'article $1^{\text {er }}$ de la Convention IV de La Haye concernant les lois et coutumes de la guerre sur terre ou l'article 25 de la Convention de La Haye de 1954. Laquelle limitait les parties à donner « des instructions » aux seules « forces armées de terre ${ }^{1995}$.

Dès lors, la RDC a intériorisé cette obligation de diffuser les règles du DIH. Il ressort de sa Constitution de la transition du 04 avril 2003, article 47 alinéa 4, que : "L'Etat a le devoir d'assurer la diffusion et l'enseignement [...] de tous les instruments régionaux et internationaux relatifs [...] au droit international humanitaire dûment ratifiés ${ }^{1996}$. De même pour les instruments de droits de l'homme. En revanche, une telle disposition n'existe pas dans l'Acte constitutionnel de Transition du 09 avril 1994. Lequel ne s'intéresse expressément qu'à la diffusion des instruments de droits de l'homme ${ }^{1997}$. Elle se trouve, par ailleurs, reconduite par la Constitution du 18 février 2006 en son article 45 alinéa 6 en des termes quasi-identiques ${ }^{1998}$.

\footnotetext{
${ }^{1991}$ Lire les articles 47 de la CG I ; 48 de la CG II ; 127 de la CG III et 144 de la CG IV

${ }^{1992}$ DAVID, Eric, « Diffusion du droit humanitaire à l'université », in RICR, n`764, CICR, Genève, 1987, pp. 157-158 ; DAVID, Eric, Principes de droit des conflits armés, 5è édition, op.cit., p. 638.

1993 RDC et Rwanda ne sont pas parties au PA III du 08 décembre 2008. Pour sa part, la République d'Ouganda y a adhéré à cet instrument le 21 mai 2008.

${ }_{1994}$ Article 19 du PA II

${ }^{1995}$ Cet article disposait : « Les Puissances contractantes donneront à leurs forces armées de terre des instructions qui seront conformes au Règlement concernant les lois et coutumes de la guerre sur terre, annexé à la présente Convention»; DAVID, Eric, «Diffusion du droit humanitaire à l'université », «art. cit. », pp. 157-158 ; DAVID, Eric, Principes de droit des conflits armés, 5è édition, op.cit., p. 638.

1996 Article 47, alinéa 4, de la Constitution de la transition du 04 avril 2003 in http://www.droitcongolais.info/etat autorites_rdc.html (Source consultée le 15 décembre 2015).

${ }^{1997}$ L'article 35 de l'Acte constitutionnel de Transition disposait : «L'Etat a le devoir d'assurer la diffusion de l'enseignement du présent Acte, de la Déclaration Universelle des Droits de l'Homme, de la Charte Africaine des Droits de l'Homme et des Peuples, ainsi que de tous les instruments internationaux dûment ratifiés et relatifs aux droits de l'Homme.
}

L'Etat a l'obligation d'intégrer les droits de la personne humaine dans les programmes de formation scolaire, des Forces Armées et des services de Sécurité » in http://www.droitcongolais.info/etat autorites rdc.html (Source consultée le 15 décembre 2015).

\footnotetext{
${ }^{1998}$ L'article 45, alinéa 6, de la Constitution du 18 février 2006 dispose : « Les pouvoirs publics ont le devoir d'assurer la diffusion et l'enseignement de la Constitution, de la Déclaration universelle des droits de l'homme, de la Charte africaine des droits de l'homme et des peuples, ainsi que de toutes les conventions régionales et internationales relatives aux droits de l'homme et au droit international humanitaire dûment ratifiées » in in
} 
Il se dégage donc de ce qui précède que la diffusion des règles du DIH est une obligation à la fois internationale et constitutionnelle pour l'Etat congolais.

La diffusion au sens «plus largement possible» en temps de paix et en temps de guerre comme le veulent bien les CG et les PA résulte de l'obligation « de respecter et de faire respecter en toutes circonstances » le $\mathrm{DIH}^{1999}$ (cf. supra). Elle fait donc appel à différentes mesures. Elle implique notamment la possession et la connaissance des instruments du DIH par les autorités militaires et civiles compétentes; des instruction dans des écoles et autres établissements de formation; la formation du personnel qualifié pour faciliter l'application du $\mathrm{DIH}$; l'adjonction de conseillers juridiques aux forces armées ${ }^{2000}$. Au sens encore plus général de la promotion du DIH, des mesures telles que la traduction des règles du DIH en quatre langues nationales du pays (Kiswahili, lingala, kikongo et tshiluba), au besoin en dialectes pour le cas de milices ethniques, par exemple, devraient être prises.

En ce qui concerne la diffusion des règles de protection de l'enfant, différents efforts sont fournis par la RDC. En dehors de l'œuvre des ONG de défense des droits de l'homme dans ce sens, des voies de diffusion étatiques sont assurées telles que la publication au Journal Officiel et en langues nationales de la Convention relative aux droits de l'enfant; d'autres publications officielles telles que le Livre Blanc du Ministère des droits humain ou la « Revue Libota » du Ministère des affaires sociales et de la famille ${ }^{2001}$; la publication en 34.000 exemplaires (jusqu'en octobre 2007) du manuel d'enseignement «Programme national d'éducation civique et morale avec intégration des droits de l'homme » élaboré par la Direction des programmes scolaires et matériels didactiques du Ministère de l'enseignement primaire et secondaire, en collaboration avec le Haut Commissariat des Nations Unies aux droits de l'Homme (HCDH). Il existe, en outre, des programmes de formation aux droits de l'enfant assurés par les ministères ayant des responsabilités dans ce domaine à l'intention de leur personnel et autres ${ }^{2002}$.

A propos de la diffusion du Protocole facultatif à la Convention relative aux droits de l'enfant concernant l'implication d'enfants dans les conflits armés, par exemple, elle était assurée au niveau étatique par la Commission Nationale de Désarmement, Démobilisation et de Réinsertion (CONADER, créée par décret n03/042 du 18 décembre 2003) remplaçante du

http://www.droitcongolais.info/etat_autorites_rdc.html (Source consultée le 15 décembre 2015).

1999 MULINEN, Frédéric de, «Instruction du droit de la guerre dans les forces armées. Vingt années d'expériences », in RICR, n764, op.cit., p. 171.

2000 DAVID, Eric, Principe de droit des conflits armés, $5^{\mathrm{e}}$ édition, op.cit., pp. 638-639; DEYRA, Michel, Le droit dans la guerre, op.cit., p. 163 ; Préparation de la Réunion du Groupe d'experts intergouvernemental pour la protection des victimes (Genève, 23-27 janvier 1995), Note du gouvernement Suisse, Genève, mars 1994, in RICR, n809, CICR, Genève, septembre - octobre 1994, p. 459.

2001 Comité des droits de l'enfant, Examen des Rapports présentés par les Etats parties en application de l'article 44 de la Convention, Rapports initiaux des Etats parties devant être soumis en 1992, additif, République Démocratique $d u \quad$ Congo, CRC/C/3/Add.57, $8 \quad$ août $2000, \quad$ p. $16, \quad \S 49, \quad$ in http://tbinternet.ohchr.org/ layouts/treatybodyexternal/TBSearch.aspx?Lang=en\&TreatyID=5\&TreatyID=10\&T reatyID=11\&DocTypeID=29\&DocTypeCategoryID=4 (Source consultée le 20 décembre 2015).

2002 Comité des droits de l'enfant, Examen des Rapports présentés par les Etats parties en application de l'article 44 de la Convention, Rapports périodiques des Etats parties devant être soumis en 1997, République Démocratique du Congo, CRC/C/COD/2, 24 juillet 2008, op.cit., pp. 16-17, §§60-64. 
Bureau National pour la Démobilisation et la Réinsertion (BUNADER, créé par l'arrêté n 001/2001 du 13 janvier 2001). La CONADER est elle-même remplacée depuis 2007 par l'Unité d'Exécution du Programme National de Désarmement, Démobilisation et Réinsertion (UEPNDDR) à la suite de l'Ordonnance n07/057 du 14 juillet 2007 (cf. infra). Cette Unité travaillait en étroite collaboration avec l'UNICEF, la MONUSCO et le CICR. Ainsi, à l'époque de la CONADER, des affiches, brochures, dépliants et panneaux avec un message principal «Plus jamais un seul enfant dans les forces et groupes armés » adressé à la communauté nationale étaient édités et traduits en quatre langues nationales ${ }^{2003}$.

Le gouvernement congolais reconnaît tout de même dans son Rapport périodique soumis en 2007 au Comité des droits de l'enfant que les populations civiles en zones rurales sont en marge des débats sur les droits de l'enfant. D'où un grand effort à fournir en leur faveur surtout que c'est elles qui se trouvent plus exposées en zones de conflits ${ }^{2004}$.

Par ailleurs, la promotion des règles du DIH en général et de celles protégeant les enfants en temps de conflits armés, en particulier, en zones urbaines comme en zones rurales, est largement soutenue par le CICR , l'UNICEF, la MONUSCO, des ONG en RDC. Limitonsnous ici au CICR pour dire ce qui suit.

Présent en RDC depuis 1978, le CICR a tout au long des conflits armés en RDC réservé une place de choix dans son programme à la promotion des règles du DIH dont celles relatives à la protection des enfants en général en période des hostilités et celles liées à l'interdiction de recrutement et de participation des enfants aux hostilités. Ces règles sont donc enseignées aux membres de forces et groupes armés, de la police et à la population civile. Au-delà de tout, une diplomatie humanitaire agissante déployée par le CICR permet à ses délégués de garder un contact permanent avec les membres de forces et groupes armés afin de les amener à observer les règles de protection de l'enfant.

A titre illustratif, en fin d'année 2000, un séminaire de promotion du DIH était organisé à Kinshasa depuis 1998, à l'attention de 48 officiers supérieurs de l'Etat Major interarmées de la force d'intervention spéciale, des forces terrestres, aériennes et navales. Un autre séminaire en même période sur la chirurgie de guerre était tenu à l'attention de 56 médecins et infirmiers des $\mathrm{FAC}^{2005}$. Entre juillet et septembre 2002, un atelier sur la mise en œuvre du

\footnotetext{
${ }^{2003}$ Voy. Comité des droits de l'enfant, Examen des Rapports présentés par les Etats parties en application du paragraphe 1 de l'article 8 du Protocole facultatif à la Convention relative aux droits de l'enfant, concernant l'implication d'enfants dans les conflits armés, Rapports initiaux des Etats parties attendus en 2004, République Démocratique du Congo, CRC/C/OPAC/COD/1, 18 avril 2011, pp. 22 et 24, §§93-94 et 98.

${ }^{2004}$ Comité des droits de l'enfant, Examen des Rapports présentés par les Etats parties en application de l'article 44 de la Convention, Rapports périodiques des Etats parties devant être soumis en 1997, République Démocratique $d u \quad$ Congo, $\quad \mathrm{CRC} / \mathrm{C} / \mathrm{COD} / 2, \quad 24$ juillet 2008, p. 18, $\$ 65$, in http://tbinternet.ohchr.org/_layouts/treatybodyexternal/TBSearch.aspx?Lang=en\&TreatyID=5\&TreatyID=10\&T reatyID=11\&DocTypeID=29\&DocTypeCategoryID=4 (Source consultée le 20 décembre 2015).

${ }^{2005}$ MUMBALA Abelungu, Junior, De l'application du droit international humanitaire en situation de conflits armés (Etude de cas de la RDC), Chaire Unesco des droits de l'Homme, Université de Lubumbashi, 2007-2008, p. 91. MUMBALA Abelungu, Junior «Le droit international humanitaire sur le champs de bataille : mythe ou réalité ? cas du conflit armé en République Démocratique du Congo », in KIZOBO, Obweng (dir.), Actes des journées scientifiques de l'Institut Supérieur de Commerce de Lubumbashi, Presses Universitaires de Lubumbashi, Lubumbashi, 2010, p. 143.
} 
DIH dans les lieux de détention était organisé au profit des responsables œuvrant dans ce secteur par le CICR et les Ministères de la justice et des droits Humains de la RDC. Suivant toujours la même période, un séminaire sur le DIH a été tenu à Mbandaka (ex-Equateur) à l'attention des officiers des FAC. De nombreuses séances de sensibilisation sur le DIH à l'endroit d'autres officiers des FAC ont été organisées à Mitwaba, Kikanda, Malemba Nkulu et Kamina à l'ex- Katanga ainsi qu'à Mbanza Ngungu, Matadi et Kitona dans l'ex- BasCongo $^{2006}$. Au courant du troisième trimestre de l'année 2013, par exemple, la diffusion du DIH et de l'action humanitaire du CICR a été entreprise auprès des membres de forces armées et de sécurité (près de 4900), des groupes armés (200) et de la société civile (2781). Les provinces du Nord et du Sud Kivu, du Katanga, de la Province orientale, du Kasaï occidental et de Kinshasa ont été des cibles ${ }^{2007}$. En 2015, de janvier à juin, le CICR a tenu de nombreuses activités de formation ou de sensibilisation aux normes du DIH. Le public cible est constitué notamment des officiers d'état-major (180) de Bukavu, Goma, Kisangani, Lubumbashi, Kamina et Kinshasa et des officiers (80) de la $25^{\mathrm{e}}$ promotion de l'école de commandement et d'Etat-major. Ont été également concernés par ces sensibilisations les autres membres de FARDC et de la MONUSCO (plus de 1300), de la PNC du Nord-Kivu (252), de la légion nationale d'intervention (100), des groupes armés (plus de 290) et de la société civile (plus de 4400), etc. ${ }^{2008}$ Suivant cette même période de l'année 2015, il faudrait souligner la diplomatie humanitaire agissante menée par le CICR auprès des forces et groupes armés afin de leur rappeler les règles du DIH relatives à la protection des civils. 135 démarches écrites ou orales sont signalées à cet effet ${ }^{2009}$.

Rappelons que «[1]' instruction du droit de la guerre doit débuter en temps de paix tout en ayant en vue la guerre ${ }^{2010}$. Ainsi des notions de base du DIH sont enseignées notamment dans les écoles militaires congolaises dont l'Académie militaire de Kananga (ex- Ecole de Formation des Officier (EFO)). Il existe par ailleurs des institutions étrangères spécialisées dans l'organisation des cours internationaux de DIH à l'attention des officiers des forces armées. C'est le Cas de l'Institut International de Droit humanitaire de San Remo (Italie) ${ }^{2011}$. «En organisant à San Remo des Cours internationaux sur le droit des conflits armés pour officier, l'Institut international de droit humanitaire entend aider les gouvernements à se conformer à leur obligation d'assurer le respect du droit des conflits armés ou droit de la guerre dans leurs forces armées $»^{2012}$. Lors de nos passages à ce prestigieux institut pour suivre le $23^{\mathrm{e}}$ Cours avancé sur le Droit des conflits armés (30 septembre - 04 octobre 2013) et le $31^{\mathrm{e}}$ Cours pour les Directeurs de programmes de formation en Droit international

\footnotetext{
2006 Ibid.

2007 CICR, Délégation de Kinshasa, Principales activités du CICR en RDC, CICR, octobre 2013, in http://www.afriquinfos.com/articles/2013/10/23/principales-activites-cicr-234728.asp (Source consultée le 06 décembre 2013).

${ }^{2008}$ CICR, Délégation du CICR en RDC, Principales activités du CICR en RDC. Faits \& chiffres. Janvier-Juin 2015, in https://www.icrc.org/fr/document/republique-democratique-du-congo-faits-essentiels-janvier-juin-2015 (Source consultée le 06 décembre 2015).

${ }^{2009}$ Ibid.

2010 MULINEN, Frédéric de, «Instruction du droit de la guerre dans les forces armées. Vingt années d'expériences », in RICR, $\mathrm{n}^{\circ} 764$, op.cit., p. 171 ; Lire avec intérêt HAMPSON, Françoise J., « Combattre dans les règles : instruction aux forces armées en matière de droit humanitaire », in RICR, $\mathrm{n}^{\circ} 776$, mars-avril 1989, pp. 117-131.

${ }^{2011}$ Voy. http://www.iihl.org/ (Source consultée le 06 décembre 2015).

2012 MULINEN, Frédéric de, «Instruction du droit de la guerre dans les forces armées. Vingt années d'expériences », in RICR, n764, op.cit., p. 179.
} 
humanitaire (01-05 septembre 2014), aucune présence d'officier militaire congolais n'a été signalée. En revanche, des représentants des Etats tels que Burkina Faso, Burundi, République centrafricaine, Comores, France, Israël, Côte d'Ivoire, Nigeria, Ghana, Guinée Conakry, Mali, Madagascar, Sénégal, etc. étaient présents. Et donc, pour un temps où les violations du DIH sont fréquentes, rater de telles assises n'est point compréhensible.

En outre, de plus en plus, le CICR s'intéresse aux milieux universitaire en renforçant la capacité des étudiants dans le domaine de DIH. Ainsi, il organise des séminaires et sensibilise des étudiants sur la question. L'on note, par exemple, la sensibilisation de 1300 étudiants en droit et en relations internationales sur le DIH au premier trimestre $2015^{2013}$. D'autre part, le CICR organise et soutient des concours de plaidoiries de DIH dans les milieux universitaires. C'est le cas de l'organisation par lui du concours national de droit international humanitaire dont la première édition a eu lieu du 25 au 27 octobre 2010. Ou encore de son soutien au Concours régional de plaidoiries des Grands lacs en droit international humanitaire et des droits humains ${ }^{2014}$.

D'après le Responsable de la communication du CICR/RDC (2013), Annick Bouvier, le CICR ne cesse de faire passer le message de respect du DIH applicable aux enfants aux forces et groupes armés. Mais en dépit de cette insistance, le recrutement d'enfants au Kivu demeure un phénomène courant ${ }^{2015}$.

Par ailleurs, « il n'est guère de diffusion qui puisse atteindre ses buts [...] sans que les moyens de communication de masse ne soient mis à contribution ${ }^{2016}$. Et « la musique apparaît à coup sûr comme l'instrument idéal pour la réalisation de la tâche de diffusion ${ }^{2017}$. Ainsi, pour un Etat dont la capitale est réputée «capitale de la musique africaine », il est plus qu'important de se servir de ce moyen pour diffuser les règles du DIH. En Côte d'Ivoire, à titre exemplatif, le CICR avait produit en 2006 un album musical Refrain humanitaire, interprété par des artistes locaux, en vue de sensibiliser le grand public à ses principes d'action et au respect de ses emblèmes ${ }^{2018}$.

En RDC, en dehors des chansons à «l'honneur du Chef », face à la guerre, les gouvernements successifs se sont lancés dans plus de sponsorisation de chansons patriotiques où la «paix » était prônée. On citera par exemple la Chanson Tokufa pona Congo [Mourir pour le Congo] ou débat national. Lesquelles ont été interprétées, dès les premières années (1998-1999) de la «deuxième guerre de libération», par les grandes stars de la musique congolaise respectivement pour la sensibilisation de la population pour lutter contre l'« envahisseur » et

2013 CICR, Délégation du CICR en RDC, Principales activités du CICR en RDC. Faits \& chiffres, Janvier-Juin 2015, Rapport d'activités, op. cit., in https://www.icrc.org/fr/document/republique-democratique-du-congofaits-essentiels-janvier-juin-2015 (Source consultée le 16 décembre 2015).

${ }^{2014}$ http://www.iphr-ipdh.org/concours-dih-dh-2015.html (Source consultée le 16 décembre 2015).

2015 Lire «76 anciens enfants soldats réunifiés avec leurs proches par le CICR », in http://www.souslemanguier.com/nouvelles/news.asp?id=11\&idnews=56505\&pays=148\&rub=1 (Source consultée le 06 décembre 2015). Lire aussi CICR, «République démocratique du Congo : lutter contre le recrutement des enfants », in https://www.icrc.org/fr/document/republique-democratique-du-congo-lutter-contrele-recrutement-des-enfants (Source consultée le 07 décembre 2015).

${ }^{2016}$ MUTOY, Mubiala, «Les Etats africains et la promotion des principes humanitaires », in RICR, $\mathrm{n}^{\circ} 776$, CICR, mars-avril 1989, p. 114.

2017 Ibid.

2018 PICCININI, Carlo, «Refrain humanitaire : un projet musical du CICR », in https://www.icrc.org/fre/resources/documents/film/cote-ivoire-video-180906.htm (Source consultée le 16 décembre 2016). 
pour l'organisation du dialogue national. Les règles du DIH n'ont donc pas de place dans de telles chansons connues d'ailleurs du grand public.

Toutefois, dans le domaine de la protection de l'enfant, il existe une excellente chanson interprétée par l'artiste musicien Jean Goubald Kalala, intitulée Bayibi nga bomuana ${ }^{2019}$ (Ils m'ont volé mon enfance). L'artiste dénonce, en gros, le phénomène «Enfants soldats » au profit d'une enfance saine. Une telle chanson dans le contexte congolais devrait en principe bénéficier d'un soutien étatique. Mais, on en est encore très loin!

De tout ce qui précède, la prévention des violations des règles du DIH assurant la protection de l'enfant ne se limite pas en phase de «diffusion». D'autres mesures ou mécanismes devraient être institués. C'est le cas, par exemple, de la Commission nationale de mise en œuvre du DIH comme c'est le cas dans de nombreux pays du monde (cf. supra). La création d'une telle commission est d'ailleurs perçue par le CICR comme « une mesure essentielle pour faire appliquer le droit international humanitaire ${ }^{2020}$. Elle se charge généralement d'aider les autorités gouvernementales dans l'adoption des textes législatifs et réglementaires d'application du DIH et dans la diffusion de ce droit ${ }^{2021}$. Après près de deux décennies de conflits armés, la RDC n'a toujours pas un organisme national de mise en œuvre du DIH. La mise en œuvre du DIH reste du ressort des mécanismes des droits de l'homme avec toutes les conséquences de brouillage de sa spécificité. En revanche, il ne sera point nié certains efforts que fournit l'Etat congolais notamment dans l'adoption des lois protégeant l'enfant. Il s'agit par exemple de la loi portant protection de l'enfant du 09 janvier 2009 et des lois sur les violences sexuelles du 20 juillet 2006 (cf. infra). La création de certains mécanismes nationaux prenant en charge la question de l'enfant rentre également dans ce cadre (cf. infra). Le problème réside plus dans le fonctionnement de ces mécanismes. Lesquels sont généralement dépourvus des moyens conséquents pour mener à bien leurs missions.

De nombreuses activités de promotion des règles du DIH protégeant les enfants en situation de conflits armés sont fréquemment rappelées par les ONG œuvrant en RDC. Ainsi, lors des journées internationales des enfants soldats (12 février) ou des droits de l'enfant (20 novembre) ou encore de la journée de l'enfant africain (16 juin), des campagnes sont organisées dans différentes villes du pays par des ONG de protection de l'enfant, appelant au respect de ces règles (cf. Section IV du présent chapitre, §2). Il existe même des ONG spécialisées dans la diffusion du DIH. C'est le cas de l'Agence de Diffusion du Droit international Humanitaire en Afrique Centrale (ADDIHAC). Créée le 25 septembre 1993 à Kinshasa, l'ADDIHAC est une ONG de droit congolais. Une de ses missions consiste à la diffusion du DIH en organisant des conférences, des séminaires, des colloques, représentations théâtrales, des campagnes de sensibilisation et des publications mensuelles

\footnotetext{
2019 Voy. https://www.youtube.com/watch?v=pLsw77jEjuo\&list=RDpLsw77jEjuo\#t=2 (Source consultée le 16 décembre 2015).

2020 Préparation de la Réunion du Groupe d'experts intergouvernemental pour la protection des victimes (Genève, 23-27 janvier 1995), Protection des victimes de la guerre - Suggestions du Comité international de la Croix-Rouge, Genève, avril 1994, in RICR, n809, CICR, Genève, septembre - octobre 1994, p. 469.

${ }^{2021}$ Voy. par exemple les rôles des Commissions nationales de mise du DIH en Argentine, en Bolivie ou en Uruguay, voy. DUTLI, Maria Teresa, « Mise en œuvre du droit international humanitaire - Mesures nationales informations reçues par le Comité international de la Croix-Rouge sur les mesures nationales de mise en œuvre adoptées par les Etats », in RICR, n 809, CICR. Genève, septembre - octobre 1994, pp. 508-510.
} 


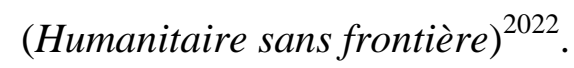

En conclusion, la promotion du DIH en vue de prévenir les violations des règles de protection de l'enfant en RDC reste en grande partie l'œuvre du CICR et de nombreuses autres ONG. Le CICR fait davantage usage d'une diplomatie humanitaire agissante à ce sujet. Bien que la diffusion du DIH soit une obligation à la fois internationale et constitutionnelle en RDC, il se pose encore des problèmes pour des mécanismes de mise en œuvre sous cet angle. On note d'une part l'absence de mécanisme tel que la Commission nationale de mise en œuvre du DIH. Laquelle devrait aider le gouvernement à la fois dans la diffusion et dans l'adoption des lois et règlements dans ce sens. D'autre part, les moyens de communication de masse dont la chanson ne sont pas suffisamment exploités pour faire passer le message humanitaire. Les ONG œuvrant dans le domaine de protection de l'enfant sont, par ailleurs, d'un apport très positif dans la sensibilisation des règles de protection de l'enfant. Toutefois, la sensibilisation aux règles du DIH de protection de l'enfant, voire des droits de l'homme, n'est nullement synonyme de respect de ces règles. Il faudrait encore d'autres mécanismes dont les mécanismes de contrôle.

\section{\$2 Mécanismes de contrôle du droit international humanitaire en RDC : le CICR et la protection des enfants en situation de conflits armés en RDC}

Rappelons qu'aux premières années des conflits armés en RDC, les parties au conflit étatiques et non étatiques - ont conclu l'Accord de Lusaka, un accord de paix impliquant le cessez-le-feu (cf. supra). Celui-ci indiquait en son article $1^{\text {er }} \S 3$ que le cessez-le-feu comportait la cessation de tous les actes de violence contre la population civile dont le recrutement et l'utilisation des enfants soldats.

Force est de constater que la mise en œuvre des dispositions substantielles de cet accord ont été problématiques. Ce qui vaut de même pour d'autres accords subséquents conclus dans ce cadre. Or, le fait pour les parties d'avoir reconnu, à travers l'Accord de Lusaka, la gravité des violations des droits humains et du DIH, et décidé d'elles-mêmes de mettre fin à cette pratique devrait constituer un élément efficace à son application. Mais hélas! l'application de l'Accord de Lusaka s'est avérée hypothétique. Des raisons sont avancées pour justifier une telle situation. D'aucuns considèrent que les nombreuses violations de l'Accord de Lusaka et le manque réel de volonté politique des parties signataires quant à sa mise en œuvre, témoignent de la fragilité des bases sur lesquelles il a été conclu ${ }^{2023}$. Ainsi, cet accord «n'est plus ni moins un marché des dupes, un habile arrangement qui porte en lui-même des dispositions et des non-dits qui en rendent l'application hypothétique ${ }^{2024}$. D'autres estiment que «les accords de Lusaka ne seront pas appliqués parce qu'ils contiennent trois erreurs fatales à savoir : le manque de la qualification de la nature du conflit [Pas au sens du DIH], la non-identification de belligérants ainsi que l'absence de la considération des enjeux de la guerre $»^{2025}$.

En effet, l'Accord de Lusaka, doit-on le dire, a éludé les «vraies bases » du conflit en RDC. Il

\footnotetext{
${ }^{2022}$ Voy. http://www.addihac.centerall.com/ (Source consultée le 15 décembre 2015).

${ }^{2023}$ MUKULUMANYA wa Ngate Zenda, La guerre de l'Est : enjeux, Vérités Oubliées et Perspectives de paix, op.cit., p.14.

${ }^{2024}$ Ibid.

${ }^{2025}$ MALEMBA M. N'Sakila, Identité post-tribale au Congo Kinshasa, op. cit., pp.109-110.
} 
ne s'est préoccupé que des conséquences. Seules les préoccupations sécuritaires étaient au centre $^{2026}$. Il devait au départ cerner les causes profondes ${ }^{2027}$ ou les vrais enjeux du conflit dont l'enjeu économique. Lequel semble plus préoccupant. Qualifiée de «scandale géologique », la RDC détient d'innombrables richesses : le gaz méthane des lacs, l'or des montagnes, les verts pâturages, le pétrole sous terre... qui sont là des repères qui exposent la population à la haine et à la convoitise aveugle d'autres parties - étatiques et non étatique ${ }^{2028}$. Bien plus, il est d'un argument de l'ordre des Relations internationales, un secret de polichinelle, que la RDC a connu ou connaît un «conflit ou guerre par procuration $»^{2029}$. Ceci pour dire que certaines puissances, plus préoccupées par la conquête des richesses dont regorge la RDC, et profitant de l' «inexistence » de cet Etat, se servent des pays voisins de l'est (Burundi, Ouganda, Rwanda) voire des mouvements rebelles en les armant superbement pour mettre à terre l'armée congolaise (cf. supra). Le fait pour l'Accord de Lusaka de ne pas prendre en compte ces « acteurs invisibles » et de ne se contenter que des « acteurs visibles ou apparents » des conflits, a occasionné son mauvais départ qui sera très conséquent sur son application. En dépit de sa qualification de fondement essentiel du processus de paix en RDC par la communauté internationale ${ }^{2030}$ (cf. supra), l'Accord de Lusaka, sauf quelques exceptions près, ne sera donc pas mis en application comme souhaité. D'où les rappels fréquents faits par le CS/NU aux parties de l'appliquer (cf. supra).

Cependant, signifions que dans le processus de la mise en œuvre des dispositions de l'Accord de Lusaka, il a été convenu par les parties d'instituer la Commission Militaire Mixte (CMM). Composée des représentants des parties et dirigée par un Président neutre désigné par l'UA (ex OUA), la CMM sera chargée de régler et de surveiller la cessation des hostilités telle que prévue par l'accord ${ }^{2031}$.

En ce qui concerne le CICR, les parties à l'Accord de Lusaka se sont convenues de permettre son accès immédiat et sans réserve « afin de permettre les arrangements pour la libération des prisonniers de guerre et autres personnes détenues en raison de la guerre ainsi que l'évacuation et l'inhumation des morts et les soins aux blessés ${ }^{2032}$. Au regard du point $3.1 \mathrm{du}$ Chapitre 3 de l'annexe « $\mathrm{A}$ » dudit accord, les parties ont l'obligation de coopérer avec les délégués du CICR en leur fournissant renseignements et assistance nécessaires.

\footnotetext{
${ }^{2026}$ Lire les articles II et III (précisément les points 20, 21, 22) de l'Accord de Lusaka.

${ }^{2027}$ KITIMA Kasendwe, Jean-Lucien épingle par exemple comme causes constantes de l'insécurité ou facteurs déstabilisateurs dans la région des Grands Lacs : 1. La présence des milices surarmées et incontrôlées ; 2 . La perméabilité des frontières, d'où des incursions fréquentes; 3. L'exode massif et inédit des populations (Réfugiés et personnes déplacées); 4. La culture de la haine et de la vengeance (intolérance); 5 . La prééminence des solutions militaires aux problèmes des sociétés ; 5. L'état critique et parfois précaire des droits humains et des droits humanitaires ; 6. La recrudescence des conflits interethniques ; 7. Les relations orageuses dans les rapports entre Etats; 9. La précarité des institutions nationales (source du sous-développement généralisé), 10. Les guerres civiles sans nombre; 11. La situation préoccupante des économies des pays de la sous-région (mauvaise gestion et pauvreté grandissante). Voy. KITIMA Kasendwe, Jean-Lucien, «Les Relations Internationales post-conflit : cas de la RDC», « art.cit. », 72. Il est à remarquer que les vraies causes du conflit armé en RDC seront renvoyées pour traitement au dialogue national ouvert conformément à l'article III, point 19, de l'Accord de Lusaka.

${ }^{2028}$ Voy. KITIMA Kasendwe, Jean-Lucien, «Les Relations Internationales post-conflit: cas de la RDC», «art.cit. », pp. $70-71$.

${ }^{2029}$ Ibid., p. 70.

${ }^{2030}$ Lire NGOY, Théodore, L'Accord de Lusaka : la paix piégée, op.cit.,, pp. 2-3.

${ }^{2031}$ Lire Chapitre 7 de l'Accord de cessez-le feu de Lusaka

${ }^{2032}$ Lire Point 9 de l'article III de l'accord de l'Accord de Lusaka
} 
Et sur le terrain, le CICR a répondu à son obligation telle que prévue par l'accord. Dans le même ordre d'idée, il ne s'est pas empêché d'accomplir ses tâches humanitaires « naturelles » conformément aux CG et PA, précisément au bénéfice des enfants . Démontrons dans les lignes qui suivent quelques exemples des missions remplies par cet organisme.

En RDC, rappelons que le CICR est présent depuis 1978. Il est formé actuellement d'une délégation à Kinshasa et de sous-délégations à Bukavu, Goma, Kisangani et Lubumbashi ainsi que des bureaux à Manono, Uvira, Beni et Bunia ${ }^{2033}$. La lecture de différents rapports d'activités de cet organisme en RDC renseignent en général que celui-ci se focalise sur la prévention des violences à l'encontre des civils; les visites des personnes privées de liberté; la réunification des familles séparées par les conflits; l'amélioration des soins de santé; la subvention aux besoins essentiels; les facilités d'accès à l'eau et l'amélioration d'assainissement; la coopération et le soutien à la société nationale de la Croix-Rouge (CroixRouge/RDC) ; et la promotion du DIH et de l'action humanitaire du $\mathrm{CICR}^{2034}$. Il revient de constater que, sans faire expressément allusion aux enfants, toutes ces activités sont également profitables aux enfants en leur qualité notamment de personnes civiles voire de combattants ou participant aux hostilités. Elles rentrent donc dans le cadre de protection générale des enfants. Ces activités sont déployées indistinctement dans les cas de CANI ou de CAI.

Par ailleurs, concernant la protection spéciale des enfants en conflits armés en RDC, il y a lieu d'indiquer que « [...] le CICR travaille à renforcer la protection des mineurs à travers des activités de sensibilisation auprès des porteurs d'armes pour prévenir leur enrôlement, en facilitant le retour des enfants auprès de leurs familles et communautés et en soutenant des activités visant à prévenir qu'ils soient recrutés à nouveau ${ }^{2035}$. De la vie de «combattant » à la vie civile, les enfants passent par un temps d'attente (quelques mois) aux Centres de transit et d'orientation érigés par le CICR dans différentes zones de conflits en RDC. Ils y réapprennent la vie civile pour une réintégration sans difficultés dans leurs familles ou communautés. Les «capacités d'autoprotection» des enfants contre des nouveaux recrutements sont développées pendant leur séjour aux Centres. Des séances de sensibilisation à l'endroit des communautés sont également incluses. Dans ce processus de réintégration, le CICR investit dans la formation professionnelle des enfants. Ensemble avec la Croix-Rouge de la RDC, il organise des activités ludiques et récréatives impliquant tous les enfants, question d'inclure les ex-enrôlés ${ }^{2036}$.

Il va sans dire que les activités de protection qu'entreprend le CICR sur les enfants concernent spécifiquement le rétablissement des liens familiaux, des visites aux enfants privés de libertés bien que non indiqués expressément dans les différents rapports établis et la

\footnotetext{
${ }^{2033}$ Lire CICR, Délégation du CICR en RDC, Principales activités du CICR en RDC. Faits \& chiffres. JanvierJuin 2015, Rapport d'Activités, op. cit., in https://www.icrc.org/fr/document/republique-democratique-ducongo-faits-essentiels-janvier-juin-2015 (Source consultée le 06 décembre 2015).

${ }^{2034}$ Lire les différents rapports d'activités du CICR repris dans cette partie du travail pour s'en rendre compte.

${ }^{2035}$ CICR, «République démocratique du Congo: lutter contre le recrutement des enfants», in https://www.icrc.org/fr/document/republique-democratique-du-congo-lutter-contre-le-recrutement-des-enfants (Source consultée le 07 décembre 2015).

2036 Voy. CICR, «République démocratique du Congo: lutter contre le recrutement des enfants», in https://www.icrc.org/fr/document/republique-democratique-du-congo-lutter-contre-le-recrutement-des-enfants (Source consultée le 07 décembre 2015).
} 
protection proprement dite des enfants touchés par des violences armées à l'instar de la population civile en général. C'est à travers ce dernier type d'activités qu'il sied d'épingler la diplomatie humanitaire agissante que mène le CICR en faveur des enfants enrôlés par des forces et groupes armés. Cette diplomatie humanitaire permet d'une part aux membres de forces et groupes armés de respecter les règles du DIH protégeant l'enfant et d'autre part, d'ouvrir la voie vers la démobilisation de ces enfants. Ainsi, les lignes suivantes détaillent quelques illustrations du rôle du CICR dans ce cadre.

Rappelons que juste quelques semaines après le déclenchement de la «deuxième guerre de libération », le 28 septembre 1998, sur instruction du Chef de l'Etat congolais, le Ministre de la Justice et celui des Droits Humains ont adopté une note conjointe fixant au profit du CICR les conditions d'accès aux combattants et autres personnes capturées ainsi qu'aux détenus de guerre $^{2037}$. Les délégués du CICR se rendront donc dans tous les lieux où se trouvent des personnes protégées, prisonniers de guerre ou internés civils pour s'entretenir avec eux sans témoin, ${ }^{2038}$ en vertu du «droit d'initiative» dont dispose le CICR (cf. supra). Cette note conjointe est prise indépendamment de tout accord international. Par la suite, le CICR déploiera ses activités dans différents domaines et zones de conflits armés en RDC. Bien plus, le CICR travaille en étroite collaboration avec l'Unité d'Exécution du Programme National de Désarmement, Démobilisation et Réinsertion (UEPNDDR), la structure nationale de DDR, sur les questions de DDR.

En effet, dans son rapport de l'année 2000 "intitulé » Le C.I.C.R. en action en République Démocratique du Congo octobre - décembre 2000, par exemple, le C.I.C.R articulait son action en RDC autour de trois axes: 1. la réponse aux impératifs provoqués par le conflit ; 2 . la collaboration avec les autorités nationales pour assurer le respect du DIH et sa mise en œuvre, 3. le soutien à la Croix - Rouge de la RDC forte de quelques 40.000 volontaires actifs dans tout le pays ${ }^{2039}$. Ainsi, de nombreux déplacés ont été assistés: l'on dénombre à l'exKatanga 2.600 personnes déplacées bénéficiant d'un séminaire agricole de base ; une assistance non-alimentaire entreprise à l'endroit de 1.100 familles de novembre 2000 à février 2001 au Kasaï Oriental ; la remise de 68 bâches aux déplacés en ex-Equateur; le retour de 7.050 personnes déplacées dans le Masisi (Nord-Kivu); l'assistance en nourriture et matériels à 32.500 déplacés à Bukavu, à 10.000 déplacés dans la région semi-rurale de Kabara et de Walungu, et à 10.300 autres déplacés à UVIRA ; la réhabilitation de la ligne électrique alimentant l'Hôpital de Kadutu (Bukavu) et l'installation d'un réservoir d'eau de $10 \mathrm{~m}^{3}$ pour cet hôpital et l'achèvement d'un projet d'alimentation en eau potable à 40.000 personne ; etc. ${ }^{2040}$ Les priorités de l'année 2002 s'inscrivent dans cette même logique avec l'ajout de

\footnotetext{
${ }^{2037}$ Ministère des Droits Humains, Livre Blanc sur les Violations massives des Droits de l'Homme et des règles de base du Droit International Humanitaire par les pays agresseurs (Ouganda, Rwanda, Burundi) à l'Est de La République Démocratique du Congo couvrant la période du 2 avril 1998 au 5 novembre 1998, Kinshasa, CEDI, 1999.

2038 CICR, Comprendre le Droit Humanitaire, règles essentielles des Conventions de Genève et de leurs Protocoles additionnels, CICR., Genève, septembre 1983 - 1990, p. 10.

${ }^{2039}$ MUMBALA Abelungu, Junior, De l'application du droit international humanitaire en situation des conflits armés (Etude de cas de la RDC), Chaire Unesco des droits de l'Homme, Université de Lubumbashi, 2007-2008, op. cit., p. 91. MUMBALA Abelungu, Junior «Le droit international humanitaire sur le champs de bataille : mythe ou réalité ? cas du conflit armé en République Démocratique du Congo », « art. cit. », p. 143.

${ }^{2040}$ MUMBALA Abelungu, Junior, De l'application du droit international humanitaire en situation des conflits armés (Etude de cas de la RDC), Chaire Unesco des droits de l'Homme, Université de Lubumbashi, 2007-2008,
} 
l'élément rétablissement des liens familiaux.

Les activités d'assistance humanitaire demeurent l'essentiel des activités du CICR en RDC. Elles sont donc profitables aux enfants et renforcent leur protection en période des conflits armés. L'intention de renforcer ces activités en travaillant en collaboration avec les partenaires gouvernementaux, au profit des personnes affectées par les conflits dont les enfants au Nord et au Sud-Kivu, a été réitérée en 2007 par le Chef de la délégation du CICR, Monsieur Max Hadorn ${ }^{2041}$.

De janvier à mars 2008, les activités traditionnelles du CICR de rétablissement des liens familiaux ont abouti notamment à la réunification de 61 enfants avec leurs proches dont 12 cas d'anciens enrôlés des forces et groupes armés. 115 demandes de recherche ont reçu des réponses positives, à coté de 13.287 «Messages Croix-Rouge » collectés. Plusieurs centaines d'autres cas d'enfants non accompagnés et de demandes de recherche étaient en étude. La diplomatie humanitaire reste maintenue avec les forces et groupes armés afin de venir en assistance aux victimes des conflits armés et de prévenir des atteintes à leur vie et dignité ${ }^{2042}$. Bien que le Rapport du CICR n'indique pas le nombre d'enfants privés de liberté et visités, l'on dénombre néanmoins un effectif de 5.976 détenus en général visités en cette période. La prévention aux atteintes à la vie et à l'intégrité physique des civils dont les enfants sont également dans l'ordre du jour ${ }^{2043}$.

Il est important de préciser que cette période est une de celles délicates des conflits armés en RDC. Il s'agit de la période pendant laquelle est conclu l'Acte d'engagement de Goma. Lequel intervient à la suite de la Conférence sur la paix, la sécurité et le développement du 06 au 23 janvier 2008. Alors qu'un cessez-le feu immédiat était prévu avec retrait des troupes des parties adverses, les hostilités ont repris leur cour normal dès les dernières semaines de février de cette même année, précisément entre le CNDP et les Maï-Maï. Des populations civiles étaient contraintes de fuir les territoires de Rutshuru et Masisi (Nord-Kivu). Certaines ont continué de vivre dans des conditions précaires à Kibirizi, Kitchanga, Pinza, Buguri (NordKivu) et Minova (Sud-Kivu). Des cas de pillage, viols, violences sexuelles, actes de torture et de recrutements forcés sont demeurés élevés dans le chef des porteurs d'armes. Le CICR s'est servi de témoignages des victimes tout en gardant leur anonymat pour entrer en dialogue confidentiel avec ses partenaires - membres des forces armées et groupes armés ${ }^{2044}$.

De nombreuses personnes touchées par les conflits armés - dont les enfants- en Provinces du Nord et du Sud-Kivu, anciennes provinces Orientale et de l'Equateur restent marquées par

op. cit., p. 92. MUMBALA Abelungu, Junior «Le droit international humanitaire sur le champs de bataille : mythe ou réalité ? cas du conflit armé en République Démocratique du Congo », « art. cit. », p.144.

2041 Radio Okapi, «Kinshasa : conflits armés en RDC, le CICR veut amplifier ses activités », in http://www.radiookapi.net/sans-categorie/2007/02/08/kinshasa-conflits-armes-en-rdc-le-cicr-veut-amplifier-sesactivites (Source consultée le 08 décembre 2015).

${ }_{2042}$ Voy. CICR, « Activités du Comité International de la Croix-Rouge (CICR) en République démocratique du Congo, janvier-mars $2008 », \quad$ in https://appablog.wordpress.com/2008/04/30/rdc-activites-du-comiteinternational-de-la-croix-rouge-cicr-en-republique-democratique-du-congo-janvier---mars-2008/ $\quad$ (Source consultée le 07 décembre 2015).

2043 Voy. Ibid.

2044 CICR, «RDC : le point sur les activités du CICR dans les deux Kivu -janvier et février 2008 », in http://reliefweb.int/report/democratic-republic-congo/rdc-le-point-sur-les-activités-du-cicr-dans-les-deux-kivujanvier (Source consultée le 08 décembre 2015). 
l'assistance et la protection leur fournies par le CICR en 2010. Des détenus autrefois malnutris ont retrouvé la vigueur par l'assistance nutritionnelle du CICR. Six prisons ont été concernées $^{2045}$.

En 2011, le CICR a continué sur la même lancée. En effet, le déplacement forcé d'une grande partie des populations appauvries d'Ango, Banda, Doruma et Nyangara (Province Orientale) en 2008 a nécessité l'assistance du CICR. C'est ainsi par exemple qu'en 2011, pour subvenir aux besoins de ces populations agricoles - dont certaines avaient perdu leurs champs ou récoltes vivrières -, des semences et matériels aratoires ont été distribués à quelque 90.000 personnes dans le Haut et le Bas-Uélé, de même que les matériels de pêche. Par exemple, 375 tonnes de semence et d'outils pour 7000 familles de la région d'Ango et 1700 de Banda (BasUélé) ont été octroyés par le $\mathrm{CICR}^{2046}$.

Il sied d'affirmer qu'à travers ces activités agricoles, certains besoins fondamentaux de l'enfant sont résolus dont l'alimentation, l'habillement et le paiement des frais scolaires après écoulement des produits. C'est dans cette optique que le CICR a réhabilité quelques axes routiers et pistes d'atterrissage de Banda et Ango avec l'aide de la population civile moyennant des contrats de travail à courte durée. L'objectif principal est la réhabilitation de l'économie locale ${ }^{2047}$.

Au deuxième trimestre de l'année 2013, avec l'appui du CICR/RDC, 76 ex-enfants enrôlés par les forces et groupes armés au Nord et au Sud Kivu ont pu être réunifiés avec leurs familles. Pendant la même période, des visites du CICR ont été effectuées auprès de 120 autres déjà réunifiés avec leurs proches afin de s'assurer de leur intégration ${ }^{2048}$. Au cours du troisième trimestre de cette même année, il est à noter que 241 enfants ont été réunifiés avec leurs proches dont 98 anciennement enrôlés par les forces et groupes armés. Des visites auprès de 46 autres déjà réunifiés ont été effectuées. Celles-ci ont été accompagnées, selon l'âge des enfants concernés, de kit scolaire, d'outils agricoles ou de fourniture de démarrage de petit commerce. En même temps, près de 770 enfants non accompagnés et environ 350 enfants anciennement enrôlés par les forces et groupes armés étaient en attente (dans les centres de transit ou familles d'accueil) de réunification (fin septembre 2013). Toujours sous l'angle de réunification, le travail du CICR est également remarquable dans la collecte des lettres «Message Croix-Rouge ». En cette période, il est dénombré 12.200 lettres collectées dont 10.300 distribuées ${ }^{2049}$.

En 2014, durant la période de juillet à septembre, à la suite des allégations des violations du

${ }^{2045}$ CICR, le CICR en République Démocratique du Congo - Avril/Mai 2011, Bulletin CICR n¹/2011, 1 et 2 disponible in https://www.icrc.org (Source consultée le 08 décembre 2015).

${ }^{2046}$ Ibid.

2047 Ibid.

2048 Lire «76 anciens enfants soldats réunifiés avec leurs proches par le CICR», in http://www.souslemanguier.com/nouvelles/news.asp?id=11\&idnews=56505\&pays=148\&rub=1 $\quad$ (Source consultée le 06 décembre 2015). Lire aussi CICR, «République démocratique du Congo : lutter contre le recrutement des enfants », in https://www.icrc.org/fr/document/republique-democratique-du-congo-lutter-contrele-recrutement-des-enfants (Source consultée le 07 décembre 2015).

${ }^{2049}$ CICR, Délégation de Kinshasa, «Principales activités du CICR en RDC », CICR, octobre 2013, in http://www.afriquinfos.com/articles/2013/10/23/principales-activites-cicr-234728.asp (Source consultée le 06 décembre 2015). 
$\mathrm{DIH}$, le CICR a intensifié son rôle de prévention de violences à l'encontre des civils notamment par des dialogues confidentiels avec les différentes parties (étatiques et non étatiques) au conflit en RDC. Concernant particulièrement les enfants, les chiffres suivants sont à épingler : -265 enfants réunifiés avec leurs familles et 17 rapatriés afin de réunification avec leurs proches dans des pays limitrophes ; visite de 50 enfants anciennement enrôlés puis réunifiés; 520 enfants en attente de réunification dans des centres de transit et familles d'accueils. Plus précisément au Nord et au Sud Kivu, la préparation de retour de 237 enfants dont 31 filles anciennement enrôlés avait nécessité des sessions de sensibilisation auprès des enfants $^{2050}$. Par ailleurs, l'on note pour l'ensemble de cette année, un total de 283 enfants anciennement enrôlés par les forces et groupes armés réunifiés avec leurs familles par l'entremise du CICR ${ }^{2051}$.

En 2015, de janvier à juin, le CICR a effectué le rapatriement de 18 enfants vers les pays tiers et la réunification de 390 enfants avec leurs familles dont 260 anciennement enrôlés par les forces et groupes armés. Et afin de s'assurer de leur intégration, 153 enfants anciennement enrôlés et réunifiés avec leurs familles ont été visités par le CICR. Entretemps, sous le regard du CICR, 574 enfants étaient en attente de réunification et 674 autres accueillis et sensibilisés sur leur retour en famille ${ }^{2052}$.

Relativement à la mise en œuvre du DIH en CANI, par exemple, le MLC de Jean-Pierre Bemba avait donné l'impression de se soucier du DIH en instituant une «Cour martiale » pour juger les présumés auteurs des crimes commis sous leur juridiction. Celle-ci a été décriée par les ONG de défense des Droits de l'Homme dans la mesure où elle ne renfermait aucune caractéristique de justice équitable et impartiale.

Si différents rapports indiquent le nombre d'enfants ayant fait, suivant chaque période, l'objet de réunification avec leurs proches, rien n'est signifié au sujet des enfants privés de liberté. Il serait mal compris de ce point de vue d'admettre qu'il n'existe pas d'enfants privés de liberté dans un contexte où les enfants sont considérés comme des «acteurs principaux» sur les champs d'hostilités et dont les droits les plus fondamentaux sont fréquemment violés.

En effet, bien qu' «il n'existe pas un système coordonné de collecte, d'analyse et de centralisation des données [...] concernant les enfants arrêtés et détenus » ${ }^{2053}$ en RDC, les

2050 TSHISHIKU, Marcel, «Le CICR renforce son dialogue avec les parties en conflit en RDC», in http://7sur7.cd/new/cicr-renforce-dialogue-les-parties-en-conflits-en-rdc/ (Source consultée le 06 décembre 2015).

${ }^{2051}$ CICR, «République démocratique du Congo : lutter contre le recrutement des enfants », «art. cit. », in https://www.icrc.org/fr/document/republique-democratique-du-congo-lutter-contre-le-recrutement-des-enfants (Source consultée le 07 décembre 2015).

${ }^{2052}$ Lire CICR, Délégation du CICR en RDC, Principales activités du CICR en RDC. Faits \& chiffres. JanvierJuin 2015, op. cit., in https://www.icrc.org/fr/document/republique-democratique-du-congo-faits-essentielsjanvier-juin-2015 (Source consultée le 06 décembre 2015).

${ }^{2053}$ MONUC, Division droits de l'homme, Section Protection de l'enfant, Arrestation et détention dans les prisons et cachots de la RDC, Partie II, La détention des enfants et la justice pour mineurs, mars 2006, p. 3. Marcel IMAMI affirme d'ailleurs qu' "aucun organisme officiel ou privé n'a jusqu'ici (2013) été capable de dresser un mapping complet de la situation de détention des enfants sur l'ensemble du territoire national ». Voy. IMAMI, Marcel, «La justice des mineurs ou le risque de répétition de l'histoire ? Cas de la République Démocratique du Congo », in Actes du Colloque «Juvenile in justice » du 19 mars 2013 au Palais de justice de Charleroi, Emex \&InterCommunication, Spal, Bruxelles, 2014, p. 30. 
enquêtes de la Section de Protection de l'Enfant (SPE) de la MONUSCO (alors MONUC) révèlent des nombres variés d'enfants civils et militaires arrêtés et détenus. Ainsi, suivant la période de mai 2004 à décembre 2005 de ces enquêtes, « il y a en général un ou quatre enfants dans les prisons (à Beni et Kindu respectivement) alors qu'à Bunia et Kinshasa la population carcérale est la plus élevée, atteignant en général une trentaine d'enfants à Bunia et une soixantaine à Kinshasa. Mais cette information - précisent ces enquêtes - provient seulement de certains lieux, et n'inclut même pas tous les centres de détention existants dans ces lieux $»^{2054}$.

Concernant les enfants associés aux forces ou groupes armés (EAFGA), ce Rapport indique qu'ils ont été souvent arrêtés par les FARDC ou par les membres des groupes armés puis détenus dans des cachots ${ }^{2055}$. Ils sont souvent accusés de désertion voire d'autres infractions telles que violation de consigne, abandon de poste, dissipation de munition de guerre, association de malfaiteurs, détention illégale d'armes, etc ${ }^{2056}$. «Par exemple, à Bukavu, 12 EAFGA entre 13 et 14 ans avaient été arrêtés par l'auditorat militaire pour désertion en janvier $2005 »^{2057}$. «En avril 2005, sur 25 enfants détenus à la prison de Bunia, dix étaient des EAFGA accusés d'association de malfaiteurs et/ou de détention illégale d'armes ; sept d'entre eux étaient âgés de 10 ans à14 ans » ${ }^{2058}$.

Au-delà de tout, les efforts d'assistance et de protection déployés par le CICR ne sont pas sans difficultés (impraticabilité de certaines voies pour atteindre des victimes, difficultés sécuritaire et de logistique, etc.) sur le terrain.

Ainsi, sur le plan sécuritaire par exemple, les agents humanitaires ont fait ou font également l'objet d'harcèlement, de violences physiques et d'assassinats particulièrement dans l'Est du pays (cf. infra). Les attaques ciblées dont ils sont victimes entraînent souvent la réduction voire la suspension ou l'arrêt des activités humanitaires dans les zones concernées au dépens des populations civiles - dont les enfants - en détresse ${ }^{2059}$.

Par ailleurs, relativement à la protection des enfants, voire de la population civile en général, le CICR développe une diplomatie humanitaire agissante auprès des membres des forces et groupes armés afin de les amener à observer les règles de $\mathrm{DIH}$. Ce genre de dialogue confidentiel maintenu par le CICR vis-à-vis de ses partenaires (forces et groupes armés) vise notamment à insister sur les règles d'interdiction de recrutement et de participation des enfants aux hostilités. Lesquelles règles pèsent sur ces forces et groupes armés. Mais malgré les efforts que fournit le CICR non sans risque dans ce sens, les enfants continuent d'être recrutés par les groupes armés en présence ${ }^{2060}$. Il faudrait la présence des mécanismes appropriés à cet effet.

\footnotetext{
2054 MONUC, Division droits de l'homme, Section Protection de l'enfant, Arrestation et détention dans les prisons et cachots de la RDC, Partie II, La détention des enfants et la justice pour mineurs, op. cit., p. 3.

${ }^{2055}$ Ibid., p. 11.

2056 Ibid., pp.11-12.

2057 Ibid., p.11.

2058 Ibid.

${ }^{2059}$ Voy. BOGNA, Patrice, « Rôle de la MONUC face aux crises Humanitaires en République Démocratique », in Magazine MONUC $N^{\circ} 20$, janvier 2000, p. 7

2060 Voy. CICR, «République démocratique du Congo: lutter contre le recrutement des enfants », in https://www.icrc.org/fr/document/republique-democratique-du-congo-lutter-contre-le-recrutement-des-enfants (Source consultée le 07 décembre 2015).
} 


\section{Section II Mécanismes conventionnels des droits de l'homme et la protection des enfants en situation de conflits armés en RDC}

«Les mécanismes de contrôle mis en place pour lutter contre la victimisation des enfants et surtout contre le phénomène des enfants-soldats sont très hétérogènes, leur degré de contrainte est variable et ils peuvent atteindre l'Etat ou l'individu» ${ }^{2061}$. Ceci sera remarquable dans le sens des mécanismes conventionnels des droits de l'homme examinés ci-dessous.

La présente section se propose d'analyser les rôles des organes conventionnels des droits de l'homme - au plan universel et africain - sur la protection de l'enfant en situation de conflits armés en RDC. Il s'agira donc de l'étude du Comité des droits de l'enfant (§1); du Comité africain d'experts sur les droits et le bien-être de l'enfant et de la Commission africaine des droits de l'homme et des peuples, sous l'angle du système africain de protection ( $\$ 2)$; du Comité des droits de l'homme $(\S 3)$ et du Comité contre la torture $(\S 4)$.

\section{§1. Comité des droits de l'enfant}

Le Comité des droits de l'enfant est l'organe institué par la Convention relative aux droits de l'enfant (article 43) pour veiller à sa mise en œuvre par les Etats. Ces derniers soumettent des rapports sur des mesures prises «pour donner effet aux droits reconnus par [cette] convention et sur les progrès réalisés dans la jouissance de ces droits » (article 44). En vertu de l'article 8 $\mathrm{du}$ Protocole facultatif se rapportant à la Convention relative aux droits de l'enfant, concernant l'implication d'enfants dans les conflits armés, le Comité des droits de l'enfant étend sa compétence sur des dispositions consacrées dans ce dernier instrument.

Ainsi, il sera ici question d'étudier les différents rapports soumis par la RDC (avec quelques références aux Républiques du Rwanda et de l'Ouganda) au Comité des droits de l'enfant, principalement sur la situation des enfants en temps de conflits armés, sans oublier les observations finales dudit Comité à cet effet. Il s'agira des trois rapports relatifs à la mise en œuvre de la Convention relative aux droits de l'enfant et d'un rapport initial concernant le Protocole précité.

En effet, le rapport initial de la RDC devait être soumis en 1992 soit deux ans après sa ratification de la Convention relative aux droits de l'enfant, conformément à l'article $44 \mathrm{de}$ ladite convention. C'est avec retard, soit le 14 juin 2000, que ce rapport sera finalement soumis et défendu en mai 2001.

Au sujet de la mise en œuvre de l'article 38 de la Convention relative aux droits de l'enfant, le présent rapport ne formule que des «vœux » à réaliser par l'Etat congolais. Il ne fournit nullement des explications sur des réalisations effectuées à ce sujet ${ }^{2062}$. A ce propos, il affirme que « [1]'Etat renforcera la pratique des règles du droit humanitaire en cas de conflit interne et

\footnotetext{
${ }^{2061}$ MARTIN CHENUT, Kathia, « la protection des enfants en temps de conflit et le phénomène des enfantssoldats », « art.cit. », p. 217.

2062 Comité des droits de l'enfant, Examen des Rapports présentés par les Etats parties en application de l'article 44 de la Convention, Rapports initiaux des Etats parties devant être soumis en 1992, additif, République Démocratique du Congo, CRC/C/3/Add.57, 8 août 2000, op. cit., voy. pp. 47-49, §§175-180.
} 
international $[\ldots]$ en assistant les enfants qui en sont victimes » (nous soulignons) ${ }^{2063}$. Ce Rapport reconnaît les avancées adoptées - mais non appliquées - par la Conférence Nationale Souveraine (CNS) notamment sur la fixation de l'âge de recrutement à 18 ans $^{2064}$.

Par ailleurs, ce Rapport fait état de certaines incohérences de faits et de droit - de par ces affirmations-, lesquelles méritent d'être relevées ici.

En effet, ce Rapport qui intervient en une période cruciale où les enfants congolais n'étaient rien d'autre que le symbole de la guerre même - avec le phénomène Kadogo - se place à la défensive. Il affirme par exemple: «La guerre de libération de 1996-97 et la volonté populaire de sauvegarde de la souveraineté nationale face à la guerre d'agression imposée à la République démocratique du Congo ont conduit bon nombre de jeunes Congolais à se faire enrôler dans les forces combattantes $[\ldots] »^{2065}$.

Ceci devrait être perçu comme une manière de justifier insidieusement la présence des enfants au rang des forces armés de l'AFDL en dépit du processus de désarmement, de démobilisation et de réinsertion engagé par la suite ${ }^{2066}$.

Sur le plan du droit, certains passages de ce Rapport ne nous paraissent pas corrects. Par exemple lorsqu'il affirme : «Etant donné les contradictions entre la Convention relative aux droits de l'enfant et les Conventions de Genève (Protocoles additionnels) sur l'âge de recrutement et d'enrôlement des enfants [...] ${ }^{2067}$ (nous soulignons). Non, il ne s'agit pas de contradictions mais plutôt de statu quo que déplore d'ailleurs la doctrine (cf. supra). Il existe de nombreuses autres affirmations insoutenables sur le plan du droit telles que celle au sujet de l'applicabilité directe des conventions internationales des droits de l'homme par les cours et tribunaux congolais.

En effet, des Rapports adressés par la RDC aux organes des droits de l'homme ne cessent d'affirmer que « [1]'article 153, alinéa 4, du même texte [Constitution de la RDC du 18 février 2006] énonce formellement pour la première fois l'application directe des conventions internationales par les instances judiciaires, [...] $»^{2068}$ (nous soulignons). Ce point de vue est également confirmé par une étude ${ }^{2069}$. Il faudrait préciser qu'une telle interprétation ne semble pas exacte. Dorénavant, cet article ne consacre pas expressément les termes «application

\footnotetext{
2063 Ibid., p. 47, §175.

${ }^{2064}$ Ibid., p. $48, \S 177$.

2065 Ibid., p. 12, 27.

${ }^{2066}$ Voy. la suite du paragraphe 27 de ce Rapport.

${ }^{2067}$ Ibid., p. 48, $\$ 180$.

2068 Comité des droits de l'enfant, Examen des Rapports présentés par les Etats parties en application du paragraphe 1 de l'article 8 du Protocole facultatif à la Convention relative aux droits de l'enfant, concernant l'implication d'enfants dans les conflits armés, Rapports initiaux des Etats parties attendus en 2004, République Démocratique du Congo, CRC/C/OPAC/COD/1, 18 avril 2011, op. cit., p. 10, §33. Voy. aussi Comité des droits de l'enfant, Examen des Rapports présentés par les Etats parties en application de l'article 44 de la Convention, Rapports périodiques des Etats parties devant être soumis en 1997, République Démocratique du Congo, CRC/C/COD/2, 24 juillet 2008, op. cit., p. 11, §34, Bureau International Catholique pour l'Enfance, Section Protection de l'Enfant de la MONUC, Save The Children UK et UNICEF, La Protection légale et judiciaire des enfants en RDC. Problèmes centraux et propositions, op.cit., p. 3.

${ }^{2069}$ Voy. MWAGALWA, Thomas Furaha, «Réflexions sur les obstacles à réprimer le crime de recrutement et d'utilisation d'enfants soldats commis en République Démocratique du Congo », in RDPC, Vol. 93, 3/2013, p. 216.
} 
directe $»^{2070}$. Il fait plutôt un simple « rappel formel » de l'application des conventions internationales par les juridictions nationales. Car les cours et tribunaux, autant que le gouvernement et le parlement, sont des organes d'application du droit international pour un Etat. En d'autres termes, même en l'absence d'un tel article, les juridictions congolaises appliqueront normalement les conventions internationales. Comme cela a été déjà le cas avant la consécration de cette disposition.

La question de l'application directe est fonction des dispositions conventionnelles en présence. Il faudrait préalablement rappeler avec Joe VERHOEVEN que trois types d'obligations sont perceptibles dans des conventions des droits fondamentaux. Les premières sont dépourvues de caractère contraignant et assimilables à des simples déclarations d'intentions ; les deuxièmes sont non directement applicables (ou n'ayant pas d'effet direct) alors que les troisièmes sont directement applicables (ou ayant effet direct) ${ }^{2071}$. S'agissant de ces dernières, elles doivent répondre notamment aux critères objectifs voire subjectifs d'application directe. En effet, ces dispositions pourront être d'applicabilité directe si elles s'avèrent complètes et précises ${ }^{2072}$, (ou encore claires, précises et inconditionnelles ${ }^{2073}$ ) (conditions objectives). Il est fait également combinaison de critères - subjectifs et objectifs pour conclure ou non à l'applicabilité directe : «intention des parties, objet de la disposition, précision de cette dernière et nécessité ou non de mesures d'exécution par le relais du droit interne ${ }^{2074}$. Précisons que l'intention des parties intervient notamment lorsque les dispositions conventionnelles ne sont pas claires ${ }^{2075}$. Ainsi, « l'applicabilité directe désigne pour un acte international - une aptitude à être appliqué dans l'ordre juridique interne sans le relais, la médiation ou le complément du droit interne ${ }^{2076}$. La disposition conventionnelle est donc directement applicable parce qu'elle confère directement des droits aux particuliers. Ces derniers peuvent s'en prévaloir devant les instances judiciaires ${ }^{2077}$. Ou encore, elle est directement applicable parce qu'elle impose des obligations devant être sanctionnées directement par les cours et tribunaux ${ }^{2078}$. En conclusion, il n'existe donc pas d'application

\footnotetext{
${ }^{2070}$ Article 153, alinéa 4, de la Constitution de la RDC : « Les Cours et Tribunaux, civils et militaires, appliquent les traités internationaux dûment ratifiés, les lois, les actes réglementaires pour autant qu'ils soient conformes aux lois ainsi que la coutume pour autant que celle-ci ne soit pas contraire à l'ordre public ou aux bonnes mœurs ».

${ }^{2071}$ VERHOEVEN, Joe, «La mise en œuvre de la Convention des Nations Unies sur les droits de l'enfant. Observations en droit des gens », in MEULDERS-KLEIN, M.T. (dir.), La Convention sur les droits de l'enfant et la Belgique, op.cit., p. 63.

${ }^{2072}$ LUNDA BULULU, Vincent, « Les juridictions congolaises et l'application des conventions internationales relatives aux droits de l'homme », « art.cit. », p. 997.

${ }^{2073}$ Voy. VERHOEVEN, Joe, « La mise en œuvre de la Convention des Nations Unies sur les droits de l'enfant. Observations en droit des gens », in MEULDERS-KLEIN, M.T. (dir.), La Convention sur les droits de l'enfant et la Belgique, op.cit., p. 66.

${ }^{2074}$ ALLAND, Denis, Manuel de droit international public, op.cit., p. 191. Voy. aussi les pages 209-211. Voy. MASTOR, Wanda, "A propos de son caractère self executing ", in NEIRINCK, Claire et BRUGGEMAN, Maryline (dir.), La Convention internationale des dfroits de l'enfant (CIDE), une Convention particulière, Dalloz, Paris, 2014, p. 9.

${ }^{2075}$ LUNDA BULULU, Vincent, « Les juridictions congolaises et l'application des conventions internationales relatives aux droits de l'homme », «art.cit. », in Droit du pouvoir, Pouvoir du droit. Mélanges offerts à Jean Salmon, op.cit., p. 994.

${ }^{2076}$ ALLAND, Denis, Manuel de droit international public, op.cit., p. 208.

2077 Ibid., p. 209. Voy. Aussi MASTOR, Wanda, «A propos de son caractère self executing », « art. cit. », p. 8.

${ }^{2078}$ LUNDA BULULU, Vincent, «Les juridictions congolaises et l'application des conventions internationales relatives aux droits de l'homme », « art.cit. », p. 994.
} 
directe ou immédiate automatique et/ou intégrale pour une convention voire des conventions. Et comme le dirait plus claireement Lunda Bululu : «Il est indéniable que toutes les conventions portant sur les droits de l'homme ne sont pas directement applicables [...] ${ }^{2079}$.

Et aux termes termes des observations finales du Comité des droits de l'enfant au sujet de ce premier Rapport, celui-ci est demeuré préoccupé par le fait que les enfants soient tués délibérément et impunément par les forces armées étatiques (sans les nommer) et des groupes armés en RDC. Il s'inquiète également du recrutement des enfants de moins de quinze ans. Tout en étant satisfait de la création du BUNADER, il s'interroge sur l'efficacité d'un tel organe $^{2080}$. Il exhorte l'Etat congolais au processus de paix devant tenir compte de la protection et de la promotion des droits de l'enfant. La RDC devrait, au sens du Comité, s'opposer à la tuerie et autres violences exercées sur les enfants. Elle devrait donc interdire le recrutement, la participation des enfants au conflit armé et s'engager dans le processus de DDR. D'où l'importance de doter le BUNADER des ressources humaines et financières suffisantes $^{2081}$.

A propos du deuxième Rapport périodique de la RDC au Comité des droits de l'enfant, celuici devait être soumis en 1997. Il le sera finalement le 23 octobre 2007 pour être défendu le 21 janvier 2009.

En effet, le présent Rapport reconnaît «la paupérisation des familles » ${ }^{2082}$ comme cause explicative d'enrôlement massif des enfants dans les groupes armés à partir de 1996, contrairement au précédent rapport qui insiste sur la volonté patriotique des «jeunes » de prendre part à la «libération » ou de faire face à «l'agression». Toutefois, affirmons que les deux facteurs sont effectivement parmi les causes explicatives d'enrôlement des enfants dans les forces et groupes armés (cf. Premier chapitre de la deuxième partie). Des efforts ont été fournis par le gouvernement avec l'appui des institutions internationales pour sortir les enfants de cette situation.

A cet effet, il est évoqué des avancées au plan législatif à la suite du Décret-loi nº66/2000 du 09 juin 2000 portant démobilisation et réinsertion des groupes vulnérables présents dans les forces combattantes, à savoir la promulgation de la Constitution du 18 février 2006 dont l'article 190 dispose que «[n]ul ne peut, sous peine de haute trahison [...] entretenir une jeunesse armée ${ }^{2083}$ ou encore la loi $n^{\circ} 04 / 023$ du 12 décembre 2004 dont l'article 7 fixe à dix-huit ans l'âge de réquisition. Le rapport note également le remplacement du BUNADER par la CONADER. Laquelle se charge de la «coordination et du suivi de toutes les actions menées en faveur des enfants associés aux forces et groupes armés ». On notera également

2079 Ibid., p.1000.

${ }^{2080}$ Comité des droits de l'enfant, Examen des Rapports présentés par les Etats parties en application de l'article 44 de la Convention, Observations finales du Comité des droits de l'enfant, République Démocratique $d u$ Congo, CRC/C/15/Add.153, 9 juillet 2001, p. 13, $\$ 64, \quad$ in http://tbinternet.ohchr.org/_layouts/treatybodyexternal/Download.aspx?symbolno=CRC\%2fC\%2f15\%2fAdd.15 3\&Lang=en (Source consultée le 21 janvier 2016).

${ }^{2081}$ Ibid., p. 14, $\$ 65$.

${ }^{2082}$ Comité des droits de l'enfant, Examen des Rapports présentés par les Etats parties en application de l'article 44 de la Convention, Rapports périodiques des Etats parties devant être soumis en 1997, République Démocratique du Congo, CRC/C/COD/2, 24 juillet 2008, op. cit., p. 47, §201.

${ }^{2083}$ Ibid., p. 48, $\$ 202$. 
que c'est la Banque mondiale qui finance ce programme $\mathrm{DDR}^{2084}$.

« Au 30 avril 2006, 29291 enfants certifiés dans les centres d'orientation ont été retirés des forces et groupes armés, dont 15220 bénéficient du programme de réinsertion sociale et économique qui est exécuté sur terrain par environ 9 ONG internationales et 35 ONG nationales, auxquelles l'UNICEF apporte également son appui. La présence des enfants dans certaines brigades surtout non intégrées devient ainsi marginale ${ }^{2085}$ note le rapport.

Dans le cadre du Programme international pour l'élimination du travail des enfants (IPEC), l'on note la mise en œuvre du projet interrégional de prévention et réinsertion des enfants impliqués dans les conflits armés. Et en vue de faciliter l'accueil des enfants désarmés et démobilisés en communautés, un programme de sensibilisation à cet effet a été mis en œuvre dans toutes les provinces du pays. La réinsertion économique reste tout de même problématique suite à la situation économique générale chaotique et aux difficultés financières du programme même. D'où le risque de «re-enrôlement » de ces enfants ${ }^{2086}$.

Ce Rapport épingle également l'existence de Structure d'encadrement transitoire (SET) où passent les enfants avant leur réunification familiale (30 jours maximum) mais manquant des psychologues qualifiés. D'où la difficulté de réadaptation des enfants. La situation envisagée était de confier la mission aux ONG internationales et nationales expertes ${ }^{2087}$.

La mise en œuvre de la Convention relative des droits de l'enfant -précisément son article 38 qui nous préoccupe - passe aussi par la Coopération de la RDC avec la CPI (cas Thomas Lubanga). Les instructions données par l'Etat Major des FARDC en mai 2005 aux Commandants de ne pas recruter des personnes âgées de moins dix-huit ans et des poursuites éventuelles contre des contrevenants vont dans ce même sens ${ }^{2088}$.

En dépit des efforts fournis par la RDC comme l'indique le Rapport précédent, le Comité des droits de l'enfant note que la RDC a une responsabilité directe, par ses forces armées, dans les violations des droits de l'enfant par des groupes armés non étatiques ${ }^{2089}$. Elle n'a donc pas pu protéger les enfants et empêcher ces violations. Le Comité note en outre des « répercussions terribles » du conflit armé sur les civils dont particulièrement les enfants en dépit de l'Accord de Goma de 2008. Lequel n'est d'ailleurs pas d'application. L'enlèvement des enfants en vue d'être utilisés par les groupes armés demeure une préoccupation du Comité des droits de $l^{\prime}$ enfant $^{2090}$. Celui-ci regrette le manque des ressources suffisantes pour le fonctionnement de

\footnotetext{
${ }^{2084}$ Ibid., p. 48, §203.

${ }^{2085}$ Ibid., p. 48, 204 .

${ }^{2086}$ Comité des droits de l'enfant, Examen des Rapports présentés par les Etats parties en application de l'article 44 de la Convention, Rapports périodiques des Etats parties devant être soumis en 1997, République Démocratique du Congo, CRC/C/COD/2, 24 juillet 2008, op. cit., pp. 48-49, §§ 206-209.

${ }^{2087}$ Ibid., p. 49, $\$ 209$.

${ }^{2088}$ Ibid., p. 49, $\$ 211-212$.

2089 Voy. aussi dans ce sens, ASADHO, Le Gouvernement congolais viole ses obligations internationales relatives à la protection des droits de l'enfant, Rapport circonstanciel à l'occasion de la journée internationale de l'Enfant africain, PDH n ${ }^{\circ}$ Spécial - ASADHO, juin 2008, p. 6.

${ }^{2090}$ Comité des droits de l'enfant, Examen des Rapports présentés par les Etats parties en application de l'article 44 de la Convention, Observations finales : République Démocratique du Congo, CRC/C/COD/CO/2, 10 février $2009, \quad$ p. $\quad 16, \quad \$ 67, \quad$ in http://tbinternet.ohchr.org/ layouts/treatybodyexternal/Download.aspx?symbolno=CRC $\% 2 \mathrm{fC} \% 2 \mathrm{fCOD} \% 2 \mathrm{fCO} \%$
} 
la nouvelle structure de DDR, créée en décembre 2003, CONADER remplaçant du BUNADER. L'absence d'aide à la démobilisation pour les ex- enfants enrôlés occasionnerait leur «re-enrôlement» par les groupes armés. Enfin, le Comité est troublé du fait que les enfants ayant commis différentes infractions à caractère militaire soient traités non comme victimes mais arrêtés, détenus et jugés par les juridictions militaires ${ }^{2091}$. Ce qui paraît d'ailleurs illégal au regard de l'article 114 de la Loi n ${ }^{\circ} 023 / 2002$ du 18 novembre 2002 portant Code de justice militaire ${ }^{2092}$ qui exclut de la compétence des juridictions militaires des personnes âgées de moins de dix-huit ans.

Différentes recommandations seront formulées à l'endroit de la RDC. Celle-ci devrait notamment veiller au respect de l'Accord de Goma; prendre toutes les mesures possibles pour la protection des enfants avec renforcement des ressources humaines et financières; appliquer complètement des recommandations du Secrétariat de l'ONU sur les enfants en conflits armés en RDC; intensifier des efforts pour mettre fin aux souffrances causées aux enfants par les conflits armés ; doter le programme DDR des ressources humaines et financières suffisantes ; traiter les enfants en attente de démobilisation et réinsertion comme victimes ${ }^{2093}$.

Dans un document unique, se trouvent élaborés les troisième, quatrième et cinquième rapports de la RDC adressés au Comité des droits de l'enfant. Ces rapports tiennent compte des observations finales et recommandations formulées par le Comité des droits de l'enfant le 30 janvier 2009. Concernant la situation des enfants en conflits armés, il a été réitéré à l'Etat congolais de prendre «des mesures possibles» pour la protection des enfants notamment en déployant des ressources humaines et financières pour leur démobilisation. L'usage des «mesures possibles» sera également repris par le Comité contre la torture au sujet précisément de la démobilisation des enfants (cf. infra). Ce qui n'augure pas une protection spéciale efficace.

En réponse, «[1]e Gouvernement a réactivé l'UEPNDDR avec la mobilisation de dizaines de millions de dollars au travers des partenaires internationaux (72 millions de dollars par la Banque Mondiale et le Fonds Africain de Développement), et en décembre 2009, un montant de 1.290359 dollars a été disponibilisé pour le volet démobilisation ${ }^{2094}$.

Toujours sous cet angle, la RDC devait mettre en application les recommandations du rapport $\mathrm{du}$ SG/NU (S/2005/693) «concernant la prohibition du recrutement d'enfants, leur démobilisation et réinsertion, l'élaboration d'une stratégie nationale et régionale et la lutte

2f2\&Lang=en (Source consultée le 22 janvier 2016).

2091 Ibid., p. $17 \$ 72$.

${ }^{2092}$ L'article 114 de la Loi n ${ }^{\circ} 023 / 2002$ du 18 novembre 2002 portant Code de justice militaire dispose : « Les juridictions militaires sont incompétentes à l'égard des personnes âgées de moins de dix-huit ans ». Voy. Loi $\mathrm{n}^{\circ} 023 / 2002$ du 18 novembre 2002 portant Code de justice militaire, in Journal Officiel de la République Démocratique du Congo -Numéro Spécial -20 mars 2003, p. 25.

${ }^{2093}$ Comité des droits de l'enfant, Examen des Rapports présentés par les Etats parties en application de l'article 44 de la Convention, Observations finales : République Démocratique du Congo, CRC/C/COD/CO/2, 10 février 2009, p. 16, $\S 68-71$ et p. $17, \S 73$.

$2094 \quad 3^{\mathrm{e}}, \quad 4^{\mathrm{e}}, \quad 5^{\mathrm{e}} \quad$ Rapport version finale, RDC, op. $\quad$ cit., $\quad$ p. $33, \quad \S 28, \quad$ in http://tbinternet.ohchr.org/ layouts/treatybodyexternal/TBSearch.aspx?Lang=en\&TreatyID=5\&TreatyID=10\&T reatyID=11\&DocTypeID=29\&DocTypeCategoryID=4 (Source consultée le 10 janvier 2016). 
contre l'impunité $»^{2095}$.

En réponse, le gouvernement note son Plan d'action avec l'Equipe spéciale de surveillance et d'information des Nations Unies concernant les enfants associés à des forces ou à des groupes armés en RDC. Pour prévenir le recrutement d'enfants dans les groupes armés, il est fait rappel des mesures législatives prises : le décret-loi $n^{\circ}$ 66/2000 portant démobilisation et réinsertion des groupes vulnérables présents au sein des forces combattantes et la loi portant protection de l'enfant du 10 janvier 2009. Arguments qui nous paraissent incompréhensibles car antérieurs à la période des recommandations (30 janvier 2009) ${ }^{2096}$.

Suivant ces Rapports, les statistiques fournies par l'UEPNDDR pour la période de 2004 à 2011, attestent que 35.082 enfants ont été sortis des forces et groupes armés ${ }^{2097}$.

Le tableau présenté ci-dessous, pour la période d'avant décembre 2007, est plus explicatif au sujet des enfants associés aux forces ou groupes armés (EAFGA). Il repartit entre les 11 provinces de la RDC et par type de réinsertion les 30.594 enfants sortis des forces et groupes armés $^{2098}$. Rappelons toutefois que ces statistiques de l'UEPNDRR sont contredites par celles fournies par la «base de données de l'UNICEF [qui] mentionne 16.903 [enfants] sortis fin 2006 et 19.995 enfants [sortis] fin $2007 »^{2099}$ (cf. infra).

Tableau $n^{\circ} 1$ Statistiques ventilées des EAFGA pris en charge par catégories et par province (avant décembre 2007)

\begin{tabular}{|l|l|l|l|l|l|l|l|l|l|l|l|l|}
\hline & $\begin{array}{l}\text { BD } \\
\text { D }\end{array}$ & BC & EQ & $\begin{array}{l}\text { K } \\
\text { OR }\end{array}$ & $\begin{array}{l}\text { K } \\
\text { OC }\end{array}$ & KT & KN & SK & NK & PO & MA & $\begin{array}{l}\text { TOTA } \\
\text { L }\end{array}$ \\
\hline Eafga sortis & 150 & 357 & 3247 & 488 & 262 & 2355 & 170 & 4980 & 6736 & 9448 & 2221 & 30594 \\
\hline $\begin{array}{l}\text { Eafga } \\
\text { Réunifiés }\end{array}$ & 135 & 16 & 2451 & 488 & 114 & 1652 & 175 & 3058 & 4489 & 8203 & 2279 & 23060 \\
\hline $\begin{array}{l}\text { Eafga } \\
\text { Scolarisés }\end{array}$ & 1 & 5 & 210 & 86 & 4 & 628 & 0 & 312 & 2078 & 2335 & 872 & 6531 \\
\hline $\begin{array}{l}\text { Eafga } \\
\text { Formés }\end{array}$ & 6 & 2 & 1642 & 208 & 22 & 163 & 148 & 1133 & 2329 & 3009 & 1529 & 10191 \\
\hline $\begin{array}{l}\text { Total } \\
\text { ESFGA en } \\
\text { réinsertion } \\
\text { Economique }\end{array}$ & 7 & 7 & 1852 & 294 & 26 & 791 & 148 & 1445 & 4407 & 5344 & 2401 & 16722 \\
\hline
\end{tabular}

(Source : $3^{\mathrm{e}}, 4^{\mathrm{e}}, 5^{\mathrm{e}}$ Rapport version finale, RDC, op. cit., p. 34, §29, in http://tbinternet.ohchr.org/_layouts/treatybodyexternal/TBSearch.aspx?Lang=en\&TreatyID= 5\&TreatyID=10\&TreatyID=11\&DocTypeID=29\&DocTypeCategoryID=4 (Source consultée le 10 janvier 2016), Voy. aussi Comité des droits de l'enfant, Examen des

\footnotetext{
2095 Ibid., p. 33, §29.

2096 Ibid.

2097 Ibid.

${ }^{2098}$ Ibid.

2099 BODINEAU, Sylvie, Rapport d'Evaluation du programme 2007-2011 pour les Enfants associés aux Forces et aux Groupes Armés en RDC, UNICEF RDC op.cit., 11
} 
Rapports présentés par les Etats parties en application du paragraphe 1 de l'article 8 du Protocole facultatif à la Convention relative aux droits de l'enfant, concernant l'implication d'enfants dans les conflits armés, Rapports initiaux des Etats parties attendus en 2004, République Démocratique du Congo, CRC/C/OPAC/COD/1, 18 avril 2011, op. cit., p. 27, § 102. Ce Tableau est originellement issu du Ministère des Affaires Sociales (RDC), rapport des activités de suivi et évaluation des activités du PNDDR/enfants. Décembre 2007).

Par ailleurs, par le biais du Ministère de la Défense Nationale et des Anciens Combattants, il sera renseigné la présence d'aucun enfant dans les rangs des FARDC déjà en $2010^{2100}$. Cette affirmation sera également contredite par les Observations finales du Comité des droits de l'enfant en ces termes :

«[...] Le Comité note en particulier avec préoccupation que, alors que ce sont les Forces armées de la République démocratique du Congo qui ont recruté le plus d'enfants en 2010, comme l'a souligné le Secrétaire général de l'Organisation des Nations Unies (S/2010/369, par. 19) et qu'elles continuent d'enrôler et d'utiliser des enfants, l'État partie refuse d'admettre leur présence au sein des forces armées. Le Comité est vivement préoccupé par la présence d'enfants dans presque toutes les brigades des forces armées de la République démocratique du Congo, de même, au sein de la Garde républicaine placée sous l'autorité directe du Président et dans la Police nationale, ce qui constitue une grave violation des obligations de l'État partie au titre du Protocole facultatif $»^{2101}$.

Pour l'UNICEF RDC, par ce « déni accru du gouvernement concernant le recrutement d'enfants par les FARDC » ${ }^{2102}$, la situation ne peut être considérée comme réglée. On assiste alors à la persistance du recrutement et d'utilisation d'enfants par les FARDC et les groupes armés, aux appuis peu concluant à la réinsertion d'enfant et à de nombreux ré-enrôlement ${ }^{2103}$.

Une étude du GRIP, datant du 03 août 2015, va dans le même sens en épinglant l'enrôlement de centaines d'enfants, "par erreur», par les FARDC de 2012 à 2014 mais relâchés ${ }^{2104}$. L'absence totale d'enfants dans les rangs des FARDC n'est donc pas encore avérée. Le Rapport du SG/NU sur Le sort des enfants en temps de conflit armé du 20 avril 2016 confirme cette situation $^{2105}$. Il y a lieu de remarquer que la RDC a du mal à observer ses obligations

$2100 \quad 3^{\mathrm{e}}, \quad 4^{\mathrm{e}}, \quad 5^{\mathrm{e}} \quad$ Rapport version finale, $\mathrm{RDC}, \quad$ op. $\quad$ cit., $\quad$ p. $\quad 34, \quad \S 29, \quad$ in http://tbinternet.ohchr.org/_layouts/treatybodyexternal/TBSearch.aspx?Lang=en\&TreatyID=5\&TreatyID=10\&T reatyID=11\&DocTypeID=29\&DocTypeCategoryID=4 (Source consultée le 10 janvier 2016).

${ }^{2101}$ Comité des droits de l'enfant, Examen des Rapports présentés par les Etats parties en application du paragraphe 1 de l'article 8 du Protocole facultatif à la Convention relative aux droits de l'enfant, concernant l'implication d'enfants dans les conflits armés, Observations finales : République Démocratique du Congo, Cinquante-neuvième session 16 janvier-03 février 2012, CRC/C/OPAC/COD/CO/1, 07 mars 2012, \$30, http://tbinternet.ohchr.org/layouts/treatybodyexternal/Download.aspx?symbolno=CRC $\% 2 \mathrm{fC} \% 2 \mathrm{fOPAC} \% 2 \mathrm{fCO}$ D\%2fCO\%2f1\&Lang=en (Source consultée le 22 janvier 2016).

${ }^{2102}$ BODINEAU, Sylvie, Rapport d'Evaluation du programme 2007-2011 pour les Enfants associés aux Forces et aux Groupes Armés en RDC, UNICEF RDC, op.cit., p. 4.

2103 Ibid.

${ }^{2104}$ FOFACK, Eric Wilson, « Les Enfants victimes des conflits armés : pratiques et lutte en Afrique », in Note d'Analyse du GRIP, 03 août 2015, Bruxelles, http://www.grip.org/fr/node/1788 (Source consultée le 24 janvier 2016).

${ }^{2105} \S 53$ de la Résolution AG/NU et CS/NU A/70/836-S/2016/360, Le sort des enfants en temps de conflit armé, Rapport du Secrétaire général, in http://www.un.org/fr/sc/documents/sgreports/2016.shtml (Source consultée le 5 juillet 2016). 
internationales et nationales en faveur du non recrutement des personnes de moins de 18 ans dans ses forces armées.

Le dernier Rapport est celui relatif au Protocole facultatif à la Convention relative aux droits de l'enfant, concernant l'implication d'enfants dans les conflits armés. Conformément à l'article 8, paragraphe $1^{\mathrm{er}}$, dudit Protocole, la soumission de ce dernier Rapport devait s'effectuer en 2004. Suite au retard «habituel », ledit Rapport sera finalement soumis en janvier 2009. En somme, ce Rapport ne fait que des «rappels» des mesures prises par la RDC au sujet de l'enrôlement et de la participation des enfants aux hostilités ${ }^{2106}$. Lesquelles mesures ont été déjà épinglées dans les rapports précédents et analysées largement dans le cadre de cette dissertation.

Pour sa part, en termes d'observations finales, le Comité des droits de l'enfant affirme dorénavant que les présentes observations doivent se lire conjointement avec celles du 09 février 2009. En grande partie, les recommandations formulées ci-avant y sont rappelées. C'est dans ce sens qu'il réitère les préoccupations qu'il exprime depuis 2001 au sujet des responsabilités de plusieurs Etats étrangers, groupes armés et sociétés privées sur les conséquences de ces conflits armés sur les enfants. Il s'agit précisément des violations de la Convention relative aux droits de l'enfant, du présent protocole et des règles du DIH. Peu de progrès ont donc été réellement accomplis dans la mise en œuvre des recommandations des mécanismes des droits de l'homme de l'ONU sur les enfants impliqués dans les conflits armés. Certaines mesures législatives ont été tout de même adoptées dont la déclaration établissant à dix-huit ans l'âge minimum d'engagement volontaire, l'adoption en 2007 des Engagements de Paris et de la loi de protection de l'enfant en $2009^{2107}$. Faisons remarquer qu'au sujet des observations finales qu'il adressa au Rwanda concernant les enfants soldats en juillet 2004, le Comité des droits de l'enfant avait fait plutôt usage d'un langage diplomatique. Il pointa seuls les «groupes armés » et non les «forces armées » comme responsables de recrutement des enfants de moins de quinze ans au Rwanda et en $\mathrm{RDC}^{2108}$. Pour leur part, les Observations finales du Comité des droits de l'enfant adressées à la République de l'Ouganda en septembre 2005 ne feront pas allusion au cas de recrutement des enfants en RDC par l'armée ougandaise. Le Comité se limitera à faire part de sa préoccupation sur le recrutement des enfants en Ouganda en dépit de la nouvelle loi sur les forces de défense du peuple de l'Ouganda fixant à dix-huit ans l'âge minimum de recrutement. Préoccupation qui vaut de

\footnotetext{
${ }^{2106}$ Voy. Comité des droits de l'enfant, Examen des Rapports présentés par les Etats parties en application du paragraphe 1 de l'article 8 du Protocole facultatif à la Convention relative aux droits de l'enfant, concernant l'implication d'enfants dans les conflits armés, Rapports initiaux des Etats parties attendus en 2004, République Démocratique du Congo, CRC/C/OPAC/COD/1, 18 avril 2011, op. cit., pp. 13-30, §§42-122.

${ }^{2107}$ Comité des droits de l'enfant, Examen des Rapports présentés par les Etats parties en application du paragraphe 1 de l'article 8 du Protocole facultatif à la Convention relative aux droits de l'enfant, concernant l'implication d'enfants dans les conflits armés, Observations finales: République Démocratique du Congo, Cinquante-neuvième session 16 janvier-03 février 2012, CRC/C/OPAC/COD/CO/1, 07 mars 2012, op ; cit., §§46.

${ }^{2108}$ Comité des droits de l'enfant, Examen des Rapports présentés par les Etats parties en application de l'article 44 de la Convention, Observations finales : Rwanda, CRC/C/15/Add.234, Trente-sixième session, $1^{\text {er }}$ juillet 2004, $\quad$ p. $\quad 15 \quad \$ 62, \quad$ in http://tbinternet.ohchr.org/layouts/treatybodyexternal/Download.aspx?symbolno=CRC\%2fC\%2f15\%2fAdd.23 4\&Lang=en (Source consultée le 22 janvier 2016).
} 
même pour les cas d'enlèvement et de traitement cruel, inhumain et dégradant infligés aux enfants par l'Armée de Résistance du Seigneur ${ }^{2109}$.

Au sujet du Plan d'action, le Comité indique que la RDC n'a toujours pas adopté un Plan d'action assorti d'échéance pour mettre fin au recrutement et à l'utilisation des enfants en dépit des appels des instances internationales et engagement pris par la RDC ${ }^{2110}$. La RDC demeure responsable direct de recrutement et de l'utilisation des enfants dans les conflits malgré ses affirmations contraires ${ }^{2111}$.

En conclusion, les différents Rapports soumis par la RDC au Comité des droits de l'enfant révèlent sa volonté d'assurer la protection spéciale de l'enfant en période de conflits armés. Toutefois, comme le reconnaissent ces Rapports, la protection de l'enfant contre les effets des conflits armés n'est pas encore totalement effective en RDC. Les enfants restent encore victimes des hostilités - « civils » et « combattants ». Et l'Etat congolais, premier responsable de la protection spéciale de ses enfants ne s'acquitte pas de ses obligations comme il se doit. Il existe d'enfants dans les rangs des FARDC autant dans les rangs de divers groupes armés opérant au pays. Bien plus, concernant réellement la protection spéciale des enfants «civils» et «combattants »- pendant les hostilités, il n'existe pas jusque là un véritable mécanisme étatique opérationnel en pleine période des hostilités assurant cette protection. L'ensemble des mécanismes présentés dans ces différents Rapports sont antérieurs et postérieurs aux hostilités, et non opérant réellement pendant les hostilités. Or, c'est pendant la période des hostilités que se pose la question de protection spéciale avec acuité. En outre, la pauvreté manifeste des familles, les crises et conflits ethniques encourageant le sens « d'autoprotection communautaire », la volonté délibérée des forces et groupes armés de se servir fréquemment des enfants y compris le climat d'insécurité permanente en zones des conflits armés, le déni du gouvernement congolais à propos du recrutement d'enfants par les FARDC, les faiblesses de l'UEPNDDR, l'échec de suivi des enfants démobilisés, etc., sont autant de facteurs qui remettent par ailleurs en cause le processus de désarmement, de démobilisation et de réinsertion et conduisent «à de nombreux ré-enrôlements » ${ }^{2112}$.

Au-delà de tout, les observations finales et recommandations formulées par le Comité des droits de l'enfant permettent une mise en œuvre «progressive » de la protection spéciale de

\footnotetext{
${ }^{2109}$ Comité des droits de l'enfant, Examen des Rapports présentés par les Etats parties en application de l'article 44 de la Convention, Observations finales : Ouganda, Quarantième session, Genève, 12-30 septembre 2005, CRC/C/UGA/CO/2, 23 novembre 2005, pp. 13 et 14, $\$ \S 65$ et 67, in http://tbinternet.ohchr.org/layouts/treatybodyexternal/Download.aspx?symbolno=CRC $\% 2 \mathrm{fC} \% 2 \mathrm{fUGA} \% 2 \mathrm{fCO} \%$ 2f2\&Lang=en (Source consultée le 22 janvier 2016).

${ }^{2110}$ Comité des droits de l'enfant, Examen des Rapports présentés par les Etats parties en application du paragraphe 1 de l'article 8 du Protocole facultatif à la Convention relative aux droits de l'enfant, concernant l'implication d'enfants dans les conflits armés, Observations finales: République Démocratique du Congo, Cinquante-neuvième session 16 janvier-03 février 2012, CRC/C/OPAC/COD/CO/1, 07 mars 2012, op. cit., $\S \S 14-15$.

${ }^{2111}$ Comité des droits de l'enfant, Examen des Rapports présentés par les Etats parties en application du paragraphe 1 de l'article 8 du Protocole facultatif à la Convention relative aux droits de l'enfant, concernant l'implication d'enfants dans les conflits armés, Observations finales: République Démocratique du Congo, Cinquante-neuvième session 16 janvier-03 février 2012, CRC/C/OPAC/COD/CO/1, 07 mars 2012, op. cit., $\$ 30$.

2112 BODINEAU, Sylvie, Rapport d'Evaluation du programme 2007-2011 pour les Enfants associés aux Forces et aux Groupes Armés en RDC, op.cit., p. 4.
} 
l'enfant en période des conflits armés bien que le Comité des droits de l'enfant paraîsse luimême « démuni de pouvoirs réels » ${ }^{2113}$.

\section{§2. Système africain de protection des droits de l'enfant}

Sous ce paragraphe, il sera question d'étudier le rôle de la «Commission africaine des droits de l'homme et des peuples » et du «Comité africain d'experts sur les droits et le bien-être de l'enfant » sur la protection de l'enfant en RDC.

En effet, la Commission africaine des droits de l'homme et des peuples, à travers son site internet, n'indique aucun rapport initial ou périodique soumis par la RDC. Elle catégorise tout de même la RDC parmi les «Etats qui sont en retard par trois ou plus de rapports ». Pour son cas précisément, la RDC est en retard de quatre rapports pour une période de 1997-2007. Période qui nous concerne dans le cadre de la présente dissertation.

Par ailleurs, il y a lieu de signifier, dans le cadre de la Commission africaine des droits de l'homme et des peuples, qu'une mission d'information concernant les populations autochtones a été effectuée du 09 au 25 août 2009 par le Groupe de travail sur les populations/Communautés Autochtones en Afrique. Un des objectifs de cette mission était de collecter des informations sur la situation des autochtones en RDC. A l'issue de cette mission, il a été recommandé à la RDC au sujet des enfants autochtones de «[p]rendre des mesures pour protéger les droits des enfants issus de viols et abandonnés ${ }^{2114}$ et de «[s]'assurer que les auteurs d'actes de violence envers les populations autochtones, y compris les auteurs de pratiques d'esclavage et de viols, sont traduits en justice ${ }^{2115}$.

De différentes résolutions adoptées par la Commission africaine des droits de l'homme et des peuples au sujet de la RDC, aucune d'elles n'est spécifiquement réservée au sujet des enfants. Quelques unes d'entre elles se préoccupent toutefois, dans la généralité, de la situation des enfants dans les conflits armés en RDC. C'est notamment le cas de la Résolution 241 sur la situation des droits de l'homme en République Démocratique du Congo adoptée à Naïrobi le 24 juillet 2013. Cette dernière se dit «préoccupée par la dégradation continue de la situation des droits de l'homme à l'est de la République Démocratique du Congo suite aux multiples attaques contre les populations civiles par les divers groupes rebelles armés, y compris les viols et autres violences à l'égard des femmes et des enfants ». La Résolution (284) sur la répression des violences sexuelles sur les femmes en République Démocratique du Congo, adoptée en 55è session ordinaire de la Commission africaine des droits de l'homme et des peuples tenue à Luanda du 28 avril au 12 mai 2014, invite la RDC à prendre des mesures nécessaires pour incorporer en législation nationale le Protocole de Maputo ${ }^{2116}$. Rappelons

\footnotetext{
${ }^{2113}$ VERHOEVEN, Joe, «La mise en œuvre de la Convention des Nations Unies sur les droits de l'enfant. Observations en droit des gens », in MEULDERS-KLEIN, M.T. (dir.), La Convention sur les droits de l'enfant et la Belgique, op.cit., p. 69.

${ }^{2114}$ Voy. Point 16 http://www.achpr.org/fr/states/democratic-republic-of-congo/missions/indig-2009/ (Source consultée le 16 janvier 2016).

${ }^{2115}$ Ibid., Voy. Point 18.

${ }^{2116}$ Voy. l'avant-dernier considérant de la Résolution (284) sur la répression des violences sexuelles sur les femmes en République Démocratique du Congo in http://www.achpr.org/fr/sessions/55th/resolutions/284/ (Source consultée le 16 janvier 2016).
} 
que son article 11, paragraphe 4, contient une disposition de grande importance formulée comme suit: «Les États prennent toutes les mesures nécessaires pour qu'aucun enfant, surtout les filles de moins de 18 ans, ne prenne part aux hostilités et, en particulier, à ce qu'aucun enfant ne soit enrôlé dans l'armée ${ }^{2117}$ (cf. supra pour les commentaires sur cet article).

En clair, il va sans dire que les deux résolutions réitèrent de nombreuses recommandations exprimées par leurs prédécesseurs. Elles déplorent des graves violations des droits de l'homme et du DIH dont sont victimes les civils, particulièrement les femmes et jeunes filles. Elles formulent les vœux de voir les auteurs de tels actes traduits en justice ${ }^{2118}$.

En outre, il est encore à noter que dans ses mécanismes spéciaux (Rapporteurs, Comité et Groupes de travail $)^{2119}$, la Commission africaine des droits de l'homme et des peuples ne comporte pas un mécanisme spécial réservé aux questions des enfants en général et dans les conflits armés en particulier. Ce qui pose quand-même problème pour un continent qui souffre le plus des conflits armés dont les enfants sont des cibles directes des belligérants. Mais cela s'explique aussi en partie par le fait que la Charte africaine des droits de l'homme et des peuples, elle-même, se préoccupe moins de la protection de l'enfant, en dehors de son article 18, §3. Cette mission sera entreprise par la Charte africaine des droits et du bien-être de l'enfant.

Concernant la Charte africaine des droits et du bien-être de l'enfant, il n'existe aucun rapport de mise en œuvre de cet instrument soumis par la RDC $^{2120}$, Etat partie depuis le 28 mars 2001 (cf. supra). Rappelons que le site internet de la Commission africaine des droits de l'homme et des peuples ne reprend pas la RDC comme Etat partie à cet instrument (Un des quatre Etats n'ayant pas signé ni ratifié cet instrument) ${ }^{2121}$. Ce qui est aussi confirmé par le site du Comité africain d'experts sur les droits et le bien-être de l'enfant (CAEDBE) ${ }^{2122}$. Cependant, le Journal officiel de la République Démocratique du Congo - Instruments internationaux et régionaux relatifs aux droits de l'Homme ratifiés par la République Démocratique du Congo, $43^{\mathrm{e}}$ année, Numéro spécial, du 5 décembre 2002 - précise qu'elle a ratifié cet instrument. Argument confirmé devant la Cour internationale de justice dans l'affaire des activités armées contre l'Ouganda ${ }^{2123}$.

Par ailleurs, s'il faut reconnaître une avancée considérable des droits de l'enfant sur le plan

\footnotetext{
${ }^{2117}$ Lire l'article 11, $\S 4$ du Protocole à la Charte africaine des droits de l'homme et des peuples relatif aux droits de la femme, in http://www.achpr.org/fr/instruments/women-protocol/\#14 (Source consultée le 14 octobre 2015). ${ }^{2118}$ Voy. les résolutions 90, 103, 139 et 173 de la Commission africaine des droits de l'homme et des peuples sur la RDC, in http://www.achpr.org/fr/states/democratic-republic-of-congo/ (Source consultée le 16 janvier 2016).

${ }_{2119} \mathrm{Il}$ existe au total 15 mécanismes spéciaux, voy. http://www.achpr.org/fr/mechanisms/ (Source consultée le 16 janvier 2016).

${ }_{2120}$ Voy. L'état des rapports initiaux soumis au Comité africain d'experts sur les droits et le bien-être de l'enfant, in http://www.acerwc.org/initial-reports/ (Source consultée le 21 janvier 2016).

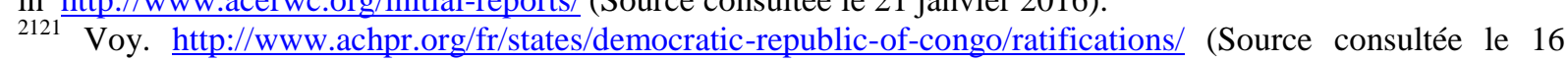
janvier 2016).

${ }_{2122}$ Voy. http://www.acerwc.org/ratification-data/ (Source consultée le 01 février 2016).

${ }^{2123}$ Voy. République Démocratique du Congo, Affaire relative aux activités armées sur le territoire du Congo (République Démocratique du Congo c. Ouganda), Cour internationale de justice, Mémoire de la République Démocratique du Congo, Vol. I, Juillet 2000, p. 149.
} 
africain par rapport au reste du monde, cet état de droit ne va de la même manière avec la pratique. En clair, le CAEDBE souffre d'un sérieux problème de ressources financières et humaines au point que ce sont des agences internationales tels que l'UNICEF, ou des ONG telles que Save The Children Suede, Plan international qui lui viennent en aide ${ }^{2124}$. Ce qui pose question de son efficacité à l'instar de la Commission africaine des droits de l'homme et des peuples. Il est d'un constat que le niveau bas des recettes fiscales rend notamment difficile l'investissement dans le bien-être de l'enfant par les gouvernements africains ${ }^{2125}$. Il s'agirait là d'un problème général pour la quasi-totalité des pays africains. C'est dans ce sens que l'Union des Coalitions Ouest-Africaines pour l'enfance (UCOA) mène une campagne auprès des Etats en faveur des enfants après avoir constaté qu'aucun d'eux n'alloue plus de $1 \%$ de son budget à des questions de protection de l'enfant ${ }^{2126}$.

Concernant la situation des conflits armés en RDC, elle a fait l'objet d'une "première communication interétatique introduite devant la Commission africaine [des droits de l'homme et des peuples]» ${ }^{2127}$. La RDC, partie demanderesse, en faisant observer à ladite Commission les différentes «violations graves et massives des droits de l'homme et des peuples » commises par les Républiques du Burundi, de l'Ouganda et du Rwanda, a toutefois manqué l'occasion d'y faire attester juridiquement les nombreuses violations des règles des droits de l'homme et du DIH protégeant spécialement les enfants. Elle s'est d'ailleurs limitée entre autres à demander à la Commission de considérer ces violations comme contraires aux dispositions pertinentes de la Charte africaine des droits de l'homme et des peuples (articles 2, $4,6,12,16,17,19,20,21,22$ et 23$)^{2128}$. Demande à la suite de laquelle, la Commission indiquera les violations des articles $2,4,5,12.1$ et 12.2, 14, 16, 17, 18.1 et 18.3, 19, 20, 21, 22 et 23 de ladite Charte ${ }^{2129}$.

Sous l'angle des droits de l'homme, précisément de la Charte africaine des droits de l'homme et des peuples, la RDC n'a pas fait mention dans sa plainte de l'article 18, §3, de cet instrument. Pourtant, il s'agirait d'un article qui serait considéré comme "une porte largement ouverte » aux instruments de protection de l'enfant. Cet article dispose : «L'Etat a le devoir de veiller à l'élimination de toute discrimination contre la femme et d'assurer la protection des droits de la femme et de l'enfant tels que stipulés dans les déclarations et conventions internationales » (nous soulignons). En clair, « [1] cadre de référence nécessaire à l'accomplissement de ce devoir est largement défini $[\ldots] \gg{ }^{2130}$. Toutefois, le « devoir » dans

${ }^{2124}$ AFFA'A MINDZIE, Mireille, «Protection régionale des droits de l'enfant en Afrique » «art.cit.» http://www.pambazuka.net/fr/category.php/comment/44469 (Source consultée le 31 janvier 2016).

${ }^{2125}$ ACPF, Budgetiser pour les Enfants en Afrique. La Rhétorique, la Réalité et le Tableau de bord. Supplément au Rapport Africain sur le Bien-être de l'enfant 2011, The Africain Child Policy Forum, Addis Abeba, 2011, p. 5.

2126 Voy. http://www.conafesenegal.org/index.php/mediatheque/videos/2-uncategorised/60-aucun-pays-n-aalloue-plus-de-1-de-son-budget-deplore-le-president-de-1-ucoa-prise-en-charge-des-droits-des-enfants-enafrique-de-l-ouest (Source consultée le 02 février 2016).

2127 Commission africaine des droits de l'homme et des peuples, Communication n²27/99 République Démocratique $d u$ Congo/ Burundi, Rwanda, Ouganda, $\$ 51$ in http://www.achpr.org/fr/communications/decision/227.99/ (Source consultée le 16 janvier 2016).

2128 Ibid., $\$ \$ 8$ et 10

2129 Ibid., Voy. « Décision ».

${ }^{2130}$ NGOMO, Angéline-Florence, «Article 18, alinéa 3 », in KAMTO, Maurice (dir.), La Charte africaine des droits de l'homme et des peuples et le protocole y relatif portant création de la Cour africaine des droits de l'homme et des peuples. Commentaire article par article, Bruylant, Bruxelles, 2011, p. 420. 
le sens de cette disposition semble plus moral que juridique ${ }^{2131}$. Dans le cadre de la présente affaire, c'était donc à la Commission africaine des droits de l'homme et des peuples, agissant proprio motu $^{2132}$, de constater un tel manquement pour le reprendre dans le dispositif de sa « décision ».

$\mathrm{Au}$ regard du $\mathrm{DIH}$, de nombreuses violations des règles de protection spéciale des enfants n'ont pas expressément été épinglées particulièrement par la partie demanderesse. Cependant, en vertu des articles 60 et 61 de la Charte africaine des droits de l'homme et des peuples, différentes violations des règles du DIH commises notamment contre les civils, dont particulièrement les viols des filles et des femmes ${ }^{2133}$, ont été évoquées et condamnées par la Commission africaine des droits de l'homme et des peuples.

En effet, la RDC «énumère une série de massacres, viols, mutilations, déportations massives de populations et pillage des possessions des populations ${ }^{2134}$. Violations perpétrées par les trois Etats précités et rentrant dans le cadre du DIH.

Pour sa part, tenant compte des CG et de leurs PA dans l'examen de la présente communication, la Commission africaine des droits de l'homme et des peuples, considère en vertu des articles $60^{2135}$ et $61^{2136}$ de la Charte africaine des droits de l'homme et des peuples, ces instruments du DIH comme «principes généraux du droit reconnus par les Etats africains ${ }^{2137}$. Rappelons avec Maurice KAMTO que «[1]'article 60 est consacré aux « sources » du droit dont la « commission s'inspire » dans l'accomplissement de sa mission, cependant que l'article 61 indique les «sources» du droit qu'elle «prend aussi en considération comme moyens auxiliaires de détermination des règles de droit $»^{2138}$. Tout ceci dans le but de donner une meilleure protection des droits humains ${ }^{2139}$.

En dépit de réfutations ou d'objections des parties défenderesses (Ouganda et Rwanda), la Commission considère que cette série d'actes perpétrés sont en violation de leurs obligations découlant notamment du titre III de la CG IV et du PA I, voire de la Convention de La Haye

\footnotetext{
${ }^{2131}$ Ibid., p. 422.

${ }^{2132}$ Nous estimons de notre part que cela se dégage de son rôle « inquisitorial » analysé notamment sur pied des articles 46,51 et 52 de la Charte africaine des droits de l'homme et des peuples, un peu comparable aux articles 48, 49 et 50 du Statut de la Cour internationale de justice.

2133 Commission africaine des droits de l'homme et des peuples, Communication $n^{\circ} 227 / 99$ République Démocratique du Congo/ Burundi, Rwanda, Ouganda, op. cit., §86.

${ }^{2134}$ Ibid., $\$ 69$.

${ }^{2135}$ Lire pour approfondissement DECAUX, Emmanuel « Article 60 », in KAMTO, Maurice (dir.), La Charte africaine des droits de l'homme et des peuples et le protocole y relatif portant création de la Cour africaine des droits de l'homme et des peuples. Commentaire article par article, op. cit., pp. 1105-1116.

${ }^{2136}$ Lire pour approfondissement KAMTO, Maurice, «Article $61 »$, in KAMTO, Maurice (dir.), La Charte africaine des droits de l'homme et des peuples et le protocole y relatif portant création de la Cour africaine des droits de l'homme et des peuples. Commentaire article par article, op. cit., 1117-1140.

2137 Commission africaine des droits de l'homme et des peuples, Communication $n^{\circ} 227 / 99$ République Démocratique du Congo/ Burundi, Rwanda, Ouganda, op. cit., $\$ \S 70$ et 78, voy. aussi les $\S \S 83,84$ et 86.

${ }^{2138}$ KAMTO, Maurice, «Article 61 », « art. cit. », in KAMTO, Maurice (dir.), La Charte africaine des droits de l'homme et des peuples et le protocole y relatif portant création de la Cour africaine des droits de l'homme et des peuples. Commentaire article par article, op. cit., 1117.

2139 ANKUMAH, Evelyn A., The African Commission on Human and Peoples' Rights. Practices and Procedures, Martinus Nijhoff publishers, The Hague/London/Boston, 1996, p.182.
} 
(IV) concernant les lois et coutumes de la guerre sur terre ${ }^{2140}$.

Par ailleurs, pour tout dire, les « recommandations» de la Commission africaine des droits de l'homme et des peuples, contenues dans son rapport, dépendent du «bon vouloir» de l'organe politique et «politisé » qui est la Conférence des chefs d'Etat et de gouvernement (articles 52, 53, 54 de la Charte), l'organe décideur, seul qui peut «lui conférer une valeur plus solennelle ${ }^{2141}$. Il n'existe donc « aucune liaison obligatoire quant au résultat de la requête $»^{2142}$. Il est fait remarquer en outre à cet égard l'existence de deux lacunes de la Charte africaine des droits de l'homme et des peuples : 1. « [1] Charte africaine n'a pas prévu un cadre de suivi de l'exécution des décisions sur les communications après leur adoption par la Conférence des Chefs d'Etat et de gouvernement $»^{2143} .2$ « [...] [a]ucune sanction [n'est] prévue à l'encontre d'un Etat partie qui viole les dispositions de la Charte africaine ou qui refuse d'exécuter les décisions de la Commission africaine ${ }^{2144}$.

A lumière de tout ce qui précède, la protection spéciale de l'enfant dans le système africain reste problématique précisément en période de conflits armés. Non seulement les mécanismes qui existent ne sont pas efficaces dans la mesure où leurs actes juridiques n'ont pas force exécutoire, mais il est à noter également l'absence de «mécanismes spéciaux » réservés aux enfants en général et ceux affectés par les conflits armés en particulier. Précisément, pour la RDC, il est remarquable de constater que la situation de l'enfant en période de conflits armés suscite peu d'engouement au plan africain. Au départ, l'Etat congolais, premier protecteur de ses enfants, ne stimule pas assez ces mécanismes à s'intéresser à ces questions. L'absence des Rapports appropriés et d'indications précises dans sa plainte, par exemple, confirme ce point de vue.

\section{§3. Comité des droits de l'homme}

Suivant l'article 40, §1, du PIDCP auquel la RDC est partie, les Etats parties ont l'obligation de présenter des rapports sur des mesures prises pour donner effet aux droits y consacrés et sur les progrès réalisés pour leur jouissance. Il s'agit du rapport initial, à soumettre un an après l'entrée en vigueur du PIDCP à l'égard de l'Etat concerné et des rapports périodiques à présenter à la demande du Comité des droits de l'homme (article 40, $\S 1$ a, b). Il sied d'indiquer que contrairement à différents instruments des droits de l'homme, le PIDCP ne précise pas la fréquence de soumission des rapports périodiques. Seul le Comité est donc compétent pour déterminer «la périodicité normale» pour l'examen des rapports étatiques $^{2145}$.

\footnotetext{
${ }^{2140}$ Commission africaine des droits de l'homme et des peuples, Communication $n^{\circ} 227 / 99$ République Démocratique du Congo/ Burundi, Rwanda, Ouganda, op. cit., \$\$79, 82, 84, 86, 87 et 89.

${ }^{2141}$ GHERARI, Habib, «La Commission africaine des droits de l'homme et des peuples (Bilan d'une jurisprudence) », in TAVERNIER, Paul (dir.), Regards sur les droits de l'homme en Afrique, L'Harmattan, Paris, 2008, p. 138.

${ }^{2142}$ ATANGANA AMOUGOU, Jean-Louis, « Article 53 », in KAMTO, Maurice (dir.), La Charte africaine des droits de l'homme et des peuples et le protocole y relatif portant création de la Cour africaine des droits de l'homme et des peuples. Commentaire article par article, op. cit., p. 989.

${ }^{2143}$ MANIRAKIZA, Egide, La Subsidiarité procédurale dans le système africain de protection des droits de l'homme, Thèse de doctorat en droit, Facultés Universitaires Notre-Dame de la Paix, janvier 2009, p. 195.

${ }^{2144}$ Ibid., p. 204.

${ }^{2145}$ MUTZENBERG, Patrick, Agir pour la mise en cuvre des droits civils et politiques. L'apport du Comité des
} 
De 1996 à ce jour, période de la présente étude, la RDC n'a présenté qu'un seul rapport périodique au Comité des droits de l'homme. Il s'agit du troisième rapport périodique soumis quinze ans après la présentation du deuxième (30 mai 1989). Suivant le gouvernement congolais, le retard observé pour les rapports attendus de la RDC semble se justifier par le changement institutionnel intervenu entre temps dont la perte de l'autonomie de l'ancien Ministère des droits et libertés du citoyen incorporé au Ministère de la justice. Ce qui a entraîné par conséquent la disparition de l'organe de préparation des rapports périodiques, le «Comité de suivi des pactes internationaux ». L'instabilité politique et institutionnelle engendrée à la suite des réformes politiques majeures intervenues le 24 avril 1990 et les deux « guerres de libérations » justifieraient également, selon la RDC, ledit retard.

A propos de la situation de l'enfant en conflits armés, rappelons qu'il n'existe pas une disposition du PIDCP le protégeant spécifiquement en cette période. Cependant, dans son Observation générale $\mathrm{n}^{\circ} 17$ de 1989 , le Comité des droits de l'homme attirait « l'attention des États parties sur la nécessité d'inclure dans leurs rapports des informations sur les mesures adoptées pour assurer qu'aucun enfant ne participe directement à un conflit armé » ${ }^{2146}$.

Mais, il existe des dispositions du PIDCP qui protègent expressément l'enfant en tout temps temps de paix et temps de conflits armés. Bien plus, en tant que personne, l'enfant bénéficie de tous les droits civils du PIDCP en dépit du non exercice par lui des droits politiques dont ceux inscrits notamment dans l'article 25 de celui-ci ${ }^{2147}$. Ainsi, en tout temps, à titre des «mesures spéciales » de protection de l'enfant, celui-ci a donc droit sans discrimination aux mesures de protection issues de sa famille, de la société et de l'Etat (article 24, § 1). Il a en outre droit à l'interdiction de la peine de mort (article $6, \S 5$ ), à sa séparation d'adultes, au traitement rapide de son dossier en tant que prévenu (article $10, \S 2$, b) et à un régime pénitentiaire approprié en tant que condamné (article 10, §3). L'intérêt de l'enfant (mineur) peut conduire à faire exception à la publicité du procès (article $14, \S 1)^{2148}$.

Concernant les mesures «spéciales » prises par la RDC pour la protection de l'enfant au regard de l'article 24 du PIDCP, il n'est indiqué dans son rapport que des mesures législatives et administratives. Il s'agit notamment de la consécration constitutionnelle de l'article 24 précité, de l'incrimination et de la répression des actes attentatoires aux droits de l'enfant par

droits de l'homme, L'Harmattan, Paris, 2014, p. 36.

${ }^{2146}$ Comité des droits de l'homme, Observation générale $n^{\circ} 17$ : Article 24 (Droits de l'enfant), Trente$\begin{array}{llllllll}\text { cinquième session } & \text { (1989), } & 29 & \text { septembre } & 1989, & \S & 3 & \text { in }\end{array}$ http://tbinternet.ohchr.org/ layouts/treatybodyexternal/TBSearch.aspx?Lang=fr\&TreatyID=8\&DocTypeID=11 (Source consultée le 20 janvier 2016).

${ }^{2147}$ HENNEBEL, Ludovic, Le régionalisme comme garant de l'universalisme des droits de l'homme: le cas du mécanisme de recours individuel de la Convention américaine des droits de l'homme, Thèse de doctorat en Droit, Vol. II, ULB, 2004-2005, p. 484.

2148 Voy. aussi Comité des droits de l'homme, Observation générale $n^{\circ} 17$ : Article 24 (Droits de l'enfant), Trente-cinquième session (1989), $29 \quad$ septembre $\quad 1989, \quad \S \quad 2 \quad 2 \quad$ in http://tbinternet.ohchr.org/_layouts/treatybodyexternal/TBSearch.aspx?Lang=fr\&TreatyID=8\&DocTypeID=11

(Source consultée le 20 janvier 2016); HENNEBEL, Ludovic, Le régionalisme comme garant de l'universalisme des droits de l'homme: le cas du mécanisme de recours individuel de la Convention américaine des droits de l'homme, op.cit., p. 484. 
le Code pénal, et de quelques dispositions du Code de la famille ${ }^{2149}$. En dehors des Etablissements de garde et d'éducation de l'Etat (EGEE), en application de l'Ordonnance n³44 du 17 septembre 1965 portant régime pénitentiaire, présentés au sujet des enfants privés de liberté ${ }^{2150}$, aucun «mécanisme » de prise en charge des «mesures spéciales »au sujet des enfants en période de paix ou de conflits armés n'est mentionné. Il faudrait toutefois préciser qu'en termes de " mesures », celles-ci ne doivent pas se limiter aux « actes législatifs et aux décisions administratives ou judiciaires. Elles doivent être comprises dans un sens général $^{2151}$. Les mesures spéciales sont celles qui tiennent compte des spécificités - dont les vulnérabilités physique et psychiques - que présente l'enfant (cf. infra).

Ainsi, au sujet de l'article 24 du PIDCP, le Comité des droits de l'homme fait observer que « [1]'application de cette disposition nécessite l'adoption par les États de mesures spéciales en ce sens, qui s'ajoutent à celles qu'ils sont par ailleurs tenus de prendre en vertu de l'article $2[\ldots]{ }^{2152}$. Ces mesures sont donc complémentaires à celles générales ${ }^{2153}$. C'est d'ailleurs en cela qu'elles sont dites «mesures spéciales ». Il s'agit toutefois d'une obligation souvent sous-estimée par les Etats. Lesquels présentent des renseignements insuffisants à la manière de mise en œuvre de cette obligation, indique le Comité des droits de 1'homme ${ }^{2154}$. Au regard de l'article 24, ces mesures n'étant pas précisées contrairement à ce qui est observé au niveau des articles $6, \S 5,10 \S \S 2-3,14 \S 1$, il revient donc à l'Etat de les définir «en fonction des exigences de la protection des enfants qui se trouvent sur son territoire ou relèvent de sa compétence $»^{2155}$. Suivant le Comité des droits de l'homme, ces mesures peuvent être aussi d'ordre économique, social ou culturel. Elles consisteraient par exemple, en l'adoption de mesures au plan économique et social pour la réduction de la mortalité infantile, la disparition de la malnutrition chez les enfants et la prévention des actes de violence ou de traitements cruels et inhumains des enfants, etc. Dans le domaine culturel, ces mesures devraient favoriser l'épanouissement de la personnalité de l'enfant ${ }^{2156}$.

\footnotetext{
2149 Comité des droits de l'homme, Examen des Rapports présentés par les Etats parties en application de l'article $40 \mathrm{du}$ Pacte, Troisième rapport périodique, République Démocratique du Congo, CCPR/C/COD/2005/3, 3 mai 2005, pp. 46-48, $\S \S \quad 270-281$, in http://tbinternet.ohchr.org/_layouts/TreatyBodyExternal/TBSearch.aspx?Lang=fr\&TreatyID=8\&DocTypeID=29 \&DocTypeID=45 (Source consultée le 20 janvier 2016).

${ }^{2150}$ Ibid., p. 22, $\S \S 116-120$.

${ }^{2151}$ MUTZENBERG, Patrick, Agir pour la mise en $2 u v r e$ des droits civils et politiques. L'apport du Comité des droits de l'homme, op.cit., p. 30.

2152 Comité des droits de l'homme, Observation générale $n^{\circ} 17$ : Article 24 (Droits de l'enfant), Trente$\begin{array}{llllllll}\text { cinquième } & \text { session } & \text { (1989), } & 29 & \text { septembre } & 1989, & \S & 1\end{array}$ http://tbinternet.ohchr.org/_layouts/treatybodyexternal/TBSearch.aspx?Lang=fr\&TreatyID=8\&DocTypeID=11 (Source consultée le 20 janvier 2016).

${ }^{2153}$ BURGORGUE-LARSEN, Laurence, « article 24 », in DECAUX, Emmanuel (dir.), Le Pacte international relatif aux droits civils et politiques. Commentaire article par article, Ed. Economica, Paris, 2011, p. 520.

2154 Comité des droits de l'homme, Observation générale n'17: Article 24 (Droits de l'enfant), Trentecinquième session (1989), 29 septembre 1989, op. cit. $\S 1$.

${ }^{2155} \mathrm{Ibid}$. § 3. Voy. aussi BURGORGUE-LARSEN, Laurence, « article 24 », op. cit., pp. 519-520.

${ }^{2156}$ Comité des droits de l'homme, Observation générale $n^{\circ} 17$ : Article 24 (Droits de l'enfant), Trentecinquième session (1989), 29 septembre 1989, op. cit., § 3.
} 


\section{\$4. Comité contre la torture}

La RDC a adhéré à la Convention contre la torture et autres peines ou traitements cruels, inhumains ou dégradants du 10 décembre $1984^{2157}$, le 18 mars 1996. En vertu de l'article 19, paragraphe 1 , de cette convention, la RDC devait, un an après son adhésion, présenter son Rapport initial faisant part des mesures qu'elle a prises pour rendre effective ladite convention sur son territoire. Les Rapports périodiques devront intervenir tous les quatre ans.

Avec son « retard habituel », la RDC a attendu huit ans pour présenter son rapport initial, soit de 1997 à 2005. Chose que le Comité contre la torture regrettera. Il félicitera tout de même l'Etat congolais de son Rapport initial conforme à ses directives générales. De ce Rapport, le Comité retiendra comme points positifs la ratification par la RDC des principaux instruments des droits de l'homme et l'existence d'une proposition de loi de mise en œuvre de la présente convention au plan national. Cependant, en termes de points négatifs, le Comité retient l'inexistence en droit congolais d'une définition de la torture conforme à l'article $1^{\mathrm{er}}$ de la Convention contre la torture; l'inexistence de la compétence universelle en matière de torture ; l'inexistence des dispositions en droit congolais donnant effets notamment aux article 6 et 9, etc. D'où l'importance de recommander à la RDC de prendre des mesures législatives, administratives et judiciaires de prévention et de répression des actes de torture ${ }^{2158}$. Elle devrait fournir précisément pour ses manquements relevés ci-dessus, dans un délai d'un an, des renseignements sur des mesures prises ${ }^{2159}$. Précisons qu'au niveau du Comité des droits de l'enfant, une recommandation a été faite dans le même sens à la RDC de se doter d'une législation définissant le «crime de torture » conformément à la Convention contre la torture $^{2160}$. C'est ainsi qu'elle promulguera la Loi $n^{\circ} 11 / 008$ du 09 juillet 2011 portant criminalisation de la torture $^{2161}$. Cette loi de deux articles met à jour le décret du 30 janvier 1940 portant Code pénal congolais en insérant des dispositions définissant les actes de torture conformément à la Convention contre la torture et les incriminant.

Concernant le cas des enfants en RDC, le Comité s'est préoccupé de la situation de vulnérabilité générale des enfants face à la torture et autres traitements cruels, inhumains ou dégradants dont particulièrement les enfants combattants au sein des groupes armés. En cela, il recommande à la RDC d' "adopter et [d']appliquer des mesures législatives et administratives d'urgence pour protéger les enfants, en particulier les enfants abandonnés, des

\footnotetext{
${ }^{2157}$ Voy. Convention contre la torture et autres peines ou traitements cruels, inhumains ou dégradants du 10 décembre 1984 in Nations Unies in Recueil des traités, vol. 1465, New-York, 1996, pp. 123-132 disponible in https://treaties.un.org/pages/ViewDetails.aspx?src=TREATY\&mtdsg no=IV-9\&chapter=4\&lang=fr $\quad$ (Source consultée le 15 janvier 2016).

2158 Voy. Rapport du Comité contre la torture, Trente-cinquième session (14-25 nov. 2005) Trente-sixième session ( $1^{\text {er }}-19$ mai 2006), Assemblée générale, Documents officiels, soixante et unième session, supplément n ${ }^{\circ} 44$ (A/61/44), pp. 19-23, http://tbinternet.ohchr.org/ layouts/treatybodyexternal/Download.aspx?symbolno=A\%2f61\%2f44\&Lang=fr (Source consultée le 15 janvier 2016). 2159 Ibid., p. 23, \$26, point 17.

$2160 \quad 3^{\mathrm{e}}, \quad 4^{\mathrm{e}}, \quad 5^{\mathrm{e}}$ Rapport version finale, RDC, op. cit., p. 14, $\$ 14, \quad$ in http://tbinternet.ohchr.org/ layouts/treatybodyexternal/TBSearch.aspx?Lang=en\&TreatyID=5\&TreatyID=10\&T reatyID=11\&DocTypeID=29\&DocTypeCategoryID=4 (Source consultée le 10 janvier 2016)

${ }^{2161}$ Voir la Loi $n^{\circ} 11 / 008$ du 09 juillet 2011 portant criminalisation de la torture, in http://leganet.cd/Legislation/DroitPenal/Loi.11.008.09.07.2011.htm (Source consultée le 15 janvier 2016).
} 
violences sexuelles et assurer leur réhabilitation et réinsertion. Le Comité, en outre, recommande à l'État partie de prendre toutes les mesures possibles pour que tous les enfants soldats soient démobilisés, ainsi que de veiller à leur réadaptation et réinsertion sociale ${ }^{2162}$ Les termes «mesures possibles» ont été plusieurs fois repris par le Comité des droits de l'enfant au sujet de diverses questions de protection de l'enfant (cf. supra). Ce qui nous paraît critiquable.

Par ailleurs, jusqu'au 15 mai 2015, date mentionnée dans le dernier rapport du Comité contre la torture ${ }^{2163}$, la RDC n'avait pas encore soumis ses deuxième, troisième et quatrième rapports attendus depuis le 16 avril $2009^{2164}$.

Près de vingt ans comme partie à la Convention contre la torture et autres peines ou traitements cruels, inhumains ou dégradants, la RDC n'a soumis qu'un seul rapport au lieu de quatre. En même temps, la lecture de différents rapports du Comité contre la torture attestent aussi que les Etats ne s'empressent généralement pas à soumettre leurs rapports initiaux, périodiques ou complémentaires. Ils finissent tout de même par répondre aux observations et recommandations finales du Comité. Lesquelles influent non moins sur l'amélioration des droits de l'enfant notamment dans les milieux carcéraux.

De tout ce qui précède, il sied de conclure que les organes conventionnels des droits de l'homme, examinés ci-dessus, ne sont pas véritablement des mécanismes de mise en œuvre «appropriés » de la protection spéciale de l'enfant en période de conflits armés en RDC. N'intervenant que tard après les faits à la suite des Rapports leur soumis par la RDC, ces organes n'ont de surcroît pas assez de pouvoir réel de contraindre la RDC et les groupes armés y opérant dans leurs différents manquements. La RDC ne s'empresse pas - au tant pour d'autres Etats tels que les Républiques de l'Ouganda et du Rwanda - de soumettre ses Rapports. L'état de mise en œuvre de ces conventions ne cesse de poser problème en dépit de quelques satisfactions. Par exemple, c'est depuis plus d'une décennie que le Comité des droits de l'enfant réitère ses «mêmes préoccupations » au sujet des mesures de protection des enfants en conflit armé en RDC. De leur côté, les Rapports d'activités des Comités dépendent du sort que leur réservent les instances «politiques »supérieures. Néanmoins, il ne serait nullement affirmé l'inutilité des activités de ces organes conventionnels au sujet de la protection spéciale de l'enfant en conflit armé en RDC. Ceci pour dire que les différentes recommandations et observations finales que formulent ces Comités à l'issue des Rapports étatiques permettent une mise en œuvre «progressive» de la protection spéciale de l'enfant en RDC.

2162 Rapport du Comité contre la torture, Trente-cinquième session (14-25 nov. 2005) Trente-sixième session ( $1^{\text {er }}-19$ mai 2006), Assemblée générale, Documents officiels, soixante et unième session, supplément $n^{\circ} 44$ (A/61/44), op. cit., pp. 22-23, §26, point 14.

${ }^{2163}$ Voy. Rapport du Comité contre la torture, cinquante-troisième session (3-28 novembre 2014) cinquantequatrième session (20 avril-15 mai 2015) Assemblée générale, Documents officiels, soixante-dixième session

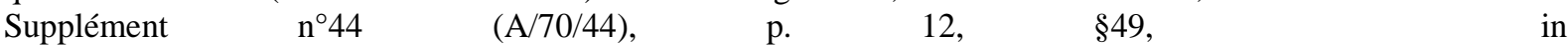
http://tbinternet.ohchr.org/_layouts/treatybodyexternal/Download.aspx?symbolno=A\%2f70\%2f44\&Lang=fr (Source consultée le 15 janvier 2016).

${ }^{2164}$ Rapport du Comité contre la torture, cinquante et unième session (28 octobre-22 novembre 2013), cinquantedeuxième session (28 avril - 23 mai 2014), p. 280, http://tbinternet.ohchr.org/_layouts/treatybodyexternal/Download.aspx?symbolno=A\%2f69\%2f44\&Lang=fr (Source consultée le 15 janvier 2016). 


\section{Section III La protection des enfants en situation de conflits armés en RDC dans le système de l'ONU}

Cette section analyse essentiellement, au regard de leurs rôles assurés dans la protection des enfants en conflits armés en RDC et de surcroit dans la promotion du DIH applicable à cet effet, les cas du CS/NU et du Secrétariat de l'ONU (§1), de la MONUSCO (ex-MONUC) (2) et de l'UNICEF (§3). Ces mécanismes dans le cas spécifiquement de la RDC comblent, dans une certaine mesure, certaines faiblesses décelées au niveau des mécanismes conventionnels de protection de l'enfant en situation de conflits armés (cf. supra). Ainsi, sous cette section, il ne serait donc pas examiné les rôles de nombreuses agences onusiennes œuvrant en RDC au profit des enfants $^{2165}$.

\section{§1. l'ONU et la protection des enfants dans les conflits armés en RDC : Cas du Conseil de sécurité et du Secrétariat}

L'ONU «s'efforce de normaliser les relations internationales, d'introduire plus de justice, plus de respect du Droit, de susciter plus d'aversion à l'égard des procédures de force, et de créer les conditions qui préparent ou sauvegardent le maintien de la paix [...] ${ }^{2166}$. Se trouvant aussi au cœur de la problématique de la paix et de la sécurité internationales ${ }^{2167}$, la question de protection des civils, des enfants, a toujours constitué une préoccupation constante de l'ONU ${ }^{2168}$. Le CS/NU leur accorde «la plus grande attention » lorsqu'il examine des questions dont il est saisi ${ }^{2169}$. Elle est une «priorité absolue » pour le cas de la RDC avec la MONUSCO (cf. infra).

En effet, dès sa qualification de «menace pour la paix, la sécurité et la stabilité dans la région ${ }^{2170}$ par la résolution S/RES/1234 (1999) du CS/NU, le conflit armé en RDC fait régulièrement l'objet des résolutions des Nations Unies, principalement du CS/NU. Alors que nombreux sont déjà des institutions onusiennes et des organismes internationaux qui se préoccupent directement ou indirectement de la protection des enfants ${ }^{2171}$, il est en outre créé

\footnotetext{
2165 Voy. les différentes agences onusiennes œuvrant en RDC sous ce lien : http://cd.one.un.org/content/unct/rdc/fr/home/a-propos.html (Source consultée le 22 février 2016).

2166 CHAUMONT, Charles, L'O.N.U, Presses Universitaires de France, Paris, 1964, p. 64.

2167 Voy. le $\$ 9$ de la résolution 1314 (2000) du CS/ NU in http://www.un.org/fr/documents/scres.shtml (Source consultée le 19 février 2016). Cette résolution «note que les pratiques consistant à prendre délibérément pour cible des populations civiles ou autres personnes protégées, y compris les enfants, et à commettre des violations systématiques, flagrantes et généralisées du droit international humanitaire et du droit relatif aux droits de l'homme, y compris aux droits de l'enfant, dans les situations de conflit armé peuvent constituer une menace contre la paix et la sécurité internationales [...]».

${ }^{2168}$ GRIP, L'ONU dans tous ses états. Son histoire - Les principes et les faits- Les nouveaux défis -Quelles réformes?, Collection «GRIP-Informations », Bruxelles, octobre 1995, p. 28. Voy. aussi EMMANUELLI, Claude, International humanitarian Law, op.cit. pp. 51-52 ; MOIR, Lindsay, The Law of internal armed conflict, op.cit., pp. 251-221.

${ }^{2169} \S 1$ de la résolution 1379 (2001) du CS/NU http://www.un.org/fr/documents/scres.shtml (Source consultée le 19 février 2016).

${ }^{2170}$ Voy. le $11^{\mathrm{e}}$ considérant de la Résolution S/RES/1234 (1999) du 09 avril 1999.

2171 DHOMMEAUX, Jean, «L'Enfant dans l'ordre juridique international », in GADBIN, Daniel et KERNALEGUEN, Francis (dir.), Le Statut juridique de l'enfant dans l'espace européen, Bruylant, Bruxelles, 2004, p. 29. Voy. aussi BODINEAU, Sylvie, Figure d'enfants soldats. Puissance et vulnérabilité, op.cit., p. 11. Voy. aussi pour la RDC, les différentes agences onusiennes y œuvrant:
} 
par l'ONU des mécanismes plus spécifiques traitant de la protection des enfants en période de conflits armés, notamment en RDC. C'est précisément les cas du Mécanisme de surveillance et de communication de l'information sur les enfants et les conflits armés et du Groupe de travail sur les enfants et les conflits armés créés par le CS/NU ${ }^{2172}$. Ou encore du Secrétariat $^{2173}$ avec le Bureau du Représentant spécial du Secrétaire général pour les enfants et les conflits armés ${ }^{2174}$.

Par sa résolution 1612 (2005), adoptée à sa 5235e séance le 26 juillet 2005, le CS/NU prendra note du plan d'action présenté par le SG/NU pour la mise en place du Mécanisme de surveillance et de communication de l'information sur les enfants et les conflits armés tel que demandé au paragraphe 2 de sa résolution 1539 (2004) ${ }^{2175}$. Il priera le SG/NU de mettre en place sans tarder ce mécanisme et de l'appliquer dans un premier temps, dans la limite des ressources disponibles et en étroite consultation avec les pays concernés, aux parties aux conflits armés mentionnées dans la liste annexée au rapport du Secrétaire général ${ }^{2176}$. Le CS/NU décidera par la même résolution de créer un groupe de travail composé de tous les membres du Conseil qui sera chargé d'examiner les rapports du Mécanisme de surveillance et de communication de l'information sur les enfants et les conflits et de recommander au CS/NU des mesures à prendre pour favoriser la protection des enfants touchés par les conflits armés, voire à d'autres organismes onusiens ${ }^{2177}$. « [C]omblant effectivement le fossé entre l'action politique aux plus hauts niveaux et l'action sur le terrain ${ }^{2178}$.

Après discussions avec les organisations pertinentes, il est établi par le SG/NU que c'est sur six violations graves que ce mécanisme de surveillance mettrait l'accent ${ }^{2179}$ : le massacre ou la mutilation; le recrutement ou l'utilisation d'enfants soldats; les attaques dirigées contre des écoles ou des hôpitaux; le viol d'enfants et autres actes graves de violences sexuelles à leur

http://cd.one.un.org/content/unct/rdc/fr/home/a-propos.html (Source consultée le 22 février 2016).

${ }^{2172}$ Pour mieux comprendre le fonctionnement de ce mécanisme, lire Watchlist on children and Armed conflict, Mécanisme 1612 de surveillance et de communication. Dossier de ressources et outils pour ONG, Watchlist on children and Armed conflict, 2014, 122 p. Document pdf téléchargeable sur google.

2173 Rappelons qu'à titre historique vis-à-vis de la situation en RDC, alors République du Congo, le SG/NU a joué un rôle important (notamment sur base de l'article 99 de la Charte de l'ONU) dans l'intervention de force internationale de police sur son territoire (ONUC), voire par la suite de l'évolution de la crise congolaise. Lire VAN LANGENHOVE, Fernand, Le Rôle proéminent du Secrétaire général dans l'opération des Nations Unies au Congo, op.cit., 260 p. Voy. aussi TAUBENFELD, Howard J., « The Applicability of the laws of war in civil war », « art. cit. », p. 514.

${ }^{2174}$ Pour mieux comprendre l'historique et l'évolution du Bureau du Représentant spécial du Secrétaire général pour les enfants et les conflits armés, voy. https://childrenandarmedconflict.un.org/fr/qui-sommesnous/historique/ (Source consultée le 22 février 2016).

$2175 \$ 2$ de la résolution 1612 (2005) du CS/NU, op. cit., http://www.un.org/fr/documents/view_doc.asp?symbol=S/RES/1612\%20(2005) (Source consultée le 19 février 2016). Voy. \$2 de la Résolution 1539 (2004) adoptée par le Conseil de sécurité à sa 4948 e séance, le 22 avril 2004 in http://www.un.org/fr/documents/view_doc.asp?symbol=S/RES/1539\%20(2004) (Source consultée le 19 février 2016).

$2176 \quad \S 3$ de la résolution $1612 \quad(2005)$ du CS/NU, op. cit., in http://www.un.org/fr/documents/view_doc.asp?symbol=S/RES/1612\%20(2005) (Source consultée le 19 février 2016 )

2177 Ibid., $\$ 8$

2178 Bureau du Représentant Spécial du Secrétaire général pour les enfants et les conflits armés, Examen stratégique décennal de l'Etude Machel : les enfants et les conflits armés dans un monde en mutation, op.cit., 47. 2179 Ibid. 
égard; l'enlèvement d'enfant; et le refus de l'accès à l'aide humanitaire ${ }^{2180}$.

Avec pour «vocation et finalité uniques de protéger les enfants touchés par les conflits » ${ }^{2181}$, ce mécanisme sera chargé de recueillir et de communiquer rapidement des informations objectives, exactes et fiables sur la situation des enfants touchés par les conflits armés. Et ce quand bien même certaines de ces graves violations peuvent être commises en dehors de conflits armés ${ }^{2182}$. Il bénéficiera de la participation et de la coopération des Etats, des organismes onusiens et de la société civile ${ }^{2183}$. Les informations qu'il recueille serviront à l'établissement des rapports du $\mathrm{SG} / \mathrm{NU}$ à l'AG/NU et au CS/NU. Elles pourront aussi servir à d'autres organismes intéressés à la protection des enfants touchés par les conflits armés ${ }^{2184}$. Ce Mécanisme de surveillance et d'information soumet lui-même ses rapport au Groupe de travail du CS/NU créé à cet effet ${ }^{2185}$. Dans un temps relativement court, ce mécanisme passera du projet pilote dans sept pays Burundi, Côte d'Ivoire, Népal, République Démocratique du Congo, Somalie, Soudan et Sri Lanka - à une mise en œuvre effective dans 11 pays $^{2186}$.

Dans le cadre de ce processus, différents rapports ont été adoptés par le SG/NU sur la situation des enfants touchés par les conflits armés en RDC. En effet, le premier dans ce cadre est le rapport A/59/695-S/2005/72 du SG/NU soumis sur demande et en application de la résolution 1539 (2004) du CS/NU afin d'établir l'état de sa mise en œuvre et d'autres résolutions antérieures à savoir les résolutions 1379 (2001) et 1460 (2003) sur le respect des engagements pris et des progrès réalisés par les parties pour faire cesser le recrutement et l'emploi d'enfants dans les conflits armés et les graves violations ${ }^{2187}$.

Ce rapport fait une nette évolution en dents de scie sur l'interdiction de recrutement et utilisation des enfants dans les conflits armés en RDC. Il y est donc démontré suivant la période du 10 novembre 2003 à décembre 2004, que la RDC avait effectivement adopté une politique et l'ensemble de procédures de DDR des enfants des FARDC et des groupes armés au début de l'année 2004. Cette politique, conforme à la législation congolaise adoptée en 2003, répond et renforce son engagement d'exclusion de la présence et d'interdiction de recrutement de tout individu de moins de 18 ans dans les forces et groupes armés. Cette politique a bénéficié de l'appui de la MONUC, de l'UNICEF et d'autres partenaires. Sa mise en œuvre sous la période indiquée a occasionné le retrait de quelque 5000 enfants - dont un petit nombre de filles - des forces et groupes armés ${ }^{2188}$. En Ituri, par exemple, d'importants groupes armés - les Forces

$2180 \$ 68$ du Rapport du Secrétaire général sur les enfants et les conflits armés, A/59/695-S/2005/72, in http://www.un.org/fr/documents/view_doc.asp?symbol=S/2005/72 (Source consultée le 21 février 2016).

$\begin{array}{lllllllll}2181 & \$ 4 & \text { de } & \text { la } & \text { résolution } 1612 & (2005) & \text { du } & \text { CS/NU, op. cit., } & \text { in }\end{array}$ http://www.un.org/fr/documents/view_doc.asp?symbol=S/RES/1612\%20(2005) (Source consultée le 19 février 2016).

${ }^{2182} \$ 68$ du Rapport du Secrétaire général sur les enfants et les conflits armés, A/59/695-S/2005/72, op. cit., in http://www.un.org/fr/documents/view_doc.asp?symbol=S/2005/72 (Source consultée le 21 février 2016).

$\begin{array}{lllllllll}2183 & \text { Voy. } & \$ 2 & \text { de } & \text { la } & \text { résolution } & 1612 & \text { (2005) du } & \text { CS/NU }\end{array}$ http://www.un.org/fr/documents/view_doc.asp?symbol=S/RES/1612\%20(2005) (Source consultée le 19 février 2016).

${ }^{2184}$ Ibid., $\$ 6$.

2185 Ibid., $\$ 8$.

${ }^{2186}$ Bureau du Représentant Spécial du Secrétaire général pour les enfants et les conflits armés, Examen stratégique décennal de l'Etude Machel : les enfants et les conflits armés dans un monde en mutation, op.cit., 47. $2187 \$ 1$ du Rapport du Secrétaire général sur les enfants et les conflits armés, A/59/695-S/2005/72, in http://www.un.org/fr/documents/view_doc.asp?symbol=S/2005/72 (Source consultée le 20 février 2016).

${ }_{2188} \S 16$ du Rapport du Secrétaire général sur les enfants et les conflits armés, A/59/695-S/2005/72 in 
armées populaires congolaises (FAPC), le Front nationalistes et intégrationniste (FNI), le Parti pour l'Unité et la sauvegarde du Congo (PUSIC), l'Union des Patriotes congolais (UPC- faction de Thomas Lubanga) et l'UPC-faction de Floribert Kisembo - ont officiellement pris part au programme de désarmement et de réinsertion communautaire mis en œuvre au début de septembre 2004. Ils ont effectué bien avant même la mise en œuvre dudit programme la libération d'un nombre indéterminé d'enfants. Mais, il sera par la suite signalé de nombreux cas de rerecrutement, d'arrestation et de harcèlement des enfants ayant bénéficié de ce programme par ces groupes armés à Kpandroma et Mahagi ${ }^{2189}$. Ainsi, des milliers d'enfants demeurent dans les forces et groupes armés en RDC suivant cette période. Le recrutement, bien que non systématique, s'est donc poursuivi ${ }^{2190}$. D'un autre côté, des pillages et attaques des écoles, des hôpitaux et des centres de nutrition dans le Sud-Kivu en juin 2004 seraient commis par les troupes de Nkunda et Mutebusi. Il est fait état des informations de massacres en charge des rebelles de l'ex-RCD-Goma en date des 18 et 19 décembre 2004 à Nyabiondo, également en charge de Maï Maï, des FDLR, des FNI et des FAPC au cours de cette même année ${ }^{2191}$. A la base, l'absence d'intégration véritable de diverses unités militaires dont certaines continuaient le recrutement d'enfants. Cette lenteur de restructuration pèse sur la fin des hostilités et constitue un risque permanent de recrutement (ou re-recrutement) et d'utilisation d'enfants dans les conflits armés en $\mathrm{RDC}^{2192}$.

En vertu de la résolution 1612 (2005) du CS/NU, différents rapports seront présentés au CS/NU et au Groupe de travail sur les enfants et les conflits armés par le Mécanisme de surveillance et de communication de l'information sur les enfants et les conflits armés. Les informations contenues dans ces rapports sont reprises et présentées sous la responsabilité du SG/NU à l'AG/NU et au CS/NU. Ainsi, pour la période de juillet 2005 à mai 2006, le premier rapport sur la RDC a été présenté. Celui-ci retient que malgré quelques progrès réalisés, les six graves violations contre les enfants se sont poursuivies impunément dans les provinces du Katanga, du Nord-Kivu, du SudKivu, en Ituri, etc. ${ }^{2193}$ Ces actes seraient principalement le fait des FARDC, de la Police congolaise, des groupes Maï Maï, de quelques éléments proches des Forces démocratiques de libération du Rwanda (FDLR), voire d'autres groupes armés ayant refusé de prendre part au processus d'intégration de l'armée et au processus de $\mathrm{DDR}^{2194}$. Le SG/NU recommandera à l'issue de ce rapport la libération complète et inconditionnelle des garçons et filles des forces et groupes armés avec attention particulière au Général Laurent Nkunda; la poursuite judiciaire des présumés auteurs avec protection des témoins et victimes de criminalité dont les enfants; 1'appui aux institutions judiciaires pour mieux s'acquitter de leurs tâches; l'inscription de la protection de l'enfant dans le processus de la réforme du secteur de sécurité, etc. ${ }^{2195}$

\footnotetext{
http://www.un.org/fr/documents/view_doc.asp?symbol=S/2005/72 (Source consultée le 20 février 2016). ${ }^{2189}$ Ibid., $\S 17$.

${ }^{2190} \mathrm{Ibid}, \S 18$.

${ }^{2191}$ Ibid., $\$ 22$

${ }^{2192}$ Ibid., $\$ 15$

2193 Voy. Résumé du Rapport du Secrétaire général sur les enfants et les conflits armés en République Démocratique du Congo S/2006/389, in http://www.un.org/fr/documents/view_doc.asp?symbol=S/2006/389 (Source consultée le 20 février 2016).

2194 Voy. Résumé du Rapport du Secrétaire général sur les enfants et les conflits armés en République Démocratique du Congo S/2006/389 in http://www.un.org/fr/documents/view_doc.asp?symbol=S/2006/389 (Source consultée le 20 février 2016).

${ }^{2195}$ Voy. Ibid., $§ \$ 55-62$.
} 
Le deuxième rapport, S/2007/391, établi pour la période de juin 2005 à mai 2007 et présenté le 28 juin 2007. Il s'intéresse particulièrement au district de l'Ituri et aux provinces du Nord-Kivu et du Sud-Kivu ${ }^{2196}$. Concernant le recrutement d'enfants par les forces et groupes armés, ce rapport fait un constat de diminution de $8 \%$ comparativement à la période précédente ${ }^{2197}$. Une diminution de $20 \%$ des cas de meurtre et d'atteintes physique d'enfants par rapport à l'année antérieure à cette période a été également constatée ${ }^{2198}$. Aucune attaque contre les écoles et hôpitaux n'a été signalée sauf les cas de leur occupation par les forces et groupes armés ${ }^{2199}$. Cette situation s'expliquerait notamment par l'intégration de l'armée, la diminution du nombre de zones de combat, la mise en place du programme de DDR des enfants ${ }^{2200}$.

Toutefois, les FARDC et la Police congolaise sont reprises comme les principaux auteurs des cas de violations graves des droits de l'enfant attestés, respectivement à $50 \%$ et $19 \%{ }^{2201}$. Les groupes Maï Maï, des milices présentes en Ituri et d'autres éléments armés étrangers sont responsables des autres cas $(30 \%)^{2202}$.

En dépit de ces progrès constatés, l'impunité des auteurs de ces graves violations demeure une des lacunes majeures (cf. infra). Les recommandations du CS/NU dans ce sens, dont l'arrestation de Laurent Nkunda, ne seraient pas observées. D'où la nécessité de mettre fin à une telle impunité et redoubler d'efforts pour que cessent le recrutement et l'utilisation d'enfants dans les forces et groupes armés - qui tiennent principalement aux défaillances du «brassage ». Bien plus, la mobilisation des fonds est requis pour achever le travail de démobilisation et la réinsertion des enfants, en dépit des efforts déployés par le gouvernement avec l'appui des partenaires onusiens et $\mathrm{ONG}^{2203}$.

Un troisième rapport couvrant la période de juin 2007 à septembre 2008 a été établi. C'est le rapport S/2008/693. Il se focalise sur les provinces de Nord-Kivu, Sud-Kivu, Katanga (NordKatanga) et le district d'Ituri où sévissent les groupes armés. Dans le même élan que son prédécesseur, il constate la diminution du nombre d'allégations de graves violations commises sur les enfants tout en indiquant que ceux-ci demeurent les principales victimes de ces conflits armés. Le recrutement et l'utilisation d'enfants continuent tout de même par les forces et groupes armés. Les groupes Maï Maï compteraient, par exemples, plus d'enfants dans leurs rangs suivis par le $\mathrm{CNDP}^{2204}$. Les cas de re-recrutement dû à la défaillance du DDR sont aussi signalés sans oublier les cas de violences sexuelles. En revanche, des progrès dans le sens de poursuites judiciaires entamées par le gouvernement congolais ont été observés ${ }^{2205}$.

\footnotetext{
2196 §1 du Rapport du Secrétaire général sur les enfants et les conflits armés en République Démocratique du Congo S/2007/391, in http://www.un.org/fr/documents/view_doc.asp?symbol=S/2007/391 (Source consultée le 20 février 2016).

${ }^{2197}$ Ibid., $\$ 17$.

${ }^{2198}$ Ibid., $\$ 12$.

${ }^{2199}$ Ibid., \$50.

2200 Voy. Ibid., $\S ~ 12,17$.

2201 Ibid., \$9.

${ }^{2202}$ Ibid., $\$ 10$

2203 Voy. Résumé

2204 \$20 Rapport du Secrétaire général sur les enfants et les conflits armés en République Démocratique du Congo, S/2008/693 in http://www.un.org/fr/documents/view_doc.asp?symbol=S/2008/693 (Source consultée le 20 février 2016).

2205 Ibid., voy. Résumé.
} 
Le quatrième rapport (rapport S/2010/359), couvrant la période d'octobre 2008 à décembre 2009, présenté le 9 juillet 2010, fait état de la dégradation de la situation des enfants touchés par les conflits en RDC comparativement à la période précédente. Les opérations militaires conjointes contre les FDLR et l'Armée de Résistance du Seigneur (LRA) exposeront les enfants au danger et les rendront vulnérables aux risques de recrutement et d'exploitation, de violences sexuelles et d'atteintes à l'intégrité physique ${ }^{2206}$. Nombreux seront donc des civils et des enfants victimes de ces opérations militaires du fait des exactions des FARDC et des représailles des groupes armés $^{2207}$. D'où la proposition de stratégie régionale. Ainsi, dans l'ensemble, il y aura augmentation des graves violations contre les enfants ${ }^{2208}$. Alors que le nombre d'enfants libérés des groupes armés en l'espace de quelques mois en 2009, a été à celui de toute l'année 2008, de nombreux cas de recrutement et de re-recrutement d'enfants ont été également signalés dans le chef des FARDC notamment dans les $\mathrm{Kivu}^{2209}$. Les ex-groupes armés (ex : ex-CNDP, exPARECO) nouvellement intégrés au sein des FARDC seraient responsables de ces violations. Les brigades intégrées seraient responsables d'environ $78 \%$ de recrutement d'enfants au sein des FARDC $^{2210}$. La mise en place de stratégie nationale de violence sexuelle, l'élan de lutte contre l'impunité, ... sont autant des progrès sous cette période ${ }^{2211}$.

Le cinquième rapport (S/2014/453) présenté le 30 juin 2014, pour la période de janvier 2010 à décembre 2013, révèle des exactions commises par toutes les parties contre les enfants. En dépit de la poursuite de recrutement, d'utilisation d'enfants dans les conflits armés et graves violations contre les enfants, le progrès accomplis sous cette période reste la signature en octobre 2012, par la RDC et l'ONU, du plan d'action visant à mettre fin au recrutement et à l'utilisation des enfants dans les conflits armés et aux violences sexuelles commises par les FARDC ${ }^{2212}$.

Ces rapports établis par le SG/NU font également l'objet de suivi par le Bureau du Représentant spécial du Secrétaire général pour les enfants et les conflits armés. Celui-ci fait part des épreuves auxquelles sont confrontés les enfants dans les conflits armés à l'AG/NU, au CS/NU, au Conseil des droits de 1'homme ${ }^{2213}$, au Gouvernement congolais à l'instar

\footnotetext{
2206 Voy. Résumé du Rapport du Secrétaire général sur les enfants et les conflits armés en République Démocratique du Congo, S/2010/359 in http://www.un.org/fr/documents/view_doc.asp?symbol=S/2010/369 (Source consultée le 21 février 2016).

${ }^{2206} \$ 8$ Résolution S/RES/1258 (1999) adoptée par le CS/NU à sa $4032^{\mathrm{e}}$ séance, le 06 août 1999, op. cit.

2207 §16 Rapport du Secrétaire général sur les enfants et les conflits armés en République Démocratique du Congo, S/2010/359, op. cit. .

2207 §8 Résolution S/RES/1258 (1999) adoptée par le CS/NU à sa 4032 e séance, le 06 août 1999, op. cit.

2208 \$15 Rapport du Secrétaire général sur les enfants et les conflits armés en République Démocratique du Congo, S/2010/359, op. cit.. Des cas de meurtres et d'atteintes à l'intégrité physique des enfants ( $\$ 31-34)$, des violences sexuelles (\$\$35-38), d'enlèvements d'enfants (\$\$39-41), d'attaques contre les écoles (\$\$42-45) étaient en augmentation notamment dans des zones d'opérations militaires. Sauf exception, l'accès des organismes humanitaires est demeuré aussi problématique dans différents territoires (\$§46-47).
}

${ }^{2209}$ Ibid., $§ \S 18-19$.

${ }^{2210}$ Ibid., $\$ 19$.

2211 Ibid., voy. Résumé

2212 Voy. Résumé du Rapport du Secrétaire général sur les enfants et les conflits armés en République Démocratique du Congo, S/2014/453, in http://www.un.org/fr/documents/view_doc.asp?symbol=S/2014/453 (Source consultée le 21 février 2016).

${ }^{2213}$ Voy. par exemple Rapport sur la Promotion et protection de tous les droits de l'homme, civils, politiques, économiques, sociaux et culturels y compris le droit au développement, A/HRC/9/3, Rapport annuel de la Représentante spéciale du Secrétaire général pour les enfants et les conflits armés, Radhika Coomaraswamy du 27 juin 2008, 9è session, in $\underline{\text { http://daccess-dds- }}$ 
d'autres gouvernements afin d'aboutir à des solutions. Les domaines prioritaires sont ici privilégiés $^{2214}$.

Le Conseil des droits de l'homme, ci-dessus mentionné, est aussi un organe de contrôle des droits de l'enfant ${ }^{2215}$. Des questions des droits de l'enfant sont également traitées par lui. Il y a par exemple sa résolution 12/6 du 31 octobre 2009 sur les droits fondamentaux des enfants migrants où il demande aux Etats de prendre des mesures appropriées pour promouvoir et protéger, sans discrimination, les droits fondamentaux des enfants migrants ${ }^{2216}$. Ou encore sa $9^{\mathrm{e}}$ session tenue à la suite du Rapport de la Représentante spéciale du Secrétaire général pour les enfants et les conflits armés, session au cours de laquelle il est relevé le fait que les droits de l'homme et le DIH se concentrent plus sur les Etats alors que des acteurs non-étatiques commettent des graves violations contre les enfants en conflits armés. D'où la nécessité de leur responsabilité ${ }^{2217}$. Bien plus, différentes de ses résolutions traitent de la situation globale des droits de 1'homme en RDC ${ }^{2218}$. C'est donc auprès du Conseil des droits de l'homme que la Commission Nationale de Préparation et de Suivi de l'Examen Périodique Universel de la République Démocratique du Congo («Commission EPU/RDC) (cf. supra) rend son service.

Il ressort de tous ces rapports que les graves violations contre les enfants en temps de conflits armés sont permanentes en RDC. Elles sont à charge de toutes les parties au conflit y compris les FARDC voire la Police congolaise. Lesquelles se distinguent dans certains cas dans la perpétration de ces violations. C'est en dents de scie qu'évolue le processus de protection spéciale des enfants en conflits armés en RDC. Il existe donc des périodes où les cas de graves violations contre les enfants sont en augmentation, ou encore des situations où des diminutions sont constatées. La variation reste tout de même fonction d'augmentation ou non des zones de combat. L'absence d'intégration de l'armée ou le refus de certains groupes armés d'intégrer les FARDC

ny.un.org/doc/UNDOC/GEN/G08/146/16/PDF/G0814616.pdf?OpenElement (Source consultée le 22 février 2016).

${ }^{2214}$ Bureau du Représentant spécial du Secrétaire général pour les enfants et les conflits armés, « Notre travail » in https://childrenandarmedconflict.un.org/fr/qui-sommes-nous/notre-travail// (Source consultée le 22 février 2016).

2215 Voy. par exemple son Rapport sur la Promotion et protection de tous les droits de l'homme, civils, politiques, économiques, sociaux et culturels y compris le droit au développement, A/HRC/9/21, présenté par Mme Najat Maalla M'jid, Rapporteuse spéciale sur la vente d'enfants, la prostitution des enfants et la pornographie mettant en scène des enfants, 31 juillet 2008, 9è session, in http://daccess-ddsny.un.org/doc/UNDOC/GEN/G08/148/42/PDF/G0814842.pdf?OpenElement (Source consultée le 22 février 2016) ; Rapport sur la Promotion et protection de tous les droits de l'homme, civils, politiques, économiques, sociaux et culturels y compris le droit au développement, A/HRC/10/16, Rapport soumis par la Rapporteuse spéciale sur la traite des êtres humains en particulier les femmes et les enfants, Joy Ngozi Ezeilo, du 20 février 2009, 10è session, in http://daccess-ddsny.un.org/doc/UNDOC/GEN/G09/111/29/PDF/G0911129.pdf?OpenElement (Source consultée le 22 février 2016) ; Résolution adoptée par le Conseil des droits de l'homme 12/6 Les droits de l'homme des migrants : migration et droits de l'enfant, A/HRC/RES/12/6, 12 è session, 31 octobre 2009, Point 3 de l'ordre du jour, in http://daccess-dds-ny.un.org/doc/RESOLUTION/GEN/G09/165/58/PDF/G0916558.pdf?OpenElement (Source consultée le 22 février 2016), etc.

${ }^{2216}$ Voy. Résolution adoptée par le Conseil des droits de l'homme 12/6 Les droits de l'homme des migrants : migration et droits de l'enfant, A/HRC/RES/12/6, 12 è session, 31 octobre 2009, Point 3 de l'ordre du jour, in http://daccess-dds-ny.un.org/doc/RESOLUTION/GEN/G09/165/58/PDF/G0916558.pdf?OpenElement (Source consultée le 22 février 2016).

${ }^{2217}$ MARTIN CHENUT, Kathia, « la protection des enfants en temps de conflit et le phénomène des enfantssoldats » « art.cit. », p. 224

2218 Voy. par exemple ses résolutions 10/33 du 27 mars 2009, 13/22 du 26 mars 2010, 16/35 du 25 mars 2011, 19/27 du 23 mars 2012, 24/27 du 27 septembre 2013 et 27/27 du 26 septembre 2014, etc. 
justifierait également la commission de ces graves violations. De la même manière, l'intégration de certains groupes armés au sein des FARDC a accentué des cas de graves violations en charge de celles-ci. Ces rapports ne restant que partiels car des difficultés d'accès à certaines zones de combat par l'équipe spéciale mandatée à cet effet n'a point permis de recueillir toutes les informations au sujet de la situation des enfants touchés par les conflits armés en RDC. Les résultats desdits rapports, bien que partiels, emploient le Représentant spécial du Secrétaire général pour les enfants et les conflits armés a joué un grand rôle diplomatique auprès des parties au conflit en RDC afin de les amener à répondre à leurs obligations de protection des enfants en conflits armés. Il revient également au CS/NU de tirer toutes les conséquences de ces graves violations contre les enfants. Celui-ci prend notamment des mesures (sanctions) contre leurs auteurs.

En effet, d'importantes résolutions du CS/NU invitent les États à prendre les mesures nécessaires pour empêcher la liberté des mouvements de capitaux et des personnes responsables de recrutement et d'emploi d'enfants dans les conflits armés et d'autres graves violations contre les enfants en RDC. Ces sanctions prises initialement dans le cadre e la résolution 1698 (2006) du 31 juillet 2006 sont régulièrement mises à jour par le CS/NU ${ }^{2219}$.

En appui aux sanctions prises par le CS/NU contre les auteurs des graves violations contre les enfants, le Conseil, au sein de l'Union européenne, a adopté notamment la Position commune 2008/369/PESC du Conseil du 14 mars 2008 concernant l'adoption des mesures restrictives à l'encontre de la République Démocratique du Congo et abrogeant la position commune 2005/440/PESC. Celle-ci instruit aux Etats membres de l'UE «de prendre des mesures nécessaires pour empêcher l'entrée ou le passage en transit sur leur territoire $[\ldots] \gg{ }^{2220}$ notamment des responsables politiques et militaires recrutant ou employant les enfants dans les conflits armés en RDC en violation du droit international applicable ; des personnes opérant et commettant des graves violations contre les enfants ${ }^{2221}$. Le gel des fonds, d'autres avoirs financiers et des ressources électroniques en leur possession ou sous leur contrôle a été également décrété ${ }^{2222}$. Disons que la présente position commune n'est qu'une mise à jour de la position commune adoptée par l'Union européenne initialement à l'égard des personnes agissant en violation d'embargo en RDC. Elle se trouve elle-même abrogée et mise à jour par la décision 2010/788/PESC du Conseil qui voudrait être respectueuse des droits fondamentaux ${ }^{2223}$ dont différentes mesures assurent l'exécution (cf. supra).

\footnotetext{
${ }^{2219}$ Voy. pour approfondissement le $\S 4$ de la dernière section du Chapitre précédent sur les Résolutions du Conseil de sécurité des Nations Unies et la protection spéciale des enfants en situation de conflits armés en $R D C$.

${ }^{2220}$ Article 4 de la Position commune 2008/369/PESC du Conseil du 14 mars 2008 concernant l'adoption des mesures restrictives à l'encontre de la République Démocratique du Congo et abrogeant la position commune 2005/440/PESC, in Journal Officiel de l'Union européenne $\mathrm{n}^{\circ} \mathrm{L} 127 / 84 \mathrm{du} 15$ mai 2008 in http://eurlex.europa.eu/legal-content/FR/TXT/?uri=uriserv:OJ.L_.2008.127.01.0084.01.FRA\&toc=OJ:L:2008:127:TOC (Source consultée le 21 février 2016).

${ }^{2221}$ Article 3 de la Position commune 2008/369/PESC du Conseil du 14 mars 2008 concernant l'adoption des mesures restrictives à l'encontre de la République Démocratique du Congo et abrogeant la position commune 2005/440/PESC, in Journal Officiel de l'Union européenne $\mathrm{n}^{\circ} \mathrm{L} 127 / 84$ du 15 mai 2008, in http://eurlex.europa.eu/legal-content/FR/TXT/?uri=uriserv:OJ.L_.2008.127.01.0084.01.FRA\&toc=OJ:L:2008:127:TOC (Source consultée le 21 février 2016).

${ }^{2222}$ Ibid., article 5.

2223 Voy. Décision 2010/788/PESC du Conseil du 20 décembre 2010 concernant l'adoption de mesures
} 
Il se dégage de tout ce qui précède que la protection spéciale des enfants en situation de conflits armés en RDC, bien qu'encore faible au regard de la persistance des graves violations contre les enfants, ne serait pas à ce stade de mise en œuvre sans l'apport des Nations Unies principalement du CS/NU et du SG/NU, voire de la MONUSCO ou de l'UNICEF (cf. infra). Les organes qu'ils créent- le Mécanisme de surveillance et de communication de l'information, le Bureau du représentant spécial du Secrétaire général pour les enfants et les conflits armés, etc. - permettent aux Nations Unies d'être régulièrement informées de la situation des enfants touchés par les conflits armés en RDC précisément et de trouver des solutions idoines. Ce rôle est d'autant plus important si l'on sait que l'Etat congolais, premier protecteur des enfants sur son territoire, se désengage avec ses forces armées. Paradoxalement, les FARDC sont reprises parmi les principaux responsables des cas de recrutement, de re-recrutement et d'utilisation d'enfants dans les conflits armés, voire d'autres graves violations du DIH ou du DIDH contre les enfants.

Il est toutefois prudent de ne pas trop espérer en ces « organes politiques » guidés - parfois si pas souvent- par «les intérêts » des Etats que par «l'intérêt supérieur » de l'enfant pour la mise en œuvre efficace et efficiente des règles du DIH ou du DIDH.

\section{§2. La MONUSCO (ex-MONUC) et la protection des enfants dans les conflits armés en RDC}

Dans le but d'aider la Commission militaire mixte établie par l'Accord de Lusaka, ainsi que les Etats parties à œuvrer pour l'effectivité dudit accord, le CS/NU, par la résolution $1258 \mathrm{du}$ 6 août 1999 adoptée à la $4032^{\mathrm{e}}$ séance, autorisait le déploiement de 90 membres du personnel militaire de liaison des Nations Unies, ainsi que du personnel civil, politique, humanitaire et administratif voulu, dans les capitales des Etats signataires dudit accord de cessez-le-feu et au quartier général provisoire de la Commission militaire mixte, et dans les quartiers généraux militaires des principaux belligérants au cas où les conditions sécuritaires le permettaient ${ }^{2224}$. Par la résolution 1279 du 30 novembre 1999 du même Conseil, ce personnel déployé constituera la Mission de 1'Organisation des Nations Unies en République Démocratique du Congo (MONUC) jusqu'au $1^{\text {er }}$ mars $2000^{2225}$. Dès lors, l'histoire de la MONUC restera extrêmement liée à celle des conflits armés en RDC depuis $1999^{2226}$. A son début, la MONUC s'occupera essentiellement de la mise en œuvre de l'Accord de Lusaka ${ }^{2227}$. Son mandat sera par la suite évolutif tant sur le plan matériel que sur le plan temporel au point de devenir une

restrictives à l'encontre de la République Démocratique du Congo et abrogeant la position commune 2008/369/PESC, in Journal officiel de l'Union européenne L 336/30 du 21 décembre 2010, in http://eurlex.europa.eu/legal-content/FR/TXT/?uri=celex\%3A32010D0788 (Source consultée le 21 février 2016).

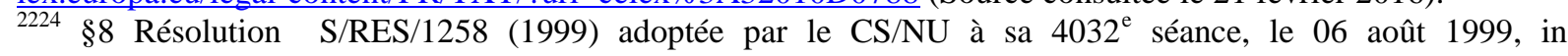
http://www.un.org/fr/documents/view_doc.asp?symbol=S/RES/1258(1999) (Source consultée le 14 février 2016).

${ }^{2225}$ Voy. $\$ 4$ de la Résolution S/RES/1279 (1999) adoptée par le CS/NU à sa $4076^{\mathrm{e}}$ séance, le 30 novembre 1999 ,

http://www.un.org/fr/documents/view_doc.asp?symbol=S/RES/1279(1999)\&TYPE=\&referer=http://www.un.or $\mathrm{g} / \mathrm{fr} / \mathrm{sc} /$ documents/resolutions/1999.shtml\&Lang=F (Source consultée le 14 février 2016).

${ }^{2226}$ ZEEBROEK, Xavier, MEMIER, Marc et SEBAHARA, Pamphile, La Mission des Nations Unies en RD Congo. Bilan d'une décennie de maintien de la paix et perspectives, Rapport du GRIP 2011/4, Bruxelles, p. 5.

2227 Voy. $§ 5$ de la Résolution S/RES/1279 (1999) adoptée par le CS/NU à sa $4076^{\mathrm{e}}$ séance, le 30 novembre 1999 ,

http://www.un.org/fr/documents/view_doc.asp?symbol=S/RES/1279(1999)\&TYPE=\&referer=http://www.un.or $\mathrm{g} / \mathrm{fr} / \mathrm{sc} /$ documents/resolutions/1999.shtml\&Lang=F (Source consultée le 14 février 2016). 
mission polyvalente s'occupant «un peu de tout». D'où les risques omniprésents de confusion et de dérapage ${ }^{2228}$. L'augmentation de ses effectifs afin de répondre à son mandat évolutif fera d'elle « une des missions les plus vastes et les plus complexes de l'histoire de l'ONU » ${ }^{2229}$. C'est avec la résolution 1925 du CS/NU du 28 mai 2010 que la MONUC devient MONUSCO - Mission de l'Organisation des Nations Unies pour la Stabilisation en République Démocratique du Congo. Changement de dénomination dû à l'entrée de la RDC dans une nouvelle phase - phase de stabilisation et de consolidation de la paix ${ }^{2230}$. Avant d'être successivement prolongé, le mandat de la MONUSCO couvrira initialement la période du $1^{\text {er }}$ juillet 2010 au 30 juin 2011. Ce renforcement continuel du mandat de la MONUSCO traduit que rien n'est encore définitivement réglé sur la situation sécuritaire en $\mathrm{RDC}^{2231}$.

A travers sa résolution 1925 (2010), le CS/NU rappelle une fois de plus que c'est à la RDC qu'incombe notamment la responsabilité première d'assurer la sécurité de son territoire, de protéger les civils conformément aux droits de l'homme et au DIH. Ainsi, suivant son mandat, la MONUSCO vient en appui de la RDC sous les angles indiqués. Tout de même, des opérations offensives unilatérales contre les groupes armés sont aussi menées par la MONUSCO $^{2232}$. En effet, le mandat de la MONUSCO est donc d'assurer la protection des civils, la stabilisation et consolidation de la paix en RDC.

Au sujet de la protection des civils qui nous préoccupe, la MONUSCO se charge d'assurer la protection effective des civils - dont les enfants - contre les violations des droits de l'homme et du DIH. Elle doit également soutenir la RDC à la répression judiciaire de tels actes. Dans cette optique, la MONUSCO doit collaborer étroitement avec la RDC à la réalisation de son Plan d'action (cf. supra) afin d'empêcher que des sévices graves soient infligés aux enfants $^{2233}$. Tout ceci est encore rappelé dans différentes résolutions subséquentes dont les résolutions S/RES/2053 (2012) ${ }^{2234}$ et S/RES/2147 (2014) du CS/NU ${ }^{2235}$. La protection des civils - dont les enfants - demeure une priorité de la MONUSCO, comme le réitère la résolution S/RES/2053 (2012) du CS/NU ${ }^{2236}$. Elle doit à ce titre collaborer étroitement à la

2228 ZEEBROEK, Xavier, MEMIER, Marc et SEBAHARA, Pamphile, La Mission des Nations Unies en RD Congo. Bilan d'une décennie de maintien de la paix et perspectives, op.cit., p. 5.

${ }^{2229}$ Ibid., p. 6.

${ }^{2230}$ Voy. le $18^{\text {e }}$ considérant et les $\$ \S 1$ et suivants de la Résolution S/RES/1925 (2010) adoptée par le CS/NU à sa 6324 ${ }^{\mathrm{e}}$ séance, le 28 mai 2010, in http://www.un.org/fr/documents/view_doc.asp?symbol=S/RES/1925\%20(2010) (Source consultée le 14 février 2016).

${ }^{2231}$ ZEEBROEK, Xavier, MEMIER, Marc et SEBAHARA, Pamphile, La Mission des Nations Unies en RD Congo. Bilan d'une décennie de maintien de la paix et perspectives, op.cit., p. 5.

2232 Ibid., p.31.

${ }^{2233}$ Voy. $\$ 12$, particulièrement les points $c, d, e, h$ de la Résolution S/RES/1925 (2010) adoptée par le CS/NU à

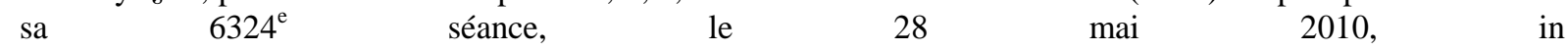
http://www.un.org/fr/documents/view doc.asp?symbol=S/RES/1925\%20(2010) (Source consultée le 14 février 2016).

${ }^{2234}$ Voy. $\$ \S 13$ et 23 de la Résolution S/RES/2053 (2012) adoptée par le CS/NU à sa $6792^{\text {e }}$ séance, le 27 juin 2012, in http://www.un.org/fr/documents/view doc.asp?symbol=S/RES/2053(2012) (Source consultée le 14 février 2016).

${ }^{2235}$ Voy. $\$ 4 d$ de la Résolution S/RES/2147 (2014), adoptée par le CS/NU à sa 7150 séance, le 28 mars 2014 in http://www.un.org/fr/documents/view doc.asp?symbol=S/RES/2147(2014) (Source consultée le 14 février 2016).

${ }^{2236}$ Voy. $\$ \S 1$ et 6 de la Résolution S/RES/2053 (2012) adoptée par le CS/NU à sa $6792^{\mathrm{e}}$ séance, le 27 juin 
poursuite des actions contre les groupes armés œuvrant en $\mathrm{RDC}^{2237}$ et également avec les instances onusiennes œuvrant au profit des enfants en conflits armés en RDC. Lesquelles instances coopèrent avec le gouvernement congolais. C'est donc le cas de la Représentante spéciale du Secrétaire général pour le sort des enfants en temps de conflits armés et la Représentante du Secrétaire général chargée des questions des violences sexuelles commises en période de conflits armés ${ }^{2238}$. Les résolutions subséquentes du CS/NU sur la situation de conflits armés en RDC renforcent davantage le mandat de la MONUSCO sous cet angle. Ainsi, la résolution 2147 (2014) du CS/NU autorise la MONUSCO à prendre «toutes les mesures nécessaires » pour assurer la protection efficace des civils dont les enfants ${ }^{2239}$. Plus concrètement, la MONUSCO, de concert avec le Gouvernement de la RDC, devra prendre toutes les mesures nécessaires pour déceler les menaces qui pèsent sur les enfants notamment les atteintes au DIH. Elle devra «veiller à ce qu'il soit tenu compte de la protection des enfants [...] dans toutes ses opérations et tous les aspects stratégiques de son action [...] $»^{2240}$. Elle collabore en outre avec les FARDC et la Brigade d'intervention - instituée par la Résolution S/RES/2098 (2013) du CS/NU- en vue de la neutralisation des groupes armés. Ces derniers représentent des sérieuses menaces vis-à-vis des civils dont les enfants ${ }^{2241}$.

Par ailleurs, la protection des enfants en situation de conflits armés en RDC n'est pas un mandat récemment institué avec la nouvelle appellation de la mission onusienne en RDC, la MONUSCO. Sous l'appellation «MONUC », la mission onusienne en RDC s'est également occupée de la protection des civils en conflits armés en général et des enfants en particulier. Il importe de rappeler au départ que la MONUC se chargeait, au regard de la Résolution S/RES/1279 (1999) portant sa création, de veiller à la mise en œuvre de l'Accord de Lusaka. Ce dernier contient des dispositions humanitaires profitables aux civils en général et aux enfants en particulier. La Résolution S/RES/1279 (1999) paraît d'ailleurs très précise à cet égard lorsqu'elle dispose en son point 5 e que la MONUC s'acquittera notamment de: «Maintenir la liaison avec toutes les parties à l'Accord de cessez-le-feu afin de faciliter l'acheminement de l'aide humanitaire aux personnes déplacées, aux réfugiés, aux enfants et autres personnes touchées et d'aider à la défense des droits de l'homme, y compris les droits de l'enfant ${ }^{2242}$ (nous soulignons). La Résolution suivante, la S/RES/1291 du 24 février 2000, réitère ce mandat. Il y est clairement indiqué que dans l'acheminement de l'aide humanitaire, une attention particulière devrait être portée sur les groupes vulnérables dont les enfants et les enfants soldats démobilisés dans les limites de capacités de la MONUC et dans des conditions sécuritaires acceptables ${ }^{2243}$. La protection des civils en général fait également

2012, in http://www.un.org/fr/documents/view doc.asp?symbol=S/RES/2053(2012) (Source consultée le 14 février 2016).

${ }^{2237}$ Ibid., voy. $\$ 20$.

${ }^{2238}$ Ibid., voy. $\$ 23$.

${ }^{2239} \S 4$ a) de la Résolution S/RES/2147 (2014), adoptée par le CS/NU à sa $7150^{\mathrm{e}}$ séance, le 28 mars 2014, in http://www.un.org/fr/documents/view_doc.asp?symbol=S/RES/2147(2014) (Source consultée le 14 février 2016).

${ }_{2240}$ Ibid., § 4 a) iii).

${ }^{2241}$ Ibid., $\$ 4$ b.

${ }^{2242} \S 5$, $e$ de la Résolution S/RES/1279 (1999) adoptée par le CS/NU à sa $4076^{\text {e }}$ séance, le 30 novembre 1999, in

http://www.un.org/fr/documents/view_doc.asp?symbol=S/RES/1279(1999)\&TYPE=\&referer=http://www.un.or $\mathrm{g} / \mathrm{fr} / \mathrm{sc} /$ documents/resolutions/1999.shtml\&Lang=F (Source consultée le 14 février 2016).

${ }_{2243} \$ 7 g$ de la Résolution S/RES/1291 (2000) adoptée par le CS/NU à sa $4104^{\mathrm{e}}$ séance, le 24 février 2000, in 
partie des responsabilités de la MONUC $^{2244}$. Et suivant les termes de la résolution S/RES/1291 du 24 février 2000, par laquelle le CS/NU agissait en vertu du Chapitre VII de la Charte des Nations Unies, la MONUC était également autorisée à prendre des mesures nécessaires pour «protéger les civils se trouvant sous la menace imminente de violences physiques ${ }^{2245}$. Ceci est également réaffirmé par la résolution S/RES/1417 du CS/NU ${ }^{2246}$ ou encore par la résolution S/RES/1565 (2004) ${ }^{2247}$. Quelques temps supplémentaires devraient cependant s'écouler (en 2005, cf. infra) pour que «les responsables de la mission aient la volonté politique et les moyens pour le faire ${ }^{2248}$. Bien plus, différentes résolutions du CS/NU chargent les parties en conflits armés en RDC de coopérer avec la MONUC ou l'UNICEF pour des questions de protection des enfants, de démobilisation, de rapatriement et de réadaptation des enfants recrutés et utilisés dans leurs rangs, ou de la protection des civils en général ${ }^{2249}$. Et comme le précise la MONUSCO elle-même, le mandat de protection de l'enfant comprend également «l'initiation d'un dialogue avec les parties au conflit pour mettre fin au recrutement et à l'utilisation d'enfants par les forces et groupes armés, ainsi qu'aux autres violations graves des droits de l'enfant ${ }^{2250}$.

Dans la réalisation de son mandat de protection des enfants en situation de conflits armés en RDC, la MONUSCO s'est dotée d'une Section de Protection de l'enfant. Il s'agit de la Section de Protection de l'enfant la plus vaste de toutes les missions de maintien de la paix des Nations Unies ${ }^{2251}$. Elle «s'occupe uniquement des enfants affectés par les conflits armés ${ }^{2252}$. A ce titre, elle « se consacre à la surveillance et la préparation de rapports sur la situation des enfants affectés par le conflit armé, en particulier les six violations graves des droits de l'enfant commises par les parties au conflit » ${ }^{2253}$ à savoir les «meurtres et

http://www.un.org/fr/documents/view_doc.asp?symbol=S/RES/1291(2000) (Source consultée le 14 février 2016).

${ }^{2244}$ Ibid., $\$ 8$.

2245 Ibid.

${ }^{2246}$ Voy. le $\$ 7$ de la Résolution S/RES/1417 (2002) adoptée par le CS/NU à sa 4554 e séance, le 14 juin 2002 in http://www.un.org/fr/documents/view_doc.asp?symbol=S/RES/1417(2002) (Source consultée le 14 février 2016).

${ }^{2247}$ Voy. le $\$ \quad 6$ de la Résolution 1565 (2004) adoptée par le CS/NU le 1 er octobre 2004 http://www.un.org/fr/documents/view_doc.asp?symbol=S/RES/1565\%20(2004) (Source consultée le 14 février 2016).

${ }^{2248}$ ZEEBROEK, Xavier, MEMIER, Marc et SEBAHARA, Pamphile, La Mission des Nations Unies en RD Congo. Bilan d'une décennie de maintien de la paix et perspectives, op.cit., p. 5.

${ }^{2249}$ Voy. $\$ 10$ de la Résolution 1341 (2001) adoptée par le Conseil de sécurité à sa $4282^{\mathrm{e}}$ séance, le 22 février 2001 in http://www.un.org/fr/documents/view_doc.asp?symbol=S/RES/1341(2001) (Source consultée le 14 février 2016) ; Voy. aussi le $\$ 12$ vii de la Résolution S/RES/1379 (2001) adoptée par le conseil de sécurité à sa

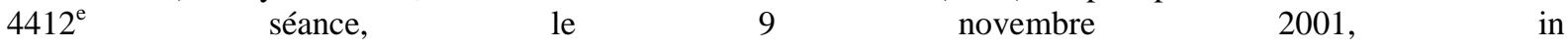
http://www.un.org/fr/documents/view_doc.asp?symbol=S/RES/1376(2001) (Source consultée le 14 février 2016) ou encore le $\$ 14$ de la Résolution S/RES/1468 (2003) adoptée par le Conseil de sécurité à sa $4723^{\mathrm{e}}$ séance, le 20 mars 2003, in http://www.un.org/fr/documents/view doc.asp?symbol=S/RES/1468\%20(2003) (Source consultée le 14 février 2016).

${ }^{2250}$ MONUSCO, Rapport sur le recrutement d'enfants par les groupes armés pendant la période du $1^{\text {er }}$ janvier 2012 аи 31 aô̂t 2013, p. 8, in https://monusco.unmissions.org/Default.aspx?tabid=11302\&language=fr-FR (Source consultée le 14 février 2016).

${ }^{2251}$ Section de Protection de l'Enfant, «A la découverte de la Section de Protection de l'Enfant de la MONUSCO », in Protéger et soutenir les enfants touchés par la violence et les conflits, Echo de la MONUSCO, Vol. VII, n42, Février 2015, p. 16.

${ }^{2252}$ Ibid.

${ }^{2253}$ MONUSCO, Rapport sur le recrutement d'enfants par les groupes armés pendant la période du $1^{\text {er }}$ janvier

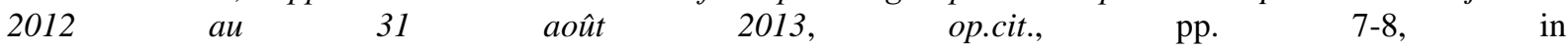
https://monusco.unmissions.org/Default.aspx?tabid=11302\&language=fr-FR (Source consultée le 14 février 
mutilations, le recrutement et l'utilisation, la violence sexuelle, les enlèvements, les attaques contre les écoles et les hôpitaux et le refus d'accès humanitaire» ${ }^{2254}$. «Le but en est d'améliorer la prévention, la sensibilisation et la responsabilisation des auteurs $»^{2255}$.

C'est grâce à la MONUSCO, à travers ses rapports, que la situation des procès sur des crimes internationaux ont pu avancer, tant soit peu, au plan national (cf. infra). Ce sont également les rapports de la MONUSCO (MONUC) qui ont permis à la RDC d'asseoir ses éléments de preuve dans l'affaire des Activités militaires (RDC c. Ouganda) devant la CIJ (cf. infra) ${ }^{2256}$.

La sensibilisation sur des questions de protection des enfants sera perçue par la Section de Protection de l'Enfant comme «la meilleure arme» pour plaider auprès des Chefs de milices $^{2257}$. La Section de Protection de l'Enfant détient à cet égard un personnel spécialisé implanté à travers le pays précisément à Kinshasa et dans des bureaux de terrain à Goma, Beni, Bukavu, Uvira, Dungu, Bunia, Kisangani et Kalemie. Bien que les questions de protection de l'enfant soient prises en compte dans différents programmes des divisions ou sections de la MONUSCO, c'est donc la Section de Protection de l'Enfant qui assure la coordination du travail de la MONUSCO lié à la protection de l'enfant ${ }^{2258}$.

Par ailleurs, les questions des droits de l'homme de manière générale sont examinées au sein de la MONUSCO par sa Division des Droits de l'Homme établie depuis 2000. Elle se charge de la promotion et de la défense des droits de l'homme avec une attention particulière sur les enfants. Elle incorpore en son sein depuis 2008 le Bureau Conjoint des Nations Unies aux Droits de l'Homme (BCNUDH) en RDC. Celui-ci a pour approche globale de préparer le terrain au départ de la MONUSCO en sensibilisant les citoyens et les institutions étatiques sur les droits de l'homme ${ }^{2259}$. Son travail quotidien « consiste à rapporter les violations des droits de l'homme, assister les victimes à chercher et obtenir des recours à ces violations ${ }^{2260}$.

En marge de ce qui précède, la protection des civils - dont les enfants- par la MONUSCO n'est pas aussi facile sur le champ opérationnel. En effet, de 2000 à 2003, la MONUC reste marquée par une « extrême faiblesse de l'action militaire » pour s'interposer entre belligérants afin de protéger les civils en dépit de son rôle positif de médiation dans le retrait des troupes étrangères $^{2261}$. Pendant la période de transition et du processus électoral (2003-2006), la prise de la ville de Bukavu en avril 2004 par les troupes du général Laurent Nkunda et du colonel Jules Mutebusi durant plus d'une semaine, suivie des pires exactions à l'endroit des civils et

2016).

${ }^{2254}$ MONUSCO, Rapport sur le recrutement d'enfants par les groupes armés pendant la période du $1^{\text {er }}$ janvier 2012 aи 31 août 2013, op.cit., p.8, in https://monusco.unmissions.org/Default.aspx?tabid=11302\&language=frFR (Source consultée le 14 février 2016).

$\frac{2255}{\text { Ibid. }}$.

2256 CIJ, Affaire des Activités armées sur le territoire du Congo (République démocratique du Congo c. Ouganda), arrêt du 19 décembre 2005, Recueil 2005, p. 232, §182.

2257 Section de Protection de l'Enfant, «A la découverte de la Section de Protection de l'Enfant de la MONUSCO », in Protéger et soutenir les enfants touchés par la violence et les conflits, Echo de la MONUSCO, op.cit., p. 16.

${ }^{2258}$ Ibid.

${ }^{2259}$ Voy. http://monusco.unmissions.org/Default.aspx?tabid=11239 (Source consultée le 14 février 2016).

2260 Voy. Ibid.

${ }^{2261}$ ZEEBROEK, Xavier, MEMIER, Marc et SEBAHARA, Pamphile, La Mission des Nations Unies en RD Congo. Bilan d'une décennie de maintien de la paix et perspectives, op.cit., p. 7. 
des enfants en particulier ${ }^{2262}$ était une occasion de plus de déceler l'inefficacité de la MONUC de répondre à son mandat de protection des civils ${ }^{2263}$. D'où la réaction de la population à travers d'importantes manifestations dans différentes villes du pays - dont principalement Kinshasa - contre la présence de la MONUC. Ce qui entraînera d'importants changements au sein de la mission, de renforcement de son mandat et d'augmentation considérable de ses effectifs. L'approche d'action militaire sera finalement entreprise. La résolution 1592 du 30 mars 2005 insistera sur l'utilisation de «tous les moyens nécessaires» pour dissuader des tentatives d'usage de la force par des groupes armés et assurer la protection des civils. C'est à ce titre que les groupes armés de l'Ituri seront désarmés le $1^{\text {er }}$ avril $2005^{2264}$. Et afin de prévenir des attaques contre les civils, et en appui aux FARDC, des tactiques d'encerclement et de recherche des groupes armés seront plus menées par la MONUC en cette période de 2003-2006 ${ }^{2265}$. De 2006 à 2008, la protection des civils devient sa «priorité absolue » alors que son départ est réclamé par la $\mathrm{RDC}^{2266}$. La résolution 1925 (2010) du CS/NU du 28 mai 2010 renforce davantage cette position de protection prioritaire des civils $(\$ 11)^{2267}$.

En 15 ans, la MONUC passant à la MONUSCO, s'est transformée de la mission d'observation en une mission multidimensionnelle sous chapitre VII de la Charte des Nations Unies avec des tâches variées ${ }^{2268}$. Elle est habilitée à recourir à «tous les moyens nécessaires » pour protéger les civils dont le recours à la force. Toutefois, le recours à la force par cette mission onusienne pour protéger les civils est un ultime recours conditionné préalablement par la menace imminente de violence physique des civils, l'intention hostile persistante et l'absence des civils sur les zones d'opération ${ }^{2269}$. Les cas d'abus sexuels dont sont présumés auteurs les Casques bleus ${ }^{2270}$, voire des trafics illicites ${ }^{2271}$, demeurent de nature à ternir l'image de la mission onusienne en RDC et ne facilite guère une bonne perception de ses activités par la population. En outre, l'appui de la MONUSCO à certaines unités des

${ }^{2262}$ Voy. § 22 du Rapport du Secrétaire général sur les enfants et les conflits armés, A/59/695-S/2005/72, in http://www.un.org/fr/documents/view_doc.asp?symbol=S/2005/72 (Source consultée le 20 février 2016).

${ }^{2263}$ ZEEBROEK, Xavier, MEMIER, Marc et SEBAHARA, Pamphile, La Mission des Nations Unies en RD Congo. Bilan d'une décennie de maintien de la paix et perspectives, op.cit., p. 7.

${ }^{2264}$ Voy. le $§ 17$ du Rapport du Secrétaire général sur les enfants et les conflits armés, A/59/695-S/2005/72, in http://www.un.org/fr/documents/view_doc.asp?symbol=S/2005/72 (Source consultée le 20 février 2016).

${ }^{2265}$ ZEEBROEK, Xavier, MEMIER, Marc et SEBAHARA, Pamphile, La Mission des Nations Unies en RD Congo. Bilan d'une décennie de maintien de la paix et perspectives, op.cit., 8.

2266 Ibid., p. 9.

${ }^{2267}$ Lire aussi SZUREK, Sandra, «Prévention des violations des droits de l'homme et maintien de la paix », in DECAUX, Emmanuel et TOUZE, Sébastien (dir.), La Prévention des violations des droits de l'homme. Actes du Colloque des 13 et 14 juin 2013, op.cit., p. 182.

${ }^{2268}$ ZEEBROEK, Xavier, MEMIER, Marc et SEBAHARA, Pamphile, La Mission des Nations Unies en RD Congo. Bilan d'une décennie de maintien de la paix et perspectives, op.cit., p. 10.

${ }^{2269}$ Ibid., p. 12.

${ }^{2270}$ Lire AG/NU, Res. A/70/729, Dispositions spéciales visant à prévenir l'exploirtation et les atteintes sexuelles, Rapport du Secrétaire général, $\$ 8$ a ; $\$ 11, \quad 12$ et 17-18 http://reliefweb.int/sites/reliefweb.int/files/resources/N1604057.pdf (Source consultée le 31 octobre 2016) ; Human Rights Watch, "ONU: Mettre fin aux abus sexuels commis par des casques bleus", in https://www.hrw.org/fr/news/2016/03/04/onu-mettre-fin-aux-abus-sexuels-commis-par-des-casques-bleus

(Source consultée le 31 octobre 2016), etc.

${ }^{2271}$ Lire par exemple, «RDC: Des casques bleus de l'ONU impliqués dans trafic de tenues de l'armée congolaise », in http://afrique.kongotimes.info/rdc/echos provinces/8581-rdc-casques-bleus-onu-impliquesdans-trafic-tenues-armee-congolaise-fardc-garde-republicaine-nord-kivu-ukrainiens-monusco-commerce.html

(Source consultée le 31 octobre 2016). Lire aussi «Le Gouvernement dénonce un trafic illicite», in http://www.lareference.cd/2011/08/le-gouvernement-denonce-un-trafic-illicite.html (Source consultée le 31 octobre 2016). 
FARDC distinguées dans les exactions diverses sur les civils a suffi à remettre en cause sa neutralité et sa crédibilité auprès des populations affectées ${ }^{2272}$. C'est ainsi que certains «acteurs humanitaires ont dû non seulement afficher leur indépendance à l'égard de la [MONUSCO], mais ils ont refusé d'être intégrés dans des convois protégés par celle-ci, malgré les risques encourus [...] [pour être finalement pris au sérieux par l'ensemble des populations et] pouvoir accéder à toutes les populations civiles déplacées à secourir, quelles que soient leur ethnie et leur affiliation politique et militaire $»^{2273}$.

Par ailleurs, pour les cas des violations des droits humains, précisément les atteintes sexuelles, dont les casques bleus seraient auteurs, «[1]e Secrétaire général renvoie soit au pays hôte soit à l'État de nationalité les affaires impliquant les fonctionnaires ou experts en mission des Nations Unies pour établir leur responsabilité pénale ${ }^{2274}$. Entretemps, des mesures conservatoires sont généralement prises à l'encontre des intéressés. Ainsi, «lorsque des allégations d'exploitation ou d'atteintes sexuelles sont fondées, tous les paiements relatifs aux individus concernés qui étaient suspendus ou en attente ne seront pas effectués à compter de la date de l'incident, et tous ceux qui ont déjà été effectués seront déduits des versements futurs à l'État Membre » ${ }^{2275}$. A titre illustratif, pour la MONUSCO, le Département de l'appui aux missions a été informé, en 2015, du renvoi d'un Volontaire des Nations Unies, à son Etat de nationalité, mis en cause dans une affaire constatée en 2014. L'enquête ayant établi qu'il avait exploité dix femmes à des fins sexuelles et commis une atteinte sexuelle sur mineur alors qu'il était affecté à la MONUSCO. Deux autres affaires d'atteinte sexuelle sur mineur antérieures à 2015, concernant la MONUSCO, ont été renvoyées aux États de nationalité des auteurs présumés des faits. Le Bureau des affaires juriques a demandé aux États concernés quelles mesures ont été prises à la suite de ces renvois ${ }^{2276}$. Sans chercher à énumérer tous les cas, comparativement à la situation des groupes et forces armés, les violations des droits humains ou du DIH sur les enfants en charge de la MONUSCO ne paraissent pas aussi systématiques bien que parfois en augmentation ${ }^{2277}$.

En clair, il y a lieu de dire en conclusion que la protection des civils et des enfants en particulier sur le terrain d'opération par la MONUSCO évolue en dents de scie - faute des moyens nécessaires- alors que la Section de Protection de l'Enfant joue un grand rôle préventif dans la sensibilisation des questions de protection des enfants affectés par les conflits armés.

\section{§3. L'UNICEF et la protection des enfants en conflits armés en RDC}

Créé par le par la résolution 57 (1) du 11 décembre 1946 de l'AG/NU sous la dénomination de Fonds International de Secours à l'Enfance (FISE) en remplacement de l'Administration

\footnotetext{
2272 BOINET, Alain, «Les contraintes humanitaires dans un contexte de conflit ou de catastrophe : Afghanistan, Irak, R.D.C., Soudan, Mali, Syrie », in BIAD, Abdelwahab (dir.), L'action humanitaire internationale entre le droit et la pratique, éd. Nemesis - Anthemis, Bruxelles, 2016, p. 233.

${ }^{2273}$ Ibid.

${ }^{2274}$ AG/NU, Res. A/70/729, Dispositions spéciales visant à prévenir l'exploitation et les atteintes sexuelles, Rapport du Secrétaire général, § 64.

${ }^{2275}$ Ibid., $\$ 62$.

${ }^{2276} \mathrm{Ibid}, \S \S 17-18$

${ }^{2277}$ Lire AG/NU, Res. A/70/729, Dispositions spéciales visant à prévenir l'exploitation et les atteintes sexuelles, Rapport du Secrétaire général, §§ 22, 26, 27, 28, 29 et 32.
} 
des Nations Unies pour le Secours et la Reconstruction avec reprise de certaines de ses fonctions, le Fonds des Nations Unies pour l'Enfance est mieux connu par l'acronyme UNICEF - United Nations of International Children's Emergency Fund. Il doit son actuelle appellation à la résolution 802 (VIII) de l'AG/NU adoptée le 6 octobre $1953^{2278}$. Laquelle résolution maintient toutefois le symbole FISE ${ }^{2279}$. Dès sa création, l'UNICEF était confronté à différents problèmes de la guerre. L'essentiel de son mandat consistait à « répondre aux besoins urgents en aliments, médicaments et vêtements des enfants victimes de la $2^{\text {ème }}$ guerre mondiale $»^{2280}$ (dont essentiellement les enfants d'Europe). Une fois cette mission terminée, il fut jugé important de recadrer la mission d'un tel organisme sous un angle permanent. Ainsi, ce mandat, fondé sur les secours d'urgence, fut modifié en 1950. L'Assemblée générale des Nations Unies élargit la mission de l'UNICEF, au-delà de secours d'urgence, à des programmes à long terme ainsi qu'à des besoins persistants ${ }^{2281}$ en faveur des enfants des pays en développement ${ }^{2282}$. Ce mandat de portée générale sera confirmé par l'Assemblée en 1953 lors du changement de dénomination. Depuis lors, l'implication de la guerre sur les enfants notamment dans les pays en voie de développement restera au centre des préoccupations de $1^{\prime} \mathrm{UNICEF}^{2283}$.

La RDC qui vit depuis deux décennies sous les feux des conflits armés n'est pas moins concernée par des bienfaits de programmes de l'UNICEF. C'est donc l'endroit indiqué d'étudier le rôle de l'UNICEF sur la protection spéciale des enfants en situation de conflits armés en RDC.

En effet, l'UNICEF est au cœur de la protection spéciale de l'enfant en RDC - en temps de paix et de conflits armés. Et c'est dès les premiers moments des conflits armés en RDC que l'UNICEF, accompagné d'autres acteurs de protection de l'enfance, agit en faveur des enfants affectés par ces conflits armés. Il se préoccupait - avec d'autres acteurs gouvernementaux, non gouvernementaux et intergouvernementaux de protection de l'enfance - à la prévention de recrutement et d'utilisation des enfants dans les forces et groupes armés, mais également à la réduction de leur présence au sein des forces et groupes armés, suivies de leur réinsertion familiale ou sociale. Différents types d'activités se trouvent menés par l'UNICEF à cet effet.

2278 Voy. KARUNATILLEKE, Kesera, op.cit., 13-18 et GEANITON, Thierry, op.cit., 13-17.; HERMANT, Daniel, «L'espace problématique de la violence politique des enfants », in La violence politique des enfants, Cultures et Conflits, $\mathrm{n}^{\circ} 18$, Paris, L'Harmattan, 1995, p. 181.

${ }^{2279}$ Voy. le paragraphe 3 de la Résolution 802 (VIII), de l'AG/NU sur les Fonds des Nations Unies pour l'Enfance (FISE) du 06 octobre 1953.

2280 DEVROEY-ZOLLER, Chantal, «L'UNICEF, l'enfant et la guerre », in Commission communautaire française, La Guerre et l'enfant, Actes du Colloque organisé par l'Association internationale des journées universitaires de la paix à l'Institut de Sociologie de l'Université Libre de Bruxelles le mercredi 2 mars 1983, op. cit., p. 31

2281 Voy. Histoire de l'UNICEF, les étapes de 1946-1955, étape 1950, in http://www.unicef.org/french/about/history/index milestones 46 55.html (Source consultée le 30 janvier 2016). 2282 DEVROEY-ZOLLER, Chantal, «L'UNICEF, l'enfant et la guerre », «art. cit.», p. 31. Lire pour approfondissement KARUNATILLEKE, Kesera, op.cit., 13-18 et GEANITON, Thierry, op.cit., 13-17.; HERMANT, Daniel, «L'espace problématique de la violence politique des enfants », «art. cit. », p. 181. Voy. également la panoplie d'ouvrages traitant de l'historique de l'UNICEF présentés par l'UNICEF: http://www.unicef.org/french/about/history/index publications.html (Source consultée le 27 janvier 2016).

${ }^{2283}$ DEVROEY-ZOLLER, Chantal, «L'UNICEF, l'enfant et la guerre », « art. cit. », p. 31. Le CS/NU ne cesse d'ailleurs de saluer les initiatives de l'UNICEF, voy par exemple le $\$ 5$ de la Résolution 1612 (2005) du CS/NU, in http://www.un.org/fr/documents/view_doc.asp?symbol=S/RES/1612\%20(2005) (Source consultée le 19 février 2016). 
Le premier type d'activités concerne les «interventions ad hoc et préparation du PNDDR » suivant la période de 1997 à 2004. Sous cette période, précisément de 1997 à 2002, « des activités de plaidoyer et sensibilisation ainsi que de retrait, prise en charge intérimaire, réunification familiale et appui à la réinsertion d'approximativement 2000 enfants ont été organisées sous diverses formes ${ }^{2284}$. Lesquelles activités concourent non moins à l'exécution des programmes et engagements gouvernementaux dont l'Accord de Lusaka. Entre 2003-2004, dans le cadre du programme de démobilisation dit «intérimaire » où intervenaient différents acteurs de protection de l'enfance au profit des activités de retrait et de réunification familiale des enfants, l'UNICEF jouera un rôle important. Il coordonnera les activités participatives de ces acteurs en vue d'élaboration d'un « cadre opérationnel pour les enfants » à intégrer au PNDDR ${ }^{2285}$.

Le deuxième type d'activités, de 2004 à 2006, se rapporte à la « mise en œuvre du PNDDR : la plus forte période de démobilisation des ex-combattants ». Suivant les statistiques de l'UEPN-DRR, en fin décembre 2007, 30.594 enfants ont été démobilisés. Statistiques contredites par la base des données de l'UNICEF qui fait état de 19.995 enfants sortis des forces et groupes armés en fin $2007^{2286}$. Pendant cette période, l'UNICEF cède, ensemble avec le Comité Technique de Planification et Coordination (CTPC), le relais à la CONADER en matière de coordination des activités relatives aux enfants. Entre temps, le Mécanisme de surveillance et communication de l'information concernant les violations graves des droits de l'enfant en temps de conflits (créé en fin 2005) sera placé sous la responsabilité conjointe de l'UNICEF et de la MONUC 2287 .

De 2007 à 2010, c'est la période marquée par la naissance et la persistance de divers foyers de conflits en dépit notamment de l'intégration des groupes armés. Une occasion de plus de créer des enfants soldats. Suite à la suspension et à la restructuration de l'UEPN DDR, l'UNICEF reprendra la tête et la coordination des agences de protection de l'enfance sans oublier son rôle relativement classique de protection des enfants en général et de mise en œuvre du PNDDR de la partie «enfant ${ }^{2288}$. Alors que certaines ONG internationales se retirent de certaines zones, il financera certains de ses partenaires stratégiques pour combler le vide laissé par la fin du financement du MDRP aux $\mathrm{ONG}^{2289}$. Avec la reprise des activités de l'UEPN DDR en 2009, " l'UNICEF a dû accroître son implication directe et indirecte, ceci sans pour autant être en mesure d'influencer des approches $»^{2290}$.

Avec la fin des activités de l'UEPNDDR relative aux enfants en fin $2011^{2291}$ et l'affaiblissement des ONG internationales sur le terrain, entraînant par conséquent une suite hypothétique pour les activités de démobilisation et de réinsertion des enfants, l'UNICEF

\footnotetext{
${ }^{2284}$ BODINEAU, Sylvie, Rapport d'Evaluation du programme 2007-2011 pour les Enfants associés aux Forces et aux Groupes Armés en RDC, UNICEF RDC, op. cit., p. 10.

2285 Ibid. p. 11.

${ }^{2286} \mathrm{Ibid}$. Lire la note infrapaginale 3 sur la page 11.

${ }^{2287}$ Ibid., pp.11-12.

${ }^{2288}$ Ibid., p. 13.

${ }^{2289}$ Ibid., p. 12.

${ }^{2290}$ Ibid., p. 14.

${ }^{2291}$ Ibid., p. 16.
} 
continuera à agir. Il activera une nouvelle forme de partenariat consistant à financer les ONG locales pour l'exécution des activités de prévention et de réponses. Il financera les ONG internationales pour le renforcement et suivi des ONG locales ${ }^{2292}$.

Il ressort de l'évaluation effectuée par l'UNICEF RDC de ses activités que le soutien des ONG locales a été porteur des fruits que celui des ONG internationales. En outre, dans certaines situations, l'UNICEF n'a donc pas pleinement joué son rôle afin d'assurer que le processus formel ou informel de DDR réponde mieux aux exigences des droits des enfants. C'est notamment dans le cas du « degré d'inclusion d'enfants vulnérables dans les projets qui permettrait d'établir un environnement protecteur plus efficace pour tous ${ }^{2293}$.

Par ailleurs, les activités de l'UNICEF vis-à-vis des enfants en temps de conflits armés en RDC ne se limitent pas uniquement aux cas des enfants associés aux forces ou groupes armés. Elles concernent également tous les autres enfants touchés par les conflits armés. A ce titre, tout l'environnement où vit l'enfant se trouve concerné par les actions de l'UNICEF. A titre indicatif, en 2006, 1'UNICEF exhortait la communauté internationale à financer des mesures destinées à sauver des vies humaines des déplacés et autres personnes affectées par les conflits en $\mathrm{RDC}^{2294}$. Il s'engagera également dans des projets de développement à long terme au-delà d'aide d'urgence ${ }^{2295}$.

La RDC passe pour «l'un des pays où sévit l'une des pires crises humanitaires de la planète ${ }^{2296}$, la « crise humanitaire la plus meurtrière au monde depuis la deuxième guerre mondiale ${ }^{2297}$ comme le mentionnera avec précision l'UNICEF dans son Rapport de juillet 2006. En juin 2011, par exemple, la population déplacée était estimée à 1,6 millions de personnes dont l'essentiel était des enfants. Victimes des violences sexuelles et autres atrocités indicibles de la part des forces et groupes armés, les enfants sont en outre exposés, avec leur vulnérabilité particulière, à différents types de maladies occasionnées par le contexte de guerre (ex : le Choléra avec 16.680 cas recensés en octobre 2011) mais également à l'interruption de leur scolarité suite aux conflits armés. A titre d'exemple, en septembre 2010, 7,6 millions d'enfants n'allaient pas à l'école dont $34 \%$ en zone de conflit ${ }^{2298}$. Ainsi, en collaboration avec le Gouvernement de la RDC, d'autres organismes de l'ONU et des ONG, l'UNICEF se préoccupe de répondre à différents besoins des enfants touchés par les conflits

\footnotetext{
2292 Ibid., p. 17.

2293 Ibid. p.3.

${ }^{2294}$ UNICEF, SOS, République Démocratique du Congo. Reportage de Martin Bell sur les enfants piégés par la guerre, op.cit. p. 2. Voy. http://www.unicef.org/childalert/drc/ (Source consultée le 30 janvier 2016).

2295 Ibid.
}

2296 UNICEF, 2012 - Action humanitaire de l'UNICEF pour les enfants, Division de la Communication, UNICEF, New-York, Janvier 2012, p. 33. Dans un de ses Rapports sur la RDC en juillet 2006, pour décrire ce qu'il appelle "la véritable tragédie humaine » en RDC, l'UNICEF titra une des parties «Un tsunami tous les six mois ». Ceci pour dire que «tous les six mois, le bilan des morts et disparitions dues au conflit en RDC équivaut au nombre total de décès causés par le tsunami de l'Océan indien en 2004 ». Voy. UNICEF, SOS, République Démocratique du Congo. Reportage de Martin Bell sur les enfants piégés par la guerre, op.cit. 2. Voy. http://www.unicef.org/childalert/drc/

(Source consultée le 30 janvier 2016).

\footnotetext{
${ }^{2297}$ UNICEF, SOS, République Démocratique du Congo. Reportage de Martin Bell sur les enfants piégés par la guerre, op.cit. p. 2. Voir http://www.unicef.org/childalert/drc/ (Source consultée le 30 janvier 2016).

${ }^{2298}$ UNICEF, 2012 - Action humanitaire de l'UNICEF pour les enfants, op.cit., p. 33.
} 
armés $^{2299}$. Par exemple, pour l'an 2012, en dehors de ses nombreuses aides apportées à l'environnement de vie de l'enfant (familles, communautés, etc.), l'UNICEF, en collaboration avec ses partenaires précités, se concentrera notamment sur la distribution de fournitures et aide pour soigner environ 154000 enfants souffrant de malnutrition, la vaccination contre la rougeole de 11 millions d'enfants âgés de 6 mois à 15 ans, voire la distribution de comprimés vermifuges et/ou de suppléments de vitamine A à 14 millions $\mathrm{d}^{\prime}$ enfants $^{2300}$. Les vaccinations d'enfant visent également d'autres maladies telles que tuberculose, coqueluche, fièvre jaune, polio, tétanos en $2005^{2301} .275000$ enfants vulnérables et affectés par la crise devront recevoir une éducation formelle et non formelle de qualité, comprenant, entre autres, une formation professionnelle et une insertion socioéconomique sans compter la formation de 5000 enseignants ${ }^{2302}$. En février 2015, après une mission de terrain effectuée au Nord-Kivu, le Représentant de l'UNICEF en RDC, Pascal Villeneuve, déclarera que la situation de l'enfant affecté par les conflits armés précisément l'enfant soldat s'améliore par rapport aux années antérieures. En ce sens, les mécanismes et le plan d'action mis en œuvre par le gouvernement visant la prévention d'enrôlement et la démobilisation des enfants dans les forces et groupes armés fonctionnaient. Il reconnaît néanmoins que beaucoup reste à faire ${ }^{2303}$.

Ainsi comparé aux autres mécanismes de protection des enfants en situation de conflit armé en RDC, l'UNICEF est perçu comme l'épicentre des actions de protection dirigées en faveur de l'enfant à différents niveaux. On ne perdra pas de vues, par exemple, qu'en sa qualité d'organe subsidiaire des Nations Unies spécialisé dans la protection de l'enfance, l'UNICEF se fait représenter lors de l'examen de l'application de la Convention relative aux droits de l'enfant par le Comité des droits de l'enfant. Il peut être invité par ledit Comité à donner ses avis spécialisés sur l'application de la Convention (cf. article 45 de la Convention relative aux droits de l'enfant) ${ }^{2304}$. Il est également sollicité par des organisations intergouvernementales telles que l'Union africaine ou l'Union européenne pour des missions de protection de l'enfant.

En conclusion de la présente section, affirmons qu'il existe encore de nombreuses agences des Nations Unies qui interviennent dans le cadre de conflits armés en RDC en faveur de la population civile dont les enfants. Contribuant ainsi à leur protection. Elles n'ont cependant pas fait l'objet des présentes analyses pour des raisons justifiées ci-dessus. Toutefois, les mécanismes onusiens analysés sous ce cadre ont pour mandat de travailler en collaboration et en soutien aux mécanismes gouvernementaux congolais. Lesquels ont la mission première de protection, sous leur juridiction, des enfants en conflits armés. Ces mécanismes onusiens

2299 Voy. par exemple les différentes actions entreprises par l'UNICEF de 2005 à 2015 sur http://www.unicef.org/french/infobycountry/drcongo newsline.html (Source consultée le 30 janvier 2016).

${ }^{2300} \mathrm{UNICEF}, 2012$ - Action humanitaire de l'UNICEF pour les enfants, op.cit., p. 33.

2301 Voy. «Life-saving immunization drive launches in DR Congo », in http://www.unicef.org/french/infobycountry/drcongo 25279.html (Source consultée le 30 janvier 2016).

${ }^{2302} \mathrm{UNICEF}, 2012$ - Action humanitaire de l'UNICEF pour les enfants, op.cit., 33.

${ }^{2303}$ LUKESSO, Denise, « Pascal Villeneuve, Représentant de l'UNICEF en RD Congo « Enfants Soldats : la situation s'est améliorée globalement dans l'Est » », in Protéger et soutenir les enfants touchés par la violence et les conflits, Echo de la MONUSCO, op.cit., p. 7.

${ }^{2304}$ Voy. VERHOEVEN, Joe, « La mise en œuvre de la Convention des Nations Unies sur les droits de l'enfant. Observations en droit des gens », in MEULDERS-KLEIN, M.T. (dir.), La Convention sur les droits de l'enfant et la Belgique, op.cit., p. 69. 
œuvrent également en collaboration avec des mécanismes intergouvernementaux et non gouvernementaux. Certains, comme l'Union européenne, appuient les mesures prises par le CS/NU contre les auteurs des graves violations contre les enfants en RDC. Toutefois, en dépit de leur travail, la protection de l'enfant en situation de conflits armés en RDC n'est pas encore effective. Les enfants demeurent victimes «permanentes » de nombreuses graves violations du DIH. D'une part l'Etat congolais, premier protecteur des enfants sur son territoire, ne joue pas pleinement son rôle, suivi des groupes armés. D'autre part, ces mécanismes subsidiaires à la protection de l'enfant en RDC, n'ont pas toujours des moyens conséquents pour répondre à leurs tâches.

\section{Section IV Mécanismes gouvernementaux et non gouvernementaux de protection des enfants en situation de conflits armés en RDC}

La présente section examine la contribution des mécanismes gouvernementaux (non juridictionnels) $(\$ 1)$ et non gouvernementaux (\$2) dans la protection des enfants en situation de conflits armés en RDC.

\section{§1. Mécanismes gouvernementaux de protection des enfants en situation de conflits armés en RDC}

La ratification (ou l'adhésion) par la RDC (à) de nombreuses conventions internationales des droits de l'homme dont celles liées aux droits de l'enfant a occasionné, dès la décennie 90, le processus d'installation d'un certain nombre de mécanismes de protection à cet effet. Le constat établi démontre que ces mécanismes concernent majoritairement la situation de l'enfant et de ses droits en temps de paix. Clairement, ils s'attèlent donc essentiellement aux «droits de l'homme» de l'enfant.

Bien que les droits de l'homme concernent également les conflits armés, certains de ces mécanismes institués en RDC ont connu de sérieuses difficultés de fonctionnement durant les deux «guerres de libération ». Par ailleurs, la protection spéciale de l'enfant au sens du DIH ne semble pas être conséquemment prise en charge par des mécanismes appropriés. Un mécanisme approprié tel que Commission nationale de mise en œuvre du DIH n'est pas encore à l'ordre du jour. Pour l'heure, de manière disparate, le DIH relatif à la protection de l'enfant semble pris en charge. C'est dans cette optique que le présent paragraphe s'attèle à analyser ces différents mécanismes et voir dans quelle mesure ils jouent leur rôle dans la protection spéciale de l'enfant en situation de conflits armés en RDC.

Ainsi, le présent paragraphe s'interrogera sur le rôle des mécanismes de protection spéciale de l'enfant existant, en période de conflits armés (A). En dernier lieu, il s'occupera d'appréhender le rôle que jouent les mécanismes généraux des droits de l'homme dans la protection des enfants en temps de conflits armés (B).

\section{A - Mécanismes de Protection spéciale de l'enfant en temps de conflits armés ?}

Sous ce point, il est question d'épingler les mécanismes qui dans leurs missions, fonctions ou attributions s'occupent spécialement de la protection de l'enfant - en lien avec des conflits 
armés -. Sont épinglés dans ce contexte : le Conseil National de l'Enfant (A.1), le Comité national de lutte contre les pires formes de travail des enfants (A.2), l'UEPNDDR (A.3), les cas des mécanismes institués par la loi n 09/001 du 10 janvier 2009 (A.4), le Plan d'action du 04 octobre 2012 pour mettre fin au recrutement et à l'utilisation d'enfants (A.5), l'Agence Nationale de lutte contre les violences faites à la femme et à la jeune et petite fille (AVIFEM) (A.6), le Fonds National pour la promotion de la femme et la protection de l'enfant (FONAFEM) (A.7), le Représentant personnel du Chef de l'Etat en charge de la lutte contre les violences sexuelles et le recrutement des enfants (A.8).

\section{A.1 Le Conseil National de l'Enfant}

Le Conseil National de l'Enfant (CNEN) est créé par l'Arrêté 11/CAB/VM/AFF.SO.F/98 du 13 mai 1998 portant création et organisation du Conseil National de l'Enfant ${ }^{2305}$. Le CNEN vient en restructuration de l'ancien Comité National de l'Enfant (CNE) créé en 1994. Avant l'adoption de la Convention relative aux droits de l'enfant, il existait en RDC des mécanismes similaires dont le Comité national pour la protection et le bien-être de l'enfance et de la jeunesse réformé et réorganisé notamment par l'Arrêté CAB/2100/018/MJS/71 du 9 juin 1971 portant réforme et réorganisation du Comité national pour la protection et le bien-être de l'enfance et de la jeunesse en République démocratique du Congo.

Bien avant l'institution du CNEN, différentes mesures ont été prises en faveur de l'enfant. En 1992, le «Plan d'Action National pour la survie, la protection et le développement de l'Enfant d'ici à l'an 2000 » était élaboré par une commission composée des représentants des institutions gouvernementales, non gouvernementales et intergouvernementales œuvrant pour le bien-être de l'enfant en RDC. C'est également la même année qu'il y a eu création de la « Direction de la Protection de l'enfant» par le Ministère des affaires sociales et familles. Et en 1997, l'intégration de la notion de «droits de l'enfant» dans le programme d'éducation civique $^{2306}$.

En termes de mission, suivant l'article 2 de l'arrêté portant sa création, le CNEN veille à la mise en œuvre de la politique nationale de protection de l'enfant et sert d'organe conseil au gouvernement congolais. Les fonctions du CNEN détaillées en article 3 de l'arrêté précité consistent à : " - élaborer les indicateurs de suivi et évaluation du plan d'action national pour l'enfant; - assurer le suivi et l'évaluation du plan d'action national; -présenter au gouvernement un rapport annuel sur la situation de l'enfant en République démocratique du Congo $^{2307}$ ». Accompagné dans sa mission par des Comités provinciaux, le CNEN réserve également des places des membres notamment aux ONG s'occupant des enfants (article 4).

Créé exactement à quatre jours de la date du premier anniversaire de l'accession de Laurent Désiré Kabila au pouvoir, il était souhaitable que le CNEN puisse se préoccuper primordialement du phénomène en vogue en RDC : Le phénomène «Kadogo », les enfants

\footnotetext{
${ }^{2305}$ Voy. http://www.leganet.cd/Legislation/Droit\%20civil/Dpersonnes/AM.13.05.1998.htm (Source consultée le 29 octobre 2015).

${ }^{2306}$ RDC, Ministère des Affaires sociales et famille, Rapport national sur le suivi du sommet mondial pour les Enfants, décembre 2000, p. 2.

${ }_{2307}$ Voy. l'article 3 http://www.leganet.cd/Legislation/Droit\%20civil/Dpersonnes/AM.13.05.1998.htm (Source consultée le 29 octobre 2015).
} 
soldats qui ont renversé Mobutu. Si c'est vraiment et réellement dans l'intérêt de l'enfant qu'un tel mécanisme a été créé, la politique d'éradication de ce phénomène devrait être d'une mention spéciale dans sa mission ou ses fonctions. Il y a lieu de comprendre que la présence de kadogo dans les rangs de la nouvelle armée nationale - FAC - était encore importante. Et surtout que la méfiance du nouveau pouvoir vis-à-vis des ex-FAZ était palpable.

Le manque d'intérêt réservé au phénomène kadogo était encore plus remarquable dans le Rapport national sur le suivi du sommet mondial pour les Enfants, de décembre 2000, du Ministère des Affaires sociales et famille, cité ci-dessus. Ce Rapport reconnaît, par exemple, le non respect des droits de l'enfant contenus dans la convention relative aux droits de l'enfant suite notamment à l'absence de son harmonisation avec la législation nationale. Et surtout à sa vulgarisation insuffisante ${ }^{2308}$. Le Constat le plus remarquable est le fait que ce rapport reconnaît l'amplification de phénomènes tels que les enfants de et dans la rue; les enfants exploités économiquement et sexuellement, situation aggravée avec le conflit armé. Mais nullement, la mention est faite au sujet du phénomène enfants soldats, les kadogo. En énumérant par la suite, les enfants nécessitant des mesures spéciales, les enfants soldats n'ont pas répertoriés ${ }^{2309}$. Ce n'est nullement un oubli mais une volonté délibérée. Il est à signaler que c'est par pression de la «communauté internationale» et de la société civile que le Décret-loi $n^{\circ} 066$ du 09 juin 2000 portant démobilisation et réinsertion des groupes vulnérables présents au sein des forces combattantes a été promulgué.

Par ailleurs, le CNEN joue un rôle important pour les rapports à soumettre au Comité des droits de l'enfant (article 44 de la Convention relative aux droits de l'enfant).

Il est créé également au sein du Ministère du genre, de la famille et de l'enfant, la Cellule d'Etudes et de planification pour la promotion de la femme, de la famille et la protection de l'enfant par l'Ordonnance $n^{\circ}$ 07/070 du 20/11/2007 portant création, organisation de la Cellule d'Etudes et de Planification de la promotion de la Femme, de la Famille et de la protection de l'Enfant (CEPFE). Par différentes études menées sur la question des enfants notamment, il aide le Ministère à réaliser ses objectifs fixés.

\section{A.2 Comité National de lutte contre les pires formes de travail des enfants}

Le Comité National de lutte contre les pires formes de travail des enfants est institué par la Loi $n^{\circ} 015 / 2002$ du 16 octobre 2002 portant Code du travail en son article 4 . «Ce Comité a pour mission : - d'élaborer la stratégie nationale en vue de l'éradication des pires formes de travail des enfants ; - d'assurer le suivi de la mise en cuvre de la stratégie et d'évaluer le niveau d'application des mesures préconisées» (article 4). Et suivant l'article 3 a «le recrutement forcé ou obligatoire des enfants en vue de leur utilisation dans des conflits armés » est une des pires formes de travail des enfants abolies par le Code de travail congolais (cf. supra).

Aucun rapport élaboré par cet organisme sur la question de recrutement et d'utilisation des

\footnotetext{
${ }^{2308}$ RDC, Ministère des Affaires sociales et famille, Rapport national sur le suivi du sommet mondial pour les Enfants, décembre 2000, op.cit., p. 10.

${ }^{2309}$ Ibid., p. 11.
} 
enfants en conflits armés en RDC n'a été retrouvé.

\section{A.3 Unité d'Exécution du Programme National de Désarmement, Démobilisation et Réinsertion (UEPNDDR)}

A la suite du décret-loi n066/2000 du 9 juin 2000 portant démobilisation et réinsertion des groupes vulnérables présents dans les forces combattantes, son exécution avait été confiée au Bureau National pour la Démobilisation et la Réinsertion (BUNADER) remplacé par la Commission Nationale de Démobilisation et de Réinsertion (CONADER), créée par le décret n 03/042 du 18 décembre 2003. La CONADER sera elle-même remplacée en 2007 par 1'Unité d'Exécution du Programme National de Désarmement, Démobilisation et Réinsertion (cf. Ordonnance $\mathrm{n}^{\circ} 07 / 057$ du 14 juillet 2007). Ainsi, à la suite de la campagne «Plus jamais un seul enfant dans les forces et groupes armés » menée par la CONADER ${ }^{2310}$ avec l'appui financier de la Banque mondiale, au 30 avril 2006, 29.291 enfants certifiés dans les centres d'orientation ont été retirés des forces et groupes armés dont 15.220 bénéficiaient du programme de réinsertion sociale et économique ${ }^{2311}$. Toutefois, la sortie des filles demeurait problématique. Certaines étaient devenues «épouses» des soldats, d'autres craignaient l'exclusion sociale à la suite de leur identification, etc. ${ }^{2312}$ Suivant ces estimations, bien que contredites par l'UNICEF, son travail aurait produit des résultats conséquents en décembre 2007 (cf. Supra, Tableau sur les Statistiques ventilées des EAFGA pris en charge par catégories et par province (avant décembre 2007) ).

Il importe de mentionner que le fonctionnement de l'UEPNDDR connaîtra de sérieux problèmes des ressources financières et humaines. Dès sa création, entre juillet 2007 et fin 2008, l'ex-CONADER connaîtra l'interruption de ses activités - pour raison de restructuration $^{2313}$ - et la fin des financements directs octroyés par le Multi-Country Demobilization and Reintegration Programm (MDRP). Suivant sa restructuration, l'UEPNDDR sera placé sous le Ministère de la Défense et non sous une responsabilité interministérielle comme la CONADER. En 2009, à la reprise de ses activités, l'UEPNDRR sera fortement affaibli en termes de personnel et d'infrastructure pour assurer la coordination des activités consacrées aux enfants. Relai que prendront l'UNICEF et certaines ONG spécialisées ${ }^{2314}$. «Contrairement à leurs engagements, le gouvernement et la BAD n'apportent aucune ressource à l'UENPDDR qui devient progressivement un organe d'exécution du programme de la Banque Mondiale et ne prend aucune initiative allant au-delà de ce programme. On note en particulier l'établissement d'une base de données uniquement centrée sur la capacité à rendre des comptes quant à la réalisation des activités du programme [...]

\footnotetext{
${ }^{2310}$ Voy. Comité des droits de l'enfant, Examen des Rapports présentés par les Etats parties en application du paragraphe 1 de l'article 8 du Protocole facultatif à la Convention relative aux droits de l'enfant, concernant l'implication d'enfants dans les conflits armés, Rapports initiaux des Etats parties attendus en 2004, République Démocratique du Congo, CRC/C/OPAC/COD/1, 18 avril 2011, op. cit., p. 22, §93.

${ }^{2311}$ Comité des droits de l'enfant, Examen des Rapports présentés par les Etats parties en application de l'article 44 de la Convention, Rapports périodiques des Etats parties devant être soumis en 1997, République Démocratique du Congo, CRC/C/COD/2, 24 juillet 2008, op. cit.,, p. 48, §§202-204.

2312 Ibid., p. 48, §205. Voy. Aussi BODINEAU, Syvie, Figures d'enfants soldats. Puissances et vulnérabilité... pp. 48 et 91.

${ }^{2313}$ Voy. BODINEAU, Sylvie, Rapport d'Evaluation du programme 2007-2011 pour les Enfants associés aux Forces et aux Groupes Armés en RDC, UNICEF RDC op.cit., 12.

${ }^{2314}$ Ibid., p. 3.
} 
$»^{2315}$.

Bien plus, le déni accru du gouvernement congolais au sujet du recrutement des enfants par les FARDC associé à l'amoindrissement considérable des ressources financières et humaines allouées à l'UEPNDDR aurait logiquement pour conséquence la disparition de celle-ci. Déjà en octobre 2011, «l'UEPNDRR n'aura plus de fonds ni de services dirigés aux enfants » ${ }^{2316}$. Au-delà de tout, de «nombreux ré-enrôlements » ${ }^{2317}$ à l'Est de la RDC - non étudiés sérieusement - sont de nature à remettre en question le travail effectué depuis le BUNADER.

\section{A.4 Mécanismes institués suivant la loi ${ }^{\circ} 09 / 001$ du 10 janvier 2009 portant protection de l'enfant?}

La loi $n^{\circ} 09 / 001$ du 10 janvier 2009 portant protection de l'enfant ne prévoit pas des mécanismes devant assurer la protection des enfants sur le champ de bataille ou zones de conflit. En clair, l'on ne saurait point assurer la protection des droits de l'Homme ou la mise en œuvre du DIH sans l'institution des mécanismes appropriés. Et dans le cas d'espèce, étant donné qu'il s'agit des enfants, eux-mêmes qui méritent une protection spéciale, il aurait été facile de créer par cette loi des mécanismes spécifiques adaptés aux besoins des enfants en situation de conflits armés. Il est dit simplement que l'Etat garantit la protection, l'éducation et les soins nécessaires aux enfants affectés par les conflits armés...(cf. l'art.72). Aucun mécanisme spécifiquement lié en cette situation conflictuelle n'a donc été adopté. Il est à constater que cette nouvelle loi ne saurait pas, avec simplement ces trois articles liés à la protection des enfants en situations de conflits armés, protection dite exceptionnelle (cf. les art. 71,72 et 73), assurer efficacement la protection spéciale des enfants sur le champ de bataille.

Ainsi pour tout dire, la mise en œuvre de cette Protection exceptionnelle reste donc problématique faute des mécanismes adéquats.

\section{A.5 Le plan d'action du 04 octobre 2012 pour mettre fin au recrutement et à l'utilisation d'enfants ainsi qu'aux violences sexuelles perpétrées par les FARDC}

«Un plan d'action est un engagement écrit liant l'Organisation des Nations Unies et les parties figurant sur la liste des auteurs de graves violations à l'encontre des enfants publiée dans le rapport annuel du Secrétaire général sur le sort des enfants en temps de conflit armé. Chaque partie élabore un plan en fonction de sa situation propre et adopte des mesures concrètes assorties d'échéances qui lui permettront de garantir l'application du droit international, de se faire retirer de la liste du Secrétaire général et de mieux protéger les enfants ${ }^{2318}$.

Le plan d'action est institué en vertu des résolutions 1612 (2005) et 1882 (2009) du CS/NU

\footnotetext{
${ }^{2315}$ Ibid., pp.12-13.

${ }^{2316}$ Ibid., p. 4.

${ }^{2317} \mathrm{Ibid}$.

2318 «Plans d'action conclus avec des forces et groupes armés ", in https://childrenandarmedconflict.un.org/fr/notre-travail/plans-daction/ (Source consultée le 01 novembre 2015).
} 
installant le Mécanisme de Surveillance et de Communication de l'information du CS/NU. Ce plan d'action signé par la RDC vise des mesures de prévention, d'éradication et de réinsertion des enfants associés aux forces armées et services de sécurité de la RDC. Il prévoit en outre des mesures de protection contre les violences sexuelles. La lutte contre l'impunité par la poursuite des auteurs de ces violations et la prise en charge des enfants victimes, conformément au droit national et international sont également concernées. Il est signé le 04 octobre 2012 entre le Gouvernement congolais, le Représentant du SG/NU pour la RDC, Roger Meece et le Vice-Représentant de 1'UNICEF en RDC, Sylvie Fouet ${ }^{2319}$. La mise en œuvre de ce plan d'action devrait permettre le retrait de FARDC de la liste du SG/NU des parties recourant aux enfants dans les conflits armés et commettant des violations graves. Rappelons que les FARDC sont inscrites en 2005 sur la liste en annexe du Rapport du SG/NU sous cette appellation, et en 2003 sous la dénomination de FAC.

Concrètement, le plan d'action signé par la RDC «comporte quatre volets: - L'accès, la vérification et l'identification des enfants présents dans les rangs des forces de sécurité; - Les services de réinsertion et de soutien aux enfants victimes; - La mise en place de mécanismes de responsabilisation des auteurs de violations, et - La mise en œuvre d'un cadre de collaboration entre le gouvernement et les partenaires onusiens ${ }^{2320}$. En outre, ce «plan d'action prévoit des étapes et mesures pour protéger les filles et les garçons des violences sexuelles $»^{2321}$.

La signature de ce plan d'action a été saluée par le Groupe de travail sur le sort des enfants en temps de conflits armé, la Représentante Spéciale du Secrétaire général pour les enfants et les conflits armés, Mme Leila Zerrougui ${ }^{2322}$, etc. Cependant, les efforts salués du Gouvernement congolais pour mettre fin à la présence des enfants dans ses forces armées et services de sécurité n'ont pas empêché les membres de ce Groupe de travail en juillet 2014 de demeurer préoccupés par «les violations et sévices continus à l'encontre des enfants et par le fait que leurs auteurs ne soient pas tenus de répondre de leurs actes. Ils ont également souligné combien il importait d'adopter une approche globale qui prenne en compte les causes profondes du conflit ${ }^{2323}$.

\footnotetext{
${ }^{2319}$ Lire « Le Gouvernement de la République démocratique du Congo a signé le plan d'action pour mettre fin au recrutement d'enfants associés aux forces armées congolaises ", in http://graminternational.org/blog/2012/11/04/le-gouvernement-de-la-republique-democratique-du-congo-a-signe-un-plandaction-pour-mettre-fin-au-recrutement-denfants-associes-aux-forces-armees-congolaises/ (Source consultée le 31 octobre 2015) ou UNICEF, la République Démocratique du Congo adopte le Plan d'Action visant à mettre fin au recrutement d'enfants, in http://caritasdev.cd/fr/index.php?view=article\&catid=14\&id=1672\%3Alarepublique-democratique-du-congo-adopte-le-plan-daction-visant-a-mettre-fin-au-recrutementdenfants\&format=pdf\&option=com content p. 1, (Source consultée le 01 novembre 2015).

2320 «Le Gouvernement de la République démocratique du Congo a signé le plan d'action pour mettre fin au recrutement d'enfants associés aux forces armées congolaises », op. cit., in http://graminternational.org/blog/2012/11/04/le-gouvernement-de-la-republique-democratique-du-congo-a-signe-un-plandaction-pour-mettre-fin-au-recrutement-denfants-associes-aux-forces-armees-congolaises/ (Source consultée le 31 octobre 2015).

${ }^{2321}$ Ibid.

${ }^{2322}$ Ibid.

${ }^{2323}$ Le Groupe de travail sur le sort des enfants en temps de conflits armés, Conclusions concernant les enfants et les conflits armés en République démocratique $d u$ Congo, S/AC.51/2014/3, in http://www.un.org/ga/search/view_doc.asp?symbol=S/AC.51/2014/3\&referer=/english/\&Lang=F, §3, (Source
} 
Pour sa part, le Représentant permanent de la RDC, présent aux travaux du 21 juillet 2014 de ce Groupe de travail, reconnaît en dépit de l'amélioration que «les Groupes armés non étatiques continuaient de recruter et d'utiliser des enfants, en violation du droit international applicable $»^{2324}$. La signature de ce plan d'action et la nomination du Représentant personnel du Chef de l'Etat en charge de la lutte contre les violences sexuelles et le recrutement des enfants (cf. infra) sont autant d'efforts que fournit la RDC dans ce domaine, soulignait son Représentant à ces assises ${ }^{2325}$. Il paraît tout de même vrai que rien n'atteste « réellement » que la RDC ne recrute plus d'enfants. Dans le même sens, en février 2015, après une mission de terrain effectuée au Nord-Kivu, le Représentant de l'UNICEF en RDC, Pascal Villeneuve, déclarera que les mécanismes et le plan d'action mis en œuvre par le gouvernement visant la prévention d'enrôlement et la démobilisation des enfants dans les forces et groupes armés fonctionnent. Néanmoins beaucoup reste à faire ${ }^{2326}$.

A la lumière de ce qui précède, le plan d'action se présente comme un instrument établissant des mesures et mécanismes appropriés pour la protection de l'enfant au sens du DIH voire du DIDH. Mais le plus grand défi à relever reste sa mise en œuvre reconnaît plus d'un acteur ${ }^{2327}$. La RDC n'étant pas encore retirée de la liste car la pratique de recours aux enfants et les violations graves des droits de l'enfant n'y sont pas encore totalement éradiquées ${ }^{2328}$. D'autre part, l'obligation de l'Etat congolais de protéger les enfants se trouve être enfreinte notamment par la pratique des groupes armés de recrutement et d'utilisation continus des enfants voire des violations graves dont les violences sexuelles (cf. infra).

\section{A.6 Agence nationale de lutte contre les violences faites à la Femme et à la Jeune et Petite Fille (AVIFEM)}

En effet, il a été promulgué le Décret $\mathrm{n}^{\circ}$ 09/38 du 10 octobre 2009 portant création, organisation et fonctionnement de l'Agence nationale de lutte contre les violences faites à la Femme et à la Jeune et Petite Fille. Cette Agence a pour mission générale : «[...] l'exécution de la stratégie nationale de lutte contre toutes les formes des violences basées sur le genre, spécialement celles faites à la Femme, à la Jeune et Petite fille ${ }^{2329}$. Comme on peut bien le remarquer cette Agence créée au sein du Ministère du Genre, de la famille et de l'enfant ne s'occupe que d'un aspect très spécifique de situations des enfants.

Un autre mécanisme de ce type a été investi au sein des FARDC, le 30 mars 2015. Il s'agit de

consultée le 31 octobre 2015).

${ }^{2324}$ Ibid.

2325 Ibid.

${ }^{2326}$ LUKESSO, Denise, «Pascal Villeneuve, Représentant de l'UNICEF en RD Congo «Enfants Soldats : la situation s'est améliorée globalement dans l'Est » », in Protéger et soutenir les enfants touchés par la violence et les conflits, op.cit., p. 7.

${ }^{2327}$ Lire « Le Gouvernement de la République démocratique du Congo a signé le plan d'action pour mettre fin au recrutement d'enfants associés aux forces armées congolaises », op. cit., in http://graminternational.org/blog/2012/11/04/le-gouvernement-de-la-republique-democratique-du-congo-a-signe-un-plandaction-pour-mettre-fin-au-recrutement-denfants-associes-aux-forces-armees-congolaises/ (Source consultée le 01 novembre 2015).

2328 Voy. Watchlist on Children and Armed Conflic, Monthly Update october 2015 in http://watchlist.org/ (Source consultée le 01 novembre 2015).

${ }^{2329}$ Décret $n^{\circ}$ 09/38 du 10 octobre 2009 portant création, organisation et fonctionnement de l'Agence nationale de lutte contre les violences faites à la Femme et à la Jeune et Petite Fille, disponible sur http://www.leganet.cd/Legislation/Droit\%20Public/DH/D.09.38.10.10.2009.htm $\quad$ (Source consultée le 20 septembre 2012). 
la Commission nationale chargée de la lutte contre les violences sexuelles.

\section{A.7 Fonds National pour la Promotion de la Femme et la Protection de I'Enfant (FONAFEM)}

Il sera également adopté le Décret n ${ }^{\circ}$ 09/37 du 10 octobre 2009 portant création, organisation et fonctionnement d'un Etablissement public dénommé «Fonds National pour la Promotion de la Femme et la Protection de l'Enfant ». Suivant l'article 4 du décret précité, "Le Fonds a pour mission générale la mobilisation et la gestion des ressources en rapport avec la promotion de la Femme et la Protection de l'Enfant. A ce titre, il est chargé notamment de contribuer à la mise en cuvre de la politique nationale sur le Genre et de renforcer le financement des programmes, projets et activités relatifs à la promotion de la Femme et la protection de l'Enfant $[\ldots] »^{2330}$.

\section{A.8 Représentant personnel du Chef de l'Etat en charge de la lutte contre les violences sexuelles et le recrutement des enfants}

En 2014, par l'Ordonnance $n^{\circ} 14 / 021$ du 08 juillet 2014 portant nomination d'un Représentant personnel $d u$ Chef de l'Etat en charge de la lutte contre les violences sexuelles et le recrutement des enfants ${ }^{231}$, Madame Jeanine Mabunda Liyoko sera nommée à ce titre. La présente ordonnance ne précise cependant pas la mission ou les fonctions reconnues à cet organe. Toutefois, il y a lieu de penser que cette nomination résulte du plan d'action signé le 04 octobre 2012 par le gouvernement congolais pour mettre fin au recrutement et à l'utilisation d'enfants ainsi qu'aux violences sexuelles perpétrées par les FARDC.

Au plan international, cette nomination sera saluée notamment par Zainab Hawa Bangura et Leila Zerrougui respectivement Représentante spéciale du Secrétaire général de l'ONU sur les violences sexuelles en conflit et la Représentante spéciale du Secrétaire général de l'ONU pour les enfants et les conflits armés. Lesquelles font d'ailleurs part de leur soutien et de leur coopération vis-à-vis de cet organe ${ }^{2332}$.

Par ailleurs, signifions que l'installation des Tribunaux pour enfants à travers les pays depuis l'an 2011 constitue un mécanisme de protection des droits de l'enfant bien que ne rentrant pas spécifiquement dans les cas de situations de conflits armés.

\section{B - Mécanismes non juridictionnels nationaux de promotion et de protection des droits de l'homme}

Il est ici question d'analyser les rôles des mécanismes non juridictionnels (généraux) des droits de l'homme, institués par l'Etat congolais, dans la protection de l'enfant en période de conflits armés.

\footnotetext{
2330 Décret n 09/37 du 10 octobre 2009 portant création, organisation et fonctionnement d'un Etablissement public dénommé «Fonds National pour la Promotion de la Femme et la Protection de l'Enfant», disponible sur http://www.leganet.cd/Legislation/Droit\%20Public/DH/D.09.37.10.10.09.htm (Source consultée le 20 septembre 2012).

${ }^{2331}$ Lire http://www.digitalcongo.net/article/100998\#O021 (Source consultée le 23 octobre 2015).

${ }^{2332}$ Voy. http://www.un.org/apps/newsFr/storyF.asp?NewsID=32967\#.ViqeXzkVeQs (Source consultée le 23 octobre 2015).
} 


\section{B.1 De l'Observatoire National des Droits de l'Homme à la Commission Nationale des droits de l'Homme}

En RDC, l'Observatoire National des Droits de l'Homme qui pouvait jouer un rôle conséquent en rapport avec la promotion voire la protection du DIH a été dissout par la Constitution du 18 février 2006.

En effet, l'Observatoire National des Droits de l'Homme était revêtu du statut d'institution d'appui à la démocratie sous la constitution de la transition du 04 avril 2003 en son article 154 à l'instar de la Commission électorale indépendante, de la Haute autorité des médias, de la Commission vérité et réconciliation et de la Commission de l'éthique et de la lutte contre la corruption. L'actuelle constitution du 18 février 2006, telle que modifiée par la loi $n^{\circ} 11 / 002$ du 20 janvier 2011 portant révision de certains articles de la Constitution de la République Démocratique du Congo du 18 février 2006, en son Titre V, articles 211 et 212, ne reconduit que deux de ces cinq institutions d'appui à la démocratie avec changement de dénomination. A savoir la Commission électorale indépendante devenue Commission électorale nationale indépendante et la Haute autorité des médias sous la dénomination de Conseil supérieur de l'audiovisuel et de la communication. Ce qui paraît tout de même paradoxal par rapport aux nombreux droits humains proclamés par ce texte constitutionnel et surtout par rapport à la réalité catastrophique des droits humains sur le terrain. Tout de même, l'article 222, alinéa 3, de cette constitution prévoit la possibilité de créer d'autres institutions d'appui à la démocratie. Et la création de la Commission Nationale des Droits de l'homme (CNDH) s'incrit dans ce sens.

En effet, le 06 décembre 2012, l'Assemblée nationale a suivi l'exemple du Sénat et adopté la loi instituant la Commission Nationale des Droits de l'homme, un organe indépendant chargé de la promotion et de la protection des droits fondamentaux en $\mathrm{RDC}^{2333}$. Signifions en passant que la République du Rwanda s'est doté également de la Commission Nationale des droits de l'homme et de la Commission Nationale de lutte contre le Génocide respectivement aux articles 177 et 179 de sa constitution du 04 juin 2003. De même pour la République de l'Ouganda que félicite le Comité des droits de l'enfant dans ses observations finales de novembre 2005 à son endroit ${ }^{2334}$.

Par la Loi organique $n^{\circ} 13 / 011$ du 21 mars 2013 portant institution, organisation et fonctionnement de la Commission nationale des Droits de l'Homme en $\mathrm{RDC}^{2335}$ promulguée par le Chef de l'Etat, la CNDH a été créée. Elle est " un organisme technique et consultatif » et veille ainsi au respect des droits de l'homme et de leurs mécanismes de mise en œuvre

${ }^{2333}$ RCN, Justice \& Démocratie, Rapport d'activités 2012, Le Bulletin nº 42 , Bruxelles, Quatrième trimestre 2013, p. 13.

${ }^{2334}$ Comité des droits de l'enfant, Examen des Rapports présentés par les Etats parties en application de l'article 44 de la Convention, Observations finales : Ouganda, Quarantième session, Genève, 12-30 septembre 2005, $\mathrm{CRC} / \mathrm{C} / \mathrm{UGA} / \mathrm{CO} / 2, \quad 23$ novembre $2005, \quad$ p. $4, \quad \S 18, \quad$ in http://tbinternet.ohchr.org/_layouts/treatybodyexternal/Download.aspx?symbolno=CRC $\% 2 \mathrm{fC} \% 2 \mathrm{fUGA} \% 2 \mathrm{fCO} \%$ 2f 2 \&Lang=en (Source consultée le 22 janvier 2016).

${ }^{2335}$ Lire la Loi organique ${ }^{\circ} 13 / 011$ du 21 mars 2013 portant institution, organisation et fonctionnement de la Commission nationale des Droits de l'Homme http://www.leganet.cd/Legislation/Droit\%20Public/DH/L.13.011.21.03.2013.htm (Source consultée le 24 octobre 2015). 
(article 4). Dotée de la personnalité juridique, la CNDH « jouit de l'autonomie administrative, financière et technique » $\left(\operatorname{article~} 1^{\mathrm{er}}\right)$. Indépendante (article $\left.1^{\mathrm{er}}\right)$, elle «n'est soumise qu'à l'autorité de la loi » (article 4).

A ce titre, la CNDH exerce différentes attributions (article 6) dont :

- enquêter sur tous les cas de violations des droits de l'homme (article 6, §1);

- orienter les plaignants et victimes et les aider à ester en justice sur toutes les violations avérées des droits de l'homme (article 6, §2);

- veiller au respect des droits de la femme et de l'enfant (article 6, §4);

- veiller à l'application des normes juridiques nationales et des instruments juridiques régionaux et internationaux relatifs aux droits de l'homme dûment ratifiés par la République Démocratique du Congo (article 6, §10) ;

- promouvoir et veiller à l'harmonisation de la législation, des règlements et des pratiques nationaux avec les instruments internationaux relatifs aux droits de l'homme dûment ratifiés par la République Démocratique du Congo (article 6, §13) ;

- dresser des rapports sur l'état d'application des normes nationales et des instruments juridiques internationaux en matière des droits de l'homme (article 6, §14) ;

- émettre des avis et faire des propositions au Parlement, au Gouvernement et aux autres institutions concernant les questions relatives à la promotion et à la protection des droits de l'homme ainsi qu'au droit international humanitaire et à l'action humanitaire (article 6, §14);

La CNDH publie ses rapports d'activités (annuels, semestriels ou ponctuels) et les adresse au Président de la République, à l'Assemblée Nationale et au Sénat, au Gouvernement ainsi qu'aux Hautes juridictions de la République et leurs parquets respectifs (voir article 7). En termes d'organes, la CNDH est composée d'une Assemblée Plénière, d'un Bureau et de cinq Sous-commissions permanentes, en dehors de son Secrétariat technique et de ses Représentations provinciales (article 8). Des Sous-commissions ad hoc peuvent être créées par elle pour des questions particulières (article 13). Parmi ses Sous-commissions permanentes, il y a la Sous-commission des droits de la femme et de l'enfant (article 13, §4). C'est elle qui traite des questions spécifiquement liées aux enfants. La CNDH peut être saisie individuellement par toute personne physique victime de violation des droits de l'homme ou collectivement par un groupe de personnes. Elle peut aussi se saisir d'office (article 28). Les organisations de défense de droits de l'homme, légalement constituées, peuvent également la saisir en représentation des victimes (article 28).

Dans la mesure où l'article 13 institue une Sous-commission s'occupant des questions spécifiques des enfants et des femmes, la même logique aurait conduit au recrutement d'un membre, Représentant des organisations non gouvernementales droits spécifiques des femmes et des enfants, et non seulement un Représentant des Organisations non gouvernementales 
droits spécifiques des femmes (nous soulignons) comme le dispose l'article 14 §7 de ladite loi organique. La question de l'enfant n'a pas servi de critère de recrutement des membres de la CNDH. Il revient ainsi au règlement intérieur qui sera adopté conformément à l'article 10 de préciser les compétences de la Sous-commission des droits de la femme et de l'enfant en se laissant conduire notamment par «l'intérêt supérieur de l'enfant». Bien que s'agissant d'une Commission dont le champ d'application reste « les droits de l'homme », la CNDH ne devrait pas se perdre dans ce sillage en ignorant le DIH. Car au regard de l'article $6 \S 14$, la CNDH devrait émettre des avis et des propositions notamment sur des questions de DIH. C'est ici d'ailleurs que les questions spécifiques de protection spéciale de l'enfant en DIH devraient trouver une place de choix pour s'éclore. Encore qu'ici, ce vœu ne peut se réaliser que par la présence des « experts congolais en DIH» qui sont rares, et plus rares encore en DIH relatif à la protection des enfants. Il nous semble fort probable que la question de la protection spéciale de l'enfant risque d'être considérée sous l'angle des droits de l'homme que sous l'angle de DIH. Déjà la formulation globale de la loi organique l'atteste. Toutefois, le travail en réseaux avec d'autres organismes ou institutions poursuivant les mêmes objectifs qu'elle, comme le veut l'article $6 \S 19$, permettrait d'améliorer ses différentes difficultés.

En bref, la réussite de cette institution est fonction de la disponibilité des moyens conséquents - compétences intellectuelles, morales ; moyens financiers et matériels - de ses organes. L'on attendrait nullement de l'efficacité sans indépendance des organes et des membres qui les composent. Or, l'indépendance voire la neutralité ou l'impartialité d'une institution comme celle-ci est généralement vue comme danger vis-à-vis d'un pouvoir oppresseur de certains droits fondamentaux. La problématique de l'indépendance de la justice en RDC est un exemple à ce propos.

Le jeudi 23 juillet 2015, les neuf membres de la CNDH désignés par la société civile, entérinés le $1^{\text {er }}$ avril 2015 par l'Assemblée Nationale ${ }^{2336}$ et investis le 04 avril 2015 par ordonnance du Chef de l'Etat, conformément à l'article 17 de la loi organique sous examen $^{2337}$, ont finalement prêté serment devant la Cour constitutionnelle ${ }^{2338}$. L'heure est actuellement au processus de mise en place effective de cet organe « consultatif » et d'attente de résultat.

\section{B.2 L'Entité de Liaison des Droits de l'Homme}

L'Entité de Liaison des Droits de l'Homme est instituée par le Décret $n^{\circ} 09 / 35 d u 12$ août 2009 portant création, organisation et fonctionnement de l'Entité de Liaison de Droits de l'l'Homme en République Démocratique du Congo ${ }^{2339}$. Elle est « un cadre de concertation et de collaboration » $\left(\right.$ article $\left.1^{\mathrm{er}}\right)$ réunissant «les institutions, ministères, services publics et

${ }^{2336}$ Voy. «RDC : l'Assemblée nationale entérine les membres de la Commission nationale des droits de l'homme », in http://www.radiookapi.net/actualite/2015/04/02/rdc-lassemblee-nationale-enterine-les-membresde-la-commission-nationale-des-droits-de-lhomme (Source consultée le 25 octobre 2015).

2337 «Joseph Kabila investit les membres de la Commission nationales des droits de l'homme», in http://www.radiookapi.net/actualite/2015/04/05/joseph-kabila-investit-les-membres-de-la-commission-nationaledes-droits-de-lhomme (Source consultée le 25 octobre 2015).

2338 Voy. «RDC : création de la Commission nationale des droits de l'homme dans un climat tendu », in http://reliefweb.int/report/democratic-republic-congo/rdc-cr-ation-de-la-commission-nationale-des-droits-delhomme-dans (Source consultée le 25 octobre 2015).

2339 Voy. http://www.leganet.cd/Legislation/Droit\%20Public/DH/D.09.35.12.08.2009.htm (Source consultée le 25 octobre 2015). 
organisation » concourant à la promotion et à la protection des droits de l'homme en RDC (article 2). Elle a pour attributions d'évaluer les activités nationales des droits de l'homme ; suggérer des orientations nécessaires y relatives; veiller au respect par les parties de leurs obligations des droits de l'homme en RDC; assurer la mise en œuvre du plan national de promotion et de protection des droits de l'homme ; veiller à l'élaboration des rapports initiaux et périodiques; et enfin, examiner des causes de violations des droits de l'homme et faire des recommandations (article 3 ).

Il en ressort que par rapport à la protection spéciale de l'enfant, l'Entité de Liaison demeure un «mécanisme général » qui s'occupe des questions des droits de l'homme dont celles des enfants. Est donc là présent le risque d'une question particulière développée sous l'angle général des droits de l'homme. Bien plus, l'accent sur des questions des droits de l'homme ignore la problématique du DIH. Et par conséquent la protection spéciale de l'enfant en DIH. Toutefois dans la mesure où les représentants des organisations non gouvernementales nationales et internationales composent son Comité de Pilotage (article 5), il y a lieu d'espérer...

Par ailleurs, 1'Entité de Liaison des Droits de 1'Homme, contrairement à la CNDH est une institution à caractère «politique ». Alors que la CNDH est «apolitique ${ }^{2340}$. Elle n'est pas dotée d'une personnalité juridique et ne jouit pas d'une certaine indépendance. Tout de même, elle a un budget de fonctionnement qui émarge au Budget de l'Etat congolais ${ }^{2341}$. D'ailleurs, c'est le Premier ministre qui est le Président de son Comité de Pilotage, suivi du Ministre ayant en charge les droits humains comme Vice-Président ${ }^{2342}$. Cet organe se réunit en session ordinaire une fois par trimestre et en session extraordinaire chaque fois que les circonstances l'exigent ${ }^{2343}$. D'autres organes sont (article 4) : le Comité des experts composé des délégués des institutions et services membres (article 11) et le Secrétariat technique dirigé par un Secrétaire permanent assisté de cinq agents techniques et administratifs (article 12). Les membres de ces deux organes sont nommés, relevés de leurs fonctions et le cas échéant révoqués par le Ministre ayant les droits humains dans ses attributions, sur proposition de leurs structures d'origine pour le Comité des experts.

En termes d'effectivité sur le terrain, différentes activités sont menées par elle. L'on note par exemple ces recommandations contre l'instrumentalisation de la jeunesse à des fins électorales; pour la création de la $\mathrm{CNDH}$, pour le renforcement en capacités matérielles et

\footnotetext{
${ }^{2340}$ Lire l'article $1^{\text {er }}$ de la Loi organique $n^{\circ} 13 / 011$ du 21 mars 2013 portant institution, organisation et fonctionnement de la Commission nationale des Droits de l'Homme http://www.leganet.cd/Legislation/Droit\%20Public/DH/L.13.011.21.03.2013.htm (Source consultée le 25 octobre 2015).

${ }^{2341}$ Lire l'article 14 du Décret $n^{\circ} 09 / 35$ du 12 août 2009 portant création, organisation et fonctionnement de l'Entité de Liaison de Droits de l'l'Homme en République Démocratique du Congo in http://www.leganet.cd/Legislation/Droit\%20Public/DH/D.09.35.12.08.2009.htm (Source consultée le 25 octobre 2015).

${ }^{2342}$ Ibid., lire l'article 7.

${ }^{2343}$ Ibid., lire l'article 8.
} 
humaines du Secrétariat de l'Entité de Liaison des Droits de l'Homme; ou pour l'invitation à la Haute Cour Militaire de répondre au recours de la Voix des Sans Voix dans le dossier de l'assassinat de CHEBEYA ${ }^{2344}$; etc. Elle a consacré par exemple ses réunions des 14 et 15 février 2012 à la "Promotion et protection contre les violation des droits de l'homme après la période électorale et les défis majeurs en matière des droits de l'homme pour la nouvelle législature », avec une forte participation des institutions représentatives ${ }^{2345}$. Comme, on pourrait bien se rendre compte, il ne s'agit pas véritablement d'un mécanisme qui s'occuperait de la protection spéciale des enfants en période de conflits armés. Tout de même ces activités ne profitent non moins à la protection générale de l'enfant.

\section{B.3 La Commission Nationale de préparation et du suivi de l'Examen Périodique Universel de la République Démocratique du Congo}

La Commission Nationale de Préparation et de Suivi de l'Examen Périodique Universel de la République Démocratique du Congo ( Commission EPU/RDC ») est instituée par le Décret $n^{\circ}$ 09/36 du 12/08/2009 portant création, organisation et fonctionnement de la Commission Nationale de Préparation et de Suivi de l'Examen Périodique universel des Droits de l'Homme ${ }^{2346}$. Placée sous la coordination (article $1^{\mathrm{er}}$ ) et la Présidence (article 6) du Ministre des droits humains, la Commission EPU/RDC a pour mission la préparation et la soumission des Rapports nationaux des droits de l'homme de la RDC à l'Examen Périodique Universel du Conseil des droits de l'homme. Elle apporte son expertise à la présentation et à la défense desdits rapports. Elle fait en même temps le suivi de l'exécution des résolutions adoptées à la suite de l'Examen Périodique Universel et formule les recommandations au Gouvernement (article 3). Le Ministre du Genre, Famille et Enfant assure la Vice-Présidence (article 6).

Une fois de plus, il s'agit d'un «mécanisme général » qui ne s'occupe pas spécialement des questions des droits de l'enfant mais les traite dans la mesure où celles-ci relèvent des droits de l'homme.

\section{B.4 Le Comité Technique Interministériel d'élaboration et de suivi des rapports initiaux et périodiques des droits de l'homme (CTDH)}

Le CTDH est créé par l'arrêté n013/MDH/CAB/MBK/005/2001 du 13 décembre 2001 portant création d'un Comité Technique Interministériel d'élaboration et de suivi des rapports initiaux et périodiques des Droits de l'Homme, modifié en 2007 puis en 2009 par l'Arrêté

\footnotetext{
${ }^{2344}$ Rapport du Ministère de la justice et des Droits humains de la RDC de juillet 2011- février 2012, p. 17, point 79. Rappelons qu'à la suite des actes de violences et autres abus de droit que subissaient les défenseurs des droits humains dont le cas de l'assassinat du défenseur des droits humains Chebeya, la Cellule de défenseurs des droits humains a été créée par l' « arrêté $n^{\circ} 219 / C A B / J \& D H / 2011$ du 13 juin 2011 du Ministre de la Justice et Droits Humains comme mécanisme d'alerte idoine censé assurer la protection directe des défenseurs des droits de l'homme, en attirant l'attention des autorités concernées en cas de signalement de l'une ou l'autre violation des droits de l'homme ». Voy. Rapport du Ministère de la justice et des Droits humains de la RDC de juillet 2011- février 2012, p. 18 , point 82.

2345 Ibid. p. 17, point 80.

${ }^{2346}$ Lire Décret $n^{\circ} 09 / 36$ du 12/08/2009 portant création, organisation et fonctionnement de la Commission Nationale de Préparation et de Suivi de l'Examen Périodique universel des Droits de l'Homme in http://www.leganet.cd/Legislation/Droit\%20Public/DH/D.09.36.12.08.2009.htm (Source consultée le 25 octobre 2015).
} 
ministériel $\mathrm{n}^{\circ} 04 / \mathrm{CAB} / \mathrm{MDH} / 038 / \mathrm{KGB} / 2009$ du 12/06/2009 $9^{2347}$. Il s'agit d'une structure technique permanente du Gouvernement chargée de préparer et de rédiger tous les rapports initiaux et périodiques des droits de l'homme de la RDC vis-à-vis des instruments juridiques dont elle est partie. Il apporte son expertise à la présentation de ces rapports auprès des organes des traités concernés. Il assure le suivi (C'est cet aspect qui a été ajouté à la modification de 2009) et l'élaboration de l'application de ces traités ainsi que des recommandations des organes des traités (article 2 de l'arrêté ministériel du 12/06/2009...). Présidé par le Ministre des droits humains (article 7 de l'arrêté ministériel du 12/06/2009...), le CTDH est composé de 34 membres émanant de différents ministères dont deux du Ministère de Genre, Famille et Enfant (article 3 de l'arrêté ministériel du 12/06/2009...). Il n'incorpore pas dans sa composition les ONG des droits de l'homme mais leur accorde la possibilité de prendre part aux travaux à titre consultatif sur invitation du Ministre des Droits Humains (article 6 de l'arrêté ministériel du 12/06/2009...). Il s'agit d'un organe technique dépendant du Ministère des Droits humains. Il est doté d'un Secrétariat permanent (articles 8 et 9 de l'arrêté ministériel du 12/06/2009...).

Par ailleurs, pour ne pas chevaucher avec les travaux de la Commission EPU/RDC, huit membres du CTDH dont ceux du Ministère de Genre, Famille et Enfant sont repris dans le Comité des Experts de la Commission EPU/RDC (article 8 du Décret n ${ }^{\circ} 09 / 36$ du $12 / 08 / 2009 \ldots)$

En termes d'activités, concernant notamment les enfants, le Rapport du Ministre de la Justice et des droits humains de mars 2012 signifie notamment qu' «avec l'appui de l'UNICEF, quelques membres du Comité ont participé à la défense au Comité des Droits de l'Enfant à Genève, en date du 18 janvier 2012, du rapport initial de la RDC sur la mise en ouvre du Protocole facultatif concernant l'implication d'enfants dans les conflits armés ${ }^{2348}$. Ceci nous pousse d'ailleurs à faire remarquer que dans son Rapport initial adressé au Comité des droits de l'enfant au sujet de la mise en œuvre du Protocole facultatif concernant l'implication d'enfants dans les conflits armés, la RDC mentionnait que le Comité interministériel chargé de la conception et de l'orientation en matière de désarmement, démobilisation et réinsertion (CI-DDR) créé par décret $n^{\circ}$ 03/041 du 18 décembre 2003, est l'organisme gouvernemental responsable de l'application dudit Protocole ${ }^{2349}$. Cependant, la lecture du décret $n^{\circ} 03 / 041 \mathrm{du}$ 18 décembre 2003 portant sa création ${ }^{2350}$ ou du décret $n^{\circ} 09 / 17$ du 30 avril 2009 portant

2347 Arrêté ministériel $\mathrm{n}^{\circ} 04 / \mathrm{CAB} / \mathrm{MDH} / 038 / \mathrm{KGB} / 2009$ modifiant et complétant l'arrêté $\mathrm{n}^{\circ} 013 / \mathrm{MDH} / \mathrm{CAB} / \mathrm{MBK} / 005 / 2001 \mathrm{du} 13$ décembre 2001 portant création d'un comité interministériel d'élaboration et de suivi des rapports initiaux et périodiques des droits de l'homme in http://www.journalofficiel.cd/jordc/resloireglement.php?id_terme_initial=\&id_emetteur=\&mot titre=\&jour_sig nature $=12 \&$ mois $\_$signature $=06 \&$ annee $\_$signature $=2009 \&$ id nature $=51 \&$ lib_emetteur $=M D H \&$ lib $\_$terme initial $=$ \&chercher=Rechercher (Source consultée le 26 octobre 2015).

${ }^{2348}$ Rapport du Ministère de la justice et des Droits humains de la RDC de juillet 2011- février 2012, op. cit., p.19, point 94 .

${ }^{2349}$ Voy. Comité des droits de l'enfant, Examen des Rapports présentés par les Etats parties en application du paragraphe 1 de l'article 8 du Protocole facultatif à la Convention relative aux droits de l'enfant, concernant l'implication d'enfants dans les conflits armés, Rapports initiaux des Etats parties attendus en 2004, République Démocratique du Congo, CRC/C/OPAC/COD/1, 18 avril 2011, op. cit., p. 22, §92.

${ }^{2350}$ Décret $n^{\circ} 03 / 041$ du 18 décembre 2003 portant création du Comité interministériel chargé de la conception et de l'orientation en matière de désarmement, de démobilisation et réinsertion, in http://www.leganet.cd/Legislation/Droit\%20Public/desarmement/D.03.41.18.12.2003.htm (Source consultée le 21 décembre 2015). 
modification du premier décret n'atteste nullement cette affirmation ${ }^{2351}$.

Il ressort de tout ce qui précède que les organes ci-dessus présentés sont complémentaires dans leurs différentes missions ou attributions. La CNDH demeure un organe apolitique et indépendant. Alors que les trois autres sont politiques et dépendent notamment du Ministère des Droits humains. L'Entité de Liaison des Droits de l'homme est l'organe politique supérieur de mise en œuvre des droits de l'homme. L'Evaluation des activités nationales de mise en œuvre des droits de l'homme lui revient. Elle veille à ce titre à l'élaboration des rapports initiaux et périodiques reconnue au CTDH et à la Commission EPU/RDC (Voy. l'article 3 du Décret n09/35 du 12 août 2009 [...]. L'Entité de Liaison veille en outre au respect par les autres parties des traités des droits de l'homme. Ce qui relève d'un aspect extérieur et concourt mieux avec l'obligation de "faire respecter». Viendra ensuite la Commission EPU/RDC, instituée par Décret du Premier ministre autant que l'Entité de Liaison, qui s'attèle essentiellement à tout ce qui concerne l'Examen Périodique Universel devant le Conseil des droits de l'homme. Enfin, le CTDH créé par arrêté ministériel se charge des rapports initiaux et périodiques des droits de l'Homme de la RDC.

Bien que la question du DIH ne soit pas expressément visée par les actes constitutifs de ces organes politiques des droits de l'homme, il y a lieu de dire que les différentes violations des droits de l'homme en période des hostilités à l'Est du pays n'échapperont pas ces organes dans leurs rapports. Bien plus, à la suite des organes universels des droits de l'homme tenant compte de plus en plus des questions de DIH dans leurs activités, il y a lieu de voir ces organes politiques congolais des droits de l'homme s'apprêter à cet exercice. On en est encore loin...

\section{§2. Mécanismes non gouvernementaux de protection des enfants en situation de conflits armés en RDC}

«Depuis le début des années 1990, un important dispositif humanitaire comprenant agences internationales et ONG a été constamment déployé dans la région des Grands Lacs ${ }^{2352}$. Il suffit de se retrouver dans des villes, localités ou villages «martyrisés » par des conflits armés à l'Est de la RDC pour se rendre compte du rôle crucial que jouent les ONG, locales, nationales et internationales, pour répondre aux besoins primaires des victimes. Ces ONG se retrouvent dans différents secteurs de la vie sociale dont ceux les plus touchés par les catastrophes de ce cycle de violences en RDC, près de deux décennies durant. D'autres acteurs de la société civile tels que les institutions religieuses s'associent à cette mission salvatrice (cf. infra).

Ces ONG «portent secours à des groupes spécifiques, tels que les enfants, les femmes, les personnes âgées, les handicapés, les réfugiés ou déplacés internes [...]. Mais leur rôle ne se

\footnotetext{
${ }^{2351}$ Décret $n^{\circ} 09 / 17$ du 30 avril 2009 modifiant et complétant le décret $n^{\circ} 03 / 041$ du 18 décembre 2003 portant création du Comité interministériel chargé de la conception et de l'orientation en matière de désarmement, démobilisation et réinsertion, in http://www.leganet.cd/Legislation/JO/2009/D.09.17.30.04.09.htm (Source consultée le 21 décembre 2015).

${ }^{2352}$ BRADOL, Jean-Hervé et VIDAL, Claudine, «Les attitudes humanitaires dans la région des Grands Lacs », in Politiques internationales dans la région des Grands Lacs, Politique Africaine, 68, décembre 1997, p. 69.
} 
limite plus à celui de simple fournisseur d'aide médicale et matérielle ; elles associent progressivement à leurs opérations d'urgence des démarches visant à protéger les victimes du conflit ${ }^{2353}$. En cela, parmi elles, certaines se préoccupent principalement des questions des droits de l'homme voire du DIH et dénoncent fréquemment des violations y commises, par des publications des rapports. C'est notamment le cas de Human Rights Watch, Amnesty international, etc. ${ }^{2354}$ Ces ONG dites «de défense des droits de l'homme » œuvrent à côté de nombreuses autres ONG «humanitaires », « urgentistes » ou «développementalistes » ${ }^{2355}$ voire des agences humanitaires onusiennes.

En effet, point n'est besoin de rappeler que les conflits armés se déroulant en RDC, depuis bientôt deux décennies, ont pris stratégiquement pour cible les personnes civiles, plus précisément celles présentant des vulnérabilités dont les femmes et les enfants. Atteindre ces couches sociales, c'est atteindre indirectement des familles, des communautés ou des populations. Les différents crimes (voy. infra) commis systématiquement sur divers champs de bataille en RDC, dont ceux contre l'enfant, ne seraient pas connus du grand public sans l'apport de ces ONG. Ces dernières, surtout celles internationales, sont dotées d'expertises et de moyens conséquents pour mener à bien des investigations dans ces milieux périlleux de l'Est de la RDC. En dépit des critiques qui sont formulées à leur endroit ${ }^{2356}$, ces ONG font connaître dès les premières heures au grand public des crimes odieux commis sur des enfants $^{2357}$. Ces dénonciations ne font pas tarder généralement des réactions justificatrices ou contestatrices des autorités - gouvernementales ou intergouvernementales - qui, généralement, ne supportent pas d'être couvertes d'opprobre. En cela, il faudrait également voir un rôle dissuasif voire préventif ${ }^{2358}$ afin de ne plus tomber dans le renouvellement des crimes.

Il n'est donc généralement pas évident pour la presse de couvrir les conflits armés. Non seulement que ceux-ci sont dangereux à couvrir - au regard notamment des risques de prise d'otage ou d'assassinat voire d'action publique (action en responsabilité pénale) émise contre les journalistes ou reporters - mais également de sérieuses questions des moyens et donc du professionnalisme se posent pour réaliser un tel travail ${ }^{2359}$. Face à ces sérieuses difficultés d'information qui entraînent l'absence de la presse sur le terrain, ce sont des ONG « qui ont le

\footnotetext{
${ }^{2353}$ BETTATI, Mario, Droit humanitaire, $1^{\text {re }}$ édition, Dalloz, op.cit., p. 255.

2354 Ibid.

${ }^{2355}$ Sur différents types d'ONG, lire notamment BELANGER, Michel, Droit international humanitaire général, op.cit., pp. 108-109.

${ }^{2356}$ Voy. supra le paragraphe relatif aux Organisations non-gouvernementales comme mécanismes de promotion de la protection de l'enfant en situation de conflits armés

${ }^{2357}$ C'est le cas de nombreux témoignages rapportés par des ONG, dès les premières années du conflit en RDC, sur des situations de déportation d'enfants vers les Républiques de l'Ouganda et du Rwanda comme le reconnaît le gouvernement congolais. Voy. République Démocratique du Congo, Ministre des droits humains, La guerre d'agression en République Démocratique du Congo. Trois ans de massacre et de génocide "à huis clos», op.cit., p. 34.

${ }^{2358}$ Lire d'ailleurs dans ce sens Sir Nigel RODLEY, « NGOS and the prevention and repression of torture » in COHEN-JONATHAN et J.F. FLAUSS, (éd.), Les Organisations non gouvernementales et le droit international des droits de l'homme. International human rights law and non governemental organization, op.cit., pp. 103115.

${ }^{2359}$ Voy. MARTHOZ, Jean-Paul, «Responsabilité de protéger et devoir d'informer », in FAYER-STERN, Danièle, SANCHEZ, Belen et SCHMITZ, Marc (Coord.), Le Viol, une arme de terreur. Dans le sillage du combat du Docteur Mukwege, éditions Fédération Wallonie-Bruxelles, Grip, Mardaga, 2015, p. 111.
} 
plus souvent servi d'agence de presse, de lanceurs d'alerte, pour les médias traditionnels $»^{2360}$. Ainsi, ces ONG «disposent d'une expertise et d'une méthodologie confirmée qui leur permettent de recueillir les informations. Leurs équipes sont formées pour mener des entretiens respectueux et rigoureux avec les victimes, évaluer l'ampleur des violences et identifier les assaillants ${ }^{2361}$. Leur influence permet également qu'elles soient entendues dans les milieux de décideurs politiques. Elles forment ainsi une opinion publique non négligeable dont le rôle en DIH est prouvé ${ }^{2362}$.

Bien plus, les alertes qu'elles font constituent généralement à l'égard des juridictions compétentes - nationales et internationales - un pas vers la mise en branle du processus de la responsabilité pénale ${ }^{2363}$. C'est notamment le cas pour des affaires - Thomas Lubanga Dyilo, Bosco Ntaganda, Matthieu Ngundjolo, Germain Katanga - portées devant la CPI et concernées par des questions des crimes de guerre ou crimes contre l'humanité impliquant notamment des enfants (cf. infra). Le travail que réalisent des ONG est aussi remarquable au niveau de l'amélioration du droit congolais. Une ONG telle que RCN Justice \& Démocratie organise régulièrement des sessions de formation ou de recyclage des personnels judiciaires sur différentes questions spécifiques dont celles des droits de l'enfant ${ }^{2364}$. Depuis $2000, R C N$ Justice \& Démocratie soutient le système judiciaire congolais pour la restauration de l'Etat de droit en $\mathrm{RDC}^{2365}$.

Toujours sous l'angle d'amélioration du droit national, différentes campagnes de sensibilisations menées par des ONG en faveur des droits des personnes vulnérables dont les enfants et femmes ont abouti notamment à l'adoption des lois sur « les violences sexuelles ${ }^{2366}$ : la loi $n^{\circ} 06 / 018$ du 20 juillet 2006 modifiant et complétant le décret du 30 janvier 1940 portant Code pénal congolais et la loi $n^{\circ} 06 / 019$ du 20 juillet 2006 modifiant et

\footnotetext{
${ }^{2360}$ Ibid.,p. 112.

${ }^{2361}$ Ibid., p. 111.

${ }^{2362}$ Voy. SANDOZ, Yves (dir.), Les Moyens de mise en æuvre du droit international humanitaire. Etat des lieux, Analyse des problèmes et éléments de réflexion, op.cit., p. 100.

${ }^{2363}$ Lire avec intérêt OLIVIER, Clémentine, «Les Organisations non gouvernementales et la répression pénale internationale », «art.cit. », in COHEN-JONATHAN et J.F. FLAUSS, (éd.), Les Organisations non gouvernementales et le droit international des droits de l'homme. International human rights law and non governemental organization, op.cit., pp. 117-155. et Sir Nigel RODLEY, «NGOS and the prevention and repression of torture » "art.cit. », in COHEN-JONATHAN et J.F. FLAUSS, (éd.), Les Organisations non gouvernementales et le droit international des droits de l'homme. International human rights law and non governemental organization, op.cit., pp. 103-115.

${ }^{2364}$ Voy. par exemple sa session de formation des formateurs sur la nouvelle loi de protection de l'enfant à Kinshasa en 2009 (cf. Rapport d'Activités 2009. Bulletin n³4. Quatrième trimestre 2010, p. 17). Les différents rapports de RCN Justice et Démocratie sont consultables ici : http://www.rcn-ong.be/-Rapports-d-activites?lang=fr (Source consultée le 20 octobre 2015).

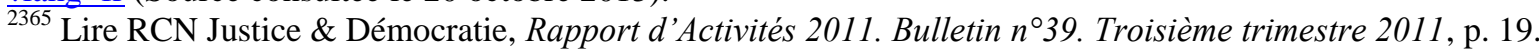

${ }^{2366}$ La loi n ${ }^{\circ} 06 / 018$ du 20 juillet 2006 modifiant et complétant le décret du 30 janvier 1940 portant Code pénal congolais ne définit pas ces termes si ce n'est qu'énumérer les infractions qui en font parties. Sur le plan international, le Protocole de Maputo de 2003 ne définit par ces termes mais plutôt les termes violence à l'égard des femmes en son article $1^{\mathrm{er}}$, $\mathrm{k}$. Pour l'UNHCR : «Les termes de violence sexuelle, violence sexiste et violence à l'égard des femmes sont communément utilisés de manière interchangeable. Tous désignent des violations des droits fondamentaux de l'homme qui perpétuent des rôles sexuellement stéréotypés, violations qui nient la dignité humaine et l'autodétermination de l'individu et font obstacle au développement humain. Ils désignent les préjudices physiques, sexuels et psychologiques qui renforcent la subordination féminine et perpétuent le pouvoir et la domination masculins ». Voy. UNHCR, La Violence sexuelle et sexiste contre les réfugiés, les rapatriés et les personnes déplacées. Principes directeurs pour la prévention et l'intervention, mai 2003, p.10.
} 
complétant le décret du 06 août 1959 portant code de procédure pénale congolais. C'est également le cas de la loi ${ }^{\circ} 09 / 001$ du 10 janvier 2009 portant protection de l'enfant (cf. supra). Ces textes législatifs assurent la protection de l'enfant. D'où, l'intérêt d'examiner le rôle des ONG sur cette épineuse question de «violences sexuelles » dont les enfants sont largement victimes durant ces conflits armés.

En effet, des fortes mobilisations sont observées de la part des ONG sur cette problématique. Celles-ci se sont regroupées sous différentes plateformes au plan local, national, et international pour faire entendre leurs voix. Rappelons que le Réseau National pour le Développement de la Femme (RENADEF) répertoriait en 2011 un total d'au moins 300 ONG œuvrant dans le domaine de violences sexuelles en RDC, dont une grande partie à l'Est du Pays $^{2367}$. Il s'agit, entre autres, d'un thème perçu comme générateur de financements importants pour les $\mathrm{ONG}^{2368}$. Ce qui expliquerait aussi l'engouement des ONG pour ce secteur. A titre exemplatif, pour l'année 2010, les financements pour des projets axés sur ces secteurs étaient estimés à 86,4 millions de dollars américains, presque l'équivalent du budget total alloué au secteur de la santé en RDC sans compter les 17 millions de dollars du Secrétaire d'Etat américain promis à l'Hôpital Panzi à Bukavu et Heal Africa à Goma, la même année ${ }^{2369}$.

De ces mobilisations, les résultats observés sont au plan international des résolutions ${ }^{2370}$, la ratification des conventions internationales qui assurent la protection des femmes dont certains aspects restent bénéfiques aux jeunes filles ou enfants. C'est le cas de la ratification le 09 juin 2008 suivie du dépôt d'instruments le 09 février 2009 par la RDC du Protocole à la Charte africaine des droits de l'Homme et des peuples relatifs aux droits de la femme ${ }^{2371}$ dit «Protocole de Maputo ». Ratification qui a bénéficié non moins de campagnes des ONG dont celle dénommée «L'Afrique pour les droits des femmes. Ratifier er respecter » ${ }^{2372}$ pilotée par une coalition de six $\mathrm{ONG}^{2373}$ au plan africain et relayée au plan national congolais par la Ligue des femmes pour le Développement et l'Education à la Démocratie (LIFDED), le Groupe Lotus, l'Association Africaine de Défense des Droits de l'Homme (ASADHO) et la Ligue des Electeurs (LE). Il sied de rappeler que le Protocole de Maputo contient une disposition très importante pour la protection spéciale de la jeune fille, et de l'enfant en général. Il s'agit de son article 11, §4 qui dispose : «Les États prennent toutes les mesures nécessaires pour qu'aucun enfant, surtout les filles de moins de 18 ans, ne prenne part aux hostilités et, en particulier, à ce qu'aucun enfant ne soit enrôlé dans l'armée ${ }^{2374}$. Cet article

\footnotetext{
2367 «Le Renadef dénombre 300 ONG des droits des femmes en RDC », in http://www.radiookapi.net/actualite/2012/02/21/le-renadef-denombre-300-ong-des-droits-des-femmes-en-rdc (Source consultée le 13 octobre 2015).

${ }^{2368}$ BRAECKMAN, Colette, L'Homme qui répare les femmes. Le combat du Docteur Mukwege, op. cit., 129. 2369 Ibid.

${ }^{2370}$ Nombreuses sont des résolutions de l'ONU dont principalement celles du CS/NU qui condamnent à plusieurs reprises des cas de violences sexuelles exercées sur des femmes dont les jeunes filles ou enfants, en particulier (cf. supra et infra), non sans influences des organisations humanitaires.

${ }^{2371}$ Cette convention est également ratifiée par l'Ouganda le 22 juillet 2010 et par le Rwanda le 25 juin 2004.

2372 Voy. http://www.africa4womensrights.org/ (Source consultée le 14 octobre 2015).

${ }^{2373}$ Fédération Internationale des Ligues des Droits de l'Homme (FIDH), African Centre for Democracy and Human Rights Studies (ACDHRS), Femmes Africa Solidarité (FAS), Women's Aid Collective (WACOL), Women in Law and Development in Africa (WILDAF) et Women and Law in South Africa (WLSA).

${ }^{2374}$ Lire l'article 11, $\$ 4$ du Protocole à la Charte africaine des droits de l'homme et des peuples relatif aux droits
} 
est une avancée significative par rapport à l'état actuel du droit international relatif à la protection de l'enfant en période de conflits armés (cf. supra). En outre, il existe une autre disposition importante qui est l'article $14 \$ 2, c$ qui dispose : «2. Les États prennent toutes les mesures appropriées pour : [... c) protéger les droits reproductifs des femmes, particulièrement en autorisant l'avortement médicalisé, en cas d'agression sexuelle, de viol, d'inceste et lorsque la grossesse met en danger la santé mentale et physique de la mère ou la vie de la mère ou du foetus ». Cet article permettrait de résorber précisément la question des enfants issus des viols notamment pendant les conflits armés. Sur la base de l'ancienne législation, la femme ne devrait pas avorter en dépit de viol survenu sur elle. Elle devrait donc supporter son «fardeau», son enfant issu de viol. Celui-ci lui rappelait le malheureux événement. Mal vu voire rejeté par la société, un tel enfant présente le risque d'être victime de viol $^{2375}$ ou encore auteur potentiel de viol $^{2376}$. Ainsi, une telle disposition serait un point de départ de solution à de tels problèmes de société. Rappelons toutefois que certaines femmes ou filles acceptent la situation comme telle : «Même après avoir été violées, elles montrent leurs enfants respectifs en disant "c'est mon trésor " [...] Même le nom que les femmes donnent à l'enfant du viol a un sens : ils s'appellent Espérance, Dieu Merci ou Espoir.... ${ }^{2377}$.

Cependant, l'article $14 \S 2, c$ est une disposition dont la formulation ne revêt pas un caractère d'applicabilité directe (disposition claire, précise et inconditionnelle). Ainsi, elle ne pourrait donc pas être évoquée par un sujet devant les instances judiciaires au profit de la femme. N'étant pas inconditionnelle, ladite disposition nécessite sa mise en œuvre par l'Etat Congolais. Il revient à celui-ci de prendre des mesures appropriées notamment législatives en autorisant l'avortement.

Sous le registre de campagnes, il y a aussi lieu d'épingler, par exemple, les appels de mai 2003 «des ONG Oxfam, Human Rights Watch, Amnesty international pour le déploiement d'une force de réaction rapide pour protéger les civils en Ituri ${ }^{2378}$. Ce qui aboutira effectivement au déploiement d'une force multinationale, Opération Artémis, à Bunia de juin à septembre $2003^{2379}$.

Au plan national, les différentes campagnes des ONG ont occasionné l'amélioration du cadre législatif et réglementaire dont l'adoption de deux lois précitées qui protègent l'enfant notamment la jeune fille à travers la répression des violences sexuelles et la loi sur la protection de l'enfant de 2009. Conscientes du fait que rien n'est acquis dans ce pays, les ONG ne cessent de militer pour le respect sinon la mise en œuvre de ces textes législatifs. En ce sens, des activités de sensibilisation sont menées par des ONG s'occupant de la protection

\footnotetext{
de la femme, in http://www.achpr.org/fr/instruments/women-protocol/\#14 (Source consultée le 14 octobre 2015). ${ }^{2375}$ Lire la préface de Denis MUKWEGE, «Dénoncer l'inacceptable et briser l'indifférence », de FAYERSTERN, Danièle, SANCHEZ, Belen et SCHMITZ, Marc (Coord.), Le Viol, une arme de terreur. Dans le sillage du combat du Docteur Mukwege, op.cit., p. 11.

${ }^{2376}$ Voy. BRAECKMAN, Colette, L'Homme qui répare les femmes. Le combat du Docteur Mukwege, op. cit., 124.

${ }^{2377}$ Ibid., p. 145-146

2378 GOEMANS, François, «République démocratique du Congo - Chronologie des événements majeurs et évolution du mandat de la Monuc », in ZEEBROEK, Les Humanitaires en guerre. Sécurité des travailleurs humanitaires en mission en RDC et au Burundi, GRIP, Bruxelles, 2004, p. 24. ${ }^{2379}$ Ibid.
} 
de l'enfant en période de conflits armés à l'endroit de forces armées, groupes armés, Police, autorités politico-administratives ou tout autre service ou institution impliqués d'une manière ou d'une autre dans la situation des enfants en conflits armés. Ainsi, lors des journées internationales des enfants soldats (12 février) ou des droits de l'enfant (20 novembre) ou encore de la journée de l'enfant africain (16 juin) des activités et manifestations dans ce sens sont organisées dans différentes villes du pays. C'est notamment le type d'activités qu'organisent en chacune de ces journées les ONG Bureau des Volontaires pour l'enfance et la Santé (BVES) et Child Soldiers International à Bukavu ${ }^{2380}$. Bien plus, des rappels au respect des droits fondamentaux ou des règles de protection de l'enfant en temps de conflits armés sont régulièrement entrepris par des associations confessionnelles dont 1'Eglise catholique réunie au sein de la Conférence Episcopale Nationale du Congo (CENCO $)^{2381}$.

Bien plus, de nombreux besoins des enfants victimes des conflits armés sont pris en charge par différentes «ONG humanitaires ou urgentistes » ou «développementaliste ». Lesquelles travaillent en collaboration avec des agences humanitaires onusiennes. C'est le cas précisément du Bureau de la Coordination des affaires humanitaires (OCHA) qui travaille depuis 1998 en RDC - aux côtés des ONG - dans la collecte, l'analyse et le partage des informations avec la communauté humanitaire afin d'aboutir à des réponses humanitaires basées sur les principes humanitaires, les droits de l'homme et le DIH. Il gère le Fonds Commun humanitaire (FIH) en coordination avec le Programme des Nations Unies pour le Développement (PNUD). Il fournit un financement simple et prévisible aux besoins humanitaires les plus critiques. Un mécanisme de financement humanitaire est lancé en 2006 en RDC à cet effet ${ }^{2382}$.

Ces ONG «humanitaires », « urgentistes » ou «développementalistes se préoccupent de différentes questions impliquant les enfants dans le cadre de conflits armés dont principalement celles de santé, d'éducation voire l'épineuse problématique de démobilisation et de réinsertion des enfants recrutés et utilisés par des groupes et forces armés. C'est ainsi qu'elles apportent des aides médicales, matérielles ou psychologiques aux enfants victimes des atrocités et ne cessent de battre campagne pour la démobilisation des enfants se trouvant dans des forces ou groupes armés. A cet effet, il y a lieu de mentionner par exemple : Médecins du Monde ${ }^{2383}$, Médecins Sans Frontières ${ }^{2384}$, War child International ${ }^{2385}$, Save The

\footnotetext{
${ }^{2380}$ Voy. http://www.child-soldiers.org/francais.php (Source consultée le 17 octobre 2015)

${ }^{2381}$ Voy. Comité Permanent des Evêques de la CENCO, « La RD Congo pleure ses enfants, elle est inconsolable (cf. Mt 2, 8). Déclaration du 13 novembre 2008 du Comité Permanent des Evêques sur la guerre dans l'Est et dans le Nord-Est de la RD Congo» in Congo-Afrique XLVII Année, (Décembre 2008) n430, pp. 791-793. Voy. aussi CENCO, Tous, pour les intérêts supérieurs de la Nation. Message des Evêques de la CENC aux fidèles catholiques et aux hommes de bonne volonté, Edition du Secrétariat Général de la CENC, KinshasaGombe, 2001, §§ 3-4 téléchargeable ici http://www.cenco.cd/?page=documents (Source consultée le 18 octobre 2015 à 15h58') ou CENCO, "Voici le temps favorable, voici maintenant le jour du salut » (2 Co 6, 2). Le Congo nous appartient. Déclaration du Comité Permanent des Evêques de la RDC sur la situation politique actuelle. Aux fidèles et aux hommes de bonne volonté, 2005, § 5 téléchargeable ici http://www.cenco.cd/?page=documents (Source consultée le 18 octobre 2015).

${ }^{2382}$ Bureau de la Coordination des affaires humanitaires in http://cd.one.un.org/content/unct/rdc/fr/home/apropos/ocha.html (Source consultée le 22 février 2016).

2383 Voy. par exemple ses récents projets sur la RDC: «Congo: Booster les soins mère-enfant», in http://www.medecinsdumonde.be/wereld/congo-booster-les-soins-mère-enfant ou «Congo : Aux côtés du Dr. Mukwege contre les violences sexuelles », in http://www.medecinsdumonde.be/wereld/congo-aux-côtés-du-drmukwege-contre-les-violences-sexuelles (Sources consultées le 21 octobre 2015).
} 
Children $^{2386}$, S.O.S Villages Enfants ${ }^{2387}$, Child Soldiers International ${ }^{2388}$ (CSI) (Enfants Soldats International), Watch List on Children and Armed conflict ${ }^{2389}$, Bureau International Catholique de 1'Enfance $(\mathrm{BICE})^{2390}$, Bureau des Volontaires pour l'enfance et la Santé $(\mathrm{BVES})^{2391}$, etc.

Pour reprendre quelques unes, au plan national, le BVES est une des principales ONG nationales œuvrant dans le domaine de protection de l'enfant et de ses droits. Créé à Bukavu le 06 mars 1992, le BVES se préoccupe de l'effectivité de la Convention relative aux droits de l'enfant et de ses protocoles voire d'autres instruments internationaux, régionaux et nationaux relatifs aux droits et à la protection de l'enfant. En ce sens, différentes activités ${ }^{2392}$ de prévention, de surveillance, de plaidoyer, d'accueil et prise en charge humanitaire, de réinsertion, de coordination des ONG et de renforcement des capacités sont menées par lui ${ }^{2393}$. Ces actions de prévention éveillent indubitablement la conscience des populations concernées et les renforcent face aux arguments manipulatoires des forces ou groupes armés dans leurs propagandes de guerre (ex : Propagande de haine ethnique) ${ }^{2394}$. Pour sa part, le Bureau International Catholique de l'Enfance a une représentation nationale en RDC dénommée Bureau National Catholique de l'Enfance (BNCE-RDC). Celui-ci œuvre essentiellement dans la ville de Kinshasa et dans les Provinces de Kasaï-Oriental et KasaïOccidental. Il s'y occupe de la promotion et de la protection des droits de différents types d'enfants dont les enfants démobilisés depuis $1996^{2395}$.

Concernant des ONG internationales, par exemple, War Child UK, en juin 2014, mettait un

2384 Voy. par exemple sa prise en charge de 127 femmes (âgées de 14 à 70 ans) agressées sexuellement à Kikamba (Sud-Kivu) au mois de mai 2015. Kikamba, territoire où œuvre MSF depuis 2010, Voy. http://www.msf.fr/actualite/articles/rdc-127-femmes-agressees-prises-en-charge-msf (Source consultée le 21 octobre 2015) ; Voy. d'autres projets sur la RDC, in http://www.msf.fr/pays/rdc (Source consultées le 21 octobre 2015).

${ }^{2385}$ Voy ; http://www.warchild.org/ (Source consultée le 17 octobre 2015).

${ }^{2386}$ Voy. https://www.savethechildren.net/ (Source consultée le 17 octobre 2015). Save the Children travaille en RDC depuis 1994. Faisant usage de l'approche holistique, en collaboration avec des partenaires locaux et internationaux, cette ONG vient en aide aux enfants pour faciliter leur accès à l'éducation et aux soins de santé. Il soutient la protection des enfants contre les exploitations et les abus. En 2012, par exemple, 391.931 bénéficiaires directs de ses services ont été dénombrés dont 250.190 enfants, voy. http://www.savethechildren.org/site/c.8rKLIXMGIpI4E/b.9084453/k.A733/Democratic_Republic of Congo.ht m (Source consultée le 18 octobre 2015)

${ }^{2387}$ Lire par exemple son Rapport annuel 2014, Aucun enfant ne devrait grandir seul, notamment les pages 16 à 19 consacrées à la situation de la RDC. Cette ONG œuvre en RDC depuis 1989. Pour l'année 2014, elle a soutenu des familles vulnérables pour qu'elles veillent elles-mêmes sur leurs enfants (voy. p.18). En cela, pour la ville de Bukavu 700 enfants ont pu être scolarisés. Ils ont eu accès aux soins de santé et connaissent leurs droits fondamentaux (voy. p.19).

${ }^{2388}$ Voy. http://www.child-soldiers.org/francais.php (Source consultée le 17 octobre 2015)

${ }^{2389}$ Lire par exemple son rapport sur l'Impact des conflits armés sur les enfants en République démocratique du Congo (RDC), New-York, juin 2003, ou encore ses rapports mensuels in www.watchlist.org (Source consultée le 17 octobre 2015)

2390 Voy. http://www.bice.org/fr/ (source consultée le 01 novembre 2015).

${ }^{2391}$ Voy. http://www.bves-rdc.org/Default.htm (Source consultée le 17 octobre 2015)

2392 Voy. par exemple par ses différentes activités menées in http://www.bves-rdc.org/Default.htm ou http://www.bves-rdc.org/News.htm (Sources consultées le 17 octobre 2015)

${ }^{2393}$ Voy. http://www.bves-rdc.org/Mission.htm (Source consultée le 17 octobre 2015)

2394 LEGROS, Pierre et LIBERT, Marianne, L'Exigence humanitaire. Le devoir d'ingérence, Ed. Lpm, Paris, 2000 , p. 191.

${ }^{2395}$ Voy. http://www.bice.org/fr/bnce-rdc et http://www.bice.org/fr/bice-en-afrique/ (Sources consultées le 01 novembre 2015). 
numéro téléphonique (117) gratuit à la disposition des enfants de Goma et de Kinshasa pour leur servir de faire part de cas de violences dont ils seraient victimes, y compris les cas d'enrôlement. A travers les services d'assistance téléphonique, ces enfants sont mis en contact avec des conseillers spécialisés pour une prise en charge appropriée ${ }^{2396}$. Cette initiative s'inscrit dans le cadre du projet «Protégeons nos enfants » piloté par War child UK et le Ministère congolais des affaires sociales, humanitaires et de solidarité nationale, et financé par l'Union européenne. Comme un des objectifs de ce projet, il y a la prévention et la sensibilisation à la protection de l'enfant ${ }^{2397}$. War child UK offre des formations aux membres de forces armées, aux policiers voire aux religieux et enseignants sur des questions de violences sexuelles contre les filles notamment. Il vient en renfort aux autorités locales sur ces questions. Euvrant en RDC depuis 2003 et travaillant avec des partenaires locaux ${ }^{2398}$, War child UK dispose également d'une cartographie des organismes et institutions de protection des enfants, notamment de Goma et de Kinshasa, afin d'identifier leurs lacunes et de leur venir en aide ${ }^{2399}$. War child Holland, pour sa part, se consacre également à la protection des enfants victimes des conflits armés en créant des opportunités économiques comme alternative à la vie d'enfant soldat voire comme possibilité de réinsertion sociale notamment au Sud-Kivu ${ }^{2400}$. Indépendants mais partenaires égaux avec des objectifs communs, War child UK et War Child Holland font parties de War Child International ${ }^{2401}$.

$\mathrm{Au}$ regard de ce qui précède, pour pouvoir fonctionner efficacement, l'idéal serait que ces ONG contribuent à la création d'un « espace humanitaire ${ }^{2402}$. Celui-ci se présente comme un espace où l'action humanitaire ne risque pas d'être instrumentalisée par des groupes ou des gouvernements $^{2403}$. Il faudrait pour cela garantir un certain nombre de conditions : «pouvoir parler librement avec les personnes concernées, évaluer leurs besoins et les satisfaire sans subir de pressions, vérifier que les secours arrivent bien à leurs destinataires ${ }^{2404}$. En cela, l'action humanitaire, fondée sur la défense des droits fondamentaux, est crédible et justifiée ${ }^{2405}$.

A dire vrai, tout ceci est l'expression du « droit d'initiative humanitaire ». Et comme le dit si bien, Robert Kolb, à ce sujet vis-à-vis du CICR : «La lettre étriquée et desséchée tuerait ici manifestement l'esprit inquiet et généreux ${ }^{2406}$.

\footnotetext{
2396 Voy. https://www.warchild.org.uk/what-we-do/democratic-republic-of-congo (Source consultée le 17 octobre 2015).

2397 Lire «RDC: un numéro gratuit pour aider les enfants victimes de violences », in http://reliefweb.int/report/democratic-republic-congo/rdc-un-num-ro-gratuit-pour-aider-les-enfants-victimes-deviolences (Source consultée le 17 octobre 2015).

${ }^{2398}$ Cuvre de Suivi, Education, Protection des enfants de la Rue ; Parlement Jeunes ; Don Bosco ; Concert d'Actions pour Jeunes et Enfants Défavorisés; Union pour la Paix et la Promotion des Droits de l'Enfant au Congo. Voy. https://www.warchild.org.uk/what-we-do/democratic-republic-of-congo (Source consultée le 17 octobre 2015).

2399 Ibid.

${ }^{2400}$ Voy. http://www.warchild.nl/land/dr-congo (Source consultée le 17 octobre 2015).

${ }^{2401}$ Voy. https://www.warchild.org.uk/about/war-child-international (Source consultée le 17 octobre 2015).

2402 BRADOL, Jean-Hervé et VIDAL, Claudine, «Les attitudes humanitaires dans la région des Grands Lacs », in Politiques internationales dans la région des Grands Lacs, Politique Africaine, op.cit., p. 69.

${ }^{2403}$ Ibid.

2404 Ibid.

${ }^{2405}$ LEGROS, Pierre et LIBERT, Marianne, L'Exigence humanitaire. Le devoir d'ingérence, op.cit., p. 190,

${ }^{2406}$ KOLB, Robert, Ius in bello. Le droit international des conflits armés, $2^{\mathrm{e}}$ édition, op.cit., p. 463.
} 
Par ailleurs, les missions de ces ONG dans ces zones dangereuses ne sont pas toujours facilitées en dépit de l'expertise et du professionnalisme dont elles font généralement preuve. D'une part, «les dispositions des responsables politiques locaux à l'égard des équipes travaillant sur place ont, selon les conjonctures, facilité ou au contraire entravé l'accès aux victimes $^{2407}$, jusqu'à, dans ce dernier cas, menacer de tuer et même tuer aussi bien le personnel national que le personnel international ${ }^{2408}$. D'autre part, les membres des ONG sont obligés de coopérer avec de nombreux groupes armés ou miliciens qui œuvrent dans la zone au péril de leur vie. Sous ce registre, il y a lieu de faire mention de l'assassinat le 26 avril 2001 par des inconnus en Ituri de six membres du CICR à bord de deux véhicules portant l'emblème de la Croix-Rouge ${ }^{2409}$, ou de série d'attaques lancées contre les humanitaires dans la collectivité de Walendu Bindi (Territoire d'Irumu en Ituri, Province orientale) par les miliciens de la Force de Résistance Patriotique de l'Ituri (FRPI) dont l'embuscade tendue aux quatre agents - dépouillés et brutalisés ${ }^{2410}$ - de Médecins Sans Frontières Suisse dans leur véhicule le 19 octobre 2014. Attaque intervenue quatre mois après le pillage du véhicule de l'ONG Solidarité, par les mêmes miliciens ${ }^{2411}$. Ou encore divers cas d'attaques du personnel humanitaire que ne cesse de déplorer le $\mathrm{CS} / \mathrm{NU}^{2412}$. Bien plus, des critiques voire des soupçons pèsent sur des ONG au regard notamment de leur manière d'agir. Guidées, pour la plupart, par les principes tels que neutralité ou impartialité, les ONG sont parfois perçues comme des complices voire des «espions » face à certains crimes ou violations des droits de l'homme de par leurs attitudes, ou de par leur silence observé. «Se taire a représenté un soutien objectif à des projets de massacre, par exemple lorsque le racket de l'aide (à partir de l'été 1994) permettait de financer des opérations terroristes lancées à partir des camps du Kivu contre le Rwanda. Se taire a offert un commode alibi à des actions organisées par un gouvernement ${ }^{2413}$. Ainsi, témoins directs des événements, tels que l'attaque et le massacre des réfugiés rwandais installés en RDC par les troupes de l'AFDL en octobre 1996 afin d'occasionner leur retour forcé au Rwanda, les acteurs humanitaires ont eu

\footnotetext{
${ }^{2407}$ La résolution 1291 (2000) adoptée par le Conseil de sécurité à sa 4104è séance du 24 février 2000 indique, par exemple, dans son préambule que dans certains secteurs de la République démocratique du Congo les agents des services d'aide humanitaire ont un accès limité aux réfugiés et aux personnes déplacées [...]. En même temps, le CS/NU ne cesse cependant pas de demander aux parties aux conflits armés en RDC de garantir au personnel humanitaire l'accès aux victimes sans entrave (Voy. par exemple la Résolutions S/RES/1304 du CS/NU du 16 juin 2000, §17; la Résolution S/RES/1332 (2000) du CS du 14 décembre 2000, §13; la Résolution S/RES/1445 du CS/NU du 04 décembre 2002, §14 ; la Résolution S/RES/1468 (2003) du CS/NU du 20 mars 2003 , §14 ; la Résolution S/RES/1565 du CS/NU du $1^{\text {er }}$ octobre 2004, §21; etc.). C'est aussi le cas de la Résolution S/RES/1341 (2001) du CS/NU du 22 février 2001 qui recommande aux parties la coopération avec l'UNICEF et les organisations humanitaires pour des questions spécifiques liées aux enfants (voy. § 10).

${ }^{2408}$ BRADOL, Jean-Hervé et VIDAL, Claudine, «Les attitudes humanitaires dans la région des Grands Lacs » in Politiques internationales dans la région des Grands Lacs, Politique Africaine, op.cit., p. 69.

${ }^{2409}$ «Six collaborateurs du CICR tués en République démocratique du Congo » in https://www.icrc.org/fre/resources/documents/misc/5fzhxr.htm (Source consultée le 13 octobre 2015).

2410 «Ituri : quatre agents de MSF dépouillés dans une attaque armée à Koni », in http://www.radiookapi.net/2015/10/20/actualite/securite/ituri-quatre-agents-de-msf-depouilles-dans-une-attaquearmee-koni (Source consultée le 24 octobre 2015).

${ }^{2411}$ Lire «Ituri : les autorités appellent la population à contribuer à la protection des humanitaires », in http://www.radiookapi.net/2015/10/23/actualite/securite/ituri-les-autorites-appellent-la-population-contribuer-laprotection (Source consultée le 24 octobre 2015)

${ }^{2412}$ Lire par exemple les Résolution S/RES/1355 (2001) du CS/NU du 15 juin 2001, § 17 et S/RES/1484 (2003) du CS/NU du 30 mai 2003, \$6, etc.

${ }^{2413}$ BRADOL, Jean-Hervé et VIDAL, Claudine, «Les attitudes humanitaires dans la région des Grands Lacs » in Politiques internationales dans la région des Grands Lacs, Politique Africaine, op.cit., p. 73.
} 
constamment à refuser ou à accepter "la complicité du silence » avec les organisateurs d'exactions et de massacres ${ }^{2414}$. Il faut parfois faire preuve de prudence, mieux de diplomatie, car délier sa langue peut être la source de son insécurité dans de telles régions, de la même manière que se taire ou ne pas prendre position ou des initiatives afin de mettre fin ou de remédier aux cas de massacre peut être perçu comme de la complicité.

Il existe également de la part de la population une perception hypothétique du travail des ONG humanitaires, ou des humanitaires en général, sur le terrain. Par exemple dans le Village de Nzibira (Territoire de Walungu au Sud-Kivu), Colette BRAECKMAN rapporte que « les villageois qui autrefois comptaient sur l'aide humanitaire, sont aujourd'hui rongés par le doute ${ }^{2415}$. Un témoignage rapporté à cet égard précise : «Lorsque le Comité international de la Croix-Rouge nous paie 7 dollars pour transporter des caisses jusqu'à la forêt et nous précise qu'il nous suffit de les déposer et de partir, nous nous demandons ce qu'elles contiennent et à qui ces colis sont destinés. Se pourrait-il que nos ennemis soient approvisionnés sinon entretenus par une "communauté internationale " qui n'aurait pas intérêt à ce que la région se pacifie vraiment? " ${ }^{2416}$. C'est dans le même sens que les ONG sont facilement incomprises à la suite l'orientation d'aide humanitaire ou de leur action en méconnaissance des enjeux du terrain. Tout ceci influe non moins sur l'efficacité même de l'action humanitaire à engager. A ces conditions, l'évidence d'un espace humanitaire n'est donc pas réalisable.

A la lumière de tout ce qui précède, malgré les critiques formulées, l'apport des ONG dans l'édification de la protection de l'enfant en périodes de conflits armés en RDC est très capital. Leur présence dans certains village et localités faisant défaut criant de l'autorité de l'Etat congolais, voire dans des villes- permet la prise en charge de l'enfant et résout par là ses multiples difficultés. Ainsi, sans elles, il est certain que de nombreuses populations seraient à la merci totale des forces et groupes armés plus que ce qu'on connaît actuellement. En outre, certaines informations liées notamment aux cas de commission de crimes ne seraient pas mises au jour. Ainsi, l'opinion publique nationale et internationale dont elles forment constitue un poids nécessaire à la mise en œuvre du DIH en général, et de la protection spéciale de l'enfant en conflits armés en particulier.

\section{Section V Les Mécanismes de sanction des graves violations des règles du DIH de protection des enfants en situation de conflits armés en RDC: La responsabilité en question}

«Le mot « responsabilité », aujourd'hui d'usage courant, ne semble guère très ancien dans la terminologie juridique. Il aurait été emprunté à l'Angleterre par les philosophes du XVIII ${ }^{\mathrm{e}}$ siècle ${ }^{2417}$. En droit international, c'est à la deuxième moitié du XIX ${ }^{\mathrm{e}}$ siècle que paraîtront «les premiers essais de reconstruction systématique ${ }^{2418}$ de cette notion. Tout de même, la

\footnotetext{
2414 Ibid.

${ }^{2415}$ BRAECKMAN, Colette, L'Homme qui répare les femmes. Le combat du Docteur Mukwege, op. cit., 116.

2416 Ibid.

${ }^{2417}$ QUENEUDEC, Jean-Pierre, La Responsabilité international de l'Etat pour les fautes personnelles, L.G.D.J, Paris, 1966, p. 2.

${ }^{2418}$ VILLALPANDO, Santiago, L'Emergence de la Communauté international dans la responsabilité des Etats,
} 
pratique de la responsabilité pour faits illicites existe depuis toujours dans tout ordre juridique $^{2419}$. Ainsi, par exemple, dans les sociétés primitives, nous renseigne Georges SCELLE, la notion de responsabilité a été objective et collective ${ }^{2420}$. Au sens étymologique, «responsabilité » dérive de «responsable», qui dérive lui-même du latin «responsus», participe passé de «respondere »qui veut dire «se porter garant, répondre ${ }^{2421}$. «Etre responsable, c'est [donc] répondre de ses actes et, dans certains cas, des actions d'un autre. Cependant, répondre de ses actes, cela suppose préalablement que l'on soit responsable ${ }^{2422}$. « [1]a «Responsabilité » est [donc] une situation juridique [...] créée par la survenance d'un fait ou d'un acte dommageables, actes ou faits-conditions prévus par le Droit positif. Ces actes ou ces faits sont imputés par la règle de Droit à un agent juridique qui en est souvent, mais non pas nécessairement, l'auteur et ils conditionnent l'obligation pour cet agent juridique de réparer le préjudice causé, ce mode de réparation variant selon les catégories des dommages et des victimes ${ }^{2423}$. Cette expression est donc d'usage dans différentes disciplines juridiques.

Traiter de la question de la responsabilité pour des graves violations du DIH contre les enfants appelle à l'analyse du problème sous les angles de responsabilité pénale internationale (individuelle) et de responsabilité internationale (de l'Etat). Dans un premier temps, il sera question d'étudier la manière dont les instances juridictionnelles nationales appréhendent cette problématique (\$1), ensuite au niveau de la CPI (\$2).

Définissons d'emblée la « responsabilité pénale internationale (individuelle) comme « [r]ègle du droit pénal international aux termes de laquelle tout auteur d'un fait qui constitue une infraction internationale est responsable de ce chef et est passible d'un châtiment qui est prononcé, selon le cas, par un tribunal interne ou une juridiction pénale internationale $»^{2424}$. Cette notion requiert l'incrimination en droit international et l'application de celle-ci en droit national $^{2425}$. Il faudrait donc qu'il y ait faute ou manquement (culpabilité), et que celle-ci ou celui-ci soit imputable à son auteur (imputabilité) ${ }^{2426}$. Ce qui supposerait la capacité juridique: l'âge requis, l'absence d'altération naturelle ou pathologique des facultés mentales $^{2427}$ ou le discernement et la liberté au moment de faits ${ }^{2428}$.

éd. Graduate Institute Publications, Genève, 2005. 528 p. (Publication sur OpenEdition Books, 01 septembre 2014, disponible sur http://books.openedition.org/iheid/1168?lang=fr\#ftn3 (Source consultée le 07 avril 2016). 2419 Ibid.

${ }^{2420}$ SCELLE, Georges, Manuel élémentaire de Droit international public, éditions Domat-Montchrestien, Paris, 1943, p. 677.

${ }^{2421}$ CORNU, Gérard, Vocabulaire juridique, $11^{\mathrm{e}}$ édition mise à jour sous la direction de l'Association Henri Capitant, «Quadrige », PUF, Paris, 2016, p. 918.

${ }^{2422}$ QUENEUDEC, Jean-Pierre, La Responsabilité international de l'Etat pour les fautes personnelles, op.cit., p. 2.

${ }^{2423}$ SCELLE, Georges, Manuel élémentaire de Droit international public, op.cit., p. 676.

${ }^{2424}$ LA ROSA, Anne-Marie, Dictionnaire de droit international pénal. Termes choisis, Publications de l'Institut Universitaire de Hautes Etudes Internationales, PUF, Genève-Paris, 1998, p. 93.

${ }^{2425}$ Ibid., p. 94. «D'aucuns soutiennent qu'il y a responsabilité pénale internationale dès que l'incrimination existe ; d'autres estiment qu'il est nécessaire que l'incrimination soit assortie d'une sanction pénale »., (Voy. LA ROSA, Anne-Marie, op.cit., p. 94).

${ }^{2426}$ BEZIZ-AYACHE, Annie, Dictionnaire de droit pénal général et procédure pénale, $4^{\mathrm{e}}$ édition, Ellipses, Paris, 2008, p. 258. Voy. aussi LAINGUI, André, «Responsabilité pénale », in LOPEZ, Gérard et TZITZIS, Stamatios (dir.), Dictionnaire des Sciences criminelles, Dalloz, Paris, 2004, pp. 832-833.

${ }^{2427}$ LAINGUI, André, « Responsabilité pénale », in LOPEZ, Gérard et TZITZIS, Stamatios (dir.), Dictionnaire des Sciences criminelles, op.cit., p. 833. 
Au-delà de ces aspects de responsabilité individuelle, il sera finalement analysé la responsabilité internationale des Etats (définition cf. infra) impliqués dans les conflits armés sur ces questions des graves violations du DIH contre les enfants (§3).

\section{§1. La justice congolaise : mécanisme efficace pour la répression des graves violations du DIH contre les enfants et de réparation des dommages?}

La répression des graves violations du $\mathrm{DIH}^{2429}$ sur des enfants et la réparation des dommages sont d'une grande importance dans leur protection spéciale. La nécessité reconnue de la CPI pour la réalisation de cette lourde mission sur la sphère de la $\mathrm{RDC}^{2430}$, ne doit nullement occulter le rôle de premier plan que doit accomplir celle-ci. A l'instar d'autres juridictions internationales, la CPI en dépit de son indépendance affirmée reste tributaire de la coopération des Etats notamment pour recueillir des éléments de preuve, convoquer les témoins, effectuer des perquisitions ou des saisies, faire exécuter des mandats d'arrêts, des peines, etc. ${ }^{2431} \mathrm{La}$ CPI étant complémentaire aux juridictions nationales (cf. supra), la répression de différents crimes commis sur des enfants est une responsabilité première qui incombe à l'Etat congolais. Responsabilité régulièrement rappelée par les Nations Unies (cf. supra). Toutefois, cette mission est loin d'être valablement accomplie au regard de nombreux obstacles ruinant le système judiciaire congolais. Lesquels empêchent son efficacité. Ceci vaut de même pour le cas de réparation des dommages qui demeurent quasi-inexistants en dépit de jugements et arrêts rendus.

Dès lors, il y a lieu d'appréhender la problématique de l'efficacité de la « justice congolaise » comme mécanisme devant assurer la répression des graves violations du DIH sur les enfants, en présentant globalement l'état de cette répression devant les instances judicaires nationales (A), en examinant les obstacles de ce système de répression (B) et dégager ensuite quelques suggestions (C) pour une protection spéciale efficace et efficiente des enfants en situation de conflits armés.

\footnotetext{
${ }^{2428}$ BEZIZ-AYACHE, Annie, Dictionnaire de droit pénal général et procédure pénale, op.cit., p. 258.

${ }^{2429}$ Hormis de nombreux Rapports des Organismes nationaux et internationaux, signifions que les questions de répression des graves violations du DIH en RDC sont abordées dans différentes études juridiques, suivant différentes approches au regard des thèses démontrées. Par exemple, BOKOLOMBE Batuli Yaseme, Sam, De la prévention et de la répression des violations graves du droit international humanitaire en République Démocratique du Congo. Critique de la responsabilité pénale internationale, Ed. Droit \& Société «DES», Kinshasa, 2013, 539 p. ; NGOY Walupakah, Providence et MUYA Miyanga, Sandra, Le Droit de la guerre à l'épreuve du conflit armé en République démocratique du Congo, op.cit., pp. 274-296.; KAZADI Mpiana, Joseph, La Position du droit international dans l'ordre juridique congolais et l'application de ses normes, op.cit., pp. 277-444 ; LWAMBA Katansi, Crimes et châtiments dans la région des Grands Lacs. Cour pénale internationale, Tribunaux pénaux, internationaux Tribunaux pénaux nationaux, L'Harmattan, Paris, 235 p.; BAKAMA Bope, Eugène, La Justice congolaise face aux crimes internationaux commis en RDC, op.cit., 270

${ }_{2430}^{\mathrm{p} . \text { Lire FOFE DJOFIA MALEWA, Jean-Pierre, La Cour pénale internationale : institution nécessaire aux pays }}$ des Grands Lacs africains. La justice pour la paix et la stabilité en R-D Congo, en Ouganda, au Rwanda et au Burundi, Collections « Points de vue concrets », L'Harmattan, Paris, 2006, 231 p.

${ }^{2431}$ CASSESE, Antonio, «Y a-t-il un conflit insurmontable entre souveraineté des Etats et justice pénale internationale ? ", in CASSESE, Antonio et DELMAS-MARTY, Mireille (dir), Crimes internationaux et juridictions internationales, Presses Universitaires de France, Paris, 2002, p. 17.
} 


\section{A. La Répression des graves violations du DIH contre les enfants et réparation des dommages en RDC}

En effet, partie aux CG depuis le 24 février 1961 « avec effet rétroactif à compter du 30 juin 1960 , date de son indépendance ${ }^{2432} »$, la RDC devait répondre à l'obligation qu'imposent ces instruments, précisément les articles 49(1), 50(1), 129(1) et 146 respectivement de la Ière, IIè, IIIè et IVè CG du 12 août 1949, de «[...] prendre toute mesure législative nécessaire pour fixer les sanctions pénales adéquates à appliquer aux personnes ayant commis, ou donné l'ordre de commettre, l'une ou l'autre des infractions graves [...]». Disposition qu'on retrouvera plus tard à l'article 86 du PA 1 de 1977. C'est aussi dans ce sens que s'inscrit l'Ordonnance-Loi $n^{\circ} 72 / 060$ du 25 septembre 1972 portant Code de justice militaire définissant notamment les crimes contre l'humanité, les crimes de guerre et le crime de génocide. Toutefois, le Code pénal ordinaire qui date du 30 juillet 1940 (avec ses modifications subséquentes) sans viser expressément ces infractions graves incorpore au moins « un certain nombre d'infractions susceptibles de prendre place dans le système protecteur de la nature humaine de la personne ${ }^{2433}$. Le Code pénal militaire de 1972 sera abrogé par la Loi $n^{\circ} 024 / 2002$ du 18 novembre 2002 portant Code pénal militaire ${ }^{2434}$. Celui-ci définit notamment les crimes contre l'humanité et les crimes de guerre en reprenant les infractions graves définies dans les textes conventionnels précités. La promulgation de ce dernier Code pénal militaire coïncide avec le champ d'application temporelle du Statut de Rome en RDC. Et en vertu de l'article $112^{2435}$ de l'Acte constitutionnel de transition du 9 avril 1994, alors d'application en cette période, le Statut de Rome aura primauté sur les lois dont la loi n024/2002 du 18 novembre 2002 portant Code pénal militaire. Ce qui juridiquement oblige les juridictions congolaises de se référer au Statut de Rome pour des dispositions similaires avec l'actuel Code pénal militaire. Celui-ci traite de la manière cidessous le crime de génocide, les crimes contre l'humanité et les crimes de guerre ${ }^{2436}$.

\section{A. 1. Du crime de génocide, des crimes contre l'humanité et des crimes de guerre en droit congolais}

En effet, l'article 164 définit le crime de génocide comme «l'un des actes ci-après commis dans l'intention de détruire, en tout ou en partie, un groupe national, politique, racial, ethnique, ou religieux notamment [...] ». Il est repris entres autre : «les mesures visant à

\footnotetext{
2432 CIJ, Affaire des Activités armées sur le territoire du Congo (République démocratique du Congo c. Ouganda), arrêt du 19 décembre 2005, Recueil 2005, p. 243, §217.

${ }^{2433}$ AKELE ADAU, Pierre et SITA MUILA AKELE, Angélique, Les Crimes contre l'humanité en droit congolais, éd. CEPAS, Kinshasa, p. 8.

${ }^{2434}$ Loi n ${ }^{\circ} 024 / 2002$ du 18 novembre 2002 portant Code pénal militaire in Journal officiel, n ${ }^{\circ}$ Spécial, 20 mars 2003, pp. 71-109.

${ }^{2435}$ L'article 112 de l'Acte constitutionnel de la transition du 09 avril 1994 dispose : «Les traités et accords internationaux régulièrement ratifiés ou approuvés ont, dès leur publication, une autorité supérieure à celle des lois, sous réserve pour chaque traité ou accord, de son application par l'autre partie ».

${ }^{2436}$ Lire, avec beaucoup d'intérêt sur ces différents crimes abordés de manière plus approfondie que dans la présente étude, MUTATA LUABA, Laurent, Droit pénal militaire Congolais. Des peines et incriminations de la compétence des juridictions militaires en R.D Congo, éditions du Service de Documentation et d'Etudes du Ministère de la justice et Garde des Sceaux, Kinshasa, 2005, pp. 508-572 et MUTATA LUABA, Laurent, Les crimes internationaux en droit pénal congolais et en droit pénal international, Séminaire de formation des Magistrats sur la poursuite judiciaire des violations massives des droits de l'homme (Mbandaka, 20-24 février 2006), éd. Avocat Sans Frontière/Mission permanente en RDC, 2006, 70 p.
} 
entraver les naissances au sein du groupe », «le transfert forcé d'enfants d'un groupe à un autre groupe », etc. A travers ces formules intelligibles apparaissent respectivement les actes d'un « génocide biologique » ${ }^{2437}$ et « le procédé de « génocide culturel » visant la disparition des traits caractéristiques du groupe dans les nouvelles générations ${ }^{2438}$. Cette définition ajoute l'élément «groupe politique ». Lequel n'existe pas dans la définition que fournit l'article II de la Convention pour la prévention et la répression du crime de génocide du 9 décembre 1948 ou encore dans celle que donne l'article 6 du Statut de Rome. On rappellera que cet article 6 reprend littéralement la définition de la Convention de 1948 précitée $^{2439}$.

Les crimes contre l'humanité se trouvent définis au niveau de l'article 165 du Code pénal militaire :

«[1]es crimes contre l'humanité sont des violations graves du droit international humanitaire commises contre toutes populations civiles avant ou pendant la guerre.

Les crimes contre l'humanité ne sont pas nécessairement liés à l'état de guerre et peuvent se commettre, non seulement entre personnes de nationalité différente, mais même entre sujets d'un même Etat ${ }^{2440}$.

Et au regard de l'article 166 du même instrument,

«[c]onstituent des crimes contre l'humanité et réprimées conformément aux dispositions du présent Code, les infractions graves énumérées [...] portant atteinte, par action ou par omission, aux personnes et aux biens protégés par les Conventions de Genève du 12 août 1949 et les Protocoles Additionnels du 8 juin 1977, sans préjudice des dispositions pénales plus graves prévues par le Code Pénal ordinaire $»^{2441}$.

Il est énuméré à la suite de cette disposition, différentes infractions graves dont

«1. les tortures ou autres traitements inhumains, y compris les expériences biologiques ; [...] 3. le fait de contraindre à servir dans les Forces Armées de la puissance ennemie ou de la partie adverse un prisonnier de guerre ou une personne civile protégée par les Conventions ou les Protocoles Additionnels relatifs à la protection des personnes civiles pendant la guerre ; [...] 5. la déportation, le transfert ou le déplacement illicites, la détention illicite d'une personne civile protégée par les Conventions ou les Protocoles Additionnels ; $[\ldots] »^{2442}$.

Une lecture cursive de cette disposition permet d'affirmer qu'elle dépasse largement le cadre des articles 50, 51, 130 et 147 respectivement de la Ière, IIè, IIIè et IVè CG et se range sur le

2437 MUTATA LUABA, Laurent, Les crimes internationaux en droit pénal congolais et en droit pénal international, Séminaire de formation des Magistrats sur la poursuite judiciaire des violations massives des droits de l'homme (Mbandaka, 20-24 février 2006), op. cit., p. 28.

${ }^{2438}$ Ibid., p. 29.

${ }^{2439}$ FIERENS, Jacques, Droit humanitaire pénal, op.cit., p. 217.

${ }^{2440}$ Article 165 de la Loi n ${ }^{\circ} 024 / 2002$ du 18 novembre 2002 portant Code pénal militaire

${ }^{2441}$ Ibid., article 166

${ }^{2442}$ Ibid. 
libellé de l'article 85 du PA I. Bien plus, les infractions graves reprises sous l'expression de crimes contre l'humanité présentent le double avantage d'être réprimées en temps de paix comme en temps de conflits armés et de concerner clairement tant les CAI que les CANI. Ce qui dépasse d'une certaine manière le cadre conventionnel (CG et PA I et II) et le renforce davantage. Il ne s'agit nullement d'une nouveauté. Ainsi, le Code pénal militaire congolais s'aligne aux côtés de nombreuses législations nationales qui étendent la notion d'infractions graves aux $\mathrm{CANI}^{2443}$.

Toutefois, s'il est vrai qu'il est admis que les crimes contre l'humanité ne nécessitent pas l'existence d'un état de conflit armé, cependant, dans ses articles, le CPM crée la confusion en définissant les crimes contre l'humanité comme infractions graves uniquement sous l'angle des CG et des PA. Lesquels ne s'appliquent qu'en temps de conflits armés ${ }^{2444}$.

Par ailleurs, en mentionnant au paragraphe 3 de son article 166 que le fait de contraindre une personne civile protégée par les Conventions ou les Protocoles Additionnels à servir dans les Forces Armées de la puissance ennemie ou de la partie adverse est constitutif des crimes contre l'humanité, le Code pénal militaire offre tout de même au juge national un cadre législatif d'appréciation de situation de recrutement et d'utilisation des enfants aux hostilités. Une interprétation audacieuse permettrait de rendre encore plus claire une telle disposition au profit des enfants. Dans la même optique, signalons l'article 190 qui interdit «tout enrôlement» de la part de l'ennemi. Ainsi, «[t]out enrôlement par l'ennemi ou ses agents sera puni de mort ». Ces remarques ne nous refuseraient point d'affirmer que le Code pénal militaire congolais n'est pas très protecteur de l'enfant. La «protection spéciale » de celui-ci est inexistante si ce n'est que la «protection générale » réservée aux personnes civiles ou combattantes dont bénéficie l'enfant. Pour preuve, le terme «enfant » n'est repris que trois fois dans ce texte (articles $33 \S 5 ; 130$ et $164 \S 5)$ et «mineur», une seule fois à côté de « enfant mineur » (article $164 \S 5)$.

Ainsi pour réprimer expressément le recrutement et l'utilisation des enfants dans les conflits armés, au plan de la législation nationale, la mission sera accomplie par la loi n ${ }^{\circ} 09 / 001 \mathrm{du} 10$ janvier 2009. Celle-ci dispose, sans effort de détails, en son article 187, alinéa 2: «[...] l'enrôlement ou l'utilisation des enfants âgés de moins de dix-huit ans dans les forces et groupes armés et la police sont punis de dix à vingt ans de servitude pénale principale ${ }^{2445}$.

Les crimes de guerre, quant à eux, se trouvent également définis par ce Code en son article 173. "Par crime de guerre, il faut entendre toutes infractions aux lois de la République commises pendant la guerre et qui ne sont pas justifiées par les lois et coutumes de la guerre ». Au regard de l'article 174, seuls sont poursuivis sous le crime de guerre «ceux qui,

\footnotetext{
${ }^{2443}$ Voy. GRADITZKY, Thomas, «La responsabilité pénale individuelle pour violation du droit international humanitaire applicable en situation de conflit armé non international », in RICR, n 829 , mars 1998, pp. 38-44.

${ }^{2444}$ Centre International pour la Justice Transitionnelle, Justice pénale. Champs de la responsabilité pénale dans l'est de la RDC. Analyse du cadre législatif et de la réponse judiciaire aux crimes internationaux (2009-2014), op.cit., p. 6.

${ }^{2445}$ Lire l'article 187 la Loi $\mathrm{n}^{\circ} 009 / 01$ du 10 janvier 2009 portant Protection de l'enfant, op. cit., in http://www.leganet.cd/Legislation/JO/2009/L.09.001.10.01.09.htm\#TV (Source consultée le 10 janvier 2016)
} 
lors de la perpétration des faits, étaient au service de l'ennemi ou d'un allié de l'ennemi, à quelque titre que ce soit [...]». Ces dispositions posent de sérieux problèmes en termes de garanties des droits de l'homme. L'article 173 se présente comme une disposition « attrapetout ». En l'absence de catégorisation d'actes prohibés, la largesse et l'imprécision «manifeste» du Code pénal militaire sur ce point permettraient d'ériger de nombreuses violations de législations pénales nationales en crimes de guerre. Le silence de l'article 174 au sujet des crimes que commettraient les éléments des FARDC au service de leur commandement reste éloquent et coupable. Bien plus, le texte ne fait pas mention des peines pour les cas de crime de guerre contrairement aux crimes contre l'humanité punis de servitude pénale à perpétuité (article 167) ou de mort (articles 168 et 169), ou encore de génocide puni de mort (article 164). Pour le Tribunal Militaire de Garnison de l'Ituri, « le législateur congolais n'avait nullement l'intention de laisser impuni ce crime atroce dont il a reconnu la haute gravit[é] en ratifiant le [Statut de Rome] ${ }^{2446}$. «[C]ette omission de la pénalité n'est en définitive qu'une erreur purement matérielle ${ }^{2447}$. Il importe «dans ces conditions de chercher à combler les lacunes de la législation interne en trouvant appui sur le [Statut de Rome]» ${ }^{2448}$. Par ailleurs, dans un autre jugement rendu le 2 août 2006, le même tribunal affirmera sans indication de base légale, - contredisant ainsi l'argument d'absence de la technique de «pénalité par renvoi» en ces infractions de crimes de guerre ${ }^{2449}$-, que «le législateur congolais entendait, pour leur répression, que le juge militaire se réfère aux peines prévues en droit interne pour les différentes infractions aux lois de la République qui ne deviennent crimes de guerre, au regard de ce Code Pénal Militaire que par le fait d'être commises pendant la guerre en violation des lois et coutumes de la guerre ${ }^{2450}$. Ces propos seront confirmés dans un autre jugement rendu par la même juridiction le 19 février $2007^{2451}$. Dans tous les cas, comme l'affirme si bien le Tribunal Militaire de Garnison de Mbandaka, c'est la loi « la plus favorable au prévenu [qui] sera d'application ${ }^{2452}$. Et «par principe une loi est moins sévère lorsqu'elle prévoit une peine moindre et le cas échéant comporte moins d'incriminations $»^{2453}$.

De ce qui précède, il va sans dire que la réalisation de ces crimes requiert la réunion de différents éléments constitutifs - élément moral et élément matériel. Un régime répressif se rapporte également à chaque crime ${ }^{2454}$. A la suite d'une lecture comparée avec le Statut de Rome, il se dégage que les définitions fournies par le Code pénal militaire congolais ne

\footnotetext{
2446 TMG de l'Ituri, L'Auditeur Militaire et les parties civiles contre le Capitaine Blaise BONGI MASSABA, RP n018/2006, Jugement du 24 mars 2006.

2447 Ibid.

2448 TMG de l'Ituri, L'Auditeur Militaire et les parties civiles contre le Capitaine Blaise BONGI MASSABA, RP n018/2006, Jugement du 24 mars 2006.

2449 MUTATA LUABA, Laurent, Droit pénal militaire Congolais. Des peines et incriminations de la compétence des juridictions militaires en R.D Congo, op.cit., p. 572.

${ }^{2450}$ TMG de l'Ituri, L'Auditeur Militaire de Garnison, Ministère Public et parties civiles contre Monsieur KAHWA PANGA MANDRO Ives, RP n039/2006, Jugement du 2 août 2006.

2451 TMG de l'Ituri, L'Auditeur Militaire de Garnison, Ministère Public et parties civiles contre Capitaine François MULESA MULOMBO alias BOZIZE, et al., , RP n¹01/2006, Jugement du 19 février 2007.

${ }^{2452}$ TMG de Mbandaka, L'Auditeur Militaire, Ministère public et les parties civiles contre les prévenus KAHENGA MUMBERE Papy, et al., RP n086/2005, RP 101/2006, Jugement du 20 juin 2006.

2453 Ibid.

${ }^{2454}$ Lire avec beaucoup d'intérêt MUTATA LUABA, Laurent, Les crimes internationaux en droit pénal congolais et en droit pénal international, Séminaire de formation des Magistrats sur la poursuite judiciaire des violations massives des droits de l'homme (Mbandaka, 20-24 février 2006), op. cit.,pp. 21-55.
} 
correspondent pas avec celles fournies par le Statut de Rome. Il combine les définitions de crime de guerre et de crime contre l'humanité. Les crimes contre l'humanité tels qu'il est défini correspondent une de définitions des crimes de guerre du Statut de Rome (article 8, §2 (a) $)^{2455}$. La liste des actes criminels pouvant constituer des crimes contre l'humanité prévue au Code pénal militaire n'est pas aussi complète que celle prévue par le Statut de Rome. Des actes tels que les disparitions forcées, l'apartheid, et les « autres actes inhumains de caractère analogue » ne sont pas prévus par le Code pénal militaire ${ }^{2456}$.

\section{A. 2. Aperçu global de quelques affaires des graves violations du DIH contre les enfants devant les instances judicaires congolaises : Répression et réparation ?}

L'entrée en vigueur du Statut de Rome le $1^{\text {er }}$ juillet 2002, notamment vis-à-vis de la RDC (Etat qui l'a ratifié le 11 avril 2002), devrait produire des effets juridiques conséquents dont son application par les juridictions congolaises et la coopération entre l'Etat et cette instance.

En effet, les Cours et tribunaux sont des organes d'application des instruments internationaux auxquels leur Etat est partie. En RDC, un « rappel formel » sur la question est fait par l'article 153, alinéa 4, de l'actuelle Constitution : «[1]es Cours et Tribunaux, civils et militaires, appliquent les traités internationaux dûment ratifiés, les lois, les actes réglementaires pour autant qu'ils soient conformes aux lois ainsi que la coutume pour autant que celle-ci ne soit pas contraire à l'ordre public ou aux bonnes mœurs $»^{2457}$.

Et c'est depuis janvier 2006 que les juridictions militaires font application des dispositions du Statut de Rome pour des questions de crimes internationaux auxquelles elles sont confrontées. La première juridiction en cette matière a été le Tribunal Militaire de Garnison de Mbandaka dans un jugement avant dire droit dans l'affaire des Mutins de Mbandaka prononcé le 12 janvier 2006. Jugement confirmé sur le fond le 20 juin 2006 et en appel le 15 juin 2007. Le même tribunal a été amené à prononcer le 12 avril 2006 un jugement faisant applicabilité directe du Statut de Rome (affaire Songo Mboyo) et confirmé en appel par la Cour Militaire de l'Equateur (7 juin 2006). Suivant la même période, la démarche d'applicabilité directe du Statut de Rome a été suivie dans différentes affaires. C'est notamment le cas du Tribunal Militaire de Garnison de l'Ituri dans les affaires Bongi (24 mars 2006), Kahwa (2 août 2006) et Bavi (19 février 2007). Ce procédé ne sera pas réfuté en appel par la Cour Militaire de la Province Orientale quand bien même seules ces deux dernières affaires seront confirmées ${ }^{2458}$. Des juridictions du Nord et du Sud-Kivu se prononceront également dans différentes affaires en faisant application directe du Statut de Rome ${ }^{2459}$.

Pour motiver leurs démarches, les juridictions militaires fondent leur raisonnement sur des

\footnotetext{
${ }^{2455}$ MWAGALWA, Thomas Furaha, «Réflexions sur les obstacles à réprimer le crime de recrutement et d'utilisation d'enfants soldats commis en République Démocratique du Congo », «art.cit. », p. 214.

${ }^{2456}$ Centre International pour la Justice Transitionnelle, Justice pénale. Champs de la responsabilité pénale dans l'est de la RDC. Analyse du cadre législatif et de la réponse judiciaire aux crimes internationaux (2009-2014), op.cit., p. 6.

${ }^{2457}$ L'article 153, alinéa 4, de la Constitution de la RDC, op. cit.,

${ }^{2458}$ Avocats Sans Frontières, Etudes de jurisprudence. L'application du Statut de Rome de la Cour pénale internationale par les juridictions de la République Démocratique du Congo, op.cit., p.13.

${ }^{2459}$ Voy. MWAGALWA, Thomas Furaha, «Réflexions sur les obstacles à réprimer le crime de recrutement et d'utilisation d'enfants soldats commis en République Démocratique du Congo », «art.cit. », p. 217.
} 
textes constitutionnels et législatifs, voire leur propre jurisprudence. En effet, le Tribunal Militaire de Garnison de Mbandaka dans l'affaire Songo Mboyo, par exemple, évoque l'article 153, alinéa 4, de l'actuelle Constitution qui rappelle l'application des instruments juridiques internationaux notamment par les juridictions militaires. Remarquant qu'il se trouve devant deux législations (interne et internationale) régissant toutes le même objet (le crime contre l'humanité), ce Tribunal évoque par la suite l'article 215 de la Constitution congolaise, comme mode de règlement de conflit des lois. Lequel article prône l'autorité supérieure des accords internationaux sur les lois nationales. «A ce principe de règlement de conflit des lois [conclut le Tribunal], le statut de Rome de la CPI est très favorable aux prévenus écartant la peine capitale et dispose des mécanismes protecteurs des victimes efficaces pour être retenu dans le cadre du procès en cours ${ }^{2460}$. Cette même conclusion sera également réitérée par le même tribunal dans une autre affaire concernant les crimes contre l'humanité où il sera en outre souligné en termes de motivation le fait que «la loi nationale [Loi nº24/2002 du 18 novembre 2002 portant code pénal militaire] entretienne une confusion entre le crime contre l'humanité et le crime de guerre qui du reste clairement défini par le Statut de Rome de la Cour Pénale Internationale $»^{2461}$.

Dans une affaire concernant les crimes de guerre, le Tribunal Militaire de Garnison de l'Ituri, avant d'évoquer l'article 215 précité, et sans faire allusion à l'article 153, alinéa 4 sus-évoqué, fait remarquer que la législation nationale en cette matière accuse « une lacune criante ${ }^{2462}$ en ce sens qu'elle ne prévoit pas de peine. En revanche, il juge cela comme « une erreur purement matérielle ${ }^{2463}$ dans la mesure où «le législateur congolais n'avait nullement l'intention de laisser impuni ce crime atroce [...] ${ }^{2464}$. D'où, la nécessité pour ledit Tribunal « de chercher à combler les lacunes de la législation interne en trouvant appui sur le traité de Rome portant statut de la cour pénale internationale (sic) ratifié par la RDC [...]» ${ }^{2465}$. Dans une autre affaire concernant les crimes de guerre, le même Tribunal Militaire de Garnison de l'Ituri évoquait respectivement les articles 215 et 153, alinéa 4 précités suivis du Décret-loi $\mathrm{n}^{\circ} 003 / 2002$ du 30 mars 2002 portant ratification du Statut de la Cour pénale internationale par la République Démocratique du Congo pour conclure que «le droit positif congolais a introduit dans son arsenal des lois le Statut de la Cour Pénale Internationale, lequel devient désormais un instrument juridique faisant partie intégrante de la législation pénale congolaise $[\ldots] »^{2466}$. Cette conclusion est aussi lisible dans l'affaire Kahwa ${ }^{2467}$, devant le même tribunal, pour des questions des crimes contre l'humanité et crimes de guerre mais avec une logique juridique peu ordonnée que dans l'affaire précédente ${ }^{2468}$. Au-delà des textes, la jurisprudence

\footnotetext{
2460 TMG de Mbandaka, L'Auditeur Militaire, Ministère public et les parties civiles contre les prévenus Lieutenant Eliwo et al., RP n ${ }^{\circ} 084 / 2005$, Jugement du 12 avril 2006, p. 12. (Affaire Songo Mboyo)

2461 TMG de Mbandaka, L'Auditeur Militaire, Ministère public et les parties civiles contre les prévenus KAHENGA MUMBERE Papy, et al., RP n086/2005, RP 101/2006, Jugement du 20 juin 2006.

${ }^{2462}$ TMG de l'Ituri, L'Auditeur Militaire et les parties civiles contre le Capitaine Blaise BONGI MASSABA, RP n 018/2006, Jugement du 24 mars 2006.

${ }^{2463}$ Ibid.

${ }^{2464}$ Ibid.

2465 Ibid.

${ }^{2466}$ TMG de l'Ituri, L'Auditeur Militaire, Ministère public et les parties civiles contre Capitaine François MULESA MULOMBO alias BOZIZE et al. , RP n¹01/2006, Jugement du 19 février 2007.

2467 TMG de l'Ituri, L'Auditeur Militaire, Ministère public et les parties civiles contre Monsieur KAHWA PANGA MANDRO Ives, RP n³9/2006, Jugement du 2 août 2006.

2468 Dans cette affaire, le TMG de l'Ituri ne suit pas la logique d'hiérarchie des normes. Il commence par la
} 
nationale évolutive en la matière est donc successivement reprise dans la motivation de ce dernier tribunal.

Cependant, il est attesté que la jurisprudence congolaise «a, dans la plupart des affaires analysées, interprété de manière fort douteuse les exigences contextuelles [des crimes internationaux]; et que cette interprétation contestable expose ces tribunaux au risque de confusion entre les crimes de droit international et ceux de droit commun ${ }^{2469}$.

Rappelons tout de même que de 1996 à 2003, la succession de conflits armés en RDC avait perturbé le fonctionnement des institutions dont la justice. Situation qui laissera des millions de victimes sans recours judiciaire. Et suivant cette période, le système judiciaire congolais restera marqué par la présence des juridictions d'exception dont la Cour d'Ordre militaire ${ }^{2470}$. Cette dernière fonctionnera sans tenir compte des garanties judiciaires fondamentales. De nombreux civils critiques au pouvoir en place y seront jugés. Dans les territoires sous occupation, des groupes armés organiseront à leur tour des simulacres de procès. A Kisangani, en dépit du rapport accablant de l'ONU sur les massacres du 14 mai 2002 établissant les meurtres de 103 civils et l'exécution d'au moins 60 soldats par le RCD-Goma, aucune autorité militaire ou civile ne sera inquiétée. Le procès qu'organisera le Conseil opérationnel de guerre sur neuf militaires aboutira à l'acquittement de six d'entre eux et de trois condamnés. Lesquels s'évaderont par la suite ${ }^{2471}$.

La lutte contre l'impunité sera fort timidement amorcée en périodes de transition ${ }^{2472}$ et posttransition. Situation qui se justifie par l'adoption de la constitution de transition de 2003, des lois de réforme de la justice militaire dont celle abrogeant la Cour d'Ordre Militaire ${ }^{2473}$ et la ratification par la RDC du Statut de Rome portant création de la CPI. Sans oublier les pressions constantes exercées par l'opinion publique nationale et internationale constituée de la Société civile et des organismes internationaux ${ }^{2474}$. D'ailleurs, c'est grâce à ces pressions

« conclusion » soulignée ci-haut en évoquant de manière renversée respectivement le Décret-loi nº03/2002 du 30 mars 2002 portant ratification du Statut de Rome par la RDC, les dispositions législatives (Code Pénal Militaire) et constitutionnelles (articles 215 et 153), voire la jurisprudence nationale en la matière.

2469 MBOKANI, Jacques B., «L'application du Statut de Rome par les Tribunaux congolais. Vers une banalisation de crimes de droit international ? », « art. cit.», pp. 113-114.

${ }^{2470}$ Décret-Loi n019 du 23 août 1997 portant création de la Cour d'Ordre Militaire

2471 Nations Unies, Haut Commissariat aux droits de l'homme, Rapport du Projet Mapping concernant les violations les plus graves des droits de l'homme et du droit international humanitaire commises entre mars 1993 et juin 2003 sur le territoire de la République démocratique du Congo, Août 2010, pp. 408-409, §§851-854.

2472 Exemple de l'affaire d'Ankoro (Katanga), jugement du 20 décembre 2004. Cette affaire concerne les incidents occasionnés à la suite des violents affrontements entre les FAC et les Mayi-Mayi en novembre 2002 à Ankoro (Katanga). Au moins 70 personnes avaient perdu la vie, des milliers de maisons incendiées et détruites, des centaines de bâtiments privés et publics (hôpitaux, écoles et églises) pillés. A l'issue du procès, 7 de 28 militaires arrêtés furent inculpés notamment de crimes contre l'humanité sur base du Code de Justice Militaire de 1972.

${ }^{2473}$ L'article 379 de la Loi n023/2002 du 18 novembre 2002 portant Code de justice militaire abroge le Décretloi n ${ }^{\circ} 019$ du 23 août 1997 portant création de la Cour d'Ordre Militaire. Et l'article 376 de cette loi dispose que «Trente jours après la date d'entrée en vigueur de la présente loi, la Cour d'Ordre Militaire et le Parquet près cette juridiction cesseront définitivement de fonctionner». Voy. Loi n ${ }^{\circ} 023 / 2002$ du 18 novembre 2002 portant Code de justice militaire in Journal Officiel de la République Démocratique du Congo -Numéro Spécial -20 mars 2003.

${ }^{2474}$ Nations Unies, Haut Commissariat aux droits de l'homme, Rapport du Projet Mapping concernant les 
constantes des ONG et de la MONUC précisément que la majorité des décisions seront rendues $^{2475}$. Il va sans dire que face à un nombre incommensurable de graves violations du DIH commises en RDC depuis le début des conflits armés en $1996^{2476}$, seul un nombre minime de ces crimes graves ont été poursuivis en justice congolaise ${ }^{2477}$. En mars 2009, Avocats Sans Frontières répertoriait 13 affaires ${ }^{2478}$. Spécifiquement pour la répression de recrutement et d'utilisation des enfants aux hostilités, seuls trois cas ont été portés devant le juge comme l'atteste une étude de $2013^{2479}$. Dans une de ses récentes études qui date de juillet 2015, pour la période de janvier 2009 à décembre 2014, le Centre International pour la Justice Transitionnelle (ICTJ) identifiait au moins 39 procédures pour des affaires des crimes internationaux engagées par les cours et tribunaux de l'est de la RDC dont 13 effectivement jugées $^{2480}$. A notre tour de relever deux autres affaires ${ }^{2481}$ concernant le recrutement d'enfants dans les conflits armés parmi les 39 répertoriées par l'étude d'ICTJ.

Au regard de ces différentes affaires portées devant les juridictions militaires congolaises, la quasi-majorité concerne les attaques lancées contre les civils dont les enfants ne se trouvent point épargnés - directement ou indirectement. Ceci pour dire que « [m]ême lorsqu'ils ne sont pas des victimes directes, le fait de voir leurs parents tués ou violés, leurs biens pillés et leurs lieux d'habitation incendiés laisse en eux de profonds traumatismes ${ }^{2482}$. De ces affaires, il y a lieu d'épingler le cas de celle concernant des meurtres, blessures, viols et pillages commis contre les civils par les militaires, du 3 au 4 juillet 2005, à Mbandaka en réaction à l'assassinat de leur compagnon d'armes. Affaire portée devant le Tribunal Militaire de Garnison de Mbandaka $^{2483}$. Les attaques contre les civils dont les enfants aboutissant notamment à la

violations les plus graves des droits de l'homme et du droit international humanitaire commises entre mars 1993 et juin 2003 sur le territoire de la République démocratique du Congo, op.cit., pp. 409-410, §855.

${ }^{2475}$ Nations Unies, Haut Commissariat aux droits de l'homme, Rapport du Projet Mapping concernant les violations les plus graves des droits de l'homme et du droit international humanitaire commises entre mars 1993 et juin 2003 sur le territoire de la République démocratique du Congo, op.cit., p. 423, §889.

${ }^{2476}$ Voy. par exemple des graves violations du DIH sur des enfants répertoriées au deuxième chapitre du Rapport du Projet Mapping concernant les violations les plus graves des droits de l'homme et du droit international humanitaire commises entre mars 1993 et juin 2003 sur le territoire de la République démocratique du Congo, Août 2010, 336-359.

${ }^{2477}$ WETSH'OKONDA KOSO, Marcel, République démocratique du Congo. La justice militaire et le respect des droits de l'homme - L'urgence du parachèvement de la réforme. Une étude d'AfriMAP et de l'Open Society Initiative for Southern Africa Johannesbourg, 2009, pp. 3 et 5.

2478 Avocats Sans Frontières, Etudes de jurisprudence. L'application du Statut de Rome de la Cour pénale internationale par les juridictions de la République Démocratique du Congo, Avocats Sans Frontières, Bruxelles-Kinshasa, mars 2009, pp. 112-124.

${ }^{2479}$ Voy. MWAGALWA, Thomas Furaha, «Réflexions sur les obstacles à réprimer le crime de recrutement et d'utilisation d'enfants soldats commis en République Démocratique du Congo », « art.cit. », pp. 218-223.

${ }^{2480}$ Centre International pour la Justice Transitionnelle, Justice pénale. Champs de la responsabilité pénale dans l'est de la RDC. Analyse du cadre législatif et de la réponse judiciaire aux crimes internationaux (2009-2014), ICTJ New-York - ICTJ Goma, p. 17. Voy. le Tableau (résumé) présenté à la page 22 de cette étude et la présentation résumée de ces différentes affaires de la page 41 à la page 69 de cette étude.

${ }^{2481}$ Il s'agit des affaires Lcl Bedi Mobuli Engangela alias Col. 106 (RMP 1377/MTL 2011) et M23 (RMP 0297/BBM 2012) respectivement devant la Cour Militaire du Sud-Kivu et celle du Nord-Kivu. Voy. Centre International pour la Justice Transitionnelle, Justice pénale. Champs de la responsabilité pénale dans l'est de la RDC. Analyse du cadre législatif et de la réponse judiciaire aux crimes internationaux (2009-2014), op.cit., pp. 41 et 61.

${ }^{2482}$ Nations Unies, Haut Commissariat aux droits de l'homme, Rapport du Projet Mapping concernant les violations les plus graves des droits de l'homme et du droit international humanitaire commises entre mars 1993 et juin 2003 sur le territoire de la République démocratique du Congo, Août 2010, p. 366, §655.

${ }^{2483}$ TMG de Mbandaka, L'Auditeur Militaire, Ministère pub)lic et les parties civiles contre les prévenus KAHENGA MUMBERE Papy, et al., RP n086/2005, RP 101/2006, Jugement du 20 juin 2006. Voir le 
condamnation pour crimes contre l'humanité ont été reconnues dans différentes affaires dont l'affaire Fizi I/ Baraka (Lcl Kibibi Mutuare et al. $)^{2484}$ où de nombreux enfants ont été battus, poignardés et appelés à assister aux viols de leurs mères (janvier 2011 à Fizi). De même pour l'affaire Kazungu (Maniraguha et al.) ${ }^{2485}$ confirmant des cas des meurtres et d'enlèvement des enfants dans le cadre des attaques lancées contre différents villages du Sud-Kivu, de juin 2006 à janvier 2007. C'est également le cas de l'affaire Balumisa Manasse et al attestant des attaques lancées contre la population civile à Katasomwa Centre, Katasomwa Rijiwe, Katasomwa Parc, Kitendebwa, Mwewa Chibangi, etc. Des pillages d'écoles et des viols collectifs ont suivi ces attaques du 26-28 septembre 2009 ${ }^{2486}$. Des cas de viols sont également signalés dans l'affaire Minova où 33 filles ont été répertoriées comme victimes de viol et autres violences sexuelles à Minova (Nord-Kivu) du 20 au 30 novembre $2012^{2487}$, etc.

Par ailleurs, différentes affaires pendantes devant les juridictions militaires - avec des enfants comme victimes - n'ont pas pu aboutir faute de financement (RMP 1526/BKL/2014) 2488 $^{248}$ pour raison d'insécurité (RMP 0223/MLS/10 RP 055/2011). Par exemple pour cette dernière dite affaire Kibua-Mpofi Walikale (Ltcl. Mayele et al.), du 30 juillet au 2 août 2010, 380 hommes, femmes et enfants seraient victimes de viols; de nombreux autres enfants seraient également victimes d'enlèvement, de travaux forcés et d'autres traitements cruels, inhumains et dégradants de la part du Ltcl Mayele et consorts ${ }^{2489}$.

Encore très peu d'affaires se rapportent aux cas de recrutement et d'utilisation d'enfants aux hostilités. Il s'agit des affaires Biyoyo (2006), Bwansolu (2008), Gédéon (2009) ${ }^{2490}$, Lcl. Bedi Mobuli Engangela alias Colonel $106(2014)^{2491}$. Il y a également l'affaire M23 (RMP 0297/BBM/2012) qui concerne plutôt le mandat d'arrêt lancé le 23 janvier 2014 contre le Colonel Makenga Sultani et consorts, entre autres pour crime de guerre par viol, meurtre et recrutement d'enfants (250 enfants) commis aux mois de juin, juillet et août 2012 à Rutshuru $\left(\right.$ Nord-Kivu) ${ }^{2492}$.

Que dire de réparation?

Suivant la Cour Militaire de l'Equateur, en rappel des articles 77 et 226 du Code de justice

\footnotetext{
Jugement de cette affaire reproduit in Conseil National des droits de l'homme en Islam, Comité Provincial de l'Equateur, Rapport d'observation du procès sur les crimes contre l'humanité tenu devant le Tribunal militaire de Garnison de Mbandaka sous RMP 279/GMZ/05, RP 086/005 et RP 101/106, mars 2007, pp. 27-86.

${ }^{2484}$ Affaire RP 043/11, RMP 1337/MTI./2011

${ }^{2485}$ RP 275/09 et 521/10, RMP 581/TBK/07 et 1673/KMC/10 (procès), RPA 0177

${ }^{2486}$ CM Sud-Kivu, Affaire RP 038 RMP 1427 NGG/2009 RMP 1280/MTL/09

${ }^{2487}$ CMO du Nord-Kivu, Affaire Minova, RP 003/2013, RMP 0372/BBM/013

${ }^{2488}$ Cette affaire traite entre autres des meurtres de 8 enfants présumés commis le 06 juin 2014.

${ }^{2489}$ CMO du Nord-Kivu, affaire Kibua-Mpofi Walikale (Ltcl. Mayele et al.), RMP 0223/MLS/10 RP 055/2011.

${ }^{2490}$ Pour ces trois premières affaires, voy. aussi l'étude de MWAGALWA, Thomas Furaha, « Réflexions sur les obstacles à réprimer le crime de recrutement et d'utilisation d'enfants soldats commis en République Démocratique du Congo », « art.cit. », pp. 218-223.

${ }^{2491}$ Centre International pour la Justice Transitionnelle, Justice pénale. Champs de la responsabilité pénale dans l'est de la RDC. Analyse du cadre législatif et de la réponse judiciaire aux crimes internationaux (2009-2014), op.cit., p. 41.

${ }^{2492}$ Centre International pour la Justice Transitionnelle, Justice pénale. Champs de la responsabilité pénale dans l'est de la RDC. Analyse du cadre législatif et de la réponse judiciaire aux crimes internationaux (2009-2014), op.cit., p. 61.
} 
militaire et d'une jurisprudence établie, la juridiction militaire ne peut prononcer d'office des dommages-intérêts en réparation des préjudices causés. Il faudrait que la personne lésée puisse se constituer partie civile et en faire la réclamation. Et les préjudices doivent résulter de faits infractionnels ${ }^{2493}$. Pour ces actions en dédommagement, les parties civiles réclament réparation conjointement aux auteurs des infractions, faits générateurs des dommages, et à l'Etat, étant civilement responsable. Des questions de capacité juridique d'ester en justice se posent également ${ }^{2494}$. On imaginera bien pour les enfants qu'ils se feront représenter par des personnes majeures juridiquement capables (parents ou tuteurs, par exemple).

Il ressort de tout ce qui précède que différentes juridictions militaires congolaises saisies de ces questions prononcent au profit des parties civiles victimes, si préjudice établi en lien avec les faits infractionnels, des dédommagements. Généralement, ce sont des sommes colossales $^{2495}$ (par rapport notamment aux soldes du militaires, par exemple) qui sont prononcées. Cependant, les victimes sont loin de recouvrer leurs droits. L'Etat congolais demeurant insolvable.

\section{B. Des obstacles à la répression des graves violations du DIH contre les enfants en RDC}

Sur ce peu de décisions rendues en matière de répression des crimes internationaux, plus particulièrement sur des questions des graves violations du DIH sur des enfants, les ressources disponibles dans ces domaines de droit international indiqués (DIH ou droit international pénal) sont faiblement mobilisées par les instances judiciaires. Situation qui s'expliquerait en partie par la méconnaissance du juge congolais de ces branches spécifiques du droit auquel sa formation accorderait peu d'intérêt (cf. supra). Une formation «plus nettement orientée vers le droit interne ${ }^{2496}$. Sous ce registre, ce passage éloquent du jugement du Tribunal Militaire de Garnison du Haut-Katanga dans l'affaire Gédéon Kyungu Mutanga, concernant l'enrôlement de plus ou moins 300 enfants de moins de quinze ans en vue de leur participation aux hostilités, mérite d'être rappelé:

«Faisant droit aux argumentations de la défense, le tribunal relève que [durant] la période allant du 15/10/2003 au 12/5/2006, date de la reddition du prévenu principal accompagné de ses 'bana ', aucune guerre n'a été déclarée. En plus, en RDC, seul le chef de l'Etat peut déclarer un état [de] guerre pour que les lois et coutumes de guerre soient observes par les belligérants $»^{2497}$ (nous soulignons).

Il est fait remarquer, par exemple, pour les affaires concernant le recrutement et l'utilisation

\footnotetext{
${ }^{2493}$ CM de l'Equateur, affaire Songo Mboyo, RPA n¹4/2006, feuillets n³8-40.

${ }^{2494}$ Ibid.

${ }^{2495}$ Par exemple dans l'affaire Songo Mboyo en appel les condamnés devraient payer in solidum avec la RDC au moins la somme de 5.000 dollars américain en monnaie locale à chacune de partie civile victime (29 au total). Voy. CM de l'Equateur, affaire Songo Mboyo, RPA n¹4/2006, feuillets $n^{\circ} 44-45$. Ou encore dans l'affaire Mulesa où 12 condamnés devraient verser in solidum avec la RDC la somme totale de 315.000 dollars américains aux parties civiles victimes. Voy. TMG de l'Ituri, RP n¹01/206.

2496 MUTATA LUABA, Laurent, Les crimes internationaux en droit pénal congolais et en droit pénal international, Séminaire de formation des Magistrats sur la poursuite judiciaire des violations massives des droits de l'homme (Mbandaka, 20-24 février 2006), op.cit, p. 4.

${ }^{2497}$ Avocats Sans Frontières, Recueil de décisions de justice et de notes de plaidoiries en matière de crimes internationationaux, décembre 2010, p. 59. Document disponible sur https://issuu.com/avocatssansfrontieres/docs/asf_rdc_crimesinternationaux_part2/8 (Source consultée le 20 mai 2016).
} 
d'enfants aux hostilités la passivité du juge quant à l'analyse du droit et des faits (ex : détermination d'âges d'enfants, lien entre recrutement et conflit armé, etc.). Il se contentera du réquisitoire ${ }^{2498}$. Analysant ces différentes affaires des graves violations du DIH, le Rapport du Projet Mapping arrive à la conclusion que « toutes ces affaires ont également démontré les limites opérationnelles des magistrats militaires, particulièrement les affaires d'Ankoro, de Kahwa Mandro, de Kilwa et de Katamisi où enquêtes bâclées et douteuses, actes judiciaires mal rédigés ou insuffisamment motivés, mauvaises décisions, droits de la défense foulés aux pieds et immixtions diverses sont les manquements qui ont caractérisé ces décisions ${ }^{2499}$. Dans le même ordre d'idée, l'étude de Jacques Mbokani, précédemment citée, atteste que la jurisprudence congolaise «a, dans la plupart des affaires analysées, interprété de manière fort douteuse les exigences contextuelles [des crimes internationaux][...]» ${ }^{2500}$ (nous soulignons).

En outre, l'indépendance de la justice, dans une société où «l'impunité reste la règle et les poursuites suivies de condamnation des auteurs, l'exception $»^{2501}$, est appréhendée comme un des obstacles majeurs au bon fonctionnement de la justice congolaise ${ }^{2502}$. Or de l'indépendance se dégage la confiance, la crédibilité du système judiciaire vis-à-vis des justiciables potentiels. "Sans elle, il serait difficile d'envisager une collaboration effective sur le plan international ${ }^{2503}$. En effet, sauf quelques exceptions près, depuis toujours le pouvoir exécutif n'a point prouvé clairement sa bonne volonté de permettre au pouvoir judiciaire de mener sa lourde mission en toute indépendance. Celle-ci est d'ailleurs vue comme un grand danger à son endroit ${ }^{2504}$. Bien plus, l'indépendance des magistrats en tant qu'individus et en tant que corps reste problématique à plusieurs égards. La situation est encore catastrophique au niveau de la justice militaire qui est vue comme « un instrument du pouvoir judiciaire au service du commandement $»^{2505}$. Sous cet angle, dans une de ses observations finales adressées à la RDC, le Comité des droits de l'enfant signifiait être « préoccupé par le nombre d'enquêtes auxquels les commandants des Forces armées de la République démocratique du Congo ont fait obstruction et par le refus persistant de l'Etat partie [RDC] d'arrêter et de

\footnotetext{
${ }^{2498}$ Voy. MWAGALWA, Thomas Furaha, «Réflexions sur les obstacles à réprimer le crime de recrutement et d'utilisation d'enfants soldats commis en République Démocratique du Congo », « art.cit. », p. 223.

${ }^{2499}$ Nations Unies, Haut Commissariat aux droits de l'homme, Rapport du Projet Mapping concernant les violations les plus graves des droits de l'homme et du droit international humanitaire commises entre mars 1993 et juin 2003 sur le territoire de la République démocratique du Congo, Août 2010, p. 423, §888.

${ }^{2500}$ MBOKANI, Jacques B., "L'application du Statut de Rome par les Tribunaux congolais. Vers une banalisation de crimes de droit international ? » «art. cit», pp. 113-114.

${ }^{2501}$ BAKAMA BOPE, Eugène, La Justice congolaise face aux crimes internationaux commis en RDC, op. cit., p. 29.

${ }^{2502}$ Lire WETSH'OKONDA KOSO, Marcel, République démocratique du Congo. La justice militaire et le respect des droits de l'homme - L'urgence du parachèvement de la réforme. Une étude d'AfriMAP et de l'Open Society Initiative for Southern Africa Johannesbourg, 2009, pp.71-77 ; MUMBALA ABELUNGU, Junior, « La question de l'indépendance du pouvoir judiciaire en RDC », in YAV Katshung, Joseph (dir.), La justice congolaise au banc des accusés ?, op.cit., pp. 102-112 ; MWAGALWA, Thomas Furaha, «Réflexions sur les obstacles à réprimer le crime de recrutement et d'utilisation d'enfants soldats commis en République Démocratique du Congo », « art.cit. », pp. 224-225 ;

${ }^{2503}$ DIAKITE, Kemoko, La Justice pénale internationale en Afrique. Aspects juridiques, défis et perspectives, op.cit., pp. 73-74.

${ }^{2504}$ Voy. MUMBALA ABELUNGU, Junior, «La question de l'indépendance du pouvoir judiciaire en RDC » «art. cit. », pp. 103 et 113.

${ }^{2505}$ Nations Unies, Haut Commissariat aux droits de l'homme, Rapport du Projet Mapping concernant les violations les plus graves des droits de l'homme et du droit international humanitaire commises entre mars 1993 et juin 2003 sur le territoire de la République démocratique du Congo, Août 2010, p. 448, §955.
} 
transférer le général Bosco Ntaganda » ${ }^{2506}$.

Au sujet de l'impunité, celle-ci est généralisée voire institutionnalisée. Ainsi, par exemple, les lois et décret d'amnistie adoptés entre 2003 et 2009 - excluant expressément de leur champ les crimes de guerre, les crimes contre l'humanité et le génocide- ont représenté des obstacles à la poursuite des crimes en question. Le 9 février 2009, le ministre de la Justice a demandé aux autorités judiciaires militaires de suspendre toutes les poursuites contre des membres de certains groupes armés, dont le CNDP, et de ne pas engager de nouvelles poursuites en prévision de la loi d'amnistie de mai $2009^{2507}$. Bien plus, des auteurs de ces graves violations se trouvent promus en grades. C'est le cas de Jean Pierre Biyoyo promu au grade de Lieutenant Colonel alors qu'il a été condamné à mort par le TMG de Bukavu notamment pour détention illégale d'enfants. Ou encore le cas de la promotion au grade de Général au sein de l'armée nationale des seigneurs de guerre réputés dans le recrutement et l'utilisation d'enfants aux hostilités : Jérôme Kakwaku, Floribert Kisembo, Bosco Ntaganda et Germain Katanga (cf. infra $)^{2508}$. Ces deux derniers seront tout de même rattrapés par la CPI. Le transfert de nombreux suspects de l'affaire Songo Mboyo vers d'autres régions s'inscrit également sous ce registre ${ }^{2509}$. Ces obstacles se joignent à celui d'absence de ressources humaines, financières et matérielles adéquates (un effectif de magistrats faible, absence de formation et de recyclage des magistrats, un budget insuffisant pour une indépendance réelle, la quasi-absence des Bibliothèques, d'outils d'enquête, un délabrement avancé des Bâtiments de «Palais de justice », des bâtiments pénitentiaires, etc.) qui ruine le système judiciaire congolais. Notons par exemple que l'état de délabrement, y compris les mesures sécuritaires, des bâtiments pénitentiaires occasionnent fréquemment l'évasion des accusés ou condamnés. C'est le cas d'évasion en 2011 de la prison centrale de Kassapa (Lubumbashi) de Gédéon Kyungu alors condamné à la peine capitale.

Par ailleurs, il a été constaté que les enfants ayant commis différentes infractions à caractère militaire étaient traités non comme victimes mais arrêtés, détenus et jugés par les juridictions militaires ${ }^{2510}$. Sous le régime de la Cour d'Ordre Militaire, « [s]ept enfants ont ainsi été jugés séparément à Kinshasa, Mbandaka et Matadi entre 1999 et 2002 et condamnés à la peine capitale. Ils avaient été inculpés «d'association de malfaiteurs », «d'homicide volontaire», de

\footnotetext{
2506 Comité des droits de l'enfant, Examen des Rapports présentés par les Etats parties en application du paragraphe 1 de l'article 8 du Protocole facultatif à la Convention relative aux droits de l'enfant, concernant l'implication d'enfants dans les conflits armés, Observations finales :République démocratique du Congo, Cinquante-neuvième session, CRC/C/OPAC/COD/CO/1, 7 mars 2012, op. cit., §38-a.

2507 Amnesty International, Il est temps que justice soit rendue. La République Démocratique du Congo a besoin d'une nouvelle stratégie en matière de justice. Campagne en faveur de la justice internationale. Amnesty International, Document public AFR 62/006/2011, AILRC-FR, Août 2011, pp. 12 et 32.Voy. aussi BAKAMA BOPE, Eugène, La Justice congolaise face aux crimes internationaux commis en RDC, op.cit., p. 124.

2508 Nations Unies, Haut Commissariat aux droits de l'homme, Rapport du Projet Mapping concernant les violations les plus graves des droits de l'homme et du droit international humanitaire commises entre mars 1993 et juin 2003 sur le territoire de la République démocratique du Congo, Août 2010, p. 346, §683.

${ }^{2509}$ Ibid., p. 412, §862.

2510 Comité des droits de l'enfant, Examen des Rapports présentés par les Etats parties en application de l'article 44 de la Convention, Observations finales : République Démocratique du Congo, CRC/C/COD/CO/2, 10 février $2009, \quad 372, \quad 17 \quad$ in http://tbinternet.ohchr.org/_layouts/treatybodyexternal/Download.aspx?symbolno=CRC $\% 2 \mathrm{fC} \% 2 \mathrm{fCOD} \% 2 \mathrm{fCO} \%$ 2f2\&Lang=en (Source consultée le 22 janvier 2016).
} 
« dissipation d'armes » et de «meurtre en temps de guerre ». Dans six cas la peine a été commuée en une peine à perpétuité par décret présidentiel et un enfant a été exécuté à Kinshasa le 15 janvier 2002, seulement 30 minutes après le prononcé du verdict ${ }^{2511}$. Sous le régime de la Loi $\mathrm{n}^{\circ} 023 / 2002$ du 18 novembre 2002 portant Code de justice militaire ${ }^{2512}$ dont l'article 114 exclut de la compétence des juridictions militaires des personnes âgées de moins de 18 ans, des EAFGA âgés entre 13 et 14 ans ont été arrêtés par l'Auditorat Militaire de Bukavu pour désertion en janvier 2005. 12 autres cas ont été relevés à Goma en octobre 2005. Situation remarquable également à Kisangani et Kalemie (Katanga) au cours de la période mai 2004 et décembre 2005. Et la raison invoquée par les Magistrats était la méconnaissance des normes applicables alors que certains étaient réticents se dessaisir de ces dossiers ${ }^{2513}$.

Enfin, il sied de conclure avec le Rapport Mapping des Nations Unies que : «les poursuites engagées $[\ldots]$ au regard des violations du droit international humanitaire ne satisfont ni les obligations internationales de la RDC en matière de répression des infractions graves aux Conventions de Genève et des violations graves des droits de l'homme imposées par les instruments de droit international dont la RDC est partie, ni les standards internationaux en matière de lutte contre l'impunité ${ }^{2514}$.

\section{Que proposer ?}

Des tentatives de solutions sont apportées par des réformes du système judiciaire mais sans succès remarquables. Sous l'angle de répression des graves violations du DIH sur des enfants, il y a eu les tentatives de création d'une "Cour spécialisée mixte » ou des «chambres spécialisées de premier degré » au niveau des Cours d'appels de Goma, Lubumbashi et Mbandaka et d'une «chambre spécialisée d'appel » à la Cour de cassation, rejetées par le Parlement ${ }^{2515}$. Depuis 2013, en vertu de 1'article 91, §1, de la Loi organique $n^{\circ} 13 / 011-B d u$ 13 avril 2013 portant organisation, fonctionnement et compétence de juridiction de l'ordre judiciaire, les Cours d'appel connaissent au premier degré « du crime de génocide, des crimes de guerre et des crimes contre l'humanité commis par les personnes relevant de leur compétence et de celle des tribunaux de grande instance ${ }^{2516}$. Compétence jadis reconnue exclusivement aux juridictions militaires. Des réformes sont également entreprises pour tout

\footnotetext{
2511 Nations Unies, Haut Commissariat aux droits de l'homme, Rapport du Projet Mapping concernant les violations les plus graves des droits de l'homme et du droit international humanitaire commises entre mars 1993 et juin 2003 sur le territoire de la République démocratique du Congo, op.cit., p. 356, §715.

${ }^{2512}$ L'article 114 de la Loi n ${ }^{\circ} 023 / 2002$ du 18 novembre 2002 portant Code de justice militaire dispose : «Les juridictions militaires sont incompétentes à l'égard des personnes âgées de moins de dix-huit ans ». Voy. Loi $\mathrm{n}^{\circ}$ 023/2002 du 18 novembre 2002 portant Code de justice militaire, in Journal Officiel de la République Démocratique du Congo -Numéro Spécial -20 mars 2003, p. 25.
}

2513 MONUC, Division droits de l'homme, Section Protection de l'enfant, Arrestation et détention dans les prisons et cachots de la RDC, Partie II, La détention des enfants et la justice pour mineurs, op. cit., pp. 11-12.

${ }^{2514}$ Nations Unies, Haut Commissariat aux droits de l'homme, Rapport du Projet Mapping concernant les violations les plus graves des droits de l'homme et du droit international humanitaire commises entre mars 1993 et juin 2003 sur le territoire de la République démocratique du Congo, op.cit., p. 424, \$890.

${ }^{2515}$ Lire BAKAMA BOPE, Eugène, La Justice congolaise face aux crimes internationaux commis en RDC, op.cit., pp. 66-73 et 79-80

${ }^{2516}$ Article 91, §1, de la Loi organique $n^{\circ} 13 / 011-B$ du 13 avril 2013 portant organisation, fonctionnement et compétence de juridiction leordre judiciaire disponible sur http://leganet.cd/Legislation/Droit\%20Judiciaire/LOI.13.011.11.04.2013.htm (Source consultée le 1er mars 2016). 
le système au niveau constitutionnel. C'est notamment le cas de la composition du Conseil supérieur de la magistrature qui ne laisse désormais aucune place aux membres du pouvoir exécutif (Président de la République ou Ministre de la justice) (cf. article 152 de la Constitution de la RDC). Par ailleurs, pour une justice à la hauteur de l'ampleur des graves violations du DIH commises contre les enfants, il nous paraît important d'instituer une juridiction pénale spéciale pour la RDC: «Tribunal pénal international spécial pour la $\mathrm{RDC} »$.

En effet, la proposition de la création d'un Tribunal pénal international ou d'un Tribunal spécial pour la RDC n'est pas une idée nouvelle. Emise à la fois par les institutions gouvernementales et par la société civile congolaises, voire par l'opinion internationale, cette idée naît dès les premières années de conflits armés en RDC, précisément de « la deuxième guerre de libération ». Elle est une des demandes de la RDC dans le cadre de la procédure liée à sa communication adressée à la Commission africaine des droits de l'homme et des peuples contre les Républiques du Burundi, de l'Ouganda et du Rwanda. Communication datée du 24 février 1999 et reçue par la Commission le 8 mars 1999 (cf. supra) ${ }^{2517}$. La RDC priait la Commission d'indiquer des mesures appropriées pour sanctionner les auteurs des crimes de guerre et des crimes contre l'humanité dont « la création d'un tribunal ad hoc ${ }^{2518}$. Celui-ci devrait être créé en collaboration avec les Nations Unies ${ }^{2519}$. L'idée de la création d'un tribunal ad hoc est aussi perceptible dans le cadre du processus de paix à travers le prédialogue inter congolais tenu à Gaborone (Botswana) du 20 au 25 août $2001^{2520}$. En avril 2002, dans le cadre du Dialogue inter congolais, la résolution $n^{\circ} 5$ de la Commission Paix et Réconciliation reconduisait cette proposition. Et dans son discours à la cinquante-huitième session de l'AG/NU du 24 septembre 2003 à New-York, le Président de la RDC soulignait l'importance de «l'établissement, avec l'assistance de l'ONU, d'un Tribunal pénal international pour la République Démocratique du Congo ${ }^{2521}$, pour une justice équitable gage de la paix ${ }^{2522}$. Il faudrait faire observer tout de même que dans leur réclamation d'institution d'un Tribunal pénal international pour la RDC, les dirigeants du Camp AFDLKabila ne prennent pas en considération la période 1996 à 1997. Période où ils seraient responsables de différents crimes internationaux. La seule période visée est celle de la « seconde guerre de libération », d'août 1998 à juin $2003^{2523}$. Mais « [c]ela ne correspond ni à la morale ni à la logique historique ni à une bonne politique judiciaire ${ }^{2524}$. Toutefois, qu'il soit dit qu'il n'existe aucune requête officielle de création d'un Tribunal pénal international

2517 Commission africaine des droits de l'homme et des peuples, Communication $n^{\circ} 227 / 99$ République Démocratique $d u \quad$ Congo/ Burundi, Rwanda, Ouganda, $\$ 1$ in http://www.achpr.org/fr/communications/decision/227.99/ (Source consultée le 30 mars 2016).

${ }^{2518}$ Ibid., $\$ 11, \mathrm{f}$.

2519 Ibid.

2520 Voy. International Crisis Group (ICG), Le Dialogue intercongolais : Poker menteur ou négociation politique ? ICG Rapport Afrique n³7, Bruxelles-Naïrob- Kinshasa, 16 novembre 2001, pp. 6 et 14-15. Voy. aussi LWAMBA Katansi, Crimes et châtiments dans la région des Grands Lacs. Cour pénale internationale, Tribunaux pénaux internationaux, Tribunaux pénaux nationaux, op. cit., pp. 139-140.

${ }^{2521}$ AG/NU, Documents officiels, A/58/PV. 10, Cinquante-huitième session, $10^{\mathrm{e}}$ séance plénière, Mercredi 24 septembre 2003, p. 16.

2522 Ibid.

2523 MAMPUYA, Auguste, «Responsabilité et réparations dans le conflit des Grands-Lacs au Congo-Zaïre », « art.cit. », pp. 705-706.

${ }^{2524}$ Ibid., p. 706. 
pour la $\operatorname{RDC}^{2525}$.

Si des voix unanimes s'élèvent pour la création d'un Tribunal pour la RDC, des divergences demeurent tout de même autour du contenu de cette juridiction spéciale. Les questions se posent donc au sujet de sa composition, de sa compétence temporelle (des crimes commis dès 1960 à ce jour ou juste après 1996 ?), du droit applicable (droit international ou droit congolais ?), de son degré d'indépendance et d'impartialité , de son financement, etc.

Par exemple, tout en reconnaissant la création du Tribunal pénal international pour la RDC comme étant l'idéal au regard de l'ampleur des atrocités commises particulièrement en RDC, Moïse CIFENDE estime que l'obtention d'une telle juridiction «quelque justiciable qu'en soit l'idée [...] relève de l'illusion ${ }^{2526}$. Ceci se justifie par rapport à l'absence des moyens politiques et diplomatiques suffisants pouvant amener la RDC à atteindre un tel objectif au sein du CS/NU. Il propose en lieu et place l'extension de la compétence du TPIR tout en étant favorable également à un tribunal spécial de nature mixte pour la $\mathrm{RDC}^{2527}$. Avec l'appui des ONG internationales, la Société civile congolaise plaide depuis plusieurs années pour la mise en place d'un «Tribunal spécialisé et mixte » avec une composante à la fois congolaise et internationale, avec un siège en $\mathrm{RDC}^{2528}$.

Par ailleurs, il nous paraît que face aux crimes indicibles du DIH et des droits de l'homme commis en RDC et offensant toute la communauté humaine, l'idée d'une juridiction internationale supranationale, se servant du modèle TPIY ou TPIR, s'avère plus que nécessaire. Toutefois, cette juridiction devrait être composée en très grande partie des juges internationaux (garantie d'indépendance et d'impartialité) mais aussi de quelques juges congolais afin d'offrir davantage du sens à la continuité après la fin de sa mission. Pour ne pas alourdir sa mission, minimiser ses finances et le rendre davantage efficace, ce tribunal aura pour compétence temporelle la période d'octobre 1996 à juillet 2002. Ceci lui permettrait évidemment de repartir ses tâches avec la CPI dont la compétence temporelle débute le $1^{\mathrm{er}}$ juillet 2002. Son siège serait établi sur un des Etats voisins de la RDC entretenant avec celleci des relations moins conflictuelles (ex : Zambie). Le droit congolais devrait faire partie du droit applicable en marge du droit international applicable. Appréhender le droit congolais par une juridiction supranationale permettrait d'entendre un autre «son de cloche » en termes d'interprétation. Lequel pourrait permettre de peaufiner sa jurisprudence. Au-delà de tout, une place importante doit être réservée à la victime - enfant. Lui accordant, contrairement à ce qui est vécu, l'initiative d'action pénale à travers des ONG spécialisées des questions d'enfants. Ceci permettrait d'apporter une correction au système pénal international existant mais aussi au système pénal congolais, en matière de répression des crimes internationaux notamment,

\footnotetext{
${ }^{2525}$ Nations Unies, Haut Commissariat aux droits de l'homme, Rapport du Projet Mapping concernant les violations les plus graves des droits de l'homme et du droit international humanitaire commises entre mars 1993 et juin 2003 sur le territoire de la République démocratique du Congo, Août 2010, p. 479, §1032.

2526 CIFENDE KACIKO, Moïse, «La Répression pénale des violations graves du droit international humanitaire : le cas de la République Démocratique du Congo », inAnnales de droit de Louvain, Vol. 61, ${ }^{\circ} 4$, 2001, p. 501.

${ }^{2527}$ Ibidem, pp. 501-502.

${ }^{2528}$ BONNEAU, Karine et CARBONI, Montserrat, RDC. Les victimes des crimes sexuels obtiennent rarement justice et jamais réparation. Changer la donne pour combattre l'impunité, Rapport de la Fédération Internationale des Ligues des droits de l'Homme, FIDH (éd. Françaises), Paris, octobre 2013, p. 67.
} 
où la participation de la victime au procès est limitée à «sa constitution en partie civile pour la réparation ou l'indemnisation des préjudices subis. Elle ne dispose [donc] d'aucune initiative pour la mise en mouvement de l'action pénale, dont le monopole revient au Ministère public, lequel peut surseoir l'instruction pour inopportunité des poursuites ou insuffisance de preuves et priver ainsi la victime de son intérêt à la réparation ${ }^{2529}$.

En marge de cette juridiction pénale internationale «hautement souhaitable, tant sur le plan moral que juridique ${ }^{2530}$, la réinstallation ou la redynamisation des institutions de justice transitionnelle (Commission Vérité et réconciliation) aux niveaux national et provincial demeure d'une grande nécessité au regard d'innombrables crimes perpétrés sous la période indiquée voire plus. Crimes pour lesquels les institutions judiciaires ne sauraient pas toujours apporter des réponses appropriées.

Au regard de tout ce qui précède, il va sans dire que l'installation d'une telle juridiction reste tributaire d'une diplomatie humanitaire agissante de la part de l'Etat congolais. Par ailleurs, le fait que le pouvoir politique congolais regorge certains de ces présumés criminels, il est fort probable que cela ne puisse fonctionner correctement. D'où le rôle de pression de la société civile.

\section{\$2 La Cour pénale internationale et la répression des graves violations du DIH contre les enfants en RDC}

«[L]es juridictions internationales sont les seules à pouvoir donner une réponse judiciaire appropriée et adéquate lorsqu'il s'agit de juger des crimes internationaux très complexes. Et cela arrive surtout quand ces crimes impliquent des hauts dirigeants politiques et militaires, des chefs d'Etats ou de gouvernement, et quand les éléments de preuve étant éparpillés sur de nombreux territoires, les recherches demandent des moyens qui vont au-delà de ce que peut faire un juge national ${ }^{2531}$.

De cette réflexion d'Antonio CASSESE, il s'en suit qu'une juridiction pénale internationale doit être efficace afin de mieux répondre aux «attentes des populations du monde, assoiffées de la vraie justice, égale pour tous ${ }^{2532}$. D'où l'intérêt d'examiner quelques critères d'efficacité d'une juridiction pénale internationale (A), avant d'examiner la situation de la $\mathrm{RDC}(\mathrm{B})$ et de répondre si la CPI est efficace pour la répression des crimes de guerre et crimes contre l'humanité portés sur des enfants en RDC (C).

\section{A. Quelques critères d'efficacité de la justice pénale internationale}

Et pour être efficace, une juridiction pénale internationale doit satisfaire à un certain nombre

\footnotetext{
${ }^{2529}$ KAZADI, Mpiana, Joseph, «La Cour pénale internationale et la République Démocratique du Congo : 10 ans après. Etude de l'impact du Statut de Rome dans le droit interne congolais », in RQDI, 25.1 (2012), p. 90.

${ }^{2530}$ MAMPUYA, Auguste, «Responsabilité et réparations dans le conflit des Grands-Lacs au Congo-Zaïre », «art.cit. », p. 704.

2531 CASSESE, Antonio, «Y a-t-il un conflit insurmontable entre souveraineté des Etats et justice pénale internationale ? », « art.cit », p. 28.

${ }^{2532}$ FOFE DJOFIA MALEWA, Jean-Pierre, L'administration de la preuve devant la Cour pénale internationale. Règles procédurales et méthodologiques, L'Harmattan, Paris, 2015, p. 11.
} 
des conditions ou critères qui ne sont rien d'autre que des défis à relever. A cet égard, JeanPierre FOFE DJOFIA MALEWA retient les critères de supranationalité, d'indépendance, de moyens d'action et d'indemnisation des victimes ${ }^{2533}$. Kemoko DIAKITE retient, pour sa part, en dehors de l'indépendance de la justice, les défis de la coopération des Etats, de vulgarisation du contenu des conventions de droit pénal international et des procédures courtes $^{2534}$. Analysons brièvement ces critères, auxquels nous ajouterons le critère de protection des témoins, avant d'examiner si la CPI satisfait ou non.

- Critère de supranationalité : une instance judiciaire supranationale permettrait d'atteindre des présumés criminels relevant de différentes nationalités de manière égale, sans haine ni complaisance $^{2535}$.

- Critère d'indépendance: l'indépendance reste le critère déterminant pour tout système judiciaire. Elle crée une certaine crédibilité vis-à-vis des justiciables. Elle permet à l'instance judiciaire d'échapper à toute emprise de tout pouvoir, afin de rechercher et d'établir la vérité $^{2536}$. Cette indépendance vaut de même pour le système judiciaire national afin d'envisager une collaboration franche et effective ${ }^{2537}$.

- Critère de moyens d'action : établir la vérité sur des faits criminels complexes dans le cadre de la justice pénale internationale exige des moyens humains, financiers, matériels ou de pression conséquents ${ }^{2538}$. Sans lesquels, rien ne sera fait. On rappellera, par exemple, que « [c]haque affaire traitée à Arusha a coûté environ 31 millions de dollars ${ }^{2539}$. Il faudrait toutefois faire observer avec Antonio CASSESE que les juridictions internationales n'ont en réalité pas le pouvoir de «commander» (Pas de police, par exemple, pour faire exécuter ces actes). Elles dépendent donc des Etats ${ }^{2540}$.

- Critère de participation et d'indemnisation des victimes: Dès les tribunaux militaires internationaux de Nuremberg et de Tokyo aux TPIY et TPIR, la justice pénale internationale est demeurée tournée vers les criminels et s'intéressait moins aux victimes ${ }^{2541}$. C'est avec l'avènement de la CPI que la victime aura «droit à l'information, à la participation et à

2533 Idem, Jean-Pierre, La Cour pénale internationale: institution nécessaire aux pays des Grands Lacs africains. La justice pour la paix et la stabilité en R-D Congo, en Ouganda, au Rwanda et au Burundi, op.cit., p. 127.

${ }^{2534}$ DIAKITE, Kemoko, La Justice pénale internationale en Afrique. Aspects juridiques, défis et perspectives, op.cit., pp. 73-74.

${ }^{2535}$ FOFE DJOFIA MALEWA, Jean-Pierre, La Cour pénale internationale : institution nécessaire aux pays des Grands Lacs africains. La justice pour la paix et la stabilité en R-D Congo, en Ouganda, au Rwanda et au Burundi, op.cit., pp. 128-129.

${ }^{2536}$ Idem, Jean-Pierre, L'administration de la preuve devant la Cour pénale internationale. Règles procédurales et méthodologiques, op.cit., p. 11.

${ }^{2537}$ DIAKITE, Kemoko, La Justice pénale internationale en Afrique. Aspects juridiques, défis et perspectives, op.cit., p. 74.

${ }^{2538}$ FOFE DJOFIA MALEWA, Jean-Pierre, La Cour pénale internationale : institution nécessaire aux pays des Grands Lacs africains. La justice pour la paix et la stabilité en R-D Congo, en Ouganda, au Rwanda et au Burundi, op.cit., pp. 130-131.

${ }^{2539}$ FIERENS, Jacques, Droit humanitaire pénal, op.cit., p. 208.

${ }^{2540}$ CASSESE, Antonio, «Y a-t-il un conflit insurmontable entre souveraineté des Etats et justice pénale internationale ? », « art. cit. », p. 17.

2541 JEANGENE VILMER, Jean-Baptiste, Réparer l'irréparable. Les réparation aux victimes devant la Cour pénale internationale, Presses Universitaires de France, Paris, 2009, p. 2. Voy. aussi FIERENS, Jacques, Droit humanitaire pénal, op.cit., p. 204. 
réparation. De simple témoin, la victime devient un acteur à part entière $»^{2542}$. Toutefois, sa participation à la procédure reste passive $\mathrm{e}^{2543}$. Elle ne pourrait pas actionner la procédure en se portant partie civile. Ceci dit, au-delà de la répression, la réparation - dont l'indemnisation demeure nécessaire. Elle supposera donc l'audition, sinon la participation des victimes à la procédure. Chose qui n'est pas aussi facile pour elle. Car «accepter de témoigner, c'est évoquer la haine, les traques, les insultes, d'éternelles humiliations ${ }^{2544}$. C'est « ravive[r] inévitablement les traumatismes $»^{2545}$. Et la justice se verra efficace si elle de résorber effets du crime sur la victime.

- Critère de protection des témoins : le procès Mathieu Ngudjolo intenté au plan national par le Tribunal de grande instance de Bunia donnant lieu à son acquittement le 3 juin 2004, faute des preuves, est une excellente illustration de l'importance des mesures de protection des témoins. En effet, il a été révélé que tous les témoins qui devaient déposer au cours de l'instruction s'étaient finalement rétractés par crainte de représailles du groupe armé FNI auquel appartenait Mathieu Ngudjolo ${ }^{2546}$. Ceci dit, un témoin sécurisé est rassuré de dire « toute la vérité, rien que la vérité ». Laquelle sera d'un grand intérêt pour l'issue de l'affaire.

Au-delà des critères ci-dessus examinés, il existe un défi à relever par la justice pénale internationale, celui de voir ses décisions rendues dans un délai relativement court. Ce qui n'est donc pas les cas.

\section{B. La situation de la RDC devant la Cour pénale internationale}

Deux ans après sa ratification du Statut de Rome, et conformément à l'article 14 dudit traité, la RDC a déféré la situation de l'ensemble de son territoire au Procureur de la CPI. En juillet 2003, celui-ci indiquait que cette situation était une priorité pour son bureau. Depuis lors une analyse de cette situation s'imposait dont particulièrement le cas du territoire d'Ituri. En septembre 2003, il lui paraissait déjà préférable d'obtenir ce renvoi de la RDC en dépit de sa compétence proprio motu ${ }^{2547}$ (article $15 \S 1$ du Statut de Rome). C'est ainsi qu'après examen de différents renseignements, le Procureur adressera une requête aux fins de délivrance d'un mandat d'arrêt contre Thomas Lubanga dyilo à la Chambre préliminaire I. Laquelle requête recevra une réponse positive. Un mandat d'arrêt sera donc délivré par la Chambre préliminaire I le 10 février 2006 contre Thomas Lubanga Dyilo ${ }^{2548}$. A ce jour, six affaires

\footnotetext{
2542 JEANGENE VILMER, Jean-Baptiste, Réparer l'irréparable. Les réparation aux victimes devant la Cour pénale internationale, op.cit., pp. 2-3.

${ }^{2543}$ LWAMBA Katansi, Crimes et châtiments dans la région des Grands Lacs. Cour pénale internationale, Tribunaux pénaux internationaux, Tribunaux pénaux nationaux, op.cit., p. 198.

2544 VANDERMEERSCH, Damien, Comment devient-on Génocidaire? Et si nous étions tous capables de massacrer nos voisins, GRIP, Bruxelles, p. 29.

${ }^{2545}$ Ibid.

${ }^{2546}$ Nations Unies, Haut Commissariat aux droits de l'homme, Rapport du Projet Mapping concernant les violations les plus graves des droits de l'homme et du droit international humanitaire commises entre mars 1993

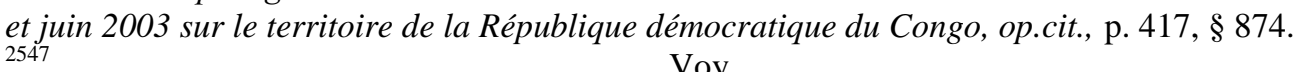

Voy

https://www.icccpi.int/fr_menus/icc/press \%20and\%20media/press\%20releases/2004/Pages/prosecutor\%20receives\%20referral\% 20of\%20the\%20situation\%20in\%20the\%20democratic\%20republic\%20of\%20congo.aspx (Source consultée le 18 mars 2016). 
concernent la situation de la RDC. Elles se concentrent notamment sur les cas d'attaques contre les civils, de viols, d'esclavages sexuels, de destruction des biens et pillages, meurtres, tortures, persécutions, etc. constitutifs de crimes de guerre et de crimes contre l'humanité. L'enfant n'est donc point épargné de ces faits en tant que civil. Et quatre de ces affaires se préoccupent aussi d'enrôlement, de conscription d'enfants de moins de quinze ans et de leur participation active aux hostilités (affaires Thomas Lubanga, Matthieu Ngudjolo, Germain Katanga, Bosco Ntaganda). D’où leur examen.

\section{B. 1 Affaire Thomas Lubanga Dyilo}

Suivant cette affaire, le mandat d'arrêt lancé indiquait qu'il y avait des motifs raisonnables de croire que Thomas Lubanga Dyilo était responsable des crimes de guerre consistant à l'enrôlement, à la conscription et à la participation active des enfants de moins de quinze ans aux hostilités conformément aux articles 8-2-b xxvi et 25-3-a du Statut de Rome ${ }^{2549}$. Une décision de confirmation de telles charges interviendra le 29 janvier $2007^{2550}$. Cinq ans après cette confirmation des charges, le verdict sera rendu en date du 14 mars 2012 et confirmé en appel le $1^{\mathrm{er}}$ décembre 2014. Entretemps, une décision relative à la peine, prononcée le 10 juillet 2012, condamnait Thomas Lubanga Dyilo à une peine unique d'une durée totale de 14 ans d'emprisonnement ${ }^{2551}$. Peine de laquelle sera déduit son temps de détention passé à La Haye $^{2552}$. De ce jugement, il y a lieu de conclure que :

«La Chambre [de Première instance I] est convaincue au-delà de tout doute raisonnable que la mise en œuvre du plan commun tendant à mettre sur pied une armée dans le but de prendre et de conserver le contrôle de l'Ituri, aussi bien politiquement que militairement, a abouti à la conscription et à l'enrôlement d'enfants de moins de 15 ans au sein de l'UPC/FPLC entre le 1er septembre 2002 et le 13 août 2003. De même, la Chambre est convaincue au-delà de tout doute raisonnable que l'UPC/FPLC a fait participer activement des enfants de moins de 15 ans à des hostilités, notamment au cours de batailles. Durant la période visée, ces enfants ont été utilisés comme soldats et comme gardes du corps de hauts responsables, dont l'accusé ${ }^{2553}$.

04\%200106/court\%20records/chambers/pre\%20trial\%20chamber\%20i/Pages/warrant\%20of\%20arrest.aspx (Source consultée le 18 mars 2016).

${ }^{2549}$ CPI, Le Procureur c. Thomas Lubanga Dyilo, affaire NICC-01/04-01/06, Chambre de préliminaire I, Sous $\begin{array}{lllll}\text { scellés Mandat d'arrêt, } & 10 & \text { février } & 2006, & \text { https://www.icc- }\end{array}$ cpi.int/fr_menus/icc/situations\%20and\%20cases/situations/situation\%20icc\%200104/related\%20cases/icc\%2001 04\%200106/court\%20records/chambers/pre\%20trial\%20chamber\%20i/Pages/warrant\%20of\%20arrest.aspx

(Source consultée le 18 mars 2016). 2550

https://www.icc-

cpi.int/fr_menus/icc/situations\%20and\%20cases/situations/situation\%20icc\%200104/related\%20cases/icc\%2001 04\%200106/court\%20records/chambers/pre\%20trial\%20chamber\%20i/Pages/decision\%20on\%20the\%20confir mation\%20of\%20charges.aspx (Source consultée le 18 mars 2016).

2551 CPI, Le Procureur c. Thomas Lubanga Dyilo, affaire $\mathrm{N}^{\circ} \mathrm{ICC}-01 / 04-01 / 06$, Chambre de première instance I, décision relative à la peine rendue en application de l'article 76 du Statut, 10 juillet 2012, pp. 42-43, §107, in https://www.icc-

cpi.int/fr_menus/icc/situations\%20and\%20cases/situations/situation\%20icc\%200104/related\%20cases/icc\%2001 04\%200106/court\%20records/chambers/trial\%20chamber\%20i/Pages/2901.aspx (Source consultée le 19 mars 2016).

${ }^{2552}$ Ibid., p. 43, $\$ 108$.

${ }^{2553}$ CPI, Le Procureur c. Thomas Lubanga Dyilo, affaire $N^{\circ}$ : ICC-01/04-01/06, Chambre de première instance I, 
Ainsi, Thomas Lubanga Dyilo sera déclaré : «[coupable] des crimes de conscription et d'enrôlement d'enfants de moins de 15 ans dans la FPLC et du fait de les avoir fait participer activement à des hostilités, au sens des articles 8-2-e-vii et 25-3-a du Statut, de début septembre 2002 au 13 août $2003 »^{2554}$.

\section{B. 2 Affaires Germain Katanga et Mathieu Ngudjolo Chui}

Dans le cadre de la présente affaire, le mandat d'arrêt lancé à l'encontre de Germain Katanga en date du 2 juillet 2007 indiquait qu'il y avait motifs raisonnables de croire que Germain Katanga était pénalement responsable entre autres « du crime de guerre consistant à faire participer activement des enfants de moins de quinze ans à des hostilités sanctionné par l'article 8-2-bxxvi ou 8-2-vii du Statut ${ }^{2555}$. Le cas du crime de guerre pour des attaques dirigées contre les civils qui ne participent pas directement aux hostilités est également repris contre Germain Katanga ${ }^{2556}$. En date du 06 juillet 2007, un autre mandat d'arrêt sera lancé contre Matthieu Ngudjolo Chui avec le même chef d'accusation précité ${ }^{2557}$.

A la suite de la décision de confirmation des charges, la Chambre préliminaire I conclura «qu'il existe des preuves suffisantes donnant des motifs substantiels de croire que le 24 février 2003, Germain Katanga et Mathieu Ngudjolo Chui ont commis conjointement, au sens de l'article 25-3-a du Statut, le crime consistant à utiliser des enfants de moins de 15 ans pour les faire participer activement à des hostilités constitutif d'un crime de guerre visé à l'article 8-b-xxvi du Statut ${ }^{2558}$.

Le 21 novembre 2012, la disjonction des charges à l'encontre de Germain Katanga et Mathieu aura lieu. Le 18 décembre 2012 interviendra le verdict pour Mathieu Ngudjolo Chui. A cet effet, la Chambre de première instance II constate que la présence d'enfants dans les groupes armés en Ituri était un phénomène généralisé. Présence remarquée également dans le territoire de Djugu dont le groupement de Bedu-Ezekere. Il sera constaté également la présence des enfants de moins de quinze ans venant de ce groupement dans l'attaque de Bogoro le 24 février 2003. Cependant la Chambre conclut «qu'elle ne dispose pas de suffisamment

\footnotetext{
jugement, 14 mars 2012, pp. 645-646, $\quad$ $\quad 1355, \quad$ in $\quad \underline{\text { https://www.icc- }}$ cpi.int/fr_menus/icc/situations\%20and\%20cases/situations/situation\%20icc\%200104/related\%20cases/icc\%2001 04\%200106/court\%20records/chambers/trial\%20chamber\%20i/Pages/2842.aspx (Source consultée le 18 mars 2016).

${ }^{2554}$ Ibid., p. $648, \S 1358$.

2555 CPI, Le Procureur c. Germain Katanga, $N^{\circ} I C C-01 / 04-01 / 07$, Sous scellés Urgent Mandat d'arrêt à l'encontre de Germain Katanga, La Chambre préliminaire I 2 juillet 2007, p. 7, in https://www.icccpi.int/fr_menus/icc/situations\%20and\%20cases/situations/situation\%20icc\%200104/related\%20cases/icc\%2001 04\%200107/court\%20records/chambers/pre\%20trial\%20chamber\%20i/Pages/warrant\%20of\%20arrest\%20for\% 20germain\%20katanga.aspx (Source consultée le 19 mars 2016).

2556 Ibid.

${ }^{2557}$ CPI, Le Procureur c. Mathieu Ngudjolo Chui, $N^{\circ} I C C-01 / 04-01 / 07$, Sous scellés Mandat d'arrêt à l'encontre de Mathieu Ngudjolo Chui, La Chambre préliminaire I, 6 juillet 2007, pp. 6-7, in https://www.icccpi.int/fr_menus/icc/situations\%20and\%20cases/situations/situation\%20icc\%200104/related\%20cases/icc\%2001 04\%200107/court\%20records/chambers/pre\%20trial\%20chamber\%20i/Pages/warrant\%20of\%20arrest\%20for\% 20mathieu\%20ngudjolo\%20chui.aspx (Source consultée le 19 mars 2016).

${ }^{2558}$ CPI, Le Procureur c. Germain Katanga et Mathieu Ngudjolo Chui, N ${ }^{\circ}$ ICC-01/04-01/07, Décision relative à la confirmation des charges, La Chambre préliminaire I, 30 septembre 2008, p. 219, §574, in https://www.icccpi.int/fr_menus/icc/situations\%20and\%20cases/situations/situation\%20icc\%200104/related\%20cases/icc\%2001 04\%200107/court\%20records/chambers/pre\%20trial\%20chamber\%20i/Pages/decision\%20on\%20the\%20confir mation\%20of\%20charges.aspx (Source consultée le 19 mars 2016).
} 
d'éléments de preuve démontrant par exemple l'existence de formations militaires données aux enfants de moins de 15 ans sur ordre de l'accusé, de leur utilisation, par ce dernier, en tant que gardes du corps personnels ou à toute autre fin, avant, pendant et après l'attaque, ce qui ne lui permet pas d'établir au-delà de tout doute raisonnable, l'existence d'un lien entre ce dernier et les enfants présents à Bogoro le 24 février $2003{ }^{2559}$. Mathieu Ngudjolo Chui sera déclaré non coupable de crime de guerre consistant à l'utilisation d'enfants de moins de quinze ans pour la participation active aux hostilités (article 8-2-b-xxvi) voire d'autres accusations dont il était poursuivi. Il sera donc acquitté ${ }^{2560}$. Décision confirmée en Chambre d'appel le 7 avril $2015^{2561}$. Il purge sa peine actuellement en RDC.

Par ailleurs, la décision concernant Germain Katanga sera rendue le 07 mars 2014. Celui-ci sera déclaré à l'unanimité non coupable du crime de guerre consistant à l'utilisation d'enfants de moins de quinze ans en vue de leur participation active aux hostilités. Il sera tout de même déclaré coupable notamment du crime de guerre du fait d'attaque contre la population civile, voire d'autres crimes de guerre et crimes contre l'humanité ${ }^{2562}$. Une peine d'emprisonnement de 12 ans a été prononcée le 23 mai 2014. De laquelle sera déduit le temps de détention ${ }^{2563}$. Trois juges de la Chambre d'appels, nommés à cet effet, ont procédé au réexamen de la peine prononcée pour la réduire. C'est ainsi qu'il a été finalement décidé que la fin de la peine interviendra le 18 janvier 2016. Restent encore des décisions sur des mesures des réparations à allouer aux victimes ${ }^{2564}$.

\section{B. 3 Affaire Bosco Ntaganda}

Un premier mandat d'arrêt a été délivré à l'encontre de Bosco Ntaganda le 22 août 2006 par la Chambre préliminaire I pour ne pas produire d'effets. A la base, la non coopération des autorités congolaises au nom de « la paix sociale ». Il ressortait dudit mandat d'arrêt qu'il y

${ }^{2559}$ CPI, Le Procureur c. Germain Katanga et Mathieu Ngudjolo Chui, $N^{\circ}$ ICC-01/04-01/07, jugement en application de l'article 74 du Statut, La Chambre de première instance II, 18 décembre 2012, pp. 213-214, § 516, in

https://www.icc-

cpi.int/fr_menus/icc/situations\%20and\%20cases/situations/situation\%20icc\%200104/related\%20cases/ICC-0104-02-12/court-records/chambers/trial\%20chamber\%20ii/Pages/3.aspx (Source consultée le 19 mars 2016 ).

${ }^{2560}$ Ibid., p. 215 , point XI.

2561 ICC, The Prosecutor v. Mathieu Ngudjolo Chui, $N^{\circ} I C C-01 / 04-02 / 12$ A, Judgement on the Prosecutor's appeal against the decision of Trial Chamber II entitled «judgment pursuant to article 74 of the Statute », The Appeals Chamber, 7 avril 2015, \$296, 117 in https://www.icccpi.int/FR_Menus/icc/situations\%20and\%20cases/situations/situation\%20icc\%200104/related\%20cases/icc-0104-02-12/court-records/chambers/appeals\%20chamber/pages/271.aspx (Source consultée le 19 mars 2016).

2562 CPI, Le Procureur c. Germain Katanga, $N^{\circ} I C C-01 / 04-01 / 07$, jugement rendu en application de l'article 74 du Statut, La Chambre de première instance II, 7 mars 2014, point XII, 709-710 in https://www.icccpi.int/fr_menus/icc/situations\%20and\%20cases/situations/situation\%20icc\%200104/related\%20cases/icc\%2001 04\%200107/court\%20records/chambers/trial\%20chamber\%20ii/Pages/3436.aspx (Source consultée le 19 mars 2016).

${ }^{2563}$ CPI, Le Procureur c. Germain Katanga, $N^{\circ} I C C-01 / 04-01 / 07$, décision relative à la peine (article 76 du Statut), La Chambre de première instance II, 23 mai 2014, §170, 70-71 in https://www.icccpi.int/FR_Menus/icc/situations \%20and\%20cases/situations/situation\%20icc\%200104/related\%20cases/icc\%20 0104\%200107/court\%20records/chambers/trial\%20chamber\%20ii/pages/3484.aspx (Source consultée le 19 mars 2016).

2564

Voy.

https://www.icccpi.int/fr_menus/icc/situations\%20and\%20cases/situations/situation\%20icc\%200104/Pages/situation\%20index.a spx (Source consultée le 19 mars 2016). 
avait des motifs raisonnables de croire que Bosco Ntaganda était pénalement responsable, suivant le Statut de Rome, des crime de guerre consistant à procéder à l'enrôlement, à la conscription et à la participation active d'enfants de moins de 15 ans $^{2565}$. Dans le même sens, des cas présumés d'attaques des civils, de viols, d'esclavages sexuels, de pillages, de déplacements des civils, etc. lui seront reprochés. Un second mandat d'arrêt plus élaboré sera émis par la Chambre préliminaire II en date du 13 juillet $2012^{2566}$. Bosco Ntaganda fera une reddition volontaire à la CPI le 22 mars 2013. Et le 9 juin 2014, une décision de confirmation des charges sera rendue par la Chambre préliminaire II. Et l'ouverture du procès a eu lieu le 2 septembre 2015. Il est actuellement en détention ${ }^{2567}$.

\section{B. 4 Affaire Callixte Mbarushimana}

Callixte Mbarushimana fera l'objet d'un mandat d'arrêt émis par la Chambre préliminaire I en date du 28 septembre 2010. La Chambre préliminaire I se disait convaincue, dans son mandat d'arrêt, que le sieur précité était pénalement responsable des crimes de guerre constitués d'attaques contre la population civile, de destruction des biens, de meurtres, de viols, de traitements inhumains et de crimes contre l'humanité constitués d'actes de torture, de persécution, etc. ${ }^{2568}$ Ces actes seraient commis dans différents villages ${ }^{2569}$ du Nord-Kivu et du Sud-Kivu par les troupes des Forces Démocratiques pour la Libération du Rwanda (FDLR) dont il serait Secrétaire exécutif. Le 16 décembre 2011, la Chambre préliminaire décidera de ne pas confirmer ses charges. Mburushimana sera acquitté et remis en liberté le 23 décembre $2011^{2570}$.

\section{B.5 Affaire Sylvestre Mudacumura}

Actuellement en fuite, Sylvestre Mudacumura fait l'objet d'un mandat d'arrêt émis par la Chambre préliminaire II depuis le 13 juillet 2012. Il serait pénalement responsable de neuf chefs de crimes de guerre dans les Kivu (Attaques contre la population civile, meurtres,

${ }^{2565}$ CPI, Le Procureur c. Bosco Ntaganda, $N^{\circ} I C C-01 / 04-02 / 06$, Sous scellés Mandat d'arrêt, La Chambre préliminaire, 22 août 2006, p. 4 in $\underline{\text { https://www.icc- }}$ cpi.int/fr_menus/icc/situations\%20and\%20cases/situations/situation\%20icc\%200104/related\%20cases/icc\%2001 04\%200206/court\%20records/chambers/pre\%20trial\%20chamber\%20i/Pages/warrant\%20of\%20arrest.aspx (Source consultée le 19 mars 2016).

${ }^{2566}$ Voy. ICC, The Prosecutor v. Bosco Ntaganda, $N^{\circ} I C C-01 / 04-02 / 06$, decision on the Prosecutor's application under article 58, Pre-Trial Chamber II, in https://www.icccpi.int/fr_menus/icc/situations\%20and\%20cases/situations/situation\%20icc\%200104/related\%20cases/icc\%2001 04\%200206/court\%20records/chambers/ptc-II/Pages/36.aspx (Source consultée le 19 mars 2016). 2567 Voy.

https://www.icccpi.int/fr_menus/icc/situations\%20and\%20cases/situations/situation\%20icc\%200104/Pages/situation\%20index.a spx (Source consultée le 19 mars 2016).

2568 CPI, Le Procureur c. Callixte Mbarushimana, N ${ }^{\circ} I C C-01 / 04-01 / 10$, Urgent Scellés, Mandat d'arrêt à l'encontre de Callixte Mbarushimana, La Chambre préliminaire I, 28 septembre 2010, pp. 6-7 in https://www.icccpi.int/fr_menus/icc/situations\%20and\%20cases/situations/situation\%20icc\%200104/related\%20cases/icc01040 110/court\%20records/chambers/pre\%20trial\%20chamber\%20i/Pages/2.aspx (Source consultée le 19 mars 2016).

${ }^{2569}$ Voy. CPI, Le Procureur c. Callixte Mbarushimana, $N^{\circ} I C C-01 / 04-01 / 10$, Urgent Scellés, Mandat d'arrêt à l'encontre de Callixte Mbarushimana, La Chambre préliminaire I, 28 septembre 2010, 4-5 in https://www.icccpi.int/fr menus/icc/situations\%20and\%20cases/situations/situation\%20icc\%200104/related\%20cases/icc01040 110/court\%20records/chambers/pre\%20trial\%20chamber\%20i/Pages/2.aspx (Source consultée le 19 mars 2016). https://www.icccpi.int/fr_menus/icc/situations\%20and\%20cases/situations/situation\%20icc\%200104/Pages/situation\%20index.a spx (Source consultée le 19 mars 2016). 
mutilations, traitements cruels, viols, torture, destructions de biens, pillages et atteintes à la dignité humaine) $)^{2571}$.

\section{La Cour pénale internationale est-elle efficace pour réprimer les graves violations du DIH contre les enfants en RDC ?}

L'examen successif des critères d'efficacité d'une justice pénale internationale et des affaires relatives à la situation de la RDC devant la CPI appelle logiquement à s'interroger sur l'efficacité de cette juridiction vis-à-vis de la répression des graves violations du DIH contre les enfants en RDC constitutives des crimes de guerre et des crimes contre l'humanité.

En effet, à la lumière de ce qui précède, la CPI se présente incontestablement comme une juridiction supranationale, universelle et permanente dont s'est dotée la «communauté internationale » après un long chemin ${ }^{2572}$. Elle «assume une mission importante pour la sauvegarde de l'humanité, celle de poursuivre et de sanctionner les auteurs des crimes les plus graves qui touchent l'ensemble de la communauté internationale et qui menacent la paix, la sécurité, le bien-être, la vie des humains ${ }^{2573}$. En dépit des critiques précisément des Etats africains sur la prétendue « instrumentalisation » de la CPI dont le Bureau du Procureur, la CPI paraît tout de même comme une instance juridictionnelle indépendante notamment dans sa fonction judiciaire (Chambre d'appel, Chambres de première instance I, II, III, IV, V(A), V(B), VI et VII, Chambres préliminaires I et II). Cette indépendance est suivie de l'impartialité. Par rapport aux moyens d'action, la CPI tente de disposer des moyens humains, matériels et financiers à la hauteur de sa mission. Les juge de la CPI doivent répondre aux critères de moralité (impartialité, intégrité), aux conditions d'exercice des plus hautes fonctions judiciaires; avoir des compétences dans le domaine de droit pénal et de la procédure pénale, ou du droit international (DIH et droits de l'homme); avoir connaissance requise d'une des langue de travail de la Cour (article 36-3-a-b-c). Il s'agit en principe de juristes de très haut niveau. Les conditions de recrutement du personnel ne sont pas aussi simples à la CPI. En outre, sur le plan financier, son budget programme 2015, par exemple, s'élevait à 130665600 euros (Cent trente millions et six cents mille six cents) ${ }^{2574}$ répondant à ses besoins. On notera, par exemple, que Jean-Pierre Bemba versait 2068000 euros (deux millions soixante-huit mille) pour rembourser les frais engagés pour assurer sa défense ${ }^{2575}$. Sans faire allusion aux moyens matériels voire ceux de pression, lesquels restent également dépendants des engagements et contributions des Etats, la CPI répond donc à ce dernier critère. Les Unités des victimes et témoins attestent de l'intérêt de cette juridiction pour cette catégorie. Différentes formes de réparation sont prévues (restitution, indemnisation ou la réhabilitation, article 75 du Statut de la CPI) en dehors d'un Fonds au profit des victimes

https://www.icccpi.int/fr_menus/icc/situations\%20and\%20cases/situations/situation\%20icc\%200104/Pages/situation\%20index.a spx (Source consultée le 19 mars 2016).

${ }^{2572}$ BERKOVICZ, Grégory, La place de la Cour pénale internationale dans la Société des Etats, op.cit., p.336.

2573 FOFE DJOFIA MALEWA, Jean-Pierre, L'administration de la preuve devant la Cour pénale internationale. Règles procédurales et méthodologiques, op.cit., p. 501.

${ }^{2574}$ Résolution et décisions adoptées par l'Assemblée des Etats parties à la Cour Pénale internationale, Troisième partie, $\quad$ ICC-ASP/13/20, p. 18, in https://www.icccpi.int/fr_menus/asp/resolutions/sessions/Pages/2014\%20-\%2013th\%20session.aspx (Source consultée le 19 mars 2016 ).

${ }^{2575}$ Ibid., p. 20. 
(article 79 du Statut de Rome). Il ne reste que la matérialisation de la réparation des victimes -dont les enfants- au-delà de la révolution juridique opérée par la CPI dans l'histoire de la justice pénale internationale (cf. supra).

Bien que la CPI réponde aux différents critères présentés ci-dessus, il s'avère qu'elle a un grand défi à relever, celui de délai relativement court pour le traitement des affaires. En effet, de l'examen des affaires concernant la RDC, il faudrait au moins 5 ans pour qu'une affaire soit finalement jugée ${ }^{2576}$. Situation qui ne prendrait pas toujours en compte l'évolution de l'état des victimes voire de leurs ayants droit. Avec ce temps long réservé à une seule affaire, il est clair que très peu d'affaires seront concernées par cette Cour. Au-delà de tout, spécifiquement à la situation de la RDC, la CPI ne saurait véritablement lutter contre l'impunité du moins pour la période postérieure au $1^{\text {er }}$ juillet 2002. Sa compétence temporelle se trouvant limitée, différents crimes internationaux y perpétrés avant le $1^{\text {er }}$ juillet 2002 resteront impunis. D'où la nécessité d'une juridiction pénale internationale supranationale en RDC (cf. supra) pour ne pas créer une situation discriminatoire à l'égard des présumés criminels et victimes. Situation discriminatoire déjà critiquée suite à la «sélectivité territoriale » des affaires par la CPI. Affaires ne concernant que le district d'Ituri. S'il est certes vrai que la justice pénale internationale est inéluctablement sélective, il y a lieu de la rendre le moins discriminatoire possible ${ }^{2577}$. Et dans le cas d'espèce, bien que le district d'Ituri soit considéré par le Chef de l'Etat congolais, lors de son discours devant l'Assemblée générale des Nations Unies le 24 septembre 2003, comme « une plaie béante qu'une moindre négligence pourrait s'aggraver ${ }^{2578}$, la CPI ferait encore mieux de voir la situation des deux Kivu, «provinces martyres » de tous les conflits armés en RDC, voire des Provinces Orientale ou de l'Equateur.

\section{§3 La Cour internationale de justice et la situation de la RDC : cas particulier des enfants}

Après une définition de la responsabilité pénale internationale à l'introduction de la présente section, il est dès lors logique de consacrer un bref aperçu de la question de la responsabilité internationale des Etats (A) avant de s'appesantir sur la manière dont les questions des graves violations des règles du DIH et des droits de l'enfants ont été traitées par la CIJ (B).

\section{A. Bref aperçu de la Responsabilité internationale des Etats}

En droit international, s'agissant spécifiquement des Etats, la «Responsabilité », et dans le cas d'espèce la responsabilité internationale des Etats, est appréhendée comme «l'institution juridique en vertu de laquelle l'Etat auquel est imputable un acte illicite selon le droit international doit réparation à l'Etat à l'encontre duquel cet acte a été commis ${ }^{2579}$. Il s'agit

\footnotetext{
${ }^{2576}$ Il a fallu 6 ans pour le jugement de l'affaire Thomas Lubanga Dyilo, 7 ans pour l'affaire Germain Katanga et 5 ans pour l'affaire Mathieu Ngudjolo.

${ }^{2577}$ Voy. TURGIS, Noémie, La justice transitionnelle en droit international, Bruylant, Bruxelles, 2014, pp. 455456.

${ }^{2578}$ AG/NU, Documents officiels, A/58/PV. 10, Cinquante-huitième session, $10^{\mathrm{e}}$ séance plénière, Mercredi 24 septembre 2003, op.cit., 16.

${ }^{2579}$ ROUSSEAU, Charles, Droit international public, Tome V les rapports conflictuels, éd. Sirey, Paris, 1983, p. 6.
} 
donc des «conséquences découlant d'un fait internationalement illicite attribuable à un [Etat] ${ }^{2580}$. Comme l'exprime si bien l'article $1^{\text {er }} \mathrm{du}$ Projet d'articles de la CDI sur la Responsabilité de l'Etat pour fait internationalement illicite, «[t]out fait internationalement illicite de 1'Etat engage sa responsabilité internationale ${ }^{2581}$. En clair, des nouvelles relations juridiques naissent entre ces Etats en raison de ce fait illicite ${ }^{2582}$. Il sied de préciser que la doctrine est partagée au sujet de la nature et du contenu de ces obligations. D'une part, c'est l'acception traditionnelle de la responsabilité basée sur la «réparation » qui est soutenue, comme c'est le cas de la définition précédente fournie par Charles Rousseau. D'autre part, différents éléments sont pris en compte au-delà du seul aspect de «réparation ». C'est l'approche des travaux de la CDI où la responsabilité pour fait internationalement illicite est vue comme une «situation complexe » à la suite du manquement ${ }^{2583}$. En ce sens d'ailleurs, 1'article 28 du Projet d'articles de la CDI précité indique que la Responsabilité internationale comporte les «conséquences juridiques » énoncées dans la deuxième partie de ce Projet d'articles à savoir : maintien du devoir d'exécuter l'obligation (art. 29), cessation et non répétition [du fait internationalement illicite] (art. 30) et réparation (art. 31). Il s'agira également des « contre-mesures » bien que non inscrites en cette partie (Chapitre II, Troisième partie $)^{2584}$. Partant de cette dernière conception, suivant Roberto Ago, la responsabilité internationale de l'Etat désigne «Toutes les formes de relations juridiques nouvelles qui peuvent naître en droit international du fait illicite d'un Etat ${ }^{2585}$.

Il résulte de ce qui précède que le manquement (commission par action ou par omission) par un Etat d'une obligation internationale suffit pour constituer un fait internationalement illicite. Il n'est donc plus question de dommage ${ }^{2586}$. La responsabilité internationale devient donc «objective ». C'est donc la violation du droit international par elle-même qui se trouve «sanctionnée » par l'engagement de la responsabilité . Le dommage demeure tout de même dans la majorité des cas une condition nécessaire à la réparation ${ }^{2587}$. «L'obligation de réparer trouve son origine matérielle dans le dommage, c'est-à-dire dans le préjudice causé soit au ressortissant de l'Etat, soit à l'Etat lui-même, soit cumulativement à l'Etat et à son ressortissant ${ }^{2588}$. C'est donc l'aspect de réparation qui nous préoccupera plus dans les lignes

\footnotetext{
${ }^{2580}$ SALMON, Jean-Salmon (dir.), Dictionnaire de droit international public, op.cit., p. 999.

${ }^{2581}$ Résolution A/RES/56/83 du 12 décembre 2001 sur la Responsabilité de l'Etat pour fait internationalement illicite http://www.un.org/french/documents/ga/res/56/ (Source consultée le 5 avril 2016).

${ }^{2582}$ CRAWFORD, James, The International Law Commission's Articles on State Responsibility. Introduction, Text and Commentaries, Cambridge University Press, Cambridge, 2002, p. 77.

${ }^{2583}$ SALMON, Jean-Salmon (dir.), Dictionnaire de droit international public, op.cit., p. 999.

2584 Ibid.

2585 PELLET, Alain, «Les Rapports de Roberto Ago à la CDI », in International Law FORUM du droit international, novembre 2002, Vol. 4 issue 4, p. 226. Voy. aussi Ago, R., Troisième rapport sur la responsabilité des Etats, A.C.D.I., 1971, Vol. II, 1 ${ }^{\mathrm{e}}$ Partie, p. 213 cité par SALMON, Jean-Salmon (dir.), Dictionnaire de droit international public, op.cit., p. 999 ; CRAWFORD, James, The International Law Commission's Articles on State Responsibility. Introduction, Text and Commentaries, op.cit., p. 77.

${ }^{2586}$ Jean-Pierre QUENEUDEC, dans sa thèse de doctorat publiée en 1966 (op. cit., p. 2), citant le cours de Charles Rousseau de l'année académique 1959-1960, faisait remarquer pour celui-ci, comme certains auteurs, « [p]our que la responsabilité surgisse, il n'est pas nécessaire qu'il y ait dommage ». En revanche, lui même soutenait qu' «[i]l ne suffit cependant pas de constater l'illicéité de l'acte d'un Etat pour que celui-ci en soit rendu responsable. [...], il faut aussi, semble t-il, qu'un dommage ait été causé pour que la responsabilité internationale puisse être engagée ». Solution notamment dégagée par l'arrêt de la Cour permanente de Justice Internationale du 26 mars 1925 dans l'affaire Mavrommatis renseigne l'auteur.
}

${ }^{2587}$ PELLET, Alain, « Les Rapports de Roberto Ago à la CDI », « art. cit. », p. 227. 
suivantes.

En effet, en DIH, la question de responsabilité est réglée par l'article 91 du PA I en ces termes : « [1]a Partie au conflit qui violerait les dispositions des Conventions ou du présent Protocole sera tenue à indemnité, s'il y a lieu. Elle sera responsable de tous actes commis par les personnes faisant partie de ses forces armées ». Cette disposition, n'excluant pas les règles et principes développés ci-dessus, rappelle l'article 3 de la Convention (IV) de La Haye du 18 octobre 1907 concernant les lois et coutumes de la guerre sur terre qui renseigne : « [1]a Partie belligérante qui violerait les dispositions dudit Règlement sera tenue à indemnité, s'il y a lieu. Elle sera responsable de tous actes commis par les personnes faisant partie de sa force armée ${ }^{2589}$. A la base, cette disposition découlerait de la proposition allemande à la deuxième Conférence de La Haye de $1907^{2590}$. «Le principe de la proposition allemande n'a pas soulevé d'objection. Mais une discussion s'est engagée au sujet de la distinction qu'elle consacrait entre les populations des Etats belligérants et celles des Etats neutres. Dans les deux cas, a-t-on dit, il $\mathrm{y}$ a violation du droit et, au moins en règle, la réparation devrait-être la même ${ }^{2591}$. Bien plus, du point de vue de l'Allemagne, imputer la responsabilité à l'Etat pour tous les actes commis par les membres de ses forces armées, n'est que l'extension au droit des gens du principe du droit privé, selon lequel le maître est responsable de ses préposés ou agents ${ }^{2592}$. Tout de même, la réparation pour des conséquences préjudiciables occasionnées par la violation du droit de la guerre existe bien avant 1907. Ceci n'est donc qu'une consécration conventionnelle de la règle coutumière $^{2593}$.

$\mathrm{Au}$ sujet de la réparation, la CIJ, dans l'affaire Avena et autres ressortissants mexicains (Mexique c. Etats-Unis d'Amérique), la CIJ réaffirme le principe général applicable aux conséquences juridiques d'un fait internationalement illicite, énoncé par la Cour permanente de justice internationale dans l'affaire d'Usine de Chorzow en 1927, selon lequel « [...] la violation d'un engagement [international] entraîne l'obligation de réparer dans une forme

${ }^{2588}$ ROUSSEAU, Charles, Droit international public, Tome V les rapports conflictuels, op.cit., p. 12.

2589 Article 3 de la Convention (IV) concernant les lois et coutumes de la guerre sur terre du 18 octobre 1907, in Deuxième Conférence internationale de la Paix, La Haye 15 juin - 18 octobre 1907, Actes et documents, Tome I, Séances plénières de la Conférence, Ministère des affaires étrangères, , Imprimerie Nationale, La Haye, 1907, p. 627. Textes disponibles sur https://www.icrc.org/dih/INTRO/195 (Source consultée le 07 avril 2016).

${ }^{2590}$ La proposition de la délégation d'Allemagne concernait «De l'indemnisation pour violation du Règlement de 1899 concernant les lois et coutumes de la guerre sur terre (Annexe1) » et se présentait comme suit : Article 1 : «La Partie belligérante qui violera les dispositions de ce Règlement au préjudice de personnes neutres sera tenue de dédommager ces personnes du tort qui leur a été causé. Elle sera responsable de tous actes commis par les personnes faisant partie de sa force armée. La fixation du dommage causé et de l'indemnité à payer, à moins qu'une indemnisation immédiate en espèces n'ait été prévue, pourra être remise à plus tard, si la Partie belligérante estime que cette fixation est incompatible, pour le moment, avec les opérations militaires ». Article 2 : «En cas de violation au préjudice de la Partie adverse, la question de l'indemnisation sera réglée lors de la conclusion de la paix ». Voy. Deuxième Conférence internationale de la Paix, La Haye 15 juin - 18 octobre 1907, Actes et documents, Tome III, Séances plénières de la Conférence, Ministère des affaires étrangères, , Imprimerie Nationale, La Haye, 1907, p. 247. Ou Deuxième Conférence internationale de la Paix, La Haye 15 juin - 18 octobre 1907, Actes et documents, Tome I, Séances plénières de la Conférence, Ministère des affaires étrangères, op.cit., p. 103. Pour approfondir l'analyse sur l'origine de l'article 3 précité, voy. ARGENT, Pierre d', Les Réparations de guerre en droit international public. La responsabilité internationale des Etats à l'épreuve de la guerre, Bruylant-L.G.D.J, Bruxelles-Paris, 2002, pp. 507 et ss.

${ }^{2591}$ Deuxième Conférence internationale de la Paix, La Haye 15 juin - 18 octobre 1907, Actes et documents, Tome I, Séances plénières de la Conférence, Ministère des affaires étrangères, op.cit., p. 103.

2592 Ibid.

2593 ARGENT, Pierre d', Les Réparations de guerre en droit international public. La responsabilité internationale des Etats à l'épreuve de la guerre, op.cit., p. 443. 
adéquate ». "Quant a savoir ce qui constitue « une réparation dans une forme adéquate », cela dépend, suivant la Cour, manifestement, des circonstances concrètes de chaque affaire ainsi que de la nature exacte et de l'importance du préjudice, puisqu'il s'agit de déterminer quelle est la « réparation dans une forme adéquate » qui correspond à ce préjudice ${ }^{2594}$. Cela ne se présume donc $\operatorname{pas}^{2595}$.

Dans la sentence finale Erythrée/Ethiopie ${ }^{2596}$, la Commission de réclamation tient pertinemment compte de la situation économique générale des Parties, voire des individus afin de déterminer l'indemnisation relative aux violations du jus in bello $(\S \S 18,26)$. De même pour veiller à ce que le fardeau financier ultime imposé à une partie ne soit pas très excessif (\$22). De nombreux compromis (§38), la nature, la gravité et l'ampleur des actes illicites particuliers sont pris en compte. (§40). Aucun plafonnement ne peut-être établi (§23) Ainsi, l'indemnisation se limite à un rôle correctif, et non punitif (§26).

Au-delà de cette théorisation, quid de la situation de la responsabilité internationale de l'Etat (Ouganda) devant la CIJ pour violations des règles du DIH (ou du DIDH) protégeant l'enfant en conflits armés en RDC?

\section{B. La Cour internationale de justice et la protection des enfants dans les conflits armés en RDC}

Les violations du DIH et DIDH concernant les enfants en situation de conflits armés en RDC ont constitué une des questions au centre de débats dans l'affaire des Activités armées (RDC c. Ouganda) devant la CIJ.

En effet, sous cet angle, la RDC, partie demanderesse, à présenté au départ les différentes situations dans lesquelles les populations civiles en général ont été atteintes par les graves violations du DIH et du DIDH. Ces situations ne concernent non moins les enfants. Et de manière particulière, la RDC relève des cas d'enfants recrutés et utilisés par les forces armées ougandaises (UPDF).

Devant la CIJ, la RDC a argué que les forces armées ougandaises (UPDF) ont commis des massacres des civils à grande échelle en particulier en Ituri ; des actes de tortures et d'autres formes de traitement inhumain et dégradant; des actes de représailles contre des civils soupçonnés d'avoir abrité des ennemis. Les pillages des biens des civils au "profit personnel »des soldats ougandais et la destruction délibérée des villages, des habitations privées ont été également épinglés à charge de l'Ouganda durant ses opérations en $\mathrm{RDC}^{2597}$. La RDC se réfère également aux combats entre les forces armées ougandaises et rwandaises à Kisangani en 1999 et 2000 occasionnant de très nombreux morts des civils et des dommages

\footnotetext{
${ }^{2594}$ CIJ, Affaire Avena et autres ressortissants mexicains (Mexique c. Etats-Unis d'Amérique), arrêt du 31 mars 2004, Recueil 2004, p. 59, §119.

2595 Ibid., p. 60, $\$ 123$.

${ }^{2596}$ Commission des réclamations Erythrée / Ethiopie, Ethiopia's Damages Claims, sentence arbitrale finale, 17 août 2009.

2597 CIJ, Affaire des activités armées sur le territoire du Congo (République démocratique du Congo c. Ouganda), arrêt du 19 décembre 2005, , Recueil 2005, pp. 232-233, §§ 183-184
} 
considérables aux infrastructures et habitations ${ }^{2598}$.

Concernant spécialement les enfants,

« [1]a RDC affirme que, en 2000, plusieurs centaines d'enfants congolais ont été recrutés de force par les UPDF et emmenés en Ouganda pour y suivre une formation idéologique et militaire. En particulier, selon la RDC, de nombreux enfants auraient été enlevés en août 2000 dans les régions de Bunia, Beni et Butembo et auraient reçu une formation militaire au camp de Kyankwanzi, en Ouganda, en vue d'être incorporés dans les forces armées ougandaises. La RDC affirme que les enfants ainsi enlevés n'ont pu quitter le camp d'entraînement de Kyankwanzi pour être définitivement rapatriés en RDC qu'au début de juillet 2001, après des efforts persistants menés par l'UNICEF et les Nations Unies en faveur de leur libération ${ }^{2599}$.

Pour étayer ses affirmations, la RDC s'appuie sur diverses sources dont les résolutions du CS/NU, les rapports établis par des organismes onusiens (ex : MONUC, Rapporteur spécial de la Commission des droits de l'homme), et des ONG nationales et internationales ${ }^{2600}$. La RDC conclut ainsi que les forces armées ougandaises ont manqué à leur obligation de protection des populations civiles, en lançant des attaques indiscriminées ${ }^{2601}$, voire à l'obligation de vigilance, en tant que puissance occupante (en Ituri particulièrement), de faire respecter le DIH et les droits de l'homme ${ }^{2602}$.

Pour répondre aux allégations de la RDC, «[1]'Ouganda soutien[dra] que la RDC a systématiquement manqué de fournir des éléments de preuves crédibles au soutien de ses allégations $[\ldots] »^{2603}$. Les sources d'informations auxquelles se référait la RDC seraient partisanes aux yeux de l'Ouganda (Par exemple, l'Association africaine des droits de l'homme - ASADHO, vue comme ONG pro-congolaise). Il fait remarquer que la MONUC ne disposait pas d'un personnel qualifié « pour procéder à des enquêtes de nature spécifiquement juridique ${ }^{2604}$. Dans le même sens, au sujet de recrutement forcé d'enfants-soldats, l'Ouganda affirme que les allégations de la RDC «se limitent à des accusations tout à fait générales dépourvues de tout support probatoire $»^{2605}$.

Les arguments avancés par l'Ouganda n'ont rien d'étonnant car face à un Etat demandeur qui doit apporter des preuves de violation d'une obligation internationale (Principe Actori incumbit probatio), l' « Etat défendeur peut se contenter de se retrancher derrière la règle de la

\footnotetext{
${ }^{2598}$ Ibid., p. 233, § 186.

${ }^{2599}$ Ibid., p. 233, § 185. Voy. aussi République Démocratique du Congo, Affaire relative aux activités armées sur le territoire du Congo (République Démocratique du Congo c. Ouganda), Cour internationale de justice, Réplique de la République Démocratique du Congo, Vol. I, mai 2002, pp.330-331.

${ }^{2600}$ Voy. CIJ, Affaire des activités armées sur le territoire du Congo (République démocratique du Congo c. Ouganda), arrêt, Recueil 2005, pp. 232-234, §§ 182-188. . Voy. aussi République Démocratique du Congo, Affaire relative aux activités armées sur le territoire du Congo (République Démocratique du Congo c. Ouganda), Cour internationale de justice, Réplique de la République Démocratique du Congo, op.cit., pp. 330331.

${ }^{2601}$ CIJ, Affaire des activités armées sur le territoire du Congo (République démocratique du Congo c. Ouganda), arrêt du 19 décembre 2005, Recueil 2005, p. 233, § 186.

2602 CIJ, Affaire des Activités armées sur le territoire du Congo (République démocratique du Congo c. Ouganda), arrêt du 19 décembre 2005, Recueil 2005, p. 234, § 189.

${ }^{2603}$ Ibid., p. 234, § 191.

${ }^{2604}$ Ibid., p. 235, § 191.

${ }^{2605}$ Ibid., § 192.
} 
charge de la preuve, en insistant sur la circonstance que les faits ne seraient pas suffisamment établis ${ }^{2606}$.

Toujours au sujet de recrutement d'enfants-soldats, l'Ouganda arguera par la suite que ces enfants étaient «sauvés » des conflits ethniques à Bunia et d'une mutinerie au sein de RCDML, puis emmenés à Kyankwanzi pour des «soins et conseils » et rapatriés via l'UNICEF et la Croix-Rouge ${ }^{2607}$.

Pour trancher, la Cour prendra en considération des éléments de preuve contenus dans des documents des Nations Unies «dans la mesure où ils ont une valeur probante et sont corroborés, si nécessaires, par d'autres sources crédibles ${ }^{2608}$. Elle ne procédera tout de même pas à l'examen de « chacun des incidents allégués » par la RDC ${ }^{2609}$.

«La Cour estime dès lors qu'il existe une concordance suffisante entre les informations émanant de sources crédibles pour la convaincre que des violations massives des droits de l'homme et de graves manquements au droit international humanitaire ont été commis par les UPDF sur le territoire de la RDC ${ }^{2610}$. Au sujet de recrutement d'enfants, « [1]a Cour estime qu'il existe des éléments de preuve convaincants du fait que des enfants-soldats ont été entraînés dans les camps d'entraînement des UPDF et que celles-ci n'ont rien fait pour empêcher leur recrutement dans les zones sous leur contrôle ${ }^{2611}$.

Dès lors, il revenait à la Cour de répondre en premier lieu à la question d'attribution des actes des UPDF à l'Ouganda. Aucune difficulté ne se posait car les UPDF étaient un organe de l'Etat ougandais. Ainsi, le comportement de cet organe est considéré comme le fait de l'Etat ougandais en vertu du droit international coutumier ${ }^{2612}$. En outre, «tous les actes commis » par les UPDF relèvent de la responsabilité de l'Ouganda ${ }^{2613}$ au regard de l'article 3 de la Convention de La Haye (IV) concernant les lois et coutumes de la guerre sur terre de 1907 et de l'article 91 du PA I. En second lieu, la Cour devait répondre à la question de savoir si ce comportement était constitutif de violation des obligations internationales de l'Ouganda. Pour ce faire, elle va procéder à la recension des instruments juridiques applicables en l'espèce notamment ceux du DIH et des droits de l'Homme auxquels l'Ouganda et la RDC sont parties, en relevant les «dispositions pertinentes ${ }^{2614}$. Elle conclut que l'Ouganda est responsable des violations du DIH et du DIDH commises par les UPDF $^{2615}$.

Concernant la situation des enfants, au sens de la CIJ, seuls les articles 38, paragraphes 2 et 3 de la Convention relative aux droits de l'enfant, et 1,2, 3 (paragraphe 3), 4, 5 et 6 du

\footnotetext{
${ }^{2606}$ CORTEN, Olivier, Méthodologie du droit international public, op.cit., p. 254.

2607 CIJ, Affaire des Activités armées sur le territoire du Congo (République démocratique du Congo c. Ouganda), arrêt du 19 décembre 2005, Recueil 2005, p. 235, § 192.

2608 Ibid., p. 239, § 205.

${ }^{2609}$ Ibid., $\$ 206$.

2610 Ibid., $\$ 207$.

2611 CIJ, Affaire des Activités armées sur le territoire du Congo (République démocratique du Congo c. Ouganda), arrêt du 19 décembre 2005, Recueil 2005, p. 241, §210.

2612 Ibid., p. 242, 213.

${ }^{2613}$ Voy. Ibid., $\$ 214$.

${ }^{2614}$ Ibid., pp. 243-244, §217-219.

${ }^{2615}$ Ibid., p. 245, §220. Voy. aussi § 345, point 3, p. 280.
} 
Protocole facultatif concernant l'implication d'enfants dans les conflits armés se trouvent violés dans le cas d'espèce ${ }^{2616}$.

A l'unanimité des juges, la Cour a instruit à la République de l'Ouganda de réparer ce préjudice causé. «[L]a nature, les formes et le montant ${ }^{2617}$ de cette réparation devront être déterminés par les deux parties. La Cour n'interviendra qu'en cas d'absence d'accord. C'est donc à ce dernier stade que la présente affaire se situe ${ }^{2618}$. En date du 12 mai 2015, suite à l'échec de la dernière négociation sur l'indemnisation de la RDC par la République de l'Ouganda, attesté par un communiqué conjointement signé par les deux parties le 19 mars 2015 à Pretoria, la RDC saisit la CIJ afin que celle-ci tranche la question ${ }^{2619}$. La Cour fixait la date d'expiration du délai du dépôt du mémoire de la RDC au 06 janvier $2016^{2620}$. Ce dépôt a été finalement reporté au 28 avril 2016 à la demande de la RDC, sans objection de la partie adverse, la République de l'Ouganda ${ }^{2621}$.

De ce qui précède, il revient de constater que la question de violations des règles du DIH et du DIDH contre des enfants - dont leur recrutement forcé et leur transfert vers l'Ouganda - n'est pas développée dans le raisonnement de la Cour. La RDC, elle-même, n'avait pas fait autant $^{2622}$. Sous cet aspect, la Cour s'intéresse plus aux éléments factuels qu'à la discussion en droit. La CIJ ne se limite qu'à évoquer les dispositions qu'elle considère « pertinentes ». A cet égard, elle ne fait pas expressément allusion aux dispositions du «DIH» protégeant spécialement les enfants dont par exemple les articles 49 , al. $1^{\mathrm{er}}, 50$, al.2 et 51 de la CG IV qu'évoquait la partie demanderesse (RDC) ${ }^{2623}$.

Au rang des instruments du DIDH, la Cour retient l'article 38, paragraphes 2 et 3, de la Convention relative aux droits de l'enfant et écarte, par exemple, l'article 22 de la Charte africaine des droits et du bien-être de l'enfant évoqué par la RDC. ${ }^{2624}$ Lequel, rappelons-le, assure une protection plus efficace à l'enfant que l'article 38, paragraphes 2 et 3 de la Convention relative aux droits de l'enfant. En l'absence de toute motivation, il y a lieu de se demander qu'est-ce qui justifie telle démarche. D'autres dispositions pourraient également être évoquées en l'espèce, par exemple, les articles 77 et 78 du PA I qui traitent respectivement de la protection et de l'interdiction d'évacuation des enfants.

Ainsi, au sujet du transfert de plusieurs enfants congolais vers les camps d'entraînement des UPDF en Ouganda, aucune « disposition pertinente » n'est évoquée à cet effet par la Cour. Il

\footnotetext{
${ }^{2616}$ Ibid., p. 244, §219.

${ }^{2617}$ Voy. Ibid., p. 257, §260.

${ }^{2618}$ Voy. p. 257, §260, Voy/ aussi p. 281, §345, points 5-6.

2619 Voy. CIJ, Affaire des Activités armées sur le territoire du Congo (République démocratique du Congo c. Ouganda), Ordonnance du $1^{\mathrm{er}}$ juillet 2015, Rôle général n²116, p.3.

${ }^{2620}$ Voy. Ibid., p. 4.

2621 Voy. CIJ, Affaire des Activités armées sur le territoire du Congo (République démocratique du Congo c. Ouganda), Ordonnance du 10 décembre 2015, p. 2.

${ }^{2622}$ Voy. République Démocratique du Congo, Affaire relative aux activités armées sur le territoire du Congo (République Démocratique du Congo c. Ouganda), Cour internationale de justice, Mémoire de la République Démocratique du Congo, Vol. I, op.cit., pp.146-149 et 187-192 ou République Démocratique du Congo, Affaire relative aux activités armées sur le territoire du Congo (République Démocratique du Congo c. Ouganda), Cour internationale de justice, Réplique de la République Démocratique du Congo, op.cit., p. 343.

2623 Ibid.

2624 Ibid.
} 
aurait été souhaitable d'évoquer, par exemple, les articles 49, al. $1^{\text {er }}$ de la CG IV ou 78 du PA I interdisant respectivement les transferts forcés ou les déportations forcées des personnes protégées en dehors du territoire occupé et l'évacuation des enfants vers un pays étranger par une partie au conflit. La Cour n'épingle donc en ce sens que des dispositions relevant des instruments du DIDH. En dehors des dispositions du DIH coutumier contenues dans le règlement de La Haye de 1907, les dispositions du DIH évoquées sont celles qui protègent les populations civiles ou des personnes civiles en général, à savoir : la distinction entre civils et combattants (article $48 \mathrm{du}$ PAI), la protection générale des personnes civiles (article 51 du PA I) ; la protection générale des biens à caractère civil (article 52 du PA I), la précaution dans l'attaque (article 57 du PA I), la précaution contre les effets des attaques (article 58 du PA I) et les garanties fondamentales (article 75, paragraphes 1 et 2 du PA I).

Bien plus, la Cour ne s'est pas donné non plus la peine d'interpréter ces «dispositions pertinentes » dont celles relatives à la protection des enfants. Une occasion manquée de l'évolution, par la jurisprudence de La Haye, des règles du DIH - voire du DIDH- assurant la protection des enfants en situation de conflits armés.

Près de dix ans après le prononcé de l'arrêt, la réparation au profit des victimes tarde à venir. La RDC estimait cette réparation à dix milliards de dollars américains. Somme qui ne serait pas issue d'une sérieuse évaluation ${ }^{2625}$. D'où l'idée de la création d'une «Commission Nationale d'indemnisation des victimes » - que suggérait Fidèle ZEGBE - pour l'évaluation des dommages subis mais aussi pour l'octroi d'indemnisation aux victimes voire leur assistance matérielle, médicale, psychologique et sociale ${ }^{2626}$. Toutefois, ce que redoutaient certains auteurs - dont l'auteur précité - est donc arrivé : le défaut d'accord entre parties sur la question de réparation les reconduit vers la CIJ (cf. supra). Cette absence de réparation conduit à s'interroger sur la suite de l' «enfance non réparée » de multiples enfants déportés vers l'Ouganda, recrutés et utilisés par les UPDF, mutilés, etc. Et comment s'y prendre avec les familles des enfants décédés? Que dire des «enfants mineurs d'hier » devenus actuellement majeurs ? Bien qu'il y ait lieu d'espérer à la réparation, celle-ci n'aurait tout de même point un sens correctif ni punitif, peut-être symbolique.

\footnotetext{
${ }^{2625}$ Voy. ZEGBE Zegs, Fidèle, « Activités armées sur le territoire du Congo (RDC c. Ouganda) : plaidoyer pour une Commission Nationale d'indemnisation des victimes », points 5 et 45 in http://www.congovision.com/forum/zegs1.html (Source consultée le 28 mars 2016).

${ }^{2626}$ Voy. Ibid., points 48 à 59.
} 


\section{Conclusion du Chapitre III}

Après une étude des règles du DIH relatives à la protection des enfants applicables en conflits armés en RDC au chapitre précédent, la logique voudrait que le chapitre suivant se consacre à l'examen de la mise en œuvre de ces règles. C'est donc l'objet du présent chapitre.

En effet, ce chapitre a abordé successivement dans le cadre des conflits armés en RDC, l'étude des mécanismes de protection des enfants institués par les CG et leurs PA (Section I) et par les instruments des droits de l'homme (Section II), avant de se préoccuper des mécanismes intergouvernementaux -principalement dans le cadre de l'ONU- (Section III), gouvernementaux et non gouvernementaux (Section IV). C'est en dernier lieu qu'il examinera les mécanismes de sanction - voire de réparation - au niveau national et international (Section V). L'essentiel de l'interrogation résidait sur l'efficacité de ces mécanismes.

A la lumière de ce qui précède, rappelons que la mise en œuvre du DIH est une responsabilité qui incombe primordialement à l'Etat, dans le cas d'espèce à la RDC et aux autres Etats parties aux conflits armés dont les Républiques de l'Ouganda et du Rwanda (parties demeurées très actives à ces conflits de manière directe et indirecte). En ce sens, cette mise en œuvre s'est avérée très problématique. S'il est vrai que la RDC a institué différents mécanismes pour assurer la mise en œuvre d'une part de la démobilisation des EAFGs (ex : UEPNDDR) et d'autre part des droits de l'enfant, il n'existe cependant pas des mécanismes spécifiquement liés au DIH à l'instar des Commissions nationales de mise en œuvre du DIH. Bien plus, concernant réellement la protection spéciale des enfants - «civils» et «combattants »- pendant les hostilités, il n'existe pas un véritable mécanisme étatique opérationnel en pleine période des hostilités et assurant cette protection. L'ensemble des mécanismes sont antérieurs et postérieurs aux hostilités, et non opérant réellement pendant les hostilités. Or, c'est pendant la période des hostilités que se pose la question de protection spéciale avec acuité. En outre, les mécanismes institués en RDC sont à leur tour heurtés à différentes difficultés de ressources afin de fonctionner efficacement.

Sur le terrain, la protection spéciale de l'enfant sur le champ de batailles ne constitue cependant pas une préoccupation primordiale des parties au conflit. Différents Rapports des organisations internationales et des ONG attestent que les forces armées de la RDC, par exemple, sont l'une des parties aux conflits armés - internationaux et non internationaux - qui recrutent et utilisent le plus les enfants, sans compter de nombreux cas d'autres graves violations du DIH sur des enfants dont elles seraient responsables. Les fonctions que remplissent des ONG pour venir en aide aux enfants victimes des conflits armés demeurent louables. Tout de même, le climat d'insécurité régnant sur le terrain ne permet pas toujours aux humanitaires d'accomplir leur mission. Nombreux sont donc victimes des graves violations du DIH.

Les graves violations du DIH sur des enfants en RDC ont préoccupé les juridictions nationales (militaires) et internationales (CPI et CIJ). Les avancées à cet égard demeurent maigres. Dans le même ordre d'idées, les organes de droits de l'homme au niveau africain et 
international se sont intéressés à cette question pour ne pas aboutir à des résultats avec « effets » sur terrain.

Au plan international, en termes des mécanismes du DIH, le CICR s'est avéré d'une grande importance notamment au regard de sa diffusion du DIH, de sa diplomatie humanitaire ainsi que de sa mise en œuvre du DIH au profit des enfants victimes des conflits armés en RDC. En dépit de son expérience, le CICR éprouve tout de même certaines difficultés de fonctionnement que d'autres organismes humanitaires sur le terrain. L'UNICEF et la MONUSCO sont aussi d'une grande utilité pour la protection des enfants en conflits armés en $\mathrm{RDC}$, sur le terrain. C'est également à travers leurs rapports voire leur pression que la situation des enfants devant les instances judiciaires a pu progresser un tant soit peu. Le CICR, l'UNICEF et la MONUSCO voire de nombreuses ONG internationales et nationales demeurent toutefois des mécanismes de mise en œuvre des règles de protection spéciale des enfants en conflits armés, sans lesquels la situation des enfants en RDC serait encore plus catastrophique.

En dépit de leur caractère politique, les apports de l'ONU, à travers précisément le CS/NU et le SG/NU, de l'UE sont appréciables pour l'avancée de la protection des enfants en période de conflits armés en RDC. L'UA reste tout de même à la traine.

Que proposer à l'issue de cette analyse ?

Puisque la mise en œuvre du DIH est une responsabilité première qui incombe à l'Etat, il y a lieu de suggérer un mécanisme spécifique du DIH en RDC. Nous pensons à la création d'une « Commission Nationale de mise en œuvre du droit international humanitaire » qui réserverait des départements spécifiques pour des personnes vulnérables dont les enfants. Il sera prévu en son sein un mécanisme devant intervenir en pleins conflits armés en collaboration avec les humanitaires. Il nous semble qu'avec des mécanismes nationaux efficaces, les mécanismes internationaux n'interviendront qu'à titre de « renfort ». Or dans la situation présente, ce sont des mécanismes internationaux qui assument les fonctions que devait assumer l'Etat Congolais. Les forces armées de celui-ci se trouvent régulièrement reprises comme « auteurs » des graves violations du DIH sur des enfants.

Il faudrait également prévoir l'installation d'un Tribunal pénal international pour la RDC pour faire face aux différentes graves violations du DIH contre les enfants.

Dans le même ordre, il y a lieu de penser à un répondant au plan international. S'il existe pour les droits de l'homme des répondants au niveau international (Conseil des droits de l'homme) pourquoi ne pas penser à un tel organe pour une branche aussi spécifique qui est le DIH. Ceci développerait indubitablement des approches d'interprétation propres au DIH. A cet égard, il y aurait un Rapporteur spécial pour des questions des enfants en DIH. Celui-ci, estimonsnous, travaillerait en étroite collaboration avec le Représentant spécial du SG/NU pour les enfants et les conflits armés voire d'autres organes intergouvernementaux, gouvernementaux et non gouvernementaux s'occupant de ce secteur. Pour le reste, il serait très utile de renforcer les mécanismes du DIH existants. 
Cette dernière proposition rejoint celle que partage la $32^{\mathrm{e}}$ conférence du Mouvement international de la Croix-Rouge de décembre 2015. En effet, dans la mesure où les CG font partie de rares traités ne comportant pas d'obligations de présentation de rapports périodiques, le CICR, conjointement avec le gouvernement suisse, suggérait à la Conférence de se prononcer en faveur notamment de «la mise en place d'un système de présentation de rapports périodiques ». Toutefois, certains Etats attachés au cadre juridique existant, avec ses mécanismes, ne seront pas prêts à admettre l'idée de création des nouveaux mécanismes ${ }^{2627}$. D'où la non approbation de telle proposition.

2627 Voy. Entretien de Helen Durham présenté par CRAWFORD, Julia, « La Volonté politique de respecter le droit de la guerre existe-t-elle, s'interroge le CICR », in JusticeInfo.Net disponible sur http://www.justiceinfo.net/fr/component/k2/27200-«-le-sommet-humanitaire-mondial-devra-promouvoir-lerespect-du-droit-de-la-guerre-»,-déclare-la-directrice-du-département-du-droit-international-et-des-politiqueshumanitaires-du-cicr.html?Itemid=102 (Source consultée le 17 mai 2016). 


\section{Conclusion de la seconde partie}

Les conflits armés en RDC présentent des causes multidimensionnelles et interdépendantes. Essentiellement présentés comme «guerre par procuration» pour l'exploitation des ressources naturelles de la RDC, les conflits armés en RDC tiennent également pour cause la situation socio-politique de la région et du pays en particulier.

De 1996 à ce jour, ces conflits armés complexes ont revêtu des qualifications variées en DIH : CANI, CANI internationalisé et CAI. Et pour mieux les circonscrire afin de dégager avec prudence les règles applicables, trois périodes ont été cernées à savoir d'octobre 1996 à mai 1997; d'août 1998 à juin 2003; et de juin 2003 à ce jour. En fonction des acteurs étatiques et non étatiques, les règles applicables en CAI et en CANI, suivant précisément l'état de ratification de nombreux instruments applicables - dont ceux du DIH et du DIDH-, ont été déterminées. Des règles issues des accords régionaux, spéciaux et de la législation nationale congolaises ont été également concernées.

Pour atteindre l'objectif de conquête du pouvoir et de contrôle des ressources naturelles de la RDC, le recrutement et l'utilisation des enfants aux hostilités restent le mode opérationnel indiqué des belligérants. De l'engagement «volontaire»- appréhendé comme «l'absence d'alternative » - et de conscription, différentes raisons expliquent de telles pratiques. L'enfant civil, avec sa vulnérabilité psychique ou morale et physique naturelle, souffre atrocement des effets de ces conflits armés. Le traitement qui lui est réservé ne va pas dans le sens de son intérêt supérieur. Victime des atrocités indicibles, il demeure la «cible légitime » des parties à ces conflits armés. Sa santé et son éducation sont en péril.

De ce qui précède, s'il est admis qu'il existe - en dépit des critiques formulées - des règles assurant la protection des enfants civils en conflits armés (CANI et CAI), la situation des enfants soldats n'est pas enviable. En somme, ils sont doublement victimes des pratiques des «Seigneurs de guerre » et des forces armées étatiques d'une part et d'un droit des conflits armés assurant très faiblement leur protection d'autre part. Ce droit caractérisé par une multitude de sources assure une «prohibition relative » de recrutement et de participation des enfants aux hostilités. Il se trouve en outre marqué par la présence des mécanismes multiples à efficacité relative. Ainsi, le tout concourt à une « protection spéciale » relative, mieux moins efficace, de l'enfant en situation de conflits armés.

Les enfants soldats méritent donc mieux sur les champs de bataille. La vulnérabilité physique, l'absence de discernement dont ils font preuve conduisent à affirmer qu'ils ne sont pas « réellement» comme des combattants adultes. D'où un traitement non égalitaire, autrement c'est de la «discrimination». Et d'autant plus qu'ils se retrouvent généralement sur les champs de bataille indépendamment de leur «bonne volonté ». C'est ainsi qu'en pleines hostilités, nous estimons qu'il revient aux Etats principalement à la RDC de «prendre des mesures nécessaires pour rendre les enfants moins nuisibles et moins victimes » au plan législatif et administratif. 


\section{CONCLUSION GENERALE}

La présente étude sur «Le droit international humanitaire et la protection des enfants en situation de conflits armés (Etude de cas de la République Démocratique du Congo » a porté sa principale interrogation sur le contenu et l'efficacité de la protection spéciale de l'enfant civil ou soldat - en situation de conflits armés. La RDC, pays dont les conséquences des conflits armés de près de deux décennies sur les enfants sont catastrophiques, est son cadre précis d'investigation.

En effet, la protection de l'enfant en situation de conflits armés est le fruit d'une évolution. Laquelle est due - comme pour le reste du DIH - notamment aux nouvelles méthodes de combat, nouvelles formes des conflits armés ayant pris notamment pour cibles les enfants.

Ces règles du DIH se trouvent complétées par celles du DIDH. Ce dernier fait expressément référence, à travers ses instruments, au DIH dans ce cas précis. Ces règles sont en outre renforcées par celles du DIPé mais également et surtout par différentes résolutions des organisations internationales dont particulièrement celles de l'ONU. Le soft-law, bien que non revêtu du caractère obligatoire, reste d'un apport non moins important à cet égard.

De la lecture de ces différents instruments, la protection de l'enfant en situation de conflits armés varie suivant le type de conflit armés et selon que l'enfant est civil ou soldat. Elle est à la fois générale et spéciale au regard de chacun de ces statuts. Enfin, elle est aussi fonction de l'âge de l'enfant.

L'enfant civil de moins de quinze ans, ne prenant pas directement part aux hostilités bénéficie d'une protection générale en vertu notamment des règles de la CG IV, de l'article 3 commun aux CG, des PA I et II suivant qu'il se retrouve en CAI ou en CANI (Sans oublier les instruments du DIDH). Cette protection «conditionnelle » du DIH cesse dès lors que l'enfant prend directement part aux hostilités et pendant la durée de cette participation. L'enfant perd par là son immunité de protection et devient une cible légitime de la partie adverse. Cette protection générale est doublée de la protection spéciale afin de répondre aux vulnérabilités physiques, mentales ou psychiques de l'enfant. Il va sans dire que ces vulnérabilités qui ne disparaissent pas au moment de la participation directe de l'enfant aux hostilités cesseront cependant d'être couvertes de la protection spéciale dès l'instant de cette participation et durant tout le déroulement de celle-ci.

L'enfant soldat de moins de quinze ans, participant directement aux hostilités, et revêtu du statut de combattant, bénéficie de la protection générale réservée aux «combattants » au regard notamment des principes et règles régissant la conduite des hostilités. Ses vulnérabilités ne sont plus prises en compte en DIH, lequel le traite au même rang que des combattants adultes. En toute logique, il paraît non moins discriminatoire de vouloir traiter identiquement un enfant, personne se trouvant en situation de vulnérabilité particulière, qu'un adulte. 
Néanmoins, une protection spéciale est réservée à l'enfant qui participe directement aux hostilités et tombe au pouvoir d'une partie adverse, qu'il soit ou non prisonnier de guerre (cf. articles $77 \S 3$ du PA I ; $4 \S 3 d$ du PA II). En outre, des garanties fondamentales liées au traitement humain reste de mise dans toutes circonstances.

Bien plus, l'âge de moins de quinze ans est donc celui ancré en DIH conventionnel et coutumier. Le Statut de Rome de la CPI confirme cette consécration d'interdiction de recrutement et de participation active d'enfants de moins de quinze ans aux hostilités (cf. art. $8 \S 2 \mathrm{~b}$ xxvi et $8 \S 2$ e vii). Mais la tendance d'interdiction d'enrôlement obligatoire et de participation directe des personnes de moins de dix-huit ans aux hostilités est de plus en plus présente et approuvée en DIDH et dans la pratique du DIH. Cette tendance est largement appuyée par l'ONU, le CICR voire des ONG. Ce droit est encore très avancé au plan régional africain à cet égard. Celui-ci interdit de manière absolue le recrutement - obligatoire et volontaire - et la participation - directe et indirecte - des enfants (moins de dix-huit ans) aux hostilités (cf. Protocole de Maputo).

Dans la même optique, sous l'angle régional africain, les présentes recherches attestent de l'existence d'un droit international coutumier fixant un standard de protection de l'enfant équivalent au moins à l'article 22 de la Charte africaine des droits et du bien-être de l'enfant interdisant le recrutement et la participation directe des enfants (personnes de moins de dixhuit ans) aux hostilités. Ceci est encore approuvé dans le cadre de trois Etats très impliqués dans les conflits armés sous examen : Ouganda, RDC et Rwanda.

Il se dégage que la protection de l'enfant contre son recrutement et sa participation aux hostilités est suffisamment assurée par les règles du DIH complétées par celles du DIDH, voire du DIPé. En revanche, il ressort que le DIH en général, et le complément lui apporté par ces branches précitées, accorde une faible protection spéciale aux enfants qui participent directement aux hostilités. Il est donc insuffisant et lacunaire sous cet angle. La logique de la protection spéciale qui tient à répondre aux vulnérabilités particulières de l'enfant s'interrompt face à un enfant de moins de quinze ans (ou plus) qui participe directement aux hostilités alors que ses vulnérabilités demeurent.

Ainsi, s'il est admis qu'il existe - en dépit des critiques formulées - des règles assurant la protection des enfants civils en conflits armés (CANI et CAI), la situation des enfants soldats n'est donc pas enviable. En somme, ils sont doublement victimes des pratiques des «Seigneurs de guerre » et des forces armées étatiques, d'une part et d'un droit des conflits armés assurant très faiblement leur protection, d'autre part. Ce qui atteste que les Etats n'ont pas souhaité s'engager inconditionnellement avec des règles plus protectrices de l'enfance en conflits armés.

Toutefois, la coutume en général, suivant l'étude du CICR, ne démontrerait pas que l'enfant combattant ou civil qui prend part aux hostilités est généralement attaqué par les parties au combat.

Il se révèle que le régime de protection de l'enfant en temps de conflits armés n'est point à 
mesure de lui assurer une protection spéciale efficace. Des sérieux écueils sont à épingler au niveau de la formulation de certaines obligations conventionnelles. Des termes utilisés pour assurer la protection spéciale à l'enfant en période de conflits armés s'avèrent plus « permissifs » et «réducteurs » de ladite protection. A la base, les Etats, «au nom de leur souveraineté », se refusent de souscrire des «obligations inconditionnelles». Ils ont donc des larges marges de manœuvres dans la mise en œuvre des obligations souscrites. Les instruments assurant la protection spéciale de l'enfant se divergent notamment sur l'âge des enfants et la teneur d'obligations. Ils créent une certaine fragmentation des règles.

En dehors des écueils décelés au niveau des règles en question, il est remarquable que le DIH n'institue pas à proprement parler des mécanismes spéciaux qui s'occuperaient de «la protection spéciale » de l'enfant en période de conflits armés. Selon les spécialistes de la question, le DIH n’organise pas suffisamment sa mise en œuvre. Les mécanismes institués conventionnellement en $\mathrm{DIH}$ pour assurer la protection générale des personnes civiles posent en règle générale des problèmes de dysfonctionnement. Par là, l'absence d'une institution spécialement réservée à la protection de l'enfant en temps de conflits armés, ou son dérèglement, s'avérait envisageable. Tout de même, celle-ci paraît plus qu'importante car il n'existe pas, à dire vrai, de protection spéciale sans l'institution des mécanismes spéciaux. Il paraît inefficace qu'une protection spéciale soit l'œuvre des mécanismes classiques ou généraux.

Toutefois, le DIDH apporte une énorme contribution à travers ses mécanismes conventionnels. C'est le cas notamment du Comité des droits de l'enfant. Celui-ci développe et précise davantage le contenu de la protection spéciale de l'enfant notamment en conflits armés. Mais, il se trouve limité dans l'examen périodique des rapports étatiques de cinq ans et ne peut examiner des questions urgentes d'enfants. En outre, son pouvoir reste très limité en termes de recommandations adressées aux Etats. Il pourrait cette fois-ci, conformément au troisième protocole entré en vigueur en avril 2014, recevoir des communications individuelles au sujet des violations des droits de l'enfant.

Des mécanismes non conventionnels viennent également en appui de la protection spéciale de l'enfant en conflits armés. L'ONU, à travers ses multiples mécanismes, s'est avérée d'une grande importance pour la mise en œuvre du DIH, singulièrement de la protection de l'enfant en conflits armés. L'ONU s'est approprié le DIH, droit qui s'est plus développé en dehors de ses enceintes. L'enfant se trouve au centre des multiples activités de ses organes (AG/NU, CS/NU, Secrétariat, ECOSOC/NU, CIJ, etc.). Malgré la présence de ces différentes institutions onusiennes et des organismes internationaux qui se préoccupent de la protection des enfants, l'ONU ne cesse de créer des mécanismes plus spécifiques traitant de la protection des enfants en période de conflits armés, notamment en RDC. C'est précisément les cas du Mécanisme de surveillance et de communication de l'information sur les enfants et les conflits armés et du Groupe de travail sur les enfants et les conflits armés créés par le CS/NU, ou encore du Secrétariat avec le Bureau du Représentant spécial du Secrétaire général pour les enfants et les conflits armés. On ne parlerait point de protection de l'enfant sans faire allusion à l'UNICEF. Ce dernier est à la base d'adoption et de ratification de différents instruments juridiques contraignants voire de soft-law s'intéressant aux problèmes d'enfants en conflits armés. Il travaille en collaboration avec des $\mathrm{ONG}$, lesquelles ne sont donc point à négliger dans la 
promotion de la protection de l'enfant en période de conflits armés. Des organisations régionales telles que l'UE et l'UA réservent également de l'intérêt à cette question.

A la lumière de ce qui précède, la mise en œuvre du DIH est une responsabilité qui incombe primordialement à l'Etat.

Dans le cadre des conflits armés complexes en RDC, de 1996 à ce jour, revêtus des qualifications variées en DIH de CANI, CANI internationalisé et CAI, la mise en œuvre du DIH lié à la protection spéciale de l'enfant s'est avérée très problématique.

En effet, si la législation en vigueur en RDC semble apporter un éclairage certain par rapport à l'interdiction de l'enrôlement et de l'utilisation des enfants dans les forces, groupes armés ou la police (en temps de paix et de conflits armés) voire leur criminalisation (voy. les articles 71 et 87 de la loi n09/001 du 10 janvier 2009 portant protection de l'enfant), rien ne semble être dit sur les mécanismes ou organes devant veiller sur cette protection. Bien plus, la question de la protection des enfants sur le champ de bataille, mieux en pleines hostilités, ne semble pas être abordée. L'article 72, alinéa 1, de la loi nº9/001 du 10 janvier 2009 portant protection de l'enfant dispose simplement que « [1]'Etat garantit la protection, l'éducation et les soins nécessaires aux enfants affectés par les conflits armés, les tensions ou troubles civils, spécialement à ceux trouvés et non identifiés par rapport à leur milieu famille ». Ainsi, le droit congolais de la protection de l'enfant en situation de conflits armés tombe dans les pièges du DIH et du DIDH.

Alors que la RDC a institué différents mécanismes pour assurer la mise en œuvre d'une part de la démobilisation des EAFGA (ex : UEPNDDR) et d'autre part des droits de l'enfant en général, il n'existe cependant pas des mécanismes spécifiquement liés au DIH à l'instar des Commissions nationales de mise en ceuvre du DIH. Bien plus, concernant réellement la protection spéciale des enfants - «civils » et «combattants » - pendant les hostilités, il n'existe pas un véritable mécanisme étatique opérationnel en pleine période des hostilités et assurant cette protection. L'ensemble des mécanismes sont opérationnels en période antérieure et postérieure aux hostilités, et non opérant réellement pendant les hostilités au profit de la protection spéciale de l'enfant. Or, c'est pendant la période des hostilités où se pose la question de protection spéciale avec acuité. En outre, les mécanismes institués en RDC sont à leur tour butés à différentes difficultés de ressources (humaines, financières, logistiques, etc.) afin de fonctionner efficacement.

Sur le terrain donc, la protection spéciale de l'enfant sur le champ de batailles ne constitue cependant pas une préoccupation primordiale des parties au conflit. Différents Rapports des organisations internationales et des ONG attestent que les forces armées de la RDC, par exemple, sont l'une des parties aux conflits armés - internationaux et non internationaux - qui recrutent et utilisent plus les enfants, sans compter de nombreux cas d'autres graves violations du DIH sur des enfants dont elles seraient responsables. La situation reste encore très alarmante pour les enfants soldats filles. Recrutées de force par les forces et groupes armés, elles sont généralement exploitées sexuellement, contraintes aux travaux domestiques ou militaires et participent non moins directement aux hostilités. Devenues épouses des 
combattants voire mères, les enfants soldats filles sont très difficilement relâchées par les forces et groupes armés. Au demeurant, elles ne sont pas si facilement identifiables notamment pour crainte personnelle de stigmatisation mais également par le fait que leur présence est généralement niée par leurs bourreaux.

Par ailleurs, les fonctions que remplissent des ONG pour venir en aide aux enfants victimes des conflits armés demeurent louables. Tout de même, le climat d'insécurité régnant sur le terrain ne permet pas toujours aux humanitaires d'accomplir leur mission. Nombreux sont donc victimes des graves violations du DIH.

Les graves violations du DIH sur des enfants en RDC ont préoccupé les juridictions nationales (militaires) et internationales (CPI et CIJ). Les avancées à cet égard demeurent maigres. L'impunité fait encore son règne. Dans le même ordre d'idées, les organes de droits de l'homme au niveau africain et international se sont intéressés à cette question pour ne pas aboutir aux résultats avec « effets » sur terrain.

Au plan international, en termes des mécanismes du DIH, le CICR s'est avéré d'une grande utilité notamment au regard de sa diffusion du DIH, de sa diplomatie humanitaire ainsi que de sa mise en œuvre du DIH au profit des enfants victimes des conflits armés en RDC. En dépit de son expérience, le CICR éprouve tout de même certaines difficultés de fonctionnement que d'autres organismes humanitaires sur le terrain. L'UNICEF et la MONUSCO sont aussi d'une grande importance pour la protection des enfants en conflits armés en RDC, sur terrain. C'est également à travers leurs rapports voire leur pression que la situation des enfants devant les instances judiciaires ont pu progresser un tant soit peu. Le CICR, l'UNICEF et la MONUSCO voire de nombreuses ONG internationales et nationales demeurent toutefois des mécanismes de mise en œuvre des règles de protection spéciale des enfants en conflits armés, sans lesquels la situation des enfants en RDC serait encore plus catastrophique.

En dépit de leur caractère politique, les apports de l'ONU, à travers précisément le CS/NU et le SG/NU, de l'UE sont appréciables pour l'avancée de la protection des enfants en période de conflits armés en RDC. L'UA reste tout de même à la traine.

De ce qui précède, il va sans dire qu'à travers une grille méthodologique centrée sur la technique juridique, les hypothèses émises au départ de cette dissertation se trouvent confirmées.

Que suggérer au regard de ces résultats de recherche?

Deux ordres de suggestions nous semblent utiles au regard même de ces résultats recherche et de l'interrogation initiale. Il s'agit de suggestions sous l'angle des règles et des mécanismes de protection spéciale de l'enfant en conflits armés. 


\section{A. Pour l'efficacité des règles de protection spéciale de l'enfant en période d'hostilités en particulier et de conflits armés en général :}

- Les enfants soldats méritent donc mieux sur les champs de bataille. La vulnérabilité physique, l'absence de discernement dont ils font preuve conduit à affirmer qu'ils ne sont pas « réellement» comme des combattants adultes. La logique de protection spéciale ne devrait pas cesser face à cette participation. Et d'autant plus que les enfants se retrouvent généralement sur les champs de bataille indépendamment de leur «bonne volonté ». C'est ainsi qu'en pleines hostilités, nous estimons qu'il revient aux Etats notamment, principalement à la RDC, de «prendre des mesures nécessaires pour rendre les enfants moins nuisibles et moins victimes » au plan législatif et administratif. Seuls les moyens non létaux seraient recommandés. Et pour qu'une telle mesure ne soit pas à la base de recrutement et d'utilisation massive des enfants par les forces ou des groupes armés, un «système de surveillance mutuelle entre Etats » sur les champs de bataille est à encourager. Chaque Etat devra signaler « en toute urgence » et à « tout moment » la présence des enfants dans les rangs des forces ou groupes armés ennemis au niveau des instances onusiennes habilitées, dont le $\mathrm{CS} / \mathrm{NU}$, pour des mesures conséquentes. C'est donc ici qu'il faudrait renforcer le rôle que joue le Mécanisme de surveillance et de communication de l'information sur les enfants et les conflits armés (cf. infra). Tout ceci vient en complément de l'appréciation rigoureuse du principe de proportionnalité lors de l'attaque et d'un test rigoureux entre nécessités militaires et considérations humanitaires que suggère une partie de la doctrine.

- La RDC est partie, au plan universel et régional, à plusieurs instruments juridiques relatifs à la protection de l'enfant en situation de conflits armés. Cet Etat s'est doté en outre d'un arsenal juridique - disparate - qui se rapporte à cette protection. Toutefois, la question de la protection de l'enfant est faiblement prise en compte au plan national. Il est remarquable que la loi n009/01 du 10 janvier 2009 sur la protection de l'enfant n'y réserve que trois articles sur un total de deux cent deux. Elle ne prévoit aucun mécanisme spécifique pour faire face à cette protection qu'elle qualifie pour autant d'exceptionnelle (cf. supra)

Dès lors, il est important de plaider pour l'adoption d'une nouvelle loi sur la protection « complète » de l'enfant en conflits armés. Celle-ci devra déterminer les mesures (obligations de résultat) que doivent prendre les différentes parties au conflit en faveur des «enfants civils» et des «enfants soldats». Et ensemble avec toutes les autres réglementations antérieures, elles formeront ce qu'il convient d'appeler le "Code congolais de protection de l'enfant en situation de conflits armés ». Ceci rendrait visibles les règles relatives à la protection de l'enfant en période de conflits armés qui demeurent très disparates.

- C'est également ici le lieu indiquer de faire valoir les activités de promotion des règles du $\mathrm{DIH}$ à l'endroit des autorités militaires et civiles mais également au profit des enfants.

La prévention des violations des règles du DIH de protection de l'enfant, voire du DIH en général, implique la promotion de ces règles. L'entreprise de promotion du DIH requiert différentes activités possibles au rang desquelles des mesures de «diffusion » sont à classer. Ces dernières sont d'une grande importance bien qu'insuffisantes à elles seules. Pour le cas de la RDC, elles sont à la fois une obligation internationale (cf. les articles 47 de la CG I ; 48 de 
la CG II ; 127 de la CG III et 144 de la CG IV CG ; 83 du PA I ; 19 du PA II) et constitutionnelle (art. 45 alinéa 6 de la Constitution du 18 février 2006). Cette diffusion au sens «plus largement possible » en temps de paix et en temps de guerre exigera diverses mesures dont la possession et la connaissance des instruments du DIH par les autorités militaires et civiles compétentes ; des instructions dans des écoles et autres établissements de formation ; la formation du personnel qualifié pour faciliter l'application du DIH ; etc. Il faudrait envisager des mesures telles que la traduction des règles du DIH, précisément des règles de protection de l'enfant en général et d'interdiction d'enrôlement et de participation directe des enfants aux hostilités en quatre langues nationales du pays (Kiswahili, lingala, kikongo et tshiluba), au besoin en dialectes pour le cas de milices ethniques. Ceci renforce déjà quelques efforts fournis au niveau national à ce sujet, en dehors de ceux généralement entrepris par des ONG dont le CICR en RDC. C'est le cas de la publication en Journal Officiel et en langues nationales de la Convention relative aux droits de l'enfant; d'autres publications officielles telles que le Livre Blanc du Ministère des droits humain ou la « Revue Libota » du Ministère des affaires sociales et de la famille; la publication en 34.000 exemplaires (jusqu'en octobre 2007) du manuel d'enseignement "Programme national d'éducation civique et morale avec intégration des droits de l'homme » élaboré par la Direction des programmes scolaires et matériels didactiques du Ministère de l'enseignement primaire et secondaire, en collaboration avec le Haut Commissariat des Nations Unies aux droits de l'Homme (HCDH), etc. C'est également le cas de la diffusion du Protocole facultatif à la CDE concernant l'implication d'enfants dans les conflits armés ou des affiches, brochures, dépliants et panneaux avec un message principal «Plus jamais un seul enfant dans les forces et groupes armés » adressé à la communauté congolaise en quatre langues nationales par la Commission Nationale de Désarmement, Démobilisation et de Réinsertion (CONADER).

\section{B. Pour l'effectivité et l'efficacité des mécanismes de protection spéciale de l'enfant en situation de conflits armés}

- Puisque la mise en œuvre du DIH est une responsabilité première qui incombe à l'Etat, et qu'il n'existerait pas de protection spéciale sans l'institution des mécanismes spécifiques, il y a lieu d'en suggérer un en RDC: la «Commission Nationale de mise en aeuvre du droit international humanitaire ». Celle-ci réserverait une place de choix pour la protection spéciale de l'enfant en conflits armés. Il sera prévu en son sein un mécanisme devant intervenir en pleins conflits armés en collaboration avec les organismes humanitaires existants.

- Avec des mécanismes nationaux efficaces, les mécanismes internationaux n'interviendront qu'à titre subsidiaire. Or dans la situation présente, ce sont des mécanismes internationaux qui assument les fonctions que devait assumer l'Etat Congolais. D'autant plus que les forces armées de celui-ci se trouvent régulièrement cités comme « auteurs » des graves violations du DIH sur des enfants. D'où, l'établissement d'un Tribunal pénal international pour la RDC, en l'absence d'institutions judiciaires efficaces en RDC, pour établir des responsabilités et servir de prévention des graves violations du DIH contre les enfants.

En effet, face aux tentatives des solutions apportées par des réformes du système judiciaire 
mais sans succès remarquables, la proposition de la création d'un Tribunal pénal international ou d'un Tribunal spécial pour la RDC est souhaitable. Celle-ci n'est pas une idée nouvelle. Emise à la fois par les institutions gouvernementales et par la société civile congolaises, voire par l'opinion internationale, cette idée naît dès les premières années de conflits armés en RDC, précisément de «la deuxième guerre de libération ». Toutefois, il n'existe aucune requête officielle de création d'un Tribunal pénal international pour la RDC.

Ainsi, si des voix unanimes s'élèvent pour la création d'un Tribunal pour la RDC, des divergences demeurent tout de même au tour du contenu de cette juridiction spéciale. Les questions se posent donc au sujet de sa composition, de sa compétence temporelle (des crimes commis dès 1960 à ce jour ou juste après 1996 ?), du droit applicable (droit international ou droit congolais ?), de son degré d'indépendance et d'impartialité, de son financement, voire le doute au sujet de sa matérialisation, etc. La Société civile congolaise plaide depuis plusieurs années pour la mise en place d'un « Tribunal spécialisé et mixte » c'est-à-dire avec une composante à la fois congolaise et internationale, avec un siège en RDC.

Face aux crimes indicibles du DIH et des droits de l'homme commis en RDC et offensant toute la communauté humaine, l'idée d'une juridiction internationale supranationale, servant du modèle TPIY ou TPIR, s'avère plus que nécessaire. Toutefois, cette juridiction devrait être composée en très grande partie des juges internationaux (garantie d'indépendance et d'impartialité) mais aussi de quelques juges congolais afin d'offrir davantage de sens à la continuité après la fin de sa mission. Pour ne pas alourdir sa mission, minimiser ses finances et le rendre davantage efficace, ce tribunal aura pour compétence temporelle la période d'octobre 1996 à juillet 2002. Ceci lui permettrait évidemment de repartir ses tâches avec la CPI dont la compétence temporelle débute le $1^{\text {er }}$ juillet 2002. Son siège serait établi sur un Etat voisins de la RDC entretenant avec celle-ci des relations moins conflictuelles (ex : Zambie). Le droit congolais devrait faire partie du droit applicable en marge du droit international applicable. Appréhendé le droit congolais par une juridiction supranationale permettrait d'avoir un autre «son de cloche» en termes d'interprétation. Lequel pourrait permettre de peaufiner sa jurisprudence. Au-delà de tout, une place importante doit être réservée à la victime - enfant. Leur accordant, contrairement à ce qui est vécu, l'initiative d'action pénale à travers des ONG spécialisées des questions d'enfants. Ceci permettrait d'apporter une correction au système pénal international existant mais aussi au système pénal congolais, en matière de répression des crimes internationaux notamment, où la participation de la victime au procès est limitée.

Toutefois, l'obtention d'un tel tribunal reste tributaire d'une diplomatie humanitaire agissante de la part de l'Etat congolais mais également d'une pression de la société civile.

- En marge de cette juridiction pénale internationale, la rédynamisation des institutions de justice transitionnelles (Commissions Vérité et réconciliation) demeure d'une grande nécessité au regard d'innombrables crimes perpétrés sous la période indiquée voire plus. Crimes pour lesquels les institutions judiciaires ne sauraient pas toujours apporter des réponses appropriées. 
- L'idée de la création d'une «Commission Nationale d'indemnisation des victimes » - déjà suggérée - pour l'évaluation des dommages subis mais aussi pour l'octroi d'indemnisation aux victimes voire leur assistance matérielle, médicale, psychologique et sociale demeure d'actualité.

- S'il existe pour les droits de l'homme des répondants au niveau international (Conseil des droits de l'homme) pourquoi ne pas penser à un tel organe pour une branche aussi spécifique qui est le DIH. Ceci développerait indubitablement des approches d'interprétation propres au DIH. Ce vœu déjà formulé par le CICR est ici réitéré et soutenu.

Enfin, il ressort de cette étude que pour que la protection spéciale de l'enfant soit suffisante ou complète, des règles et mécanismes doivent être efficaces avant - pendant - et après les hostilités. Par là, il s'agirait donc d'une protection spéciale tout au long des conflits armés. Laquelle devrait s'inscrire dans un environnement global protecteur de l'enfant - en temps de paix et de conflits armés. 


\section{BIBLIOGRAPHIE ${ }^{2628}$}

\section{Sources conventionnelles}

\section{a. Traités internationaux ${ }^{2629}$}

- Convention (II) concernant les lois et coutumes de la guerre sur terre et son annexe: Règlement concernant les lois et coutumes de la guerre sur terre. La Haye, 29 juillet 1809.

- Convention (IV) concernant les lois et coutumes de la guerre sur terre et son annexe : Règlement concernant les lois et coutumes de la guerre sur terre. La Haye, 18 octobre 1907.

- Charte des Nations Unies. San Francisco, 26 juin 1945.

- Statut de la Cour internationale de justice. San Francisco, 26 juin 1945.

- Convention (I) de Genève pour l'amélioration du sort des blessés et des malades dans les forces armées en campagne, 12 août 1949.

- Convention (II) de Genève pour l'amélioration du sort des blessés, des malades et des naufragés des forces armées sur mer, 12 août 1949.

- Convention (III) de Genève relative au traitement des prisonniers de guerre, 12 août 1949.

- Convention (IV) de Genève relative à la protection des personnes civiles en temps de guerre, 12 août 1949.

- Convention européenne de sauvegarde des droits de l'homme et des libertés fondamentales, 4 novembre 1950.

- Convention pour la protection des biens culturels en cas de conflit armé, 14 mai 1954

- Pacte international relatif aux droits civils et politiques, 16 décembre 1966.

- Pacte international relatif aux droits économiques, sociaux et culturels, 16 décembre 1966.

- Convention de Vienne sur le droit des traités, 23 mai 1969.

- Convention de l'Organisation Internationale du Travail concernant les soins médicaux et les indemnités de maladie, (Convention n ${ }^{\circ} 130$ ), 25 juin 1969

- Convention de l'Organisation de l'Unité Africaine régissant les aspects propres aux

\footnotetext{
${ }^{2628}$ Cette bibliographie ne reprend pas: certains Rapports d'ONG jugés moins importants, les Communiqués de presses des Organisations internationales, les mémoires de DEA ou de Spécialisation consultés pour l'élaboration de cette thèse. Certains cours, à l'exception de ceux de l'Académie de Droit international de La Haye, n'y sont pas non plus repris.

${ }^{2629}$ Les traités internationaux repris ci-dessus sont consultables dans le Recueil des Traités des Nations Unies en ligne: https://treaties.un.org/pages/UNTSOnline.aspx?id=3\&clang=fr . Ils peuvent également être consultés directement sur les sites internets des organisations internationales concernées, ou encore du CICR pour les conventions relatives au DIH.
} 
problèmes des réfugiés en Afrique, 10 septembre 1969

- Convention américaine relative aux droits de l'homme, 22 novembre 1969.

- Protocole additionnel (I) aux Conventions de Genève du 12 août 1949 relatif à la protection des victimes des conflits armés internationaux, 8 juin 1977.

- Protocole additionnel (II) aux Conventions de Genève du 12 août 1949 relatif à la protection des victimes des conflits armés non internationaux, 8 juin 1977.

- Charte africaine des droits de l'homme et des peuples, 27 juin 1981.

- Convention contre la torture et autres peines ou traitements cruels, inhumains ou dégradants, 10 décembre 1984.

- Convention européenne sur la reconnaissance de la personnalité juridique des organisations non gouvernementales, 24 avril 1986.

- Charte africaine des droits et du bien-être de l'enfant, 11 juillet 1990.

- Convention des Nations Unies relative aux droits de l'enfant, 20 novembre 1989.

- Statut du Tribunal pénal international pour l'ex-Yougoslavie (annexé à la résolution 827 du Conseil de sécurité de l'ONU), 25 mai 1993.

- Statut du Tribunal pénal international pour le Rwanda (annexé à la résolution 955 du Conseil de sécurité de l'ONU), 8 novembre 1994.

- Protocole relatif à la Charte africaine des droits de l'homme et des peuples portant création d'une Cour africaine des droits de l'homme et des peuples, 9 juin 1998.

- Statut de la Cour pénale internationale, 17 juillet 1998.

- Convention de l'Organisation Internationale du Travail concernant l'interdiction des pires formes de travail des enfants et l'action immédiate en vue de leur élimination (Convention $\mathrm{n}^{\circ}$ 182), 17 juin 1999.

- Protocole facultatif à la Convention relative aux droits de l'enfant, concernant l'implication d'enfants dans les conflits armés, 25 mai 2000.

- Statut du Tribunal spécial pour la Sierra Leone, annexé à l'Accord entre les Nations Unies et le gouvernement sierra léonais sur la création d'un Tribunal spécial pour la Sierra Leone, 16 janvier 2002.

- Protocole à la Charte africaine des droits de l'homme et des peuples relatif aux droits des femmes, 11 juillet 2003 .

- Pacte sur la Paix, la Sécurité, la Stabilité et le Développement dans la Région des Grands Lacs, 15 décembre 2006

- Traité de Lisbonne modifiant le Traité sur l'Union européenne et le Traité instituant la 
Communauté européenne, 13 décembre 2007, Journal Officiel de l'Union européenne, 2007/C 306/01, 17.12.2007.

- Convention de l'Union africaine sur la protection et l'assistance aux personnes déplacées en Afrique, 22 octobre 2009.

- Protocole facultatif à la Convention relative aux droits de l'enfant établissant une procédure de présentation de communications, 19 décembre 2011.

- Charte des droits fondamentaux de l'Union européenne, 7 décembre 2000, Journal Officiel de l'Union européenne, 2012/C 326/02, 26.10.2012.

\section{b. Accords de paix}

- Accord de cessez-le-feu en République Démocratique du Congo (Accord de Lusaka) du 10 juillet 1999.

- Protocole d'accord signé entre les gouvernements de la R.D.C et du Rwanda sur le retrait des troupes rwandaises du territoire congolais et le désarmement des forces ex-FAR et

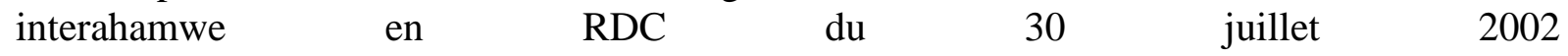
http://democratie.francophonie.org/IMG/pdf/Protocole_d_Accord_RDC_Rwanda_retrait_trou pes_rwandaises.pdf (Source consultée le 10 mai 2015).

- Accord entre les gouvernements de la République Démocratique du Congo et de la République de l'Ouganda sur le retrait des troupes ougandaises de la République Démocratique du Congo, sur la coopération et la normalisation des relations bilatérales entre les deux pays du 6 septembre 2002 http://www.droitcongolais.info/files/0.4.36.-Accord-du-6septembre-2002--RDC-Ouganda-_Retrait-des-troupes-ougandaises-de-la-RDC.pdf $\quad$ (Source consultée le 10 mai 2015).

- Accord global et inclusif sur la transition en République Démocratique du Congo du 16 décembre 2002 in http://www.irinnews.org/pdf/in-depth/dial_rdc.pdf (Source consultée le 14 mai 2015).

- Acte d'engagement de Goma du 23 janvier 2008, in «Accord de paix signé à Goma » http://www1.rfi.fr/actufr/articles/097/article_61837.asp (Source consultée le 22 avril 2015).

- Accord de paix entre le Gouvernement et le Congrès National pour la Défense du Peuple (CNDP) du 23 mars 2009, in http://radiookapi.net/files/Accord-CNDP-Gvt-23-mars-2009pdf.pdf?55c0b5 (Source consultée le 22 avril 2015).

\section{Législations nationales}

\section{a. $\mathbf{R D C}^{2630}$}

- Constitution de la République Démocratique du Congo du 18 février 2006, in Journal Officiel de la République Démocratique du Congo, $47^{\mathrm{e}}$ année, numéro spécial, Kinshasa 18 février 2006, pp. 3-78.

${ }^{2630}$ Documents consultables au site internet du journal officiel de la RDC $:$ http://www.leganet.cd/JO.htm 
- Constitution de la République Démocratique du Congo modifiée par la loi n¹1/002 du 20 janvier 2011 portant révision de certaines articles de la Constitution de la République Démocratique du Congo du 18 février 2006 (Textes coordonnés), in Journal officiel spécial, 5 février 2011.

- Constitution de la République Démocratique du Congo du $1^{\text {er }}$ aout 1964, in Moniteur congolais, $5^{\mathrm{e}}$ année, numéro spécial du $1^{\mathrm{er}}$ août 1964, pp. 1-33.

- Acte constitutionnel de la transition du 09 avril 1994.

- Décret-loi constitutionnel n003 du 27 mai 1997 relatif à l'organisation et à l'exercice du pouvoir en République Démocratique du Congo

- Constitution de la transition du 04 avril 2003.

- Loi 81-003 du 17 juillet 1981 portant statut du personnel de carrière de services publics de l'Etat.

- Loi n ${ }^{\circ} 87-010$ portant Code de la Famille du $1^{\text {er }}$ août 1987.

- Loi $\mathrm{n}^{\circ} 004 / 2001$ du 20 juillet 2001 portant dispositions générales applicables aux Associations sans but lucratif et aux établissements d'utilité publique.

- Loi n $\mathrm{n}^{\circ} 015 / 2002$ du 16 octobre 2002 portant Code du travail, Journal Officiel de la République Démocratique du Congo, 43e année, Numéro spécial, 25 octobre 2002, pp. 4-80.

- Loi n04/023 du 12 novembre 2004 portant organisation générale de la défense et des Forces armées

- Loi n ${ }^{\circ} 023 / 2002$ du 18 novembre 2002 portant Code de justice militaire, in Journal Officiel de la République Démocratique du Congo-Numéro Spécial -20 mars 2003, p. 25.

- Loi $\mathrm{n}^{\circ} 024 / 2002$ du 18 novembre 2002 portant Code pénal militaire in Journal officiel, $\mathrm{n}^{\circ}$ Spécial, 20 mars 2003, pp. 71-109.

- Loi nº6/018 du 20 juillet 2006 modifiant et complétant le décret du 30 janvier 1940 portant Code pénal congolais

- Loi ${ }^{\circ} 09 / 001$ du 10 janvier 2009 portant protection de l'enfant.

- Loi $\mathrm{n}^{\circ} 11 / 008$ du 09 juillet 2011 portant criminalisation de la torture.

- Loi organique $\mathrm{n}^{\circ} 13 / 011$ du 21 mars 2013 portant institution, organisation et fonctionnement de la Commission nationale des Droits de l'Homme

- Loi organique $\mathrm{n}^{\circ} 13 / 011-\mathrm{B}$ du 13 avril 2013 portant organisation, fonctionnement et compétence de juridiction de l'ordre judiciaire.

- Ordonnance-loi n ${ }^{\circ} 66-455$ du 16 août 1966 portant création d'un service civique obligatoire in Moniteur Congolais n²3 du 15-12-1966. 
- Décret-Loi nº19 du 23 août 1997 portant création de la Cour d'Ordre Militaire

- Décret-loi $\mathrm{n}^{\circ} 066$ du 9 juin 2000 portant démobilisation et réinsertion des groupes vulnérables présents au sein des forces combattantes

- Décret-loi 001-2002 du 26 janvier 2002 portant organisation générale de la défense et des forces armées congolaises

- Ordonnance $n^{\circ} 60$ portant création d'une académie militaire, $3^{\mathrm{e}}$ année, $\mathrm{n}^{\circ} 17$ du 23 juillet 1962.

- Décret $n^{\circ} 09 / 17$ du 30 avril 2009 modifiant et complétant le décret n03/041 du 18 décembre 2003 portant création du Comité interministériel chargé de la conception et de l'orientation en matière de désarmement, démobilisation et réinsertion.

- Décret n09/35 du 12 août 2009 portant création, organisation et fonctionnement de l'Entité de Liaison de Droits de l'l'Homme en République Démocratique du Congo.

- Décret n09/36 du 12/08/2009 portant création, organisation et fonctionnement de la Commission Nationale de Préparation et de Suivi de l'Examen Périodique universel des Droits de l'Homme.

- Décret $n^{\circ}$ 09/37 du 10 octobre 2009 portant création, organisation et fonctionnement d'un Etablissement public dénommé «Fonds National pour la Promotion de la Femme et la Protection de l'Enfant».

- Décret $n^{\circ}$ 09/38 du 10 octobre 2009 portant création, organisation et fonctionnement de l'Agence nationale de lutte contre les violences faites à la Femme et à la Jeune et Petite Fille.

- Arrêté ministériel $\mathrm{n}^{\circ} 04 / \mathrm{CAB} / \mathrm{MDH} / 038 / \mathrm{KGB} / 2009$ modifiant et complétant l'arrêté $\mathrm{n}^{\circ} 013 / \mathrm{MDH} / \mathrm{CAB} / \mathrm{MBK} / 005 / 2001$ du 13 décembre 2001 portant création d'un comité interministériel d'élaboration et de suivi des rapports initiaux et périodiques des droits de l'homme.

\section{b. Rwanda}

- Constitution du Rwanda du 04 juin 2003.

- République du Rwanda, Loi 27/2001 relative aux droits et à la protection de l'enfant contre les violences du 28 avril 2001. 


\section{Résolutions, Rapports et autres documents des organisations internationales et sociétés savantes}

\section{1. Organisation des Nations unies}

\section{a. Conseil de sécurité (http://www.un.org/fr/sc/documents/resolutions/)}

Résolution S/RES/808 (1993)

Résolution S/RES/827 (1993)

Résolution S/RES/955 (1994)

Résolution S/RES/1234 (1999)

Résolution S/RES/1258 (1999)

Résolution S/RES/1261 (1999)

Résolution S/RES/1279 (1999)

Résolution S/RES/1693 (2006)

Résolution S/RES/1291 (2000)

Résolution S/RES/1698 (2006)

Résolution S/RES/1304 (2000)

Résolution S/RES/1711 (2006)

Résolution S/RES/1314 (2000)

Résolution S/RES/1736 (2006)

Résolution S/RES/1332 (2000)

Résolution S/RES/1742 (2007)

Résolution S/RES/1355 (2001)

Résolution S/RES/1751(2007)

Résolution S/RES/1341 (2001)

Résolution S/RES/1756 (2007)

Résolution S/RES/1379 (2001)

Résolution S/RES/1768 (2007)

Résolution S/RES/1771 (2007)

Résolution S/RES/1417 (2002)

Résolution S/RES/1794 (2007)

Résolution S/RES/1445 (2002)

Résolution S/RES/1797 (2008)

Résolution S/RES/1460 (2003)

Résolution S/RES/1799 (2008)

Résolution S/RES/1468 (2003)

Résolution S/RES/1804 (2008)

Résolution S/RES/1484 (2003)

Résolution S/RES/1807 (2008)

Résolution S/RES/1522 (2004)

Résolution S/RES/1843 (2008)

Résolution S/RES/1533 (2004)

Résolution S/RES/1856 (2008)

Résolution S/RES/1539 (2004)

Résolution S/RES/1857 (2008)

Résolution S/RES/1552 (2004)

Résolution S/RES/1896 (2009)

Résolution S/RES/1555 (2004)

Résolution S/RES/1906 (2009)

Résolution S/RES/1565 (2004)

Résolution S/RES/1925 (2010)

Résolution S/RES/1592 (2005)

Résolution S/RES/1952 (2010)

Résolution S/RES/1596 (2005)

Résolution S/RES/1991 (2011)

Résolution S/RES/1612 (2005)

Résolution S/RES/1616 (2005)

Résolution S/RES/2021 (2011)

Résolution S/RES/2076 (2012)

Résolution S/RES/2078 (2012)

Résolution S/RES/1621 (2005)

Résolution S/RES/2053 (2012)

Résolution S/RES/1628 (2005)

Résolution S/RES/1635 (2005)

Résolution S/RES/1649 (2005)

Résolution S/RES/2098 (2013)

Résolution S/RES/1653 (2006)

Résolution S/RES/2136 (2014)

Résolution S/RES/2147 (2014)

Résolution S/RES/1654 (2006)

Résolution S/RES/2198 (2015)

Résolution S/RES/1669 (2006)

Résolution S/RES/1671 (2006)

Résolution S/RES/2211 (2015)

b. Assemblée générale (http://www.un.org/fr/sections/documents/general-assemblyresolutions/ )

- Résolution 802 (VIII), de l'AG/NU sur les Fonds des Nations Unies pour l'Enfance (FISE) 
du 06 octobre 1953.

- Résolution 1386 (XIV) du 20 novembre 1959 « Déclaration des droits de l'enfant».

-Résolution 2675 (XXV) du 9 décembre 1970 de 1’AG/NU.

- Résolution 3318 (XXIX) du 14 décembre 1974, Déclaration sur la protection des femmes et des enfants en période d'urgence et de conflit armé.

- Résolution A/RES/43/131 du 8 décembre 1988, Assistance humanitaire aux victimes des catastrophes naturelles et situations d'urgence du même ordre.

- Résolution A/49/643 4 novembre 1994.

- Résolution A/51/306 du 26 août 1996 de l'AG/NU, Promotion et protection des droits des enfants . Impact des conflits armés sur les enfants ».

- Résolution A/RES/56/83 du 12 décembre 2001 sur la Responsabilité de l'Etat pour fait internationalement illicite.

- AG/NU, Rapport du Comité préparatoire pour la création d'une Cour Criminelle internationale, Volume II (Compilation des propositions), Documents officiels. Cinquante et unième session supplément $\mathrm{n}^{\circ} 22 \mathrm{~A}(\mathrm{~A} / 51 / 22), 325 \mathrm{p}$.

- Résolution A/67/845- S/2013/245 Le sort des enfants en temps de conflit armé, Rapport du SG/NU.

- Résolution A/70/836-S/2016/360, Le sort des enfants en temps de conflit armé, Rapport du SG/NU.

- Résolution A/70/729, Dispositions spéciales visant à prévenir l'exploirtation et les atteintes sexuelles, Rapport du SG/NU

\section{c. Secrétariat (http://www.un.org/fr/sc/documents/sgreports/)}

- Nations Unies, Secrétariat, Respect du droit international humanitaire par les forces des Nations Unies, Circulaire du SG/NU, ST/SGB/1999/13, 6 août 1999.

- Bureau du Représentant Spécial du Secrétaire général pour les enfants et les conflits armés, Examen stratégique décennal de l'Etude Machel: les enfants et les conflits armés dans un monde en mutation, UNICEF, New-York, 2009, 224 p.

- Rapport du Secrétaire général sur les enfants et les conflits armés, A/59/695-S/2005/72.

- Rapport du Secrétaire général sur les enfants et les conflits armés en République Démocratique du Congo S/2006/389.

- Rapport du Secrétaire général sur les enfants et les conflits armés en République Démocratique du Congo S/2007/391.

- Rapport du Secrétaire général sur les enfants et les conflits armés en République Démocratique du Congo, S/2008/693. 
- Rapport du Secrétaire général sur les enfants et les conflits armés en République Démocratique du Congo, S/2010/359.

- Rapport du Secrétaire général sur Le sort des enfants en temps de conflit armé, S/2013/245, 15 mai 2013.

- Rapport du Secrétaire général sur les enfants et les conflits armés en République Démocratique du Congo, S/2014/453.

- Rapport du Secrétaire général sur Le sort des enfants en temps de conflit armé, S/2016/360, 20 avril 2016.

- Bureau du Représentant Spécial du Secrétaire Général pour les Enfants et les conflits armés, Les Nations unies et l'Union africaine s'unissent pour protéger les enfants affectés par les conflits armés, Communiqué de Presse du 19 septembre 2013 in https://childrenandarmedconflict.un.org/fr/press-release/onu-et-ua-sunissent-pour-protegerles-enfants/ (Source consultée le 31 janvier 2016).

- Le Groupe de travail sur le sort des enfants en temps de conflits armés, Conclusions concernant les enfants et les conflits armés en République démocratique du Congo, S/AC.51/2014/3.

\section{d. Conseil des droits de l'homme (http://www.ohchr.org/FR/HRBodies/HRC/Pages/HRCIndex.aspx )}

- Rapport sur la Promotion et protection de tous les droits de l'homme, civils, politiques, économiques, sociaux et culturels y compris le droit au développement, A/HRC/9/3, Rapport annuel de la Représentante spéciale du Secrétaire général pour les enfants et les conflits armés, Radhika Coomaraswamy du 27 juin 2008, 9è session, 19 p.

- Rapport sur la Promotion et protection de tous les droits de l'homme, civils, politiques, économiques, sociaux et culturels y compris le droit au développement, A/HRC/9/21, présenté par Mme Najat Maalla M'jid, Rapporteuse spéciale sur la vente d'enfants, la prostitution des enfants et la pornographie mettant en scène des enfants, 31 juillet 2008, 9è session, 14 p.

- Rapport sur la Promotion et protection de tous les droits de l'homme, civils, politiques, économiques, sociaux et culturels y compris le droit au développement, A/HRC/10/16, Rapport soumis par la Rapporteuse spéciale sur la traite des êtres humains en particulier les femmes et les enfants, Joy Ngozi Ezeilo, du 20 février 2009, 10è session, 27 p.

- Résolution adoptée par le Conseil des droits de l'homme 12/6 Les droits de l'homme des migrants : migration et droits de l'enfant, A/HRC/RES/12/6, 12 è session, 31 octobre 2009, Point 3 de l'ordre du jour, 5 p.

\section{e. Comité des droits de l'homme (http://www.ohchr.org/FR/HRBodies/CCPR/Pages/CCPRIndex.aspx)}

- Comité des droits de l'homme, Observation générale $n^{\circ} 17$ : Article 24 (Droits de l'enfant), Trente-cinquième session (1989), 29 septembre 1989.

- Comité des droits de l'homme, Examen des Rapports présentés par les Etats parties en 
application de l'article 40 du Pacte, Troisième rapport périodique, République Démocratique du Congo, CCPR/C/COD/2005/3, 3 mai 2005.

\section{f. Comité contre la torture \\ (http://www.ohchr.org/fr/hrbodies/cat/pages/catindex.aspx)}

- Rapport du Comité contre la torture, Trente-cinquième session (14-25 nov. 2005) Trentesixième session ( $1^{\mathrm{er}}-19$ mai 2006), Assemblée générale, Documents officiels, soixante et unième session, supplément $\mathrm{n}^{\circ} 44(\mathrm{~A} / 61 / 44), 304 \mathrm{p}$.

- Rapport du Comité contre la torture, cinquante et unième session (28 octobre-22 novembre 2013), cinquante-deuxième session (28 avril - 23 mai 2014), 518 p.

- Rapport du Comité contre la torture, cinquante-troisième session (3-28 novembre 2014) cinquante-quatrième session (20 avril-15 mai 2015) Assemblée générale, Documents officiels, soixante-dixième session Supplément n44 (A/70/44), 20 p.

\section{g. Comité des droits de l'enfant \\ (http://www.ohchr.org/EN/HRBodies/CRC/Pages/CRCIndex.aspx)}

- Comité des droits de l'enfant, Examen des Rapports présentés par les Etats parties en application de l'article 44 de la Convention, Rapports initiaux des Etats parties devant être soumis en 1992, Ouganda, CRC/C/3/Add.40, 17 juin 1996, 78 p.

- Comité des droits de l'enfant, Examen des Rapports présentés par les Etats parties en application de l'article 44 de la Convention, Rapports initiaux des Etats parties devant être soumis en 1992, additif, République Démocratique du Congo, CRC/C/3/Add.57, 8 août 2000, $60 \mathrm{p}$.

- Comité des droits de l'enfant, Examen des Rapports présentés par les Etats parties en application de l'article 44 de la Convention, Observations finales du Comité des droits de l'enfant, République Démocratique du Congo, CRC/C/15/Add.153, 9 juillet 2001, 17 p.

- Comité des droits de l'enfant, Examen des Rapports présentés par les Etats parties en application de l'article 44 de la Convention, deuxième rapport périodique des Etats parties devant être soumis en 1998, Rwanda, CRC/C/70/Add.22, 8 octobre 2003, 83 p.

- Comité des droits de l'enfant, Examen des Rapports présentés par les Etats parties en application de l'article 44 de la Convention, Observations finales: Rwanda, CRC/C/15/Add.234, Trente-sixième session, $1^{\mathrm{er}}$ juillet 2004, 20 p.

- Comité des droits de l'enfant, Examen des Rapports présentés par les Etats parties en application de l'article 44 de la Convention, Deuxième Rapport périodiques des Etats parties devant être soumis en 1997, Ouganda, CRC/C/65/Add.33, 5 novembre 2004, 77 p

- Comité des droits de l'enfant, Examen des Rapports présentés par les Etats parties en application de l'article 44 de la Convention, Observations finales: Ouganda, Quarantième session, Genève, 12-30 septembre 2005, CRC/C/UGA/CO/2, 23 novembre 2005, 18 p

- Comité des droits de l'enfant, Examen des rapports présentés par les Etats parties conformément au paragraphe 1 de l'article 8 du Protocole facultatif à la Convention relative aux droits de l'enfant, concernant l'implication d'enfants dans les conflits armés, Rapports 
internationaux des Etats parties attendus en 2005, Tunisie, CRC/C/OPAC/TUN/1, 30 août 2007, 12 p.

- Comité des droits de l'enfant, Examen des Rapports présentés par les Etats parties en application de l'article 44 de la Convention, Observations finales: Ouganda, Quarantième session, Genève, 12-30 septembre 2005, CRC/C/UGA/CO/2, 23 novembre 2005, 18 p.

- Comité des droits de l'enfant, Examen des rapports présentés par les Etats parties conformément au paragraphe 1 de l'article 8 du Protocole facultatif à la Convention relative aux droits de l'enfant, concernant l'implication d'enfants dans les conflits armés, Rapports internationaux des Etats parties attendus en 2006, République-Unie de Tanzanie, CRC/C/OPAC/TZA/1, 19 octobre 2007, 10 p.

- Comité des droits de l'enfant, Examen des Rapports présentés par les Etats parties en application du paragraphe 1 de l'article 8 du Protocole facultatif à la Convention relative aux droits de l'enfant, concernant l'implication d'enfants dans les conflits armés, Rapports initiaux des Etats parties attendus en 2004, Ouganda, CRC/C/OPAC/UGA/1, 7 juillet 2008, $44 \mathrm{p}$.

- Comité des droits de l'enfant, Examen des Rapports présentés par les Etats parties en application de l'article 44 de la Convention, Rapports périodiques des Etats parties devant être soumis en 1997, République Démocratique du Congo, CRC/C/COD/2, 24 juillet 2008, 55 p.

- Comité des droits de l'enfant, Examen des Rapports présentés par les Etats parties en application de l'article 44 de la Convention, Observations finales : République Démocratique du Congo, CRC/C/COD/CO/2, 10 février 2009, 23 p.

- Comité des droits de l'enfant, Examen des Rapports présentés par les Etats parties en application du paragraphe 1 de l'article 8 du Protocole facultatif à la Convention relative aux droits de l'enfant, concernant l'implication d'enfants dans les conflits armés, Rapports initiaux des Etats parties attendus en 2004, République Démocratique du Congo, CRC/C/OPAC/COD/1, 18 avril 2011, 30 p.

- Comité des droits de l'enfant, Examen des Rapports présentés par les Etats parties en application du paragraphe 1 de l'article 8 du Protocole facultatif à la Convention relative aux droits de l'enfant, concernant l'implication d'enfants dans les conflits armés, Rapports initiaux des Etats parties attendus en 2004, Rwanda, CRC/C/OPAC/RWA/1, 6 décembre 2011, 35 p.

- Comité des droits de l'enfant, Examen des Rapports soumis par les Etats parties en application de l'article 44 de la Convention, Troisième et quatrième rapports périodiques des Etats parties devant être soumis en 2008, Rwanda, CRC/C/RWA/ 3-4, 01 mars 2012, 100 p.

- Comité des droits de l'enfant, Examen des rapports présentés par les Etats parties conformément au paragraphe 1 de l'article 8 du Protocole facultatif à la Convention relative aux droits de l'enfant, concernant l'implication d'enfants dans les conflits armés, Rapports internationaux des Etats parties attendus en 2004, Maroc, CRC/C/OPAC/MAR/1, 19 juin 2012, $10 \mathrm{p}$. 


\section{h. Commission du droit international}

- CDI, Détermination du droit international coutumier. Textes des projets de conclusion provisoirement adoptés par le Comité de rédaction, Soixante-septième session, Genève, 4 mai-5 juin et 6 juillet- 7 août 2015,5 p.

\section{2. Union Africaine}

- OUA, Conseil des Ministres, Rés. 1659 (LXIV), Résolution sur la condition des enfants africains en situation de conflits armés.

- Résolution (241) sur la situation des droits de l'homme en République Démocratique du Congo http://www.achpr.org/fr/sessions/14th-eo/resolutions/241/ (Source consultée le 16 janvier 2016)

- Résolution (284) sur la répression des violences sexuelles sur les femmes en République Démocratique du Congo in http://www.achpr.org/fr/sessions/55th/resolutions/284/ (Source consultée le 16 janvier 2016).

- Union africaine, Conseil exécutif, Vingt et unième session ordinaire (9-12 juillet 2012) EX.CL/744(XXI), Rapport du Comité africain d'Experts sur les droits et le bien-être de l'enfant (ACERWC), 9 p.

- Protocole relatif à la création du Conseil de paix et de sécurité de l'Union africaine du 09 juillet 2002.

\section{III.3. Union européenne (http://eur-lex.europa.eu/oj/direct-access.html?locale=fr)}

- Position commune 2002/829/PESC du Conseil du 21 octobre 2002 concernant la fourniture de certains équipements à destination de la République Démocratique du Congo in Journal Officiel de l'Union européenne ${ }^{\circ} \mathrm{L} 285$ du 23 octobre 2002

- Position commune 2005/440/PESC du Conseil du 13 juin 2005 concernant l'adoption de mesures restrictives à l'encontre de la République Démocratique du Congo et abrogeant la position commune 2002/829/PESC in Journal Officiel de l'Union européenne n ${ }^{\circ}$ L152/22 du 15 juin 2005.

- Position commune 2008/179/PESC du Conseil du 29 février 2008 modifiant la position commune 2005/440/PESC concernant l'adoption de mesures restrictives à l'endroit de la République démocratique du Congo in Journal Officiel de l'Union européenne ${ }^{\circ}$ L57/37 du $1^{\mathrm{er}}$ mars 2008.

- Position commune 2008/369/PESC du Conseil du 14 mars 2008 concernant l'adoption des mesures restrictives à l'encontre de la République Démocratique du Congo et abrogeant la position commune 2005/440/PESC, in Journal Officiel de l'Union européenne ${ }^{\circ}$ L127/84 du 15 mai 2008.

- Décision 2010/788/PESC du Conseil du 20 décembre 2010 concernant l'adoption de mesures restrictives à l'encontre de la République Démocratique du Congo et abrogeant la 
position commune 2008/369/PESC, in Journal officiel de l'Union européenne L 336/30 du 21 décembre 2010.

\section{4. Résolutions de l'Institut de droit international}

\section{(http://justitiaetpace.org/resolutions.php?lang=eng)}

- IDI, Session de Cambridge, «La sanction pénale à donner à la Convention de Genève du 22 août 1864 », Résolution du 12 août 1895.

- IDI, Session de Venise, Règles sur le bombardement des villes ouvertes par des forces navales, Résolution du 29 septembre 1896, article $1^{\text {er }}$; Institut de Droit International, Session de Gand, Régime de la neutralité, Résolution des 21, 22, 24 et 25 septembre 1906.

- IDI, Session de Bruxelles, Projet de convention relative à la condition juridique des associations internationales, Résolution du 12 août 1923.

- IDI, Session de Bath, les Conditions d'attribution d'un statut international à des associations d'initiative privée, Résolution du 11 septembre 1950.

- IDI, Session d'Edimbourg, La distinction entre les objets militaires et non militaires en général et notamment les problèmes que pose l'existence des armes de destruction massive, $5^{\mathrm{e}}$ Commission, Résolution du 9 septembre 1969.

- IDI, Session de Zagreb, Les Conditions d'application des règles humanitaires relatives aux conflits armés aux hostilités dans lesquelles les forces des Nations Unies peuvent être engagées, $1^{\text {ère }}$ Commission, Résolution du 3 septembre 1971.

- IDI, Session de Wiesbaden, Les Conditions d'application des règles autres que les règles humanitaires, relatives aux conflits armés aux hostilités dans lesquelles les forces des Nations Unies peuvent être engagées, ${ }^{\text {ère }}$ Commission, Résolution du 13 août 1975.

- IDI, Session de Berlin, L'application du droit international humanitaire et des droits fondamentaux de l'homme dans les conflits armés auxquels prennent part des entités non étatiques, Résolution du 25 août 1999.

- IDI, Session de Bruges, L'Assistance humanitaire, $16^{\mathrm{e}}$ Commission, Résolution du 2 septembre 2003.

- IDI, Session de Santiago, Problèmes actuels du recours à la force en droit international Action humanitaire -, $10^{\mathrm{e}}$ Commission, Sous-groupe B, Résolution du 27 octobre 2007.

- IDI, Session de Rhodes, Problèmes actuels du recours à la force en droit international, $10^{\mathrm{e}}$ Commission, Sous-groupe D, L'autorisation du recours à la force par les Nations unies, Résolution du 9 septembre 2011.

- IDI, Session de Tallinn, Régime juridique des épaves des navires de guerre et des épaves des autres navires d'Etat en droit international, $9^{\mathrm{e}}$ Commission, Résolution du 29 août 2015. 
- Rapports et documents du CICR et de l'UNICEF (sites : www.icrc.org et www.unicef.org )

- CICR, Projet de Protocole additionnel aux Conventions de Genève du 12 août 1949 relatif à la protection des victimes des conflits armés internationaux, in CICR., Projets de Protocoles additionnels aux Conventions de Genève du 12 août 1949. Commentaires, Genève, octobre 1973, $182 \mathrm{p}$.

- CICR, Préparation de la Réunion du Groupe d'experts intergouvernemental pour la protection des victimes (Genève, 23-27 janvier 1995), Protection des victimes de la guerre Suggestions du Comité international de la Croix-Rouge, Genève, avril 1994 in RICR, n809, CICR, Genève, septembre - octobre 1994, pp. 465-482.

- CICR, «République démocratique du Congo : lutter contre le recrutement des enfants ».

- CICR, «Activités du Comité International de la Croix-Rouge (CICR) en République démocratique du Congo, janvier-mars 2008 ».

- CICR, «Comment le terme «conflit armé » est-il défini en droit international humanitaire ? », Prise de position, mars 2008.

- CICR, «RDC : le point sur les activités du CICR dans les deux Kivu -janvier et février $2008 »$.

- CICR, «Le CICR en République Démocratique du Congo - Avril/Mai 2011 », Bulletin CICR n ${ }^{\circ} 1 / 2011$.

- CICR, Les enfants touchés par les conflits armés ou d'autres situations de violence, Genève, Atelier du 14-16 mars 2011, Genève, Rapport d'octobre 2011, 2011, pp. 9-10.

- CICR, «République démocratique du Congo : lutter contre le recrutement des enfants ».

- CICR, Délégation de Kinshasa, «Principales activités du CICR en RDC », CICR, octobre 2013.

- CICR, Délégation du CICR en RDC, Principales activités du CICR en RDC. Faits \& chiffres. Janvier-Juin 2015, Rapport d'Activités.

- UNICEF, Le recrutement forcé des enfants soldats en RDC doit cesser.

- UNICEF, SOS, République Démocratique du Congo. Reportage de Martin Bell sur les enfants piégés par la guerre, Juillet 2006, 9 p.

- UNICEF, 2012 Action humanitaire de l'UNICEF pour les enfants, 66 p.

- UNICEF, la République Démocratique du Congo adopte le Plan d'Action visant à mettre fin au recrutement d'enfants.

- BODINEAU, Sylvie, Rapport d'Evaluation du programme 2007-2011 pour les Enfants associés aux Forces et aux Groupes Armés en RDC, UNICEF RDC, Mai-juin 2011, 75 p. 


\section{Jurisprudence}

\section{a. Cour internationale de justice \\ (http://www.icj-cij.org/homepage/index.php?\&lang=fr)}

- CIJ, Interprétation des traités de paix conclu avec la Bulgarie, la Hongrie et la Roumanie (deuxième phase), avis consultatif du 18 juillet 1950, Recueil 1950, p. 221.

- CIJ, Affaire du Plateau continental de la mer du Nord, arrêt du 20 février 1969, Recueil 1969 , p. 3.

- CIJ, Affaire Barcelona Traction, Light and Power Company, Limited (Belgique c. Espagne), arrêt du 5 février 1970, Recueil 1970, p. 3.

- CIJ, Conséquences juridiques pour les Etats de la présence continue de l'Afrique du Sud en Namibie (Sud-ouest africain) nonobstant la résolution 276 (1970) du Conseil de sécurité, avis consultatif du 21 juin 1971, Recueil 1971, p. 16.

- CIJ, Affaire du Plateau continental (Jamahiriya arabe libyenne c. Malte), arrêt du 3 juin 1985, Recueil 1985, p. 13.

- CIJ, Affaire des Activités militaires et paramilitaires au Nicaragua et contre celui-ci (Nicaragua c. Etats Unis d'Amérique), arrêt du 27 juin 1986, Recueil 1986, p. 14.

- CIJ, Affaire de Licéité de la menace ou de l'emploi d'armes nucléaire, Avis consultatif du 8 juillet 1996, Recueil 1996, p. 226.

- CIJ, Affaire Avena et autres ressortissants mexicains (Mexique c. Etats-Unis d'Amérique), arrêt du 31 mars 2004, Recueil 2004, p. 12.

- CIJ, Conséquences juridiques de l'édification d'un mur dans le territoire palestinien occupé, avis consultatif du 9 juillet 2004, Recueil 2004, p.136.

- CIJ, Affaire des Activités armées sur le territoire du Congo (République démocratique du Congo c. Ouganda), arrêt du 19 décembre 2005, Recueil 2005, p. 168.

- CIJ, Affaire de l'Application de la Convention pour la prévention et la répression du crime de génocide (Bosnie-Herzégovine c. Serbie-et-Monténégro), arrêt du 27 février 2007, Recueil 2007, p. 43.

- CIJ, Conformité au droit international de la déclaration unilatérale d'indépendance relative au Kosovo, avis consultatif du 22 juillet 2010, Recueil 2010, p. 403.

- CIJ, Affaire relative à l'Application de la Convention internationale sur l'élimination de toutes les formes de discrimination raciale (Georgie c. Fédération de Russie), exceptions préliminaires, arrêt du $1^{\text {er }}$ avril 2011, Recueil 2011, p. 70.

- CIJ, Affaire des Questions concernant l'obligation de poursuivre ou d'extrader (Belgique c Sénégal), arrêt du 20 juillet 2012, Recueil 2012, p. 422.

- CIJ, Affaire des Activités armées sur le territoire du Congo (République démocratique du 
Congo c. Ouganda), Ordonnance du $1^{\mathrm{er}}$ juillet 2015, Rôle général n¹16, p.3.

- CIJ, Affaire des Activités armées sur le territoire du Congo (République démocratique du Congo c. Ouganda), Ordonnance du 10 décembre 2015, p. 2.

\section{b. Arbitrage international}

- Affaire du Lac Lanoux (Espagne, France), Sentence du 16 novembre 1957, Recueil des Sentences Arbitral des Nations Unies, Vol. XII, pp. 281-317.

- Commission des réclamations Erythrée / Ethiopie, Ethiopia's Damages Claims, sentence arbitrale finale, 17 août 2009.

\section{c. Cour pénale internationale (https://www.icc-cpi.int/about?In=fr)}

- CPI, Le Procureur c. Thomas Lubanga Dyilo, affaire N ${ }^{\circ}$ ICC-01/04-01/06, Chambre de préliminaire I, Sous scellés Mandat d'arrêt, 10 février 2006.

- CPI, Le Procureur c. Bosco Ntaganda, $N^{\circ} I C C-01 / 04-02 / 06$, Sous scellés Mandat d'arrêt, La Chambre préliminaire, 22 août 2006.

- ICC, The Prosecutor v. Bosco Ntaganda, $N^{\circ} I C C-01 / 04-02 / 06$, decision on the Prosecutor's application under article 58, Pre-Trial Chamber II.

- CPI, Le Procureur c. Thomas Lubanga Dyilo, Chambre préliminaire I, décision sur la confirmation des charges $\mathrm{N}^{\circ} \mathrm{ICC}-01 / 04-01 / 06,29$ janvier 2007, $134 \mathrm{p}$.

- CPI, Le Procureur c. Germain Katanga, $N^{\circ} I C C-01 / 04-01 / 07$, Sous scellés Urgent Mandat d'arrêt à l'encontre de Germain Katanga, La Chambre préliminaire I 2 juillet 2007.

- CPI, Le Procureur c. Mathieu Ngudjolo Chui, $N^{\circ} I C C-01 / 04-01 / 07$, Sous scellés Mandat d'arrêt à l'encontre de Mathieu Ngudjolo Chui, La Chambre préliminaire I, 6 juillet 2007.

- CPI, Le Procureur c. Germain Katanga et Mathieu Ngudjolo Chui, N ICC-01/04-01/07, Décision relative à la confirmation des charges, La Chambre préliminaire I, 30 septembre 2008.

- CPI, Le Procureur c. Callixte Mbarushimana, $N^{\circ} I C C-01 / 04-01 / 10$, Urgent Scellés, Mandat d'arrêt à l'encontre de Callixte Mbarushimana, La Chambre préliminaire I, 28 septembre 2010 .

- CPI, Le Procureur c Thomas Lubanga Dyilo, affaire NICC-01/04-01/06, jugement du 14 mars 2012.

- CPI, Le Procureur c. Thomas Lubanga Dyilo, affaire №ICC-01/04-01/06, Chambre de première instance I, décision relative à la peine rendue en application de l'article $76 \mathrm{du}$ Statut, 10 juillet 2012.

- CPI, Le Procureur c. Germain Katanga et Mathieu Ngudjolo Chui, N ${ }^{\circ}$ ICC-01/04-01/07, jugement en application de l'article $74 \mathrm{du}$ Statut, La Chambre de première instance II, 18 décembre 2012. 
- CPI, Le Procureur c. Germain Katanga, $N^{\circ}$ ICC-01/04-01/07, jugement rendu en application de l'article 74 du Statut, La Chambre de première instance II, 7 mars 2014.

CPI, Le Procureur c. Germain Katanga, $N^{\circ} I C C-01 / 04-01 / 07$, décision relative à la peine (article 76 du Statut), La Chambre de première instance II, 23 mai 2014.

- ICC, The Prosecutor v. Mathieu Ngudjolo Chui, $N^{\circ} I C C-01 / 04-02 / 12$ A, Judgement on the Prosecutor's appeal against the decision of Trial Chamber II entitled « judgment pursuant to article 74 of the Statute », The Appeals Chamber, 7 avril 2015.

\section{d. Tribunal spécial pour la Sierra Leone}

- TSSL, Prosecutor against Moinina Fofana, Allieu Kondewa, Case nºSCSL-04-14-T, Trial Chamber I, judgement, 2 août 2007.

\section{e. Tribunal pénal international pour l'ex-Yougoslavie (http://www.icty.org/action/cases/4)}

- TPIY, Le Procureur c. Dusco TADIC alias «DULE», Chambre d'Appel, Arrêt relatif à l'appel de la défense concernant l'exception préjudicielle, 2 octobre 1995.

- TPIY, Le Procureur c. Dusco TADIC alias «DULE», Chambre de première instance Affaire n' ${ }^{\circ}$ T-94-1-T, jugement du 07 mai 1997.

- TPIY, Le Procureur c. Zejnil Delalic et al., Affaire NIT-96-21, Chambre de première instance, jugement du 16 novembre 1998.

- TPIY, Le Procureur c. Dusko Tadic, Affaire NIT-94-1-A, Chambre d'Appel, Arrêt du 15 juillet 1999.

- TPIY, Le Procureur c. Zoran KUPRE[KI], Mirjan KUPRE[KI], Vlatko KUPRE[KI], Drago JOSIPOVI], Dragan PAPI], Vladimir [ANTI], alias «VLADO », Affaire N ${ }^{\circ}$ IT-95-16-T, La Chambre de première instance, Jugement rendu le 14 janvier 2000, 364 p.

- TPIY, Le Procureur c. Tihomir BLASKIC, Affaire n' ${ }^{\circ}$ TT-95-14-T, Chambre de première instance, jugement du 3 mars 2000, 272 p.

- TPIY, Le Procureur c. Stanislav Galic, Affaire NIT-98-29-T, la Chambre de première instance I, jugement rendu le 5 décembre 2003, 371 p.

\section{f. Tribunal pénal international pour le Rwanda (http://unictr.unmict.org/fr/cases)}

- TPIR, Le Procureur c. Jean-Paul AKAYESU, Affaire nICTR-96-4-T, jugement, Chambre de première instance I, 2 septembre 1998.

- TPIR, Le Procureur c. Georges Anderson NDERUBUMWE RUTAGANDA, Affaire ${ }^{\circ}$ ICTR96-3-T, jugement et sentence, Chambre de première instance I, 6 décembre 1999.

- TPIR, Le Procureur c. Alfred MUSEMA, n ICTR-96-13-T, jugement et sentence, Chambre de première instance I, 27 janvier 2000. 
- TPIR, Le Procureur c. Ignace BAGILISHEMA, Affaire nICTR-95-1A-T, jugement, Chambre de première Instance I, 7 juin 2001.

- TPIR, Le Procureur c. Laurent SEMANZA, Affaire nICTR-97-20-T, jugement et sentence, Chambre de première Instance III, 15 mai 2003.

\section{g. Cour européenne des droits de l'homme \\ (http://www.echr.coe.int/Pages/home.aspx?p=home\&c=fra)}

- CEDH, affaire Ilascu et autres c. Moldova et Russie, arrêt du 08 juillet 2004.

- CEDH, affaire Al-Jedda c. Royaume-Uni, arrêt 07 juillet 2011.

- CEDH, Affaire jeunesse c. Pays-Bas (Requête $n^{\circ}$ 12738/10), Arrêt du 3 octobre 2014.

\section{h. Cour de justice de l'Union européenne (http://curia.europa.eu/jcms/jcms/j_6/fr/)}

- CJCE, Affaire C-540/03, Parlement européen c/ Conseil de l'Union européenne, Arrêt de la Cour (grande chambre) du 27 juin 2006, Rec., I-5809.

- CJCE, Affaire C-244/06, Dynamic Medien Vertriebs GmbH c/ Avides Media AG, arrêt de la Cour (troisième chambre) du 14 février 2008, Rec., I-533.

\section{i. Cour et Commission africaines des droits de l'homme et des peuples}

- Commission africaine des droits de l'homme et des Peuples, Congrès du Peuple Katangais $c$. Zaïre (2000), RADDH 298 (CADHP 1995), in Sélection de documents-clé de l'Union Africaine relatifs aux droits de l'Homme, Pretoria University Law Press, PULP 2006, p. 129.

- Commission africaine des droits de l'homme et des peuples, Communication $n^{\circ} 227 / 99$ République Démocratique du Congol Burundi, Rwanda, Ouganda, in http://www.achpr.org/fr/communications/decision/227.99/ (Source consultée le 16 janvier 2016).

\section{j. Chambres Africaines Extraordinaires}

- Chambres Africaines Extraordinaires, Prononcé et résumé du jugement dans l'affaire le Parquet Général contre Hissein Habré, Chambre Africaine Extraordinaire d'Assises, 30 mai 2016, disponible sur http://www.chambresafricaines.org/index.php/le-coin-desmedias/communiqué-de-presse/639-document-prononce-et-resume-du-jugement-dans-

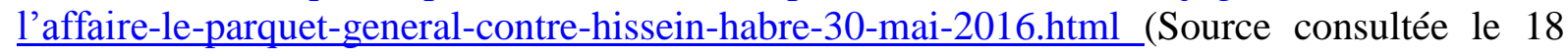
juillet 2016).

\section{k. Juridictions nationales congolaises}

- TMG de l'Ituri, L'Auditeur Militaire et les parties civiles contre le Capitaine Blaise BONGI MASSABA, RP n ${ }^{\circ} 018 / 2006$, Jugement du 24 mars 2006.

- TMG de Mbandaka, L'Auditeur Militaire, Ministère public et les parties civiles contre les 
prévenus Lieutenant Eliwo et al., RP n084/2005, Jugement du 12 avril 2006. (Affaire Songo Mboyo)

- TMG de l'Ituri, L'Auditeur Militaire de Garnison, Ministère Public et parties civiles contre Monsieur KAHWA PANGA MANDRO Ives, RP n039/2006, Jugement du 2 août 2006.

- TMG de l'Ituri, L'Auditeur Militaire de Garnison, Ministère Public et parties civiles contre Capitaine François MULESA MULOMBO alias BOZIZE, et al., , RP n¹01/2006, Jugement du 19 février 2007.

- TMG de Mbandaka, L'Auditeur Militaire, Ministère pub)lic et les parties civiles contre les prévenus KAHENGA MUMBERE Papy, et al., RP n086/2005, RP 101/2006, Jugement du 20 juin 2006, in Conseil National des droits de l'homme en Islam, Comité Provincial de 1'Equateur, Rapport d'observation du procès sur les crimes contre l'humanité tenu devant le Tribunal militaire de Garnison de Mbandaka sous RMP 279/GMZ/05, RP 086/005 et RP 101/106, mars 2007, pp. 27-86.

\section{Doctrine}

\section{a. Ouvrages}

- AIVO, Gérard, Le Statut de combattant dans les conflits armés non internationaux, Bruylant, Bruxelles, 2013, 512 p.

- AKELE ADAU, Pierre et SITA MUILA AKELE, Angélique, Les Crimes contre l'humanité en droit congolais, éd. CEPAS, Kinshasa, 1999, 80 p.

- ALLAND, Denis, Manuel de droit international public, P.U.F, Paris, 279 p.

- ANKUMAH, Evelyn A., The African Commission on Human and Peoples' Rights. Practices and Procedures, Martinus Nijhoff publishers, The Hague/London/Boston, 1996, $246 \mathrm{p}$.

- ARGENT, Pierre d', Les Réparations de guerre en droit international public. La responsabilité internationale des Etats à l'épreuve de la guerre, Bruylant-L.G.D.J, BruxellesParis, 2002, 902 p.

- ARRASSEN, Mohamed, Conduite des hostilités. Droit des conflits armés et désarmement, Bruylant, Bruxelles, 1986, 605 p.

- ARSAC Pierre, CHARLOT Jean-Luc. et PALLARD Henri, Etat de droit, droits fondamentaux et diversité Culturelle, édition l'Harmattan, Paris 1999, 367 p.

- ASCENCIO, Hervé. Ascencio, DECAUX, Emmanuel et PELLET Alain, Droit international Pénal, éd. A. Pedone, Paris, 2000, 1053 p.

- ASPREMONT, Jean d' et HEMPTINE, Jérôme de, Droit international humanitaire, A. Pedone, Paris, 2012, 508 p.

- ATTAL-GALY, Yaël, Droits de l'homme et catégories d'individus, L.G.D.J-EJA, Paris, 2003, 638 p. 
- Avocats Sans Frontières, Etudes de jurisprudence. L'application du Statut de Rome de la Cour pénale internationale par les juridictions de la République Démocratique du Congo, Avocats Sans Frontières, Bruxelles-Kinshasa, mars 2009, 143 p.

- BABIKER Mohamed Abdelsalam et al (dir.), Enfants-soldats et droits des enfants en situation de conflit et post-conflit. Réalités et enjeux, L'Harmattan, Paris, 2013, 299 p.

- BADIDIKE, Jean-Pierre (éd.), Guerre et droits de l'homme en République Démocratique du Congo. Regard du Groupe Justice et Libération, L'Harmattan-RDC, Kinshasa, 2009, 271 p.

- BADIE, Bertrand, La diplomatie des droits de l'Homme. Entre éthique et volonté de puissance, éd. Fayard, Paris, 2002, 324 p.

- BAKAMA BOPE, Eugène, La justice congolaise face aux crimes internationaux commis en $R D C$, L'Harmattan, Paris, 2014, 270 p.

- BALLALOUD, Jacques, Droits de l'homme et organisations internationales. Vers un nouvel ordre humanitaire mondial, éd. Montchrestien, Paris, 1984, 243 p.

- BANNELIER, Karine, et al. (dir), L'intervention en Irak et le droit international, Pedone, Paris, 2004, 378 p.

- Banque Mondiale, Briser la spirale des conflits. Guerre civile et politique de développement, Editions De Boeck Université, Bruxelles 2005, 247 p.

- BASUE, Babu Kazadi (dir.), Le droit international à l'épreuve des enjeux sécuritaires en République Démocratique du Congo, P.U.K, Kinshasa, 2002, 262 p.

- BEIGBEDER, Yves, Le Rôle international des organisations non gouvernementales, Bruylant, L.G.D.J, Bruxelles, Paris, 1992, 195 p.

- BELANGER, Michel, Droit international humanitaire général, Gualino éditeur, EJA, Paris, 2007, $156 \mathrm{p}$.

- BENCHIKH, Madjid, (dir.), Les Organisations internationales et les conflits armés, L'Harmattan, Paris, 2001, 312 p.

- BERKOVICZ, Grégory, La place de la Cour pénale internationale dans la Société des Etats, L'Harmattan, Paris, 2005, 395 p.

- BETTATI, Mario, Droit humanitaire, $1^{\text {re }}$ édition, Dalloz, Paris, 2012, 321 p.

- Idem, Droit humanitaire, Textes introduits et commentés, Editions du Seuil, Paris 2000, 282 p.

- BIAD, Abdelwahab, Droit international humanitaire, $2^{\mathrm{e}}$ édition, Ellipses, Paris, 2006, 139 p.

- Idem, La Cour internationale de justice et le droit international humanitaire. Une lex specialis revisitée par le juge, Bruylant, Bruxelles 2011, 210 p.

- Idem (dir.), L'action humanitaire internationale entre le droit et la pratique, éd. Nemesis - 
Anthemis, Bruxelles, 2016, 270 p.

- Idem et TAVERNIER, Paul (dir.), Le droit international humanitaire face aux défis du XXIe Siècle, Bruylant, Bruxelles, 2012, 325 p.

- BIRUKA, Innocent, La protection de la femme et de l'enfant dans les conflits armés en Afrique, éd. L'Harmattan, Paris, 2006, 500 p.

- BLOED, Arie, et al., (ed.), Monitoring human rights in Europe. Comparing international procedures and mechanisms, Martinus Nijhoff Publishers, The Netherlands, 1993, 338 p.

- BODINEAU, Sylvie, Figures d'enfants soldats. Puissance et vulnérabilité. Regard anthropologique sur l'intervention humanitaire de protection des «enfants soldats » en République démocratique du Congo entre 1996 et 2011, Presses de l'Université Laval, Québec, 2012, 124 p.

- BOKOLOMBE, Batuli Yaseme, Sam, De la prévention et de la répression des violations graves du droit international humanitaire en République Démocratique du Congo. Critique de la responsabilité pénale internationale, Ed. Droit \& Société «DES », Kinshasa, 2013, 539 p.

- BONNEAU, Karine et CARBONI, Montserrat, RDC. Les victimes des crimes sexuels obtiennent rarement justice et jamais réparation. Changer la donne pour combattre l'impunité, Rapport de la Fédération Internationale des Ligues des droits de l'Homme, FIDH (éd. Françaises), Paris, octobre 2013, 81 p.

- BONNIER, Henry, L'Enfant soldat, édition du Club France Loisirs, Paris, 1987, 341 p.

- BOSLY, Henri D. et VANDERMEERSCH, Damien, Génocide, crimes contre l'humanité et crimes de guerre face à la justice. Les juridictions internationales et les tribunaux nationaux, éd. Bruylant, Bruxelles-Paris, 2012, 285 p.

- BOSSEKOTA, W'atsia, Rebâtir le Congo Démocratique: De la bonne gouvernance étatique et du rôle clé de P.M.E. - P.M.I. (Tome I), édition P.U. Bel Campus, Kinshasa 1999.

- BOUSTANY, Katia et DORMOY, Daniel, (dir.), Génocide(s), éditions Bruylant, éditions de 1’Université de Bruxelles, 1999, 518 p.

- BOUTHOUL, Gaston, La Guerre, P.U.F, Paris 1953, 119 p.

- BRAECKMAN, Colette, Le Dinosaure. Le Zaïre de Mobutu, Librairie Arthème Fayard, Paris, 1992, 383 p.

- Idem, et al., KABILA prend le pouvoir, les prémices d'une chute - La campagne Victorieuse de l'A.F.D.L. Le Congo d'aujourd'hui, édition GRIP, Bruxelles, 1998, 192 p.

- Idem, L'enjeu Congolais : l'Afrique Centrale après Mobutu, Arthème Fayard, Paris, 1999, $428 \mathrm{p}$.

- Idem, L'Homme qui répare les femmes. Le combat du Docteur Mukwege, GRIP-André Versaille éditeur, Bruxelles, 2012, 156 p. 
- BRAILLARD, P. et DJALILI, M.-R. ; Les Relations Internationales, $6^{\mathrm{e}}$ édition P.U.F., Paris, 2002, 128 p.

- BREMS, Eva, Human Rights : Universality and Diversity, Martinus Nijhoff publishers, The Hague - Boston - London, 2001, 574 p.

- BRENU, Henri, Guerre « juste » et Guerre mondiale, Sogédipresse, Bruxelles, 1960, 16 p.

- BRETON-LE GOLF, Gaëlle, L'influence des Organisations non gouvernementales (ONG) sur la négociation de quelques instruments internationaux, Bruylant, éditions Yvon Blais, Bruxelles, 2001, 263 p.

- BRETTON, Philippe, Le droit de la guerre, Librairie Armand Collin, Paris, 1970.

- BRICMONT, Jean, Impérialisme humanitaire. Droits de l'homme, droit d'ingérence, droit du plus fort ? Edition revue et augmentée, Editions Aden, Bruxelles, 2009, 303 p.

- BRIGGSS, Jimmie, Meninos soldados. Quando as grianças vào à guerra, éd. Caleidoscopio_Ediçào e Artes GrAficas, SA, Casla de Cambra, 2008, 222 p.

- BUHRER, Jean-Claude et LEVENSON, Claude B., L'ONU contre les droits de l'homme, Mille et une nuits, Librairie Arthème Fayard, Paris, 2003, 296 p.

- BUIRETTE, Patricia et LAGRANGE, Philippe, Le droit international humanitaire, éd. La découverte, Paris 2008, 122 p.

- BULA-BULA, Sayeman, Droit international humanitaire, Academia-Bruylant s.a, LouvainLa-Neuve, 2010, 402 p.

- Bureau international des droits des enfants, Les enfants et les conflits armés. Un guide en matière de droit international humanitaire et de droit des droits de la personne, Bureau international des droits des enfants, Montréal, Québec, 2010, 509 p.

- CAPRON, Claire et DELSEMME, Florence, La vie en prison. 80 visiteurs témoignent, éd. Couleur Livres, Charleroi, 2009, 101 p.

- CASSESE, Antonio et DELMAS-MARTY, Mireille (dir), Crimes internationaux et juridictions internationales, Presses Universitaires de France, Paris, 2002, 267 p.

- Centre International pour la Justice Transitionnelle, Justice pénale. Champs de la responsabilité pénale dans l'est de la RDC. Analyse du cadre législatif et de la réponse judiciaire aux crimes internationaux (2009-2014), ICTJ New-York - ICTJ Goma, 77 p.

- CHAMPEIL-DESPLATS, Véronique et LOCHAK, Danièle (dir.), A la recherche de l'effectivité des droits de l'homme, Presses Universitaires de Paris 10, Paris, 2008, 265 p.

- CHAPLEAU Philippe, Enfants-soldats. Victimes ou criminels de guerre ? éditions du Rocher, Monaco, 2007, 306 p.

- CHAUMETTE, Anne-Laure et THOUVENIN, Jean-Marc (dir.), La responsabilité de protéger, dix ans après. The Responsability to protect, ten years on, Actes du colloque du 14 novembre 2011, Paris, éd. Pedone, 2013, 206 p. 
- CHAUMONT, Charles, L'O.N.U, P.U.F, Paris, 1964, 126 p.

- CHETAIL, Vincent (dir.), Permanence et mutation du droit des conflits armés, Bruylant, Bruxelles, 2013, 683 p.

- CHEUZEVILle, Hervé, KADOGO, Enfants des guerres d'Afrique Centrale, Soudan, Ouganda, Rwanda, R.D Congo L'Harmattan, Paris, 2003, 312 p.

- Coalition contre l'utilisation d'enfants soldats et UNICEF, Guide du Protocole facultatif concernant l'implication d'enfants dans les conflits armés, UNICEF, New-York, mai 2004, $71 \mathrm{p}$.

- COHEN-JONATHAN G. et FLAUSS, J.F. (éd.), Les Organisations non gouvernementales et le droit international des droits de l'homme. International human rights law and non governemental organization, Bruylant, Bruxelles, 2005, 258 p.

- COHENDET Marie- Anne, Méthodes de travail : droit public, éd. Montchestien (3è éditions), Paris, 1998.

- COHN, Ilene et GOODWIN-GILL, Guy S., Child Soldiers. The role of children in Armed conflict. A study for the Henry Dunant Institute, Geneva, Clarendon Press, Oxford, 1994, 228 p.

- COMBACAU, Jean et SUR, Serge, Droit international public, éd. Montchrestien, 7è édition, Paris, 2006, 813 p.

- Commission Justice et Paix Ruanda, Burundi et République Démocratique du Congo : Analyse de la situation et perspectives, édition Commission Justice et Paix, Bruxelles, 1998.

- CONDORELLI, Luigi et LA ROSA SYLVIE SCHERRER, Anne-Marie, (dir.), Les Nations Unies et le droit international humanitaire. The United Nations and international humanitarian law. Acte du Colloque international à l'occasion du cinquantième anniversaire de l'ONU (Genève - 19, 20, 21 octobre 1995), Paris, éd. A. Pedone, Paris, 1996, 506 p.

- COOLSAET, Rik, La Politique extérieure de la Belgique. Au cœur de l'Europe, le poids d'une petite puissance, éd. De Boeck Université, Bruxelles, 2002, 391 p.

- CORTEN, Olivier, Méthodologie du droit international public, Editions de l'Université de Bruxelles, Bruxelles 2009, 291 p.

- Idem, Le droit contre la guerre, 2 éditions, éd. A. Pedone, Paris, 2014, 932 p.

- CORTEN, Olivier et KLEIN, Pierre, Droit d'ingérence ou obligation de réaction?, éd. Bruylant, Bruxelles, 1992, 283 p.

- Idem (dir.), Les Conventions de Vienne sur le droit des traités. Commentaire article par article, Vol. II, Bruylant, Bruxelles, 2006, pp. 1075-1924.

- COURSIER, Henri, Etudes sur la formation du droit humanitaire, CICR, Genève, 1952, 106 p.

- Idem, La Croix-Rouge Internationale, PUF, Paris, 1962, 128 p. 
- COUVEINHES-MATSUMOTO, Florian, L'effectivité en droit international, Bruylant, Bruxelles, 2014, 692 p.

- CRAWFORD, James, The International Law Commission's Articles on State Responsibility. Introduction, Text and Commentaries, Cambridge University Press, Cambridge, 2002, 387 p.

- CUMIN, David, Le droit de la guerre. Traité sur l'emploi de la force armée en droit international, Vol. 2, L'Harmattan, Paris, 2015, pp. 460-1214.

- Idem, Manuel de droit de la guerre, éd. Larcier, Bruxelles, 2014, 534 p.

- CURRAT, Philippe, Les crimes contre l'humanité dans le statut de la Cour pénale internationale, Bruylant, L.G.D.J, Schulthess, Bruxelles, Genève-Zurich-Bâle, Paris, 2006, $806 \mathrm{p}$.

- DABONE, Zakaria, Le droit international public relatif aux groupes armés non étatiques, Schulthess, L.G.D.J, Genève-Zurich-Bâle - Paris, 2012, 419 p.

- DAILlIER, Patrick, FORTEAU, Mathias et PELLET, Alain, Droit international public, Paris, L.G.D.J Lextenso éditions, 8è édition, 2009, 1709 p.

- DAVID, Eric, Mercenaires et Volontaires Internationaux en Droit des gens, Ed. de l’Université de Bruxelles, Bruxelles 1978, 459 p.

- Idem, Principes de droit des conflits armés, $2^{\mathrm{e}}$ édition, Bruylant, Bruxelles, 1999, 860 p.

- Idem, Principes de droit des conflits armés, 5è édition, Bruylant, Bruxelles, 2012, 1151 p.

- Idem, TULKENS, Françoise et VANDERMEERSCH, Damien Code de droit international humanitaire 2012, 5è édition à jour au $1^{\mathrm{er}}$ janvier 2012, Bruylant, Bruxelles 2012, 844 p.

- DECAUX, Emmanuel, La Réciprocité en droit international, L.G.D.J, Paris, 1980, 374 p.

- Idem (dir.), Le Pacte international relatif aux droits civils et politiques. Commentaire article par article, Ed. Economica, Paris, 2011, 996 p.

- Idem et TOUZE, Sébastien (dir.), La Prévention des violations des droits de l'homme. Actes du Colloque des 13 et 14 juin 2013, éd. A. Pedone, Paris, 2015, 230 p.

- DEKEUWER-DEFOSSEZ, Françoise, Le droit de l'enfant, P.U.F, Paris, 2010, 126 p.

- DELNOY, Paul, Eléments de Méthodologie juridique. 1. Méthodologie de l'interprétation juridique 2. Méthodologie de l'application du droit, 2è édition De Boeck \& Larcier s.a, Bruxelles, 2006, 440 p.

- DEYRA, Michel, L'essentiel du droit des conflits armés, éd. Gualino Lextenso, Paris 2002, $130 \mathrm{p}$.

- Idem, Le droit dans la guerre, éd. Gualino Lextenso, Paris 2009, 283 p. 
- DIAKITE, Kemoko, La Justice pénale internationale en Afrique. Aspects juridiques, défis et perspectives, L'Harmattan, Paris, 2014, 231 p.

- DINSTEIN, Yoram, The Conduct of Hostilities under the Law of international Armed Conflict, Cambridge University Press, Cambridge, 2004, 275 p.

- Idem, War Aggression and self-defence, fith edition, Cambridge University Press, Cambridge, 2012, 375 p.

- DITEND Yav, Grevisse, Les Pesanteurs de la Formation Universitaire au Congo, éd. P.U.L., Lubumbashi, 2000.

- DJIENA Wembou, Michel-Cyr et FALL Daouda, Droit international humanitaire. Théories générales et réalités africaines, éd. L'harmattan, Paris 2000, 432 p.

- DREYFUS S., La thèse et le mémoire de doctorat en droit, édition Armand Collins, Paris 1971.

- DRUMBL, Mark A., Reimagining Child Soldiers in International law and policy, Oxford University Press, Oxford New-York, 2012, 254 p.

- DUPUY, Pierre-Marie et KERBRAT, Yann, Droit international public, $11^{\mathrm{e}}$ édition, Dalloz, Paris, 2012, 912 p.

- EISEMANN, Pierre Michel et PAZARTZIS, Photini (dir.), La jurisprudence de la Cour internationale de justice, éd. A. Pedone, Paris, 2008, 1007 p.

- EL HAJI, Hamid, L'applicabilité de la coutume dans les conflits armés, L'Harmattan, Paris, 2015, $241 \mathrm{p}$.

- El KOUHENE, Mohamed, Les garanties fondamentales de la personne en droit humanitaire et droits de l'homme, Dordrecht, Martinus Nijhoff Publishers, 1986, 258 p.

- EMANUELLI, Claude, Droit international public, Montréal, Wilson \& Lafleur Ltée, 1998, p. 512 .

- Idem, Droit international public. Contribution à l'étude du droit international selon la perspective canadienne, Montréal, Wilson \& Lafleur Ltée, 1998, 585 p.

- Idem, International humanitarian Law, Bruylant - éd. Yvon Blais, Bruxelles - Québec, 2009, 425 p.

- ERGEC, Rusen et HAPPOLD, Matthew, Protection européenne et internationale des droits de l'homme, $3^{\mathrm{e}}$ éditions, Larcier, Bruxelles, 2014, 333p.

- FAYER-STERN, Danièle, SANCHEZ, Belen et SCHMITZ, Marc (Coord.), Le Viol, une arme de terreur. Dans le sillage du combat du Docteur Mukwege, éditions Fédération Wallonie-Bruxelles, GRIP, Mardaga, Bruxelles, 2015,157 p.

- FERNANDEZ, Julian, La Politique juridique extérieure des Etats-Unis à l'égard de la Cour pénale internationale, Pedone, Paris, 2010, 649 p. 
- FIERENS, Jacques, Droit humanitaire pénal, éd. Larcier, Bruxelles, 2014, 372 p.

- FLAUSS, Jean-François, (dir.), Les Nouvelles frontières du droit international humanitaire, Bruylant, Bruxelles, 2003, 218 p.

- FLECK, Dieter (ed.), The Handbook of humanitarian law in armed conflicts, Oxford University Press, New-York, 1995, 589 p.

- FOFE DJOFIA MALEWA, Jean-Pierre, La Cour pénale internationale : institution nécessaire aux pays des Grands Lacs africains. La justice pour la paix et la stabilité en $R-D$ Congo, en Ouganda, au Rwanda et au Burundi, Collections "Points de vue concrets », L'Harmattan, Paris, 2006, 231 p.

- Idem, L'administration de la preuve devant la Cour pénale internationale. Règles procédurales et méthodologiques, L'Harmattan, Paris, 2015, 530 p.

- FONTANEL, Jacques, Les dépenses militaires et le désarmement, Publisud, Paris, 1995, $136 \mathrm{p}$.

- FREYMOND, Jacques, Guerres, Révolutions, Croix-Rouge. Réflexions sur le rôle du Comité international de la Croix-Rouge, Institut universitaire de Hautes études internationales, Genève, 1976, 222 p.

- FURET, Marie-Françoise, MARTINEZ, Jean-Claude et DORANDEU, Henri, La guerre et le droit, éd. A. Pedone, Paris, 1979, 335 p.

- GADBIN, Daniel et KERNALEGUEN, Francis (dir.), Le Statut juridique de l'enfant dans l'espace européen, Bruylant, Bruxelles, 2004, 514 p.

- GAGGIOLI, Gloria, L'influence mutuelle entre les droits de l'homme et le droit international humanitaire à la lumière du droit à la vie, éd. A. Pedone, Paris, 614 p.

- GASSER, Hans Peter, Le droit international humanitaire : Introduction, édition Paul Haupt Berne, Stuttgart Vienne, 1993.

- GERE, François, Pourquoi les guerres? Un siècle de géopolitique, Paris, éd. Courrier International - Larousse, 2002, 191 p.

- GHERARI, Habib et SZUREK, Sandra (dir.), L'Emergence de la société civile internationale. Vers la privatisation du droit international, CEDIN Paris X, Cahiers internationaux, A. Pedone, Paris, 2003, 350 p.

- GOY, Raymond, La Cour internationale de justice et les droits de l'homme, Nemesis Bruylant, Bruxelles, 2002, 222 p.

- GREEN, L.C., The contemporary law of armed conflict, Manchester University Press, Manchester - New-York, 1993, 374 p.

- GRIP, L'ONU dans tous ses états. Son histoire - Les principes et les faits- Les nouveaux défis-Quelles réformes ?, Collection « GRIP-Informations », octobre 1995, Bruxelles, 203 p.

- GROTIUS, Hugo Le droit de la guerre et de la paix, Paris, P.U.F, 1999, 868 p. (Ouvrage 
traduit par P.PRADIER-FODERE et édité par D. ALLAND et S. GOYARD-FABRE).

- Idem, Le droit de la guerre et de la paix (1625) traduit par P. PRADIER-FODERE, et édité par D. ALLAND, et S. GOYARD-FABRE, $2^{\mathrm{e}}$ édition, PUF, 2012, 868 p.

- HABIBU, Jean Bosco, L'effectivité du Statut de la Cour Pénale Internationale: Référence spéciale à la situation concernant la République Démocratique du Congo, édition de l’ACAT, Bukavu, 2007, 294 p.

- HADDAD Adnan, Pistes de réflexion sur les causes externes et internes de conflits dans la région des Grands-Lacs (Cas de la Guerre de la République Démocratique du Congo), éd. P.U.L., Lubumbashi, 1999.

- HAJJAMI, Nabil, La Responsabilité de protéger, éd. Bruylant, Bruxelles, 2013, 558 p.

- HAPPOLD, Matthew, Child Soldiers in international law, Manchester University Press, Manchester, 2005, 183 p.

- HAROUEL-BURELOUP, Véronique, Traité de droit humanitaire, $1^{\text {er }}$ édition, PUF, Paris, 2005, 556 p.

- HENCKAERTS, Jean-Marie et DOSWALD-BECK, Louise, Droit international humanitaire coutumier, Volume I : Règles, Bruxelles, Bruylant-CICR, 2006, 878 p.

- HENSEL, Howard M. (ed.), The law of armed conflict. Constraints on the contemporary use of military force, Ashgate Publishing Limited - Ashgate Publishing Company, Hampshire Burlington, 2006, 266 p.

- HOLZGREFE J. L., et Robert O. KEOHANE (éd.), Humanitarian intervention. Ethical, legal, and political dilemmas, Cambridge, Cambridge University Press, 2004, 350 p.

- HUBER, Max, La pensée et l'action de la Croix-Rouge, édition du CICR, Genève, 1954, $376 \mathrm{p}$.

- Institut des Nations Unies pour la Recherche sur le Désarmement (UNIDIR), Les enfants dans les conflits armés in Forum du désarmement, 2011/3, Genève, Octobre 2013, 72 p.

- JACQMIN, Denis et RIGO, Emese, Cour pénale internationale. Quelle justice pour les crimes de masse? éd. Couleur livres, Mons, 2014, 75 p.

- JEANGENE VILMER, Jean-Baptiste et CHUNG, Ryoa, (dir.), Ethique des relations internationales, PUF, Paris, 2013, 474 p.

- Idem, Réparer l'irréparable. Les réparation aux victimes devant la Cour pénale internationale, Presses Universitaires de France, Paris, 2009, 200 p..

- JEWSIEWICKI, Bogumil, et KLAUBER, Véronique, (éd.), Université de Lubumbashi 1990-2002. Société en détresse, pari sur l'avenir, L’Harmattan, Paris, 2003, 241 p.

- KAMTO, Maurice (dir.), La Charte africaine des droits de l'homme et des peuples et le protocole y relatif portant création de la Cour africaine des droits de l'homme et des peuples. Commentaire article par article, Bruylant, Bruxelles, 2011, 1628 p. 
- Idem, L'agression en droit international, Paris, éd. A. Pedone, 2010, 464 p.

- KARUNATILLEKE, Kesera Le Fonds des Nations Unies pour l'enfance (F.I.S.E U.N.I.C.E.F.), Paris, A. Pedone, 1967, 319 p.

- KAZADI MPIANA, Joseph, La Position du droit international dans l'ordre juridique congolais et l'application de ses normes, éd. Publibook, Paris, 2013, 564 p.

- KEBA Mbaye, Les droits de l'homme en Afrique, 2è édition, éd. A.Pedone, Paris, 2002, 386 p.

- KEITETSI, China, La petite fille à la kalachnikov. Ma vie d'enfant soldat, Grip- édition Complexe, Bruxelles, 2004, 265 p.

- KELSEN, Hans, Théorie générale du droit et de l'Etat suivi de la doctrine du droit naturel et le positivisme juridique, (Traduit par Béatrice Laroche et Valérie Faure, introduction de Stanley L. Paulson), Bruylant, L.G.D.J, Bruxelles-Paris, 1997, 517 p.

- KERBRAT, Yann, La référence au Chapitre VII de la Charte des Nations Unies dans les résolutions à caractère humanitaire du Conseil de sécurité, L.G.D.J, Paris, 1995, 120 p.

- KHERAD, Rahim (dir), Les Implications de la guerre en Irak, Colloque international, mercredi 12 mai et Jeudi 13 mai 2004, Faculté de droit, d'économie et de gestion de l'Université d'Angers, Pedone, Paris, 2004, 248 p.

- KNITEL, Hans G, Les Délégations du Comité International de la Croix-Rouge, Presses de Savoie, Genève, 1967.

- KOLB, Robert, Ius in bello. Le droit international des conflits armés, Helbing \& Lichtenhahn, Bruylant, Bâle-Genève-Munich, Bruxelles, 2003, 299 p.

- Idem, Ius in bello. Le droit international des conflits armés, $2^{\mathrm{e}}$ édition, Helbing \& Lichtenhahn, Bruylant, Bâle-Genève-Munich, Bruxelles, 2009, 551 p.

- KOUROUMA, Ahmadou, Allah n'est pas obligé, édition du Seuil, Paris, 2000, 221 p.

- KOUTROULIS, Vaios, Le début et la fin de l'application du droit de l'occupation, éd. Pedone, Paris, 2010, 334 p.

- KOYAGIALO Ngbase Te Gerengbo, Louis Alphonse, Massacre de Lubumbashi (11-12 mai 1990), L'Harmattan, Paris, 2012, 220 p.

- KUPER, Jenny, International law concerning child civilians in Armed conflict, Clarendon Press, Oxford, 1997, 283 p.

- LA PRADELLE, Paul de, La conférence diplomatique et les Nouvelles Conventions de Genève du 12 août 1949, Les éditions internationales, Paris, 1951, 423 p.

- LABANA Lasay'Abar, Le conflit en relations internationales, Analyse des concepts de base, Maison édition Sirices, Kinshasa, 2004. 
- LANOTTE, Olivier, République Démocratique du Congo. Guerres sans frontières. De Joseph-Désiré Mobutu à Joseph Kabila, Bruxelles, Grip-éditions Complexe, 2003, 264 p.

- LATTY, Franck, La lex sportiva. Recherche sur le droit transnational, éd. Martinus Nijhoff Publishers, Leiden Boston, 2007, 849 p.

- LAVAlLEE, Carmen, La Protection internationale des droits de l'enfant. Entre idéalisme et pragmatisme, Bruylant, Bruxelles, 2015, 420 p.

- LEBORGNE, Anne, et al. (dir.), La Convention de New-York sur les droits de l'enfant. Vingt ans d'incidences théoriques et pratiques, Presses Universitaires d'Aix-Marseille, 2012, $86 \mathrm{p}$.

- LEGROS, Pierre et LIBERT, Marianne, L'Exigence humanitaire. Le devoir d'ingérence, Ed. Lpm, Paris, 2000, 214 p.

- LEROUX, Nicolas, La Condition juridique des O.N.G internationales, éditions Bruylant, éditions Yvon Blais, Bruxelles, Québec, 2009, 577 p.

- LOMBART, Laurent, Le Tribunal pénal spécial sierra-léonais, éd. Publibook, Paris, 2003, $97 \mathrm{p}$.

- LOUYOT, Alain, Gosses de guerre, Robert Laffont, Paris, 1989, 252 p.

- Idem, Les enfants soldats, éd. Perrin, Paris, 2007, 216 p.

- LUNDA Bululu, La conclusion des traités en droit constitutionnel zaïrois. Etude de droit international et de droit interne, éditions Bruylant, éditions de l'Université de Bruxelles, Bruxelles, 1984, $456 \mathrm{p}$.

- Idem, Conduire la première transition au Congo-Zaïre, L'Harmattan, Paris, 2003, 344 p.

- LWAMBA Katansi, Crimes et châtiments dans la région des Grands Lacs. Cour pénale internationale, Tribunaux pénaux, internationaux Tribunaux pénaux nationaux, L'Harmattan, Paris, $235 \mathrm{p}$.

- MADI DJABAKATE, Mohamed, Le Rôle de la Cour pénale internationale en Afrique, L'Harmattan, Paris, 2014, 124 p.

- MALEMBA M. N'Sakila, Identité post-tribale au Congo Kinshasa, édition M.E.S., Kinshasa 2003.

- MATHESON, Michael J. et MOMTAZ, Djamchid (dir.), Les Règles et institutions du droit international humanitaire à l'épreuve des conflits armés récents. Rules and Institutions of International Humanitarian Law Put to the test of Recent Armed conflicts, Martinus Nijhoff Publishers, Leiden/Boston, 2010, 1032 p.

- MATTEI, Jean-Matthieu, Histoire du droit de la guerre (1700-1819). Introduction à l'histoire du droit international, Tome I, Presses Universitaires d'Aix-Marseille, Aix-enProvence, 2006, 632 p.

- MAYSTRE Magali Les enfants soldats en droit international. Problématiques 
contemporaines au regard du droit international humanitaire et du droit international pénal, éd. A. Pedone, Paris, 2010, 202 p.

- McCONNAN, Isobel et UPPARD, Sarah, Des enfants Pas des soldats, Londres, The Save the Children, 2002.

- MEJRI, Khaled, Le droit international humanitaire dans la jurisprudence internationale, éd. L’Harmattan, Paris, 727 p.

- MELZER, Nils, Guide interprétatif sur la notion de participation directe aux hostilités en droit international humanitaire, CICR, Genève, octobre 2010, 88 p.

- MEULDERS-KLEIN, M.T. (dir.), La Convention sur les droits de l'enfant et la Belgique, Kluwer éditions juridiques Belgique, E. Story-scientia, Bruxelles, 1992, 189 p.

- MEUNIER, Guillemette, L'application de la Convention des Nations Unies relatives aux droits de l'enfant dans le droit interne des Etats parties, L'Harmattan, Paris, 2002, 253 p.

- MiLlET-DEVALlE, Anne-Sophie (dir.), L'Union européenne et le droit international humanitaire, A. Pedone, Paris, 2010, 302 p.

- MINCKE, Christophe, L'efficacité, efficience et légitimité démocratique du ministère public. Quand l'arbre cache la forêt, Presses Universitaires de Louvain, 2002, 142 p.

- MOIR, Lindsay, The Law of internal armed conflict, Cambridge University Press, Cambridge 2002, 306 p.

- MORANGE, Jean, Manuel des droits de l'homme et libertés publiques, PUF, Paris, 2007, $278 \mathrm{p}$.

- MOREAU, Thierry, RASSON-ROLAND, Anne et VERDUSSEN, Marc (dir.), Le droit de l'enfant au respect, éd. Anthemis, Limal, 2013, 216 p.

- MORELLI, Anne, Principes élémentaires de propagande de guerre utilisables en cas de guerre froide, chaude ou tiède..., éd. Labor, Bruxelles, 2003, 93 p.

- MOVA, Sakanyi H., le droit International Humanitaire : protection des Victimes ou droit d'Ingérence Humanitaire ?, éd. Safari, Lubumbashi, 1998.

- MPINGA Kasenda et D.J GOULD, Les Réformes administratives (1972-1973), Kinshasa, Presses Universitaires du Zaïre, 1975, 338 p.

- MUKENDI, Germain et KASONGA, Bruno, Kabila. Le retour du Congo, éd. Quorum SPRL, Ottignies, 1997, 269 p.

- MUKULUMANYA, Wa Ngate Zenda, La guerre de l'Est enjeux, vérités oubliées et perspectives de paix, édition Zenda, Kinshasa 2000.

- MULINEN, Fréderic De, Manuel sur le droit de la guerre pour les forces armées, CICR, Genève, 2012, 242 p. 
- MUTATA LUABA, Laurent, Droit pénal militaire Congolais. Des peines et incriminations de la compétence des juridictions militaires en R.D Congo, éditions du Service de Documentation et d'Etudes du Ministère de la justice et Garde des Sceaux, Kinshasa, 2005, $665 \mathrm{p}$.

- Idem, Les crimes internationaux en droit pénal congolais et en droit pénal international, Séminaire de formation des Magistrats sur la poursuite judiciaire des violations massives des droits de l'homme (Mbandaka, 20-24 février 2006), éd. Avocat Sans Frontière/Mission permanente en RDC, 2006, 70 p.

- MUTOY MUBIALA, Le système régional africain de protection des droits de l'Homme, Bruylant, Bruxelles, 2005, 299 p.

- MUTZENBERG, Patrick, Agir pour la mise en ouvre des droits civils et politiques. L'apport du Comité des droits de l'homme, L'Harmattan, Paris, 2014, 299 p.

- NEIRINCK, Claire et BRUGGEMAN, Maryline (dir.), La Convention internationale des droits de l'enfant (CIDE), une Convention particulière, Dalloz, Paris, 2014, 278 p.

- NGOY Walupakah, Providence et MUYA Miyanga, Sandra, Le droit de la guerre à l'épreuve du conflit armé en République démocratique du Congo, Publibook, Paris, 2015, 367 p.

- NGOY, Théodore, L'Accord de Lusaka: la paix piégée, Seconde édition CERBIPAD, Kinshasa, 2002, 372 p.

- NORTON MOORE, John (ed.), Law and civil war in the modern world, The Johns Hopkins University Press, Baltimore-London, 1974, 648 p.

- OLLANDET, Jérôme, La Conférence internationale sur la région des Grands Lacs. Une dynamique nouvelle d'intégration en Afrique, L'Harmattan, Paris, 2014, 288 p.

- OST, François et VAN DE KERCHOVE, Michel, De la pyramide au réseau? Pour une théorie dialectique du droit, Facultés universitaires Saint-Louis, Bruxelles, février 2010, 597 p.

- OWONA, Joseph, Droit international Humanitaire, L'Harmattan, Paris, 2012, 210 p.

- PAUVERT, Bertrand et LATOUR, Xavier, Libertés publiques et droits fondamentaux, éd. Studyrama, Levallois-Perret, 2011, 342 p.

- PELLET, Allain et MIRON, Alina (dir.), Les grandes décisions de la jurisprudence française de droit international public, Dalloz, Paris, 2015, 783 p.

- PICTET, Jean S. (dir.), Commentaire, IV La Convention de Genève relative à la protection des personnes civiles en temps de guerre, CICR, Genève, 1956, 729 p.

- Idem, Les principes du droit international humanitaire, CICR, Genève, 1966, 66 p.

- Idem, Commentaire I. La Convention de Genève pour l'amélioration du sort des blessés et des malades dans les forces armées en campagne, CICR, Genève, 1952, 542 p. 
- Idem, Une institution unique en son genre : Le Comité international de la Croix-Rouge, Genève-Paris, Institut Henry-Dunant, éd.A.Pedone, 1985, 110 p.

- PLOT, Bernadette, Ecrire une thèse ou un mémoire en sciences humaines, Editions Champion, Paris 1986, 305 p.

- PREUMONT, Marc, Mémento du droit de la jeunesse 2014, éd. Wolters Kluwer Belgium SA, Waterloo, 2014, 287 p.

- PUTMAN, Emmanuel et EGEA, Vincent (dir.), La Convention de New-York sur les droits de l'enfant. Vingt ans d'incidences théoriques et pratiques, Presses Universitaires d'AixMarseille, Aix-en-Provence, 2012, 86 p.

- QUENEUDEC, Jean-Pierre, La Responsabilité international de l'Etat pour les fautes personnelles, L.G.D.J, Paris, 1966, 275 p.

- REBUT, Didier, Droit pénal international, $2^{\mathrm{e}}$ édition, Dalloz, Paris, 2014, 712 p.

- REMACLE E. et al. (dir.), L'Afrique des Grands Lacs. Des conflits à la paix ?, P.I.E. Peter Lang S.A., Bruxelles, 2007, 289 p.

- République Française, Ministère de la défense, Direction des affaires juridiques, Manuel de droit des conflits armés, SGA/Com, Paris, 2003, 142 p.

- REUTER, Paul, Introduction au droit des traité, Librairie Armand Colin, Paris, 1972, 236 p.

- REYCHLER, Luc et MIGABO KALERE, Jean (éd.), RDC Congo. Pays de l'avenir. Construisons ensemble une paix durable pour un meilleur destin, Livre Ouvert, vol.87, UNIRDCONGO \& IPRA, Leuven, 2010, 164 p.

- RICHARD, Pierre-Olivier, Aldo AJELLO, Cavalier de la paix. Quelle politique européenne commune pour l'Afrique. Entretiens avec le Représentant spécial de l'Union européenne pour la région des Grands Lacs, Grip et éditions Complexe, Bruxelles, 2000, 134 p.

- RIVIER, Raphaële, Droit international public, 2è édition, P.U.F, Paris, 2013, 701 p.

- ROSENCZVEIG, Jean-Pierre, Le droit des enfants, éd. Bayard, Paris, 2011, 125 p.

- ROUSSEAU, Charles, Droit international public, Tome V les rapports conflictuels, éd. Sirey, Paris, 1983, 504 p.

- Idem, Le droit des conflits armés, A. Pedone, Paris, 1983, 629 p.

- ROUSSEAU, Nicolas, Peut-on empêcher les crimes de masses? La responsabilité de protéger à l'épreuve de la réalité, éditions Couleur livres Asbl, Bruxelles, 2012, 90 p.

- ROUVILLOS, Frédéric, Libertés fondamentales, éd. Flammarion/Champs Université, Roubaix, 405 p.

- ROYAL, Ségolène, Les droits des enfants, Dalloz, Paris, 2007, 182 p. 
- RUBELLIN-DEVICHI, Jacqueline et FRANK, Rainer (dir.), L'Enfant et les Conventions internationales, Presses Universitaires de Lyon, Lyon, 1996, 492 p.

- RURANGWA, Révérien, Génocidé, éd. Presses de la Renaissance, Paris, 2006, 231 p.

- RYFMAN, Philippe, La Question humanitaire. Histoire, problématique, acteurs et enjeux de l'aide humanitaire internationale, Ellipses Editions Marketing S.A., Paris, 1999, 208 p.

- Idem, Les ONG, éditions La Découverte, Paris, 2004, 122 p.

- SABAKINU Kivulu (dir.), Démocratie et paix en République Démocratique du Congo, P.U.K, Kinshasa, 1999.

- SANDOZ Yves, SWINARSKI, Christophe et ZIMMERMANN, Bruno, (éd.), Commentaire des protocoles additionnels de 1977 aux conventions de Genève de 1949, CICR/Martinus Nijhoff Publishers, Genève/Dordrecht, 1986, 1646 p.

- SANDOZ, Yves (dir.), Les Moyens de mise en ouvre du droit international humanitaire. Etat des lieux, Analyse des problèmes et éléments de réflexion. Institut International de Droit humanitaire, Sanremo, juillet 2006, 110 p.

- SASSÒLI, Marco et BOUVIER, Antoine A., Un droit dans la guerre ?, Vol.1, CICR, Genève, 2003, 1469 p.

- SCELLE, Georges, Manuel élémentaire de droit international public, éditions DomatMontchrestien, Paris, 1943, 745 p.

- SCHABAS, William A. (ed.), International criminal law, Cambridge University Press, Cambridge, 2016, 408 p.

- SCHINDLER, Dietrich et TOMAN, Jiri, Droit des conflits armés, CICR \& Institut HenryDunant, Genève, 1996, 1470 p.

- SCHMITZ, Marc, (coord.), La guerre. Enfants admis. 300.000 enfants-soldats dans le monde: comment combattre ce fléau? éd. GRIP - éditions Complexe, Bruxelles, 2001, 184 p.

- SEGIHOBE BIGIRA, Jean-Paul, Le Congo en droit international, Presses Universitaires Ryckmans (PUR), Bruxelles, 2011, 264 p.

- SHAYGAN, Farideh, La Compatibilité des sanctions économiques du Conseil de sécurité avec les droits de l'homme et le droit international humanitaire, Bruylant, Bruxelles, 2008, $686 \mathrm{p}$.

- SICART-BOZEC, Michele, Les juges du tiers monde à la cour internationale de justice, éd. Economica, Paris, 326 p.

- SOREL, Jean Marc et FOUCHARD Isabelle, Les tiers aux conflits armés et la protection des populations civiles, éd. A.Pedone, Paris, 2010, 238 p.

- SOREL, Jean-Marc et POPESCU, Corneliu-Liviu (dir.), La protection des personnes vulnérables en temps de conflit armé, éd. Bruylant, Bruxelles, 2010, 326 p. 
- SUN TZU, L'art de la guerre. Traduit du chinois et commenté par Jean Levi, Librairie Arthème Fayard/Pluriel, Paris, 2010, 328 p.

- SWINARSKI Christophe (éd.), Etudes et essais sur le droit international humanitaire et sur les principes de la Croix-Rouge en l'honneur de Jean PICTET - Studies and essays on international Humanitarian law and Red Cross principles in honour of Jean PICTET, Comité International de la Croix-Rouge, Martinus Nijhoff Publishers, Genève - La Haye, 1984, 1143 p.

- TAVERNIER, Paul (dir.), Recueil juridique des droits de l'Homme en Afrique, Tome I, vol. 2, 2000-2004, Bruylant, Bruxelles, 2005, 755 p.

- Idem (dir.), Regards sur les droits de l'homme en Afrique, L'Harmattan, Paris, 2008, 307 p.

- TAVERNIER, Paul et BURGORGUE-LARSEN, Laurence (dir.), Un siècle de droit international humanitaire. Centenaire des Conventions de la Haye, Cinquantenaire des Conventions de Genève, Bruylant, Bruxelles, 2001, 262 p.

- TAVERNIER, Paul et HENCKAERTS, Jean-Marie (dir.), Droit international humanitaire coutumier : enjeux et défis contemporains, Bruylant, Bruxelles, 2008, 289 p.

- THÜRER, Daniel, International humanitarian law : Theory, practice, context, Ail-Pocket, Hague Academy of International Law, The Hague, 2011, 500 p.

- TIGNINO, Mara, L'eau et la guerre. Eléments pour un régime juridique, Bruylant, Bruxelles, 2011, 489 p.

- TINIERE, Romain et VIAL, Claire (dir.), La Protection des droits fondamentaux dans l'Union européenne. Entre évolution et permanence, Bruylant, Bruxelles, 2015, 414 p.

- TORRELLI, Maurice (éd.), La protection internationale des droits de l'enfant, Paris, P.U.F, 1983, $218 \mathrm{p}$.

- Idem, Le droit international humanitaire, P.U.F, 1985, 127 p.

- TREFON, Theodore (dir.), Réforme au Congo (RDC). Attentes et désillusions, Musée royal de l'Afrique centrale - L'Harmattan, Paris, 2009, 275 p.

- Idem, Congo, la mascarade de l'aide au développement, , Academia-L'Harmattan, LouvainLa-neuve, 2013, 194 p.

- TSHIBANGU, Kalala, Les Résolutions de l'ONU et les destinataires non étatiques, éd. Larcier, Bruxelles, 351 p.

- TURGIS, Noémie, La justice transitionnelle en droit international, Bruylant, Bruxelles, 2014, 627 p.

- YOUF, Dominique, Penser les droits de l'enfant, PUF, Paris, 2002, 184 p.

- VAN LANGENHOVE, Fernand, Le Rôle proéminent du Secrétaire général dans l'opération des Nations Unies au Congo, Institut Royal des relations internationales \& 
Martinus Nijhoff, La Haye, 1964, 260 p.

- VAN STEENBERGHE, Raphaël, La légitime défense en droit international public, Larcier, Bruxelles, 2012, 608 p.

- Idem (dir.), Droit international humanitaire : un régime spécial de droit international ?, Bruylant, Bruxelles, 2013, 352 p.

- VAN REYBROUCK, David, Congo. Une histoire, éd. Actes Sud, Paris, 2012, 711 p.

- VANDERMEERSCH, Damien, Comment devient-on Génocidaire? Et si nous étions tous capables de massacrer nos voisins, GRIP, Bruxelles, 158 p.

- VERHAEGEN, Benoit, Rébellions au Congo, Tome I, Léopoldville-Bruxelles, I.R.E.SLovanium-Léopoldville, I.N.E.P-Léopoldville et C.R.I.S.P-Bruxelles, 1966, 568 p.

- Idem, Rébellions au Congo. Maniema, Tome II, Bruxelles-Kinshasa, C.R.I.S.P - Bruxelles, I.R.E.S -Kinshasa, 1969,830 p.

- VERHEY, Beth, Atteindre les filles. Etudes sur les filles associées aux groupes et forces armées en République Démocratique du Congo, Save the Children UK et le groupe des ONG: CARE, IFESH et IRC, Novembre 2004, 41 p.

- VEUTHEY, Michel, Guérilla et droit humanitaire, Genève, CICR, 1983, 451 p.

- VILJOEN, Frans, International Human Rights Law in Africa, Oxford University Press, New-York, 2007, 670 p.

- VILLALPANDO, Santiago, L'Emergence de la Communauté internationale dans la responsabilité des Etats, éd. Graduate Institute Publications, Genève, 2005. 528 p.

- VITE, Sylvain, Les Procédures internationales d'établissement des faits dans la mise en cuvre du droit international humanitaire, éditions Bruylant et éditions de l'Université de Bruxelles, Bruxelles 1999, 485 p.

- WETSH'OKONDA KOSO, Marcel, République démocratique du Congo. La justice militaire et le respect des droits de l'homme - L'urgence du parachèvement de la réforme. Une étude d'AfriMAP et de l'Open Society Initiative for Southern Africa Johannesbourg, 2009, 89 p.

- WHITMAN, Shelly, ZAYED, Tanya et CONRADI, Carl, Enfants soldats : Un guide pour les intervenants du secteur de la sécurité, 2è édition, The Roméo Dallaire, Child Soldiers initiative et Dalhousie University, octobre 2013, 191 p.

- WILLAME, Jean-Claude, Banyarwanda et Banyamulenge. Violences ethniques et gestion de l'identitaire au Kivu, L'Harmattan, Paris, 1997, 156 p.

- Idem, La guerre du Kivu. Vues de la salle climatisée et de la véranda, GRIP, Bruxelles, 2010, $172 \mathrm{p}$.

- YABILI YALALA, Asan, Code de la Zaïrianisation. Recueil de textes et règlements des décisions du 30 novembre 1973 et du 30 novembre 1974, éd. Mwanga-Hebdo, Lubumbashi, 
$145 \mathrm{p}$.

- YACOUB, Joseph, Les droits de l'homme sont-ils exportables? Géopolitique d'un universalisme, Ellipses Editions Marketing S.A., Paris, 2005, 223 p.

- YAV Katshung, Joseph (dir.), La justice congolaise au banc des accusés?, Presses Universitaires de Lubumbashi, Lubumbashi, juin 2010, 186 p.

- ZANI, Mamoud, La Convention internationale des droits de l'enfant: portées et limites, Publisud, Paris, 1996, 223 p.

- ZEEBROEK, Xavier (coord.), Les Humanitaires en guerre. Sécurité des travailleurs humanitaires en mission en RDC et au Burundi, GRIP, Bruxelles, 2004, 185 p.

- ZEEBROEK, Xavier, MEMIER, Marc et SEBAHARA, Pamphile, La Mission des Nations Unies en RD Congo. Bilan d'une décennie de maintien de la paix et perspectives, Rapport du GRIP 2011/4, Bruxelles, 39 p.

- ZORGBIBE, Charles, La guerre civile, Paris, P.U.F, 1975, 208 p.

\section{b. Articles, cours et contributions à un ouvrage collectif}

- ABI SAAB, Georges, «Vers un mécanisme global de protection de la population civile en temps de conflit armé ?", in SOREL, Jean Marc et FOUCHARD Isabelle, Les tiers aux conflits armés et la protection des populations civiles, op. cit., pp. 221-228.

- ACKE, Arianne, «La perspective des droits de l'enfant. Conventions et instruments juridiques internationaux», in Enfants en guerre, Rapport de Conférence de la Commission Femmes et Développement, (S. éd), Bruxelles, p. 25.

- AFFA'A MINDZIE, Mireille, « Protection régionale des droits de l'enfant en Afrique », in Pambazuka News http://www.pambazuka.net/fr/category.php/comment/44469 (Source consultée le 31 janvier 2016).

- AIVO, Gérard, «Le rôle des accords spéciaux dans la rationalisation des conflits armés non internationaux », in RQDI, Vol. 27. 1 (2014), pp.1-30.

- AKELE, Adau, «Droit international humanitaire, les droits de l'homme et les situations des troubles internes », in Zaïre Afrique, n²16, XXXV année juin 1995.

- ALFREDSON, Lisa, «Enfants soldats, déplacement et sécurité humaine », in Forum du désarmement, Trois, 2002, pp.19-30.

- AMANN, Diane Marie, «Children», in SCHABAS, William A. (ed.), International criminal law, op. cit., pp. 252-271.

- ANDENDE, Apindia, «Le droit International Humanitaire et l'avenir du droit Congolais », in Le droit Congolais face à son avenir (Actes des journées scientifiques de la Faculté de Droit de l'Université Protestante du Congo du 25 au 27 mai 2000), Kinshasa, 2000, pp. 1329. 
- ANG, Fiona, «Article 38. Children in Armed Conflicts », in ALEN, André, et al., (éd.), A commentary on the United Nations Convention on the Rights of the Child, Martinus Nijhoff Publishers, Leiden, 2005, 64 p.

- ARZOUMANIAN, Naïri et PIZZUTELLI, Francesca, «Victimes et bourreaux : questions de responsabilité liées à la problématique des enfants-soldats en Afrique », in RICR, $\mathrm{n}^{\circ} 852$, décembre 2003, pp. 827- 856.

- ATANGANA AMOUGOU, Jean-Louis, «Article $53 »$, in KAMTO, Maurice (dir.), La Charte africaine des droits de l'homme et des peuples et le protocole y relatif portant création de la Cour africaine des droits de l'homme et des peuples. Commentaire article par article, op. cit., pp. 985-995.

- AUDEOUD, Olivier, «Le Statut de la société civile internationale, un statut pour les O.N.G » ? in GHERARI, Habib et SZUREK, Sandra (dir.), L'Emergence de la société civile internationale. Vers la privatisation $d u$ droit international, CEDIN Paris X, Cahiers internationaux, op. cit., pp. 23-32.

- AUVRET-FINCK, Josiane, « L'utilisation du DIH dans les instruments de la PESC », in MILLET-DEVALLE, Anne-Sophie (dir.), L'Union européenne et le droit international humanitaire, op. cit., pp. 45-74.

- AYISSI, Anatole et MAIA, Catherine, «La lutte contre le drame des enfants soldats ou le conseil de sécurité contre le terrorisme à venir... », in RTDH. (58/2004), pp. 341-352.

- Idem, «Les filles-soldats, grandes oubliées des conflits armés en Afrique », in Etudes 2004/7 (Tome 401), pp. 19-29 disponible sur http://www.cairn.info/revue-etudes-2004-7page-19.htm (Source consultée le 15 avril 2016).

- AYISSI, Anatole, «Protéger les enfants dans les conflits armés : concrétiser les engagements pris », in Forum du désarmement. Les enfants et la sécurité, Trois, 2002, pp. 517 http://www.unidir.org/files/publications/pdfs/les-enfants-et-la-securite-en-582.pdf (Source consultée le 12 avril 2015).

- BAILLON, Thierry, «A l'écoute des enfants-soldats», in SCHMITZ, Marc (Coord.), op.cit., pp. 97-109.

- BANZA, Kasanda, «La question des enfants soldats (Cas de la RDC) », in Le travail en Afrique noire: servitude ou libération? Actes des premières journées philosophiques Théophile Reyn tenues à Lubumbashi du 07 au 09 novembre 2002, Publication de l'Institut Facultaire Théophile Reyn Lubumbashi, RDC 2004.

- BARBERIS, Julio A., «Réflexions sur la coutume internationale », in AFDI, XXXVI 1990, pp. 9-46.

- BARBIER, S., «Les Commissions d'enquête et d'établissement des faits », in ASCENCIO, Hervé. Ascencio, DECAUX, Emmanuel et PELLET Alain, Droit international Pénal, op. cit., pp. 697-713.

- BENNOUNA, Mohamed, «La Convention des Nations Unies relative aux droits de l'enfant », in AFDI, XXXV, 1989, pp. 433-445. 
- BERGEAL, Catherine, «La Coutume et la conduite des hostilités », in TAVERNIER, Paul et HENCKAERTS, Jean-Marie (dir.), Droit international humanitaire coutumier : enjeux et défis contemporains, op. cit., pp. 101-108.

- BERGHEZAN, Georges, «Le Cancer des groupes armés au cœur de l'instabilité au Congo », in Les Nouvelles du Grip, Trimestriel n69, 3/13, Lettre d'information du Groupe de recherche et d'information sur la paix et la sécurité (GRIP), pp. 1-4.

- BES, Clélie, «Le droit international reconnaît-il le concept de Guerre préventive ? », in KHERAD, Rahim (dir), Les Implications de la guerre en Irak, Colloque international, mercredi 12 mai et Jeudi 13 mai 2004, Faculté de droit, d'économie et de gestion de l'Université d'Angers, op. cit..

- BETTATI, Mario, Allocution d'ouverture au colloque de Nanterre sur la responsabilité de protéger, Société française pour le Droit international, La responsabilité de protéger, éditions A. Pedone, Paris, pp.11-14.

- BIAD, Abdelwahab, «Affaire des activités armées sur le territoire du Congo, République démocratique du Congo c. Ouganda (Arrêt du 19 décembre 2005) », in Bulletin du CREDHO n¹6 -décembre 2006, pp.113-118.

- BLISHCHENKO, Igor P., «Les principes du droit international humanitaire » in SWINARSKI, Christophe (éd.), Etudes et essais sur le droit international humanitaire et sur les principes de la Croix-Rouge en l'honneur de Jean PICTET - Studies and essays on international Humanitarian law and Red Cross principles in honour of Jean PICTETop.cit., pp. 291-300.

- BOINET, Alain, «Les contraintes humanitaires dans un contexte de conflit ou de catastrophe : Afghanistan, Irak, R.D.C., Soudan, Mali, Syrie », in BIAD, Abdelwahab (dir.), $L$ 'action humanitaire internationale entre le droit et la pratique, op. cit., pp. 229-238.

- BOISSON DE CHAZOURNES, Laurence et CONDORELLI, Luigi, « De la responsabilité de protéger » ou d'une nouvelle parure pour une notion déjà bien établie », in RGDIP, 20061, pp. 11-18.

- BOISSON DE CHAZOURNES, Laurence, «Les résolutions des organes des Nations Unies, et en particulier celles du Conseil de sécurité, en tant que source de droit international humanitaire », in CONDORELLI, Luigi et LA ROSA SYLVIE SCHERRER, Anne-Marie, (dir.), Les Nations Unies et le droit international humanitaire. The United Nations and international humanitarian law. Acte du Colloque international à l'occasion du cinquantième anniversaire de l'ONU (Genève - 19, 20, 21 octobre 1995), Paris, éd. A. Pedone, pp. 149173.

- BOTHE, Michael, «Le droit de la guerre et les Nations Unies. A propos des incidents armés au Congo », in Etudes et travaux de l'Institut universitaires des hautes études internationales, n5, éd. Droz, Genève, 1967, pp. 135-243.

- BOUCAUD, Pascale, «Droit des enfants en droit international -Traités régionaux et droit humanitaire », in $R T D H, \mathrm{n}^{\circ} 12$, octobre 1992, pp. 447-470.

- BOUKONGOU, Jean-Didier, «Le Système africain de protection des droits de l'enfant. 
Exigences universelles et prétentions africaines », in $C R D F, \mathrm{n}^{\circ} 5,2006$, pp. 97-108.

- BOUTEMEUR, Famila, et al., «L'Afrique demain développement et sécurité », in Association des auditeurs et cadres des hautes études de l'armement, Géostratégie et armement au XXI siècle, La Documentation française, Paris, 2014, pp. 73-139.

- BRADOL, Jean-Hervé et VIDAL, Claudine, «Les attitudes humanitaires dans la région des Grands Lacs », in Politiques internationales dans la région des Grands Lacs, Politique Africaine, 68, décembre 1997, pp. 69-77.

- BRAECKMAN, Colette , «Le rêve brisé des enfants-soldats en République Démocratique du Congo », SCHMITZ, Marc (Coord.), La guerre. Enfants admis. 300.000 enfants-soldats dans le monde: comment combattre ce fléau?,op.cit., pp. 42-53.

- BRAECKMAN, Colette, «Afrique centrale : des enfances immolées », in Nouvelle Tribune Internationale des droits de l'enfant, Bulletin trimestriel de défenses des enfantsinternational $n^{\circ}$ 6, Bruxelles juillet 2004, pp. 2-5.

- BRETT, Rachel, «Adolescents volunteering for armed forces or armed groups », in RICR, Vol. 85, n 852,2003 , pp. 857-866.

- BUGNION, François, «Les enfants soldats, le droit international humanitaire et la Charte africaine des droits et du bien-être de l'enfant », in Revue Africaine de droit international et comparé, Vol. 12, n², 2000, pp. 262-275.

- BULA BULA, Sayeman, «L'accord de Syrte du 18 avril 1999 pour le règlement des différends dans les Grands Lacs. Note de lecture », in https://sbulabula.wordpress.com/publications/laccord-de-syrte-du-18-avril-1999/ (source consultée le 10 mai 2015).

- BURGORGUE-LARSEN, Laurence, «article 24 », in DECAUX, Emmanuel (dir.), Le Pacte international relatif aux droits civils et politiques. Commentaire article par article, op. cit., pp. 515-527.

- CANTWELL, Nigel, «La genèse de l'intérêt supérieur de l'enfant dans la Convention relative aux droits de l'enfant », in J.D.J, 2013/3, n³23, pp. 8-11.

- CASSESE, Antonio, «Y a-t-il un conflit insurmontable entre souveraineté des Etats et justice pénale internationale ? », in CASSESE, Antonio et DELMAS-MARTY, Mireille (dir), Crimes internationaux et juridictions internationales, op. cit., pp. 13-29.

- CHABERT, Cyril «Applicabilité directe et réception de la Convention de New-York », in LEBORGNE, Anne, et al. (dir.), La Convention de New-York sur les droits de l'enfant. Vingt ans d'incidences théoriques et pratiques, Presses Universitaires d'Aix-Marseille, 2012, pp. 917.

- CHAUMETTE, Anne-Laure, «La responsabilité de protéger, interrogations sémantiques », in CHAUMETTE, Anne-Laure et THOUVENIN, Jean-Marc (dir.), La responsabilité de protéger, dix ans après. The Responsability to protect, ten years on, Actes du colloque du 14 novembre 2011, op. cit., pp. 7-18.

- CHRISTAKIS, Théodore, «Vers une reconnaissance de la notion de guerre préventive », in 
BANNELIER, Karine, et al. (dir ), L'intervention en Irak et le droit international, op. cit., pp. $9-45$.

- CICR, «Dispositions du droit international humanitaire accordant une protection spéciale aux enfants », in RICR, nº759, mai-juin 1986, p. 173.

- CICR, «Protection des victimes de la guerre » Préparation de la Réunion du Groupe d'experts intergouvernemental pour la protection des victimes de la guerre, Genève 23-27 janvier 1995, Suggestions du CICR, op.cit., p. 472.

- CICR, «Protection des victimes de la guerre » Préparation de la Réunion du Groupe d'experts intergouvernemental pour la protection des victimes de la guerre, Genève 23-27 janvier 1995, Suggestions du CICR, Genève, avril 1994, Revue Internationale de la CroixRouge, $\mathrm{n}^{\circ}$ 809, C.I.C.R. Genève, septembre - octobre 1994, pp. 465-482.

- CICR, «Troubles et tensions internes : pour une nouvelle approche humanitaire?», in RICR, $\mathrm{n}^{\circ} 769$, janvier - février 1988, pp. 3-8.

- CICR, comprendre le Droit Humanitaire, Règles essentielles des Conventions de Genève et leurs Protocoles additionnels, Genève, CICR 1990.

- CICR. «Mise en œuvre du droit International Humanitaire», in Chronique semestrielle de législation et de jurisprudences nationales, juillet - décembre 2001, RICR, $\mathrm{n}^{\circ} 845$, mars 2002, pp. $245-254$.

- CIFENDE KACIKO, Moïse, «La Répression pénale des violations graves du droit international humanitaire : le cas de la République Démocratique du Congo », inAnnales de droit de Louvain, Vol. 61, n²4, 2001, pp. 477-508.

- COLLIN, Martine, «Le droit à l'enfance », in Coordination pédagogique Démocratie ou Barbarie du Ministère de la Communauté française de Belgique, Droits humains : Regards d'aujourd'hui 1948-1998, Ministère de la Communauté française de Belgique, Bruxelles, 1998, pp. 127-128.

- CONDORELLI, Luigi, «La Commission internationale humanitaire d'établissement des faits : un outil obsolète ou un moyen utile de mise en œuvre du droit international humanitaire? », in TAVERNIER, Paul et BURGORGUE LARSEN, Laurence (dir.), Un siècle de droit international humanitaire. Centenaire des Conventions de la Haye et cinquantenaire des Conventions de Genève, op. cit., pp. 87-99.

- CONDORELLI, Luigi, «La responsabilité de protéger, nouvelle norme du droit international ? », in CHAUMETTE, Anne-Laure et THOUVENIN, Jean-Marc (dir.), La responsabilité de protéger, dix ans après. The Responsability to protect, ten years on, Actes du colloque du 14 novembre 2011, op.cit., pp. 163-168.

- DAOUDI, Riad, «La codification des droits de l'enfant: analyse des prises de position gouvernementales », in TORRELLI, Maurice (éd.), La protection internationale des droits de l'enfant, op. cit., pp. 21-40

- DARIO, Battistella, «Les facteurs de conflits : vers de nouveaux types de conflits ? , in Les conflits dans le monde, Cahier français $\mathrm{N}^{\circ}$ 290, Paris, 1998, p. 43. 
- DAVID, Eric « La Protection juridique de l'enfant contre les effets directs des hostilités » in Commission communautaire française, La Guerre et l'enfant, Actes du Colloque organisé par l'Association internationale des journées universitaires de la paix à l'Institut de Sociologie de l'Université Libre de Bruxelles le mercredi 2 mars 1983, Centre bruxellois de Recherche et de Documentation pédagogique, Service Enseignement, Bruxelles, 1990, pp. 5-16.

- Idem, «Diffusion du droit humanitaire à l'université », in RICR, n 764, CICR, 1987, pp. 157-170.

- Idem, « La Cour pénale internationale fait-elle preuve de partialité à l'encontre de l'Afrique ?», in Justice en ligne. Comprendre et communiquer http://www.justice-enligne.be/article596.html (Source consultée le 27 février 2016).

- Idem, «Introduction au droit international humanitaire », in KOLANOWSKI, Stéphane (dir.), Défis contemporains en droit international humanitaire, Actes du Colloque de Bruges, 27-28 octobre 2000. Current Challenges in international Humanitarian Law, CICR et Collège d'Europe, Proceeding of the Bruges Colloquium 27-28 october 2000, Bruxelles, mai 2001, pp. 14-19.

- Idem, «La protection juridique de l'enfant contre les effets directs des hostilités », in $L a$ guerre et l'enfant, Commission Communautaire Française, Collection Document, Bruxelles, 1990, pp. 5-16.

- Idem, «La qualification des conflits dans le cadre de lutte contre l'Etat islamique », in Le jihadisme et la lutte contre EI : aspect de droit international, Journée d'Etude du 21 mars 2016 du Centre d'Etude de Droit Militaire et Droit de la guerre (http://www.ismllwbe.org/session/2016.htm (Source consultée le 24 août 2016).

- Idem, «La répression pénale internationale: l'avenir de la Cour Pénale Internationale », in TAVERNIER, Paul et BURGORGUE LARSEN, Laurence (dir.), Un siècle de droit international humanitaire. Centenaire des Conventions de La Haye. Cinquantenaire des Conventions de Genève, op. cit.. pp. 185-200.

- DECAUX, Emmanuel «Article $60 »$, in KAMTO, Maurice (dir.), La Charte africaine des droits de l'homme et des peuples et le protocole y relatif portant création de la Cour africaine des droits de l'homme et des peuples. Commentaire article par article, op. cit., pp. 11051116.

- DELOOZ, François et KOLANOWSKI, Stéphane, «Introduction au droit international humanitaire », in Actualité du droit international humanitaire, éd. La Charte, Bruxelles, 2001, pp. 5-26

- DEVROEY-ZOLLER, Chantal, «L'UNICEF, l'enfant et la guerre », in Commission communautaire française, La Guerre et l'enfant, Actes du Colloque organisé par l'Association internationale des journées universitaires de la paix à l'Institut de Sociologie de l'Université Libre de Bruxelles le mercredi 2 mars 1983, op. cit., pp. 31-42.

- DHOMMEAUX, Jean, «L'Enfant dans l'ordre juridique international », in GADBIN, Daniel et KERNALEGUEN, Francis (dir.), Le Statut juridique de l'enfant dans l'espace européen, op. cit. pp. 4-30.

- DIUR, Katond «Coopération Militaire et paix au sein des pays de la SADC », in 
SABAKIBU, Kivulu (dir.), Démocratie et Paix en République Démocratique du Congo, op. cit.

- DJIENA Wembou, Michel-Cyr, «Le droit Humanitaire Africain : sources, contenu et portée », in Revue Africaine de Droit International et Comparé, éd. Sociétés Africaines de Droit International et Comparé, mars 2001.

- DOUGUELI, Georges, «Human Rights Watch. Une armée en campagne », in Jeune Afrique. Hebdomadaire international indépendant, $\mathrm{n}^{\circ} 2747$, du $1^{\mathrm{er}}$ au 7 septembre 2013, pp. 22-28.

- DUBUISSON, François, «Les obligations internationales de l'Union européenne et de ses Etats membres concernant les relations économiques avec les colonies israéliennes », in RBDI, 2013/2, pp. 408-489.

- DUPENDANT, Jeanne, «Cour de Cassation. Compétence du juge judiciaire - Contrôle de conventionnalité - Doctrine «Matter»-Hiérarchie des normes -Primauté du droit international - Réciprocité -souveraineté -Union européenne (ordre juridique) », in PELLET, Allain et MIRON, Alina (dir.), Les grandes décisions de la jurisprudence française de droit international public, pp. 82-96.

- DUTLI, Maria Teresa, «Enfant-combattants prisonniers », in RICR n785, Septembre octobre 1990, pp. 456-470.

- DUTLI, Maria Teresa, «Mise en œuvre du droit international humanitaire - Mesures nationales - informations reçues par le Comité international de la Croix-Rouge sur les mesures nationales de mise en œuvre adoptées par les Etats », in RICR, $n^{\circ} 809$, CICR, Genève, septembre - octobre 1994, pp. 506-511.

- EGEA, Vincent, «L'intérêt supérieur de l'enfant : menace ou chance pour le droit civil ?», in PUTMAN, Emmanuel et EGEA, Vincent (dir.), La Convention de New-York sur les droits de l'enfant. Vingt ans d'incidences théoriques et pratiques, op. cit., pp. 35-49.

- FERRARO, Tristan, «Le droit international humanitaire dans la politique étrangère et de sécurité commune de l’Union européenne », in RICR, Vol. 84, n846, pp. 435-461.

- FIERENS, Jacques, «Responsable de quoi ?», in Actes du Colloque, Responsabilité individuelle versus déresponsabilisation collective - jeune et responsable ?, JDJ, $n^{\circ} 306$, juin 2011, pp. 3-8.

- FONSEKA, Bhavani, «The Protection of Child Soldiers in International Law », in AsiaPacific Journal on Human Rights and the Law, 2001, vol. 2, n², pp. 69-89.

- FRUMER, Philippe, «Quand droits de l'homme et droit international humanitaire s'emmêlent - Un regard critique sur l'arrêt Hassan c. Royaume-Uni », in RTDH (102/2015), pp. 481-507.

- FURAHA MWAGALWA, Thomas, «Réflexions sur les obstacles à réprimer le crime de recrutement et d'utilisation d'enfants soldats commis en République Démocratique du Congo » in Revue de droit pénal et de criminologie, 2013/1, pp. 218-223.

- GASSER, Hans-Peter, «Les normes humanitaires pour les situations de troubles et tensions 
internes. Aperçu des derniers développements », in RICR, n801, mai-juin 1993, pp. 238-244.

- Idem, «Protection of the civilian population», in FLECK, Dieter (ed.), The Handbook of humanitarian law in armed conflicts, Oxford University Press, New-York, 1995, pp. 209-292.

- Idem, «Un minimum d'humanité dans les situations de troubles et tensions internes : proposition d'un Code de conduite », in RICR, n769, janvier - février 1988, pp. 39 - 60.

- GAUDREAU, Julie, «Les réserves aux Protocoles additionnels aux Conventions de Genève pour la protection des victimes de la guerre », in $R I C R, n^{\circ} 849$, mars 2003.

- GHERARI, Habib, « La Commission africaine des droits de l'homme et des peuples (Bilan d'une jurisprudence) », in TAVERNIER, Paul (dir.), Regards sur les droits de l'homme en Afrique, L'Harmattan, op. cit., pp. 133-163.

- GNAMOU-PETAUTON, Dandi, «Les Etats africains et le droit international humanitaire », in TAVERNIER, Paul (dir.), Recueil juridique des droits de l'Homme en Afrique, Tome I, vol. 2, 2000-2004, Bruylant, Bruxelles, 2005, pp. 358-395.

- GNAMOU-PETAUTON, Dandi, «Les mécanismes régionaux africains de protection des droits de l'homme », in TAVERNIER, Paul (dir.), Regards sur les droits de l'homme en Afrique, op. cit., pp. 254-275.

- GOEMANS, François, « République démocratique du Congo - Chronologie des événements majeurs et évolution du mandat de la Monuc », in ZEEBROEK, Les Humanitaires en guerre. Sécurité des travailleurs humanitaires en mission en RDC et au Burundi, op. cit., pp. 21-27.

- GOUTTENOIRE, Adeline, « La consécration de l'intérêt supérieur de l'enfant dans l'Union européenne », in TINIERE, Romain et VIAL, Claire (dir.), La Protection des droits fondamentaux dans l'Union européenne. Entre évolution et permanence, op. cit., pp. 233-245.

- GRADITZKY, Thomas, «La responsabilité pénale individuelle pour violation du droit international humanitaire applicable en situation de conflit armé non international », in RICR, n'829, mars 1998, pp. 38-44, disponible sur https://www.icrc.org/fre/resources/documents/misc/5fzgbw.htm (Source consultée le 20 octobre 2016).

- GRANET, Frédérique, «La Convention de New York sur les droits de l'enfant et sa mise en œuvre en France », in RUBELLIN-DEVICHI, Jacqueline et FRANK, Rainer (dir.), L'Enfant et les Conventions internationales, Presses Universitaires de Lyon, op. cit., pp. 95-114.

- GRAZIANI, Laurene et SERSTE, Nastassia, «Children and war : past and présent », in J.D.J, n ${ }^{\circ} 358$-octobre 2016, pp. 29-31.

- GUELLALI, Amna, «Lex speciali, droit international humanitaire et droits de l'homme : leur interaction dans les conflits armés », in RGDIP, 2007-3, pp. 539-574.

- GUICHAONA A. et Vital C., «Les politiques internationales dans la région des Grands Lacs Africains », in Politiques internationales dans la Région des Grands Lacs, Politiques africains $\mathrm{N}^{\circ} 68$, édition Karthala, Paris, décembre 1997.

- HAMPSON, Françoise J., «Combattre dans les règles : instruction aux forces armées en 
matière de droit humanitaire », in RICR, $\mathrm{n}^{\circ} 776$, mars-avril 1989, pp. 117-131.

- HAPPOLD Matthew, "Child Soldiers in International Law : the legal Regulation of Children's Participation in Hostilities », in Netherlands International Law Review, vol. 48, 2000, pp. 27-52.

- Idem, «Protecting Children in Armed Conflict : Harnessing the Security Counci's «Soft Power » », in Israël Law Review, Vol. 43, 2010, pp. 360-380.

- HARMON SNOW K., et D. BAROUSKI, D., « Derrière les chiffres : la souffrance indicible au Congo », in http://www.droitcongolais.info/files/derriere_les_chiffres_la_souffrance.pdf (Source consultée le 28 août 2013).

- HEMPTINNE, Jérôme de, « La définition de la notion de «population civile » dans le cadre du crime contre l'humanité. Commentaire critique de l'arrêt Martic », in RGDIP, 2010/1, pp. 93-104.

- HENCKAERTS, Jean-Marie, «Etude du CICR sur le droit international humanitaire coutumier: objet, caractéristique, conclusions et pertinence », in TAVERNIER, Paul et HENCKAERTS, Jean-Marie (dir.), Droit international humanitaire coutumier : enjeux et défis contemporains, op. cit., pp. 25-67.

- Idem, «Importance actuelle du droit coutumier », in Paul TAVERNIER et BURGORGUELARSEN Laurence (dir.), Un siècle de droit international humanitaire, op. cit., pp. 21-28.

- HERMANT, Daniel, «L'espace problématique de la violence politique des enfants », in $L a$ violence politique des enfants, Cultures et Conflits, $\mathrm{n}^{\circ} 18$, Paris, L’Harmattan, 1995, pp. 181196.

- HOLZGREFE, J. L., « The humanitarian intervention debate », in J. L., HOLZGREFE et Robert O. KEOHANE (éd.), Humanitarian intervention. Ethical, legal, and political dilemmas, Cambridge, Cambridge University Press, op. cit., pp. 15 - 52.

- HONWANA, Alcinda, «Innocents et coupables. Les enfants-soldats comme acteurs tactiques », in Enfants, jeunes et politiques, Le Dossier, Politique africaine ${ }^{\circ} 80$, décembre 2000, pp. 58-78.

- HUYBRECHTS, Pierre, «Quels règles et mécanismes internationaux pour protéger les enfants dans la guerre ? », in LORIAUX, G., Les enfants soldats, Kindsoldaten, Journée d'études du 20 janvier 2005, Centre d'Etudes de Droit Militaire et de Droit de la guerre, a.s.b.1, Bruxelles, 2005, pp. 23-45.

- IDZUMBUIR Assop J., «Le système onusien de protection des droits de l'homme : le groupe nécessitant une protection spéciale : cas des femmes et des enfants ", in Droits de l'homme et droit international humanitaire, Séminaire de formation cinquantenaire de la Déclaration universelle de Droits de l'homme, 18 nov.-10 déc.1998, P.U.K., Kinshasa 1999.

- IMAMI, Marcel, «La justice des mineurs ou le risque de répétition de l'histoire ? Cas de la République Démocratique du Congo », in Actes du Colloque "Juvenile in justice » du 19 mars 2013 au Palais de justice de Charleroi, Emex \&InterCommunication, Spal, Bruxelles, 2014, pp. 19-36. 
- JASICA, Roman, «Protection de la population civile et ses contraintes », in Le Droit international humanitaire. Problèmes actuels et perspectives d'avenir, Les Cahiers du Droit public, Université de Clermont I, Bordeaux, 1987, pp. 57-62.

- JEANGENE VILMER, Jean-Baptiste, «L'éthique de la guerre », in JEANGENE VILMER, Jean-Baptiste et CHUNG, Ryoa, (dir.), Ethique des relations internationales, PUF, Paris, 2013, pp. 157-190.

- JESSEMAN, Christine, «The protection and participation rights of the child soldiers : an African global perspective », in African Human Rights Law Journal, vol. 1, n¹, 2001, pp. 140-154.

- KAGANDA MULUMEODERWA, Philippe, «Analyse des modèles de réinsertion des enfants ex-soldats filles à l'Est de la R.D. Congo », in RDPC, Vol. 93, N², 2013, pp. 80-112.

- KALINDYE Byanjira D. et al., «Les enfants soldats face au droit international humanitaire en République Démocratique du Congo », in Nouvelle Tribune Internationale des Droits de l'enfant, $\mathrm{N}^{\circ}$ 6, juillet 2004, pp. 9-15.

- KALONJI, Anne, «La protection des enfants au cœur des premières poursuites intentées devant la Cour pénale internationale et le tribunal spécial pour la Sierra Leone », Sociétés et jeunesses en difficulté, n ${ }^{\circ} 6 / 2008$, disponible sur http://sejed.revues.org/index4933.htmlp (Source consultée le 26 mai 2016).

- KAMTO, Maurice, «Article $61 »$, in KAMTO, Maurice (dir.), La Charte africaine des droits de l'homme et des peuples et le protocole y relatif portant création de la Cour africaine des droits de l'homme et des peuples. Commentaire article par article, op. cit., 1117-1140.

- KAMUNDU Yawara, «L'homme, un animal conflictuel », in Conflits et identités, Actes des Journées philosophiques de CANISIUS, avril 1997, éditions LOYOLA, Kinshasa, 1998.

- KAPETA, Nzovu Ilunga, «La question de la nationalité et les perspectives de paix en République Démocratique du Congo », in SABAKIBU, Kivulu (dir.), op.cit., p. 119.

- KARL-HEINZ, Kamp, «La défense préemptive : une nouvelle réalité politique », disponible sur http://www.journal.forces.gc.ca/vo6/no2/views-vues-fra.asp (Source consultée le 12 mars 2013).

- KATWEMBE Roger et VAHIGHENE, Robert, «Enfants congolais : enfants sans soldats », in Nouvelle Tribune Internationale des Droits de l'enfant, $\mathrm{N}^{\circ}$ 6, juillet 2004, pp. 6-8.

- KAZADI, Mpiana, Joseph, «La Cour pénale internationale et la République Démocratique du Congo: 10 ans après. Etude de l'impact du Statut de Rome dans le droit interne congolais », in RQDI, 25.1 (2012), pp. 57-90.

- KEMFOUET KENGNY, Emile Derlin, «Etats et acteurs non étatiques en Droit international humanitaire », in $\operatorname{RQDI}(2008) 21.2,98 \mathrm{p}$.

- KITIMA, Kasendwe, «La crise dans les Grands-Lacs et ses conséquences sécuritaires pour les pays de la sous-région », in Les Mélanges de la pléiade congolaise, Vol I (juin 2003 mars 2005), Kinshasa, éditions La pléiade Congolaise 2005, pp. 96-105. 
- Idem, «Les mécanismes de promotion, de maintien et de consolidation de la paix et de la sécurité collective en Afrique subsaharienne », in Les mélanges de la pléiade congolaise, Vol 1, Kinshasa, édition Pléiade Congolaise, 2005, pp. 182-189.

- Idem, «Les relations Internationales post-conflits : cas de la R.D.C. », in Les Mélanges de la pléiade congolaise ? Vol I, Kinshasa, édition de la Pléiade Congolaise, 2005, pp. 70-77.

- KOLB, Robert, «Commentaires iconoclastes sur l'obligation de faire respecter le droit international humanitaire selon l'article 1 commun des Conventions de Genève de 1949 », in RBDI, 2013/2, pp. 513-520.

- KOSIRNIK, René, «Droit international humanitaire et protection de réfugiés », in SWINARSKI Christophe (Réd.), Etudes et essais sur le droit international humanitaire et sur les principes de la Croix-Rouge en l'Honneur de Jean PICTET - Studies and essays on international humanitarian law and Red Cross principles in honour of Jean PICTET, op. cit.,pp. 387-400.

- KOUTROULIS, Vaios, «L'affaire des activités armées sur le territoire du Congo (Congo c. Ouganda) : Une lecture restrictive du droit de l'occupation ? », in RBDI, 2006/2, pp. 703-741.

- KÜNTZIGER, Isabelle et GALAND, Renaud, «Quels règles et mécanismes internationaux pour protéger les enfants dans la guerre ? ", in SCHMITZ Marc (Coord.), La Guerre Enfants admis. 300.000 enfants-soldats dans le monde: comment combattre ce fléau, op. cit., pp. 127-147.

- LAGRANGE, Philippe, «Forces des Nations Unies et respect du droit international humanitaire. De l'importance de la notion de participation aux hostilités », in BIAD, Abdelwahab et TAVERNIER, Paul (dir.), Le Droit international humanitaire face aux défis du XXIe Siècle, op.cit., pp. 291-311.

- LANOTTE, Olivier, «La guerre en République Démocratique du Congo (1998-2004)», in REMACLE Eric et ROSOUX (dir.), L'Afrique des Grands Lacs. Des conflits à la paix, Bruxelles, P.I.E PETER LANG, op. cit., pp. 41-62.

- LARRALDE, Jean-Manuel, «Les réponses du droit international à la question des enfants soldats », in $C R D F, \mathrm{n}^{\circ} 5,2006$, pp. 65-78.

- LEROY, Yann, «La notion d'effectivité en droit », in Droit et société, 2013/3 (n79), pp. 715-732.

- LOCHAK, Daniel, «Conseil d'Etat. Acte clair - Conventions internationales (interprétation) - Office du juge (interprétation) Question préjudicielle - Réciprocité », in PELLET, Allain et MIRON, Alina (dir.), Les grandes décisions de la jurisprudence française de droit international public, op.cit., pp. 192-204.

- LUNDA BULULU, Vincent, «Les juridictions congolaises et l'application des conventions internationales relatives aux droits de l'homme», in Droit du pouvoir, Pouvoir du droit. Mélanges offerts à Jean Salmon, Bruylant, Bruxelles, 2007, pp. 983-1004.

- MAMPUYA, Auguste, «Responsabilité et réparations dans le conflit des Grands-Lacs au Congo-Zaïre », in RGDIP, 2004-3, pp. 679-707. 
- MARTHOZ, Jean-Paul, «Responsabilité de protéger et devoir d'informer », in FAYERSTERN, Danièle, SANCHEZ, Belen et SCHMITZ, Marc (Coord.), Le Viol, une arme de terreur. Dans le sillage du combat du Docteur Mukwege, op. cit., pp.105-115.

- MARTIN CHENUT, Kathia, «La protection des enfants en temps de conflit et le phénomène des enfants-soldats », in SOREL, Jean-Marc et POPESCU, Corneliu-Liviu (dir.), La protection des personnes vulnérables en temps de conflit armé, op. cit.,pp. 159-255.

- MARTIN, Fanny, «Le droit international humanitaire devant les organes de contrôle des droits de l'Homme », in Droits fondamentaux, $\mathrm{n}^{\circ} 1$, juillet - décembre 2001, www.droitsfondamentaux.org, pp 119-148 (Source consultée le 22 avril 2014).

- MASTOR, Wanda, «A propos de son caractère self executing », in NEIRINCK, Claire et BRUGGEMAN, Maryline (dir.), La Convention internationale des dfroits de l'enfant (CIDE), une Convention particulière, op. cit., pp. 7-13.

- MAVUNGU, Jean Pierre, «Les Rapports entre les Droits de l'Homme et le Droit International Humanitaire », in Droits de l'Homme et droit International Humanitaire, Séminaire de Formation Cinquantenaire de la DUDH du 18 novembre au 10 décembre 1999, P.U.K., Kinshasa, 1999.

- MAZYAMBO, Makengo Kisala, André, «Le désarmement, la démobilisation et la réinsertion des combattants en République Démocratique du Congo », in BASUE, Babu Kazadi (dir.), Le Droit international à l'épreuve des enjeux sécuritaires en République Démocratique du Congo, op. cit., pp. 201-250.

- MBOKANI, Jacques B., «L'application du Statut de Rome par les Tribunaux congolais. Vers une banalisation de crimes de droit international ?», in RDIDC, 2014/1, pp.113-166.

- MEDJOUBA, Faria et STEFANELLI, Justine, «La prise en considération du droit international humanitaire par l'Union européenne- Une introduction », in SOREL, Jean-Marc et POPESCU, Corneliu-Liviu (dir.), La protection des personnes vulnérables en temps de conflit armé, op.cit., pp. 87-130.

- MEGRET, Frédéric, «La diversification des acteurs impliqués dans les conflits armés : vers un dépassement de la "participation directe aux hostilités », in SOREL, Jean-Marc et FOUCHARD, Isabelle (dir.), Les tiers aux conflits armés et la protection des populations civiles, op. cit., pp. 49-81.

- MERMET, Joel, «Protocole facultatif à la Convention relative aux droits de l'enfant concernant l'implication d'enfants dans les conflits armés : quel progrès pour la protection des droits de l'enfant?», in Actualité et droit international. Revue d'analyse juridique de l'actualité internationale, juin $\quad 2002, \quad 7 \quad 7$ p.; http://www.ridi.org/adi/articles/2002/200206mer.htm (Source consultée le 12 avril 2015).

- MERON, Theodor, «Projet de déclaration type sur les troubles et tensions internes », in $R I C R, \mathrm{n}^{\circ} 769$, janvier - février 1988, pp. 62-80.

- MEYER, Antoine, «La protection de l'enfance dans les conflits armés : perspectives de mise en œuvre des normes du droit international humanitaire et du droit international des droits de l'homme », in BIAD, Abdelwahab et TAVERNIER, Paul (dir.), Le Droit international humanitaire face aux défis du XXIe Siècle, Bruylant, Bruxelles, 2012, pp. 219- 
243.

- MICHEL, Nicolas, «Le droit international humanitaire entre frustrations, réussites et interrogations ", in FLAUSS, Jean-François, (dir.), Les Nouvelles Frontières du Droit international humanitaire, op. cit., pp.11-13.

- MOMTAZ Djamchid, «Les défis des conflits armés asymétriques et identitaires au droit international humanitaire », in MATHESON Michael J. et MOMTAZ, Djamchid, (dir.) op.cit., pp. 4-137.

- Idem, «Les règles relatives à la protection de l'environnement au cours des conflits armés à l'épreuve du conflit entre l'Irak et le Koweit », in AFDI, vol. XXXVII, 1991, pp. 203-219.

- MOREAU, Jean-Louis, «De la décolonisation à la zaïrianisation. Le sort des capitaux belges au Congo », in IRIC-UMR 8138, http://irice.univ-paris1.fr/spip.php?article594 (Recherchée le 23 février 2014).

- MOREAU, Thierry, «Intérêt et droits de l'enfant ou les deux éléments constitutifs du droit de l'enfant au respect. L'exemple du placement et de la privation de liberté », in MOREAU, Thierry, RASSON-ROLAND, Anne et VERDUSSEN, Marc (dir.), Le droit de l'enfant au respect, op. cit., pp. 145-176.

- MUKWEGE, Denis «Dénoncer l'inacceptable et briser l'indifférence », de FAYERSTERN, Danièle, SANCHEZ, Belen et SCHMITZ, Marc (Coord.), Le Viol, une arme de terreur. Dans le sillage du combat du Docteur Mukwege, op.cit., pp. 9-15.

- MULINEN, Frédéric de, «Instruction du droit de la guerre dans les forces armées. Vingt années d'expériences », in RICR, n764, pp. 171-182.

- MULUMA, Munanga Tizi, A., «Corruption et pauvreté. Que faire pour la relance socioéconomique en RD Congo », in Congo-Afrique $\mathrm{N}^{\circ} 430$, Kinshasa, éd.Cepas, décembre 2008, pp. 819-833.

- MUMBALA ABELUNGU, Junior, « Le droit international humanitaire et la protection des enfants en situation de conflits armés en République démocratique du Congo », in Droit et cultures. Revue internationale interdisciplinaire 64 (2012), pp. 207-235, disponible sur http://droitcultures.revues.org/2913 (Source consultée le 15 février 2016).

- Idem « La question de l'indépendance du pouvoir judiciaire en RDC », in YAV Katshung, Joseph (dir.), La justice congolaise au banc des accusés ?, op. cit, pp. 91-113.

- Idem, «Le droit international humanitaire sur le champ de bataille : mythe ou réalité ? cas du conflit armé en République Démocratique du Congo », in KIZOBO, Obweng (dir.), Actes des journées scientifiques de l'Institut Supérieur de Commerce de Lubumbashi, Presses Universitaires de Lubumbashi, Lubumbashi, 2010.

- MUTOY, Mubiala, « Le Comité régional pour la prévention du génocide de la Conférence internationale sur la Région des Grands Lacs », in DECAUX, Emmanuel et TOUZE, Sébastien (dir.), La Prévention des violations des droits de l'homme. Actes du Colloque des 13 et 14 juin 2013, op. cit., pp. 115-123.

- Idem, «Les Etats africains et la promotion des principes humanitaires », in RICR, $\mathrm{n}^{\circ} 776$, 
CICR, mars-avril 1989.

- Idem, «Les Etats africains et la promotion des principes humanitaires », in $R I C R, \mathrm{n}^{\circ} 776$, CICR, mars-avril 1989, pp. 97-115.

- MWAGALWA, Thomas Furaha, «Réflexions sur les obstacles à réprimer le crime de recrutement et d'utilisation d'enfants soldats commis en République Démocratique du Congo », in $R D P C$, Vol. 93, 3/2013, pp. 211-232.

- NAHLIK, Stanislaw E., Précis abrégé de droit international humanitaire, extrait de la Revue Internationale de la Croix-Rouge, Genève, Juillet-Août 1984, pp. 3-48.

- NDAM NJOYA, Adamou, «La Conception africaine », in Les dimensions internationales du droit humanitaire, Institut Henry Dunant -UNESCO -Pedone, Genève-Paris, 1986, pp. 2130 .

- NDONDOBONI Lubali Esambela, «La redéfinition de la guerre en République Démocratique du Congo », in Economie de guerre, bonne gouvernance et développement en République Démocratique du Congo (Actes des journées scientifiques organisées par la Faculté d'Administration et Sciences Economiques), Revue de la Faculté d'Administration des Affaires et Sciences Economiques de l'Université Protestante au Congo, CEDI, Kinshasa, 1999.

- NGOIE Tshibambe, «La politique de bon voisinage: analyse d'un principe de la politique étrangère de la RDC », in Congo-Afrique, n412-413, Kinshasa, éd. Cepas, février-mars 2007, pp. 153-168.

- NGOMO, Angéline-Florence, «Article 18, alinéa 3 », in KAMTO, Maurice (dir.), La Charte africaine des droits de l'homme et des peuples et le protocole y relatif portant création de la Cour africaine des droits de l'homme et des peuples. Commentaire article par article, op. cit., pp. 413-429.

- NIYUNGEKO, Gérard, «La mise en œuvre du droit international humanitaire et le principe de la souveraineté des Etats », in RICR, n788, mars-avril 1991, pp.113-141.

- NTIRUMENYERWA M. Kimonyo, « Le système de protection des droits de l'homme: Mécanismes de protection fondés par la Charte des Nations - Unies: Ecosoc, CDH, HCNUDH », in Droits de l'homme et droit international humanitaire, séminaire de formation cinquantenaire de la Déclaration universelle de Droits de l'homme 18 nov.-10 déc.1998, P.U.K., Kinshasa 1999.

- NTUMBA Luaba Lumu, «Grandes puissances et avenir de la République Démocratique du Congo », in SABAKINU Kivulu (dir.), Démocratie et paix en République Démocratique du Congo, op. cit., p. 222.

- OLIVIER, Clémentine, «Les Organisations non gouvernementales et la répression pénale internationale » in COHEN-JONATHAN et J.F. FLAUSS, (éd.), Les Organisations non gouvernementales et le droit international des droits de l'homme. International human rights law and non governemental organization, op.cit., pp. 117-155.

- OTTEVAERE, Anne, «Adoptions internationales et intérêt supérieur de l'enfant », in J.T, 2008/18, n6310, pp. 309-314. 
- PARQUE, Véronique, «Le rôle de la communauté internationale dans la gestion du conflit en République Démocratique du Congo », in L'Afrique des Grands Lacs, Annuaire 19992000, 33 p. in http://www.ua.ac.be/objs/00111074.pdf (Source consultée le 10 mai 2015).

- PELLET, Alain, «Les Rapports de Roberto Ago à la CDI », in International Law FORUM du droit international, novembre 2002, Vol. 4 issue 4, pp. 222-249.

- PERRAKIS, Stelios, «Le droit international humanitaire et ses relations avec les droits de l'homme. Quelques considérations », in TAVERNIER, Paul et HENCKAERTS, Jean-Marie (dir.), Droit international humanitaire coutumier : enjeux et défis contemporains, op. cit., pp. 115-137.

- PICTET, Jean S., «Le droit international humanitaire : définition », in Les dimensions internationales du droit humanitaire, , Institut Henry Dunant -UNESCO -Pedone, GenèveParis, 1986, pp. 13-16.

- Idem, «La formation du droit international humanitaire », in RICR, Vol. 84, $\mathrm{N}^{\circ} 846$, juin 2002, pp. 321-344.

- PLATTNER, Denise, «La protection de l'enfant dans le droit international humanitaire », in $R I C R, \mathrm{n}^{\circ} 747$, mai-juin 1984, pp.148-161.

- POURTIER, Roland, «Conflits en cours et zone de Tension : la guerre des Grands Lacs », in ROUGNOY, Philippe (dir.), Les conflits dans le monde, Cahier français, $\mathrm{n}^{\circ} 290$, Paris 1998.

- RAMASY, Juvence F., «La protection juridique et politique des enfants dans les conflits armés en Afrique. Inventaire des dispositions légales et politiques », in BABIKER, Mohamed Abdelsalam, DAUBLAIN, Maxense et VAHLAS, Alexis (dir.), Enfants-soldats et droits des enfants en situation de conflit et post-conflit. Réalités et enjeux, op. cit., pp. 263-281.

- RASSON, Anne-Catherine, «La protection juridictionnelle des droits fondamentaux de l'enfant : une utopie ? », in RTDH (106/2016), pp. 481-521.

- REMACLE, Eric et MARTINELLI, Marta, «La RDC, laboratoire des actions militaires et de police européenne », in REMACLE, Eric et al. (dir.), L'Afrique des Grands Lacs. Des Conflits à la paix ? op. cit., pp. 203-239.

- REMACLE, Robert, «La conduite des opérations militaires au regard du droit des conflits armés », in Actualité du Droit international humanitaire, Bruxelles, éd. La Charte 2001, pp. $27-40$.

- REYCHLER, Luc, «Les crises et leurs fondements. La prévention des conflits violents », in Fondations Roi Baudoin et Médecins Sans Frontières, Conflits en Afrique. Analyse des crises et pistes pour une prévention. La communauté internationale : quelle responsabilité ?, GRIPEd. Complexe, Bruxelles, 1997, pp. 39-66.

- RINIKER, Anne, «Le Comité International de la Croix-Rouge et les conflits armés », in BENCHIKH, Madjid, (dir.), Les Organisations internationales et les conflits armés, op. cit., pp.159-165. 
- ROSAS, Allan, «International monitoring mechanisms in situations of armed conflict », in BLOED, Arie, et al., (ed.), Monitoring human rights in Europe. Comparing international procedures and mechanisms, Martinus Nijhoff Publishers, The Netherlands, 1993, pp. 221246.

- RUET, Céline, «La vulnérabilité dans la jurisprudence de la Cour européenne des droits de l'homme », in RTDH (102/2015), pp. 317 - 340.

- SANDOZ Yves, «La notion de protection dans le droit international humanitaire et au sein du Mouvement de la Croix-Rouge », in SWINARSKI Christophe (éd.), Etudes et essais sur le droit international humanitaire et sur les principes de la Croix-Rouge en l'honneur de Jean PICTET - Studies and essays on international Humanitarian law and Red Cross principles in honour of Jean PICTET, Comité International de la Croix-Rouge, Martinus Nijhoff Publishers, Genève - La Haye, 1984, pp. 975-987.

- SCHABAS, William A., «L'affaire Akayesu et ses enseignements sur le droit du génocide », in BOUSTANY, Katia et DORMOY, Daniel, (dir.), Génocide(s), op. cit., pp.11130.

- SCHMITZ, Marc, «Les enfants-soldats, un phénomène universel de plus en plus préoccupant », in SCHMITZ, Marc, (coord.), La guerre. Enfants admis. 300.000 enfantssoldats dans le monde: comment combattre ce fléau?, op. cit., pp. 19-41.

- SCHNEIDER, Catherine, «Autonomie de la protection internationale des droits de l'homme au sein du droit international », in ARSAC Pierre, CHARLOT Jean-Luc. et PALLARD Henri, Etat de Droit, Droits Fondamentaux et Diversité Culturelle, édition l'Harmattan, Paris 1999, pp. 11-29.

- SINGER, Sandra, «La protection des enfants dans les conflits armés » in RICR, $\mathrm{n}^{\circ} 759$, maijuin 1986, pp.135-172.

- Sir Nigel RODLEY, «NGOS and the prevention and repression of torture », in COHENJONATHAN G. et FLAUSS, J.F (éd.), Les Organisations non gouvernementales et le droit international des droits de l'homme. International human rights law and non governemental organization, op.cit., pp. 103-115.

- SOREL, Jean-Marc, «Convention de Vienne de 1969, article 31 Règle générale d'interprétation » in CORTEN, Olivier et KLEIN, Pierre (dir.), Les Conventions de Vienne sur le droit des traités. Commentaire article par article, Vol. II, op. cit., pp. 1289-1338.

- SOUMAORO, Souleymane, «La qualification des conflits armés », in MATHESON, Michael J. et MOMTAZ, Djamchid, op.cit., pp. 179-215.

- SPIRY, Emmanuel, «Interventions humanitaires et interventions d'humanité : la pratique française face au droit international in RGDIP 1998-2, pp. 407-434.

- STERN, Brigitte, «La Coutume au cœur du droit international. Quelques réflexions », in Mélanges offerts à PAUL REUTER. Le droit international : Unité et diversité, Pedone, Paris, 1981, pp. 479-499.

- SUNGA, Lyal S., "NGO Insolvement in international human rights monitoring », in COHEN-JONATHAN G. et J.F. FLAUSS, (éd.), Les Organisations non gouvernementales et 
le droit international des droits de l'homme. International human rights law and non governemental organization, op. cit., , pp. 41-69.

- SZUREK, Sandra, "Prévention des violations des droits de l'homme et maintien de la paix », in DECAUX, Emmanuel et TOUZE, Sébastien (dir.), La Prévention des violations des droits de l'homme. Actes du Colloque des 13 et 14 juin 2013, op.cit., p. 182. pp. 161-183.

- TAUBENFELD, Howard J., «The Applicability of the laws of war in civil war », in NORTON MOORE, John (ed.), Law and civil war in the modern world, The Johns Hopkins University Press, Baltimore-London, op. cit., pp. 499-517.

- TAVERNIER, Paul, «De 1899 à 1999: Eclatement ou approfondissement du droit international humanitaire », in TAVERNIER, Paul et BURGORGUE-LARSEN, Laurence (dir.), Un siècle de droit international humanitaire. Centenaire des Conventions de La Haye et cinquantenaire des Conventions de Genève, op. cit., pp. 1-17.

- TAVERNIER, Paul, «Réflexion sur les mécanismes assurant le respect du Droit International Humanitaire conformément aux Conventions de Genève et aux Protocoles additionnels », in Actualités et Droit International, Revue d'analyse juridique et d'actualités internationales http://www.ridi.org/adi/200004 (Source consultée le 25 novembre 2015).

- THERY, Irène, « Nouveaux droits de l'enfant, la potion magique », in Coordination pédagogique Démocratie ou Barbarie du Ministère de la Communauté française de Belgique, Droits humains : Regards d'aujourd'hui 1948-1998, Ministère de la Communauté française de Belgique, Bruxelles, 1998, pp. 124-126.

- THONIER, Jean-Paul, «Le militaire en opération multinationale face aux enfants-soldats », in BABIKER, Mohamed Abdelsalam, DAUBLAIN Maxence et VAHLAS Alexis (dir), Enfants-soldats et droits des enfants en situation de conflit et poste-conflitr. Réalités et enjeux, op. cit., pp. 189-197.

- TIGROUDJA, Hélène, «La Cour suprême israélienne et la protection des personnes en temps de conflit », in RGDIP, 2009- 3, pp. 555-588.

- TRAHAN, Anne-Marie, «Les enfants et les conflits armés », in Liber Amicorum Peter Leuprecht, Bruylant, Bruxelles, 2012, pp. 151-160.

-VAN ASSCHE Cédric, «Légitime défense préventive. Légal?», in http://www.lalibre.be/debats/opinions/legitime-defense-preventive-legal-

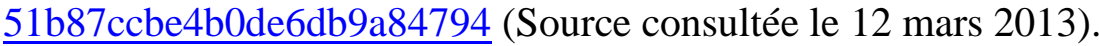

- VAN STEENBERGHE, Raphaël, «Théorie des sujets », in VAN STEENBERGHE, Raphaël, (dir.), Droit international humanitaire : un régime spécial de droit international ?, op. cit., pp. 15-71.

- VANDEWIELE, Tiny, «Optional Protocol: The involvement of Children in Armed conflicts », in ALEN, André, et al., (éd.), A commentary on the United Nations Convention on the Rights of the Child, Martinus Nijhoff Publishers, Leiden, 2006, 66 p.

- VERHOEVEN, Joe, «La mise en œuvre de la Convention des Nations Unies sur les droits de l'enfant. Observations en droit des gens », in MEULDERS-KLEIN, M.T. (dir.), La Convention sur les droits de l'enfant et la Belgique, Kluwer éditions juridiques Belgique, E. 
Story-scientia, Bruxelles, 1992, pp. 61-70.

- VEUTHEY, Michel, «L'Union européenne et l'obligation de faire respecter le droit international humanitaire », in MILLET-DEVALLE, Anne-Sophie (dir.), L'Union européenne et le droit international humanitaire, op. cit., pp. 189-216.

- VIRCOULON, Thierry, «Réforme de la justice : réalisations, limites et questionnements », in TREFON, Theodore (dir.), Réforme au Congo (RDC). Attentes et désillusions, Musée royal de l'Afrique centrale - L'Harmattan, op. cit., pp. 87-102.

- WERY, Michel, « Lutter contre les armes légères : un moyen de prévention », in Marc SCHMITZ (coord.), La guerre. Enfants admis, op. cit.,, pp. 175-178.

- WILDE d'ESTMAEL, T. de, «L'Union européenne et la résolution des conflits », in REMACLE E. et al. (dir.), L'Afrique des Grands Lacs. Des conflits à la paix ?, op. cit.

- WODIE, Vangah Francis, «L'Afrique et le droit humanitaire », in RICR, $\mathrm{n}^{\circ} 761$, septembreoctobre 1986, pp. 259-277.

- YEYONGNON, M., «Les juridictions internationales ou internationalisées compétentes pour connaître des violations les plus graves du droit international humanitaire commises en Afrique», in TAVERNIER, Paul, (dir.) Regards sur les droits de l'homme en Afrique, op. cit.. 277-298.

- ZANG, Laurent, MEYE, Lydie Ella et ZOCK, Françis, « Conflits intraétatiques et génocide défaillance de l'Etat et du système international au Rwanda », in BOUSTANY, Katia et DORMOY, Daniel, (dir.), op.cit., pp. 466-486.

- ZASOVA, Svetiana, «Le rôle des organisations internationales dans l'incitation des groupes armés au respect du droit international humanitaire : Quo vadimus ?», in SOREL, Jean-Marc et FOUCHARD, Isabelle Les tiers aux conflits armés et la protection des populations civiles, op. cit., pp. 133-152.

- ZEGBE Zegs, Fidèle, «Activités armées sur le territoire du Congo (RDC c. Ouganda) : plaidoyer pour une Commission Nationale d'indemnisation des victimes », in http://www.congovision.com/forum/zegs1.html (Source consultée le 28 mars 2016).

\section{c. Thèses de doctorat}

- AFFA'A MINDZIE, Mireille, La Protection internationale des droits de l'enfant, Thèse de doctorat, Droit international, Université de Strasbourg, 2001.

- BUHEDMA, Abdulaziz M. Contribution à l'étude de la réaffirmation et du développement du droit international humanitaire applicable dans les conflits armés internationaux: Des projets du CICR aux protocoles additionnels adoptés en 1977, Thèse de doctorat d'Etat en Droit, Université d'Orléans, 1985, 291 p.

- COUTURIER-BOURDINIERE, Lucile, La protection internationale des droits de l'enfant, Thèse de doctorat en droit, discipline: Droit international, droit européen, relations internationales, Université Panthéon-Assas (Paris II), juillet 1999, 726 p. 
- DAXHELET, Marie-Laure, L'étude des processus défensifs, adaptatifs et anti-traumatiques chez les enfants soldats congolais, Thèse de doctorat en psychologie, Université du Québec à Montréal, janvier 2013, 89 p.

- DIKPO, Thélesphore Toliton, La question des enfants soldats: quels problèmes pour la défense du droit, le maintien, la garantie et la promotion de la sécurité internationale?, Thèse de doctorat, Droit-Science politique, Université Jean Moulin Lyon III, 2008, 667 p.

- FURAHA MWAGALWA, Thomas, L'interdiction de la participation aux hostilités, la démobilisation et la réinsertion des enfants soldats en République démocratique du Congo, Thèse de doctorat en droit, Université Saint-Louis - Bruxelles, Juillet 2014, 533 p.

- GEANITON, Thierry, Aspects récents de l'Action du fonds des Nations unies pour l'enfance (UNICEF) en matière de protection internationale de l'enfant, Thèse de doctorat en droit, Université Paris 1, 1995, 398 p.

- HENNEBEL, Ludovic, Le régionalisme comme garant de l'universalisme des droits de l'homme: le cas du mécanisme de recours individuel de la Convention américaine des droits de l'homme, Thèse de doctorat en Droit, Vol. II, ULB, 2004-2005, 575 p.

- HOSSEIN RANJBARIAN, Amir, La criminalisation des violations graves du droit international humanitaire commises au cours de conflits armés non internationaux, Thèse de doctorat en droit, discipline : Droit public, Université Paris 13, 2001, 373 p.

- JACQUIER, Caroline, La protection des enfants soldats par le droit international, Thèse de doctorat en Droit, Université Paul Cézanne (Aix-Marseille 3), 2006, 758 p.

- JOKL, Marcelle, De l'interprétation des traités normatifs d'après la doctrine et la jurisprudence internationales, Thèse de doctorat, faculté de droit, Université de Caen, éd. A. Pedone, Paris, 1935, 194 p.

- KANE, Ameth Fadel, La protection des droits de l'enfant pendant les conflits armés en droit international, Thèse de doctorat en droit, Université de Lorraine, juin 2014, 490 p.

- KANTENGA MWAMBA, Dieudonné, De la construction de la figure de l'enfant-soldat aux expériences de socialisation. Le cas de la RD Congo, Thèse de doctorat en Criminologie, Ecole de Criminologie de l'Université de Lubumbashi, 2014, 516 p.

- KIKI SONAGNON, Lydie, Les Organisations internationales dans le règlement des conflits en Afrique de l'Ouest, Thèse de doctorat en Droit international public, Université Paris 1 Panthéon-Sorbonne, Université de Cocody-Abidjan, 2012, 530 p.

- KISHIBA Fitula, Gilbert., De la "Communauté Internationale » face aux conflits en Afrique Contemporaine. Repères pour l'alternative à la Charte des Nations Unies, Thèse de Doctorat en Droit, Université de Lubumbashi, mars 2005, 487 p.

- KOKOUVI DODZI, Luc Akakpo, Les enfants accusés de crimes internationaux: d'une justice hétérogène à une homogénéité des théories et des pratiques, Thèse de doctorat en droit, Université d'Ottawa, 2013, 417 p.

- MALLEIN, Jean, La Situation juridique des combattants dans les conflits armés non 
internationaux, Thèse de doctorat d'Etat en Droit, Université de Grenoble, 1978, 623 p.

- MANIRAKIZA, Egide, La Subsidiarité procédurale dans le système africain de protection des droits de l'homme, Thèse de doctorat en droit, Facultés Universitaires Notre-Dame de la Paix, janvier 2009, 374 p.

- NGONDZI, Jonas Remy, Enfants-soldats, conflits armés, liens familiaux : Quels enjeux de prise en charge dans le cadre du processus de DDR? Approches comparatives entre les deux Congo, Thèse de doctorat en science politique, Université Montesquieu Bordeaux IV, décembre 2013, 493 p.

- SANTIVASA, Saratoon, La protection internationale des enfants dans les conflits armés, Thèse de doctorat, Droit international, Université Paris II, 1995.

- ZINA, Seydina Ousmane, Analyse critique de l'économie politique de l'utilisation des "enfants soldats» (Etude de cas du pays du fleuve Mano (Libéria, Sierra Léone, Côte d'Ivoire), Thèse de doctorat en Sciences politiques et sociales, Université de Liège, 20132014.

\section{d. Dictionnaires}

- ARNAUD, André-Jean et al. (dir.), Dictionnaire encyclopédique de théorie et de sociologie $d u$ droit, $2^{\mathrm{e}}$ édition, L.G.D.J, Paris, 1993, 758 p.

- BATTISTELA, Dario, et al., Dictionnaire des relations internationales, $3^{\mathrm{e}}$ édition, Dalloz, 2012, 572 p.

- BEMBA, Joseph, Dictionnaire de la justice internationale, de la paix et du développement, L'Harmattan, Paris, 20045, 403 p.

- BEZIZ-AYACHE, Annie, Dictionnaire de droit pénal général et procédure pénale, $4^{\mathrm{e}}$ édition, Ellipses, Paris, 2008, 312 p.

- BLEDSOE, Robert L. et BOCZEK, Boleslaw A., The international law dictionary, Santa Barbara, Oxford, California, England, 422 p.

- BOUCHET-SAULNIER, Françoise, Dictionnaire pratique du Droit humanitaire, éd. La Découverte \& Syros, Paris, 1998, 420 p.

- Idem, Dictionnaire pratique du droit humanitaire, éd. La Découverte, Paris, 2013, 862 p.

- CHAGNOLlAUD, Dominique et DRAGO, Guillaume, Dictionnaire des droits fondamentaux, Dalloz, Paris, 2010, 751 p.

- CORNU, Gérard, Vocabulaire juridique, $11^{\mathrm{e}}$ édition mise à jour sous la direction de l’Association Henri Capitant, «Quadrige », PUF, Paris, 2016, 1101 p.

- FOX, James R., Dictionary of international and comparative law, Third edition, Oceana Publication, Dobbs Ferry, New-York, 2003, 369 p.

- KDHIR, Moncef, Dictionnaire juridique de la Cour internationale de justice, $2^{\mathrm{e}}$ édition, Bruylant, Bruxelles, 2000, 527 p. 
- LA ROSA, Anne-Marie, Dictionnaire de droit international pénal. Termes choisis, Publications de l'Institut Universitaire de Hautes Etudes Internationales, PUF, Genève-Paris, 1998, 118 p.

- SALMON, Jean, (dir.), Dictionnaire de droit international public, Bruylant, Bruxelles, 2001, 1198 p.

- TZITZIS, Stamatios (dir.), Dictionnaire des Sciences criminelles, Dalloz, Paris, 2004, 1013 p.

\section{e. Autres publications}

- «L'organisation partenaire BVES-RDC appelle à plus de bruit dans les communautés pour dire NON au recrutement et à l'utilisation d'enfants soldats en République Démocratique du Congo », in http://www.child-soldiers.org/francais_report_reader.php?id=741 (Source consultée le 04 mai 2014).

- ACPF, Budgetiser pour les Enfants en Afrique. La Rhétorique, la Réalité et le Tableau de bord. Supplément au Rapport Africain sur le Bien-être de 1'enfant 2011, The Africain Child Policy Forum, Addis Abeba, 2011, 33 p.

- BOGNA, Patrice, «Rôle de la MONUC face aux crises Humanitaires en République Démocratique », in Magazine MONUC N²0, janvier 2000, p. 7.

- Centre régional d'information des Nations unies pour l'Europe occidentale, Enfants de la République démocratique du Congo, http://www.unric.org/fr/actualite/2727-enfants-de-larepublique-democratique-du-congo (Source consultée le 31 octobre 2015).

- FOFACK, Eric Wilson, « Les Enfants victimes des conflits armés : pratiques et lutte en Afrique », in Note d'Analyse du GRIP, 03 août 2015, Bruxelles, http://www.grip.org/fr/node/1788 (Source consultée le 24 janvier 2016).

- FOFACK, Eric Wilson, «Les enfants victimes des conflits armés dans le monde : Permanence et mutation d'une préoccupation mondiale », in Note d'analyse du GRIP du 21 août

http://www.operationspaix.net/DATA/DOCUMENT/8099 v Les_enfants_victimes_des_con flits_armes_dans_le_monde Permanence_et_mutation_dune_preoccupation_mondiale.pdf ( Source consultée le 11 avril 2015).

- Institut National de la Statistique Kinshasa-RD-Congo, L'épidémiologie du VIH/Sida en $R D C$. Une analyse secondaire de l'EDS-RDC -2007, XXVIè Congrès Général de la population, Marraketch, Maroc du 26 septe au 02 oct. 2009, 18 p., in http://iussp2009.princeton.edu/papers/90584 (Source consultée le 06 août 2014).

- Intervention de Jean SALMON au débat au tour de la Conférence d'Alain PELLET sur le «Discours et réalité du droit international. Reims : apport et limite d'une méthode» in Réalités du droit international contemporain. Les rapports entre l'objet et la méthode en droit international (Actes de la huitième rencontre de Reims, pp. 27-28 mai 1989), Presses universitaires de Reims, Reims, (sans année), p. 36.

- MUSAVULI, Boniface, «RD Congo - Armée: Une bombe à retardement », article 
disponible sur http://desc-wondo.org/fr/exclusif-rd-congo-armee-une-bombe-a-retardementboniface-musavuli/ (Source consultée le 11 septembre 2016).

- NGANGOUE, Nana Rosine, «La protection des civils : priorités des priorités », in MONUC face à la protection des populations civiles, MONUC Magazine, Vol. VIII, n 45, 2009, p. 5.

- OUAYORO, E., «Les Ressources minérales de la RDC, bénédiction ou malédiction ? Comment peuvent-elles contribuer au développement durable de la RDC ? », in Ministère des Mines de la RDC, Rapport final des travaux de la conférence sur la bonne gouvernance et la transparence dans le secteur minier de la RDC tenue à Lubumbashi les 30 et 31 janvier 2013 http://mines-rdc.cd/fr/documents/Rapport_final_conference_lushi.pdf (Source consultée le 28 août 2013).

- PICCININI, Carlo, «Refrain humanitaire : un projet musical du CICR » in https://www.icrc.org/fre/resources/documents/film/cote-ivoire-video-180906.htm $\quad$ (Source consultée le 16 décembre 2016).

- TOEKA KAKALA Taylor, «RD CONGO: Les groupes armés intensifient l'utilisation d'enfants », in http://www.ips.org/fr/rd-congo-les-groupes-armes-intensifient-lutilisationdenfants/ (source consultée le 05 mai 2014).

- TSHISHIKU, Marcel, «Le CICR renforce son dialogue avec les parties en conflit en RDC » in http://7sur7.cd/new/cicr-renforce-dialogue-les-parties-en-conflits-en-rdc/ (Source consultée le 06 décembre 2015).

\section{Rapports et autres documents}

- Convention (IV) concernant les lois et coutumes de la guerre sur terre du 18 octobre 1907 et son annexe Règlement concernant les lois et coutumes de la guerre sur terre in Deuxième Conférence internationale de la Paix, La Haye 15 juin - 18 octobre 1907, Actes et documents, Tome I, Séances plénières de la Conférence, Ministère des affaires étrangères, Imprimerie Nationale, La Haye, 1907, pp. 626 - 637. Textes disponibles sur https://www.icrc.org/dih/INTRO/195 (Source consultée le 07 avril 2016).

- Déclaration de Genève sur les droits de l'enfant, 1924, in http://www.humanium.org/fr/normes/declaration-de-geneve-1924/ (Source consultée le 18 juillet 2015).

- Deuxième Conférence internationale de la Paix, La Haye 15 juin - 18 octobre 1907, Actes et documents, Tome III, Séances plénières de la Conférence, Ministère des affaires étrangères, , Imprimerie Nationale, La Haye, 1907, 1180 p.

- Acte portant création de l'Union Internationale de Secours aux Enfants (Save the Children Fund: Central Union) du 06-08 janvier 1920, Archives d'Etat in http://etat.geneve.ch/dt/archives/union_internationale_secours_aux_enfants-66-21931069.html (Source consultée le 18 juillet 2015).

- Diplomatic documents of Switzerland 1945-1972, Union Internationale de Secours aux Enfants in http://db.dodis.ch/organization/22141 (Source consultée le 18 juillet 2015). 
- Code Lieber disponible sur https://ihl-databases.icrc.org/dih-traites/INTRO/110 (Source consultée le 14 août 2016).

- Préparation de la Réunion du Groupe d'experts intergouvernemental pour la protection des victimes (Genève, 23-27 janvier 1995), Note du gouvernement Suisse, Genève, mars 1994, in RICR, n809, CICR, Genève, septembre - octobre 1994, pp. 454-464.

- Principes du Cap et meilleures pratiques Concernant le recrutement d'enfants dans les forces armées et la démobilisation et la réinsertion sociale des enfants soldats en Afrique adoptés au Symposium sur la Prévention du recrutement d'enfants dans les forces armées et sur la démobilisation et la réinsertion sociale des enfants-soldats en Afrique, entre les 27 et 30 avril 1997, (Document disponible sur http://www2.unicef.org:60090/french/emerg/index_childsoldiers.html (Source consultée le 15 mai 2016).

- RDC, Ministère des Droits Humains, Livre blanc sur les violations délibérées de l'accord de cessez-le-feu de Lusaka du 10 juillet 1999, de la Charte Internationale des Droits de l'Homme, des règles de base du Droit International Humanitaire ainsi que des résolutions pertinentes du Conseil de Sécurité de l'ONU par les Agresseurs (Ouganda, Burundi, Ruanda) et leurs complices Congolais du RCD et du MLC dans les territoires occupés de la R.D.C. couvrant la période du 11 juillet 1999 au 31 décembre 1999, 5 ans, édition Kinshasa juin 2000.

- RDC, Affaire relative aux activités armées sur le territoire du Congo (République Démocratique $d u$ Congo c. Ouganda), Cour internationale de justice, Mémoire de la République Démocratique du Congo, Vol. I, Juillet 2000, 275 p.

- RDC, Ministère des Affaires sociales et famille, Rapport national sur le suivi du sommet mondial pour les Enfants, décembre 2000, 18 p

- CENCO, Tous, pour les intérêts supérieurs de la Nation. Message des Evêques de la CENC aux fidèles catholiques et aux hommes de bonne volonté, Edition du Secrétariat Général de la

- CENCO, Kinshasa-Gombe, 2001, téléchargeable sur http://www.cenco.cd/?page=documents (Source consultée le 18 octobre 2015)

- RDC, Ministre des droits humains, La guerre d'agression en République Démocratique du Congo. Trois ans de massacre et de génocide "à huis clos», Livre Blanc, Numéro spécial, Kinshasa, Octobre 2001, 88 p.

- RDC, Affaire relative aux activités armées sur le territoire du Congo (République Démocratique du Congo c. Ouganda), Cour internationale de justice, Réplique de la République Démocratique du Congo, Vol. I, mai 2002, 400 p.

- UNHCR, La Violence sexuelle et sexiste contre les réfugiés, les rapatriés et les personnes déplacées. Principes directeurs pour la prévention et l'intervention, mai 2003, 171 p.

- Watchlist on Children and Armed Conflict, Impact des conflits armés sur les enfants en République démocratique du Congo (RDC), New-York, juin 2003, disponible en ligne : http://www.watchlist.org (Recherche menée le 05 août 2014).

- Amnesty international, République Démocratique du Congo - Enfants en guerre, AI index :Afr 62/034/2003. Secrétariat international, document public, 43 p., in 
http://www.kongo-kinshasa.de/dokumente/ngo/ai_enfants_0903.pdf(Source consultée le 05 août 2014).

- Bureau International Catholique pour l'Enfance, Section Protection de l'Enfant de la MONUC, Save The Children UK et UNICEF, La Protection légale et judiciaire des enfants en RDC. Problèmes centraux et propositions, Documents de discussion, décembre 2004, 23 p.

- CENCO, «Voici le temps favorable, voici maintenant le jour du salut» (2 Co 6, 2). Le Congo nous appartient. Déclaration du Comité Permanent des Evêques de la RDC sur la situation politique actuelle. Aux fidèles et aux hommes de bonne volonté, 2005, téléchargeable sur http://www.cenco.cd/?page=documents (Source consultée le 18 octobre 2015).

- MONUC, Division des droits de l'homme, Rapport sur les conditions de détention dans les prisons et cachots de la RDC, octobre 2005, 42 p.

- MONUC, Division droits de l'homme, Section Protection de l'enfant, Arrestation et détention dans les prisons et cachots de la RDC, Partie II, La détention des enfants et la justice pour mineurs, mars 2006, $32 \mathrm{p}$.

- Les Principes et lignes directrices sur les enfants associés aux forces armées ou aux forces armées février 2007 , http://www.unicef.org/french/protection/files/ParisPrincipesFrench310107.pdf (Source consultée le 18 juillet 2016).

- RDC, Rapport National sur le Développement Humain 2008, Restauration de la paix et Reconstruction, PNUD 2008, p.17. http://www.undp.org.cd (Source consultée le 28 août 2013).

- ASADHO, Le Gouvernement congolais viole ses obligations internationales relatives à la protection des droits de l'enfant, Rapport circonstanciel à l'occasion de la journée internationale de l'Enfant africain, $\mathrm{PDH} \mathrm{n}^{\circ}$ Spécial - ASADHO, juin 2008, 15 p.

- Comité Permanent des Evêques de la CENCO, «La RD Congo pleure ses enfants, elle est inconsolable (cf. Mt 2, 8). Déclaration du 13 novembre 2008 du Comité Permanent des Evêques sur la guerre dans l'Est et dans le Nord-Est de la RD Congo », in Congo-Afrique XLVII Année, (Décembre 2008) n430, pp. 791-793.

- RCN Justice \& Démocratie, Rapport d'Activités 2009. Bulletin $n^{\circ} 34$. Quatrième trimestre 2010, disponible http://www.rcn-ong.be/-Rapports-d-activites-?lang=fr (Source consultée le 20 octobre 2015).

- Résolution et décisions adoptées par l'Assemblée des Etats parties à la Cour Pénale internationale, Troisième partie, ICC-ASP/13/20, 22 p.

- Bureau du Représentant spécial du Secrétaire général pour les enfants et les conflits armés, «Notre travail» in https://childrenandarmedconflict.un.org/fr/qui-sommes-nous/notretravail/ (Source consultée le 22 février 2016).

- Action des Chrétiens pour l'abolition de la torture, Effectivité des droits des enfants en République Démocratique à l'aune des objectifs du millénaire pour le développement. Regard sur la situation particulière des enfants dans les territoires de Kabare au Sud-Kivu, éd. ACAT/Sud-Kivu, Bukavu, janvier 2010, 78 p. 
- Nations Unies, Haut Commissariat aux droits de l'homme, Rapport du Projet Mapping concernant les violations les plus graves des droits de l'homme et du droit international humanitaire commises entre mars 1993 et juin 2003 sur le territoire de la République démocratique du Congo, Août 2010, 562 p.

- Avocats Sans Frontières, Recueil de décisions de justice et de notes de plaidoiries en matière de crimes internationationaux, décembre 2010, Document disponible sur https://issuu.com/avocatssansfrontieres/docs/asf_rdc_crimesinternationaux_part2/8 (Source consultée le 20 mai 2016).

- Amnesty International, Il est temps que justice soit rendue. La République Démocratique du Congo a besoin d'une nouvelle stratégie en matière de justice. Campagne en faveur de la justice internationale. Amnesty International, Document public AFR 62/006/2011, AILRCFR, Août 2011, 66 p.

- RCN Justice \& Démocratie, Rapport d'Activités 2011. Bulletin $n^{\circ} 39$. Troisième trimestre $2011,31 \mathrm{p}$.

- PNUD, Rapport sur le Développement humain 2013 : L'essor du Sud Le progrès humain dans un monde diversifié?, in http://hdr.undp.org/en/media/HDR_2013_FR.pdf, (Source consultée le 28 août 2013).

- Doing Business 2014 http://francais.doingbusiness.org/reports/global-reports/doingbusiness-2014 (Source consultée le 12 mars 2014).

- Rapport final du Groupe d'experts sur l'exploitation illégale des ressources naturelles et autres formes de richesse de la République Démocratique du Congo in http://www.grip.org/bdg/g2004.html (Source consultée 28 août 2013).

- Journée internationale contre l'utilisation d'enfants soldats, Déclaration commune de l'Union Africaine et de l'Union Européenne (Addis-Abeba-Bruxelles, 12 février 2011), in http://www.ambafrance-au.org/spip.php?page=mobile_art\&art=4054 (Source consultée le 26 novembre 2013).

- MONUSCO, Rapport sur le recrutement d'enfants par les groupes armés pendant la période du $1^{\text {er }}$ janvier 2012 au 31 août 2013, 28 p., in https://monusco.unmissions.org/Default.aspx?tabid=11302\&language=fr-FR $\quad$ (Source consultée le 14 février 2016).

- Statut des Chambres africaines extraordinaires au sein des juridictions sénégalaises pour la poursuite des crimes internationaux commis au Tchad durant la période du 7 juin 1982 au $1^{\text {er }} \quad$ décembre $\quad 1990 \quad \mathrm{du} \quad 22$ août $2012, \quad$ in http://www.chambresafricaines.org/index.php/presentation-des-chambres/contexte-decreation.html (Source consultée le 18 mars 2016).

- RCN, Justice \& Démocratie, Rapport d'activités 2012, Le Bulletin n42, Bruxelles, Quatrième trimestre 2013, 31 p.

- Watchlist on children and Armed conflict, Mécanisme 1612 de surveillance et de communication. Dossier de ressources et outils pour ONG, Watchlist on children and Armed 
conflict, 2014, 122 p.

- Watchlist on children and armed conflict, Impact des conflits armés sur les enfants en République démocratique du Congo (RDC), 41 p., in http://watchlist.org/ (Source consultée le 06 août 2014).

- FIDH, « Sommet de l'Union africaine sur la Cour pénale internationale : La protection des dirigeants au détriment des victimes et de la paix », in http://www.fidh.org/fr/afrique/unionafricaine/14151-sommet-de-l-union-africaine-sur-la-cour-penale-internationale-la (Source consultée le 27 février 2016). 
TABLE DES MATIERES

RESUME

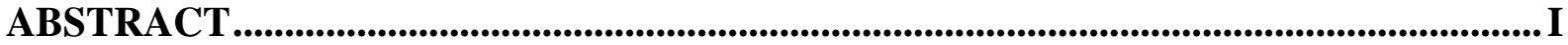

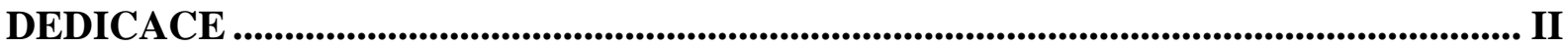

REMERCIEMENTS ...........................................................................................................III

LISTE DE PRINCIPALES ABREVIATIONS ............................................................................VII

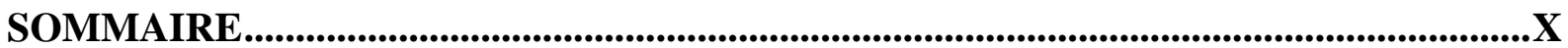

INTRODUCTION...................................................................................................................

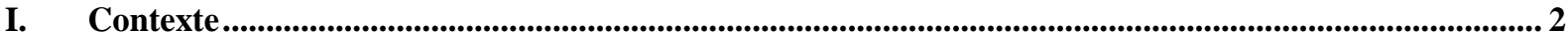

I. 1. Protection générale accordée aux enfants en situation de conflits armés ...........................................2

I. 2. Protection spéciale accordée aux enfants en situation de conflits armés............................................. 4

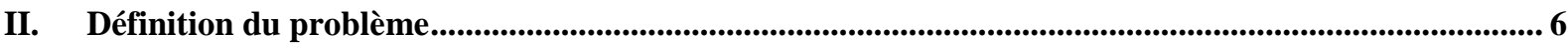

II.1. Formulation des dispositions relatives à la protection des enfants en situation de conflits armés laissant

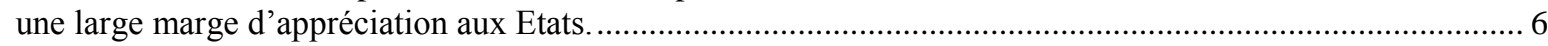

II.2. Différence de protection entre les catégories d'âges d'enfants : protection sélective des enfants .............8

II.3. Mécanismes de mise en œuvre des mesures de protection des enfants en situation de conflits armés ..... 10

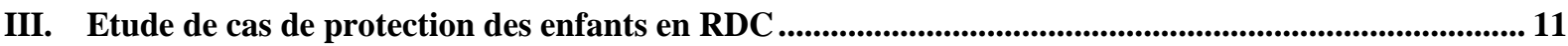

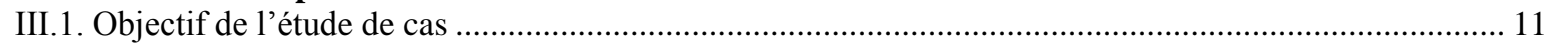

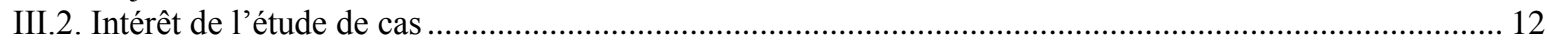

IV. Des questions et hypothèses de recherche............................................................................................ 17

IV.1. Etude du régime de protection spéciale de l'enfant en situation de conflits armés en RDC ................. 17

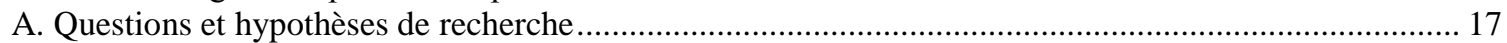

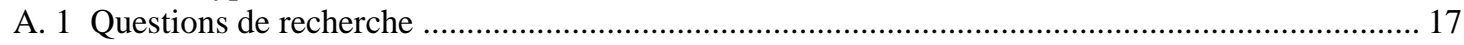

A. 2 Hypothèses de recherche .................................................................................................... 17

IV.2. Etude des mécanismes de protection spéciale de l'enfant en situation de conflits armés en RDC ......... 17

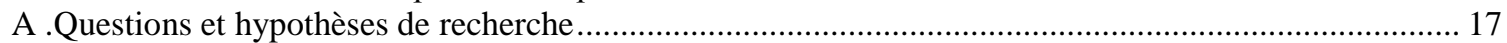

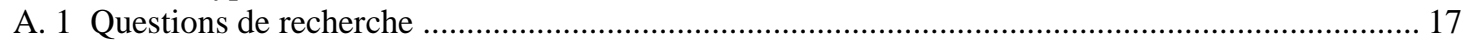

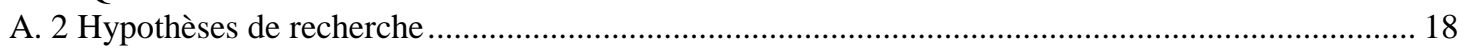

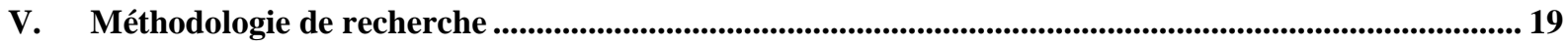

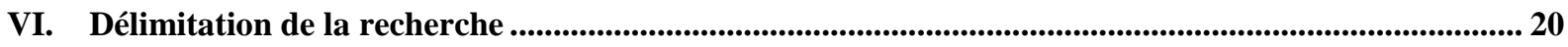

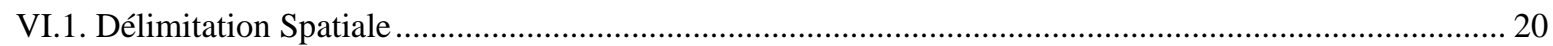

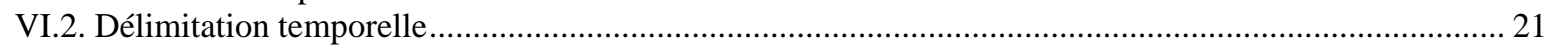

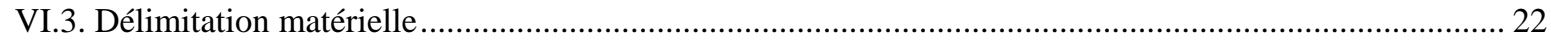

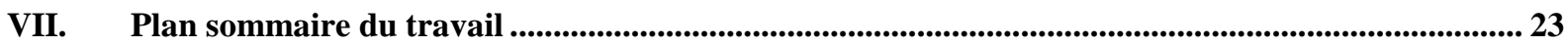




\section{LE DROIT INTERNATIONAL HUMANITAIRE ET LA PROTECTION DES ENFANTS EN SITUATION DE CONFLITS ARMES}

CHAPITRE PREMIER DEFINITION DU CADRE CONCEPTUEL .....................................................28

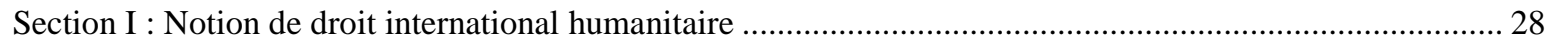

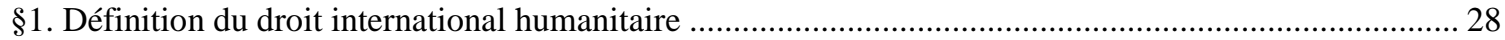

§. Aperçu historique du droit international humanitaire ................................................................ 38

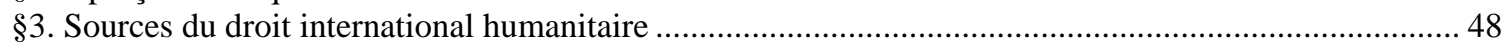

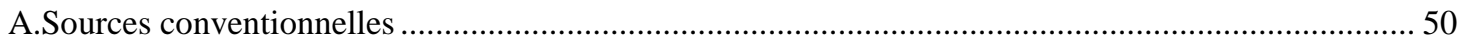

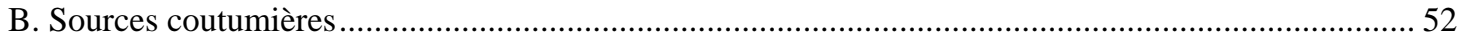

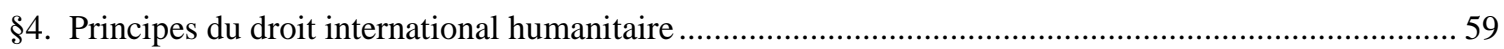

A. Le principe de limitation du choix des moyens et méthodes à disposition des belligérants .................. 61

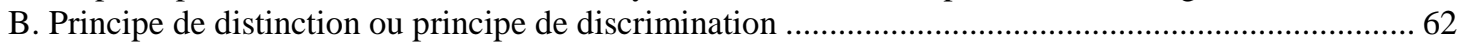

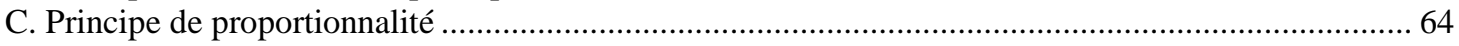

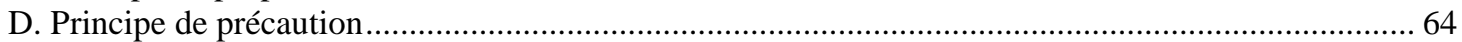

Section II Notions d'enfant et d'enfant soldat et aperçu historique de la protection et des droits de l'enfant.. 66

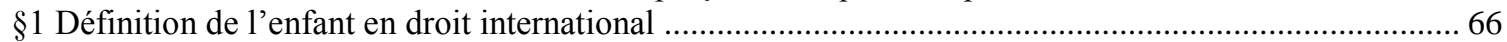

\$2 Notions d'enfant soldat ou d'enfant associé à une force ou à un groupe armé (EAFGA) ..................... 70

§3. Aperçu historique de la protection et des droits de l'enfant : de l'objet des droits à sujet des droits .... 71

Section III Notions de recrutement et de participation aux hostilités ....................................................... 79

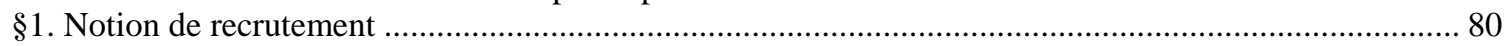

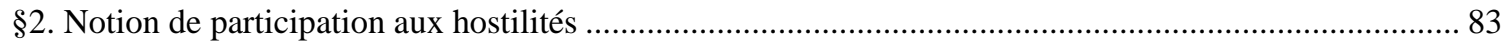

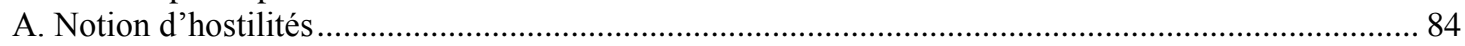

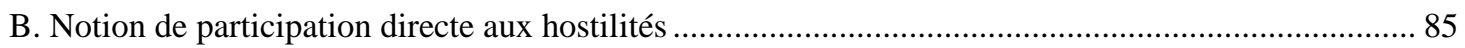

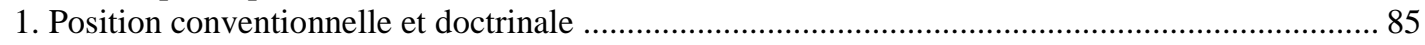

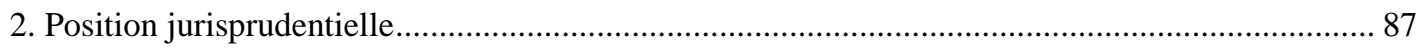

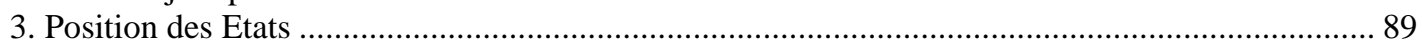

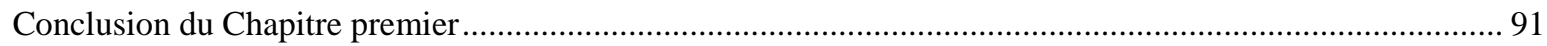

\section{CHAPITRE II DROIT INTERNATIONAL HUMANITAIRE : REGLES ET MECANISMES DE}

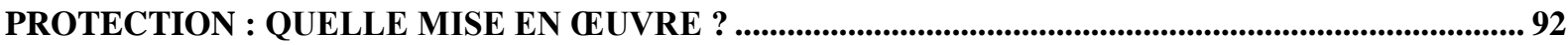

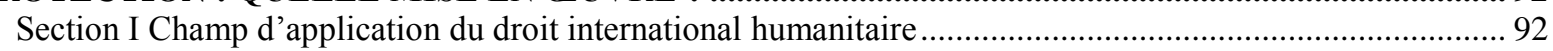

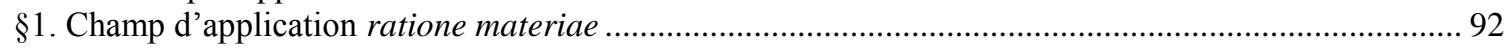

A. Les conflits armés internationaux (CAI) .......................................................................... 96

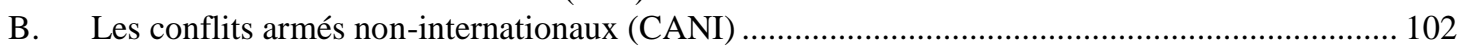

B. 1. Les CANI suivant l'article 3 commun aux CG : «CANI de basse intensité » ....................... 102

B. 2. Les CANI suivant l'article $1^{\mathrm{er}}$ du PA II : «CANI de haute intensité ».............................. 107

C. Les conflits armés internes internationalisés ..................................................................... 111

§2. Champ d'application ratione persona e...................................................................................... 119

A. Les blessés, les malades et les naufragés ................................................................................. 120

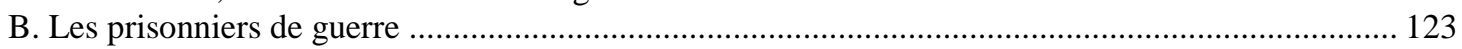

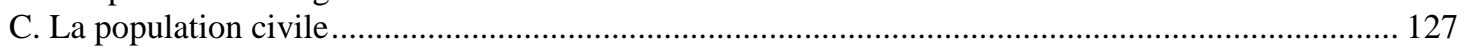

§3. Champ d'application ratione temporis et ratione loci ................................................................... 131

Section II Mise en œuvre du droit international humanitaire ............................................................. 132

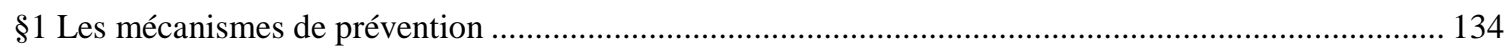

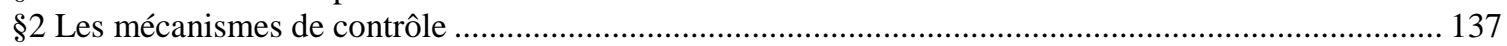

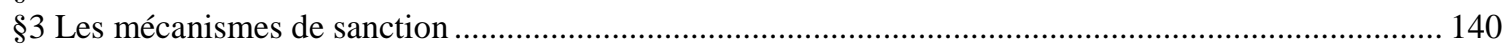

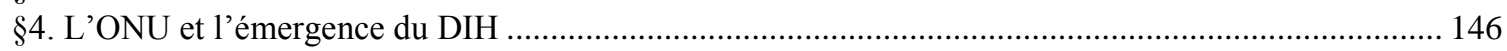

$\S 5$. Les facteurs non-juridiques liés à la mise en œuvre du droit international humanitaire ..................... 150

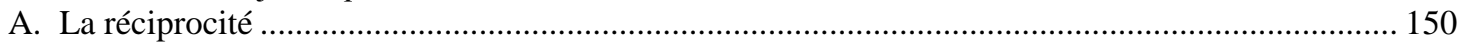

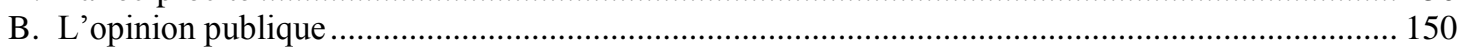

C. L'efficacité militaire, l'éthique humanitaire et la reconstruction de la paix post-conflit................. 152

Section III Les limites relatives à l'application du droit international humanitaire .................................. 153

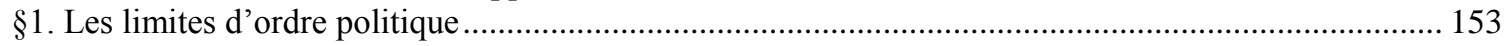

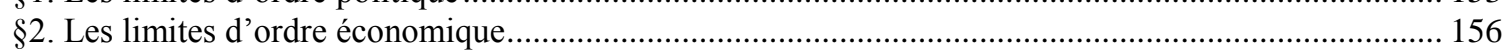

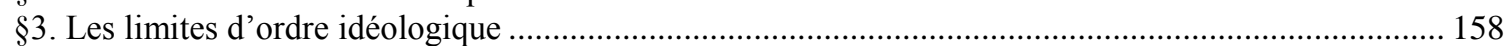

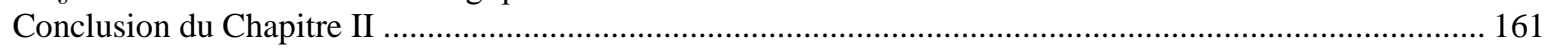




\section{CHAPITRE III LES REGLES DE PROTECTION DES ENFANTS DANS LES CONFLITS ARMES EN DROIT INTERNATIONAL HUMANITAIRE ...................................................................................... 162}

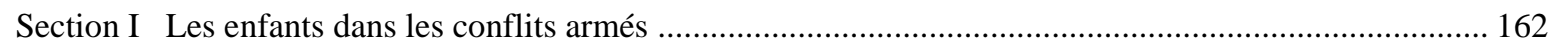

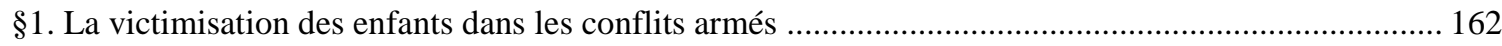

§2. L'utilisation des enfants dans les conflits armés : un phénomène omniprésent ............................... 164

Section II Les instruments juridiques applicables ........................................................................ 167

$\S 1$. Les Conventions de Genève du 12 août 1949 et leurs protocoles additionnels du 08 juin 1977 ......... 168

A. La protection générale de l'enfant en situation de conflits armés dans les Conventions de Genève du

12 août 1949 et leurs Protocoles additionnels du 08 juin 1977 ...................................................... 169

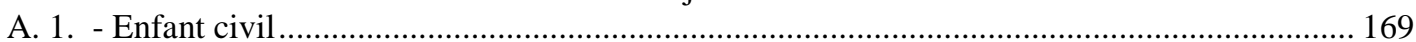

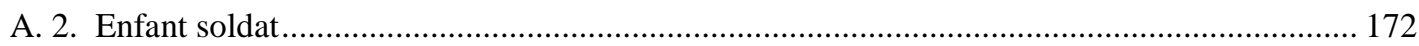

B. La Protection spéciale de l'enfant en situation de conflits armés dans les Conventions de Genève du

12 aout 1949 et leurs Protocoles additionnels du 08 juin 1977 : enfant civil et enfant soldat.............. 173

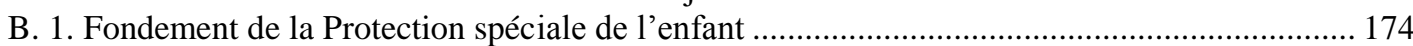

B. 2. Protection spéciale de l'enfant civil ....................................................................... 175

B. 3. Protection spéciale de l'enfant soldat ........................................................................... 185

$\S 2$. La Convention relative aux droits de l'enfant et le Protocole facultatif se rapportant à la Convention relative aux droits de l'enfant, concernant l'implication d'enfants dans les conflits armés...................... 192

A. Contenu global de la CDE ........................................................................................... 192

B. Protection spéciale de l'enfant en conflit armé................................................................. 193

B. 1. Suivant la CDE ....................................................................................................... 193

B. 2. Suivant le Protocole facultatif se rapportant à la Convention relative aux droits de l'enfant, concernant l'implication d'enfants dans les conflits armés du 25 mai 2000 ................................. 198

$\S 3$. La Convention de l'OIT $\left(\mathrm{n}^{\circ} 182\right)$ concernant l'interdiction des pires formes de travail des enfants et l'action immédiate en vue de leur élimination du 17 juin 1999 ............................................................ 200 $\S 4$. La protection de l'enfant en situation de conflits armés dans le système africain de protection des droits

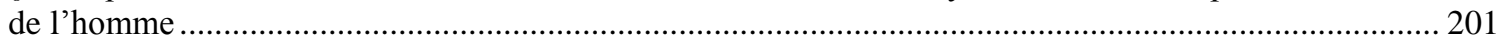

A. La Charte africaine des droits et du bien-être de l'enfant adoptée à Addis-Abéba (Ethiopie) le 11 juillet 1990

B. Le Protocole à la Charte africaine des droits de l'Homme et des peuples relatifs aux droits des femmes adopté à Maputo (Mozambique) le 11 juillet 2003

C. Convention de l'Union africaine sur la protection et l'assistance aux personnes déplacées en Afrique

(Convention de Kampala) adoptée par le Sommet spécial de l'Union tenu le 22 octobre 2009 .......... 206

§5. Le Statut de Rome portant création de la CPI........................................................................... 207

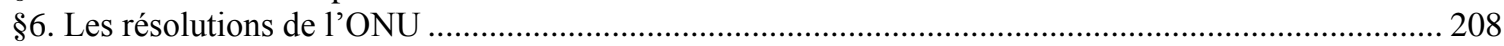

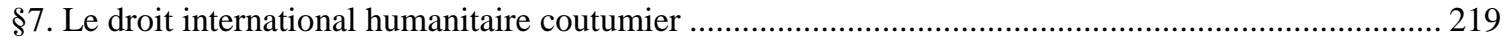

A. Au plan universel ...................................................................................................... 219

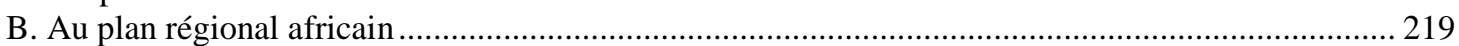

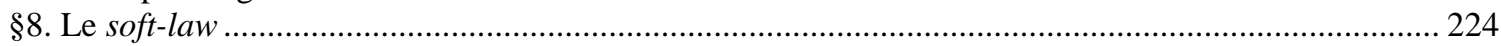

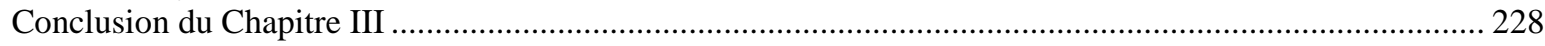

\section{CHAPITRE IV LES MECANISMES DE PROTECTION DES ENFANTS EN SITUATION DE}

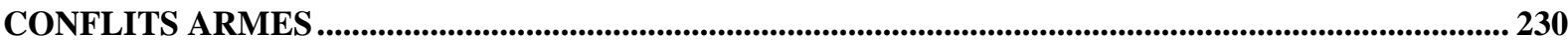

Section I. Les Mécanismes conventionnels de protection de l'enfant en situation de conflits armés ............ 230

$\S 1$. Les Mécanismes de protection de l'enfant dans les Conventions de Genève du 12 août 1949 et leurs

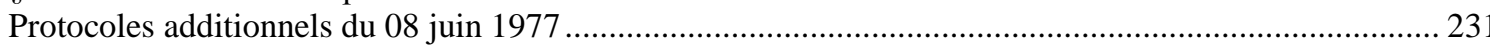

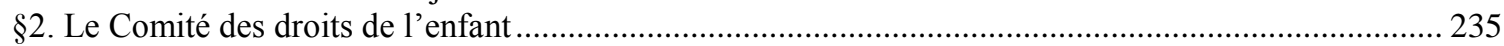

$\S 3$. La mise en œuvre de la Convention de l'OIT n ${ }^{\circ} 182$ concernant l'interdiction des pires formes de travail des enfants et l'action immédiate en vue de leur élimination .................................................. 239

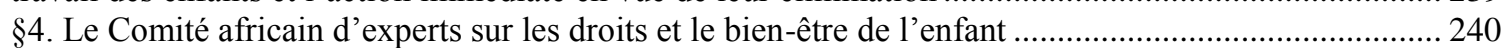

§. La Cour pénale internationale comme mécanisme de protection de l'enfant en situation de conflits

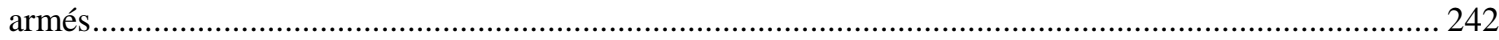

Section II Les Mécanismes non conventionnels de protection de l'enfant en situation de conflits armés ..... 248

$\S 1$. Les mécanismes de l'ONU de protection de l'enfant en situation de conflits armés ..........................248

$\S 2$. Les Organisations internationales comme mécanismes de protection de l'enfant en situation de conflits

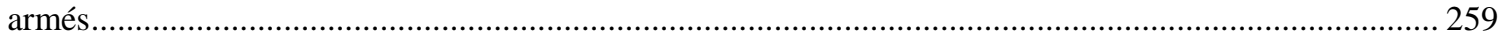

§3. Les ONG comme mécanismes de promotion de protection de l'enfant en situation de conflits armés.

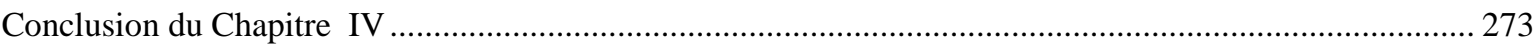




\section{LE DROIT INTERNATIONAL HUMANITAIRE ET LA PROTECTION DES ENFANTS EN SITUATION DE CONFLITS ARMES EN REPUBLIQUE DEMOCRATIQUE DU CONGO.}

CONFLITS ARMES ET ENFANTS EN REPUBLIQUE DEMOCRATIQUE DU CONGO

Section I Les Conflits armés en République Démocratique du Congo.................................................... 279

$\S 1$. Situations socio-économiques de la République démocratique du Congo......................................2280

§2. Genèse et évolution des conflits armés en République Démocratique du Congo .............................. 284

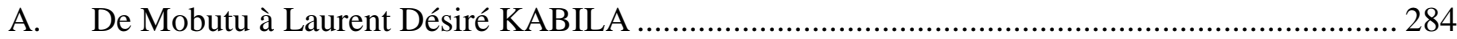

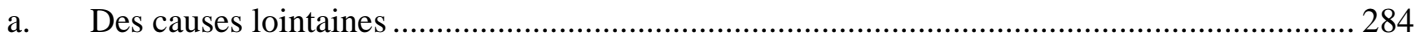

b.Des causes directement liées à « la première guerre de libération » ......................................... 291

B. De Laurent-Désiré KABILA au M23 ................................................................................ 298

§3. Le Conseil de sécurité des Nations Unies et les Conflits armés en RDC ....................................... 304

$\S 4$. Aperçu du processus de paix en République Démocratique du Congo ............................................. 314 Section II Recrutement et participation des enfants aux conflits armés en République Démocratique du Congo

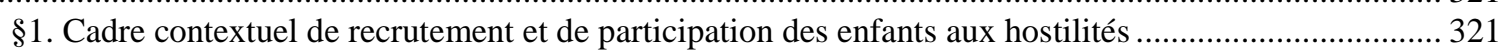

§2. Recrutement des enfants aux conflits armés en République Démocratique du Congo ...................... 323

A. Méthodes de recrutement ................................................................................................ 323

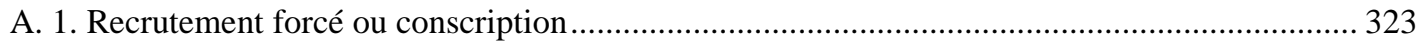

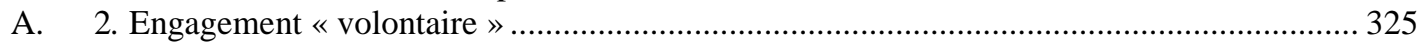

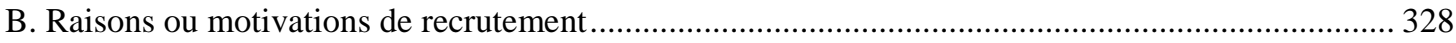

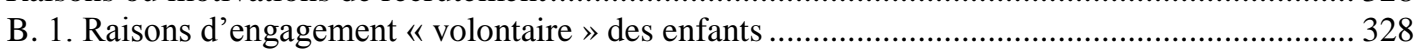

a. Raisons d'ordre socio-économique ....................................................................... 328

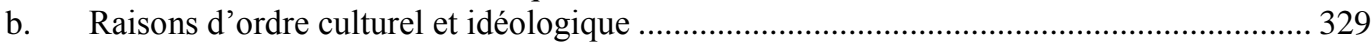

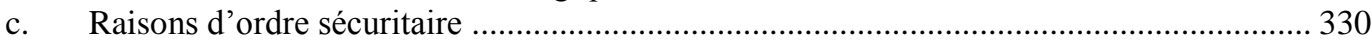

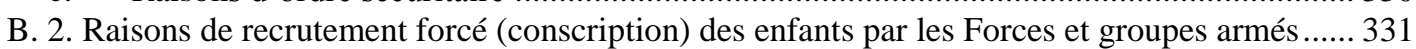

§3. Participation des enfants aux conflits armés ................................................................................ 332

A. Identification des Recruteurs et des enfants participants aux conflits armés........................... 332

B. Méthodes de participation des enfants aux hostilités.......................................................... 337

Section II Impacts des conflits armés sur les enfants en République Démocratique du Congo .....................340

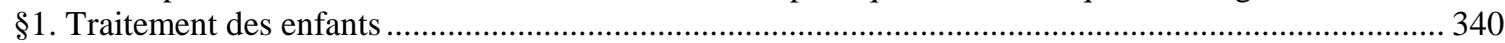

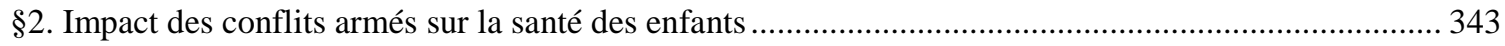

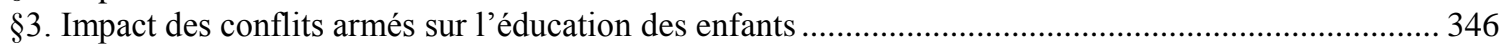

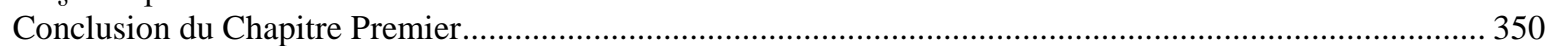

\section{CHAPITRE II LES REGLES DU DROIT INTERNATIONAL HUMANITAIRE RELATIVES A LA} PROTECTION DES ENFANTS EN RDC.

Section I Nature et conséquences juridiques des conflits armés en RDC au regard du droit international

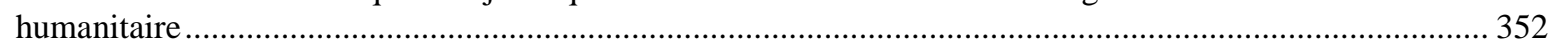

$\S 1$ Nature juridique des conflits armés en RDC en droit international humanitaire ............................... 353

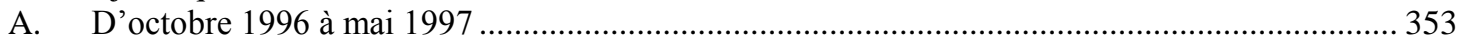

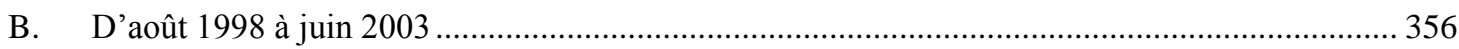

C. De juin 2003 à ce jour (Période des conflits armés intermittents) ........................................... 360

§. Conséquences juridiques de la qualification des conflits armés en RDC au regard du droit international humanitaire : Identification des sources conventionnelles des règles assurant la protection générale des enfants - combattants et civils - en conflits armés

A. Dans le cadre de CAI (et CANI internationalisé) en RDC ...................................................... 362

B. Dans le cadre de CANI en RDC ..................................................................................... 366

Section II Le droit international humanitaire applicable à la protection spéciale des enfants en RDC .......... 368

$\S 1$. Règles du DIH assurant la protection spéciale des enfants - combattants et civils - en CAI en RDC 370

A. Règles du DIH assurant la protection spéciale des enfants civils en CAI en RDC ....................... 370

A. 1. Règles du DIH assurant la protection spéciale des enfants civils en CAI en RDC : Règles issues des instruments juridiques universels....

A. 2. Règles du DIH assurant la protection spéciale des enfants civils en CAI en RDC : règles issues 
des Accords régionaux et spéciaux signés entre parties aux conflits armés ................................. 373

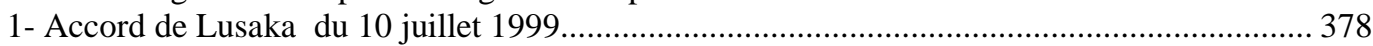

2. Pacte sur la Paix, la Sécurité, la Stabilité et le Développement dans la Région des Grands Lacs,

dit « Pacte ou Traité de Nairobi », du 15 décembre 2006 ...................................................... 380

B. Règles du DIH assurant la protection spéciale des enfants combattants en CAI en RDC ................ 382

B. 1. La protection spéciale des enfants combattants en CAI : des règles du DIH issues des instruments juridiques universels applicables en RDC .......................................................... 382

B.2 La protection spéciale des enfants combattants en CAI : des règles du DIH issues des Accords régionaux et spéciaux signés entre parties aux conflits armés en RDC........................................ 387

1. La Charte africaine des droits et du bien-être de l'enfant du 11 juillet 1990 ......................... 387

2. Accord de Lusaka du 10 juillet 1999 .............................................................................. 388

3. Pacte sur la Paix, la Sécurité, la Stabilité et le Développement dans la Région des Grands Lacs,

dit «Pacte ou Traité de Nairobi », du 15 décembre 2006 ..................................................... 388

4. Le Protocole à la Charte africaine des droits de l'Homme et des peuples relatif aux droits des

femmes adopté à Maputo (Mozambique) le 11 juillet 2003 ................................................... 389

5. Convention de l'Union africaine sur la protection et l'assistance aux personnes déplacées en

Afrique (Convention de Kampala) adoptée par le Sommet spécial de l'Union tenu le 22 octobre 2009

$\S 2$. Règles du DIH assurant la protection spéciale des enfants - combattants et civils - en CANI en RDC

A. Règles du DIH issues des instruments universels assurant la protection spéciale des enfants combattants et civils - en CANI en RDC....

B. Règles du DIH issues des instruments régionaux et spéciaux assurant la protection spéciale des enfants - combattants et civils - en CANI en RDC.

B.1 Accord global et inclusif sur la transition en République Démocratique du Congo .................. 393

B. 2 Acte d'engagement de Goma du 23 janvier 2008

B.3 Accord de paix entre le Gouvernement et le Congrès National pour la Défense du Peuple

(CNDP) du 23 mars 2009.

§3. Le DIH coutumier et la protection spéciale des enfants en situation de conflits armés en RDC ......... 396 Section III Des Règles en complément des règles du DIH dans la protection spéciale des enfants en conflits armés en RDC

$\S 1$. Règles du droit international des droits de l'homme relatives à la protection spéciale des enfants en conflits armés en RDC

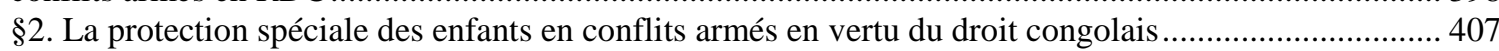

A. De la réglementation de recrutement et de participation des enfants aux hostilités en RDC .......... 411

B. Droit congolais protégeant spécialement l'enfant en période de conflits armés : la loi nº9/001 du 10

janvier 2009 portant protection de l'enfant .............................................................................. 418

§3. Les Résolutions du Conseil de sécurité des Nations Unies et la protection spéciale des enfants en situation de conflits armés en RDC ............................................................................................ 421

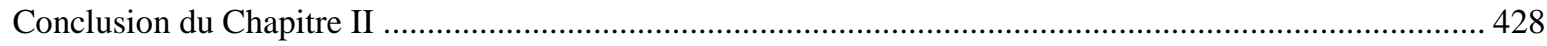

\section{CHAPITRE III LES MECANISMES DE PROTECTION DES ENFANTS EN SITUATION DE} CONFLITS ARMES EN RDC

Section I Mécanismes de protection des enfants en situation de conflits armés institués par les Conventions de

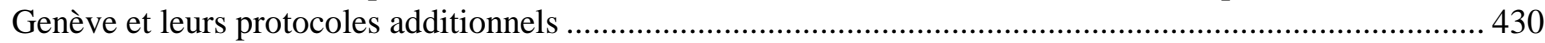

$\S 1$ Mécanismes de prévention du droit international humanitaire en RDC ........................................... 430

$\S 2$ Mécanismes de contrôle du droit international humanitaire en RDC : le CICR et la protection des

enfants en situation de conflits armés en RDC

Section II Mécanismes conventionnels des droits de l'homme et la protection des enfants en situation de conflits armés en RDC.

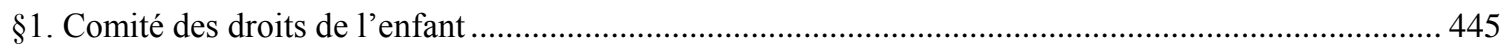

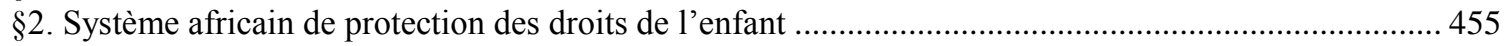

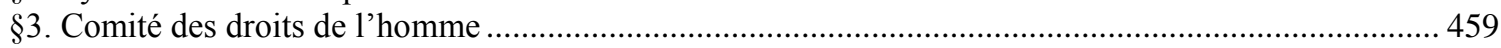

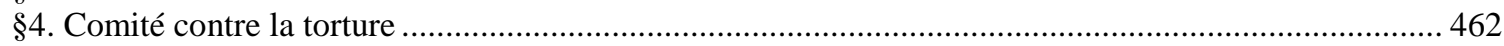

Section III La protection des enfants en situation de conflits armés en RDC dans le système de 1'ONU ...... 464

$\S 1$. l'ONU et la protection des enfants dans les conflits armés en RDC : Cas du Conseil de sécurité et du

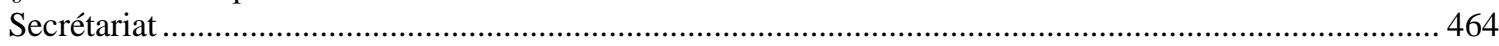

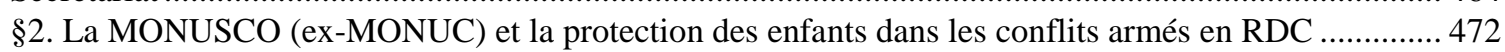

§3. L'UNICEF et la protection des enfants en conflits armés en RDC................................................. 478

Section IV Mécanismes gouvernementaux et non gouvernementaux de protection des enfants en situation de

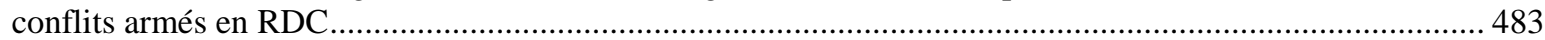

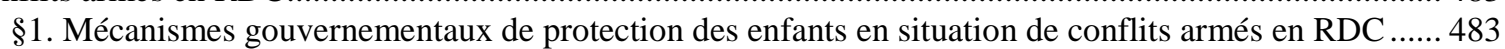


A - Mécanismes de Protection spéciale de l'enfant en temps de conflits armés ? ............................ 483

A.1 Le Conseil National de l'Enfant ....................................................................................... 484

A.2 Comité National de lutte contre les pires formes de travail des enfants ................................ 485

A.3 Unité d'Exécution du Programme National de Désarmement, Démobilisation et Réinsertion

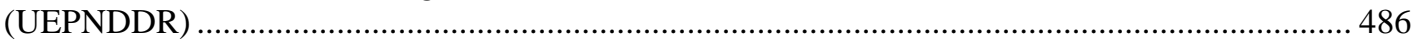

A.4 Mécanismes institués suivant la loi n09/001 du 10 janvier 2009 portant protection de l'enfant?

A.5 Le plan d'action du 04 octobre 2012 pour mettre fin au recrutement et à l'utilisation d'enfants ainsi qu'aux violences sexuelles perpétrées par les FARDC.................................................... 487 A.6 Agence nationale de lutte contre les violences faites à la Femme et à la Jeune et Petite Fille (AVIFEM) ............................................................................................................ 489

A.7 Fonds National pour la Promotion de la Femme et la Protection de l'Enfant (FONAFEM) ..... 490 A.8 Représentant personnel du Chef de l'Etat en charge de la lutte contre les violences sexuelles et le recrutement des enfants ....................................................................................................... 490

B - Mécanismes non juridictionnels nationaux de promotion et de protection des droits de l'homme 490

B.1 De l'Observatoire National des Droits de l'Homme à la Commission Nationale des droits de l'Homme

B.2 L'Entité de Liaison des Droits de l'Homme ............................................................................... 493

B.3 La Commission Nationale de préparation et du suivi de l'Examen Périodique Universel de la République Démocratique du Congo ................................................................................. 495

B.4 Le Comité Technique Interministériel d'élaboration et de suivi des rapports initiaux et périodiques des droits de l'homme (CTDH) ................................................................................ 495

§2. Mécanismes non gouvernementaux de protection des enfants en situation de conflits ..................... 497 Section V Les Mécanismes de sanction des graves violations des règles du DIH de protection des enfants en situation de conflits armés en RDC : La responsabilité en question....................................................506 $\S 1$. La justice congolaise : mécanisme efficace pour la répression des graves violations du DIH contre les enfants et de réparation des dommages?....

A. La Répression des graves violations du DIH contre les enfants et réparation des dommages en RDC

A. 1. Du crime de génocide, des crimes contre l'humanité et des crimes de guerre en droit congolais

A. 2. Aperçu global de quelques affaires des graves violations du DIH contre les enfants devant les instances judicaires congolaises : Répression et réparation ? ................................................. 513

B. Des obstacles à la répression des graves violations du DIH contre les enfants en RDC ....................518

C. Que proposer ?

\$2 La Cour pénale internationale et la répression des graves violations du DIH contre les enfants en RDC

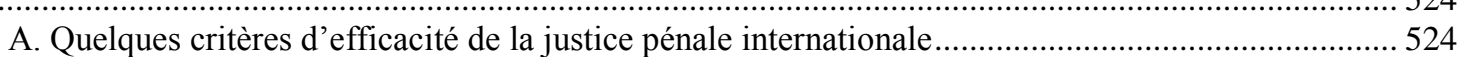

B. La situation de la RDC devant la Cour pénale internationale ....................................................... 526

B. 1 Affaire Thomas Lubanga Dyilo ..................................................................................... 527

B. 2 Affaires Germain Katanga et Mathieu Ngudjolo Chui ........................................................ 528

B. 3 Affaire Bosco Ntaganda ................................................................................... 529

B. 4 Affaire Callixte Mbarushimana ............................................................................... 530

B.5 Affaire Sylvestre Mudacumura............................................................................... 530

C. La Cour pénale internationale est-elle efficace pour réprimer les graves violations du DIH contre les

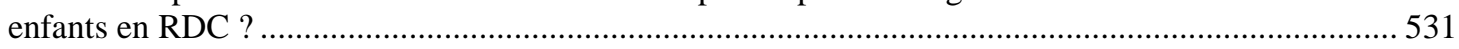

$\S 3$ La Cour internationale de justice et la situation de la RDC : cas particulier des enfants .......................532

A. Bref aperçu de la Responsabilité internationale des Etats ....................................................... 532

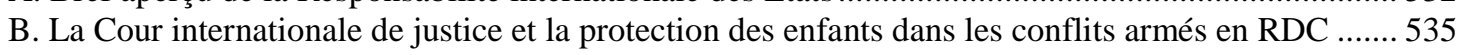

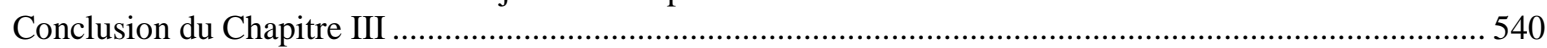

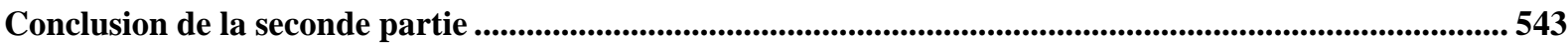

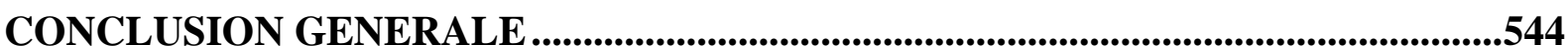

A. Pour l'efficacité des règles de protection spéciale de l'enfant en période d'hostilités en particulier et de conflits armés en général : .........................................................................................................................................549

B. Pour l'effectivité et l'efficacité des mécanismes de protection spéciale de l'enfant en situation de conflits armés 
BIBLIOGRAPHIE

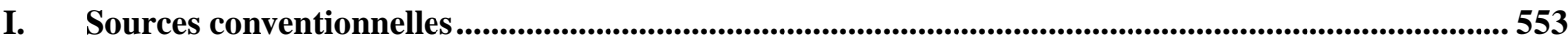

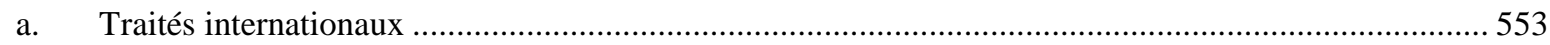

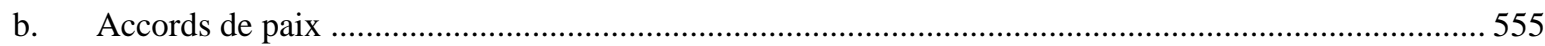

II. Législations nationales......................................................................................................................... 555

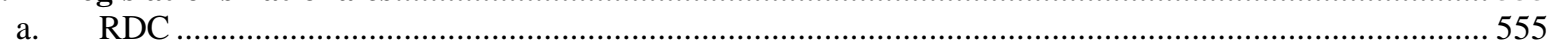

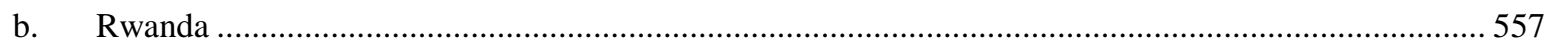

III. Résolutions, Rapports et autres documents des organisations internationales et sociétés savantes. 558

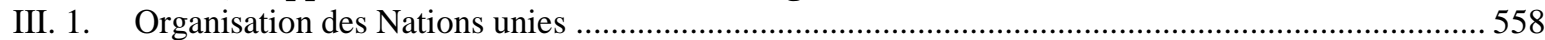

a. $\quad$ Conseil de sécurité (http://www.un.org/fr/sc/documents/resolutions/) ……..................................558

b. Assemblée générale (http://www.un.org/fr/sections/documents/general-assembly-resolutions/ ) ... 558

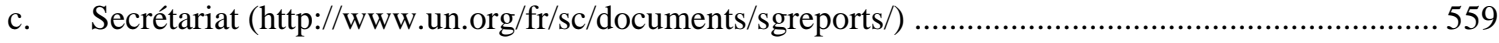

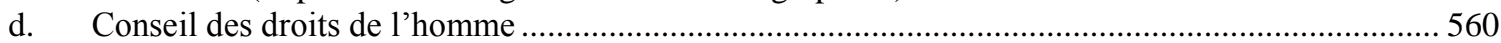

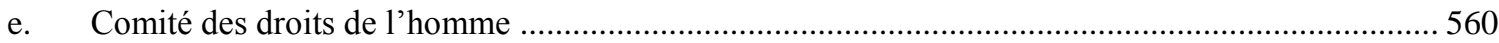

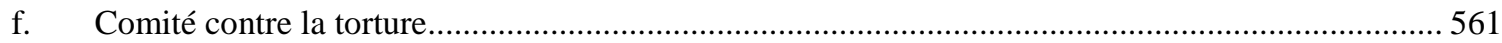

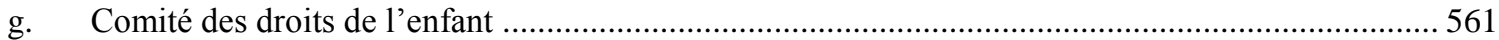

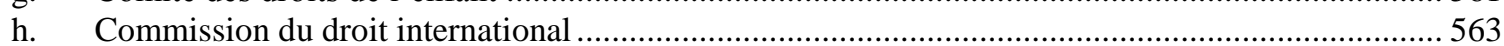

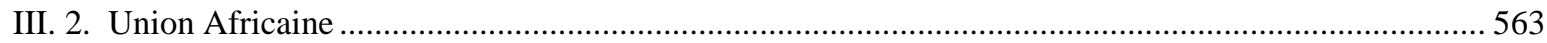

III.3. Union européenne (http://eur-lex.europa.eu/oj/direct-access.html?locale=fr)............................... 563

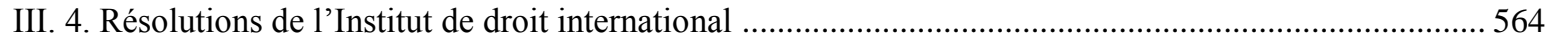

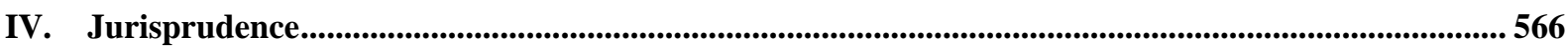

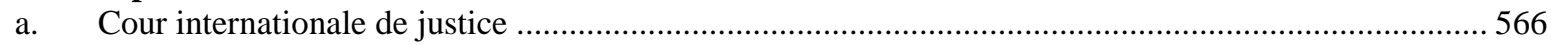

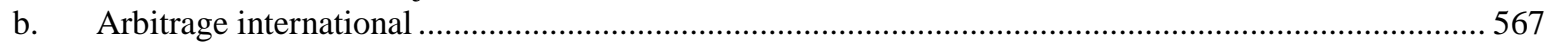

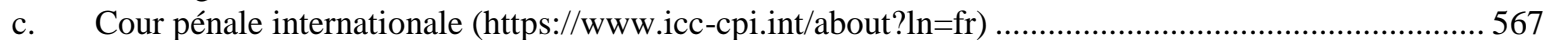

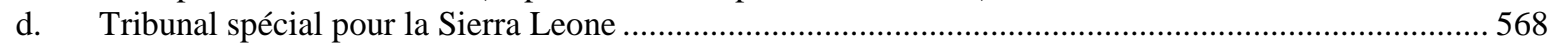

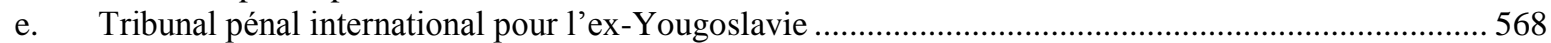

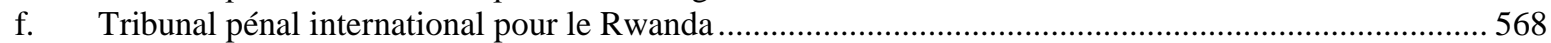

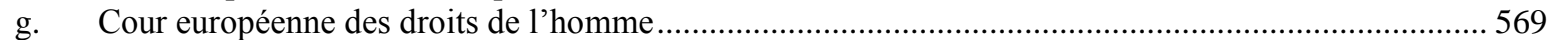

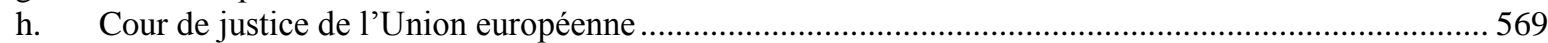

i. $\quad$ Cour et Commission africaines des droits de l'homme et des peuples ..............................................569

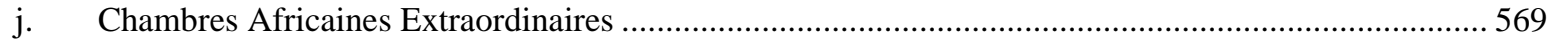

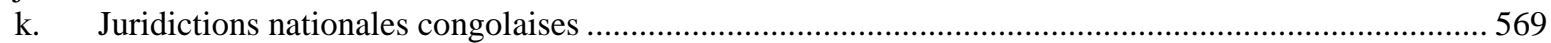

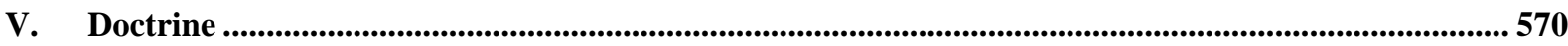

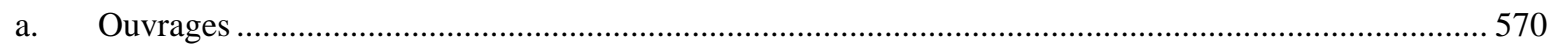

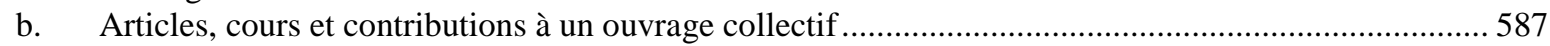

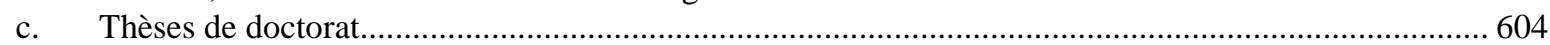

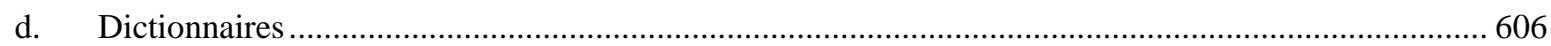

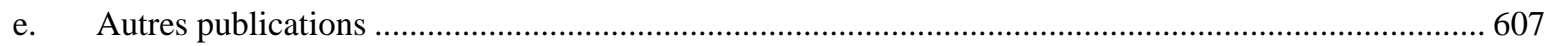

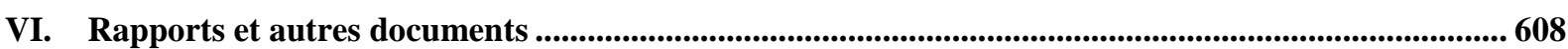

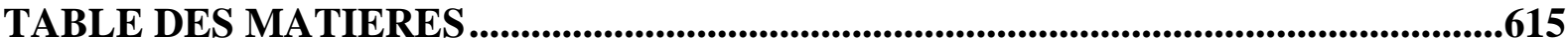


